\title{
WestVirginiaUniversity
}

THE RESEARCH REPOSITORY @ WVU

Graduate Theses, Dissertations, and Problem Reports

2009

\section{Chemical and physical properties of abandoned underground coal mine pools}

\author{
Eric F. Perry \\ West Virginia University
}

Follow this and additional works at: https://researchrepository.wvu.edu/etd

\section{Recommended Citation}

Perry, Eric F., "Chemical and physical properties of abandoned underground coal mine pools" (2009). Graduate Theses, Dissertations, and Problem Reports. 2890.

https://researchrepository.wvu.edu/etd/2890

This Dissertation is protected by copyright and/or related rights. It has been brought to you by the The Research Repository @ WVU with permission from the rights-holder(s). You are free to use this Dissertation in any way that is permitted by the copyright and related rights legislation that applies to your use. For other uses you must obtain permission from the rights-holder(s) directly, unless additional rights are indicated by a Creative Commons license in the record and/ or on the work itself. This Dissertation has been accepted for inclusion in WVU Graduate Theses, Dissertations, and Problem Reports collection by an authorized administrator of The Research Repository @ WVU.

For more information, please contact researchrepository@mail.wvu.edu. 
Chemical and Physical Properties

of Abandoned Underground Coal Mine Pools

by

\section{Eric F. Perry}

Dissertation submitted to the Eberly College of Arts and Sciences at West Virginia University

in partial fulfillment of the requirements

for the degree of

Doctor of Philosophy

in

Geology

Approved by

Henry Rauch, Ph.D.

John Renton Ph.D.

John Sencindiver Ph.D.

Jeffrey Skousen Ph.D.

Dorothy Vesper Ph.D.

Department of Geology and Geography

Morgantown, West Virginia

2009

Keywords: geochemistry, hydrogeology, mine water

Copyright 2009 Eric Perry 


\section{Abstract \\ Chemical and Physical Properties of Abandoned Underground Coal Mine Pools}

\section{by Eric F. Perry}

Long term drainage quality of five closed underground coal mines in West Virginia and Pennsylvania was investigated for mineral reactions, chemical processes, and hydrogeologic controls. Three mines were flooded and had circumneutral water with dissolved iron and sulfate. Two unflooded mines had acidic water with high concentrations of iron, aluminum and sulfate. The monitoring record ranged from 12 to 35 years for the five mine-pools.

The two acidic mine-pools had large long term declines in chemical concentration and flux. Both mine-pools approached equilibrium for hydrous iron sulfate minerals of the jarosite series. One mine-pool also exhibited equilibrium for the hydrous aluminum sulfate mineral jurbanite.

Annual recharge rate for the unflooded mines was 0.28 and 0.36 gallon/A-min. About $75 \%$ of the total annual chemical flux is discharged in a six month period.

Flooding profoundly affected drainage quality of closed mines. Three mines had circumneutral $\mathrm{pH}$ after inundation and flushing. Extreme chemical stratification can occur in flooded mines. One mine-pool with two pumping rates had greater chemical concentrations at increased pumping rate.

Significant in-situ acid consumption occurred in all five mine-pools. The unflooded mine-pools consumed 50 to $70 \%$ of original mine acidity, and neutralization exceeded $100 \%$ in the flooded net alkaline mine-pools. Mineral weathering accounts for most in-situ acid consumption.

Chemical concentration time trends fit a first order decay function. Decay constants for total acidity, iron, sulfate, aluminum and total dissolved solids were on the order of $10^{-4} /$ day in all minepools. Decay times of 30 to 70 years were estimated to approach suitable water composition. Decay constants are useful for estimating long term trends.

Flushing model calculations suggest that chemical concentration change in mine-pools is largely a function of transport of reactants and products, not chemical kinetics. 


\section{ACKNOWLEDGMENTS}

The author wishes to thank his adviser, Dr. Henry Rauch for the consistent guidance, encouragement and constructive suggestions he provided throughout the course of this work. Committee members Drs. John Sencindiver, Jeff Skousen, Jack Renton and Dorothy Vesper improved the content of this work at various stages with thought provoking questions and timely suggestions. The Department of Geology and Geography at West Virginia University provided opportunity for this "non-traditional" student to undertake and complete the program.

Employees of the West Virginia Dept of Environmental Protection (WVDEP) and Pennsylvania Dept of Environmental Protection (PADEP) generously provided data, site access and working insights and observations for three of the mine-pools studied. Mike Reese, Charles Miller and others from WVDEP were especially helpful for two West Virginia sites, while Rich Beam and Dan Sammarco provided information for Pennsylvania study sites. Bill Aljoe with the US Dept of Energy provided an excellent data set for part of the monitoring record at one mine-pool. Long term association with professional colleagues Keith Brady and Robert Evans helped shape some of the tasks in this work.

Finally, the author thanks his wife Jane, and son Isaac for their support, understanding and patience in completing this work. 


\section{Table of Contents}

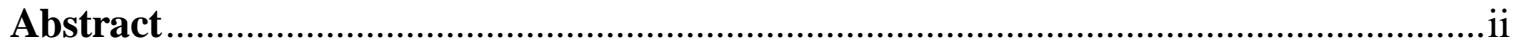

Acknowledgement ...................................................................................................... iv

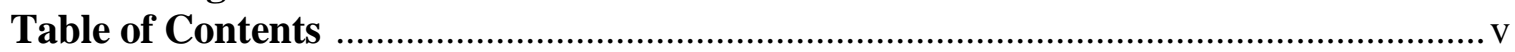

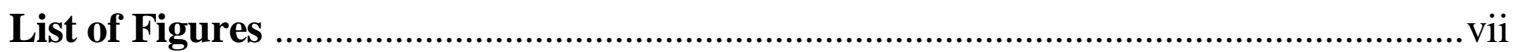

List of Tables ..........................................................................................................

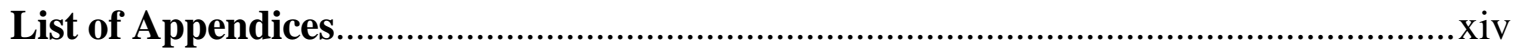

Chapter 1 Introductions and Summary Findings ………….......................................... 1

1.1 The Extent of Mine Drainage Pollution in Appalachia ............................................... 1

1.2 Objectives, Source Data and Methodology …………………...................................... 2

1.3 Summary Findings of This Research ………………..............................................

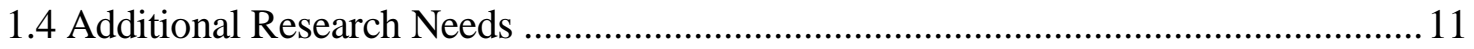

Chapter 2 Mining, Stratigraphic and Hydrogeologic Conditions .................................13

2.1 Underground Coal Mining Methods …………….................................................. 13

2.2 Stratigraphy and Mineral Composition .....................................................................15

2.3 Hydrogeology of Unmined and Mined Rocks in the Appalachian Plateau ................18

Chapter 3 Chemical and Hydrologic Properties of Partly Flooded Mines ...................22

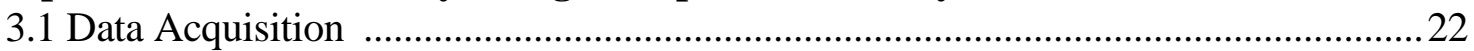

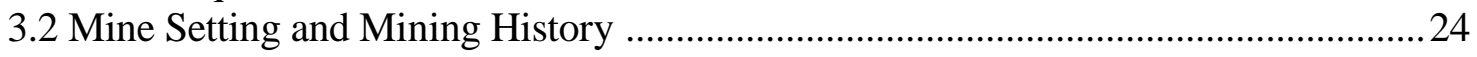

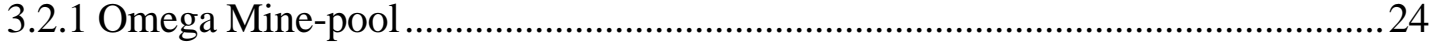

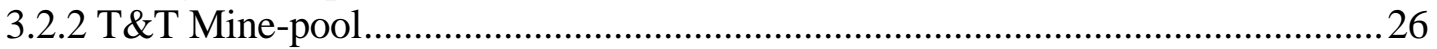

3.3 Water Quality in Partly Flooded Mines ……………............................................2

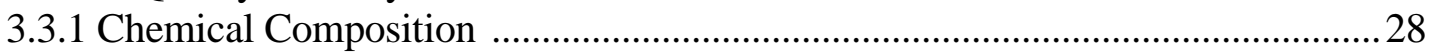

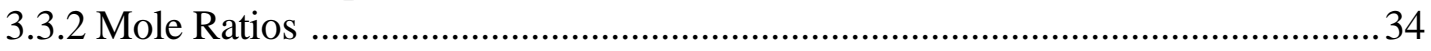

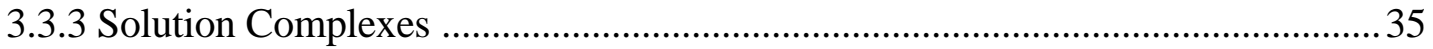

3.3.4 Redox State of Partly Flooded Mines ................................................................... 41

3.4 Mineral Controls on Metal Solubility .................................................................51

3.4.1 Aluminum Minerals...................................................................................52

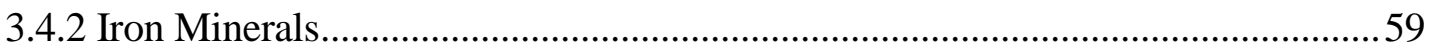

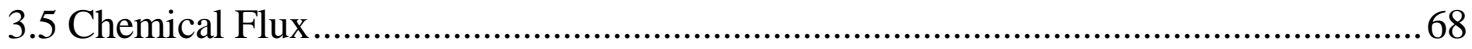

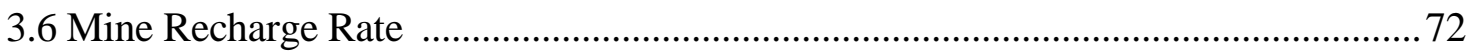

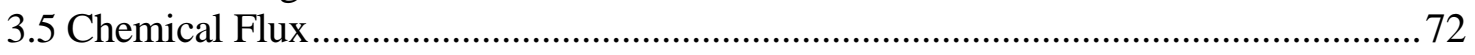

3.7 Chapter Three Summary Findings and Observations ..................................................78

Chapter 4 Chemical and Hydrologic Properties of Flooded Mines .................................8 84

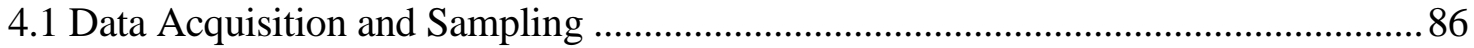

4.1.1 Sampling Flooded Mines - Spatial Variability ……………………………….......8

4.1.2 Pumping Effects on Mine-pool Composition …………………………………....90

4.2 Water Quality in Flooded Mines ...........................................................................90

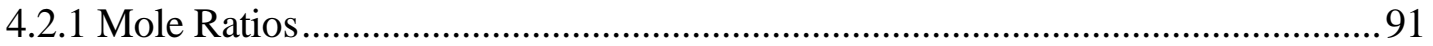

4.2.2 Cation Exchange, Sodium for Calcium and Magnesium ……………………....95

4.2.3 Sulfate Complexes ...........................................................................................99

4.2.4 Mineral Solubility Controls ................................................................................98

4.2.5 Sulfate Reduction in Flooded Mine-pools ........................................................ 104

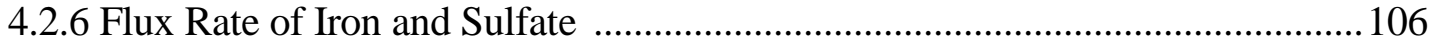


4.3 A Conceptual Model of Water Quality in Flooded Mines ....................................... 107

4.4 Fluid Storage and Transmissivity in Flooded Mine-pools .................................... 109

4.5 Chapter Four Summary Findings and Observations ............................................. 114

Chapter 5 Temporal Trends and Geochemical Behavior of Mine-pools .................... 119

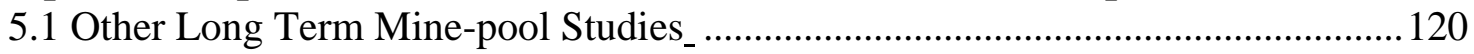

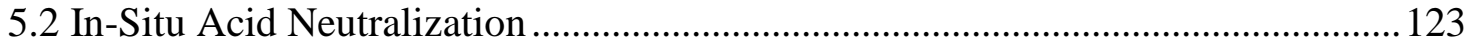

5.2.1 Neutralization from Mass Balance Difference Sulfate and Observed Acidity.. 124

5.2.1.1 Neutralization in the Partly Flooded, Acidic, Omega Mine-pool .................. 127

5.2.1.2 Neutralization in the Partly Flooded, Acidic, T\&T Mine-pool..................... 130

5.2.1.3 Neutralization in the Flooded, Neutral, Barnes\&Tucker mine-pool.............. 131

5.2.1.4 Neutralization in the Flooded, Circumneutral Hahn Discharge Mine-pool .132

5.2.1.5 Neutralization in the Arden-Westland Discharge, Westland Mine................ 133

5.2.2 Neutralization Estimate by Mass Balance Cation Sum...................................... 135

5.2.3 Neutralization Ratio From Speciated Mine Water Solutions .............................. 136

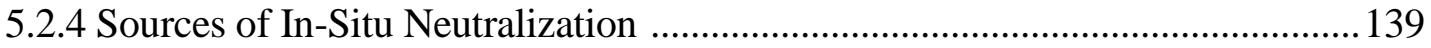

5.2.4.1 Neutralization from Aluminum Mineral Weathering ................................... 140

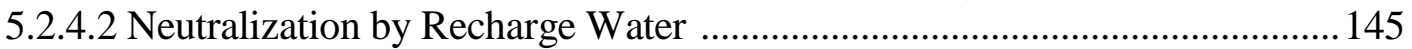

5.2.4.3 Neutralization By Carbonate Mineral Weathering ....................................... 147

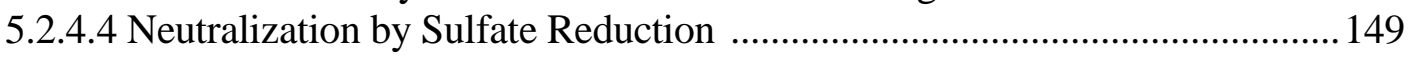

5.2.4.5 Neutralization From Oxyhydroxide Minerals .........................................150

5.2.4.6 Neutralization by Cation Exchange ......................................................... 150

5.3 Decay Functions for Estimating Time Dependent Chemical Composition.............. 151

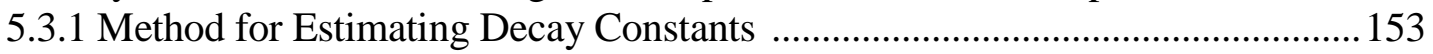

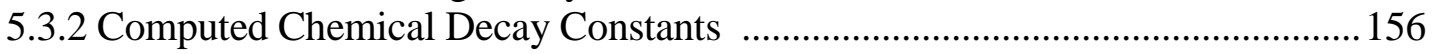

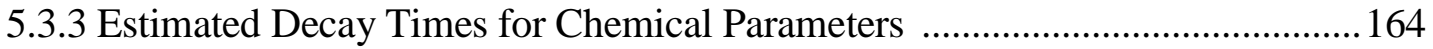

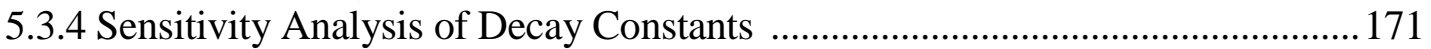

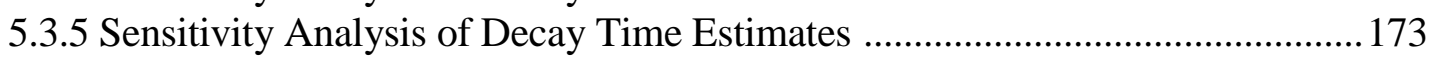

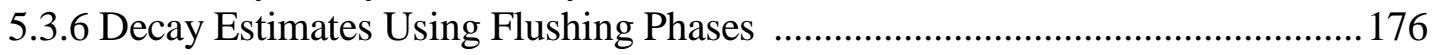

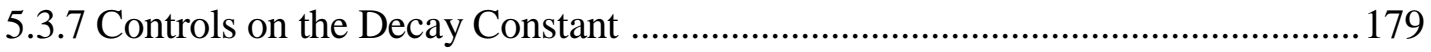

5.4 Application of Pyrite Weathering Kinetics to Mine-pools ....................................... 183

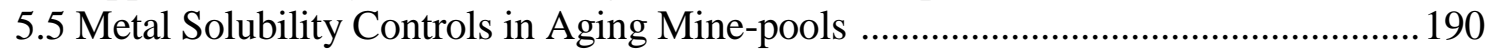

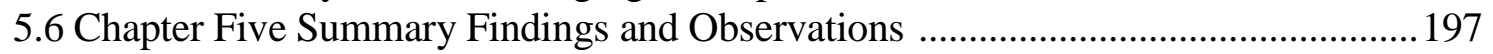

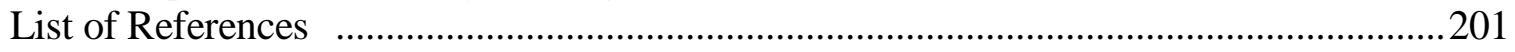




\section{List of Figures}

Figure 1-1 Muddy Creek, Preston County, WV, Degraded by Multiple Acid Discharges From Closed Underground Mines.......................................................................................2

Figure 2-1 Schematic of Room and Pillar development in Underground Coal Mines ....... 13

Figure 2-2 Portion of Underground Mine Map for T\&T Mine-pool, Illustrating Room and Pillar Mining Method and Variable Dimensions of Mine Development ....................14

Figure 2-3 Schematic of Longwall mining ………………........................................... 15

Figure 2-4 General Location Map of Mine-pools Studied in West Virginia and

Pennsylvania .16

Figure 2-5 Generalized Stratigraphic Column of Upper Pennsylvanian System Rocks in Northern West Virginia Showing Principal Coals, Limestones, Sandstones and Fireclays

Figure 2-6 Omega Mine Face-up Area Showing Vertical Fractures in Sandstone Overburden .18

Figure 2-7 Simplified Cross Section of Barrier Pillars and Overburden Conditions after Mine Closure .20

Figure 3-1 Extent of Omega Mineworks, Coal Outcrop and Discharges ...........................25

Figure 3-2 T\&T Mine-pool Complex ................................................................................2

Figures 3-3a-d Time Series Cation Milliequivalents Composition of Three Discharges and Combined Flow from the Omega Mine-pool

Figure 3-4 a and b Time Series Plot of Chemical Concentrations, Omega Mine-pool Combined Discharge 32

Figure 3-5 a and b Time Series Plot of Chemical Concentrations, T\&T Mine-pool Main

Discharge 33

Figure 3-6 Iron to Sulfate Mole Ratio, Omega Mine-pool Combined Flow, Smoothed Data

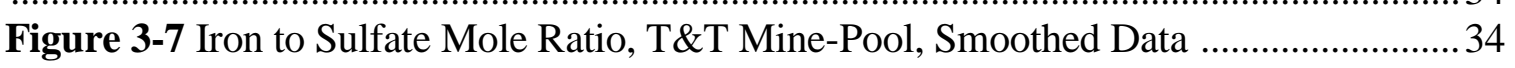

Figure 3-8 Distribution of Most Abundant Sulfate Complexes, Omega PM-21 Discharge, Initial Flush (1996) and Long Term Drainage, and High (Apr, May) and Low (Oct, Sep) Discharge Periods.

Figure 3-9 Distribution of Most Abundant Sulfate Complexes, T\&T Main Discharge, Initial Flush (1994) and Long Term Drainage (2003, 2007), and High (Jun) and Low (Sep)

Discharge Periods

Figure 3-10 Distribution of Most Abundant Aluminum Complexes, Omega Mine-pool

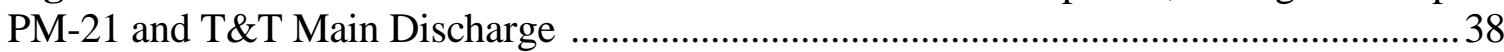

Figure 3-11 Distribution of Most Abundant Fe II Complexes, Omega Mine-pool PM-21 and T\&T Main Discharge

Figure 3-12 Distribution of Most Abundant Fe III Complexes, Omega Mine-pool PM-21 and T\&T Main Discharge ......................................................................................... 40

Figure 3-13 Distribution of Most Abundant Ca Complexes, Omega Mine-pool PM-21 ...41

Figure 3-14 Plot of Eh Measured and Eh Calculated from $\mathrm{Fe}^{2+} / \mathrm{Fe}^{3+}$ Half Reaction and $\mathrm{Fe}^{2+} / \mathrm{Fe}^{3+} \& \mathrm{O}_{2}$ 45

Figure 3-15 Plot of Eh Measured and Eh Calculated from $\mathrm{Fe}^{2+} / \mathrm{Fe}(\mathrm{OH}) 3$ am, $\mathrm{Fe}^{2+} /$ Goethite, and $\mathrm{O}_{2} /$ Pyrite ................................................................................... 48 
Figure 3-16 Stability of Hydrous Al-Sulfate Minerals as a Function of pH, Omega Minepool, Discharge DEF. Samples from 1993-2008 ….......................................................55 Figure 3-17 Time Series of Jurbanite Saturation Index, DEF, Marshall and PM-21 Springs,

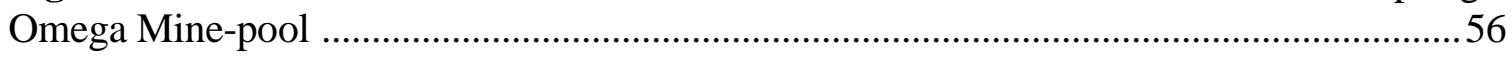

Figure 3-18 Time Series of Gypsum Saturation Index, DEF, Marshall and PM-21Springs,

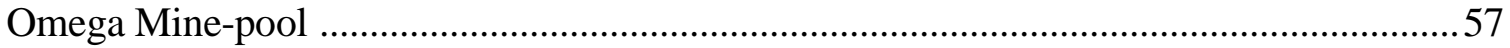

Figure 3-19 Time Series of Jurbanite and Gypsum Saturation Index, T\&T Mine-pool ....59 Figure 3-20 Stability of Selected Fe Oxyhydroxide and Hydrous Sulfate Minerals, Omega Mine-pool, and Composition of DEF Spring

Figure 3-21 Stability of Selected Fe Oxyhydroxide and Hydrous Sulfate Minerals, Omega Mine-pool, and Composition of PM-21 Spring 62 Figure 3-22 Stability of Selected Fe Oxyhydroxide and Hydrous Sulfate Minerals, Omega Mine-pool, and Composition of Marshall Spring . .63

Figure 3-23 Stability of Selected Fe Oxyhydroxide and Hydrous Sulfate Minerals, T\&T Mine-pool, and Composition of Waters .63

Figure 3-24a Eh/pH Diagram for Fe Minerals of Omega Mine-pool Spring DEF ...........65

Figure 3-24b Eh/pH Diagram for Fe Minerals of Omega Mine-pool Spring PM-21 ........65

Figure 3-24c Eh/pH Diagram for Fe Minerals of Omega Mine-pool Marshall Spring......66

Figure 3-24d Eh/pH Diagram for Fe Minerals of T\&T Mine-pool .................................... 66

Figures 3-25 Time series of -pQ $\mathrm{Fe}(\mathrm{OH})_{3}$ Values, Omega Mine-pool, DEF, PM-21 and Marshall Springs

Figure 3-26 Omega Mine-pool Estimated Chemical Flux, $\mathrm{Kg} /$ Year, for Total Dissolved Solids, Sulfate and Total Acidity 68

Figure 3-27 T\&T Mine-pool Estimated Chemical Flux, Kg/Year, for Total Dissolved Solids, Sulfate and Total Acidity

Figure 3-28 Omega Mine-pool Sulfate Flux and Flow, 1993 to 2001

Figure 3-29 Seasonal Distribution of Total Acidity and TDS Flux in Omega Mine-pool .71

Figure 3-30 Seasonal Distribution of Total Acidity and TDS Flux in T\&T Mine-pool ....72

Figure 3-31 Omega Mine-pool Estimated Annual Recharge (gal/A-min) and Annual

Precipitation 74

Figure 3-32 T\&T Mine-pool Estimated Annual Recharge (gal/A-min) and Annual Precipitation 75

Figure 3-33 Plot of Estimated Recharge vs. Overburden Depth, Using Leavitt's (1997)

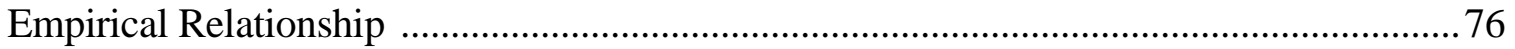

Figure 3-34 Seasonal Distribution of Recharge Characteristics, Omega Mine-pool .......... 77

Figure 3-35 Seasonal Distribution of Recharge Characteristics, T\&T Mine-pool .............78

Figure 4-1 Profile of Specific Conductance in a Mine-pool Water Column, Shannopin Mine, Greene Co, PA

Figure 4-1 Profile of Specific Conductance in a Mine-pool Water Column with Turbulent

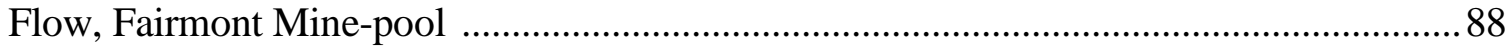

Figure 4-3a Iron to Sulfate Mole Ratio Barnes\&Tucker Mine-pool, Yearly Mean Data ..92

Figure 4-2b Iron to Sulfate Mole ratio, Arden-Westland Mine-pool .................................92

Figure 3-3c Iron to Sulfate Mole Ratio, Hahn Mine-pool .................................................92

Figure 4-3d Iron to Sulfate Mole ratio, Fairmont Mine-pool ...........................................92

Figure 4-4a Calcium to Carbonate Carbon Milliequivalent Ratio, Hahn Mine-pool ........94 
Figure 4-4b Calcium to Bicarbonate Milliequivalent Ratio, Arden-Westland Mine-pool 94 Figure 4-5 Distribution of Most Abundant Calcium Species in Five Flooded Mine-pools

Figure 4-6 Distribution of Most Abundant S(VI) Species in Five Flooded Mine-pools ...98 Figure 4-7 Distribution of Most Abundant Fe(II) Species in Five Flooded Mine-pools ...98 Figure 4-8a Eh/pH diagram for Iron in Four Flooded Mine-pools.................................... 102 Figure 4-8b Eh/pH diagram for Iron in Four Flooded Mine-pools ................................. 103 Figure 4-9 Conceptual Model of Geochemical Processes in Flooded Mine-pools ........... 109 Figure 4-10 Time Series Plot of Aquifer Head and Barometric Pressure, Fairmont Minepool, Beth 41 Mine 110

Figure 4-11 Uniontown Mine-pool, semi-log Plot of Aquifer Drawdown vs. Time and Estimated Transmissivity and Storativity Using Theis Method. 113

Figure 4-12 Fairmont Mine-pool. Head Response to Pumping in Three Mines 114 Figure 5-1 Neutralization Ratio for Raw Data, Omega Mine-pool, Main Treatment Inlet 128

Figure 5-2 Neutralization Ratio for Omega mine-pool, Main Treatment Inlet, Smoothed Data 128

Figure 5-3 Neutralization Ratio for Omega Mine-pool, Marshall Discharge, Smoothed Data

Figure 5-4 Neutralization Ratio for T\&T Mine-pool, Smoothed Data .... 130 Figure 5-5 Neutralization Ratio, Mostly Flooded, Circumneutral, Barnes \&Tucker Minepool, Yearly Average Data....

Figure 5-6 Neutralization Ratio, Computed With (Blue) and Without Alkalinity (Red) Mostly Flooded, Circumneutral Hahn Discharge Mine-pool.

Figure 5-7 Neutralization Ratio, Computed With (Blue) and Without Alkalinity (Red) Mostly Flooded, Neutral Arden-Westland Mine-pool ..................................................... 134

Figure 5-8 Mean Acid Producing and Acid Consuming Solution Complexes and Reactions, Omega Mine-pool .................................................................................... 138 Figure 5-9 "Pyrite Acidity"(Blue), Base Neutralizers (Red), and $\mathrm{H}^{+}$Consumption from Alumino-Silicate Mineral Weathering (Green), Omega Mine-pool .................................. 141 Figure 5-10 "Pyrite Acidity", Base Neutralizers, and $\mathrm{H}^{+}$Consumption from AluminoSilicate Mineral Weathering, T\&T Mine-pool

Figure 5-11 Mean Neutralization Ratio and Effective Neutralization Ratio Percentages (Excluding $\mathrm{H}^{+}$Consumption by $\mathrm{Al}$ Minerals), Omega Mine-pool .....

Figure 5-12 Mean Neutralization Ratio and Effective Neutralization Ratio Percentages (Excluding $\mathrm{H}^{+}$Consumption by Al Minerals), T\&T Mine-pool. 144

Figure 5-13 Estimated Percentage of Neutralization Supplied by Recharge Water, Hahn Mine-pool Discharge.

Figure 5-14 Hahn Discharge Distribution of Total $\mathrm{Ca}$ and $\mathrm{Mg}$ Neutralization in Initial Flushing and Post Flushing

Figure 5-15 Omega Discharge Distribution of Total $\mathrm{Ca}$ and $\mathrm{Mg}$ Neutralization before Grout Injection .....

Figure 5-16 Arden-Westland Discharge Distribution of Total $\mathrm{Ca}$ and $\mathrm{Mg}$ Neutralization Initial Flushing 148

Figure 5-17 Conceptual Cation Exchange in Acid Waters 151 
Figure 5-18 Time Series Plot of Fe Concentration, Hahn Discharge, Showing Exponential

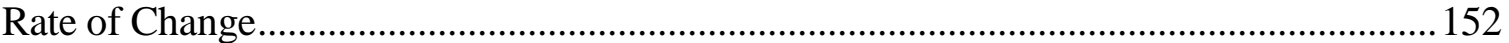

Figure 5-19 Log-log Scale Plot of Iron vs. Time Hahn Discharge....................................152

Figure 5-20 Log-log Scale Plot of Iron vs. Time Omega Mine-pool Discharge ............... 153

Figure 5-21 Plot of Ln(Ct/Co), Iron Concentration, Against t, Time, Hahn Discharge .... 155

Figure 5-22 Plot of Ln(Ct/Co), Iron Date Against t, Time, Omega Mine .........................156

Figure 5-23 Chemical Concentration Decay Constants by Parameter, Degree of Flooding and Flushing Stage.

Figure 5-24 Comparison of Chemical Decay Constants Mostly Flooded to Mostly Unflooded, and Early Flushing to Late Leaching, for Five Mine-pools

Figure 5-25a Fe to Sulfate Mole Ratio, Hahn Mine-pool

Figure 5-25b Fe to Sulfate mole ratio, Omega Mine-pool

Figure 5-26 Estimated Time in Years for Iron to "Decay" to $3.5 \mathrm{mg} / \mathrm{L}$, for Five Mines and Different Flooding Phases 168

Figure 5-27 Estimated Time in Years for Aluminum to "Decay" to One mg/L, for Five mines and Different Flooding Phases 168

Figure 5-28 Estimated Time in Years for Sulfate to "Decay" to $250 \mathrm{mg} / \mathrm{l}$, for Five Mines and Different Flooding Phases .....

Figure 5-29 Estimated Time in Years for Total Dissolved Solids to "Decay" to $500 \mathrm{mg} / \mathrm{L}$, for Five Mines and Different Flooding Phases

Figure 5-30 Estimated Time in Years for Total Acidity to "Decay" to $300 \mathrm{mg} / \mathrm{L}$, for Four Mines and Different Flooding Phases .....

Figure 5-31 Estimating Decay Constant Using Different Initial Concentrations on the Same Data Set.

Figure 5-32 Estimated Decay Times for Total Acidity to Reach $300 \mathrm{mg} / \mathrm{L}$, Based on Different Starting Concentrations, Omega and Hahn Mine-pools 174

Figure 5-33 Estimated Decay Times for Sulfate to Reach $250 \mathrm{mg} / \mathrm{L}$, Based on Different Starting Concentrations, Omega and Hahn Mine-pools....

Figure 5-34 Estimated Decay Times for Iron to Reach $10 \mathrm{mg} / \mathrm{L}$, Based on Different Starting Concentrations, Omega and Hahn Mine-pools.... 175

Figure 5-35. Estimated Decay Times for TDS to Reach $500 \mathrm{mg} / \mathrm{L}$, Based on Different Starting Concentrations, Omega and Hahn Mine-pools .................................................. 175 Figure 5-36 Estimated Decay Times for Aluminum to Reach One mg/L, Based on Different Starting Concentrations, Omega Mine-pool .................................................. 175

Figure 5-37 Total Acidity Decay Functions, Hahn Mine-pool .......................................... 177

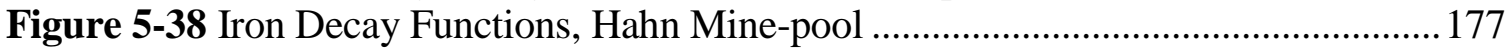

Figure 5-39 Sulfate Decay Functions, Hahn Mine-pool.................................................... 177

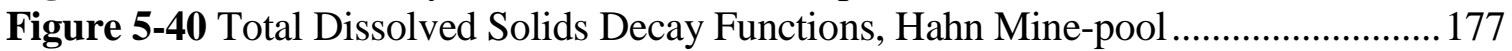

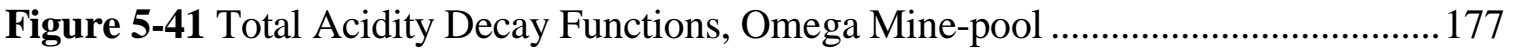

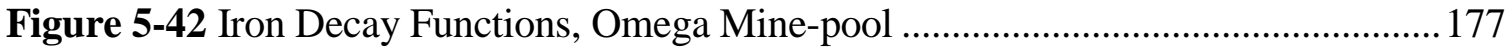

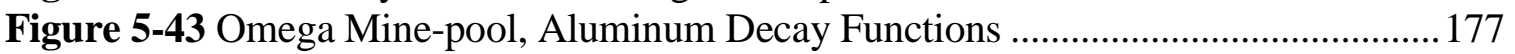

Figure 5-44 Omega Mine-pool, Sulfate Decay Functions.................................................. 177

Figure 5-45 Omega Mine-pool. Total Dissolved Solids Decay Functions ........................ 178

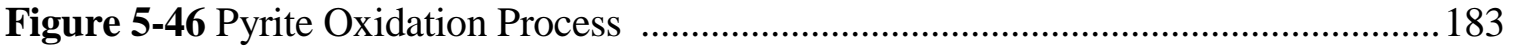


Figure 5-47 Calculated Pyrite Consumption Rate Using Williamson and Rimstidt's (1994) General Rate Law with Dissolved Oxygen and $\mathrm{pH}$.....................................................185

Figure 5-48 Shrinking Core Model of Pyrite Oxidation by Oxygen Diffusion................. 188

Figure 5-49 Relative Oxygen Flux Rate and Percent of Pyrite Grain Reacted ................. 189

Figure 5-50 Simulation Results of Long Term Iron Solubility Controls in the Aged Acid

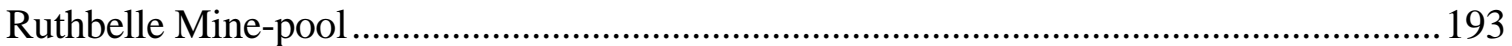

Figure 5-51 Simulation Results of Long Term Aluminum Solubility Controls in the Aged Acid Ruthbelle Mine-pool ......................................................................................... 195

Figure 5-52 Simulation Results of Long Term Iron Solubility Controls in the Aged Circumneutral Acme Mine-pool 196 


\section{List of Tables}

Table 1-1 General Characteristics of Long Term Mine-pool Discharge Data Sets ................4 Table 3-1 Regression Results Estimating Sulfate from TDS at Three Discharges, Omega Mine-pool

Table 3-2 Omega Mine Summary Water Quality for Three Discharges at Two Time Periods

Table 3-3 Summary Water Quality Data T\&T 2 Mine-pool, Mostly Unflooded Upper Freeport Mine-Works

Table 3-4 Measured (Observed) and Calculated Eh values from $\mathrm{Fe}^{2+} / \mathrm{Fe}^{3+}$ couple for Acid Mine Waters

Table 3-5 Measured and Calculated Eh values from $\mathrm{Fe}^{2+} / \mathrm{Fe}^{3+}$ and $\mathrm{O}_{2}$ Couple for Acid Mine Waters

Table 3-6 Correlation coefficients among Aluminum, Iron, Calcium, Sulfate and $\mathrm{pH}$ in Acid Mine Waters, Omega and T\&T Mine-pools...

Table 3-7 -pQ $\mathrm{Fe}(\mathrm{OH})_{3}$, Omega, T\&T Mine-pools

Table 3-8 Average Long Term Iron and Sulfate Flux from Two Partly Flooded and Three

Flooded Mine-pools

Table 4-1 Summary Information on Four Flooded Mine-pools

Table 4-2 Comparison of Mine Water Composition at Flooded and Partly Flooded Conditions

Table 4-3 Chemical Composition of Stratified Mine-pool Waters

Table 4-4 Spatial Variation in Water Quality of Fairmont Mine-pool

Table 4-5 Effect of Pumping Rate on Water Quality from Barnes\&Tucker Mine-pool...90

Table 4-6 Water Composition and General Chemistry of Five Flooded Mine-pools .......91

Table 4-7 Composition of Source and End of Flow-path Waters Showing Sodium

Enrichment and Calcium and Magnesium Depletion, Barnes\&Tucker Mine-pool ..............96

Table 4-8 Chemical Composition of Five Mine-pools Speciated in PHREEQCI..............97

Table 4-9 Mineral Saturation Indices and $\log \mathrm{pCO}_{2}$ for Five Flooded Mine-pools ..........99

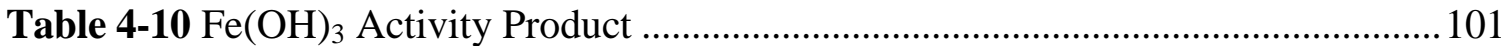

Table 4-11 Equilibrium Redox Conditions for Sulfate Reduction to FeS ........................106

Table 4-12 Average Long Term Iron and Sulfate Flux from Three Flooded and Two Partly

Flooded Mine-pools

Table 4-13 Wells Used in Storage and Transmissivity Estimates ....................................110

Table 4-14 Specific Storage, Porosity and Storativity Estimated from Head and

Barometric Pressure

Table 5-1 Summary Water Quality Characteristics of Five Mine-pools

Table 5-2 Neutralization Ratio by Cation Sum and Mass Balance difference Methods.135

Table 5-3 Solution Complexes With Hydrolysis That Produce $\mathrm{H}^{+}$

Table 5-4 Solution Complexes and Reactions That Consume $\mathrm{H}^{+}$....

Table 5-5 Chemical Characteristics of Recharge Waters for Five Mine-pools ................ 140

Table 5-6 Fraction of Neutralization Supplied From Recharge Water Relative to Estimated Total Neutralization. 146 
Table 5-7 Chemical Concentration Decay Constants $\left(\mathrm{d}^{-1}\right)$ Estimated Using Different Data for Two Acidic Mostly Unflooded Mines

Table 5-8 Decay Constants $\left(\mathrm{d}^{-1}\right)$ Estimated from Chemical Concentration for Three Mostly Flooded Circumneutral Mine-pools 158

Table 5-9 Estimated Decay Time for Total Acidity to Decline to 50, 10, 5 and 1\% of Initial Concentration. .165

Table 5-10 Estimated Decay Time for Aluminum to decline to 50, 10, 5 and 1\% of Initial Concentration .... 165

Table 5-11 Estimated Decay Time for Iron to decline to 50, 10, 5 and $1 \%$ of Initial Concentration ..... 166

Table 5-12 Estimated Decay Time for Sulfate to decline to 50, 10, 5 and $1 \%$ of Initial Concentration 166

Table 5-13 Estimated Decay Time for TDS to decline to 50, 10, 5 and $1 \%$ of Initial Concentration 167

Table 5-14 Estimated Years to Attain Target Parameter Concentration Based on "Decay" Calculation, And Initial Concentration $\left(\mathrm{C}_{\mathrm{o}}\right)$ 170

Table 5-15 Range of Decay Constant Values 172

Table 5-16 Range of Decay Times in Years from Best Fit and 95th Percentile Values of k Table 5-17 Decay Curve Fitting Median Residual Percentages, Hahn and Omega Minepools 176

Table 5-18 Correlation coefficents ( $\mathrm{r}$ ) among decay constant $(\mathrm{k})$ parameters .179

Table 5-19 Apparent Dissolution Rate, R, for Sulfate, Estimated from Different Mineral Controls and Slow Flush Rate Equation .... 181

Table 5-20 Apparent Dissolution Rate, R, for Sulfate, Estimated from Different Mineral Controls and Rapid Flush Rate Equation 182

Table 5-21 Data for Estimating Pyrite Oxidation Rate in Five Mine-pools with Williamson and Rimstidt's (1994) Rate Laws..... 186 Table 5-22 Chemical Composition of Aged Acidic, Partly Flooded and Circumneutral Flooded Mine-pools 191

Table 5-23 Mineral Indices of Aged Acidic, Partly Flooded, and Circumneutral Flooded Mine-pools 192 


\section{List of Appendices}

Appendix A Long-Term Water Quality Trends In a Partly Flooded Underground Coal Mine 220

Appendix B Modeling rock-water interactions in flooded underground coal mines, Northern Appalachian Basin 240

Appendix C Ground-Water Flow and Quality in A Fully Flooded Underground Complex

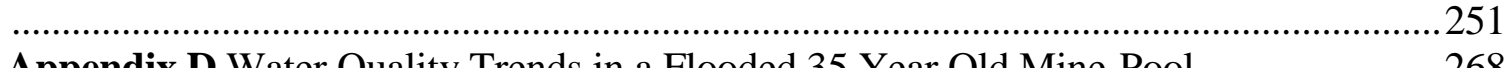

Appendix D Water Quality Trends in a Flooded 35 Year Old Mine-Pool .........................268

Appendix E Omega Mine-pool Raw Chemical Data ..........................................................28

Appendix F T\&T Mine-pool Raw Chemical Data _.............................................................337

Appendix G Hahn Mine-pool Raw Chemical Data............................................................344

Appendix H Barnes and Tucker Raw Chemical Data........................................................356

Appendix I Arden-Westland Mine-pool Raw Chemical Data ............................................358

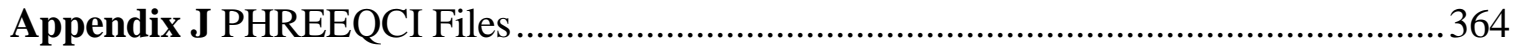




\section{CHAPTER 1: INTRODUCTION AND SUMMARY FINDINGS}

\subsection{The Extent of Mine Drainage Pollution in Appalachia}

Acid and metal rich water from closed underground coal mines has degraded many streams and aquifers in the Appalachian region. Over 80 years ago, polluted drainage from Appalachian coal mines was described as a "problem of long standing", a "public nuisance" and an expense to the mining industry (Crichton, 1927). The Appalachian Regional Commission (1969) published an assessment of coal mine drainage impacts in eight states. That study reported that water quality in more than 10,000 stream miles was affected by mine drainage. About 5,700 miles were reported to be acidic; and about $75 \%$ of the low pH streams were in the Susquehanna, Allegheny, Monongahela and Potomac River basins. The most severe acid drainage from bituminous coal mines was concentrated in southwestern Pennsylvania, northern West Virginia, and western Maryland. The Commission report also estimated that $80 \%$ of the drainage came from abandoned mines and that abatement would cost more than 6 billion dollars in 1969 values. At that time, there was no formal government funding mechanism for abatement.

The Clean Water Act (CWA), passed into federal statute in 1972, and the Surface Mining Control and Reclamation Act (SMCRA) in 1977, established national standards for water discharges from coal mines and environmental standards for reclamation. SMCRA established a fund for reclaiming abandoned mined lands with priority given to public safety, but a portion of the projects do address water pollution abatement as well. Although the incidence of "new" sources of mine drainage pollution has declined in Pennsylvania (Smith et al, 2000) and elsewhere, pollution from old or abandoned sites remains a widespread problem in the region.

Koryak et al. (2004) noted that total acidity levels have been gradually declining over a period of several decades in the Allegheny River basin, which they attribute in part to depletion of the source mineral pyrite within old mines. However, sulfate, a soluble product of pyrite oxidation, was leached from the Monongahela and Allegheny River basins at annual loading rates of $644 \mathrm{Kg}$ per hectare and $368 \mathrm{Kg}$ per hectare in the 1990s (Sams and Beer, 1999). Many individual drainage basins remain degraded. Figure 1-1 illustrates the condition of Muddy Creek, in Preston County, WV. This basin has multiple sources of acid drainage, including one of the mines examined in this study. The stream has a $\mathrm{pH}$ of about 3.2, iron and aluminum in the tens of $\mathrm{mg} / \mathrm{L}$ and sulfate concentration of about $1000 \mathrm{mg} / \mathrm{L}$. Most of the local mines have been closed for more than ten years and some are approaching 50 years in age. The stream has little value for biota, consumption or recreation in its current state.

The art and science of mine drainage prediction and mitigation is more advanced for surface mining effects than underground mine effects. The largest pollutant loads and impacts are however, usually associated with underground mine drainage, and observations suggest the effects can persist on the order of decades. 


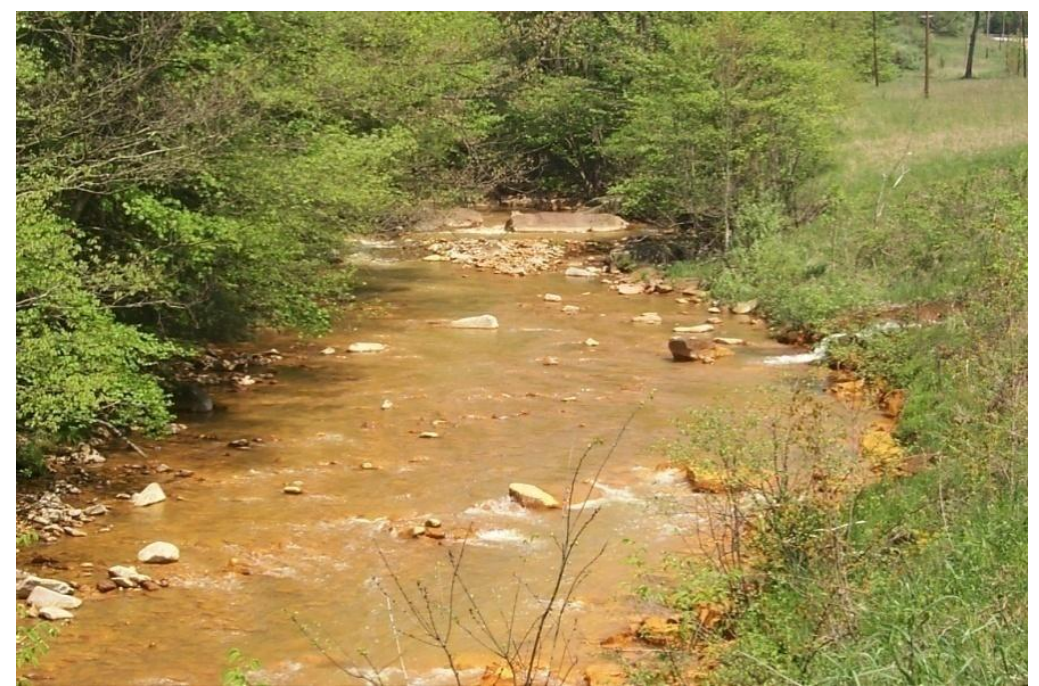

Figure 1-1. Muddy Creek, Preston County, WV, Degraded by Multiple Acid Discharges from Closed Underground Mines.

\subsection{Objectives, Source Data and Methodology}

In the work described in this study, the author examined the chemical and hydrogeologic processes and conditions in five underground mine-pools, with an overall objective of:

- identifying common variables, processes and "rules of thumb" that could improve the understanding, remediation and management of mine-pools.

These five mine-pools are a subset of the total population of closed mines, in that these discharge water of objectionable quality and require chemical treatment to comply with water quality standards. Some mine-pools not included in this study generate water of acceptable quality without intervention.

Some specific questions that were addressed in this work included:

- How long does the discharge of objectionable concentrations of metals, sulfate and acidity last in partly flooded and fully flooded mines?

- Are there identifiable mineral reactions controlling the concentrations of metals and sulfate in flooded and partially flooded mine-pools?

- What is the magnitude of seasonal variation in recharge/discharge in partly flooded mines?

- How much does recharge water and mineral weathering contribute to in-situ acid neutralization?

- What are the short term effects of in-situ treatment on mine pool quality? 
- How should flooded or flooding mines be sampled for chemical characterization?

- What hydrologic conditions favor abatement or attenuation of mine drainage pollutants, and what hydrologic conditions favor continued mobilization of acid drainage?

- What are the likely sources/sinks for iron?

- How is water quality likely to change after flushing several mine pool volumes?

While the mine-pools in this study are pollution sources and liabilities to society at this time, they are also potential water resources. One of the subject mine-pools, Barnes and Tucker, is located in Cambria County, PA. The pumped and treated discharge releases about 22,700 liters per minute into the Ohio River basin. The mine-pool has been examined by the Commonwealth of Pennsylvania as a potential source for augmenting flow in the Susquehanna Basin, where water demand is approaching limits of the current supply. In West Virginia, Lessing and Hobba (1981) reported that several mine-pools in low sulfur underground coal mines have been developed as water supplies for consumptive use.

This work is an applied study, utilizing data collected by the author, and data acquired from other sources. Multiple source data introduced concerns about consistency, and these concerns were addressed by simple quality control methods including charge balance checks, acidity calculations, and examining expected relationships between parameters. Much of the data was originally collected for project monitoring purposes, and includes occasional missing values or apparent entry errors. These are real world data, with all of their imperfections. These data sets represent the type of information that companies, regulators or environmental groups base decisions on. The drawbacks to these data sets are that they lack an additional level of detailed analysis that could provide further understanding of the processes at work in mine-pools. For example, none of the five mine-pools were directly accessible for in-mine sampling of sediment and rocks for mineralogical characterization. Potential water-mineral interactions were inferred from geochemical calculations, water composition and literature reports for similar conditions, rather than by direct sampling.

Five mine-pools with reasonably complete long term (i.e. greater than ten years) water quality monitoring were selected for analysis. Two are partly flooded, and discharge acidic, metal rich drainage, while the other three have circumneutral water. The flooded mine-pools however, still discharge waters with objectionable concentrations of Fe and sulfate. General characteristics of the five mine-pools are summarized in table 1-1. Additional, more limited data, for three other flooded mine-pools, the "Fairmont mine-pool" located in Marion County, WV, the "Shannopin mine-pool" in Greene County, PA, and the "Uniontown mine-pool", in Fayette County, PA are also included in chapter four.

Each mine-pool has a unique associated history that could affect water composition. The two partly flooded mine-pools, Omega and T\&T, both had in-situ treatment, including injection of flyash and cement, and impure limestone, respectively. These events were included in overall evaluation of 
mine-pool behavior. The Omega and T\&T mine-pools are managed by West Virginia Dept of Environmental Protection (WVDEP), which generously shared their data and insights with the author. The US Dept of Energy also provided a data set for part of the record at the Omega minepool. The Barnes and Tucker mine-pool receives leakage from an overlying mine-pool that flooded midway through the monitoring record. This mine-pool is managed by the Pennsylvania Dept of Environmental Protection (PADEP), which also shared data and observations with the author. Data for the Hahn and Arden-Westland mine-pools were originally reported by Donovan et al. (1999), and this dissertation does not repeat work already reported for these two sites.

Table 1-1

General Characteristics of Long Term Mine-pool Discharge Data Sets

\begin{tabular}{|c|c|c|c|c|c|c|c|}
\hline Mine & Coal bed & Location & $\begin{array}{c}\text { Period } \\
\text { of } \\
\text { Record }\end{array}$ & $\begin{array}{c}\text { Sample } \\
\text { Frequency }\end{array}$ & $\begin{array}{c}\text { Water } \\
\text { Quality } \\
\text { Conditions }\end{array}$ & $\begin{array}{c}\text { Flow/Pump } \\
\text { Data }\end{array}$ & Remarks \\
\hline T\&T \#2 & $\begin{array}{l}\text { Upper } \\
\text { Freeport }\end{array}$ & $\begin{array}{c}\text { Preston Co., } \\
\text { WV }\end{array}$ & $\begin{array}{l}1994- \\
2007\end{array}$ & $\begin{array}{l}\text { Weekly to } \\
\text { quarterly }\end{array}$ & $\begin{array}{c}\text { pH 2-3, } \\
\text { high Fe, } \mathrm{Al}, \\
\mathrm{SO}_{4}\end{array}$ & $\begin{array}{l}\text { Daily flow } \\
\text { since } 1995\end{array}$ & $\begin{array}{c}\text { Mine } \\
\text { flooding \& } \\
\text { blowout } \\
1994\end{array}$ \\
\hline Omega & $\begin{array}{c}\text { Upper } \\
\text { Freeport }\end{array}$ & $\begin{array}{c}\text { Monongalia } \\
\text { Co., WV }\end{array}$ & $\begin{array}{l}1993- \\
2007\end{array}$ & $\begin{array}{l}\text { Weekly to } \\
\text { quarterly }\end{array}$ & $\begin{array}{c}\text { pH 2-3, } \\
\text { high Fe, } \mathrm{Al} \text {, } \\
\mathrm{SO}_{4}\end{array}$ & $\begin{array}{l}\text { Daily flow } \\
\text { since } 1997\end{array}$ & $\begin{array}{l}\text { Full suite } \\
\text { chem. } \\
\text { samples } \\
\text { 1993-1999 }\end{array}$ \\
\hline Hahn & Pittsburgh & $\begin{array}{c}\text { Washington } \\
\text { Co., PA }\end{array}$ & $\begin{array}{l}1980- \\
1999\end{array}$ & $\begin{array}{l}\text { Weekly to } \\
\text { monthly }\end{array}$ & $\begin{array}{c}\text { pH 6-7, } \\
\text { high } \mathrm{Fe}, \mathrm{Na}\end{array}$ & $\begin{array}{c}\text { Average } \\
13,250 \\
\text { L/min }\end{array}$ & $\begin{array}{l}\text { Full suite } \\
\text { chem. } \\
\text { samples } \\
\text { 1984-1994 }\end{array}$ \\
\hline $\begin{array}{c}\text { Arden- } \\
\text { Westland }\end{array}$ & Pittsburgh & $\begin{array}{c}\text { Washington } \\
\text { Co., PA }\end{array}$ & $\begin{array}{l}1986- \\
1999\end{array}$ & Monthly & $\begin{array}{c}\text { pH 6-7, } \\
\text { high } \mathrm{Fe}, \mathrm{Na}\end{array}$ & $\begin{array}{c}\text { Average } \\
6800 \mathrm{~L} / \mathrm{min}\end{array}$ & $\begin{array}{l}\text { Some full } \\
\text { suite chem. } \\
\text { samples }\end{array}$ \\
\hline Barnes\&Tucker & $\begin{array}{c}\text { Lower } \\
\text { Kittanning }\end{array}$ & $\begin{array}{c}\text { Cambria } \\
\text { Co., } \\
\text { PA }\end{array}$ & $\begin{array}{l}1969- \\
2005\end{array}$ & $\begin{array}{l}\text { Daily to } \\
\text { quarterly }\end{array}$ & $\begin{array}{c}\text { pH 6-6.5, } \\
\text { high Fe }\end{array}$ & $\begin{array}{c}\text { Average } \\
22,700- \\
26,500 \\
\mathrm{~L} / \mathrm{min}\end{array}$ & $\begin{array}{c}\text { Initially } \\
\text { acidic, } \\
\text { leakage from } \\
\text { overlying } \\
\text { mine-pool }\end{array}$ \\
\hline
\end{tabular}

Relatively few long term mine-pool data sets exist that include sampling at close intervals of days to a few months. Thus, the research could either concentrate on a small number of sites with more extensive information, or elect a larger number of sites having more sparse data sets. Mack and Skousen (2008), and work cited therein, followed the latter approach, examining more than 40 mines over multiple decades, but with limited sampling events. Their work produced some valuable general conclusions and observations on rate of change in chemical composition of mine waters. The current study focused on a few mines in an attempt to provide more detailed analysis and insight on mine-pool geochemistry and hydrogeology. 
The chapters of the dissertation are organized as follows:

- Chapter one (this chapter), Introduction and Summary Findings. Provides an overview of the purpose of the research, principal findings and conclusions from chapters three, four and five, and assessment of additional research needs on mine-pools.

- Chapter two, Mining, Stratigraphic and Hydrogeologic Conditions, provides a short discussion of underground mining methods, stratigraphic and mineralogical considerations, conceptual discussion of ground-water recharge, storage and discharge in the Appalachian region, and general hydrologic properties of mine-pools.

- Chapter three, Chemical and Hydrologic Properties of Partly Flooded Mines, provides geochemical, mineralogical and flux calculations and recharge estimates for two acidic partly flooded mines.

- Chapter four, Chemical and Hydrologic Properties of Flooded Mines, provides geochemical, mineralogical and flux calculations for three mostly flooded underground mine-pools. Spatial variation in chemical composition, sampling considerations, and pumping effects on chemical composition are described.

- Chapter five, Temporal Trends and Geochemical Behavior of Mine-pools, provides calculations of in-situ acid neutralization by mineral weathering, recharge water and other mechanisms, estimating time dependent chemical composition using decay functions, metal solubility controls in aging mine-pools, and mineral weathering kinetics.

Appendices A, B, C, and D contain four published conference and journal papers by the author. Observations, conclusions and parts of those papers are incorporated into chapters three and four. The complete text of the four papers is included in the appendices as supplemental information.

- Appendix A includes a 2004 conference proceedings paper "Long-Term Water Quality Trends in a Partly Flooded Underground Coal Mine" presented at the National Meeting of the American Society of Mining and Reclamation and the $25^{\text {th }}$ West Virginia Surface Mine Drainage Task Force.

- Appendix B contains the journal paper "Modelling Rock-Water Interactions in Flooded Underground Coal Mines, Northern Appalachian Basin" Geochemistry: Exploration, Environment, Analysis, Vol. 1, 2001.

- Appendix C contains the 2004 conference proceedings paper "Ground-Water Flow and Quality in a Fully Flooded Underground Mine Complex", National Meeting of the American Society of Mining and Reclamation and the 25th West Virginia Surface Mine Drainage Task Force. 
- Appendix D contains the 2005 conference proceedings paper "Water Quality Trends in a Flooded 35 Year Old Mine-Pool", National Meeting of the American Society of Mining and Reclamation.

Chapters three, four and five each contain a summary of findings for the respective section, and those findings are also incorporated into this chapter.

Chemical data from the five mine-pools are contained in appendices E, F, G, H and I. Input files for two geochemical models are in Appendix J. They were run in the software PHREEQCI.

\subsection{Summary Findings of This Research}

In chapter three geochemical processes are examined in two closed underground coal mines, Omega and T\&T that are less than 30\% flooded. Both mines discharged water with $\mathrm{pH}$ ranging from about 2.5 to 3.5 , containing $10 \mathrm{~s}$ to hundreds of $\mathrm{mg} / \mathrm{L}$ of $\mathrm{Fe}$ and $\mathrm{Al}$, and sulfate concentrations of 1,000 to nearly $5,000 \mathrm{mg} / \mathrm{L}$. After more than 10 years, both mines still discharge acidic drainage, but chemical concentrations have declined. Chemical composition, mole ratios, solution complexes and chemical flux rates were examined as a function of time and from multiple discharge points. Potential solubility controls on $\mathrm{Fe}$ and $\mathrm{Al}$ activity were assessed from chemical equilibrium calculations. Recharge rate and seasonality were estimated in simple water budgets for both mines. The principal observations and findings from Chapter 3, Chemical and Hydrologic Properties of Partly Flooded Mines are:

- Conceptually, partly flooded mines can be viewed as large reactor and leaching chambers, that are regularly supplied with oxygen to oxidize pyrite, and water to rinse out soluble weathering products.

- Chemical concentrations and flux declined during the monitoring period, however overall water quality remains severely degraded. Significant short term (days to a few months) variations in concentration, flux and flow were common to both mine-pools, but long term (months to years) trends are also evident.

- Both mines had in-situ treatment consisting of grout injection in the Omega mine, and limestone injection in the T\&T mine-pool. Chemical concentrations increased and water quality actually declined for 1 to 2 years after remediation, as stored weathering products were flushed from each mine. Each site has had some treatment sludge with excess alkalinity injected into the mine-works. The overall effect of treatment sludge return on mine-pool chemical composition is minimal or is masked by other processes.

- Chemical concentrations are inversely related to flow in the Omega mine-pool, increasing during low recharge periods of late summer and autumn. The distinct seasonal behavior in the Omega mine-pool suggests the complex has little additional ground-water storage capacity, beyond that in the mine-pool. The T\&T mine-pool had little or indistinct seasonality in chemical concentrations. 
- An estimated 60 to $80 \%$ of the Fe associated with pyrite weathering is missing from aged mine-pool water. A large fraction of the Fe from pyrite weathering is therefore being attenuated within the mine-pool, even in very acidic conditions. The retention mechanisms could include hydrous sulfate minerals, oxyhydroxide minerals, cation exchange or adsorption.

- Mine-pool chemistry is very responsive to large imposed stresses. Both mine-pools had substantial increases in concentration and flux for several years after in-situ treatment. The T\&T mine-pool also experienced a short term major "blowout" event in 2003 resulting in a large flux of pollutants. The T\&T "blowout" was not associated with any anthropogenic activities. Rather it appears to have resulted from disruption of existing flow-paths, rapid head buildup, followed by failure of a barrier, pillars, or other subsidence that rapidly relieved the hydraulic pressure. Roof falls or partial collapse, and pillar failure are extremely difficult to predict on a temporal basis, but can affect chemical flux on short and long term bases by altering ground-water flow patterns.

- Sulfate, $\mathrm{Al}$ and $\mathrm{Fe}(\mathrm{III})$ form significant amounts of complexes in mine water. Complex formation, in general, increases the quantity of the element that can dissolve in solution and the solubility of the contributing mineral.

- Eh readings in acid mine waters can be used to estimate system redox conditions for iron. $\mathrm{Fe}^{2+} / \mathrm{Fe}^{3+}$ activities are sufficiently large that both species can be sensed by the electrode and the couple is readily reversible. Measured $\mathrm{Eh}$ and Eh calculated from $\mathrm{Fe}^{2+} / \mathrm{Fe}^{3+}$ activities had a median difference of -32 millivolts. Eh measurements collected from 2002 to 2007 for both mine-pools were consistent, indicating reproducible results and/or stable redox conditions.

- There is little change in water composition with respect to Al minerals over more than ten years in the Omega mine-pool. Three springs in the Omega mine-pool are near apparent equilibrium for jurbanite $\left(\mathrm{AlOHSO}_{4}\right)$ and approach stability for alunite $\left(\mathrm{KAl}_{3}\left(\mathrm{SO}_{4}\right)_{2}(\mathrm{OH})_{6}\right)$. The T\&T mine-pool is apparently under-saturated for $\mathrm{Al}_{-} \mathrm{SO}_{4}$ minerals.

- Both partly flooded mine-pools approach apparent saturation for H-Jarosite $\left(\mathrm{H}_{3} \mathrm{OFe}_{3}\left(\mathrm{SO}_{4) 2}(\mathrm{OH})_{6}\right)\right.$. With the exception of one spring (Marshall) in the Omega mine-pool, both mine-pools show little change in composition with respect to Fe minerals over time.

- Annual chemical flux has declined in both partly flooded mine-pools. The Omega mine-pool flux is irregular from year to year, and after 14 years has declined to about $1 / 3$ of its initial load. The T\&T mine-pool has a consistent rate of change in annual chemical flux and has declined more rapidly than the Omega mine-pool.

- Flux has a strong seasonal component. About $75 \%$ of annual chemical flux is discharged in a six month peak recharge period from January to June in both partly flooded mine-pools. 
- Average long term flux rates, normalized to mine area, are within about one order of magnitude for $\mathrm{Fe}$ and sulfate in both partly flooded mine-pools, and sulfate flux rate is greater than for Fe flux. Normalized flux rates are likely over-estimated since total rock surface area in caved and fractured rock exceeds plan view mine area. Flux rates normalized to mine area do provide a consistent basis for comparison among mines, however.

- Median annual recharge is 0.28 and 0.36 gal/A-min for the two partly flooded mines. Median recharge in spring is from 0.5 to $0.8 \mathrm{gal} / \mathrm{A}-\mathrm{min}$ for the two partly flooded mine-pools. Both partly flooded mine-pools approach base-flow conditions of about 0.1 gal/A-min recharge in the autumn.

These findings are discussed in more detail in chapter three.

In Chapter four, Chemical and Hydrologic Properties of Flooded Mines, geochemical processes were examined in three closed underground coal mines, Barnes\&Tucker, Hahn, and ArdenWestland, supplemented with more limited data from three other flooded mine-pools. The Barnes\&Tucker and Hahn mine-pools initially produced acidic water, but both mine-pools developed circumneutral $\mathrm{pH}$ after flooding. Initial flooding data for the Arden-Westland mine-pool were not in the record, and this mine produced circumneutral $\mathrm{pH}$ water after flooding. Two other flooded mine-pools, Uniontown and Shannopin, also produced acid water during initial flooding, but later evolved into circumneutral pools. Fully or mostly flooded mines can transition from acid to neutral drainage within a decade. The principal findings and observations in flooded mine-pools are:

- Flooding profoundly affects aqueous chemistry of flooded mine-pools. Each mine-pool, initially contained or discharged low $\mathrm{pH}$ waters, or discharges acid water from small unflooded sections. After flooding, mine water shifted to circumneutral, net alkaline conditions, although Fe, sulfate and TDS remained elevated. The typical $\mathrm{pH}$ shift was three to four S.U.

- Extreme vertical stratification of chemical conditions can occur in mine-pool wells and shafts. Transitions can be abrupt, and include one to two order of magnitude changes in parameter concentrations. Samples collected at the beginning of a pumping cycle may not represent long term conditions, as turbulent flow and mixing occur over time.

- Varying stress on the mine-pool, in the form of changing pumping rates, may affect discharge quality. Flushing within the mine-pool is not uniform, and includes preferred flowpaths and short circuiting. Some sections of the mine-pool may have limited fluid exchange.

- Mine-pool water quality exhibits spatial variability. Water in recharge zones, at the beginning of the mine-pool flow-path are the least mineralized. Water becomes more mineralized as it migrates through the mine-pool flow system. 
- Flooded mine-pools are deficient in Fe with respect to sulfate; indicating most iron originally liberated by pyrite oxidation has been retained in the mine-pool. About 60 to $80 \%$ of the Fe is "missing" from the discharge waters.

- Flooded mine-pools consume large amounts of acidity in-situ. Two moles of $\mathrm{H}^{+}$, generated per mole of sulfide to sulfate oxidation, are consumed within the flow system. Net alkaline waters are discharged from each flooded mine-pool.

- Cation exchange of $\mathrm{Na}$ for $\mathrm{Ca}$ and $\mathrm{Mg}$ is a prominent feature in flooded mine-pools.

- Flooded mine-pools contain little or no detectable oxygen, a condition that favors inhibition of pyrite oxidation.

- Flooded mine-pools may approach saturation for one or more minerals especially during early flooding. Gypsum, calcite, dolomite and $\mathrm{Fe}$ oxyhydroxides were near apparent equilibrium in several mine-pools. The waters tend become under-saturated for carbonate minerals and gypsum as the mine-pool ages.

- Computed $\mathrm{pCO}_{2}$ values are up to several hundred times atmospheric conditions, suggesting the mine-pools do not readily exchange gases with the above-ground atmosphere and that chemical weathering of carbonates is ongoing.

- $\mathrm{Eh} / \mathrm{pH}$ plots based on field measured values show mine-pool waters near equilibrium with respect to poorly crystalline $\mathrm{Fe}(\mathrm{OH})_{3}$.

- Sulfate reduction may occur in flooded mine-pools. Computed Eh for the S(-II)/S(VI) couple approaches conditions of FeS formation in one mine-pool.

- Long term flux rates of Fe and sulfate, normalized to area of mine-works, varied about one order of magnitude for each parameter. There was no discernible difference in flux rate between flooded and partly flooded mines. Normalized flux rates are likely over-estimated since total rock surface area in caved and fractured rock exceeds plan view mine area. Flux rates normalized to mine area do provide a consistent basis for comparison among minepools, however.

- Flooded mine-pools that are subdivided by barrier pillars can be visualized as a series of compartments, each with large internal hydraulic conductivity, and small hydraulic gradient and specific storage. Flooded mine-pools behave as confined or leaky confined aquifers.

- Head in confined mine-pools responds to pumping over distances of tens of $\mathrm{km}$. This behavior has practical significance, in that large mine-pools can be controlled by a single pumping facility.

These findings are discussed in more detail in chapter four. 
Chapter five, Temporal Trends and Geochemical Behavior of Mine-pools, addresses in-situ neutralization, longevity of pollutant discharges from flooded and unflooded mines and metal solubility controls in aging mine-pools. The principal observations and findings are:

- A large fraction of the acidity attributable to pyrite oxidation was missing from all five mine-pools. The missing acidity is described as in-situ neutralization and exceeds $100 \%$ in the flooded net alkaline mine-pools. Significantly, the two acid mine-pools had neutralization ratios on the order of 60 to $70 \%$. In-situ neutralization mechanisms include carbonates, alumino-silicates and oxyhydroxides, and alkaline recharge from ground-water infiltration.

- Mineral weathering constituted about 60 to $95 \%$ of the in-situ neutralization, depending on mine-pool age and flooding state. Mineralogy of the residual coal, floor and roof rock is the principal control for in-situ weathering. Mineral weathering was reflected by increased concentrations of $\mathrm{Ca}, \mathrm{Mg}$ and in acidic mine-pools, $\mathrm{Al}$.

- Two methods for estimating neutralization ratio, cation summation and neutralization by difference produced similar estimates. Either can provide a useful estimate of in-situ weathering. A third method for estimating neutralization based on speciated solutions, was also useful for acidic waters containing appreciable Fe(III).

- Long term chemical concentration data often fit a first order type reaction plot. Decay constants are on the order of $10^{-4} / \mathrm{d}$ are with few exceptions, and range over an order of magnitude, for total acidity, Fe, Al, sulfate and TDS.

- Chemical "decay" or rate of change with time can be divided into early flushing and late or long term leaching phases. The early phase includes the flushing of accumulated salts and acid weathering products and rapid concentration declines. The late phase includes the continued weathering of pyrite and other minerals and removal of "juvenile acidity". Separate decay values should be used to model early and late phase water quality conditions.

- Time periods to reach specified water quality concentrations, ranged in general, from about 30 to 70 years duration. Aluminum was predicted to have the longest decay period, in some instances exceeding 100 years. The range of statistical uncertainty can span one to two decades.

- Decay rates are useful for long term trend estimates. They are less useful for estimating concentration at specific points in time.

- The decay constant is a lumped variable that includes both chemical reaction and transport elements. A simple model of slow flushing of the mine-pool relative to mineral dissolution rates produced reasonable results. A model assuming rapid flushing relative to mineral 
dissolution produced results deemed unreasonable. This analysis implies that transport controls observed decay more than chemical kinetics.

- Pyrite oxidation rates estimated from published rate data were about an order of magnitude faster in unflooded mines compared to flooded mines. The rates are sensitive to oxygen content.

- Advective transport of oxygen and weathering products in flooded mines could influence decay rates, and airflow driven by barometric changes may be important for oxygen transport in partly flooded mines.

- The decay constant has no provision for complying with mineral solubility constraints as the mine-pool ages. Samples of aged mine-pools seem to retain dissolved metals such as Fe and Al in the range of a few to a few tens of $\mathrm{mg} / \mathrm{L}$. Simulations of aged mine-pools, including acid water with dissolved $\mathrm{Fe}$ and $\mathrm{Al}$, and a circumneutral water with dissolved $\mathrm{Fe}$, showed that metals will not be removed by precipitation of common mine-pool minerals.

These findings are discussed in more detail in chapter five.

\subsection{Additional Research Needs}

The work conducted in this dissertation left some questions unanswered and raised new ones. The understanding of both physical and chemical mine-pool processes is still incomplete. Future minepool research should consider the following:

- For mine-pools exhibiting seasonal behavior, a predictive expression is needed that honors the underlying long term trend, while modeling seasonal or cyclic change. Time dependent prediction of chemical concentration or flux can be estimated using first order decay equations. The constant does not account for seasonality and estimates become less certain as the rate of change $(\mathrm{dc} / \mathrm{dt})$ slows.

- What is the long term (i.e. multiple decades) chemical composition of mine-pools? A chemical "decay" curve has a long tail, where the rate of change $(\mathrm{dc} / \mathrm{dt})$ in concentration or flux approaches zero. The slope and length of the tail becomes sensitive to small changes in chemical weathering and transport rates. Estimates derived from first order decay implicitly assume that constant hydrogeologic and geochemical conditions persist in the mine-pool, and that solubility or kinetic constraints do not affect behavior at low concentration or flux rate. Observations of several mine discharges for mine-pools 50 or more years old suggests that metal concentrations of a few $\mathrm{mg} / \mathrm{L}$ can persist, and concentration or flux decay becomes asymptotic. This implies that chemical weathering and transport have reached a steady state condition that could be maintained indefinitely.

- Estimation of ground-water flow and transport in a dual porosity mine-pool system is needed. An improved understanding of dual porosity flow, beginning with simulations, could yield improved understanding of how rapidly chemical pollutants are transported 
in and removed from mine-pools. A related question is: how rapidly will chemical concentration and flux reach values considered acceptable for some prescribed use? Mine-pools include a wide range in pore size that allows both true porous media and "pipeline" or turbulent flow to occur. The two flow systems may generate different flushing rates and efficiencies.

- How does one estimate the initial water chemistry composition of a mine-pool that is beginning to flood? At present, estimates of expected mine water composition are based in part on the analogue approach of examining existing underground mines that are believed to have similar hydrologic and geochemical conditions. A reliable predictive model that incorporates site specific geology, stratigraphy, and geochemical composition of the rocks and recharge water is needed to estimate the "starting point" for mine-pools.

- Simple flushing models should be pursued for estimating leaching efficiency in minepools.

- Improved characterization is needed for the composition and solubility of hydrous sulfate minerals associated with mine-pools. Some common mine-pool minerals, such as gypsum are well characterized. Others such as copiapite do not have published reproducible thermodynamic data. Others such as schwertmannite have variable composition.

- Could mine-pool pumping scenarios be developed that would accelerate flushing of pollutants from the system?

- Can $\mathrm{pH}$ and redox conditions be manipulated in-situ to induce pollutant removal within the mine-pool? Flooding is a primary example of redox management in mine-pools. Completely flooded or mostly flooded mines in this study evolved from acidic to circumneutral $\mathrm{pH}$ within about a decade, apparently by stopping or limiting further pyrite oxidation. Mine-pool $\mathrm{pH}$ adjustment has been attempted in a few mines, usually by injection of soluble bases. The two partly flooded mine-pools in this study had flyash and limestone injection. Post injection water quality showed little or modest improvement. The concept has merit, but alkaline sediment injection methods and rates, and water chemistry/base interactions need further development.

- Could passive treatment technology be modified to work in-situ in mine-pools?

Solutions to these issues could improve the understanding and management of mine-pools, reduce adverse effects on water resources and biota, and turn environmental liabilities into resources. 


\section{Chapter 2 Mining, Stratigraphic and Hydrogeologic Conditions}

The quantity and quality of water discharging from closed underground mines is a function of three principal components: mining methods and conditions, stratigraphy and mineral composition, and hydrogeologic properties of the overburden and mine aquifer. This chapter provides a brief summary of mining methods, stratigraphy and mineralogy, and finally a short summary of groundwater recharge storage and discharge concepts for mine-pools in the Appalachian region. These concepts underlie the more detailed analyses in chapters three, four and five.

\subsection{Underground Coal Mining Methods}

Underground coal mines studied in this work had coal extracted using the room and pillar techniques. Figure 2-1 is a schematic representation of room and pillar development. Rooms ranging from about 18 to 30 feet wide are developed in parallel, separated by intact pillars left for roof support. Cross cuts are driven at right angles, resulting in a rectangular patter of rooms and pillars. There are several variations in pattern of development, but each follows the basic concepts shown in figure $2-1$.

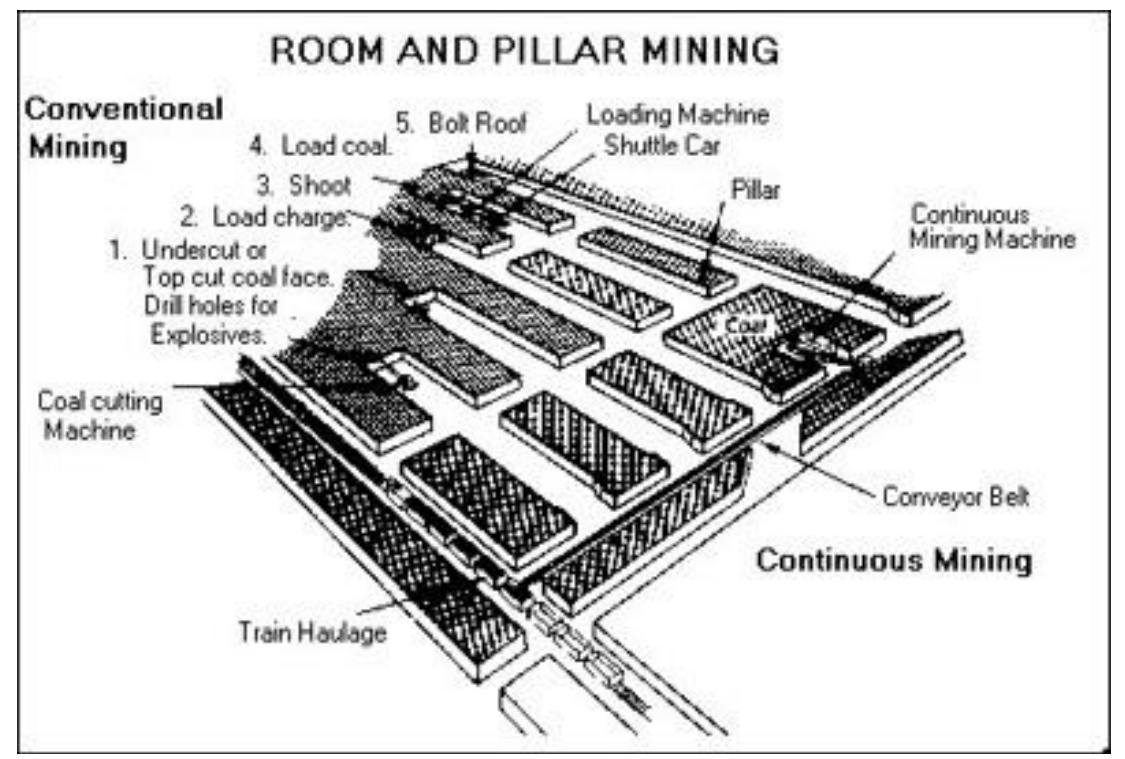

Figure 2-1. Schematic of Room and Pillar Development in Underground Coal Mines. Adapted from United Mine Workers of America (http://www.umwa.org/)

After initial development, more coal may be extracted by retreat mining; where additional coal is removed from the existing pillars. Retreat mining (or second mining) removes a portion of the roof support, and increases the likelihood of subsidence. A retreat mined section can consist of a mixture of standing pillars with open void, partially subsided rooms, and fully subsided areas that are filled with a mixture of caved, broken rock from the overlying strata. The mine-pool matrix material may, therefore, vary in lithology, particle size and mineral composition. Extraction rates in room and pillar mining range from around 50 to as much as $80 \%$, depending on mining conditions (Peng, 1986). The size of the pillars is based on overburden load, mining height and rock strength. Prior to about 1970, nearly all underground coal mining in the United 
States utilized room and pillar methods. Figure 2-2 shows part of the underground mine-map for the T\&T mine complex. The mine was developed using room and pillar methods, but the final geometry of the mine is complicated by topography, geologic structure, geologic variability, mineral ownership and other factors. The other room and pillar mines studied in this project also have irregular dimensions.

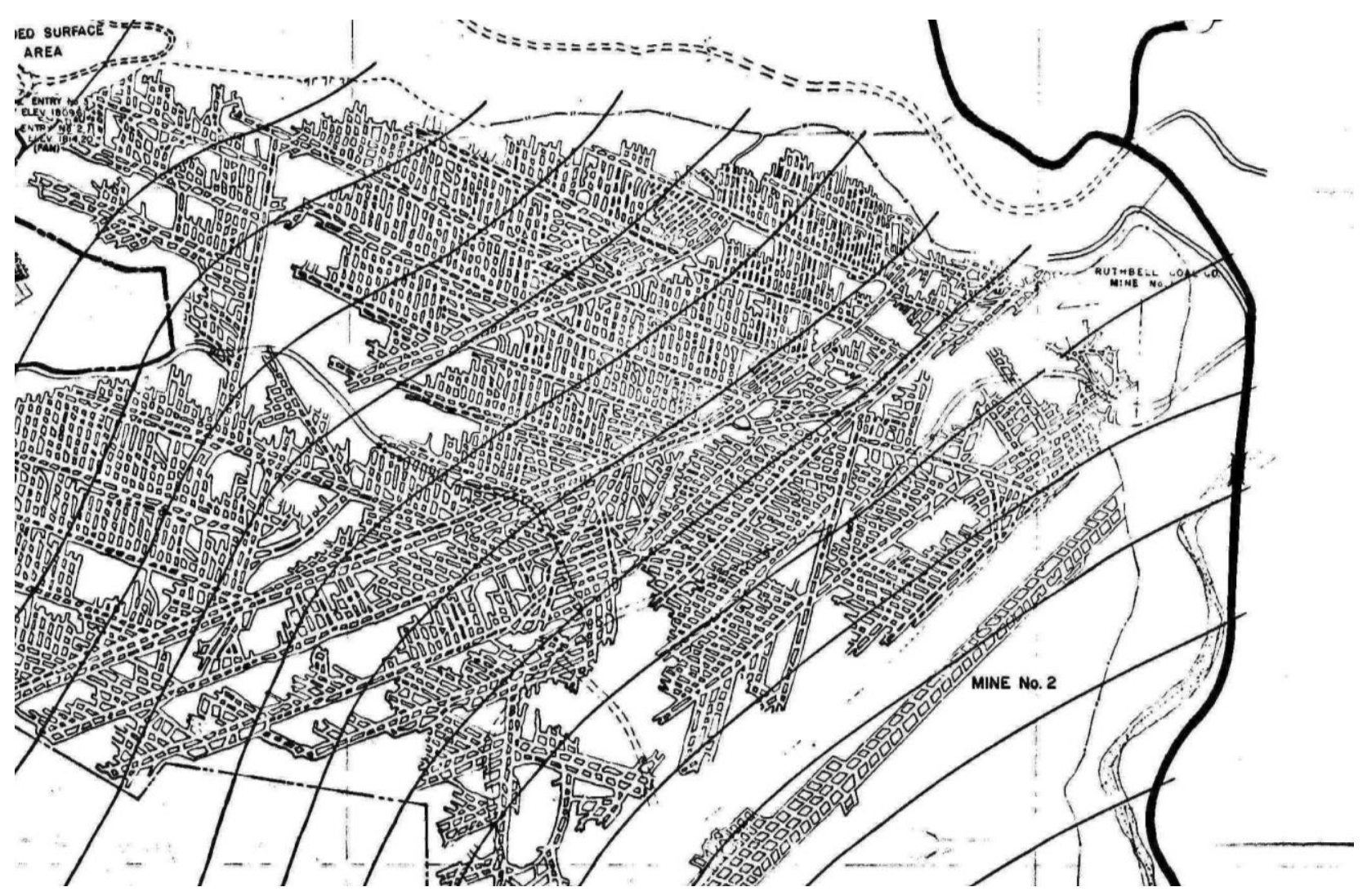

Figure 2-2. Portion of Underground Minemap for T\&T Mine-pool, Illustrating Room and Pillar Mining Method and Variable Dimensions of Mine Development. Approximate Scale 1"= 1000 feet.

Longwall extraction is the second principal underground coal mining method used in the US. Although none of the mines in this study used longwall mining, much of the literature on subsidence and ground control focuses on longwall extraction. Figure 2-3 is a schematic of longwall mining. Rectangular panels are laid out in widths ranging up to 1200 feet, and lengths extending to 10,000 feet. Coal is extracted using a shear or "plow" that passes back and forth along the active face, with the immediate working area supported by moveable hydraulic shields. As mining and the shields advance, the unsupported roof collapses into the mined out area. Adjacent rectangular panels are separated by chain pillars which provide access and ventilation. The final mine geometry is generally more regular than room and pillar, and the entire panel area is subsided. The "gob" or subsided material is a mixture of caved and broken material overlying the coal bed. Mining effects on mine-pool hydrology are further developed in section 2.3. 


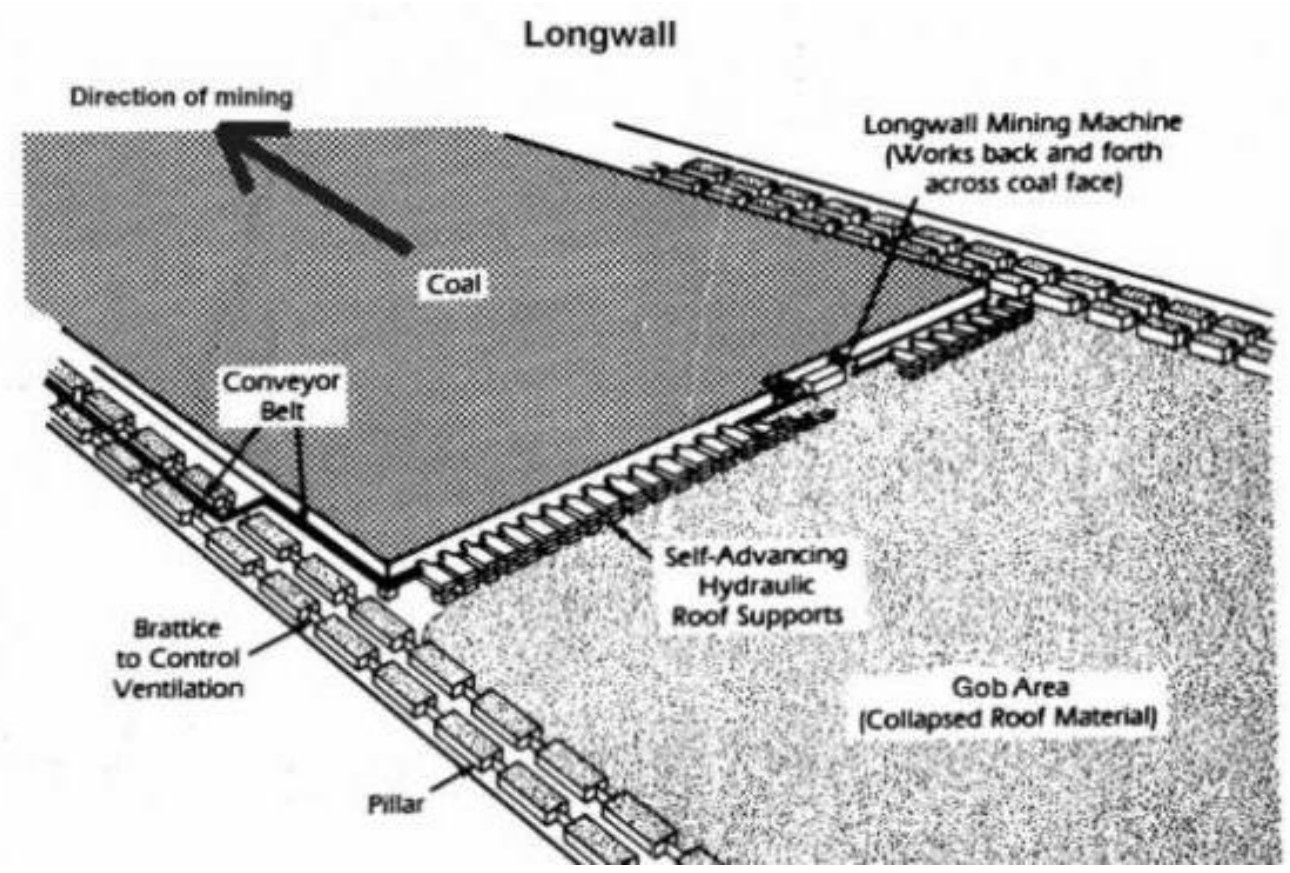

Figure 2-3. Schematic of Longwall Mining.

Adapted from United Mine Workers of America (http://www.umwa.org/)

\subsection{Stratigraphy and Mineral Composition.}

Stratigraphy and mineralogy of Pennsylvanian system rocks have been described both in terms of classical geology (see for example Arkle et al., 1979 for discussion of West Virginia, and Edmunds et al., 1979 for Pennsylvania), coal geology (see Donaldson et al.,1979) and in the context of mine drainage (see Brady et al., 1998). The mines in this study are developed in Upper Pennsylvanian rocks in the Allegheny and Monongahela groups in northern West Virginia (Preston, Monongalia and Marion Counties) and western Pennsylvania(Washington, Cambria and Fayette Counties). Figure 2-4 shows the general location, stratigraphic group and coal bed of mine-pools in this study.

The rocks in the study area were deposited in a foreland basin extending along a north-northeast axis across West Virginia into Pennsylvania. Basin subsidence created characteristic cyclothems, or repetitive sequences of coal, shale, mudstone, limestone and sandstone (Arkle et al., 1979; Edmunds et al., 1979). Stratigraphic relationships are complicated by repeated transgressions and regressions of inland seas, varying basin subsidence and shifting depositional environments including marine, lacustrine swamps, coastal plains and upper and lower delta plains. As a result, rock layers are frequently lenticular or discontinuous and vary in chemical and mineralogical composition over distances of kilometers or less. The basin also includes a series of low angle folds, with anticlines and synclines whose axes are generally oriented north-northeast along strike. These folds and regional dip influence the extent of flooding and flow direction in mine-pools.

Brady et al. (1998) made the following observations about these rocks in the context of mine drainage predictions in Pennsylvania: 
- Acid drainage problems are more prevalent in the lower Allegheny group than in stratigraphically higher rocks.

- Pyrite and carbonate content are influenced by paleoclimate and depositional environment. Rocks formed in brackish waters were supplied with both Fe and sulfate and therefore have pyrite, but often contain few carbonates. Hence their tendency is to produce acid drainage. Marine rocks may contain abundant carbonates and pyrite and produce waters of high dissolved solids content. Fresh water limestones may be important alkalinity sources.

\section{Mine-pool Locations, Group and Coal Bed}

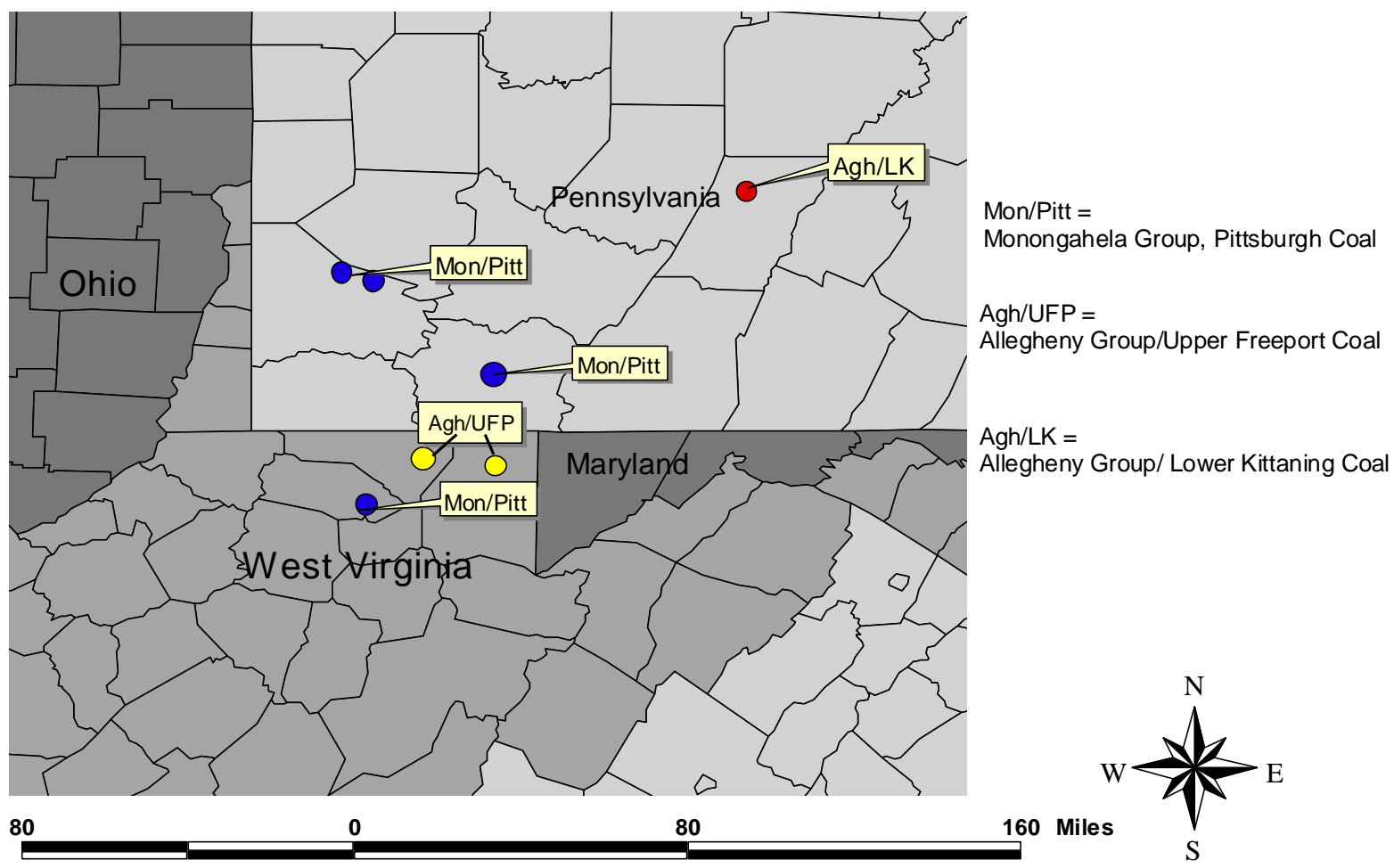

Figure 2-4. General Location Map of Mine-pools Studied in West Virginia and Pennsylvania.

Four are in the Monongahela Group, Pittsburgh coal bed; two are in the Allegheny Group, Upper Freeport coal bed, and one is located in the Allegheny Group, Lower Kittanning coal bed.

Dulong et al. (2002) characterized the mineralogy and chemical composition of Upper Pennsylvanian rocks in several deep rocks cores. Their data support the regional observations of Brady et al. (1998). A generalized stratigraphic column for northern Appalachia is shown in figure 2-5. The Monongahela group, which includes the Pittsburgh coal at its base, contains limestones, abundant limy shales and mudstones, and high sulfur rocks. The Allegheny group (figure 2-5) which includes the Kittanning and Freeport coal beds contains few carbonates and some pyritic 
zones, hence the tendency to produce acidic drainage. Local stratigraphy is described in more detail in county level geologic survey reports in West Virginia and Pennsylvania.

\begin{tabular}{|c|c|}
\hline 1 & END OF THE LATE PALEOZOIC \\
\hline $\begin{array}{l}\text { Dunkard } \\
\text { Group } 335 \mathrm{~m}+ \\
(1100 \mathrm{ft})\end{array}$ & $\begin{array}{l}\text { Proctor sandstone } \\
\text { Windy Gap limestone } \\
\text { Nineveh coal } \\
\text { Nineveh limestone } \\
\text { Jollytown sandstone } \\
\text { Jollytown coal } \\
\text { Hundred sandstone } \\
\text { Upper Washington limestone } \\
\text { Lower Marietta sandstone } \\
\text { Washington coal } \\
\text { Waynesburg sandstone } \\
\text { Cassville shale-Elm Grove limestone }\end{array}$ \\
\hline $\begin{array}{l}\text { Monongahela } \\
\text { Group } \\
70-122 \mathrm{~m}+ \\
(230-400 \mathrm{ft})\end{array}$ & $\begin{array}{l}\text { Waynesburg coal } \\
\text { Gilboy sandstone } \\
\text { Uniontown coal } \\
\text { Benwood limestone } \\
\text { Sewickley coal } \\
\text { Redstone coal } \\
\text { Redstone limestone } \\
\text { Upper Pittsburgh sandstone } \\
\text { Pittsburgh coal }\end{array}$ \\
\hline $\begin{array}{l}\text { Conemaugh } \\
\text { Group } \\
137-259 \mathrm{~m} \\
(450-850 \mathrm{ft})\end{array}$ & $\begin{array}{l}\text { Lower Pittsburgh sandstone } \\
\text { Elk Lick coal } \\
\text { Ames limestone' } \\
\text { Harlem coal } \\
\text { Saltsburg sandstone } \\
\text { Woods Run limestone' } \\
\text { Bakerstown coal } \\
\text { Pine Creek limestone' } \\
\text { Buffalo sandstone } \\
\text { Brush Creek limestone' } \\
\text { Brush Creek coal } \\
\text { Mahoning sandstone }\left\{\begin{array}{l}\text { Mahoning coal } \\
\text { Thornton fire clay }\end{array}\right. \\
\text { Uffington shale }\end{array}$ \\
\hline $\begin{array}{l}\text { Allegheny } \\
\text { Formation } \\
30-91 \mathrm{~m} \\
(100-300 \mathrm{ft})\end{array}$ & $\begin{array}{l}\text { Upper Freeport coal } \\
\text { Bolivar fire clay } \\
\text { Upper Freeport sandstone } \\
\text { Lower Freeport coal } \\
\text { Upper Kittanning coal } \\
\text { Washingtonville limestone' } \\
\text { Middle Kittanning coal } \\
\text { Hamden (Columbiana) limestone' } \\
\text { Lower Kittanning coal } \\
\text { Lower Kittanning clay } \\
\text { Vanport (Ferriferous) limestone' } \\
\text { Clarion fire clay }\end{array}$ \\
\hline $\begin{array}{l}\text { Pottsville } \\
\text { Group } \\
15(?)-61 \mathrm{~m} \\
(50-200 \mathrm{ft})\end{array}$ & $\begin{array}{l}\text { Homewood sandstone } \\
\text { Mercer coal } \\
\text { Connoquenessing sandstone } \\
\text { Sharon sandstone(?) }\end{array}$ \\
\hline
\end{tabular}

Figure 2-5. Generalized Stratigraphic Column of Upper Pennsylvanian System Rocks in

Northern West Virginia Showing Principal Coals, Limestones, Sandstones and Fireclays.

The mines in this study are in the Pittsburgh coal (base of Monongahela Group) and Upper Freeport and Middle Kittanning coals (Allegheny Formation). Adapted from Arkle et al., 1979. 


\subsection{Hydrogeology of Unmined and Mined Rocks in the Appalachian Plateau}

Chemical attributes of mine-pools are influenced by the quantity and quality of recharge water entering the pool, and water storage and transmission properties of the new mine-pool aquifer. This section provides a conceptual overview of ground-water flow and storage in unmined rocks, and the similarities and differences compared to aquifers developed in underground mine-works.

Callaghan et al. (1998) provide a summary review of ground flow water systems in the Appalachian plateau. They distinguish three types of flow systems; a shallow system in fractured and weathered regolith, a second system at intermediate depth, and deep regional flow systems, generally located below base level drainage. The shallow flow system is characterized by short residence times and rapid ground-water movement. Fracture flow dominates and the openings may be regular joints or stress relief fractures. Wyrick and Borchers (1981) noted that stress relief fractures were the most transmissive part of the aquifer. Callaghan et al. (1998) estimate that permeability increases due to joints and fractures may extend as deep as 500 feet. The Omega and T\&T mine-pools are at depths generally less than 250 feet and contain thick sandstones in the overburden. Figure 2-6 shows the face-up area for the mine entries at the Omega mine. There are

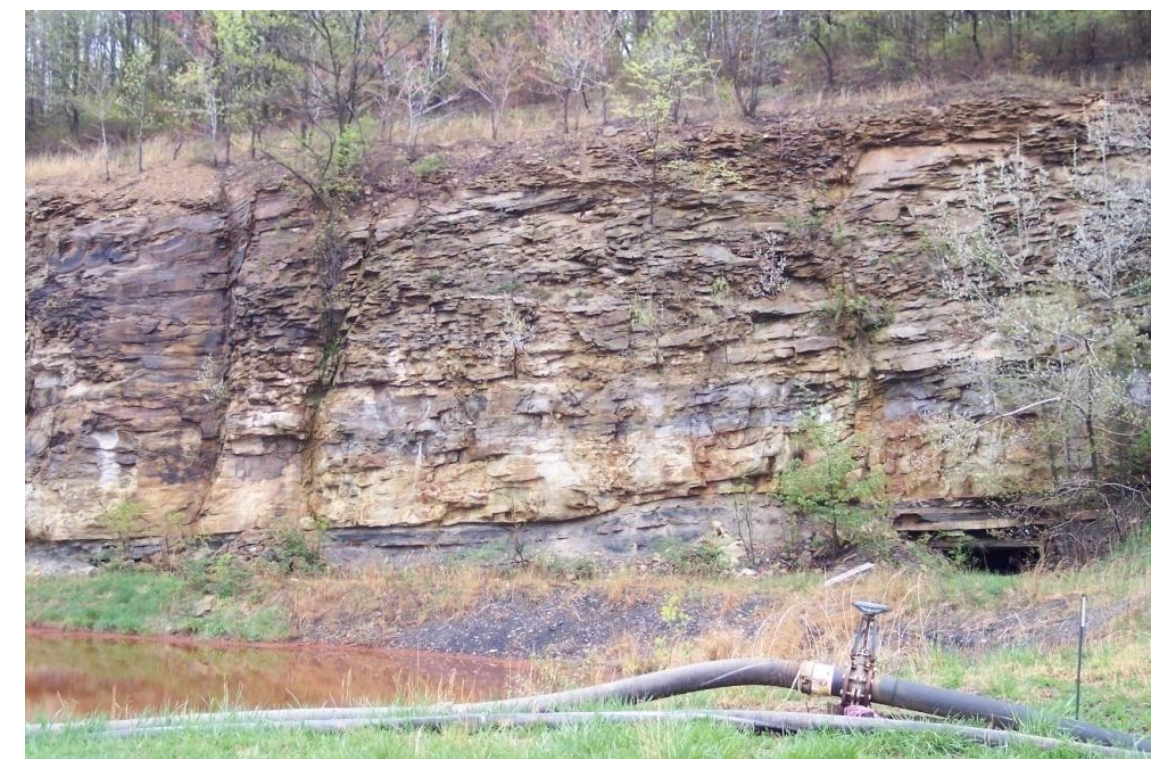

Figure 2-6. Omega Mine Face-up Area Showing Vertical Fractures in Sandstone Overburden. Partially Open Mine Entry at Right.

several prominent vertical fractures exposed in the highwall, which would promote rapid infiltration and mine-pool response to recharge events. Stoner et al. (1987) estimate that as much as 99\% of ground-water recharge, circulation and discharge occurs in the shallow ground-water zone.

Sames and Moebs (1989) indicate that the effects of stress relief fractures in underground coal mines are not significant under more than about 300 feet of cover. Bruhn (1985) found that hydraulic conductivity decreased as depth increased from about 150 to 300 feet at a West Virginia mine site. In Greene County, PA, Stoner et al. (1987) report that hydraulic conductivity decreased by about one order of magnitude per 100 feet of depth to a depth of about 500 feet. McCoy (2002) 
found that at depths greater than about 500 feet, mine inflow rate and overburden thickness are unrelated. Thus it appears that at depth, fractures are less frequent with fewer interconnections and mine inflow rate is controlled more by primary porosity of the rocks.

Kozar and Mathes (2001) reported median aquifer transmissivity of 150 and $850 \mathrm{ft}^{2} /$ day, in the Monongahela and Allegheny groups, respectively in West Virginia. Well depths were mostly between 100 and 200 feet. Hobba (1981) noted that transmissivity and hydraulic conductivity generally increased in rocks above underground coal mines.

The intermediate and deep flow systems have progressively longer residence times and slower ground-water circulation patterns. Fractures are less common, and primary, or intergranular hydraulic conductivity controls the movement of ground-water. The Barnes\&Tucker, Hahn, Arden-Westland, and Fairmont mine-pools are located mainly in the intermediate and regional ground-water systems.

The development of underground mines, coal removal and dewatering during active operations generates stresses in the overburden rocks and aquifers. The immediate to short term effects can include subsidence and partial to complete dewatering (Cifelli and Rauch, 1986; Hobba, 1981; Kendorski, 1993). After closure and the onset of flooding, ground-waters may recover partially to completely (Booth, 1986; Booth, 2007; Liu et al., 1997), but the new mine-pool aquifer may have properties very different from the original bedrock aquifers.

Burby et al. (2000) for example, found that underground mine discharges had behavior similar to springs in karst aquifers. Adams and Younger (2001) found that ground-water flow in flooding mines in the UK could be adequately simulated by treating the mine as a series of ponds connected by pipes and applying pipe flow formulations. These findings and observations of subsidence and physical weathering suggest that mine-pools may have a dual flow (porosity) system consisting of large voids and rapid flow, and a slower Darcian component.

When mine-pools begin to form in abandoned workings, the new aquifer is recharged from ground-water infiltrating from overlying rocks, or in some instances, lateral flow and leakage from adjacent mines. Kendorski (1993) developed a five layer model which shows that large variation in aquifer properties is possible. He based his model on data from over 65 cases of high extraction mining (primarily longwall or room and pillar retreat mining) and extensive review of existing literature. Many of the case studies were in Appalachia and the Illinois basin. His generalized model identified five zones of differing hydrogeologic properties as illustrated in figure 2-7. They include:

- A zone of collapse and disaggregation (physical weathering) that extends six to ten times the mined thickness (height) above a panel (I, Caved Zone).

- A zone of continuous fracturing extending up to 24 times the mining height which allows for dewatering of intercepted aquifers or surface waters on at least a temporary basis (II, Fractured Zone). 
- A dilated leaky zone extending 24 to 60 times mining height with increased ground-water storativity and low vertical transmissivity. (III, Dilated Zone).

- A constrained leaky zone above zone III, and below zone V, described below, where storativity and transmissivity are not affected (IV, Constrained Zone).

- Surface fracturing to depths of as much as 50 feet below ground surface (V, Surface Fracture Zone).

Kendorski (1993) comments that the caved zone height is in part a function of rock lithology, where more competent sandstones and limestones limit caving to six times mining height or less. Particle shape also influences caving as equidimensional blocks produce more rubble volume and void space. Kendorski's model is illustrated in figure 2-7, for a case of mines developed in two

Zone I -Collapsed Overburden, 6 to 10x mine height

Zone II- Zone of Fracturing, extending up to $24 \mathrm{x}$ mine height

Zone III-Dilated Zone, horizontal bedding plane seperations and fractures, extending about 24 to $60 \mathrm{x}$ mine height Zone IV- Leaky Aquitard Zone

Zone V-Surface Fracture Zone

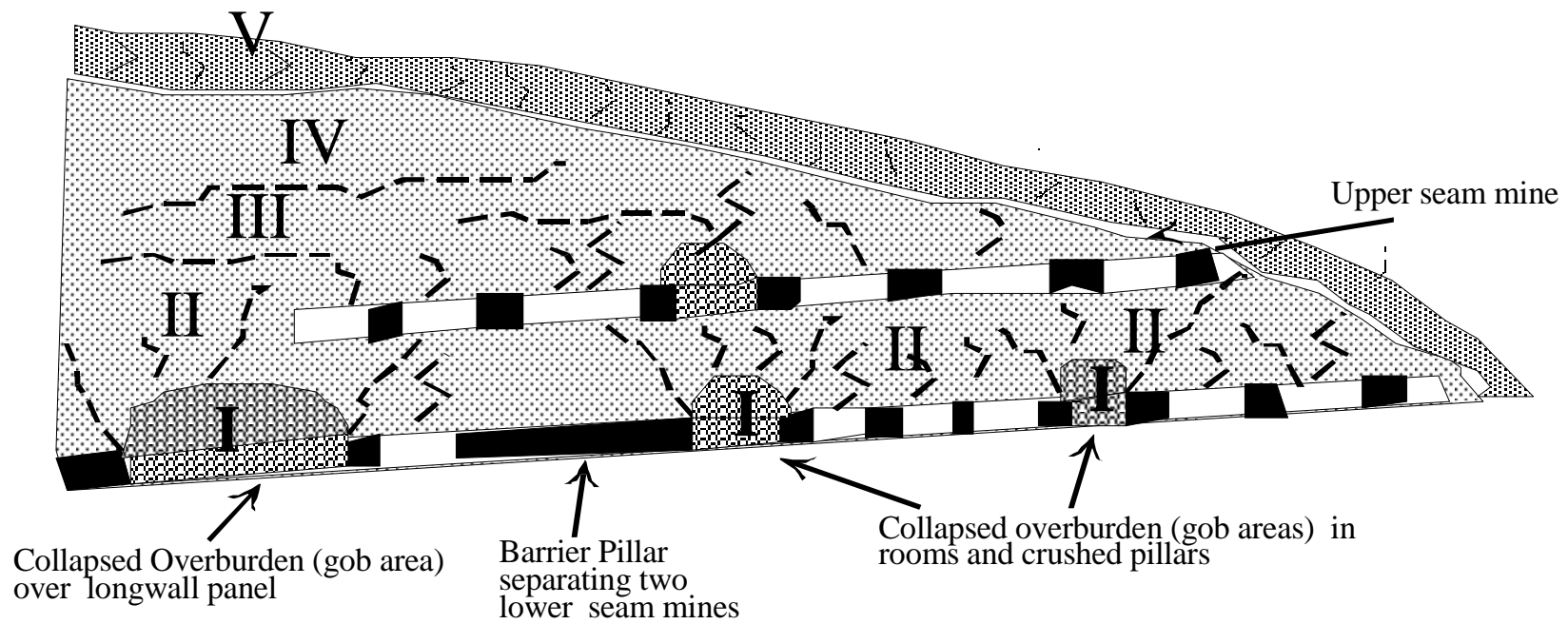

Figure 2-7. Simplified Cross Section of Barrier Pillars and Overburden Conditions after Mine Closure. (Modified from Kendorski, 1993).

coal beds. The propagation of zones I and II result in hydraulic connection between the mines. The Barnes\&Tucker mine-pool, described in chapter four is an example of a mine-pool connected across two coal beds.

Krendorski's generalized model served as the basic concept on which mine-pools were evaluated in this study. Two significant implications of the model are: 
- Mine-pool water quality is not determined solely by rocks at mine level. Caving deposits disaggregated rocks from the overburden into the mine-works. These materials are available to participate in chemical weathering reactions in the mine-pool, and influence chemical composition.

- Water storage and conductance may vary spatially. Mine-pool aquifer thickness is variable depending on extent of caving, and conductance can include both pipe flow and porous media components.

Chapters three and four examine partly flooded and mostly flooded mine-pools in more detail, while chapter five addresses long term trends in chemical composition. 


\section{Chapter 3: Chemical and Hydrologic Properties of Partly Flooded Mines}

Partly flooded or "above drainage" underground mines are often continuing sources of acidic drainage after closure or abandonment. Skousen et al. (2006) reported on long term water quality of above drainage mines in northern West Virginia. Most mines had decreasing pollutant concentrations as they aged, but with few exceptions, they continued to discharge low $\mathrm{pH}$ water with $\mathrm{Fe}, \mathrm{Al}$, sulfate and other chemicals. Conceptually, partly flooded mines can be viewed as large reactor and leaching chambers, that are regularly supplied with oxygen to oxidize pyrite, and water to rinse soluble weathering products. Flooding mines, as discussed in chapters four and five, at some stage, become depleted in oxygen, and pyrite weathering is restricted or halted.

This chapter investigates some fundamental chemical and hydrogeologic processes in two partly flooded underground mines in northern West Virginia. Drainage from these and similar mines often degrade the receiving watershed, and few strategies, except chemical or passive treatment, are effective in reducing impacts. An improved understanding of the processes operating in closed partly flooded mines may provide insight into the duration and severity of pollution, and what reclamation schemes could be applied to these mine-pools.

\subsection{Data Acquisition}

Water quality analyses for the above-drainage mines were obtained from three sources including:

- samples collected by the author for the Omega and T\&T mine-pools,

- samples collected by the West Virginia Dept of Environmental Protection (WVDEP) for the Omega and T\&T mine-pools. Data were provided by the special reclamation unit and retrieved from a file search in the Philippi, WV office of WVDEP,

- samples collected by the US Dept of Energy (USDOE) office in Pittsburgh, PA from 1993 to 1999 for the Omega mine record. These data were made available to the author.

The author collected and preserved mine-pool samples following guidelines suggested by Cherceri et al. (1998). This included appropriate filtering, preservation and containers, and field measured $\mathrm{pH}, \mathrm{Eh}$, specific conductance, and dissolved oxygen.

Data obtained from WVDEP were analyzed at two different labs, with the change of service occurring in October 2001. Samples collected by the USDOE were analyzed at its' contract lab and the author's samples were analyzed at a fourth commercial lab. This introduced some uncertainty and limitations into the analyses. Where feasible, data were examined for quality control using charge balance, conductance/TDS relationships and similar techniques. A total of about 290 samples were compiled for the T\&T mine-pool for the period 1994 to 2007. Multiple sample points exist at the Omega mine-pool and the number of samples varies. The main treatment inlet monitoring point includes about 230 samples from 1993 to 2007. 
WVDEP data include standard mine drainage analyses for $\mathrm{pH}, \mathrm{Fe}, \mathrm{Mn}, \mathrm{Al}$, sulfate, total acidity, TDS and Specific Conductance. The USDOE data include mine drainage parameters plus major cations and anions, Fe(II) determinations, and selected trace elements. Fe(III) was determined as the difference between total dissolved Fe and dissolved Fe(II). Most samples from both sources also include an instantaneous flow measurement. Total acidity was calculated from metals in $\mathrm{mg} / \mathrm{L}$ and $\mathrm{pH}$ as:

$$
\text { Acidity }_{\text {total }}=50\left[(2 * \mathrm{Fe}(\mathrm{II}) / 56)+(2 * \mathrm{Mn} / 55)+\left(3^{*} \mathrm{Al} / 27\right)+\left(1000^{*} 10^{\wedge-\mathrm{pH}}\right)\right]
$$

Kirby and Cravotta (2005), and Cravotta and Kirby (2005) discuss, in detail, theoretical and practical aspects of acidity measurements in mine waters. They concluded that Fe should be represented as $\mathrm{Fe}$ (II) in acidity calculations after examining Fe speciation in mine water. Unless otherwise noted, total acidity data are calculated values using equation 3-1.

Sampling has been conducted on monthly intervals, and at times more frequently for both the Omega and T\&T mine-pools. Some monitoring points have periods of no discharge and hence no chemical analyses.

The WVDEP also provided daily flow and on-site precipitation data for part of the record at both mine-pools. This information was used for developing recharge and water budget estimates.

A large change in sulfate concentration occurred in October 2001 for both the Omega and T\&T mine-pools, corresponding to the change in analytical lab service. No other chemical parameters exhibited similar change, nor were there any known changes in discharge, treatment etcetera that could reasonably account for the observed sulfate change. Sulfate concentrations were regressed against other chemical parameters to determine if a consistent estimator relationship could be identified. Potential predictors included Fe, Al, flow, total acidity and TDS. Dissolved solids provided the most consistent relationship among sample locations for the period 1993 to 1999. The computed regression for sulfate on TDS at three monitoring points; Marshall, DEF, and Treatment Inlet discharges, percentage of variation explained, and lower and upper bounds at $95 \%$ are shown in table 3-1.

Table 3-1

Regression Results Estimating Sulfate from TDS at Three Discharges, Omega Mine-pool

\begin{tabular}{ccccc}
\hline Site & Regression & $\mathrm{R}^{2}$ & $\begin{array}{c}95 \% \text { Confidence } \\
\text { Lower bound }\end{array}$ & $\begin{array}{c}95 \% \text { Confidence } \\
\text { Upper Bound }\end{array}$ \\
\hline Marshall & $\begin{array}{c}\mathrm{SO}_{4}(\mathrm{mg} / \mathrm{L})= \\
0.666 * \mathrm{TDS}\end{array}$ & $96.9 \%$, & 0.645 & 0.686 \\
Discharge & $\begin{array}{c}\mathrm{SO}_{4}(\mathrm{mg} / \mathrm{L})= \\
\text { DEF Discharge }\end{array}$ & $95.65 \%$ TDS & 0.634 & 0.681 \\
Treatment Inlet & $\begin{array}{c}\mathrm{SO}_{4}(\mathrm{mg} / \mathrm{L})= \\
0.676 * \mathrm{TDS}\end{array}$ & $96.8 \%$ & 0.657 & 0.696 \\
\hline
\end{tabular}


Slope for the three regressions are similar, with relatively narrow upper and lower bounds on $95 \%$ confidence limits. Samples collected by the author from 2002 to 2008, and analyzed at a different lab, had sulfate values comparable to those estimated for the WVDEP data, and sulfate/TDS ratios similar to the slopes in table 3-1. A similar analysis was conducted for the T\&T mine-pool data. A slope of 0.58 was the "best fit" estimator for sulfate from TDS for the T\&T data. The derived TDS-sulfate relationships were used to estimate sulfate data for WVDEP samples after October, 2001.

\subsection{Mine Setting and Mining History}

\subsubsection{Omega Mine}

The Omega mine is a small underground mine in the Upper Freeport coal bed at the top of the Allegheny Group (Hennen and Reger, 1913). The mine-works covers about 69 hectares and are located in Monongalia County, West Virginia. Coal thickness is commonly about $1.3 \mathrm{~m}$, with a shale parting. The West Virginia Geological and Economic Survey (2002) reports an average total sulfur content of about $2.5 \%$ and average pyritic sulfur content of about $1.7 \%$ for the Upper Freeport coal bed. The Bolivar fireclay, a hard siliceous mudrock, immediately underlies the coal bed. At this mine, the Uffington shale overlies the coal bed and is commonly less than $0.6 \mathrm{~m}$ thick based on observations of exposed strata in the face-up area. The Mahoning and Buffalo sandstones comprise most of the overburden above the Uffington shale. These rocks may reach a combined thickness exceeding $30 \mathrm{~m}$, and where exposed at the mine face-up, they display prominent vertical fractures. The mine has a maximum overburden thickness of about 76 meters, and is located above the local base level drainage. The Omega mine is contained within a broad ridgetop on the western flank of the Chestnut Ridge anticline, and strata dip about $11 \%$ to the northwest (Gray et al., 1998) The rocks in this section contain few carbonates (Hennen and Reger, 1913).

Coal was extracted by room and pillar methods from the Upper Freeport coal bed until mine closure in 1989. Recovery ranged from $50 \%$ in first mined areas, to over $70 \%$ in areas of second mining. Data presented by EPRI (2001) indicates that most of the mine-works had 60 to $70 \%$ extraction. Average mining height was about $1.3 \mathrm{~m}$. In the early 1990s, acid drainage began seeping from several locations along the coal crop-line (figure 3-1). Further details of the Omega mine are provided by EPRI (2001) and by Perry and Rauch (2004, Appendix A). There are no adjacent underground mines and the Omega complex is surrounded by unmined coal.

The Omega mine discharge features are shown in figure 3-1. An estimated $30 \%$ or less of the mine-works are flooded, and the mine-pool drains by gravity discharges along the down-dip coal outcrop. The mine-pool is not pumped. After closure, the mine partially flooded, and the general ground-water flow pattern within the mine-works is inferred to be in the direction of dip.

Mine drainage was collected and treated after several lateral boreholes were drilled into the northern mine-works to divert mine-water away from a section adjoining a stream, Cobun Creek, with a public water supply (Morgantown reservoir). Treatment sludge was initially injected into the mine-works for disposal. The West Virginia Department of Environmental Protection (WVDEP) assumed control of the site in the mid 1990's and disposes of the material offsite. 


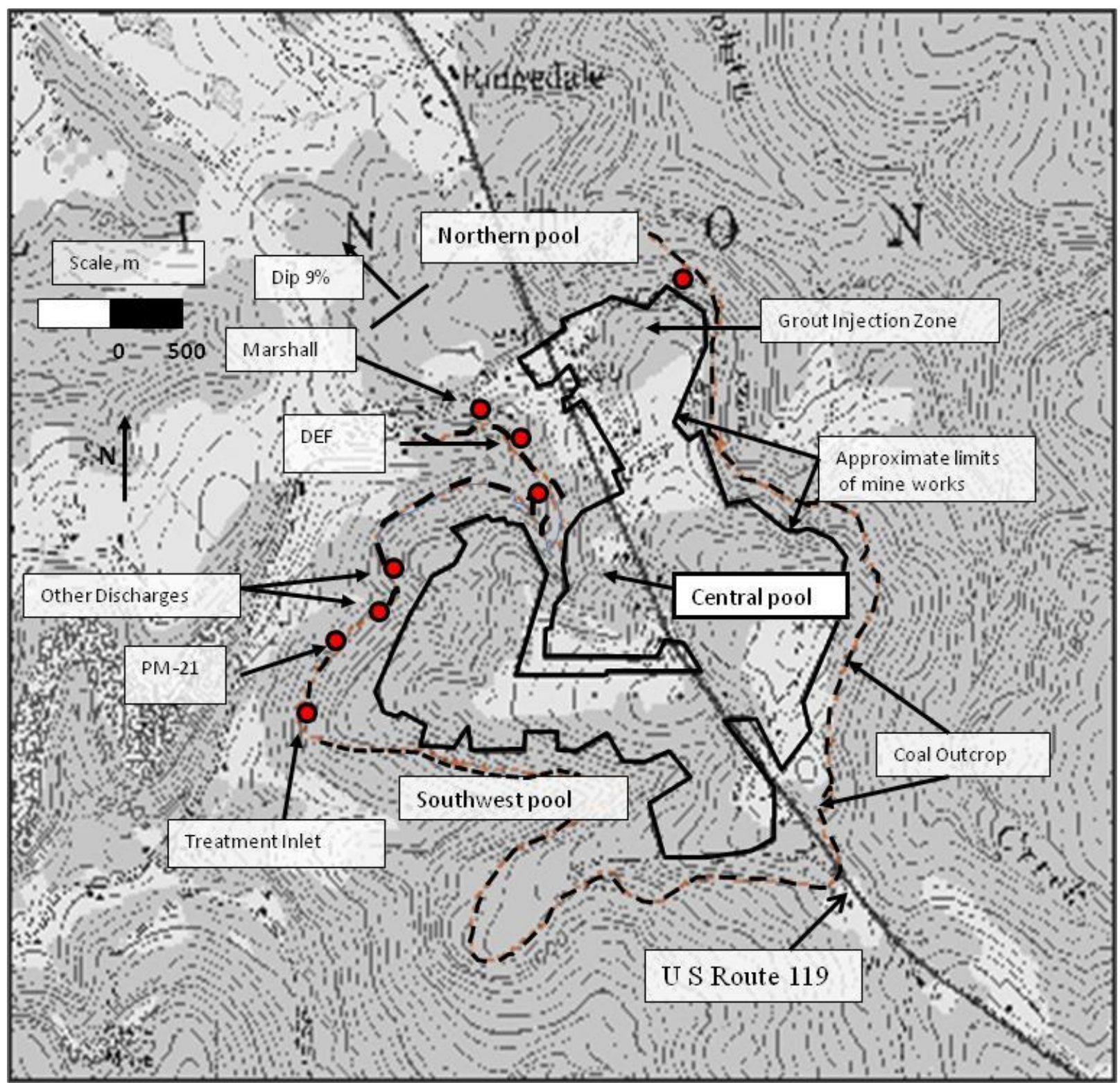

Figure 3-1. Extent of Omega Mineworks (black line), Coal Outcrop (dashed line) and Discharges (circles).

WVDEP also installed a series of pipelines and manholes to more easily and securely collect, sample, measure, and convey mine-water to the treatment facility. In some instances, several adjacent seeps were combined into a single monitoring point. In 1998, a cooperative state, federal and privately funded grouting project was initiated to reduce or abate acidic discharges in the north lobe (Figure 3-1) of the mine (Gray et al., 1998; EPRI, 2001). This area comprises about 10.5 hectares, or $15 \%$ of the mined area, but was estimated to be discharging about $55 \%$ of the acid load (EPRI, 2001). About $61,000 \mathrm{~m}^{3}$ of grout mix containing fluidized-bed combustion ash, flyash and cement were injected in the North Lobe. Subsequent drilling and borehole camera observations confirmed that, in general, the grout mixture provided near complete filling of mine voids. Water 
quality remained poor after grouting; however, flow, and consequently acid load, decreased (EPRI, 2001).

Summary data for four Omega mine discharges at two different time periods are shown in table 3-2. The 1993-1994 data represent conditions in the first few years after the mine closed, partly flooded and began to discharge. The 2001 data are indicative of long term conditions, after the grout injection and initial flushing occurred. Acidity and metal concentrations declined over the seven year period but overall water quality remains poor. Median values for one year periods illustrate the high concentrations of $\mathrm{Al}, \mathrm{Fe}$ and sulfate. With the exception of the Marshall discharge in 2001, $\mathrm{pH}$ was less than three. Post-grouting, the Marshall discharge quality has shown a modest increase in $\mathrm{pH}$ to about 3.5, compared to less than 3.0 prior to grout treatment. The Marshall drainage has also been enriched in $\mathrm{Ca}$, and approaches saturation for gypsum after grouting (Perry and Rauch, 2004). Some acid neutralization must be provided by dissolution of the grout material, based on increases in $\mathrm{Ca}, \mathrm{Mg}$, and $\mathrm{Na}$ from pre to post grouting. Except for PM-21 in 1993, total acidity exceeds $1000 \mathrm{mg} / \mathrm{L} \mathrm{CaCO}_{3} \mathrm{Eq}$.

Table 3-2

Omega Mine Summary Water Quality

for Three Discharges at Two Time Periods ${ }^{(1)}$

\begin{tabular}{cccccccc}
\hline Site & Date & Grouting & $\mathrm{pH}$ & $\begin{array}{c}\text { Total Acidity } \\
\text { (mg/L) }\end{array}$ & $\begin{array}{c}\text { Fe } \\
\text { (mg/L) }\end{array}$ & $\begin{array}{c}\text { Al } \\
\text { (mg/L) }\end{array}$ & $\begin{array}{c}\text { Sulfate } \\
\text { (mg/L) }\end{array}$ \\
\hline Treatment Inlet & 2/93 to $1 / 94$ & Pregrout & 2.94 & 2000 & 677 & 129 & 3316 \\
Treatment Inlet & 2001 & Postgrout & 2.8 & 1336 & 368 & 109 & 2300 \\
Marshall & 2/93 to 1/94 & Pregrout & 2.62 & 4550 & 1612 & 274 & 5975 \\
Marshall & 2001 & Postgrout & 3.3 & 1893 & 689 & 107 & 3275 \\
PM-21 & 2/93 to1/94 & Pregrout & 2.99 & 464 & 119 & 41 & 2856 \\
PM-21 & 2001 & Postgrout & 2.80 & 1300 & 214 & 139 & 2570 \\
DEF & 2/93 to1/94 & Pregrout & 2.71 & 2000 & 664 & 129 & 3141 \\
DEF & 2001 & Postgrout & 2.60 & 1261 & 313 & 103 & 2201 \\
\hline
\end{tabular}

(1) Median values. $\mathrm{pH}$ in S.U. Acidity in $\mathrm{CaCO}_{3} \mathrm{Eq}$.

\subsubsection{T\&T Mine-pool}

The T\&T mine-pool consists of about 588 hectares of mine-works in the Upper Freeport coal bed, the same coal mined at the Omega site. The T\&T mine-pool, located in Preston county West Virginia, consists of three adjoining mines, as shown in figure 3-2. All three mines are located above the local base level drainage and dip to the southeast at about $8 \%$ southeast toward the axis of the nearby Kingwood syncline. The coal bed is about $1.2 \mathrm{~m}$ thick, and is overlain by several massive sandstones up to $18 \mathrm{~m}$ thick, interbedded with thinner shale units. The section contains few carbonates, and maximum overburden thickness is about $80 \mathrm{~m}$. The author has observed subsidence cracks in land overlying the mine complex.

Barrier pillars of varying thickness separate the three mines, and the barrier is known to be breached in at least one location. The Ruthbelle mine, located in the northeast part of the complex, closed in the 1950s, while the T\&T 2 and T\&T 3 mine closed in the early and mid 1990s. The 
three mines are hydrologically connected, and most of the mine-pool discharge occurs at the former portals of the T\&T 2 mine. Leakage from the adjacent Ruthbelle and T\&T 3 mines contributes part of the drainage that discharges from the T\&T 2 mine (figure 3-2). All discharges are gravity drainage.

The T\&T 2 mine is at the lowest elevation of the three workings and is the principal discharge point for the entire complex. The entries were developed along strike and mining proceeded up-dip from that location. This design allowed gravity drainage of the mine-works during operation. After closure, about $20 \%$ of the lower mine-works flooded to the elevation of the entries. The mine-pool contains about 300 million L of ground-water, as estimated from examining mine maps. A small pool may also be present up-dip of the coal barrier between the No. 3 and No. 2 mine-works.

A high volume discharge of acidic, poor quality water developed at the T\&T No.2 portal area within six months of sealing the mine in 1994. The discharge volume subsequently declined but water quality remained poor. The drainage has been treated with conventional chemical methods since that time and treatment sludge is periodically reinjected into the up-dip end of the complex. About 72,000 metric tons of limestone byproduct (70\% $\mathrm{CaCO}_{3}$ Eq.) was injected into the mine from late 1999 to 2001 in an attempt to treat acid water in-situ.

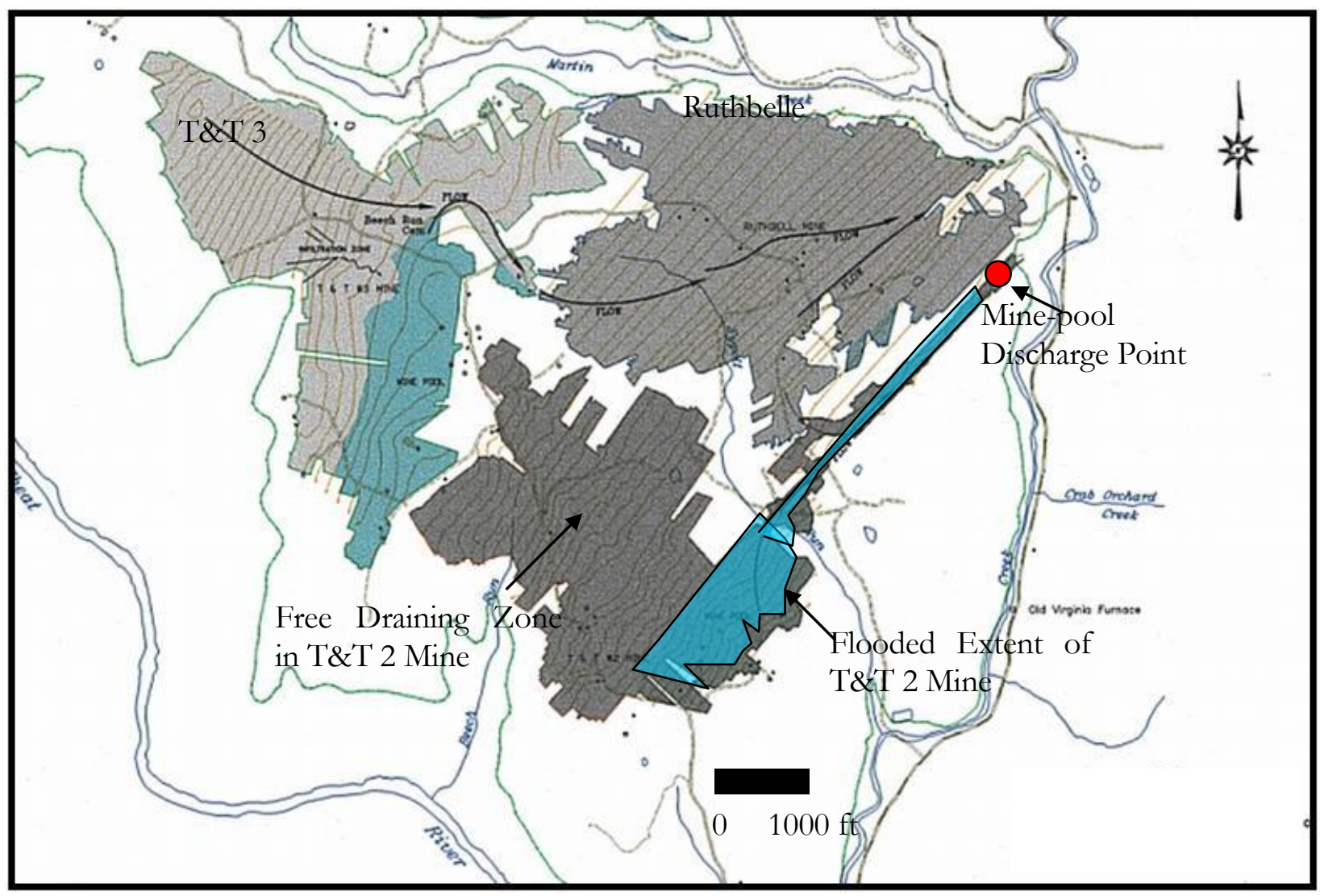

Figure 3-2. T\&T Mine-pool. Dip is to Southeast at 8\%. Main Discharge is from No. 2 Mine and represents draianage from T\&T 2, T\&T 3 and Ruthbelle mines. Scale in feet. 
Table 3-3 provides summary water quality data for the T\&T mine-pool in early flushing stage (1994), about two years after closure (1996); and about 10 years after closure (2006) and 5 years after limestone injection ceased. Water quality data immediately after closing are sporadic, and $\mathrm{Al}$ is not included in many of the analyses. The No.2 portal drainage was sampled by the author in 1994 about two months after the mine-pool began to discharge. This single event sample is included in table 3-3 to represent very early flushing water quality.

Table 3-3

Summary Water Quality Data T\&T 2 Mine-pool, Mostly Unflooded Upper Freeport Mine-Works ${ }^{(1)}$

\begin{tabular}{lcccccc}
\hline Location & Date & $\mathrm{pH}$ & $\begin{array}{c}\text { Total Acidity, } \\
\mathrm{mg} / \mathrm{L}\end{array}$ & $\begin{array}{c}\mathrm{Fe}, \\
\mathrm{mg} / \mathrm{L}\end{array}$ & $\begin{array}{c}\mathrm{Al}, \\
\mathrm{mg} / \mathrm{L}\end{array}$ & $\begin{array}{c}\mathrm{SO}_{4} \\
\mathrm{mg} / \mathrm{L}\end{array}$ \\
\hline No. 2 Portal & 1994 & 2.8 & 1320 & 455 & 90 & 1910 \\
No. 2 Portal & 1996 & 2.6 & 728 & 216 & 40 & 1320 \\
No. 2 Portal & 2006 & 2.78 & 300 & 44 & 25.2 & 963 \\
Ruthbelle & 1996 & 2.6 & 238 & 36.3 & 14.7 & 382 \\
Ruthbelle & 2006 & 2.9 & 91 & 4.7 & 3.5 & 172 \\
\hline
\end{tabular}

(1) Median values in 1996 and 2006. The 1994 data are a single event sample collected by the author. $\mathrm{pH}$ in S.U., Acidity in $\mathrm{CaCO}_{3} \mathrm{Eq}$.

The Ruthbelle mine discharges some of the overflow but generally comprises only one to three percent of the total outflow from the mine-pool. The Ruthbelle overflow drains from an abandoned entry about 100 meters north of the main mine-pool discharge at the T\&T 2 mine. Most of the Ruthbelle drainage flows into T\&T 2 mine and exits the mine-pool through that point. It is included in table 3-3 because the mine-works are much older than other parts of the complex. Drainage quality of Ruthbelle may therefore indicate how the T\&T mine water quality will evolve as it matures.

\subsection{Water Quality in Partly Flooded Mines}

\subsubsection{Chemical Composition}

The Omega and T\&T mine-pools are characterized by high concentrations of dissolved metals, sulfate and total acidity. Tables 3-2 and 3-3 provide summary water quality information for both mine-pools soon after closure and after a period of flushing. Time series plots of cation composition (milliequivalent basis) of three individual discharges and the combined flow to the Omega treatment facility are shown in figures 3-3a-d. All four waters are composed of more than $98 \%$ sulfate in the anion fraction. The three individual discharges are located in different subsections of the mine-pool. PM-21 is located at the up-dip end of the mine and is near where treatment sludge was returned to the mine-works. Composition of the water has changed from $\mathrm{Ca}-$ $\mathrm{Mg}-\mathrm{SO}_{4}$ during early flushing to Fe-Al-SO4 as the mine-pool has aged (fig 3-3a).

Omega mine discharge DEF, located in the middle subsection of the mine-pool (fig 3-1), was initially an $\mathrm{Fe}-\mathrm{Al}-\mathrm{SO}_{4}$ solution. The long term drainage contains a greater percentage of $\mathrm{Al}$ and 
decreasing fraction of $\mathrm{Fe}$. Calcium and $\mathrm{Mg}$ fractions remain constant. The third discharge, Marshall, is located at the down-dip end of the pool and receives drainage from the grouted north
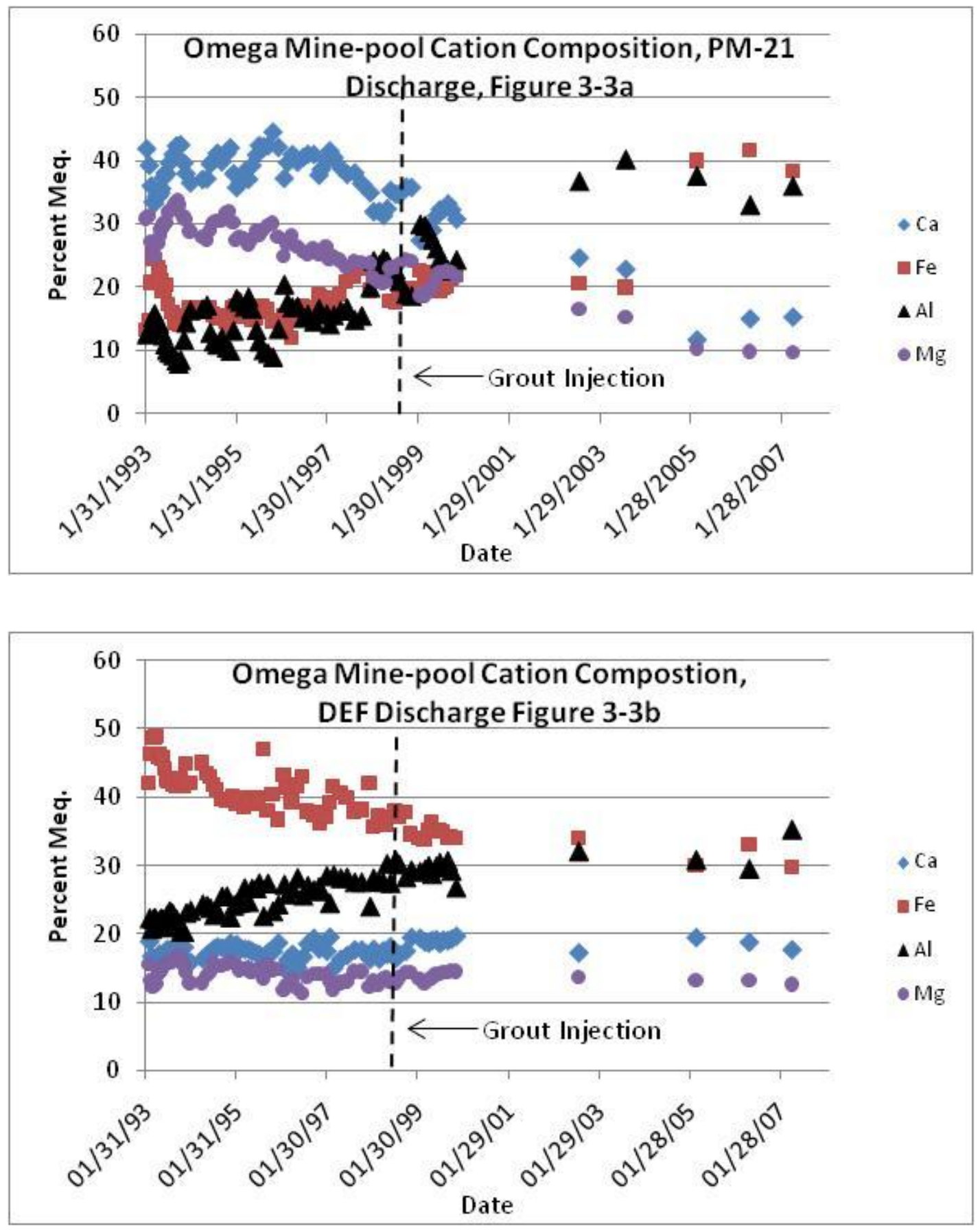

Figures 3-3a-b. Time Series Cation Milliequivalents Composition of Three Discharges and Combined Flow from the Omega Mine-pool. Calcium (diamond), Iron (square), Aluminum (triangle), and Magnesium (circle). 

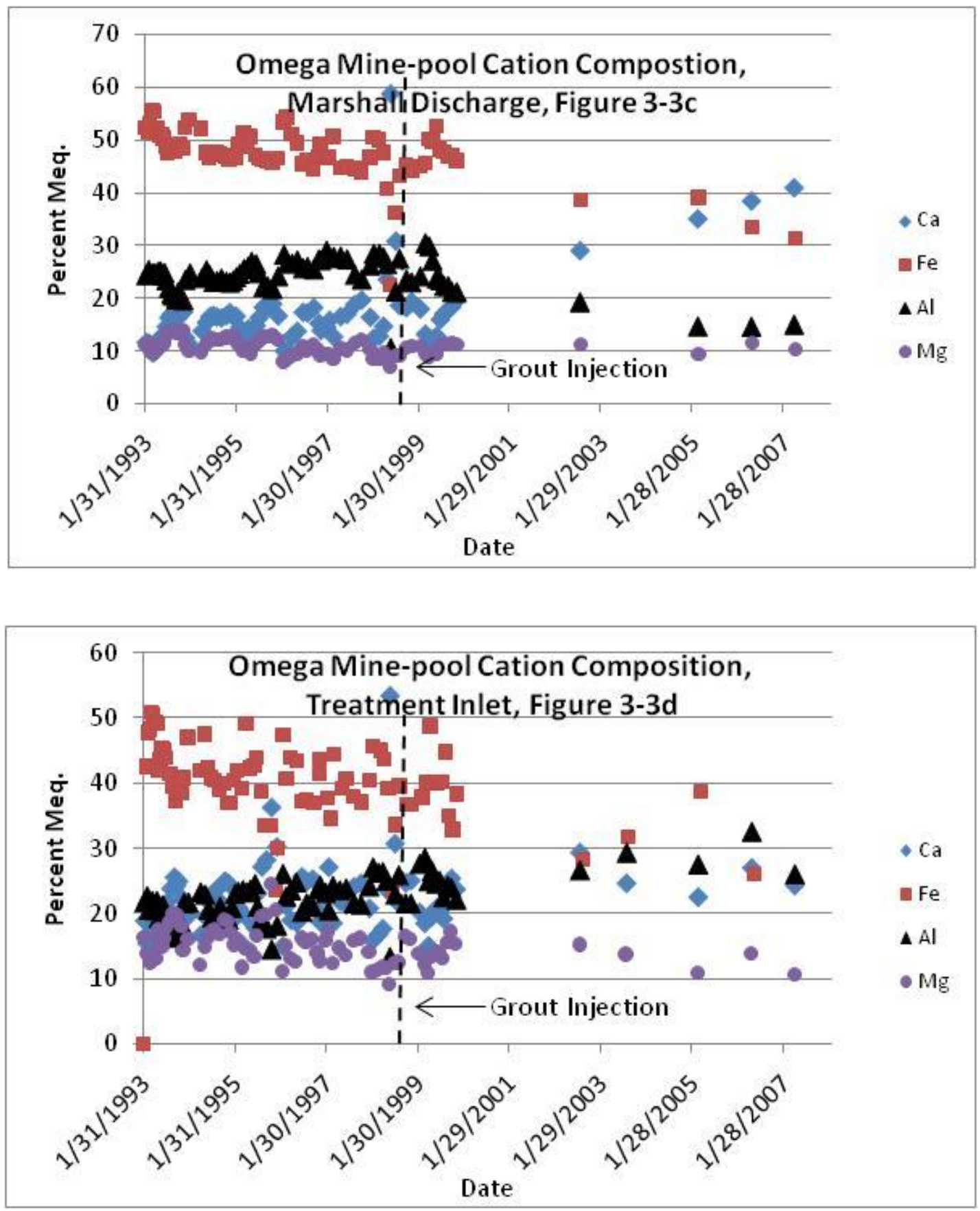

Figures 3-3c-d. Time Series Cation Milliequivalents Composition of Three Discharges and Combined Flow from the Omega Mine-pool. Calcium (diamond), Iron (square), Aluminum (triangle), and Magnesium (circle).

section. This water was also an $\mathrm{Fe}-\mathrm{Al}-\mathrm{SO}_{4}$ solution initially, but shifted to a $\mathrm{Ca}-\mathrm{Fe}-\mathrm{SO}_{4}$ composition after grout injection. The treatment inlet, which is the combined flow from all discharges, is an $\mathrm{Fe}-\mathrm{Al} / \mathrm{Ca}-\mathrm{SO}_{4}$ mixture. In two of three Omega mine discharges and the combined flow, Al comprises greater percentage of the cation charge as the mine-pool ages, and Fe declines with time. The $\mathrm{Al}$ decline post grouting at the Marshall discharge suggests that the flyash/cement injection is reducing $\mathrm{Al}$ mobility in this part of the mine-pool. The increasing $\mathrm{Ca}$ also indicates the 
grout mixture is influencing solution chemistry in this part of the mine-pool. The decline in Ca and $\mathrm{Mg}$ at PM-21 with increasing age suggests the source mineral(s) are being depleted in this part of the pool. Both elements however comprise a relatively constant fraction of the combined minepool flow. These three plots (figures 3-3 a, b, and d) show a trend of increasing Al composition in the cation fraction as the mine-pool ages, and declining, though still significant proportion of Fe. Aluminum therefore may persist in the mine-pool for a prolonged period if geochemical conditions remain the same.

The T\&T mine-pool does not have an extended time series record of major ion analysis. A single sample collected by the author in 1994 showed the water had an $\mathrm{Fe}-\mathrm{Ca}-\mathrm{SO}_{4}$ composition (milliequivalent basis). Samples collected from 2002 to 2007 by the author are $\mathrm{Ca}-\mathrm{Mg}_{-} \mathrm{SO}_{4}$ type waters (milliequivalent basis).

The two mines, although located in the same stratigraphic interval, produced waters of somewhat different composition. Chemical weathering in the Omega mine-pool is sufficiently aggressive that $\mathrm{Fe}$ and $\mathrm{Al}$, normally minor or trace constituents in ground-water, are the dominant cations on a milliequivalent basis. The T\&T mine-pool while containing substantial dissolved $\mathrm{Fe}$ and $\mathrm{Al}$, still has $\mathrm{Ca}$ and $\mathrm{Mg}$ as the dominant cations on a milliequivalent basis. Both mine-pools contain sulfate as the dominant anion. Site specific geochemical analyses of the coal, roof and floor rock could not be located for either mine. However, EPRI (2001) reports a zone of high pyrite content present in the Omega mine.

Figures 3-4a and $\mathrm{b}$ and 3-5a and $\mathrm{b}$ are time series plots of $\mathrm{Fe}, \mathrm{Al}$, and sulfate at the main discharge points for the Omega and T\&T mine-pools for 14 and 12 years, respectively. Both figures show substantial declines in Fe and sulfate concentration of 50 to over $80 \%$ from initial conditions. Al concentration also declined but to lesser extent. Two other features are evident on figure 3-4a and 3-5a. First is a large short term variation, resulting in considerable scatter. Second are short term increases in chemical concentrations, corresponding to the grout and limestone injection in the two mine-pools.

The raw data scatter in figures 3-4a and 3-5a obscure more subtle trends and features that may be present in the data sets. Log and other types of transforms, nonparametric tests, and graphical methods can sometimes improve resolution of scattered data and detect trends and differences (Cleveland and Terpenning, 1982; Hirsch et al., 1982; Hirsch and Slack, 1984; Hirsch et al., 1991). A simple moving average or median, and locally weighted scatter plot smoothing (LOWESS), can be used to smooth time series data (Helsel and Hirsch, 1992; Cleveland and Devlin, 1988). The LOWESS procedure requires repetitive computations of least squares regression and application of weighting factors to the raw data.

The moving median or average method was attempted first as a simple, intuitive smoother. A five point moving average was computed on the raw data as follows:

$$
\text { Smoothed } \mathrm{n}=\left(\mathrm{n}_{I-2}+\mathrm{n}_{I-1}+\mathrm{n}_{i}+\mathrm{n}_{I+1}+\mathrm{n}_{I+2}\right) / 5
$$


Figures 3-4b and 3-5b show smoothed Fe, Al and sulfate data for the two mine-pools. The declining trends, and short term increases after grout and limestone injection become more obvious in the smoothed data sets. A cyclic, seasonal concentration trend is also visible in the smoothed
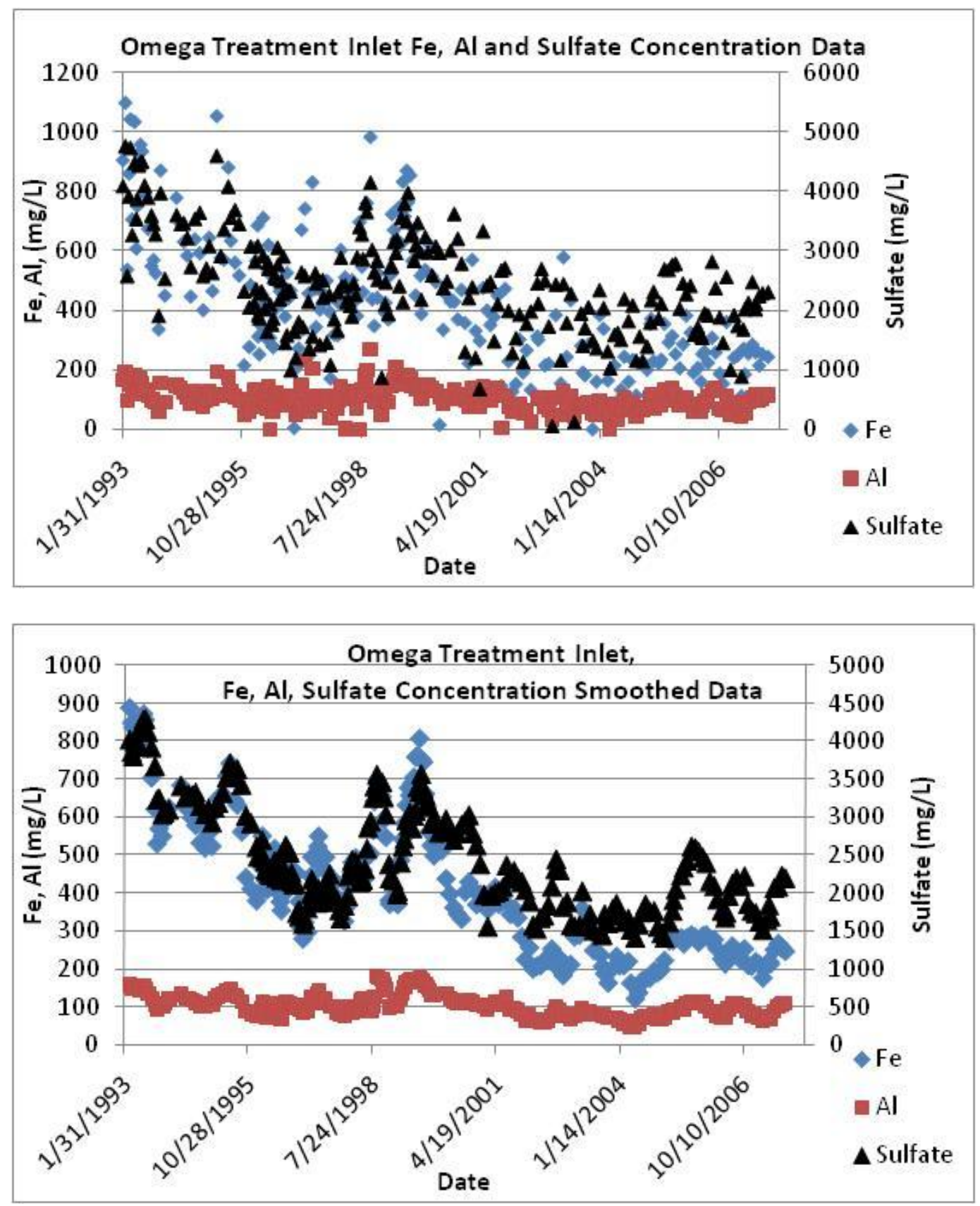

Figure 3-4 a and b. Time Series Plot of Chemical Concentrations, Omega Mine-pool Combined Discharge. $\mathrm{Fe}$ (diamond) and $\mathrm{Al}$ (square) on left axis, Sulfate (triangle) on right axis, in $\mathrm{mg} / \mathrm{L}$. Raw and smoothed data.

Omega data that would be difficult to detect in the raw scatter plot. The five point smoothing was adequate to delineate underlying trends and features. It was used to identify seasonality, which is 
described in this section, and sections 3.3.3 and 3.3.4. In the Omega mine-pool, chemical concentrations were seasonal and inversely related to mine discharge rate. Maximum chemical concentrations occurred in late summer to autumn when flow rates were lowest. The observed time dependent trends and smoothing techniques are analyzed further in chapter five to establish trends and predictions in long term chemical composition of partly flooded and flooded mine-pools.
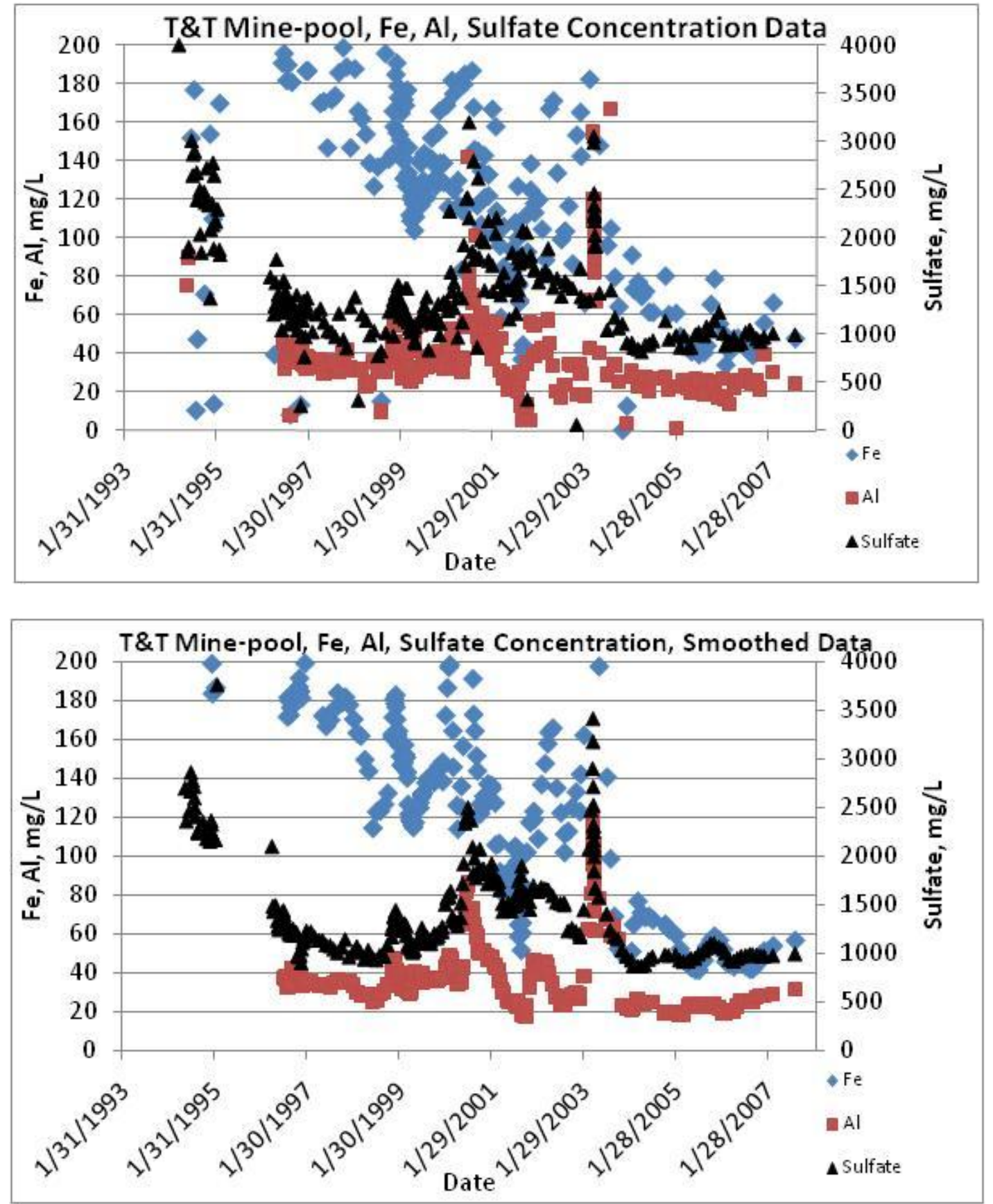

Figure 3-5 a and b. Time Series Plot of Chemical Concentrations, T\&T Mine-pool Main Discharge. $\mathrm{Fe}$ (diamond) and $\mathrm{Al}$ (square) on left Axis, Sulfate (triangle) on right Axis, mg/L. Raw and smoothed data. 


\subsubsection{Mole Ratios}

Oxidation of pyrite should yield a solution containing one mmole Fe to two mmoles sulfate, if pyrite weathers congruently, and soluble sulfate and Fe are retained in solution. Under these circumstances, a mole ratio plot can aid understanding of the mineral reactions and physical hydrology of the mine-pool. Figures 3-6 and 3-7 are smoothed time series plots of Fe to sulfate mole ratio for the Omega and T\&T mine-pools, respectively. The heavy black line on both figures is the expected composition based on pyrite stoichiometry. Each mine-pool is deficient in iron with respect to sulfate. The largest ratios occur in the early phases of flushing. For early phase mine data the Omega mine has ratios of about 0.3 to 0.4 , accounting for about 60 to $80 \%$ of Fe from pyrite, while the T\&T mine-pool has Fe to sulfate mole ratios of 0.2 to 0.4 , representing 40 to $80 \%$ of $\mathrm{Fe}$ from pyrite. The Omega mine-pool also exhibits a seasonal trend, with maximum ratios occurring in the spring at high recharge/discharge rates, and low ratios in the fall during low recharge/discharge rates. The seasonal trend in Omega mine-pool may reflect less conservative

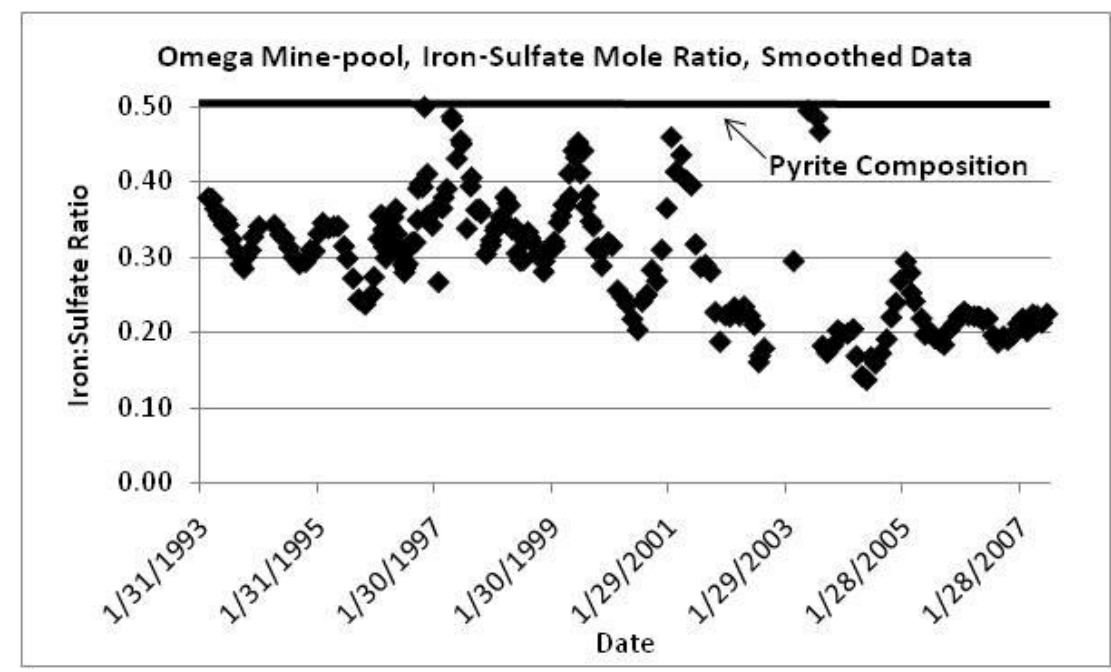

Figure 3-6. Iron to Sulfate Mole Ratio, Omega Mine-pool Combined Flow, Smoothed Data.

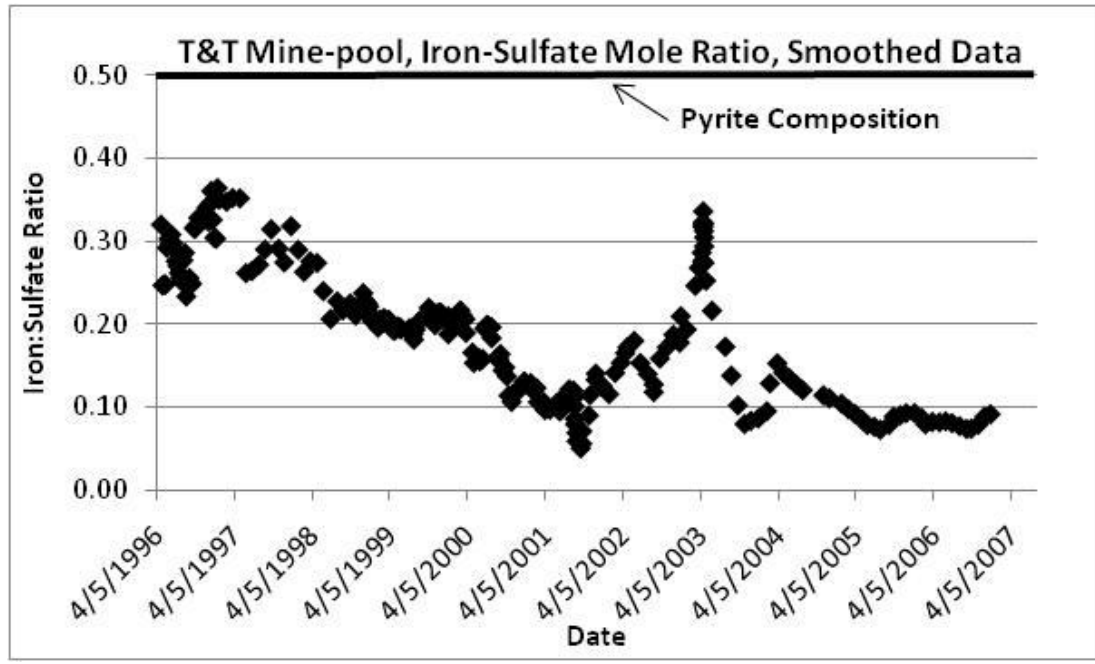

Figure 3-7. Iron to Sulfate Mole Ratio, T\&T Mine-Pool, Smoothed Data. 
behavior of Fe with respect to sulfate. The larger ratio during high flow conditions suggests more Fe is being flushed from the mine-pool at these times, and relatively more Fe is being retained in the mine during low discharge periods. Sulfate concentration is less affected by mine discharge rate than Fe. The T\&T mine-pool shows no obvious seasonal trend.

Iron-sulfate mole ratio declines in both mine-pools as they age, and after injection of grout and limestone. The ratio declines to about 0.2 in the Omega mine-pool and about 0.1 in the T\&T minepool, indicating respectively that 60 to $80 \%$ of iron from pyrite weathering in these mine-pools is not accounted for in the discharges. Both mine-pools approach a constant long term ratio.

These data yield the following interpretations and conclusions:

- Iron is being retained in the mine-pool both as short term storage and long term weathering products.

- The fraction of iron retained within the mine from pyrite weathering is significant, even in acid mine-pools, and may be more than half of the initial source.

- The fraction retained increases as the mine-pool ages and approaches a constant condition.

- Seasonal variation in the Omega mine-pool implies some Fe is in short term storage and is flushed during high recharge periods. Storage in soluble Fe salts could account for the observed behavior and enrichment of the discharge with iron during flushing.

- Iron to sulfate mole ratio could provide a means of distinguishing early flushing from long term weathering in mine-pools. This observation is used in chapter five to help differentiate short and long term leaching trends.

- Iron storage mechanisms within the mine could include formation of soluble salts, oxyhydroxides of varying solubility, adsorption, cation exchange or possibly other mechanisms.

Aluminum to sulfate mole ratio was calculated for the Omega combined flow and the T\&T discharge. Most ratio values are from 0.1 to 0.15 in both mine-pools with a maximum of about 0.2. Both mine-pools are at or approach apparent saturation for the mineral jurbanite (section 3.4) which contains $\mathrm{Al}$ and sulfate in a one to one mole ratio. Thus, both mine-pools contain a large excess of sulfate relative to $\mathrm{Al}$ and jurbanite composition.

\subsubsection{Solution Complexes}

The speciation of elements in partly flooded mine-pools and the solid phase aquifer matrix partly controls the quantity of that element in solution. The sulfate ion can form aqueous complexes with various cations, and these complexes can comprise a significant percentage of the total element in 
solution. The two partly flooded mine-pools contain substantial concentrations of sulfate, Fe Al, and other major and minor elements. Sample events that included major cation and anion analysis were speciated in PHREEQCI (Parkhurst and Appelo, 1999). In the Omega mine-pool, this included about 90 sampling events collected by the US Dept of Energy and the author. The T\&T mine-pool includes seven sampling events collected by the author. Figures 3-8 and 3-9 show the distribution of sulfate complex species (mole/L) as a percentage of total S(VI) for the PM-21 spring in the Omega mine-pool, and the T\&T main discharge.

The Omega sulfate species are shown in figure 3-8 for early flushing (1996) and long term conditions (2007), and at high and low discharge periods (respectively for April, May and September, October). Uncomplexed sulfate is the principal species, but significant amounts of $\mathrm{S}(\mathrm{VI})$ are complexed with $\mathrm{Fe}, \mathrm{Al}, \mathrm{Ca}$ and $\mathrm{Mg}$. As the mine-pool aged, the amount of uncomplexed sulfate has declined to less than $50 \%$ of total $\mathrm{S}(\mathrm{VI})$, and $\mathrm{Al}$ and $\mathrm{Fe}$ sulfate complexes each comprise between 15 and $20 \%$ of the total. During early flushing, $\mathrm{CaSO}_{4}{ }^{\circ}$ was the second most abundant species but was replaced by Fe and $\mathrm{Al}$ sulfate complexes by 2007 . The shift reflects the decline in soluble $\mathrm{Ca}$, and relative persistence of $\mathrm{Al}$ and $\mathrm{Fe}$. A small seasonal shift in percent amounts of $\mathrm{Al}-\mathrm{SO}_{4}$ and $\mathrm{Fe}-\mathrm{SO}_{4}$ species is also shown in figure 3-8. During initial flushing in April, 1996 (high discharge rate period), $\mathrm{Al}-\mathrm{SO}_{4}$ species were more abundant than $\mathrm{Fe}_{-} \mathrm{SO}_{4}$. By May 2007, the trend was reversed and percent $\mathrm{Fe}_{-} \mathrm{SO}_{4}$ species were more abundant than $\mathrm{Al}-\mathrm{SO}_{4}$. The seasonal and long term differences in sulfate speciation may reflect changes in chemical activity, and suggest individual elements may have characteristic leaching behavior influenced by source minerals and discharge conditions.

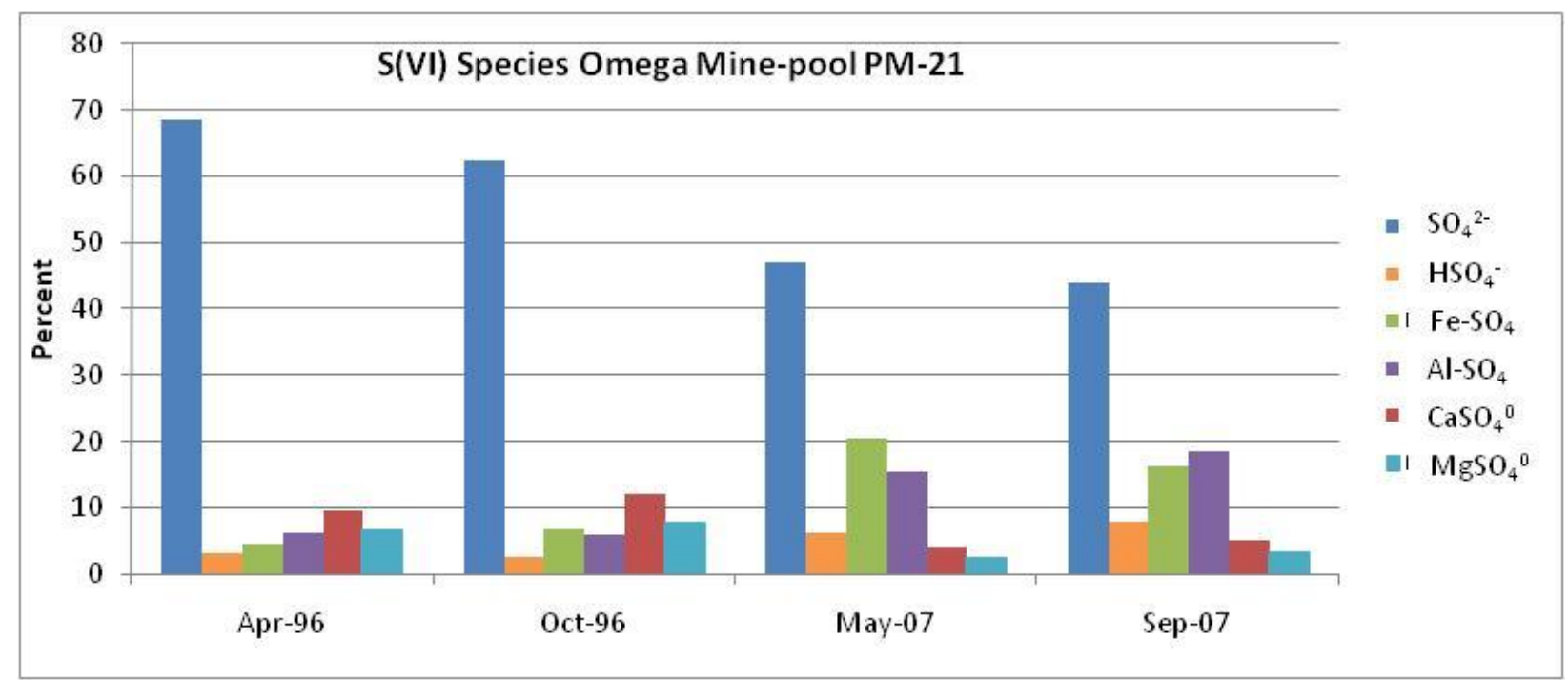

Figure 3-8. Distribution of Most Abundant Sulfate Complexes, Omega PM-21 Discharge, Initial Flush (1996) and Long Term Drainage (2007), and High (Apr, May) and Low (Oct, Sep) Discharge Periods. $\mathrm{Fe}_{-} \mathrm{SO}_{4}$ includes $\mathrm{Fe}(\mathrm{II})$ and $\mathrm{Fe}(\mathrm{III})$ combined, $\mathrm{Al}_{-} \mathrm{SO}_{4}$ includes $\mathrm{AlSO}_{4}{ }^{+}$and $\mathrm{Al}\left(\mathrm{SO}_{4}\right)_{2}{ }^{-}$.

Figure 3-9 shows sulfate species distribution for early and long term flushing, and seasonal low and high recharge periods in the T\&T mine-pool. Unlike the Omega mine-pool, $\mathrm{CaSO}_{4}{ }^{\circ}$ is the 
second most abundant sulfate species after uncomplexed sulfate in long tern leaching (2003 and 2007) at the T\&T site, and may result from the limestone addition. Iron and $\mathrm{Al}_{-} \mathrm{SO}_{4}$ complexes were more abundant in 1994. The propensity for sulfate to complex with $\mathrm{Fe}, \mathrm{Al}, \mathrm{Ca}$ and $\mathrm{Mg}$ will, in general, increase the amount of source mineral that can dissolve, and contributes to the high concentrations of metals observed in these mine waters.

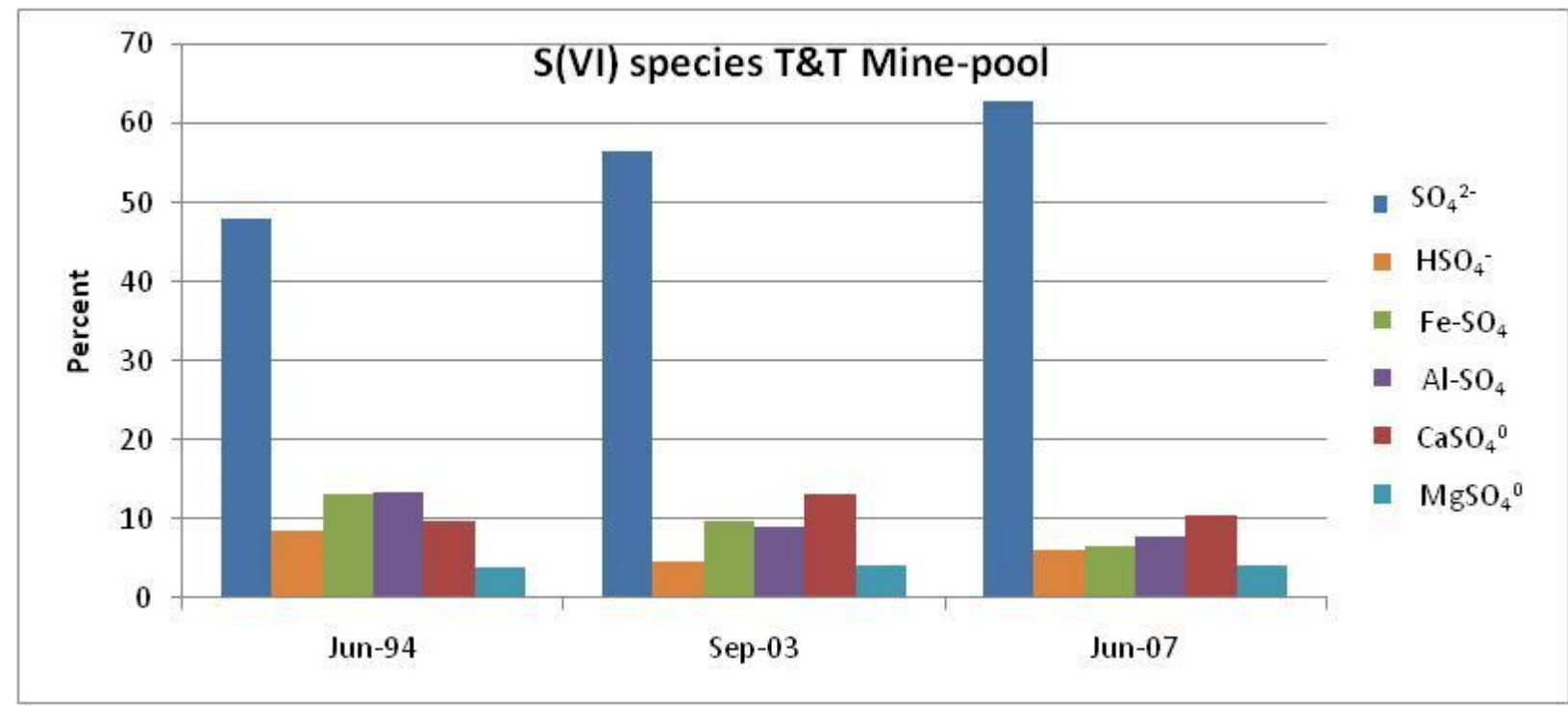

Figure 3-9. Distribution of Most Abundant Sulfate Complexes, T\&T Main Discharge, Initial Flush (1994) and Long Term Drainage (2003, 2007), and High (Jun) and Low (Sep) Discharge Periods. $\mathrm{Fe}_{-} \mathrm{SO}_{4}$ includes $\mathrm{Fe}(\mathrm{II})$ and $\mathrm{Fe}(\mathrm{III})$ combined. $\mathrm{Al}-\mathrm{SO}_{4}$ includes $\mathrm{AlSO}_{4}{ }^{+}$and $\mathrm{Al}\left(\mathrm{SO}_{4}\right)_{2}{ }^{-}$.

Figure 3-10a and b shows the abundance of principal species of Al, expressed as a fraction of total solution $\mathrm{Al}$ (mole/L basis) for the Omega and T\&T mine-pools for the same sample dates and conditions as in figure 3-8 and 3-9. The distribution of species is consistent between sampling conditions and mines. About $70 \%$ of soluble $\mathrm{Al}$ is complexed with sulfate as $\mathrm{AlSO}_{4}{ }^{+}$, and $\mathrm{Al}^{3+}$ comprises 15 to $20 \%$ of total dissolved Al. This increases the amount of $\mathrm{Al}$ that can dissolve from source minerals including alumino-silicates, oxyhydroxides and sulfates.

The Al sulfate mineral jurbanite dissolves as follows:

$$
\mathrm{AlOHSO}_{4}+\mathrm{H}^{+} \leftrightarrow \mathrm{Al}^{3+}+\mathrm{SO}_{4}^{2-}+\mathrm{H}_{2} \mathrm{O}
$$

The log equilibrium constant in PHREEQCI for jurbanite is -3.23. Reaction 3-3 involves only $\mathrm{Al}^{3+}$ and does not include the formation of $\mathrm{AlSO}_{4}{ }^{-}$. Using data from the May, 2007 sample from the Omega mine-pool shown in figure 3-10, the water was equilibrated in PHREEQCI to saturation with jurbanite. The total dissolved $\mathrm{Al}$, including complexes, is $6.16 \times 10^{-3} \mathrm{~mole} / \mathrm{L}$. Solving the equilibrium expression for equation 3-3, and specifying $\mathrm{Al}^{3+}$ as the only aluminum species present, gives an estimated dissolved $\mathrm{Al}$ of $1.28 \times 10^{-3}$ mole/L. Thus, the formation of the $\mathrm{Al}-\mathrm{SO}_{4} \mathrm{species}$ increases the quantity of the mineral jurbanite that can dissolve by a factor of almost five, and the concentration of total soluble $\mathrm{Al}$ in the Omega mine-pool. 

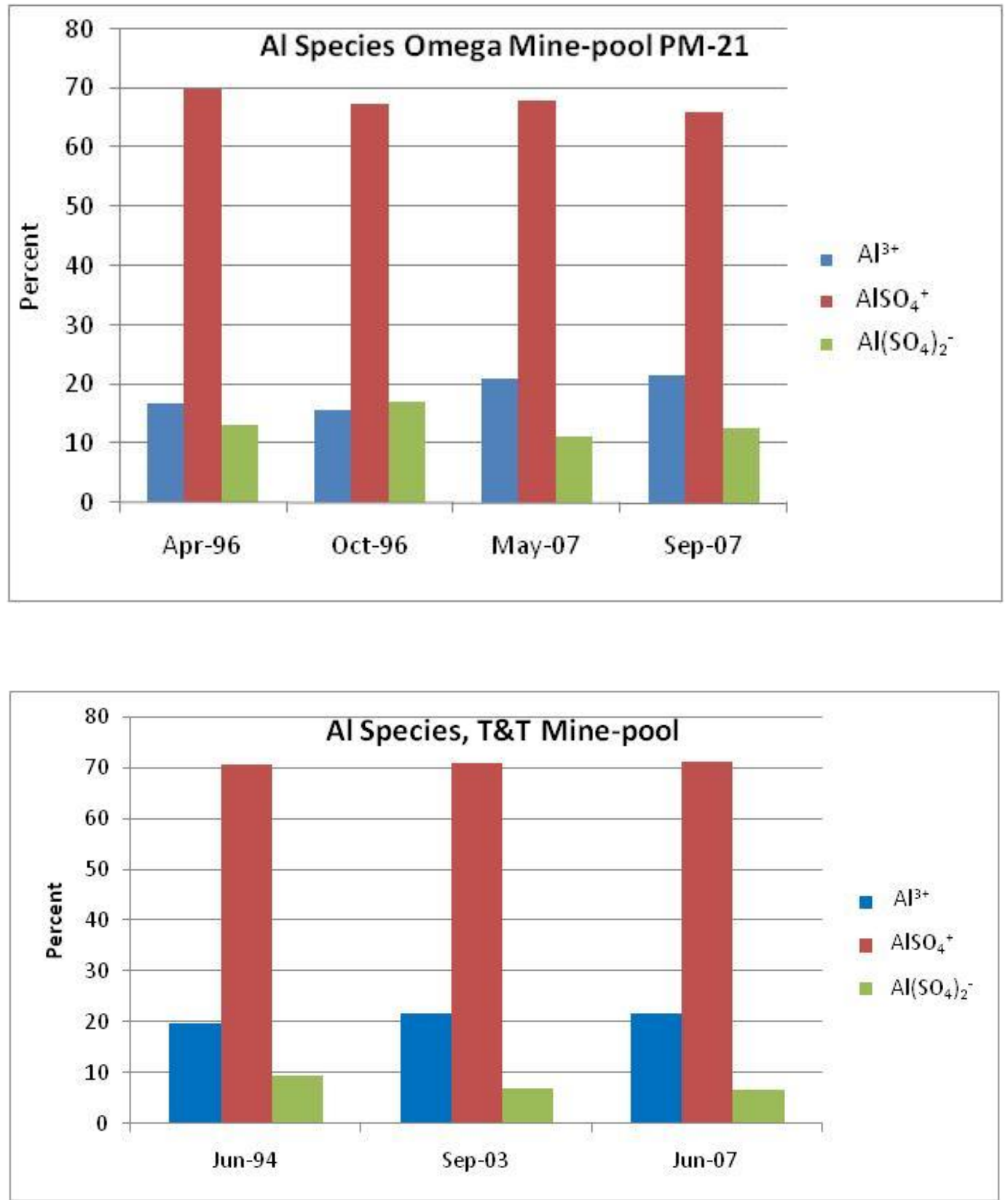

Figure 3-10 a-b. Distribution of Most Abundant Aluminum Complexes,

Omega Mine-pool PM-21 and T\&T Main Discharge. 
Figures 3-11 $\mathrm{a}$ and $\mathrm{b}$ shows the distribution of the most abundant Fe II species for the same Omega and T\&T mine-pool sampling events as described previously. Uncomplexed $\mathrm{Fe}^{2+}$ is most abundant species, and comprises about $70 \%$ of total dissolved Fe (II). There is little variation between mines or sampling conditions.
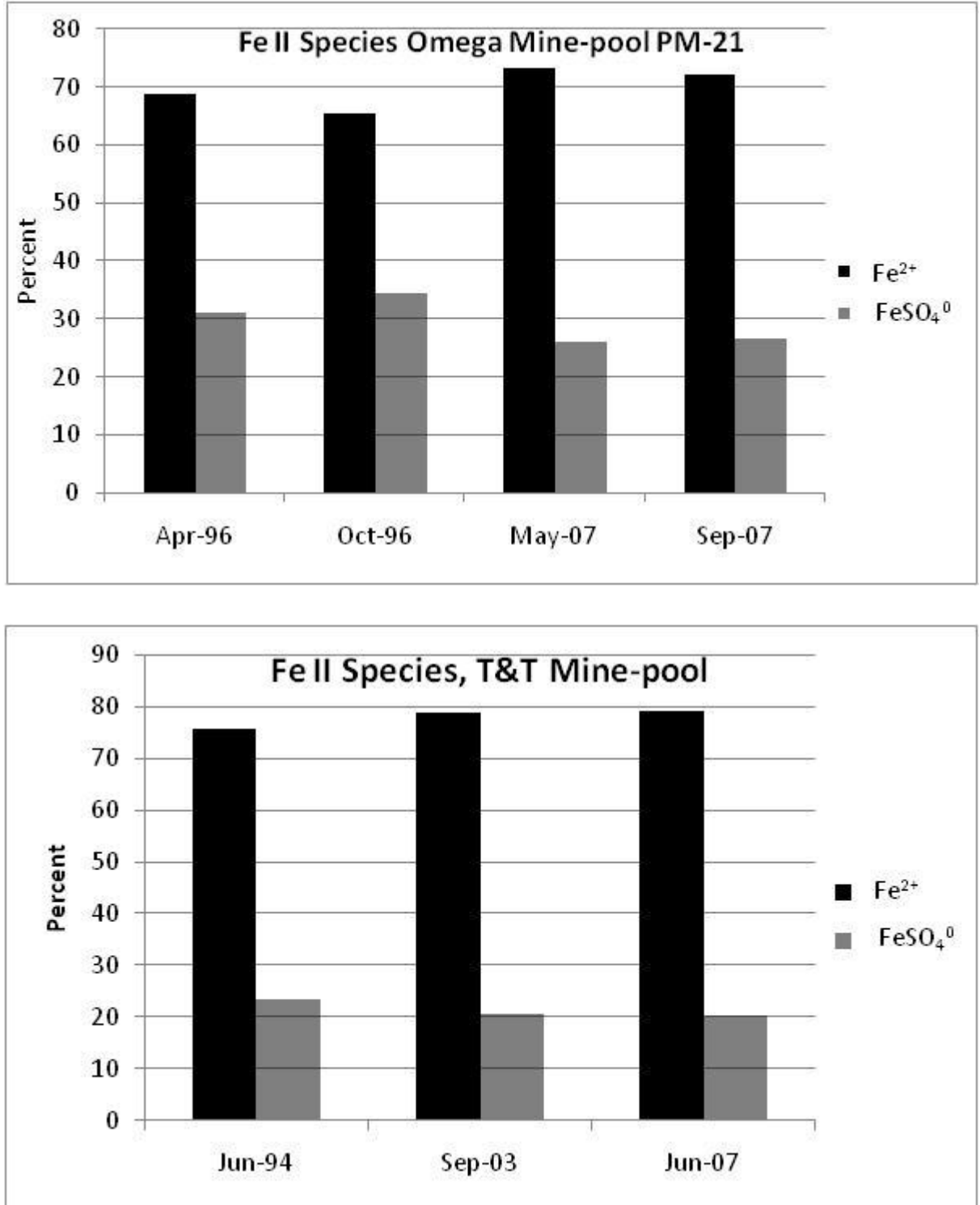

Figure 3-11a-b. Distribution of Most Abundant Fe II Complexes, Omega Mine-pool PM-21 and T\&T Main Discharge.

Figure 3-12a-b shows the distribution of the most abundant Fe (III) species for the Omega and T\&T mine-pools under early and long term flushing and low and high discharge conditions. As with $\mathrm{Al}$, about 70 to $80 \%$ of the dissolved $\mathrm{Fe}$ (III) is complexed with sulfate. The degree of $\mathrm{Fe}$ complexing is dependent on the charge state. For Fe(II) species, $\mathrm{Fe}^{2+}$ is the dominant species, while 
for $\mathrm{Fe}(\mathrm{III})$; the $\mathrm{FeSO}_{4}{ }^{+}$complex is the dominant species (figures 3-11 and 3-12). Like Al, the affinity for Fe to form complexes with sulfate increases the concentration of soluble Fe that can be maintained by mineral dissolution.
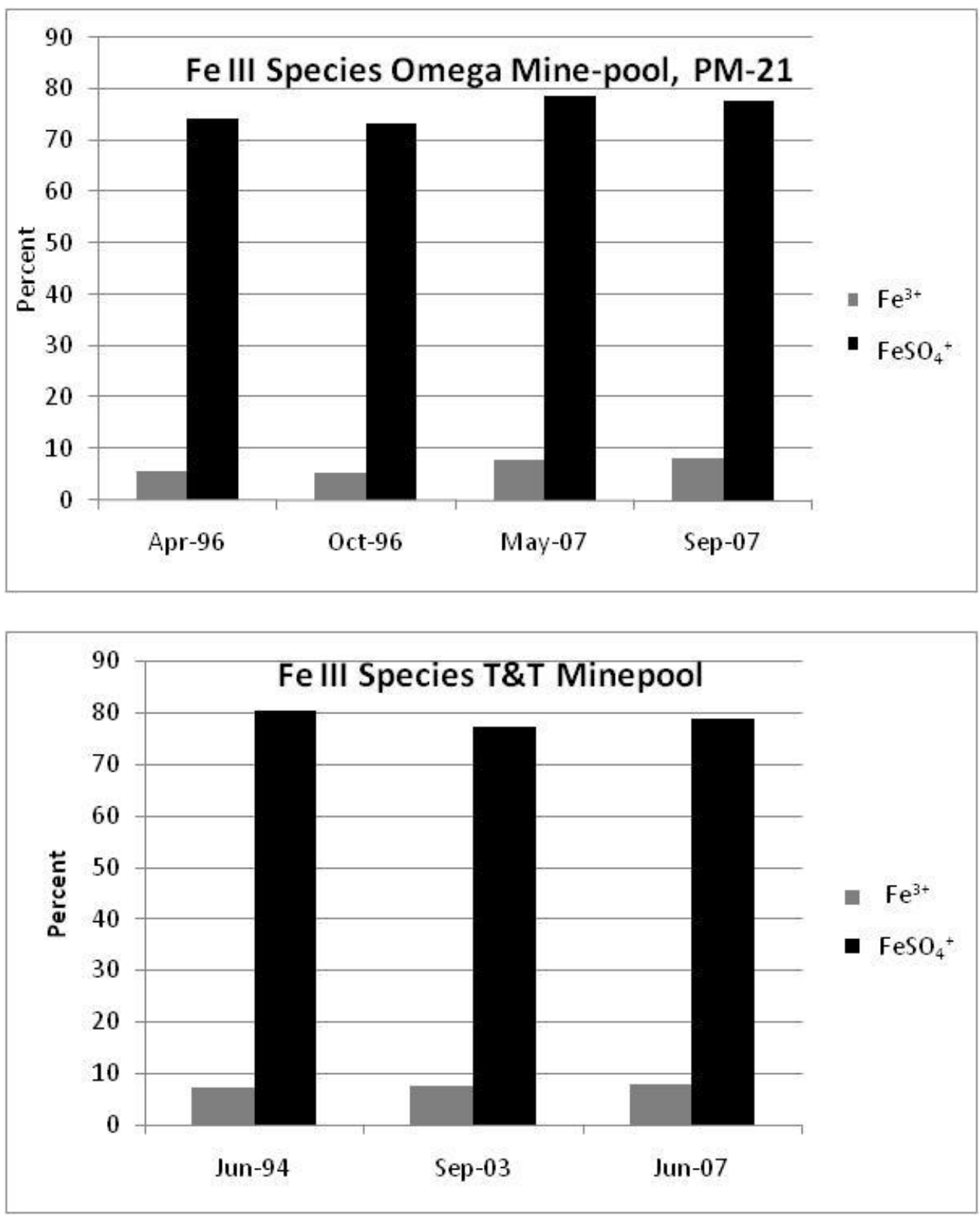

Figure 3-12a-b Distribution of Most Abundant Fe III Complexes, Omega Mine-pool PM-21 and T\&T Main Discharge.

Figure 3-13 shows the distribution of $\mathrm{Ca}$ species in solution for the same set of samples from the Omega mine-pool PM-21 discharge. Only two species are abundant, $\mathrm{Ca}^{2+}$ and $\mathrm{CaSO}_{4}{ }^{\circ}$, and there is little difference in distribution between early and late flushing or high and low discharge periods. Using data from the May, 2007 sample from the Omega mine-pool shown in figure 3-13, the 
solution was equilibrated in PHREEQCI to saturation with gypsum. The total dissolved Ca including all complexes is $1.269 \times 10^{-2} \mathrm{~mole} / \mathrm{L}$. Solving the equilibrium expression and specifying $\mathrm{Ca}^{2+}$ as the only calcium species yields a total dissolved $\mathrm{Ca}$ of $8.142 \times 10^{-3} \mathrm{~mole} / \mathrm{L}$. The formation of $\mathrm{CaSO}_{4}{ }^{\circ}$ increases total soluble $\mathrm{Ca}$ about $55 \%$ if gypsum dissolution is the controlling reaction. Sulfate complexes with $\mathrm{Al}, \mathrm{Fe}$ and $\mathrm{Ca}$ substantially increase the dissolved concentrations of each of those elements that can be sustained in mine waters.

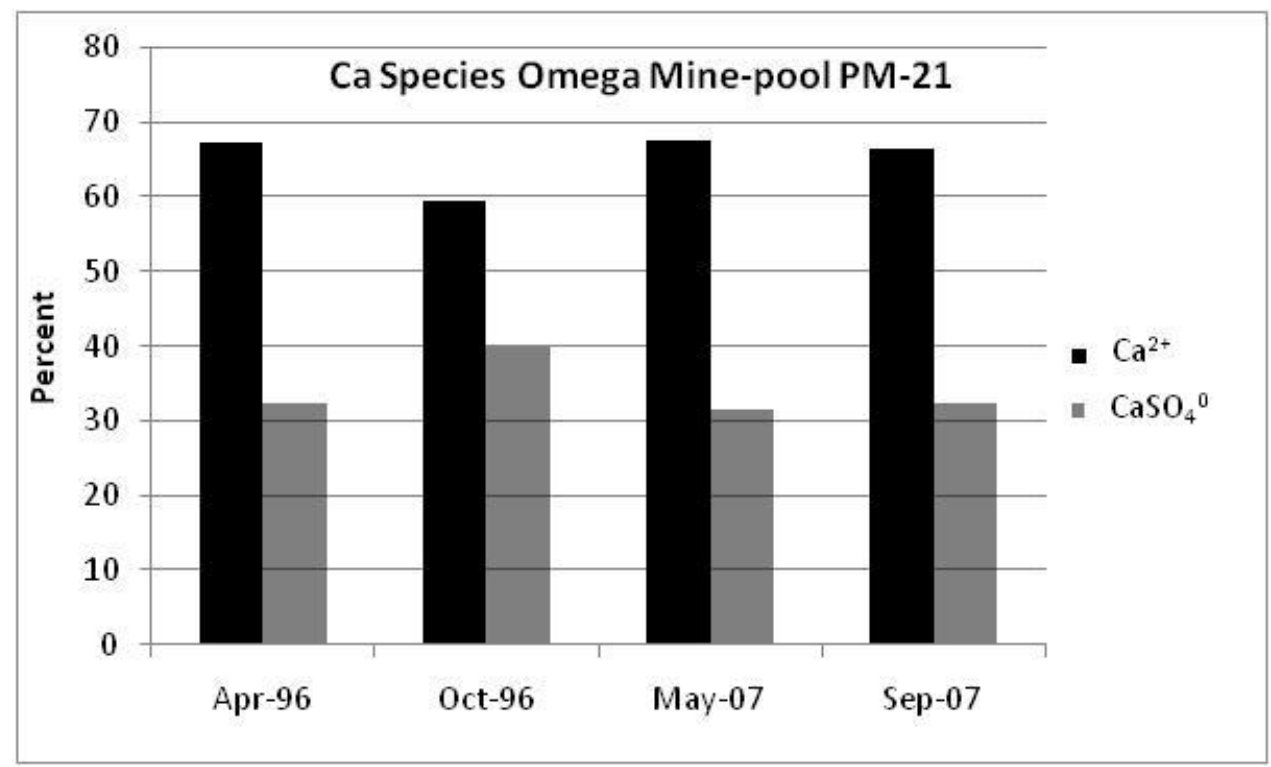

Figure 3-13. Distribution of Most Abundant Ca Complexes, Omega Mine-pool PM-21.

\subsubsection{Redox State of Partly Flooded Mines}

The reduction/oxidation (redox) state of waters in partly flooded mines has a large effect on sulfide oxidation; species distribution of elements with multiple valence states including Fe, Mn, As and others; and formation and dissolution of minerals containing those elements. In acid mine waters, good agreement between $\mathrm{Fe}(\mathrm{II}) / \mathrm{Fe}$ (III) distribution and measured (observed) Eh (Nordstrom et al.,1979; Auque et al.,2008; Nordstrom, 2009) has been found. This agreement can be attributed to the high concentrations of Fe often present in mines water, making it easier for the electrode to sense $\mathrm{Fe}^{2+}$ and $\mathrm{Fe}^{3+}$. The iron couple is also readily reversible (Langmuir, 1997). Christensen et al. (2000), in a review of redox characterization techniques, also concluded that the $\mathrm{Fe}^{2+1} \mathrm{Fe}^{3+}$ couple was reversible, and sufficiently rapid to be useful in ground-water studies. Studies of the Berkley pit in Montana, a large abandoned and partly flooded copper mine, have also shown good agreement between $\mathrm{Fe}^{2+} / \mathrm{Fe}^{3+}$ equilibrium Eh and measured Eh (Davis and Ashenberg, 1989) if both species were present in readily detectable amounts, and the minor species was at least $5 \%$ of the total Fe.

Some ground-waters are at internal disequilibrium, and lack a single overall redox value (Lindberg and Runnells, 1984) resulting in a mixed potential. Acid mine waters are, however, systems where measured Eh may be a reliable index of the redox state for iron. 
The author collected a set of measurements of Eh, dissolved oxygen and Fe(II) from the Omega and T\&T mine-pools and several other locations with the objective of comparing field measured Eh values against equilibrium or system Eh calculated from various couples including:

- $\mathrm{Fe}^{2+} / \mathrm{Fe}^{3+}$,

- $\mathrm{Fe}^{2+} / \mathrm{Fe}(\mathrm{OH})_{3}$,

- $\mathrm{Fe}^{2+} / \mathrm{FeOOH}$

- $\mathrm{O}_{2} / \mathrm{FeS}_{2}$

Goethite and $\mathrm{Fe}(\mathrm{OH})_{3}$ were selected to represent end members of ferric oxyhydroxide minerals ranging from low solubility to poorly crystalline. Several studies (Macalady et al., 1990; Back and Barnes, 1965; Gang and Langmuir, 1974) have noted apparent equilibrium between $\mathrm{Fe}^{2+}$ and oxyhydroxide minerals in some waters. The pyrite/oxygen couple was selected to determine if dissolved oxygen is related to measured Eh.

Field Eh was measured with a portable meter and $\mathrm{Pt}$ electrode with $\mathrm{Ag} / \mathrm{AgCl}$ solution that was calibrated against Zobell's solution before and after each field use. Readings were obtained by immersing the probe into the discharge at or near the point of emergence. Stable readings were usually obtained within ten seconds in acid, iron rich waters, suggesting the waters are well poised. The raw Eh reading was corrected to the standard hydrogen electrode scale using compiled tabular values of temperature correction factors and from equation 3-4 (Nordstrom and Wilde, 1998):

$$
\text { Ehsys. = Ehmeas. }+ \text { Eref. }
$$

For example, at $15^{\circ} \mathrm{C}$, the correction factor for the $\mathrm{Ag} / \mathrm{AgCl}$ probe is 212 millivolts. An instrument reading of 440 millivolts yields an equivalent Eh of 652 millivolts on the hydrogen electrode scale. The Pt electrode was rinsed periodically in an acid bath followed by distilled water to prevent fouling of the probe.

Dissolved oxygen was measured with a portable meter by immersing the probe in the discharge where Eh was measured. Both Eh and dissolved oxygen were measured prior to the discharge aerating as it flowed to the surface.

Samples were also collected for ferrous iron determination, filtered through a 0.45 micron filter for removing colloidal constituents, stored in opaque bottles, preserved with $\mathrm{HCl}$ and kept chilled until analysis. Ferrous iron determinations were run usually within 24 hours of collection using a colorimeter and 1,10 phenathroline. The instrument had a resolution of $0.01 \mathrm{mg} / \mathrm{L}$ but samples often had to be diluted by a factor of ten or sometimes 100 to read on scale. Ferric iron was determined as the difference between total dissolved Fe and ferrous iron. A method has been developed to measure Fe(III) directly using acetohydroxamic acid (To et al., 1999), but high concentrations of $\mathrm{Fe}$ (II) can interfere with the Fe (III) determination. To et al. compared Fe(III) data determined directly from the complexing technique with $\mathrm{Fe}(\mathrm{III})$ determined by difference for a set of acid mine water samples. They found that Fe(III) concentration by difference was 
typically greater than $\mathrm{Fe}$ (III) by direct determination. A system Eh calculated on the basis of $\mathrm{Fe}$ (III) by difference would yield a greater apparent Eh value than one calculated from the direct determination.

Water samples were speciated in PHREEQCI using ferrous/ferric iron data as the basis for calculating system Eh in the first set of comparisons. Stipp (1990) compared calculated iron species concentrations to solutions of known composition for acid mine waters. She found good agreement between the two sets of values and concluded that that modeling of mine water solutions was a feasible approach to estimating solution composition. System Eh of the $\mathrm{Fe}^{2+} / \mathrm{Fe}^{3+}$ couple was computed from the half-reaction and corresponding equilibrium expression:

$$
\begin{gathered}
\mathrm{Fe}^{2+} \leftrightarrow \mathrm{Fe}^{3+}+\mathrm{e}^{-} \quad \log \mathrm{K}_{\mathrm{eq}}=-13.02 @ 25^{\circ} \mathrm{C} \\
K e q=\frac{\left(e^{-}\right)\left(F e^{3+}\right)}{F e^{2+}}
\end{gathered}
$$

in units of molar activity;

$$
\begin{gathered}
\log \mathrm{e}-+\log \mathrm{Fe}^{3+}-\log \mathrm{Fe}^{2+}=\log \mathrm{K}_{\mathrm{eq}} \\
-\mathrm{pe}+\log \mathrm{Fe}^{3+}-\log \mathrm{Fe}^{2+}=\log \mathrm{K}_{\mathrm{eq}} \\
\text { pe }=-\log \mathrm{K}_{\mathrm{eq}}+\log \mathrm{Fe}^{3+}-\log \mathrm{Fe}^{2+}
\end{gathered}
$$

where pe is the negative $\log$ of $\mathrm{e}^{-}$activity and $\log \mathrm{K}_{\mathrm{eq}}$ is the $\log$ equilibrium constant. Eh and pe are related by the expression:

$$
p e=\frac{(n F) E h}{2.303 R T}
$$

derived from the Nernst equation, where $\mathrm{Eh}$ is in volts, $\mathrm{n}$ is the number of electron moles transferred, $\mathrm{F}$ is the Faraday constant, $\mathrm{R}$ is the gas constant and $\mathrm{T}$ is absolute temperature. For consistency, Eh values are expressed at $25^{\circ} \mathrm{C}$. The equilibrium constants Keq, are obtained from the thermodynamic databases in PHREEQCI, so that Eh values are calculated consistently, whether done directly in PHREEQCI or in a spreadsheet.

The median difference between observed and calculated Eh is -32 millivolts for the half reaction described in 3-5 (see table 3-4). The largest differences are at the Omega Marshall discharge in 2005 and treatment inlet in 2008. Since the treatment inlet is a composite of all discharges at this mine, and has flowed several hundred meters through a partially full collection pipe, this water may not be at internal equilibrium. There is no obvious explanation for the difference for the 2005 Marshall sample. Lindberg and Runnells (1984) reported differences of several hundred millivolts for some redox couples. The differences in table 3-4 are biased towards calculated Eh exceeding measured Eh (median difference $=-32$ millivolts). This could result from $\mathrm{Fe}^{3+}$ being overestimated when $\mathrm{Fe}$ (III) was determined by difference between total dissolved $\mathrm{Fe}$ and $\mathrm{Fe}$ (II). To et al. (1999) noted that Fe(III) determined by difference is a potential error source. 
Table 3-4

Measured (Observed) and Calculated Eh values from $\mathrm{Fe}^{2+} / \mathrm{Fe}^{3+}$ couple for Acid Mine Waters

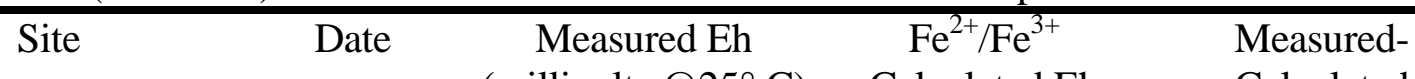

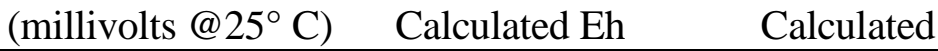

\begin{tabular}{|c|c|c|c|c|}
\hline $\begin{array}{l}\text { Omega Treatment } \\
\text { Inlet }\end{array}$ & $3 / 22 / 2005$ & 622 & 696 & -74 \\
\hline Omega PM-21 & $3 / 22 / 2005$ & 661 & 661 & 0 \\
\hline Omega PM-24 & $3 / 22 / 2005$ & 646 & 641 & 5 \\
\hline Omega PM-23 & $3 / 22 / 2005$ & 619 & 685 & -66 \\
\hline Omega Marshall & $3 / 22 / 2005$ & 497 & 662 & -165 \\
\hline Omega DEF & $3 / 22 / 2005$ & 708 & 690 & 18 \\
\hline Omega DEF2 & $3 / 22 / 2005$ & 626 & 648 & -22 \\
\hline Omega $815 \mathrm{HI}$ & $3 / 22 / 2005$ & 600 & 659 & -59 \\
\hline Omega Seep E & $3 / 22 / 2005$ & 657 & 651 & 6 \\
\hline $\begin{array}{l}\text { Omega Treatment } \\
\text { Inlet }\end{array}$ & $8 / 27 / 08$ & 596 & 792 & -196 \\
\hline Omega PM-21 & $8 / 27 / 08$ & 646 & 723 & -77 \\
\hline Omega PM-24 & $8 / 27 / 08$ & 601 & 629 & -28 \\
\hline Omega PM-23 & $8 / 27 / 08$ & No sample & & \\
\hline Omega Marshall & $8 / 27 / 08$ & 564 & 643 & -79 \\
\hline Omega DEF & $8 / 27 / 08$ & 611 & 669 & -58 \\
\hline Omega DEF2 & $8 / 27 / 08$ & 608 & 629 & -21 \\
\hline Omega $815 \mathrm{HI}$ & $8 / 27 / 08$ & No sample & & \\
\hline Omega Seep E & $8 / 27 / 08$ & No sample & & \\
\hline T\&T Main Discharge & $5 / 15 / 2005$ & 724 & 656 & 68 \\
\hline T\&T Mine 3 & $5 / 15 / 2005$ & 724 & 744 & -20 \\
\hline Ruthbelle & $5 / 15 / 2005$ & 744 & 679 & 65 \\
\hline Rt 26 discharge & $5 / 15 / 2005$ & 652 & 703 & -51 \\
\hline T\&T Main Discharge & $5 / 13 / 2008$ & 695 & 736 & -41 \\
\hline T\&T Mine 3 & $5 / 13 / 2008$ & 684 & 720 & -36 \\
\hline Ruthbelle & $5 / 13 / 2008$ & 646 & 736 & -90 \\
\hline Rt 26 discharge & $5 / 13 / 2008$ & 655 & 661 & -6 \\
\hline Sterling 1 & $5 / 3 / 2005$ & 797 & 797 & 0 \\
\hline Sterling 6 & $5 / 3 / 2005$ & 770 & 795 & -25 \\
\hline \multirow[t]{2}{*}{ Commercial } & $5 / 3 / 2005$ & 605 & 669 & -64 \\
\hline & & & $\begin{array}{c}\text { Median } \\
\text { difference }\end{array}$ & nill \\
\hline
\end{tabular}

Nordstrom et al. (1979) plotted measured versus calculated $\mathrm{Eh}$ from $\mathrm{Fe}^{2+} / \mathrm{Fe}^{3+}$ for acid mine waters. The data plot included a band extending +/- 30 millivolts from the one to one plot of observed and calculated Eh. They viewed the $+/-30$ millivolts as a type of confidence interval containing most of the data and constituting a degree of uncertainty in the comparison. Nordstrom et al.'s data are for Eh of about 600 to 800 millivolts. Table 3-4 data would require a slightly larger 
grouping of spanning about 100 millivolts. The tenth and $90^{\text {th }}$ percentiles of measured minus calculated values in table 3-4 are -85 and +11 millivolts, respectively. A later paper by Nordstrom (2000) was more cautious about the use of Eh. At more reduced conditions, approaching those measured in flooded mine-pools, Nordstrom found measured Eh was greater than calculated. The deviation was attributed in part to the decreasing $\mathrm{Fe}^{3+}$ concentration, and the difficulty of the electrode detecting small amounts of uncomplexed ferric iron. Nonetheless, used carefully, redox measurements based on $\mathrm{Fe}^{2+} / \mathrm{Fe}^{3+}$ were deemed to have value in characterizing iron rich mine water.

Figure 3-14 is a plot similar to Nordstrom et al. (1979). The solid line represents an exact match of measured and computed Eh, with bands at +/- 30 and 50 millivolts. Most data fall within or near the 50 millivolts boundary, with the exception of the two outliers previously described.

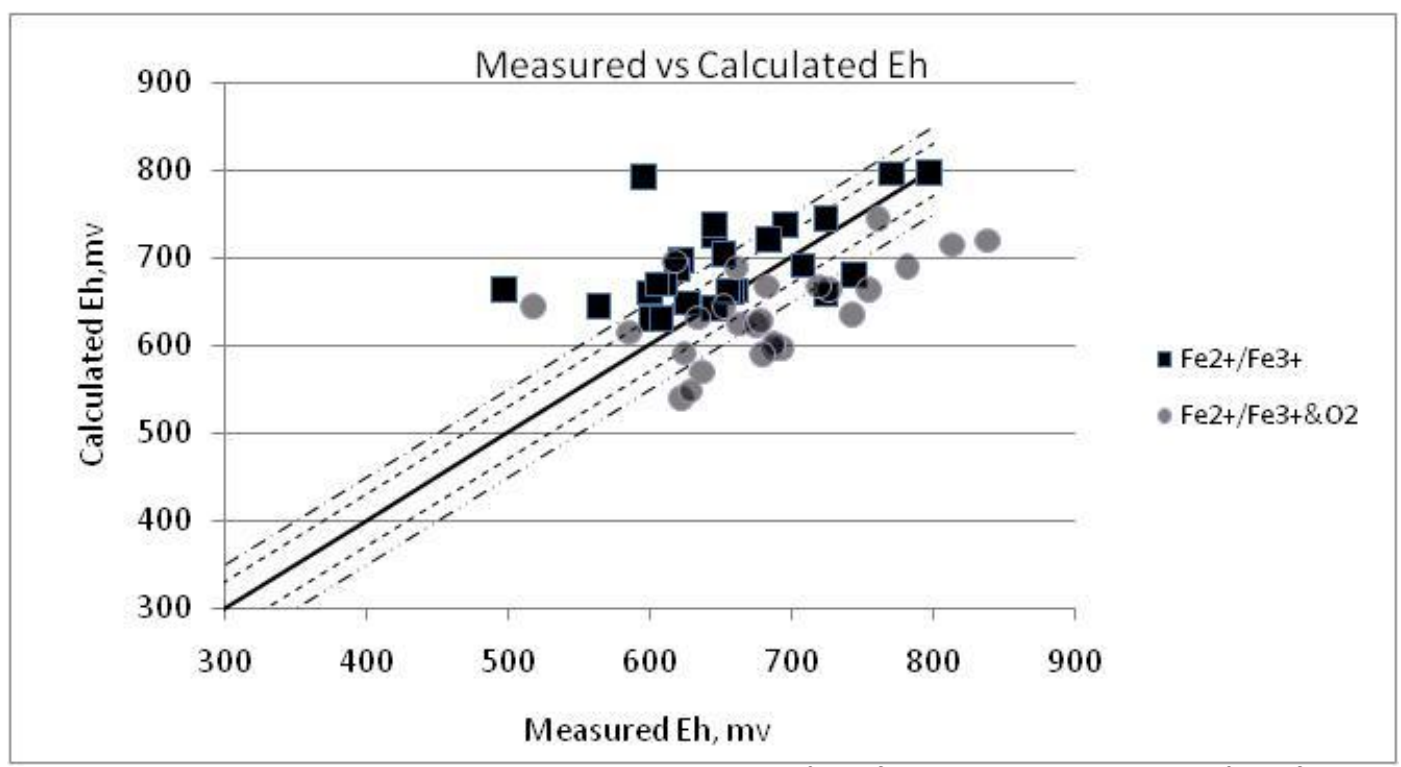

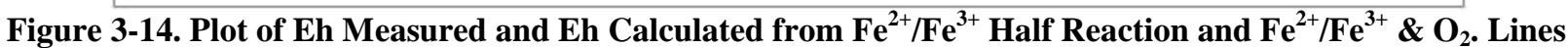
are at $+/-30$ (fine dashes) and +/-50 (large dashes) millivolts from match between measured and calculated.

What effect does uncertainty in Eh measurement have on estimates of solubility for minerals containing redox sensitive elements? The analysis for the Omega PM-21 spring sampled in 2005 (table 3-4) was assigned Eh values of +50 millivolts and -50 millivolts from the measured value, while holding all other parameters constant. The water was speciated and saturation indices examined for poorly crystalline $\mathrm{Fe}(\mathrm{OH})_{3}$ and goethite. Saturation index for $\mathrm{Fe}(\mathrm{OH})_{3}$ was -0.84 , -0.18 and +0.15 at Eh of 611 millivolts, 661 millivolts, and 711 millivolts, respectively. The water is either under-saturated or slightly super-saturated for poorly crystalline $\mathrm{Fe}(\mathrm{OH})_{3}$, depending on the Eh value specified. Goethite saturation index was $+4.52,+5.19$ and +5.51 for the three specified redox states. Interpretation of goethite behavior is not affected by the choice of Eh value. For waters with redox sensitive minerals near saturation, Eh can be a critical variable for interpreting rock-water interactions. 
The $\mathrm{Fe}^{2+} / \mathrm{Fe}^{3+}$ couple was also examined by explicitly incorporating oxygen into the oxidation reaction by combining two half reactions as follows:

$$
\begin{array}{crl}
\mathrm{Fe}^{2+} \leftrightarrow \mathrm{Fe}^{3+}+\mathrm{e}^{-} & \log \mathrm{K}_{\mathrm{eq}}=-13.02 @ 25^{\circ} \mathrm{C} \\
0.5 \mathrm{H}_{2} \mathrm{O} \leftrightarrow 0.25 \mathrm{O}_{2}+\mathrm{H}^{+}+\mathrm{e}^{-} & \log \mathrm{K}_{\mathrm{eq}}=-20.78 @ 25^{\circ} \mathrm{C}
\end{array}
$$

Rearranging and combining:

$$
\begin{aligned}
\mathrm{Fe}^{2+} \leftrightarrow \mathrm{Fe}^{3+}+\mathrm{e}^{-} & \log \mathrm{K}_{\mathrm{eq}}=-13.02 @ 25^{\circ} \mathrm{C} \\
\mathrm{H}^{+}+0.25 \mathrm{O}_{2}+\mathrm{e}^{-} \leftrightarrow 0.5 \mathrm{H}_{2} \underline{\underline{\mathrm{O}}} & \log \mathrm{K}_{\mathrm{eq}}=+20.78 @ 25^{\circ} \mathrm{C} \\
\mathrm{Fe}^{2+}+\mathrm{H}^{+}+0.25 \mathrm{O}_{2} \leftrightarrow \mathrm{Fe}^{3+}+0.5 \mathrm{H}_{2} \mathrm{O} & \log \mathrm{K}_{\mathrm{eq}}=+7.76 @ 25^{\circ} \mathrm{C}
\end{aligned}
$$

This ferrous to ferric oxidation reaction in 3-6c is the second step of the four step weathering sequence for pyrite. The corresponding equilibrium expression is:

$\left(\mathrm{Fe}^{3+}\right)\left(\mathrm{H}_{2} \mathrm{O}\right)^{0.5} /\left[\left(\mathrm{Fe}^{2+}\right)\left(\mathrm{H}^{+}\right)\left(\mathrm{O}_{2}\right)^{0.25}\right]=\mathrm{K}_{\mathrm{eq}}$, or if the activity of water is near 1 ,

$\left(\mathrm{Fe}^{3+}\right) /\left[\left(\mathrm{Fe}^{2+}\right)\left(\mathrm{H}^{+}\right)\left(\mathrm{O}_{2}\right)^{0.25}\right]=\mathrm{K}_{\mathrm{eq}}$ or

$\log \left(\mathrm{Fe}^{3+}\right)-\log \left(\mathrm{Fe}^{2+}\right)+\mathrm{pH}-0.25 \log \left(\mathrm{O}_{2}\right)=\log \mathrm{K}_{\mathrm{eq}}$

Find $\Delta \mathrm{G}_{\mathrm{r}}^{\circ}$

$\Delta \mathrm{G}_{\mathrm{r}}^{\circ}=-1.364 \log \mathrm{K}_{\mathrm{eq}}$

$\Delta \mathrm{G}_{\mathrm{r}}^{\circ}=-1.364(+7.76)$

$\Delta \mathrm{G}_{\mathrm{r}}^{\circ}=-10.58 \mathrm{kcal} / \mathrm{mole}$

Find $\mathrm{E}^{\circ}$

$\mathrm{E}^{\circ}=-\Delta \mathrm{G}_{\mathrm{r}} / \mathrm{nF}$

where $n=$ number of electron moles transferred, $F$ is Faraday constant, $23.061 \mathrm{kcal} / \mathrm{V}$

$\mathrm{E}^{\circ}=-\Delta \mathrm{G}_{\mathrm{r}} / \mathrm{nF}$

$\mathrm{E}^{\circ}=-(-10.58) /(1)(23.061)$

$\mathrm{E}^{\circ}=0.458 \mathrm{~V}$

Find Eh with the Nernst Equation

$\mathrm{Eh}=\mathrm{E}^{\circ}+(\mathrm{RT} / \mathrm{nF})^{*} 2.303 * \log \left(\left(\mathrm{Fe}^{3+}\right)\left(\mathrm{H}_{2} \mathrm{O}\right)^{0.5} /\left(\mathrm{Fe}^{2+}\right)\left(\mathrm{H}^{+}\right)\left(\mathrm{O}_{2}\right)^{0.25}\right)$ 
Where $\mathrm{R}=1.987 \mathrm{x} 10^{-3} \mathrm{kcal} /$ mole-deg; $\mathrm{T}$ is absolute temperature; $\mathrm{n}$ and $\mathrm{F}$ are as previously defined.

$\mathrm{Eh}=0.458+0.0592 *\left(\log \mathrm{Fe}^{3+}+0.5 \log \mathrm{H}_{2} \mathrm{O}-\log \mathrm{Fe}^{2+}-\log \mathrm{H}^{+}-0.25 \log \mathrm{O}_{2}\right)$

$\mathrm{Eh}=0.458+0.0592 *\left(\log \mathrm{Fe}^{3+}+0.5 \log \mathrm{H}_{2} \mathrm{O}-\log \mathrm{Fe}^{2+}+\mathrm{pH}-0.25 \log \mathrm{O}_{2}\right)$

For most solutions, activity of $\mathrm{H}_{2} \mathrm{O}$ is one or near one and the expression reduces to

$\mathrm{Eh}=0.458+0.0592 *\left(\log \mathrm{Fe}^{3+}-\log \mathrm{Fe}^{2+}+\mathrm{pH}-0.25 \log \mathrm{O}_{2}\right)$

Calculated and measured Eh results for the $\mathrm{Fe}^{2+} / \mathrm{Fe}^{3+}$ and $\mathrm{O}_{2}$ couple are shown in table 3-5 and plotted in figure 3-14. The tenth and $90^{\text {th }}$ percentiles of measured minus calculated values in table

Table 3-5

Measured and Calculated Eh values from $\mathrm{Fe}^{2+} / \mathrm{Fe}^{3+}$ and $\mathrm{O}_{2}$ Couple for Acid Mine Waters

\begin{tabular}{|c|c|c|c|c|}
\hline Site & Date & $\begin{array}{l}\text { Measured Eh } \\
\left(\mathrm{mv} @ 25^{\circ} \mathrm{C}\right)\end{array}$ & $\begin{array}{c}\mathrm{Fe}^{2+} / \mathrm{Fe}^{3+} \text { and } \mathrm{O}_{2} \\
\text { Calculated Eh }\end{array}$ & Measured-Calculated \\
\hline Omega Treatment Inlet & $3 / 22 / 2005$ & 653 & 643 & 10 \\
\hline Omega PM-21 & $3 / 22 / 2005$ & 694 & 596 & 98 \\
\hline Omega PM-24 & $3 / 22 / 2005$ & 688 & 596 & 92 \\
\hline Omega PM-23 & $3 / 22 / 2005$ & 661 & 688 & -27 \\
\hline Omega Marshall & $3 / 22 / 2005$ & 518 & 644 & -126 \\
\hline Omega DEF & $3 / 22 / 2005$ & 743 & 633 & 110 \\
\hline Omega DEF2 & $3 / 22 / 2005$ & 664 & 623 & 41 \\
\hline Omega $815 \mathrm{HI}$ & $3 / 22 / 2005$ & 625 & 590 & 35 \\
\hline Omega Seep E & $3 / 22 / 2005$ & 688 & 600 & 88 \\
\hline Omega Treatment Inlet & $8 / 27 / 08$ & 618 & 695 & -77 \\
\hline Omega PM-21 & $8 / 27 / 08$ & 675 & 621 & 54 \\
\hline Omega PM-24 & $8 / 27 / 08$ & 623 & 538 & 85 \\
\hline Omega PM-23 & $8 / 27 / 08$ & No sample & & \\
\hline Omega Marshall & $8 / 27 / 08$ & 586 & 614 & -28 \\
\hline Omega DEF & $8 / 27 / 08$ & 637 & 568 & 69 \\
\hline Omega DEF2 & $8 / 27 / 08$ & 629 & 547 & 82 \\
\hline Omega $815 \mathrm{HI}$ & $8 / 27 / 08$ & No sample & & \\
\hline Omega Seep E & $8 / 27 / 08$ & No sample & & \\
\hline T\&T Main Discharge & $5 / 15 / 2005$ & 754 & 663 & 91 \\
\hline T\&T Mine 3 & $5 / 15 / 2005$ & 761 & 745 & 16 \\
\hline Ruthbelle & $5 / 15 / 2005$ & 782 & 689 & 93 \\
\hline Rt 26 discharge & $5 / 15 / 2005$ & 683 & 666 & 17 \\
\hline T\&T Main Discharge & $5 / 13 / 2008$ & 727 & 663 & 64 \\
\hline T\&T Mine 3 & $5 / 13 / 2008$ & 719 & 667 & 52 \\
\hline Ruthbelle & $5 / 13 / 2008$ & 678 & 627 & 51 \\
\hline \multirow[t]{2}{*}{ Rt 26 discharge } & $5 / 13 / 2008$ & 680 & 589 & 91 \\
\hline & & & Median difference & 59 \\
\hline
\end{tabular}


3-5 are -2 and +99 millivolts, respectively, and the median difference of measured minus calculated is +59 millivolts. Figure 3-14 shows that including oxygen in the Eh expression biases the data toward measured exceeding calculated. Fewer points fall within $+/-50$ millivolts of the match line than using the $\mathrm{Fe}^{2+} / \mathrm{Fe}^{3+}$ couple only. The $\mathrm{Fe}^{2+} / \mathrm{Fe}^{3+}$ couple provides slightly better agreement between observed and calculated Eh.

The second potential redox couple is poorly crystalline Fe hydroxide and ferrous iron.

$$
\begin{array}{rlrl}
\mathrm{Fe}(\mathrm{OH})_{3}(\mathrm{am})+3 \mathrm{H}^{+} & \leftrightarrow \mathrm{Fe}^{3+}+3 \mathrm{H}_{2} \mathrm{O} & \log \mathrm{K}_{\mathrm{eq}} @ 25^{\circ}=4.891 \\
\mathrm{Fe}^{2+} \leftrightarrow \mathrm{Fe}^{3+}+\mathrm{e}^{-} & \log \mathrm{K}_{\mathrm{eq}} @ 25^{\circ}=-13.02
\end{array}
$$

Rearranging and combining 3-12a and 3-12b:

$$
\begin{array}{cc}
\mathrm{Fe}^{2+} \leftrightarrow \mathrm{Fe}^{3+}+\mathrm{e}^{-} & \log \mathrm{K}_{\mathrm{eq}}=-13.02 \\
\mathrm{Fe}^{3+}+3 \mathrm{H}_{2} \mathrm{O} \leftrightarrow \mathrm{Fe}(\mathrm{OH})_{3}(\mathrm{am})+3 \mathrm{H}^{+} & \log \mathrm{K}_{\mathrm{eq}}=-4.891 \\
\mathrm{Fe}^{2+}+3 \mathrm{H}_{2} \mathrm{O} \leftrightarrow \mathrm{Fe}(\mathrm{OH})_{3}(\mathrm{am})+3 \mathrm{H}^{+}+\mathrm{e}^{-} & \log \mathrm{K}_{\mathrm{eq}}=-17.911
\end{array}
$$

The corresponding equilibrium expression is:

$3 \log \mathrm{H}^{+}+\log \mathrm{e}^{-}-\log \mathrm{Fe}^{2+}=\log \mathrm{K}_{\mathrm{eq}}$

$3 \log \mathrm{H}^{+}-$pe $-\log \mathrm{Fe}^{2+}=\log \mathrm{K}_{\mathrm{eq}}$

-pe $=\log \mathrm{K}_{\mathrm{eq}}+3 \mathrm{pH}+\log \mathrm{Fe}^{2+}$

pe $=-\log \mathrm{K}_{\mathrm{eq}}-3 \mathrm{pH}-\log \mathrm{Fe}^{2+}$

Results for the $\mathrm{Fe}^{2+} / \mathrm{Fe}(\mathrm{OH})_{3}(\mathrm{am})$ data are shown in figure 3-15. There is no obvious relation

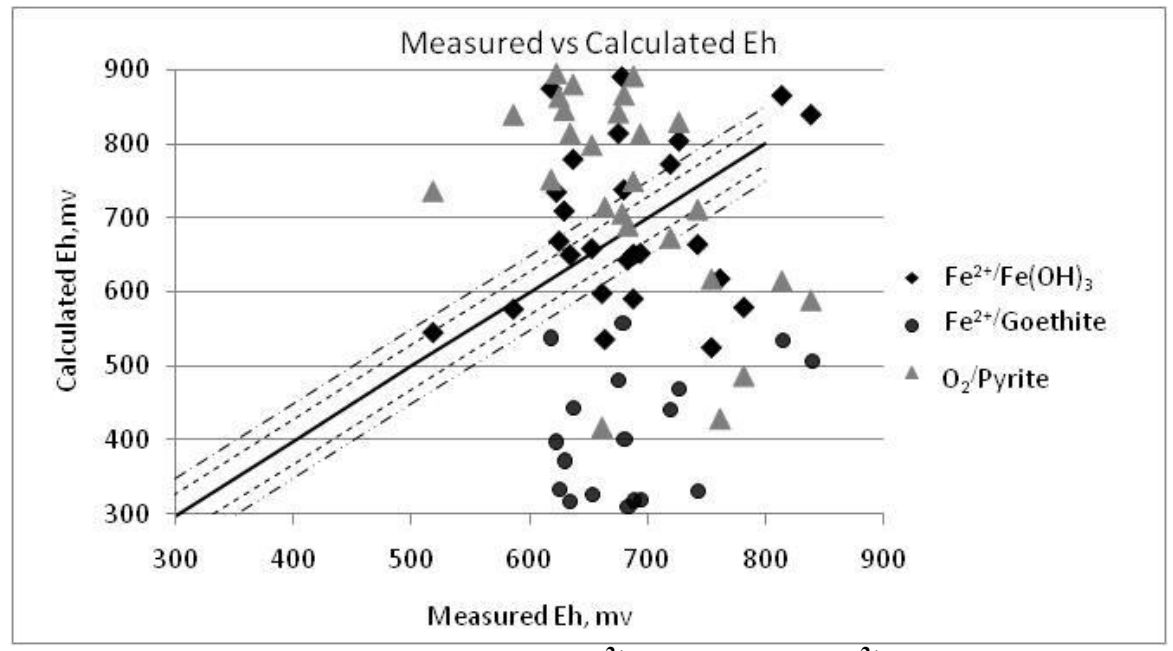

Figure 3-15. Plot of Eh Measured and $\mathrm{Eh}$ Calculated from $\mathrm{Fe}^{2+} / \mathrm{Fe}(\mathrm{OH}) 3 \mathrm{am}, \mathrm{Fe}^{2+} / \mathrm{Goethite}$, and $\mathrm{O}_{2} / \mathrm{Py}$ rite. Lines are at +/- 30 (fine dashes) and +/-50 (large dashes) millivolts from match between measured and calculated. 
between measured $\mathrm{Eh}$, and Eh calculated based on equilibrium with $\mathrm{Fe}(\mathrm{OH})_{3}$. Although the median difference is minus ten millivolts, there is considerable scatter among data pairs, and the tenth and $90^{\text {th }}$ percentile differences are -139 and +135 millivolts, respectively.

The third potential redox couple is goethite and ferrous iron:

$$
\begin{array}{rlrl}
\mathrm{FeOOH}+ & 3 \mathrm{H}^{+} \leftrightarrow \mathrm{Fe}^{3+}+2 \mathrm{H}_{2} \mathrm{O} & & \log \mathrm{K}_{\mathrm{eq}} @ 25^{\circ}=-1.0 \\
\mathrm{Fe}^{2+} \leftrightarrow \mathrm{Fe}^{3+}+\mathrm{e}^{-} & & \log \mathrm{K}_{\mathrm{eq}} @ 25^{\circ}=-13.02
\end{array}
$$

Rearranging and combining:

$$
\begin{array}{cr}
\mathrm{Fe}^{3+}+2 \mathrm{H}_{2} \mathrm{O} \leftrightarrow \mathrm{FeOOH}+3 \mathrm{H}^{+} & \log \mathrm{K}_{\mathrm{eq}} @ 25^{\circ}=1.0 \\
\hline \hline \mathrm{Fe}^{2+} \leftrightarrow \mathrm{Fe}^{3+}+\mathrm{e}^{-} & \log \mathrm{K}_{\mathrm{eq}} @ 25^{\circ}=-13.02 \\
\mathrm{Fe}^{2+}+2 \mathrm{H}_{2} \mathrm{O} \leftrightarrow \mathrm{FeOOH}+3 \mathrm{H}^{+}+\mathrm{e}^{-} & \log \mathrm{K}_{\mathrm{eq}} @ 25^{\circ}=-12.02
\end{array}
$$

The corresponding equilibrium expression is:

$$
\begin{aligned}
& 3 \log \mathrm{H}^{+}+\log \mathrm{e}^{-}-\log \mathrm{Fe}^{2+}=\log \mathrm{K}_{\mathrm{eq}} \\
& \log \mathrm{e}^{-}=\log \mathrm{K}_{\mathrm{eq}}-3 \log \mathrm{H}^{+}+\log \mathrm{Fe}^{2+} \\
& -\mathrm{pe}=\log \mathrm{K}_{\mathrm{eq}}+3 \mathrm{pH}+\log \mathrm{Fe}^{2+} \\
& \text { pe }=-\log \mathrm{K}_{\mathrm{eq}}-3 \mathrm{pH}-\log \mathrm{Fe}^{2+}
\end{aligned}
$$

Eh results calculated from $\mathrm{Fe}^{2+} /$ goethite are plotted on figure 3-15. The median difference between measured and calculated values is 322 millivolts. The results are biased to measured exceeding calculated Eh. Measured Eh does not reflect $\mathrm{Fe}^{2+} /$ goethite equilibrium.

The final couple considered was pyrite and oxygen:

$$
\mathrm{FeS}_{2}+\mathrm{H}_{2} \mathrm{O}+3.5 \mathrm{O}_{2} \rightarrow 2 \mathrm{SO}_{4}^{2-}+\mathrm{Fe}^{2+}+2 \mathrm{H}^{+}
$$

The pyrite/oxygen reaction was compiled from the following four reactions:

$$
\begin{array}{ll}
\mathrm{SO}_{4}{ }^{2-}+10 \mathrm{H}^{+}+8 \mathrm{e}^{-} \leftrightarrow \mathrm{H}_{2} \mathrm{~S}+4 \mathrm{H}_{2} \mathrm{O} & \log \mathrm{K}_{\mathrm{eq}} @ 25^{\circ}=40.644 \\
\mathrm{FeS}_{2}+2 \mathrm{H}^{+}+2 \mathrm{e}^{-} \leftrightarrow \mathrm{Fe}^{2+}+2 \mathrm{HS}^{-} & \log \mathrm{K}_{\mathrm{eq}} @ 25^{\circ}=-18.479 \\
\mathrm{H}_{2} \mathrm{~S} \leftrightarrow \mathrm{HS}^{-}+\mathrm{H}^{+} & \log \mathrm{K}_{\mathrm{eq}} @ 25^{\circ}=-6.99
\end{array}
$$




$$
2 \mathrm{H}_{2} \mathrm{O} \leftrightarrow \mathrm{O}_{2}+4 \mathrm{H}^{+}+4 \mathrm{e}^{-} \quad \log \mathrm{K}_{\text {eq }} @ 25^{\circ}=-86.08
$$

The first step is to rearrange Equation 3-14b and combine and it with 3-14c as:

$$
\left[\mathrm{H}_{2} \mathrm{~S}+4 \mathrm{H}_{2} \mathrm{O} \leftrightarrow \mathrm{SO}_{4}{ }^{2-}+10 \mathrm{H}^{+}+8 \mathrm{e}^{-} \log \mathrm{K}_{\text {eq }}=-40.644\right] \times 2 \quad \log \mathrm{K}_{\text {eq }}=-40.644 \times 2
$$

$\underline{\mathrm{FeS}}_{2}+2 \mathrm{H}^{+}+2 \mathrm{e}^{-} \leftrightarrow \mathrm{Fe}^{2+}+2 \mathrm{HS}^{-} \quad \log \mathrm{K}_{\underline{e q}}=-18.479$

$\mathrm{FeS}_{2}+8 \mathrm{H}_{2} \mathrm{O}+2 \mathrm{H}_{2} \mathrm{~S} \leftrightarrow \mathrm{Fe}^{2+}+2 \mathrm{SO}_{4}{ }^{2-}+2 \mathrm{HS}^{-}+18 \mathrm{H}^{+}+14 \mathrm{e}^{-} \quad \log \mathrm{K}_{\mathrm{eq}}=-99.767$

The second step is to rearrange and combine equation 3-14d and 3-14f as:

$$
\begin{aligned}
& {\left[\mathrm{H}_{2} \mathrm{~S} \leftrightarrow \mathrm{HS}^{-}+\mathrm{H}^{+}\right] \times 2} \\
& \log \mathrm{K}_{\mathrm{eq}}=-6.99 \times 2 \\
& \underline{\mathrm{FeS}}_{2}+8 \mathrm{H}_{2} \underline{\underline{\mathrm{O}}+2 \mathrm{H}_{2}} \underline{\underline{\mathrm{S} \leftrightarrow \mathrm{Fe}^{2+}+2 \mathrm{SO}_{4}}} \underline{{ }^{2-}+2 \mathrm{HS}^{-}+18 \mathrm{H}^{+}+14 \mathrm{e}^{-}} \quad \log \mathrm{K}_{\mathrm{eq}}=-99.767 \\
& \mathrm{FeS}_{2}+8 \mathrm{H}_{2} \mathrm{O} \leftrightarrow \mathrm{Fe}^{2+}+2 \mathrm{SO}_{4}{ }^{2-}+16 \mathrm{H}^{+}+14 \mathrm{e}^{-} \quad \log \mathrm{K}_{\mathrm{eq}}=-113.75
\end{aligned}
$$

The third step is to rearrange equation $3-14 \mathrm{e}$ and combine with $3-14 \mathrm{~g}$ as:

$$
\begin{aligned}
& {\left[\mathrm{O}_{2}+4 \mathrm{H}^{+}+4 \mathrm{e}^{-} \leftrightarrow 2 \mathrm{H}_{2} \mathrm{O}\right] \times 3.5} \\
& \log \mathrm{K}_{\mathrm{eq}}=86.08
\end{aligned}
$$

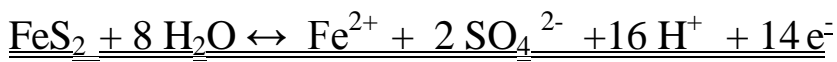

$$
\begin{aligned}
& \log \mathrm{K}_{\mathrm{eq}}=-113.75 \\
& \mathrm{FeS}_{2}+\mathrm{H}_{2} \mathrm{O}+3.5 \mathrm{O}_{2} \leftrightarrow \mathrm{Fe}^{2+}+2 \mathrm{SO}_{4}{ }^{2-}+2 \mathrm{H}^{+} \\
& \log \mathrm{K}_{\text {eq }}=187.53
\end{aligned}
$$

The corresponding equilibrium expression is:

$\log \left(\mathrm{Fe}^{2+}\right)+2 \log \left(\mathrm{SO}_{4}{ }^{2-}\right)+2 \log \left(\mathrm{H}^{+}\right)-3.5 \log \left(\mathrm{O}_{2}\right)=\log \mathrm{K}_{\mathrm{eq}}$

Find $\Delta \mathrm{G}_{\mathrm{r}}^{\circ}$

$\Delta \mathrm{G}_{\mathrm{r}}^{\circ}=-1.364 \log \mathrm{K}$

$\Delta \mathrm{G}_{\mathrm{r}}^{\circ}=-1.364(+187.53)$

$\Delta \mathrm{G}_{\mathrm{r}}^{\circ}=-255.79 \mathrm{kcal} / \mathrm{mole}$ 
Find $\mathrm{E}^{\circ}$

$$
\begin{aligned}
& \mathrm{E}^{\circ}=-\Delta \mathrm{G}_{\mathrm{r}} / \mathrm{nF} \\
& \mathrm{E}^{\circ}=-\Delta \mathrm{G}_{\mathrm{r}} / \mathrm{nF} \\
& \mathrm{E}^{\circ}=-(-255.79) /(14)(23.061) \\
& \mathrm{E}^{\circ}=0.792 \mathrm{~V} \\
& \mathrm{Eh}=\mathrm{E}^{\circ}+(\mathrm{RT} / \mathrm{nF})^{*} 2.303 *\left[\log \left(\left(\mathrm{SO}_{4}{ }^{2-}\right)^{2}\left(\mathrm{Fe}^{2+}\right)\left(\mathrm{H}^{+}\right)^{2} /\left(\mathrm{O}_{2}\right)^{0.25}\right)\right] \\
& \mathrm{Eh}=0.792+0.592 *\left[\left(2^{*} \operatorname{logSO}{ }_{4}{ }^{2-}+\log \mathrm{Fe}^{2+}+2 \log \mathrm{H}^{+}-0.25 \log \mathrm{O}_{2}\right)\right] \\
& \mathrm{Eh}=0.792+0.592^{2-}\left[\left(2^{*} \operatorname{logSO}{ }_{4}{ }^{2-}+\log \mathrm{Fe}^{2+}-2 \mathrm{pH}-0.25 \log \mathrm{O}_{2}\right)\right]
\end{aligned}
$$

Calculated values from the pyrite/oxygen couple are plotted in figure 3-15. There is considerable scatter and no obvious relationship between measured Eh and values calculated from pyrite and oxygen. The median difference between measured and calculated Eh is -110 millivolts with the tenth and $90^{\text {th }}$ percentiles at -239 and +246 millivolts, respectively.

The $\mathrm{Fe}^{2+} / \mathrm{Fe}^{3+}$ couple provided the closest agreement between measured and calculated Eh of the four equilibrium reactions considered. Some of the disparity may result from over-estimating $\mathrm{Fe}$ (III) by difference, rather than a direct measurement. To et al. (1999) suggests over-estimation of $\mathrm{Fe}$ (III) occurs when using the difference method. This would result in over estimating Eh, which is dominant error found in figure 3-15. The other couples displayed no consistent relation to measured Eh with differences up to several hundred millivolts. The $\mathrm{Fe}^{2+} / \mathrm{Fe}^{3+}$ couple relationship with Eh in acid mine waters is consistent with the findings of Nordstrom et al. (1979) and Stipp (1990). Redox measurements and controls in flooded circumneutral mine-pools are examined in chapter four.

\subsection{Mineral Controls on Metal Solubility}

Iron and $\mathrm{Al}$ are major components of waters draining from the Omega and $\mathrm{T} \& \mathrm{~T}$ mine-pools. Iron can be derived directly from pyrite oxidation or dissolution of other Fe bearing minerals including oxyhydroxides, sulfates, carbonates and silicates. The large number of potential sources and sinks makes reaction path identification difficult for Fe. Section 3.3.2 showed that waters from both mine-pools are deficient in $\mathrm{Fe}$ with respect to sulfate from pyrite weathering. Section 5.2 presents data suggesting that mineral weathering reactions are consuming much of the acidity in-situ. Soluble aluminum also has a variety of potential sources and sinks. This section examines some possible mineral and chemical controls on mobility of $\mathrm{Fe}$ and $\mathrm{Al}$, since these two elements are principal pollutants in these mine-pools. Much of the analysis is based on assumption of local equilibrium and the application of thermodynamic calculations. A large body of literature on sulfate minerals has been summarized in review volumes "Sulfate Minerals, Crystallography, Geochemistry and Environmental Significance" (Alpers et al., 2000) and "Acid Sulfate Weathering" (Kittrick et al., 1982) These references and other citations provide considerable 
background on the weathering, formation, solubility and stability of metal sulfates associated with pyrite weathering.

\subsubsection{Aluminum Minerals}

Aluminum is mobilized indirectly by sulfide weathering and dissolution reactions caused by the resulting low $\mathrm{pH}$ (acid waters), including dissolution of oxyhydroxides and silicates. The dissolution of poorly crystalline $\mathrm{Al}(\mathrm{OH})_{3}$ is a function of $\mathrm{pH}$ and $\mathrm{Al}$ activity:

$$
\mathrm{Al}(\mathrm{OH})_{3(\mathrm{am})}+3 \mathrm{H}^{+} \leftrightarrow \mathrm{Al}^{3+}+3 \mathrm{H}_{2} \mathrm{O} \quad \log \mathrm{K}_{\mathrm{eq}}=10.8 @ 25^{\circ}
$$

Complete feldspar dissolution is:

$\mathrm{KAlSi}_{3} \mathrm{O}_{8}+4 \mathrm{H}^{+}+4 \mathrm{H}_{2} \mathrm{O} \leftrightarrow \mathrm{K}^{+}+\mathrm{Al}^{3+}+3 \mathrm{H}_{4} \mathrm{SiO}_{4}{ }^{0}$

Kaolinite dissolution in strongly acidic conditions is:

$$
\mathrm{Al}_{2} \mathrm{Si}_{2} \mathrm{O}_{5}(\mathrm{OH})_{4}+6 \mathrm{H}^{+} \leftrightarrow 2 \mathrm{Al}^{3+}+2 \mathrm{H}_{4} \mathrm{SiO}_{4}{ }^{0}+\mathrm{H}_{2} \mathrm{O} \quad \log \mathrm{K}_{\mathrm{eq}}=7.435 @ 25^{\circ}(3-20)
$$

For each mineral, $\mathrm{H}^{+}$activity strongly influences the dissolution reactions.

Commonly recognized aluminum bearing minerals associated with acid drainage include $\mathrm{Al}(\mathrm{OH})_{3}$, both as a poorly crystalline form, and as gibbsite; alunite, jurbanite, basaluminite, halotrichite, pickeringite, aluminocopiapite and others (Bigham and Nordstrom, 2000; Rose and Cravotta, 1998; Hammarstrom et al., 2005; Cravotta, 1994; Karathanasis et al. 1988). The minerals vary in crystallinity and composition. Many are poorly crystalline, hydrous sulfates and are moderately to highly soluble. These soluble minerals may precipitate during drier mine periods and redissolve during wet periods and recharge events, liberating $\mathrm{Al}, \mathrm{Fe}$, sulfate, $\mathrm{H}^{+}$and other metals.

Zodrow (1980), and Zodrow and McCandlish (1978) identified a series of hydrated sulfate minerals in underground coal mines in Nova Scotia including alunite, halotrichite, pickeringite, and aluminocopiapite. Brant and Foster (1959) identified halotrichite in underground mine entries in Ohio. The mine-works had similar conditions to the Omega and T\&T mines. Bayless and Olyphant (1993) were able to relate ground-water chemistry and surface water runoff composition to the occurrence of acid generating sulfate salts at an abandoned coal mine in Indiana. Hammarstrom et al. (2005) also related water quality to the occurrence and dissolution of soluble mineral groups including halotrichite and copiapite at several metal mines in the eastern US. Highest metal loads occurred during spring runoff and intense summer storms. Leaching experiments showed the salts all produced acidic waters of $\mathrm{pH}$ two to three with $\mathrm{Al}$ and $\mathrm{Fe}$ concentrations in the 10 s to 100 s of $\mathrm{mg} / \mathrm{L}$.

Neither the Omega nor T\&T mine-works were accessible for direct sampling of sediments and observation of minerals. Therefore, possible mineral controls on Al activity in these mine-pools were assessed indirectly by examining mineral saturation indices, and reviewing subject literature to identify minerals identified in similar settings, and graphical analysis. 
Nordstrom (1982b) reviewed the aqueous chemistry of $\mathrm{Al}$, in particular, behavior in acid waters. He estimated solubility of the mineral jurbanite $\left(\mathrm{Al}\left(\mathrm{SO}_{4}\right) \mathrm{OH}^{*} 5 \mathrm{H}_{2} \mathrm{O}\right)$ and concluded that it may control Al solubility in acid waters and soils. Jurbanite solubility data were subsequently incorporated into several common thermodynamic databases for minerals used in geochemical modeling. Based on apparent jurbanite solubility, acid waters from coal mines, metal mines and acid sulfate soils (van Breeman, 1973; Davis and Ashenberg, 1989; Eary, 1999; Perry and Rauch, 2004) have been variously reported to attain or approach equilibrium for the mineral. Bigham and Nordstrom (2000) however, concluded that the reported solubility of jurbanite was not reliable, and the ion activity product likely reflected a correlation between $\mathrm{Al}$ and sulfate activity at $\mathrm{pH}$ less than 4.5, rather than mineral control. They suggested that Al has few mineral solubility constraints at $\mathrm{pH}$ less than 4.5. Nonetheless, poorly crystalline hydrous Al sulfate compounds are present in acid mine water sediments (Kim and Kim, 2003), and apparent equilibrium with jurbanite has been noted in coal mine drainage (Cravotta, 2008b). Therefore, in this work, thermodynamic calculations refer to "apparent" equilibrium with respect to jurbanite.

Aluminum and other water quality parameters were compared to each other in a simple correlation to test Bigham and Nordstrom's observations of $\mathrm{Al} / \mathrm{sulfate} / \mathrm{pH}$ relationships in these data sets. Results are summarized in table 3-6 for three springs and the combined discharge from the Omega mine-pool, and the main discharge from the T\&T mine-pool.

Table 3-6

Correlation coefficients among Aluminum, Iron, Calcium, Sulfate and $\mathrm{pH}$ in Acid Mine Waters, Omega and T\&T Mine-pools

\begin{tabular}{cccccc}
\hline & $\begin{array}{c}\text { Omega } \\
\text { PM-21 }\end{array}$ & $\begin{array}{c}\text { Omega } \\
\text { DEF }\end{array}$ & $\begin{array}{c}\text { Omega } \\
\text { Marshall }\end{array}$ & $\begin{array}{c}\text { Omega } \\
\text { Main Inlet }\end{array}$ & $\begin{array}{c}\text { T\&T } \\
\text { Main } \\
\text { Discharge }\end{array}$ \\
\hline $\mathrm{Al}$ vs. $\mathrm{SO}_{4}$ & $0.15^{*}$ & 0.54 & 0.70 & 0.68 & 0.56 \\
$\mathrm{Ca}$ vs. $\mathrm{SO}_{4}$ & 0.94 & 0.97 & 0.39 & 0.65 & 0.42 \\
$\mathrm{Fe}$ vs. SO & 0.46 & 0.68 & 0.82 & 0.80 & 0.79 \\
$\mathrm{Al}$ vs. pH & -0.52 & $0.07^{*}$ & 0.41 & $0.01^{*}$ & 0.18 \\
\hline
\end{tabular}

(1) Values followed by $*$ are not significant at $p=0.05$

No relationship between $\mathrm{Al}$ concentration and $\mathrm{pH}$ is evident in three of five discharges. These waters span a narrow $\mathrm{pH}$ range of only a few tenths of a $\mathrm{pH}$ unit and all $\mathrm{pH}$ values are less than 4.5. Thus one chemical parameter, $\mathrm{pH}$, is nearly invariant, while $\mathrm{Al}$ concentration has a wider range, resulting in low $\mathrm{r}$ values. Four of five correlation coefficients for $\mathrm{Al}$ versus $\mathrm{pH}$ are positive, and one is negative. An inverse relationship with negative correlation was expected if $\mathrm{Al}$ concentration increases as $\mathrm{pH}$ declines. Aluminum and sulfate have a moderate correlation for four discharges, and are unrelated in the fifth. The strongest overall correlations are between Fe and sulfate, with four discharges having an $r$ value of 0.68 or greater. The Omega and T\&T data sets do not follow the $\mathrm{Al}$ and sulfate correlation as closely as Bigham and Nordstrom (2000) suggest they might, and the mineral jurbanite was retained in the overall analysis as a potential source/sink for Al. 
Jambor et al. (2000), and Bigham and Nordstrom (2000), reviewing a large set of literature summarized the formation of various aluminum sulfate mineral groups as a function of $\mathrm{pH}$ as follows:

Basaluminite $\left(\mathrm{Al}_{4}(\mathrm{OH})_{10} \mathrm{SO}_{4} * 5 \mathrm{H}_{2} \mathrm{O}\right.$, monoclinic crystal system) forms at $\mathrm{pH}$ of about five to six;

Jurbanite $\left(\mathrm{Al}\left(\mathrm{SO}_{4}\right) \mathrm{OH}^{*} 5 \mathrm{H}_{2} \mathrm{O}\right.$, monoclinic crystal system $)$ forms at intermediate $\mathrm{pH}$ of about three to five, and;

Alunogen $\left(\mathrm{Al}_{2}\left(\mathrm{SO}_{4}\right)_{3} * 17 \mathrm{H}_{2} \mathrm{O}\right.$, triclinic mineral system) forms at $\mathrm{pH}$ of about two to three.

The $\mathrm{pH}$ dependence is related to the $\mathrm{Al}$ to sulfate mole ratio, where the most acidic waters contain the highest sulfate concentrations, and consequently form the most sulfate rich minerals. Thermodynamic data are not available for all hydrous Al sulfate minerals, and calculations were performed for minerals with published equilibrium constants. The constant for alunogen was taken from Nordstrom (1982b).

Figure 3-16 is a plot of stability fields of several Al bearing minerals that could control Al activity in acid mine waters, and 77 sample analyses from discharge DEF in the Omega mine-pool from 1993 to 2008. The plot was constructed to include jurbanite, kaolinite, poorly crystalline $\mathrm{Al}(\mathrm{OH})_{3}$, gibbsite, alunite, basaluminite and alunogen. Dissolution reactions used to construct figure 3-16 include equations 3-18 and 3-20 and the following:

$$
\begin{gathered}
\mathrm{Al}(\mathrm{OH})_{3}(\text { gibbsite })+3 \mathrm{H}^{+} \leftrightarrow \mathrm{Al}^{3+}+3 \mathrm{H}_{2} \mathrm{O} \quad \begin{array}{c}
\log \mathrm{K}_{\mathrm{eq}}=8.11 @ 25^{\circ} \\
\mathrm{KAl}_{3}\left(\mathrm{SO}_{4}\right)_{2}(\mathrm{OH})_{6} \text { (alunite) }+6 \mathrm{H}^{+} \leftrightarrow \mathrm{K}^{+}+3 \mathrm{Al}^{3+}+2 \mathrm{SO}_{4}^{2}+6 \mathrm{H}_{2} \mathrm{O} \\
\log \mathrm{K}_{\mathrm{eq}}=-1.4 @ 25^{\circ}
\end{array} \\
\mathrm{AlOHSO}_{4}+\mathrm{H}^{+} \text {(jurbanite) } \leftrightarrow \mathrm{Al}^{3+}+\mathrm{SO}_{4}^{2-} \begin{array}{c}
+\mathrm{H}_{2} \mathrm{O} \\
\log \mathrm{K}_{\mathrm{eq}}=-3.23 @ 25^{\circ}
\end{array} \\
\mathrm{Al}_{4}(\mathrm{OH})_{10} \mathrm{SO}_{4}(\text { basaluminite })+10 \mathrm{H}^{+} \leftrightarrow 4 \mathrm{Al}^{3+}+\mathrm{SO}_{4}^{2-}+10 \mathrm{H}_{2} \mathrm{O} \\
\log \mathrm{K}_{\mathrm{eq}}=22.7 @ 25^{\circ} \\
\mathrm{Al}_{2}\left(\mathrm{SO}_{4}\right)_{3} * 17 \mathrm{H}_{2} \mathrm{O} \text { (alunogen) } \leftrightarrow 2 \mathrm{Al}^{3+}+3 \mathrm{SO}_{4}^{2-}+17 \mathrm{H}_{2} \mathrm{O} \\
\log \mathrm{K}_{\mathrm{eq}}=-6.98 @ 25^{\circ}
\end{gathered}
$$

Each reaction was rewritten as an equilibrium expression and solved for $\mathrm{Al}^{3+}$ activity over a $\mathrm{pH}$ range of zero to 14 . Log sulfate activity was fixed at -2.275 , a typical value for the DEF spring. Kaolinite calculations required a value for $\mathrm{Si}$, and total $\log \mathrm{Si}$ activity was fixed at -3.47 . That value was derived from water samples collected by the author that included Si analysis. Alunite calculations required a value for $\mathrm{K}^{+}$activity. The $\log$ activity was fixed at -4.0 as a representative value. 
As an example, alunite dissolution (equation 3-22) when written as an equilibrium expression in $\log$ form is:

$$
\begin{aligned}
& \log \mathrm{K}^{+}+3 \log \mathrm{Al}^{3+}+2 \log \mathrm{SO}_{4}^{2-}-6 \log \mathrm{H}^{+}=\log \mathrm{K}_{\mathrm{eq}} \\
& \log \mathrm{Al}^{3+}=\left(\log \mathrm{K}_{\mathrm{eq}}-\log \mathrm{K}^{+}-2 \log \mathrm{SO}_{4}^{2-}-6 \mathrm{pH}\right) / 3
\end{aligned}
$$

The calculated $\mathrm{Al}^{3+}$ activities were then substituted into the equilibrium expression for the following $\mathrm{Al}$ species using the appropriate constants:

- $\mathrm{Al}$ hydroxy species $\mathrm{AlOH}^{2+}, \mathrm{AlOH}_{2}{ }^{+}, \mathrm{AlOH}_{3}{ }^{0}$, and $\mathrm{AlOH}_{4}{ }^{-}$

- $\mathrm{Al}$ sulfate species $\mathrm{AlSO}_{4}{ }^{+}, \mathrm{Al}\left(\mathrm{SO}_{4}\right)^{2-}, \mathrm{HSO}_{4}{ }^{-}$and $\mathrm{AlHSO}_{4}{ }^{+}$

The activity of $\mathrm{Al}^{3+}$ was plotted on the $\mathrm{y}$ axis of figure 3-16 as a function of $\mathrm{pH}$. The 77 sample analyses are also plotted.

The plot shows that water composition, in terms of $\mathrm{Al}$ activity and $\mathrm{pH}$ has varied little over a 15 year period. DEF samples approach equilibrium for two minerals; jurbanite and alunite. Saturation indices were calculated for both minerals in PHREEQCI, and DEF waters approach apparent equilibrium for jurbanite. The median jurbanite saturation index for 77 samples is -0.15 . Indices range from a minimum of -0.92 in 2008 to slight super-saturation at a maximum of 0.17 . Alunite has a median saturation index of -4.6, and all others minerals shown on figure 3-16 are also undersaturated by multiple orders of magnitude.

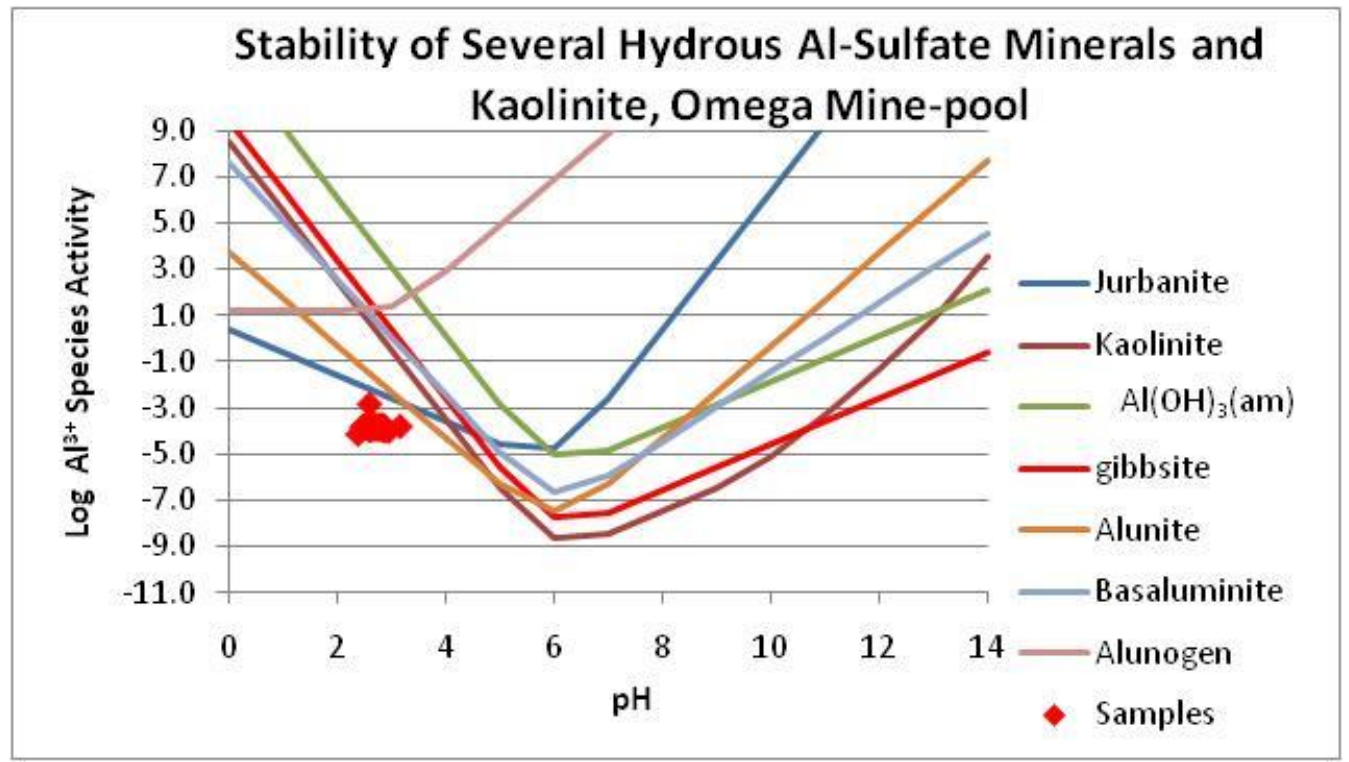

Figure 3-16. Stability of Hydrous Al-Sulfate Minerals as a Function of pH, Omega Mine-pool, Discharge DEF. Samples from 1993-2008. Total log molar activity of $\mathrm{Al}^{3+}$ on y axis.

Log sulfate activity fixed at $\mathbf{- 2 . 2 7 5}$; $\log$ silica activity fixed at $\mathbf{- 3 . 4 7}$; $\log$ potassium activity fixed at $\mathbf{- 4 . 0}$ 
Figure 3-17 shows a time series plot of jurbanite saturation index for the DEF discharge and two other springs in the Omega mine-pool, Marshall and PM-21. Waters in the DEF discharge approach the apparent equilibrium saturation index of 0 , suggesting that jurbanite poses an upper limit to $\mathrm{Al}$ concentration at site DEF. Waters at the Marshall discharge are slightly oversaturated for jurbanite. Slight oversaturation suggests that within the mine, a slightly more soluble poorly crystalline phase of jurbanite is forming, jurbanite reaction rates are slow, the "dissolved" fraction on which the saturation index calculations were based contains colloidal Al, or jurbanite is not actually forming. Without direct sampling of mine sediments, it is difficult to determine which scenario is occurring. Beginning about 2006, saturation indices for the three springs show an irregular decline towards increasing under-saturation in DEF and PM-21 and near equilibrium in the Marshall spring.

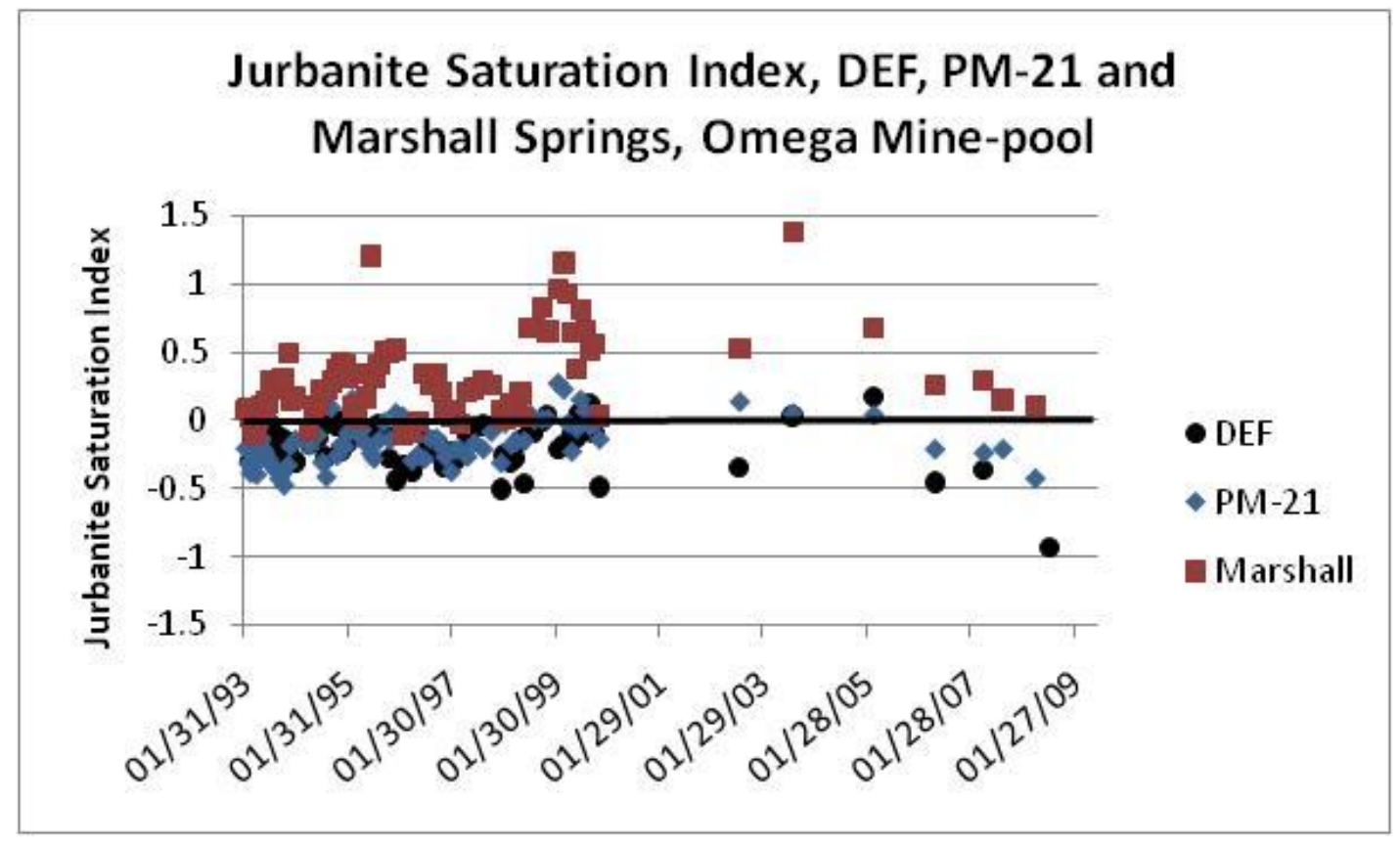

Figure 3-17. Time Series of Jurbanite Saturation Index, DEF, Marshall and PM-21 Springs, Omega Mine-pool.

If a jurbanite-like mineral is present, it could form as an alteration product of an alumino-silicate and sulfate. The alteration from kaolinite to jurbanite could occur as:

$$
\mathrm{Al}_{2} \mathrm{Si}_{2} \mathrm{O}_{5}(\mathrm{OH})_{4}+4 \mathrm{H}^{+}+2 \mathrm{SO}_{4}{ }^{2-}+\mathrm{H}_{2} \mathrm{O} \leftrightarrow 2 \mathrm{AlOHSO}_{4}+2 \mathrm{H}_{4} \mathrm{SiO}_{4}{ }^{0}
$$

The equilibrium expression is:

$$
\mathrm{K}_{\mathrm{eq}}=2 \log \mathrm{H}_{4} \mathrm{SiO}_{4}{ }^{0}-4 \log \mathrm{H}^{+}-2 \log \mathrm{SO}_{4}{ }^{2-} \quad \mathrm{K}_{\mathrm{eq}}=10.665 @ 25^{\circ}
$$


Substituting values for $\log$ sulfate activity of -2.275 , and $\log$ Si activity of -3.47 , as in figure 3-16, the equilibrium $\mathrm{pH}$ is 3.26 for jurbanite/kaolinite transformation. Actual $\mathrm{pH}$ values are about 0.5 to 0.8 units less, indicating that transformation from kaolinite to jurbanite is favored.

With various sulfate minerals present or potentially present in mine-pool sediments, common ion effects are possible. Figure 3-18 is a time series plot of the same three springs in the Omega minepool, but with gypsum saturation index plotted. With the exception of samples from the Marshall discharge in 1998-1999, the springs are slightly to moderately under-saturated with respect to gypsum. Super-saturation at Marshall was attained when cement grout and flyash, sources of $\mathrm{Ca}$ and sulfate, were injected in a section of the mine-works adjacent to the spring. Under-saturation with respect to gypsum could result from the dissolution of a more soluble sulfate bearing mineral, thereby suppressing dissolution of the less soluble gypsum. Gypsum saturation indices also show a time dependent trend, with waters becoming progressively more under-saturated as the mine-pool ages.

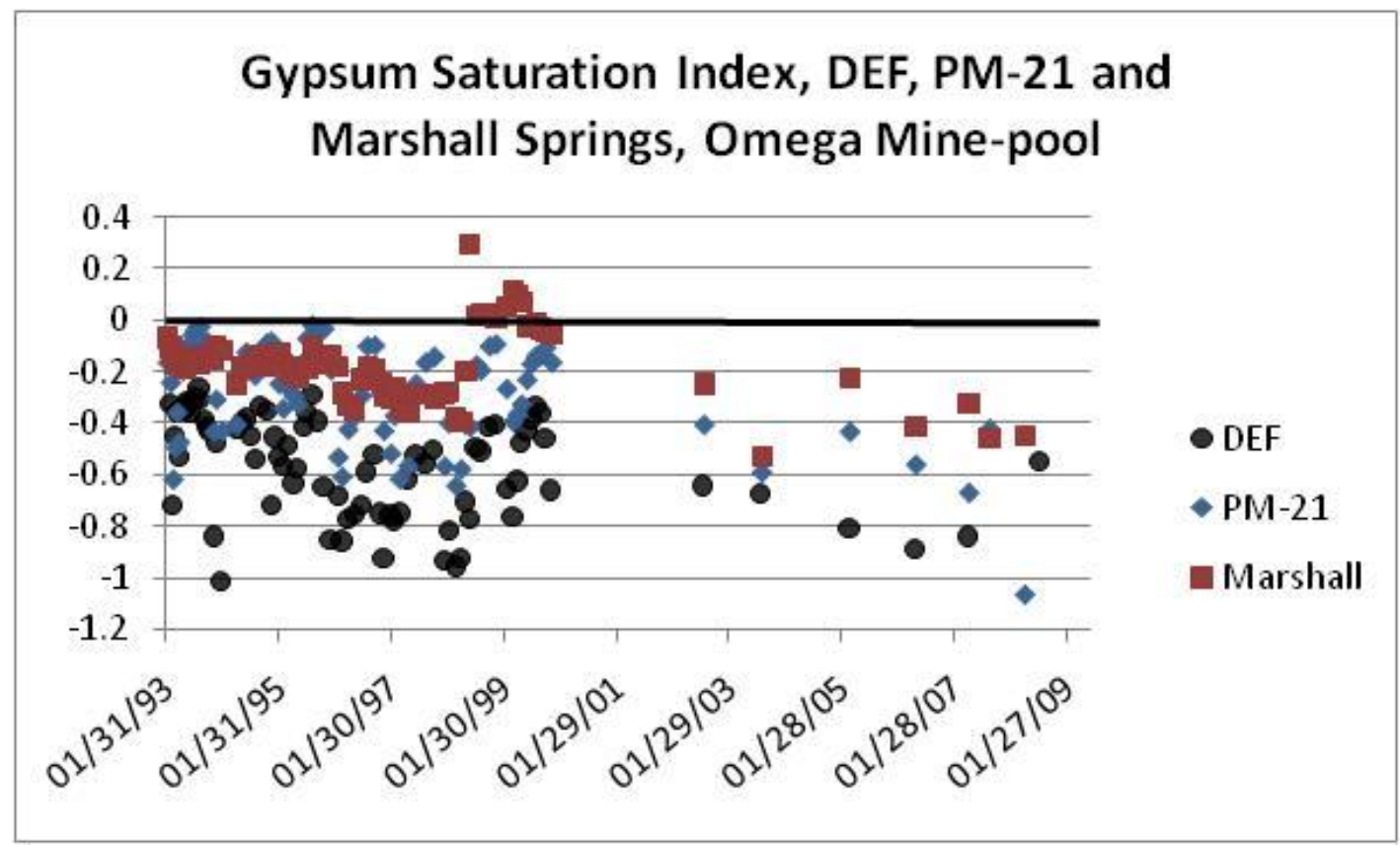

Figure 3-18. Time Series of Gypsum Saturation Index, DEF, Marshall and PM-21Springs, Omega Mine-pool.

A limited number of complete suite samples were available to compute chemical activities and mineral saturation indices for the T\&T mine-pool. Chemical activities were estimated by indirect methods as follows for samples that did not include all major cations and anions.

- Sulfate was assumed to approximate the total quantity of anion charge. Chloride was less than $5 \mathrm{mg} / \mathrm{L}$ in author collected samples and the acidic $\mathrm{pH}$ precludes significant bicarbonate or carbonate. 
- The cation fraction was composed mainly of $\mathrm{Ca}, \mathrm{Mg}, \mathrm{Al}$ and $\mathrm{Fe}$. $\mathrm{Na}$ and $\mathrm{K}$ were present at a few $\mathrm{mg} / \mathrm{L}$ in author collected samples and were not included in charge calculations.

- $\mathrm{Fe}(\mathrm{II}) / \mathrm{Fe}(\mathrm{III})$ ratio was calculated from measured Eh and averaged about 0.8/0.2 in the main drainage.

- Sum cation charge was assumed to equal sum anion charge (electro-neutrality principle). Cation charge was estimated from reported Al and Fe data. "Missing" cation charge was distributed between $\mathrm{Ca}$ and $\mathrm{Mg}$ in a mole ratio of 0.76:0.24. This ratio was based on the complete suite samples.

- Ionic strength was calculated from:

$$
\mathrm{I}=\sum \mathrm{m}_{\mathrm{i}} \mathrm{z}_{\mathrm{i}}^{2}
$$

where $\mathrm{I}$ is ionic strength, $\mathrm{m}_{\mathrm{i}}$ is molal concentration, and $\mathrm{z}$ is valence of the $i$ th element. Ionic strength was then used to estimate log activity coefficients with the extended Debye Huckel equation:

$$
\log \gamma_{i}=\left(-\mathrm{A} z_{i}^{2}\right)(\mathrm{I})^{\wedge 0.5} /\left(\left(1+\mathrm{B}_{\mathrm{a} 0}(\mathrm{I})^{\wedge 0.5}\right)\right.
$$

where $\log \gamma_{\mathrm{I}}$ is $\log$ activity coefficient, $\mathrm{A}$ and $\mathrm{B}_{\mathrm{a} 0}$ are constants, and $\mathrm{I}$ is as previously defined.

Chemical activity was estimated from the activity coefficient derived as described above, total element concentration, and speciation data in section 3.3.3. The complexing information presented in section 3.3.3 was used to estimate the fractions of $\mathrm{Al}^{3+}, \mathrm{Ca}^{2+}$ and $\mathrm{SO}_{4}{ }^{2-}$ present in solution. Twenty percent of the dissolved $\mathrm{Al}$ is present as uncomplexed $\mathrm{Al}^{3+}$, about $55 \%$ of dissolved sulfate is present as $\mathrm{SO}_{4}{ }^{2-}$, and about $70 \%$ of dissolved calcium is present as $\mathrm{Ca}^{2+}$. These fractions were used to estimate chemical concentrations from total dissolved $\mathrm{Al}$, sulfate and $\mathrm{Ca}$ data reported in the WVDEP date set. Chemical activities and mineral saturation indices computed with this indirect method were compared to values calculated in PHREEQCI for complete suite samples. The two methods agreed within about ten percent. Mineral saturation indices were computed for jurbanite and gypsum in the final step.

Jurbanite and gypsum saturation indices estimates for the T\&T mine-pool are shown in figure 3-19 using smoothed data. Unlike the Omega mine-pool, T\&T mine waters are under-saturated with respect to both minerals. Aluminum, sulfate and calcium activities in T\&T mine-pool are apparently not limited by jurbanite and gypsum. After limestone injection, saturation indices increased for both minerals, especially gypsum. The gypsum increase likely results from additional $\mathrm{Ca}^{2+}$ activity. Both mineral indices also show short term scatter, and a small indistinct seasonal trend. Indices generally increase as much as 0.2 units during drier portions of the year, when mine waters should be more concentrated. Neither mineral appears to control Al or sulfate activity in the T\&T mine-pool. The limestone injection process actually increased the degree of solution 
saturation. That condition has persisted for more than 6 years after in-situ treatment, and shows no obvious declining trend.

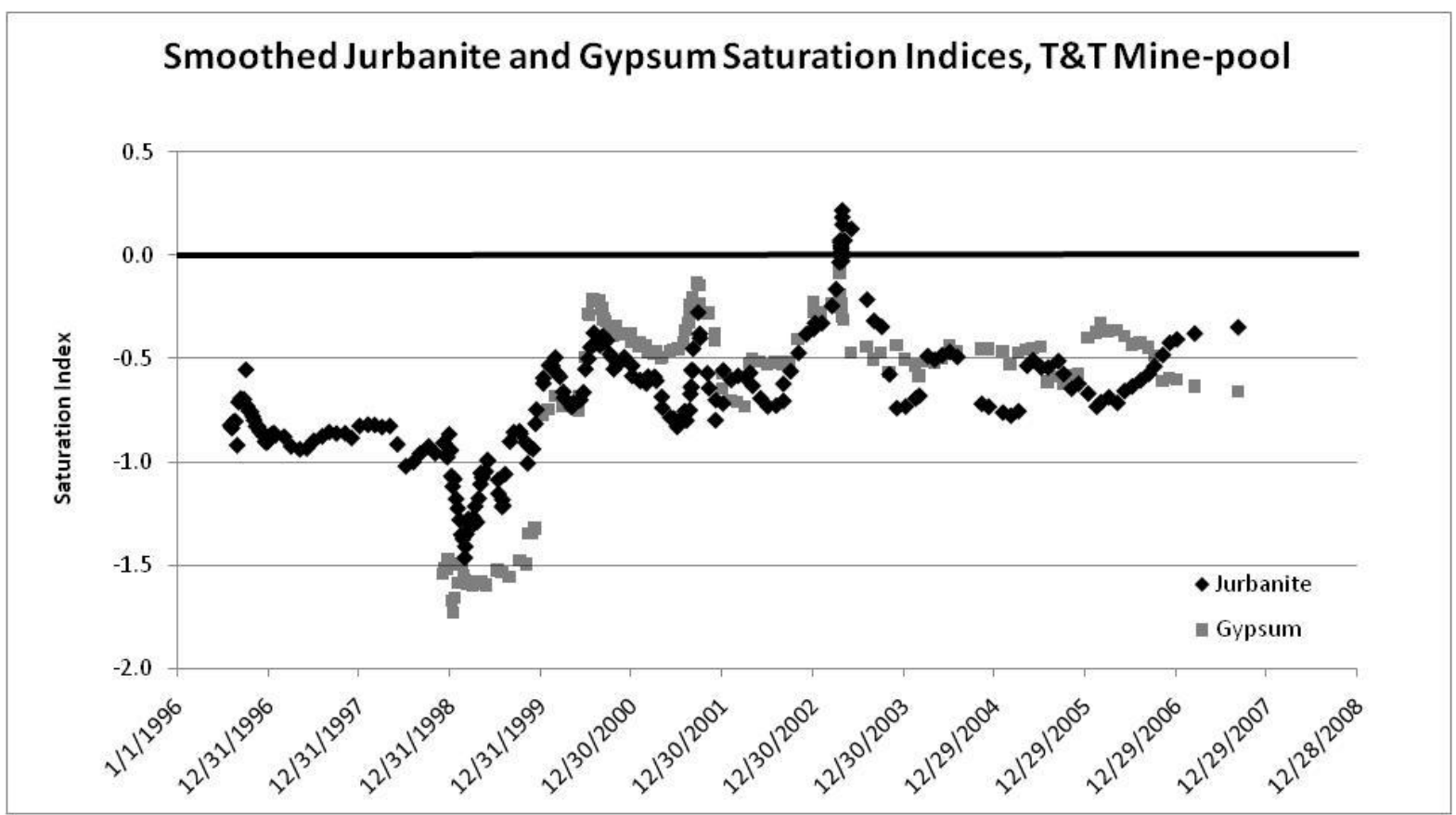

Figure 3-19. Time Series of Jurbanite and Gypsum Saturation Index, T\&T Mine-pool.

What is the source of soluble Al in these mine-pools? The most obvious and abundant source is alumino-silicate minerals. Many weather slowly even under acid conditions. Kaolinite dissolution, for example, is about eight orders of magnitude slower than dolomite weathering under acid conditions (Palandri and Kharaka, 2004). The slow kinetics of most alumino-silicate weathering could result in waters under-saturated for these minerals, even if they are supplying soluble Al to the mine water. The Omega and T\&T mine-pools are under-saturated with respect to kaolinite by three to seven orders of magnitude.

\section{$\underline{\text { 3.4.2 Iron Minerals }}$}

Like aluminum, iron can reside in a number of minerals associated with acid drainage, including sulfates and oxyhydroxides. Iron may be present as $\mathrm{Fe}(\mathrm{II})$ or $\mathrm{Fe}(\mathrm{III})$ and may occur in mixed valence states within the same mineral, such as copiapite. Iron minerals commonly identified as in mine drainage sediments include poorly crystalline $\mathrm{Fe}(\mathrm{OH})_{3}$, ferrihydrite, goethite, melanterite, copiapite, halotrichite, schwertmannite, jarosite and others (Zodrow and McCandlish, 1978; Zodrow et al.,1979; Bowell and Bruce, 1995; Cravotta, 1994; Rose and Cravotta, 1998; Kaires et al., 2005; Jerz and Rimstidt, 2004; Hammarstrom et al., 2005; Bigham and Nordstrom, 2000; Alpers et al., 2000). The oxyhydroxide minerals can vary in solubility over six orders of magnitude (Langmuir and Whittemore, 1971) and may scavenge or sorb trace elements from mine waters (Smith, 1999; Bowell and Bruce 1995; Filipek et al., 1987; Bigham and Nordstrom, 2000). 
In aerated, oxidized mine-pools like Omega and T\&T, Fe(III) minerals may be present in abundance. The preferred mineral state will also be influenced by $\mathrm{pH}$. In general, goethite is the most stable phase above a $\mathrm{pH}$ of about 3.5 to 4.0 , schwertmannite, a hydrous hydroxysulfate, is stable at intermediate $\mathrm{pH}$ of about three to five, and jarosite is stable in oxidizing, acid environments (Bigham and Nordstrom, 2000, Bigham et al., 1996). Both jarosite and schwertmannite are considered metastable with respect to goethite. The conversion rate for schwertmannite to goethite is $\mathrm{pH}$ dependent. Jonsson et al. (2005) found that schwertmannite to goethite conversion was complete in 187 days at $\mathrm{pH} 9$, while at $\mathrm{pH} 6$, conversion was not complete at 514 days, and that higher sulfate concentration also slowed the conversion rate. A long term weathering experiment by Bigham et al. (1996) also confirmed conversion to goethite. Thus, a number of Fe minerals may form initially in acid mine-pools, but some may transform to more stable compounds like goethite as the mine-pool ages.

Schwertmannite was only recognized as a mineral in 1990 (Bigham et al., 1990). It has a formula of indefinite composition and its dissolution is given by Yu et al. (1999) as:

$$
\mathrm{Fe}_{8} \mathrm{O}_{8}(\mathrm{OH})_{8-2 \mathrm{x}}\left(\mathrm{SO}_{4}\right)_{\mathrm{x}}{ }^{*} \mathrm{n} \mathrm{H}_{2} \mathrm{O}+(8+2 \mathrm{x}) \mathrm{H}_{2} \mathrm{O} \leftrightarrow 8 \mathrm{Fe}^{3+}+24 \mathrm{OH}^{-}+\mathrm{x} \mathrm{SO}_{4}{ }^{2-}+2 \mathrm{x} \mathrm{H}^{+}
$$

where $1.74<\mathrm{x}<1.86$ and $8.17<\mathrm{n}<8.62$. The estimated $\log \mathrm{K}_{\mathrm{eq}}$ is $10.5 \pm 2$. Solubility data from $\mathrm{Yu}$ et al. (1999) were added to the PHREEQCI calculations using the keyword "Phases" to estimate schwertmannite saturation state in the Omega and T\&T mine-pools. The composition parameter, $\mathrm{x}$, was set at 1.80, corresponding to midpoint of the reported formula range, and $\log \mathrm{K}_{\mathrm{eq}}$ was set to 10.5 . One set of calculations was conducted using the upper limit of $\log \mathrm{K}_{\mathrm{eq}}=12.5$.

Jarosite is the $\mathrm{Fe}$ bearing member of the jarosite-alunite group with the general composition $\mathrm{AB}\left(\mathrm{SO}_{4}\right)_{2}(\mathrm{OH})_{6}$, where $\mathrm{B}$ is $\mathrm{Fe}^{3+}$ (jarosite) or $\mathrm{Al}^{3+}$ (alunite) and $\mathrm{A}$ is usually $\mathrm{K}^{+}, \mathrm{Na}^{+}$or $\mathrm{H}^{+}$. Substitution for both the A cation and $\mathrm{Fe}^{3+}$ can occur (Baron and Palmer, 1996). The equilibrium expression for $\mathrm{K}$ jarosite is:

$$
\mathrm{KFe}_{3}\left(\mathrm{SO}_{4}\right)_{2}(\mathrm{OH})_{6}+6 \mathrm{H}^{+} \leftrightarrow \mathrm{K}^{+}+3 \mathrm{Fe}^{3+}+2 \mathrm{SO}_{4}{ }^{2-}+6 \mathrm{H}_{2} \mathrm{O} \quad \log \mathrm{K}_{\mathrm{eq}}=-9.21 @ 25^{\circ} \mathrm{C}
$$

H-Jarosite and Na-Jarosite dissolve in analogous manner and have log equilibrium constants of -5.39 and -5.28 , respectively. The low $\mathrm{pHs}$ of less than three and oxidizing conditions in both mine-pools are amenable to jarosite formation.

The reported solubility for K-jarosite varies significantly. The various thermodynamic databases available for use with PHREEQCI contain equilibrium constants over 5 orders of magnitude. The Wateq4F and PHREEQC databases both use a $\log$ Keq of -9.21 , the Lnl data base compiled by Lawrence Livermore National Laboratory uses a log Keq of -9.34, while the MinteqV4 database, compiled for USEPA, uses a log K of -14.8. Baron and Palmer (1996) conducted jarosite solubility experiments and reported a $\log \mathrm{K}$ of -11 . They also reviewed other literature on jarosite solubility which they found ranged over 7 orders of magnitude. Finally, they noted that their experiments, conducted in the range of 5 to $35^{\circ} \mathrm{C}$, took about 6 months to approach equilibrium. Thus, while jarosite is thermodynamically favored in acid, oxidizing mine-pools, the rate of formation may be constrained. After examining the data summarized by Baron and Palmer and discussions in Alpers 
et al. (2000), the jarosite equilibrium constant in the Wateq4F and PHREEQC was selected for use in calculating solubility of K-Jarosite. A set of calculations using Baron and Palmer's value of log Keq $=-11$ was also conducted to examine effect on apparent solubility.

Mineral saturation indices were calculated in PHREEQCI for about 80 complete suite sample events at the DEF, PM-21 and Marshall springs in the Omega mine-pool and about six sample events collected by the author in the T\&T mine-pool. The Omega sample events included analysis of all major cations and anions plus $\mathrm{Fe}(\mathrm{II}) / \mathrm{Fe}(\mathrm{III})$ analysis for data collected by the US Dept of Energy from 1993 to 1999. Samples collected by the author included Eh measurements, and $\mathrm{Fe}(\mathrm{II}) / \mathrm{Fe}(\mathrm{III})$ distributions were estimated from the redox data.

Figures 3-20 to 3-23 show the stability of selected Fe oxyhydroxide and hydrous sulfate minerals plotted with mine-pool composition. Lines on the graphs represent equilibrium for the mineral as a function of $\mathrm{pH}$ and $\log \mathrm{Fe}^{3+}$ activity, and were computed from the equilibrium expression and constant, in the same manner as Al stability in figure 3-16. For mineral dissolution involving sulfate and $\mathrm{K}^{+}$, representative log activity values were fixed as the median of all speciated samples for that sample point. Activity values on which the calculations are based are included in the caption material for figures 3-20 to 3-23, respectively. Chemical activities did not vary greatly over the monitoring record. The log sulfate activity for the Marshall spring, for example, ranged from -1.86 to -2.32 over more than 10 years and 80 samples. Median chemical activity values, therefore provide a reasonable approximation of entire data sets, and allow plotting of multiple samples on a single graph. The equilibrium constant was varied for schwertmannite and K-jarosite to examine effects on apparent solubility.

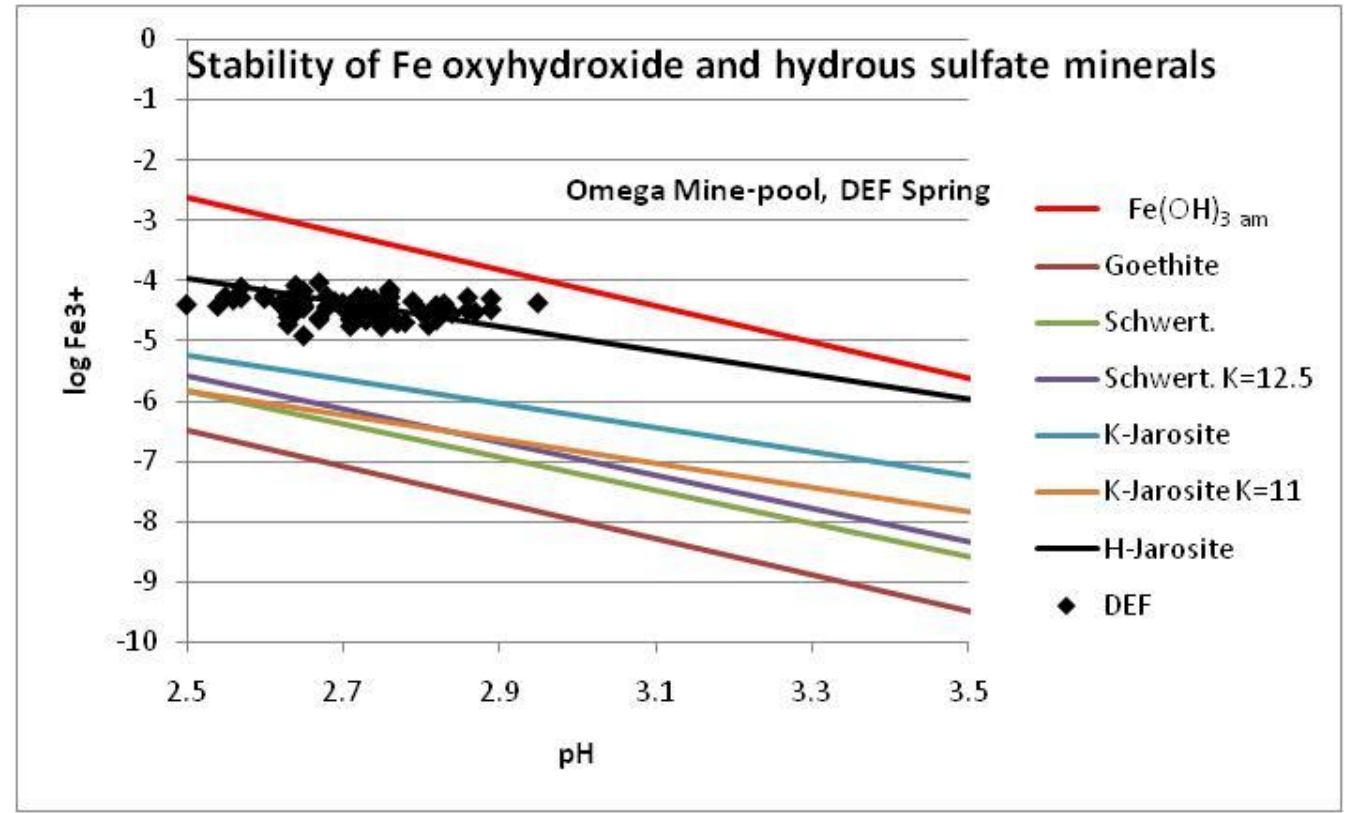

Figure 3-20. Stability of Selected Fe Oxyhydroxide and Hydrous Sulfate Minerals, Omega Mine-pool, and Composition of DEF Spring. Log activity of $\mathrm{SO}_{4}{ }^{2-}$ fixed at-2.23, $\log$ activity of $\mathrm{K}^{+}$fixed at -4.71 . 
Equivalent solubility information for Fe and sulfate system minerals could be provided in an Eh$\mathrm{pH}$ diagram, but figures 3-20 to 3-23 facilitate the display of several minerals concurrently. Three springs from the Omega mine-pool, DRF, PM-21 and Marshall are shown in figure 3-20, 3-21 and 3-22. Figure 3-23 shows samples from the T\&T mine-pool. In figure 3-20, DEF spring, most

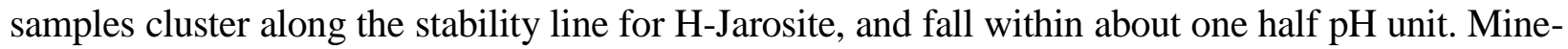
pool DEF composition is consistent with respect to these minerals over the 80 samples and approximately 13 years represented in figure 3-20.

Results for the PM-21 spring are in figure 3-21. As with the DEF spring, most samples cluster along the H-Jarosite stability line. However a few samples approach stability for poorly crystalline $\mathrm{Fe}(\mathrm{OH})_{3}$ even under the strongly acid conditions. Three samples plot near stability for K-Jarosite, and one sample shows apparent near equilibrium with schwertmannite. Varying the schwertmannite equilibrium constant from ten to 12 has little effect on mineral stability interpretations for these waters.

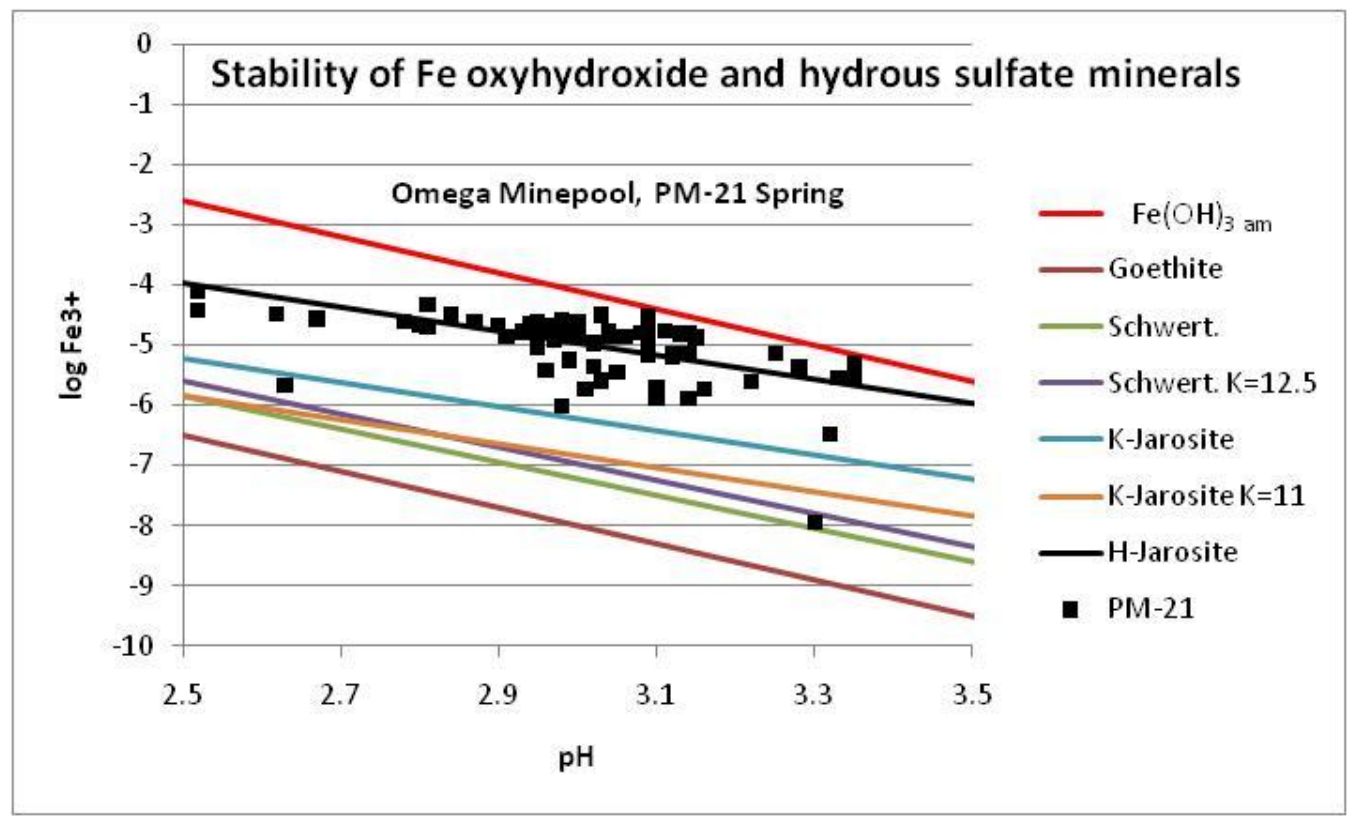

Figure 3-21. Stability of Selected Fe Oxyhydroxide and Hydrous Sulfate Minerals, Omega Mine-pool, and Composition of PM-21 Spring. $\mathrm{Log}$ activity of $\mathrm{SO}_{4}{ }^{2-}$ fixed at-2.14, $\log$ activity of $\mathrm{K}^{+}$fixed at $\mathbf{- 3 . 8 1}$.

Results for the Omega mine-pool, Marshall spring, in figure 3-22 show two data groups, which correspond to pre- and post- grout injection in to the mine-pool. One group of samples with pH less than about 3.0, range from slight super-saturation for K-Jarosite to approaching equilibrium with $\mathrm{H}$-Jarosite. After grout injection, $\mathrm{Fe}^{3+}$ activity is scattered over five orders of magnitude, and apparent equilibrium is displayed for several different iron minerals. Grout injection in 1999 changed the flow characteristics and chemical composition of this part of the mine-pool, and the discharge showed large short term variation for several years after (Perry and Rauch, 2004). By 2007, the latest sampling, the waters were near stability for H-Jarosite or poorly crystalline $\mathrm{Fe}(\mathrm{OH})_{3}$ (figure 3-22). 


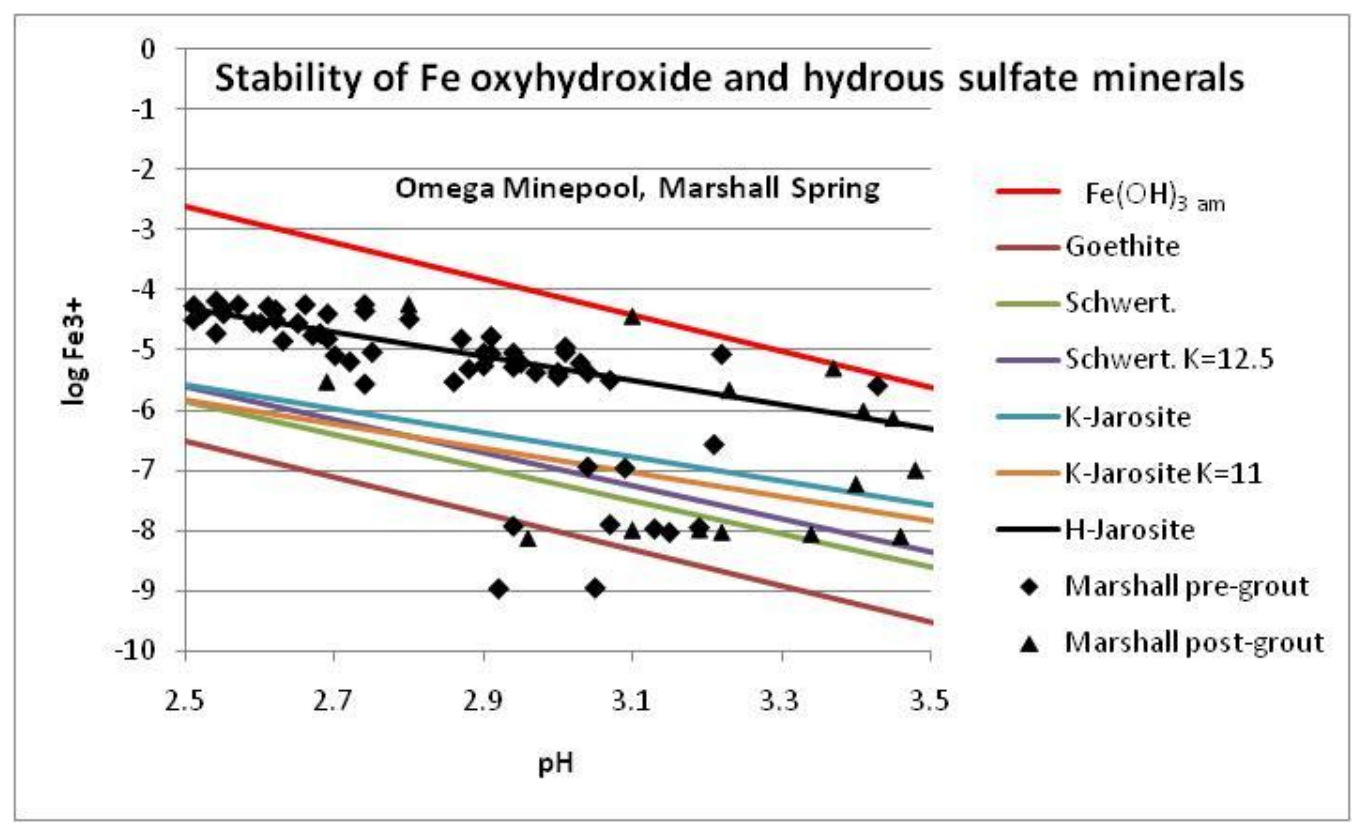

Figure 3-22. Stability of Selected Fe Oxyhydroxide and Hydrous Sulfate Minerals, Omega Mine-pool, and Composition of Marshall Spring. Log activity of $\mathrm{SO}_{4}{ }^{2-}$ fixed at-2.01, $\log$ activity of $\mathrm{K}^{+}$fixed at -3.76 . Pregrout samples (diamond) and post grout (triangle) shown.

Figure 3-23 shows results for the T\&T mine-pool. The plot is limited to samples which included measured Eh to estimate $\mathrm{Fe}(\mathrm{II}) / \mathrm{Fe}$ (III) distribution. The WVDEP data source which comprises most of the information for this site does not routinely include Fe(II) analysis or Eh measurement.

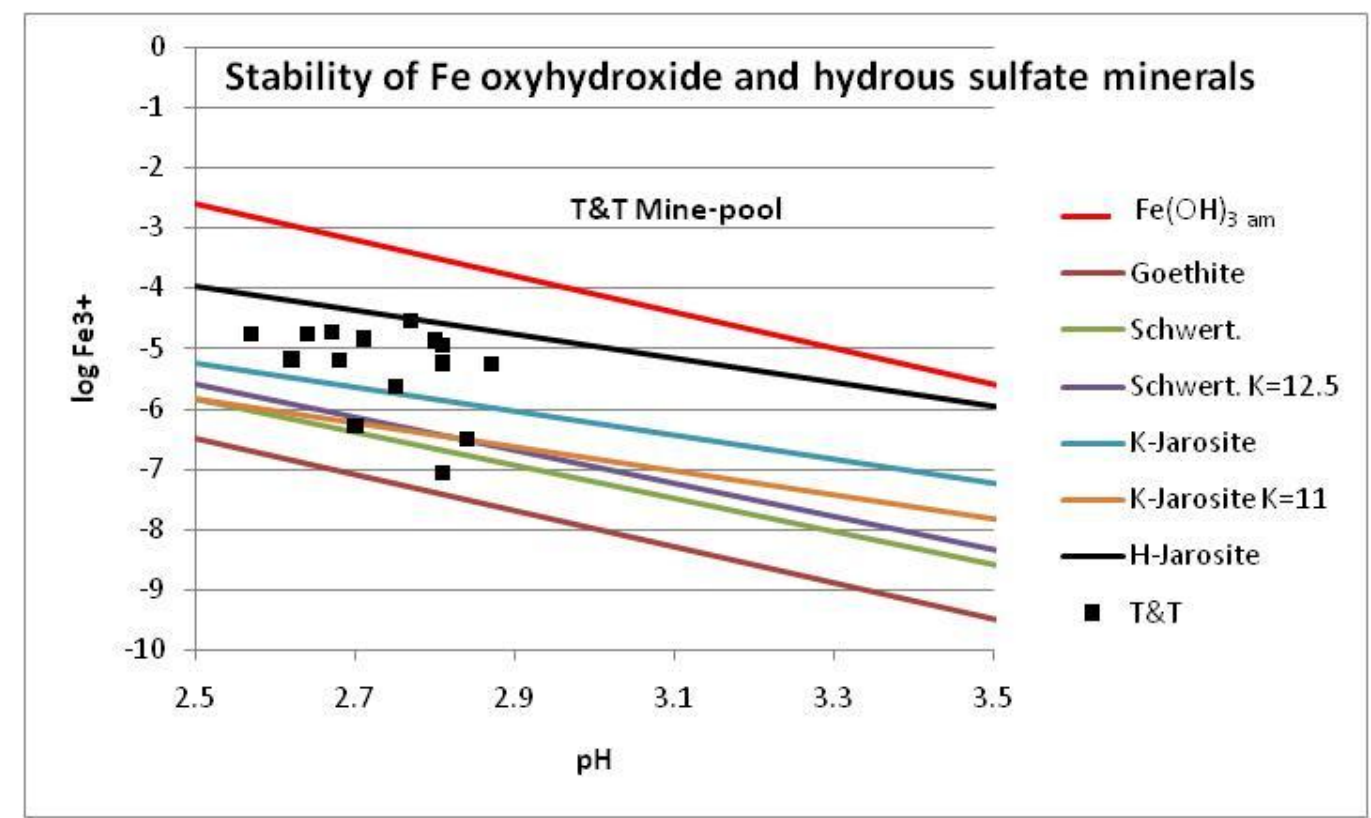

Figure 3-23. Stability of Selected Fe Oxyhydroxide and Hydrous Sulfate Minerals, T\&T Mine-pool, and Composition of Waters. Log activity of $\mathrm{SO}_{4}{ }^{2-}$ fixed at-2.48, $\log$ activity of $\mathrm{K}^{+}$fixed at $\mathbf{- 4 . 2 1}$. 
The waters in figure 3-23 are scattered between K-Jarosite and H-Jarosite, with no clear trend. Either the mine-pool does not approach equilibrium for any single mineral, or the sediments vary sufficiently in composition and crystallinity, that equilibrium is defined within a "window" of conditions.

Figures 3-24a-d are conventional $\mathrm{Eh} / \mathrm{pH}$ diagrams for selected $\mathrm{Fe}$ minerals for the same waters plotted in figures 3-20 to 3-23, and were generated using Geochemist Workbench version 6. Poorly crystalline $\mathrm{Fe}(\mathrm{OH})_{3}$ and $\mathrm{H}$-Jarosite were specified as the oxyhydroxide and hydrous sulfate minerals controlling $\mathrm{Fe}$ activity in both mine-pools. Chemical activities for $\mathrm{Fe}^{2+}$ and $\mathrm{SO}_{4}{ }^{2-}$ were fixed as the median value of speciated waters for each respective sample point, and that data is included in the caption material for each figure. Hematite, goethite and several other $\mathrm{Fe}$ oxyhydroxide minerals were not plotted since they may not be the first minerals to precipitate from mine water. Siderite is not included in figures 3-24a-d, because no direct measurement of aqueous $\mathrm{CO}_{2}$ was available, and siderite is not stable at the $\mathrm{pH}$ values of 2.5 to 3.5 that characterize these mine-pools. To simplify the display, aqueous complexes of Fe and sulfate were not plotted unless they represented the preferred species on significant portions of the diagram. Dark shaded areas in figures 3-24a-d represent $\mathrm{Eh} / \mathrm{pH}$ conditions where dissolved species are the preferred state, and lighter shading represents an environment where solid phase minerals are likely to form.

Data for the three springs in the Omega mine-pool include about 80 samples at each location from 1994 to 2007, while the T\&T mine-pool data include 16 samples from 1994 to 2007. Each figure shows the mine-pool waters near apparent equilibrium for H-Jarosite. Individual samples may be slightly under- or super-saturated, but overall $\mathrm{pH} / \mathrm{Eh}$ conditions have changed little over a 14 year period. The DEF samples (figure 3-24a) for example plot in a tight cluster spanning less than one $\mathrm{pH}$ unit and less than 100 millivolts, respectively. The Marshall Spring samples exhibit somewhat greater scatter, and that is attributable to the grout injection adjacent to the spring. Samples collected prior to grouting exhibit near apparent equilibrium for H-Jarosite, like the other two springs. During grouting and shortly after, the Marshall spring waters were more under-saturated with respect to $\mathrm{H}-\mathrm{J}$ arosite.

The complex $\mathrm{FeSO}_{4}{ }^{0}$ is the preferred state for two Omega mine-pool sites; PM-21 and Marshall waters (figures 3-24 c and d) at $\mathrm{Eh} / \mathrm{pH}$ conditions bounded by pyrite, $\mathrm{Fe}(\mathrm{OH})_{3}$, and $\mathrm{H}$-Jarosite. Uncomplexed $\mathrm{Fe}^{2+}$ is the preferred soluble species in the Omega mine-pool DEF spring and the T\&T mine-pool (figures 3-24 a and d). Larger sulfate activity values in the PM-21 and Marshall waters favor $\mathrm{FeSO}_{4}{ }^{0}$ over uncomplexed $\mathrm{Fe}^{2+}$. As expected, all four mine-pool discharges are far from thermodynamic stability for pyrite. Individual samples are about 200 to 400 millivolts or more from equilibrium with pyrite. Only a few samples in the Omega mine-pool Marshall spring and T\&T mine-pool plot within the stability field for poorly crystalline $\mathrm{Fe}(\mathrm{OH})_{3}$. Figures 3-24 a-d like figures 3-20 to 3-23, indicate that hydrous sulfate minerals of the jarosite series are likely controls for Fe solubility in these waters. 


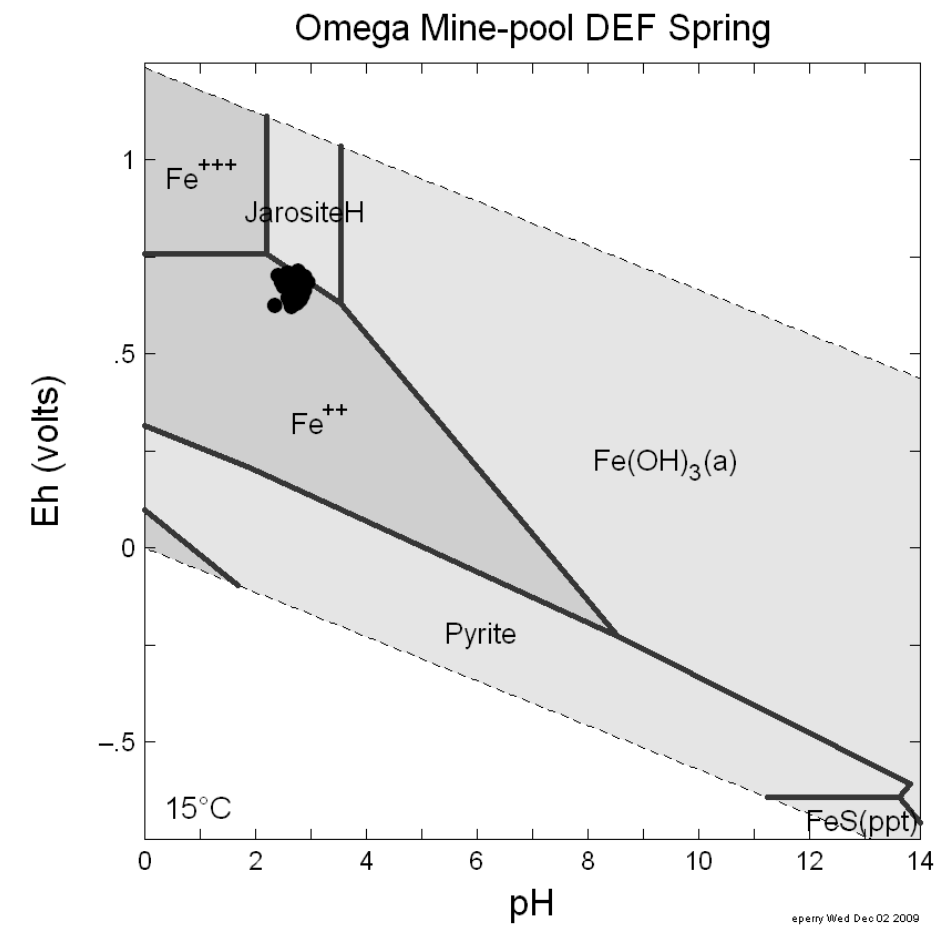

Figure 3-24a. Eh/pH Diagram for Fe Minerals of Omega Mine-pool Spring DEF. H-Jarosite and poorly crystalline $\mathrm{Fe}(\mathrm{OH})_{3}$ specified as controlling minerals. $\mathrm{Log} \mathrm{Fe}^{2+}$ activity fixed at $\mathbf{- 2 . 7 8}, \log \mathrm{SO}_{4}{ }^{2-}$ activity fixed at $-2.23, \log \mathrm{K}^{+}$activity fixed at $\mathbf{- 4 . 7 1}$. $\mathrm{Se}_{-} \mathrm{SO}_{4}$ complexes not shown. Approximately 80 samples plotted.

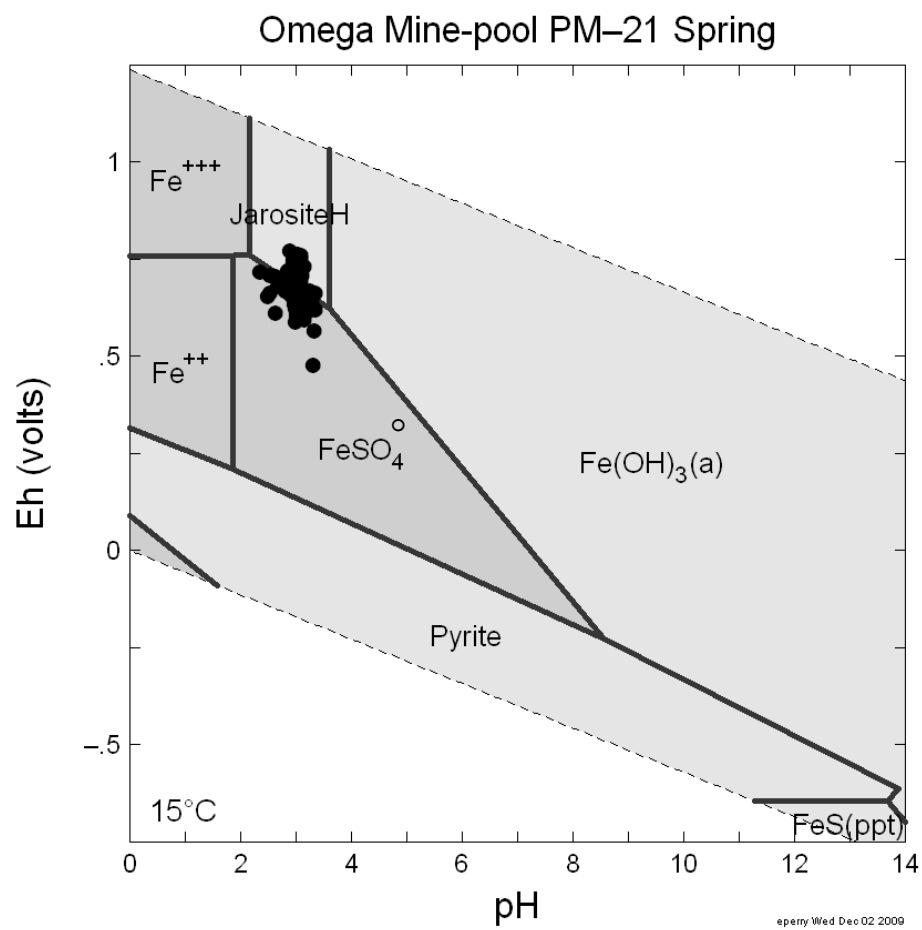

Figure 3-24b. Eh/pH Diagram for Fe Minerals of Omega Mine-pool Spring PM-21. H-Jarosite and poorly crystalline $\mathrm{Fe}(\mathrm{OH})_{3}$ specified as controlling minerals. $\mathrm{Log} \mathrm{Fe}^{2+}$ activity fixed at $-3.51, \log \mathrm{SO}_{4}{ }^{2-}$ activity fixed at $\mathbf{- 2 . 1 4}, \log \mathrm{K}^{+}$activity fixed at $\mathbf{- 3 . 8 1}$ for spring PM-21. Approximately 80 samples plotted. 


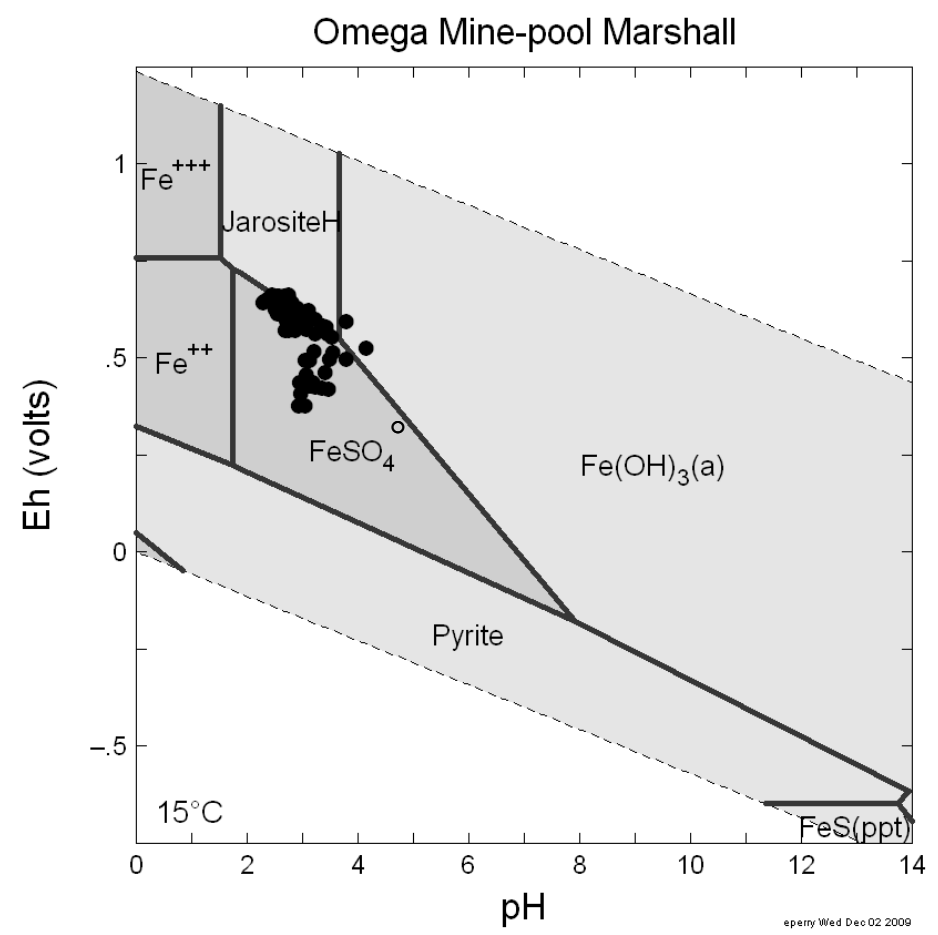

Figure 3-24c. Eh/pH Diagram for Fe Minerals of Omega Mine-pool Marshall Spring. H-Jarosite and poorly crystalline $\mathrm{Fe}(\mathrm{OH})_{3}$ specified as controlling minerals. $\mathrm{Log} \mathrm{Fe}^{2+}$ activity fixed at $-2.29, \log \mathrm{SO}_{4}{ }^{2-}$ activity fixed at $-\mathbf{2 . 0 1}, \log \mathrm{K}^{+}$activity fixed at $\mathbf{- 3 . 7 6}$ for Marshall spring. Approximately 80 samples plotted.

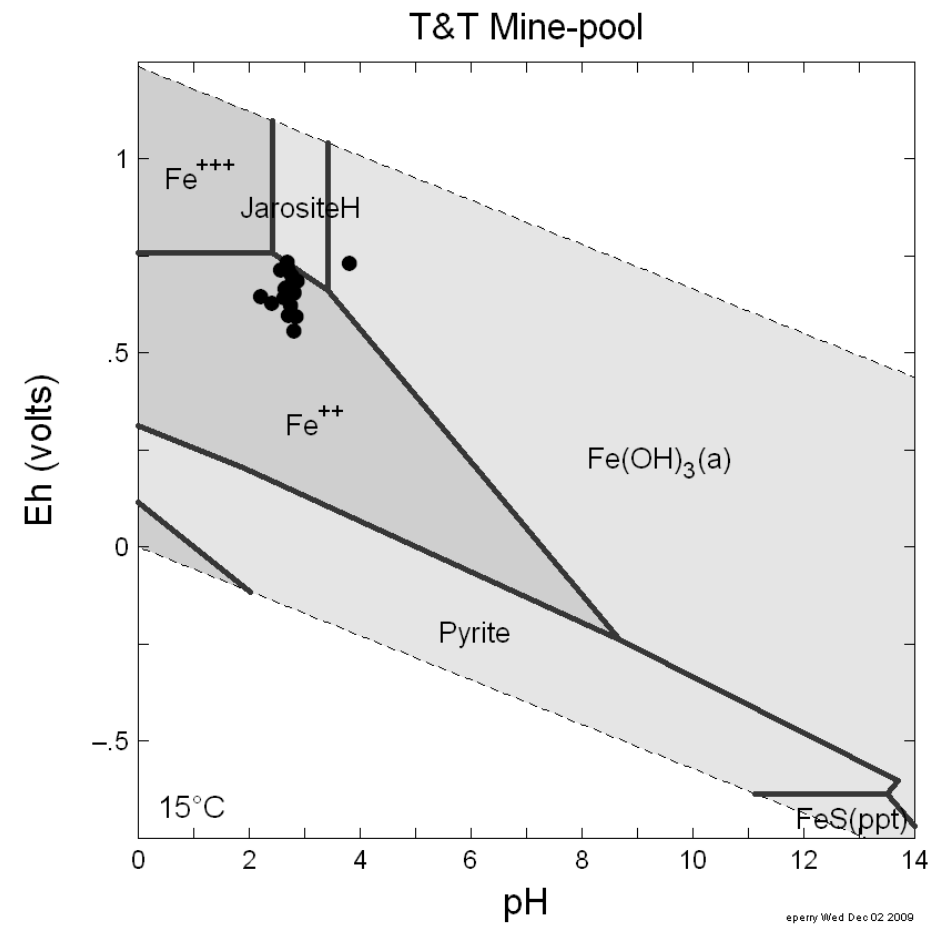

Figure 3-24d. Eh/pH Diagram for Fe Minerals of T\&T Mine-pool. H-Jarosite and poorly crystalline $\mathrm{Fe}(\mathrm{OH})_{3}$ specified as controlling minerals. $\mathrm{Log} \mathrm{Fe}^{2+}$ activity fixed at $-\mathbf{3 . 7 0}, \log \mathrm{SO}_{4}{ }^{2-}$ activity fixed at $-2.48, \log \mathrm{K}^{+}$ activity fixed at $\mathbf{- 4 . 2 1}$ for $\mathrm{T} \& \mathrm{~T}$ Mine-pool. $\mathrm{Fe}_{-} \mathrm{SO}_{4}$ complexes not shown. Sixteen samples plotted. 
Figures 3-20 to 3-23 include goethite and poorly crystalline $\mathrm{Fe}(\mathrm{OH})_{3}(\mathrm{am})$. These two minerals span about 6 orders of magnitude in solubility, and a range of oxyhydroxides with intermediate solubilities occur in between these end members (Langmuir and Whittemore, 1971; Langmuir, 1997). Langmuir and Whittemore (1971) provided an extensive review of stability of Fe oxyhydroxides including particle size and concentration effects. They observed that the greater the degree of over-saturation for crystalline phases, the faster precipitates formed, and these materials were more soluble. Langmuir and Whittemore also suggest that dissolution reactions for various Fe oxyhydroxide minerals could be written in a common form and thermodynamic stability expressed as a function of $\mathrm{Fe}^{3+}$ and $\mathrm{OH}^{-}$activity:

$$
\begin{gathered}
\mathrm{Fe}^{3+}+3 \mathrm{OH}^{-} \leftrightarrow \mathrm{Fe}(\mathrm{OH})_{3} \text { and } \\
-\mathrm{pQ}=-\log \left(\mathrm{Fe}^{3+}\right)\left(\mathrm{OH}^{-}\right)^{3}
\end{gathered}
$$

The activity product -pQ ranges from about 37.3 to 43.3 for amorphous to crystalline phases. The -pQ relationship makes it possible to compute an apparent stability for water containing a mixture of Fe oxyhydroxide minerals. The log activities of uncomplexed $\mathrm{Fe}^{3+}$ and $\mathrm{OH}^{-}$were substituted into equation 3-33b and the expression solved for -pQ for the speciated water samples from DEF, PM-21 and Marshall springs in the Omega mine-pool and the T\&T mine-pool. These are the same samples plotted in figures 3-20 to 3-23 and 3-24a-d. Figures 3-25 a-c are time series plots of -pQ $\mathrm{Fe}(\mathrm{OH})_{3}$ for the DEF, PM-21 and Marshall springs in the Omega mine-pool.
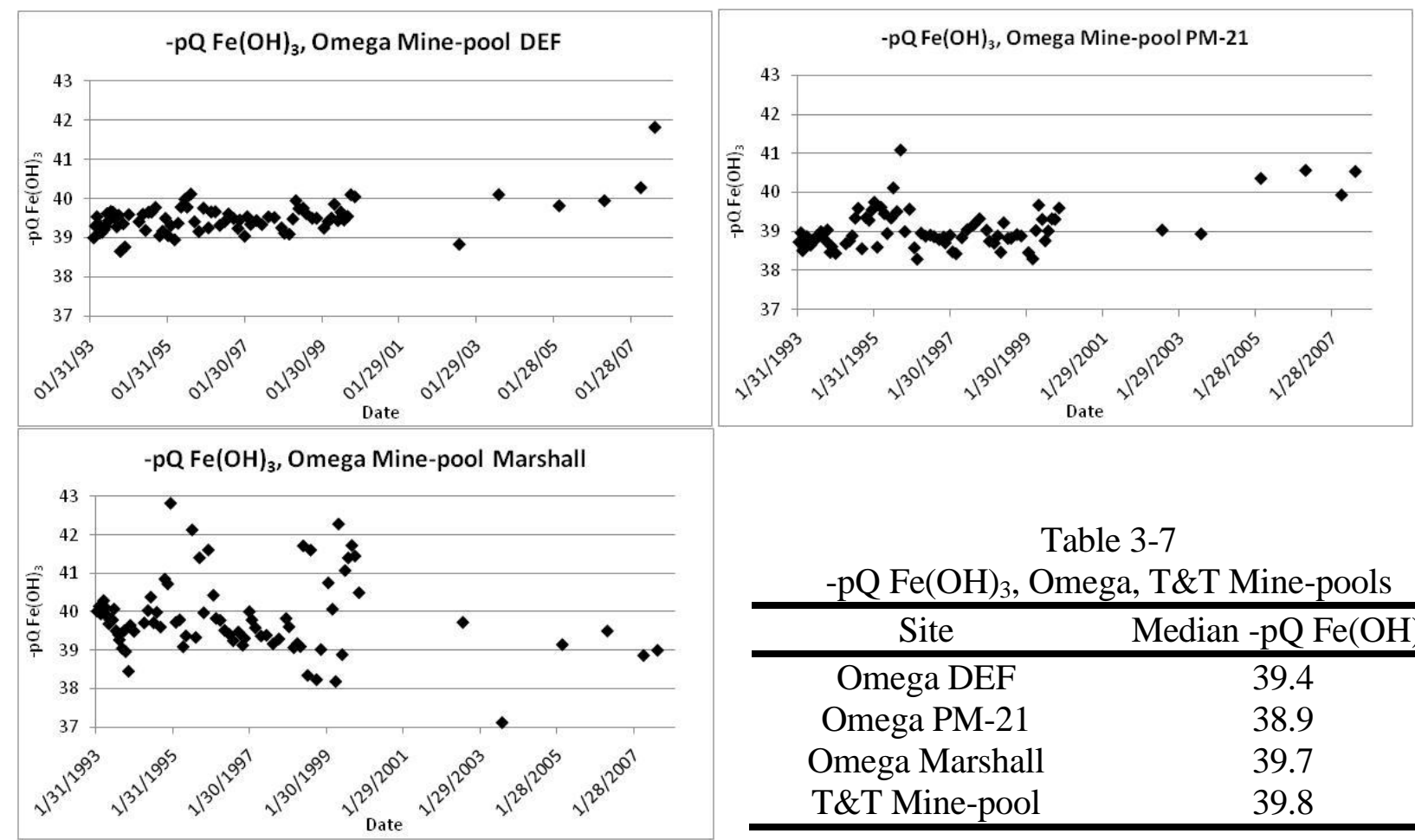

Table 3-7

Figures 3-25a-c. Time series of -pQ $\mathrm{Fe}(\mathrm{OH})_{3}$ Values, Omega Mine-pool, DEF, PM-21 and Marshall Springs. 
Median values for the three springs and the T\&T mine-pool are in table 3-7. The median -pQ values range within one order of magnitude and are characteristic of more soluble $\mathrm{Fe}$ oxyhydroxides. The long term data for DEF and PM-21 suggest a small increase in -pQ $\mathrm{Fe}(\mathrm{OH})_{3}$ toward less soluble Fe oxyhydroxides. A transformation to more stable mineral phases as the minepool ages is consistent with the observations that jarosite, schwertmannite and others are metastable with respect to goethite (Bigham and Nordstrom, 2000; Jonsson et al., 2005). No time series trend is apparent in the Marshall discharge, however. This spring was disturbed by grout injection in 1999, and may have not had sufficient time to establish a discernible long term trend.

\subsection{Chemical Flux}

Chemical flux or load is a primary factor controlling the magnitude of off-site impacts to aquifers and receiving streams. Clearly, water of given chemical composition flowing at 5 liters per minute will discharge less pollution than one at 25 liters per minute. Nearly all of the chemical analyses for the Omega and T\&T mine-pools included an instantaneous flow value compiled by WVDEP, US Dept of Energy or the author. Thus it was possible to compute the chemical flux as:

$$
\text { Flux }(\mathrm{kg} / \text { day })=\text { Flow }(\mathrm{gpm}) \times 1440 \mathrm{~min} / \text { day } x \text { Concentration }(\mathrm{mg} / \mathrm{L}) \times 3.785(\mathrm{~L} / \mathrm{gal}) \div 10^{\wedge}(\mathrm{mg} / \mathrm{Kg})
$$

where the constants are units conversion factors. The flux was expressed in moles or kg per day or year by appropriate conversion factors as needed. Iron and sulfate flux were expressed as moles on the basis of $55.85 \mathrm{~g} / \mathrm{mole}$ for Fe and $96 \mathrm{~g} / \mathrm{mole}$ for sulfate, respectively.

Chemical flux was summarized by estimated yearly totals and by month for both the Omega and T\&T mine-pools. Figures 3-26 and 3-27 show estimated yearly chemical flux for total dissolved

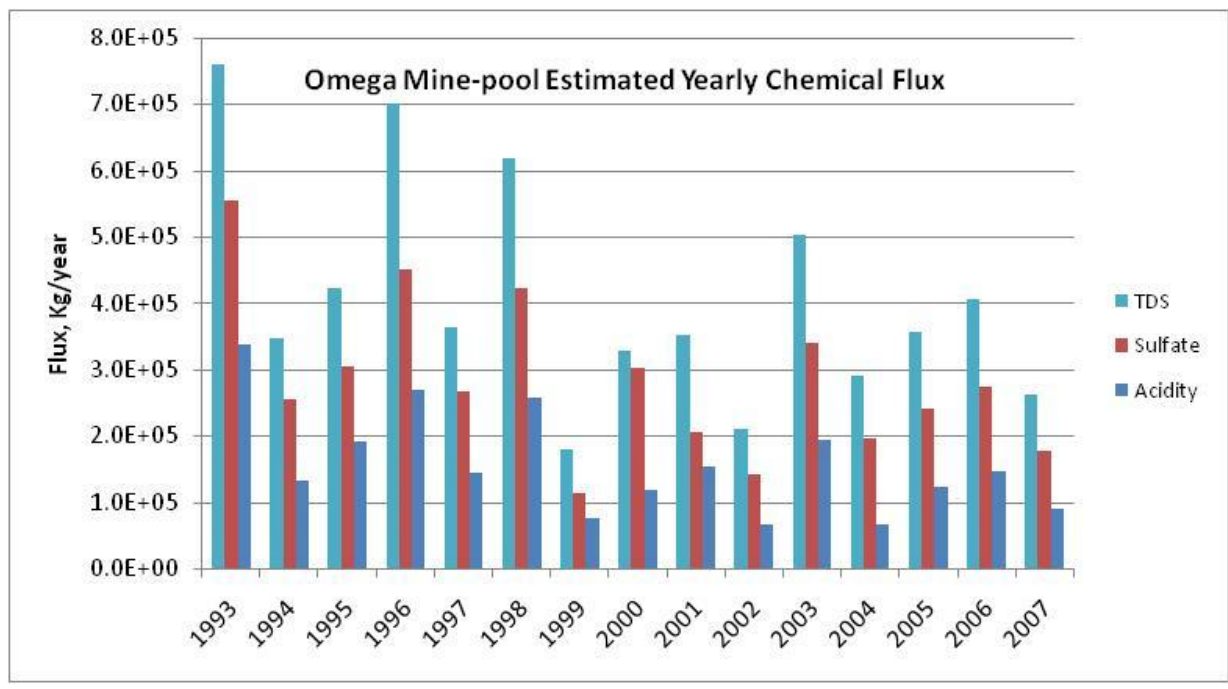

Figure 3-26. Omega Mine-pool Estimated Chemical Flux, Kg/Year, for Total Dissolved Solids, Sulfate and Total Acidity. 


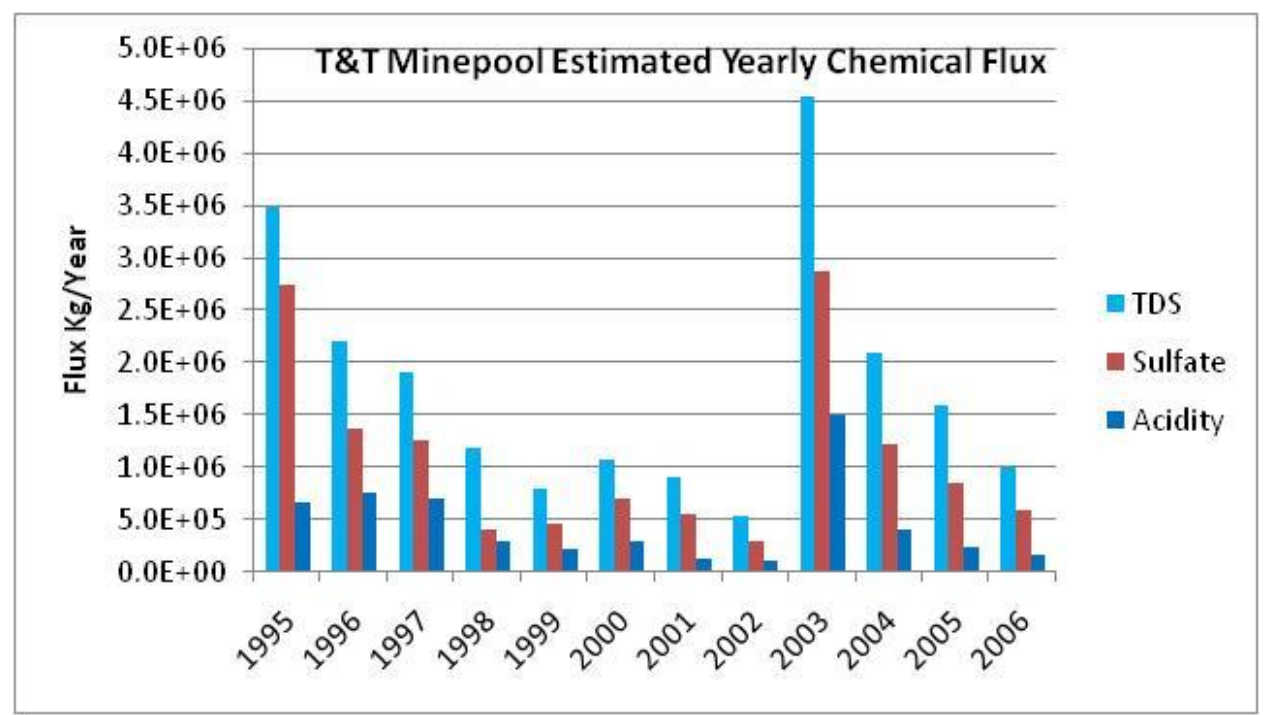

Figure 3-27. T\&T Mine-pool Estimated Chemical Flux, Kg/Year, for Total Dissolved Solids, Sulfate and Total Acidity.

solids, sulfate and total acidity in $\mathrm{kg} / \mathrm{year}$ for the two mine-pools. The Omega mine-pool data in figure 3-26 represent the combined outflow of all discharges, and display an irregular decline in chemical flux from year to year. Flux reached a minimum in 1999, during the period of grout injection. All three flux parameters are significantly correlated with flow $(r>0.7)$, indicating that flow is the dominant component of flux. Figure 3-27, modified from Perry and Rauch (2004, Appendix A), graphically displays the relationship between sulfate flux and flow in the Omega mine-pool. Hawkins (1994), in an extensive study of surface mine discharges, also found flow to be the dominant component of flux.

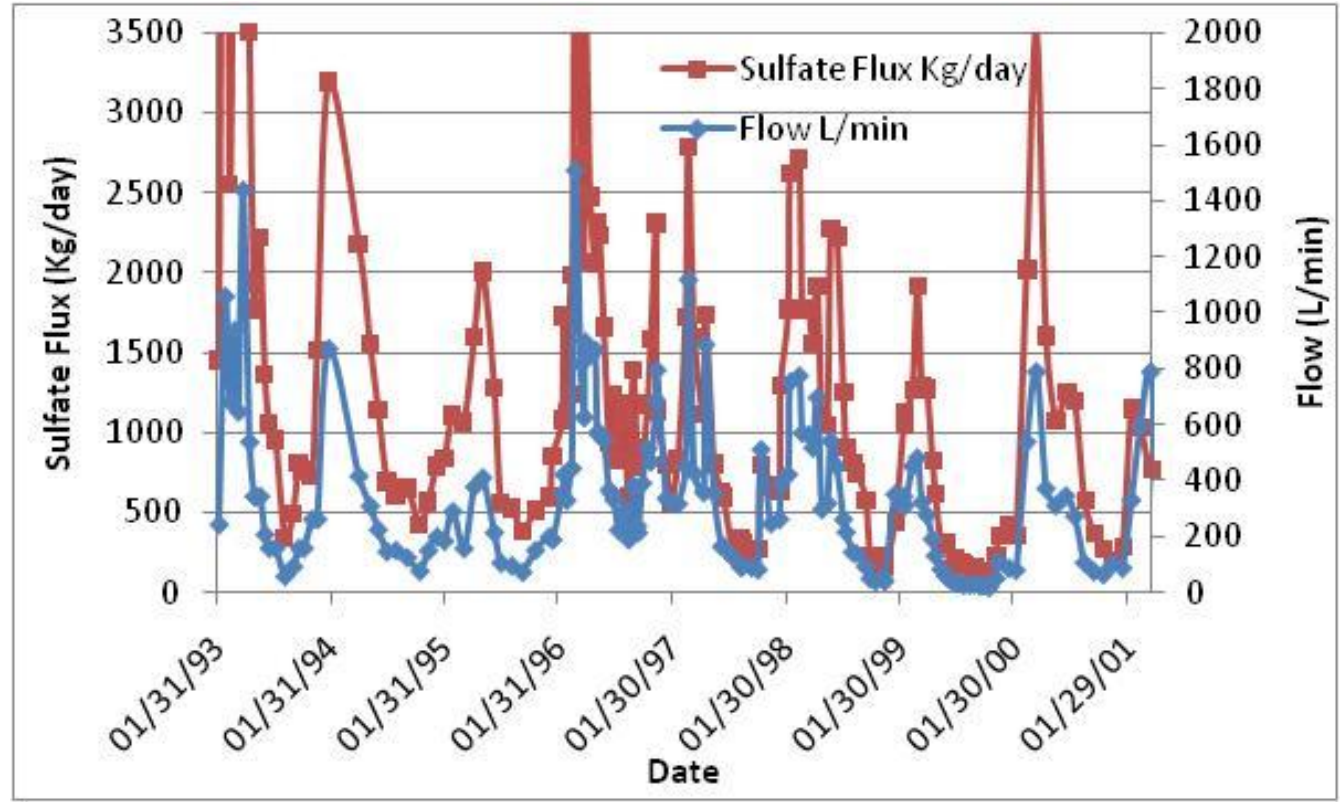

Figure 3-28. Omega Mine-pool Sulfate Flux and Flow, 1993 to 2001. 
The T\&T mine-pool (figure 3-27), displays a more consistent decline in chemical flux rate to 1999, when limestone injection began. Flux increased during the two year period of in-situ treatment suggesting that the short term effect was to displace stored weathering products. A similar short term increase was noted after grout injection in the Omega mine-pool (Perry and Rauch, 2004; figure 3-26). A large flux surge occurred in 2003 (figure 3-27) in the T\&T mine-pool. In April of that year, a rapid buildup in mine pool water level occurred, followed by "blow-out" of high volume flow and increased chemical concentration.The mine-pool water level increase and following blow-out probably occurred after existing flow-paths were blocked or constricted. The cause is speculative but could include subsidence and caving of roof material into mine voids, or blockage by treatment sludge which is periodically injected into part of the mine-works for disposal. Since 2003, the annual flux rate has again declined from year to year in a consistent manner. By 2006, flux rates had declined to about $25 \%$ or less of 2003 values.

The two mine-pools exhibit different behaviors with respect to yearly flux. The T\&T mine-pool flux exhibits a systematic decline, and except for the injection and blow-out events, does not appear to be affected by shorter term fluctuations in flow or recharge. This mine-pool must have additional ground-water storage that can attenuate high recharge periods. The Omega mine-pool, however, is more responsive to yearly fluctuations in flow and recharge, and appears to have limited extra ground-water storage capacity to attenuate high recharge periods. The T\&T mineworks cover about 8.5 times more area than Omega, while the estimated mine-pool volumes differ by a factor of about 2.6 .

Flux rates are declining about 3 to 4 times more rapidly in the T\&T mine-pool than in the Omega mine-pool. This may be a function of chemical and mineral concentrations in the two mine-pools. While both produce acid drainage, chemical concentrations are about 3 to 5 times greater in Omega, indicating significant ongoing active chemical weathering.

Flux rates exhibit a strong seasonal trend. Figure 3-29a-b and 3-30a-b display monthly flux data over 13 and 14 year periods respectively in the Omega (all discharges combined) and T\&T minepools. Graph values are median data for each month compiled over the period of record. The Omega mine-pool is further divided into pre and post grout injection. Both mine-pools discharge about $75 \% \pm$ of the yearly flux in a six month period from January to June. Monthly flux rate did decline in the Omega mine-pool after grouting compared to pre-grouting, and decreases occurred across all months and seasons. The spike in April flux data in the T\&T mine-pool resulted from the large blow-out event in April 2003 and another large discharge event in April, 1995. More flow and water quality measurements were taken during these two events, and these extreme conditions are over-represented in the data compilation. Sulfate, Fe and $\mathrm{Al}$ fluxes are similar to that shown for TDS and total acidity for both mine-pools. The period of March to about June produces the peak monthly fluxes. Chemical consumption for active or passive treatment is also seasonal, as is the potential impact of untreated discharges to aquifers and surface waters. Baseline sampling for sizing treatment systems should include seasonality criteria. 

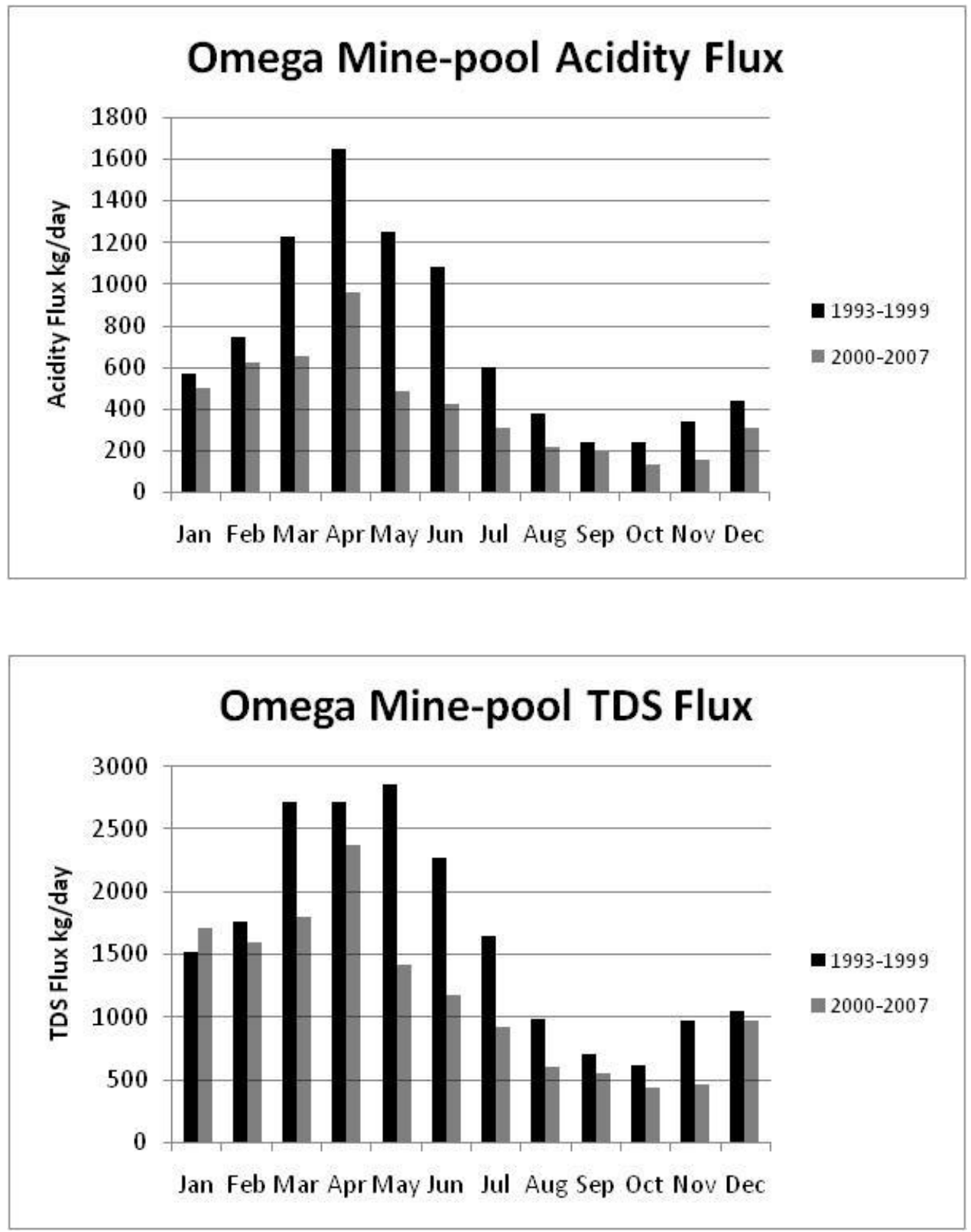

Figure 3-29a-b. Seasonal Distribution of Total Acidity and TDS Flux in Omega Mine-pool. 

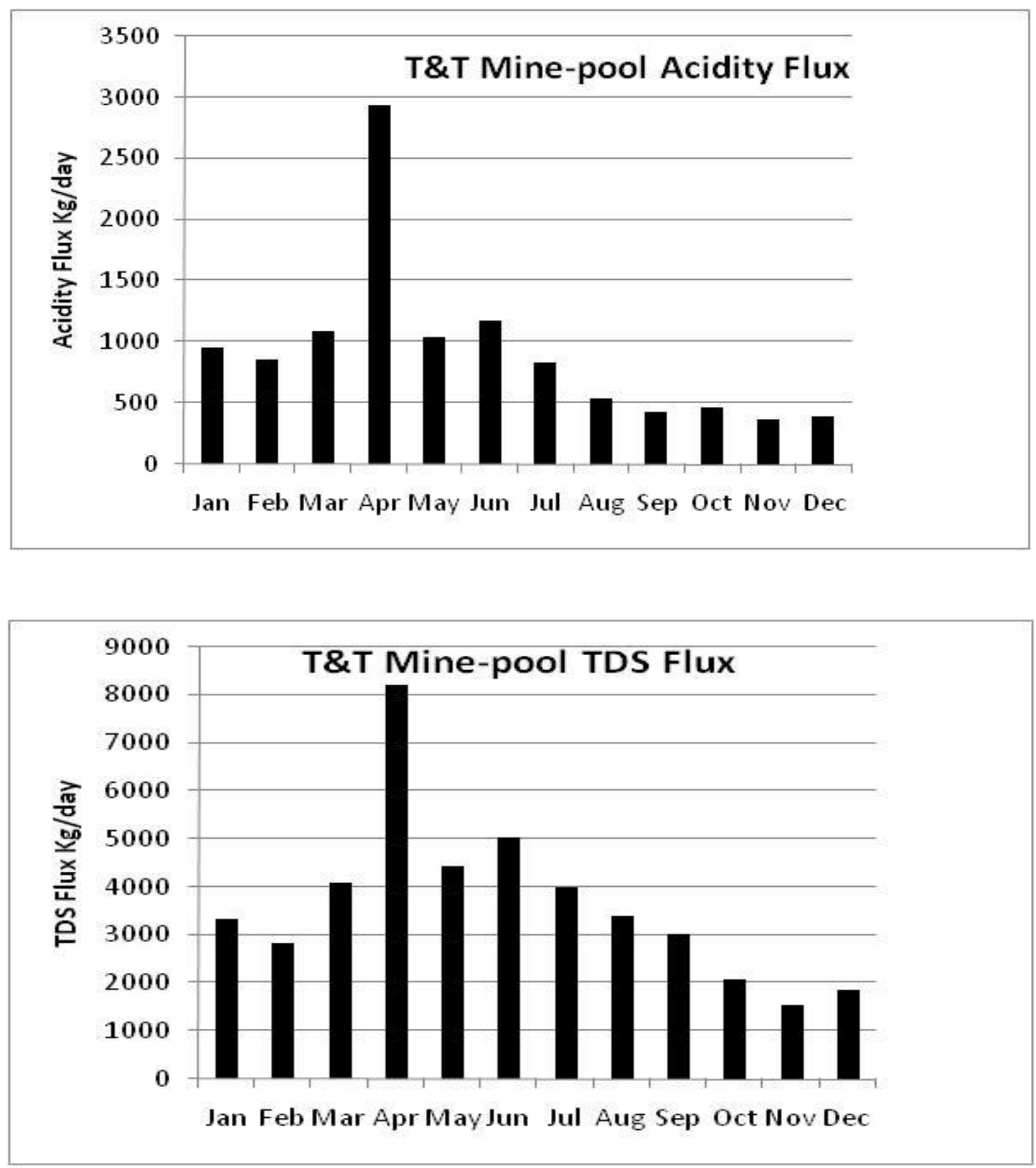

Figure 3-30 a-b. Seasonal Distribution of Total Acidity and TDS Flux in T\&T Mine-pool.

Long term Fe and sulfate flux rates were estimated for the Omega and T\&T mine-pools as an average over the period of record. The flux rates were normalized to a $\mathrm{m}^{2}$ of mine-works for comparison between each other, and to three mostly flooded mine-pools (chapter four). Flux rate is expressed as mole $/ \mathrm{m}^{2}$-s, consistent with expression of reaction rate constants. It was hypothesized that flux would be different between unflooded mines and mostly flooded mines. Flux rates in flooded mines were anticipated to be less on the premise of slower pyrite weathering rates under flooded conditions. The Omega and T\&T mine-pool discharge rates were determined from monitoring data obtained from West Virginia DEP. Results are shown in table 3-8 and comparison of all five mine-pools is presented in section 4.2.6. 
Table 3-8

Average Long Term Iron and Sulfate Flux From

Two Partly Flooded and Three Flooded Mine-pools

\begin{tabular}{cccccc}
\hline Mine-pool & Flooding State & $\begin{array}{c}\text { Area } \\
(\text { Hectares })\end{array}$ & $\begin{array}{c}\text { Average Q } \\
(\mathrm{L} / \mathrm{Min})\end{array}$ & $\begin{array}{c}\text { Fe Flux } \\
\left(\mathrm{mole} / \mathrm{m}^{2} \mathrm{~s}\right)\end{array}$ & $\begin{array}{c}\text { Sulfate Flux } \\
\left(\mathrm{mole} / \mathrm{m}^{2} \mathrm{~s}\right)\end{array}$ \\
\hline $\begin{array}{c}\text { Barnes\&Tucker } \\
\text { Hahn }\end{array}$ & Flooded & 5700 & 19000 & $9.49 \times 10^{-9}$ & $3.48 \times 10^{-8}$ \\
Frden-Westland & Flooded & 5900 & 13250 & $7.04 \times 10^{-8}$ & $2.69 \times 10^{-7}$ \\
Omega & P. Flooded & 69 & 268 & $3.42 \times 10^{-8}$ & $1.37 \times 10^{-7}$ \\
T\&T & P. Flooded & 588 & 1139 & $7.33 \times 10^{-9}$ & $4.72 \times 10^{-8}$ \\
& & & & & \\
\hline
\end{tabular}

\subsection{Mine Recharge Rate}

Chemical flux is determined in part by mine-pool discharge as described in section 3.5. Mine-pool discharge in turn is a function of ground water recharge. Daily mine-pool discharge and on-site precipitation data collected by WVDEP were summarized into annual and seasonal estimates of recharge rate for the two mine-pools. The estimates include several assumptions as follows:

- Infiltration is assumed to be vertical, such that the area of mine-works and land surface area contributing recharge are equal. McCoy (2002) estimated recharge to underground mines using this method.

- Net ground-water storage change in the mine-pool is zero, and discharge equals recharge.

- Measured drainage points represent mine-pool discharge and mine-pool diffuse leakage is minor.

The first assumption of vertical infiltration neglects the observation that underground mines act as ground-water sinks (Hobba, 1981; Bruhn, 1986) and a ground-water cone of depression may develop. Cifelli and Rauch (1986) showed an "angle of influence" exists in rocks overlying a mine, defining a zone where aquifer dewatering occurs. They estimated the angle of influence at 16 and 24 degrees for two case studies. The land area contributing inflow to the mine may therefore exceed the mine-works area. However, both the Omega and T\&T mine-pools underlie hilltops, which limit the amount of additional land area that could contribute inflow. The contributing area is a function of angle, overburden thickness and stratigraphy. Since recharge rates are customarily expressed per unit area of mine-works, infiltration from rocks outside the vertical recharge zone will increase the estimated recharge rate. Neither mine has wells that could be used to estimate the 
angle of influence. The T\&T mine-pool area was estimated as the sum of the three individual, but hydrologically connected mines; T\&T 2 , T\&T 3 and Ruthbelle.

No net storage change is a reasonable assumption over extended periods of time. Water level measurements in two wells in the T\&T mine-pool showed essentially steady state conditions from 2002 to 2007, with the exception of a "blowout" event in 2005.

The third assumption is difficult to quantify, but is based on the premise that hydraulic conductivity and ground-water flow velocity through open or partially collapsed mine-works is several orders of magnitude greater than flow through intact bedrock and soils.

Figure 3-31 and 3-32 display estimated average daily recharge rate for the two mine-pools from 1996 and 1997 respectively, through 2007. Rate was determined as total discharge per unit time divided by mine area. The yearly estimate is a median of the daily values for that year. Total annual precipitation is also plotted. The Omega mine-pool recharge ranges from a minimum of 0.13 to a maximum of $0.59 \mathrm{gal} / \mathrm{A}-\mathrm{min}$, with an overall median of $0.36 \mathrm{gal} / \mathrm{A}$-min for the ten year record. The T\&T mine-pool average daily recharge rate ranges from 0.17 to $0.46 \mathrm{gal} / \mathrm{A}$-min with an overall median of $0.28 \mathrm{gal} / \mathrm{A}-\mathrm{min}$. Behavior of the two mine- pools is similar, and the annual and average daily recharge rate varies by a factor of two to three over the period of record. Both mine-pools exhibited low recharge rates in 1999, and an overall correlation coefficient of $r=0.53$ when compared to each other. The two mine-pools are sufficiently close (about $27 \mathrm{~km}$ ) that they can be considered to have similar annual climatic conditions. It was expected that precipitation

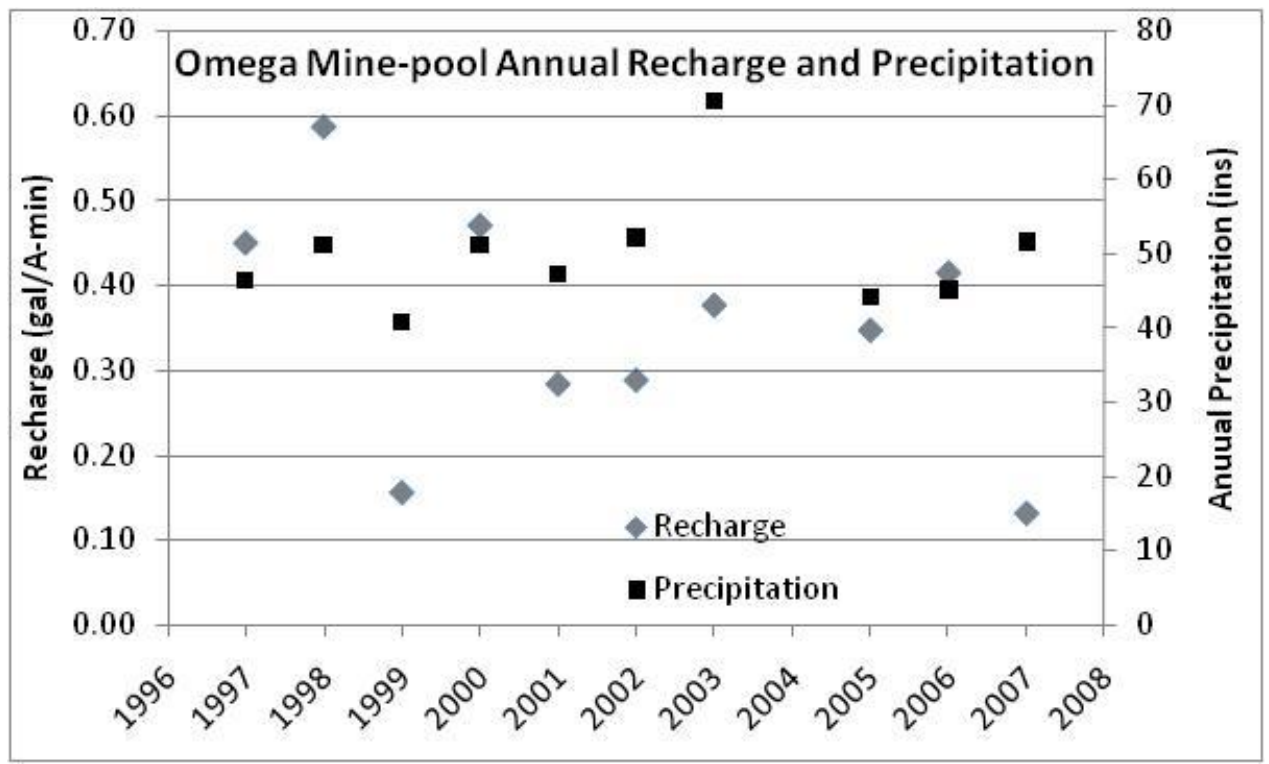

Figure 3-31. Omega Mine-pool Estimated Annual Recharge (gal/A-min) and Annual Precipitation. 


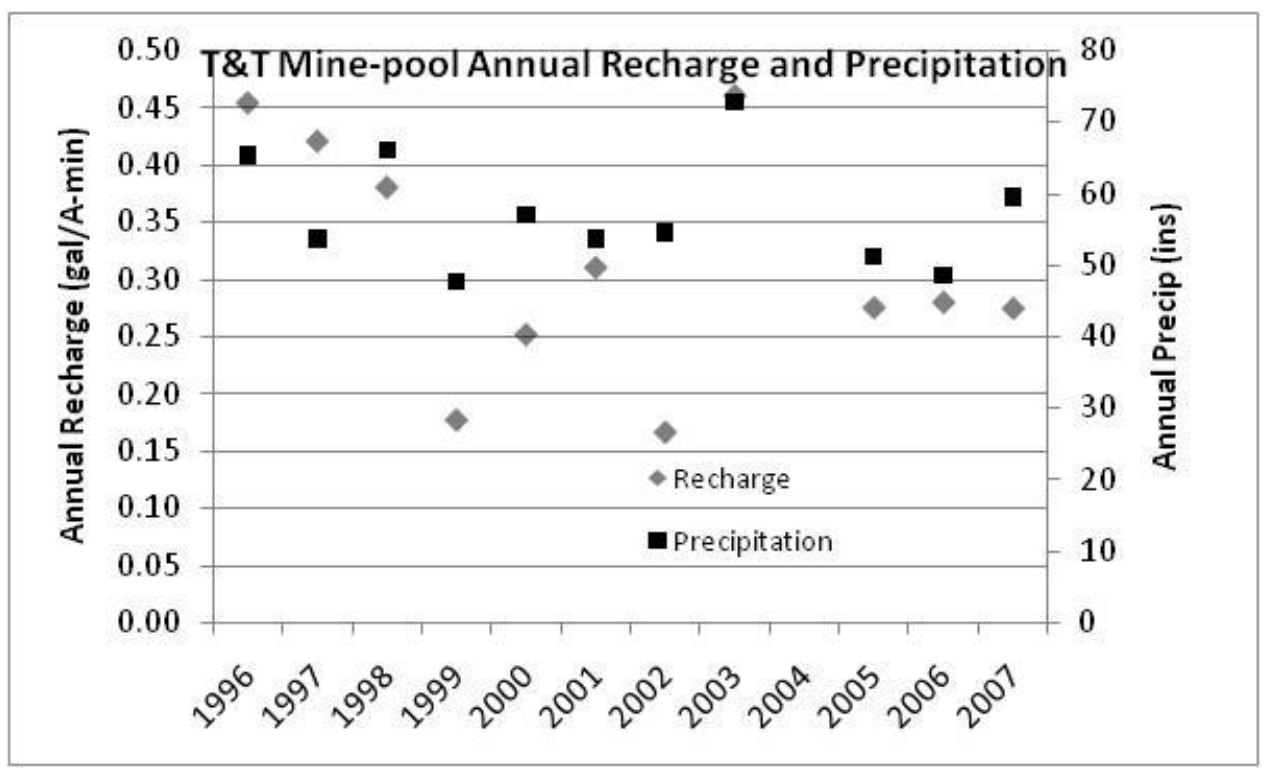

Figure 3-32. T\&T Mine-pool Estimated Annual Recharge (gal/A-min) and Annual Precipitation.

would be a principal control on recharge rate, but considerable scatter exists when comparing data on an annual basis.The precipitation/discharge relationship might be resolved further by examining the record in smaller time increments.

A general relationship has been observed to exist between overburden thickness and mine inflow rates, where mine recharge rate decreases for increasing cover. For the Appalachian region, mine water inflow rates have been reported to range from less than 0.05 gal/A-min to rates approaching 1.0 gal/A-min (Crichton, 1927; Parizek, 1974; Stoner et al., 1987; Tieman and Rauch, 1987). Carpenter and Herndon (1933) examined discharge records for 243 underground mines in the Monongahela River basin, and commented that annual precipitation affected mine discharge quantities, especially for mines under thin overburden. They reported a range for recharge rates from 0.21 to $0.84 \mathrm{gal} / \mathrm{A}$-min for mines under 100 to about 300 feet of overburden. Carpenter and Herndon estimated recharge under a "normal" precipitation year to be about 0.69 gal/A-min or about two times the values compiled for the Omega and T\&T mine-pools. Another early study by Collins (1923) gave an estimate of $0.62 \mathrm{gal} / \mathrm{A}-\mathrm{min}$ from a series of measured mine inflow rates from several counties in western Pennsylvania with average overburden depth of 250 feet. Hawkins et al. (2005) reported an average recharge rate of 0.27 gal/A-min for the Barnes\&Tucker mine-pool based on pumping records, which is similar to the Omega and T\&T mine-pools. The Barnes\&Tucker mine-pool is discussed in more detail in chapter four.

The data reported by Carpenter and Herndon (1933), and Collins (1923) all seem to have been conducted on operating mines that were actively removing ground-water inflow. The Omega and T\&T mines are however closed, and discharge by gravity flow. Mine inflow rates reported in the literature are often developed from pumping and flow data acquired during active mining, when head differential between the mine-works and overlying aquifers is maximized. After abandonment, flooding can reduce the head differential. Under these circumstances, the head differential between the mine pool and overlying aquifers will diminish, and the inflow rate to the 
mine pool should decline. In above drainage mines, head increase should be small and recharge may be supplied mostly by fracture flow. Mine differences in flooding state and active versus abandoned status may account for some of the difference between the early studies and these two mine-pools.

Leavitt (1997) developed a recharge estimate equation based on pump records in active mines, most located in northern Appalachia, of the form:

$$
\mathrm{L}=1.117 * \mathrm{e}^{\wedge}(-0.0045 * \mathrm{H})
$$

where $\mathrm{L}$ is the mine inflow rate in gallons/Acre-min and $\mathrm{H}$ is the overburden thickness in feet. Figure 3-33 is a plot of estimated mine inflow rate using Leavitt's relationship. Inflow rate is sensitive to overburden thickness at depths of less than about 500 to 600 feet. Using an average overburden thickness of 150 and 250 feet for the Omega and T\&T mine-pools, respectively, Leavitt's equation estimates a recharge rate of $0.56 \mathrm{gal} / \mathrm{A}-\mathrm{min}$ for the Omega site, compared to 0.36 estimated from site discharge data, or an over-estimate of 56 percent. The T\&T mine-pool estimate is $0.36 \mathrm{gal} / \mathrm{A}$-min from Leavitt's equation compared to 0.28 from discharge data, a difference of 28 percent, but providing reasonable agreement between the two methods for the T\&T site. Leavitt's equation was derived from a data set with overburden thicknesses greater than

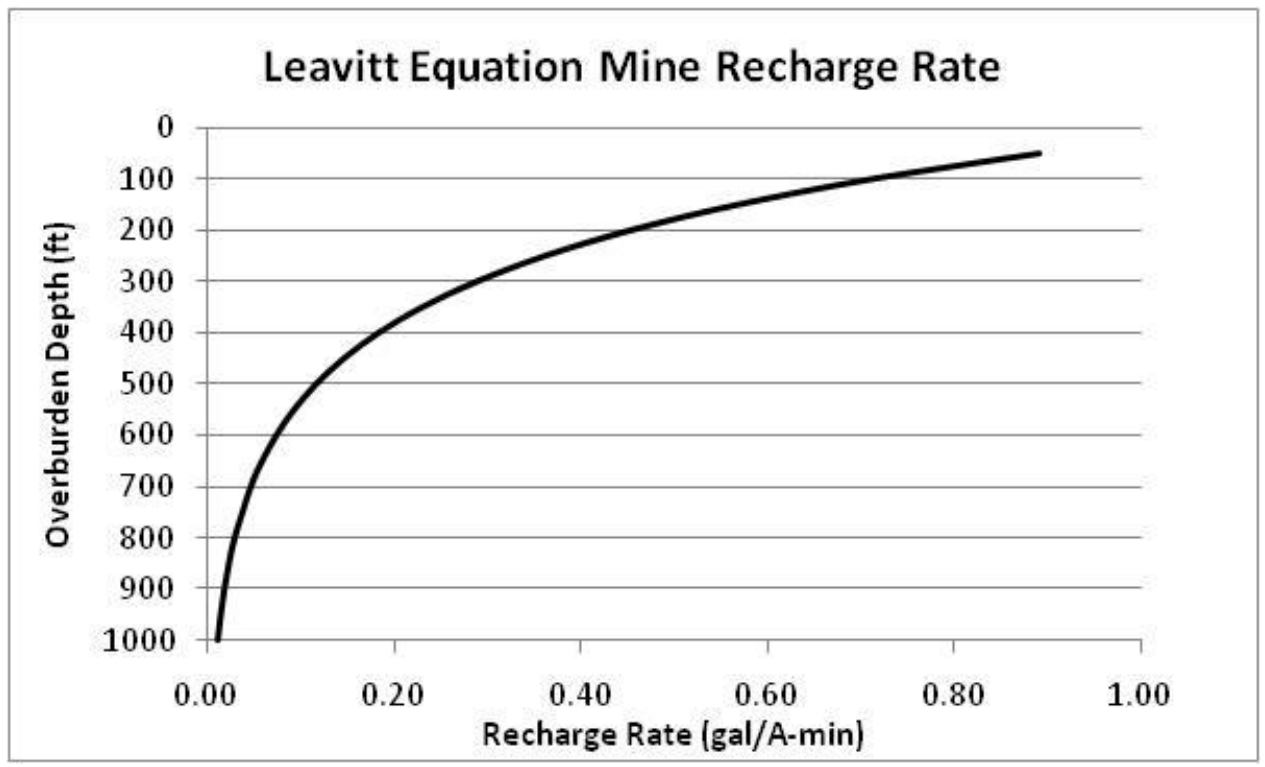

Figure 3-33. Plot of Estimated Recharge vs. Overburden Depth, Using Leavitt's (1997) Empirical Relationship.

that of the Omega mine, and the predictive relationship may be less accurate for shallow overburden depths. A single value is often specified or described for annual recharge rate to minepools. A long-term average or median rate is useful for estimating trends and general conditions but actual rates vary from year to year. The tenth and $90^{\text {th }}$ percentiles for annual recharge in the 
Omega and T\&T mine-pools are 0.15 and 0.48 ; and 0.17 and 0.45 gal/A-min, respectively. These values can define a reasonable range of values for mines in similar conditions.

Recharge relationships were also estimated on a seasonal basis by summarizing monthly data over the period of record. Figures 3-34 and 3-35 show the median estimated recharge rate for the two mine-pools, and the estimated fraction of precipitation occurring as recharge. The plots have seasonal trends that are similar to the chemical flux data in figures 3-29 and 3-30. Maximum recharge occurs in March for both mine-pools, with rates exceeding 0.5 and 0.8 gal/A-min, respectively. Minimum recharge rates are very similar for the two mine-pools, declining to 0.11 (Omega) and 0.12 (T\&T) gal/A-min in November. These data represent a lower limit or base-flow condition for mine-pools in similar settings.

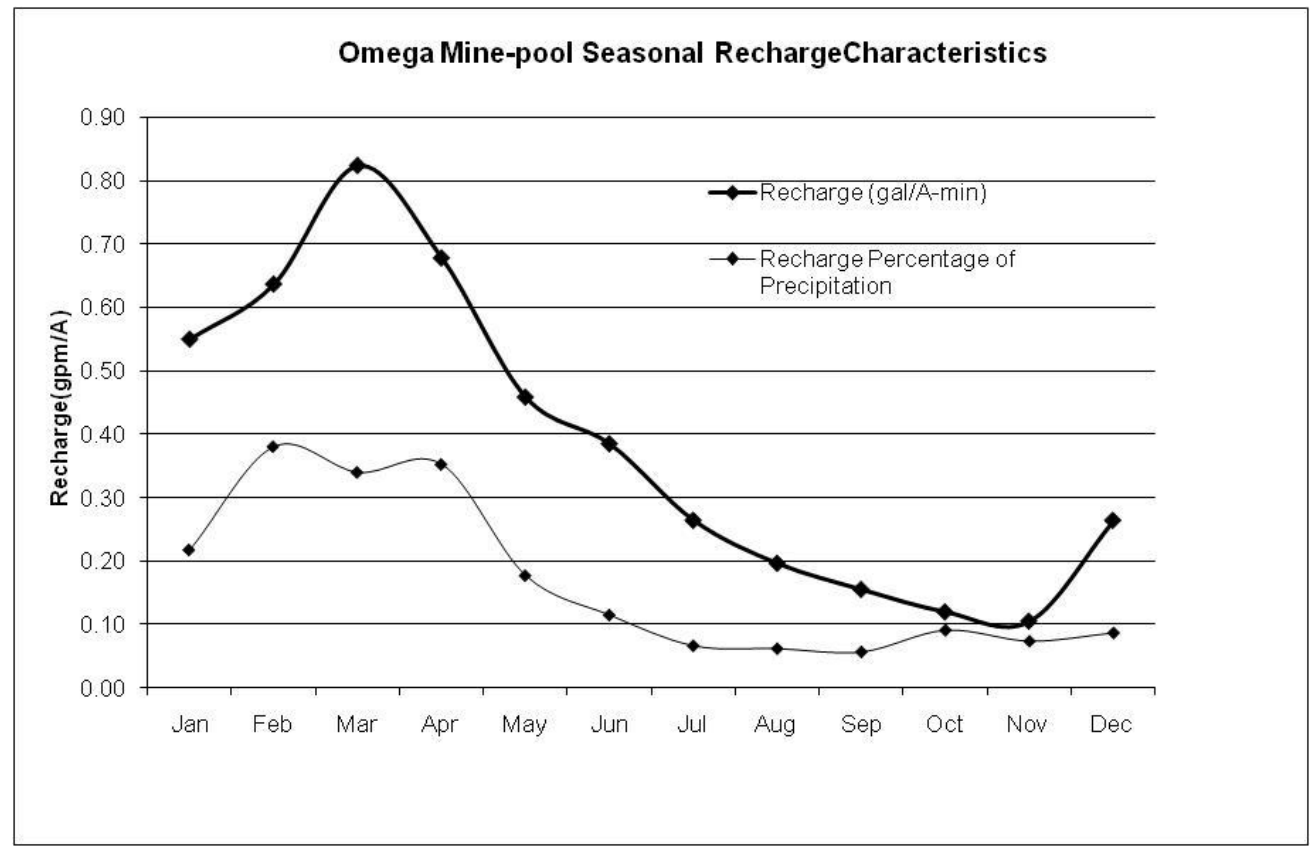

Figure 3-34. Seasonal Distribution of Recharge Characteristics, Omega Mine-pool.

Median monthly recharge rate in gal/A-min based on 1997-2007 flow and precipitation data.

Both mine-pools exhibit year to year fluctuation in monthly recharge rate and the values in figure 3-34 and 3-35 should be used as trend indicators. The 3 month period of September to November is an overall period of minimal recharge, while maximum recharge occurs in the 6 month period of January to June. The seasonal distribution data between the two pools has a correlation coefficient of $r=0.94$, confirming similar behavior of the two mine-pools. The percentage of precipitation occurring as recharge is also seasonally distributed, and ranges from about 6 to $38 \%$ in the Omega mine-pool, and 6 to $20 \%$ in the T\&T mine-pool. Minimal values occur during the base-flow period of late summer to autumn, when evapotranspiration (ET) is high, and precipitation can occur as intense short duration storm events. The maximum fraction of precipitation intercepted as recharge is late winter, when ET is low. Hobba (1981) summarizing data from several sources, estimated annual ET as about $50 \%$ of total precipitation for the Monongahela River basin. The remaining 
$50 \%$ is divided among runoff, recharge and ground-water storage change. Figures 3-34 and 3-35 show that mine recharge distribution has a strong seasonal component. It should be considered in mine water planning and mitigation.

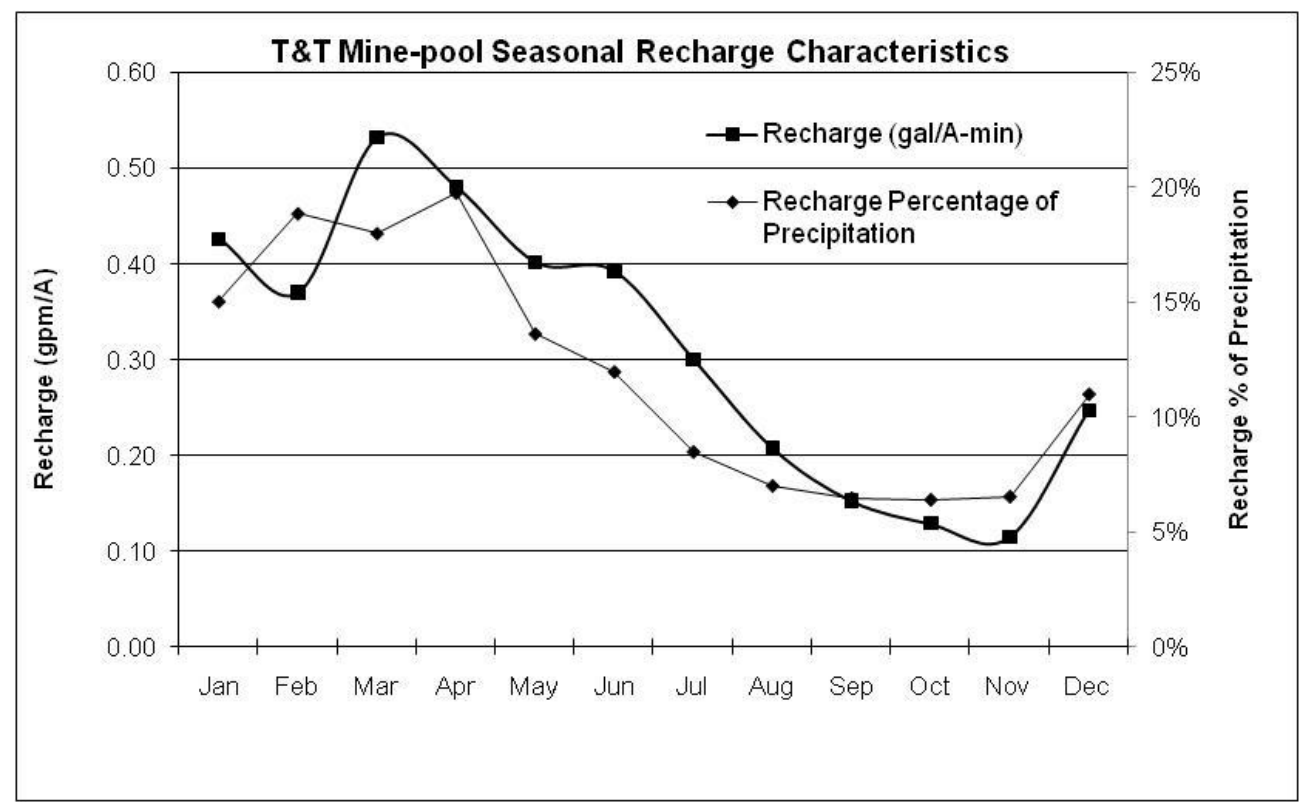

Figure 3-35. Seasonal Distribution of Recharge Characteristics, T\&T Mine-pool. Median monthly recharge rate in gal/A-min Based on 1996-2007 flow and precipitation data.

\subsection{Chapter 3 Summary Findings and Observations}

In chapter three water quality, chemical flux and recharge characteristics of two partly flooded, acidic mine-pools were examined over a period exceeding ten years. Chemical concentrations and flux declined during the monitoring period, however overall water quality remains severely degraded. Significant short term variations in concentration, flux and flow were common to both mine-pools, but long term trends were also evident. The principal findings and observations for this chapter are summarized as follows:

- Conceptually, partly flooded mines can be viewed as large reactor and leaching chambers, that are regularly supplied with oxygen to oxidize pyrite, and water to rinse soluble weathering products.

- Data for the two mine-pools were obtained from different sources and consistency was an issue. Total Dissolved Solids was a suitable estimator for sulfate concentration, but the relationship was mine specific. Sulfate represented about $58 \%$ of TDS in the T\&T mine-pool, and $67 \%$ in the Omega mine-pool.

- The two mines are an estimated 20 to $30 \%$ flooded and discharge by gravity drainage. The Omega mine is a small (68 hectares) complex, with relatively short flow paths, 
while the T\&T mine-pool includes about 588 hectares of workings in three hydrologically connected mines.

- Both mines had in-situ treatment consisting of grout injection in the Omega mine and limestone injection in the T\&T mine-pool. Water quality actually declined for 1 to 2 years after remediation, as stored weathering products were displaced and flushed from each mine. The Marshall discharge, adjacent to the grout injection zone in the Omega mine-pool, has since injection shown an increase of about one $\mathrm{pH}$ unit.

- Each site has had some treatment sludge with excess alkalinity injected into the mineworks. The overall effect on mine-pool composition appears minimal or is masked by other processes.

- The Omega mine-pool has multiple discharge points which vary in individual concentration. The overall character of the mine-pool is consistent however, with low $\mathrm{pH}$ water (2.5-3.5), and $\mathrm{Al}$ and Fe concentrations in the tens to hundreds of $\mathrm{mg} / \mathrm{L}$. The T\&T mine-pool is also acidic, but with $\mathrm{Fe}$ and $\mathrm{Al}$ now in the tens of $\mathrm{mg} / \mathrm{L}$.

- The cation fraction of the Omega mine-pool has increasing portions of $\mathrm{Al}$ and $\mathrm{Fe}$ as the mine-pool ages, with $\mathrm{Ca}$ and $\mathrm{Mg}$ as the other major cations. The anion fraction is dominated by sulfate. The $\mathrm{T} \& \mathrm{~T}$ mine-pool is $\mathrm{Ca}-\mathrm{Mg}-\mathrm{SO}_{4}$ type water, and is progressively enriched in $\mathrm{Al}$ as the mine-pool ages. In both mine-pools, $\mathrm{Al}$ concentration is declining more slowly than other components.

- The Omega mine-pool has about 2 to 5 times greater chemical concentrations than the T\&T mine-pool even though both are developed in the same coal bed. Only limited site specific geochemical rock data were located for the Omega mine, which indicates pyrite is abundant in this mine and few carbonates are present. The Omega mine-pool continues to undergo intense chemical weathering more than 15 years after closure.

- Simple time series plots of chemical concentration show considerable short term variation and data scatter in both mine-pools. Since the mine-pools are being stressed repeatedly at short intervals by recharge events, short term variability is expected.

- A five point moving average provided smoothed data sets that more clearly displayed seasonality and other subtle trends and features in both mine-pools. Chemical concentrations are inversely related to flow in the Omega mine-pool, increasing during low recharge periods of late summer and autumn.

- The distinct seasonal behavior in the Omega mine-pool suggests the complex has little additional ground-water storage capacity, beyond that in the mine-pool. The T\&T minepool had little or indistinct seasonality in chemical concentrations, suggesting some 
additional storage capacity is available to dampen seasonal effects and variable recharge events.

- The possible differences in storage behavior may result from mine size and topographic position. The Omega mine-pool is small, and ground-water should have a short travel distance within the mine-works to a discharge point. The T\&T complex is about 8 times larger, with longer average travel distance. The Omega mine-pool is located almost entirely above the local base level drainage, with about 8 major and several minor springs draining the mine-works. The lowest portion of the T\&T mine-pool is located below base level drainage with one major and three smaller outlets. The below drainage portion of the mine-works may provide some dampening effect on seasonal and individual recharge events.

- Time series plots of iron to sulfate mole ratios showed that discharge water from both mine-pools are deficient in dissolved $\mathrm{Fe}$ with respect to sulfate, based on pyrite composition. The Fe deficiency increases as the mine-pool ages and approaches a constant value. An estimated 60 to $80 \%$ of the Fe associated with pyrite weathering is missing from aged mine-pool discharge water. A large fraction of the Fe from pyrite weathering is therefore being attenuated within the mine-pool, even in very acidic conditions. The retention mechanisms could include hydrous sulfate minerals, oxyhydroxide minerals, cation exchange or adsorption.

- Iron to sulfate ratio was greatest during high flow periods in the Omega mine-pool indicating flushing of $\mathrm{Fe}$ minerals. The ratio declined in low flow conditions indicating more storage during these periods. The T\&T mine-pool displayed similar seasonal behavior; the variation was smaller than in the Omega mine. The flushing dependent mole ratios suggest some $\mathrm{Fe}$ is attenuated in relatively soluble phases, such as hydrous sulfate minerals.

- Mole ratios may be useful for distinguishing initial flushing from long term leaching. The T\&T mine-pool approached steady state $\mathrm{Fe}: \mathrm{SO}_{4}$ ratio about 7 years after closure. The initial record for the Omega mine-pool from 1989 to 1993 is sparse. However, after grout injection in 1999, $\mathrm{Fe}: \mathrm{SO}_{4}$ ratio rapidly increased then declined slowly approaching a steady state after about 5 years. This second event approximates an initial flush.

- Both mine-pools contained a large excess of sulfate to $\mathrm{Al}$ on a mole basis (range from 7:1 to 10:1). These conditions should promote formation of $\mathrm{Al}^{-\mathrm{SO}_{4} \text { minerals, including }}$ sulfate rich minerals such as alunite or jurbanite.

- Mine-pool chemistry is very responsive to large imposed stresses. Both mine-pools had substantial increases in concentration and flux for several years after in-situ treatment. The T\&T mine-pool also experienced a short term major "blowout" event in 2003 resulting in a large flux of pollutants. These events established a new flushing cycle followed by gradual declines in concentration and flux. The T\&T "blowout" was not 
associated with any anthropogenic activities. Rather it appears to have resulted from disruption of existing flow-paths, rapid head buildup, followed by failure of a barrier, pillars, or other subsidence that rapidly relieved the hydraulic pressure. Roof falls or partial collapse, and pillar failure are extremely difficult to predict on a temporal basis, but can affect chemical flux on short and long term bases by altering ground-water flow patterns.

- Sulfate, $\mathrm{Al}$ and $\mathrm{Fe}(\mathrm{III})$ form significant amounts of complexes in mine water. Complex formation, in general, increases the quantity of the contributing mineral and element that can dissolve in solution. The distribution of complexes also changed as the mine-pools aged.

- About $70 \%$ of total dissolved sulfate was uncomplexed $\mathrm{SO}_{4}{ }^{2-}$ in the Omega mine-pool during initial flushing. $\mathrm{CaSO}_{4}{ }_{4}$ was the second most abundant sulfate species. In the aged mine-pool, uncomplexed $\mathrm{SO}_{4}{ }^{2-}$ had declined to about $50 \%$ of the total sulfate, and $\mathrm{Fe}-\mathrm{SO}_{4}$ and $\mathrm{Al}-\mathrm{SO}_{4}$ species had replaced $\mathrm{CaSO}_{4}{ }^{\circ}$ as the secondary species. The T\&T mine-pool had 40 to $50 \%$ of total sulfate present as uncomplexed $\mathrm{SO}_{4}{ }^{2-}$, and $\mathrm{CaSO}_{4}{ }^{\circ}$ was more abundant in the aged mine-pool after limestone injection.

- Most dissolved $\mathrm{Al}$, about $70 \%$ of the total, was present as $\mathrm{Al}-\mathrm{SO}_{4}$ species in both minepools. This increases the quantity of $\mathrm{Al}-\mathrm{SO}_{4}$ minerals, and amount of $\mathrm{Al}$ that can dissolve. About five times more jurbanite could dissolve in these mine waters because of complex formation, than if dissolved $\mathrm{Al}$ was present only as $\mathrm{Al}^{3+}$. The distribution of $\mathrm{Al}-\mathrm{SO}_{4}$ species showed little change as the mine-pools aged.

- About 70 to $80 \%$ of $\mathrm{Fe}(\mathrm{II})$ is present as uncomplexed $\mathrm{Fe}^{2+}$ in these waters and there is little difference by age or mine-pool.

- Ferric iron is a much stronger complexing agent than Fe(II). Seventy to $80 \%$ of dissolved $\mathrm{Fe}(\mathrm{III})$ occurs as $\mathrm{Fe}-\mathrm{SO}_{4}$ species. In general, this increases the solubility of $\mathrm{Fe}(\mathrm{III})-\mathrm{SO}_{4}$ minerals such as schwertmannite, and amount of Fe(III) that can dissolve.

- Measured Eh and Eh calculated from $\mathrm{Fe}^{2+} / \mathrm{Fe}^{3+}$ activities had a median difference of -32 millivolts. Results were similar to other studies. Two potential error sources included the necessity to dilute samples containing high Fe concentrations and determining $\mathrm{Fe}$ (III) by difference rather than directly. Dilution by a factor of ten or 100 reduced resolution of $\mathrm{Fe}$ (II) concentration. Ferric iron may be over-estimated when determined by difference and results in over-estimating Eh.

- Stable Eh readings were obtained within a few seconds indicating well poised systems. Measurements collected from 2002 to 2007 for both mine-pools were consistent, indicating reproducible results and/or stable redox conditions. Individual sample points fell within a range of 50 to 100 millivolts over the five year record. 
- Eh readings in acid mine waters can be used to estimate system redox conditions for iron. $\mathrm{Fe}^{2+} / \mathrm{Fe}^{3+}$ activities are sufficiently large that both can be sensed by the electrode and the couple is readily reversible.

- Measured Eh did not have a consistent relationship with $\mathrm{Fe}^{2+} / \mathrm{Fe}(\mathrm{OH})_{3}, \mathrm{Fe}^{2+} / \mathrm{Goethite}$, or $\mathrm{O}_{2} /$ Pyrite redox couples.

- Uncertainty in redox state affects computed saturation index for Fe minerals especially if the water is near equilibrium for a mineral.

- A large number of $\mathrm{Fe}$ and $\mathrm{Al}$ oxyhydroxides and hydrous sulfates could form in acid mine-pools. They are potential sinks for metals. Many, however, are soluble and dissolve during flushing events.

- Three springs in the Omega mine-pool are near apparent equilibrium for jurbanite $\left(\mathrm{AlOHSO}_{4}\right)$ and approach stability for alunite $\left(\mathrm{KAl}_{3}\left(\mathrm{SO}_{4}\right)_{2}(\mathrm{OH})_{6}\right)$. There is little change in water composition with respect to $\mathrm{Al}$ minerals over more than ten years in the Omega mine-pool. Al activity and mineral saturation state in the T\&T mine-pool were estimated from indirect methods utilizing charge balance and ionic strength principles. This minepool is apparently under-saturated for $\mathrm{Al}-\mathrm{SO}_{4}$ minerals. Neither mine-pool was directly accessible for sediment sampling.

- Both mine-pools approach apparent saturation for H-Jarosite $\left(\mathrm{H}_{3} \mathrm{OFe}_{3}\left(\mathrm{SO}_{4}\right)_{2}(\mathrm{OH})_{6}\right)$. With the exception of one spring (Marshall) in the Omega mine-pool, both mine-pools show little change in composition with respect to Fe minerals over time.

- Apparent thermodynamic stability of mine-pool waters with respect to Fe oxyhydroxides was assessed from a modified activity product, -pQ. Both partly flooded mine-pools have -pQ values characteristic of poorly crystalline, soluble Fe oxyhydroxides.

- Common ion effects for sulfate, $\mathrm{Fe}, \mathrm{Al}$ and $\mathrm{Ca}$ can suppress dissolution of less soluble minerals, and complicate interpretation of mine water composition. Some hydrous sulfate minerals lack reliable thermodynamic data and their solubility cannot be assessed quantitatively.

- Annual chemical flux has declined in both mine-pools. The Omega mine-pool flux is irregular from year to year, and after 14 years has declined to about 1/3 of its initial load. The T\&T mine-pool has a consistent rate of change in annual chemical flux and has declined more rapidly than the Omega mine-pool. The 2003 "blowout" in T\&T increased flux, but it has declined each subsequent year. 
- Irregular flux rate in the Omega mine-pool suggests that loading is sensitive to variations in precipitation. Such behavior could result from limited additional ground-water storage in the mine, where large recharge events quickly pass through the mine. The more regular response in the T\&T mine-pool suggests a mechanism that dampens response, such as the ability to store additional ground-water recharge during exceptionally wet periods and release it slowly.

- Flux has a strong seasonal component. About $75 \%$ of annual chemical flux is discharged in a six month peak recharge period from January to June in both mine-pools.

- Average long term flux rates (mole basis) normalized to mine area are within about one order of magnitude for Fe and sulfate in both mine-pools. Sulfate flux rate is greater than for Fe flux.

- There is no clear distinction in flux rate between partly flooded and mostly flooded mines when normalized to mine area.

- Median annual recharge is 0.28 and $0.36 \mathrm{gal} / \mathrm{A}-\mathrm{min}$ for the T\&T and Omega mines, respectively, varies from year to year, and is at least partly dependent on precipitation and overburden thickness.

- Recharge, like flux, has a seasonal component. Median recharge in spring is from 0.5 to $0.8 \mathrm{gal} / \mathrm{A}$-min for the two mine-pools, and also varies from year to year.

- Both mine-pools approach base-flow conditions of about 0.1 gal/A-min recharge in the autumn. 


\section{Chapter 4: Chemical and Hydrologic Properties of Flooded Mines}

Flooding and inundation of closed underground mines, tailings and waste rock containing pyrite has been suggested as a useful mine closure practice (Robertson et al., 1997, Jakubick et al., 2002). Stoertz et al. (2001), for example, attributed a pH increase from about 2.7 to greater than 5, and a decline in specific conductance, to flooding in a small underground mine in Ohio. The flooding principle is based on exclusion of oxygen to halt or at least inhibit pyrite oxidation and acid production. In northern Appalachia, mines located mostly or entirely below the local base level drainage usually flood after mine closure. Flooding rate and extent are a function of recharge, potential discharge locations and interaction with other hydrologically connected mines and aquifers. The author describes in this chapter the conceptual development of chemical conditions in closed, flooded underground mines, and applies those concepts to existing mine-pools in West Virginia and Pennsylvania, USA.The final section presents observations and measurements of quantitative ground-water parameters that are useful for managing mine-pools.

Four mostly to fully flooded mine-pools are analyzed in this chapter. Additional background is provided in the conference papers contained in Appendices B, C and D, and by Donovan et al. (1999) for the Hahn and Arden-Westland mine-pools. Some basic information is shown in table 4-1. Three of the mine-pools are located in the Pittsburgh coal bed, which extends over parts of four states in northern Appalachia (Ruppert et al., 1999). It has been mined extensively. The Barnes\&Tucker mine-pool is in central Pennsylvania in the Lower Kittanning and Lower Freeport coal beds and has been extensively mined in that locale.

Table 4-1

Summary Information on Four Flooded Mine-pools

\begin{tabular}{|c|c|c|c|c|}
\hline Mine-pool & Location & Coal bed & Flooding State & Area \\
\hline $\begin{array}{l}\text { Barnes\&Tucker } \\
\text { (Lancashire 15) }\end{array}$ & $\begin{array}{c}\text { Cambria } \\
\text { County, PA }\end{array}$ & $\begin{array}{l}\text { Lower Kittanning, } \\
\text { Lower Freeport }\end{array}$ & $\begin{array}{l}\sim 80 \% \text { Flooded, Pumped } \\
\text { to Control Discharge }\end{array}$ & $\begin{array}{c}5700 \\
\text { Hectares }\end{array}$ \\
\hline $\begin{array}{c}\text { Hahn } \\
\text { (Montour 4,10) }\end{array}$ & $\begin{array}{l}\text { Washington } \\
\text { County, PA }\end{array}$ & Pittsburgh & $\begin{array}{l}\text { 70\% Flooded, Pumped } \\
\text { to Control Discharge }\end{array}$ & $\begin{array}{c}5900 \\
\text { Hectares }\end{array}$ \\
\hline $\begin{array}{c}\text { Arden- } \\
\text { Westland }\end{array}$ & $\begin{array}{l}\text { Washington } \\
\text { County, PA }\end{array}$ & Pittsburgh & $\begin{array}{l}\text { 80\% Flooded, Pumped } \\
\text { to Control Discharge }\end{array}$ & $\begin{array}{c}5100 \\
\text { Hectares }\end{array}$ \\
\hline Fairmont & $\begin{array}{c}\text { Marion County, } \\
\text { WV }\end{array}$ & Pittsburgh & $\begin{array}{l}\sim 100 \% \text { Flooded, } \\
\text { Pumped to Control } \\
\text { Discharge }\end{array}$ & $\begin{array}{c}12100 \\
\text { Hectares }\end{array}$ \\
\hline
\end{tabular}

How important is flooding to halt the production of acid drainage? Table 4-2 shows paired mine water samples at flooded and partly flooded conditions, from either the same sample point at different flooding states, or two different sample points in the same mine-pool. The first two entries in table 4-2 are located within the city of Fairmont, WV, and are separated from each other by about $0.8 \mathrm{~km}$. Both are located in the Pittsburgh coal bed and are about 80 years old. The acid discharge drains from a small section of unflooded mine-works, while the circumneutral water sample is from a fully flooded section. The flooded section water is lower in 
metals, sulfate and Total Dissolved Solids (TDS), and in fact, meets most water quality use standards except for Fe.

Table 4-2

Comparison of Mine Water Composition at Flooded and Partly Flooded Conditions ${ }^{(1)}$

\begin{tabular}{ccccccccc}
\hline Mine-pool & Location & Flooding State & $\begin{array}{c}\text { Sample } \\
\text { Date }\end{array}$ & $\mathrm{pH}$ & $\mathrm{Fe}$ & $\mathrm{Al}$ & $\mathrm{SO}_{4}$ & $\begin{array}{c}\text { Total } \\
\text { Dissolved } \\
\text { Solids }\end{array}$ \\
\hline Fairmont & Marion Co., WV & Flooded & $4 / 6 / 2004$ & 6.68 & 4.31 & 0.33 & 153 & 442 \\
Fairmont & Marion Co., WV & $\begin{array}{c}\text { Partly } \\
\text { Flooded }\end{array}$ & $4 / 6 / 2004$ & 2.58 & 15.6 & 21.3 & 668 & 992 \\
Barnes\&Tucker & Cambria Co., PA & Flooded & $10 / 6 / 2005$ & 6.98 & 38.1 & 0.06 & 276 & 614 \\
Barnes\&Tucker & Cambria Co., PA & Partly & $10 / 6 / 2005$ & 2.63 & 73.8 & 43.9 & 1037 & 1496 \\
& & Flooded & & & & & & \\
Hahn & Washington Co., PA & Flooded & $2 / 94-10 / 95$ & 6.60 & 87 & 0.2 & 1445 & 2999 \\
Hahn & Washington Co., PA & Partly & $7 / 84-7 / 85$ & 4.40 & 931 & 20.6 & 7000 & 11370 \\
& & Flooded & & & & & & \\
Uniontown & Fayette Co., PA & Flooded & $8 / 05-3 / 08$ & 6.13 & 50.0 & 0.04 & 691 & 1286 \\
Uniontown & Fayette Co., PA & Partly & $1974-1975$ & 3.20 & 113 & 11 & 1950 & - \\
\hline
\end{tabular}

(1) $\mathrm{pH}$ in S.U., all others in $\mathrm{mg} / \mathrm{L}$. Fairmont and Barnes\&Tucker data are individual samples collected by the author. Hahn data are medians of $n=14$ and $n=50$ analyses, respectively, and were reported by Donovan et al., 1999. $\mathrm{n}=14$ for Uniontown samples 8/05-3/08 collected by the author. 1974-1975 data from Ackenheil Associates (1977).

Similar conditions exist in the Barnes\&Tucker samples.The circumneutral water is from the main pumped discharge, fully flooded section of the mine-pool, which has been inundated since about 1970. The acidic water drains from the same stratigraphy and mine complex, but is in a small unflooded section that has been abandoned for at least 50 years.

The Hahn water samples are from the main pumped discharge, but at two different stages of flooding in the mine-pool. The acidic water from 1984-1985 is from the initial filling of the mine-works, and contains very high concentrations of all reported parameters. Ten years later, the mostly flooded mine-pool produced circumneutral water, and metals and TDS had declined significantly. The final data pair in table $4-2$ is from a high volume discharge $(15,000 \mathrm{~L} / \mathrm{min})$, draining fully flooded mine-works in the Pittsburgh coal bed near Uniontown, PA. The mineworks are in a syncline that flooded and began to discharge about 1960, after mining and dewatering ceased. The drainage was still acidic 14 years after closure, but now discharges circumneutral water with reduced concentrations of Fe and sulfate. Anecdotal information obtained from Pennsylvania DEP personnel (Beam, 2005) suggests the pool turned net alkaline about 1980. 
The principal difference within each paired data set in table 4-2 is flooding state. Each entry in the unflooded category has acidic drainage and elevated chemical concentrations compared to the flooded sample. These example data illustrate that flooding can profoundly affect mine-pool composition, and suggests flooding stops or at least slows pyrite oxidation.

\subsection{Data Acquisition and Sampling}

Water quality analyses for the flooded mines were obtained by a combination of methods. These included:

- samples collected by the author for the Fairmont, Barnes\&Tucker and Uniontown minepools,

- review of published data,

- searching files in various offices of the federal government, and state government in West Virginia and Pennsylvania, and,

- unpublished company monitoring records where accessible

The author collected samples for the Fairmont, Uniontown, and Barnes\&Tucker mine-pools following guidelines suggested by Cherceri et al. (1998), US EPA and the USGS. This included appropriate filtering, preservation and containers, and field measured $\mathrm{pH}, \mathrm{Eh}$, specific conductance, and dissolved oxygen. Field alkalinity was also run for selected samples. The chemical data used for the Hahn and Arden-Westland mine-pools were originally reported by Donovan et al. (1999), and the mining and flooding history of both is given therein. Some data for the Fairmont and Barnes\&Tucker mine-pools were obtained by file searches in government and company monitoring records. Mining and flooding history of the Barnes\&Tucker mine-pool is given in Appendix D and by Hawkins et al. (2005). Features of the Fairmont mine-pool are described in Appendix C.

Data discussed in this chapter were obtained from multiple sources, sampled by different individuals, analyzed in different labs, and collected for various purposes and parameters. This introduced some uncertainty and limitations into the analyses. Where feasible, data were examined for quality control using charge balance, conductance/TDS relationships and similar techniques. Data limitations are discussed where appropriate in subsequent sections of this chapter. The Barnes\&Tucker, Hahn, and Arden-Westland data sets provide reasonably continuous time series information. The Fairmont mine-pool data are more dispersed. Data from other mine-pools are included in specific analyses, and background information is included as needed.

\subsubsection{Sampling Flooded Mines - Spatial Variability}

A basic prerequisite for characterizing chemical quality in large mine-pools is the collection of "representative samples". Figures 4-1 and 4-2 are vertical profiles of specific conductance in two mine-pool wells. Chemical samples from the top and bottom of the water columns of these two wells are shown in table 4-3. The vertical conductance profile was done by lowering a Solinst 
Conductance/Temperature probe to predetermined depths beginning at the top of the water column, and collecting readings once the instrument had equilibrated with water in that zone. Water quality samples were collected using a Kemmerer sampler that was open at both ends, and lowering it to the predetermined depth. At the appropriate depth, a "messenger" weight sent down the line closed the sampler, and the water was retrieved. The figures and tables illustrate the extent of stratification that can occur in a mine-pool well or flooded shaft, and the significance of sampling techniques.

Figure 4-1 is from the Shannopin mine-pool in Greene County, PA. This mine, covering about 4000 hectares in the Pittsburgh coal bed, closed abruptly in the early 1990's and was abandoned. The conductance profile and chemical samples were collected from a partly inundated shaft while flooding was in process, and the "beach" line between flooded and unflooded sections was nearby. The mine-pool developed over about a ten year period, and is now controlled by pumping. The vertical conductance profile was conducted when mine-pool head increased to about ten meters above coal elevation at this shaft during flooding. No pumping was underway when this profile was collected. Specific conductance was nearly constant from the top of the water column at 47 meters to near top of the coal. At mine level, specific conductance abruptly increased by almost an order of magnitude.

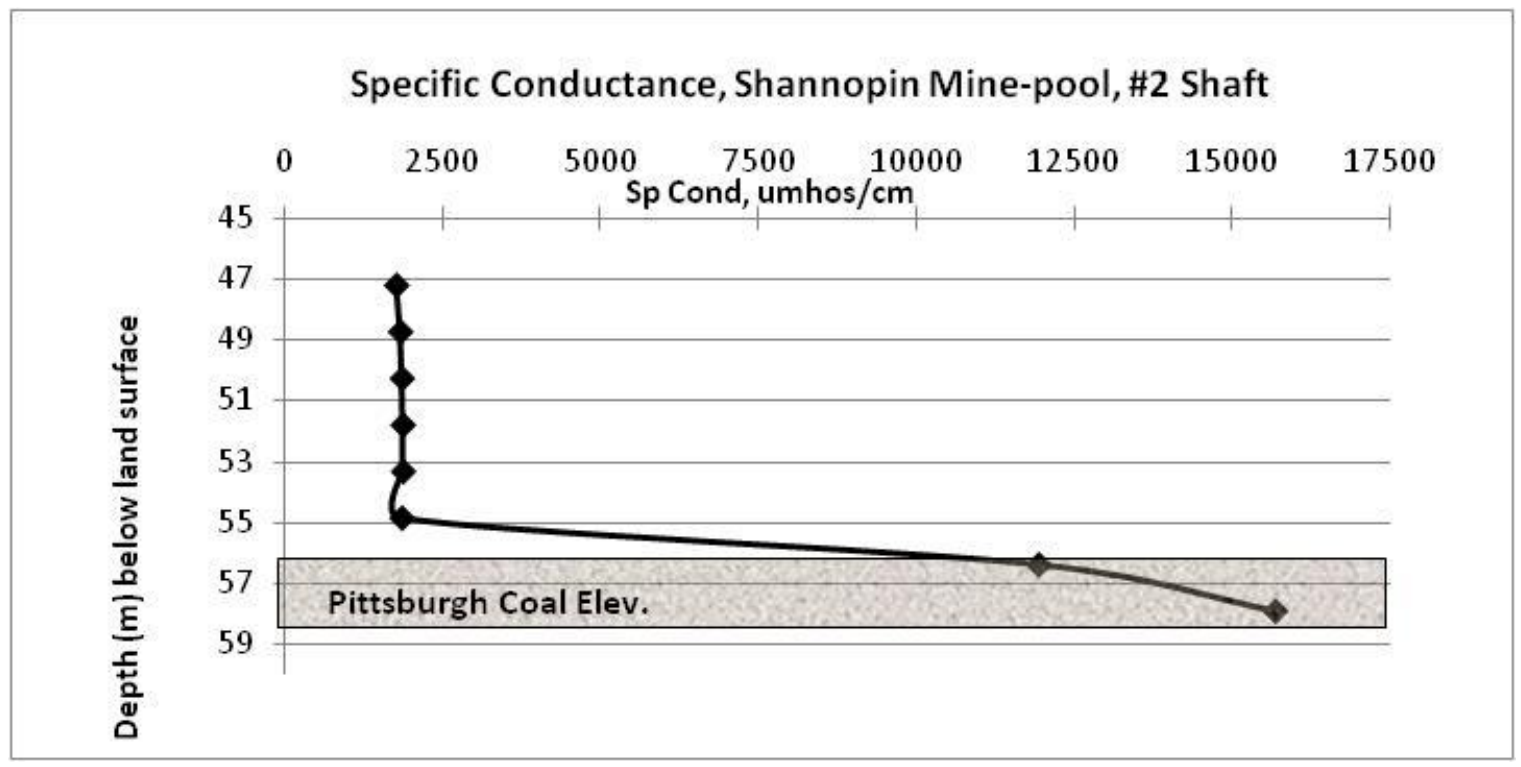

Figure 4-1. Profile of Specific Conductance in a Mine-pool Water Column, Shannopin Mine, Greene Co, PA. Conductance profile measured and chemical samples collected 10/25/2000.

Extreme differences in water chemistry between top and bottom of the water column are evident in table 4-3. Iron concentration, for example, is 160 times greater at the bottom, sulfate is enriched by a factor of about 20, and total acidity exceeds $3000 \mathrm{mg} / \mathrm{L}$. Low pH water at the bottom of the shaft likely represents acid drainage flowing from the unflooded sections just up-dip of the shaft and mixing with the main mine-pool. Higher $\mathrm{pH}$ water at the top of the shaft probably represents ground water from the overburden that has undergone only limited mixing with water from the mine-works. The abrupt vertical transition in water chemistry suggests that flow in the mine-pool is laminar with no turbulent mixing. 
Figure 4-2 is a conductance profile from the Fairmont mine-pool. Conductance measurements and water quality samples were collected as described previously. The "Siphon" well is in the main ground-water withdrawal structure for the mine-pool (see Appendix C) and represents water at the end of the mine-pool flow-path. The Fairmont mine-pool is essentially 100 percent flooded, and the water chemistry reflects the inundated condition with a measured Eh of 8 millivolts in the bottom of the well. About 5,000 L/min is removed via a pipeline and discharges into an adjacent mine-pool. The turbulent flow has caused some mixing in the well from coal elevation to about 15 $\mathrm{m}$ below ground surface. The top few meters of the water column remain chemically distinct, however, as shown in table 4-3. Iron is enriched by a factor of about 36 at the bottom of the water column, sulfate concentration is about five times greater, and alkalinity differs by a factor of about three. The lower $\mathrm{pH}$ at the top of the water column compared to water at mine level may reflect differences between a mixture of mine-pool and ground water and mine-pool water only. Turbulent mixing may also introduce oxygen into the top of the water column and promote Fe oxidation, followed by hydrolysis with $\mathrm{H}^{+}$production and consumption of alkalinity.

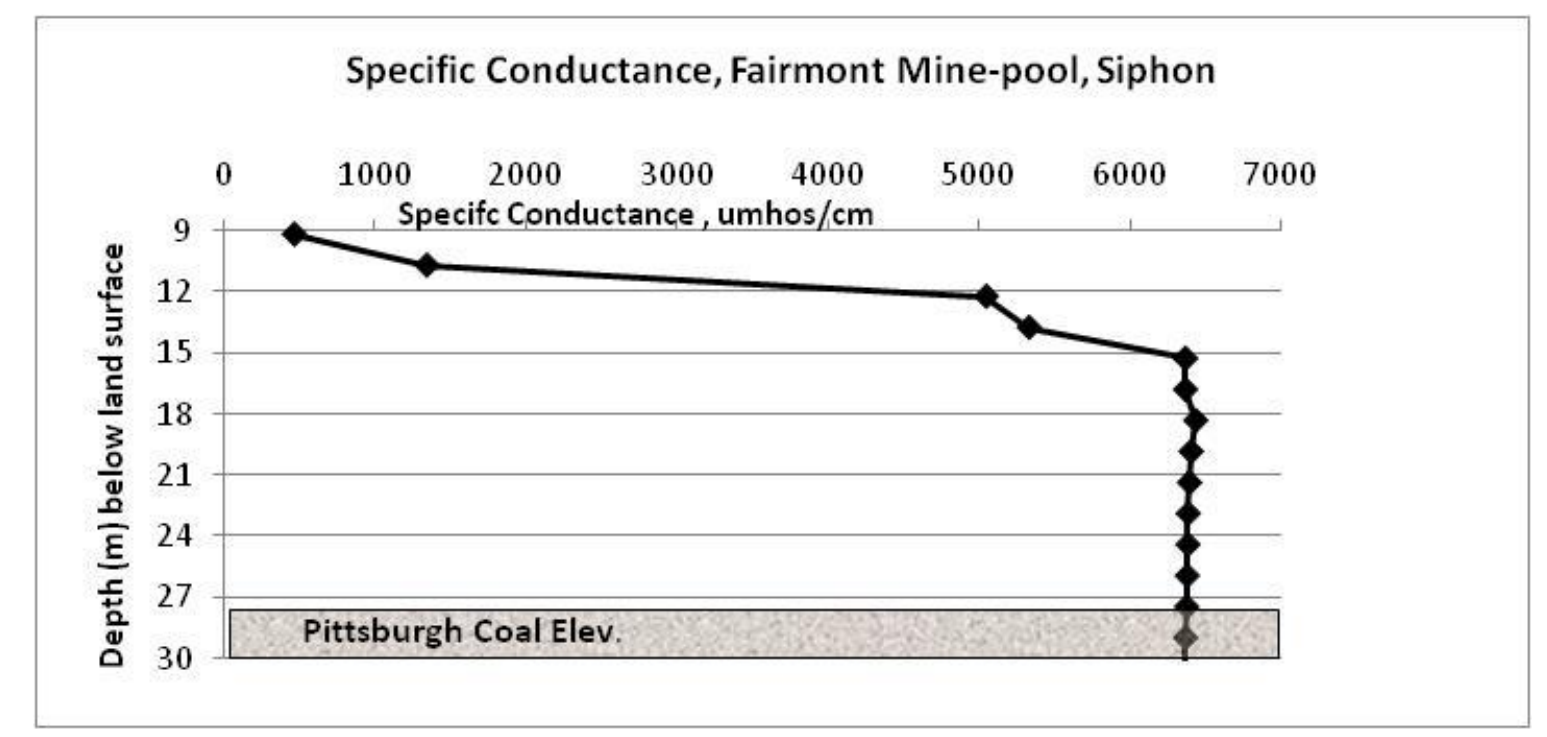

Figure 4-2. Profile of Specific Conductance in a Mine-pool Water Column with Turbulent Flow, Fairmont Mine-pool. Conductance profile measured 2/28/2001 and chemical samples collected 5/2/2001.

The data in figures 4-1 and 4-2 and table 4-3 show that sampling can misrepresent mine-pool conditions, if stratification is not considered. Nuttall and Younger (2004) also found stratification in flooded coal mines in the UK. They describe a case where initial sampling from top of the water column gave data that greatly under-estimated treatment needs. As test pumping was carried out over 50 days, mine-pool water became more mineralized, and Fe concentration increased by a factor of nearly 100. They concluded that stratification is likely in wells and shafts that are recharging gradually, and attempts to pump only the "best" water stratified at the top of the column is likely to fail, because pumping induces turbulent flow and greater mixing. They also noted that metals such as Fe and $\mathrm{Zn}$ showed the most extreme stratification, up to two orders of magnitude. Their observations are similar to the Fe data in the Shannopin mine-pool with an enrichment factor of 160. Finally, they noted that water quality changes were likely to be most profound after exchange of at least one shaft volume. Ladwig et al. (1984) also found pronounced chemical 
stratification in flooded anthracite mines of eastern Pennsylvania, USA. In most instances, their data also show abrupt transitions in $\mathrm{pH}$, Eh and chemical composition.

Table 4-3

Chemical Composition of Stratified Mine-pool Waters ${ }^{(1)}$

\begin{tabular}{cccccccccccc}
\hline Sample & $\mathrm{pH}$ & $\mathrm{Eh}$ & $\mathrm{TDS}$ & $\begin{array}{c}\text { Alkalinity } \\
\text { (Acidity) }\end{array}$ & $\mathrm{Fe}$ & $\mathrm{Al}$ & $\mathrm{Ca}$ & $\mathrm{Mg}$ & $\mathrm{Na}$ & $\mathrm{SO}_{4}$ & $\mathrm{Cl}$ \\
\hline $\begin{array}{c}\text { Shannopin } \\
\text { Top Column }\end{array}$ & 7.75 & 287 & 806 & $\begin{array}{c}272 \\
(-)\end{array}$ & 8.9 & 0.25 & 24.6 & 6.2 & 239 & 299 & 39 \\
$\begin{array}{c}\text { Shannopin } \\
\text { Bottom } \\
\text { Column }\end{array}$ & 4.65 & 350 & 10460 & $\begin{array}{c}- \\
(3220)\end{array}$ & 1429 & 184 & 201.3 & 204.8 & 812 & 6104 & 70 \\
$\begin{array}{c}\text { Fairmont } \\
\text { Top Column }\end{array}$ & 6.37 & 150 & 1179 & $\begin{array}{c}169 \\
(-)\end{array}$ & 1.7 & 0.04 & 10.7 & 11.9 & 317 & 588 & 52 \\
$\begin{array}{c}\text { Fairmont } \\
\text { Bottom } \\
\text { Column }\end{array}$ & 6.98 & 8 & 5182 & $\begin{array}{c}523 \\
(-)\end{array}$ & 60.9 & 0.03 & 185.7 & 91.9 & 1053 & 3237 & 141 \\
\hline
\end{tabular}

(1) $\mathrm{pH}$ in S.U., Eh in millivolts, Specific Conductance in $\mu \mathrm{mhos} / \mathrm{cm}$, Acidity and Alkalinity as mg/L $\mathrm{CaCO}_{3}$ Eq. All others in $\mathrm{mg} / \mathrm{L}$.

A chemical characterization and sampling program in pumped or non-pumped mine-pools must recognize potential for stratification and turbulent mixing. Samples from the top of the water column likely do not represent main mine-pool composition. Treatment or other water management decisions should be based on samples typical of the mine-pool.

Water quality may show significant lateral variation across a mine-pool. Table 4-4 includes analyses from three wells located in the Fairmont mine-pool (Appendix C). They are in different parts of the flow system; a recharge area (mine 38 well), intermediate flow-path (Mine 63) and end of flow-path for the mine-pool (Siphon). The mine-pool has circumneutral $\mathrm{pH}$ at each well, in each part of the flow system. Recharge water at Mine 38 is a mixed $\mathrm{Na}-\mathrm{Ca}-\mathrm{HCO}_{3}-\mathrm{SO}_{4}$ type; Mine 63 at an intermediate flow-path position is a $\mathrm{Na}-\mathrm{SO}_{4}-\mathrm{HCO}_{3}$ type water, while the siphon at the end

Table 4-4

Spatial Variation in Water Quality of Fairmont Mine-pool ${ }^{(1)}$

\begin{tabular}{cccccccccccc}
\hline Site & $\begin{array}{c}\text { Flow-Path } \\
\text { Location }\end{array}$ & $\begin{array}{c}\mathrm{pH} \\
\text { (field) }\end{array}$ & Alkalinity & $\mathrm{TDS}$ & $\mathrm{Fe}$ & $\mathrm{Mn}$ & $\mathrm{Ca}$ & $\mathrm{Mg}$ & $\mathrm{Na}$ & $\mathrm{Cl}$ & $\mathrm{SO}_{4}$ \\
\hline Mine 38 & Recharge & 7.32 & 179.8 & 548 & 3.44 & 0.53 & 60.7 & 14.1 & 105.7 & 34.1 & 207 \\
Mine 63 & Intermediate & 7.31 & 589.6 & 3301 & 33.9 & 0.64 & 158.4 & 33.1 & 853.4 & 44.2 & 1697 \\
Siphon & End & 7.20 & 568.7 & 5194 & 134.8 & 1.63 & 250.6 & 89.7 & 1254 & 119.9 & 2812 \\
\hline
\end{tabular}

(1) $\mathrm{pH}$ in S.U., Alkalinity in $\mathrm{mg} / \mathrm{L} \mathrm{CaCO}_{3}$, all others in $\mathrm{mg} / \mathrm{L}$. TDS = Total Dissolved Solids. Mine-pool samples collected $12 / 17 / 2002$ by the author. 
of flow-path is a Na-SO $\mathrm{SO}_{4}$ water. Mine-pool composition becomes progressively mineralized and enriched in $\mathrm{Na}$ and sulfate as water moves from recharge to discharge areas. Iron concentration is variable, and is enriched by a factor of about 40 from recharge to the end of the flow-path. Location within the mine-pool flow system is another sampling variable.

\subsubsection{Pumping Effects on Mine-pool Composition}

The Barnes\&Tucker mine-pool (Appendix D) is controlled by one pumped discharge, and the quality is affected by the pumping rate. Most water samples collected from October, 2000 to May, 2004 included field notes indicating pumping rate at the time of sample collection. A total of 41 sampling events from that time period were analyzed using summary statistics and nonparametric comparisons. A Mann-Whitney test compared median water chemistry of data grouped by discharge rate. Median water quality values are shown in table 4-5, and each parameter is significantly different by discharge rate at the $p=0.05$ level of significance.

Raw water quality declines when the pumping rate is increased. Median acidity is about 1.6 times greater at higher discharge rate, while alkalinity decreases from 230 to $169 \mathrm{mg} / \mathrm{L}$.

Table 4-5

Effect of Pumping Rate on Water Quality from Barnes\&Tucker Mine-pool ${ }^{(1)}$

\begin{tabular}{ccccccccc}
\hline $\begin{array}{c}\text { Discharge } \\
\text { Rate } \\
(\mathrm{L} / \mathrm{min})\end{array}$ & $\mathrm{pH}$ & Alkalinity & $\begin{array}{c}\text { Calculated } \\
\text { Acidity }\end{array}$ & $\begin{array}{c}\text { Net } \\
\text { Alkalinity }\end{array}$ & Iron & Sulfate & Manganese & Aluminum \\
\hline 12300 & 6.7 & 230 & 58.4 & 170.7 & 32.6 & 298.6 & 0.60 & 0.5 \\
24600 & 6.5 & 169.3 & 93.6 & 52.8 & 47.7 & 401.5 & 1.00 & 6.5 \\
\hline
\end{tabular}

(1) $\mathrm{pH}$ in standard units, Alkalinity, Calculated Acidity and Net Alkalinity in $\mathrm{mg} / \mathrm{L} \mathrm{CaCO}_{3}$ Eq., all others in $\mathrm{mg} / \mathrm{L}$. Values are medians.

(2) 17 samples collected during 12,300 L/min pump discharge rate. 24 samples collected during 24,600 L/min pump discharge rate.

Concentrations of iron, sulfate and manganese also increase about 50, 37 and 68\% respectively at higher pumping rates. Total aluminum concentration also increases with pumping rate. Most of the aluminum is likely in suspended or colloidal form, and not dissolved, because of solubility constraints at neutral $\mathrm{pH}$.

Pumping rate effects on water quality show that if stress on the mine-pool is increased, water is delivered from storage areas with more acid weathering products, and/or areas that have undergone less flushing and leaching. These may be zones with slow or limited ground-water circulation within the mine-pool. Winters and Capo (2004), and Aljoe and Hawkins (1991) have suggested that "short circuiting" and preferential flow-paths probably exist in mine-pools.

\subsection{Water Quality in Flooded Mines}

The chemical composition of large flooded mines in northern Appalachia is significant for the capacity to degrade other aquifers and surface waters. If water quality issues can be overcome , these new aquifers are potential ground-water resources. Discharge rates from flooded mines in this study are on the order of thousands of $\mathrm{L} / \mathrm{min}$. While the focus of this study was on mines 
discharging polluted water, some mine-pools produce water with quality that is acceptable for use without treatment. Lessing and Hobba (1981), for example reported on mine waters in West Virginia that are used as public water supplies with minimal or no treatment needed. Thus, whether viewed as a pollution source or potential resource, these mine-pools are important regional ground-water features.

Table 4-6 shows the overall composition of five flooded mine-pools, based on the relative abundance of major cations and anions. Each analysis is from the main pumped or flowing discharge point for the mine-pool, and represents water at the end of the flow-path. Median $\mathrm{pH}$, alkalinity, and dissolved solids are also shown. Time flooded ranges from 7 years to as long as 48 years. The mine-pools share a general set of common traits.

Four of five mine-pools have $\mathrm{Na}$ as the dominant cation (meq basis) and sulfate is the most abundant anion in each. The Uniontown mine-pool is $\mathrm{Ca}-\mathrm{Mg}-\mathrm{SO}_{4}$ water. Alkalinity concentrations range from moderate to very high. With the exception of the Fairmont mine-pool, $\mathrm{pH}$ values range from 6.13 to 6.58, suggesting that they are carbonate buffered systems with relatively high pCO. Equilibrium calculations performed with PHREEQCI on some of these data estimated $\log \mathrm{pCO}_{2}$ values of about -0.8 to -1.5 . Cravotta (2008a, 2008b) in a detailed study of about 140 mine discharges in Pennsylvania USA found a mean $\log \mathrm{pCO}_{2}$ of minus one for his sample set. Dissolved solids concentrations are more variable, and are inversely related to minepool age.

Table 4-6

Water Composition and General Chemistry of Five Flooded Mine-pools ${ }^{(1)}$

\begin{tabular}{|c|c|c|c|c|c|c|c|c|}
\hline Mine-pool & Location & $\begin{array}{c}\text { Years } \\
\text { Flooded }\end{array}$ & Date & $\mathrm{n}$ & $\mathrm{pH}$ & Alkalinity & TDS & $\begin{array}{l}\text { Water } \\
\text { Type }\end{array}$ \\
\hline Barnes\&Tucker & $\begin{array}{c}\text { Cambria Co., } \\
\text { PA }\end{array}$ & $34-35$ & $\begin{array}{l}4 / 04- \\
10 / 05\end{array}$ & 9 & 6.39 & 131 & 668 & $\mathrm{Na}-\mathrm{SO}_{4}$ \\
\hline Hahn & $\begin{array}{l}\text { Washington } \\
\text { Co., PA }\end{array}$ & 11 & $\begin{array}{l}1 / 95- \\
12 / 95\end{array}$ & 10 & 6.58 & 344 & 2926 & $\mathrm{Na}-\mathrm{SO}_{4}$ \\
\hline Arden-Westland & $\begin{array}{c}\text { Washington } \\
\text { Co., PA }\end{array}$ & 10 & $\begin{array}{l}1 / 95- \\
10 / 95\end{array}$ & 10 & 6.25 & 138 & 1841 & $\begin{array}{c}\mathrm{Na}-\mathrm{Ca}- \\
\mathrm{SO}_{4}\end{array}$ \\
\hline Fairmont & $\begin{array}{l}\text { Marion Co., } \\
\text { WV }\end{array}$ & $7-9$ & $\begin{array}{l}4 / 02- \\
4 / 04\end{array}$ & 9 & 7.55 & 564 & 4932 & $\mathrm{Na}-\mathrm{SO}_{4}$ \\
\hline Uniontown & $\begin{array}{l}\text { Fayette Co., } \\
\text { PA }\end{array}$ & $45-48$ & $\begin{array}{l}8 / 05- \\
3 / 08\end{array}$ & 13 & 6.13 & 224 & 1286 & $\begin{array}{c}\mathrm{Ca}-\mathrm{Mg}- \\
\mathrm{SO}_{4}\end{array}$ \\
\hline
\end{tabular}

(1) $\mathrm{pH}$ in S.U., alkalinity in $\mathrm{mg} / \mathrm{L} \mathrm{CaCO}_{3}$ Eq., and TDS in $\mathrm{mg} / \mathrm{L}$. Water types based on dominant cations and anions using median values. $n=$ number of samples.

\subsubsection{Mole Ratios}

Figures 4-3a-d are time series plots of Fe: $\mathrm{SO}_{4}$ mole ratio for the Barnes\&Tucker, Hahn, ArdenWestland and Fairmont mine-pools. Sample intervals vary from weekly to monthly for most of 
the Hahn, Arden-Westland and Fairmont mine-pool samples. The Barnes\&Tucker data are based on mean annual water quality data. Assuming pyrite is the principal source of Fe and sulfate in these mine waters, dissolution should yield a mole ratio of one $\mathrm{Fe}$ to two $\mathrm{SO}_{4}$. The one to two ratio is identified by the bold line in each plot. All four mine-pools are deficient in Fe with respect to sulfate. As much as 60 to $80 \%$ of the expected Fe is missing, which suggests significant attenuation by mineral formation, adsorption, or exchange. The ratios are greatest during the early flushing and development of the mine-pool, but approach a steady state as the mine-pool ages. The change in slope observed in three of the four plots may indicate the change from initial flushing to long term weathering that has been described by Younger (2000) for flooded coal mines in the UK. This suggests it is in a long term weathering phase. The Fairmont mine-pool, although more recently flooded, shows no obvious change over a 6 year period (figure 4-3d). Iron to sulfate mole ratios in the flooded mines approach a value of about 0.1 to 0.2 , long-term. The partly flooded T\&T mine described in chapter three also approaches a ratio of about 0.1 long-term. The partly flooded Omega mine (chapter three) has the largest $\mathrm{Fe}: \mathrm{SO}_{4}$

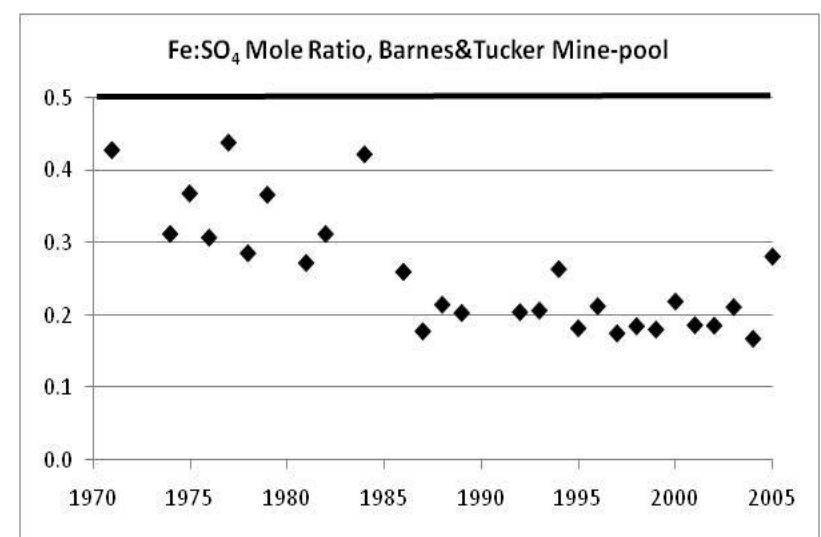

Figure 4-3a. Iron to Sulfate Mole Ratio Barnes\&Tucker Mine-pool, Yearly Mean Data.

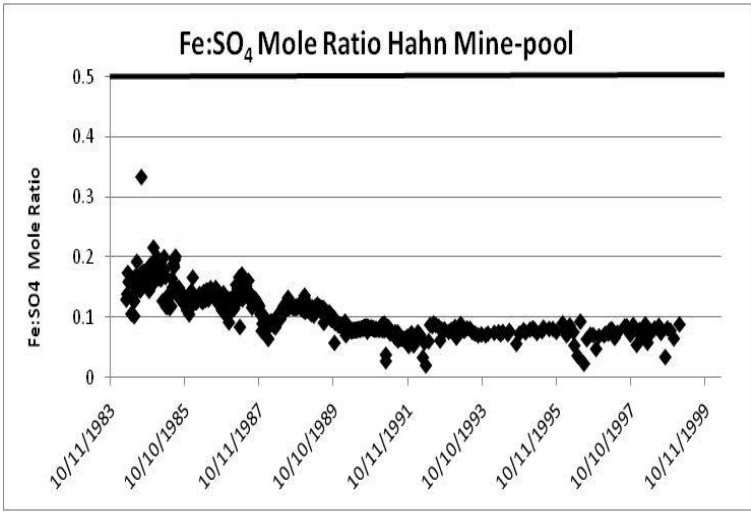

Figure 4-3c. Iron to Sulfate Mole Ratio, Hahn Mine-pool.

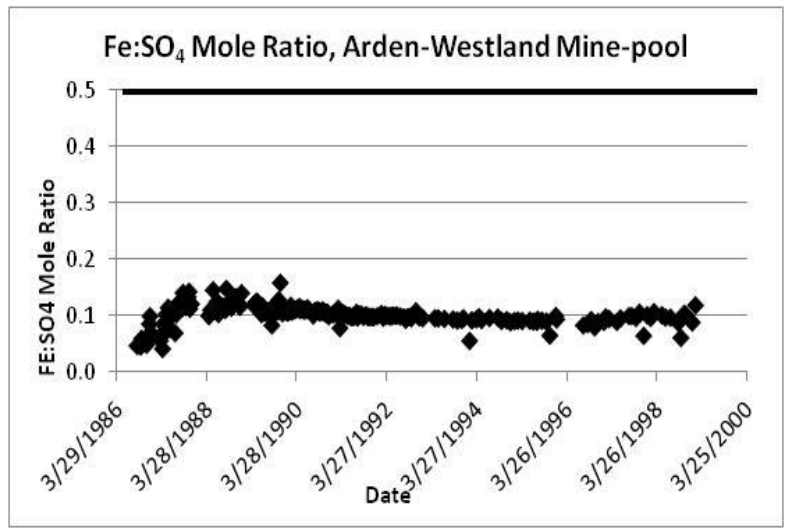

Figure 4-3b. Iron to Sulfate Mole ratio, ArdenWestland Mine-pool.

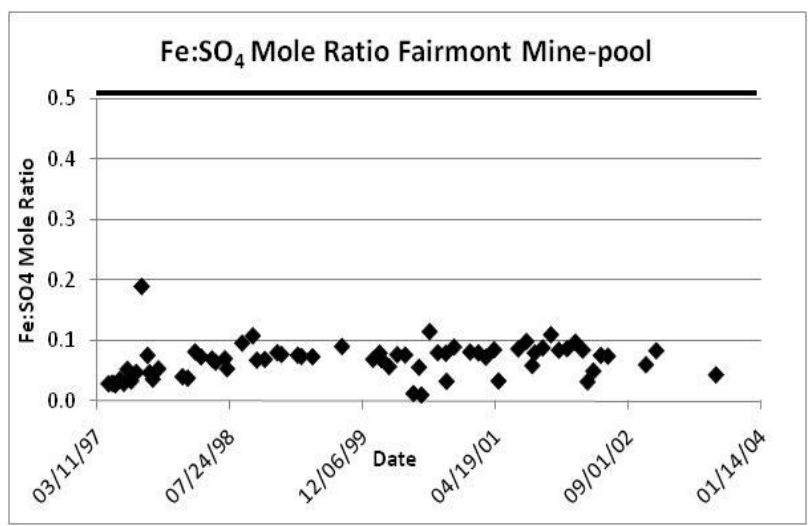

Figure 4-3d. Iron to Sulfate Mole ratio, Fairmont Mine-pool. 
ratio, and the least $\mathrm{Fe}$ attenuation of any mine examined. Any conceptual or analytical model of Fe circulation in flooded or partly flooded mine-pools needs to account for $\mathrm{Fe}$ attenuation in-situ.

Figures 4-4a and4-4b show time series plots of $\mathrm{Ca}$ to carbonate carbon $\left(\mathrm{H}_{2} \mathrm{CO}_{3}+\mathrm{HCO}_{3}{ }^{-}\right.$ $+\mathrm{CO}_{3}{ }^{2-}$ ) ratio on a milliequivalent basis, and $\mathrm{pH}$, for the Hahn and Arden-Westland mine-pools. The graphs were constructed by speciating samples in PHREEQCI that had $\mathrm{pH}$, alkalinity and major cations and anion reported and assuming a temperature of $15^{\circ} \mathrm{C}$. The calculated equilibrium concentrations of carbonate species $\mathrm{CO}_{2(\mathrm{aq})}, \mathrm{HCO}_{3}{ }^{-}$, and $\mathrm{CO}_{3}{ }^{2-}$ were summed and plotted as ratio to $\mathrm{Ca}$ concentration. $\mathrm{pH}$ is included on the plots to indicate the dominant calcite dissolution process. Following convention, $\mathrm{CO}_{2(\mathrm{aq})}$ is represented as $\mathrm{H}_{2} \mathrm{CO}_{3}$. Calcium data for other mine-pools were not available for long periods and hence are not included here.

The mine-pools in figures 4-4a-b have ratios of about one to ten during initial flushing. If calcite is the only source of soluble $\mathrm{Ca}$ and alkalinity in these mine-pools, and carbonate species are conserved in the mine-pool, then the ratios should range from about 0.5 to one depending on $\mathrm{pH}$. At low $\mathrm{pH}$ (less than about 5), calcite dissolution is dominated by the reaction:

$$
\mathrm{CaCO}_{3}+2 \mathrm{H}^{+} \leftrightarrow \mathrm{H}_{2} \mathrm{CO}_{3}+\mathrm{Ca}^{2+}
$$

where two milliequivalents of $\mathrm{Ca}$ are dissolved and two milliequivalents of $\mathrm{H}_{2} \mathrm{CO}_{3}$ are produced. Under these conditions, and if there are no other sources or sinks for $\mathrm{Ca}$ or carbonate, the $\mathrm{Ca}$ to carbonate carbon ratio should approach one.

At circumneutral $\mathrm{pH}(\sim 7)$ the dominant dissolution reaction is

$$
\mathrm{CaCO}_{3}+\mathrm{H}^{+} \leftrightarrow \mathrm{HCO}_{3}^{-}+\mathrm{Ca}^{2+}
$$

where two milliequivalents of $\mathrm{Ca}$ are dissolved and one milliequivalent of $\mathrm{HCO}_{3}{ }^{-}$is produced. Under these conditions, and if there are no other sources or sinks for $\mathrm{Ca}$ or carbonate, the $\mathrm{Ca}$ to carbonate carbon ratio should approach 0.5 .

The equilibrium distribution of carbonate species is commonly represented as:

$$
\begin{array}{ll}
\mathrm{CO}_{2(\mathrm{~g})}+\mathrm{H}_{2} \mathrm{O} \leftrightarrow \mathrm{H}_{2} \mathrm{CO}_{3} & \mathrm{pK}=1.32 @ 15^{\circ} \mathrm{C} \\
\mathrm{H}_{2} \mathrm{CO}_{3} \leftrightarrow \mathrm{H}^{+}+\mathrm{HCO}_{3}^{-} & \mathrm{pK}=6.42 @ 15^{\circ} \mathrm{C} \\
\mathrm{HCO}_{3}^{-} \leftrightarrow \mathrm{H}^{+}+\mathrm{CO}_{3}{ }^{2-} & \mathrm{pK}=10.43 @ 15^{\circ} \mathrm{C}
\end{array}
$$

From $\mathrm{pH}$ data in figures $4-4 \mathrm{a}$ and $4-4 \mathrm{~b}$ and equations $4-3$ to $4-5$, the dominant carbonate species under equilibrium conditions in these two mine-pools are $\mathrm{H}_{2} \mathrm{CO}_{3}$ and $\mathrm{HCO}_{3}{ }^{-}$.

The large early $\mathrm{Ca}$ to carbonate ratios show that mine-waters initially may have $\mathrm{Ca}$ sources other than just calcite, such as gypsum; or that carbonate is lost to other processes, such as gas leakage through fractures. Both mines are below local base level drainage and do not crop out to the surface. They have median $\mathrm{pCO}_{2}$ values of -1.31 and -1.45 for the Hahn and Arden Westland pools, respectively. The $\mathrm{pCO}_{2}$ values are more 
than 100 times atmospheric conditions and would create a strong gradient for gaseous diffusion. No direct evidience was found for $\mathrm{CO}_{2}$ gas leakage from either mine.

As the mine-pools age, the $\mathrm{Ca}$ to carbonate ratios approaches 0.5 in the Hahn mine-pool and one in the Arden-Westland mine-pool. Based on reported $\mathrm{pH}$ of about 6.5 to seven in the aged mine-pools, calcite dissolution with bicarbonate production (equation 4-2) is the dominant reaction. The Ca to carbonate ratio of 0.5 in the mature (after about 1993) Hahn mine-pool corresponds to the expected conditions if calcite controls alkalinity concentration (equation 4-2). The $\mathrm{Ca}$ to carbonate ratio of one in the Arden-Westland mine-pool is about twice the expected amount if alkalinity concentration is controlled by

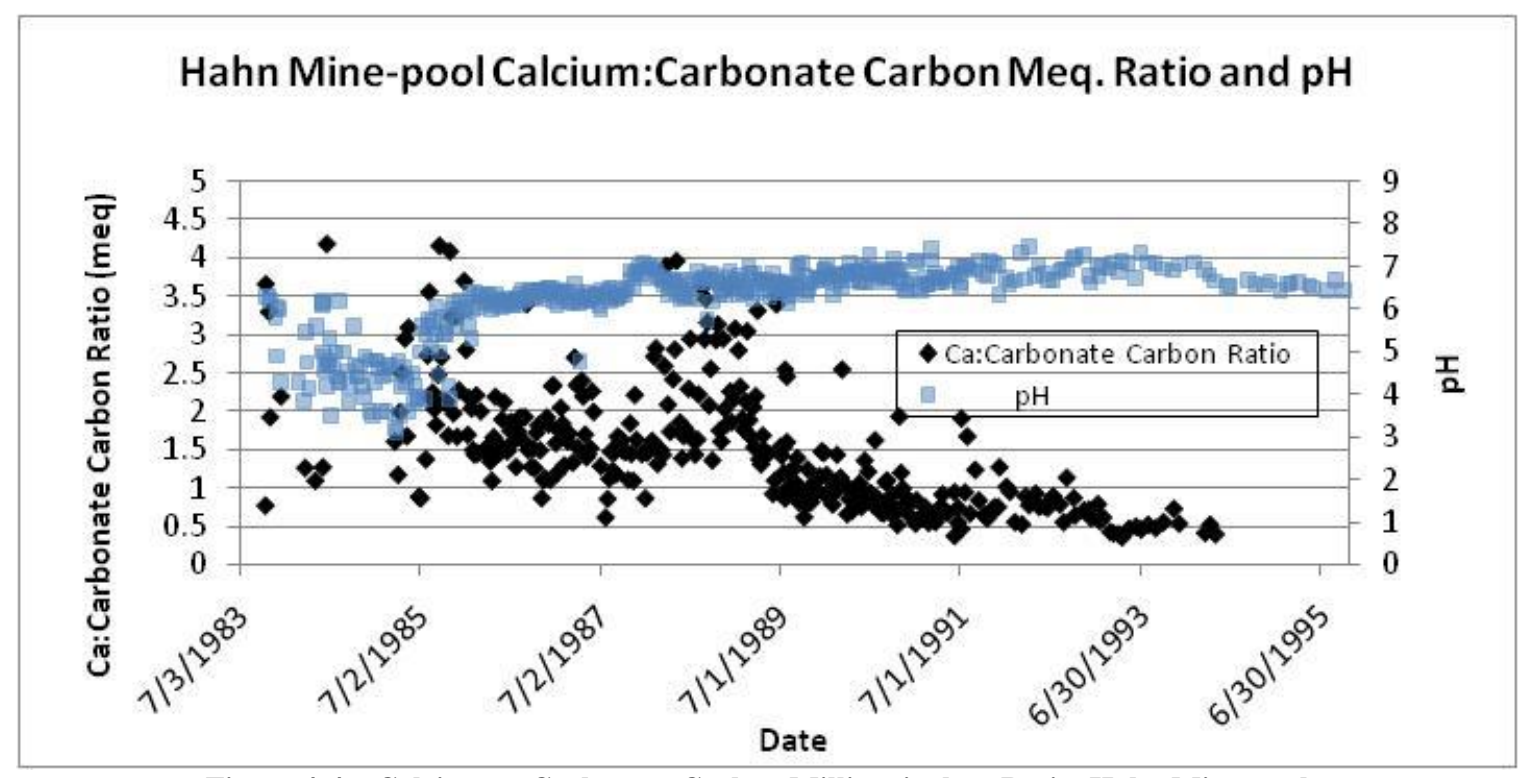

Figure 4-4a. Calcium to Carbonate Carbon Milliequivalent Ratio, Hahn Mine-pool. Carbonate carbon is sum of $\mathrm{H}_{2} \mathrm{CO}_{3}$ and $\mathrm{HCO}_{3}^{-}$.

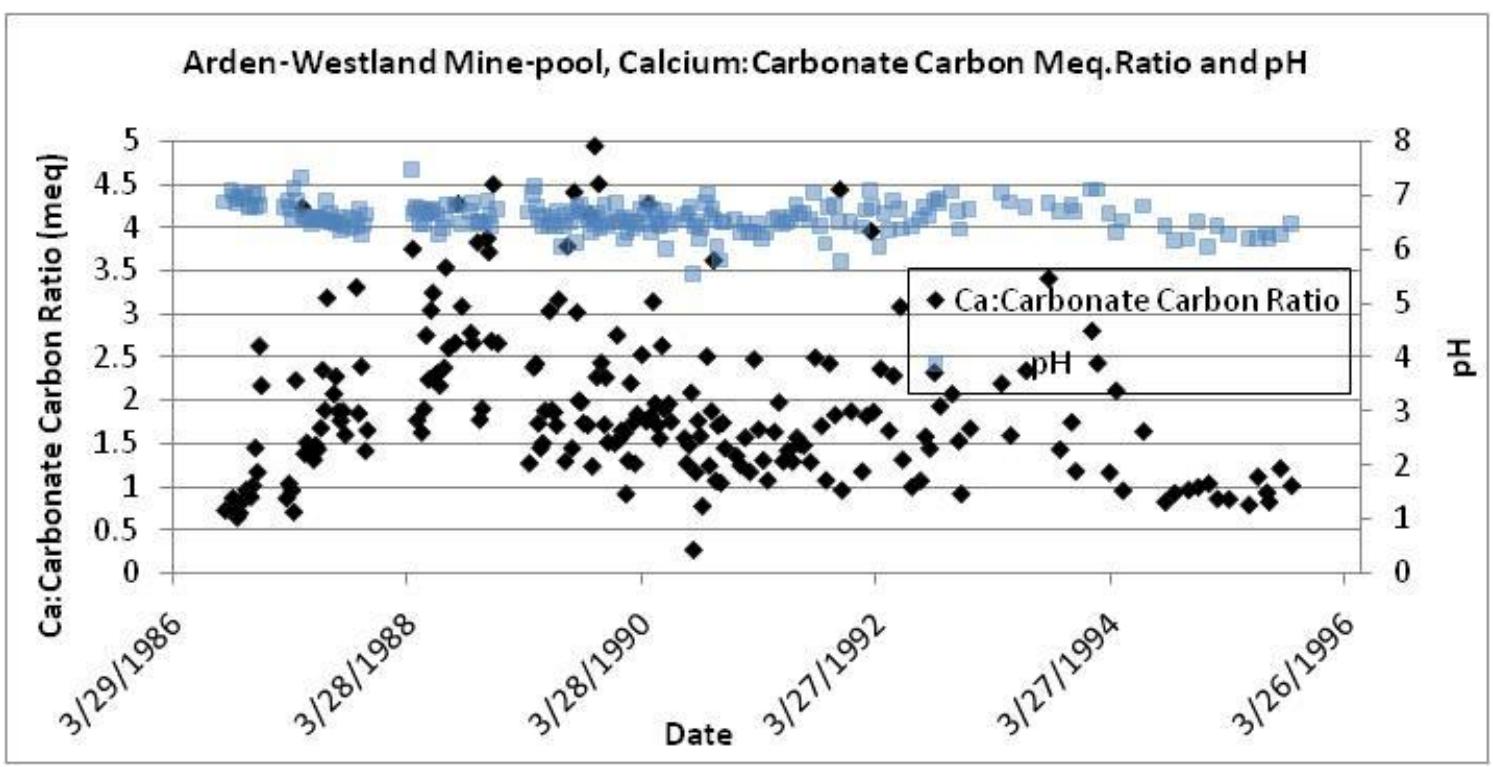

Figure 4-4b. Calcium to Carbonate Carbon Milliequivalent Ratio, Arden-Westland Mine-pool. Carbonate carbon is sum of $\mathrm{H}_{2} \mathrm{CO}_{3}$ and $\mathrm{HCO}_{3}$. 
calcite at circumneutral $\mathrm{pH}$ (equation 4-2). Either carbonate is being lost from the minepool, or $\mathrm{Ca}$ is still being generated from source minerals or processes other than calcite at the end of the monitoring record. Magnesium which can dissolve from dolomite or magnesian calcite, was not included in the calculations.

A large fraction of alkalinity concentration in mine-pools with calcareous rocks may be explained by $\mathrm{Ca}$ concentrations and calcite dissolution in the aging mine-pools. Mugunthan et al. (2004) developed a geochemical model of water quality in the Uniontown mine-pool. Their model included significant dissolution of calcite in fractured and caved overburden as the most satisfactory explanation of the observed $\mathrm{Ca}$ and alkalinity concentrations. Conceptual models of mine-pool composition should account for sources and sinks of $\mathrm{Ca}$, other elements, and alkalinity.

Each flooded circumneutral mine-pool contains dissolved sulfate as a residual of pyrite weathering. The initial weathering of pyrite produces two moles $\mathrm{H}^{+}$as reduced $\mathrm{S}$ is oxidized to S(VI) as shown:

$$
\mathrm{FeS}_{2}+7 / 2 \mathrm{O}_{2}+\mathrm{H}_{2} \mathrm{O} \rightarrow \mathrm{Fe}^{2+}+2 \mathrm{SO}_{4}{ }^{2-}+2 \mathrm{H}^{+}
$$

A water like the Fairmont pool siphon in table 4-3 containing $3237 \mathrm{mg} / \mathrm{L}$ sulfate, represents over 67 mmoles of $\mathrm{H}^{+}$produced and consumed in-situ, or the equivalent of $3350 \mathrm{mg} / \mathrm{L}$ total acidity, based on equation 4-6. Conceptual models of flooded circumneutral mine-pools must account for large amounts of in-situ consumption of $\mathrm{H}^{+}$.

\subsubsection{Cation Exchange, Sodium for Calcium and Magnesium}

The Barnes\&Tucker mine-pool, also called the Lancashire 15 mine-pool (Appendix D) is enriched in sodium and depleted in calcium and magnesium in the end of the flow-path. Table 4-7 shows typical composition of the end of flow-path (main discharge) water and source waters that recharge the mine-pool. The source waters include ground water from unmined strata, leakage from the overlying Lower Freeport mine-pool, and drainage from adjacent unflooded and flooded Lower Kittanning mine-works. The end of flow-path water has greater $\mathrm{Na}$ concentration than any of the source waters. Calcium and $\mathrm{Mg}$ concentrations are less than all the source waters except ground-water from unmined aquifers. These data are consistent with exchange of adsorbed $\mathrm{Na}$ with solution $\mathrm{Ca}$ and $\mathrm{Mg}$. The presence of small amounts of exchangeable sodium along a lengthy flow-path would be sufficient to produce a Na-SO $\mathrm{SO}_{4}$ solution. Cation exchange of adsorbed sodium for dissolved calcium and magnesium is a feasible explanation for the observed behavior, and has been postulated in ground-water flow systems. Back (1966) in a study of water quality evolution in Atlantic Coastal Plain aquifers, observed increasing dominance of sodium over calcium and magnesium the further ground-water moved along its flowpath. Stoner et al. (1987) suggested cation exchange occurred in ground-water in Greene County, PA. Ground-water moving from recharge areas on ridge tops and hill slopes became enriched in $\mathrm{Na}$ as it moved to discharge areas in valley bottoms and foot slopes. Appelo et al. (1998), reported studies of pyrite oxidation and calcite weathering in a sandy aquifer, where they noted cation exchange of $\mathrm{Ca}$ and $\mathrm{Na}$, and $\mathrm{H}^{+}$as well. Capo et al. (2001) and Coulson et al. (1999) identified cation exchange as a probable mechanism explaining evolution and chemical composition of mine waters in flooded underground works in the Pittsburgh coal bed. 
Table 4-7

Composition of Source and End of Flow-path Waters Showing ${ }^{(1)}$

Sodium Enrichment and Calcium and Magnesium Depletion, Barnes\&Tucker Mine-pool

\begin{tabular}{ccccccccc}
\hline $\begin{array}{c}\text { Source } \\
\text { Water }\end{array}$ & $\mathrm{pH}$ & Alkalinity & $\mathrm{Fe}$ & $\mathrm{Al}$ & $\mathrm{Ca}$ & $\mathrm{Mg}$ & $\mathrm{Na}$ & $\mathrm{SO}_{4}$ \\
\hline $\begin{array}{c}\text { Flooded } \\
\text { L.K }\end{array}$ & 6.4 & 63 & 62 & 0.1 & 96 & 30 & 70 & 417 \\
$\begin{array}{c}\text { Unflooded } \\
\text { L.K. }\end{array}$ & 2.8 & 0 & 113 & 44 & 85 & 34 & 35 & 767 \\
$\begin{array}{c}\text { Lower } \\
\text { Freeport } \\
\text { Ground- } \\
\text { water }\end{array}$ & 6.3 & 124 & 0.3 & 0.2 & 75 & 19 & 11 & 157 \\
$\begin{array}{c}\text { Main } \\
\text { Discharge }\end{array}$ & 6.0 & 142 & 0.3 & 0.1 & 43 & 6 & 2 & 27 \\
\hline
\end{tabular}

(1) $\mathrm{pH}$ in S.U., alkalinity and acidity in $\mathrm{mg} / \mathrm{L} \mathrm{CaCO}_{3}$ Eq.; all others in $\mathrm{mg} / \mathrm{L}$.

(2) L.K. = Lower Kittanning coal bed.

(3) Recharge ground-water from unmined area strata. Data from McElroy, 1998.

\subsubsection{Sulfate Complexes}

The speciation of elements in flooded mine-pools and the solid phase aquifer matrix partly controls the quantity of those elements in solution. The sulfate ion can form aqueous complexes with various cations, and these complexes can comprise a significant percentage of the total cation element in solution. Mine-pools in this study contain substantial concentrations of sulfate, $\mathrm{Fe}$ and other major and minor elements. Five flooded mine-pool waters encompassing a range of $\mathrm{Fe}$, sulfate and $\mathrm{Ca}$ concentrations were speciated in PHREEQCI and the amounts of soluble complexes were tabulated. Composition of the waters is shown in table 4-8 and the distribution of sulfate, $\mathrm{Fe}$ and $\mathrm{Ca}$ is shown in figures 4-5 to 4-7. The five mine-pools are as previously described in this chapter and samples are from the principal discharge point. No pe (Eh) measurements were available for the Hahn mine-pool. As described in section 5.2.3, pe for the Hahn samples was assigned a value of zero. This represents an estimated upper bound of redox conditions that allows soluble $\mathrm{Fe}$ in the concentrations observed, if Fe solubility is controlled by $\mathrm{Fe}(\mathrm{OH})_{3}$ minerals. The early sample for the Hahn mine-pool was taken as initial flooding was near completion, and the late sample after the mine-pool reached circumneutral $\mathrm{pH}$.

Figure 4-5 shows distribution of the most abundant S(VI) species, expressed as a percentage of total $\mathrm{S}(\mathrm{VI})$ present. Uncomplexed sulfate ion is the most abundant species present in each mine water, comprising from 68 to $90 \%$ of the total. Lesser but significant percentages of sulfate are complexed with $\mathrm{Ca}, \mathrm{Fe}, \mathrm{Mg}$ and $\mathrm{Na}$. Figure 4-6 shows the distribution of the three most abundant $\mathrm{Ca}$ species. Uncomplexed calcium comprises 55 to $83 \%$ of the total $\mathrm{Ca}$. However, $\mathrm{CaSO}_{4}{ }^{0}$ is 15 to $44 \%$ of total $\mathrm{Ca}$. The abundance of this complex permits greater amounts of solid phase minerals containing $\mathrm{Ca}$ or sulfate, such as gypsum, to dissolve. Figure 4-7 shows distribution of the most abundant Fe(II) species. Uncomplexed $\mathrm{Fe}^{2+}$ comprises 50 to $72 \%$ of total $\mathrm{Fe}(\mathrm{II})$. Like calcium, a significant 
fraction of $\mathrm{Fe}$ (II) complexes with sulfate. Ten to $38 \%$ of total $\mathrm{Fe}(\mathrm{II})$ is in the complex $\mathrm{FeSO}_{4}{ }^{0}$, which enhances dissolution of minerals containing $\mathrm{Fe}^{2+}$ or sulfate. The abundance of cation-sulfate complexes enhances dissolution of minerals containing the corresponding elements, and allows larger concentrations to remain dissolved in these mine-pools.

Table 4-8

Chemical Composition of Five Mine-pools Speciated in PHREEQCI

\begin{tabular}{ccccccccccc}
\hline $\begin{array}{c}\text { Mine-pool } \\
(\text { Sample } \\
\text { Date) }\end{array}$ & $\mathrm{pe}$ & $\mathrm{pH}$ & Alkalinity & $\mathrm{Fe}$ & $\mathrm{Al}$ & $\mathrm{Ca}$ & $\mathrm{Mg}$ & $\mathrm{Na}$ & $\mathrm{SO}_{4}$ & $\mathrm{Cl}$ \\
\hline $\begin{array}{c}\text { Uniontown } \\
(8 / 05) \\
\begin{array}{c}\text { Barnes\& } \\
\text { Tucker } \\
(8 / 05)\end{array}\end{array}$ & 3.75 & 6.19 & 220 & 50.4 & 0.02 & 175 & 65.3 & 87.8 & 700 & 25 \\
$\begin{array}{c}\text { Fairmont } \\
(7 / 04)\end{array}$ & 0.26 & 7.10 & 561 & 70.4 & 0.05 & 208 & 81 & 1060 & 2850 & 123 \\
$\begin{array}{c}\text { Hahn } \\
\text { Early } \\
(7 / 84)\end{array}$ & 0 & 4.7 & $<1$ & 1008 & 24.3 & 367 & 210 & 2220 & 6650 & 693 \\
$\begin{array}{c}\text { Hahn Late } \\
(6 / 95)\end{array}$ & 0 & 6.52 & 386 & 88 & 0.21 & 150 & 50 & 770 & 1350 & 310 \\
\hline
\end{tabular}

(1) $\mathrm{pH}$ in S.U., alkalinity in $\mathrm{mg} / \mathrm{L} \mathrm{CaCO}_{3}$ Eq.; all others in $\mathrm{mg} / \mathrm{L}$.

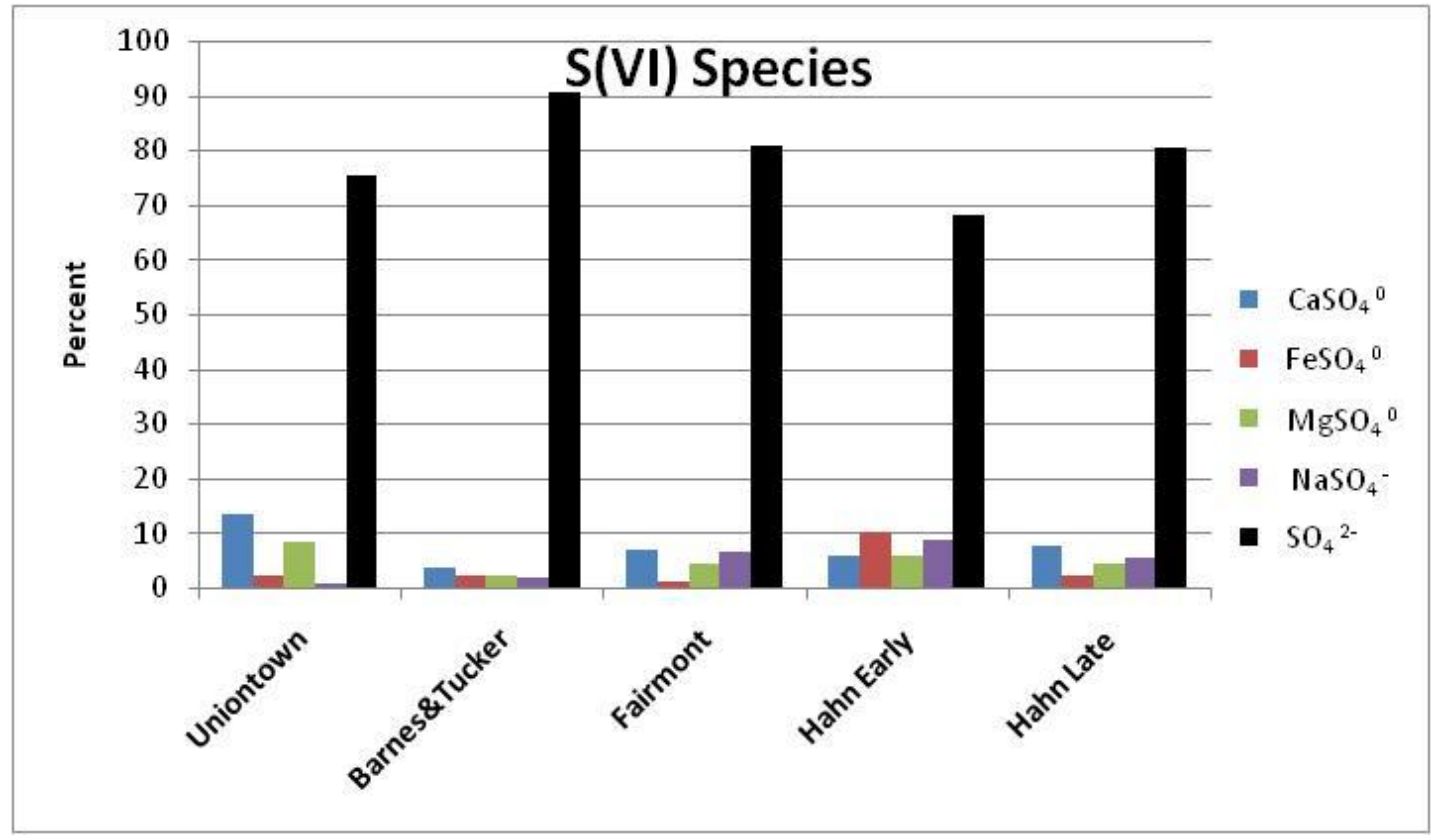

Figure 4-5. Distribution of Most Abundant S(VI) Species in Five Flooded Mine-pools. 


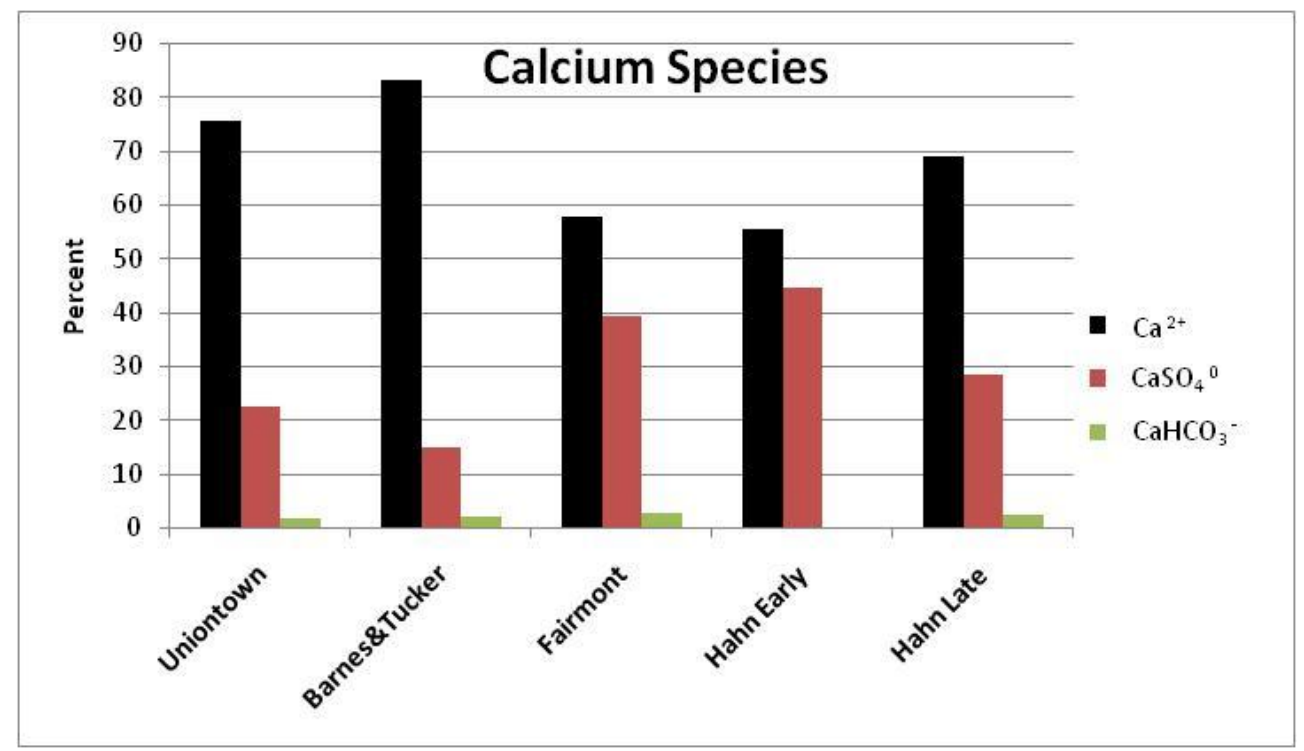

Figure 4-6. Distribution of Most Abundant Calcium Species in Five Flooded Mine-pools.

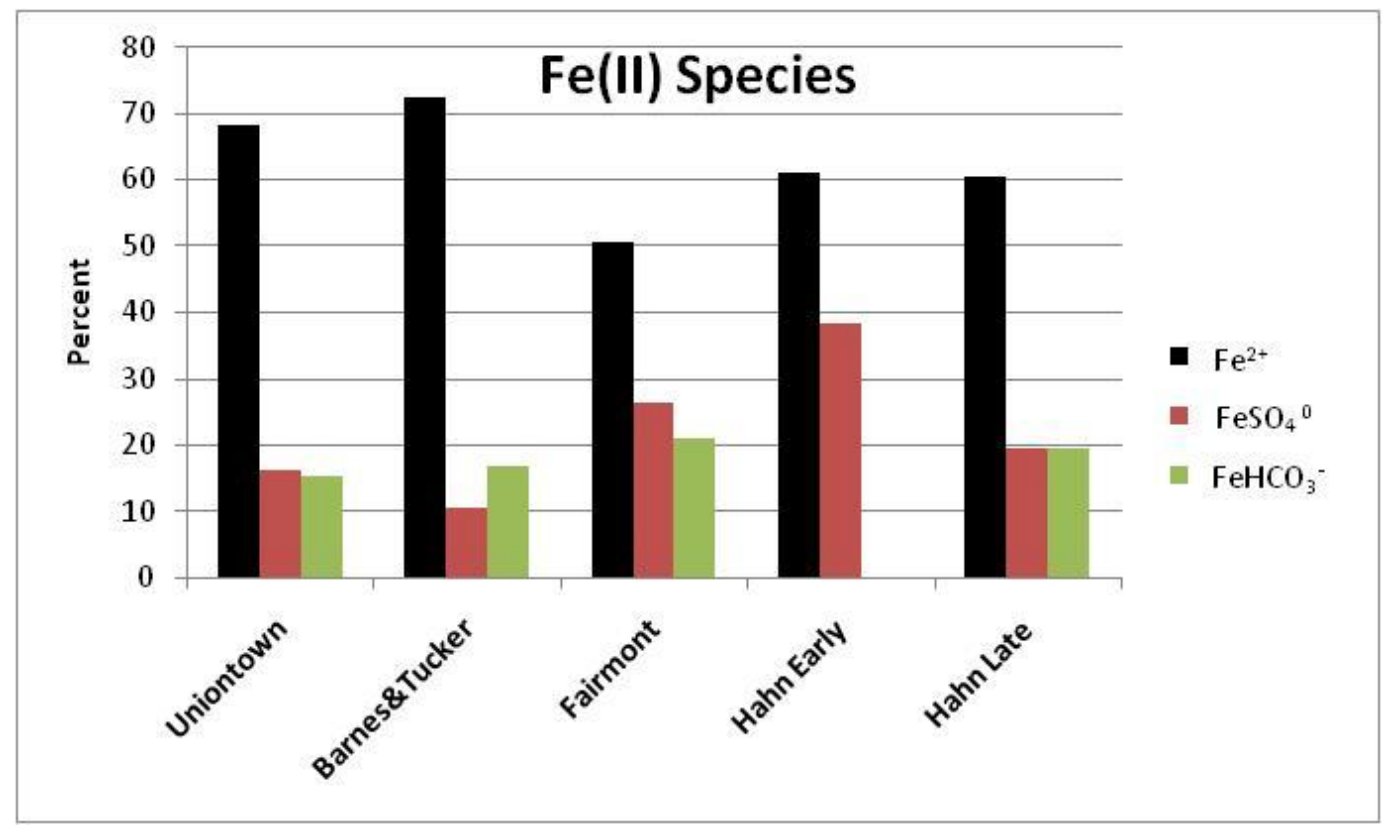

Figure 4-7. Distribution of Most Abundant Fe(II) Species in Five Flooded Mine-pools.

\subsubsection{Mineral Solubility Controls}

Minerals including oxyhydroxides, sulfates, hydroxysulfates, and carbonates can control the composition of mine waters (Nordstrom, 1982a; Rose and Cravotta, 1998). Mineral saturation indices were calculated in PHREEQCI. Selected mineral saturation indices for the five mine-pool waters (table 4-8) are summarized in table 4-9, where positive indices represent super-saturation; negative values signify under-saturation and zero values symbolize equilibrium between the mineral and the mine water. Mineral solubility controls are inferred from the saturation indices. Collection of sediments for mineral verification was not possible because the mines are closed and flooded. The Fairmont 
mine-pool is slightly over-saturated for calcite and at apparent equilibrium for dolomite. Carbonate equilibrium seems to control $\mathrm{Ca}, \mathrm{Mg}$ and alkalinity in this mine-pool.

Table 4-9

Mineral Saturation Indices and $\log \mathrm{pCO}_{2}$ for Five Flooded Mine-pools

\begin{tabular}{|c|c|c|c|c|c|c|c|c|}
\hline $\begin{array}{c}\text { Mine-pool } \\
\text { (Sample } \\
\text { Date) }\end{array}$ & $\begin{array}{l}\text { Calcite } \\
\mathrm{CaCO}_{3}\end{array}$ & $\begin{array}{c}\text { Dolomite } \\
\mathrm{CaMg}\left(\mathrm{CO}_{3}\right)_{2}\end{array}$ & $\begin{array}{l}\text { Siderite } \\
\mathrm{FeCO}_{3}\end{array}$ & $\mathrm{Fe}(\mathrm{OH})_{3}$ & $\mathrm{Fe}_{3}(\mathrm{OH})_{8}$ & $\begin{array}{l}\text { Goethite } \\
\text { FeOOH }\end{array}$ & $\begin{array}{c}\text { Gypsum } \\
\mathrm{CaSO}_{4} * 2 \\
\mathrm{H}_{2} \mathrm{O}\end{array}$ & $\begin{array}{l}\log \\
\mathrm{pCO}_{2}\end{array}$ \\
\hline $\begin{array}{c}\text { Uniontown } \\
(8 / 05)\end{array}$ & -1.00 & -2.22 & 0.65 & 0.67 & -0.18 & 6.18 & -0.67 & -0.88 \\
\hline \multicolumn{9}{|l|}{ Barnes\& } \\
\hline $\begin{array}{l}\text { Tucker } \\
(8 / 05)\end{array}$ & -1.60 & -3.43 & 0.65 & 0.30 & -0.65 & 5.79 & -1.70 & -1.13 \\
\hline $\begin{array}{c}\text { Fairmont } \\
(7 / 04)\end{array}$ & 0.10 & 0.00 & 1.80 & -0.74 & -1.32 & 4.74 & -0.34 & -1.42 \\
\hline Hahn & & & & & & & & \\
\hline $\begin{array}{l}\text { Early } \\
(7 / 84)\end{array}$ & -4.66 & -9.36 & -1.95 & -6.53 & -16.56 & -1.04 & -0.03 & -1.52 \\
\hline $\begin{array}{c}\text { Hahn Late } \\
(6 / 95)\end{array}$ & -0.64 & -1.56 & 1.29 & -1.99 & -4.76 & 3.49 & -0.63 & -0.99 \\
\hline
\end{tabular}

Donovan et al. (2003) discussed mineral saturation indices in the Hahn mine-pool. They describe an early phase after flooding was complete where mine-pool waters were near equilibrium for calcite and gypsum and concluded that gypsum was likely controlling $\mathrm{Ca}$ and sulfate concentrations. As the mine-pool aged, concentrations declined and the waters became under-saturated for both calcite and gypsum. The gypsum index of -0.03 for the early Hahn sample and -0.63 for the late Hahn sample in table 4-9 is consistent with Donovan et al.'s findings.

The Uniontown and Barnes and Tucker mine-pools have aged past the initial flushing and are under-saturated for calcite, dolomite and gypsum. No data were found for early flushing of these mine-pools (circa 1960-1970) to calculate saturation state for those minerals. $\log \mathrm{pCO}_{2}$, calculated from $\mathrm{pH}$ and alkalinity relationships is as much as 400 times atmospheric levels. The high $\mathrm{pCO}_{2}$ values suggest the mine-pools do not readily exchange gases with the above-ground atmosphere, and that there are gases likely causing active chemical weathering of rock within the mines. On several sampling events at the Fairmont mine-pool, the author observed that sample waters would begin to visibly exsolve gas if allowed to stand open to the surface atmosphere for more than a few minutes. Sample collection was conducted so as to minimize aeration and gas exchange.

Four of five mine waters are over-saturated for siderite, suggesting this mineral should be forming. However, no visual indications of solid phase siderite were found in any samples or filtered materials. The formation of siderite is usually described as a microbially mediated process involving reduction of Fe oxide minerals and precipitation as a carbonate (Ehrlich, 2002, Roh et al., 2003). Conditions favoring siderite formation include low sulfide and sulfate concentration, low $\mathrm{Eh}$, high $\mathrm{Fe}$ to $\mathrm{Ca}$ ratio, and abundant carbonate. In mine-pools, the Fe source is likely to be sulfide mineral oxidation, not $\mathrm{Fe}$ 
oxide reduction, and the mine-pools contain high sulfate concentrations. Both conditions differ from the formation model described.

Siderite composition is influenced by depositional environment. Siderite formed in freshwater environments is relatively pure, while marine based siderite has extensive substitution of $\mathrm{Mg}$ and $\mathrm{Ca}$ for Fe (Mozley, 1989). The apparent super-saturation for siderite, deviation from the depositional model and equilibrium or near equilibrium conditions for dolomite and calcite suggest that siderite does not control Fe or carbonate in these mine-pools.

Table 4-9 includes saturation indices for three Fe oxide minerals of varying solubility including poorly crystalline $\mathrm{Fe}(\mathrm{OH})_{3}, \mathrm{Fe}_{3}(\mathrm{OH})_{8}$ and goethite, $\mathrm{FeOOH}$. Water draining from mines often contains a mix of Fe-oxyhydroxide minerals (Karathanasis and Thompson, 1995; McCarty et al., 1998; Bowell and Bruce, 1995; Kaires et al. 2005). The solubility of $\mathrm{Fe}$ oxyhydroxide minerals spans over 6 orders of magnitude (Langmuir, 1997). Thus it becomes difficult to determine which Fe mineral, if any, is controlling soluble iron. Four of the five mine waters are orders of magnitude over-saturated for goethite, and so it is unlikely that it controls soluble Fe. Langmuir (1997), notes that minerals that are greatly over-saturated are unlikely controls for the component elements, due to slow kinetics or other barriers. Every water is under-saturated for $\mathrm{Fe}_{3}(\mathrm{OH})_{8}$, and this mineral is unlikely to control soluble Fe. The two oldest mine-pools, Uniontown and Barnes and Tucker, are over-saturated for the poorly crystalline $\mathrm{Fe}(\mathrm{OH})_{3}$, but the other three waters are under-saturated. Examining saturation indices for the three different $\mathrm{Fe}$ hydroxide minerals does not give clear indication of which mineral(s) might be controlling Fe activity in the flooded mine-pools.

Langmuir and Whittemore (1971) provided an extensive review of stability of $\mathrm{Fe}$ oxyhydroxides including particle size and concentration effects. They observed that the greater the degree of over-saturation for crystalline phases, the faster precipitates formed, and these materials were more soluble. The conditions described are similar to circumneutral mine-pools in table 4-9, where high soluble Fe concentration leads to significant over-saturation for goethite. Langmuir and Whittemore also suggest that dissolution reactions for various Fe oxyhydroxides including goethite, hematite, $\mathrm{Fe}(\mathrm{OH})_{3}$ and others could be rewritten in a common form based on $\mathrm{Fe}^{3+}$ and $\mathrm{OH}^{-}$activities, and thermodynamic (equilibrium) stability expressed as:

$$
\begin{gathered}
\mathrm{Fe}^{3+}+3 \mathrm{OH}^{-} \leftrightarrow \mathrm{Fe}(\mathrm{OH})_{3} \\
-\mathrm{pQ}=-\log \left[\left(\mathrm{Fe}^{3+}\right)\left(\mathrm{OH}^{-}\right)^{3}\right]
\end{gathered}
$$

Langmuir and Whittemore (1971) report that the activity product -pQ for different Fe oxyhydroxide minerals ranges from about 37.3 to 43.3 for amorphous $\mathrm{Fe}(\mathrm{OH})_{3}$ to hematite. The -pQ relationship makes it possible to compute an apparent stability for water containing a mixture of Fe oxyhydroxide minerals, that is, which Fe oxyhydroxide mineral could precipitate from the mine water. Three of the five mine waters had field measured Eh (pe) and $\mathrm{pH}$ data. The distribution of $\mathrm{Fe}(\mathrm{II})$ and $\mathrm{Fe}(\mathrm{III})$ species was calculated in PHREEQCI assuming redox equilibrium among Fe species. The log activities of uncomplexed $\mathrm{Fe}^{3+}$ and $\mathrm{OH}^{-}$were substituted into equation $4-6 \mathrm{~b}$ and the 
expression was solved for $-\mathrm{pQ}$. The pe for the Hahn mine waters was estimated based on solubility of poorly crystalline $\mathrm{Fe}(\mathrm{OH})_{3}$ and reported $\mathrm{Fe}$ concentrations. Several runs of

Table 4-10

$\mathrm{Fe}(\mathrm{OH})_{3}$ Activity Product

\begin{tabular}{cccc}
\hline $\begin{array}{c}\text { Mine-pool } \\
\text { (Sample } \\
\text { Date) }\end{array}$ & -pQ & $\begin{array}{c}\log \mathrm{Fe}^{3+} \\
\text { Activity }\end{array}$ & $\begin{array}{c}\text { log } \mathrm{OH}- \\
\text { Activity }\end{array}$ \\
\hline $\begin{array}{c}\text { Uniontown } \\
(8 / 05)\end{array}$ & 37.5 & -13.00 & -8.16 \\
$\begin{array}{c}\text { Barnes\& } \\
\text { Tucker } \\
(8 / 05)\end{array}$ & 38.0 & -13.96 & -7.99 \\
$\begin{array}{c}\text { Fairmont } \\
(7 / 04)\end{array}$ & 39.0 & -17.15 & -7.28 \\
$\begin{array}{l}\text { Hahn } \\
\text { Early }\end{array}$ & 44.8 & -15.73 & -9.68 \\
$\quad(7 / 84)$ & & & \\
Hahn Late \\
$(6 / 95)$
\end{tabular}

PHREEQCI were conducted varying the system pe until the waters were able to contain the reported $\mathrm{Fe}$ concentrations without super-saturation. A pe of 0 was assigned to the Hahn mine waters for further calculations, and $\mathrm{Fe}^{2+}$ and $\mathrm{Fe}^{3+}$ activities are therefore estimates. The $\mathrm{Fe}(\mathrm{OH})_{3}$ activity products for the three mine waters have measured $-\mathrm{pQ}$ ranging from 37.5 to 39.0 , implying that more soluble forms of $\mathrm{Fe}$ oxyhydroxides are controlling soluble Fe activity (table 410). It is consistent with the observations of Langmuir and Whittemore (1971) that waters highly over-saturated for goethite tended to produce more soluble

precipitates. Ferris et al. (1989), found ferrihydrite (ferric hhydroxide) was the principal Fe oxhydroxide precipitating from coal refuse drainage. Less soluble goethite and hematite were minor components. The two waters from the Hahn mine-pool have activity products suggesting less soluble iron minerals control soluble Fe, but the calculations depend on the estimate of pe, which determines $\mathrm{Fe}^{3+}$ activity. These estimates are considered less reliable than the $-\mathrm{pQ}$ values generated from measured pe.

Figures 4-8a and 4-8b are $\mathrm{Eh} / \mathrm{pH}$ diagrams for $\mathrm{Fe}$ and $\mathrm{Fe}$ bearing minerals for four of the flooded mine-pools included in table 4-9. Log iron, log sulfate, and log bicarbonate activities are fixed at $-3.47,-2.52$ and -2.45 , respectively in both diagrams. These values represent conditions in the Uniontown mine-pool water and are similar to chemical activities in the three other samples. In figure $4-8 \mathrm{a}, \mathrm{Fe}(\mathrm{OH})_{3}$ is assumed to control $\mathrm{Fe}$ activity. The Fe minerals siderite and goethite are not included on the plot since it is considered less likely that they control soluble Fe. Consistent with the saturation indices in table 4-9, the Uniontown and Barnes\&Tucker waters plot within the stability field for $\mathrm{Fe}(\mathrm{OH})_{3}$, while the Fairmont mine-pool water is slightly under-saturated. The Hahn mine-pool water is based on estimated pe, so its location on the Eh-axis of the plot is less certain. The plots were generated in Geochemist Workbench, version 6.

The boundaries in figure 4-8a are drawn based on chemical activities for the Uniontown mine-pool water. Plot boundaries for the other three waters differ slightly from that shown in Figure 4-8a, based on the chemical activities for each water. However, the four waters are similar so that the errors introduced by plotting all samples on one graph are small. For example, the calculated log ferrous iron activities for the four waters ranged from -3.37 to -3.62 , and log bicarbonate activities ranged from -2.23 to-2.50. 
Flooded Mine-pools Eh-pH Plot

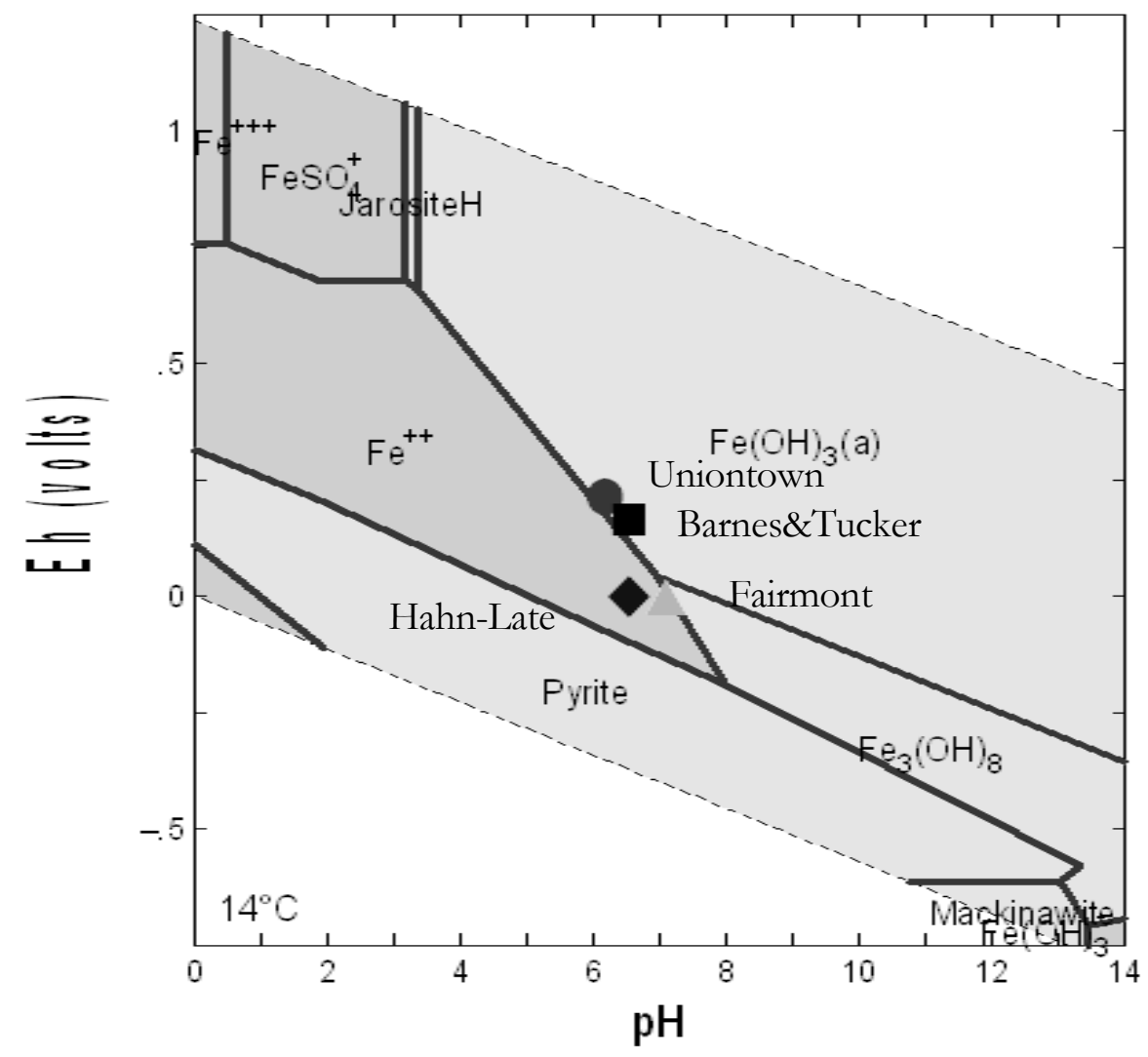

Figure 4-8a. Eh/pH diagram for Iron in Four Flooded Mine-pools. $\mathrm{Fe}(\mathrm{OH})_{3}(\mathrm{am})$ specified as controlling mineral. Diagram based on $\log \mathrm{Fe}^{2+}$ molar activity = -3.47 (total $\left.\mathrm{Fe}(\mathrm{II})=8.95 \times 10^{-4} \mathrm{~mole} / \mathrm{L}\right)$, log sulfate molar activity = $-2.522\left(\right.$ total sulfate $=7.29 \times 10^{-3}$ mole $\left./ \mathrm{L}\right), \log \mathrm{HCO}_{3}{ }^{-}$molar activity $=-2.45\left(\right.$ total $\left.\mathrm{HCO}_{3}{ }^{-}=4.11 \times 10^{-3} \mathrm{~mole} / \mathrm{L}\right)$. See table 4-9 for mineral saturation indices.

The plotting of mine waters at or near apparent equilibrium for $\mathrm{Fe}(\mathrm{OH})_{3}$ has also been noted by Gang and Langmuir (1974) in streams and ground-waters in the bituminous coal region of Pennsylvania, USA. An examination of $\mathrm{Fe}, \mathrm{pH}$, Eh and other chemical data reported from Ladwig et al. (1984) suggests that the anthracite mine-pools they studied were also near apparent equilibrium for poorly crystalline $\mathrm{Fe}(\mathrm{OH})_{3}$.

Figure $4-8 \mathrm{~b}$ does include the stability field for the iron carbonate siderite. The Fairmont and Hahn mine-pools plot within the siderite field and the Uniontown and Barnes\&Tucker mine-pools are near the boundary between siderite and $\mathrm{Fe}(\mathrm{OH})_{3}$, indicating siderite formation is thermodynamically possible in these mine-pools. However, no visual evidence of siderite precipitation was found in any sediment filtered from these mine waters, and little indication of siderite formation from mine water was found in the surveyed literature. 
Flooded Mine-pools Eh-pH Plot

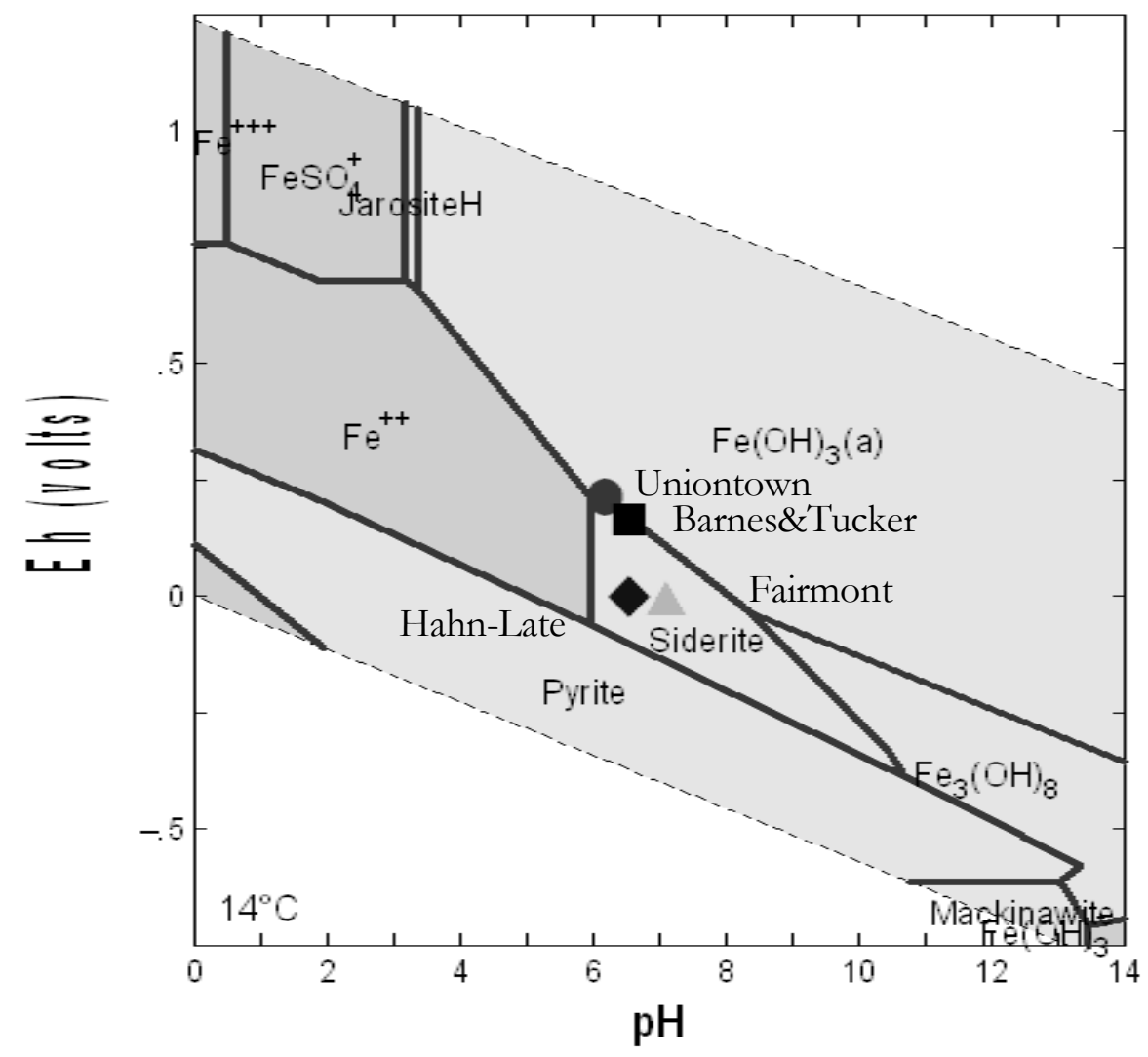

Figure 4-8b. Eh/pH diagram for Iron in Four Flooded Mine-pools. $\mathrm{Fe}(\mathrm{OH})_{3}(\mathrm{am})$ specified as controlling mineral. Diagram based on $\log \mathrm{Fe}^{2+}$ activity $=\mathbf{- 3 . 4 7}\left(\right.$ total $\left.\mathrm{Fe}(\mathrm{II})=8.95 \times 10^{-4} \mathrm{~mole} / \mathrm{L}\right)$, $\log$ sulfate activity $=\mathbf{- 2 . 5 2 2}($ total sulfate $\left.=7.29 \times 10^{-3} \mathrm{~mole} / \mathrm{L}\right), \log \mathrm{HCO}_{3}^{-}$activity $=-2.45\left(\right.$ total $\left.\mathrm{HCO}_{3}^{-}=4.11 \times 10^{-3} \mathrm{~mole} / \mathrm{L}\right)$. See table 4-9 for mineral saturation indices.

The distribution of total dissolved Fe(II) and Fe(III) used to construct figures 4-8a and $4-8 b$ was calculated from Eh (pe) measurements and the half reaction:

$$
\mathrm{Fe}^{2+} \leftrightarrow \mathrm{Fe}^{3+}+\mathrm{e}^{-} \quad \log \mathrm{K}=-13.02 @ 25^{\circ} \mathrm{C}
$$

The $\mathrm{Fe}(\mathrm{III})$ activities calculated for the four mine-pools from equation 4-7 are 10-7 mole/L or less, and are too small to provide reliable measured Eh based on the $\mathrm{Fe}^{2+} / \mathrm{Fe}^{3+}$ couple (Nordstrom, 2000). Back and Barnes (1965) examined the relationship between Eh and iron content in US Coastal Plain ground-waters. They compared measured Eh to values calculated from couples $\mathrm{Fe}^{3+} / \mathrm{Fe}(\mathrm{OH})_{3}$ and $\mathrm{Fe}^{3+} / \mathrm{Fe}_{2} \mathrm{O}_{3}$. They concluded that measured Eh was associated more closely with $\mathrm{Fe}^{3+} / \mathrm{Fe}(\mathrm{OH})_{3}$, but that $\mathrm{Fe}$ solubility was best described as intermediate between the two minerals. They also noted that at $\mathrm{pH}$ greater than about 5.0, Fe(III) concentration was so small as to be undetectable, and all measured Fe should be regarded as ferrous.

A limited set of Fe(II) samples was collected on several occasions from the Fairmont, Uniontown, and Barnes\&Tucker mine-pools. The purpose was to compare measured Eh 
with Eh calculated from $\mathrm{Fe}(\mathrm{II}) / \mathrm{Fe}$ (III) distribution in the samples. The author collected samples for $\mathrm{Fe}(\mathrm{II})$ analysis using opaque bottles and $\mathrm{HCl}$ preservative. Each sample was analyzed by complexing with phenanthroline and spectrophotometer measurement. Samples reported back as essentially all Fe(II). Most samples had to be diluted for analysis, and this limited resolution. Therefore, dissolved Fe(II) was equivalent to total dissolved Fe, and Fe(III) could not be reliably estimated from the analyses. For flooded mine-pools with very low concentrations of $\mathrm{Fe}(\mathrm{III}), \mathrm{Fe}(\mathrm{II}) / \mathrm{Fe}(\mathrm{III})$ distribution may have to be estimated from measured $\mathrm{Eh}$, rather than $\mathrm{Fe}$ speciation techniques. Redox dependent solubility relationships for Fe minerals are then based on measured Eh and assumption of equilibrium. The difficulties in reliably measuring small amounts of Fe(III) in flooded mines-pools are similar to the observations of Barnes and Back (1965) and Nordstrom (2000).

Ground-water redox measurements can be difficult to interpret. Lindberg and Runnells (1984) compared measured Eh and Eh values calculated from various redox couples for over 600 waters of diverse compositions. They found large discrepancies between measured and calculated Eh. They concluded that many waters were at internal disequilibrium, because the reaction kinetics of some redox couples were too slow and different redox couples may have different $\mathrm{Eh}$ in the same water. However, the $\mathrm{Fe}^{2+} / \mathrm{Fe}^{3+}$ couple provided the best agreement between and measured and calculated values. Nordstrom et al. (1979), compared measured and calculated Eh in acid oxidized mine waters. The calculated values were derived from the $\mathrm{Fe}^{2+/} \mathrm{Fe}^{3+}$ couple over a range of about +600 to +800 millivolts, and measured and calculated values were usually within about 30 millivolts. A later paper by Nordstrom (2000) was more cautious about the use of Eh. At more reduced conditions, approaching those measured in flooded mine-pools, measured Eh was greater than calculated. The deviation was attributed in part to the decreasing $\mathrm{Fe}^{3+}$ activity, and the difficulty of the electrode detecting small amounts of uncomplexed ferric iron. Nonetheless, used carefully, redox measurements based on $\mathrm{Fe}^{2+} / \mathrm{Fe}^{3+}$ were deemed to have value in characterizing iron rich mine water. Christensen et al. (2000) in a review of redox characterization techniques concluded that the $\mathrm{Fe}^{2+} / \mathrm{Fe}^{3+}$ couple was reversible, and sufficiently rapid to be useful in ground-water studies.

\subsubsection{Sulfate Reduction in Flooded Mine-pools}

Water samples collected from the Barnes\&Tucker, Fairmont and Uniontown mine-pools sometimes had the odor of $\mathrm{H}_{2} \mathrm{~S}$ gas. Field tests for dissolved sulfide using a methylene blue procedure were conducted at each of these mine-pools at least two different times and trace levels corresponding to the detection limit of $0.01 \mathrm{mg} / \mathrm{L}$ or greater were detected each time. A biological activity reaction test (BART) for sulfate reducing bacteria (SRB) was also conducted for each mine-pool. An aqueous sample was collected using sterile techniques and inoculated in a sealed container with media specific for SRB. A strong positive reaction was obtained in each test, indicating the presence of SRB in the three mine-pools. These observations all suggested that sulfate reduction might be taking place in flooded mine-pools.

A classic paper by Baas-Becking et al. (1960) contains a series of plots showing the range of Eh and $\mathrm{pH}$ conditions measured for different reduction/oxidation processes, including microbial sulfate reduction. The compiled sulfate reduction data showed most reported 
measurements between $\mathrm{pH} 6$ to 8.5 and Eh normally between +100 to -300 millivolts. These conditions generally match the flooded mine-pools discussed in this chapter.

Pyrite formation is usually described as a microbially mediated sequence of sulfate reduction, then $\mathrm{Fe}$ monosulfide $(\mathrm{FeS})$ formation, followed by gradual conversion to $\mathrm{FeS}_{2}$ (Schoonen and Barnes, 1991; Morse et al., 1987). Precipitated FeS, mackinawite and gregite are metastable with respect to pyrite (Berner, 1967). Berner (1970), describing the formation of pyrite in marine sediments, noted that metabolizeable organic matter is an important factor controlling pyrite formation. Flooded mine-pools contain large amounts of organic matter in the form of residual coal and other carbonaceous rock, but no data were found that addressed sulfate reduction in these conditions, especially whether these organic compounds are suitable for SRB. Other investigators have noted that sulfate reduction rates are temperature and concentration dependent (Herlihy and Mills, 1985).

Langmuir (1997) presents a redox "ladder" showing the theoretical sequence of reduction in ground-waters. Fe(III) reduction occurs before sulfate reduction, and that sequence has also been described in several large scale aquifer studies (Champ et al., 1979). A paper by Postma and Jakobsen (1996), however argues that Fe(III) and sulfate reduction can occur simultaneously depending on the stability of iron oxide minerals in the aquifer.

After reviewing field conditions and literature, the apparent equilibrium Eh needed to form FeS was calculated for the five mine-pool samples identified in tables 4-7 and 4-8. The reactions are:

$$
\begin{gathered}
\mathrm{FeS}+\mathrm{H}^{+} \leftrightarrow \mathrm{Fe}^{+2}+\mathrm{HS}^{-} \quad \log \mathrm{Keq}=-4.648 \\
\mathrm{H}_{2} \mathrm{~S} \leftrightarrow \mathrm{HS}^{-}+\mathrm{H}^{+} \quad \log \mathrm{Keq}=-6.994 \\
\mathrm{SO}_{4}^{-2}+10 \mathrm{H}^{+}+8 \mathrm{e}^{-} \leftrightarrow \mathrm{H}_{2} \mathrm{~S}+4 \mathrm{H}_{2} \mathrm{O} \quad \log \mathrm{Keq}=40.644
\end{gathered}
$$

with $\log \mathrm{k}$ values from the Wateq database in PHREEQCI. Subtracting equation 4-9 and 4-10 from 4-8 gives:

$$
\mathrm{FeS}+4 \mathrm{H}_{2} \mathrm{O} \leftrightarrow \mathrm{Fe}^{+2}+\mathrm{SO}_{4}^{-2}+8 \mathrm{H}^{+}+8 \mathrm{e}^{-} \log \mathrm{Keq}=-37.565
$$

and

$$
\log \mathrm{Fe}^{+2}+\log \mathrm{SO}_{4}^{-2}+8 \log \mathrm{H}^{+}+8 \log \mathrm{e}^{-}=-37.565
$$

Chemical activities for sulfate, $\mathrm{Fe}^{2+}, \mathrm{pH}$, and computed equilibrium redox conditions are shown in table 4-11. Measured redox values are also shown for the Uniontown, Barnes\&Tucker and Fairmont mine-pools. 
Table 4-11

Equilibrium Redox Conditions for Sulfate Reduction to FeS

\begin{tabular}{|c|c|c|c|c|c|c|}
\hline $\begin{array}{c}\text { Mine-pool } \\
\text { (Sample } \\
\text { Date) }\end{array}$ & $\begin{array}{c}\log \\
\mathrm{SO}_{4}^{-2} \\
\text { Activity }\end{array}$ & $\begin{array}{l}\log \mathrm{Fe}^{2+} \\
\text { Activity }\end{array}$ & $\begin{array}{c}\log \\
\mathrm{H}^{+} \text {Activity }\end{array}$ & $\begin{array}{c}\text { FeS } \\
\text { Formation } \\
\text { Equilibrium } \\
\text { Eh } \\
\text { (millivolts) }\end{array}$ & $\begin{array}{l}\text { Equilibrium } \\
\text { Eh } \\
\text { (millivolts) } \\
0.01 \mathrm{mg} / \mathrm{L} \\
\text { Sulfide }\end{array}$ & $\begin{array}{c}\text { Measured } \\
\text { Eh } \\
\text { (millivolts) }\end{array}$ \\
\hline $\begin{array}{c}\text { Uniontown } \\
(8 / 05)\end{array}$ & -2.52 & -3.477 & -6.13 & -129 & -110 & +214 \\
\hline \multicolumn{7}{|l|}{ Barnes\& } \\
\hline $\begin{array}{l}\text { Tucker } \\
(8 / 05)\end{array}$ & -2.81 & -3.615 & -6.39 & -147 & -125 & +222 \\
\hline $\begin{array}{c}\text { Fairmont } \\
(7 / 04)\end{array}$ & -2.02 & -3.607 & -7.10 & -184 & -169 & -15 \\
\hline Hahn & & & & & & \\
\hline $\begin{array}{l}\text { Early } \\
(7 / 84)\end{array}$ & -1.84 & -2.45 & -4.70 & -32 & - & - \\
\hline $\begin{array}{c}\text { Hahn Late } \\
(6 / 95)\end{array}$ & -2.29 & -3.37 & -6.52 & -150 & - & - \\
\hline
\end{tabular}

The equilibrium redox values for FeS formation are about 169 to 370 millivolts less than measured Eh for three mine-pools. As noted previously, trace levels of dissolved sulfide $(0.01 \mathrm{mg} / \mathrm{L}$ or more $)$ were detected in three mine-pools. The three mine-pools were speciated in PHREEQCI with the solutions including $0.01 \mathrm{mg} / \mathrm{L}$ dissolved sulfide $\left(\mathrm{H}_{2} \mathrm{~S}\right.$ and $\mathrm{HS}^{-}$) assuming equilibrium. The estimated redox conditions for the $\mathrm{S}(\mathrm{VI}) / \mathrm{S}(-\mathrm{II})$ couple (reaction 4-10) are within 15 to 22 millivolts of thermodynamic equilibrium for FeS formation (reaction 4-11). If S(-II) activity is greater than that represented by 0.01 $\mathrm{mg} / \mathrm{L}$ concentration, then computed redox approaches FeS stability more closely. Though direct evidence is lacking, the field measurements and calculations suggest that sulfate reduction and $\mathrm{FeS}$ precipitation are possible in these flooded mine-pools.

The difference between measured Eh and computed Eh for the S(VI)/S(-II) couple are consistent with reported findings of Lindberg and Runnells (1984) that a water may have more than one apparent Eh where different redox couples are present.

\subsubsection{Flux Rate of Iron and Sulfate}

Long term Fe and sulfate flux rates were estimated for three mine-pools with one principal discharge point, reported pumping rates and chemical concentration data. It was hypothesized that flux would be similar among the flooded mines and less than that for the partly flooded mines, as pyrite weathering rates were expected to be less under flooded conditions. The fluxes (mole basis) were normalized to a $\mathrm{m}^{2}$ of mine-works for comparison among each other, and to the two partly flooded mine-pools in chapter three. The mine areas were determined from the plan view extent of mining to provide a consistent basis for comparison. The actual exposed rock surface area is larger and includes roof, floor and pillar surfaces, and surfaces of fractured and disaggregated rocks. A consistent defensible technique for estimating rock surface area from mine map 
information was not developed, due to the uncertainty of estimating the extent of caving or "gob" and particle sizes. Since the flux rates in table 4-12 are based on less than actual surface area, the values are probably overestimated, but do provide a consistent basis for comparison. The Barnes\&Tucker mine-pool flux was estimated from reported yearly average discharge rate and chemical concentration. The Hahn and Arden-Westland minepools had reported long term pumping rates (Donovan et al., 1999; Pennsylvania DEP unpublished records). The Omega and T\&T mine-pool discharge rates were determined from monitoring data obtained from West Virginia DEP. Results are shown in table 4-12.

Table 4-12

Average Long Term Iron and Sulfate Flux from Three Flooded and Two Partly Flooded Mine-pools

\begin{tabular}{|c|c|c|c|c|c|}
\hline Mine-pool & $\begin{array}{l}\text { Flooding } \\
\text { State }\end{array}$ & $\begin{array}{c}\text { Area } \\
\text { (hectares) }\end{array}$ & $\begin{array}{c}\text { Average Q } \\
\text { (L/Min) }\end{array}$ & $\begin{array}{c}\text { Fe Flux } \\
\left(\mathrm{mole} / \mathrm{m}^{2} \mathrm{~s}\right)\end{array}$ & $\begin{array}{c}\text { Sulfate Flux } \\
\left(\mathrm{mole} / \mathrm{m}^{2} \mathrm{~s}\right)\end{array}$ \\
\hline Barnes\&Tucker & Flooded & 5700 & 19,000 & $9.49 \times 10^{-9}$ & $3.48 \times 10^{-8}$ \\
\hline Hahn & Flooded & 5900 & 13,250 & $7.04 \times 10^{-8}$ & $2.69 \times 10^{-7}$ \\
\hline Arden-Westland & Flooded & 5100 & 6600 & $6.2 \times 10^{-9}$ & $3.48 \times 10^{-8}$ \\
\hline Omega & $\begin{array}{l}\text { Partially } \\
\text { Flooded }\end{array}$ & 69 & 268 & $3.42 \times 10^{-8}$ & $1.37 \times 10^{-7}$ \\
\hline $\mathrm{T} \& \mathrm{~T}$ & $\begin{array}{l}\text { Partially } \\
\text { Flooded }\end{array}$ & 588 & 1139 & $7.33 \times 10^{-9}$ & $4.72 \times 10^{-8}$ \\
\hline
\end{tabular}

The flux values range over about an order of magnitude for both $\mathrm{Fe}$ and sulfate. There is no clear distinction in flux rate between flooded and partly flooded mines. Normalized flux rates therefore appear to be a function of flushing and transport. Chemical reaction rate does not seem to be a limiting factor. Pyrite weathering rates are on the order of $10^{-10}$ mole $/ \mathrm{m}^{2} \mathrm{~s}$ (Williamson and Rimstidt, 1994), where area refers to pyrite mineral surface. To sustain the average flux rates in table 4-12, available pyrite surface area would be on the order of about ten to $100 \mathrm{~m}^{2}$ per one $\mathrm{m}^{2}$ of mine-pool. These values may appear large, but are well within the range of surface areas reported for common minerals (Langmuir, 1997). Weathering rates are sometimes reported on the basis of whole rock mass, rather than specific minerals. Sheetz et al. (2009) for example, measured surface areas of 12 to $17 \mathrm{~m}^{2} / \mathrm{g}$ rock, for three shales from Upper Pennsylvanian rocks used in column weathering tests.

Although the flux rates in table 4-12 are not distinguishable on the basis of flooding state, they do provide a range of values to estimate expected loading rates from mine-works of known size.

\subsection{A Conceptual Model of Water Quality in Flooded Mines}

The preceding sections of this chapter identified some fundamental characteristics of flooded mine-pools, which can be used to develop a conceptual model of geochemical processes at work. A robust model should incorporate feasible reactions, appropriate mineral constraints and representative hydrogeologic conditions. A flooded mine-pool model should incorporate the following processes: 
- Shift from initial acid oxidizing to circumneutral reduced conditions

- Consumption of acidity in-situ and production of alkalinity.

- Cation exchange

- Attenuation of iron in-situ

- Sulfate reduction (possible)

Several studies of ground-water and surface water interaction with acid drainage were examined for common factors. Zhu and Burden (2001) stress the importance of aquifer mineralogy in constructing a ground-water reactive transport model for acid tailings. In their study, the distance of acid plume migration was sensitive to the amount of calcite in the aquifer, and Al was at apparent equilibrium with jurbanite. Broshears et al. (1996) modeled the mobility of acid drainage constituents entering a stream. They concluded that $\mathrm{Fe}$ and $\mathrm{Al}$ mobility were probably controlled by oxyhydroxides, and carbonate dissolution buffered $\mathrm{pH}$. Berger et al. (2000) modeled acid drainage discharge from a waste rock pile. The principal mechanisms controlling metals were mixing with nonpolluted streams, limestone dissolution from underlying bedrock, and adsorption onto oxide surfaces. Filipek et al. (1987) also identified mixing and oxyhydroxide precipitation as controls on mine water draining from an abandoned metal mine in California. They also found some waters were at apparent saturation for jurbanite and jarosite. Finally Appelo et al. (1998) identified calcite dissolution and cation exchange as significant processes in an aquifer containing pyrite. Metal control by oxyhydroxides, carbonate dissolution, mixing, and ion exchange are common processes in these studies.

A conceptual model was formulated based on the observed mine-pool properties and hypothesized processes described in the preceding paragraphs. It is illustrated in flow chart fashion in figure 4-9. A model based on Pittsburgh coal bed mine-pools was tested in PHREEQCI and is fully described in Appendix B. It also includes pH dependent sulfate sorption and oxyhydroxides as possible sinks for Fe and Al.

A simple model of the mostly flooded Barnes\&Tucker mine-pool is described in Appendix D. It also includes oxyhydroxide controls on $\mathrm{Fe}$ and cation exchange. It includes a small amount of continuing pyrite oxidation in unflooded sections of the minepool, and mixing of various source waters. Complete results are shown in Appendix D. 


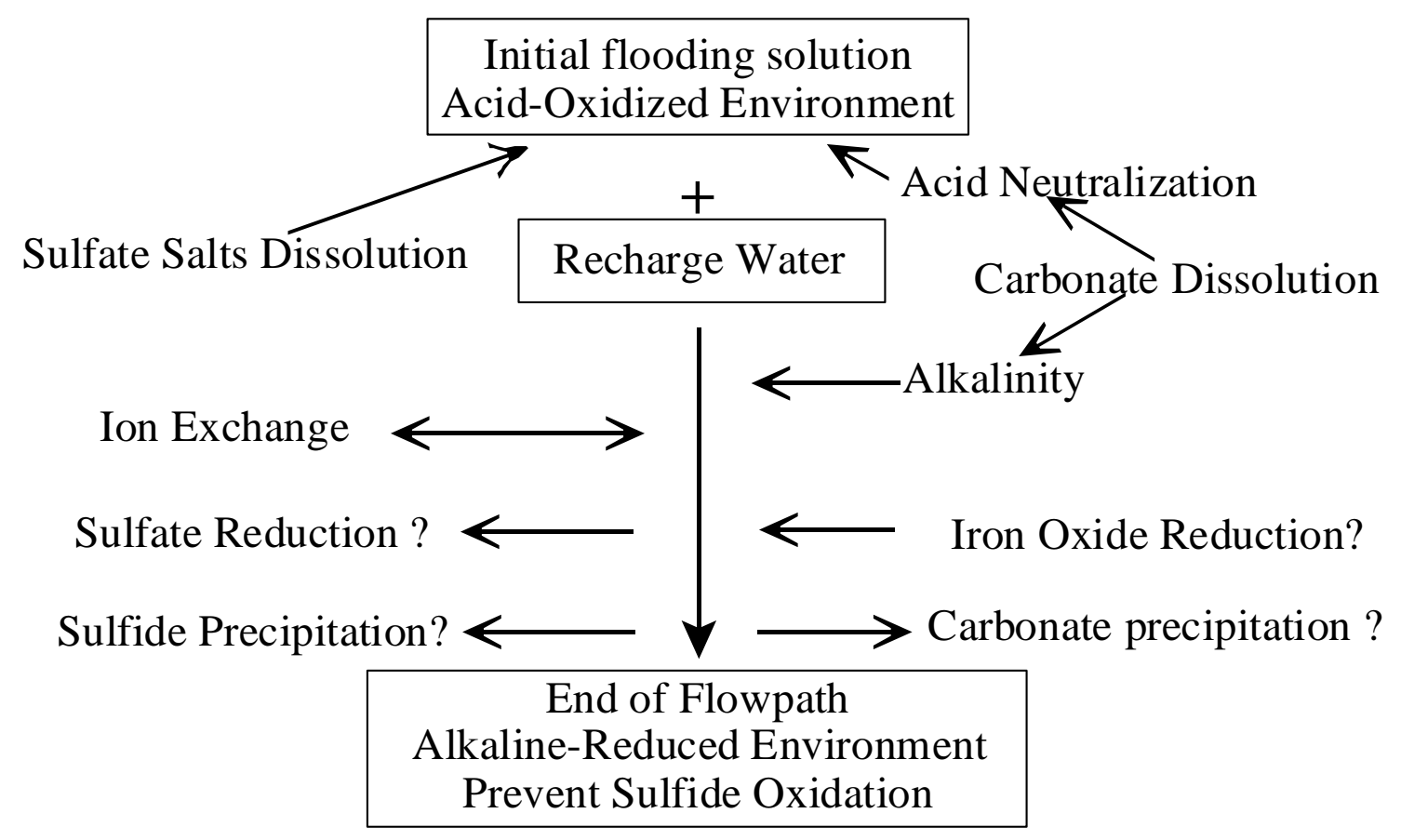

Figure 4-9. Conceptual Model of Geochemical Processes in Flooded Mine-pools.

\subsection{Fluid Storage and Transmissivity in Flooded Mine-pools}

Water storage and transmissivity properties of flooded mine-pools affect the volume and rate of recharge and discharge, and hence chemical flux. Strategies for managing or remediating mine-pools are therefore partly dependent on the quantitative hydrogeologic properties of the mine-pool. A small set of storage and transmissivity data were generated from monitoring wells in the Fairmont and Uniontown mine-pools, based on principles of aquifer response to atmospheric loading, and one aquifer (pump) test. Furbish (1991), Ritzi et al. (1991) and Rojstaczer (1988) outline many of the principles where storage and transmission properties of confined aquifers can be estimated from changes in water level (head) data and atmospheric pressure. Seo (2001) and Mehnert et al. (1999) liken barometric efficiency to small scale slug tests that are useful for estimating specific storage $\left(\mathrm{S}_{\mathrm{s}}\right)$, transmissivity $(\mathrm{T})$ and hydraulic conductivity $(\mathrm{K})$. The effect of atmospheric pressure on head was recognized as early as 1940 by Jacob (cited by Furbish, 1991). Much of the subject literature is concerned with correcting pump test and other head data for the confounding effects of atmospheric pressure variation.

Vented pressure transducers were installed in four monitoring wells in the Fairmont mine-pool and one well in the Uniontown mine-pool. The transducers were programmed to record water level and temperature on an hourly basis. These data were paired with hourly barometric pressure readings obtained from National Oceanic and Atmospheric Administration (NOAA) records for nearby weather stations. For the Fairmont minepool, pressure data were obtained for the Morgantown, WV airport about $24 \mathrm{~km}$ away. Pressure data for the Uniontown mine-pool were obtained for the station at the Uniontown, PA airport about $8 \mathrm{~km}$ away. Characteristics of the different wells are 
summarized in table 4-13. The author also reviewed mine maps, drill logs and well installation details for the Fairmont and Uniontown wells, and several borings had been inspected with a down-hole camera prior to casing installation.

Table 4-13

Wells Used in Storage and Transmissivity Estimates

\begin{tabular}{|c|c|c|}
\hline $\begin{array}{l}\text { Mine-pool } \\
\text { (Mine) }\end{array}$ & $\begin{array}{c}\begin{array}{c}\text { Well } \\
\text { Depth } \\
\text { (meters) }\end{array} \\
\end{array}$ & Comments \\
\hline $\begin{array}{c}\text { Fairmont } \\
\text { (Beth 41, North) }\end{array}$ & 107 & $\begin{array}{l}\text { In partially collapsed void, fully } \\
\text { flooded. }\end{array}$ \\
\hline $\begin{array}{c}\text { Fairmont } \\
\text { (Joanne) }\end{array}$ & 134 & In coal pillar, fully flooded \\
\hline $\begin{array}{l}\text { Fairmont } \\
\text { (Federal 1) }\end{array}$ & 88 & In open void, fully flooded \\
\hline $\begin{array}{c}\text { Fairmont } \\
\text { (Beth 41, West) }\end{array}$ & 107 & In coal pillar, fully flooded \\
\hline Uniontown & 15 & In coal pillar, fully flooded \\
\hline
\end{tabular}

Figure 4-10 displays a time series plot of hourly head and barometric pressure for a well in the Fairmont mine-pool, Beth 41, North mine. The two parameters are inversely related; head declines as atmospheric pressure increases, and head increases when pressure declines. This behavior is characteristic of confined aquifers whose elastic storage is derived from compressibility of the aquifer matrix and water.

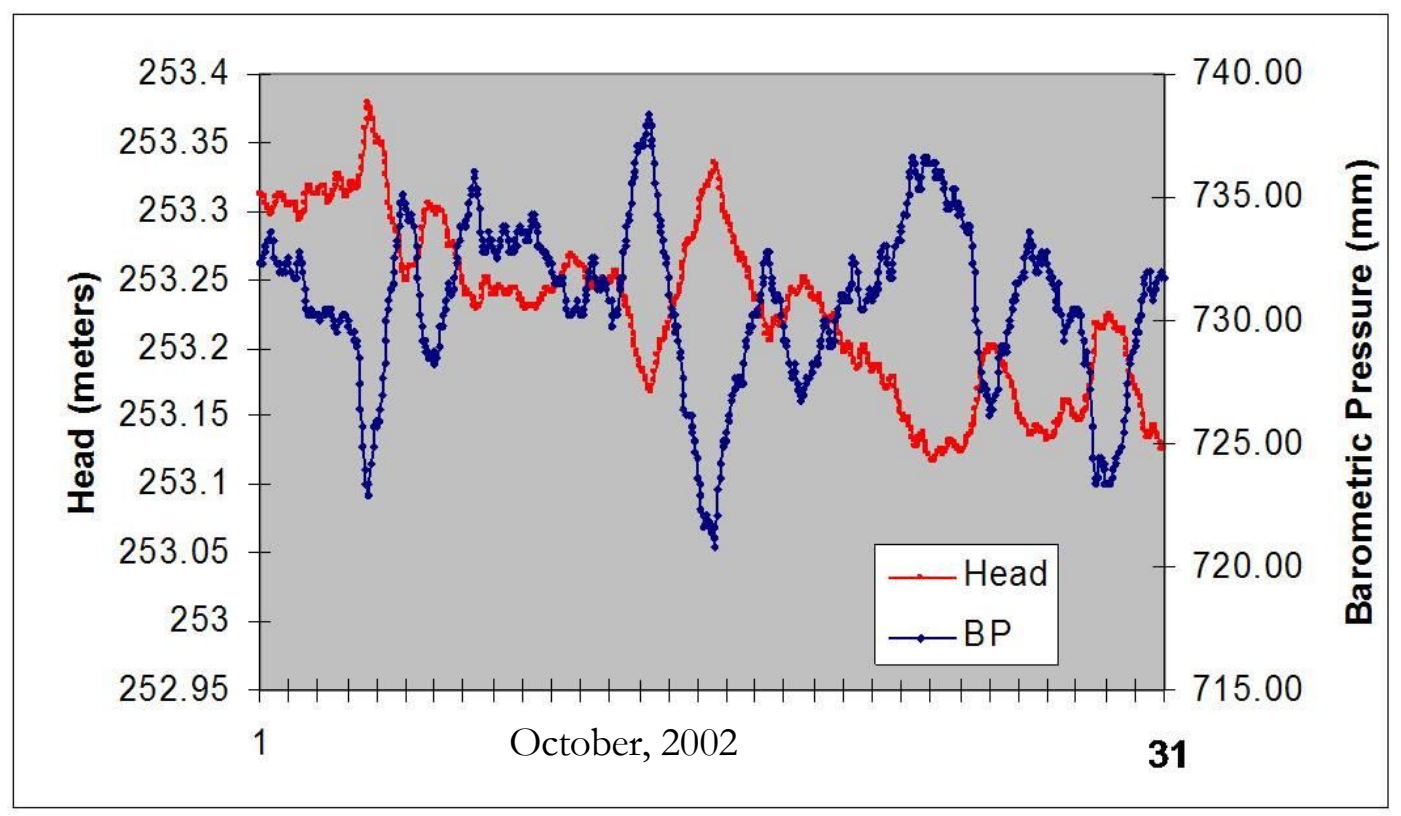

Figure 4-10. Time Series Plot of Aquifer Head and Barometric Pressure, Fairmont Mine-pool, Beth 41 Mine.

Close inspection of the head data also reveals a declining trend, independent of barometric effects. The head decline is seasonal, and this underlying influence was 
removed from the data set by linear regression methods. A least squares regression gave an estimate of the slope of the head loss/day. Davis and Rasmussen (1993), and Rasmussen and Crawford (1997) found regression to be satisfactory for removing underlying trend effects. Davis and Rasmussen (1993) also found that regression gave similar results to a method originally described by Clark (1967). Clark's technique uses a set of simple rules to identify which members in a time series respond like a barometer. A head change of zero, for example, between successive measurements is excluded from barometric efficiency calculations. Head response to atmospheric loading can be either instantaneous or delayed (Rasmussen and Crawford, 1997; Hare and Morse, 1997; Seo, 2001). In a well, the response should be instantaneous, and examination of time series data showed no apparent lag between pressure and head change, and calculations were then based on that premise.

Multiple estimates of barometric efficiency were generated for each well. The paired head and pressure readings were examined in time series plots. Periods showing a significant barometric pressure change were identified, preferably encompassing at least a 24 hour period. Figure 4-10 shows 4 distinct pressure declines in October, 2002, and these subsets were extracted for analysis. Three periods of distinct barometric pressure increase are also present and these subsets could be extracted for analysis. For each well, barometric efficiency was determined for both increasing and decreasing barometric pressure trends. Daily precipitation data were also examined for potential influence of significant recharge events. Most data sets for barometric efficiency were obtained during periods lacking large precipitation events, typically September through November.

Barometric efficiency (BE) was estimated as follows:

$$
\mathrm{BE}=\left(\mathrm{y}_{\mathrm{w}} * \mathrm{dh}\right) / \mathrm{dP}_{\mathrm{a}}
$$

where $\mathrm{y}_{\mathrm{w}}$ is the unit weight of water; $\mathrm{dh}$ is the head change; and $\mathrm{dP}_{\mathrm{a}}$ is the change in atmospheric pressure. "Tidal efficiency" (TE) was estimated as follows:

$$
\mathrm{TE}=1-\mathrm{BE}
$$

Specific Storage $\left(\mathrm{S}_{\mathrm{s}}\right)$ was estimated as follows:

$$
\mathrm{TE}=\left(\mathrm{p}_{\mathrm{w}} * \mathrm{~g} * \mathrm{~B}_{\mathrm{p}}\right) / \mathrm{S}_{\mathrm{s}}
$$

after rearranging this equation, where $p_{\mathrm{w}}$ is fluid density, $\mathrm{g}$ is the gravitational acceleration constant; and $\mathrm{B}_{\mathrm{p}}$ is compressibility of the aquifer matrix, either measured or estimated; and TE is "tidal efficiency".

Finally, porosity, $\mathrm{n}$ is estimated from:

$$
\mathrm{BE}=\left(\mathrm{p}_{\mathrm{w}} \mathrm{gnB}_{\mathrm{w}}\right) / \mathrm{S}_{\mathrm{s}}
$$

after rearranging this equation where $S_{\mathrm{s}}, \mathrm{p}_{\mathrm{w}}$ and $\mathrm{g}$ are as previously defined, and $\mathrm{B}_{\mathrm{w}}$ is fluid compressibility.

Equation 4-12 includes a term, $B_{p}$, for compressibility of the aquifer matrix. Domenico and Schwartz (1990) compiled values for vertical compressibility of sediments and rocks. 
They report a range of 6.9 to $3.3 \times 10^{-10} \mathrm{~m}^{2} / \mathrm{N}$ for "fissured rock", while Freeze and Cherry (1979) report a wider range of $10^{-8}$ to $10^{-10} \mathrm{~m}^{2} / \mathrm{N}$, and $10^{-11}$ for "sound rock". Initial calculations included a sensitivity analysis for $\mathrm{B}_{\mathrm{p}}$, varying over the range of $10^{-8}$ to $10^{-11}$. Estimated porosity, $n$, was greater than $100 \%$ when $B_{p}$ was specified as $10^{-9} \mathrm{~m}^{2} / \mathrm{N}$, indicating the aquifer compressibility estimate was too large. When $\mathrm{B}_{\mathrm{p}}$ was assigned a value of $10^{-10} \mathrm{~m}^{2} / \mathrm{N}$, this produced reasonable estimates of porosity, while a $B_{\mathrm{p}}$ value of $10^{-11} \mathrm{~m}^{2} / \mathrm{N}$, produced small values $(<3 \%)$ for porosity $(\mathrm{n})$. Based on examination of borehole videos and drilling logs for several Fairmont mine-pool wells which indicated partially open mine voids, low $\mathrm{n}$ values were deemed unreasonable. A compressibility index $\left(B_{\mathrm{p}}\right)$ value of $10^{-10} \mathrm{~m}^{2} / \mathrm{N}$ was used for all subsequent estimates.

Table 4-14 shows average values of barometric efficiency (BE), "tidal efficiency" (TE), specific storage $\left(\mathrm{S}_{\mathrm{s}}\right)$, and porosity $(\mathrm{n})$ estimated from head and atmospheric pressure data. Specific storage, $S_{\mathrm{s}}$ was estimated to be on the order of 1.5 to $4.5 \times 10^{-6} / \mathrm{m}$, and porosity estimates ranged from about 17 to $44 \%$ at three different wells. For individual wells, estimated porosity values from multiple analyses were generally within $25 \%$ relative difference. Three wells were completed in partially caved zones and crushed coal pillars, based on drilling and borehole camera observations. The fourth well was completed in an open void in the Federal 1 mine and reports a correspondingly high porosity of $82 \%$.

Since coal recovery typically ranged from at least 50 to upwards of $80 \%$, porosity data for three wells suggests the mine-pool aquifer thickness exceeds the coalbed thickness, by perhaps two to five times. For example, a porosity of $25 \%$ in an area with $50 \%$ coal removal suggests the void space may now be distributed over a thickness of two times the original mining height. The storage coefficient, $\mathrm{S}$, for the aquifer, is estimated from:

$$
\mathrm{S}=\mathrm{S}_{\mathrm{s}} \mathrm{b}
$$

where Ss is specific storage and b is saturated aquifer thickness in consistent units.

The estimated storage coefficient, $\mathrm{S}$, ranges from about $3.4 \times 10^{-6}$ to $1.5 \times 10^{-5}$ as aquifer thickness $b$ ranges from 2 ( $\sim 4$ meters) to 5 ( $\sim$ ten meters) times coal height. The high porosity estimate and intact open void in the Federal 1 well implies that aquifer thickness in this location is similar to coal height and the roof rock acts as a confining layer. The apparent low storage coefficient for the Fairmont mine-pool results in relatively large drawdown when it is pumped.

The fraction of storage attributable to water compression and expansion is indicated by barometric efficiency, and the water derived from matrix compression and expansion is attributed to "tidal efficiency" in table 4-14.

The principal disadvantage of barometric calculations is the sensitivity of the calculations to small changes in head and atmospheric pressure data. The small head changes also imply that only aquifer material near the well is being tested.

The values in table 4-14 are similar to results reported by Sahu (2004) for a mostly flooded underground mine in Ohio. Using barometric efficiency calculations, Sahu estimated specific storativity in five wells to range from $1.7 \times 10^{-6}$ to $1 \times 10^{-5}$ and porosity from 0.31 to 0.52 . Using an amplitude ratio method described by Mehnert et al. (1999), 
Sahu also estimated transmissivity as ranging from $1 \times 10^{-5}$ to $4 \times 10^{-6} \mathrm{~m}^{2} / \mathrm{s}$, and hydraulic conductivity on the order of $10^{-6} \mathrm{~m} / \mathrm{s}$. Sahu analyzed recharge/discharge characteristics of the Ohio mine-pool and concluded that it had overall low storage.

Table 4-14

Specific Storage, Porosity and Storativity Estimated from Head and Barometric Pressure ${ }^{(1)}$

\begin{tabular}{ccccc}
\hline $\begin{array}{c}\text { Mine-pool } \\
\text { (Mine) }\end{array}$ & B.E. & T.E & $\begin{array}{c}\text { Specific Storage } \\
(\text { Ss })\end{array}$ & $\begin{array}{c}\text { Porosity, } \\
(\mathrm{n})\end{array}$ \\
\hline $\begin{array}{c}\text { Fairmont } \\
\text { (Beth 41, North) }\end{array}$ & 0.65 & 0.35 & $2.9 \times 10^{-6} / \mathrm{m}$ & 0.44 \\
$\begin{array}{c}\text { Fairmont } \\
\text { (Joanne) }\end{array}$ & 0.45 & 0.55 & $1.8 \times 10^{-6} / \mathrm{m}$ & 0.19 \\
$\begin{array}{c}\text { Fairmont } \\
\text { (Federal 1) }\end{array}$ & 0.78 & 0.22 & $4.5 \times 10^{-6} / \mathrm{m}$ & 0.82 \\
$\begin{array}{c}\text { Fairmont } \\
\text { (Beth 41,West) }\end{array}$ & 0.42 & 0.58 & $1.7 \times 10^{-6} / \mathrm{m}$ & 0.17 \\
\hline
\end{tabular}

(1) B.E.= Barometric Efficiency; T.E. = "Tidal Efficiency".

Pressure transducer readings in one well in the Uniontown mine-pool recorded periodic pumping of the mine-pool. A coal reprocessing company located about three $\mathrm{km}$ from the well provided information to the author about their pumping rates and schedule in sufficient detail to permit analysis via time drawdown methods. Transmissivity was estimated using the Theis equation for radial flow to pumping wells in confined aquifers. Data transformation and curve fitting were conducted in Aqtesolv for Windows, version 4.1. A semi-log plot of drawdown versus time is shown in figure 4-11. Some deviation

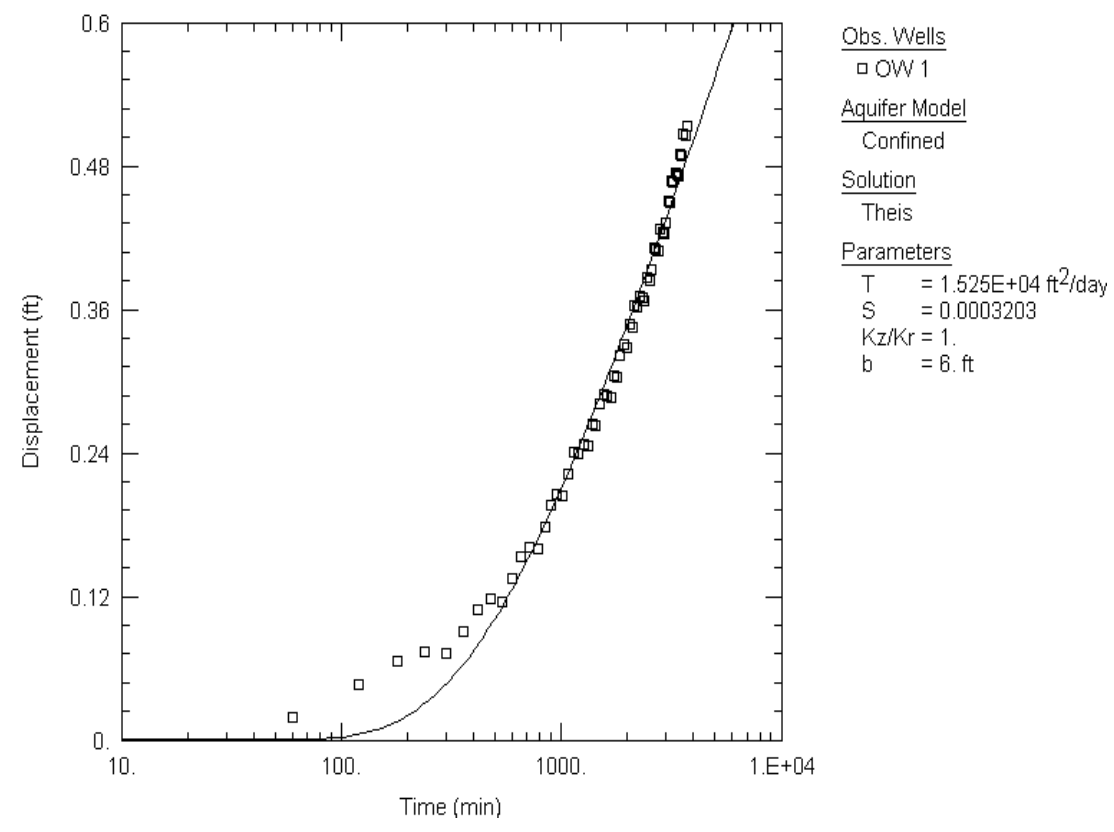

Figure 4-11. Uniontown Mine-pool, semi-log Plot of Aquifer Drawdown vs. Time and Estimated Transmissivity and Storativity Using Theis Method.

from the type curve is apparent in early pumping data, but with better fit in late data. The estimated transmissivity, assuming a six foot ( $\sim$ two meter) thick aquifer, was $1.5 \times 10^{4}$ 
$\mathrm{ft}^{2} /$ day $\left(1.6 \times 10^{-2} \mathrm{~m}^{2} / \mathrm{s}\right)$. Storativity was estimated at $3.2 \times 10^{-4}$, equivalent to specific storage of about $1.6 \times 10^{-4} / \mathrm{m}$. The storage values are about one to two orders of magnitude larger than in the Fairmont mine-pool but are also subject to uncertainty of identifying aquifer thickness. The data were also analyzed using several other solutions for leaky confined aquifers, but results showed little variation.

Figure 4-12 is a time series plot of head measurements in the Fairmont mine-pool. In April 1997, a siphon system began operating in the mine-pool to prevent mine water from discharging into overlying streams. The graph shows head response to a pumping rate of about $4500 \mathrm{~L} / \mathrm{min}$. The Williams mine well is located $18 \mathrm{~km}$ from the siphon, but head declined about 4 meters after pumping began. The Fairmont mine-pool is subdivided into individual mines separated by barrier pillars. The internal barrier pillars, and confined aquifer with elastic storage and apparent low storativity, explains the large drawdown

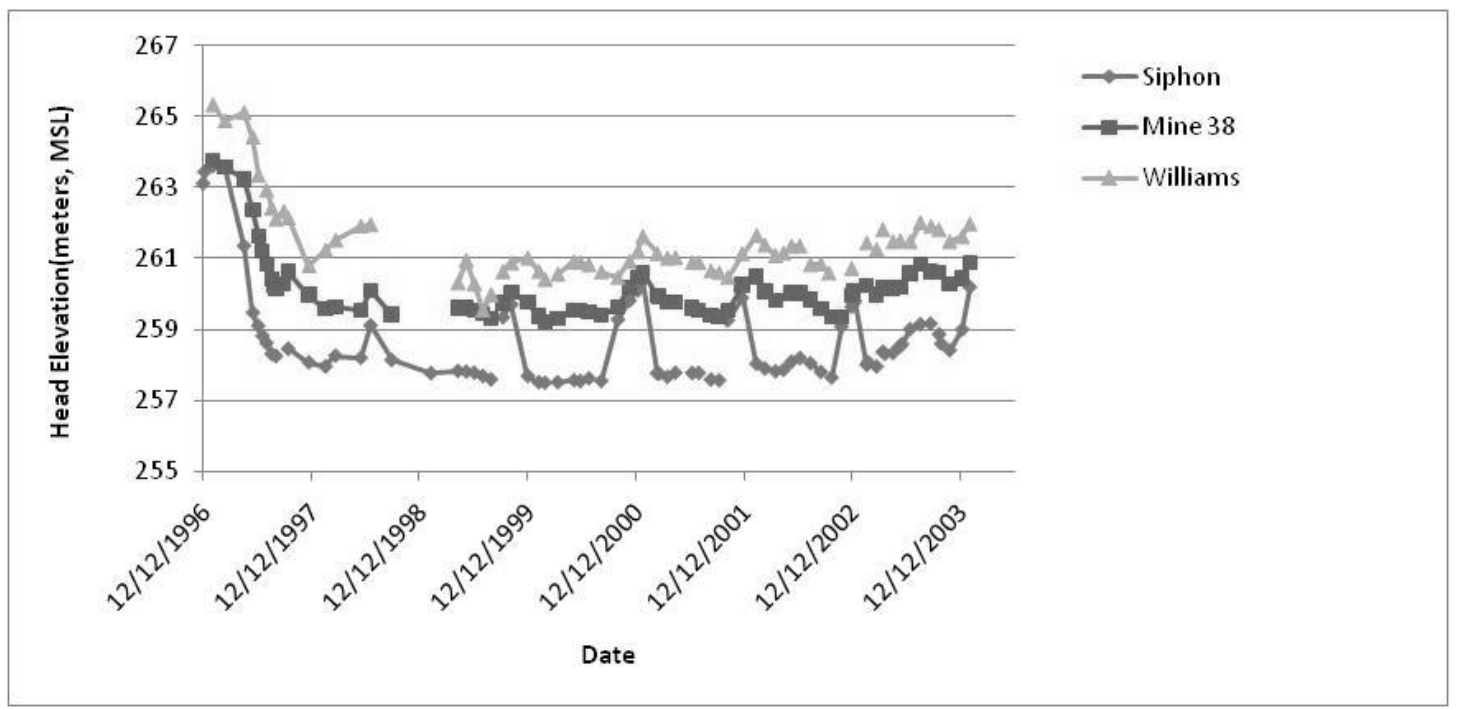

Figure 4-12. Fairmont Mine-pool. Head Response to Pumping in Three Mines. Pumping Started April, 1997 at Siphon. Williams Mine is 18 km from Siphon. Mine 38 is 2.5 km from Siphon.

observed at distance. This behavior has practical significance for controlling head in flooded confined mine-pools. The Barnes\&Tucker mine-pool exhibits a similar response to pumping, with head declines of 6 meters at a distance of about $16 \mathrm{~km}$ (Hawkins et al., 2005).

\subsection{Chapter 4 Summary Findings and Observations}

In Chapter four water quality characteristics and geochemical processes in flooded underground mines were examined. The data and observations were drawn from mines in West Virginia and Pennsylvania that have been flooded for as much as $45+$ years. These included observations on:

- Flooding effects on chemical composition

- Obtaining "representative" mine-pool samples for chemical analysis

- Chemical characteristics of flooded mine-pools 
- Fluid storage and transmissivity in flooded mine-pools.

The principal findings and conclusions for mine-pools of this chapter are summarized as follows:

- Flooding profoundly affects aqueous chemistry of flooded mine-pools. Each mine-pool initially contained or discharged low $\mathrm{pH}$ waters, or discharges acid water from small unflooded sections. After flooding, mine water shifted to circumneutral, net alkaline conditions, although Fe, sulfate and TDS remained elevated. The typical $\mathrm{pH}$ shift was three to four S.U. The Fairmont and Uniontown mine-pools are nearly $100 \%$ flooded, while the remaining mines are 70 to $80 \%$ inundated.

- Extreme vertical stratification of chemical conditions can occur in mine-pool wells and shafts. Transitions can be abrupt, and include one to two order of magnitude changes in parameter concentrations. Water samples should be collected at mine level, in the mine-pool, to represent conditions. Samples collected at the beginning of a pumping cycle may not represent long term conditions, as turbulent flow and mixing occur over time.

- Varying stress on the mine-pool, in the form of changing pumping rates, may affect discharge quality. The Barnes\&Tucker mine-pool discharge water quality declined as pumping rate increased. The behavior suggests that flushing within the mine-pool is not uniform, with preferred flow-paths and short circuiting. Some sections of the mine-pool may have limited fluid exchange, unless the mine-pool is stressed.

- Mine-pool water quality exhibits spatial variability. Concentrations of Fe, sulfate, $\mathrm{Ca}$ and other parameters vary among different wells in the Fairmont and Barnes\&Tucker mine-pools and are partly related to location in the mine-pool flow system. Waters in recharge zones, at the beginning of the mine-pool flowpath are the least mineralized. Water becomes more mineralized as it migrates through the mine-pool flow system. In the Fairmont mine-pool, dissolved solids increased by a factor of about ten from recharge to end of flow path waters. Location in the flow system is a water sampling variable.

- Flooded mine-pools were $\mathrm{Na}-\mathrm{SO}_{4}, \mathrm{Ca}-\mathrm{Mg}-\mathrm{SO}_{4}$ or mixed cation- $\mathrm{SO}_{4}$ composition.

- Flooded mine-pools are deficient in Fe with respect to sulfate; indicating most iron originally liberated by pyrite oxidation has been retained in the mine-pool. About 60 to $80 \%$ of the $\mathrm{Fe}$ is "missing" from the discharge waters. Iron retention, estimated from ion ratios, was lowest during initial flooding and increased with age. 
- Flooded mine-pools consume large amounts of acidity in-situ. Two moles of $\mathrm{H}^{+}$ generated per mole of sulfide to sulfate oxidation, are mostly consumed within the flow system. Net alkaline waters are discharged from each flooded minepool.

- Cation exchange of $\mathrm{Na}$ for $\mathrm{Ca}$ and $\mathrm{Mg}$ is a prominent feature in flooded minepools. End of flow-path waters in the Fairmont and Barnes\&Tucker mine-pools are enriched in $\mathrm{Na}$ with respect to their source waters.

- Geochemical modeling simulations described in Appendix B and summarized in chapter four show that carbonate weathering can be a significant source of acid neutralization and alkalinity. Some sulfate adsorption to $\mathrm{Fe}$ oxide sediment surfaces is possible at low $\mathrm{pH}$, and some Fe may be retained in mine-pools by ion exchange

- Iron behavior is difficult to model because of the number of possible sources and sinks.

- Flooded mine-pools contain little or no detectable oxygen, a condition that favors inhibition of pyrite oxidation. Small unflooded sections can, however, support continuing oxidation and mobilization of weathering products.

- Sulfate complexes with $\mathrm{Ca}, \mathrm{Fe}$ and other elements increases solution concentration of those parameters and allows more dissolution of the source minerals. Fifteen to $40 \%$ of total dissolved $\mathrm{Ca}$ was complexed with sulfate in five flooded mine-pools, and ten to $40 \%$ of total dissolved Fe(II) was complexed with sulfate.

- Flooded mine-pools may approach saturation for one or more minerals especially during early flooding. Gypsum, calcite, dolomite and Fe oxyhydroxides were near apparent equilibrium in several mine-pools. Iron data are more difficult to interpret due to the wide solubility range for Fe oxyhydroxides. The waters tend become under-saturated for these minerals as the mine-pool ages.

- Computed $\mathrm{pCO}_{2}$ values are up to several hundred times atmospheric conditions, suggesting that either the mine-pools do not readily exchange gases with the outside atmosphere, and that chemical weathering of carbonates is ongoing. Altenatively, a strong gas diffusion gradient is present that would promote carbon dioxide leakage from the mine.

- Apparent thermodynamic stability of mine-pool waters with respect to Fe oxyhydroxides was assessed from a modified activity product, -pQ. Most -pQ values indicate equilibrium with more soluble, less crystalline forms of $\mathrm{Fe}$ 
oxyhydroxides. Mine waters in this study are more likely to form amorphous $\mathrm{Fe}$ precipitates than goethite or hematite.

- Eh/pH plots based on field measured values show mine-pool waters near equilibrium with respect to poorly crystalline $\mathrm{Fe}(\mathrm{OH})_{3}$ and over-saturated with respect to siderite.

- $\mathrm{Fe}(\mathrm{III})$ concentration is difficult to quantify in flooded mine-pools, because it is present in such low amounts. Attempts to measure $\mathrm{Fe}(\mathrm{II}) / \mathrm{Fe}(\mathrm{III})$ with wet chemistry methods are limited by the necessity of diluting samples with high $\mathrm{Fe}$ so that the solution is within range of the spectrophotometer. For flooded minepools with very low concentrations of $\mathrm{Fe}(\mathrm{III}), \mathrm{Fe}(\mathrm{II}) / \mathrm{Fe}(\mathrm{III})$ distribution may have to be estimated from measured Eh, rather than Fe speciation techniques.

- In spite of difficulties associated with obtaining and interpreting Eh measurements, subject literature suggests Fe is one element where useful, quantitative readings can be obtained.

- Sulfate reduction may occur in flooded mine-pools. A strong positive response for sulfate reducing bacteria was obtained for several mine-pools and $\mathrm{H}_{2} \mathrm{~S}$ was also detected in mine waters. Computed Eh for the $\mathrm{S}(-\mathrm{II}) / \mathrm{S}(\mathrm{VI})$ couple approaches conditions of FeS formation in one mine-pool.

- Long term flux rates of Fe and sulfate, normalized to $1 \mathrm{~m}^{2}$ of mine-works, varied about one order of magnitude for each parameter. There was no discernible difference in flux rate between flooded and partly flooded mines. Normalized flux rates are likely over-estimated since total rock surface area in caved and fractured rock exceeds plan view mine area. The actual exposed rock surface area is larger and includes roof, floor and pillar surfaces, and surfaces of fractured and disaggregated rocks. Normalized flux rates do provide a consistent basis for comparison, however.

- Mine-pools can be partly recharged by leakage from adjacent or overlying minepools as well as ground water infiltration from unmined strata. Recharge from other mine-pools can affect mine-pool composition.

- Flooded mine-pools that are subdivided by barrier pillars can be visualized as a series of compartments, each with high internal hydraulic conductivity and low gradient. Overall head and flow between compartments is controlled by hydraulic conductivity, thickness and gradient of the barrier pillars.

- Flooded mine-pools behave as confined or leaky confined aquifers. Aquifers are thin, on the order of coal thickness, to several times coal thickness, depending on the magnitude of collapse and fracturing of the overlying rock. 
- Flooded mine-pools have low specific storage, on the order of $10^{-6} / \mathrm{m}$. The low values result in part from the low compressibility of the aquifer matrix.

- Head in confined mine-pools responds to pumping over distances of tens of $\mathrm{km}$. This behavior has practical significance, in that large mine-pools can be controlled by a single pumping facility. 


\section{Chapter 5: Temporal Trends and Geochemical Behavior of Mine-pools}

Drainage from closed underground coal mines is a significant source of water pollution in northern Appalachia and elsewhere (Kleinmann et al.; 2000; Younger, 1997). Long term chemical composition of mine-pools is of interest to government, industry and environmental organizations who estimate cost and duration of treatment, and select optimal mine closure techniques. The rate and degree of improvement or pollution abatement and the steady-state composition of mature mine-pools is the subject of this section based on the following observations and questions:

- How fast does water quality improve? In general, coal mine-pools have been observed to discharge the poorest water quality in the initial flush, followed by a gradual improvement in composition (Younger, 2000). Is improvement solely a function of time, geochemical conditions, hydrologic processes or a combination of variables?

- To what degree does water quality improve? Is complete abatement and return to background conditions a realistic expectation? Or, will the mine-pool have low but objectionable concentrations of metals, acidity, dissolved solids or other parameters for an indefinite period of time?

Long term data sets from five mine-pools, ranging from about ten to 35 years duration, were examined to address these questions. The general geologic and hydrologic setting and history of these mine-pools is described in chapters three and four, appendices A-D and by Donovan et al. (1999). The five mine-pools include two sites that are mostly unflooded, and discharge acidic water. The remaining three are mostly flooded and discharge circumneutral water. Essential features are included here in the discussion as needed.

Three principal tasks are described in this section:

- Estimate in-situ neutralization of mine-pools by a combination of processes including introduction of alkalinity from recharge water, and dissolution of carbonate and other minerals.

- Statistical fits, including decay function, of solution chemistry versus time to estimate the rate of change in concentration or flux. Regression techniques are used to estimate the time to attain reduction in concentrations of $\mathrm{Fe}, \mathrm{Al}, \mathrm{SO}_{4}$ and dissolved solids.

- Estimate the constraints on long term solution chemistry as it approaches a steady state condition using equilibrium and kinetic calculations. The kinetics of pyrite oxidation has been extensively studied as reported by Williamson and Rimstidt (1994), and Rimstidt and Vaughn (2003). 


\subsection{Other Long Term Mine-pool Studies}

Most of the published work on long term chemical behavior of mine-pools comes from either the United Kingdom (U.K.), or the Appalachian region of the U.S.A. Glover (1983) observed that drainage from flooded underground coal mines in Great Britain showed about a 50\% reduction in iron concentration for each pool volume discharged, implying an exponential decay. Younger (2000), found that Fe concentrations became asymptotic at values of about one to $40 \mathrm{mg} / \mathrm{L}$ in drainage from British coal mines after flushing for a period of a few years to several decades. Younger (1997), also characterized British mine waters as having "juvenile" and "vestigial" acidity. The latter is removed in the first flush of the mine-pool, usually within 40 years. Juvenile acidity resulting from ongoing pyrite oxidation is projected to last for hundreds of years. Wood et al. (1999), concluded that pollution from closed underground coal mines in Scotland was most severe in the first few decades, and that iron $(\mathrm{Fe})$ concentrations would decline to $30 \mathrm{mg} / \mathrm{L}$ or less within 40 years.

Younger and Thorn (2006) estimated that initial flooding of a recently closed coal mine in the U.K. would produce acidic water, based on observations of flowpath, and analyses of water encountered during mining. They correctly predicted the acidic nature of the discharge, but the actual Fe concentration was more than three times greater than predicted. They suggest that better understanding of flowpaths in mine-pools could improve water quality prediction.

Demchek et al. (2004) reported that iron concentration had decreased an average of about $80 \%$ in 44 free-draining underground mine discharges in West Virginia over a 30 year period. This study includes mines in the same coal beds, Upper Freeport and Pittsburgh, as in this work. Demchek et al. compared water quality from a 1968 survey with drainage in 1999-2000, and found that acidity had decreased an average of 56\% in Upper Freeport mines. Overall, iron concentrations declined about $80 \%$, and sulfate declined about 50 to $75 \%$. The average data included substantial variation among individual mines. Thus, while most mines show improvement in water quality, the rate and degree of chemical change seems to be influenced by site specific factors. More recently, Skousen et al. (2006) supplemented the 2004 study with some additional data. They concluded that seasonal variation should be examined further to quantify the effect of flow on underground mine chemistry. Skousen et al.'s study included a large number of mines, but with a limited number of sample events through time. Short term features are therefore difficult to identify and evaluate. All of the mines in Skousen et al.'s study were abandoned at closure, and there is no continuing legal obligation for a company (if it still exists), or for a government entity, to continue systematic water quality monitoring of underground mines abandoned before 1977.

Donovan et al. (2003) describe the flooding history and chemical evolution of a below drainage underground mine in the Pittsburgh coal bed in southwestern Pennsylvania. They describe three phases of water chemistry, including an initial flooding phase of peak concentrations of Fe and other pollutants over a two year period. Second was a transition phase lasting two to four years with decline in iron and other parameter concentrations; 
and a third phase, where Fe declined to less than ten percent of initial concentration, and net alkaline conditions developed. This data set, called the Hahn discharge, is one of the five sites analyzed in this section.

Perry and Rauch (2004, Appendix A) found that a first order decay function described the decrease in acidity, Fe, Al, and sulfate and other parameters for the first eight years of record of the Omega mine-pool, located near Morgantown, West Virginia. This small free-draining mine showed strong seasonal influences in pollutant flux and concentration, with flux rates two to three times higher in spring high discharge season, compared to the fall low flow season. Sulfate, Fe and acidity concentrations were projected to decline by half over a six to eight year period. The decline in Al concentration, however, was two to three times slower than for other parameters. The Omega mine-pool is one of the five sites analyzed in this section.

Perry et al. (2005, Appendix D) found that after 14 years and pumping approximately 21 pool volumes, $\mathrm{Fe}$ and sulfate concentrations in the Lancashire 15 mine-pool had declined to about $20 \%$ of their initial values. In 1986, leakage from an overlying mine complex further diluted the Lancashire 15 mine-pool. Since 1986, Fe and sulfate concentrations have continued a slow, irregular decline at the rate of one to two $\mathrm{mg} / \mathrm{L} / \mathrm{year}$ for $\mathrm{Fe}$ and about ten to $15 \mathrm{mg} / \mathrm{L} /$ year for sulfate. The long term concentration trends can be described with exponential models, which project that objectionable Fe levels may persist for decades. The Lancashire 15 mine-pool, also referred to as Barnes\&Tucker, is one of the five sites analyzed in this chapter.

Koryak et al. (2004) summarized more than 30 years of stream monitoring data in several major tributaries of the Allegheny River in northern Appalachia. This area has been degraded by acid drainage from abandoned coal mines. They found over three decades a steady decreasing trend in acidity, and associated increases in $\mathrm{pH}$ and alkalinity. Since the 1970s, acidity had declined by an average of 63\%. They attributed the water quality improvements to "exhaustion" of pyritic materials. The stream data are an indirect gage of the acid loading in the watershed. The observed time frames and relative improvements are consistent with the behavior described for mine-pools.

Younger (2000) described a simplified generic model for estimating iron behavior in flooded mines in the U.K. Younger's philosophy of using a simple approximation is similar to the approach taken in this work. Younger examined 81 discharge records from closed, mostly to fully flooded mines, and made the following observations:

- Flushing could be described using decay functions.

- The main period of flushing lasted about four times as long as the flooding period.

- The ratio of initial or short term to long term Fe concentration was about eight to one. 
- Fe concentration was related to sulfur content of the strata and distance to outcrop.

Younger examined a simple batch reactor flow model to describe flushing of the form:

$$
\mathrm{t}_{\mathrm{f}}=\mathrm{V}_{0} / \mathrm{Q}
$$

where $\mathrm{t}_{\mathrm{f}}=$ flushing time.

$\mathrm{V}_{0}=$ Pore volume (mine-pool volume).

$\mathrm{Q}=$ Discharge Rate, at steady state is equal to recharge.

Younger found the batch reactor model underestimated flushing time for the discharges. He attributed the lack of fit to flow-path tortuosity, which is not accounted for in a simple batch reactor.

Younger (2000) also attempted to describe mine-pool flushing using an advectiondispersion equation. He was able to obtain a good fit between model and actual discharge data for one mine by adjusting several parameters in the equation. Younger commented on the difficulty of measuring several of the variables in the equation, and stated that it was possible to obtain model fits simply by continually adjusting parameters.

Finally, Younger, building on the work of Glover (1983), devised a simple relationship:

$$
t_{f}=\left(R_{f} / 2\right) * t_{r}
$$

where $\mathrm{t}_{\mathrm{f}}=$ flushing time,

$$
\begin{aligned}
R_{f}= & \text { ratio of initial concentration to final concentration. } \\
& t_{r}=\text { time to flooding, assumed equal to half life for Fe. }
\end{aligned}
$$

Younger obtained reasonable agreement with discharge data for the part of the record that exhibited exponential decline; that is, before the time-concentration curve approaches asymptotic conditions.

There is anecdotal and observational evidence suggesting that water pollution from closed mines will persist on a time scale of decades. The author has observed underground coal mines abandoned for 80 to 100 years in northern Appalachia and the Illinois basin that still discharge water with Fe concentration exceeding most Fe water quality standards. The Argo drainage tunnel in Colorado, completed in the 1890's and designed to drain gold and silver mine-works, still discharges acidic water ( $\mathrm{pH} \mathrm{3.2)}$ with elevated metals (Al, $\mathrm{Cu}, \mathrm{Fe}, \mathrm{Zn}$ ) concentrations (Miller et al., 2007). 


\subsection{In-Situ Acid Neutralization}

An initial examination of the five mine-pool data sets revealed that a large fraction of pyrite oxidation acidity is "missing" from coal mine-pool waters, even in acid mine waters. This missing acidity has been termed "neutralization" and is attributed to $\mathrm{H}^{+}$ consumption by weathering (Hollyday and McKenzie, 1973; James, 1984). Apparent insitu consumption of acidity reduces the impact of mine waters to receiving streams and aquifers, the burden for conventional chemical or passive treatment; and perhaps duration of pollution. The mechanisms supporting in-situ acid consumption could include alkaline ground-water recharge, dissolution of carbonate minerals, dissolution of alumino-silicate minerals, and exchange and adsorption reactions.

Hollyday and McKenzie (1973) calculated "Neutralization Ratios" based on cation and anion composition, and $\mathrm{pH}$. Hollyday and McKenzie's computation methods are shown as:

$$
\text { Acid Neutralization Ratio }=\left[\sum\left(\mathrm{Ca}^{2+}, \mathrm{Mg}^{2+}, \mathrm{Na}^{+}, \mathrm{K}^{+}\right)-\sum\left(\mathrm{Cl}^{-}, \mathrm{F}^{-}\right)\right] /\left(\mathrm{SO}_{4}{ }^{2-}\right)
$$

where parameters are expressed in meq/L. The numerator is a gross estimate of alkalinity, produced from the dissolution of carbonates and other acid consuming reactions. The sulfate denominator represents the acidity produced via pyrite oxidation.

Both Hollyday and McKenzie (1973) and James (1984) reported that, in general, more than $60 \%$ of the acidity projected from pyrite oxidation was absent from the discharge water, even in mine waters with low $\mathrm{pH}$.

James (1984) subsequently modified the Acid Neutralization Ratio to account for the presence of $\mathrm{Al}, \mathrm{Fe}(\mathrm{II})$ and $\mathrm{HSO}_{4}{ }^{-}$. He calculated strong acid neutralization ratio as:

$$
\left[\sum\left(\mathrm{Ca}^{2+}, \mathrm{Mg}^{2+}, \mathrm{Na}^{+}, \mathrm{K}^{+}, \mathrm{Al}^{3+}, \mathrm{HSO}_{4}^{-}\right)-\sum\left(\mathrm{Cl}^{-}, \mathrm{F}^{-}\right)\right] /\left[\left(\mathrm{SO}_{4}{ }^{2-}\right)-\left(\mathrm{Fe}^{2+}\right)\right]
$$

where parameters are expressed in meq/L.

For waters containing appreciable $\mathrm{Al}$, dissolution of an alumino-silicate is an acid consuming reaction. Complete kaolinite dissolution consumes three moles of $\mathrm{H}^{+}$per mole of $\mathrm{Al}$ as follows:

$$
\mathrm{Al}_{2} \mathrm{Si}_{2} \mathrm{O}_{5}(\mathrm{OH})_{4}+6 \mathrm{H}^{+} \rightarrow 2 \mathrm{Al}^{3+}+2 \mathrm{H}_{4} \mathrm{SiO}_{4}+\mathrm{H}_{2} \mathrm{O}
$$

The bisulfate ion $\mathrm{HSO}_{4}{ }^{-}$is included in James' equation since its formation consumes one mole of $\mathrm{H}^{+}$. At $\mathrm{pH}$ values approaching two, bisulfate from $\mathrm{H}_{2} \mathrm{SO}_{4}$ dissociation, with a $\mathrm{pK}_{\mathrm{a}}$ of 1.99 at $25^{\circ} \mathrm{C}$, constitutes a noteworthy fraction of total sulfate in solution. Ferrous iron is subtracted in James' expression, since it represents acidity not yet produced by oxidation and hydrolysis. James' (1984) method is an improvement for waters containing significant amounts of soluble $\mathrm{Al}$, ferrous $\mathrm{Fe}$, or low $\mathrm{pH}$. 
Morin et al. (1988) describe neutralization of an acidic ground-water plume initially by carbonate, then by hydroxide and finally by alumino-silicate dissolution. Bains et al. (2000) and Blowes et al. (1992) have described similar reaction sequences for acid ground-water migrating from tailings impoundments.

Neutralization ratio was estimated three ways in this study:

- The first was a simple mass balance calculation based on pyrite stoichiometry, sulfate and acidity concentrations.

- The second set of calculations used the James (1984) method (equation 5-4) for three data sets that contained major cation and anion analysis for at a least a significant portion of the record.

- The third method involved speciating the solutions based on equilibrium calculations and summing solution complexes that either consume or liberate $\mathrm{H}^{+}$. Speciation calculations were performed using PHREEQCI (Parkhurst and Appelo, 1999), for one acidic mine-pool (Omega) and one circumneutral mine-pool (Hahn).

5.2.1 Neutralization from Mass Balance Difference Sulfate and Observed Acidity

A simple approximation of in-situ neutralization may be derived from sulfate concentration and a measure of the acidity attributable to pyrite oxidation. The summary reaction for pyrite oxidation shows that four moles of $\mathrm{H}^{+}$are produced for two moles of sulfate as follows:

$$
\mathrm{FeS}_{2}+15 / 4 \mathrm{O}_{2}+7 / 2 \mathrm{H}_{2} \mathrm{O} \rightarrow \mathrm{Fe}(\mathrm{OH})_{3}+4 \mathrm{H}^{+}+2 \mathrm{SO}_{4}^{2-}
$$

Maximum acid production (MAP) was calculated based on equation 5-6, subject to the following assumptions:

- All measured sulfate is derived from pyrite oxidation within the mine.

- No sulfate is retained in the mine-pool by precipitation or adsorption reactions.

- Iron retained in the mine-pool has undergone oxidation and hydrolysis, producing its full complement of $\mathrm{H}^{+}$in-situ.

The first assumption is approximately correct, because sulfate concentration in groundwaters entering Appalachian mine-pools is usually small relative to the mine-pool composition. For example, ground-water recharging the Barnes\&Tucker mine-pool contains an average of about $27 \mathrm{mg} / \mathrm{L}$ sulfate, based on data collected by McElroy (1998). Similar sulfate concentrations, about $40 \mathrm{mg} / \mathrm{L}$ average, were reported by Hobba (1984) for ground water of the Monongahela group rocks overlying the Pittsburgh coal bed. The "background" recharge water values are less than five percent of the concentrations observed in the mine-pools that they enter. 
The second assumption, that no sulfate is retained by precipitation or adsorption reaction, is mine-pool specific. A series of jarosite minerals of composition $\mathrm{MFe}_{3}\left(\left(\mathrm{SO}_{4}\right)_{2}(\mathrm{OH})_{6}\right.$ may form under acid oxidizing conditions, such as exists in the Omega and T\&T minepools. $\mathrm{M}$ is typically $\mathrm{K}^{+}, \mathrm{Na}^{+}$, or $\mathrm{H}^{+}$, but may include other metals as well. Gypsum, melanterite, halotrichite, schwertmannite (an Fe-hydroxy-sulfate), and many other minerals are also potential sinks for sulfate in acidic or partly flooded mine-pools. Melanterite and other highly soluble minerals may be flushed from the mine. Schwertmannite has been reported to gradually dehydrate, liberate sulfate and form goethite over a period of several years (Bigham et al., 1996; Jonsson et al., 2005). Alunite is an Al-sulfate mineral with composition analogous to jarosite, where $\mathrm{Al}$ replaces $\mathrm{Fe}$. In general, sulfate bearing solids are more likely to form in unflooded than in flooded mines or mine sections. The third assumption may not be completely correct if short term storage of Fe salts is significant.

Sulfate adsorption on Fe oxy-hydroxide precipitates that is $\mathrm{pH}$ dependent has been reported (Rose and Elliot, 2000), with increased retention at low pH. Given the potential for sulfate adsorption and mineral formation, the second assumption of conservative sulfate behavior may not always be fully met. In this instance, if sulfate is retained in the mine-pool, estimated acid production will be less than the actual amount.

Noting these assumptions, estimated maximum acid production (EMAP) within the five mine-pools studied was calculated as:

$$
\mathrm{EMAP}=\left[\mathrm{SO}_{4}(\mathrm{mg} / \mathrm{L}) * 1 \mathrm{mmole} / 96 \mathrm{mg}\right] *\left[100 \mathrm{mg} \mathrm{CaCO} \mathrm{Ca}_{3} \mathrm{Eq}\right]
$$

where two mmole of $\mathrm{H}^{+}$are produced per mmole sulfate and two mmole of $\mathrm{H}^{+}$are consumed per mmole $\mathrm{CaCO}_{3}$.

Total acidity can be calculated from dissolved metals and $\mathrm{pH}$ as:

$$
\text { Acidity }_{\text {total }}=50\left[(2 * \mathrm{Fe}(\mathrm{II}) / 56)+(2 * \mathrm{Mn} / 55)+(3 * \mathrm{Al} / 27)+\left(100 *^{*} 10^{\wedge-\mathrm{pH}}\right)\right]
$$

However, for the purpose of estimating mine water acidity directly attributable to pyrite weathering, equation 5-8 was modified to include only $\mathrm{Fe}(\mathrm{II})$ and $\mathrm{H}^{+}$. $\mathrm{Fe}$ (II) represents $\mathrm{H}^{+}$ that will be produced from iron oxidation and subsequent hydrolysis. $\mathrm{pH}$ represents $\mathrm{H}^{+}$ that has already been generated within the mine-pool from sulfide oxidation. The sum of these two parameters is acidity that can be attributed to sulfide oxidation, and is termed "pyrite acidity" (equation 5-9).

$$
\text { Acidity } \left._{\text {pyrite }}=50[(2 * \mathrm{Fe}) / 56)+\left(1000 * 10^{\wedge-\mathrm{pH}}\right)\right]
$$

Total dissolved $\mathrm{Fe}$ is presumed to originate from pyrite and represents acidity not yet generated by metal hydrolysis, while $\mathrm{pH}$ represents acid generation that has already occurred from pyrite. The difference in acidity between equations 5-9 and 5-7 is termed neutralization and represents mineral weathering, recharge water or other processes. 
The total and "pyrite acidity" calculations assumes that metal hydrolysis and $\mathrm{H}^{+}$comprise all of the mine water acidity. Carbonate acidity is not included, and is assumed to be negligible. Kirby and Cravotta (2005), and Cravotta and Kirby (2005) discuss, in detail, theoretical and practical aspects of acidity measurements in mine waters. They concluded that $\mathrm{Fe}$ should be represented as $\mathrm{Fe}$ (II) in acidity calculations after examining $\mathrm{Fe}$ speciation in mine water. Acidity calculations for the five mine-pools followed this convention unless noted otherwise.

A Neutralization Ratio was then calculated as:

$$
\text { Neutralization Ratio }=\left[\left(\text { EMAP- } \text { Acidity }_{\text {pyrite }}\right) / \text { EMAP }\right] * 100
$$

The "missing acidity" or neutralization is represented by the difference between estimated maximum acid production (EMAP) and acidity still present that can be attributed to pyrite $\left(\mathrm{Fe}\right.$ and $\left.\mathrm{H}^{+}\right)$. Dissolved metals such as $\mathrm{Al}$ and $\mathrm{Mn}$, are assumed to represent in-situ neutralization, that is, acid consumption within the mine-pool. Carbonate alkalinity is assumed to be absent. If measurable alkalinity is present, then equation 5-10 must be modified by adding alkalinity to the numerator as follows:

$$
\text { Neutralization Ratio }=\left[\left(\text { EMAP- Acidity }{ }_{\text {pyrite }}+\text { Alkalinity }\right) / \text { EMAP }\right] * 100
$$

For mine waters that are net alkaline, the neutralization ratio can exceed $100 \%$.

Median data in table 5-1 show mine-pool quality conditions soon after closure, and after about ten to 35 years of continued weathering, ground-water recharge and discharge. In each mine-pool, acidity and metals concentration have declined significantly through time, although water quality remains poor, especially in the acidic mine-pools. Iron concentrations remain elevated in all mine-pools. The two acidic mine-pools, Omega and T\&T, and the acidic Sterling 1 sub-pool in Barnes\&Tucker, contain significant dissolved aluminum, indicating the dissolution of alumino-silicates and/or aluminum oxyhydroxides. Dissolution of aluminum minerals in-situ is an acid consuming reaction, as shown for kaolinite weathering in equation 5-5. Pyrite acidity, attributable to Fe and $\mathrm{H}^{+}$, and calculated from equation 5-9, is 65 to $70 \%$ of the total acidity (equation 5-8) soon after flooding in the acidic pools. Pyrite acidity declines to about $55 \%$ of total acidity as the mine-pools age.

Table 5-1 also shows neutralization ratios computed from equation 5-10a and 5-10b. The acidic sites, Omega, T\&T, have neutralization ratios (equation 5-10a) of about 61 to $65 \%$ in early flushing, indicating considerable acid consumption is occurring. The ratios increase to $73 \%$ and $83 \%$ as the mine-pools age, and are over $70 \%$ in the $50+$ year old Sterling 1 sub-pool. The main Barnes and Tucker discharge increased from 58 to $86 \%$ neutralization ratio as it aged. The Hahn and Arden-Westland mine-pools had 77 and $88 \%$ neutralization respectively, in early flooding. Three mine-pools, Hahn, ArdenWestland and Barnes and Tucker after flooding, contained water with measureable alkalinity. Neutralization ratio (equation 5-10b) that includes carbonate alkalinity is also 
shown in table 5-1 for these three sites. Each of these mine-pools developed net alkaline water as they aged and have neutralization ratios exceeding $100 \%$. Neutralization in each mine-pool is discussed in more detail in following sections.

Table 5-1

Summary Water Quality Characteristics of Five Mine-pools ${ }^{(1)}$

\begin{tabular}{|c|c|c|c|c|c|c|c|c|c|c|}
\hline $\begin{array}{l}\text { Mine- } \\
\text { pool }\end{array}$ & Date & $\mathrm{pH}$ & $\begin{array}{c}\text { Total } \\
\text { Acidity }\end{array}$ & $\begin{array}{l}\text { Pyrite } \\
\text { Acidity }\end{array}$ & Alkalinity & $\mathrm{Fe}$ & $\mathrm{Al}$ & $\mathrm{SO}_{4}$ & $\begin{array}{c}\text { Neut. } \\
\text { Ratio } \\
1\end{array}$ & $\begin{array}{c}\text { Neut. } \\
\text { Ratio } \\
2 \\
\end{array}$ \\
\hline Omega & 1993 & 2.86 & 2200 & 1440 & - & 772 & 137 & 3915 & 64.6 & - \\
\hline Omega & 2007 & 2.63 & 1075 & 560 & - & 248 & 92 & 2021 & 73.3 & - \\
\hline $\mathrm{T} \& \mathrm{~T}$ & 1996 & 2.6 & 700 & 509 & - & 227 & 39.7 & 1270 & 61.5 & - \\
\hline $\mathrm{T} \& \mathrm{~T}$ & 2006 & 2.79 & 300 & 162 & - & 44.2 & 26.3 & 964 & 83.8 & - \\
\hline Hahn & $\begin{array}{c}1984- \\
1985\end{array}$ & 4.4 & 1831 & 1667 & 70 & 931 & 20.6 & 7000 & 77.1 & 81.8 \\
\hline Hahn & $\begin{array}{c}1994- \\
1995\end{array}$ & 6.6 & 158 & 156 & 360 & 87 & 0.2 & 1445 & 89.6 & 113.4 \\
\hline $\begin{array}{c}\text { Arden- } \\
\text { Westland }\end{array}$ & $\begin{array}{l}1986- \\
1987\end{array}$ & 6.75 & 148 & 139 & 219 & 78 & 0.2 & 1170 & 88.6 & 102 \\
\hline $\begin{array}{l}\text { Arden- } \\
\text { Westland }\end{array}$ & $\begin{array}{l}1998- \\
1999\end{array}$ & 6.8 & 131 & 127 & 146 & 71 & 0.1 & 888 & 86.2 & 102 \\
\hline $\begin{array}{l}\text { Barnes\& } \\
\text { Tucker } \\
\text { (Duman) }\end{array}$ & 1971 & 4.1 & 1500 & 1499 & 8 & 837 & - & 3432 & 58.0 & - \\
\hline $\begin{array}{l}\text { Barnes\& } \\
\text { Tucker } \\
\text { (Duman) }\end{array}$ & 2005 & 6.60 & 71 & 56 & 197 & 31 & 0.2 & 390 & 86.2 & 148 \\
\hline $\begin{array}{l}\text { Barnes\& } \\
\text { Tucker } \\
\text { Sterling } 1\end{array}$ & 2005 & 2.69 & 495 & 263 & - & 78 & 39 & 930 & 72.8 & - \\
\hline
\end{tabular}

(1) Values are median data for the specified time period. $\mathrm{pH}$ in S.U.; acidity and alkalinity in $\mathrm{mg} / \mathrm{L} \mathrm{CaCO}_{3} \mathrm{Eq}$; $\mathrm{Fe}, \mathrm{Al}, \mathrm{SO}_{4}$, in $\mathrm{mg} / \mathrm{L}$. Total acidity from equation 5-8, pyrite acidity from equation 5-9. Neut. Ratio 1 is Neutralization Ratio calculated from equation 5-10, carbonate alkalinity not included. Neut. Ratio 2 includes carbonate alkalinity.

\subsubsection{Neutralization in the Partly Flooded, Acidic Omega Mine-pool}

Figure 5-1 shows the neutralization ratio, calculated using equation 5-10a, over a 14 year period from 1993 to 2007 for the Omega Main Treatment Inlet. All drainage from the mine-pool is routed to this inlet by a series of pipelines. The samples are taken just before the raw water enters chemical treatment facilities at approximately monthly intervals. A great deal of scatter is evident in figure 5-1, but between about 60 and $80 \%$ of the maximum acid production has been consumed before the drainage enters the treatment facilities. The overall median neutralization ratio is $66 \%$. 


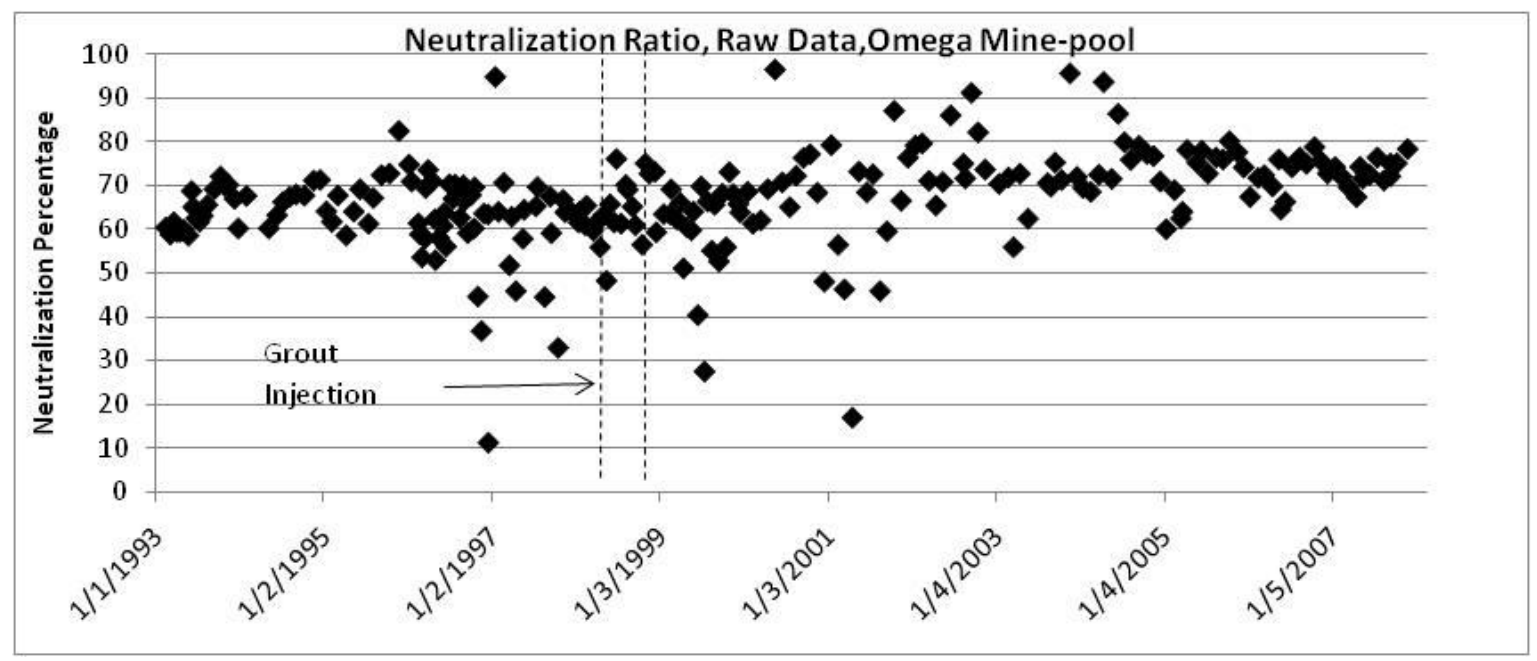

Figure 5-1. Neutralization Ratio for Raw Data, Omega Mine-pool, Main Treatment Inlet.

Figure 5-2 displays the same data set after applying a simple five point moving average, to show trends more clearly. Since samples were collected roughly at monthly intervals, or sometimes more frequently, the smoothed mean includes as much as five months temporal trend. Smoothing can cause an apparent lag in seasonal or trend display. Figure 5-2 shows a pronounced seasonal trend; with maximum neutralization of 70 to $80 \%$ occurring in the fall season, and corresponding to low flow period. Minimum neutralization of around 50\% occurs in spring season, corresponding to high flow periods. This trend may result from seasonal accumulation and flushing of metal sulfate salts (Perry and Rauch, 2004, Appendix A). They reported that about $75 \%$ of yearly acid and metal flux was discharged during high flow periods of a few months per year at this mine.

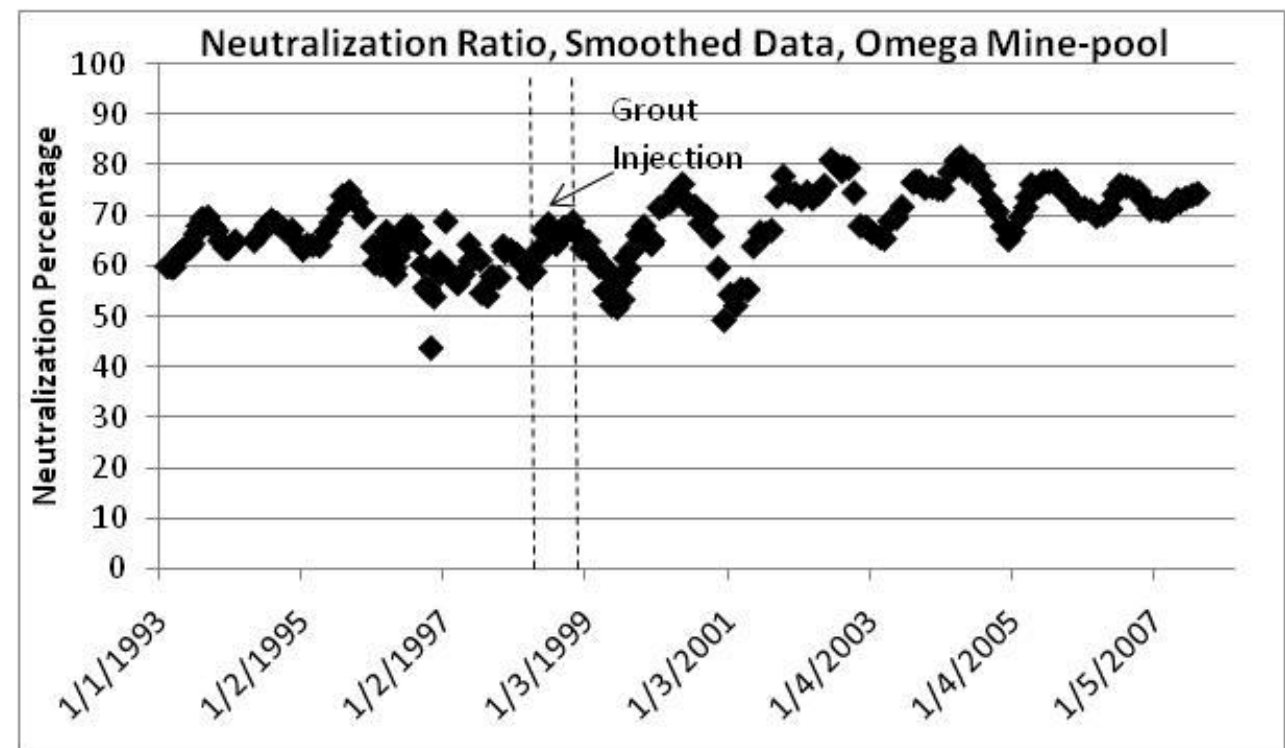

Figure 5-2. Neutralization Ratio for Omega mine-pool, Main Treatment Inlet, Smoothed Data. 
Neutralization ratio was depressed during late 1998 and all of 1999. This corresponds to grout injection in part of the mine-works. During grout injection, and for a period of about one year following, chemical concentrations of sulfate and other parameters increased in mine waters draining this section of the mine-works. The chemical concentration increase is interpreted as displacement and flushing of soluble weathering products, including hydrous-sulfate metal salts, such as melanterite, copiapite and similar minerals. The short term deterioration in water quality is discussed more detail by Perry and Rauch (2004, Appendix A). In 2000, neutralization ratio increased about eight percent over pre-grouting conditions, suggesting some benefit of additional in-situ neutralization from the grout mix. Overall median neutralization ratio was $64 \%$ before grout injection, and about $72 \%$ after grouting. It has remained between about 70 and $80 \%$ through 2007.

The trend data in figure 5-2 show that the over the 14 year period of record, neutralization ratio has remained relatively stable, except when the system was stressed during grout injection and seasonal fluctuations.

Figure 5-3 shows smoothed (five point moving average) neutralization percentage data for the Marshall discharge at the Omega mine. This drainage is located at the down-dip end of the mine-works and in close proximity to a section that was grouted with a flyash and cement mix. It is the largest flow of any drainage at the mine, comprising about 50\%

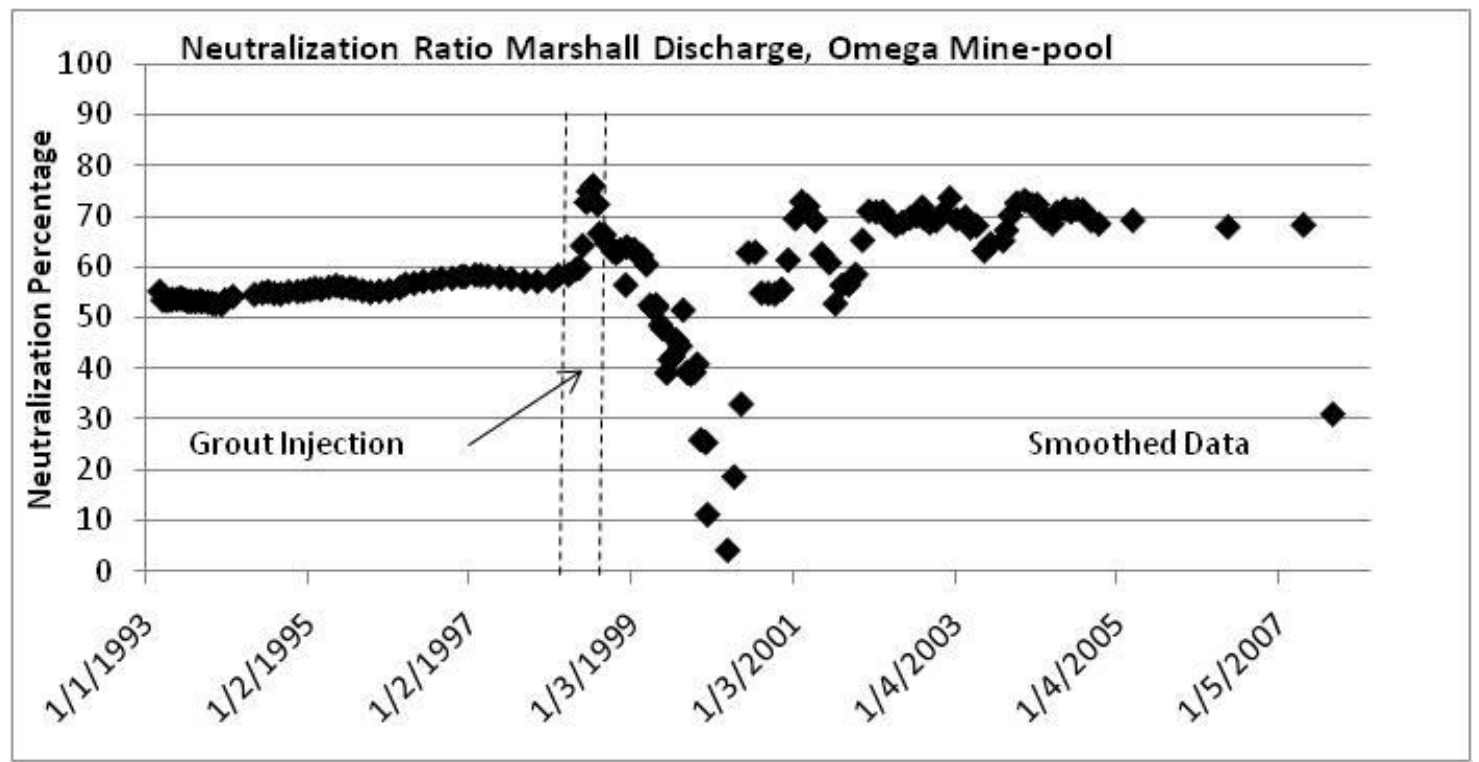

Figure 5-3. Neutralization Ratio for Omega Mine-pool, Marshall Discharge, Smoothed Data.

of the total discharge. It has some of the poorest quality water encountered in the minepool, with total acidity often exceeding $5000 \mathrm{mg} / \mathrm{L} \mathrm{CaCO}_{3}$ prior to grout injection.

Grouting response is clearly displayed in figure 5-3. Before grouting in 1998, about 50 to $60 \%$ of acidity was consumed in-situ. When grouting commenced in October, 1998, a brief and rapid rise to about $75 \%$ neutralization occurred. This was quickly followed by a 
decline, which lasted about one year, to as low as four percent neutralization in March, 2000. The rapid fluctuations are likely due to close proximity of the discharge to the grout zone, and short term neutralization by acid consuming grout material, followed by displacement of acid weathering products that had accumulated in the mine. Welch et al. (2008) showed that jarosite, for example, could dissolve congruently, liberating soluble $\mathrm{Fe}$ and sulfate at $\mathrm{pH}$ values like that in the Omega mine-pool. Acid neutralization continued to fluctuate until 2002, about four years after grout injection, and has remained at about $70 \%$.

\subsubsection{Neutralization in the Partly Flooded, Acidic T\&T Mine-pool}

Like the Omega mine, the T\&T mine complex is located above base level drainage in a sequence of rocks that contain few carbonates. The T\&T drainage also shows poor water quality, typified by low $\mathrm{pH}$, and elevated acidity, metals and sulfate. Over the ten year period from 1996 to 2006, all chemical concentrations declined in the principal discharge. The largest improvements were declines in Fe, and consequently acidity. Sulfate, Al and $\mathrm{pH}$ showed the smallest improvements. These same trends also occur in the Omega minepool (table 5-1).

Neutralization percentage in the T\&T mine-pool averaged about $72 \%$ for the period of record (figure 5-4, smoothed data five point moving average), and was calculated using equation 5-10a. The behavior is similar to the Omega mine-pool. The T\&T raw data were collected at monthly intervals or less, and the smoothed means include a maximum of five months. Neutralization Ratio actually declined from 70 to about $50 \%$ during the first few years after closure. This period was characterized by high volume discharges sometimes exceeding 7,000 L/minute, and is similar to the "first flush" behavior described for flooding underground coal mines in the United Kingdom (Younger, 2000).

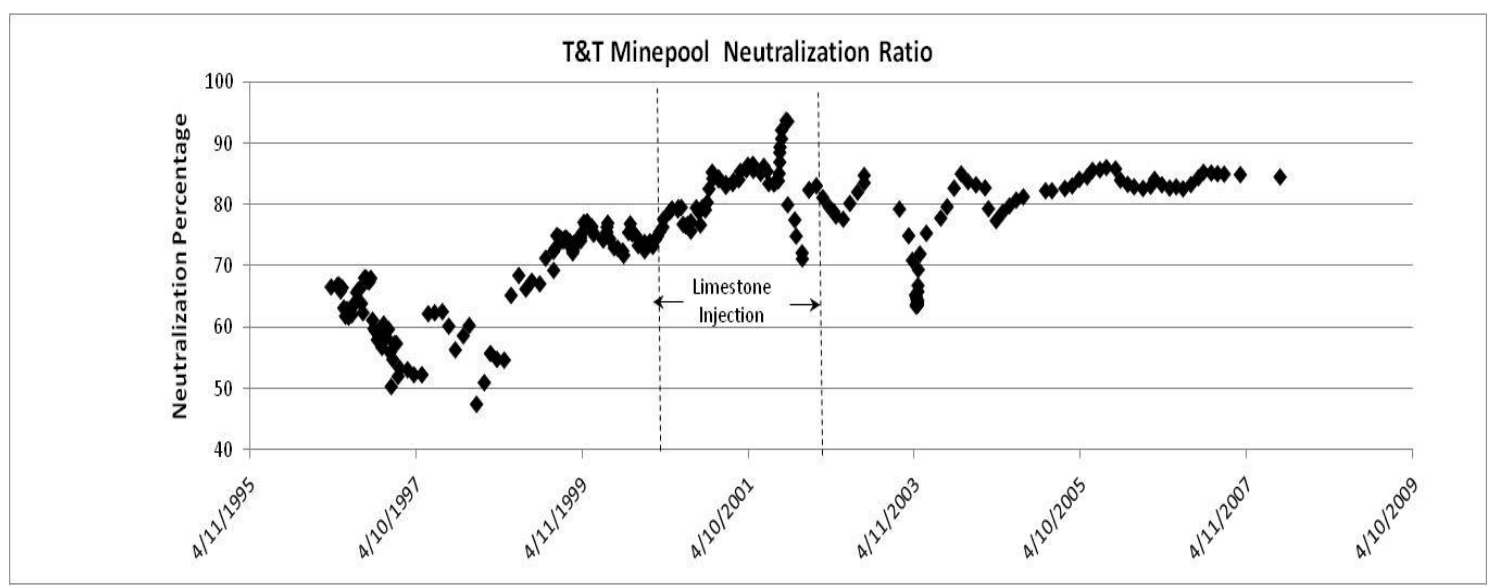

Figure 5-4. Neutralization Ratio for T\&T Mine-pool, Smoothed Data.

The extreme flows and flushing of acid weathering products likely caused the decline in neutralization percentage. The mine-pool includes about 560 hectares of workings, of which about $20 \%$ are flooded. Approximately 65,000 metric tons of limestone byproduct 
(70\% $\mathrm{CaCO}_{3}$ Eq.) were injected into the mine from late 1999 to late 2001 in an attempt to treat acid water in-situ.

Neutralization Ratio in the T\&T mine-pool increased from about 65 to $85 \%$ over a three year period from 1998 to 2001 after limestone injection. There were two rapid short term fluctuations in 2001 and 2003. Both events included a brief rapid increase in mine-pool head, followed by a large volume short duration discharge of very poor quality water. After 2004, neutralization ratio has usually exceeded $80 \%$.

Injecting a large mass of limestone into the mine-works should have had a beneficial effect on acid production and leaching. Post injection neutralization ratio is about $12 \%$ greater than immediately prior to treatment, and the amount of "pyrite acidity" did decrease during limestone injection. Injection did not; however produce large shifts in $\mathrm{pH}$, as might be expected after adding large amounts of calcium carbonate to the system. The mine-pool discharge water is slightly under-saturated for gypsum and jurbanite since limestone injection. These minerals could control $\mathrm{Ca}, \mathrm{Al}$ and sulfate concentrations, which may mask neutralization effects.

\subsubsection{Neutralization in the Flooded, Neutral, Barnes\&Tucker Mine-pool}

The Barnes\&Tucker mine-pool, located in Cambria county, Pennsylvania is pumped drainage from a mostly flooded underground mine in the Lower Kittanning coal bed within the Kittanning formation, Allegheny group. It is partially overlain by a second set of flooded mine-works in the Lower Freeport coal bed. The two mine-pools are hydraulically connected as shown by pumping and other data (Hawkins et al., 2005). The mine-pool has been flooded for over 35 years, after closing in 1969, and filling by with ground water by 1970. Further details of the chemical composition of the mine-pool are described by Perry et al. (2005, Appendix D). Summary data in table 5-1, show that the discharge was initially acidic with $\mathrm{Fe}$ and sulfate exceeding 800 and $3400 \mathrm{mg} / \mathrm{L}$, respectively.

Neutralization ratio in figure 5-5 is based on yearly average values from the main discharge, called Duman, and was calculated using equation 5-10b, which includes carbonate alkalinity. In the first years after flooding and during the initial flush, neutralization ratio was about as low 40\%, but rapidly increased to between 60 and $80 \%$. In 1986, mine-works in an overlying coal bed were abandoned and allowed to flood. Flooding of the overlying mine-works and the vertical connection between the two mines necessitated an increase in pumping rate, and increased alkalinity concentration in the Barnes and Tucker mine-pool. The upper mine-works contained water with alkalinity of about $150 \mathrm{mg} / \mathrm{L} \mathrm{CaCO}_{3}$ Eq. and negligible amounts of $\mathrm{Fe}$ (unpublished monitoring records, Lloyd, 2004). Flooding of the overlying mine-works and the vertical connection between two coal beds resulted in a rapid increase in neutralization ratio to about $140 \%$. Neutralization ratio has remained between about 90 and 140\% since that time.

Neutralization ratio was also estimated for drainage emanating from an unflooded section of the Barnes\&Tucker works in the same Lower Kittanning coal bed. The discharge, called Sterling 1, drains mine-works that were closed about 1960. Unlike the flooded pool, the Sterling 1 drainage is acidic with $\mathrm{pH}$ less than 3.0 (table 5-1). Monitoring data 
from the mid 1980s, mid 1990s and 2004-2005 have a median neutralization ratio of about $73 \%$.

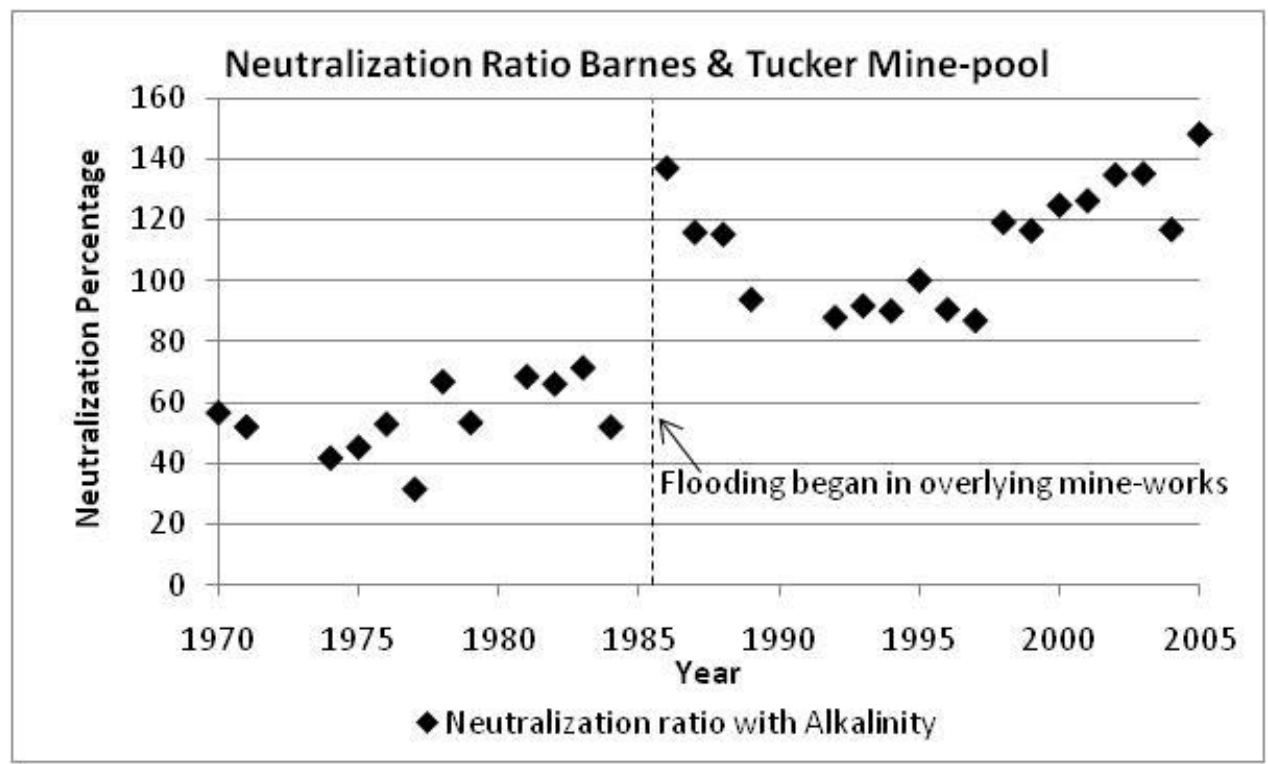

Figure 5-5 Neutralization Ratio, Mostly Flooded, Circumneutral, Barnes \&Tucker Mine-pool, Yearly Average Data.

In-situ neutralization is less efficient in the Sterling 1 drainage. The only difference between the Duman and Sterling 1 discharges is flooding state (flooded vs. unflooded). The Sterling 1 discharge neutralization ratio is similar to the behavior of the Omega and T\&T mines described previously.

\subsubsection{Neutralization in the Flooded, Circumneutral Hahn Discharge Mine-pool}

The Hahn discharge, located in Washington County, Pennsylvania, is pumped drainage from a mostly flooded underground mine (Montour 4) in the Pittsburgh coal bed. Some characteristics of the drainage quality at this mine have been described by Donovan et al. (2003). Early discharge water from the mine-pool was highly mineralized, containing over $900 \mathrm{mg} / \mathrm{L} \mathrm{Fe}$ and $7000 \mathrm{mg} / \mathrm{L}$ sulfate (table 5-1).

The mine closed in 1980 when a barrier failed between Montour 4 and an up-dip mine, and the works began to flood The Hahn drainage was initially acidic, but produced circumneutral $\mathrm{pH}$ water about five years after mine abandonment, and net alkaline water after about ten years. The mine-pool includes about 5900 hectares, of which over $70 \%$ is flooded. The pool is pumped as a controlled discharge at about 13,250 L/minute, and has an estimated residence time of about 4 years. No seasonal effects were found in neutralization ratio. Pumping dampens seasonal influences, if any occur. The mine-pool was near saturation with respect to calcite after initial flooding (Donovan et al., 2003).

Figure 5-6 shows neutralization ratio calculated with (equation 5-10b), and without including alkalinity (equation 5-10a) for the Hahn discharge. Neutralization Ratio computed with alkalinity has always been at least $80 \%$ and approached $120 \%$ about 20 
years after mine closure. The continuing increase in neutralization ratio is a function of the decline in estimated maximum acidity, and simultaneous increase in mine-pool alkalinity through time. Neutralization ratio calculated without alkalinity stabilized at about $90 \%$ in 1990, about ten years after mine closure and the start of flooding. Sulfate and iron, the two parameters that exert the greatest influence on the calculated neutralization ratio (excluding alkalinity) are decreasing in concentration at about the same rate. There is no statistically significant change $(\mathrm{p}=0.01)$ in neutralization ratio (excluding alkalinity), after about 1990. The plot and statistics indicate establishment of a near steady state condition in this form of neutralization ratio. This suggests that the initial flushing event was completed at this time. The time scale corresponds to about one and one half pool volumes of discharge, after flooding was complete in 1984, and a four year residence time.

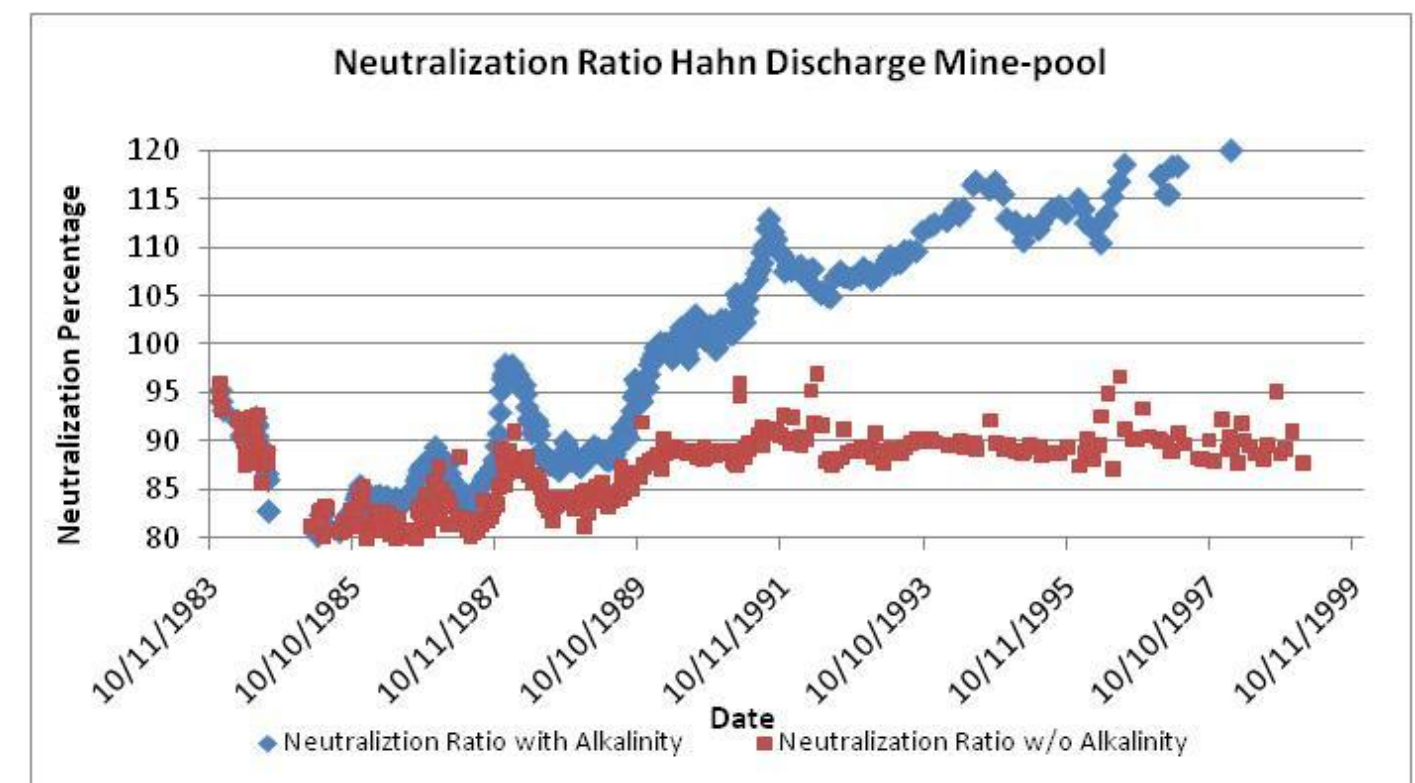

Figure 5-6. Neutralization Ratio, Computed with Alkalinity (Blue) and without Alkalinity (Red) Mostly Flooded, Circumneutral Hahn Discharge Mine-pool.

5.2.1.5 Neutralization in the Arden-Westland Discharge, Westland Mine

The Arden-Westland discharge is from a pumped mine-pool in the Arden-Westland mine in Washington County, Pennsylvania. It is located about $16 \mathrm{~km}$ southwest of the Hahn discharge, and is also in the Pittsburgh coal bed. The Westland mine covers about 5100 hectares. It is estimated to be about $80 \%$ flooded, based on examination of mine maps and water level data. The Westland mine actually surrounds and discharges through the smaller Arden mine-works, which ceased operating in the 1940s. The inclusion of water from the older Arden-Westland mine-works complicates interpretation of mine-pool chemistry.

The Westland mine closed in 1980 and was flooded by 1986. Donovan et al. (1999) estimated a 4 year residence time for the mine-pool. Unlike the Hahn drainage, ArdenWestland discharge waters are under-saturated for calcite (Donavan et al., 1999). No 
water quality data for the period 1980 to 1986 were located, so the early mine flooding history is not addressed.

Table 5-1 shows summary water quality characteristics of the mine-pool in 1986 soon after flooding was complete, and after flushing an estimated four to five pool volumes by 1998. Unlike the Hahn discharge, the Arden-Westland drainage did not display dramatic declines in pollutant concentrations after flooding. Neither did the Arden-Westland discharge acidic water in the initial period of record. Metals, sulfate and acidity were roughly an order of magnitude lower than early discharge chemistry of the Hahn. The early Arden-Westland discharge water is similar to the later Hahn water composition.

Figure 5-7 shows neutralization ratio for the Arden-Westland discharge, calculated with alkalinity (equation 5-10b), and without alkalinity (equation 5-10a). The early period of record shows a rapid decline in neutralization ratio by either method. This may represent the end of the initial flushing event rinsing accumulated acid weathering products from the mine. Figure 5-7 shows that the mine-pool approaches $100 \%$ neutralization with alkalinity by 1992 , or about 6 years after flooding was complete. The decline in metals concentrations, and estimated maximum acid production, which is calculated from sulfate concentration, is slower in the Arden-Westland mine-pool than the Hahn drainage. Sufficient alkalinity enters, or is generated in the Arden-Westland mine-pool, to approach $100 \%$ neutralization.

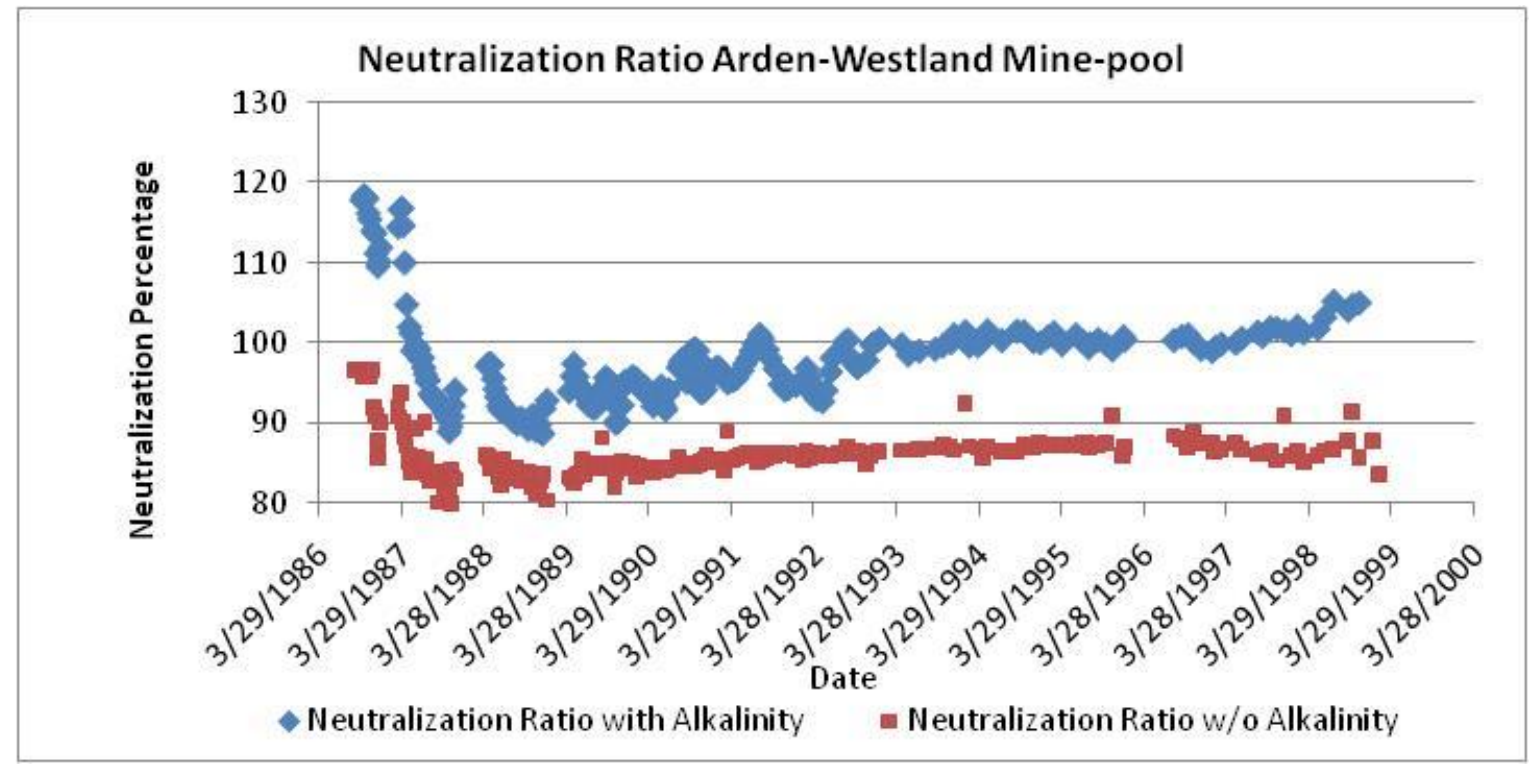

Figure 5-7. Neutralization Ratio, Computed with Alkalinity (Blue) and without Alkalinity (Red) Mostly Flooded, Neutral Arden-Westland Mine-pool.

Figure 5-7 shows that neutralization ratio, excluding alkalinity, reached a near steady condition by about 1992, or six years after flooding was complete. It is equivalent to flushing about 1.5 pool volumes after flooding was complete, and is similar to the behavior of the Hahn discharge. No seasonal effects on neutralization ratio including or excluding alkalinity were identified. Pumping dampens seasonal influences, if any occur. 


\subsubsection{Neutralization Estimate by Mass Balance Cation Sum Methods}

Neutralization ratio was also calculated for three mine-pools, one acidic (Omega) and two alkaline (Hahn and Arden-Westland) using the cation/anion summation strong acid neutralization ratio method described by James (1984) and shown in equation 5-4. The three mine-pools have major cation/anion analysis for at least a portion of the monitoring record. The average neutralization ratio derived from James cation/anion summation method (equation 5-4), and the ratio obtained from equation 5-10a for the same sample subsets are summarized in table 5-2. Equation 5-10a and James' method both estimate total acid production from sulfate concentration. Both methods are subject to underestimating total acid production if some sulfate is retained in the mine-pool. Rose and Elliot (2000) reported that some sulfate was adsorbed to Fe oxyhydroxides surfaces at low $\mathrm{pH}$. The two methods differ where James estimates neutralization equivalent from cation concentrations, while equation 5-10a estimates neutralization by difference between maximum acid production and observed $\mathrm{Fe}$ and $\mathrm{H}^{+}$. Results from equation 5-10a are identified as the difference method in table 5-2.

The average difference between James' (1984) method and equation 5-10a was only about $4 \%$ for the Omega mine-pool and about 7 to $8 \%$ for the two alkaline mine-pools. Differences between methods for individual sample events were usually less than $10 \%$. James (1984) cation summation method was consistently less than the difference method in the Hahn and Arden-Westland mine-pools. The difference method, equation 5-10a, is a lumped parameter that does not provide an account of the contributing components. Therefore it can't be readily resolved as either over or underestimating in-situ neutralization. It is possible that James method may under-estimate neutralization if other cations, for example $\mathrm{Zn}$, are present in mine water, but are not included in the calculation.

Table 5-2

Neutralization Ratio by Cation Sum and Mass Balance Difference Methods

\begin{tabular}{ccccc}
\hline Mine & $\mathrm{n}$ & $\begin{array}{c}\text { Mean Neutralization } \\
\text { Ratio, James (1984) } \\
\text { Cation Summation } \\
\text { Method }\end{array}$ & $\begin{array}{c}\text { Mean Neutralization } \\
\text { Ratio, Mass Balance } \\
\text { Method } \\
\text { (equation 5-10a) }\end{array}$ & $\begin{array}{c}\text { Mean Neutralization } \\
\text { Ratio, Speciation } \\
\text { Method }\end{array}$ \\
\hline Omega & 76 & $68.7 \%$ & $63.9 \%$ & 73.5 \\
$\begin{array}{c}\text { Hahn } \\
\text { (Montour 4) }\end{array}$ & 420 & $87 \%$ & $95 \%$ & 90.6 \\
$\begin{array}{c}\text { Arden- } \\
\text { Westland }\end{array}$ & 220 & $89 \%$ & $96 \%$ & - \\
\hline
\end{tabular}

The two methods give similar results, and either should be useful for characterizing the extent of in-situ neutralization. The mass balance by difference method (5-10a) can be used on acid waters with more limited analytical parameters. Neutralization ratio in mine waters with measurable carbonate alkalinity should be calculated using equation $5-10 \mathrm{~b}$ or a modified form of James method that includes bicarbonate and carbonate ions. 


\subsubsection{Neutralization Ratio From Speciated Mine Water Solutions}

The third method for estimating neutralization ratio consisted of speciating water data from two mine-pools, one acidic (Omega) and one circumneutral (Hahn-Montour 4). The purpose was to determine whether quantifying complexes and reactions that either consume or produce $\mathrm{H}^{+}$should be included in a neutralization calculation. The alternative was that contribution of solution complexes is small enough that they can be neglected without causing serious error. Carbonate and bicarbonate species were not included in the speciation tabulation to allow direct comparison to James' method and equation 5-10a. For mine waters with measureable alkalinity like the Hahn-Montour 4 discharge, a complete accounting of in-situ neutralization should include carbonate and bicarbonate species

Solutions reporting major cations and anions were speciated using PHREEQCI (Parkhurst and Appelo, 1999). For the Omega mine-pool, this included about 75 sample events with reported dissolved constituents of $\mathrm{Fe}^{2+}(\mathrm{Fe}(\mathrm{II}))$ and $\mathrm{Fe}^{3+}(\mathrm{Fe}(\mathrm{III}))$. The redox state of the water was calculated assuming equilibrium with the $\mathrm{Fe}(\mathrm{II}) / \mathrm{Fe}$ (III) couple. A small number of samples collected by the author at the Omega mine-pool included field measured Eh and redox state for these samples is based on that measurement. The measured and calculated Eh readings, while collected at different time periods, were consistent.

No Eh or $\mathrm{Fe}(\mathrm{II}) / \mathrm{Fe}(\mathrm{III})$ data were available for the Hahn discharge. Redox state was initially calculated for about 420 Hahn samples using the PHREEQCI default of pe equal to four. The results of this run showed over-saturation for $\mathrm{Fe}(\mathrm{OH})_{3(\mathrm{am})}$ and other less soluble Fe oxyhydroxide minerals for many samples. The pe was adjusted to zero to represent more reduced conditions in several subsequent runs. This produced solutions that were slightly under-saturated for $\mathrm{Fe}(\mathrm{OH})_{3(\mathrm{am})}$. A pe of zero therefore approximately represents a Hahn mine-pool redox state that could contain the concentrations of dissolved Fe reported in the data set, without exceeding saturation for an Fe hydroxide mineral. These adjusted runs were used to estimate distribution of redox-sensitive species of Fe for the Hahn mine-pool.

Acid consuming and acid producing species were identified, and their contributions to overall neutralization quantified by modifying equation 5-10a. The concept is summarized as:

Neutralization Ratio $=$

$\left(\left(\right.\right.$ EMAP- $\left(\right.$ Acidity $_{\text {pyrite }}+\mathrm{H}^{+}$Production $-\mathrm{H}^{+}$Consumption $\left.)\right) /$EMAP $) * 100$

where:

EMAP $=$ Estimated Maximum acid production, based on sulfate concentration as defined in equation 5-7.

Acidity pyrite $=\mathrm{pH}$, and $\mathrm{H}^{+}$not yet produced, represented by soluble iron that has not hydrolyzed, as defined in equation 5-9. 
$\mathrm{H}^{+}$Production = hydrolysis complexes and solution $\mathrm{H}^{+}$.

$\mathrm{H}^{+}$Consumption = oxidation of $\mathrm{Fe}(\mathrm{II})$ to $\mathrm{Fe}(\mathrm{III})$, and formation of $\mathrm{HSO}_{4}{ }^{-}$and related species.

Tables 5-3 and 5-4 summarize the acid producing and acid consuming complexes and reactions, respectively. $\log \mathrm{K}$ data are for $25^{\circ} \mathrm{C}$ and are drawn from the PHREEQCI databases. Table 5-3 includes a series of hydrolyzed complexes of $\mathrm{Fe}, \mathrm{Al}, \mathrm{Ca}$ and $\mathrm{Mg}$ that produce $\mathrm{H}^{+}$. The principal $\mathrm{H}^{+}$consuming processes in table 5-4 are the oxidation of ferrous to ferric $\mathrm{Fe}$, and the formation of bisulfate and related complexes. The calculated equilibrium concentrations of the components in table 5-3 were summed, and then included as $\mathrm{H}^{+}$Production in equation 5-11. The acid consuming complexes and reactions in Table 5-4 were likewise included in equation 5-11 as $\mathrm{H}^{+}$consumption. The last four entries in table 5-4 are metal bisulfate complexes. They are included as indirect acid consumers because the bisulfate ion consumes one mole of $\mathrm{H}^{+}$.

Table 5-3

Solution Complexes With Hydrolysis That Produce $\mathrm{H}^{+}$

\begin{tabular}{lcl}
\hline Reaction & Moles $\mathrm{H}^{+}$Produced & log K \\
\hline $\mathrm{Ca}^{+2}+\mathrm{H}_{2} \mathrm{O}=\mathrm{CaOH}^{+}+\mathrm{H}^{+}$ & 1 & -12.78 \\
$\mathrm{Mg}^{+2}+\mathrm{H}_{2} \mathrm{O}=\mathrm{MgOH}^{+}+\mathrm{H}^{+}$ & 1 & -11.44 \\
$\mathrm{Al}^{+3}+\mathrm{H}_{2} \mathrm{O}=\mathrm{AlOH}{ }^{+2}+\mathrm{H}^{+}$ & 1 & -5.0 \\
$\mathrm{Al}^{+3}+2 \mathrm{H}_{2} \mathrm{O}=\mathrm{Al}(\mathrm{OH})^{2+}+2 \mathrm{H}^{+}$ & 2 & -10.1 \\
$\mathrm{Al}^{+3}+3 \mathrm{H}_{2} \mathrm{O}=\mathrm{Al}(\mathrm{OH})_{3}+3 \mathrm{H}^{+}$ & 3 & -16.9 \\
$\mathrm{Al}^{+3}+4 \mathrm{H}_{2} \mathrm{O}=\mathrm{Al}(\mathrm{OH})^{4-}+4 \mathrm{H}^{+}$ & 4 & -22.7 \\
$\mathrm{Fe}^{+3}+2 \mathrm{H}_{2} \mathrm{O}=\mathrm{Fe}(\mathrm{OH})^{2+}+2 \mathrm{H}^{+}$ & 2 & -5.67 \\
$\mathrm{Fe}^{+3}+3 \mathrm{H}_{2} \mathrm{O}=\mathrm{Fe}(\mathrm{OH})_{3}+3 \mathrm{H}^{+}$ & 3 & -12.56 \\
$\mathrm{Fe}^{+3}+4 \mathrm{H}_{2} \mathrm{O}=\mathrm{Fe}(\mathrm{OH})_{4}{ }^{-}+4 \mathrm{H}^{+}$ & 4 & -21.6 \\
$\mathrm{Fe}^{+2}+2 \mathrm{H}_{2} \mathrm{O}=\mathrm{Fe}(\mathrm{OH})_{2}+2 \mathrm{H}^{+}$ & 2 & -20.57 \\
$\mathrm{Fe}^{+2}+3 \mathrm{H}_{2} \mathrm{O}=\mathrm{Fe}(\mathrm{OH})_{3}{ }^{-}+3 \mathrm{H}^{+}$ & 3 & -31.0 \\
$3 \mathrm{Fe}^{+3}+4 \mathrm{H}_{2} \mathrm{O}=\mathrm{Fe}(\mathrm{OH})_{4}+5+4 \mathrm{H}^{+}$ & 4 & -6.3 \\
$2 \mathrm{Fe}^{+3}+2 \mathrm{H}_{2} \mathrm{O}=\mathrm{Fe}_{2}(\mathrm{OH})_{2}+4+2 \mathrm{H}^{+}$ & 2 & -2.95 \\
$\mathrm{Fe}^{+2}+\mathrm{H}_{2} \mathrm{O}=\mathrm{FeOH}{ }^{+}+\mathrm{H}^{+}$ & 1 & -9.5 \\
$\mathrm{Fe}^{+3}+\mathrm{H}_{2} \mathrm{O}=\mathrm{FeOH}{ }^{+2}+\mathrm{H}^{+}$ & 1 & -2.19 \\
\hline
\end{tabular}

Table 5-4

Solution Complexes and Reactions That Consume $\mathrm{H}^{+}$

\begin{tabular}{|c|c|c|}
\hline Reaction & Moles $\mathrm{H}^{+}$Consumed & $\log \mathrm{K}$ \\
\hline $\mathrm{Fe}^{2+}+1 / 4 \mathrm{O}_{2}+\mathrm{H}^{+}=\mathrm{Fe}^{3+}+1 / 2 \mathrm{H}_{2} \mathrm{O}$ & 1 & 7.76 \\
\hline $\mathrm{H}^{+}+\mathrm{SO}_{4}^{-2}=\mathrm{HSO}_{4}^{-}$ & 1 & 1.98 \\
\hline $\mathrm{Fe}^{+2}+\mathrm{HSO}_{4}^{-}=\mathrm{FeHSO}_{4}^{+}$ & 1 from $\mathrm{HSO}_{4}^{-}$ & 1.08 \\
\hline $\mathrm{Fe}^{+3}+\mathrm{HSO}_{4}^{-}=\mathrm{FeHSO}_{4}^{+2}$ & 1 from $\mathrm{HSO}_{4}^{-}$ & 2.48 \\
\hline $\mathrm{Ca}^{+2}+\mathrm{HSO}_{4}^{-}=\mathrm{CaHSO}_{4}^{+}$ & 1 from $\mathrm{HSO}_{4}^{-}$ & 1.08 \\
\hline $\mathrm{Al}^{+3}+\mathrm{HSO}_{4}^{-}=\mathrm{AlHSO}_{4}{ }^{+2}$ & 1 from $\mathrm{HSO}_{4}^{-}$ & 0.46 \\
\hline
\end{tabular}


The mean neutralization ratio using speciation calculations was $73.5 \%$ for the Omega mine-pool (see table 5-2), compared to 68.7\% using James (1984) method, or $63.9 \%$ using the difference method based on equation 5-10a. The inclusion of hydrolysis species from table 5-3 had minimal affect on results, and typically comprised less than one percent of the acid generating capacity of the system. $\mathrm{Fe}(\mathrm{II}) / \mathrm{Fe}(\mathrm{III})$ oxidation accounted for about $80 \%$ of the $\mathrm{H}^{+}$consumption in speciation calculations, and is the main factor that produces results different from the other two methods. The mean distribution of acid producing and acid consuming complexes and processes, expressed in $\mathrm{CaCO}_{3} \mathrm{Eq}$., and is shown in figure 5-8 for the Omega mine-pool.

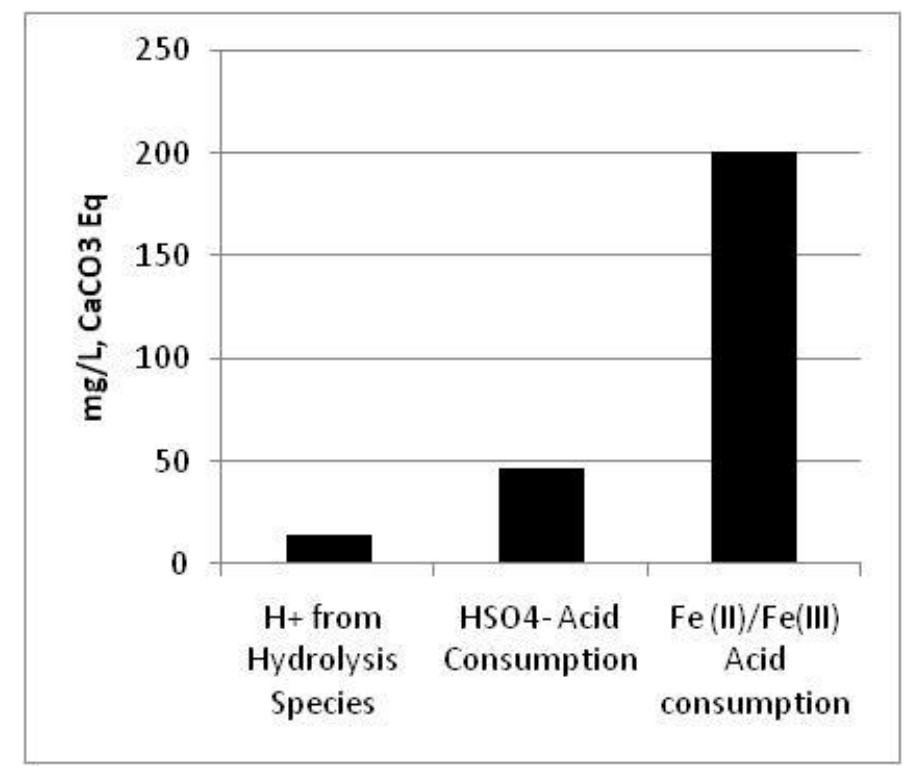

Figure 5-8. Mean Acid Producing and Acid Consuming Solution Complexes and Reactions, Omega Mine-pool. Concentrations in mg/L $\mathrm{CaCO}_{3}$ Eq.

In oxidizing environments like the Omega mine-pool, speciating the solution chemistry will probably yield a higher estimate of in-situ neutralization. This is mostly due to $\mathrm{H}^{+}$ consumption in $\mathrm{Fe}(\mathrm{II}) / \mathrm{Fe}(\mathrm{III})$ oxidation. If sufficient data are available to characterize $\mathrm{Fe}$ species distribution, speciating the water data may provide an improved estimate of insitu neutralization.

Mean neutralization in the Hahn mine-pool was $90.6 \%$ using speciated data, compared to $87 \%$ by James (1984) cation sum method and 95\% from the difference approach in equation 5-10a. Unlike the Omega mine-pool, Fe resides overwhelmingly as $\mathrm{Fe}(\mathrm{II})$ and minimal $\mathrm{H}^{+}$consumption occurs from Fe oxidation. Hydrolysis and $\mathrm{HSO}_{4}{ }^{-}$species had negligible effect on neutralization estimates.

James (1984), equation 5-10a, and the speciation method presented here, are all designed for acid waters without measureable alkalinity. A complete accounting of neutralization in mine-pools with alkalinity should include contribution of carbonate species. Equation $5-10 \mathrm{~b}$ is one such approach. James method and the speciation method could be modified to include carbonate species. 
The observed differences among methods are relatively small and each technique is suitable for estimating in-situ neutralization for planning purposes. The method of choice will be determined by the available data. In reduced mine-pool environments where $\mathrm{Fe}(\mathrm{II}) / \mathrm{Fe}$ (III) oxidation is restrained, there is little advantage to speciating solution composition to estimate in-situ neutralization.

\subsubsection{Sources of In-Situ Neutralization}

The apparent acid neutralization ratio of 60 to 80 percent in the Omega and T\&T minepools is remarkable considering that the rock strata in this geological section near the mined Upper Freeport coal bed contain few carbonates (Hennen and Reger, 1913). Limited Acid Base Accounting analyses of roof and floor rock material of the Omega mine (EPRI, 2001) show a large excess of acid generating capacity and little carbonate present. Where does the in-situ neutralization originate? The following processes were considered:

- Alumino-silicate weathering and dissolution of oxyhydroxides

- Recharge water alkalinity

- Carbonate weathering

- Sulfate reduction

- Cation exchange and adsorption reactions

Mine-pool aquifers include some overburden rocks that have been disrupted by mining. Kendorski (1993) proposed a five layer subsidence model, and a zone of fracturing extending up to 24 times mine height which includes a collapsed overburden zone estimated as six to ten times mine height. The extent and severity of sagging, cracking, bedding plane separation, breakage and collapse of the overlying strata is a function of the type of mining and remaining support, and strength characteristics of the overburden rocks. Collapse and breakage can be near instantaneous, as in long wall mining, or may occur over years as pillars and roof supports weaken. Subsidence adds chemical and mineralogical content of overburden rocks to mine-pool chemistry.

Most of the water quality data in this study were originally collected for monitoring purposes, not research. Consequently, complete suite tests, redox measurements, mineralogical samples and other data useful for detailed source analyses are not available for many water samples. However, some partitioning of processes is possible.

Table 5-5 summarizes chemical characteristics of ground-waters recharging the five mine-pools. Recharge water sulfate ranges from about 14 to $53 \mathrm{mg} / \mathrm{L}$ and is an order of magnitude or more lower than corresponding mine-pool water in table 5-1. Calcium, Mg, and $\mathrm{Na}$ concentrations in recharge waters are also significantly less than mine-pool waters. The contrasting water compositions in tables 5-1 and 5-5 show that substantial chemical weathering of various minerals must be occurring in mine-pools, and that the weathering reactions include in-situ $\mathrm{H}^{+}$consumption as well as $\mathrm{H}^{+}$generation. Data in table 5-5 for the Omega and T\&T mine-pools are site-specific overburden ground water samples, while data for the other three were estimated from published well records in the locale. 
Table 5-5

Chemical Characteristics of Recharge Waters for Five Mine-pools ${ }^{(1)}$

\begin{tabular}{ccccccccc}
\hline Mine-pool & $\mathrm{pH}$ & Alkalinity & $\mathrm{Fe}$ & $\mathrm{Al}$ & $\mathrm{SO}_{4}$ & $\mathrm{Ca}$ & $\mathrm{Mg}$ & $\mathrm{Na}$ \\
\hline Omega & 7.2 & 100 & 0.4 & 0.05 & 14 & 40 & 10 & 3.5 \\
T\&T & 6.7 & 120 & 0.6 & 0.2 & 21 & 39 & 9 & 3.9 \\
Hahn & 7.4 & 260 & 0.3 & - & 53 & 76 & 17 & 30 \\
Arden-Westland & & & 0.3 & 0.1 & 27 & 43 & 6 & 2 \\
Barnes\&Tucker & 7.0 & 142 & 0.3 &
\end{tabular}

(1) $\mathrm{pH}$ in S.U., alkalinity in $\mathrm{mg} / \mathrm{L} \mathrm{CaCO}_{3} \mathrm{Eq} ., \mathrm{Fe}, \mathrm{Al}, \mathrm{SO}_{4}, \mathrm{Ca}$,

$\mathrm{Mg}$ and $\mathrm{Na}$ in $\mathrm{mg} / \mathrm{L}$. Recharge water composition from

ground-water samples at T\&T and Omega, data from

Williams et al. (1993), for Hahn and Arden-Westland, and data from

McElroy (1998), for Barnes\&Tucker.

\subsubsection{Neutralization from Aluminum Mineral Weathering}

The Omega and T\&T mine-pool discharges contain high concentrations of dissolved Al. Ground-waters circulating in non-acidified overburden aquifers contain insignificant amounts of soluble $\mathrm{Al}$ (see table 5-5). Soluble Al must be generated by weathering reactions within the mine-works.

Alumino-silicate minerals are generally slow to dissolve in low temperature settings. Jambor et al (2002) found that alumino-silicates did contribute a small amount to the Neutralization Potential test and tended to react at rates five to eight orders of magnitude slower than for carbonates. Both Jambor et al. (2002), and Eary and Williamson (2006), report that feldspar minerals react too slowly to provide effective acid neutralization, while other mineral such as calcic plagioclase were more significant acid neutralizers. Rate data, summarized by Palandri and Kharaka (2004), show kaolinite dissolution to be ten orders of magnitude slower than calcite under acid conditions. The acid weathering constant for kaolinite is about 100 times faster than at neutral $\mathrm{pH}$, however. The slow weathering rates for alumino-silicate minerals are compensated by their abundance in rocks and sediments.

The concentrations of soluble $\mathrm{Al}$ and $\mathrm{Si}$ measured in the acidic Omega and T\&T minepools are indicative of alumino-silicate dissolution. These drainages are relatively rich in $\mathrm{Mg}$ when compared to recharge water composition, and the mineral chlorite as one $\mathrm{Mg}$ source is commonly present in these rocks (Dulong et al., 2002). The complete dissolution of chlorite consumes $\mathrm{H}^{+}$as follows:

$$
\mathrm{Mg}_{5} \mathrm{Al}_{2} \mathrm{Si}_{3} \mathrm{O}_{10}(\mathrm{OH})_{8}+16 \mathrm{H}^{+} \rightarrow 5 \mathrm{Mg}^{2+}+2 \mathrm{Al}^{3+}+3 \mathrm{H}_{4} \mathrm{SiO}_{4}+6 \mathrm{H}_{2} \mathrm{O}
$$

If $\mathrm{Al}$ is subsequently precipitated as hydroxide, the net acid consumption is still ten mmoles of $\mathrm{H}^{+}$per mmole of chlorite consumed. Weathering of other alumino-silicates is also typically acid consuming. Dolomite dissolution is another potential $\mathrm{Mg}$ source.

The dissolution of $\mathrm{Al}$ hydroxides also consumes three moles of $\mathrm{H}^{+}$per mole of $\mathrm{Al}$ : 


$$
\mathrm{Al}(\mathrm{OH})_{3}+3 \mathrm{H}^{+} \leftrightarrow \mathrm{Al}^{3+}+3 \mathrm{H}_{2} \mathrm{O}
$$

As shown in equation 5-5, congruent dissolution of Al bearing minerals like kaolinite also consumes three moles of $\mathrm{H}^{+}$per mole of $\mathrm{Al}$ produced.

Two conditions favor acid neutralization by alumino-silicates; a very aggressive chemical weathering environment, or a lengthy residence time in the mine-pool. The aggressive weathering environment exists within the Omega and T\&T mine-pools, characterized by solution $\mathrm{pH}$ of less than 3.0. That condition has persisted in those two mine-pools for more than ten years.

An average mine-pool residence time has been estimated from discharge records for the five mine-pools, and ranges from as little as 6 months to about 4 years. These estimates are based on a simple flow-through model and do not account for short circuiting, tortuosity, or no-flow zones. Nonetheless, these estimates suggest relatively short residence times in comparison to other bedrock aquifers and flow systems in Upper Pennsylvanian age rocks of the Appalachian region.

The fraction of in-situ neutralization provided by alumino-silicate and oxyhydroxide mineral weathering was estimated, based on three moles of $\mathrm{H}^{+}$per mole of Al for the Omega and T\&T mine-pools, and assuming the increases in $\mathrm{Al}$ concentration result from mineral weathering in the mine-pool.

Figure 5-9 is a time series plot of "pyrite acidity" (equation 5-9), $\mathrm{H}^{+}$consumption attributed to aluminum mineral weathering, and $\mathrm{H}^{+}$consumption attributed to $\mathrm{Ca}, \mathrm{Mg}, \mathrm{Na}$

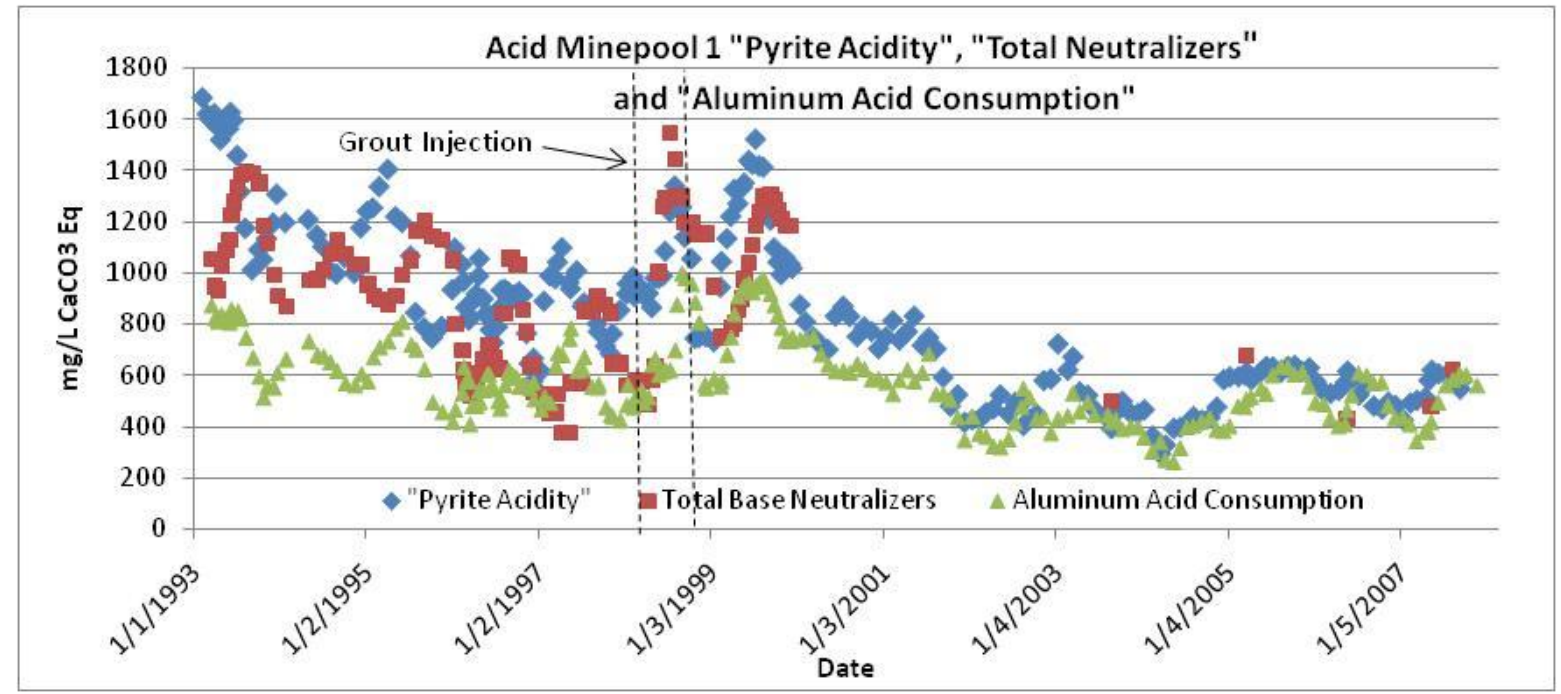

Figure 5-9. "Pyrite Acidity"(Blue), Base Neutralizers (Red), and $\mathrm{H}^{+}$Consumption from Alumino-Silicate Mineral Weathering (Green), Omega Mine-pool.

and $\mathrm{K}$ mineral weathering ("total neutralizers") in the Omega mine-pool. $\mathrm{H}^{+}$consumption was compiled as three moles $\mathrm{H}^{+}$per mole $\mathrm{Al}$, two moles $\mathrm{H}^{+}$per mole of $\mathrm{Ca}$ and $\mathrm{Mg}$, and one mole $\mathrm{H}^{+}$for $\mathrm{Na}$ and $\mathrm{K}$. Each parameter is plotted as $\mathrm{mg} / \mathrm{L} \mathrm{CaCO} 3 \mathrm{Eq}$., the customary 
units for reporting acidity and alkalinity, to facilitate direct comparison. Al mineral dissolution averages the equivalent of $465 \mathrm{mg} / \mathrm{L}$ acid consumption, or about $40 \%$ of the total neutralization occurring in the mine-pool. All three parameters decrease as the minepool ages, showing declining weathering capacity. The effects of grout injection in 1999 are clearly visible, displacing accumulated weathering products as a short term increase in acidity, bases and $\mathrm{Al}$.

Weathering of $\mathrm{Al}$ minerals is still occurring after 14 years. The long-term average dissolved $\mathrm{Al}$ content is equivalent to consuming about 1.5 mmoles of kaolinite per liter of mine-pool solution.

Figure 5-10 shows the distribution of pyrite acidity, base neutralizers and $\mathrm{H}^{+}$ consumption attributed to weathering of alumino-silicates and oxyhydroxide mineral weathering in the T\&T mine-pool. The data were compiled in the same manner as in the Omega mine-pool. Aluminum mineral dissolution averages the equivalent of $195 \mathrm{mg} / \mathrm{L}$ acid consumption, or about $20 \%$ of the total neutralization occurring in the mine-pool.

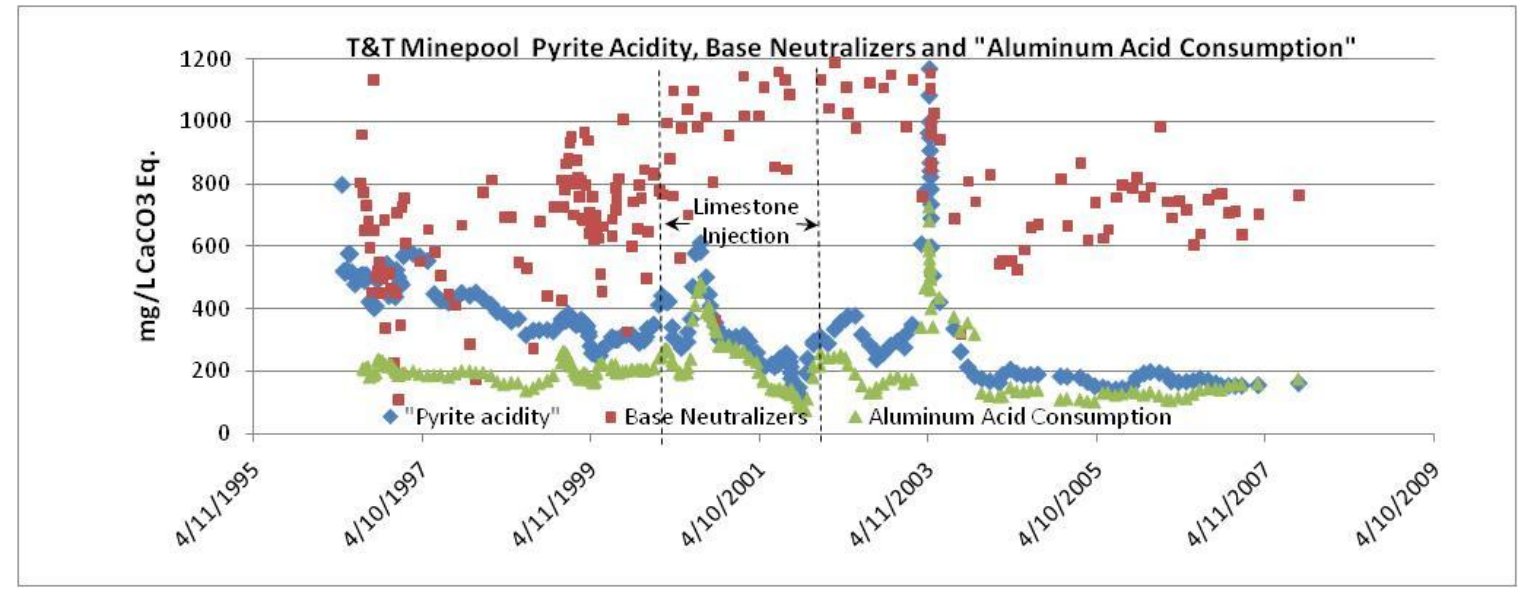

Figure 5-10. "Pyrite Acidity", Base Neutralizers, and $\mathrm{H}^{+}$Consumption from Alumino-Silicate Mineral Weathering, T\&T Mine-pool.

The long-term average dissolved $\mathrm{Al}$ content is equivalent to consuming about $0.7 \mathrm{mmoles}$ of kaolinite per liter of mine-pool solution.

Aluminum concentrations in the three circumneutral mine-pools, Hahn, Arden-Westland and Barnes\&Tucker, are minimal, due to solubility constraints. Thus, there is little direct evidence of alumino-silicate weathering in these mines. However, Al dissolution could occur in the small unflooded and presumably acidic sections, with subsequent secondary mineral formation within the pool.

The Al-sulfate mineral jurbanite is at apparent saturation or super saturation in the Omega mine-pool (Perry and Rauch, 2004, Appendix A) and approaches saturation in the T\&T mine water discharge. Direct examination of solids to confirm or refute the presence of a mineral phase is not possible, because the mine-works are not directly accessible for sediment sampling. Jurbanite could form as an alteration product of kaolinite in sulfate 
rich environments, or as a hydrolysis precipitate product, and is stable in low $\mathrm{pH}$ environments of about three to five (Nordstrom, 1982b):

$$
\begin{aligned}
& \mathrm{Al}_{2} \mathrm{Si}_{2} \mathrm{O}_{5}(\mathrm{OH})_{4}+2 \mathrm{SO}_{4}{ }^{2-}+11 \mathrm{H}_{2} \mathrm{O}+4 \mathrm{H}^{+} \leftrightarrow \\
& 2 \mathrm{AlOHSO}_{4} * 5 \mathrm{H}_{2} \mathrm{O}+2 \mathrm{H}_{4} \mathrm{SiO}_{4} \text { or } \\
& \mathrm{Al}^{3+}+\mathrm{SO}_{4}{ }^{2-}+6 \mathrm{H}_{2} \mathrm{O} \leftrightarrow \mathrm{AlOHSO}_{4} * 5 \mathrm{H}_{2} \mathrm{O}+\mathrm{H}^{+}
\end{aligned}
$$

The possible presence of a mineral phase limiting Al solubility shows that the discharge chemistry, while containing high concentrations of dissolved $\mathrm{Al}$, may actually underestimate the full extent of alumino-silicate mineral dissolution.

Should aluminum mineral weathering be counted as in-situ neutralization? Soluble Al, a component of mineral acidity in mine-pool waters, is usually removed during water treatment by base addition and hydrolysis. That neutralization process neutralizes the three moles $\mathrm{H}^{+}$generated per mole $\mathrm{Al}$ that is precipitated, equal to that originally consumed. In this case, Al weathering produces a net neutralization of zero. Partial hydrolysis, as shown in equation 5-15, generates one mole $\mathrm{H}^{+}$per mole $\mathrm{Al}$, with a net neutralization of two moles $\mathrm{H}^{+}$per mole Al.

The in-situ neutralization data for the Omega and T\&T mine-pools were recalculated to exclude acid consumption by alumino-silicate weathering, assuming that zero net neutralization describes the fate of dissolved Al draining from the mine-pool. The remaining neutralization, termed "effective neutralization" is attributable to other sources, including carbonates, recharge water alkalinity or other processes that do not regenerate acidity elsewhere in the system.

Effective Neutralization is calculated as:

$$
\text { Effective Neutralization Ratio }=\left[\left(\text { EMAP- } \text { Acidity }_{\text {total }}\right) / \text { EMAP }\right] * 100
$$

Where EMAP and Acidity total are as defined in equation 5-7 and 5-8, respectively. Acidity $y_{\text {total }}$ is computed from $\mathrm{Fe}(\mathrm{II}), \mathrm{Al}, \mathrm{Mn}$ and $\mathrm{H}^{+}$, and equation 5-16 simply assigns soluble aluminum exiting the mine-pool a net acid production/neutralization of zero.

Figures 5-11 and 5-12 show mean Neutralization Ratio and Effective Neutralization Ratio values for the Omega and T\&T mine-pools. Both of these mine-pools contain concentrations of dissolved $\mathrm{Al}$ in the tens to more than $100 \mathrm{mg} / \mathrm{L}$. The data are grouped by all records, pregrout or limestone injection and post injection. No calculations were performed for the Hahn, Arden-Westland and the Barnes\&Tucker mine-pools, because their waters contain only small amounts of soluble Al.

"Effective neutralization" in the Omega mine-pool is about 20 to $25 \%$ less when dissolved Al from mineral dissolution is excluded as a neutralization process. Nonetheless, nearly half of the maximum acid production is unaccounted for and is 
attributed to in-situ neutralization. Even after 14 years of aggressive chemical weathering, other minerals or processes must still be supplying acid neutralization to the Omega mine-pool.

A similar trend is apparent in the T\&T mine-pool. In-situ neutralization is reduced about 11 to $15 \%$ when dissolved Al from mineral dissolution is excluded. However, even with this conservative assessment of neutralization, more than half of the projected maximum acid production is "missing" and is attributed to in-situ neutralization. Other minerals or processes must still be consuming $\mathrm{H}^{+}$after more than ten years of weathering in a highly acidic environment.

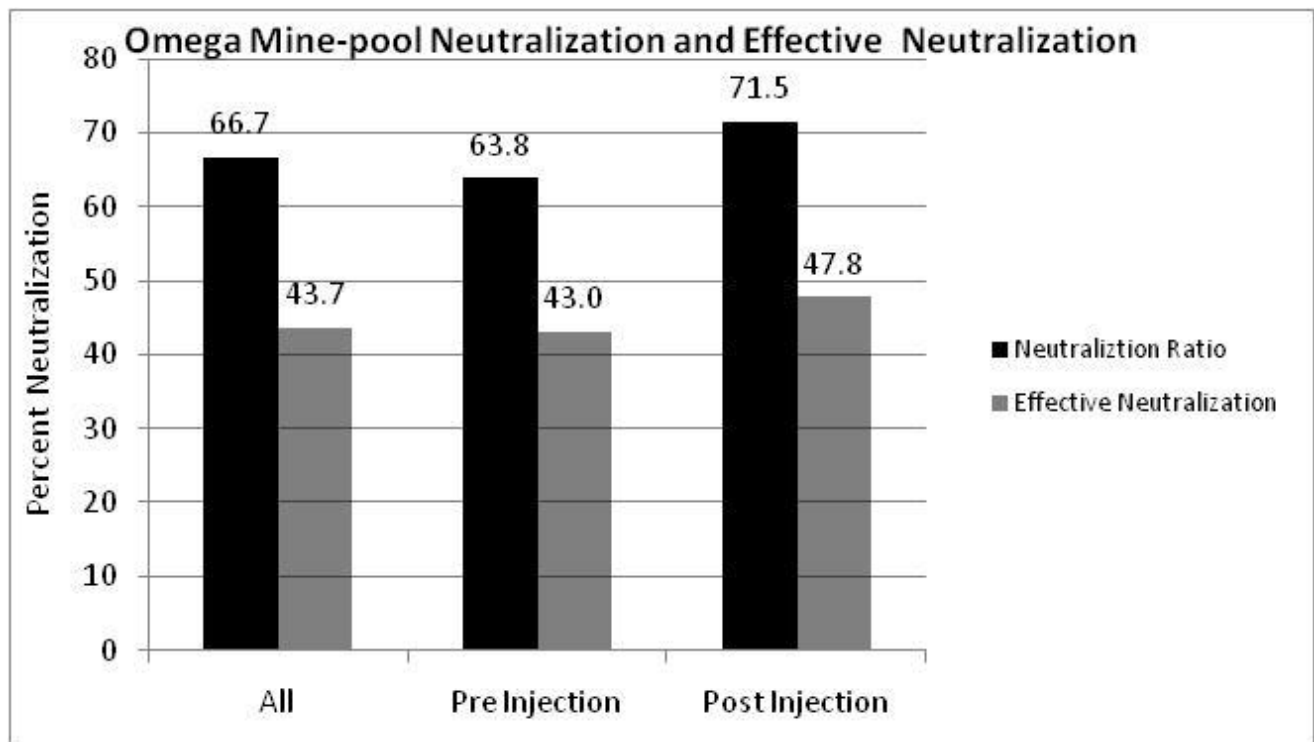

Figure 5-11. Mean Neutralization Ratio and Effective Neutralization Ratio Percentages (Excluding $\mathrm{H}^{+}$Consumption by Al Minerals), Omega Mine-pool.

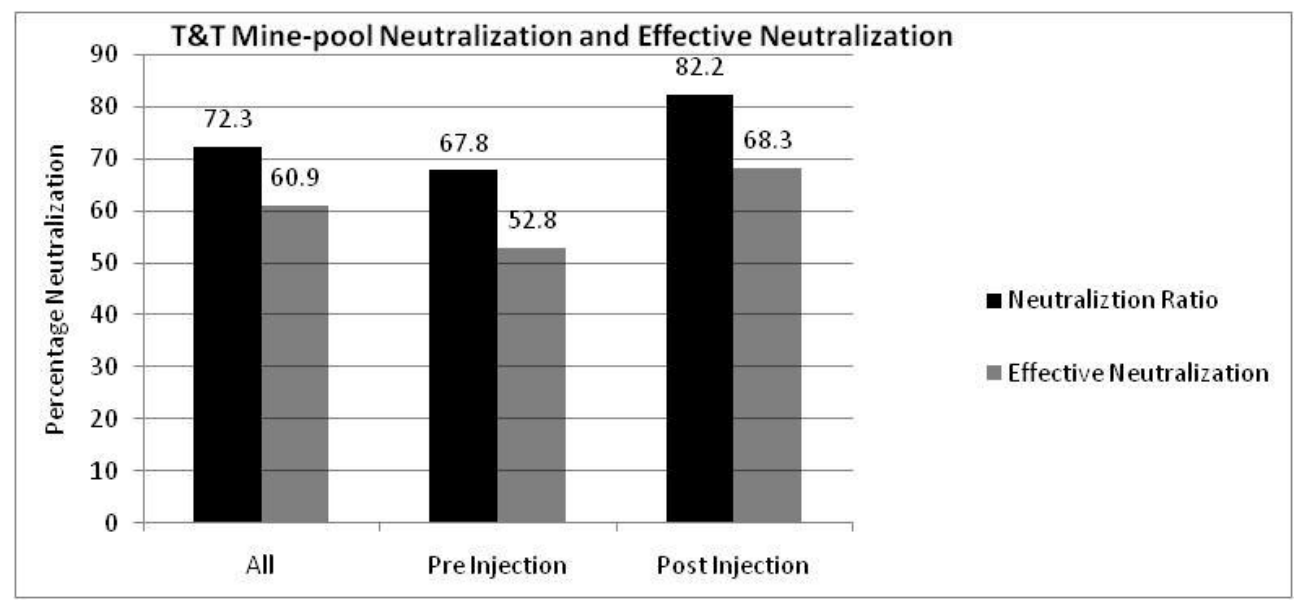

Figure 5-12. Mean Neutralization Ratio and Effective Neutralization Ratio Percentages (Excluding $\mathrm{H}^{+}$Consumption by Al Minerals), T\&T Mine-pool. 
Both mines have increased effective neutralization after grout or limestone treatment. The improvements were a relatively modest gain of about five percent over pre-treatment conditions for Omega, and over 15\% for T\&T. Neutralization data can be used to assess the effectiveness and efficiency of in-situ abatement techniques.

\subsubsection{Neutralization by Recharge Water}

The contribution of recharge water to in-situ neutralization was assessed using a mass balance approach and assuming fixed flow-through conditions. The long term net storage change, $\Delta \mathrm{S}$, in the mine-pool volume is presumed to be zero. This assumption is justified by relatively constant pumping rates and water levels in the Hahn, Arden-Westland and Barnes\&Tucker mine-pools. The Omega and T\&T mine-pools do fluctuate on a short term basis, but display no obvious long term head or discharge changes. Chemistry of recharge water entering mine-pools from overlying aquifers was assessed from a combination of sampling by the author, and review of published background water data. Recharge water alkalinity assigned to each mine is shown in table 5-5, and was assumed to be constant through time. For the Omega and T\&T mine-pools, site specific water data are similar to the average bicarbonate data reported by Hobba (1984) for rocks of the Allegheny group. Recharge alkalinity was potentially significant since it represents an essentially inexhaustible source of acid consumption. Recharge water alkalinity neutralizes acidic mine water as:

$$
\mathrm{HCO}_{3}^{-}+\mathrm{H}^{+} \leftrightarrow \mathrm{H}_{2} \mathrm{CO}_{3}
$$

Recharge water neutralization is expressed as percentage of the total neutralizers:

$\%$ Recharge Neutralization $=($ Recharge Alkalinity $/($ EMAP- Acidity pyrite $) * 100$

where EMAP and Acidity $y_{\text {prrite }}$ are as defined in equation 5-7 and 5-9. The difference of EMAP- Acidity pyrite $_{\text {is }}$ an estimate of the total strong acid neutralization, including alumino-silicate dissolution without differentiating sources. The median results are in table 5-6, summarized for all data, early and late phases of pool flooding. A time series for the Hahn discharge is shown in figure 5-12.

Recharge water alkalinity has the smallest contribution to in-situ neutralization in the two acidic mine-pools; only about 5 to $7 \%$ in Omega and 12 to $14 \%$ in T\&T. Further, the recharge water neutralization is essentially constant or near steady state for a period of more than ten years in both pools. Mineral weathering, including consumption of alumino-silicates and oxhydroxides, continues to be to the principal source of $\mathrm{H}^{+}$ consumption in these two mines. Recharge water alkalinity does not contribute significantly to neutralization in strongly acidic, aggressive weathering environments like the Omega and T\&T mine-pools.

Figure 5-13 shows a trend of increasing recharge water neutralization of the Hahn minepool as it ages. The other alkaline mine-pools also show increasing recharge water neutralization through time as mineral weathering declines (table 5-6). Figure 5-12 shows that recharge water neutralization was minor comprising less than ten percent of total 
neutralizers. Soon after flooding was complete in 1984, recharge neutralization steadily increased afterwards and was 25 to $30 \%$ of the total neutralizers by 1999 . Recharge water contributes to in-situ neutralization, and becomes more important as alkaline mine-pool water ages. This results from recharge water alkalinity remaining constant while acid production and sulfate concentration decline as the mine-pool ages. Recharge alkalinity, while important, is not the dominant neutralization process in the Hahn, Arden-Westland and Barnes\&Tucker mine-pools.

Table 5-6

Fraction of Neutralization

Supplied From Recharge Water Relative to Estimated Total Neutralization ${ }^{(1)}$

\begin{tabular}{|c|c|c|c|c|}
\hline Mine-pool & Recharge Alkalinity & All data & Early Phase & Late Phase \\
\hline Omega & 100 & $\begin{array}{c}6 \% \\
(1677)\end{array}$ & $\begin{array}{c}\text { Pre-inject 5.7\% } \\
(1765)\end{array}$ & $\begin{array}{c}\text { Post-inject } 6.3 \% \\
(1579)\end{array}$ \\
\hline $\mathrm{T} \& \mathrm{~T}$ & 120 & $\begin{array}{l}12.3 \% \\
(1002)\end{array}$ & $\begin{array}{c}\text { Pre-inject } 13.9 \% \\
(908)\end{array}$ & $\begin{array}{c}\text { Post-inject } 12 \% \\
\text { (998) }\end{array}$ \\
\hline Barnes\&Tucker & 142 & $\begin{array}{l}29 \% \\
(488)\end{array}$ & $\begin{array}{l}\text { Pre-flood } 15.6 \% \\
\text { (908) }\end{array}$ & $\begin{array}{c}\text { Post-flood } 39.5 \% \\
(360)\end{array}$ \\
\hline Hahn & 260 & $\begin{array}{l}7.6 \% \\
(3406)\end{array}$ & $\begin{array}{l}\text { Initial Flush } 4.6 \% \\
\qquad(5653)\end{array}$ & $\begin{array}{l}\text { Post-flush 19\% } \\
\text { (1337) }\end{array}$ \\
\hline Arden-Westland & 260 & $\begin{array}{l}21.3 \% \\
(1220)\end{array}$ & $\begin{array}{c}\text { Initial Flush } 20 \% \\
(1316)\end{array}$ & $\begin{array}{l}\text { Post-flush } 32 \% \\
\text { (801) }\end{array}$ \\
\hline
\end{tabular}

(1) Recharge alkalinity in $\mathrm{mg} / \mathrm{L} \mathrm{CaCO}_{3}$ Eq. Values in parentheses are estimated total neutralizers in $\mathrm{mg} / \mathrm{L} \mathrm{CaCO} 3$ Eq. Early phase is initial flooding and flushing, late phase is long term weathering.

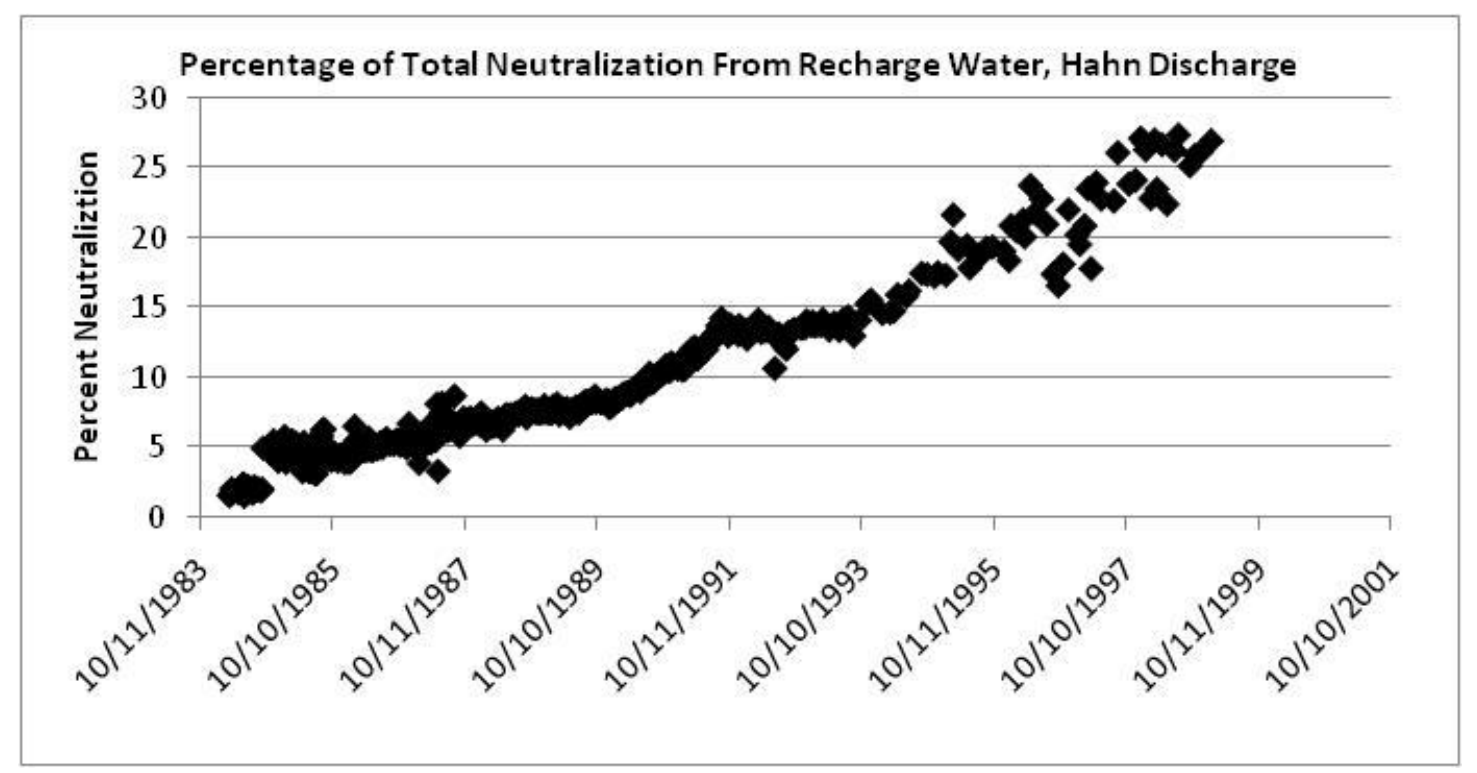

Figure 5-13. Estimated Percentage of Neutralization Supplied by Recharge Water, Hahn Mine-pool Discharge. 


\subsubsection{Neutralization by Carbonate Mineral Weathering}

Carbonate minerals are the most obvious source minerals to provide in-situ neutralization in a mine-pool aquifer. The increase in mine-pool $\mathrm{Ca}$ and $\mathrm{Mg}$ concentrations over that supplied by ground water recharge could represent weathering of carbonates within the mine-pool, and perhaps of other minerals such as chlorite as a Mg source. The additional mine-pool $\mathrm{Ca}$ and $\mathrm{Mg}$ sum exceeding recharge water concentration was converted to $\mathrm{CaCO}_{3}$ Eq., as if it all represents carbonate mineral neutralization. The amount of total neutralizers calculated from equation 5-10 (difference method), and neutralization attributed to increased mine-pool $\mathrm{Ca}$ and $\mathrm{Mg}$ were compiled for the Hahn discharge, and parts of the Omega and Arden-Westland records. Results are shown figure 5-14 to 5-16 and represent median values.

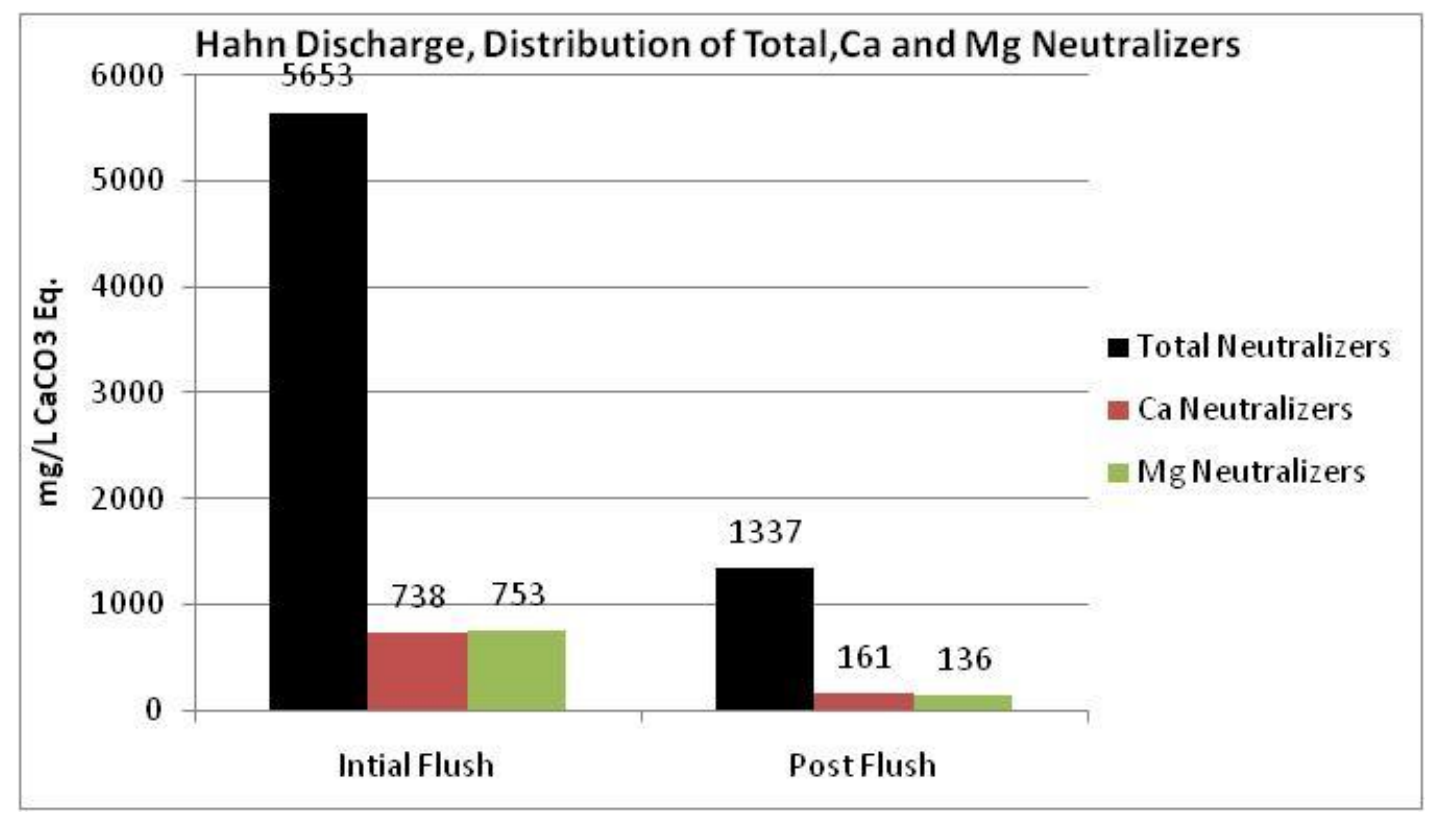

Figure 5-14. Hahn Discharge Distribution of Total

$\mathrm{Ca}$ and Mg Neutralization in Initial Flushing and Post Flushing.

The Hahn discharge has extremely high neutralization values, exceeding $5000 \mathrm{mg} / \mathrm{L}$ $\mathrm{CaCO}_{3}$ Eq. during initial flushing (fig 5-14). Calcium and $\mathrm{Mg}$ combined represent about $1500 \mathrm{mg} / \mathrm{L}$, or $26 \%$ of the total neutralizers. The remainder is attributed to $\mathrm{Na}$, which was present in excess of $2000 \mathrm{mg} / \mathrm{L}$ initially. Donovan et al. (2003) report that the pool was near saturation for calcite during initial flushing, so it seems likely that mine-pool carbonate dissolution accounts for part of the observed $\mathrm{Ca}$ and $\mathrm{Mg}$. Post-flushing neutralization values declined to less than $20 \%$ of initial conditions as shown in figure 514 , and $\mathrm{Ca}$ and $\mathrm{Mg}$ account for $22 \%$ of the total. The post-flushing waters are undersaturated for calcite (Donovan, 2003), so carbonate contribution is less certain.

The acidic Omega discharge (figure 5-15) had median neutralization of $1765 \mathrm{mg} / \mathrm{L}$ $\mathrm{CaCO}_{3}$ Eq., of which about $51 \%$ was attributable to $\mathrm{Ca}$ and $\mathrm{Mg}$. The remainder is mostly accounted for by weathering of $\mathrm{Al}$ minerals (section5.2.4.1). The waters are orders of magnitude under-saturated for calcite and the $\mathrm{Mg}$ bearing mineral chlorite, but are 
slightly under-saturated for gypsum as determined from equilibrium calculations in PHREEQCI.

The Arden-Westland drainage (figure 5-16) had the lowest total neutralizers, and Ca and $\mathrm{Mg}$ accounted for almost $70 \%$ of the total. Sodium accounted for most of the remaining neutralization. The waters were under-saturated for both calcite and gypsum as determined by equilibrium calculations in PHREEQCI.

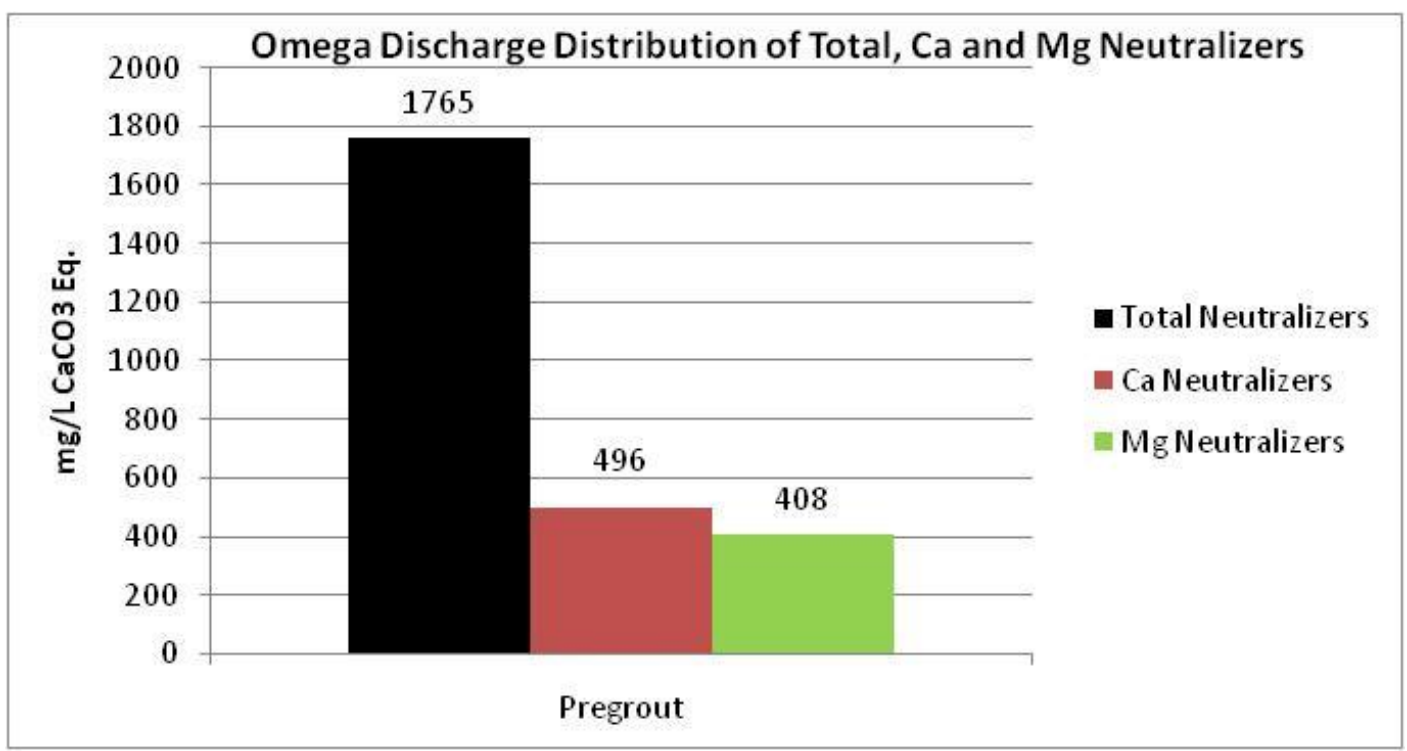

Figure 5-15. Omega Discharge Distribution of Total Ca and Mg Neutralization before Grout Injection.

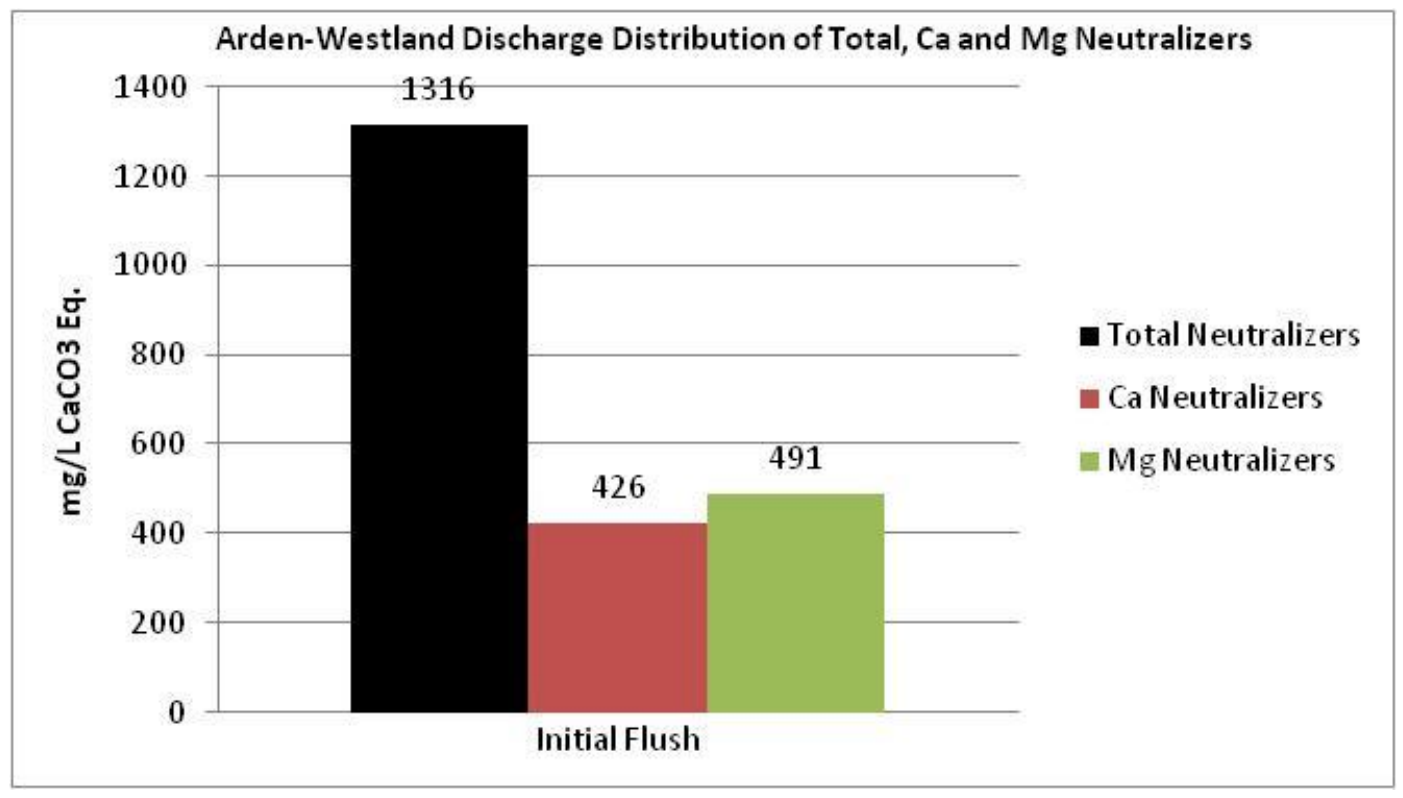

Figure 5-16 Arden-Westland Discharge Distribution of Total $\mathrm{Ca}$ and Mg Neutralization in Initial Flushing. 
All three mines show significant consumption of $\mathrm{Ca}$ and $\mathrm{Mg}$ minerals, although the precise source(s) can only be inferred from solubility considerations, solution composition and general mineralogy of the rocks. Solubility controls complicate interpretation of the discharge chemistry. Gypsum controls on soluble Ca could not be discounted for the Omega and Hahn mine-pools, and common ion effects of Ca-gypsumcalcite could control Ca. Appendix B describes inverse modeling of water quality evolution in Pittsburgh coal bed mine-pools. Those models show that carbonate dissolution, and other mineral reactions, including gypsum dissolution could explain the generation of alkaline mine waters and changes in solution composition. Modeling results described in Appendix B suggest that carbonate dissolution is probably the single most important mineral neutralization mechanism in mine-pools. Magnesium has potential source minerals other than carbonates, such as chlorite, and changes in $\mathrm{Mg}$ concentration could not be assigned solely to carbonate minerals.

\subsubsection{Neutralization by Sulfate Reduction}

Sulfate reduction occurs in oxygen poor environments, like flooded mine-pools, and produces bicarbonate alkalinity. At $\mathrm{pH} 7$ and $25^{\circ} \mathrm{C}$, the equilibrium sulfide-sulfate redox couple is -217 mill volts (Langmuir, 1997). Sulfate reduction is unlikely to take place in aerated Omega and T\&T mine-pools, where dissolved oxygen levels of one to more than five $\mathrm{mg} / \mathrm{L}$ were measured by the author. The flooded sections of Arden-Westland, Hahn and Barnes\&Tucker, however, may provide suitable conditions. The reaction is driven by heterotrophic bacteria such as the genus Desulfovibrio and is often represented as:

$$
\begin{aligned}
& 2 \mathrm{CH}_{2} \mathrm{O}+\mathrm{SO}_{4}{ }^{2-} \rightarrow \mathrm{H}_{2} \mathrm{~S}+2 \mathrm{HCO}_{3}{ }^{-} \text {or } \\
& \mathrm{CH}_{4}+\mathrm{SO}_{4}{ }^{2-} \rightarrow \mathrm{HS}^{-}+2 \mathrm{HCO}_{3}{ }^{-}+\mathrm{H}_{2} \mathrm{O}
\end{aligned}
$$

where $\mathrm{CH}_{2} \mathrm{O}$ represents organic compounds, $\mathrm{CH}_{4}$ (methane), or other simple organic molecules. The optimal $\mathrm{pH}$ range for Desulfovibrio is between about 6 and 8 (Baas Becking et al., 1969). Other microbes may also participate in or facilitate sulfate reduction (Barton, 1995).

The Estimated Maximum Acid Production (EMAP), equation 5-7, is based on two moles of $\mathrm{H}^{+}$produced per mole of $\mathrm{SO}_{4}{ }^{2-}$. Sulfate reduction, as in equation 5-19, reduces the quantity of EMAP, and produces two moles bicarbonate alkalinity per mole of $\mathrm{S}$ reduced. If the reaction proceeds further to sulfide precipitation, $\mathrm{H}^{+}$is regenerated as in the formation of $\mathrm{FeS}$ :

$$
\mathrm{Fe}^{2+}+\mathrm{H}_{2} \mathrm{~S} \rightarrow \mathrm{FeS}+2 \mathrm{H}^{+}
$$

Biological Reactivity Test (BART) vials were inoculated with raw mine water at the Omega, T\&T, and Barnes\&Tucker mine-pools. The BART vials contained nutrient media for specified groups of microbes, and could be used for presence or absence determinations. The acidic and oxygenated Omega and T\&T mine-pools returned a negative response to sulfate-reducing bacteria ( $\mathrm{SRBs}$ ). The oxygen-poor and mostly flooded Duman discharge of the Barnes\&Tucker mine-pool produced a strong positive 
response for SRBs, however. Trace amounts of dissolved sulfide were also detected in field tests, and the characteristic "rotten egg" odor of $\mathrm{H}_{2} \mathrm{~S}$ was detectable. While sulfate reduction was not directly measured in the mine-pool, circumstantial evidence suggests it is likely to occur in flooded circumneutral mine waters. Mine waters collected by the author from several wells in a large circumneutral $(\mathrm{pH} 7)$ mine-pool near Fairmont, WV, have also tested positive for SRBs.

\subsubsection{Neutralization from Oxyhydroxide Minerals}

Dissolution of existing metal oxyhydroxide minerals represent yet another potential insitu neutralization mechanism for strong acidity as shown by:

$$
\mathrm{Fe}(\mathrm{OH})_{3}+3 \mathrm{H}^{+} \leftrightarrow \mathrm{Fe}^{3+} 3 \mathrm{H}_{2} \mathrm{O}
$$

The reaction is reversible depending on $\mathrm{pH}$. During the initial acidification of a minepool aquifer, reaction 5-21 could be driven to the left and dissolve existing oxyhydroxide minerals with subsequent $\mathrm{H}^{+}$neutralization. A simple calculation suggests this could provide substantial strong acid consumption in the short term. For a mine-pool aquifer with $20 \%$ water filled porosity, $80 \%$ rock matrix with specific gravity of 2.6 , and the rock matrix contains one percent $\mathrm{Fe}(\mathrm{OH})_{3}$, a large quantity of hydroxide mineral is potentially available to react. In one $\mathrm{m}^{3}$ of aquifer, total $\mathrm{Fe}(\mathrm{OH})_{3}$ is:

mmoles $\mathrm{Fe}(\mathrm{OH})_{3}=0.8 \mathrm{~m}^{3} \times 2.6 \mathrm{~g} / \mathrm{cm}^{3} \times 10^{6} \mathrm{~cm}^{3} / \mathrm{m}^{3} \times 0.01 \times 10^{3} \mathrm{mg} / \mathrm{g} \times 1 \mathrm{mmole} / 103.85 \mathrm{mg}$

or about 200,000 mmoles of $\mathrm{Fe}(\mathrm{OH})_{3}$. The $20 \%$ water filled aquifer contains $200 \mathrm{liter} / \mathrm{m}^{3}$ of fluid. Potentially about 1000 mmoles of hydroxide per liter of solution is available. Only a very small fraction of the hydroxide need react to provide significant $\mathrm{H}^{+}$ consumption. The system potentially renews itself as the water flows into the next unit of aquifer matrix.

Oxyhydroxide neutralization likely represents a temporary acid consumption mechanism. The reaction is reversible, and as neutralization of acidic mine-pool increases $\mathrm{pH}$, oxyhydroxides precipitate and acidity is regenerated. Therefore these types of reactions are not likely to be a significant source of strong acid production. Kinetic considerations also constrain the rate of oxyhydroxide dissolution.

5.2.4.6 Neutralization by Cation Exchange Cation exchange is another reversible reaction that may remove $\mathrm{H}^{+}$from solution. Back (1966) in describing hydrochemical facies for ground water, concluded that $\mathrm{Na}$ was exchanging for $\mathrm{Ca}$ in Atlantic Coastal Plain aquifers as ground water moved through the aquifer. Back also observed that the composition of the water depended on its location in the flow system. Perry et al. (2005, Appendix D) concluded that sorbed $\mathrm{Na}$ exchanges into the aquifer for $\mathrm{Ca}$ and $\mathrm{Mg}$ in the Barnes\&Tucker mine-pool. The end of flow path Duman discharge is enriched in $\mathrm{Na}$ and depleted in $\mathrm{Ca}$ and $\mathrm{Mg}$ compared to its' source waters. The Barnes\&Tucker mine-pool has a maximum flow path of about $16 \mathrm{~km} . \mathrm{H}^{+}$could be removed from mine-pool water by exchange for $\mathrm{Na}^{+}$as graphically illustrated in figure 5-17. 
A large number of exchange sites are potentially available in an extended flow system. Using the same mine-pool aquifer example described above for hydroxide neutralization; $20 \%$ water filled porosity, $80 \%$ rock matrix; and assuming a modest cation exchange capacity of $2 \mathrm{meq} / 100 \mathrm{~g}$ of rock, the amount of exchangers is:

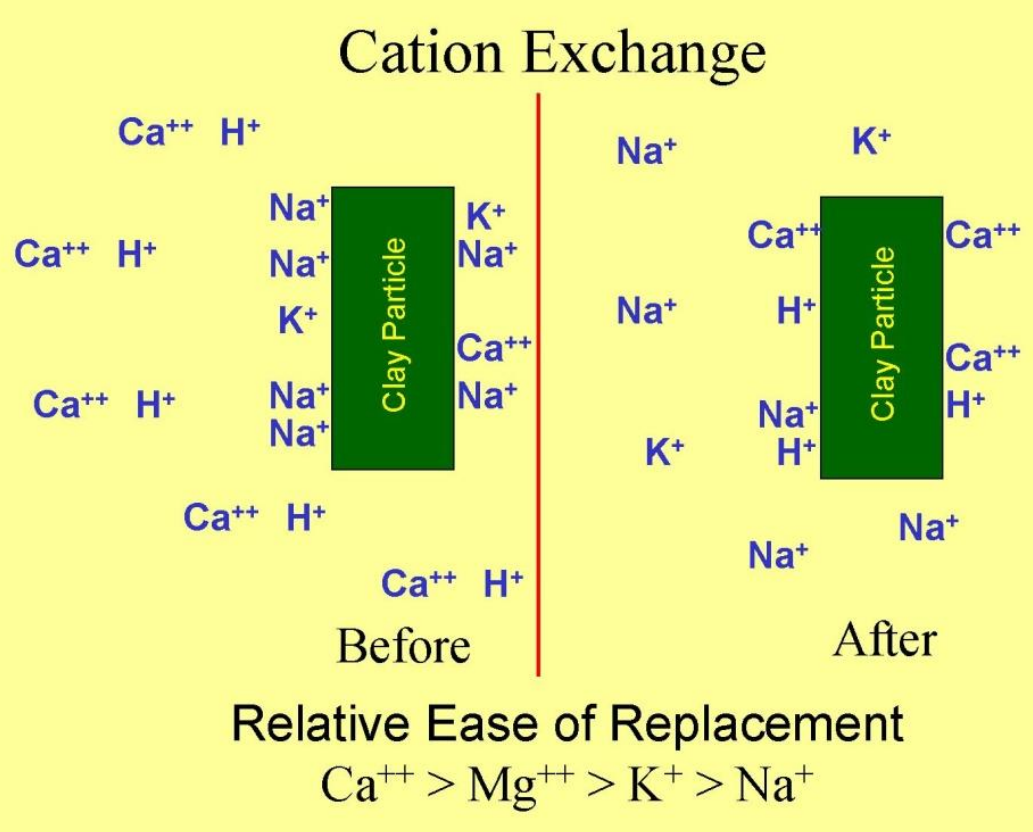

Figure 5-17. Conceptual Cation Exchange in Acid Waters. $\mathrm{H}^{+}$is Adsorbed to Exchange Sites on Clays. The Reactions are Reversible if Solution Composition Changes.

$$
\text { Total Exchangers }(\mathrm{meq})=0.8 \mathrm{~m}^{3} \times 2.6 \mathrm{~g} / \mathrm{cm}^{3} \times 10^{6} \mathrm{~cm}^{3} / \mathrm{m}^{3} \times 2 \mathrm{meq} / 100 \mathrm{~g}
$$

or $41,600 \mathrm{meq}$ in one $\mathrm{m}^{3}$ of aquifer. In the $200 \mathrm{~L}$ of aquifer solution, potentially about 208 meq of exchangers are available per liter of solution. Like hydroxide neutralization, only a small fraction of the exchange capacity need react with the solution to provide significant attenuation of $\mathrm{H}^{+}$. As with the hydroxide minerals, the system potentially renews itself as the water flows into the next unit of aquifer matrix. The exchange reactions are potentially reversible if solution composition changes. The $\mathrm{H}^{+}$exchange capacity is finite. Thus, long term acid attenuation by exchange reactions is probably limited.

\subsection{Decay Functions for Estimating Time Dependent Chemical Composition}

This section presents results of fitting decay functions to time series chemical data to describe the rate of change, and estimate future mine-pool chemical composition.

Time series plots of chemical concentrations in the five mine-pools often exhibited curvilinear behavior. Figure 5-18, iron concentration in the Hahn discharge, exemplifies this trend. A log-log scale (base ten) plot of concentration vs. time (figures 5-19 and 5-20) are similar to idealized plots of first or second order rates laws, like those shown by Langmuir (1997). The $\mathrm{X}$-axis is $\log$ scale base ten in days, and the $\mathrm{Y}$ axis is $\log$ scale 
base ten Fe concentration in $\mathrm{mg} / \mathrm{L}$ in figures 5-19 and 5-20. This suggests the long-term chemical trends can be represented by an exponential expression which describes the rate of change as a function of time, and that the changes are related to fundamental chemical principles.

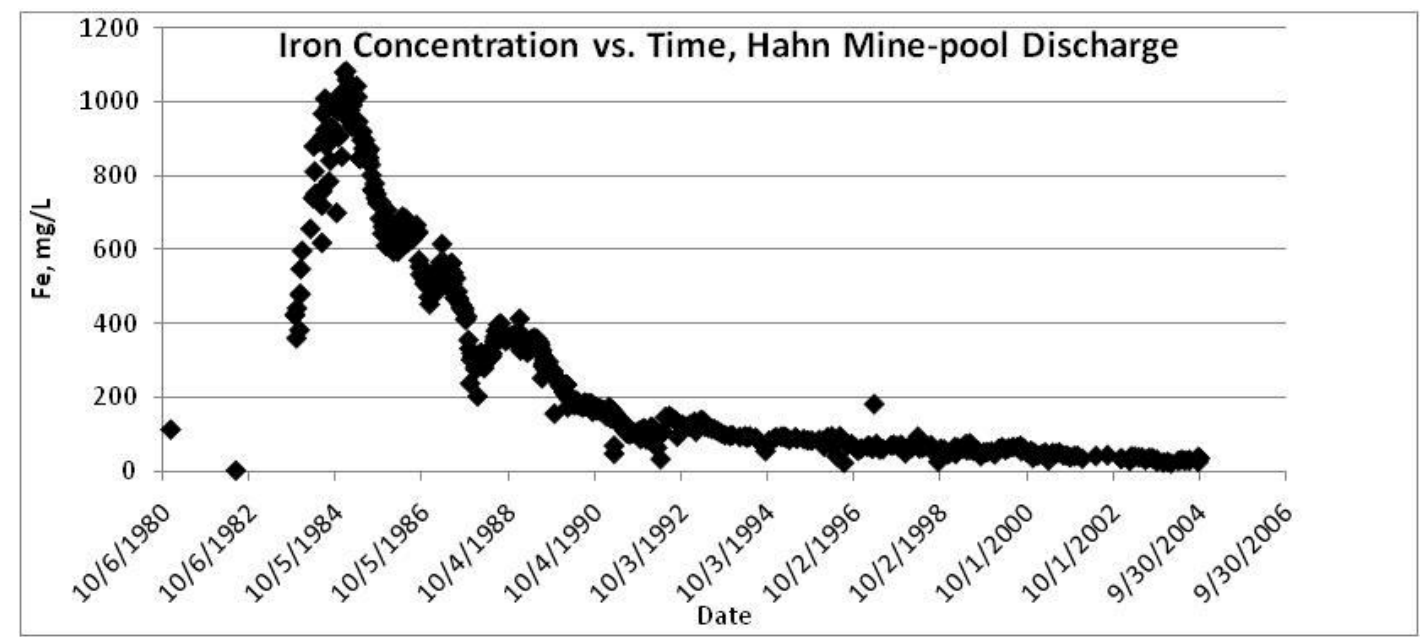

Figure 5-18. Time Series Plot of Fe Concentration, Hahn Discharge, Showing Exponential Rate of Change.

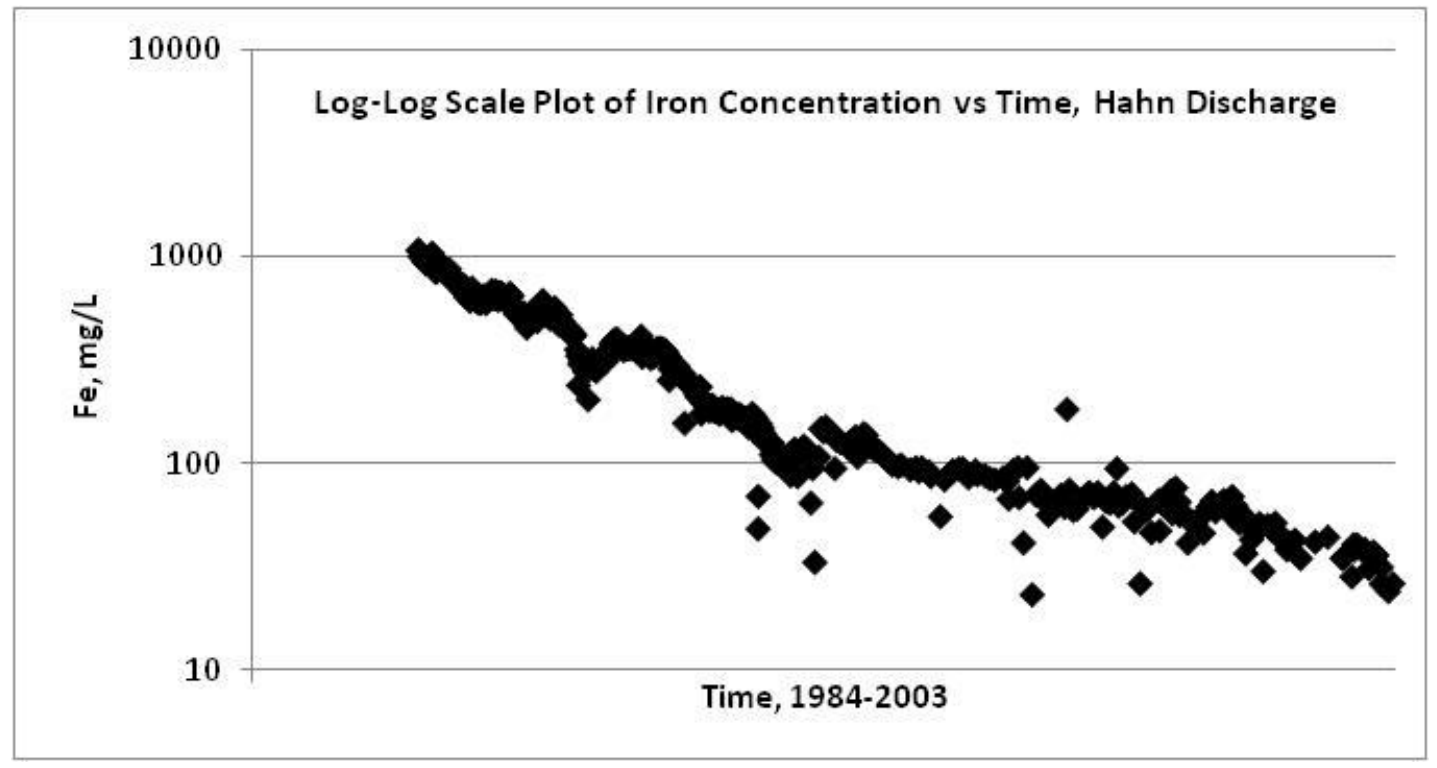

Figure 5-19. Log-log Scale Plot of Iron vs. Time Hahn Discharge. Same Data as Figure 5-18. $X$-axis is $\log$ Scale Base 10, Days, from 1984-2003. Y Axis is $\log$ Scale Base 10. Fe concentration in mg/L. 


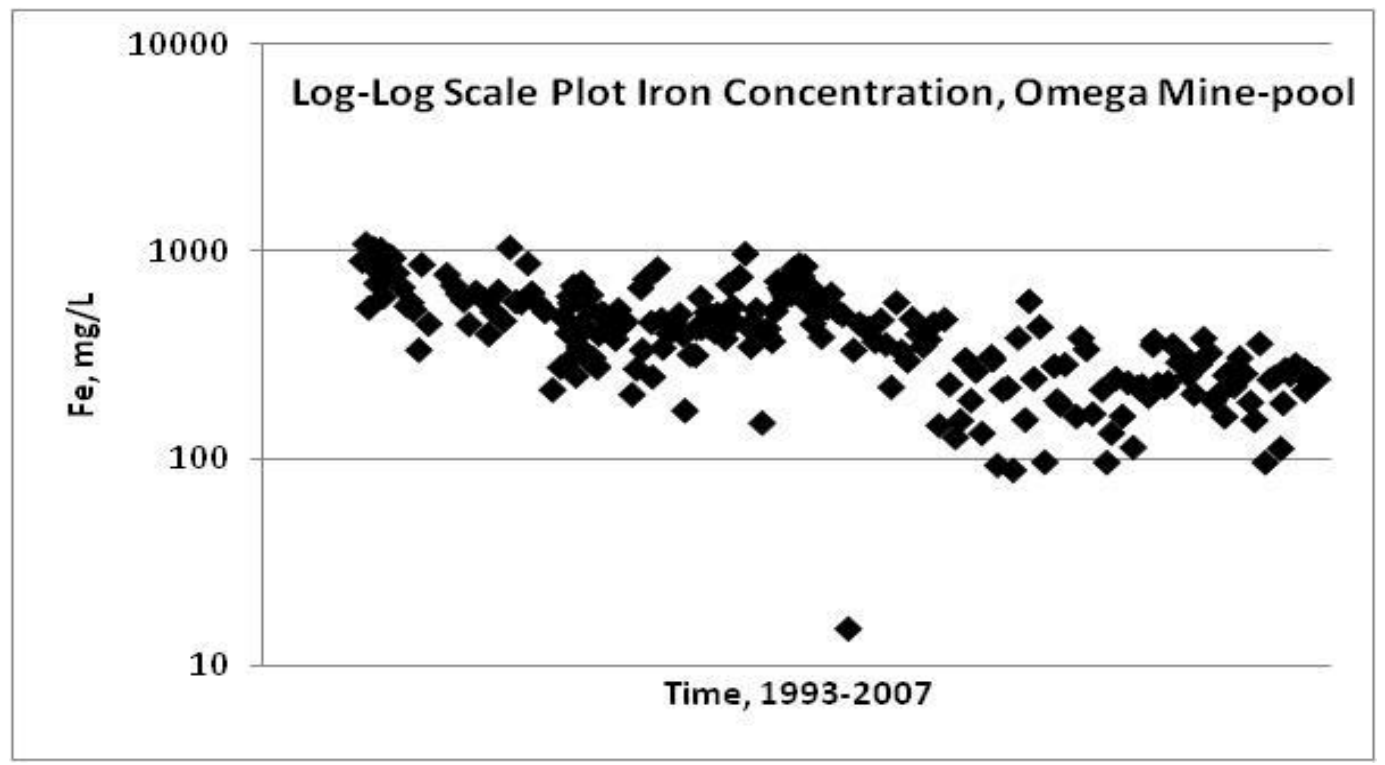

Figure 5-20. Log-log Scale Plot of Iron vs. Time Omega Mine-pool Discharge.

$\mathrm{X}$-Axis is $\log$ Scale Base 10, Days, 1993-2007. Y Axis is $\log$ Scale Base 10, Fe in mg/L.

The behavior of many chemical and biological systems has been described using a first order function of the general form:

$$
C_{t}=C_{o} \times e^{-k t}
$$

where: $\mathrm{C}_{\mathrm{t}}=$ concentration at time $\mathrm{t}$

$\mathrm{C}_{\mathrm{o}}=$ concentration at time zero

$\mathrm{e}=$ base e, approximate value of 2.718

$\mathrm{k}=$ decay constant, rate of concentration change per unit time

$\mathrm{t}=$ time

The function in equation $5-22$ is sometimes used to describe radioactive decay. The changes with time in mine-pool chemistry are not radioactive processes and therefore, strictly speaking, are not decay processes, but are a rate of change with a similar mathematical description. Gzyl and Banks (2007) use the term "decay" to describe the rate of change in $\mathrm{pH}$ and sulfate concentration in flooding Polish coal mines. The term decay is used for convenience in this chapter in the context of describing rate of change in mine-pool chemical concentration.

Decay constants (k) were estimated for chemical parameters $\mathrm{Fe}$, Al, sulfate, total dissolved solids (TDS), and total acidity, where data were available. Aluminum decay constants were computed just for the Omega and T\&T mine-pools because only these two sites had appreciable concentrations of Al.

\subsubsection{Method for Estimating Decay Constants}

Four of the five mine-pools had distinct changes in chemical composition that were related to flooding phase or in-situ treatment. Only the Arden-Westland mine-pool lacked 
distinct changes, and the early flooding record was not available for this site. The monitoring record was analyzed for decay behavior in several ways including:

- A single decay function for the entire period of record, assuming flooding phase or in-situ treatment had no effect on decay.

- Dividing the record into pre and post in-situ treatment and computing separate decay values for each period.

- Computing decay on data smoothed with a 5 point moving average.

- Computing decay based on yearly average values.

- Dividing the record based on flooding phases, and computing separate decay values for each period.

- Examining log-log scale plots of concentration against time for rate changes, manifested by change in slope.

Because each mine-pool has a unique history, and different record of sampling and analyses, not all of the above techniques were used for each mine-pool. Pertinent details of each mine-pool history are contained in chapter three and Appendix A for the Omega and T\&T mine-pools, chapter four and Donovan et al. (1999) for Hahn, Arden-Westland, and chapter four and Appendix D for the Barnes\&Tucker mine-pool. The principal events and observations used to subdivide the record for each mine-pool are summarized as follows.

Omega mine-pool - Grout injection in one section of the mine for drainage control and in-situ treatment. Separate decay constants estimated for pre and post grout injection records, and one set of $\mathrm{k}$ values for the entire period of record. Post grouting subdivided based on apparent mineral solubility controls. Smoothed data and yearly averages used to approximate the full record.

T\&T mine-pool - Limestone injection for in-situ treatment. Separate decay constants estimated for pre and post limestone injection records and one set of $\mathrm{k}$ values for the entire period of record. Post limestone injection subdivided based on apparent mineral solubility controls. Smoothed data and yearly averages used to approximate the full record.

Hahn (Montour 4) mine-pool - Initial flushing phase, followed by pumping to maintain constant pool elevation. Separate decay constants estimated for initial flushing phase and constant head phase, and one set of $\mathrm{k}$ values for the entire period of record.

Arden-Westland mine-pool - Initial flushing phase, transition period and long term flushing with pumping to control pool elevation. Separate decay values for each period and one set of $\mathrm{k}$ values for the entire period.

Barnes and Tucker mine-pool - Flooded phase with pumping to maintain constant pool elevation. Flooding of overlying vertically connected mine-works, with increased pumping to maintain constant pool elevation. Separate decay constants estimated for 
before and after flooding overlying mine-works, and one set of $\mathrm{k}$ values for the entire period of record, using yearly average values.

The decay constant, $\mathrm{k}$, was estimated by rearranging equation 5-22, to give the following:

$$
\begin{gathered}
\mathrm{C}_{\mathrm{t}} / \mathrm{C}_{\mathrm{o}}=\mathrm{e}^{-\mathrm{kt}} \\
\ln \left(\mathrm{C}_{\mathrm{t}} / \mathrm{C}_{\mathrm{o}}\right)=-\mathrm{kt} \\
\mathrm{k}=-\ln \left(\mathrm{C}_{\mathrm{t}} / \mathrm{C}_{\mathrm{o}}\right) / \mathrm{t}
\end{gathered}
$$

An $\mathrm{X}-\mathrm{Y}$ plot of $\ln (\mathrm{Ct} / \mathrm{Co})$ and $\mathrm{t}$ should yield a straight line with a slope of $\mathrm{k}$. If concentration data are expressed in consistent units, then $\mathrm{k}$ has dimensions of $\mathrm{t}^{-1}$.

Figures 5-21 and 5-22, respectively, show Fe data from the Hahn discharge (flooded mine) and Fe data from the Omega mine-pool discharge (unflooded mine) plotted in this manner. These are the same monitoring records shown in the log-log plots in figs 5-19 and 5-20, respectively.

In general, water quality data at the Hahn discharge followed a fairly distinct curvilinear trend pattern. The Hahn drainage was therefore expected to provide a good fit to a natural $\log$ decay function. Slope of the plot was determined using least squares linear regression techniques. Figure 5-21 shows good agreement between the iron data and the log function. An $\mathrm{R}^{2}$ of $89 \%$ was obtained for this plot and the results are statistically significant $(\mathrm{p}<0.01)$.

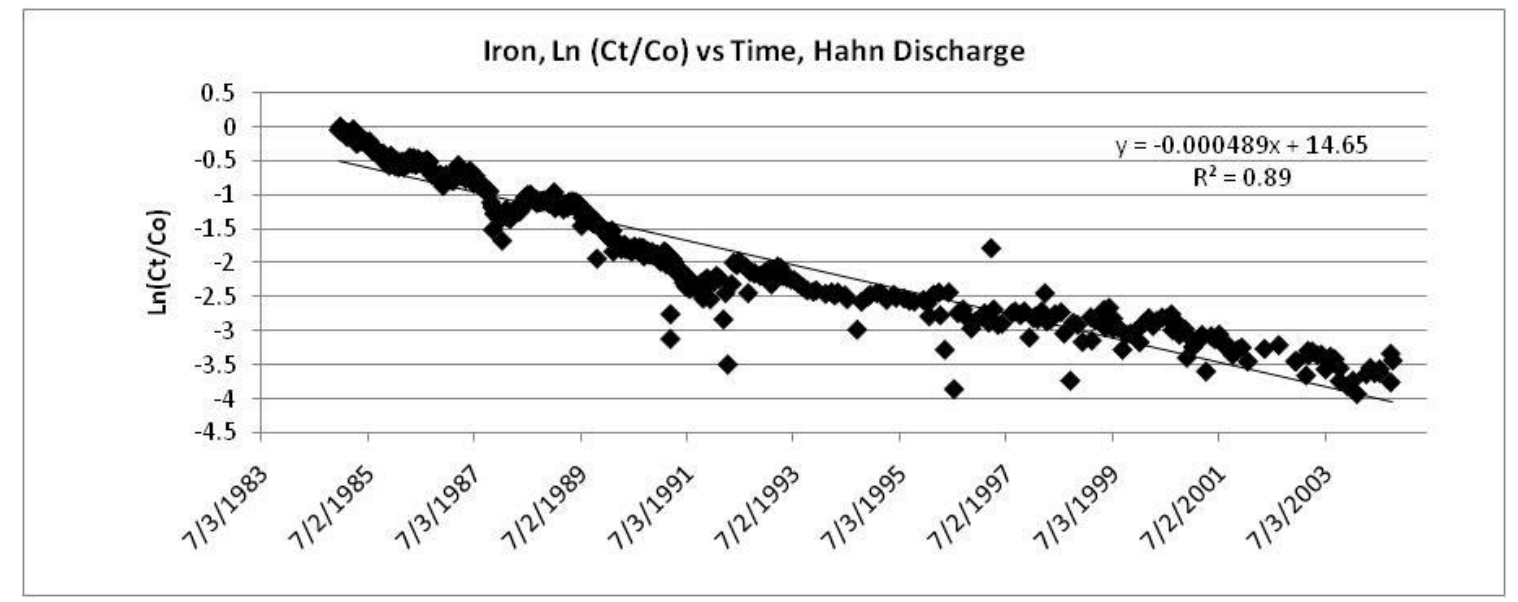

Figure 5-21. Plot of $\operatorname{Ln}(\mathrm{Ct} / \mathrm{Co})$, Iron Concentration, Against t, Time, Hahn Discharge. Slope Equal k, Decay Constant.

While the overall fit is good, closer examination of figure 5-21 reveals that the data do not plot on one continuous slope. There is a small but distinct slope change occurring about 1992. While a single decay function might provide adequate estimates of decay, two constants represent the two different stages of early flushing and long term conditions. This large, mostly flooded mine-pool displays relatively small short term 
variation. Therefore concentration changes estimated from properly derived decay functions should have a relatively narrow confidence interval.

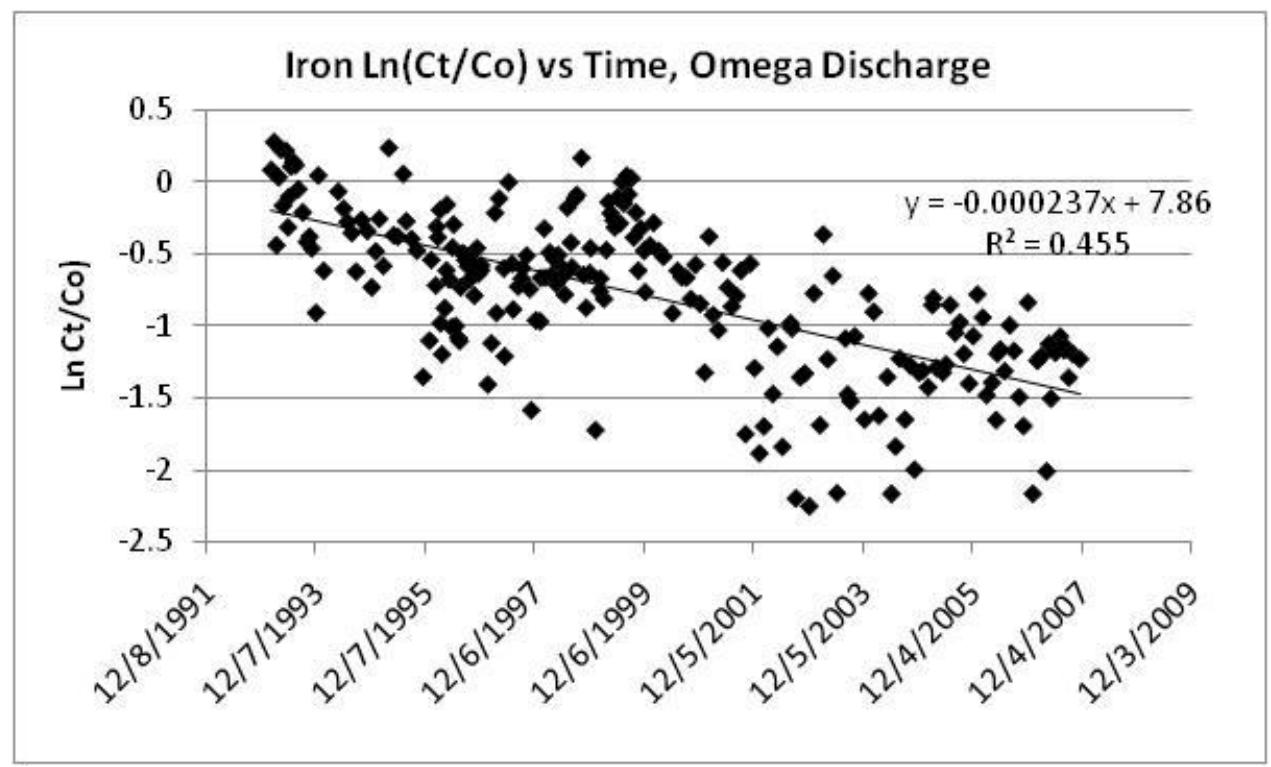

Figure 5-22. Plot of $\operatorname{Ln}(\mathrm{Ct} / \mathrm{Co})$, Iron Data Against t, Time, Omega Mine. Slope Equal k, Decay Constant.

Figure 5-22 shows much greater data scatter in the mostly unflooded Omega mine-pool. A slope change occurs about 1998, corresponding to grout injection. The regression model and slope for the entire data set are significant $(\mathrm{p}<0.01)$, but with a lower $\mathrm{R}^{2}$ of about $45 \%$. Since grouting affects the decay sequence, concentration estimates could be improved by subdividing the record into pre and post grout conditions. Data from the mostly unflooded Omega and T\&T mine-pools have large short term variations. Concentration estimates derived for these mine-pools have a relatively wider confidence interval than for pools like the Hahn discharge.

Decay constants were derived by identifying slope breaks on log-log plots, identifying known events such grout injection, and using the natural log function and regression techniques illustrated in figures 5-21 to 5-22 for the other parameters across the five mine-pools.

\subsubsection{Computed Chemical Decay Constants}

Decay constants based on concentration data for Total Acidity, Fe, Al, sulfate and TDS for the five mine-pools are shown in tables 5-7 (acidic, partly flooded Omega and T\&T mines) and 5-8 (mostly flooded circumneutral Hahn, Arden-Westland and Barnes\&Tucker mines) in units of day ${ }^{-1}$. Table 5-8 also includes constants for $\mathrm{pH}$ in the Hahn, Arden-Westland and Barnes\&Tucker mine-pools. The tables also contain the percentage coefficient of variation $\left(\mathrm{R}^{2}\right)$ to illustrate the strength of the derived relationships. Decay constants that were not statistically significant at $\mathrm{p}=0.05$ are highlighted in italics and shown as N.S. for $\mathrm{R}^{2}$. 
Table 5-7

Chemical Concentration Decay Constants $\left(\mathbf{d}^{\mathbf{- 1}}\right)$ Estimated Using Different Data for Two Acidic Mostly Unflooded Mines

\begin{tabular}{|c|c|c|c|c|c|c|c|c|c|c|c|}
\hline Mine & $\begin{array}{l}\text { Period of } \\
\text { Record }\end{array}$ & $\begin{array}{c}\text { Total } \\
\text { Acidity } \\
\mathrm{k}\left(\mathbf{d}^{-\mathbf{1}}\right)\end{array}$ & $\mathrm{R}^{2}$ & $\begin{array}{l}\text { Iron } \\
\mathrm{k}\left(\mathbf{d}^{-1}\right)\end{array}$ & $\mathrm{R}^{2}$ & $\begin{array}{c}\text { Aluminum } \\
\mathrm{k}\left(\mathbf{d}^{-\mathbf{1}}\right)\end{array}$ & $\mathrm{R}^{2}$ & $\begin{array}{l}\text { Sulfate } \\
\mathrm{k}\left(\mathbf{d}^{-1}\right)\end{array}$ & $\mathrm{R}^{2}$ & $\begin{array}{c}\text { TDS } \\
\mathrm{k}\left(\mathbf{d}^{-1}\right)\end{array}$ & $\mathrm{R}^{2}$ \\
\hline Omega all data & $\begin{array}{l}3 / 93 \text { to } \\
11 / 07\end{array}$ & $-2.35 \times 10^{-4}$ & 21.5 & $-2.59 \times 10^{-4}$ & 45.5 & $-1.09 \times 10^{-4}$ & 9.1 & $-1.31 \times 10^{-4}$ & 26.2 & $-1.05 \times 10^{-4}$ & 54.0 \\
\hline Omega all data, smoothed & $\begin{array}{c}3 / 93 \text { to } \\
11 / 07\end{array}$ & $-1.47 \times 10^{-4}$ & 44.5 & $-2.39 \times 10^{-4}$ & 65.5 & $-8.4 \times 10^{-5}$ & 20.9 & $-1.16 \times 10^{-4}$ & 39.7 & $-1.03 \times 10^{-4}$ & 36.8 \\
\hline Omega, yearly average & $\begin{array}{l}3 / 93 \text { to } \\
11 / 07\end{array}$ & $-1.56 \times 10^{-4}$ & 64.7 & $-2.43 \times 10^{-4}$ & 79.1 & $-9.1 \times 10^{-5}$ & 79.1 & $-1.25 \times 10^{-4}$ & 59.6 & $-1.1 \times 10^{-4}$ & 58.1 \\
\hline Omega, pre-grouting & $3 / 93$ to $1 / 97$ & $-2.92 \times 10^{-4}$ & 21.5 & $-3.86 \times 10^{-4}$ & 28.4 & $-1.97 \times 10^{-4}$ & 10.6 & $-4.46 \times 10^{-4}$ & 61.4 & $-3.5 \times 10^{-4}$ & 54.0 \\
\hline Omega, pre-grouting, smoothed & $3 / 93$ to $1 / 97$ & $-2.90 \times 10^{-4}$ & 43.4 & $-4.27 \times 10^{-4}$ & 68.5 & $-2.27 \times 10^{-4}$ & 34.3 & $-4.64 \times 10^{-4}$ & 82.0 & $-3.75 \times 10^{-4}$ & 75.8 \\
\hline Omega post-grouting & $6 / 99$ to $9 / 07$ & $-2.73 \times 10^{-4}$ & 22.7 & $-2.47 \times 10^{-4}$ & 8.4 & $-1.3 \times 10^{-4}$ & 4 & $-1.21 \times 10^{-4}$ & 12.1 & $-1.16 \times 10^{-4}$ & 16.1 \\
\hline Omega post-grouting, smoothed & $6 / 99$ to $9 / 07$ & $-2.0 \times 10^{-4}$ & 33.9 & $-3.01 \times 10^{-4}$ & 48.2 & $-1.54 \times 10^{-4}$ & 23.7 & $-1.43 \times 10^{-4}$ & 29.5 & $-1.48 \times 10^{-4}$ & 31.6 \\
\hline Omega immediate post-grouting & $6 / 99$ to $1 / 05$ & $-5.99 \times 10^{-4}$ & 41.4 & $-9.2 \times 10^{-4}$ & 20.2 & $-5.4 \times 10^{-4}$ & 21.2 & $-4.56 \times 10^{-4}$ & 18.4 & $-4.69 \times 10^{-4}$ & 20.6 \\
\hline $\begin{array}{l}\text { Omega immediate post-grouting, } \\
\text { smoothed }\end{array}$ & $6 / 99$ to $1 / 05$ & $-5.34 \times 10^{-4}$ & 79 & $-6.66 \times 10^{-4}$ & 80.1 & $-4.64 \times 10^{-4}$ & 70.5 & $-3.89 \times 10^{-4}$ & 76.8 & $-3.94 \times 10^{-4}$ & 79.5 \\
\hline Omega post-grouting, long term & $1 / 05$ to $9 / 07$ & $-1.3 \times 10^{-4}$ & N.S. & $-2.57 \times 10^{-4}$ & 6.9 & $-1.4 \times 10^{-4}$ & N.S. & $-1.18 \times 10^{-4}$ & N.S. & $-1.02 \times 10^{-4}$ & N.S. \\
\hline $\begin{array}{l}\text { Omega post-grouting, long term, } \\
\text { smoothed }\end{array}$ & $1 / 05$ to $9 / 07$ & $-1.58 \times 10^{-4}$ & 13.2 & $-2.66 \times 10^{-4}$ & 39.7 & $-1.46 \times 10^{-4}$ & 6.4 & $-1.43 \times 10^{-4}$ & 7.9 & $-1.23 \times 10^{-4}$ & 5.6 \\
\hline T\&T, all data & $4 / 94$ to $9 / 07$ & $-1.08 \times 10^{-4}$ & N.S & $-3.26 \times 10^{-4}$ & 19.7 & $-1.01 \times 10^{-4}$ & 4.7 & $-3.06 \times 10^{-4}$ & 5.6 & $-1.2 \times 10^{-5}$ & N.S. \\
\hline T\&T, all data, smoothed & $4 / 94$ to $9 / 07$ & $-1.62 \times 10^{-4}$ & 17.3 & $-3.86 \times 10^{-4}$ & 45.1 & $-6.2 \times 10^{-5}$ & 2.6 & $-1.05 \times 10^{-4}$ & 11.8 & $-1.5 \times 10^{-5}$ & N.S. \\
\hline T\&T, all data, yearly average & $4 / 94$ to $9 / 07$ & $-2.54 \times 10^{-4}$ & 49.3 & $-4.84 \times 10^{-4}$ & 65 & $-1.78 \times 10^{-4}$ & 30.9 & $-1.71 \times 10^{-4}$ & 31.5 & $-2.3 \times 10^{-5}$ & N.S. \\
\hline T\&T, pre-injection & $\begin{array}{l}4 / 94 \text { to } \\
11 / 96\end{array}$ & $-1.85 \times 10^{-4}$ & 13.3 & $-3.96 \times 10^{-4}$ & 8.9 & $3.9 \times 10^{-5}$ & N.S. & $-4.37 \times 10^{-4}$ & 33.5 & $-5.67 \times 10^{-4}$ & 12.2 \\
\hline T\&T, pre-injection, smooth & $\begin{array}{l}4 / 94 \text { to } \\
11 / 96\end{array}$ & $-2.36 \times 10^{-4}$ & 13.3 & $-6.46 \times 10^{-4}$ & 17.4 & $-6.2 \times 10^{-5}$ & N.S. & $-4.75 \times 10^{-4}$ & 49.3 & $-2.9 \times 10^{-5}$ & N.S. \\
\hline $\mathrm{T} \& \mathrm{~T}$, pre-injection, long term & $\begin{array}{l}11 / 96 \text { to } \\
11 / 99\end{array}$ & $-1.78 \times 10^{-4}$ & N.S & $-2.91 \times 10^{-4}$ & 4.2 & $-4.8 \times 10^{-5}$ & N.S. & $-2.13 \times 10^{-4}$ & 6.3 & $-2.22 \times 10^{-4}$ & 4.8 \\
\hline $\mathrm{T} \& \mathrm{~T}$, post-injection & $\begin{array}{l}10 / 01 \text { to } \\
9 / 07\end{array}$ & $-5.99 \times 10^{-4}$ & 26.8 & $-9.44 \times 10^{-4}$ & 23 & $-5.26 \times 10^{-4}$ & 16.5 & $-3.20 \times 10^{-4}$ & 23.4 & $-3.58 \times 10^{-4}$ & 17.0 \\
\hline T\&T, post-injection, smoothed & $\begin{array}{l}10 / 01 \text { to } \\
9 / 07\end{array}$ & $-6.47 \times 10^{-4}$ & 35.3 & $-1.05 \times 10^{-3}$ & 47.3 & $-5.57 \times 10^{-4}$ & 28.1 & $-4.36 \times 10^{-4}$ & 42.3 & $-4.59 \times 10^{-4}$ & 42.7 \\
\hline T\&T, post-injection, long term & $1 / 04$ to $9 / 07$ & $-1.31 \times 10^{-4}$ & N.S & $-4.29 \times 10^{-4}$ & 20.4 & $-9.4 \times 10^{-5}$ & N.S. & $-5.8 \times 10^{-5}$ & N.S. & $-2.2 \times 10^{-5}$ & N.S. \\
\hline $\begin{array}{c}\text { T\&T, post-injection, long term, } \\
\text { smoothed }\end{array}$ & $1 / 04$ to $9 / 07$ & $-4.2 \times 10^{-5}$ & N.S & $-2.96 \times 10^{-4}$ & 34.8 & $-3.7 \times 10^{-5}$ & N.S & $-4.0 \times 10^{-5}$ & N.S & $6.4 \times 10^{-5}$ & 14.0 \\
\hline
\end{tabular}


Table 5-8

Decay Constants $\left(\mathbf{d}^{\mathbf{- 1}}\right)$ Estimated from Chemical Concentration for Three Mostly Flooded Circumneutral Mine-pools

\begin{tabular}{|c|c|c|c|c|c|c|c|c|c|c|c|}
\hline Mine & Period of Record & $\begin{array}{l}\text { Total Acidity } \\
\mathrm{k}\left(\mathbf{d}^{-\mathbf{1}}\right)\end{array}$ & $\mathrm{R}^{2}$ & $\begin{array}{c}\text { Iron } \\
\mathrm{k}\left(\mathbf{d}^{-\mathbf{1}}\right) \\
\end{array}$ & $\mathrm{R}^{2}$ & $\begin{array}{c}\text { Sulfate } \\
\mathrm{k}\left(\mathbf{d}^{-1}\right)\end{array}$ & $\mathrm{R}^{2}$ & $\begin{array}{r}\text { TDS } \\
\mathrm{k}\left(\mathbf{d}^{-1}\right) \\
\end{array}$ & $\mathrm{R}^{2}$ & $\begin{array}{c}\mathrm{pH} \\
\mathrm{k}\left(\mathbf{d}^{-1}\right)\end{array}$ & $\mathrm{R}^{2}$ \\
\hline Hahn, long term & $5 / 93$ to $10 / 04$ & $-2.89 \times 10^{-4}$ & 68 & $-2.99 \times 10^{-4}$ & 69 & $-2.72 \times 10^{-4}$ & 47 & $-4.63 \times 10^{-4}$ & 49 & $5.2 \times 10^{-4}$ & 5 \\
\hline Arden-Westland all data & $1 / 89$ to $2 / 99$ & $-2.50 \times 10^{-4}$ & 81 & $-2.48 \times 10^{-4}$ & 80 & $-1.64 \times 10^{-4}$ & 77 & $-1.29 \times 10^{-4}$ & 76 & $-1.0 \times 10^{-5}$ & N.S \\
\hline Arden-Westland transition & $2 / 92$ to $8 / 96$ & $-3.52 \times 10^{-4}$ & 84 & $-3.53 \times 10^{-4}$ & 84 & $-2.55 \times 10^{-4}$ & 69 & $-2.09 \times 10^{-4}$ & 71 & $2.3 \times 10^{-5}$ & N.S \\
\hline Arden-Westland long term & $8 / 96$ to $10 / 99$ & $-5.6 \times 10^{-5}$ & N.S & $-4.5 \times 10^{-5}$ & N.S & $-1.08 \times 10^{-4}$ & 12 & $-1.6 \times 10^{-5}$ & N.S & $-1.2 \times 10^{-4}$ & 21 \\
\hline $\begin{array}{c}\text { Barnes\&Tucker } \\
\text { All data }\end{array}$ & $1971-2005$ & $-2.20 \times 10^{-4}$ & 87 & $-2.23 \times 10^{-4}$ & 86 & $-1.31 \times 10^{-4}$ & 87 & - & & $7.08 \times 10^{-4}$ & 15 \\
\hline $\begin{array}{l}\text { Barnes\&Tucker } \\
\text { Pre-flooding }\end{array}$ & 1971-1984 & $-2.52 \times 10^{-4}$ & 29 & $-2.52 \times 10^{-4}$ & 54 & $-1.75 \times 10^{-4}$ & 68 & - & & $1.81 \times 10^{-3}$ & 6.7 \\
\hline
\end{tabular}


The significant decay constants span about one order of magnitude, around $10^{-4} /$ day, regardless of the degree of flooding, or stage of flooding (initial flush or long term). The only exceptions are rapid $\mathrm{pH}$ increases in the early phases of flooding in the Hahn and Barnes\&Tucker minepools where $\mathrm{k}$ is about $1 \times 10^{-3} /$ day, several scenarios where the decay constant is statistically insignificant, and Al decay for parts of the record in the Omega and T\&T mine-pools. The relatively narrow range of decay constants suggests that $\mathrm{k}$ is not greatly influenced by chemical conditions, but may be in part, a function of physical conditions of mine-pool flow and leaching efficiency. All five mines are in the northern Appalachian plateau with similar hydrogeologic and climatic controls.

The two mostly unflooded mines have the most complex history and leaching behavior. This is reflected in the number of subdivisions of the record for the T\&T and Omega mine-pools. Both had episodes of grout or limestone injection approximately midway through the monitoring record, and both had periods of statistically insignificant decay rates for some parameters. Because the raw data exhibit large short term variations, decay constants were also calculated on smoothed data generated from a five point moving average and yearly averages. As expected, smoothing and combining data increased the $\mathrm{R}^{2}$ values. In many instances, decay constants computed on raw, smoothed or yearly average data were within about $20 \%$ of each other; some parameters exhibited larger differences. The use of smoothed data also enabled resolution of decay constants that could not be determined on the raw data. Table 5-7, Omega mine-pool post grouting, from $1 / 05$ to $9 / 07$ had statistically insignificant decay values based on raw data. The smoothing function reduced variation sufficiently to identify statistically significant decay values without disrupting data trends.

The three mostly flooded mine-pools (table 5-8) have decay constants spanning less than one order of magnitude, excluding $\mathrm{pH}$ change. The Hahn discharge, initial flush, has a high rate of change for Fe. With few exceptions, $\mathrm{R}^{2}$ values exceed $50 \%$, and approach $90 \%$ for some parameters, indicating relatively robust estimates for $\mathrm{k}$. The exceptions include Arden-Westland long term conditions.

$\mathrm{pH}$ changes were rapid during early flushing in the Hahn and Barnes\&Tucker mine-pools, and are on the order of about $-1 \times 10^{-3} / \mathrm{d}$. Gzyl and Banks (2007) reported decay constants of about -3 to $-5 \times 10^{-3} / \mathrm{d}$ for $\mathrm{pH}$ and sulfate concentration in flooding underground coal mines in Poland. The $\mathrm{pH}$ rate change in their study is similar to early flushing values derived here. Sulfate decay however is about three to ten times faster than for this study. Gzyl and Banks' decay values were derived for one mine which has low ionic strength waters, with sulfate concentration reported between 85 and $442 \mathrm{mg} / \mathrm{L}$, and a rapid flooding rate in comparison to the three mostly flooded mines in this study. The chemical and flooding disparity, and perhaps hydrogeologic factors, may account for difference of up to an order of magnitude between the Polish and Appalachian mine-pools. The results do suggest however, that a range of mine water pollutant decay rates can be estimated that encompass a range of conditions.

Mack and Skousen (2008) reported a survey of acidity decay in about 40 above drainage mines in West Virginia. Their surveyed mines included the T\&T complex described in this study, and other older mines in the Upper Freeport and Pittsburgh coal beds. Most of the mines had been 
closed for 50 to 70 years. They plotted acidity decay curves with k of two, five and ten percent per year and compared them to time series plots of acidity concentration. They concluded that most mines best fit a five percent per year decay curve, or about $-1.4 \times 10^{-4} /$ day. The T\&T minepool mean annual acidity most closely approximated a ten percent decay, or about $-2.7 \mathrm{x}$ $10^{-4} /$ day. This study estimated a very similar value for mean acidity decay at $-2.54 \times 10^{-4} /$ day, using the regression techniques described previously. The two and five percent per year decay curves that Mack and Skousen used are well within the range of decay constants computed in this study. Mack and Skousen's data, and this study's results, suggest it is possible to define chemical concentration decay estimates within about one order of magnitude for mines in similar hydrogeologic and geochemical settings.

The lower $\mathrm{R}^{2}$ values found with the mostly unflooded Omega and T\&T mine-pools are influenced by discharge characteristics. These two mines are gravity drained, and exhibit transient short term and seasonal variation in flow and chemical concentrations. The decay equation models longer term trends, and do not accommodate the transient conditions characteristic of these two mine-pools. In contrast, the three mostly flooded Hahn, ArdenWestland and Barnes\&Tucker mine-pools are pumped at more or less constant rates, and the flow system approaches steady state conditions.

The decay constants in tables 5-7 and 5-8 are summarized graphically by parameter, degree of flooding, and flushing stage in figure 5-23, with median values for the five mine-pools combined. Overall, Fe has the most rapid median decay or rate of concentration decrease, of the five parameters. Aluminum, which was compiled only for the two acidic mostly unflooded mines, and total dissolved solids change for all five mines, have the slowest overall decay. Total acidity and sulfate have intermediate decay rates. For every parameter, decay is most rapid during early flushing stage.

Relative decay of the five parameters is influenced by geochemical conditions in the mine-pools. In the moderately oxidizing conditions of the Omega and T\&T mine-pools, there are several possible sinks for iron, including formation of oxide, oxyhydroxide, and sulfate minerals, and adsorption/exchange reactions. Both mine-pools are near apparent equilibrium for jarosite, and over-saturated for more crystalline forms of Fe oxyhydroxide. Iron decay may reflect in part, formation of solid phases that remain in these mine-pools. In the mostly flooded mine-pools, Fe resides largely as $\mathrm{Fe}(\mathrm{II})$, and the waters are under-saturated for common Fe(II) minerals. There are no obvious mineral sinks for $\mathrm{Fe}(\mathrm{II})$, and decay is likely dependent on the recharge and exchange rates of mine-pool water.

In the Omega and T\&T mine-pools, $\mathrm{Al}$ is near or approaches apparent equilibrium with jurbanite, and the pools are under-saturated for several alumino-silicate minerals. Even with relatively slow alumino-silicate weathering rates, the two mine-pools remain capable of supplying soluble $\mathrm{Al}$, and consequently have a slow $\mathrm{Al}$ decay rate. In these two mine-pools, overall decay constants for total dissolved solids are similar to Al. These two parameters are projected to have the slowest rates of concentration change. 


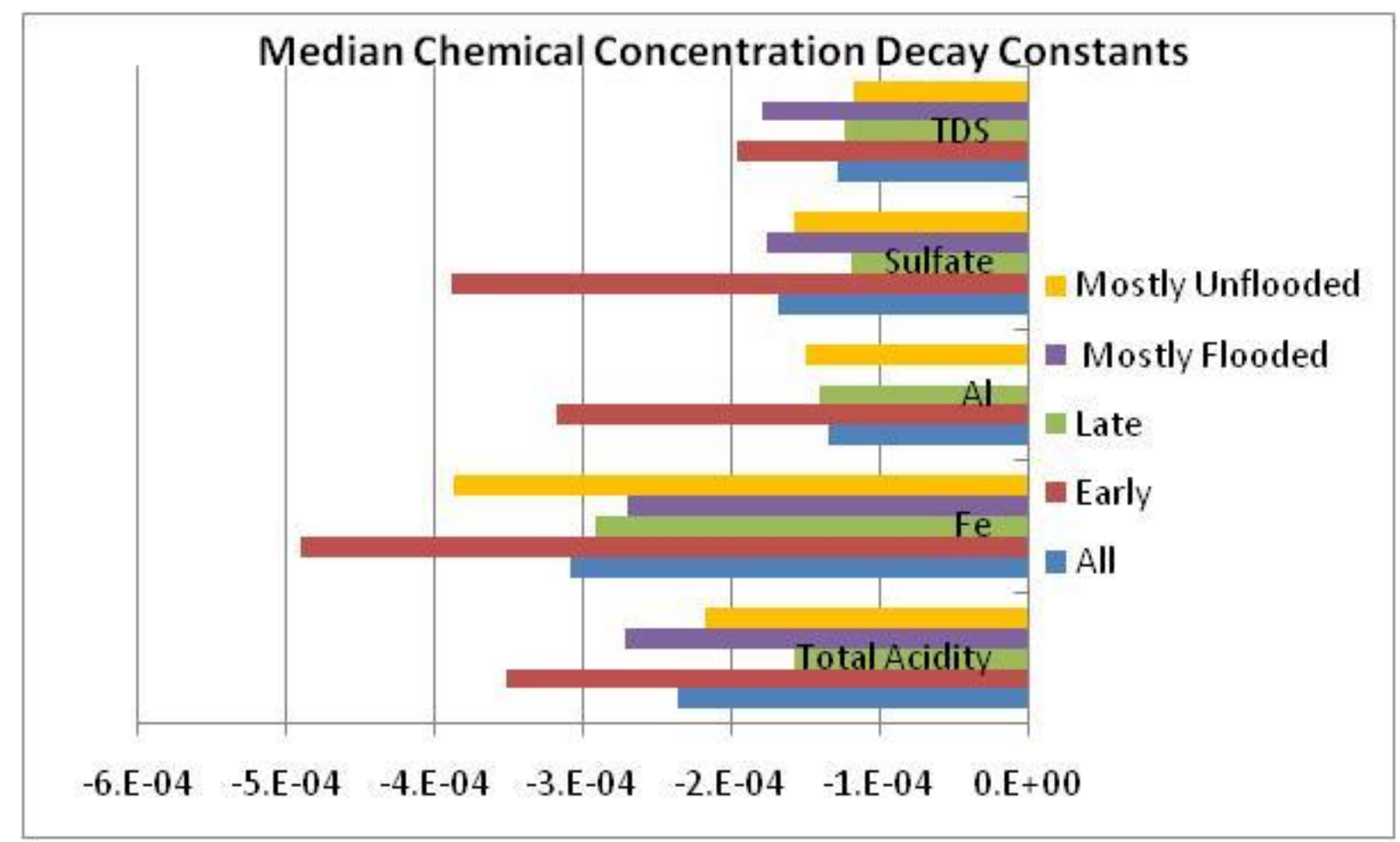

Figure 5-23. Chemical Concentration Decay Constants by Parameter, Degree of Flooding and Flushing Stage. Median Values for Five Mine-pools.

Figure 5-24 compares median decay constants as a ratio of mostly flooded to mostly unflooded, and ratio of early flushing to late leaching constants for the five mine-pools. The mostly flooded mines decay faster for total acidity, sulfate and dissolved solids in comparison to the mostly unflooded mines. Iron, however, is exceptional, with a slower decay rate in flooded mines. The

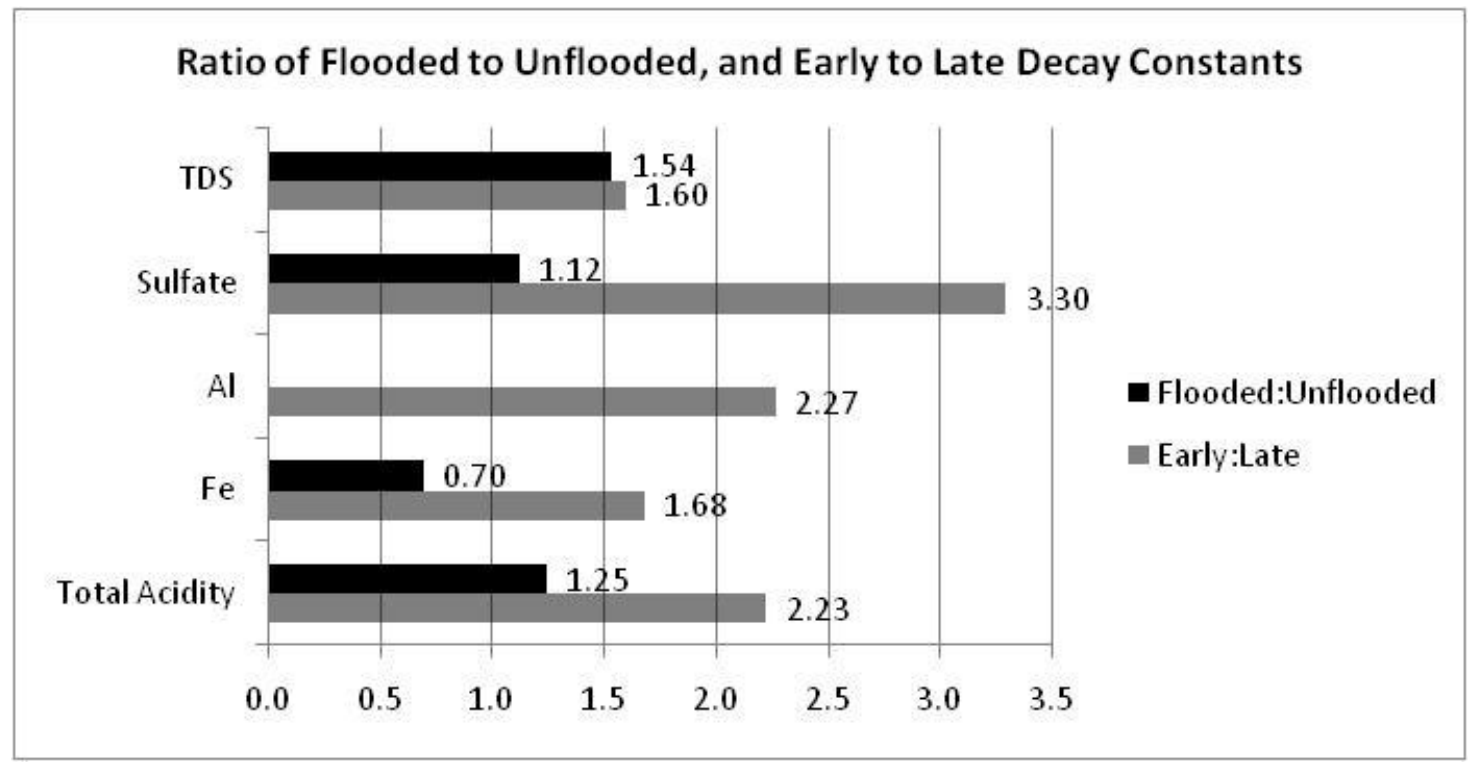

Figure 5-24. Comparison of Chemical Decay Constants Mostly Flooded to Mostly Unflooded, and Early Flushing to Late Leaching, for Five Mine-pools. 
implication is that flooding reduces weathering rates, in particular oxidation reactions, hence the decline in concentration is more rapid. The slower iron decay in flooded conditions suggests that soluble Fe may be generated from sources other than pyrite, such as the dissolution of $\mathrm{Fe}$ oxyhydroxide minerals. No redox measurements of the Hahn and Arden-Westland mine-pools are available, and the tendency for these mine-pools to dissolve Fe oxyhydroxides can only be approximated from indirect means. In section 5.2, the Hahn mine-pool was estimated to be reduced enough to at least dissolve more soluble forms of $\mathrm{Fe}(\mathrm{OH})_{3}$.

Six Eh measurements were made in the Doman (main) discharge from the mostly flooded Barnes\&Tucker mine-pool over an 18 month period by the author. Measured Eh ranged from +160 to +290 millivolts. The calculated indices were slightly under-saturated for poorly crystalline forms of $\mathrm{Fe}$ oxyhydroxides. These lines of evidence are indirect, but show that it is possible that Fe in mostly flooded, reduced mine-pools could be generated from dissolution of $\mathrm{Fe}$ oxide minerals.

Figure 5-24 also shows a comparison of decay constants for early flushing versus late or long term conditions. Early decay ranges from about 1.5 to 3 times faster than late decay for the five parameters, with the largest disparity reported for sulfate. In all parameters, the difference is likely attributed to the initial flush of accumulated and highly soluble minerals, followed by continued weathering and slower leaching of soluble minerals. Younger (1997, 2000), and Wood et al. (1999) have made similar observations to explain the discharge quality of coal mines in the U.K.

Tables 5-7 and 5-8, and figure 5-24 show that early flushing and long term conditions should be assigned separate decay values to model chemical concentration decay in mines. How should early and late decay periods be identified? For several mine-pools, events including grout injection and flooding of other mine-works clearly signal a change in conditions. Earlier in this chapter, the use of log-log scale plots was presented as a means of identifying flooding and flushing stages. A third mechanism is chemical ratios.

In chapter three and four, mine water iron to sulfate mole ratios were plotted on the assumption of pyrite stoichiometry, or one mmole Fe per two mmoles sulfate. These plots show the largest ratios present early in the monitoring record, then declining to a near constant value, with time series slope approaching zero. The approach of a near constant ratio approximately coincides with the demarcations made from log-log scale plots. A constant ratio also suggests that the initial transient flushing condition has passed and the mine-pool is in long term leaching. Figure 5-25 $\mathrm{a}$ and $\mathrm{b}$ are plots of $\mathrm{Fe}$ to sulfate mole ratios for the Hahn and Omega mine-pools, respectively.

The ratio approached near constant value in late 1989 in the Hahn mine-pool, about five years after flooding was complete. It is equivalent to the exchange of about 1.25 pool volumes. The mostly flooded Arden-Westland mine-pool displayed a near constant element ratio by 1991, about five years after flooding was complete. Based on an average four year residence time, the Arden-Westland mine-pool Fe to sulfate ratio also stabilized after discharging about 1.25 pool 
volumes. For the mostly flooded Barnes and Tucker mine-pool, the ratio stabilized after about four years or about eight pool volumes.

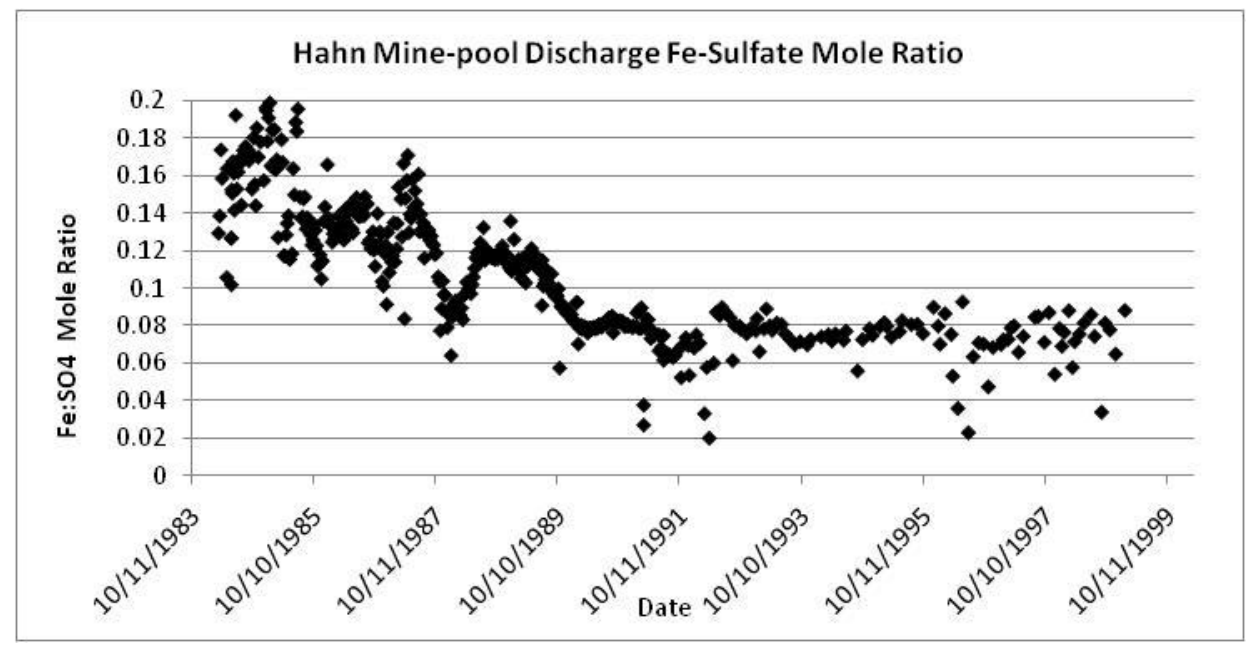

Figure 5-25a. Fe to Sulfate Mole Ratio, Hahn Mine-pool.

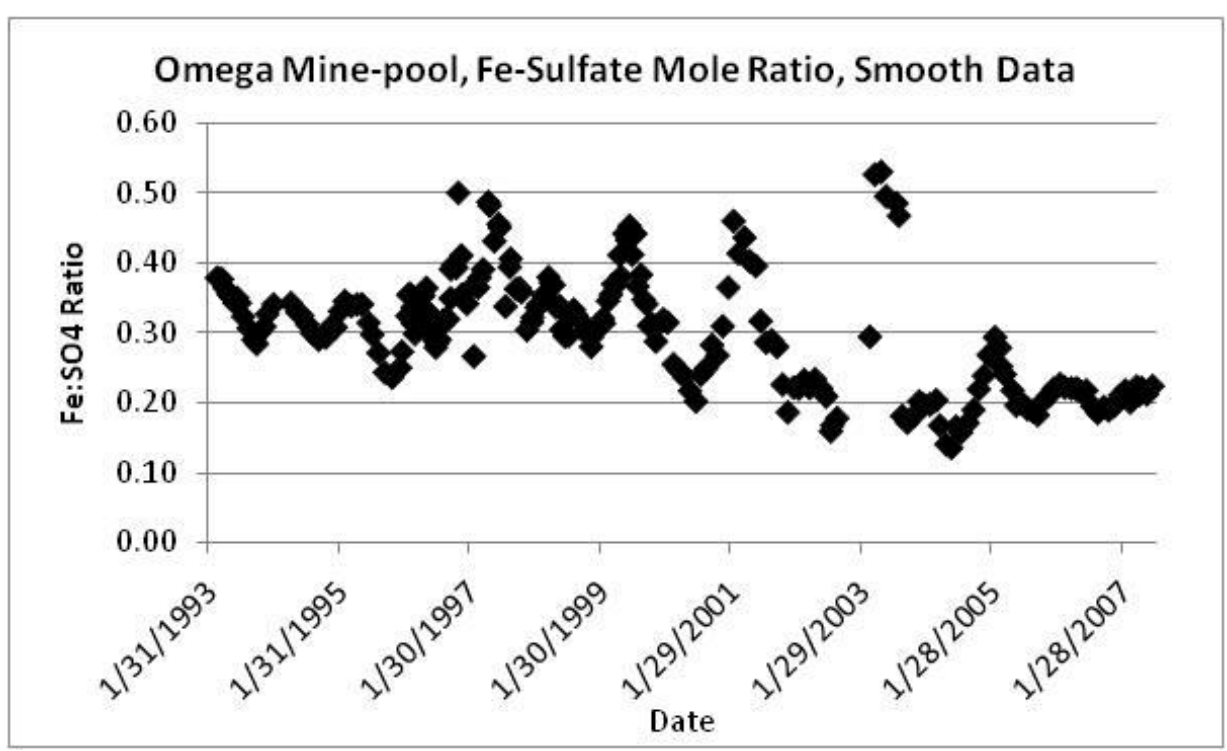

Figure 5-25b. Fe to Sulfate Mole Ratio, Omega Mine-pool.

The slope change in the Omega mine-pool (fig 5-25b) is not as obvious, but occurred around mid 1997, or about seven years after mine closure. Part of the monitoring record in this period is absent, so the exchange of water is a broad estimate of about 12 pool volumes. The T\&T minepool Fe to sulfate ratio stabilized about mid 1998, or four years after mine closure. This is equivalent to about eight pool volumes of water exchange.

For two of the three mostly flooded mines, Hahn and Arden-Westland, Fe to sulfate ratio approached a constant value after the mine-pool flushed slightly more than one pool volume. The two acidic mostly unflooded mines had less distinct slope changes, and exchanged an estimated eight to ten pool volumes before stabilizing. The contrast between flooded and mostly unflooded mines could be attributed to the active ongoing chemical weathering in the aerated partly flooded 
mine-pools, and less aggressive weathering in the mostly flooded mines. Element ratios can be a useful tool for separating initial flushing and long term leaching periods.

\subsubsection{Estimated Decay Times for Chemical Parameters}

Decay constants were used to estimate time dependent chemical concentration decline in two ways. The first was to estimate the time required for the chemical parameter to decay to a specified fraction of $0.5,0.1,0.05$, and 0.01 of the starting concentration $\mathrm{C}_{0}$. The second approach estimated the time required to reach a specified concentration.

Tables 5-9 to 5-13 show the estimated decay times in years to reach specified fractions of starting concentration, respectively, for the five parameters of total acidity, $\mathrm{Al}, \mathrm{Fe}$, sulfate and total dissolved solids (TDS). The estimates are derived from the decay constants in tables 5-7 and 5-8, using the single $\mathrm{k}$ value derived for all data. Equation 5-22 was solved for time $\mathrm{t}$ using specified fractions of $\mathrm{C}_{\mathrm{t}} / \mathrm{C}_{0}$ and the previously determined decay constant. The time estimates in this set of calculations are only dependent on the value of " $k$ ", the decay constant. For all parameters and decay constants, the "half life" or time for concentration to decline to $50 \%$ of initial conditions ranges from about three to 18 years, with most estimates between about seven to 15 years. Time to reach ten percent of initial concentration ( $\mathrm{t} 0.1$ in the tables), ranges from about two to 60 years for all parameters and decay constants. Most are between 15 and 40 years. Time to reach five percent of initial concentration ranges from about three to 78 years. Most estimates are greater than 20 years. Finally, the estimated time to reach one percent of initial concentration ranges from at least 15 to more than 100 years. Many estimates exceed 40 years. Several entries had statistically insignificant decay constants, for which time dependent concentrations were not estimated. These rates are too small to resolve. This implies longer decay times, or large variation in the data set, masking a statistically identifiable trend.

This initial summary has two significant implicit assumptions:

- Hydrogeologic conditions will remain constant through time, and

- Geochemical conditions will remain constant through time.

The hydrogeology of closed mines can be affected by pumping, and flooding or dewatering of hydrologically connected mines and aquifers. Effects from adjacent mines will be site-specific. A second issue is the alteration in aquifer properties of the mine-pool by continued physical weathering, pillar crushing and collapse of roof rock. The significance of continued weathering of aquifer rocks in underground mines is not developed here. However, Hawkins (2004) reported that hydraulic conductivity of surface mine-spoil more than 2.5 years old was less than for newly reclaimed rocks. He attributed this in part to continued physical weathering. Rhem et al. (1980) also reported that hydraulic conductivity decreased with age on surface mine spoil in North Dakota. A plausible effect of decreasing hydraulic conductivity in underground mine gob would be to reduce ground-water flow velocity and removal of chemical constituents, and hence reduce decay rates. The assumption of constant hydrogeologic conditions over a prolonged period may not be completely robust. 
Table 5-9

Estimated Decay Time for Total Acidity to Decline to 50, 10, 5 and 1\% of Initial Concentration

\begin{tabular}{|c|c|c|c|c|c|}
\hline Mine & $\begin{array}{c}\text { Initial Concentration } \mathrm{C}_{0} \\
(\mathrm{mg} / \mathrm{L})\end{array}$ & $\begin{array}{c}\mathrm{t} 0.5 \\
\text { (years) }\end{array}$ & $\begin{array}{c}\mathrm{t} 0.1 \\
\text { (years) }\end{array}$ & $\begin{array}{l}\mathrm{t} 0.05 \\
\text { (years) }\end{array}$ & $\begin{array}{l}\mathrm{t} 0.01 \\
\text { (years) }\end{array}$ \\
\hline Omega, all, $3 / 93$ to $11 / 07$ & 3169 & 8.1 & 26.8 & 34.9 & 53.7 \\
\hline Omega, pregrout, 3/93-1/97 & 3169 & 4.0 & 13.1 & 17.1 & 26.3 \\
\hline Omega, postgrout 6/99-9/07 & 2061 & 9.9 & 33 & 43 & 66.1 \\
\hline T\&T all data, 4/94-9/07 & 750 & 17.6 & 58.4 & 76 & 116.8 \\
\hline T\&T, pre inject, 4/94-11/96 & 750 & 3.5 & 11.5 & 15.0 & 23.0 \\
\hline T\&T, long term $1 / 04-9 / 07$ & 566 & N.S. ${ }^{(1)}$ & N.S. & N.S. & N.S. \\
\hline Hahn all data, 12/84 -10/04 & 2123 & 3.9 & 12.9 & 16.8 & 25.9 \\
\hline Hahn, early data, $12 / 84-8 / 91$ & 2123 & 2.3 & 7.7 & 9.9 & 15.2 \\
\hline Hahn, late data, 5/93-10/04 & 216 & 6.6 & 21.8 & 28.4 & 43.7 \\
\hline Arden-Westland all, 1/89-2/99 & 307 & 7.6 & 25.2 & 32.8 & 50.5 \\
\hline Arden-Westland, early 1/89-5/91 & 307 & 6.9 & 22.8 & 29.6 & 45.5 \\
\hline $\begin{array}{c}\text { Arden-Westland, long term } \\
\text { 8/96-2/99 }\end{array}$ & 118 & N.S. & N.S. & N.S. & N.S. \\
\hline Barnes\&Tucker all data & 1647 & 8.6 & 28.7 & 37.3 & 57.3 \\
\hline Barnes\&Tucker, pre flooding & 1647 & 7.5 & 25.0 & 32.6 & 50.1 \\
\hline $\begin{array}{l}\text { Barnes\&Tucker } \\
\text { post flooding }\end{array}$ & 133 & 17.0 & 56.3 & 73.3 & 112.6 \\
\hline
\end{tabular}

(1) N.S. = Decay constant not statistically significant. No time estimate calculated.

The second assumption, that geochemical conditions remain constant through time may also be suspect. As the mine-pool solution becomes increasingly dilute, concentrations of Fe and other elements could be controlled by mineral solubility. This prospect is examined in section 5.5.

The decay estimates summarized in tables 5-9 to 5-13 illustrate two observations of practical significance about temporal trends in water composition:

- A relatively rapid initial decline on the order of a few years to ten to 20 years. Water treatment needs are at a maximum during this time.

- A much slower decline, where water treatment demands are reduced, but are likely needed over a longer period, spanning multiple decades.

Table 5-10

Estimated Decay Time for Aluminum to decline to 50, 10, 5 and $1 \%$ of Initial Concentration

\begin{tabular}{cccccc}
\hline Mine & Initial Concentration $\mathrm{C}_{0}(\mathrm{mg} / \mathrm{L})$ & $\begin{array}{c}\mathrm{t} 0.5 \\
\text { (years) }\end{array}$ & $\begin{array}{c}\mathrm{t} 0.1 \\
\text { (years) }\end{array}$ & $\begin{array}{c}\mathrm{t} \mathrm{0.05} \\
\text { (years) }\end{array}$ & $\begin{array}{c}\mathrm{t} 0.01 \\
\text { (years) }\end{array}$ \\
\hline Omega, 3/93 to 11/07 & 147 & 17.4 & 57.9 & 75.3 & 115.7 \\
Omega, pregrout, 3/93-1/97 & 147 & 7 & 23.1 & 30.1 & 46.2 \\
Omega, postgrout 6/99-9/07 & 111 & 14.8 & 49.3 & 64.1 & 98.6 \\
T\&T all data, 4/94-9/07 & 46 & 18.8 & 62.4 & 81.2 & 124.9 \\
T\&T, pre inject, 4/94-11/96 & 46 & 0.7 & 2.2 & 2.8 & 4.3 \\
T\&T, long term 1/04-9/07 & 44 & N.S. ${ }^{(1)}$ & N.S. & N.S. & N.S. \\
\hline
\end{tabular}

(1) N.S=Decay constant not statistically significant. No time estimate calculated. 
Table 5-11

Estimated Decay Time for Iron to decline to 50,10,5 and 1\% of Initial Concentration

\begin{tabular}{|c|c|c|c|c|c|}
\hline Mine & $\begin{array}{c}\text { Initial Concentration } \mathrm{C}_{0} \\
(\mathrm{mg} / \mathrm{L})\end{array}$ & $\begin{array}{c}\mathrm{t} 0.5 \\
\text { (years) }\end{array}$ & $\begin{array}{c}\mathrm{t} 0.1 \\
\text { (years) }\end{array}$ & $\begin{array}{l}\mathrm{t} 0.05 \\
\text { (years) }\end{array}$ & $\begin{array}{l}\mathrm{t} 0.01 \\
\text { (years) }\end{array}$ \\
\hline Omega, all, $3 / 93$ to $11 / 07$ & 839 & 7.3 & 24.4 & 31.7 & 48.7 \\
\hline Omega, pre-grout, 3/93-1/97 & 839 & 3.9 & 12.9 & 16.7 & 25.7 \\
\hline Omega, post-grout 6/99-9/07 & 600 & 6.7 & 22.2 & 28.9 & 44.1 \\
\hline T\&T all data, 4/94-9/07 & 316 & 5.8 & 19.3 & 25.2 & 38.7 \\
\hline T\&T, pre-inject, 4/94-11/96 & 316 & 4.9 & 16.2 & 21.1 & 32.4 \\
\hline T\&T, long term $1 / 04-9 / 07$ & 123 & 4.4 & 14.7 & 19.1 & 29.4 \\
\hline Hahn all data, 12/84-10/04 & 1030 & 3.9 & 12.9 & 16.8 & 25.9 \\
\hline Hahn, early data, $12 / 84-8 / 91$ & 1030 & 2.3 & 7.7 & 10.1 & 15.5 \\
\hline Hahn, late data, 5/93-10/04 & 121 & 6.3 & 21.1 & 27.4 & 42.2 \\
\hline Arden-Westland all, 1/89-2/99 & 165 & 7.7 & 25.4 & 33.1 & 50.9 \\
\hline Arden-Westland, early 1/89-5/91 & 121 & 5.3 & 17.8 & 23.1 & 35.5 \\
\hline $\begin{array}{c}\text { Arden-Westland, long term } \\
\text { 8/96-2/99 }\end{array}$ & 63 & N.S. ${ }^{(1)}$ & N.S. & N.S. & N.S. \\
\hline Barnes\&Tucker all data & 920 & 8.5 & 28.3 & 36.8 & 56.6 \\
\hline Barnes\&Tucker, pre flooding & 920 & 7.5 & 25 & 32.6 & 50.1 \\
\hline $\begin{array}{l}\text { Barnes\&Tucker, } \\
\text { post flooding }\end{array}$ & 74 & 17 & 56.3 & 73.3 & 112.6 \\
\hline
\end{tabular}

(1) N.S.=Decay constant not statistically significant. No time estimate calculated.

Table 5-12

Estimated Decay Time for Sulfate to decline to 50, 10, 5 and $1 \%$ of Initial Concentration

\begin{tabular}{cccccc}
\hline Mine & $\begin{array}{c}\text { Initial Concentration } \mathrm{C}_{0} \\
(\mathrm{mg} / \mathrm{L})\end{array}$ & $\begin{array}{c}\mathrm{t} 0.5 \\
\text { (years) }\end{array}$ & $\begin{array}{c}\mathrm{t} 0.1 \\
\text { (years) }\end{array}$ & $\begin{array}{c}\mathrm{t} 0.05 \\
\text { (years) }\end{array}$ & $\begin{array}{c}\mathrm{t} \mathrm{0.01} \\
\text { (years) }\end{array}$ \\
\hline Omega, all, 3/93 to 11/07 & 4016 & 14.5 & 48.1 & 62.6 & 96.3 \\
Omega, pregrout, 3/93-1/97 & 4016 & 3.9 & 13.0 & 16.9 & 26.0 \\
Omega, postgrout 6/99-9/07 & 3242 & 15.3 & 50.9 & 66.2 & 101.7 \\
T\&T all data, 4/94-9/07 & 2885 & 6.2 & 20.6 & 26.8 & 41.2 \\
T\&T, pre inject, 4/94-11/96 & 2885 & 1.8 & 5.9 & 7.7 & 11.9 \\
T\&T, long term 1/04-9/07 & 1655 & N.S. ${ }^{(1)}$ & N.S. & N.S. & N.S. \\
Hahn all data, 12/84 -10/04 & 8300 & 4.6 & 15.2 & 19.7 & 30.3 \\
Hahn, early data, 12/84-8/91 & 8300 & 4.0 & 13.2 & 17.2 & 26.5 \\
Hahn, late data, 5/93-10/04 & 1838 & 7.0 & 23.2 & 30.2 & 46.4 \\
Arden-Westland all, 1/89-2/99 & 1672 & 11.6 & 38.5 & 50.0 & 76.9 \\
Arden-Westland, early 1/89-5/91 & 1672 & 10.7 & 35.4 & 46.1 & 70.9 \\
Arden-Westland, long term & 1060 & 17.6 & 58.4 & 76.0 & 116.8 \\
8/96-2/99 & 3692 & 12.8 & 42.6 & 55.4 & 85.2 \\
Barnes\&Tucker all data & 3692 & 10.8 & 36.0 & 46.9 & 72.1 \\
Barnes\&Tucker, pre flooding & 597 & 18.1 & 60.1 & 78.1 & 120.2 \\
Barnes\&Tucker & & & &
\end{tabular}

(1) N.S.=Decay constant not statistically significant. No time estimate calculated. 
Table 5-13

Estimated Decay Time for TDS to decline to 50, 10, 5 and 1\% of Initial Concentration

\begin{tabular}{|c|c|c|c|c|c|}
\hline Mine & $\begin{array}{c}\text { Intial Concentration } \mathrm{C}_{0} \\
(\mathrm{mg} / \mathrm{L})\end{array}$ & $\begin{array}{c}\text { t } 0.5 \\
\text { (years) }\end{array}$ & $\begin{array}{c}\text { t } 0.1 \\
\text { (years) }\end{array}$ & $\begin{array}{l}\mathrm{t} 0.05 \\
\text { (years) }\end{array}$ & $\begin{array}{l}\mathrm{t} 0.01 \\
\text { (years) }\end{array}$ \\
\hline Omega, all, $3 / 93$ to $11 / 07$ & 5315 & 18.1 & 60.1 & 78.1 & 120.2 \\
\hline Omega, pre-grout, 3/93-1/97 & 5315 & 5.5 & 18.3 & 23.8 & 36.6 \\
\hline Omega, post-grout 6/99-9/07 & 4972 & 14.2 & 47.1 & 61.2 & 94.2 \\
\hline T\&T all data, 4/94-9/07 & 2194 & $\underset{(1)}{\text { N.S. }}$ & N.S. & N.S. & N.S. \\
\hline T\&T, pre-inject, 4/94-11/96 & 2194 & 3.3 & 11.1 & 14.5 & 22.3 \\
\hline T\&T, long term $1 / 04-9 / 07$ & 2894 & N.S. & N.S. & N.S. & N.S. \\
\hline Hahn all data, 12/84 -10/04 & 11400 & 4.6 & 15.2 & 19.7 & 30.3 \\
\hline Hahn, early data, $12 / 84-8 / 91$ & 11400 & 4.4 & 14.6 & 19.0 & 29.1 \\
\hline Hahn, late data, 5/93-10/04 & 3952 & 4.1 & 13.6 & 17.7 & 27.2 \\
\hline Arden-Westland all, 1/89-2/99 & 3074 & 14.7 & 48.9 & 63.6 & 97.8 \\
\hline \multirow{2}{*}{$\begin{array}{l}\text { Arden-Westland, early } 1 / 89-5 / 91 \\
\text { Arden-Westland, long term 8/96- } \\
\text { 2/99 }\end{array}$} & 3074 & 10.7 & 35.4 & 46.1 & 70.9 \\
\hline & 2222 & N.S. & N.S. & N.S. & N.S. \\
\hline \multirow{3}{*}{$\begin{array}{c}\text { Barnes\&Tucker all data } \\
\text { Barnes\&Tucker, pre flooding } \\
\text { Barnes\&Tucker, } \\
\text { post flooding }\end{array}$} & Insuffucient Data & - & - & - & - \\
\hline & Insuffucient Data & - & - & - & - \\
\hline & Insuffucient Data & - & - & - & - \\
\hline
\end{tabular}

(1) N.S.= Decay constant not statistically significant. No time estimate calculated.

The second decay time estimate used a specific parameter concentration as a target value. The target values were selected on the basis of established water quality values for specific uses or discharge standards. The estimates then provide an indication of the time required to approach suitability for various uses. The decay equation (equation 5-22) was solved for time $t$, using the initial and target concentrations, and previously calculated decay constant. The time estimates in this set of calculations are dependent on the starting concentration $\mathrm{C}_{0}$ and the decay constant, "k". Target concentrations of $10,3.5$ and $1 \mathrm{mg} / \mathrm{L}$ were selected for Fe. One $\mathrm{mg} / \mathrm{L} \mathrm{Fe}$ is a suggested water quality standard for aquatic life (US EPA, 1986a), while the $3.5 \mathrm{mg} / \mathrm{L}$ is a 30 day average National Pollutant Discharge Elimination System (NPDES) discharge standard for coal mines. The regulatory standards are described in Title 40, Part 434 of the Code of Federal Regulations. A target concentration of one $\mathrm{mg} / \mathrm{L}$ was selected for $\mathrm{Al}$, which is similar to the recommended standard of $0.75 \mathrm{mg} / \mathrm{L}$ for aquatic life (US EPA, 1986b). Target values of 500 $\mathrm{mg} / \mathrm{L}$ total dissolved solids, and $250 \mathrm{mg} / \mathrm{L}$ for sulfate were selected based on national secondary drinking water standards. Those standards are found in Title 40, part 143 of the Code of Federal Regulations. A target value of $300 \mathrm{mg} / \mathrm{L}$ acidity was selected as a condition where passive treatment systems that add alkalinity might be feasible (Hedin et al., 1994).

The estimated times to attain target concentration values are shown in figures 5-26 to 5-30 and table 5-14 for the five mine-pools. Concentration data in the graphs (y-axis) are log base ten scale to more clearly display the difference in decay rate. Iron decay with the exception of T\&T post injection data and Hahn early flushing, ranges from 27 to 75 years to reach $3.5 \mathrm{mg} / \mathrm{L} \mathrm{Fe}$. 
Aluminum decay to one $\mathrm{mg} / \mathrm{L}$ is estimated to require 69 to more than 100 years in the acidic mostly unflooded mines. Sulfate decay to $250 \mathrm{mg} / \mathrm{L}$ is estimated to require between 15 and 58 years. The shortest decay times are for total acidity to reach $300 \mathrm{mg} / \mathrm{L}$, requiring less than 30 years for all scenarios. Parts of the Hahn, Arden-Westland and Barnes\&Tucker records are already less than $300 \mathrm{mg} / \mathrm{L}$ total acidity. Several decay scenarios have statistically insignificant rates and no estimates were calculated. They are too small to resolve. This implies longer decay.

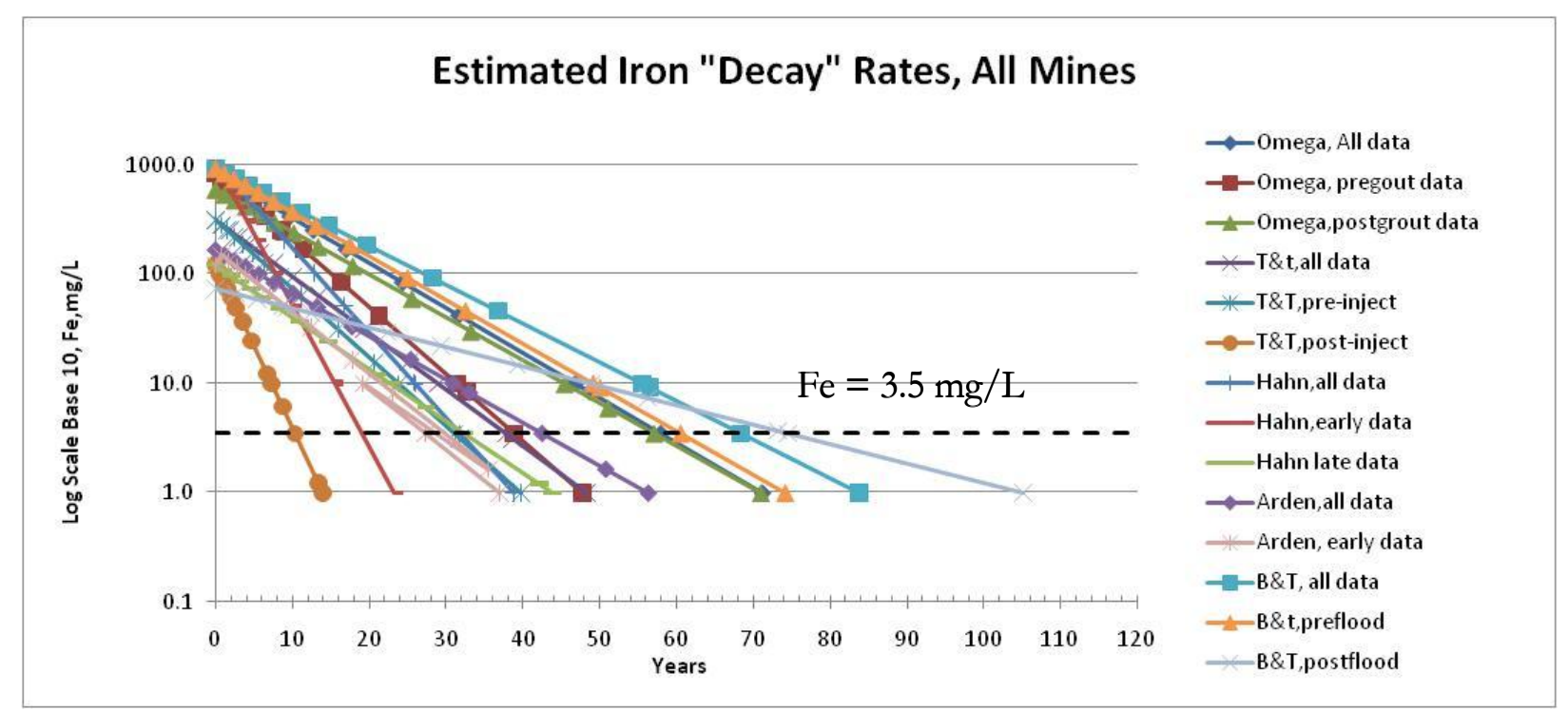

Figure 5-26. Estimated Time in Years for Iron to "Decay" to $3.5 \mathrm{mg} / \mathrm{L}$, for Five Mines and Different Flooding Phases. Concentration Axis is log Base 10 Scale. See table 5-14 for Numeric Values.

Total dissolved solids decay estimates to attain $500 \mathrm{mg} / \mathrm{L}$ were between 12 and 24 years, with the exception of the Omega mine-pool post-grouting or for the combined Omega data. This set of estimated decay times also implies near steady conditions in physical and chemical properties through time.

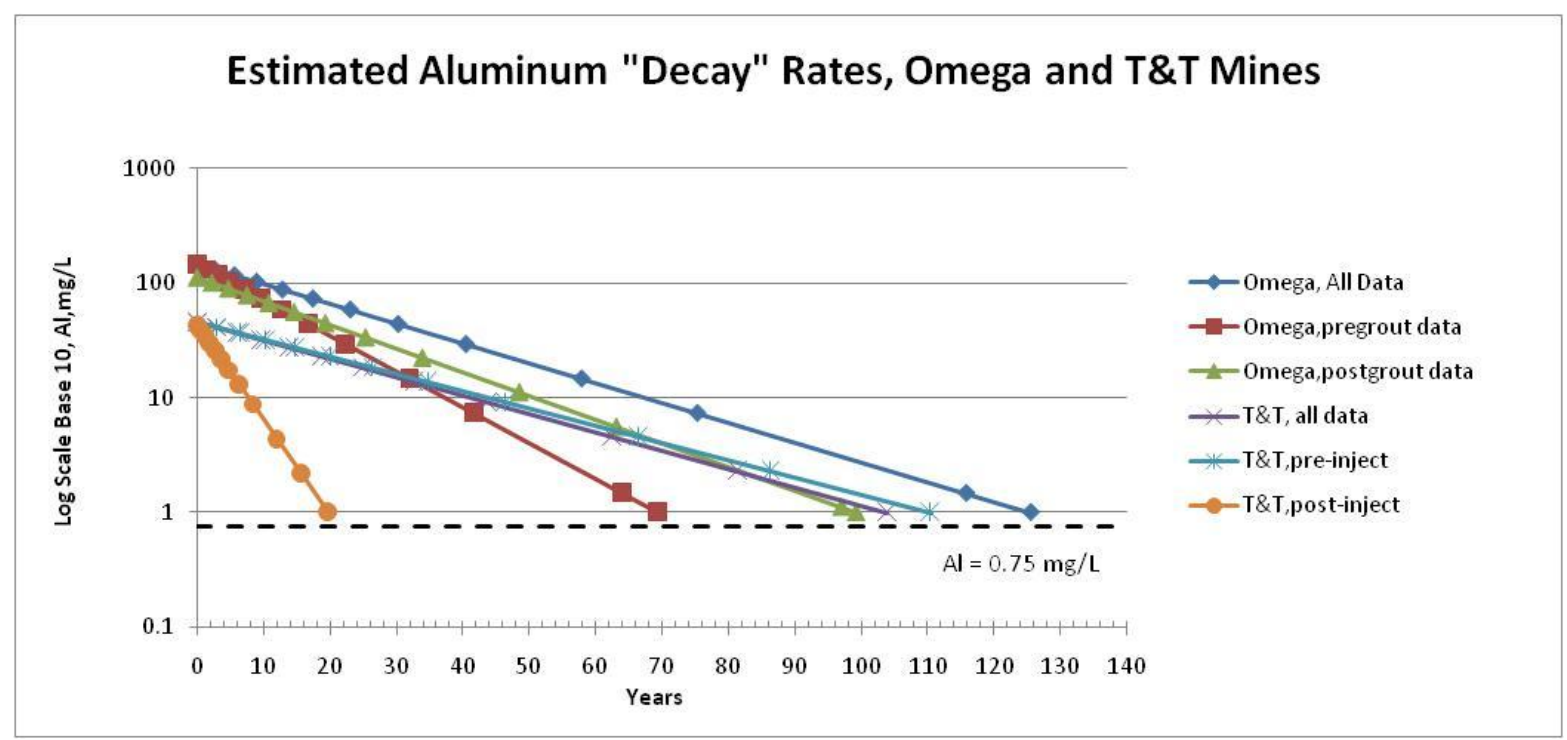

Figure 5-27. Estimated Time in Years for Aluminum to "Decay" to One mg/L, for Five mines and Different Flooding Phases. Concentration Axis is log Base 10 Scale. See table 5-14 for Numeric Values. 
The target concentration estimates show that mine-pool waters of these starting chemical compositions are likely to require decades to achieve acceptable chemistry. Excluding total acidity, most parameter decay estimates are between 20 and 70 years to achieve target concentrations.

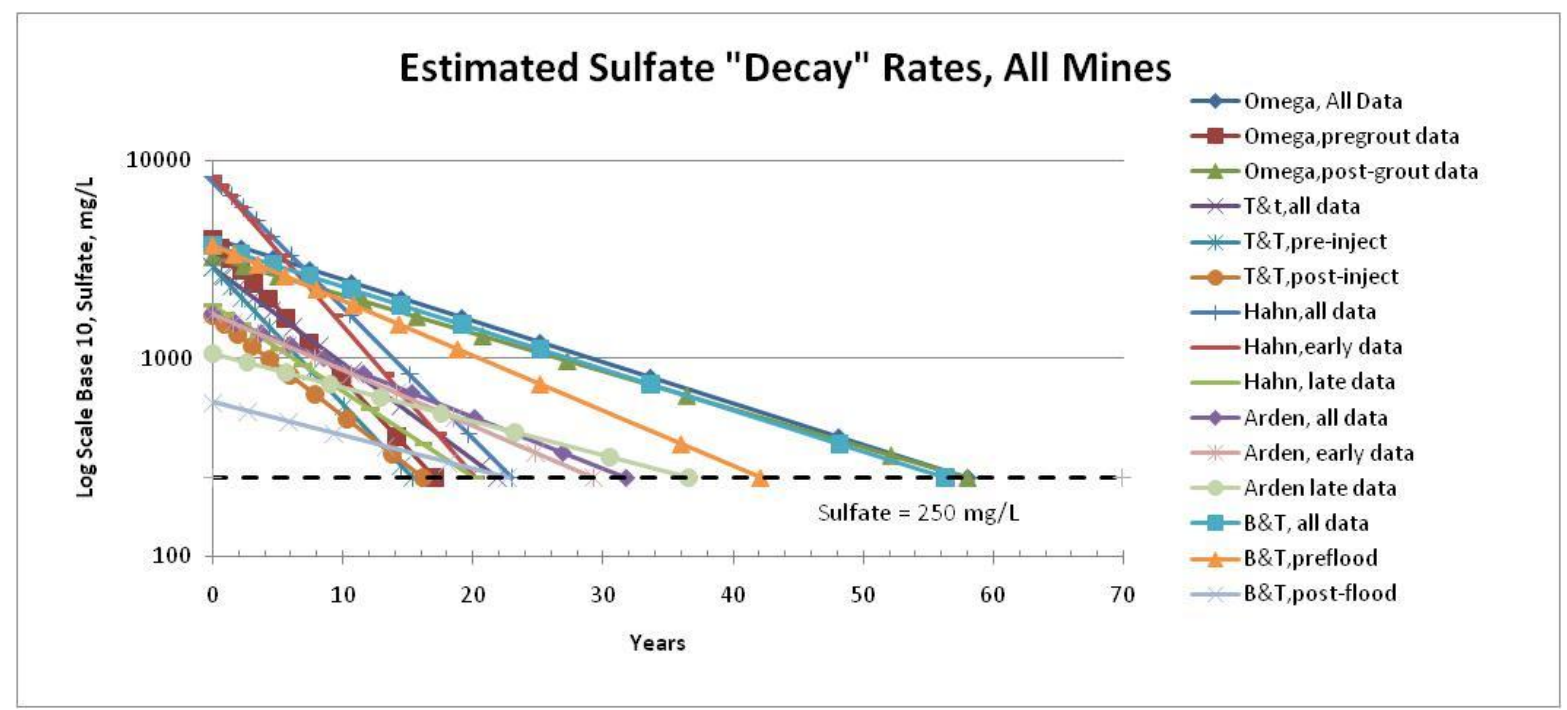

Figure 5-28. Estimated Time in Years for Sulfate to "Decay" to $250 \mathrm{mg} / \mathrm{l}$, for Five Mines and Different Flooding Phases. Concentration Axis is log Base 10 Scale. See table 5-14 for Numeric Values.

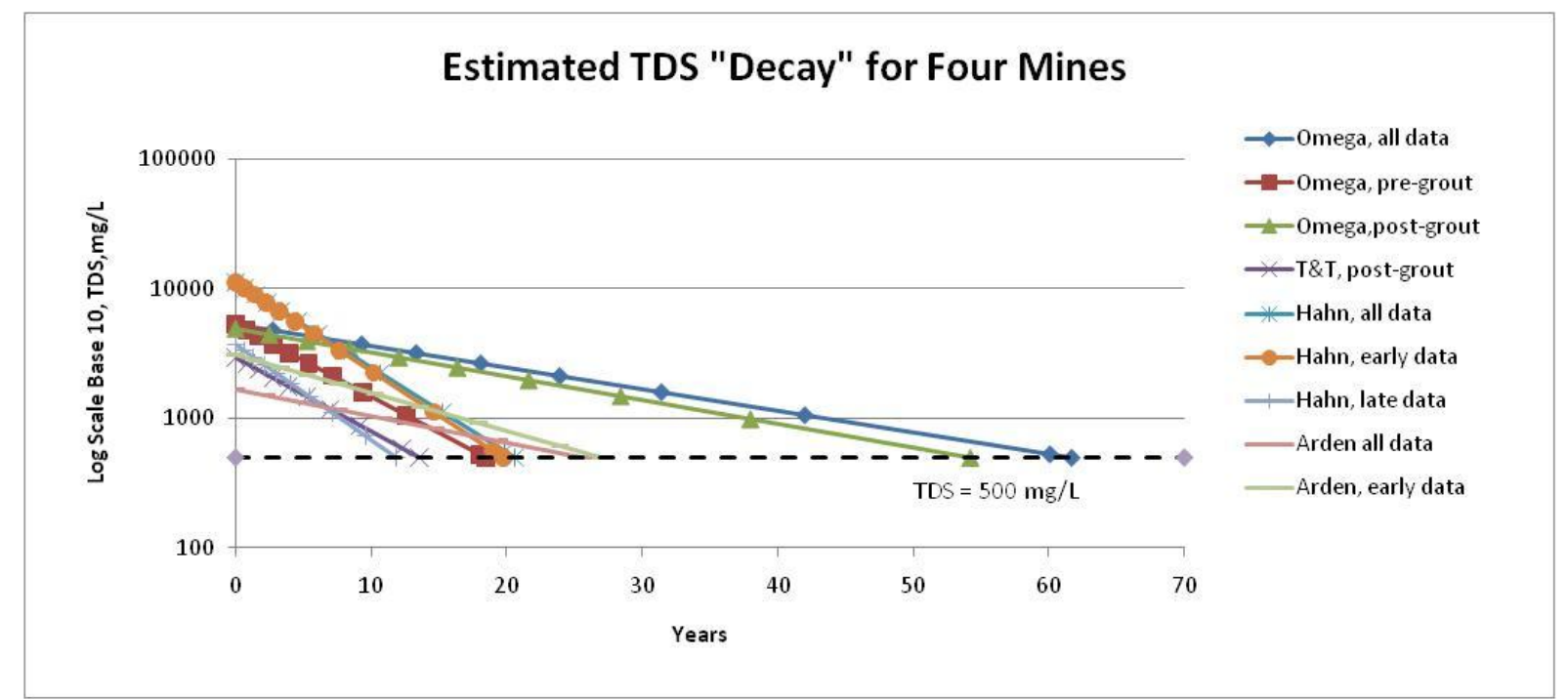

Figure 5-29. Estimated Time in Years for Total Dissolved Solids to "Decay" to $500 \mathrm{mg} / \mathrm{L}$, for Five Mines and Different Flooding Phases. Concentration Axis is log Base 10 Scale. See table 5-14 for NumericValues. 
Table 5-14

Estimated Years to Attain Target Parameter Concentration

Based on "Decay" Calculation, And Initial Concentration $\left(C_{0}\right){ }^{(1)}$

\begin{tabular}{|c|c|c|c|c|c|c|c|}
\hline Mine & $\begin{array}{c}\mathrm{Fe}, \\
10 \mathrm{mg} / \mathrm{L}\end{array}$ & $\begin{array}{c}\mathrm{Fe}, \\
3.5 \mathrm{mg} / \mathrm{L}\end{array}$ & $\begin{array}{c}\mathrm{Fe}, \\
1 \mathrm{mg} / \mathrm{L}\end{array}$ & $\begin{array}{c}\mathrm{Al}, \\
1 \mathrm{mg} / \mathrm{L}\end{array}$ & $\begin{array}{c}\text { Sulfate, } \\
250 / \mathrm{mg} / \mathrm{L}\end{array}$ & $\begin{array}{c}\text { TDS, } \\
500 \mathrm{mg} / \mathrm{L}\end{array}$ & $\begin{array}{l}\text { Acidity, } \\
300 \mathrm{mg} / \mathrm{L}\end{array}$ \\
\hline $\begin{array}{l}\text { Omega, } \\
\text { All data }\end{array}$ & $\begin{array}{c}47 \mathrm{yrs} \\
(839 \mathrm{mg} / \mathrm{L})\end{array}$ & $\begin{array}{c}58 \mathrm{yrs} \\
(839 \mathrm{mg} / \mathrm{L})\end{array}$ & $\begin{array}{c}71 \mathrm{yrs} \\
(839 \mathrm{mg} / \mathrm{L})\end{array}$ & $\begin{array}{c}125 \mathrm{yrs} \\
(147 / \mathrm{mg} / \mathrm{L})\end{array}$ & $\begin{array}{c}58 \mathrm{yrs} \\
(4016 \mathrm{mg} / \mathrm{L})\end{array}$ & $\begin{array}{c}62 \mathrm{yrs} \\
(5315 \mathrm{mg} / \mathrm{L})\end{array}$ & $\begin{array}{c}28 \mathrm{yrs} \\
(3169 \mathrm{mg} / \mathrm{L})\end{array}$ \\
\hline $\begin{array}{l}\text { Omega, } \\
\text { Pre-grout }\end{array}$ & $\begin{array}{c}31 \mathrm{yrs} \\
(839 \mathrm{mg} / \mathrm{L})\end{array}$ & $\begin{array}{c}39 \mathrm{yrs} \\
(839 \mathrm{mg} / \mathrm{L})\end{array}$ & $\begin{array}{c}48 \mathrm{yrs} \\
(839 \mathrm{mg} / \mathrm{L})\end{array}$ & $\begin{array}{c}69 \mathrm{yrs} \\
(147 / \mathrm{mg} / \mathrm{L}) \\
\end{array}$ & $\begin{array}{c}17 \mathrm{yrs} \\
(4016 \mathrm{mg} / \mathrm{L})\end{array}$ & $\begin{array}{c}19 \mathrm{yrs} \\
(5315 \mathrm{mg} / \mathrm{L})\end{array}$ & $\begin{array}{c}22 \mathrm{yrs} \\
(3169 \mathrm{mg} / \mathrm{L}) \\
\end{array}$ \\
\hline $\begin{array}{c}\text { Omega, } \\
\text { Post-grout }\end{array}$ & $\begin{array}{c}45 \mathrm{yrs} \\
(600 \mathrm{mg} / \mathrm{L})\end{array}$ & $\begin{array}{c}57 \mathrm{yrs} \\
(600 \mathrm{mg} / \mathrm{L})\end{array}$ & $\begin{array}{c}71 \mathrm{yrs} \\
(600 \mathrm{mg} / \mathrm{L})\end{array}$ & $\begin{array}{c}102 \mathrm{yrs} \\
(111 \mathrm{mg} / \mathrm{L})\end{array}$ & $\begin{array}{c}58 \mathrm{yrs} \\
(3242 \mathrm{mg} / \mathrm{L})\end{array}$ & $\begin{array}{c}54 \mathrm{yrs} \\
(4972 \mathrm{mg} / \mathrm{L})\end{array}$ & $\begin{array}{c}19 \mathrm{yrs} \\
(2061 \mathrm{mg} / \mathrm{L})\end{array}$ \\
\hline $\begin{array}{c}\text { T\&T, } \\
\text { All data }\end{array}$ & $\begin{array}{c}29 \mathrm{yrs} \\
(316 \mathrm{mg} / \mathrm{L})\end{array}$ & $\begin{array}{c}38 \mathrm{yrs} \\
(316 \mathrm{mg} / \mathrm{L})\end{array}$ & $\begin{array}{c}48 \mathrm{yrs} \\
(316 \mathrm{mg} / \mathrm{L})\end{array}$ & $\begin{array}{c}104 \mathrm{yrs} \\
(46 \mathrm{mg} / \mathrm{L})\end{array}$ & $\begin{array}{c}22 \mathrm{yrs} \\
(2885 \mathrm{mg} / \mathrm{L})\end{array}$ & N.S. & $\begin{array}{c}23 \mathrm{yrs} \\
(750 \mathrm{mg} / \mathrm{L}) \\
\end{array}$ \\
\hline $\begin{array}{c}\text { T\&T, } \\
\text { Pre-inject }\end{array}$ & $\begin{array}{c}24 \mathrm{yrs} \\
(316 \mathrm{mg} / \mathrm{L})\end{array}$ & $\begin{array}{c}31 \mathrm{yrs} \\
(316 \mathrm{mg} / \mathrm{L})\end{array}$ & $\begin{array}{c}40 \mathrm{yrs} \\
(316 \mathrm{mg} / \mathrm{L})\end{array}$ & $\begin{array}{c}110 \mathrm{yrs} \\
(46 \mathrm{mg} / \mathrm{L})\end{array}$ & $\begin{array}{c}15 \mathrm{yrs} \\
(2885 \mathrm{mg} / \mathrm{L})\end{array}$ & N.S. & $\begin{array}{c}12 \mathrm{yrs} \\
(750 \mathrm{mg} / \mathrm{L})\end{array}$ \\
\hline $\begin{array}{c}\text { T\&T, } \\
\text { Post-inject }\end{array}$ & $\begin{array}{c}5 \mathrm{yrs} \\
(123 \mathrm{mg} / \mathrm{L})\end{array}$ & $\begin{array}{c}7 \mathrm{yrs} \\
(123 \mathrm{mg} / \mathrm{L})\end{array}$ & $\begin{array}{c}10 \mathrm{yrs} \\
(123 \mathrm{mg} / \mathrm{L})\end{array}$ & $\begin{array}{c}21 \mathrm{yrs} \\
(44 \mathrm{mg} / \mathrm{L})\end{array}$ & $\begin{array}{c}16 \mathrm{yrs} \\
(1655 \mathrm{mg} / \mathrm{L})\end{array}$ & $\begin{array}{c}9 \mathrm{yrs} \\
(2894 \mathrm{mg} / \mathrm{L})\end{array}$ & $\begin{array}{c}4 \mathrm{yrs} \\
(630 \mathrm{mg} / \mathrm{L})\end{array}$ \\
\hline $\begin{array}{c}\text { Hahn, all } \\
\text { data }\end{array}$ & $\begin{array}{c}26 \mathrm{yrs} \\
(1030 \mathrm{mg} / \mathrm{L})\end{array}$ & $\begin{array}{c}32 \mathrm{yrs} \\
(1030 \mathrm{mg} / \mathrm{L})\end{array}$ & $\begin{array}{c}39 \mathrm{yrs} \\
(1030 \mathrm{mg} / \mathrm{L})\end{array}$ & & $\begin{array}{c}22 \mathrm{yrs} \\
(8300 \mathrm{mg} / \mathrm{L})\end{array}$ & $\begin{array}{c}20 \mathrm{yrs} \\
(11400 \mathrm{mg} / \mathrm{L})\end{array}$ & $\begin{array}{c}11 \mathrm{yrs} \\
(2018 \mathrm{mg} / \mathrm{L})\end{array}$ \\
\hline $\begin{array}{c}\text { Hahn, } \\
\text { early data }\end{array}$ & $\begin{array}{c}16 \mathrm{yrs} \\
(1030 \mathrm{mg} / \mathrm{L})\end{array}$ & $\begin{array}{c}19 \mathrm{yrs} \\
(1030 \mathrm{mg} / \mathrm{L})\end{array}$ & $\begin{array}{c}23 \mathrm{yrs} \\
(1030 \mathrm{mg} / \mathrm{L})\end{array}$ & & $\begin{array}{c}19 \mathrm{yrs} \\
(8300 \mathrm{mg} / \mathrm{L})\end{array}$ & $\begin{array}{c}20 \mathrm{yrs} \\
(11400 \mathrm{mg} / \mathrm{L})\end{array}$ & $\begin{array}{c}7 \mathrm{yrs} \\
(2018 \mathrm{mg} / \mathrm{L})\end{array}$ \\
\hline $\begin{array}{l}\text { Hahn, } \\
\text { late data }\end{array}$ & $\begin{array}{c}22 \mathrm{yrs} \\
(121 \mathrm{mg} / \mathrm{L})\end{array}$ & $\begin{array}{c}32 \mathrm{yrs} \\
(121 \mathrm{mg} / \mathrm{L})\end{array}$ & $\begin{array}{c}43 \mathrm{yrs} \\
(121 \mathrm{mg} / \mathrm{L})\end{array}$ & & $\begin{array}{c}20 \mathrm{yrs} \\
(1838 \mathrm{mg} / \mathrm{L})\end{array}$ & $\begin{array}{c}12 \mathrm{yrs} \\
(3685 \mathrm{mg} / \mathrm{L})\end{array}$ & \\
\hline $\begin{array}{c}\text { Arden- } \\
\text { Westland, } \\
\text { all data }\end{array}$ & $\begin{array}{c}31 \mathrm{yrs} \\
(165 \mathrm{mg} / \mathrm{L})\end{array}$ & $\begin{array}{c}43 \mathrm{yrs} \\
(165 \mathrm{mg} / \mathrm{L})\end{array}$ & $\begin{array}{c}56 \mathrm{yrs} \\
(165 \mathrm{mg} / \mathrm{L})\end{array}$ & & $\begin{array}{c}32 \mathrm{yrs} \\
(1670 \mathrm{mg} / \mathrm{L})\end{array}$ & $\begin{array}{c}24 \mathrm{yrs} \\
(3074 \mathrm{mg} / \mathrm{L})\end{array}$ & \\
\hline $\begin{array}{c}\text { Arden- } \\
\text { Westland } \\
\text { early data }\end{array}$ & $\begin{array}{c}19 \mathrm{yrs} \\
(121 \mathrm{mg} / \mathrm{L})\end{array}$ & $\begin{array}{c}27 \mathrm{yrs} \\
(121 \mathrm{mg} / \mathrm{L})\end{array}$ & $\begin{array}{c}37 \mathrm{yrs} \\
(121 \mathrm{mg} / \mathrm{L})\end{array}$ & & $\begin{array}{c}25 \mathrm{yrs} \\
(1670 \mathrm{mg} / \mathrm{L})\end{array}$ & $\begin{array}{c}24 \mathrm{yrs} \\
(3074 \mathrm{mg} / \mathrm{L})\end{array}$ & \\
\hline $\begin{array}{l}\text { Arden- } \\
\text { Westland } \\
\text { late data }\end{array}$ & N.S. & N.S. & N.S. & & $\begin{array}{c}31 \mathrm{yrs} \\
(1060 \mathrm{mg} / \mathrm{L})\end{array}$ & N.S. & \\
\hline $\begin{array}{c}\text { B\&T, } \\
\text { All data }\end{array}$ & $\begin{array}{c}56 \mathrm{yrs} \\
(920 \mathrm{mg} / \mathrm{L})\end{array}$ & $\begin{array}{c}68 \mathrm{yrs} \\
(920 \mathrm{mg} / \mathrm{L})\end{array}$ & $\begin{array}{c}84 \mathrm{yrs} \\
(920 \mathrm{mg} / \mathrm{L})\end{array}$ & & $\begin{array}{c}56 \mathrm{yrs} \\
(3692 \mathrm{mg} / \mathrm{L})\end{array}$ & & $\begin{array}{c}21 \mathrm{yrs} \\
(1647 \mathrm{mg} / \mathrm{L})\end{array}$ \\
\hline $\begin{array}{c}\text { B\&T, } \\
\text { Pre-flood }\end{array}$ & $\begin{array}{c}49 \mathrm{yrs} \\
(920 \mathrm{mg} / \mathrm{L})\end{array}$ & $\begin{array}{c}61 \mathrm{yrs} \\
(920 \mathrm{mg} / \mathrm{L})\end{array}$ & $\begin{array}{c}74 \mathrm{yrs} \\
(920 \mathrm{mg} / \mathrm{L})\end{array}$ & & $\begin{array}{c}42 \mathrm{yrs} \\
(3692 \mathrm{mg} / \mathrm{L})\end{array}$ & & $\begin{array}{c}30 \mathrm{yrs} \\
(1647 \mathrm{mg} / \mathrm{L})\end{array}$ \\
\hline $\begin{array}{c}\text { B\&T, } \\
\text { Post-flood }\end{array}$ & $\begin{array}{c}49 \mathrm{yrs} \\
(74 \mathrm{mg} / \mathrm{L})\end{array}$ & $\begin{array}{c}75 \mathrm{yrs} \\
(74 \mathrm{mg} / \mathrm{L})\end{array}$ & $\begin{array}{c}105 \mathrm{yrs} \\
(74 \mathrm{mg} / \mathrm{L})\end{array}$ & & $\begin{array}{c}23 \mathrm{yrs} \\
(597 \mathrm{mg} / \mathrm{L})\end{array}$ & & \\
\hline
\end{tabular}

(1) No Aluminum decay values for Hahn, Arden-Westland, and B\&T mine-pools, because the waters are circumneutral and contain little dissolved Al. TDS decay values for the T\&T all data record and T\&T pre-inject record are not statistically significant. TDS data not reported for most of the B\&T period of record. Acidity decay value for T\&T pre-injection data record is not statistically significant. Acidity decay values for Hahn late data, Arden-Westland, and B\&T post flooding are near or less than the target concentration of $300 \mathrm{mg} / \mathrm{L}$. 


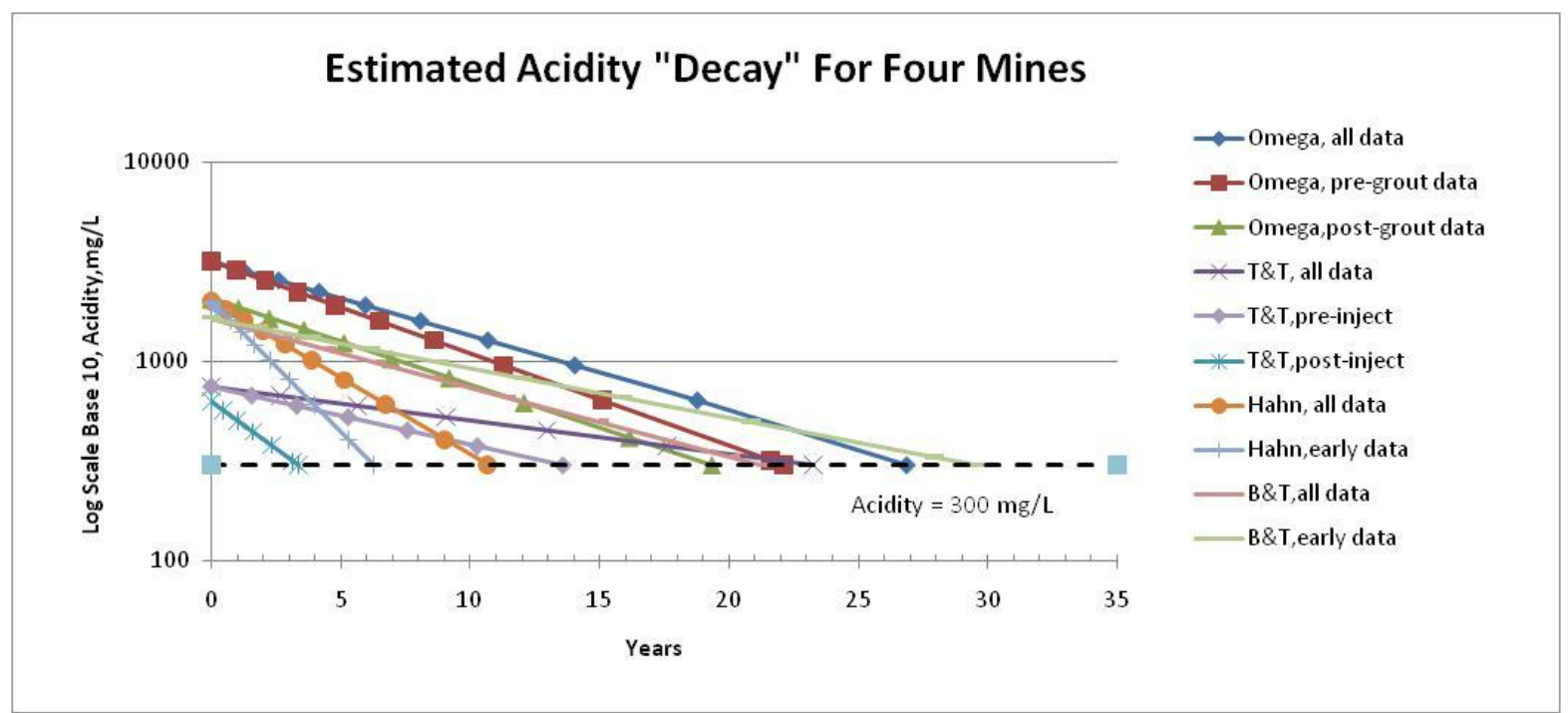

Figure 5-30. Estimated Time in Years for Total Acidity to "Decay" to $300 \mathrm{mg} / \mathrm{L}$, for Four Mines and Different Flooding Phases. Concentration Axis is log Base 10 Scale. See table 5-14 for Numeric Values.

\subsubsection{Sensitivity Analysis of Decay Constants}

The decay constants presented in this chapter were derived by regression analysis, and hence are "best fit" estimates of the slope of the fitted equation. Sensitivity of the decay constant estimate was evaluated against the initial concentration $\mathrm{C}_{0}$, and by examining the range of plus or minus two standard deviations of the estimate of " $\mathrm{k}$ ".

Estimating the decay constant $\mathrm{k}$ is not sensitive to the specified value of the initial concentration $\mathrm{C}_{0}$. This is graphically illustrated in figure 5-31. Equation 5-22 uses the ratio $\mathrm{C}_{\mathrm{t}} / \mathrm{C}_{0}$ to generate values to plot against time. If $\mathrm{C}_{0}$ is changed by an amount $\mathrm{b}$, then the ratio for every

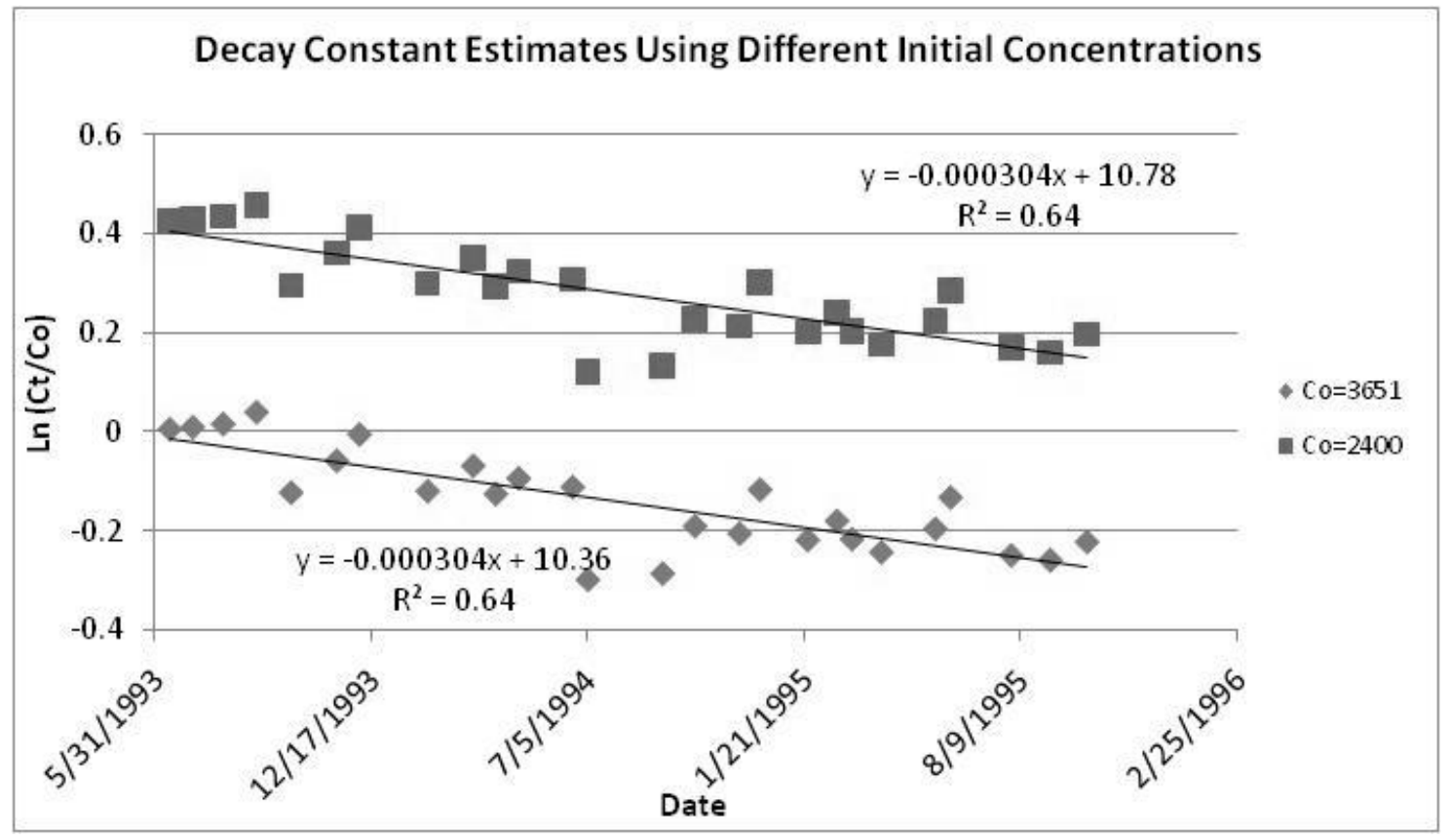

Figure 5-31. Estimating Decay Constant Using Different Initial Concentrations on the Same Data Set. 
datum point becomes $\mathrm{C}_{t} /\left(\mathrm{C}_{0}-\mathrm{b}\right)$. The variance, distribution of residuals about the fitted line and slope ("k") will remain the same. Only the line intercept value will change. Figure 5-31shows data points fitted to regression lines using $\mathrm{C}_{0}$ values of 3651 and $2400 \mathrm{mg} / \mathrm{L}$. The example data are TDS measurements from the Hahn mine-pool. Both regressions produce a decay constant of $-3.04 \times 10^{-4} / \mathrm{d}$ and $\mathrm{R}^{2}$ values of $64 \%$, but with different $\mathrm{y}$ intercepts. A "correct" initial concentration is only needed if the function is extrapolated back to time $t=0$.

Table 5-15 shows "best fit" estimates of decay constants, and a constant at +2 standard deviations (95th percentile) from the best fit value. The latter represents an upper bound of decay rate, and hence a minimum time for pollutant concentrations to decrease. The table includes constants fitted to the entire period of record. The two mostly unflooded mines, Omega and T\&T, have the largest variation about the regression and range of decay constant. The largest is for total acidity at the Omega mine-pool where $\mathrm{k}$ at the 95 th percentile is $1.35 \times 10^{-4} / \mathrm{d}$ greater than the best fit value. This gives a time range of 17 to 27 years for total acidity to decay to 300 $\mathrm{mg} / \mathrm{L}$. Other parameters in mostly unflooded mines range from 0.31 to $0.92 \times 10^{-4} / \mathrm{d}$ difference in decay constant values. The range in decay constant values produces a wider confidence interval when estimating pollutant decay behavior.

The three mostly flooded mines have smaller variances and range of decay constants. The largest difference is $0.24 \times 10^{-4} / \mathrm{d}$ for $\mathrm{Fe}$ in the Barnes\&Tucker mine-pool. This produces a time range of 19 to 21 years for total acidity to decline to $300 \mathrm{mg} / \mathrm{L}$. The smaller range of estimated decay constants in mostly flooded mines produces a smaller confidence interval for time dependent behavior. The standard deviation values in table 5-16 can be used to estimate upper and lower bounds on the decay constant, and minimum and maximum decay times.

Table 5-15

Range of Decay Constant Values ${ }^{(1)}$

\begin{tabular}{|cccccc|}
\hline & Total Acidity & Iron & Aluminum & Sulfate & TDS \\
\hline $\begin{array}{c}\text { Omega All Data } \\
\text { Best Fit k }\end{array}$ & $-2.35 \times 10^{-4}$ & $-2.59 \times 10^{-4}$ & $-1.09 \times 10^{-4}$ & $-1.31 \times 10^{-4}$ & $-1.05 \times 10^{-4}$ \\
+2 Std Dev k & $-3.70 \times 10^{-4}$ & $-3.38 \times 10^{-4}$ & $-1.62 \times 10^{-4}$ & $-1.62 \times 10^{-4}$ & $-1.88 \times 10^{-4}$ \\
\hline $\begin{array}{c}\text { T\&T All Data } \\
\text { Best Fit k }\end{array}$ & N.S. & $-3.26 \times 10^{-4}$ & $-1.01 \times 10^{-4}$ & $-3.06 \times 10^{-4}$ & N.S. \\
+2 Std Dev k & & $-4.04 \times 10^{-4}$ & $-1.71 \times 10^{-4}$ & $-3.98 \times 10^{-4}$ & \\
\hline $\begin{array}{c}\text { Hahn All Data } \\
\text { Best Fit k }\end{array}$ & $-4.88 \times 10^{-4}$ & $-4.89 \times 10^{-4}$ & no data & $-4.18 \times 10^{-4}$ & $-4.14 \times 10^{-4}$ \\
+2 Std Dev k & $-4.89 \times 10^{-4}$ & $-5.04 \times 10^{-4}$ & & $-4.27 \times 10^{-4}$ & $-4.22 \times 10^{-4}$ \\
\hline $\begin{array}{c}\text { Arden-Westland All Data } \\
\text { Best Fit k }\end{array}$ & $-2.50 \times 10^{-4}$ & $-2.48 \times 10^{-4}$ & no data & $-1.64 \times 10^{-4}$ & $-1.29 \times 10^{-4}$ \\
+2 Std Dev k & $-2.52 \times 10^{-4}$ & $-2.65 \times 10^{-4}$ & & $-1.76 \times 10^{-4}$ & $-1.39 \times 10^{-4}$ \\
\hline $\begin{array}{c}\text { B \&T All Data } \\
\text { Best Fit k }\end{array}$ & $-2.20 \times 10^{-4}$ & $-2.23 \times 10^{-4}$ & no data & $-1.48 \times 10^{-4}$ & no data \\
+2 Std Dev k & $-2.52 \times 10^{-4}$ & $-2.57 \times 10^{-4}$ & & $-1.68 \times 10^{-4}$ & \\
\hline
\end{tabular}

(1) Constant values in day ${ }^{-1}$. 


\subsubsection{Sensitivity Analysis of Decay Time Estimates}

The sensitivity of estimated time for pollutant decay was evaluated by varying two parameters in equation 5-22, the decay constant " $\mathrm{k}$ " and initial concentration " $\mathrm{C}_{0}$ ". Table 5-16 shows the estimated decay times to a target concentration, computed by varying " $\mathrm{k}$ " from the best fit and 95th percentile values shown in table 5-15. Decay times for the mostly flooded Hahn and ArdenWestland mine-pools are essentially unchanged, regardless of whether the best fit or 95th percentile value of $\mathrm{k}$ is used. The Barnes\&Tucker mine-pool estimates differ from six to 12 years. The more variable, mostly unflooded mine-pools, differ by ten to 15 years for estimates of iron, sulfate and total acidity. The largest difference occurs for aluminum and results from two factors; a low target concentration of one $\mathrm{mg} / \mathrm{L}$, and small decay constants. Unfortunately, the T\&T total acidity and total dissolved solids data have large variances, and single statistically significant decay constants could not be resolved for the entire monitoring record.

The results in table 5-16 show that chemical concentration decay in mines approaching steady state condition can be estimated within a narrow confidence of range of a decade or less. The mostly unflooded mines, which are characterized by numerous short term transient events, have a somewhat broader range of about one to two decades for most parameters. Regardless of the $\mathrm{k}$ values used, the time estimates to approach target concentrations are on the order of multiple decades.

Table 5-16

Range of Decay Times in Years from Best Fit and 95th Percentile Values of k

\begin{tabular}{|c|c|c|c|c|c|}
\hline & $\begin{array}{c}\text { Total } \\
\text { Acidity } \\
\text { Decay Time } \\
\text { to } 300 \mathrm{mg} / \mathrm{L}\end{array}$ & $\begin{array}{l}\text { Iron } \\
\text { Decay } \\
\text { Time } \\
\text { to } 1 \mathrm{mg} / \mathrm{L}\end{array}$ & $\begin{array}{l}\text { Aluminum } \\
\text { Decay } \\
\text { Time } \\
\text { to } 1 \mathrm{mg} / \mathrm{L}\end{array}$ & $\begin{array}{c}\text { Sulfate } \\
\text { Decay } \\
\text { Time } \\
\text { to } 250 \\
\mathrm{mg} / \mathrm{L}\end{array}$ & $\begin{array}{c}\text { TDS } \\
\text { Decay } \\
\text { Time } \\
\text { to } 500 \\
\mathrm{mg} / \mathrm{L}\end{array}$ \\
\hline $\begin{array}{c}\text { Omega All Data } \\
\text { Best Fit k } \\
+2 \text { Std Dev k } \\
\end{array}$ & $\begin{array}{l}27 \mathrm{yrs} \\
17 \mathrm{yrs}\end{array}$ & $\begin{array}{l}71 \mathrm{yrs} \\
56 \mathrm{yrs}\end{array}$ & $\begin{array}{c}126 \mathrm{yrs} \\
84 \mathrm{yrs}\end{array}$ & $\begin{array}{l}58 \text { yrs } \\
47 \text { yrs } \\
\end{array}$ & $\begin{array}{l}62 \mathrm{yrs} \\
34 \mathrm{yrs} \\
\end{array}$ \\
\hline $\begin{array}{l}\text { T\&T All Data } \\
\text { Best Fit k } \\
+2 \text { Std Dev k } \\
\end{array}$ & N.S. & $\begin{array}{l}48 \text { yrs } \\
39 \text { yrs } \\
\end{array}$ & $\begin{array}{c}104 \mathrm{yrs} \\
61 \mathrm{yrs}\end{array}$ & $\begin{array}{l}22 \mathrm{yrs} \\
17 \mathrm{yrs} \\
\end{array}$ & N.S. \\
\hline $\begin{array}{l}\text { Hahn All Data } \\
\text { Best Fit k } \\
+2 \text { Std Dev k } \\
\end{array}$ & $\begin{array}{l}24 \mathrm{yrs} \\
24 \mathrm{yrs} \\
\end{array}$ & $\begin{array}{l}39 \text { yrs } \\
38 \text { yrs } \\
\end{array}$ & no data & $\begin{array}{l}23 \text { yrs } \\
23 \text { yrs }\end{array}$ & $\begin{array}{l}21 \mathrm{yrs} \\
20 \mathrm{ysr}\end{array}$ \\
\hline $\begin{array}{c}\text { Arden-Westland All } \\
\text { Data } \\
\text { Best Fit k } \\
\text { +2 Std Dev k }\end{array}$ & $\begin{array}{l}<1 \\
<1 \\
\end{array}$ & $\begin{array}{l}56 \text { yrs } \\
53 \text { yrs } \\
\end{array}$ & no data & $\begin{array}{l}32 \text { yrs } \\
30 \mathrm{ysr}\end{array}$ & $\begin{array}{l}26 \mathrm{yrs} \\
24 \mathrm{yrs}\end{array}$ \\
\hline $\begin{array}{l}\text { B\&T All Data } \\
\text { Best Fit k } \\
+2 \text { Std Dev k }\end{array}$ & $\begin{array}{l}50 \mathrm{yrs} \\
44 \mathrm{yrs}\end{array}$ & $\begin{array}{l}84 \text { yrs } \\
73 \text { yrs }\end{array}$ & no data & $\begin{array}{l}56 \text { yrs } \\
44 \text { yrs }\end{array}$ & no data \\
\hline
\end{tabular}


The second time sensitivity analysis varied the value for initial concentration $\mathrm{C}_{0}$. The initial concentration was selected by identifying the single measurement, or more commonly, group of plotted measurements, that showed the beginning of a declining concentration trend. The median was used to represent the value for $\mathrm{C}_{0}$ for a group of measurements.

Decay time estimates to achieve a target concentration were calculated using a single value for $\mathrm{k}$ while varying $\mathrm{C}_{0}$ by plus or minus one, three, five, ten and 20 percent. This analysis was conducted for one mostly unflooded site, the Omega mine-pool, and one mostly flooded minepool, the Hahn discharge. These two mines had the greatest and smallest variances in parameters estimates respectively. The results are shown in figures 5-32 to 5-36.
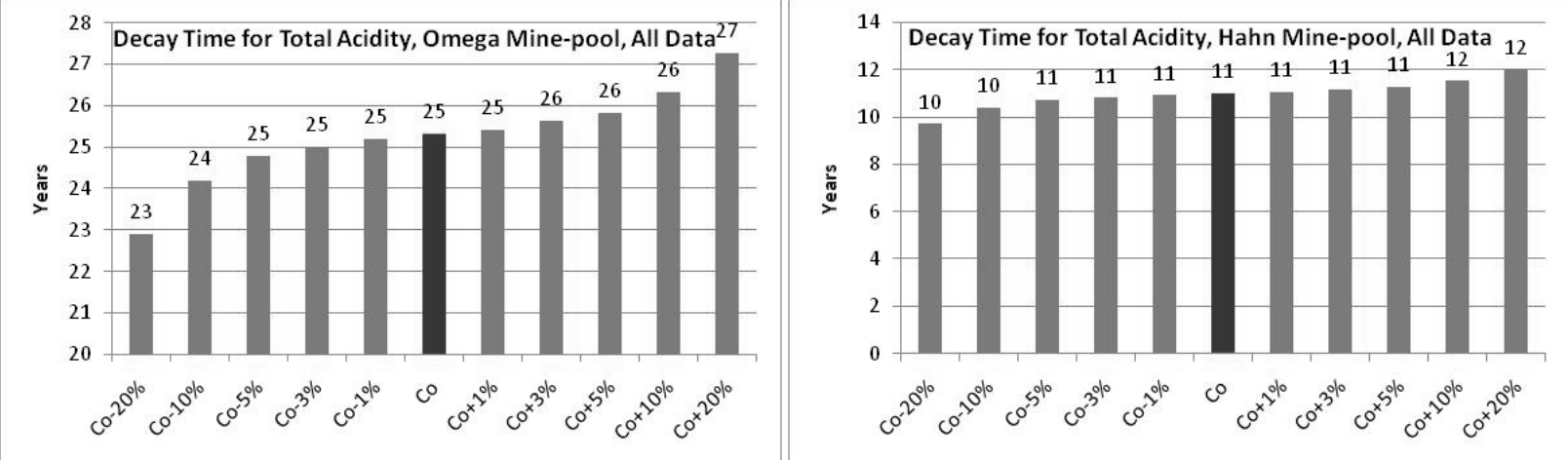

Figure 5-32. Estimated Decay Times for Total Acidity to Reach $300 \mathrm{mg} / \mathrm{L}$, Based on Different Starting Concentrations, Omega and Hahn Mine-pools. Black bars indicate $\mathrm{C}_{0}$. Gray bars show $C_{0}$ varied by $1,3,5,10$ or $20 \%$. Decay time in years.
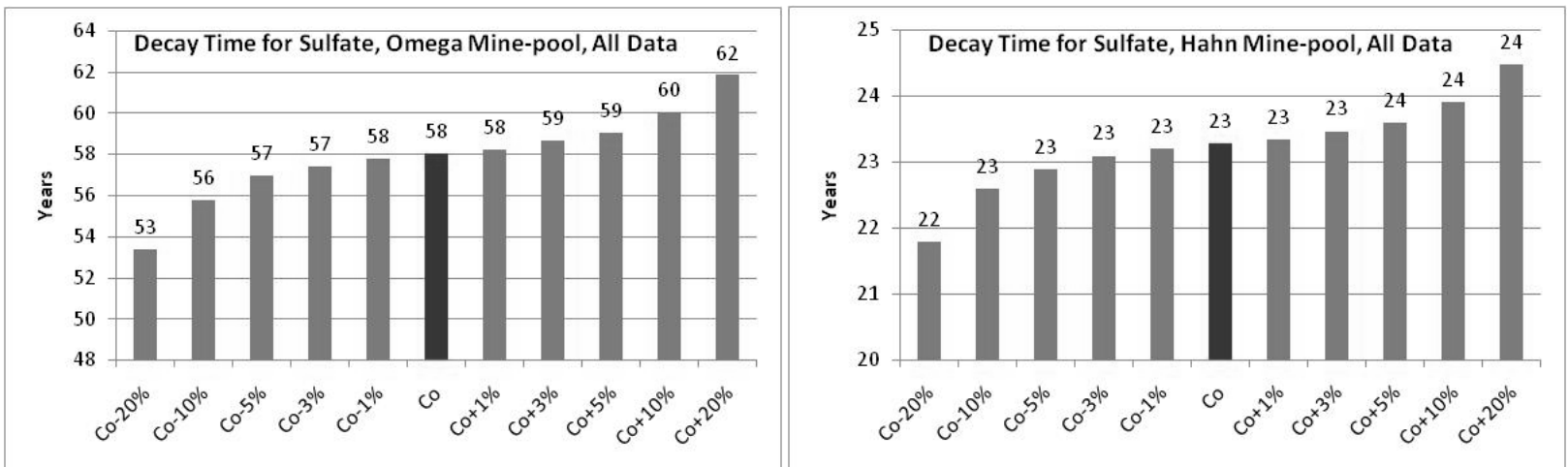

Figure 5-33. Estimated Decay Times for Sulfate to Reach $250 \mathrm{mg} / \mathrm{L}$,

Based on Different Starting Concentrations, Omega and Hahn Mine-pools. Black bars indicate $\mathbf{C}_{0}$. Gray bars show $C_{0}$ varied by $1,3,5,10$ or $20 \%$. Decay time in years. 

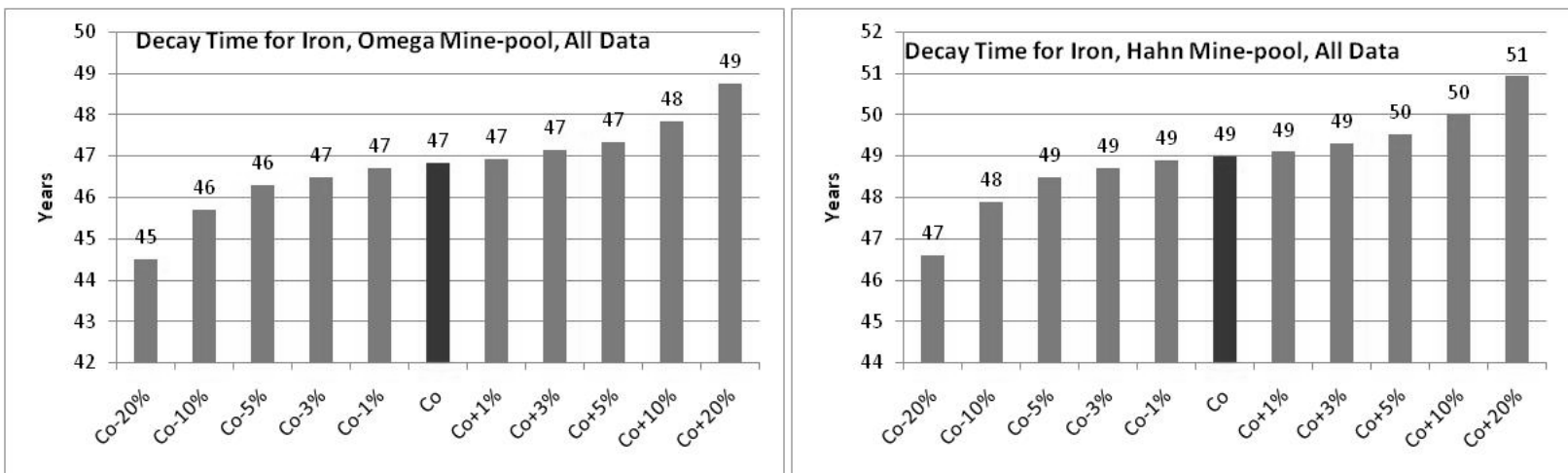

Figure 5-34. Estimated Decay Times for Iron to Reach $10 \mathrm{mg} / \mathrm{L}$,

Based on Different Starting Concentrations, Omega and Hahn Mine-pools. Black bars indicate $\mathbf{C}_{0}$. Gary bars show $\mathrm{C}_{0}$ varied by $1,3,5,10$ or $20 \%$. Decay time in years.
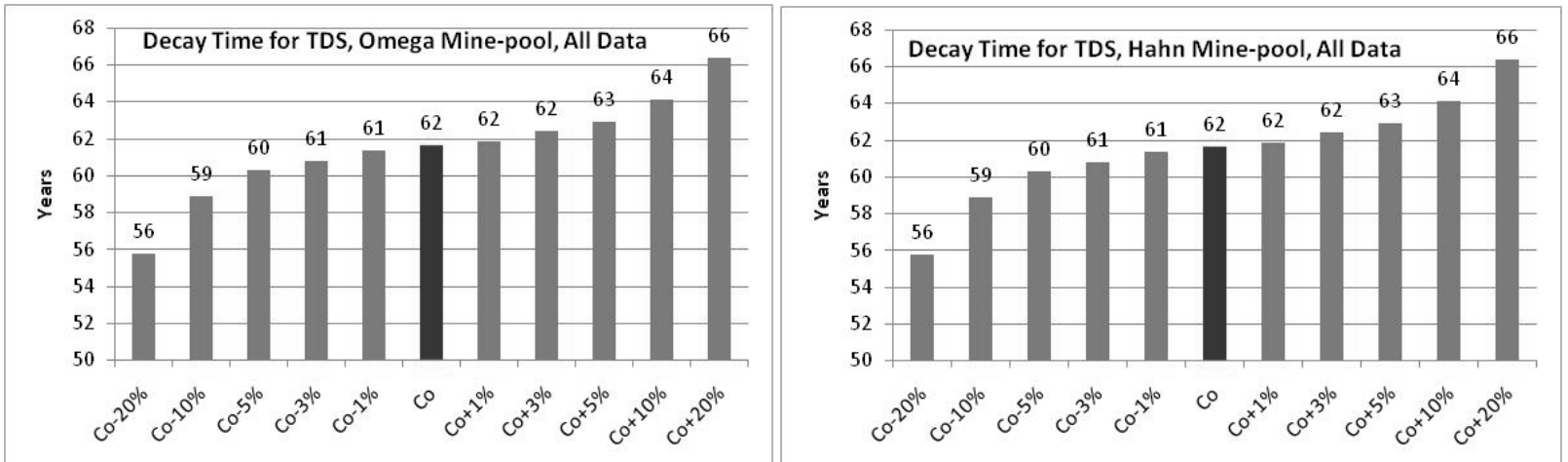

Figure 5-35. Estimated Decay Times for TDS to Reach $500 \mathrm{mg} / \mathrm{L}$,

Based on Different Starting Concentrations, Omega and Hahn Mine-pools. Black bars indicate $\mathbf{C}_{0}$. Gary bars show $\mathrm{C}_{0}$ varied by $1,3,5,10$ or $20 \%$. Decay time in years.

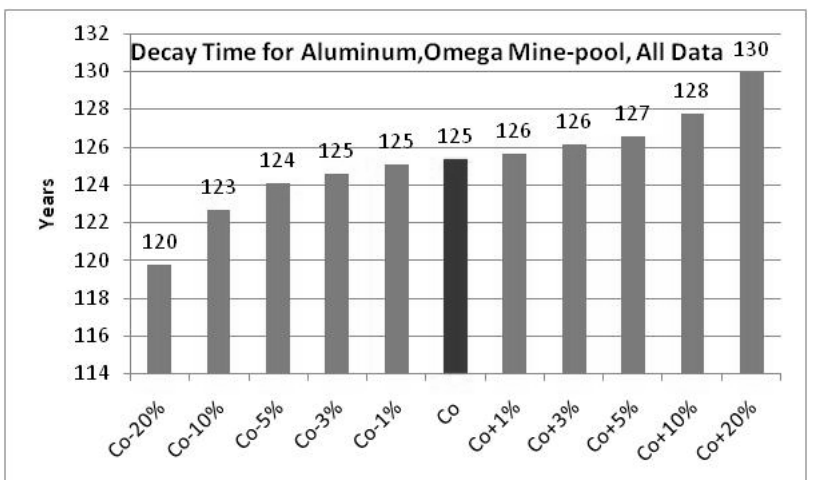

Figure 5-36. Estimated Decay Times for Aluminum to

Reach One mg/L, Based on Different Starting Concentrations,

Omega Mine-pool. Black bars indicate $\mathbf{C}_{0}$. Gray bars

show $\mathrm{C}_{0}$ varied by $1,3,5,10$ or $20 \%$. Decay time in years.

Varying the $\mathrm{C}_{0}$ for total acidity by plus or minus $20 \%$ changed the estimated decay time by $+/-$ one year in the Hahn mine-pool, and +/- five years in the Omega mine-pool (figure 5-29). Estimated decay time for sulfate ranged from 53 to 62, and 22 to 24 years, while Fe varied from 45 to 49 and 47 to 51 years, respectively for the Omega and Hahn mine-pools (figures 5-30 and 
5-31). Total Dissolved Solids decay estimates varied over a range of ten years for both minepools (figure 5-32). Aluminum decay estimates also ranged over a ten year span as $\mathrm{C}_{0}$ was varied. This set of sensitivity analyses, like the preceding evaluations, show limited response to variations in the decay equation. Regardless of the $\mathrm{C}_{0}$ values used, the time estimates to approach target concentrations are on the order of multiple decades.

\subsubsection{Decay Estimates Using Flushing Phases}

Examining the $\mathrm{R}^{2}$ values in tables 5-7 and 5-8 suggests that estimation of chemical concentration decay could be improved by assigning separate decay values to represent initial flushing (early data) and long term leaching conditions (late data). Figures 5-37 to 5-45 are time series plots of raw data decay estimated from a single $\mathrm{k}$ value, and decay estimated in two phases, early and late data. The fit of the decay lines was assessed by tabulating residuals (difference of raw data minus decay estimate) and expressing the difference as a percentage of the raw data. The median residual percentages for fitting all data to single $\mathrm{k}$ value, and by estimating early and late decay from two separate constants are shown in table 5-17.

Table 5-17

Decay Curve Fitting Median Residual Percentages, Hahn and Omega Mine-pools ${ }^{(1)}$

\begin{tabular}{cccccc}
\hline Hahn Mine-pool & $\begin{array}{c}\text { Total } \\
\text { Acidity }\end{array}$ & Iron & Aluminum & Sulfate & $\begin{array}{c}\text { Total Dissolved } \\
\text { Solids }\end{array}$ \\
\hline $\begin{array}{c}\text { Single k Residual } \\
\text { Percentage } \\
2 \begin{array}{c}\text { Phase k Residual } \\
\text { Percentage }\end{array}\end{array}$ & $39 \%$ & $31.2 \%$ & - & $6.8 \%$ & $6.2 \%$ \\
\hline $\begin{array}{c}\text { Omega Mine-pool } \\
\text { Single k Residual } \\
\text { Percentage }\end{array}$ & $\begin{array}{c}\text { Total } \\
\text { Acidity }\end{array}$ & Iron & Aluminum & Sulfate & $\begin{array}{c}\text { Total Dissolved } \\
\text { Solids }\end{array}$ \\
\hline $\begin{array}{c}\text { 2 Phase k Residual } \\
\text { Percentage }\end{array}$ & $12.1 \%$ & $16.5 \%$ & $3.1 \%$ & $18.3 \%$ & $16.0 \%$ \\
\hline
\end{tabular}

(1) Entries are median values of (raw data minus calculated data)/(raw data), expressed as percentage.

Residuals, or the difference between observed and fitted data, generally improved (decreased) when decay was modeled using two separate data phases constants compared to a single constant to represent concentration change through time. The fit for total acidity and Fe improved significantly, and sulfate residuals were less than one percent for the Hahn mine-pool (table 5-17, figures 5-37 and 5-38). Iron and total acidity were over-estimated in the middle part of the monitoring record using a single decay constant. A two phase decay model largely eliminated this difference. A single $\mathrm{k}$ calculation for TDS provided a slightly smaller median residual than decay modeled with two constants for the Hahn mine-pool. 


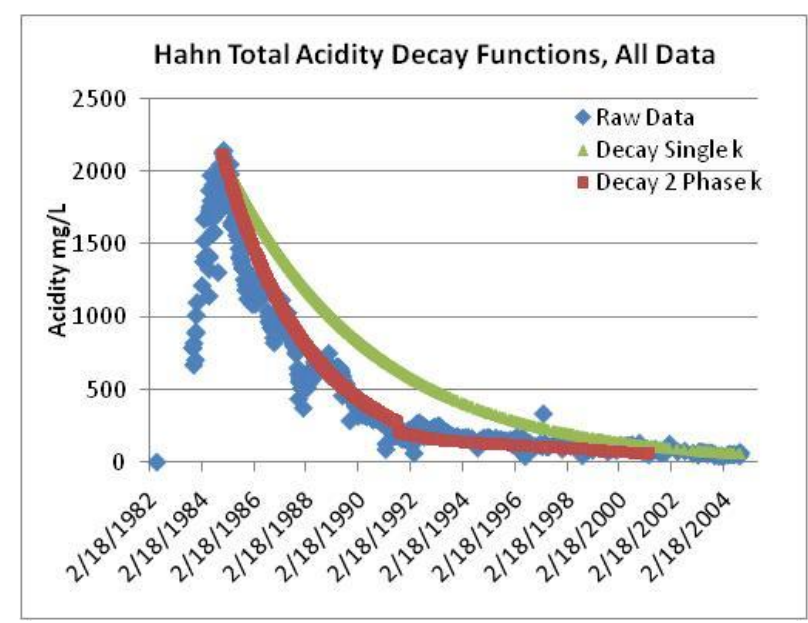

Figure 5-37. Total Acidity Decay Functions, Hahn Mine-pool.

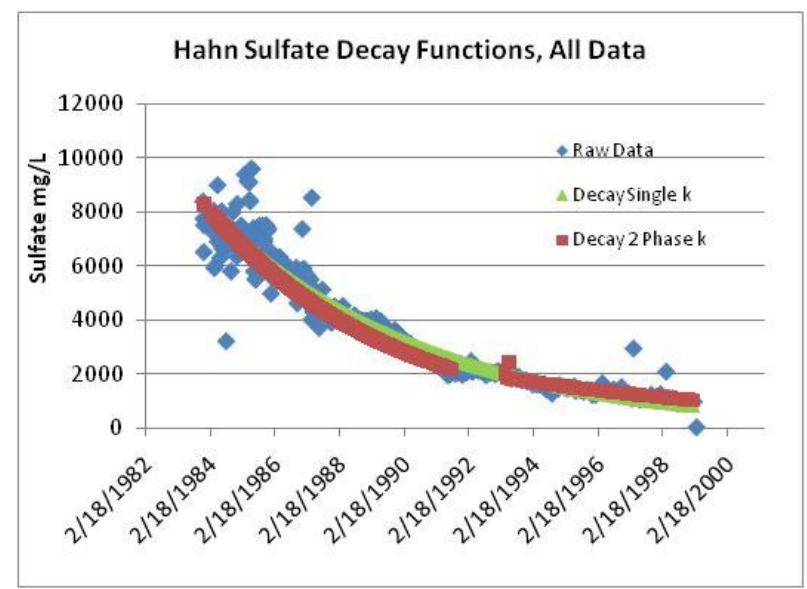

Figure 5-39. Sulfate Decay Functions, Hahn Minepool.

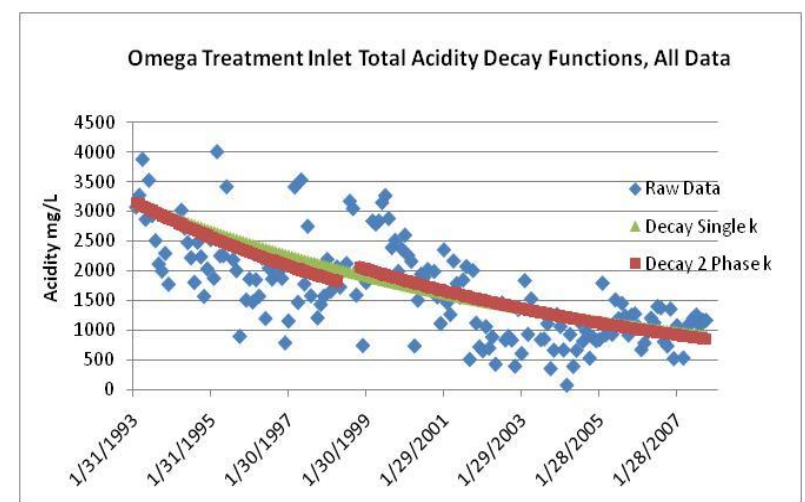

Figure 5-41. Total Acidity Decay Functions, Omega Mine-pool.

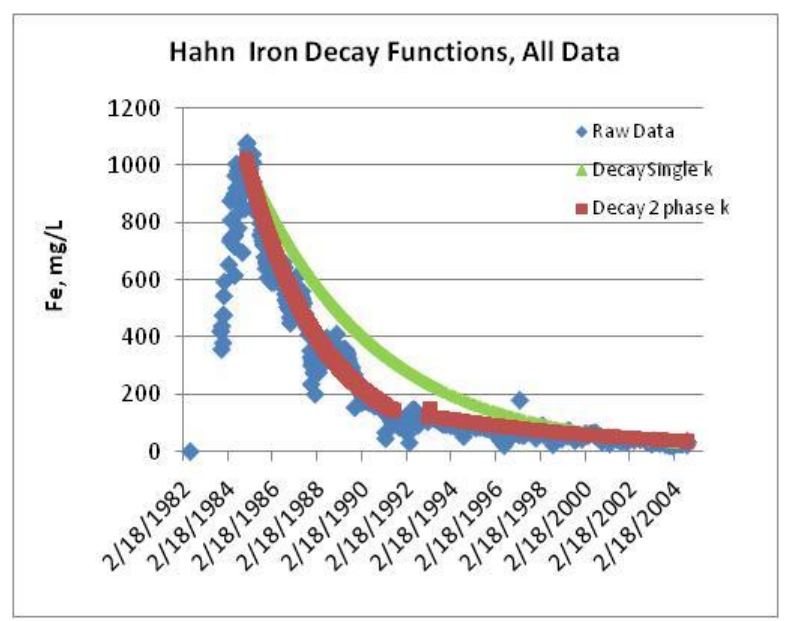

Figure 5-38. Iron Decay Functions, Hahn Minepool.

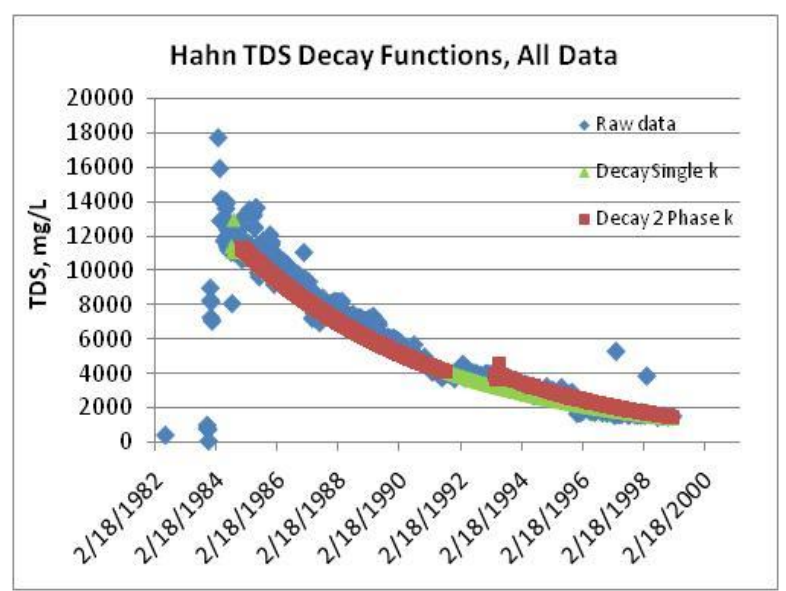

Figure 5-40. Total Dissolved Solids Decay Functions, Hahn Mine-pool.

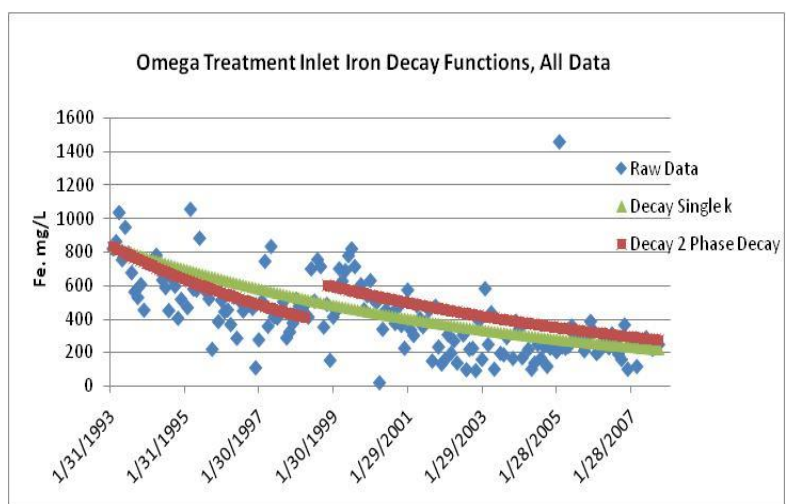

Figure 5-42. Iron Decay Functions, Omega Minepool. 


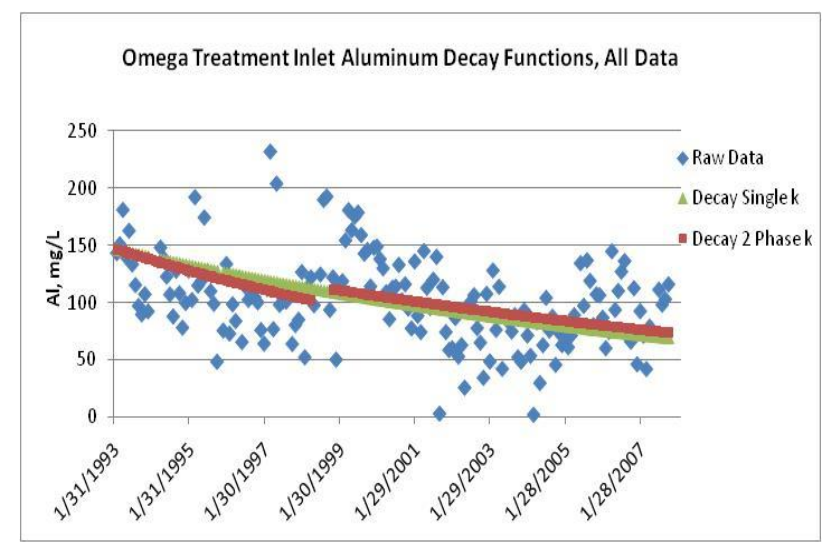

Figure 5-43. Omega Mine-pool, Aluminum Decay Functions.

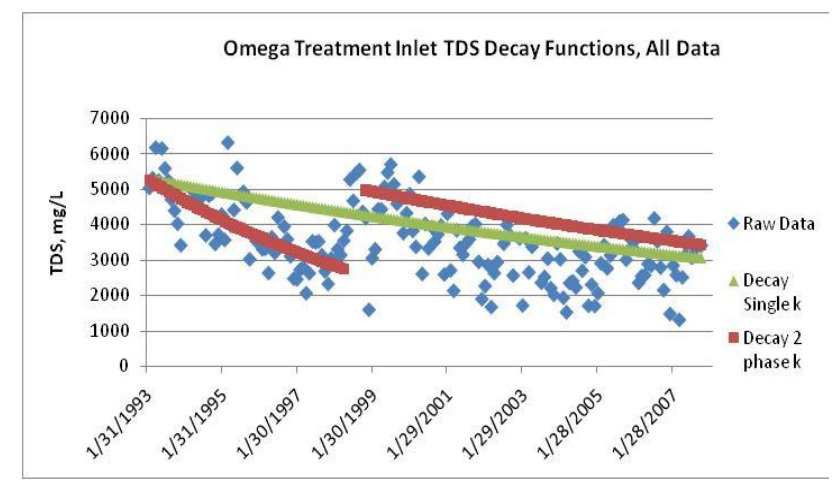

Figure 5-45. Omega Mine-pool. Total Dissolved Solids Decay Functions.

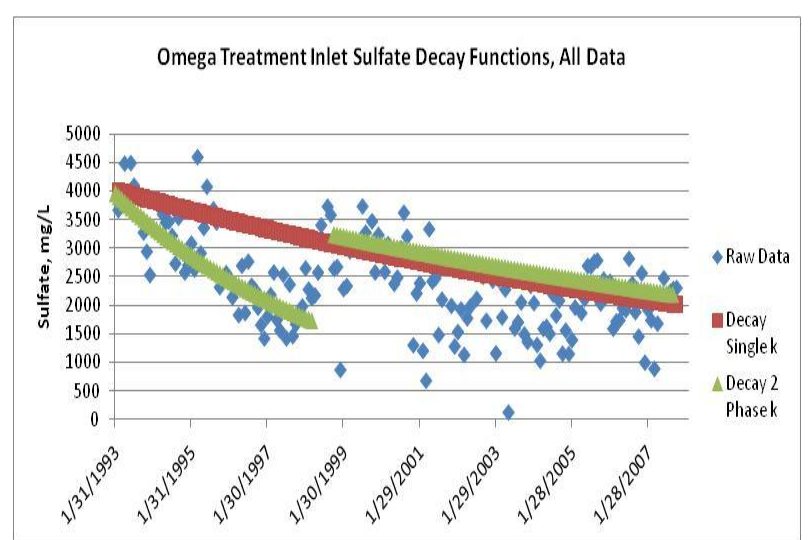

Figure 5-44. Omega Mine-pool, Sulfate Decay Functions.

Improvements in data fiting were also found in the Omega mine-pool using a two phase decay model. Residual percentages for total acidity, sulfate and total dissolved solids decreased. Aluminum decay displayed little difference in residual percentage using a one or two phase decay model, while iron residual increased when based on a two phase decay. Figures 5-44 and 5-45 also display the effects of grout injection on sulfate and total dissolved solids decay, respectively. For both parameters, decay was faster prior to grouting. Post-grouting, there is a large increase in chemical concentration, and a decline in the decay rate. Iron behaved in similar fashion (figure 5-42), but the chemical concentration initial increase was less. Aluminum decay was the parameter least affected by grouting. This may result from solubility controls on $\mathrm{Al}$ concentration, maintaining mine water at or near saturation for the Al mineral jurbanite. Mineral solubility in the Omega mine-pool in addressed in more detail in chapter three.

Data presented in figures 5-37 to 5-45 and table 5-17, show that in general, agreement between raw and calculated decay data can be improved using a two phase decay model. The poorest fit usually occurred in the middle of a curve, at the expense of closer agreement at the beginning and end of the decay line. This systematic error suggests that the decay function does not completely describe the physical and chemical processes at work. Neither does the decay equation accommodate short term and seasonal variations in chemical composition. The decay function is useful however, as a trend estimator. 


\subsubsection{Controls on the Decay Constant}

The decay constant values generally ranged over about one order of magnitude, suggesting that there might be underlying controls on the magnitude of $\mathrm{k}$. These could be either physical, chemical, or a combination of features. Dissolution rates for moderately soluble minerals are rapid relative to diffusion of reactants and products within mineral grains and bulk solution. Therefore, diffusion was considered a potential control on decay rate. Surface controlled reactions for these moderately soluble minerals are also often rapid relative to the flushing provided by ground-water flow. For example, many limestone aquifers are slightly undersaturated for calcite. This condition suggests that calcite dissolution is rapid enough to approximately compensate for dissolution transport away from the calcite grain. Transport at the macroscale was also considered a potential control on decay rate.

An initial analysis of macroscale variables included mine recharge rate, percent flooded, mine area, average residence time, maximum flow-path length and initial chemical concentration. These parameters were compared with decay constant values for all monitoring data, early or initial flushing phase, and late or long term leaching. Only sulfate and total dissolved solids decay showed any appreciable correlation with the macroscale parameters. Sulfate decay was correlated with initial concentration $(\mathrm{r}=0.60)$, and total dissolved solids with mine area $(\mathrm{r}=0.62)$, maximum flow-path length $(\mathrm{r}=0.63)$, residence time $(\mathrm{r}=0.44)$ and initial concentration $(\mathrm{r}=0.55)$. The small size of the data set precludes more rigorous statistical analysis. The decay parameters were however, correlated with each other as shown in table 5-18. The magnitude of the five decay parameters was greater or lesser as a group when considered on mine by mine basis. This suggests decay is influenced by mine specific chemical or transport properties, while the lack of a strong relationship to macroscale features implies that transport control may be at the microscale. This initial analysis prompted a closer examination of the effects of diffusion and flushing rate on mine water decay functions.

Table 5-18

\begin{tabular}{ccccc}
\multicolumn{6}{c}{ Correlation coefficents $(\mathrm{r})$ among decay constant $(\mathrm{k})$ parameters } \\
\hline Parameter & Total Acidity & $\mathrm{Fe}$ & $\mathrm{Al}$ & Sulfate \\
\hline $\mathrm{Fe}$ & 0.87 & & & \\
$\mathrm{Al}$ & 0.98 & 0.98 & & \\
Sulfate & 0.48 & 0.36 & 0.36 & \\
Total Dissolved Solids & 0.57 & 0.98 & 0.98 & 0.85 \\
\hline
\end{tabular}

Berner (1978) described a simple box model calculation to illustrate the effects of flushing and diffusion on mineral dissolution rates. Berner's equations are based on conservation of mass principles. The rate of concentration change affected by flushing is expressed as:

$$
\frac{d c}{d t}=R-\frac{F}{V} c
$$

where:

$\mathrm{c}=$ concentration dissolved

$\mathrm{t}=$ time 
$\mathrm{F}=$ Flushing rate (mass/time)

$\mathrm{V}=$ Unit Fluid Volume

$\mathrm{R}=$ Dissolution Rate, (mass/volume-time)

At high flushing rates (high ground-water flow velocities) a maximum dissolution rate is reached, controlled by the surface reaction rate on the mineral grain. At the other extreme, where flushing rate is small (low ground-water flow velocity) compared to mineral reaction rate, chemical concentration approaches saturation, and flushing or flow rate is the controlling factor. This is illustrated by the case of a limestone aquifer near saturation for calcite described previously.

In the case of small ground-water flow rates and slow flushing, Berner (1978) notes that $\mathrm{c} \approx \mathrm{C}_{\mathrm{eq}}$, or equilibrium concentration for a specified mineral phase. Under these conditions,

$$
\mathrm{R} \approx(\mathrm{F} / \mathrm{V}) \mathrm{C}_{\mathrm{eq}}
$$

or the dissolution rate is approximated as the product of flushing frequency and equilibrium concentration. If flushing frequency and equilibrium concentration values are known, then dissolution rate can be estimated.

In the case of rapid flushing of the mine-pool, Berner notes that:

$$
\mathrm{R} \approx \mathrm{k} \mathrm{C}_{\mathrm{eq}}
$$

where $\mathrm{k}$ is approximated as the product of the dissolution rate constant for a specified mineral and equilibrium concentration.

A consistent set of values for $\mathrm{R}$ could explain the observed magnitude of decay constants. Slow flushing conditions were deemed to be the more likely scenario since most of the mine-pools were near equilibrium for some minerals, especially during early flushing. Equation 5-24, slow flushing rate conditions, was used to estimate $\mathrm{R}$ for sulfate for the five mine-pools. Sulfate calculations were successively performed assuming solution control by gypsum, pyrite, and for the two acidic mine-pools, jurbanite. Single sample analyses, deemed typical of early flushing and long-term conditions, were selected for analysis.

Flushing rate, $\mathrm{F}$ in equation 5-24, was estimated as the inverse of the residence time in units of day $^{-1}$, treating the mine-pool as simple box model with uniform flow conditions. For convenience, the unit volume of fluid was taken as one liter. The equilibrium concentration, $\mathrm{C}_{\mathrm{eq}}$, for the solute was determined using PHREEQC and equilibrating the solution chemistry to a saturation index of zero for gypsum, pyrite, or jurbanite. Input data and estimated dissolution rates, $\mathrm{R}$, are shown in table 5-19. 
Table 5-19

Apparent Dissolution Rate, R, for Sulfate,

Estimated from Different Mineral Controls and Slow Flush Rate Equation.

\begin{tabular}{|c|c|c|c|c|c|c|c|c|}
\hline \multirow[t]{2}{*}{ Mine-pool } & \multirow[t]{2}{*}{ Phase } & \multirow[t]{2}{*}{$\begin{array}{l}\text { Flush } \\
\text { Rate } \\
\mathrm{F}\left(\mathrm{d}^{-1}\right)\end{array}$} & \multicolumn{2}{|c|}{$\begin{array}{l}\text { Sulfate, } \\
\text { Gypsum } \\
\text { Control }\end{array}$} & \multicolumn{2}{|c|}{$\begin{array}{c}\text { Sulfate, } \\
\text { Pyrite } \\
\text { Control }\end{array}$} & \multicolumn{2}{|c|}{$\begin{array}{c}\text { Sulfate, } \\
\text { Jurbanite } \\
\text { Control }\end{array}$} \\
\hline & & & $\begin{array}{c}\mathrm{C}_{\mathrm{eq}} \\
\mathrm{Mol} / \mathrm{L}\end{array}$ & $\begin{array}{c}\mathrm{R} \\
\mathrm{Mol} / \mathrm{L}-\mathrm{S}\end{array}$ & $\begin{array}{c}\mathrm{C}_{\mathrm{eq}} \\
\mathrm{Mol} / \mathrm{L}\end{array}$ & $\begin{array}{c}\mathrm{R} \\
\mathrm{Mol} / \mathrm{L}-\mathrm{S}\end{array}$ & $\begin{array}{c}\mathrm{C}_{\mathrm{eq}} \\
\mathrm{Mol} / \mathrm{L}\end{array}$ & $\begin{array}{c}\mathrm{R} \\
\mathrm{Mol} / \mathrm{L}-\mathrm{S}\end{array}$ \\
\hline Omega & Early & $7.40 \mathrm{E}-03$ & $4.64 \mathrm{E}-02$ & $4.20 \mathrm{E}-09$ & 4.30E-02 & $3.91 \mathrm{E}-9$ & $4.22 \mathrm{E}-02$ & $3.83 \mathrm{E}-09$ \\
\hline Omega & Late & $7.40 \mathrm{E}-03$ & 4.33E-02 & $3.76 \mathrm{E}-09$ & $3.98 \mathrm{E}-02$ & $3.47 \mathrm{E}-9$ & $3.82 \mathrm{E}-02$ & 3.33E-09 \\
\hline $\mathrm{T} \& \mathrm{~T}$ & Early & $6.85 \mathrm{E}-03$ & $2.76 \mathrm{E}-02$ & $2.30 \mathrm{E}-09$ & 2.00E-02 & $1.69 \mathrm{E}-9$ & $2.30 \mathrm{E}-02$ & $1.93 \mathrm{E}-09$ \\
\hline $\mathrm{T} \& \mathrm{~T}$ & Late & $6.85 \mathrm{E}-03$ & $1.90 \mathrm{E}-02$ & $1.54 \mathrm{E}-09$ & $8.76 \mathrm{E}-03$ & $7.27 \mathrm{E}-10$ & $1.03 \mathrm{E}-02$ & $8.48 \mathrm{E}-10$ \\
\hline Hahn & Early & $6.85 \mathrm{E}-04$ & $8.78 \mathrm{E}-02$ & $1.17 \mathrm{E}-09$ & $8.75 \mathrm{E}-02$ & 1.17E-9 & & \\
\hline Hahn & Late & $6.85 \mathrm{E}-04$ & $2.79 \mathrm{E}-02$ & $2.81 \mathrm{E}-10$ & $1.92 \mathrm{E}-03$ & $7.55 \mathrm{E}-11$ & & \\
\hline $\begin{array}{c}\text { Arden- } \\
\text { Westland }\end{array}$ & Early & $6.85 \mathrm{E}-04$ & $2.49 \mathrm{E}-02$ & $2.36 \mathrm{E}-10$ & $1.88 \mathrm{E}-02$ & $1.88 \mathrm{E}-10$ & & \\
\hline $\begin{array}{c}\text { Arden- } \\
\text { Westland }\end{array}$ & Late & $6.85 \mathrm{E}-04$ & $1.97 \mathrm{E}-02$ & $1.67 \mathrm{E}-10$ & $9.39 \mathrm{E}-03$ & $8.61 \mathrm{E}-11$ & & \\
\hline B\&T & Late & $5.48 \mathrm{E}-03$ & $1.74 \mathrm{E}-02$ & $1.11 \mathrm{E}-09$ & $4.74 \mathrm{E}-03$ & $3.06 \mathrm{E}-10$ & & \\
\hline
\end{tabular}

Dissolution calculations based on slow flushing rates did not provide a uniform set of values. The apparent dissolution rates, $\mathrm{R}$, are on the order of $10^{-9}$ to $10^{-11} \mathrm{~mol} / \mathrm{L}-\mathrm{s}$, regardless of which mineral is specified as controlling sulfate concentration. The dissolution rate is most influenced by flushing rate, not the choice of controlling mineral. The range of computed values is about 25, 50 and 5 times for gypsum, pyrite and jurbanite calculations, respectively. This is similar to the range for the decay constants themselves. Mineral mass and surface areas per unit volume of the mine-pools are not known. However, the estimated dissolution rates could support continued weathering of the duration actually observed, with relatively small amounts of accessible minerals. Thus, slow flushing relative to mineral dissolution reaction rates, in conjunction with mineral saturation data in chapters three and four provide indirect evidence that the decay constant is at least partly a transport function.

The dissolution rates in table 5-19 (mole/L-s), combined with dissolution rate constants $\left(\mathrm{mole} / \mathrm{m}^{2}-\mathrm{s}\right.$ ) could be used to estimate specific mineral surface area per liter of solution. Published rate constants for gypsum are $\log \mathrm{k}=-2.79$; and for pyrite, $\log \mathrm{k}=-7.52$ in acid solution, and $\log \mathrm{k}=-4.55$ in neutral solution (Palandri and Kharaka, 2004). No published rate data were found for jurbanite dissolution. Inspecting the values for $\mathrm{k}$, it is apparent that the computed mineral surface areas per liter of solution will be large, and the values will vary significantly, depending on which mineral is specified as controlling sulfate concentration. Surface area measurements estimated in this manner are therefore not reliable.

A set of calculations using equation 5-25, assuming rapid flushing relative to dissolution, was also compiled using the same samples and flushing rates as in table 5-19. Equation 5-25 requires a dissolution rate constant, designated $\mathrm{k}$, and the equilibrium concentration $\mathrm{C}_{\mathrm{eq}}$. Rate constants for gypsum and pyrite were taken from data compiled by Palandri and Kharaka (2004). Results are shown in table 5-20. 
Table 5-20

Apparent Dissolution Rate, R, for Sulfate,

Estimated from Different Mineral Controls and Rapid Flush Rate Equation

\begin{tabular}{|c|c|c|c|c|c|c|c|c|}
\hline \multirow[t]{2}{*}{ Mine-pool } & \multirow[t]{2}{*}{ Phase } & \multirow[t]{2}{*}{$\begin{array}{l}\text { Flush } \\
\text { Rate } \\
\mathrm{F}\left(\mathrm{d}^{-1}\right)\end{array}$} & \multicolumn{2}{|c|}{$\begin{array}{l}\text { Sulfate, } \\
\text { Gypsum } \\
\text { Control }\end{array}$} & \multicolumn{2}{|c|}{$\begin{array}{l}\text { Sulfate, } \\
\text { Pyrite } \\
\text { Control }\end{array}$} & \multicolumn{2}{|c|}{$\begin{array}{c}\text { Sulfate, } \\
\text { Jurbanite } \\
\text { Control }\end{array}$} \\
\hline & & & $\begin{array}{c}\mathrm{C}_{\mathrm{eq}} \\
\mathrm{Mol} / \mathrm{L}\end{array}$ & $\begin{array}{c}\mathrm{R} \\
\mathrm{Mol} / \mathrm{L}-\mathrm{s}\end{array}$ & $\begin{array}{c}\mathrm{C}_{\mathrm{eq}} \\
\mathrm{Mol} / \mathrm{L}\end{array}$ & $\begin{array}{c}\mathrm{R} \\
\mathrm{Mol} / \mathrm{L}-\mathrm{s}\end{array}$ & $\begin{array}{c}\mathrm{C}_{\mathrm{eq}} \\
\mathrm{Mol} / \mathrm{L}\end{array}$ & $\begin{array}{c}\mathrm{R} \\
\mathrm{Mol} / \mathrm{L}-\mathrm{s}\end{array}$ \\
\hline Omega & Early & $7.40 \mathrm{E}-03$ & 4.64E-02 & $7.53 \mathrm{E}-05$ & $4.30 \mathrm{E}-02$ & $1.18 \mathrm{E}+02$ & $4.22 \mathrm{E}-02$ & - \\
\hline Omega & Late & $7.40 \mathrm{E}-03$ & $4.33 \mathrm{E}-02$ & 7.02E-05 & $3.98 \mathrm{E}-02$ & $1.09 \mathrm{E}+02$ & $3.82 \mathrm{E}-02$ & - \\
\hline $\mathrm{T} \& \mathrm{~T}$ & Early & $6.85 \mathrm{E}-03$ & $2.76 \mathrm{E}-02$ & $4.48 \mathrm{E}-05$ & $2.00 \mathrm{E}-02$ & $5.49 \mathrm{E}+01$ & $2.30 \mathrm{E}-02$ & - \\
\hline $\mathrm{T} \& \mathrm{~T}$ & Late & $6.85 \mathrm{E}-03$ & $1.90 \mathrm{E}-02$ & $3.07 \mathrm{E}-05$ & $8.76 \mathrm{E}-03$ & $2.41 \mathrm{E}+01$ & $1.03 \mathrm{E}-02$ & - \\
\hline Hahn & Early & $6.85 \mathrm{E}-04$ & 8.78E-02 & $1.42 \mathrm{E}-04$ & 8.75E-02 & $5.52 \mathrm{E}+01$ & & \\
\hline Hahn & Late & $6.85 \mathrm{E}-04$ & 2.79E-02 & $4.52 \mathrm{E}-05$ & $1.92 \mathrm{E}-03$ & $2.24 \mathrm{E}+05$ & & \\
\hline Arden-Westland & Early & $6.85 \mathrm{E}-04$ & $2.49 \mathrm{E}-02$ & 4.03E-05 & $1.88 \mathrm{E}-02$ & $4.83 \mathrm{E}+04$ & & \\
\hline Arden-Westland & Late & $6.85 \mathrm{E}-04$ & $1.97 \mathrm{E}-02$ & $3.19 \mathrm{E}-05$ & 9.39E-03 & $2.41 \mathrm{E}+04$ & & \\
\hline $\mathrm{B} \& \mathrm{~T}$ & Late & $5.48 \mathrm{E}-03$ & $1.74 \mathrm{E}-02$ & $2.82 \mathrm{E}-05$ & 4.74E-03 & $1.22 \mathrm{E}+4$ & & \\
\hline
\end{tabular}

For rapid flushing rates, dissolution estimates are strongly influenced by the choice of controlling mineral. Dissolution estimates of sulfate based on pyrite control produced $\mathrm{R}$ values that are unreasonably high for the geochemical system being considered. Even the values derived for gypsum control indicate a rapid rate of weathering that would deplete the source mineral within a short time. These results indicate that rapid flushing relative to dissolution is not an appropriate model for these mine-pools.

Berner (1978) also describes a box model calculation for diffusion controlled dissolution as:

$$
R=\frac{D p A(C e q-C)}{r}
$$

where:

$\mathrm{R}=$ Dissolution Rate

$\mathrm{C}=$ concentration in outer solution

Ceq $=$ Equilibrium or saturation concentration

$\mathrm{r}=$ spherical radius of dissolving crystal

$\mathrm{D}=$ diffusion coefficient

$\mathrm{p}=$ porosity

$\mathrm{A}=$ Surface Area of mineral per unit volume of solution

If dissolution is strictly diffusion controlled, the dissolution rate is directly dependent on the degree of under-saturation. However, Berner also notes that equation 5-26 requires modification if dissolution is influenced by surface reactions, such as the buildup of a weathering rind on the mineral grain itself. In that case, diffusion in solution, and diffusion through the weathering rind may control the rate of reaction. That two phase weathering and diffusion process has been described for pyrite, and is reviewed in the next section. 


\subsection{Application of Pyrite Weathering Kinetics to Mine-pools}

Pyrite weathering rates are a principal determinant in estimating the intensity and longevity of acid production in sulfide bearing rocks. Lowson (1982), Nordstrom (1982a), and Rimstidt and Vaughan (2003), among others, provide detailed reviews of the oxidation process and discussion of controlling factors, including oxygen availability and microbial catalysis. This section contains a brief review of the literature on weathering rates and controlling variables, and the implications for mine-pool pollution production over time.

Pyrite weathering is characteristically described as a four step cyclic process involving decomposition of the mineral, and oxidation of sulfur and iron in the presence of water and oxygen (Nordstrom, 1982a). The individual steps are shown below and graphically in figure 5-46:

$$
\begin{gathered}
\mathrm{FeS}_{2}+7 / 2 \mathrm{O}_{2}+\mathrm{H}_{2} \mathrm{O} \rightarrow \mathrm{Fe}^{2+}+2 \mathrm{SO}_{4}{ }^{2-}+2 \mathrm{H}^{+} \\
\mathrm{Fe}^{2+}+1 / 4 \mathrm{O}_{2}+\mathrm{H}^{+} \rightarrow \mathrm{Fe}^{3+}+1 / 2 \mathrm{H}_{2} \mathrm{O} \\
\mathrm{Fe}^{3+}+3 \mathrm{H}_{2} \mathrm{O} \rightarrow \mathrm{Fe}(\mathrm{OH})_{3}+3 \mathrm{H}^{+} \\
\mathrm{FeS}_{2}+14 \mathrm{Fe}^{3+}+8 \mathrm{H}_{2} \mathrm{O} \rightarrow 15 \mathrm{Fe}^{2+}+2 \mathrm{SO}_{4}{ }^{2-}+16 \mathrm{H}^{+}
\end{gathered}
$$

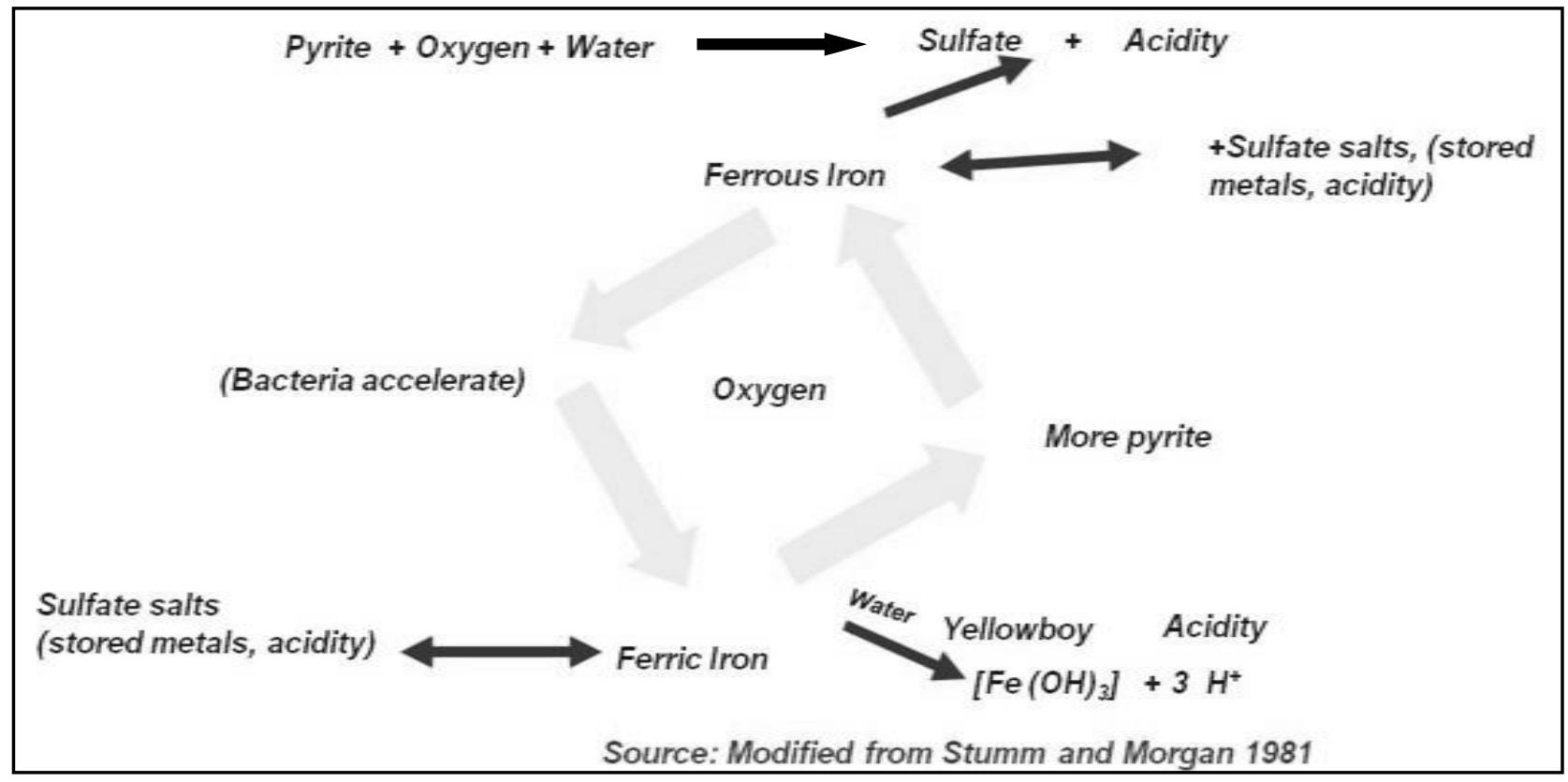

Figure 5-46. Pyrite Oxidation Process. Source, Modified From Stumm and Morgan, 1981.

The ultimate driver of the system is oxygen availability, since it is required in both the initial decomposition (equation 5-27a), and for the $\mathrm{Fe}(\mathrm{II}) / \mathrm{Fe}$ (III) couple (5-27b). Much of the literature on pyrite kinetics and field scale control technology has therefore focused on the role of oxygen. 
Hammack and Watzlaf (1990) examined oxygen effects in small and large scale column studies under abiotic and biotic conditions. They found that pyrite weathering was independent of oxygen content at values greater than one percent $\mathrm{pO}_{2}$ when Acidthiobacillus bacteria were present. At oxygen concentrations less than one percent, pyrite consumption rate was proportional to $\mathrm{pO}_{2}$. They concluded that disposal in an anoxic environment was necessary to halt pyrite oxidation. A mostly to fully flooded mine-pool may be sufficiently oxygen depleted to stop or substantially slow pyrite oxidation.

Williamson and Rimstidt (1994) published a summary paper that provides rate laws for pyrite oxidation based on oxygen concentration, $\mathrm{pH}$, ferrous/ferric iron ratios, and Eh and $\mathrm{pH}$. These relations were derived from their own experiments, and compilation of other published rate data from Smith and Shumate, (1970), Mckibben and Barnes (1986), Nicholson et al. (1988), Moses and Herman (1991) and Lowson (1982), and reviews of other studies. Williamson and Rimstidt's derived rate laws are:

$$
\mathrm{r}=10^{-8.19} \frac{\mathrm{m} \mathrm{DO}^{0.5}}{\mathrm{~m} \mathrm{H}^{+0.11}}
$$

where $\mathrm{r}$ is pyrite consumption rate in mole $/ \mathrm{m}^{2}-\mathrm{s}$, DO is dissolved oxygen concentration in mole/L, and $\mathrm{H}^{+}$is in mole/L. The rate function is applicable over a range of two to ten for $\mathrm{pH}$ and four orders of magnitude of DO. A second rate law based on ferrous/ ferric iron ratio is:

$$
\mathrm{r}=10^{-8.58} \frac{\mathrm{m} \mathrm{Fe}^{3+0.30}}{\mathrm{~m} \mathrm{Fe}^{2+0.47} \mathrm{~m} \mathrm{H}^{+0.32}}
$$

where $\mathrm{r}$ is pyrite consumption rate in mole $/ \mathrm{m}^{2}-\mathrm{s}, \mathrm{Fe}^{3+}$ concentration is in mole/ $\mathrm{L}$ and $\mathrm{H}^{+}$ concentration is in mole/L. Equation 5-29 is applicable in $\mathrm{pH}$ range 0.5 to 3.0 in the absence of oxygen. When oxygen is present, the rate law is:

$$
\mathrm{r}=10^{-6.07} \frac{\mathrm{m} \mathrm{Fe}^{3+0.93}}{\mathrm{~m} \mathrm{Fe}^{2+0.40}}
$$

and is in units consistent with equation 5-28. Equation 5-30 is also limited to a $\mathrm{pH}$ range of 0.5 to 3.0.

Two water sample analyses from each of the five mine-pools were selected for estimating pyrite oxidation rate under contrasting $\mathrm{pH}$, dissolved oxygen, and ferrous/ferric iron conditions. All samples were selected from the long term discharge phase of the record, after the initial flushing event. These samples should therefore present mostly a component of ongoing pyrite oxidation. The author collected dissolved oxygen, Eh, and ferrous iron measurements from three minepools Omega, T\&T and Barnes\&Tucker, on multiple sampling events. No such measurements are available for the Arden-Westland and Hahn mine-pools. However, inspection of the chemical data for these two (see chapter four) suggests that they must be oxygen-poor, reduced minepools. Both contain significant dissolved iron concentrations in circumneutral $\mathrm{pH}$ waters. These concentrations can only be maintained if Fe resides almost entirely as Fe(II). Since the rate of $\mathrm{Fe}(\mathrm{II})$ to $\mathrm{Fe}(\mathrm{III})$ conversion at circumneutral $\mathrm{pH}$ is rapid, with a half life on the order of hours, the persistence of $\mathrm{Fe}$ (II) in these mine-pools suggests that little or no oxygen is available. 
Finally, in section 5.2 of this study, Eh of these two mine-pools was estimated to be on the order of zero millivolts to maintain soluble iron below saturation for common hydroxide/oxide minerals. Dissolved oxygen in the Barnes and Tucker mine-pool approached the lower instrument detection limit of $0.01 \mathrm{mg} / \mathrm{L}$. This value was also assigned to the Hahn and ArdenWestland mine-pools. A value of $0.1 \mathrm{mg} / \mathrm{L}$ was also assigned to test sensitivity of $\mathrm{r}$ to varying dissolved oxygen concentrations. Data for estimating for pyrite oxidation rates are shown in table 5-21. Results using the general rate law in equation 5-28 are shown in figure 5-47 and table 5-21. Calculated rates from $\mathrm{Fe}^{2+} / \mathrm{Fe}^{3+}$ ratios for the acid mine-pools are also in table 5-21.

Pyrite consumption rates for the four acid samples with abundant dissolved oxygen, calculated with the general rate law, are about an order of magnitude faster than for the circumneutral, low oxygen mine-pools. These results agree with a conceptual model of ongoing oxidation in aerated, partly flooded mines, while weathering rates are slowed in flooded mines. Even when input dissolved oxygen is increased to $0.1 \mathrm{mg} / \mathrm{L}$ for the Hahn and Arden-Westland mine-pools, the calculated pyrite consumption rates are still two to three times slower than in the Omega and T\&T mine-pools. Conversely, if dissolved oxygen is restricted to less than $0.01 \mathrm{mg} / \mathrm{L}$ in the flooded Hahn and Arden-Westland mine-pools, the calculated consumption rates are further reduced. Pyrite consumption rates computed from $\mathrm{Fe}^{2+} / \mathrm{Fe}^{3+}$ ratios (equation 5-29) for the acid samples were similar or slightly larger (two to five times) than the rates from the general law (equation 5-27). The value for T\&T 2008 is outside the suggested $\mathrm{pH}$ range for equation 5-30, and is considered a less reliable estimate.

The magnitude of the pyrite consumption rate estimates for the five mine-pools is similar to values reported in laboratory and small scale tests. Lappako and Anston (2006) reported pyrite consumption rates ranging from $4 \times 10^{-10}$ to $1.8 \times 10^{-9} \mathrm{~mole} / \mathrm{m}^{2}$-s for pyrite-bearing rocks from a

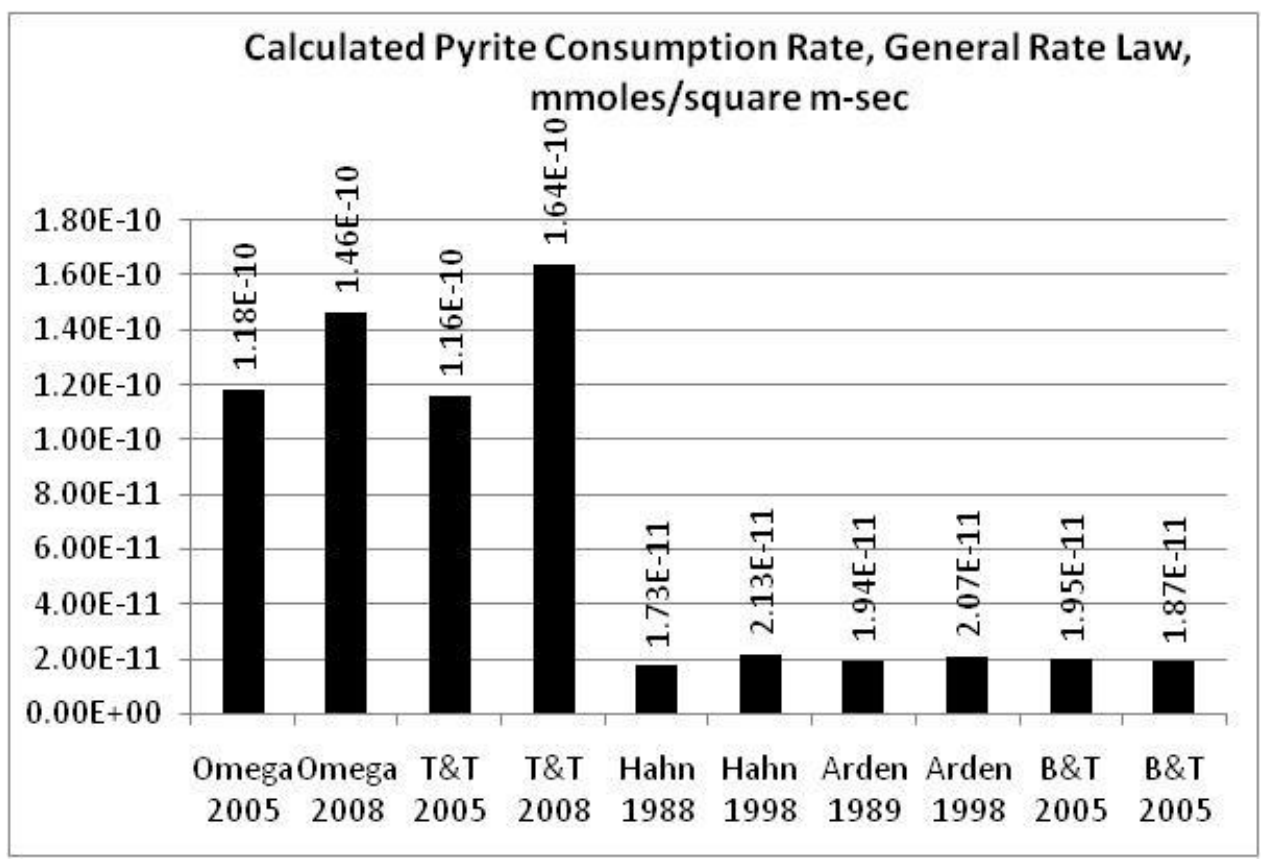

Figure 5-47. Calculated Pyrite Consumption Rate Using Williamson and Rimstidt's (1994) General Rate Law with Dissolved Oxygen and pH. 
Table 5-21

Data for Estimating Pyrite Oxidation Rate

in Five Mine-pools with Williamson and Rimstidt's (1994) Rate Laws

\begin{tabular}{|c|c|c|c|c|c|c|c|}
\hline Mine-pool & $\mathrm{pH}$ & $\begin{array}{c}\text { Dis. } \mathrm{O}_{2} \\
\mathrm{mg} / \mathrm{L}\end{array}$ & $\begin{array}{l}\text { Dis. } \mathrm{O}_{2} \\
\text { mole/L }\end{array}$ & $\begin{array}{c}\mathrm{Fe}^{2+} \\
\text { mole/L }\end{array}$ & $\begin{array}{c}\mathrm{Fe}^{3+} \\
\text { mole/L }\end{array}$ & $\begin{array}{l}\text { Rate, } \mathrm{r}^{(1)} \\
\text { from } \mathrm{pH} \\
\text { and } \mathrm{DO}\end{array}$ & $\begin{array}{l}\text { Rate, } \mathrm{r}^{(1)} \\
\text { from } \mathrm{Fe}^{2+} \\
\text { and } \mathrm{Fe}^{3+}\end{array}$ \\
\hline Omega 2005 & 2.53 & 2.97 & $9.28 \mathrm{E}-05$ & $1.39 \mathrm{E}-03$ & $2.62 \mathrm{E}-04$ & $1.18 \mathrm{E}-10$ & $5.52 \mathrm{E}-09$ \\
\hline Omega 2008 & 2.73 & 4.12 & $1.29 \mathrm{E}-04$ & $3.20 \mathrm{E}-03$ & $1.62 \mathrm{E}-05$ & $1.46 \mathrm{E}-10$ & $2.97 \mathrm{E}-10$ \\
\hline T\&T 2005 & 2.57 & 2.8 & $8.75 \mathrm{E}-05$ & $1.21 \mathrm{E}-04$ & $5.91 \mathrm{E}-05$ & $1.16 \mathrm{E}-10$ & 3.67E-09 \\
\hline T\&T 2008 & 4.36 & 2.27 & 7.09E-05 & $6.19 \mathrm{E}-04$ & $1.66 \mathrm{E}-06$ & $1.64 \mathrm{E}-10$ & $6.89 \mathrm{E}-11$ \\
\hline Hahn 1988 & 6.18 & 0.01 & $3.13 \mathrm{E}-07$ & & & $1.73 \mathrm{E}-11$ & \\
\hline Hahn 1998 & 7.00 & 0.01 & $3.13 \mathrm{E}-07$ & & & $2.13 \mathrm{E}-11$ & \\
\hline Arden-Westland 1989 & 6.63 & 0.01 & $3.13 \mathrm{E}-07$ & & & $1.94 \mathrm{E}-11$ & \\
\hline Arden-Westland 1998 & 6.90 & 0.01 & $3.13 \mathrm{E}-07$ & & & $2.07 \mathrm{E}-11$ & \\
\hline B\&T 2005 & 6.67 & 0.01 & $3.13 \mathrm{E}-07$ & & & $1.95 \mathrm{E}-11$ & \\
\hline B\&T 2005 & 6.50 & 0.01 & $3.13 \mathrm{E}-07$ & & & $1.87 \mathrm{E}-11$ & \\
\hline Hahn 1988 & 6.18 & 0.1 & $3.13 \mathrm{E}-06$ & & & $5.46 \mathrm{E}-11$ & \\
\hline Hahn 1998 & 7.00 & 0.1 & $3.13 \mathrm{E}-06$ & & & $6.72 \mathrm{E}-11$ & \\
\hline Arden-Westland 1989 & 6.63 & 0.1 & $3.13 \mathrm{E}-06$ & & & $6.12 \mathrm{E}-11$ & \\
\hline Arden-Westland 1998 & 6.90 & 0.1 & $3.13 \mathrm{E}-06$ & & & $6.55 \mathrm{E}-11$ & \\
\hline
\end{tabular}

(1) Rate in mole $/ \mathrm{m}^{2}-\mathrm{s}$.

Minnesota mine. Glesiner et al. (2006), studying the effects of oxygen concentration on Acidthiobacillus activity, reported pyrite oxidation rates on the order of $5 \times 10^{-10} \mathrm{~mole} / \mathrm{m}^{2}$-s with a range of $7 \times 10^{-12}$ to $8.9 \times 10^{-10}$, and the rate was directly proportional to oxygen content. Other studies have reported pyrite weathering rates on the basis of $\mathrm{mg} \mathrm{SO}_{4} / \mathrm{g}$ rock-unit time. As summarized by Hammack and Watzlaf (1990) consistent data from five other studies compared favorably with their own.

Jerz and Rimstidit (2004), measured pyrite oxidation rates in moist air, conditions that are analogous to aerated sections of underground mines. They found the oxidation rate to be a function of $\mathrm{pO}_{2}$ and time. Oxidation rate decreased over time, which was attributed to the formation of a thin surface layer of ferrous sulfate, possibly melanterite. The scenario described could also occur in unsaturated mine-works, where weathering products accumulate on particle surfaces, temporarily slowing pyrite consumption. Jerz and Rimstidt also note that the volume increase associated with hydrous ferrous sulfate formation could wedge apart rock fragments exposing more surface area. For partly flooded mines where the inundated zone fluctuates seasonally, and in response to individual recharge events, soluble ferrous sulfate is likely to be rinsed from the mineral surface. Less soluble minerals such as jarosite may persist, however.

The calculated pyrite consumption rates in table 5-21 provide a useful comparison among acidic, partly flooded and circumneutral and flooded mine-pools, but may overestimate actual field weathering. The rate equations reported by Williamson and Rimstidt (1994) and similar studies are usually based on laboratory scale experiments, using clean pyrite grains or rock fragments in a liquid suspension. Test time is often on the order of days or weeks. Weathering conditions are 
optimal or near optimal, and the derived values likely represent an upper bound on expected rate. Transport of reactants by advection and diffusion, especially of oxygen, and of products including $\mathrm{Fe}$ and $\mathrm{H}^{+}$may limit field oxidation rate.

Schnoor (1990) reported a study comparing weathering rates in laboratory columns and batch tests to field weathering in a small watershed using dissolved silica as a tracer. He concluded that field weathering was one to two orders of magnitude slower than lab testing based on his experiments and similar studies. Hood and Oertel (1984) used a leaching column method to simulate coal mine water quality, and compared results to field weathering. They estimated that lab weathering was about 1.5 orders of magnitude faster than field weathering.

A series of pyrite oxidation models incorporating transport and chemical weathering rates have been developed since the 1970's, including one devised for underground mines. Morth et al. (1972) developed a model for acid production based on a small partly flooded underground mine in Ohio. This pioneering modeling effort assumed chemical weathering takes places largely at the surface of the rock fragment and in fractures. Oxygen supply was assumed to be driven by barometric pressure fluctuations, and diffusion in the mine atmosphere. Morth et al. also coupled the acid production model to a quantitative hydrology module to account for transport and pollutant flux. They reported good agreement between predicted and measured parameters for several simulations encompassing a range of flow conditions. This initial model seems not to have been pursued further. The model was not designed for flooded mines.

Jaynes et al. (1984a, 1984b) developed a model to simulate acid drainage production in surface mines. As such, the model assumes oxygen transport from the surface through an unsaturated zone to, and into, pyrite bearing rock fragments. A key feature of this model is oxygen supply by gaseous diffusion, both within the unsaturated zone, and within individual rock fragments. The governing equations for oxidation within rock fragments as presented by Jaynes et al. are a form of the "shrinking core" reaction model. The general form and derivation is described by Levenspiel, 1972. The shrinking core model for oxygen flux into pyrite grains is illustrated in figure 5-48. Oxygen supply to the reaction site is assumed to be the limiting factor controlling overall pyrite oxidation. Oxidation starts at the surface of the grain, and proceeds as a uniform weathering front to the center. A weathering rind or ash layer forms as the oxidation product, so that the overall dimensions of the fragment remain the same. Soluble products counter-diffuse out of the fragment at a rate equal to inward oxygen migration. Oxygen and products must diffuse through the ash layer, which increases in thickness as weathering progresses. With these simplifying assumptions, an oxygen flux rate can be estimated, which in turn controls the pyrite oxidation rate. Wunderly et al., (1996) and Jaynes et al., (1984a) describe an oxygen flux equation based on the shrinking core model. Their respective notations differ, but are equivalent expressions. Oxygen flux is calculated by Wunderly et al. (1996) as:

$$
d \operatorname{mass} \mathrm{O}_{2} / d t=4 \pi D\left(\frac{R r_{x}}{R-r_{x}}\right) \mathrm{Uw}
$$


where:

$D$ is the diffusion coefficient in the weathered rim of the grain

$R$ is the whole grain radius

$r_{x}$ is the radius of the unreacted grain core

$\mathrm{UW}$ is the oxygen concentration at the outer surface of the particle.

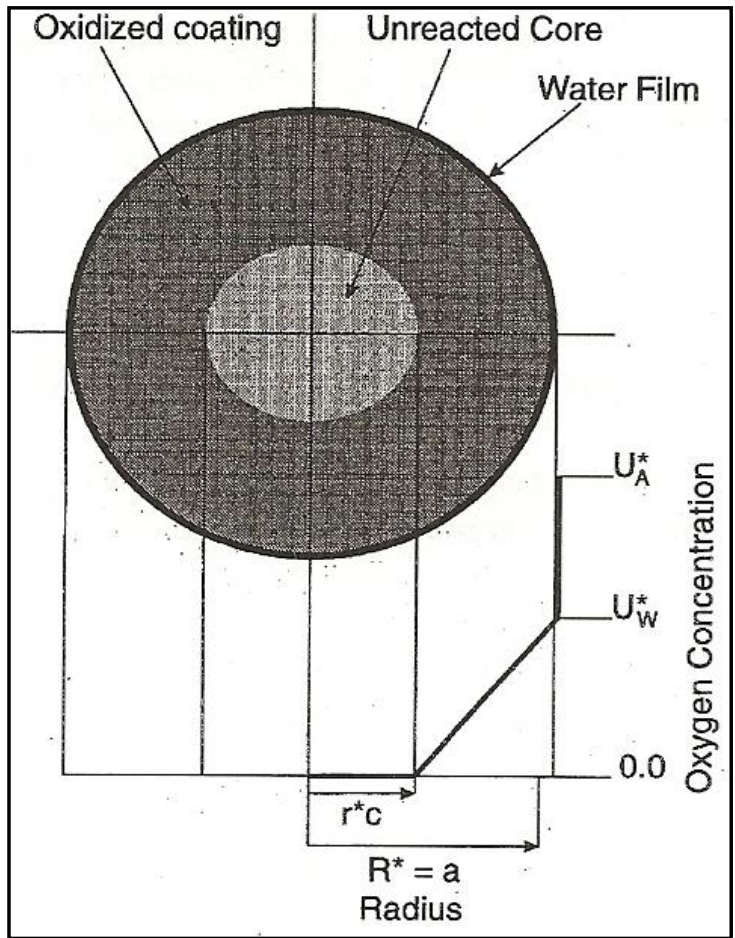

Figure 5-48. Shrinking Core Model of Pyrite Oxidation by Oxygen Diffusion. Modified fromWunderly et al., 1996.

If oxygen concentration and the diffusion coefficient are constants, oxygen flux and hence, pyrite oxidation, depends only on the position of the weathering front, $r_{x}$, within the grain. Figure 5-49 shows the relative oxygen flux as a fraction of the grain weathered. This graph was constructed by assigning a grain radius of one, and successively reducing the unreacted core radius in 100 steps. Oxygen concentration at the outer surface was maintained at one $\mathrm{mg} / \mathrm{L}$ and the diffusion coefficient was selected from Bains et al (2000), who used the model developed by Wunderly et al. (1996).

Figure 5-49 shows three significant effects. The total change in oxygen flux rate spans about seven orders of magnitude as weathering progresses from the outer surface to the center of the grain. Thus oxidation rates and acid production will slow. Second, oxygen flux decreases rapidly with formation of even a very thin weathering rind. Third, diffusion controlled pyrite weathering will proceed for extended time frames before the source mineral is exhausted, albeit with declining acid production. The shape of the flux curve is similar to a time series plot of total 
acidity, sulfate or other parameters related to acid production in mine-pools described earlier in this chapter. Oxygen diffusion is a probable micro-scale transport control on acid generation.

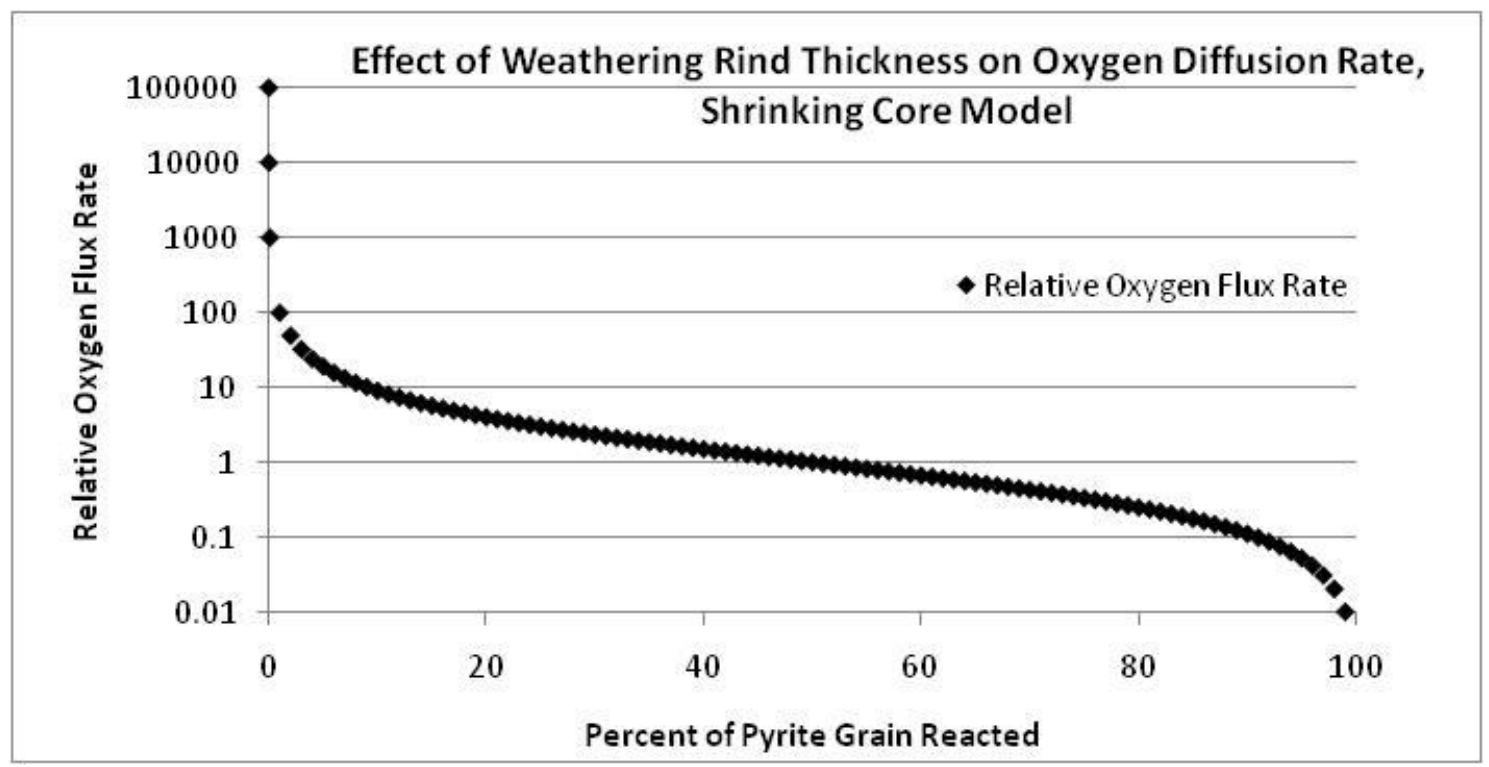

Figure 5-49. Relative Oxygen Flux Rate and Percent of Pyrite Grain Reacted.

The shrinking core model has some caveats when applied to pyrite weathering in mine-pools. First is the assumption of a uniform ash layer. If all or part of the reacted outer zone is rinsed, or diffuses away from the particle, oxygen reaches the unreacted core more rapidly. A second consideration is physical weathering of the rock or mineral grain, opening fractures and exposing new mineral surfaces to chemical attack. The magnitude of these exceptions to the shrinking core model is difficult to quantify, however.

Jaynes et al. (1984b) reported several simulations of acid drainage in surface mines using their model which is similar in concept to Wunderly et al. (1996). For simulations exceeding 25 years, they found for most runs, that less than half of the specified pyrite content had reacted. In addition to diffusion, changing tortuosity and particle size also affected the simulated weathering rates by altering oxygen transport. Their simulated water chemistry was in general agreement with samples measured from reclaimed mines.

Wunderly et al. (1996) also developed a model coupling oxygen diffusion and pyrite oxidation. Geochemical calculations were based on assumption of local thermodynamic equilibrium. Like Jaynes et al., their model, PYROX, is based on an assumption that oxygen transport to the reaction site limits the pyrite oxidation rate. Their model was evaluated using data from a tailings impoundment which included a vadose zone over saturated tailings. Their simulations were in good agreement with observed weathering and mineral reactions. Because the tailings are relatively fine grained, they concluded that convection was an unlikely transport mechanism for oxygen. Pantelis and Ritchie (1991) observed that convection is significant only in coarse grained materials with high permeability. Bains et al. (2000) used a variant of the PYROX model 
to simulate 35 years of tailings weathering. They also found good agreement between simulations and actual conditions.

The literature describing pyrite oxidation and reactive transport modeling provide several useful observations for mine-pools:

- Pyrite oxidation rates are fast if reactants are not limiting. Rates are directly proportional to oxygen content. Table 5-21 shows that oxidation in acidic, aerated mine-pools is more rapid than in flooded mines.

- Oxygen availability and transport at the macro and micro-scale can profoundly affect oxidation rate. In flooded mine-pools, the primary macro-scale transport is advection by flowing ground-water. In partly flooded mines, barometric pressure fluctuations can supply oxygen through fractures, subsidence cracks and other openings (Morth et al., 1972). Oxygen diffusion is an important control at the micro-scale within rock and mineral surfaces, shown in both experiments and analytical simulations.

- Diffusion can reduce pyrite oxidation rate, and hence flux of acid weathering products. This is expressed as declining flux as weathering slows and the mine-pool ages.

- Diffusion rate constraints effectively extend the weathering period for pyrite, which otherwise would be rapidly consumed.

A declining flux implies that at some future state, mine-pool waters should contain negligible concentrations of pyrite weathering products. Either the oxidation rate slows because of diffusion constraints on oxygen supply, or the mineral is depleted. From a mass balance consideration, complete depletion of pyrite is unlikely on a time scale of decades As pyrite oxidation slows and the mine-pool ages, could the mobility of Fe, Al, sulfate or other chemicals be controlled by others minerals? That prospect is examined in section 5.5.

\subsection{Metal Solubility Controls in Aging Mine-pools}

Time series plots of chemical concentration for pyrite weathering products such as figure 5-18, Fe concentration in the Hahn mine-pool, exhibit decreases in both absolute concentration and rate of change with time. The following questions arise when considering these time series plots:

- Will concentrations continue to decline until they reach background conditions? Or,

- Will the mine-pool establish a new chemical composition as its baseline condition?

The solution to these questions can determine how long treatment is needed to achieve specified water quality, or when the mine-pool may be viewed as a ground-water resource, rather than a liability. 
The form of the decay function described in previous sections implies a continuing decline in concentration. It has no provision for recognizing geochemical or hydrologic processes that might stop the decay process and establish a steady state condition. Mineral solubility constraints are one such process that could control chemical composition of aged mine-pools.

The author has collected water samples from mine-pools ranging up to about 100 years old, and has found that small concentrations of Fe, sulfate and $\mathrm{Al}$, and sometimes low $\mathrm{pH}$, persist. The waters remain unsuited for most uses, although the concentrations of parameters are small relative to newly formed mine-pools in analogous hydrogeologic and geochemical settings.

Two samples from mine-pools aged about 60 and 90 years were selected for analysis of possible long term geochemical controls on Fe and Al. The first site is the Ruthbelle mine-pool discharge. This mine is located immediately adjacent to the T\&T mine-pool, Upper Freeport coal bed in Preston County, WV. Mining dates to the 1950's, and because the mine is hydrologically connected to the T\&T complex, drainage from the Ruthbelle mine has been monitored by the West Virginia DEP since the mid 1990s. The author has sampled the Ruthbelle drainage on six different dates. An analysis deemed representative is shown in table 5-22. The Ruthbelle drainage represents the case of an acidic, partly flooded aged mine-pool. A second analysis is from the Acme mine-works, in Marion County, West Virginia (table 5-22) and is among four collected by the author from this site. Mining dates from the 1920s in the Pittsburgh coal bed, and the mine-pool discharge at the up-dip entries. The Acme mine-pool represents the case of a flooded circumneutral mine-pool and is in the same coal bed with similar geology as the Hahn and Arden-Westland mine-pools.

Table 5-22(1)

Chemical Composition of Aged Acidic, Partly Flooded and Circumneutral Flooded Mine-pools

\begin{tabular}{cccccccccccc}
\hline Mine $^{(2)}$ & $\mathrm{pe}$ & $\mathrm{pH}$ & Alkalinity & $\mathrm{Fe}$ & $\mathrm{Al}$ & $\mathrm{SO}_{4}$ & $\mathrm{Ca}$ & $\mathrm{Mg}$ & $\mathrm{Na}$ & $\mathrm{Cl}$ & $\mathrm{Si}$ \\
\hline $\begin{array}{c}\text { Ruthbelle } \\
\text { (partly }\end{array}$ & 13.03 & 2.68 & - & 6.63 & 4.76 & 235 & 40.5 & 14.1 & 1.3 & 5 & 6.8 \\
$\begin{array}{c}\text { flooded) } \\
\begin{array}{c}\text { Acme } \\
\text { (flooded) }\end{array}\end{array}$ & 1.83 & 6.25 & 263 & 5.15 & 0.05 & 543 & 104.3 & 39.8 & 165 & 6 & 5 \\
\hline
\end{tabular}

(1) Alkalinity in $\mathrm{mg} / \mathrm{L} \mathrm{CaCO}_{3}$ Eq. Elements in mg/L. pH in S.U.

(2) Ruthbelle sample collected 5/17/05. Acme discharge sampled 6/8/08.

Both mine-pools contain relatively small amounts of dissolved iron, and the Ruthbelle water also has about five $\mathrm{mg} / \mathrm{L}$ of dissolved Al. These metals concentrations, while easily treatable, generally exceed standards for most water uses, and thus remain problematic.

A set of mineral solubility calculations were run for both waters in PHREEQCI (Parkhurst and Appelo, 1999) to estimate saturation indices for common iron and aluminum minerals. Results are shown in table 5-23. The Ruthbelle water is under-saturated for all of the more soluble Fe oxide, hydroxide and sulfate minerals shown in the table. It is over-saturated by more than three 
orders of magnitude for the crystalline and less soluble oxyhydroxide goethite. It is also undersaturated for three minerals that potentially control $\mathrm{Al}$ availability; jurbanite, kaolinite and poorly crystalline $\mathrm{Al}(\mathrm{OH})_{3}$. The Acme discharge is also under-saturated for more soluble $\mathrm{Fe}$ minerals and more than three orders of magnitude over-saturated for goethite. Aluminum concentrations are low in the Acme water, and may be controlled by a less soluble form of $\mathrm{Al}(\mathrm{OH})_{3}$, aluminosilicates such as kaolinite, or alumino-sulfates such as alunite.

Both waters are more than three orders of magnitude over-saturated for goethite. This degree of over-saturation indicates that goethite is likely not the controlling mineral for Fe in either water. Either goethite is not present; the kinetics are so slow that its formation isn't satisfactorily addressed with equilibrium calculations, or Fe is controlled by another mineral. A number of weathering studies suggest that goethite sometimes forms as the more stable alteration product of other oxide and hydroxide minerals (Schwertmann and Taylor, 1977; Macalady et al., 1990). In mine waters and sediments goethite has been reported to form from ferrihydrite and schwertmannite (Kim et al., 2002; Jonsson et al., 2005). The total range of Fe oxide solubility can span seven orders of magnitude (Langmuir, 1997), thus control of Fe solubility in aging mine-pools may be a function of which minerals are present and the degree of crystallinity. Sediments precipitating from mine waters often contain a mixture of Fe minerals ranging from poorly crystalline to sulfate bearing to goethite (Karathanasis and Thompson, 1995; McCarty et al., 1998; Bowell and Bruce, 1995; Kaires et al. 2005). Since more soluble Fe minerals are common in mine water sediments, and both waters in table 5-23 are under-saturated for them, this analysis considered poorly crystalline $\mathrm{Fe}(\mathrm{OH})_{3}$ as a potential control. Jarosite is unlikely to influence the Acme mine water composition, since this mineral is over-saturated by 11 orders of magnitude and characteristically forms in acid oxidizing environments (Nordstrom, 1982a).

Table 5-23

Mineral Indices of Aged Acidic, Partly Flooded, and Circumneutral Flooded Mine-pools

\begin{tabular}{ccccccccc}
\hline Mine & $\mathrm{Fe}(\mathrm{OH})_{3}$ & $\mathrm{Fe}_{3}(\mathrm{OH})_{8}$ & Goethite & K-Jarosite & Schwertmannite & Jurbanite & Kaolinite & $\mathrm{Al}(\mathrm{OH})_{3}$ \\
\hline $\begin{array}{c}\text { Ruthbelle } \\
\text { (partly }\end{array}$ & -2.06 & -14.07 & 3.29 & -1.86 & -2.72 & -1.52 & -9.63 & -8.28 \\
$\begin{array}{c}\text { flooded) } \\
\begin{array}{c}\text { Acme } \\
\text { (flooded) }\end{array}\end{array}$ & -2.07 & -6.54 & 3.41 & 11.13 & -15.06 & -0.80 & 5.49 & -0.51 \\
\hline
\end{tabular}

Examining the chemical composition and mineral saturation index data in tables 5-22 and 5-23, there are no obvious mineral controls that would further reduce $\mathrm{Fe}$ and $\mathrm{Al}$ concentrations. All the minerals in table 5-23 are, however, influenced by $\mathrm{pH}$ and/or Eh (pe) conditions. Therefore, a series of simulations were conducted using PHREEQCI where $\mathrm{pH}$ and $\mathrm{Eh}$ (pe) were varied to examine effects on mineral solubility. The simulations were run in 100 steps as follows:

- The acidic Ruthbelle discharge was treated by addition of calcite at the rate of five mmole/L to adjust $\mathrm{pH}$. 
- A second simulation for the Ruthbelle water included calcite addition as before, plus the introduction of 0.1 mmole of dissolved oxygen to adjust $\mathrm{pH}$ and Eh.

- The circumneutral Acme mine water had 0.01 or 0.05 mmole dissolved oxygen added to adjust Eh.

The oxygen values were selected to represent conditions in a partly flooded mine-pool and introduction of small $\mathrm{O}_{2}$ amounts into a flooded mine-pool. The minerals listed in table 5-23 were assumed to be absent initially, but were allowed to precipitate if the solution reached saturation for that mineral. The quantity of remaining soluble Fe and Al were tabulated through each step. The initial run for each water considered all the minerals in table 5-23 as potential controls. Subsequent runs removed certain minerals to examine the effects of specific components. Remaining soluble $\mathrm{Al}$ and Fe were plotted as a function of $\mathrm{pH}$ or Eh (pe). The $\mathrm{pH}$ or pe at which saturation occurred for specific minerals was calculated by substituting chemical activities into the appropriate equilibrium expression.

Figure 5-50 shows the first set of simulation results for adding calcite, and calcite plus oxygen to the acidic Ruthbelle discharge. The initial Fe concentration of $6.53 \mathrm{mg} / \mathrm{L}$ (left $\mathrm{Y}$ axis) was reduced by mineral formation as $\mathrm{pH}$ increased. The first simulation considered K-Jarosite, schwertmannite and $\mathrm{Fe}(\mathrm{OH})_{3}$ as the potential controls on soluble Fe, with no added oxygen, and

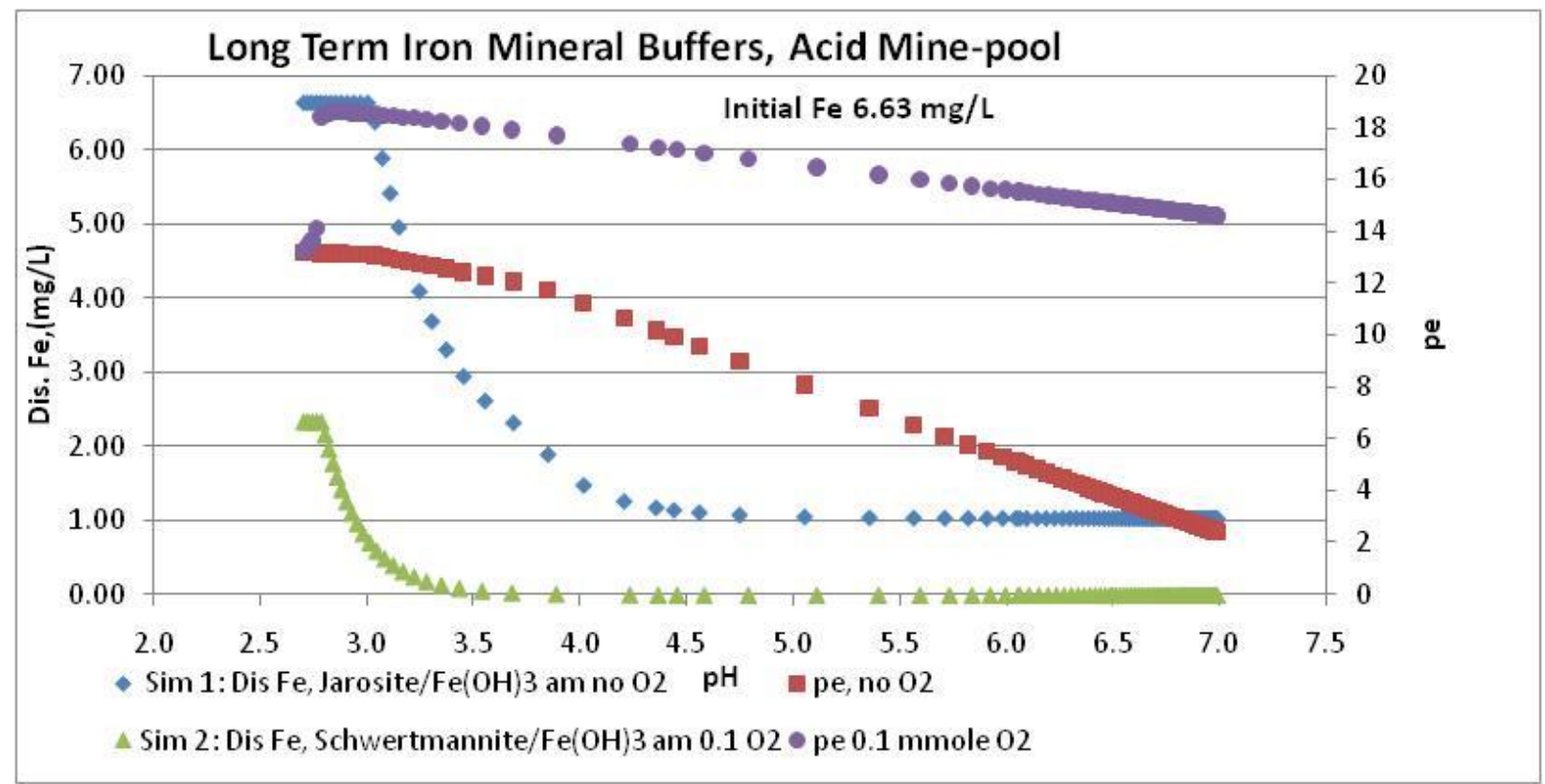

Figure 5-50. Simulation Results of Long Term Iron Solubility Controls in the Aged Acid Ruthbelle Mine-pool. Initial sulfate and potassium concentrations are $235 \mathrm{mg} / \mathrm{L}$, and $1.15 \mathrm{mg} / \mathrm{L}$, respectively.

$\mathrm{pH}$ as the only variable. Saturation for schwertmannite was not achieved, and K-Jarosite and $\mathrm{Fe}(\mathrm{OH})_{3}$ were the only minerals controlling Fe. Soluble Fe was reduced to about one mg/L by 
formation of K-Jarosite and $\mathrm{Fe}(\mathrm{OH})_{3}$. The remaining soluble $\mathrm{Fe}$ is $\mathrm{Fe}(\mathrm{II})$, and absent an oxidizer in this simulation, ferrous iron cannot react to form K-Jarosite or $\mathrm{Fe}(\mathrm{OH})_{3}$. Redox, expressed by pe, declined sharply during the simulation to about two, as oxidized species were precipitated. The complete lack of oxygen was considered unrealistic and was revised in the next run.

The equilibrium saturation $\mathrm{pH}$ for K-Jarosite saturation is 2.99 , and 3.84 for $\mathrm{Fe}(\mathrm{OH})_{3}$ am. They were calculated from the following solubility expressions and appropriate chemical activity values:

$$
\begin{gathered}
\mathrm{KFe}_{3}\left(\mathrm{SO}_{4}\right)_{2}(\mathrm{OH})_{6}+6 \mathrm{H}^{+} \leftrightarrow \mathrm{K}^{+}+3 \mathrm{Fe}^{+3}+2 \mathrm{SO}_{4}{ }^{-2}+6 \mathrm{H}_{2} \mathrm{O} \quad \log \mathrm{Kt}=-8.05 \\
\mathrm{Fe}(\mathrm{OH})_{3}+3 \mathrm{H}^{+} \leftrightarrow \mathrm{Fe}^{+3}+3 \mathrm{H}_{2} \mathrm{O} \quad \log \mathrm{Kt}=4.89
\end{gathered}
$$

The second Fe simulation for the Ruthbelle discharge included the addition of $0.1 \mathrm{mmole} / \mathrm{L}$ $(3.2 \mathrm{mg} / \mathrm{L})$ of oxygen, which is similar to actual conditions. The potential iron sinks included schwertmannite, $\mathrm{Fe}(\mathrm{OH})_{3}$ and K-Jarosite. Schwertmannite is an Fe oxyhydroxysulfate mineral of variable composition. It has been found in mine waters in Asia and North America (Bigham et al., 1990; Bigham et al., 1996; Yu et al., 1999). Because of poor crystallinity and variable composition, the reported solubility varies (Yu et al., 1999). The average composition and log K reported by $\mathrm{Yu}$ et al. were used to simulate schwertmannite behavior.

The second simulation of Ruthbelle water, adding oxygen and calcite, essentially reduced soluble iron to zero. The equilibrium $\mathrm{pH}$ for schwertmannite saturation was 2.79 and 3.79 for $\mathrm{Fe}(\mathrm{OH})_{3}$. They were calculated from equation 5-33 and 5-32. The inclusion of oxygen permitted conversion of $\mathrm{Fe}$ (II) to $\mathrm{Fe}$ (III) in the simulation, and maintained overall oxidizing conditions in the mine-pool, similar to actual conditions.

$$
\mathrm{Fe}_{8} \mathrm{O}_{8}(\mathrm{OH})_{4.4}\left(\mathrm{SO}_{4}\right)_{1.8}+20.4 \mathrm{H}^{+} \leftrightarrow 8 \mathrm{Fe}^{+3}+12.4 \mathrm{H}_{2} \mathrm{O}+1.8 \mathrm{SO}_{4}{ }^{-2} \quad \log \mathrm{k}=10.5
$$

Both Ruthbelle simulations show that if $\mathrm{pH}$ is increased to about 3.8 or greater, $\mathrm{Fe}$ could be removed as $\mathrm{Fe}(\mathrm{OH})_{3}$ before complete neutralization of the mine-pool is achieved. As the minepool sediments age and transition towards goethite, they should be less soluble.

Schwertmannite solubility is highly sensitive to $\mathrm{Fe}^{3+}$ activity, as seen in equation 5-33. Thus redox status influences which minerals actually control Fe solubility. The simulations show that Fe may be controlled by $\mathrm{K}$-Jarosite or schwertmannite at $\mathrm{pH}$ as low as about three, but both minerals are considered metastable with respect to goethite (Jonsson et al., 2005; Bigham et al., 1996). The range of $\mathrm{pH}$ and $\mathrm{Eh}$ control by schwertmannite may fluctuate, since the mineral's solubility and composition varies (Yu et al. 1999).

Figure 5-51 shows simulation results for soluble $\mathrm{Al}$ in the Ruthbelle drainage with addition of calcite. Jurbanite, kaolinite, and poorly crystalline $\mathrm{Al}(\mathrm{OH})_{3}$ were considered potential controls. The T\&T mine-pool adjacent to Ruthbelle has apparent saturation for jurbanite, and kaolinite is a 
common clay mineral in these strata (Dulong et al., 2002). The initial simulation included all three minerals, followed by runs where $\mathrm{Al}$ was considered to be controlled by one mineral only.

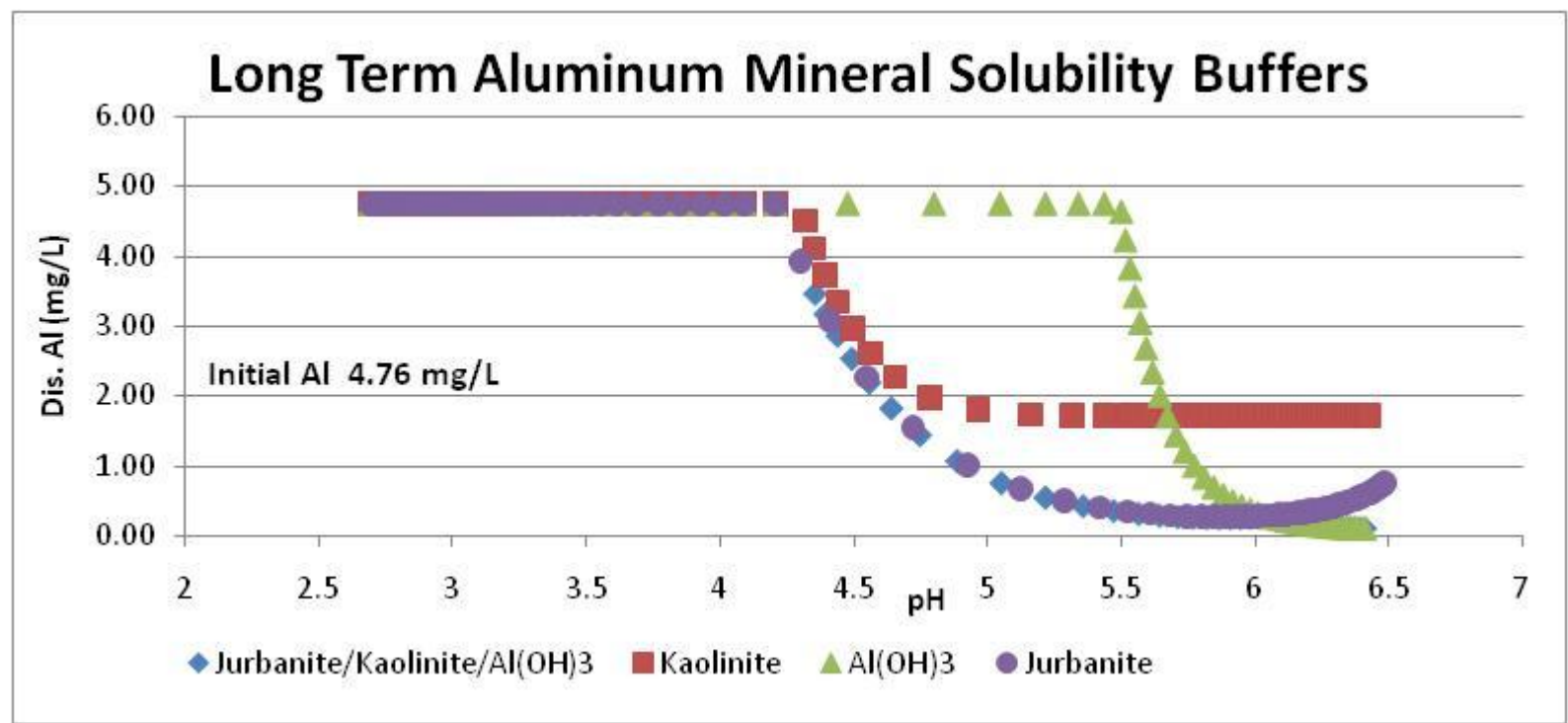

Figure 5-51. Simulation Results of Long Term Aluminum Solubility
Controls in the Aged Acid Ruthbelle Mine-pool. Initial sulfate
and silica concentrations are 235 and $6.8 \mathrm{mg} / \mathrm{L}$ respectively.

The initial run showed soluble Al to be controlled successively by jurbanite, kaolinite and $\mathrm{Al}(\mathrm{OH})_{3}$ as $\mathrm{pH}$ increased. The equilibrium $\mathrm{pH}$ for jurbanite saturation was 4.21 , kaolinite equilibrium $\mathrm{pH}$ was 4.35 , and equilibrium $\mathrm{pH}$ for $\mathrm{Al}(\mathrm{OH})_{3}$ saturation was 6.06. Soluble $\mathrm{Al}$ was reduced to about $0.1 \mathrm{mg} / \mathrm{L}$. Equilibrium $\mathrm{pH}$ was calculated for the three minerals from the expressions shown in equation 5-34, 5-35 and 5-36 with appropriate chemical activities.

$$
\begin{gathered}
\mathrm{AlOHSO}_{4}+\mathrm{H}^{+}=\mathrm{Al}^{+3}+\mathrm{SO}_{4}^{-2}+\mathrm{H}_{2} \mathrm{O} \quad \log \mathrm{Kt}=-3.23 \\
\mathrm{Al}_{2} \mathrm{Si}_{2} \mathrm{O}_{5}(\mathrm{OH})_{4}+6 \mathrm{H}^{+}=2 \mathrm{Al}^{+3}+2 \mathrm{H}_{4} \mathrm{SiO}_{4}+\mathrm{H}_{2} \mathrm{O} \quad \log \mathrm{Kt}=8.74 \\
\mathrm{Al}(\mathrm{OH})_{3}+3 \mathrm{H}^{+}=\mathrm{Al}^{+3}+3 \mathrm{H}_{2} \mathrm{O} \quad \log \mathrm{Kt}=11.78
\end{gathered}
$$

A second run, using kaolinite as the only $\mathrm{Al}$ buffer, is also shown in figure 5-47. Soluble Al was reduced to about $1.7 \mathrm{mg} / \mathrm{L}$. Kaolinite formation and additional Al removal was constrained by depleting available $\mathrm{Si}$. In the mine-pool, weathering of other silicates could provide additional $\mathrm{Si}$, and kaolinite would limit soluble Al.

A third run used $\mathrm{Al}(\mathrm{OH})_{3}$ as the only mineral sink in the Ruthbelle water. Soluble Al was reduced to about $0.1 \mathrm{mg} / \mathrm{L}$, but mineral saturation and formation was not attained until $\mathrm{pH}$ reached about 5.6. 
The final run simulating Al control used jurbanite as the controlling mineral. Soluble Al was reduced to a minimum of about $0.26 \mathrm{mg} / \mathrm{L}$ at $\mathrm{pH}$ of 5.9 . At $\mathrm{pH}$ greater than 6 , jurbanite solubility increased as did soluble Al. The equilibrium $\mathrm{pH}$ for jurbanite saturation was 4.3.

The simulations show that if Ruthbelle mine-pool $\mathrm{pH}$ is increased to about 4.3 or greater, soluble $\mathrm{Al}$ can be reduced. The lowest concentrations are attained if $\mathrm{Al}(\mathrm{OH})_{3}$ is the controlling mineral. Kaolinite formation could also effectively control soluble Al with sufficient available Si and reaction time.

The second set of simulations was performed using the circumneutral mine-pool waters from the Acme mine (tables 5-22 and 5-23). Iron is the metal of concern in this water and redox state is the primary variable to test. As in the Ruthbelle waters, goethite is over-saturated by more than three orders of magnitude, suggesting it is not controlling soluble Fe. The possible controls were considered to be schwertmannite and poorly crystalline more soluble $\mathrm{Fe}(\mathrm{OH})_{3}$. Siderite was also considered as a potential control, but is somewhat under-saturated with an index of about -0.2. A small amount of oxygen, either 0.01 or 0.05 mmoles, was added in different runs to simulate $\mathrm{O}_{2}$ introduction by recharge or planned oxidation. No pyrite or other oxidizable minerals were present in the simulation. $\mathrm{Fe}$ (II) was allowed to oxidize to $\mathrm{Fe}(\mathrm{III})$, and distributions of the ferrous and ferric iron species were a function of pe. Results are shown in figure 5-52, with soluble Fe plotted against pe.

The addition of a small quantity of oxygen increased pe and the activity of $\mathrm{Fe}^{3+}$, beginning with the first step in each run. Soluble Fe was reduced to about $2.9 \mathrm{mg} / \mathrm{L}$ when oxygen supply was limited for either schwertmannite or $\mathrm{Fe}(\mathrm{OH})_{3}$ (fig 5-48). However, the run results show that even a small shift in pe of less than 0.5 units is sufficient to affect mineral precipitation and soluble Fe. When oxygen supply was increased, soluble Fe was essentially reduced to zero by either mineral, as pe increased to about 6 .

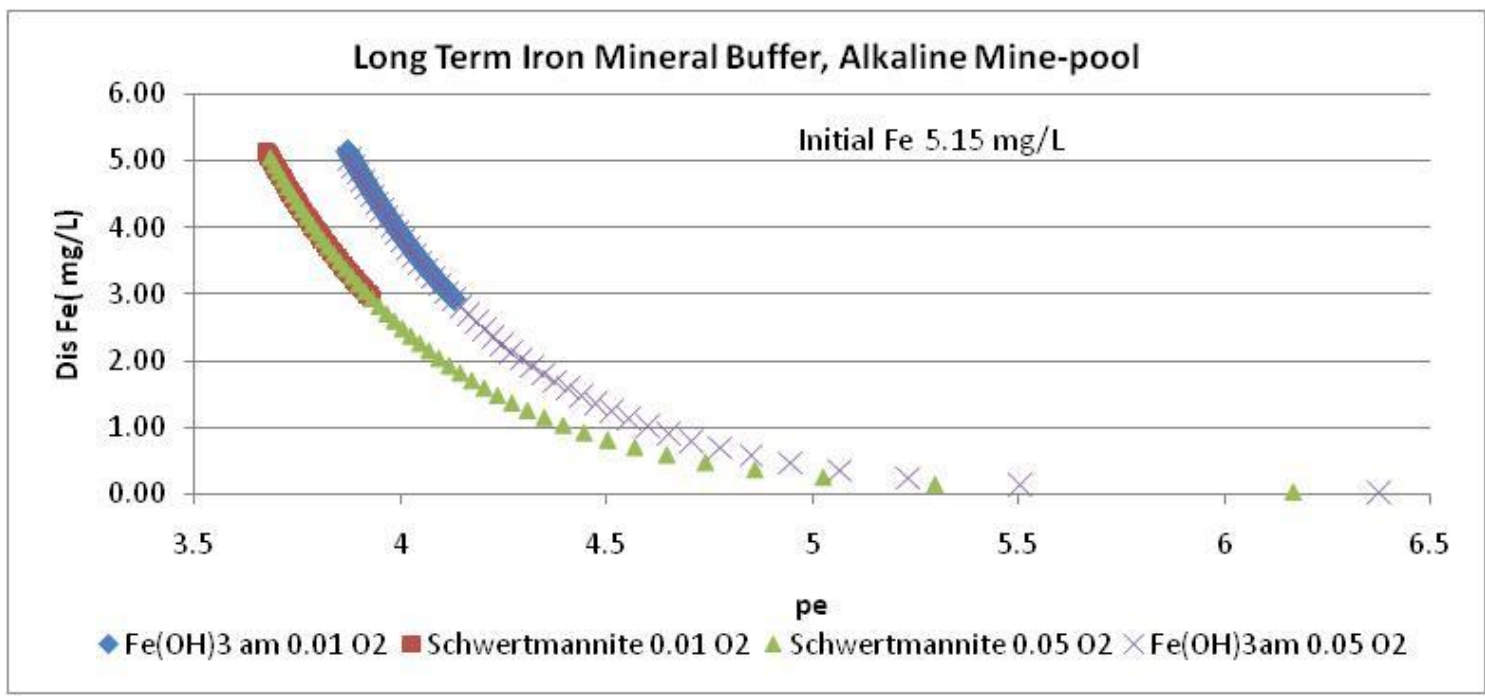

Figure 5-52 Simulation Results of Long Term Iron Solubility Controls in the Aged Circumneutral Acme Mine-pool. 
The persistence of low concentrations of soluble $\mathrm{Fe}$ and $\mathrm{Al}$ in the aged Ruthbelle and Acme mine-pools suggests that long term chemistry may be influenced by mineral solubility. Solubility calculations for both waters did not clearly identify any controlling phases that might further reduce concentrations. Both $\mathrm{Fe}$ and $\mathrm{Al}$ have multiple potential source and sink minerals of varying solubility and reaction rates. The simulation results for both waters show that dissolved metals can be reduced by manipulating $\mathrm{pH}$ and redox status, and that the magnitude of change required is not large. Other processes including ion exchange and adsorption/desorption were not explicitly included in these simulations, but could also affect soluble metals concentrations.

\subsection{Chapter 5 Summary Findings and Observations}

Chapter 5 examined long term trends in water chemistry for two partly flooded, acidic and three mostly flooded circumneutral mine-pools. The available monitoring records encompassed about to 12 to 35 years of post closure water data. The analyses included the following:

- $\quad$ Evaluated in-situ neutralization of acidity;

- $\quad$ Estimated decay constants to describe the rate of chemical concentration change;

- Examined factors that may control or contribute to the magnitude of the decay constant, including macro and micro scale transport processes.

- Conducted simulations of aged mine-pool waters to identify controls on dissolved metals concentrations.

The principal findings and conclusions of this chapter are summarized as follows:

- A large fraction of the strong acid $\left(\mathrm{H}^{+}\right)$acidity attributable to pyrite oxidation was missing from all five mine-pools. The missing acidity is described as in-situ neutralization and exceeds $100 \%$ in the flooded net alkaline mine-pools. Significantly, the two acid mine-pools had neutralization ratios on the order of 60 to $70 \%$. Thus, even in acidic mine-pools, water treatments needs are substantially reduced by the acidconsuming weathering reactions. In-situ neutralization includes consumption by weathering of carbonates, alumino-silicates and oxyhydroxides, and alkaline recharge from ground-water infiltration. Bicarbonate alkalinity from sulfate reduction in flooded mine-pools, and exchange and adsorption reactions may also contribute to apparent neutralization.

- Neutralization ratios computed from strong acid $\left(\mathrm{H}^{+}\right)$acidity persist or even increase through the monitoring record for all five mine-pools. Thus water treatment needs or off site impacts are not likely to increase over time.

- Mineral weathering constituted about 60 to $95 \%$ of the in-situ neutralization of the strong acid $\left(\mathrm{H}^{+}\right)$acidity, depending on mine-pool age and flooding state. Mineralogy of 
the residual coal, floor and roof rock is the principal control on in-situ weathering. The Omega and T\&T mine-pools are in a sequence of rocks with few carbonates and have limited acid consuming capacity. The Hahn and Arden-Westland mine-pools are in rocks containing a series of calcareous rocks with significant acid consumption capacity.

- Mineral weathering was reflected by increased concentrations of $\mathrm{Ca}, \mathrm{Mg}$ and $\mathrm{Al}$ in acidic mine-pools. Elevated $\mathrm{Ca}$ and $\mathrm{Mg}$ probably reflect carbonate weathering, but could include consumption of other minerals. Specific minerals involved could not be directly identified, but were inferred from solution composition and solubility considerations.

- Significant consumption of alumino-silicates and or Al-oxyhydroxides is occurring in the two acidic Omega and T\&T mine-pools. After more than ten years of weathering, the two mine-pools are discharging soluble Al equivalent to consuming about 0.7 and 1.5 mmole kaolinite per $\mathrm{L}$ of solution.

- Interpreting $\mathrm{Al}$ and sulfate behavior is complicated by apparent equilibrium for jurbanite in the two acid mine-pools. Acid production in these mine-pools may be underestimated if sulfate bearing minerals are retained in place.

- Soluble Al exiting the mine-pool should not be included as an overall neutralization process. The $\mathrm{H}^{+}$originally consumed in mineral weathering is offset by hydrolysis in water treatment yielding a net neutralization of zero. Some weathering reactions in the mine-pool, for example jurbanite/kaolinite transformation, can be net acid consuming.

- Two methods for estimating neutralization ratio, cation summation and neutralization by difference produced similar estimates. Either can provide a useful estimate of in-situ weathering.

- Estimating neutralization based on speciated solutions was useful for acidic waters containing appreciable $\mathrm{Fe}(\mathrm{III})$. In these waters, accounting for $\mathrm{H}^{+}$consumption by $\mathrm{Fe}(\mathrm{II}) / \mathrm{Fe}(\mathrm{III})$ oxidation did change the overall neutralization ratio. In waters dominated by $\mathrm{Fe}(\mathrm{II})$ there was little advantage to speciating solutions.

- Long term chemical concentration data often fit a first order type reaction plot. The general form of the decay (chemical concentration decline) equation was adequate to estimate the long term trends for total acidity, Fe, Al, sulfate and TDS. Computed decay (k) constants, with few exceptions, range within one order of magnitude. The rates are on the order of $10^{-4} / \mathrm{d}$.

- Percentage coefficient of variation $\left(\mathrm{R}^{2}\right)$ values approached $90 \%$ for some the flooded mine-pools, indicating robust estimates for computed decay constants. $\mathrm{R}^{2}$ were generally 
lower for the unflooded acidic mine-pools due to the higher variation inherent in these data sets.

- Chemical concentration decay can be divided into early and late mine-pool history phases. The early phase includes the flushing of accumulated salts and acid weathering products including "vestigial" acidity. Concentrations decline most rapidly during the early flushing phase. The late phase includes the continued weathering of pyrite and other minerals and removal of "juvenile acidity". Concentration ratios of Fe to sulfate may be a useful method to separate early and late phase decay.

- Some long term data such as $\mathrm{pH}$ in the acidic Omega and T\&T mine-pools had statistically insignificant chemical decay values. The rate of change is too small to be resolved in these data.

- Early phase chemical decay was about 1.5 to three times faster than late phase decay. Separate decay values should be used to model early and late phase water quality conditions. Using early and late phase decay reduces differences between predicted and actual values.

- With exception of Fe, flooded circumneutral mines have slightly faster decay rates (1.2 to 1.5 times) than unflooded acidic mines. Iron decay is slower in flooded compared to unflooded mines. Unflooded mines have a more oxidizing environment, and conditions are more favorable for the in-situ retention of Fe by formation of less soluble Fe (III) minerals. Flooded mines, in contrast, are dominated by ferrous Fe, which is soluble over a wider $\mathrm{pH}$ range and less likely to be immobilized in situ.

- $\mathrm{Al}$ has a slower decay (1.5 to two times) compared to $\mathrm{Fe}, \mathrm{SO}_{4}$, and total acidity. The slower $\mathrm{Al}$ decay rate may result from continued addition of $\mathrm{Al}$ to the system by ongoing alumino-silicate weathering and solubility controls from minerals such as jurbanite and alunite. Al decay was only computed for two acid mine-pools. The circumneutral pools had insignificant concentrations of soluble Al.

- Time frames to reach specified water quality concentrations were on the order of decades. In general, most chemical decay predictions ranged from about 30 to 70 years duration. Aluminum was predicted to have the longest decay period, in some instances exceeding 100 years. The range of statistical uncertainty can span one to two decades for these long term estimates.

- Decay rates are useful for long term chemical value trend estimates. They are less useful for estimating concentration at specific points in time. The decay function does not explicitly account for seasonal variation or other short term changes. 
- The chemical decay constant is a lumped variable that includes both chemical reaction and transport elements. It is weakly related to physical parameters including maximum flow path length, recharge rate and residence time. However the small size of the data set (five mines) precluded a rigorous analysis.

- Chemical decay constants were correlated among themselves on a mine by mine basis, suggesting site specific influence.

- A simple model of slow flushing of the mine-pool relative to mineral dissolution rates produced reasonable results. A model assuming rapid flushing relative to mineral dissolution produced results deemed unreasonable. This analysis implies that transport controls observed decay more than chemical kinetics.

- Pyrite oxidation rates estimated from published rate data were about an order of magnitude faster in unflooded mines compared to flooded mines. The rates are sensitive to oxygen content. A faster oxidation rate for pyrite in unflooded mines might be reflected as overall slower chemical decay when compared to flooded mines. Flooded mines do have slightly higher decay rates (1.2 to 1.5 times) for four of five parameters, but the differences cannot be assigned to chemical weathering with certainty.

- A literature review of selected pyrite oxidation models for tailings, spoil piles and underground mines found that all incorporate oxygen diffusion as a rate limiting process. Diffusion is treated on two scales, as oxygen transport through the rock pile or mine-pool water, and as a shrinking core model of oxygen movement within individual grains. In the shrinking core model, oxygen diffusion and corresponding weathering rates are highly sensitive to the position of the grain weathering front and buildup of a reacted layer. Transport at the micro scale could influence decay rates.

- Advective transport of oxygen and weathering products in flooded mines could influence chemical decay rates, and airflow driven by barometric changes may be important for oxygen transport in partly flooded mines.

- The chemical decay constants have no provision for complying with mineral solubility constraints as the mine-pool ages. Samples of aged mine-pools seem to retain dissolved metals such as $\mathrm{Fe}$ and $\mathrm{Al}$ in the range of a few to a few tens of $\mathrm{mg} / \mathrm{L}$. These concentrations are larger than might be estimated using decay constants.

- Simulations of aged mine-pools, including acid water with dissolved Fe and Al, and a circumneutral water with dissolved Fe, showed that metals will not likely be removed by mineral precipitation. However, relatively small manipulation of $\mathrm{pH}$ and Eh (pe), simulated by the addition of calcite and oxygen, could effectively remove metals. The large solubility range for $\mathrm{Fe}$ oxyhydroxide minerals was the greatest uncertainty in the simulations. 


\section{LITERATURE CITED}

Ackenheil Associates, 1977. Operation Scarlift Report Redstone Creek and the Uniontown Syncline, prepared for the Pennsylvania Dept of Environmental Resources, Harrisburg, PA, Project 141-2.

Adams, R., and P. Younger, 2001. A Strategy for Modeling Ground Water Rebound in Abandoned Deep Mine Systems, Ground Water, Vol 39, No.2, p 249-261.

Aljoe, W., and J. Hawkins, 1991. Investigation and Characterization of Groundwater Flow Systems in Abandoned Underground Coal Mines, in Proceedings National Meeting of the American Society for Surface Mining and Reclamation, p 241-259.

Alpers, C,, Jambor, J., and D. Nordstrom (eds), 2000. Sulfate Minerals: Crystallography, Geochemistry and Environmental Significance, Reviews in Mineralogy and Geochemistry Vol. 40, Mineralogical Society of America and Geochemical Society, 608 pps.

Appalachian Regional Commission, 1969. Acid Mine Drainage in Appalachia. Congressional House Doc. No. 91-180. Volumes I, II, and III

Appelo, C., and D. Postma, 1993. Geochemistry, Groundwater and Pollution, A.A. Balkema, Rotterdam, Netherlands, 536 pps.

Appelo, C., Verweij, E. and H. Schafer, 1998. A Hydrogeochemical Transport Model for an Oxidation Experiment with Pyrite/Calcite/Exchangers/Organic Matter Containing Sand, Applied Geochemistry, Vol. 13, p 257-268.

Arkle, T., Beissel, D., Larese, R., Nuhfer, E., Patchen, D., Smosna, R., Gillespie, W., Lund, R, Norton, C., and H. Pfefferkorn, 1979. The Mississippian and Pennsylvanian (Carboniferous) Systems in the United States, West Virginia and Maryland. US Geological Survey Professional Paper 1110-D.

Auque, L., Gimeno, M., Gomez, J., and A. Nilsson, 2008. Potentiometrically measured Eh in groundwaters from the Scandinavian Shield, Applied Geochemistry, Vol. 23, p 1820-1833.

Baas Becking, L., Kaplan, I., and D Moore, 1960. Limits of the Natural Environment in Terms of pH and Oxidation-Reduction Potentials, Journal of Geology, Vol. 68, p 243-284.

Back, W., and I. Barnes, 1965. Relation of Electrochemical Potentials and Iron Content to Groundwater Flow Patterns, US Geological Survey Professional Paper 498-C.

Back, W., 1966. Hydrochemical Facies and Ground-Water Flow Patterns in Northern Part of Atlantic Coastal Plain, US Geological Survey Professional Paper 498-A.

Bains, J., Blowes, D., Robertson, W. and E. Frind, 2000. Modelling of Sulfide Oxidation With Reactive Transport At A Mine Drainage Site, Journal Contaminant Hydrology Vol. 41, p 23-47. 
Baron, D., and C. Palmer, 1996. Solubility of Jarosite at $4-35^{\circ} \mathrm{C}$, Geochemica et Cosmochemica Acta, Vol. 60, p 185-195.

Barton, L. (ed.), 1995. Sulfate-Reducing Bacteria, Biotechnology Handbooks 8. Plenum Publishing, New York, NY, 336 pps.

Bayless, E., and G. Olyphant, 1993. Acid Generating Salts and Their Relationship to the Chemistry of Groundwater and Storm Runoff at an Abandoned Mine Site in Southwestern Indiana, USA. Journal of Contaminant Hydrology, Vol. 12, p 313-328.

Beam, R., 2005. Personal Communication, 2005, Pennsylvania Dept Environmental Protection, Ebensburg, PA

Berger, A., Bethke, C., and J. Krumhansel, 2000. A Process Model of Natural Attenuation in Drainage From a Historic Mining District, Applied Geochemistry, Vol. 15, p 655-666.

Berner, R., 1967. Thermodynamic Stability of Sedimentary Iron Sulfides, American Journal of Science, Vol. 265, p 773-785.

Berner, R., 1970. Sedimentary Pyrite Formation, American Journal of Science, Vol. 268, p 1-23.

Berner, R., 1978. Rate Control of Mineral Dissolution Under Earth Surface Conditions, American Journal of Science, Vol. 278, p 1235-1252.

Berryhill, H., Schweinfurth, S., and B. Kent, 1971. Coal-Bearing Upper Pennsylvanian and Lower Permian Rocks, Washington Area, Pennsylvania, U.S. Geological Survey Professional paper 621.

Bigham, J., Schwertmann, U., Carlson, L., and E. Murad, 1990. A Poorly Crystallized Oxyhydroxysulfate of Iron Formed by Bacterial Oxidation of Fe(II) in Acid Mine Waters, Geochemica et Cosmochemica Acta, Vol. 54, p 2743-2758.

Bigham, J., Schwertman, U., Traina, S., Winland, R. and M. Wolf, 1996. Schwertmannite and the Chemical Modeling of Iron in Acid Sulfate Waters, Geochemica et Cosmochemica Acta, Vol. 60 No. 12, p 2111-2121.

Bigham, J. and D. Nordstrom, 2000. Iron and Aluminum Hydroxysulfates from Acid Sulfate Waters, in Alpers, C., Jambor, J. and D. Nordstrom(eds), Sulfate Minerals: Crystallography, Geochemistry and Environmental Significance, Reviews in Mineralogy and Geochemistry, Vol. 40, Mineralogical Society of America and Geochemical Society, 608 pps.

Blowes, D., Jambor, J., Appleyard, E., Reardon, E., and J. Cherry, 1992. Temporal Observations of the Geochemistry and Mineralogy of a Sulfide-rich Mine Tailings Impoundment, Heathe Steele Mines, New Brunswick, Exploration and Mining Geology, I, No.3, p 251-264. 
Booth, C., 1986. Strata Movement Concepts and the Hydrogeological Impact of Underground Coal Mining, Ground Water, Vol. 24, p 507-515.

Booth, C., 2007. Confined-Unconfined Changes Above Longwall Coal Mining Due to Increases in Fracture Porosity, Environmental and Engineering Geoscience. Vol. XIII, No. 4, p 355-367.

Bowell, R., and I. Bruce, 1995. Geochemistry of Iron Ochres and Mine Waters from Levant Mine, Cornwall, Applied Geochemistry, Vol. 110, p 237-250.

Brady, K., Hornberger, R., and G. Fleeger, 1998. Influence of Geology on Post Mining Water Quality: Northern Appalachian Basin. in Coal Mine Drainage Prediction and Pollution Prevention in Pennsylvania, Pennsylvania Dept. of Environmental Protection, Harrisburg, PA.

Brant, R. and W. Foster, 1959. Magnesian Halotrichite from Vinton County, Ohio, Ohio Journal of Science, Vol. 59, No. 3, p 187-191.

Broshears, R., Runkel, R., Kimball, B., Mcknight, D., and K. Bencala, 1996. Reactive Solute Transport in an Acidic Stream: Experimental pH Increase and Simulation of Controls on pH, Aluminum and Iron, Environmental Science and Technology, Vol. 30, No. 10, p 3016-3024.

Bruemmer, G., Gerth, J., and K. Tiller, 1988. Reaction Kinetics of the Adsorption and Desorption of Nickel, Zinc and Cadmium by Goethite I, Adsorption and Diffusion of Metals, Journal of Soil Science, Vol. 39, p 37-52.

Bruhn, R., 1986. Influence of Deep Mining on the Ground Water Regime at a Mine in Northern Appalachia, in Proceedings $2^{\text {nd }}$ Workshop on Surface Subsidence Due to Underground Mining, West Virginia University, Morgantown, WV, p 234-248.

Bucek, M., and J. Emel, 1977. Long Term Effectiveness of Close Down Procedures-Eastern Underground Coal Mines. HRB Singer Inc, for US Environmental Protection Agency, EPA600/7-77-083.

Burby, T., Younos, T., and E. Anderson, 2000. Hydrologic Analysis of Discharge Sustainability from an Abandoned Underground Coal Mine, Journal of the American Water Resources Association, Vol. 36, No. 5, p 1161-1172.

Callaghan, T., Fleeger, G., Barnes, S., and A. Dalbarto, 1998. Groundwater Flow on the Appalachian Plateau of Pennsylvania. in Coal Mine Drainage Prediction and Pollution Prevention in Pennsylvania, Pennsylvania Dept. of Environmental Protection, Harrisburg, Pa.

Capo, R., Winters, W., Weaver, T., Stafford, S., Hedin, R., and B. Stewart, 2001. Hydrogeologic and Geochemical Evolution of Deep Mine Discharges, Irwin Syncline, Pennsylvania, in Proceedings West Virginia Surface Mine Drainage Task Force Symposium, Morgantown, WV, 10 pps. 
Carlson, L., and U. Schwertmann, 1990. The Effect of $\mathrm{CO}_{2}$ and Oxidation Rate on the Formation of Goethite Versus Lepidocrocite From an Fe(II) System at pH 6 and 7, Clay Minerals, Vol. $25, \mathrm{p} 65-71$.

Carpenter, L., and L. Herndon, 1933. Acid Drainage from Bituminous Coal Mines, West Virginia University Engineering Station Bulletin 10, Morgantown, WV, 38 pps.

Champ, D., Gulens, J., and R. Jackson, 1979. Oxidation-Reduction Sequences in Ground Water Flow Systems, Canadian Journal of Earth Science. Vol. 16, p 12-23.

Cherceri, L., Greenburg, A., and A. Eaton, 1998. Standard Methods for the Examination of Water and Waste Water, 20th edition, American Public Health Association, Washington, DC.

Chen, M., Soulsby, C., and P. Younger, 1999. Modelling the Evolution of Minewater Pollution at the Polkemmet Colliery, Almond Catchment, Scotland, Quarterly Journal of Engineering Geology, Vol. 32, p 351-362.

Christensen, T., Bjerg, P., Banwart, S., Jakobsen, R., Heron, G., and H. Albrechsten, 2000. Characterization of Redox Conditions in Groundwater Contaminant Plumes, Journal of Contaminant Hydrology, Vol. 45, p 165-241.

Cifelli, R., and H. Rauch, 1986. Dewatering Effects From Selected Underground Coal Mines in North-Central West Virginia, in Proceedings of Second Workshop on Surface Subsidence Due to Underground Mining, West Virginia University, Morgantown, WV, p 249-263.

Clark, W., 1967. Computing the Barometric Efficiency of a Well. Journal of Hydraulics Division, American Society of Civil Engineers, Vol. 93, p 93-98.

Cleveland, W., and I. Terpenning, 1982. Graphical Methods for Seasonal Adjustment, Journal American Statistical Association, Vol. 77, No. 377, p 52-62.

Cleveland, W., and S. Devlin, 1988. Locally Weighted Regression: An Approach to Regression Analysis by Local Fitting, Journal American Statistical Association. Vol. 83, No. 403, p 596610.

Collins, C., 1923. Pollution of Water Supplies by Coal Mine Drainage, in Engineering News Record, Vol. 91, No.16, p 638-641.

Coulson, A., Hendricks J., and J. Knapp, 1999, Cation Exchange and High Alkaline Mine Water A Case Study, in Proceedings West Virginia Surface Mine Drainage Task Force Symposium, Morgantown, WV, 11 pps.

Cravotta., C., 1994. Secondary Iron-Sulfate Minerals as Sources of Sulfate and Acidity: Geochemical Evaluation of Acidic Groundwater at a Reclaimed Surface Coal Mine in Pennsylvania, in Alpers, C. and Blowes, D. (eds), Environmental Geochemistry of Sulfide Oxidation, American Chemical Society Symposium Series 550, p 345-364. 
Cravotta., C., and C. Kirby, 2005. Net Alkalinity and Acidity 2: Practical Considerations, Applied Geochemistry, Vol. 20, p 1941-1964.

Cravotta, C., 2008a. Dissolved Metals and Associated Constituents in Abandoned Coal Mine Discharges, Pennsylvania, USA. Part 1: Constituent Quantities and Correlations, Applied Geochemistry 23, p 166-202.

Cravotta, C., 2008b. Dissolved Metals and Associated Constituents in Abandoned Coal Mine Discharges, Pennsylvania, USA. Part 2: Geochemical Controls on Constituent Concentrations, Applied Geochemistry, Vol. 23, p 203-226.

Crichton, A., 1927. Disposal of Drainage from Coal Mines, American Society of Civil Engineers Proceedings, Vol. 53, p 1656-1666.

Crouch, T., Collins, H., and J. Helgesen, 1980. Abandoned Subsurface Coal Mines as A Source of Water for Coal Conversion in Eastern Ohio. Report of Investigations 118, Ohio Dept. of Natural Resources, Division of Geological Survey, Columbus, OH.

Davis, A., and D. Ashenberg, 1989. The Aqueous Geochemistry of the Berkeley Pit, Butte, Montana, U.S.A., Applied Geochemistry Vol. 4, p 23-26.

Davis, J., and D. Kent, 1990. Surface Complexation Modeling in Aqueous Geochemistry, Reviews in Mineralogy, Mineral Water Interface Geochemistry, Mineralogical Society of America, Vol. 23, p 177-260.

Davis, R., and T. Rasmussen, 1993. A Comparison of Linear Regression With Clark's Method for Estimating Barometric Efficiency of Confined Aquifers. Water Resources Research, Vol. 29, No. 6, p 1849-1854.

Demchek, J., Skousen, J. and L. McDonald, 2004. Longevity of Acid Discharges From Underground Mines Located Above the Regional Water Table, Journal Environmental Quality Vol. 33, p 656-668.

Domenico, P., and F. Schwartz, 1990. Physical And Chemical Hydrogeology, John Wiley \& Sons Inc, New York, NY, 824 pps.

Donaldson, A., Presley, M., and J. Renton (eds.), 1979. Carboniferous Coal Guidebook, West Virginia Geological and Economic Survey, Morgantown, WV, 3 volumes.

Donaldson, A., Renton, J., Kimutis, R., Linger, D., and M. Zaidi, 1979. Distribution Pattern of Total Sulfur Content In the Pittsburgh Coal, Carboniferous Coal Guidebook, Bulletin B-37-3, West Virginia Geologic and Economic Survey, Morgantown, WV.

Donovan, J., Fletcher, J., Strager, M..and E. Werener, 1999. Hydrogeological and Geochemical Response to Mine Flooding in the Pittsburgh Coal Basin, Southern Monongahela River Basin, 
West Virginia University, National Mined Land Reclamation Center Project WV-132, Final report to US Environmental Protection Agency, 113 pps.

Donovan, J., Leavitt, B., and E. Werner, 2003. Long-Term Changes in Water Chemistry As a Result of Mine Flooding in Closed Mines of the Pittsburgh Coal Basin, USA, in Proceedings $6^{\text {th }}$ International Conference on Acid Rock Drainage, $p$ 869-875.

Donovan, J, and B. Leavitt, 2004. The Future of Mine-Water Discharges From Underground Coal Mines of The Pittsburgh Coal Basin, WV-PA, in R. I. Barnhisel (ed) Proc. Joint Conference American Society Mining and Reclamation $21^{\text {st }}$ Annual National Conference and $25^{\text {th }}$ West Virginia Surface Mine Drainage Task Force Symposium, p 518-528.

Dulong, F., Fedorko, N., Renton, J., and C. Cecil, 2002. Chemical and Mineralogical Analyses of Coal-Bearing Strata in the Appalachian Basin, US Geological Survey Open file report 02489.

Dzombzk, D., and F. Morel, 1990. Surface Complexation Modeling-Hydrous Ferric Oxide, John Wiley \& Sons, New York, NY, 393 pps.

Eary, E., and M. Williamson, 2006. Simulations of the Neutralizing Capacity of Silicate Rocks in Acid Mine Drainage Environments, in Proceedings 7th International Conference on Acid Rock Drainage, American Society for Surface Mining and Reclamation, p 564-577.

Eary, L., 1999. Geochemcial and Equilibrium Trends in Mine Pit Lakes, Applied Geochemistry, Vol. 14, p 963-987.

Edmunds, W., Berg, T., Sevon, W., Piotrowski, R., Heyman, L., and L Rickard, 1979. The Mississippian and Pennsylvanian (Carboniferous) Systems in the United States, Pennsylvania and New York. US Geological Survey Professional Paper 1110-B.

Ehrlich, H., 2002. Geomicrobiology, $4^{\text {th }}$ ed. Marcel Dekker, New York, NY, 768 pps.

EPRI, 2001, Omega Mine Injection Program: Monongalia County, West Virginia, report prepared by GAI Consultants for Electric Power Research Institute, Allegheny Energy Supply, and US Dept of Energy, EPRI, Palo Alto, CA, 169 pps.

Ferris, F., Tazaki, K., and W. Frye, 1989. Iron Oxides in Acid Mine Drainage Environments and Their Association With Bacteria, Chemical Geology, Vol. 74, p 321-330.

Filipek, L., Nordstrom, D. and W. Ficklin, 1987. Interaction of Acid Mine Drainage and Sediments of West Squaw Creek in the West Shasta Mining District, California, Environmental Science and Technology, Vol. 21, No. 4, p 388-396.

Freeze, R., and J. Cherry, 1979. Groundwater, Prentice Hall, Englewood Cliffs, NJ, 604 pps. 
Furbish, D., 1991. The Response of Water Level in a Well to a Time Series of Atmospheric Loading Under Confined Conditions. Water Resources Research, Vol.27, No. 4, p 557-568.

Gang, M., and D. Langmuir, 1974. Controls on Heavy Metals in Surface and Ground Waters, Affected by Coal Mine Drainage, in Proceedings $5^{\text {th }}$ Symposium Coal Mine Drainage Research, National Coal Association, Washington DC, p 39-69.

Giehyeon, L., Bigham, J., and G. Faure, 2002. Removal of Trace Metals by Coprecipitation with Fe, Al and Mn from Natural Waters Contaminated With Acid Mine Drainage in the Ducktown Mining District, Tennessee. Applied Geochemistry, Vol 17, No. 5, p 569-581.

Gleisner, M., Herbert, R., and P. Kockum, 2006. Pyrite Oxidation by Acidithiobacillus ferrooxidans at Various Concentrations of Dissolved Oxygen, Chemical Geology, Vol. 225, p 16-29.

Glover, H., 1983. Mine Water Pollution- An Overview of Problems and Control Strategies in the United Kingdom, Water Science Technology, Vol. 15, p 59-70.

Gray, T., Moran, T., Broschart, D., and G. Smith, 1998. Plan for Injection of Coal Combustion Byproducts into the Omega Mine for the Reduction of Acid Mine Drainage, in Proceedings of the Nineteenth Annual West Virginia Surface Mine Drainage Task Force Symposium. 9 p.

Growitz, D., 1967. Geochemistry of Mine Water, Northern Bituminous Field, West Virginia, MSc Thesis, West Virginia University, Morgantown, WV, 31 pps.

Gwin, Dobson, \& Foreman, 1972. West Branch Susquehanna River Mine Drainage Pollution Abatement Project, Operation Scarlift, prepared for Commonwealth of Pennsylvania, Harrisburg, PA, 181 p.

Gzyl, G. and D. Banks, 2007. Verification of the First Flush Phenomenon in Mine Water from Coal Mines in the Upper Silesian Coal Basin, Poland, Journal of Contaminant Hydrology, Vol. 92 p 66-86.

Hammack, R., and G. Watzlaf, 1990. The Effect of Oxygen on Pyrite Oxidation, in Proceedings Annual Meeting American Society for Surface Mining and Reclamation, Vol. 1, p 33-41.

Hammarstrom, J., Seal, R., Meier, A., and J. Kornfeld, 2005. Secondary Sulfate Minerals Associated with Acid Drainage in the Eastern US: Recycling of Metals and Acidity in Surficial Environments, Chemical Geology Vol. 215, p 407-431.

Hare, P., and R. Morse, 1997. Water-Level Fluctuations Due to Barometric Pressure Changes in an Isolated Portion of an Unconfined Aquifer, Ground Water, Vol. 35, No. 4, p 667-671.

Harrison, J., and V. Berkheiser, 1982. Anion Interactions With Freshly Prepared Hydrous Iron Oxides, Clays and Clay Minerals, Vol. 30, p 97-102. 
Hawkins, J., 1994. Assessment of Contaminant Load Changes Caused by Remining of Abandoned Coal Mines, in Proceedings International Land reclamation and Mine Drainage Conference and Third International Conference on the Abatement of Acidic Drainage, US Bureau of Mines Special Publication SP 06A-94, Vol.1, p 20-29.

Hawkins, J. 2004. Predictability of Surface Mine Spoil Hydrologic Properties in the Appalachian Plateau. Ground Water, Vol. 42, No.1, p 119-125.

Hawkins, J., Perry, E., and M. Dunn, 2005. Hydrologic Characterization of a Large Underground Mine Pool In Central Pennsylvania, in R. I. Barnhisel (ed) Proc. Conference American Society Mining and Reclamation 22st Annual National Conference, p 487-503.

Hedin, R., Nairn, R., and R. Kleinmann, 1994. Passive Treatment of Coal Mine Drainage, US Bureau of Mines IC 9389.

Helsel, D., and R. Hirsch, 1992. Statistical Methods in Water Resources, Elesevier Studies in Environmental Science 49, Amsterdam, Netherlands, 529 pps.

Hennen, R., and D. Reger, 1913. West Virginia Geological Survey County Reports, Marion, Monongalia and Taylor counties, Wheeling News Litho Co, Wheeling, WV, 844 pps..

Herlihy, A., and A. Mills, 1985. Sulfate Reduction in Freshwater Sediments Receiving Acid Mine Drainage, Applied and Environmental Microbiology, Vol. 49, No.1, p 179-186.

Hirsch, R., Slack, J. and R. Smith, 1982. Techniques of Trend Analysis for Monthly Water Quality Data. Water Resources Research, Vol. 18, No. 1, p 107-121.

Hirsch, R., and J. Slack, 1984. A Nonparametric Test for Seasonal Data With Serial Dependence, Water Resources Research, Vol. 20, No. 6, p 727-732.

Hirsch, R., Alexander, R., and R. Smith, 1991. Selection of Methods for the Detection and Estimation of Trends in Water Quality. Water Resources Research, Vol. 27, No. 5, p 803-813.

Hobba, W., 1981. Effects of Underground Mining and Mine Collapse on the Hydrology of Selected Basins in West Virginia. RI-33, West Virginia Geological and Economic Survey, Morgantown, WV.

Hobba, W., 1984. Ground-Water Hydrology of the Monongahela River Basin. US Geological Survey in cooperation with the West Virginia Dept of Natural Resources, One Sheet Atlas, Charleston, WV.

Hollyday, E., and S. McKenzie, 1973. Hydrology of the Formation and Neutralization of Acid Waters Draining From Underground Mines of Western Maryland, Report of Investigations 20, Maryland Geological Survey, Baltimore, MD, 50 pps. 
Hood, W., and A. Oertel, 1984. A Leaching Column Method for Predicting Effluent Quality from Surface Mines, in Proceedings 1984 Symposium on Surface Mining, Hydrology, Sedimentology and Reclamation, University of Kentucky, p 271-277.

Jakubick, A., Jenk, U., and R. Kahnt, 2002. Modelling of Mine Flooding and Consequences in the Mine Hydro-Geological Environment: Flooding of the Koenigstein Mine, Germany. Environmental Geology, Vol. 42, p 222-234.

Jambor, J., Nordstrom, D. and C. Alpers, 2000. Metal-sulfate Salts From Sulfide Mineral Oxidation, in Sulfate Minerals Crystallography, Geochemistry and Environmental Significance, Reviews in Mineralogy and Geochemistry Vol. 40, p 305-350.

Jambor, J., Dutrizac, J., Groat, L., and M. Raudsepp, 2002. Static Tests of Neutralization Potentials of Silicate and Aluminosilicate Minerals, Environmental Geology, Vol. 43, p 1-17.

James, C., 1984. Characterization of Water Quality For Deep Mine Effluents of Upper Freeport And Bakerstown Coal Mines In Central Preston County, West Virginia. MS Thesis, Dept of Geology and Geography, West Virginia University, Morgantown, WV, 157 pps.

Jaynes, D., Rogowski, A., and H. Pionke, 1984a. Acid Mine Drainage From Reclaimed Coal Strip Mines 1. Model Description, Water Resources Research, Vol. 20, No. 2, p 233-242.

Jaynes, D., Pionke, H., and A. Rogowski, 1984b. Acid Mine Drainage From Reclaimed Coal Strip Mines 2. Simulation Results of Model, Water Resources Research, Vol. 20, No. 2, p 243-250.

Jerz, J., and D. Rimstidt, 2004. Efflorescent Iron Sulfate Minerals: Paragenesis, Relative Stability, and Environmental Impact, American Mineralogist Vol. 88, p 1919-1932.

Johnson, C., and J. Skousen, 1995. Minesoil Properties of 15 Abandoned Mine land Sites in West Virginia, Journal of Environmental Quality, Vol. 24, p 635-643.

Jonsson, J., Persson, P., Sjoberg, S., and L. Lovgren, 2005. Schwertmannite Precipitated from Acid Mine Drainage: Phase Transformation, Sulphate Release and Surface Properties, Applied Geochemistry, Vol. 20, p 179-191.

Kaires, C., Capo, R., and G. Watzlaf, 2005. Chemical and Physical Properties of Iron Hydroxide Precipitates Associated with Passively Treated Coal Mine Drainage in the Bituminous Region of Pennsylvania and Maryland, Applied Geochemistry, Vol. 20, p 1445-1460.

Karathanasis, A., and Y. Thompson, 1995. Mineralogy of Iron Precipitates in a Constructed Acid Mine Drainage Treatment Wetland, Soil Science Society of America Journal. Vol. 59, p 17731781. 
Kendorski, F., 1993, Effect of High Extraction Mining on Surface and Ground Waters, in Proceedings $12^{\text {th }}$ Conference on Ground Control in Mining, West Virginia University, Morgantown, WV, p 412-425.

Kernic, J. 1999. Barnes and Tucker Company, Lancashire 15 and 20 Mines, Cambria County, Mine Pool and Discharge Report, unpublished report prepared for Pennsylvania Dept Environmental Protection, McMurray, PA, 11 pages.

Kim, J., Kim, S., and K. Tazaki, 2002. Mineralogical Characterization of Microbial Ferrihydrite and Schwertmannite, and Non-Biogenic Al-Sulfate Precipitates From Acid Mine Drainage in the Donghae Mine Area, Korea, Environmental Geology Vol. 42, p 19-31.

Kim, J., and S. Kim, 2003. Environmental, Mineralogical, and Genetic Characterization of Ocherous and White Precipitates from Acid Drainages in Taebaeg, Korea, Environmental Science and Technology, Vol. 37, No. 10, p 2120-2126.

Kirby, C., and C. Cravotta, 2005. Net Alkalinity and Acidity 1: Theoretical Considerations. Applied Geochemistry, Vol. 20, p 1920-1940.

Kittrick, J., Fanning, D., and L Hossner (eds), 1982. Acid Sulfate Weathering, Soil Science Society of America Special Publication 10, 234 pps.

Kleinmann, R., Hornberger, R., Leavitt, B., and D. Hyman, 2000. Introduction and Recommendation, The Nature of the Problem, In Prediction of Water Quality at Surface Coal Mines, Acid Drainage Technology Initiative, Prediction Workgroup, National Mined Land Reclamation Center, West Virginia University, Morgantown, WV, 254 pps.

Koryak, M., Stafford, L., and R. Reilly, 2004. Declining Intensity of Acid Mine Drainage in The Northern Appalachian Bituminous Coal Fields: Major Allegheny River Tributaries, Journal American Water Resources Association, Vol. 40, No. 3, p 677-689.

Kozar, M., and M. Mathes, 2001. Aquifer Characteristics Data for West Virginia, US Geological Survey Water Resources Investigation Report 01-4036.

Ladwig, K., Erickson, P., Kleinmann, R., and E. Posluszny, 1984. Stratification in Water Quality in Inundated Anthracite Mines. US Bureau of Mines, RI 8837.

Lamminen, M., Wood, J., Walker, H., Chin,Y., He, Y., and S. Traina, 2001. Effect of Flue Gas Desulfurization (FGD) By-Product on Water Quality At An Underground Mine, Journal Environmental Quality, Vol. 30, p 1371-1381.

Langmuir, D., and D. Whittemore, 1971. Variations in the Stability of Precipitated Ferric Oxyhydroxides, in Nonequilibrium Systems in Natural Water Chemistry, Advances in Chemistry Series 106, American Chemical Society, p 209-234. 
Langmuir, D., 1997, Aqueous Environmental Chemistry. Prentice Hall, Englewood Cliffs, NJ, 600 pps.

Lappako, K., and D. Anston, 2006, Pyrite Oxidation Rates From Humidity Cell Testing Of Greenstone Rock, in Proceedings 7th International Conference on Acid Rock Drainage (ICARD), American Society of Mining and Reclamation, p 1007-1025.

Larsen, F., and D. Postma, 1997. Nickel Mobilization in a Groundwater Well Field: Release by Pyrite Oxidation and Desorption from Manganese Oxides. Environmental Science and Technology, Vol. 31, No. 9, p 2589-2595.

Leavitt, B., 1993. Discharge Potential of the Fairmont Mine-pool, Unpublished Internal Report for Consol Energy Inc, Pittsburgh, PA.

Leavitt, B., 1997, AMD in the Monongahela Basin, in Proceedings $18^{\text {th }}$ West Virginia Surface Mine Drainage Task Force Symposium, West Virginia Mining and Reclamation Association.

Lessing, P., and W. Hobba, 1981. Abandoned Coal Mines in West Virginia as Sources of Water Supplies, West Virginia Geological and Economic Survey, Morgantown, WV, Circular C24, 24 pps.

Levenspiel, O., 1972. Chemcial Reaction Engineering, Advances in Chemistry Series, John Wiley \& Sons Inc., New York, NY, 668 pps.

Lindberg, R., and D. Runnells, 1984. Ground Water Redox Reactions: An Analysis of Redox State Applied to Eh Measurements and Geochemical Modeling. Science, Vol. 225 p 925-927.

Liu, J., Elsworth, D., and R. Matetic, 1997. Evaluation of the Post-Mining Groundwater Regime Following Longwall Mining. Hydrological Processes, Vol. 11, p 1945-1961.

Lloyd, D., 2004. personal communication, unpublished water quality data for Lancashire 15 mine-pool and associated mines, Lloyd Environmental Services, Commodore, PA.

Lowson, R., 1982. Aqueous Oxidation of Pyrite by Molecular Oxygen, Chemical Reviews, Vol. 82, No. 5, p 461-497.

Macalady, D., Langmuir, D., Grundl, T., and A. Elzerman, 1990. Use of Model Generated Fe ${ }^{3+}$ Ion Activities to Compute Eh and Ferric Oxyhydroxide Solubilities in Anaerobic Systems, in Chemical Modeling in Aqueous Systems, American Chemical Society Symposium Series 416, p 350-367.

Mack, B., and J. Skousen, 2008. Acidity Decay Curves of 40 Above Drainage Mines in West Virginia, in R. I. Barnhisel (ed) Proc. American Society of Mining and Reclamation National Meeting, p 612-627. 
McCarty, D., Moore, J., and A. Marcus, 1998. Mineralogy and Trace Element Association in An Acid Mine Drainage Iron Oxide Precipitate: Comparison of Selective Extractions, Applied Geochemistry, Vol. 13, p 165-176.

McCoy, K., 2002. Estimation of Vertical Infiltration into Deep Pittsburgh Coal Mines of WV-PA: A Fluid Mass Balance Approach, MS Thesis, West Virginia University, Dept of Geology and Geography, 151 pps.

McCue, J., Lucke, J. and H. Woodward, 1939. Limestones of West Virginia, West Virginia Geological Survey, Morgantown, WV, Vol. XII.

McCullogh, C., Diamond, W., Bench, B., and M. Duel, 1975. Selected Geologic Factors Affecting Mining of the Pittsburgh Coal bed, US Bureau of Mines RI 8093.

McElroy, T., 1998. Groundwater Resources of Cambria County Pennsylvania, Water Resources Report 67, Pennsylvania Dept of Conservation and Natural Resources, Bureau of Topographic and Geologic Survey, Harrisburg, PA. 49pps.

McKibben, M., and H. Barnes, 1986. Oxidation of Pyrite in Low Temperature Acidic Solutions: Rate laws and Surface Textures, Geochimica et Cosmochimica Acta, Vol. 50, No. 7, p 15091520.

Mehnert, E., Valocchi, A., Heidari, M., Kapoor, S. and P. Kumar, 1999. Estimating Transmissivity from the Water Level Fluctuations of a Sinusoidally Forced Well, Ground Water, Vol. 37, No. $6, \mathrm{p} 855-860$.

Michael Baker Consulting Engineers, 1978. Operation Scarlift Report SL-185, Blacklick Creek Watershed, Indiana Cambria Counties, prepared for Pennsylvania Dept of Environmental Resources, Harrisburg, PA, 152 p.

Miller, A., Sibrell, P., and T. Wildeman, 2007. Comparison of Sludge Characteristics Between Lime and Limestone/Lime Treatment of Acid Mine Drainage, in Proceedings National Meeting of the American Society of Mining and Reclamation, p 504-513.

Morin, K., Cherry, J., Dave, N., Lim, T., and A. Vivyurka, 1988. Migration of Acidic Ground Water Seepage From Uranium Tailings Impoundments, 1, Field Study and Conceptual Hydrogeochemical Model. Journal Contaminant Hydrology, Vol. 2, p 271-303.

Morse, J., Millero, F.,Cornwell, J., and D. Rickard, 1987. Chemistry of the Hydrogen Sulfide and Iron Sulfide Systems in Natural Waters, Earth Science Reviews, Vol. 24, p 1-42.

Morth, A., Smith, E., and K. Shumate, 1972. Pyrite Systems: A Mathematical Model, US EPA R272-002, 169 pps.

Mozley, P., 1989. Relation Between Depositional Environment and the Elemental Composition of Early Diagenetic Siderite, Geology, Vol. 17, p 704-706. 
Mugunthan, P., McDonough, K., and D. Dzombak, 2004. Geochemical Approach to Estimate the Quality of Water Entering Abandoned Underground Coal Mines, Environmental Geology, Vol. 45, p 769-780.

Nicholson, R., Gillham, R., and E. Reardon, 1988. Pyrite Oxidation in Carbonate-buffered Solution: 1. Experimental Kinetics, Geochimica et Cosmochimica Acta, Vol. 52, No. 5, p 1077-1085.

Moses, C., and J. Herman, 1991. Pyrite Oxidation at Circumneutral pH, Geochimica et Cosmochimica Acta, Vol. 55, No. 2, p 471-482.

Nordstrom, D., Jenne, E., and J. Ball, 1979. Redox Equilibria in Acid Mine Waters. in Chemical Modeling in Aqueous Systems, American Chemical Society, Vol. 93, p 51-79.

Nordstrom, D., 1982a. Aqueous Pyrite Oxidation and the Consequent Formation of Secondary Iron Minerals, in Acid Sulfate Weathering, Soil Science Society of America Special Publication 10, 234 pps.

Nordstrom, D., 1982b, The Effect of Sulfate on Aluminum Concentrations in Natural Waters, Some Stability Relationships in the System $\mathrm{Al}_{2} \mathrm{O}_{3}-\mathrm{SO}_{3}-\mathrm{H}_{2} \mathrm{O}$ at $298 \mathrm{~K}$, Geochemica et Cosmochimica Acta, Vol. 46, p 681-692.

Nordstrom, D., and F. Wilde, 1998, Oxidation Reduction Potential (Electrode Method), US Geological Survey Techniques of Water Resources Investigations, Book 9, Section 6.5.

Nordstrom, D., 2000. Aqueous Redox Chemistry and the Behavior of Iron in Acid Mine Water, in Proceedings of the Workshop on Monitoring Oxidation-Reduction Processes for Ground water Restoration. US EPA. EPA 600/R-02/002.

Nordstrom, D., 2009. Pitfalls and Limitations of Mineral Equilibrium Assumptions for Geochemical Modeling of Water-Rock Interactions at Mine Sites, in Proceedings $8^{\text {th }}$ International Conference on Acid Rock Drainage, Skelleftea, Sweden.

Nuhfer, E., 1967. Efflorescent Minerals Associated With Coal. MSc Thesis, West Virginia University, Morgantown, WV, 74 pps.

Nuttall, C., and P. Younger, 2004. Hydrochemcial Stratification in Flooded Underground Mines: An Overlooked Pitfall, Journal Of Contaminant Hydrology, Vol. 69, p 101-114.

O’Neill, B., and J. Barnes, 1979. Properties and Uses of Shales and Clays, Southwestern Pennsylvania. Mineral Resources Report 77, Pennsylvania Dept. of Conservation and Natural Resources, Bureau of Topographic and Geologic Survey, Harrisburg, PA.

Palandri, J., and Y. Kharaka, 2004. A Compilation of Rate Parameters of Water Mineral Interaction Kinetics, US Geological Survey Open File Report 2004-1068. 
Pantelis, G., and A. Ritchie, 1991. Macroscopic Transport Mechanisms as a Rate-limiting Factor in Dump Leaching of Pyritic Ores, Applied Mathematical Modelling, Vol. 15, No. 3, p 136143.

Parfitt, R., and R. Smart, 1978. The Mechanism of Sulfate Adsorption on Iron Oxides. Soil Science Society of America Journal, Vol. 42, p 48-50.

Parizek, R., 1974. Prevention of Coal Mine Drainage Formation by Well Dewatering, The Pennsylvania State University, Dept of Geology and Geophysics, Special Research Report SR52.

Parkhurst, D., and C. Appelo., 1999. User's Guide to PHREEQC (Version 2)- A Computer Program for Speciation, Batch-Reaction, One-Dimensional Transport, and Inverse Geochemical Calculations, US Geological Survey Water Resources Investigation Report 994259.

Peng, S., 1986. Coal Mine Ground Control, 2nd ed., John Wiley \& Sons, New York, NY, 459 pps.

Perry, E., 2001. Modeling Rock-Water Interactions in Flooded Underground Coal Mines, Northern Appalachian Basin, Geochemistry: Exploration, Environment, Analysis, Vol. 1, 2001, p 61-70.

Perry, E., and H. Rauch, 2004. Long Term Water Quality Trends in a Partly Flooded Underground Mine, in R. I. Barnhisel (ed) Proc. Joint Conference of American Society of Mining and Reclamation $21^{\text {st }}$ Annual National Conference and $25^{\text {th }}$ West Virginia Surface Mine Drainage Task Force Symposium p 1438-1459.

Perry, E., J. Hawkins, M. Dunn, R. Evans and J. Felbinger, 2005. Water Quality Trends in a Flooded 35 Year Old Mine-pool. in R. I. Barnhisel (ed) Proc. American Society Mining and Reclamation $22^{\text {st }}$ Annual National Conference, p 904-920.

Postma, D., and R. Jakobsen, 1996. Redox Zonation: Equilibrium Constraints on the $\mathrm{Fe}(\mathrm{III}) / \mathrm{SO}_{4}$ Reduction Interface, Geochemica Cosmochemica Acta, Vol. 60, p 3169-3175.

Rasmussen, T. and L. Crawford, 1997. Identifying and Removing Barometric Pressure Effects in Confined and Unconfined Aquifers, Ground Water, Vol. 35, No. 3, p 502-511.

Renton, J., 1979. The Mineral Content of Coal. Carboniferous Coal Guidebook. Bulletin B-37-1. West Virginia Geologic and Economic Survey, Morgantown, WV.

Rhem, B., Groenwald, G,. and K. Morin, 1980. Hydraulic Properties of Coal and Related Materials, Northern Great Plains, Ground Water, Vol. 20, p 217-236.

Rimstidt, J., and D.Vaughan, 2003, Pyrite Oxidation: A State of the Art Assessment of the Reaction Mechanism, Geochemica et Cosmochimica Acta, Vol. 67, No.5, p 873-880. 
Ritzi, R., Soroosh, S. and P. Hsieh, 1991. The Estimation of Fluid Flow Properties From the Response of Water Levels in Wells to Combined Atmospheric and Earth Tide Forces, Water Resources Research, Vol. 27, No. 5, p 883-893.

Robertson, J., Tremblay, G., and W. Fraser, 1997. Subaqueous Tailings Disposal: A Sound Solution for Reactive Tailings Disposal, in Proceedings of the Fourth International Conference on Acid Rock Drainage, Vol. 3, 1027-1041.

Roh, Y., Zhang, C., Vali, H., Lauf, R., Zhou, J., and T. Phelps, 2003. Biogeochemical And Environmental Factors In Fe Biominerlaization: Magnetite And Siderite Formation, Clays and Clay Minerals, Vol. 51, No. 1, p 83-95.

Rojstaczer, S., 1988. Determination of Fluid Flow Properties From the Response of Water Levels in Wells to Atmospheric Loading, Water Resources Research, Vol. 24, No. 11, p 1927-1938.

Rose, A., and C. Cravotta, 1998. Geochemistry of Coal Mine Drainage, in Coal Mine Drainage Prediction and Pollution Prevention in Pennsylvania, Pennsylvania Dept. Environmental Protection, Harrisburg, PA.

Rose, S., and W. Elliot, 2000. The Effects of pH Regulation on the Release of Sulfate From Ferric Precipitates Formed in Acid Mine Drainage, Applied Geochemistry, Vol. 15, p 27-34.

Ruppert, L., Tewalt, S. , and L. Bragg, 1997. Map Showing Areal Extent of Pittsburgh Coal Bed and Horizon and Mined areas of the Pittsburgh coal bed in Pennsylvania, Ohio, West Virginia and Maryland, digitally compiled by Tully, J., Pierce, J., Weller, A., and J. Yarnel, U.S. Geological Survey Open File Report 96-280.

Ruppert, L. , Tewalt, S. , Bragg, L. and R. Wallack. 1999. A Digital Resource Model of the Upper Pennsylvanian Pittsburgh Coal Bed, Monongahela Group, Northern Appalachian Basin Coal Region, USA. International Journal of Coal Geology, Vol. 41, p 3-24.

Sames, G., and N. Moebs, 1989. Hillseam Geology and Roof Instability near Outcrop in Eastern Kentucky Drift Mines, US Bureau of Mines RI 9267.

Sams, J., and K. Beer, 1999. Effects of Coal Mine Drainage on Stream Quality in the Allegheny and Monongahela River Basins- Sulfate Transport and Trends, US Geological Survey Water Resources Investigation Report 99-4208.

Sahu, P., 2004. Use of Time Series, Barometric and Tidal Analyses to Conceptualize and Model Flow in an Underground Mine, M.S. Thesis, Ohio University Dept. Geological Sciences, Athens, $\mathrm{OH}, 172 \mathrm{pps}$.

Schmidt, R., 1985. Fracture Zone Dewatering To Control Ground Water Inflow in Underground Mines, US Bureau of Mines RI 8981. 
Schnoor, J., 1990. Kinetics of Chemical Weathering: A Comparison of Laboratory and Field Weathering Rates, in Aquatic Chemical Kinetics, Reaction Rates of Processes in Natural Waters, Wiley Interscience Books, New York, NY, 557 pps.

Schoonen, M., and H. Barnes, 1991. Reactions Forming Pyrite and Marcasite From Solution II: Via FeS Precursors Below 100 C, Geochemca Cosmochemica Acta, Vol 55, p 1501-1514.

Schwertmann, U., and R. Taylor, 1977. Iron Oxides. in Minerals in Soil Environments, Soil Science Society of America, p 379-438.

Seo, H., 2001. Modeling the Influence of Changes in Barometric Pressure On Ground Water Levels in Wells, Environmental Geology, Vol. 41, p 155-166.

Sheetz, B., White, W., Shollenberger, D., and R. Hornberger, 2009. Evaluation of Particle Size and Surface Effects. in Hornberger, R., and K. Brady (eds), Development and Interpretation of the ADTI-WP2 Leaching Column Method (Kinetic Test Procedure for the Prediction of Coal Mine Drainage Quality), Final report submitted to US Office of Surface Mining, Washington D.C.

Skousen, J., McDonald, L., Mack, B., and J. Demchak, 2006. Water Quality From Above Drainage Mines Over A 35 Year Period. in Proceedings 7th International Conference on Acid Rock Drainage, American Society of Mining and Reclamation, p 2044-2054.

Smith, E., and K. Shumate, 1970. Sulfide to sulfate reaction mechanism, Water Pollution Control Res. Series 14010 US Federal Water Quality Administration.

Smith, K., 1999. Metal Sorption on Mineral Surfaces: An Overview with Examples Relating Mineral Deposits. in The Environmental Geochemistry of Mineral Deposits, Part A, Processes Methods and Health Issues, Plumlee, G., and M Logsdon (eds), Review in Economic Geology, 6A, p 161-182.

Smith, M., Brady, K., Perry, E., and J. Tarantino, 2000. Evaluation of Mining Permits Resulting in Acid Mine Drainage in Pennsylvania 1987-1996: A Post Mortem Study, in Proceedings Fifth International Conference on Acid Rock Drainage, Vol. 1, p 713-719.

Sobek, A., Schuller, W., Freeman, J. and R. Smith., 1978. Field and Laboratory Methods Applicable To Overburdens and Minesoils. U.S Environmental Protection Agency EPA600/278-054.

Stipp, S., 1990. Speciation in the $\mathrm{Fe}(\mathrm{II})-\mathrm{Fe}(\mathrm{III})-\mathrm{SO}_{4}-\mathrm{H}_{2} \mathrm{O}$ System at $25^{\circ} \mathrm{C}$ and Low pH: Sensitivity of an Equilibrium Model to Uncertainties, Environmental Science and Technology, Vol. 24, No. 5, p 699-706.

Stumm, W., and J. Morgan, 1981. Aquatic Chemistry, An Introduction Emphasizing Chemical Equilibria in Natural Waters, Wiley Interscience Books, New York, NY, 780 pps. 
Stoertz, M., Hughes, M., Wanner, N., and M. Farley, 2001. Long-term Water Quality Trends at a Sealed, Partially Flooded Underground Mine, Environmental and Engineering Geoscience, Vol. 7, No.1, p 51-65.

Stoner, J., Williams, D., Buckwalter, T., Felbinger, J. and K. Pattison, 1987. Water Resources and the Effects of Coal Mining, Greene County, Pennsylvania. Pennsylvania Geological Survey Water Resources Report 63, Harrisburg, PA.

Tieman, G., and H. Rauch, 1987. Study of Dewatering Effects at an Underground Longwall Mine Site in the Pittsburgh Seam of Northern Appalachia, in Proceedings Eastern Coal Mine Geomechanics, Bureau of Mines Technology Seminar, US Bureau of Mines IC 9137.

To, T., Nordstrom, D., Cunningham, K., Ball, J., and R. McCleskey, 1999. New Method for the Direct Determination of Dissolved Fe(III) Concentration in Acid Mine Waters, Environmental Science and Technology, Vol. 33, No. 5, p 807-813.

United Mine Workers of America, http://www.umwa.org/.

US Environmental Protection Agency, 1986. Quality Criteria For Water 1986. Office of Water Regulation and Standards EPA 440/5-86-001.

US Environmental Protection Agency. 1986b. Aluminum, Office of Water Regulation and Standards EPA 440/5-86-008.

US Geological Survey, National Water Information System (NWIS), http://waterdata.usgs.gov/nwis/qwdata .

Van Breeman, N., 1973. Dissolved Aluminum in Acid Sulfate Soils and Acid Mine Waters, Soil Science Society America Proceedings, Vol. 37, p 694-697.

Watzlaf, G., 1992. Pyrite Oxidation in Saturated and Unsaturated Coal Waste, in Proceedings of the 1992 National Meeting of the American Society for Surface Mining and Reclamation, p 191-205.

Welch, S., Kirste, D., Christy, A., Beavis, F., and F. Beavis, 2008. Jarosite Dissolution II, Reaction Kinetics, Stoichiometry and Acid Flux, Chemical Geology, Vol. 254, p 73-86.

West Virginia Geological and Economic Survey, 2002, Trace Elements in West Virginia Coals, http://www.wvgs.wvnet.edu/www/datastat/te/index.htm.

Williams, D., Felbinger, J., and P. Squilace, 1993. Water Resources and the Hydrologic Effects of Coal Mining in Washington County, Pennsylvania, US Geological Survey Open File Report 89-620.

Williamson, M., and J. Rimstidt, 1994. The Kinetics and Electrochemical Rat-Determining Step of Aqueous Pyrite Oxidation, Geochemica et Cosmochimica Acta, Vol. 58, No. 24, p 5443-5454. 
Winters, W., 2000. Hydrologic and Geochemical Evolution of a Bituminous Coal Basin: Irwin Syncline, Westmoreland County, Pennsylvania, Thesis, University of Pittsburgh, Geology and Planetary Science Dept, Pittsburgh, PA.

Winters, W., and R. Capo, 2004. Ground Water Flow Parameterization of an Appalachian Coal Mine Complex, Ground Water, Vol. 5, No. 42, p 700-710.

Wood, S., Younger, P. and N. Robins, 1999. Long-term changes in the Quality of Polluted Minewater Discharges from Abandoned Underground Coal Workings in Scotland, Quarterly Journal of Engineering Geology, Vol. 32, p 69-79.

Wunderly, M., Blowes, D., Frind, D., and C. Ptacek, 1996. Sulfide Mineral Oxidation and Subsequent Reactive Transport of Oxidation Products in Mine Tailings Impoundments: A Numerical Model, Water Resources Research, Vol. 32, No. 10, p 3173-3187.

Wyrick, G., and J. Borchers, 1981. Hydrologic Effects of Stress Relief Fracturing in an Appalachian Valley, US Geological Survey Water Supply Paper 2177.

Younger, P., 1997. The Longevity of Minewater Pollution: A Basis for Decision Making, The Science of the Total Environment, Vol. 194\&195, p 457-466.

Younger, P., 2000. Predicting Temporal Changes in Total Iron Concentrations in Waters Flowing From Abandoned Deep Mines: A First Approximation, Journal of Contaminant Hydrology, Vol. 44, p 47-69.

Younger, P., and P. Thorn, 2006. Predictions and Reality: Generation of Strongly Net-Acidic Mine waters Through Flooding of Underground Coal Mine Workings With Limestone Roof Strata, Blenkinsopp Colliery (Northumberland, UK), in Proceedings 7th International Conference on Acid Rock Drainage, American Society of Mining and Reclamation, p 25422557.

Yu, J., Heo., B, Choi, I., Pil, J., and H. Chang, 1999. Apparent Solubilities of Schwertmannite and Ferrihydrite in Natural Streams Polluted by Mine Drainage, Geochemica et Cosmochemica Acta, Vol. 63, p 3407-3416.

Zhu, C., and D. Burden, 2001. Mineralogical Compositions of Aquifer Matrix as Necessary Initial Conditions in Reactive Contaminant Transport Models. Journal of Contaminant Hydrology, Vol 51, p 145-161.

Zodrow E., and K. McCandlish, 1978. Hydrated Sulfates in the Sydney Coalfield, Cape Breton, Nova Scotia, Canadian Mineralogist, Vol. 16, p 17-22.

Zodrow E., Wiltshire, J., and K. McCandlish, 1979. Hydrated Sulfates in the Sydney Coalfield, Cape Breton, Nova Scotia.II, Pyrite and Alteration Products, Canadian Mineralogist, Vol. 17, p 63-70. 
Zodrow E., 1980. Hydrated Sulfates from the Sydney Coalfield, Cape Breton Island, Nova Scotia, Canada, the Copiapite Group, American Mineralogist, Vol. 65, p 961-967. 
$\underline{\text { Appendix A }}$

\section{LONG-TERM WATER QUALITY TRENDS IN A PARTLY FLOODED UNDERGROUND COAL MINE}

2004 National meeting of the American Society of Mining and

Reclamation and the $25^{\text {th }}$ West Virginia Surface Mine Drainage Task Force, April 18-24, 2004. Published by ASMR, 3134 Montavesta Rd., Lexington KY 40502 


\title{
LONG-TERM WATER QUALITY TRENDS IN A PARTLY FLOODED UNDERGROUND COAL MINE ${ }^{1}$
}

\author{
Eric F. Perry ${ }^{2}$ and Henry W. Rauch
}

Water quality trends for an 8 year period were analyzed for two acidic springs draining from a partially flooded underground coal mine, and the composite mine-pool outflow of 10 discharges. Time series analysis was used to separate long-term data trends from short-term noise. Short-term variation usually constituted less than 30 percent of the trend concentration. Exponential functions were fitted to the trend data, and time estimates $\left(\mathrm{t}_{50 \mathrm{C}}\right)$ for concentration to decline $50 \%$ were generated for Total Acidity, $\mathrm{Fe}, \mathrm{Al}, \mathrm{SO}_{4}, \mathrm{Co}, \mathrm{Ni}$, and $\mathrm{Zn}$ concentrations. Iron decline is similar at two springs with an estimated $t_{50 C}$ of 60 months. Sulfate $t_{50 C}$ is about 60 to 70 months at one spring and for the aggregate mine-pool. Cobalt, Ni and $\mathrm{Zn}$ declines are more rapid, with estimated $\mathrm{t}_{50 \mathrm{C}}$ of about 30 to 50 months. Aluminum decline is 2 to 3 times slower than rates for other parameters, and mine-waters are near apparent equilibrium for the mineral jurbanite, $\mathrm{Al}\left(\mathrm{SO}_{4}\right) \mathrm{OH}^{*} 5 \mathrm{H}_{2} \mathrm{O}$. Constituent fluxes are controlled mostly by flow, and decline with time. Estimated time $\left(\mathrm{t}_{50 \mathrm{~F}}\right)$ for flux to decline $50 \%$ for the composite mine-pool outflow is about 85 months for Fe, 80 months for $\mathrm{SO}_{4}$ and 105 months for acid flux. Fluxes are 1.5 to 3 times greater in spring than fall, and reflect seasonal distribution of precipitation and recharge to the mine. Most of the improvement in mine-pool discharge results from declining pollutant concentrations. These trends suggest a slow decline in pyrite oxidation, with significant water quality improvement occurring on the order of years to decades.

Additional Key Words: acidity, flux, jurbanite.

${ }^{1}$ Paper was presented at the 2004 National meeting of the American Society of Mining and Reclamation and the $25^{\text {th }}$ West Virginia Surface Mine Drainage Task Force, April 18-24, 2004. Published by ASMR, 3134 Montavesta Rd., Lexington KY 40502

${ }^{2}$ Eric Perry is a Hydrologist, Office of Surface Mining, 3 Parkway Center, Pittsburgh PA 15220.

Henry Rauch is Professor of Geology, Dept of Geology and Geography, Box 6300, West Virginia University, Morgantown WV 26506-6300. 


\section{Introduction}

Underground coal mining in Appalachia sometimes results in post-mining water pollution. Oxidation of iron disulfide minerals like pyrite generates strong acidity, low $\mathrm{pH}$, elevated concentrations of metals and sulfate, and dissolution of carbonate and silicate minerals (Nordstrom, 1982; Rose and Cravotta, 1998). The longevity of pollutional discharges from abandoned underground mine works is a function of hydrogeologic setting, and geochemistry of the residual coal and associated rocks. This paper addresses time-dependent decline behavior, and mineralogical solubility controls on water composition from a partially flooded, closed mine that is located above the local base level drainage ("above-drainage mine"). Concentrations of $\mathrm{Al}, \mathrm{Fe}$, $\mathrm{SO}_{4}$, and trace elements $\mathrm{Ni}, \mathrm{Co}, \mathrm{Zn}$ are declining through time, and respond to variations in flow, seasonality and reclamation activities. The time-dependent decline of dissolved constituents may represent depletion of stored acid products including metal sulfate salts, decreased availability of sulfide minerals, in situ neutralization, or less efficient leaching. Concentrations of some elements, including $\mathrm{Al}$ and $\mathrm{SO}_{4}$, may be controlled by precipitation/dissolution solubility reactions of specific minerals.

\section{Geologic Setting}

The Omega mine is located about $10 \mathrm{~km}$ south of Morgantown, West Virginia in the Upper Freeport coal bed. This coal is stratigraphically located at the top of the Allegheny Group (Hennen and Reger, 1913). Coal thickness is commonly about $1.2 \mathrm{~m}$, with a shale parting. The Bolivar fireclay, a hard siliceous mudrock, immediately underlies the coal bed. At this mine, the Uffington shale overlies the coal bed and is commonly less than $0.6 \mathrm{~m}$ thick. The Mahoning and Buffalo sandstones comprise most of the overburden above the Uffington shale. These rocks may reach a combined thickness exceeding $30 \mathrm{~m}$, and where exposed at the mine faceup, they display prominent vertical fractures. Maximum overburden thickness at the Omega mine is about $52 \mathrm{~m}$.

The West Virginia Geological and Economic Survey (2002) reports an average total sulfur content of about $2.5 \%$ and average pyritic sulfur content of about $1.7 \%$ for the Upper Freeport coal bed. Two core samples of Upper Freeport coal retrieved from the Omega mine complex contained over 5 and $12 \%$ total sulfur, respectively (EPRI, 2001).

The Omega mine is contained within a broad ridgetop on the western flank of the Chestnut Ridge anticline, and strata dip about $11 \%$ to the northwest. After closure, the mine partially flooded, and the general ground water flow pattern within the mine works is inferred to be in the direction of dip.

\section{Site History}

Coal was extracted by room and pillar methods from the Upper Freeport coal bed in about 69.8 ha of mine works until mine closure in 1989. Recovery ranged from 50\% in first mined areas, to over $70 \%$ in areas of second mining. Average mining height was about $1.3 \mathrm{~m}$. In the early 1990's, acid drainage began seeping from several locations along the coal cropline (Figure 1). Mine drainage was collected and treated after several lateral boreholes were drilled into the northern mine works to divert mine-water away from a section adjoining a stream with a public water supply. Treatment sludge was initially injected into the mine works for disposal. The West Virginia 
Department of Environmental Protection (WVDEP) assumed control of the site in the mid 1990's and currently treats the drainage. WVDEP discontinued sludge injection and currently disposes of the material offsite. WVDEP also installed a series of pipelines and manholes to more easily and securely collect, sample, measure, and convey mine-water to the treatment facility. In some instances, several adjacent seeps were combined into a single monitoring point. In 1998, a cooperative state, federal andoprivately funded grouting project was initiated to reduce or abate acidic discharges in the "North Lobe" (Figure 1) of the mine (Gray et al., 1998; EPRI, 2001),. This area comprises about $10.5 \mathrm{Ha}$, or $15 \%$ of the mined area, but was estimated to be discharging about $55 \%$ of the acid load (EPRI, 2001). About $61,000 \mathrm{~m}^{3}$ of grout mix containing fluidized-bed combustion ash, flyash and cement were injected in the North Lobe. Subsequent drilling and borehole camera observations confirmed that, in general, the grout mixture provided near complete filling of mine voids. Water quality remained poor after grouting; however, flow, and consequently acid load decreased (EPRI, 2001).

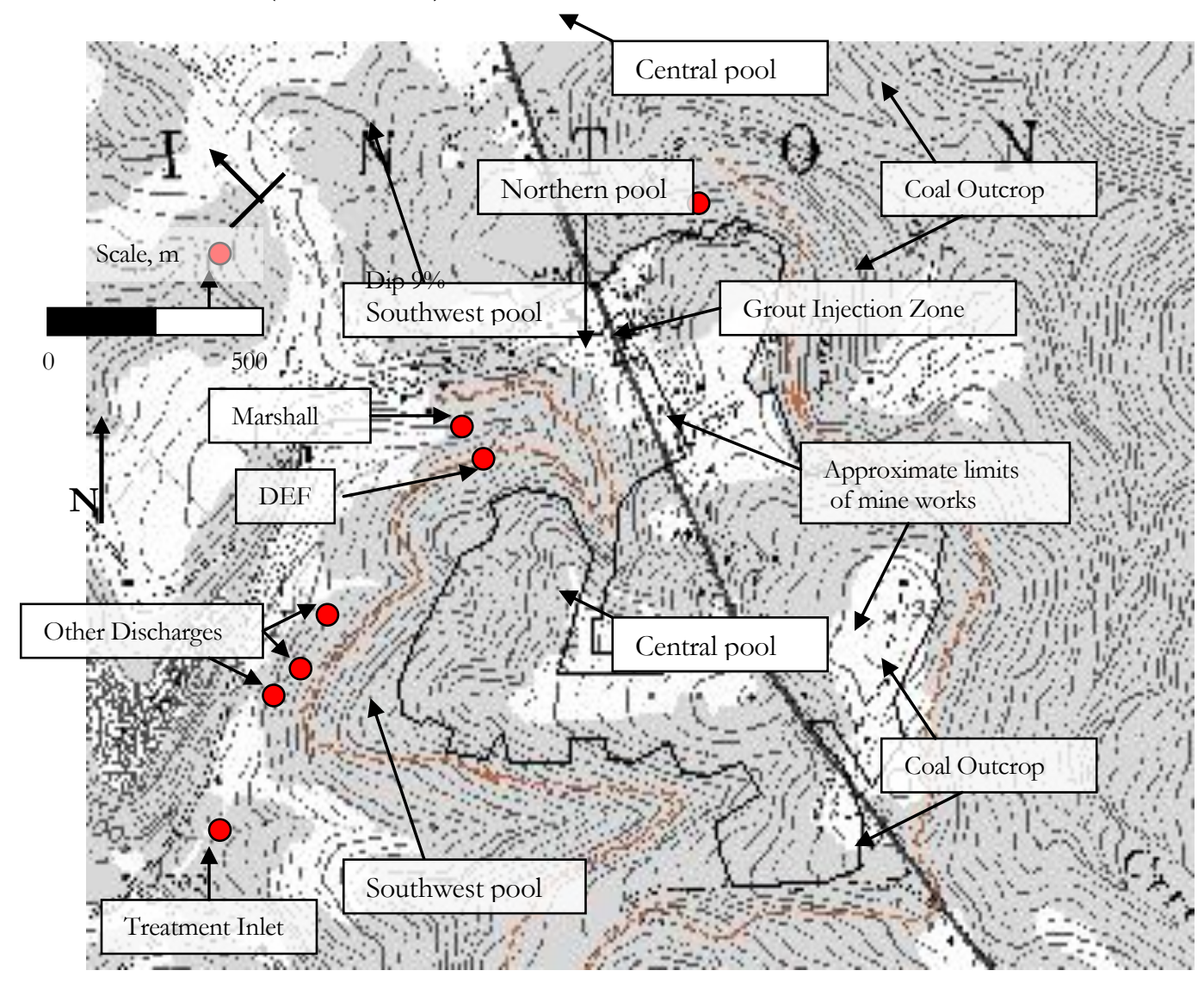

Figure 1. Extent of Omega mine works (black line), coal outcrop (dashed line) and discharge locations (red circles). (Portion of Morgantown South 7.5 min topographic quadrangle map)

\section{Methodology}

The US Department of Energy (USDOE) began monitoring water quality and flow from the principal mine discharges in 1993 on a monthly basis and continued until 1999. Data were collected for $\mathrm{pH}$, Total Acidity, $\mathrm{Fe}(\mathrm{II}), \mathrm{Fe}(\mathrm{III}), \mathrm{Al}, \mathrm{Mn}, \mathrm{SO}_{4}, \mathrm{Ca}, \mathrm{Mg}, \mathrm{Na}, \mathrm{K}, \mathrm{Cl}, \mathrm{NH}_{3}, \mathrm{As}, \mathrm{Ba}, \mathrm{Be}$, $\mathrm{Cd}, \mathrm{Co}, \mathrm{Cr}, \mathrm{Cu}, \mathrm{Ni}, \mathrm{Pb}, \mathrm{Sb}, \mathrm{Se}, \mathrm{Zn}$, and $\mathrm{Br}$. The WVDEP also began sampling discharges in 1996 at monthly intervals, and in 1997, initiated daily flow and on site precipitation measurements. 
WVDEP monitoring includes $\mathrm{pH}$, Total Acidity, $\mathrm{Fe}, \mathrm{Al}, \mathrm{Mn}, \mathrm{SO}_{4}$, specific conductance, total dissolved solids (TDS), and Total Suspended Solids (TSS). These data sets were combined into a single chronological file providing more than 8 years of data. Water samples were collected under this study during low flow conditions in 2002 and 2003 for the same parameters as the USDOE data set, plus field measurements of $\mathrm{pH}$, Eh, temperature and specific conductance. WVDEP monitoring continues as part of that organization's ongoing site management and reclamation work.

A charge balance calculation was performed on samples with all major cations and anions to assess data reliability. Total acidity was evaluated from the reported values, and acidity was also calculated based on metals concentration and $\mathrm{pH}$ using the following formula:

$$
\text { Acidity Calc }=50 *\left(3 * \mathrm{Fe} / 55.85+3 * \mathrm{Al} / 26.98+2 * \mathrm{Mn} / 54.94+1000 * 10^{-\mathrm{pH}}\right)
$$

where metal concentrations are in $\mathrm{mg} / \mathrm{L}$, and calculated acidity is in $\mathrm{mg} / \mathrm{L} \mathrm{CaCO}_{3}$ Equivalents (Eq.). The calculated acidity values were used in subsequent calculations and analyses.

All statistical analyses were performed using Statgraphics for Windows version 4.1. Mineral saturation indices were calculated using the geochemical code PHREEQC (Parkhurst and Appelo, 1999).

\section{Site Conditions}

The Omega mine is believed to contain 3 separate mine-pools based on limited water level data, examination of mine maps, structural considerations and field observations. The pools are located in the "North Lobe", the central section of the mine, and the southwest portion of the mine (Figure 1). The maximum extent of flooding is estimated to be about 23 ha for the 3 pools combined, or about $33 \%$ of the total mined area. Thus, at least two thirds of the mine works are not flooded, and are subjected to conditions favoring pyrite oxidation. Based on mine-pool discharge measurements and flooding extent, the equivalent of one to two mine-pool volumes per year are estimated to circulate through the mine works. It is believed that preferred flow paths exist in areas where voids remain open, and zones of minimal or slow ground water circulation may occur in collapsed areas. Leaching efficiency is likely to vary depending on localized conditions. Minepool discharges respond to precipitation events within a few days, suggesting rapid infiltration and flow through.

Water quality data from three monitoring points were selected for in-depth analysis. The Marshall and DEF discharges (Figure 1) are two acid springs located at and near the down dip end of the mine complex in the North Lobe mine-pool. These discharges have a continuous flow history, and represent a significant portion of the flow and acid load leaving the mine. The Marshall discharge is believed to represent water quality conditions near the end of the flow path within the North Lobe mine-pool. It is a horizontal borehole drilled into the lower end of the mine-pool. The DEF discharge is at an intermediate location on the flow path. Water quality at different flow path locations could exhibit evolutionary changes in water chemistry, as mine-water flows from unflooded to flooded portions of the mine works. The Marshall monitoring point is located near the grout injection area, and could show effects of acidic mine-pool water interacting with the 
grout. The DEF discharge was thought to be located far enough upgradient to have no significant interaction with the grout. The third monitoring point, Treatment Inlet (Figure 1), represents the combined pipe flow of all discharges, and is used to assess overall conditions.

\section{$\underline{\text { Results and Discussion }}$}

Table 1 shows median water quality data for the years 1993 at the beginning of the monitoring record, 2001 after grouting was completed, and single sample events from August, 2002 and August, 2003 for the three monitoring points. Overall water quality was very poor, exhibiting classic characteristics of acid drainage. The Marshall discharge exhibited the highest concentrations of acidity, metals, sulfate and trace elements, while DEF and the Treatment Inlet have similar composition and concentrations. At each site, there was a decline in median pollutant concentrations between 1993 and 2001. During that 8 year period median acidity, $\mathrm{Fe}, \mathrm{Al}$ and $\mathrm{SO}_{4}$ declined to about half of their initial values. Trace element concentrations of $\mathrm{Co}$, Ni and $\mathrm{Zn}$ exhibited some variation between 1993 and 2002/2003, but declined more rapidly. Sites DEF and the Treatment Inlet shows little change in $\mathrm{pH}$, while a modest improvement occurs at the Marshall site. Calcium and $\mathrm{Mg}$ show behavior similar to $\mathrm{Fe}, \mathrm{Al}$ and $\mathrm{SO}_{4}$. Sodium concentration, however, increased from 1993 to 2002/2003. Exchange of $\mathrm{Na}$ for other adsorbed cations, or dissolution of $\mathrm{Na}$ bearing minerals such as albite $\left(\mathrm{NaAlSi}_{3} \mathrm{O}_{8}\right)$ would increase solution $\mathrm{Na}$. Albite is about 8 to 10 orders of magnitude undersaturated in these waters, and Dulong et al. (2002) have shown that small amounts of albite can be present in these rocks.

Since most of the mine is not flooded, conditions are favorable for the formation of sulfate and hydroxysulfate minerals that characteristically occur in acidic environments. Melanterite, copiapite, halotrichite, gypsum, schwertmannite, various jarosites, and others are commonly present in mine spoil and underground mine works (Nuhfer, 1967; Bigham and Nordstrom, 2000; Rose and Cravotta, 1998). The specific mineral assemblage depends on $\mathrm{pH}$ and Eh conditions, as well as activities of the constituent ions. Some minerals such as melanterite are moderately soluble, and could redissolve as the mine is recharged. Mine-water outflows likely represents a combination of leaching stored sulfate minerals, and continued weathering of pyrite.

\section{$\underline{\text { Time-Series Analysis }}$}

Concentration versus time scatter plots showed month-to-month variation. However, an underlying long-term trend, and a shorter seasonal trend were also present. These trends were examined with time-series analyses, including moving average, and seasonal decomposition, which breaks the data into trend, seasonal and irregular components. Log or other data transforms and nonparametric tests (Helsel and Hirsch, 1992); locally weighted scatter plot smoothing (Cleveland and Devlin, 1988); and seasonal decomposition (Cleveland and Terpenning, 1982) are suggested methods for analyzing noisy time-series data for trends and seasonal features.

Examples of raw and trend data are shown in Figures 2, 3 and 4 for $\mathrm{Fe}, \mathrm{Al}$ and $\mathrm{SO}_{4}$ concentration data at the Marshall monitoring point. The plots display similar behavior, and there was a period of declining concentration from 1993 to late 1998. Iron and $\mathrm{SO}_{4}$ trends decrease more rapidly than Al. In 1999, there was a rapid concentration increase for all parameters, followed by resumption in decline. The spike in concentrations closely follows the grouting conducted in mid to late 1998 in the nearby "North Lobe" of the mine. Calcium and $\mathrm{Mg}$ concentrations, which had been 
Table 1 Summary Water Chemistry for Marshall, DEF and Treatment Inlet Monitoring Sites ${ }^{(1)}$

\begin{tabular}{clllllllllllllll}
\hline Site & Year $^{(2)}$ & Flow & $\mathrm{pH}$ & $\begin{array}{c}\text { Acidity } \\
\text { Calc. }\end{array}$ & $\mathrm{TDS}$ & $\mathrm{Fe}$ & $\mathrm{Al}$ & $\mathrm{Mn}$ & $\mathrm{SO}_{4}$ & $\mathrm{Ca}$ & $\mathrm{Mg}$ & $\mathrm{Na}$ & $\mathrm{Co}$ & $\mathrm{Ni}$ & $\mathrm{Zn}$ \\
\hline Marshall & 1993 & 63 & 2.62 & 8398 & 8398 & 1613 & 275 & 6.5 & 5975 & 325 & 168 & 4.7 & 1.66 & 3.75 & 13.52 \\
& 2001 & 64 & 3.30 & 4636 & 4536 & 689 & 108 & 3.7 & 2955 & $\mathrm{NM}$ & $\mathrm{NM}$ & $\mathrm{NM}$ & $\mathrm{NM}$ & $\mathrm{NM}$ & $\mathrm{NM}$ \\
& 2002 & 23 & 3.48 & 2026 & 4203 & 564 & 88.7 & 2.9 & 2462 & 298 & 71 & 18 & 0.42 & 0.98 & 3.16 \\
& 2003 & 50 & 4.15 & 1976 & 3980 & 460 & 133 & 0.83 & 2200 & 162 & 59 & 36 & 0.30 & 1.23 & 3.14 \\
DEF & 1993 & 69 & 2.71 & 2590 & 4345 & 664 & 130 & 3.5 & 3141 & 228 & 120 & 14 & 1.18 & 2.70 & 9.28 \\
& 2001 & 29 & 2.60 & 1540 & 3160 & 314 & 103 & 2.8 & 1250 & $\mathrm{NM}$ & $\mathrm{NM}$ & $\mathrm{NM}$ & $\mathrm{NM}$ & $\mathrm{NM}$ & $\mathrm{NM}$ \\
& 2002 & $\mathrm{NM}^{(3)}$ & 2.50 & 1542 & 3196 & 339 & 113 & 2.25 & 1931 & 135 & 65 & 23 & 0.44 & 1.04 & 3.07 \\
Treatment & 2003 & 29 & 2.86 & 1581 & 2820 & 349 & 115 & 2.43 & 1811 & 126 & 60 & 26 & 0.54 & 1.04 & 2.89 \\
Inlet & 1993 & 313 & 2.86 & 2896 & 5282 & 771 & 137 & 5.26 & 3915 & 288 & 147 & 5.3 & 1.20 & 2.62 & 9.12 \\
& 2001 & 186 & 2.80 & 1670 & 3406 & 365 & 104 & 3.6 & 1790 & $\mathrm{NM}$ & $\mathrm{NM}$ & $\mathrm{NM}$ & $\mathrm{NM}$ & $\mathrm{NM}$ & $\mathrm{NM}$ \\
& 2002 & 67 & 2.77 & 1377 & 3457 & 301 & 101 & 3.80 & 2004 & 247 & 77 & 15 & 0.66 & 1.45 & 4.54 \\
& 2003 & 172 & 3.11 & 979 & 2357 & 191 & 83 & 2.5 & 1404 & 155 & 52 & 20 & 0.49 & 1.05 & 3.14 \\
\hline
\end{tabular}

(1) Flow in L/min, $\mathrm{pH}$ in standard units, Acidity in $\mathrm{mg} / \mathrm{L} \mathrm{CaCO} 3 \mathrm{Eq}$. , all others in $\mathrm{mg} / \mathrm{L}$.

(2) Median concentration values for 1993 and 2001, and single sample event values for 2002 and 2003.

(3) $\mathrm{NM}=$ Not Measured 
decreasing, also increased after grouting. These data show a rapid and short-term flushing by grout injection that displaced acid weathering products already present in the mine works. This behavior suggests that leaching efficiency is low for most recharge conditions. Only extreme disturbance to the system, such as from grout injection, or very large recharge events displace major amounts of soluble weathering products. Increasing $\mathrm{Ca}$ and $\mathrm{Mg}$ likely were derived from dissolution of the ash and cement based grout.

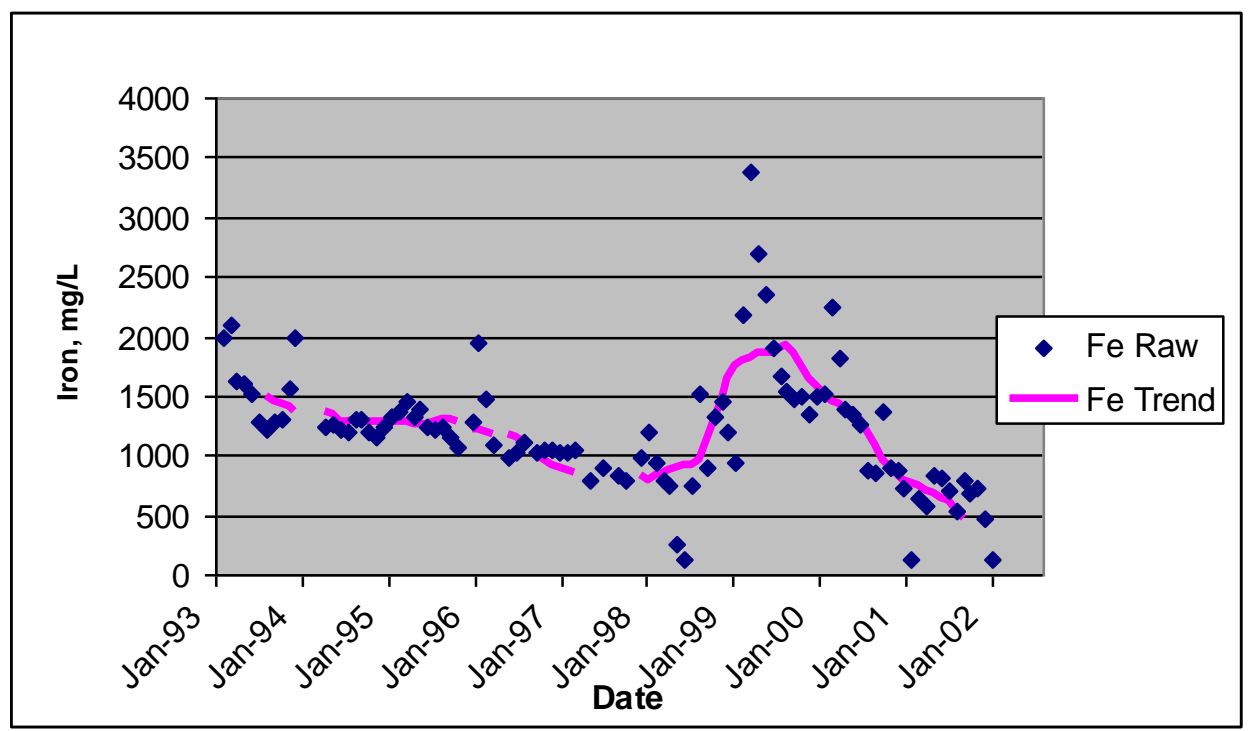

Figure 2. Iron Concentration Trend, Marshall Monitoring Point.

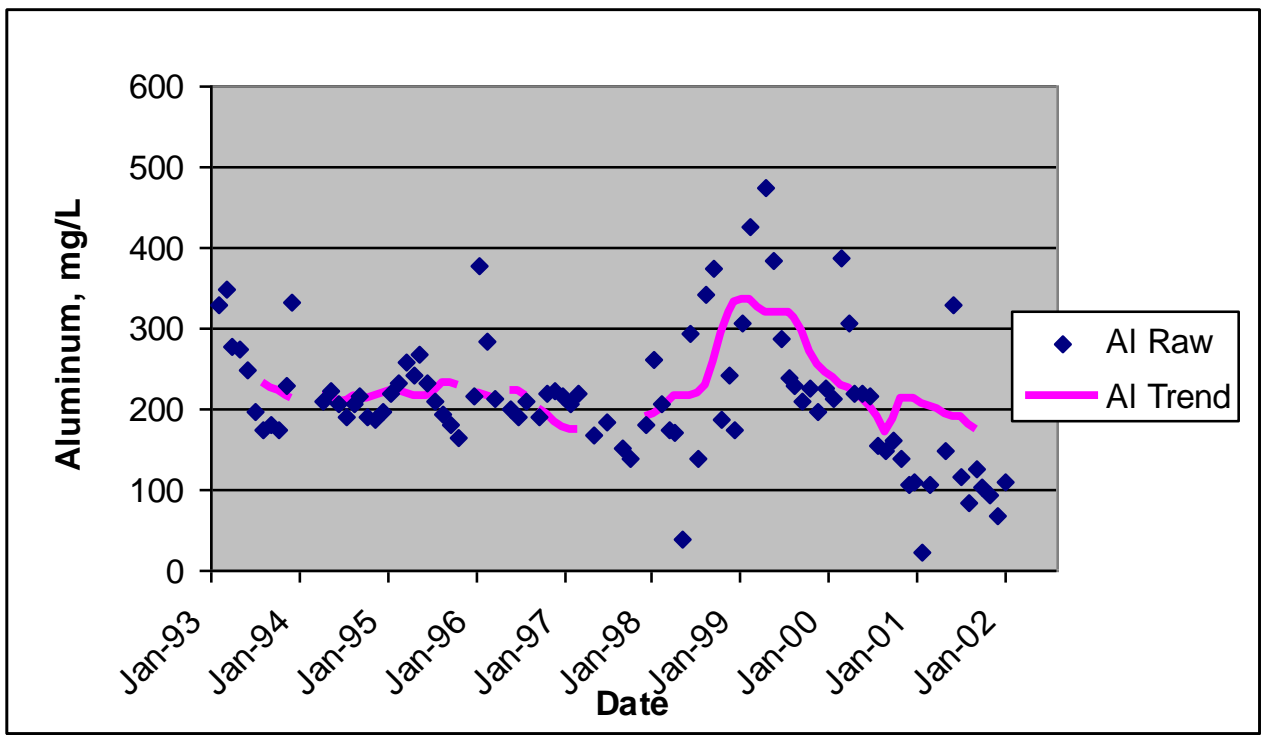

Figure 3. Aluminum Concentration Trend, Marshall Monitoring Point. 


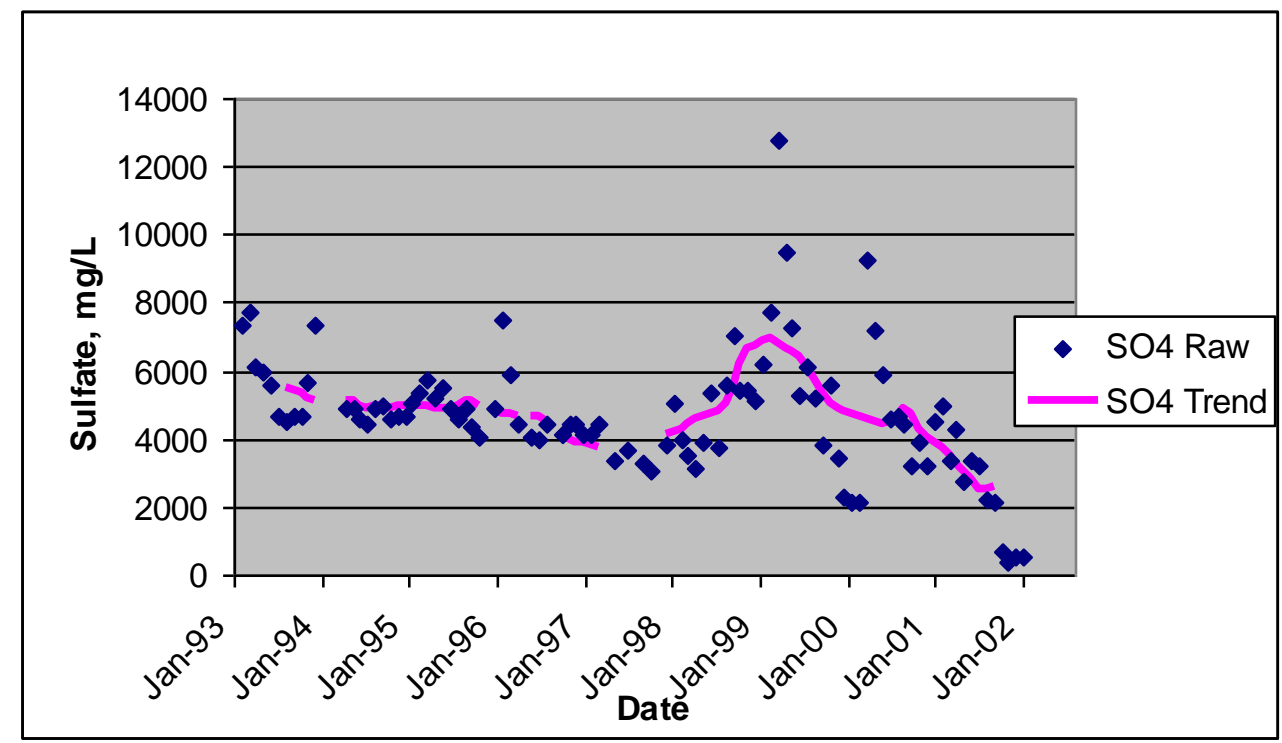

Figure 4. Sulfate Concentration Trend, Marshall Monitoring Point.

Differences between the raw unadjusted concentration and trend data represent the irregular component of the data. It may result from short-term events such as rapid recharge events, and fluctuations in mine-pool elevation or flow path.

Figure 5 is a plot of Co and Ni raw and trend data for the DEF discharge. Concentrations of both metals decreased until about 1998 (Figure 5), when grout injection occurred; then concentrations began to increase. Based on the trend data, Ni was declining slightly faster than Co. It was initially believed that site DEF was located far enough upgradient from the

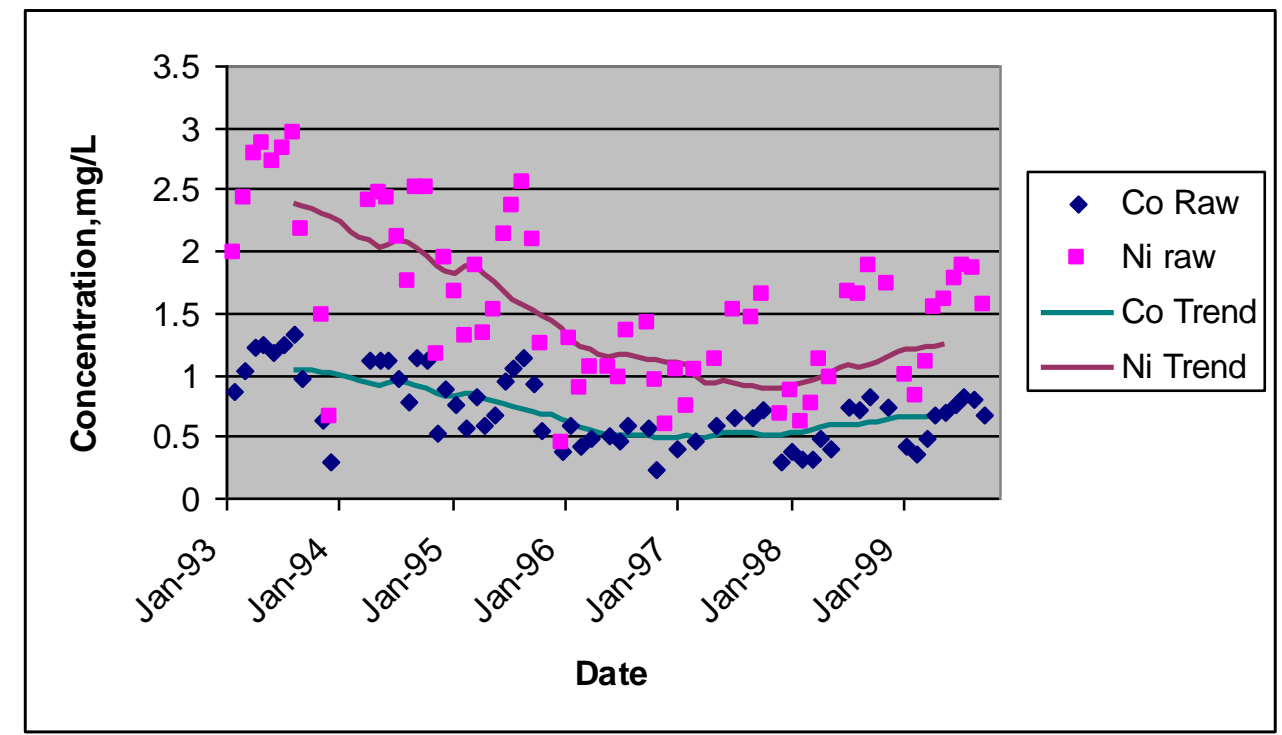

Figure 5. Cobalt and Nickel Concentrations Trends for DEF Monitoring Point. 
mine grout zone, that its water chemistry would not be influenced by grout injection. However, behavior of these elements at site DEF suggests that its' water chemistry was affected by grout injection. Cobalt and Ni-to-SO $\mathrm{SO}_{4}$ mole ratios (Figure 6) had a slow decline until about 1997. Both $\mathrm{Co}(\mathrm{r}=0.97)$ and $\mathrm{Ni}(\mathrm{r}=0.95)$ are strongly correlated to $\mathrm{SO}_{4}$ concentration. Cobalt and $\mathrm{Ni}$ are common trace inclusions in pyrite at concentrations of less than a few percent (Rimstidt and Vaughan, 2003).

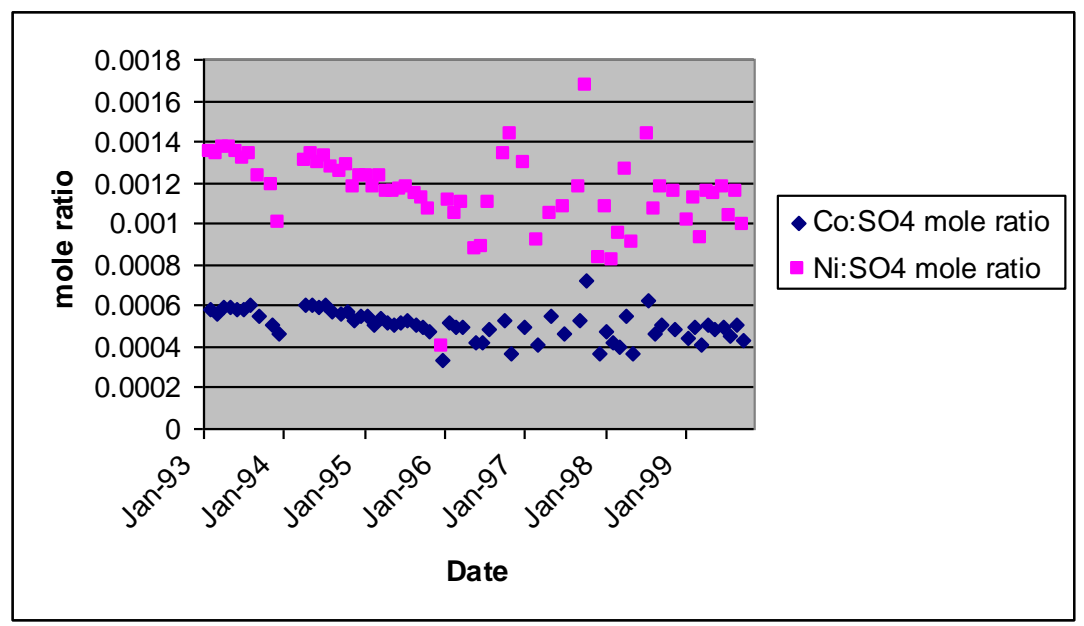

Figure 6. Cobalt and Nickel-to-Sulfate Molar Ratios, for DEF Monitoring Point.

Under the strongly acidic conditions like those at site DEF $(\mathrm{pH}<3.0)$, adsorption studies generally indicate little attenuation of $\mathrm{Ni}$ and Co (Bruemmer et al., 1988, Larsen and Postma, 1997, Geihyeon et al., 2002). If in-situ adsorption attenuation is minimal, then declining $\mathrm{Ni}$ and Co to sulfate mole ratios probably reflect a decrease in pyrite oxidation. Increased scatter in the plots for 1997 and 1998 reflects disturbance from mine site modification and grouting.

\section{Estimating Rate of Concentration Decrease}

Exponential and other model functions were fitted to the pre-grouting trend data to estimate rates at which mine-water concentrations decline over time. Least squares regression was used to examine different models. Because mine grouting impacted water chemistry, no model fitting was done for data during and immediately after grouting. Examination of different models, and their associated $\mathrm{R}^{2}$ values and residual plots, showed that the following exponential function provided a reasonable estimation of concentration change with time:

$$
\begin{gathered}
C_{t}=C_{0} * \exp ^{-k t} \quad \text { (2) or } \\
\ln \left(C_{t} / C_{0}\right)=-k t
\end{gathered}
$$


where $C_{t}$ is concentration at time $t, C_{0}$ is concentration at time zero, $\mathrm{k}$ is a constant in time $\mathrm{e}^{-1}$ units and $\mathrm{t}$ is elapsed time. The function is identical to that used to describe radioactive decay. The constant, $\mathrm{k}$, is the slope of a plot of $\ln \left(\mathrm{C}_{\mathrm{t}} / \mathrm{C}_{0}\right)$ versus $\mathrm{t}$. Other regression models generally did not describe the trends as well as an exponential function. The period required for a $50 \%$ decline in concentration, designated $t_{50 \mathrm{C}}$ in this paper, was estimated from equation 3 . Estimated $\mathrm{t}_{50 \mathrm{C}}$ for pregrouting data at the three monitoring points are summarized in Table 2. All Table 2 data are statistically significant at 0.05 alpha.

Time-to-half concentration ranges from about 5 to 8 years for Acidity, $\mathrm{Fe}, \mathrm{Ca}$ (except at Marshall site), $\mathrm{Mg}, \mathrm{SO}_{4}$, and TDS. Cobalt, $\mathrm{Ni}$ and $\mathrm{Zn}$ declined more rapidly, with time to half concentration ranging from about 2.5 to 5 years. The time to half concentration estimates in Table 2 are in general agreement with direct comparisons between 1993 and 2001summary data in Table 1.

Table 2. Estimated Time to Half Concentration, $t_{50 \mathrm{C}}$, in Months for Selected Water Quality Parameters, Pre-Grouting Conditions

\begin{tabular}{ccccccccccc}
\hline $\begin{array}{c}\text { Monitoring } \\
\text { Point }\end{array}$ & Acidity & $\mathrm{Al}$ & $\mathrm{Ca}$ & $\mathrm{Co}$ & $\mathrm{Fe}$ & $\mathrm{Mg}$ & $\mathrm{Ni}$ & $\mathrm{SO}_{4}$ & $\mathrm{TDS}$ & $\mathrm{Zn}$ \\
\hline Marshall & 79 & 212 & 117 & 49 & 61 & 60 & 54 & 96 & 93 & 45 \\
DEF & 78 & 134 & 69 & 34 & 62 & 54 & 32 & 57 & 79 & 30 \\
$\begin{array}{c}\text { Treatment } \\
\text { Inlet }\end{array}$ & 94 & 146 & 88 & 51 & 70 & 57 & 57 & 72 & 72 & 47 \\
\hline
\end{tabular}

Demchak et al. (in press) examined drainage quality from 44 above-drainage underground mines, including sites with the same stratigraphy as the Omega mine. Water quality from 1968 compared to drainage in 1999-2000 showed that acidity had decreased an average of 56\% in mine drainage from the Upper Freeport coal bed. Overall, iron concentrations declined about $80 \%$, and sulfate declined about 50 to $75 \%$. Average data (Demchak et al., in press) seem to indicate a slower rate of concentration decline than data presented here for the Omega mine. However, their data show some variation among individual mines, and the rate of chemical change seems to be influenced by site specific factors.

Drainage from flooded underground coal mines in Great Britain shows about a $50 \%$ reduction in Fe concentration for each mine-pool volume discharged (Glover, 1983), implying an exponential decay. Younger (1997) further characterized British mine-waters as consisting of two acidity sources; recently generated from ongoing sulfide oxidation, and stored acidity. Younger estimates that stored acidity is removed in the first flush of the mine-pool, usually within 40 years, while continued oxidation is projected to last for hundreds of years. Most of the long-term discharge records described by Younger (1997) exhibit an exponential decay for Fe and become asymptotic after 10 to 20 years. Long-term Fe concentrations range from 1 to $30 \mathrm{mg} / \mathrm{L}$. 
Pollutant concentration behavior in Omega mine drainage is similar to the general decay model described for British mines. Omega mine drainage has not progressed far enough through its life cycle to determine whether concentrations become asymptotic in the long term.

\section{Mineralogical Controls}

Aluminum has the longest estimated $\mathrm{t}_{50 \mathrm{C}}$ of the parameters in Table 2, ranging from about 12 to 18 years. The slow decline for $\mathrm{Al}$ is a function of mine-pool $\mathrm{pH}$, which is usually between 2.6 and 3.5. Dissolution of clay minerals, such as kaolinite, and Al hydroxide minerals is favored under these conditions as reaction 4 shows:

$$
\mathrm{Al}_{2} \mathrm{Si}_{2} \mathrm{O}_{5}(\mathrm{OH})_{4}+6 \mathrm{H}^{+} \rightarrow 2 \mathrm{Al}^{3+}+2 \mathrm{H}_{4} \mathrm{SiO}_{4}+\mathrm{H}_{2} \mathrm{O}
$$

So long as mine-pool $\mathrm{pH}$ remains below about 4.0, dissolution of clay minerals and $\mathrm{Al}$ hydroxides could occur; thus there is a large source for soluble $\mathrm{Al}$; hence concentrations may to decline more slowly than other constituents.

Saturation indices for jurbanite, an Al-hydroxysulfate, are plotted in Figure 7 for the Marshall and DEF sites. Both waters show apparent near equilibrium conditions, where DEF (intermediate flow path location) is slightly undersaturated, and Marshall (end of flow path) is slightly oversaturated. Waters in the DEF discharge approach, but do not exceed, the equilibrium saturation index of 0 , suggesting that jurbanite poses an upper limit to Al concentration at site DEF.

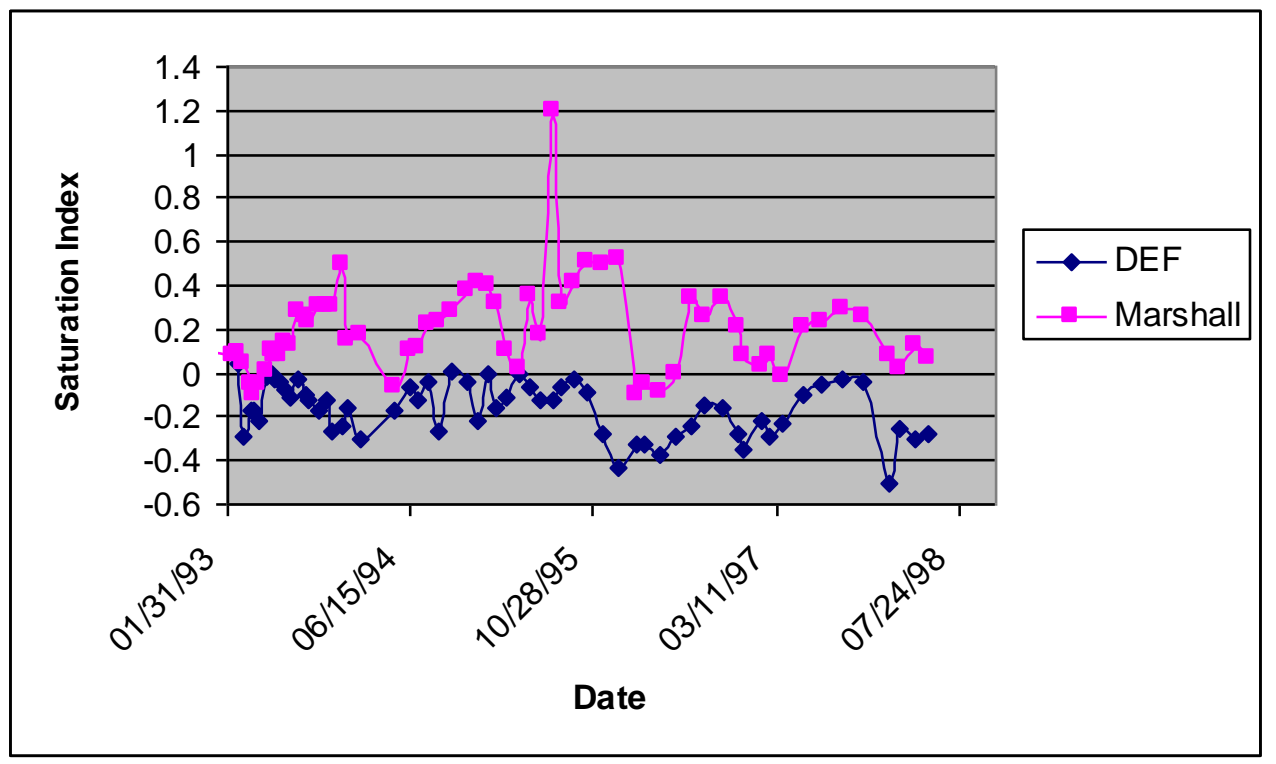

Figure 7. Jurbanite Saturation Indices at Marshall and DEF Sites.

Jurbanite is stable in acidic waters (Nordstrom, 1982b) and can persist in the $\mathrm{pH}$ range of zero up to 3 to 5 in sulfate rich waters. Jurbanite could form from kaolinite alteration as reaction 5 shows: 
$\mathrm{Al}_{2} \mathrm{Si}_{2} \mathrm{O}_{5}(\mathrm{OH})_{4}+2 \mathrm{SO}_{4}{ }^{2-}+6 \mathrm{H}_{2} \mathrm{O}+4 \mathrm{H}^{+} \rightarrow$

$2 \mathrm{Al}\left(\mathrm{SO}_{4}\right)(\mathrm{OH}) * 5 \mathrm{H}_{2} \mathrm{O}+2 \mathrm{H}_{4} \mathrm{SiO}_{4}$

Waters at the Marshall discharge are slightly oversaturated for jurbanite. Slight over saturation suggests that within the mine either a slightly more soluble poorly crystalline phase of jurbanite is forming, the jurbanite reaction rate is slow, the "dissolved" fraction on which the saturation index calculations were based, contains colloidal Al, or the jurbanite is not actually forming. Our current knowledge of the mine precludes identification of which scenario is allowing slight jurbanite super saturation at the Marshall discharge. The mine works are not accessible for sediment sampling for mineralogical analysis to confirm or deny the presence of jurbanite. However, its characteristic occurrence is in acid soils and mine-waters (Nordstrom, 1982b).

Superimposed on the overall trend in Figure 7 is a cyclic, seasonal variation in saturation index. Indices are largest in periods corresponding to low flow conditions, and smallest during high-flow periods. The inverse relation between saturation index and flow suggests mine-waters are diluted during seasonal recharge and more concentrated for drier periods of the year. Mineral saturation and precipitation should be favored during dry periods.

Goethite $(\mathrm{FeOOH})$ saturation indices for the Marshall and DEF sites, computed from measured Eh in 2002 and 2003, show the mine-waters are slightly oversaturated (indices about +0.05 to +0.5 ). Iron could be attenuated within the mine-pool by precipitation as an oxyhydoxide, either amorphous, or crystalline form such as goethite. The metastable hydroxysulfates, schwertmannite and jarosite, if present initially, may also transform to goethite with time (Bigham and Nordstrom, 2000).

In acid oxidizing sulfate waters, formation of the $\mathrm{Fe}$ bearing minerals $\mathrm{Fe}(\mathrm{OH})_{3(\mathrm{am})}$; schwertmannite, $\quad \mathrm{Fe}_{8} \mathrm{O}_{8}(\mathrm{OH})_{6} \mathrm{SO}_{4} * \mathrm{nH}_{2} \mathrm{O} ; \quad \mathrm{H}$-jarosite $\quad \mathrm{HFe}_{3}\left(\mathrm{SO}_{4}\right)_{2}(\mathrm{OH})_{6} ; \quad$ Na-jarosite $\mathrm{NaFe}_{3}\left(\mathrm{SO}_{4}\right)_{2}(\mathrm{OH})_{6}$; and $\mathrm{K}$-jarosite, $\mathrm{KFe}_{3}\left(\mathrm{SO}_{4}\right)_{2}(\mathrm{OH})_{6}$ is feasible. Mine-waters are 1 to 4 orders of magnitude undersaturated for $\mathrm{Fe}(\mathrm{OH})_{3(\mathrm{am})}$, and 2 or more orders of magnitude oversaturated for schwertmannite. These minerals are likely not present in the Omega mine. K-jaorosite is commonly 1-2 orders of magnitude oversaturated while $\mathrm{H}$-jarosite and $\mathrm{Na}$-jarosite are slightly undersaturated. K-jaorosite is reported to sometimes be super saturated without actually forming, and Na-jarosite is relatively rare (Bigham and Nordstrom, 2000). Indices decline with time, suggesting that the system is not at equilibrium with them, and they are likely not present. The cycling of iron in the Omega mine is not clearly associated with any one mineral, with the possible exception of goethite.

Figure 8 shows gypsum saturation indices for the Marshall and DEF sites. Both sites are slightly undersaturated for gypsum and are becoming more so with time. Calcium and $\mathrm{SO}_{4}$ solubility are not currently controlled by gypsum. However, in 1993-1994 at the beginning of monitoring, the Marshall discharge was near equilibrium for gypsum. No data are available prior to 1993 to estimate whether gypsum saturation was actually achieved shortly after mine closure. The gypsum 
plot (Figure 8) shows a similar seasonal dilution/concentration effect as that for the jurbanite plot (Figure 7).

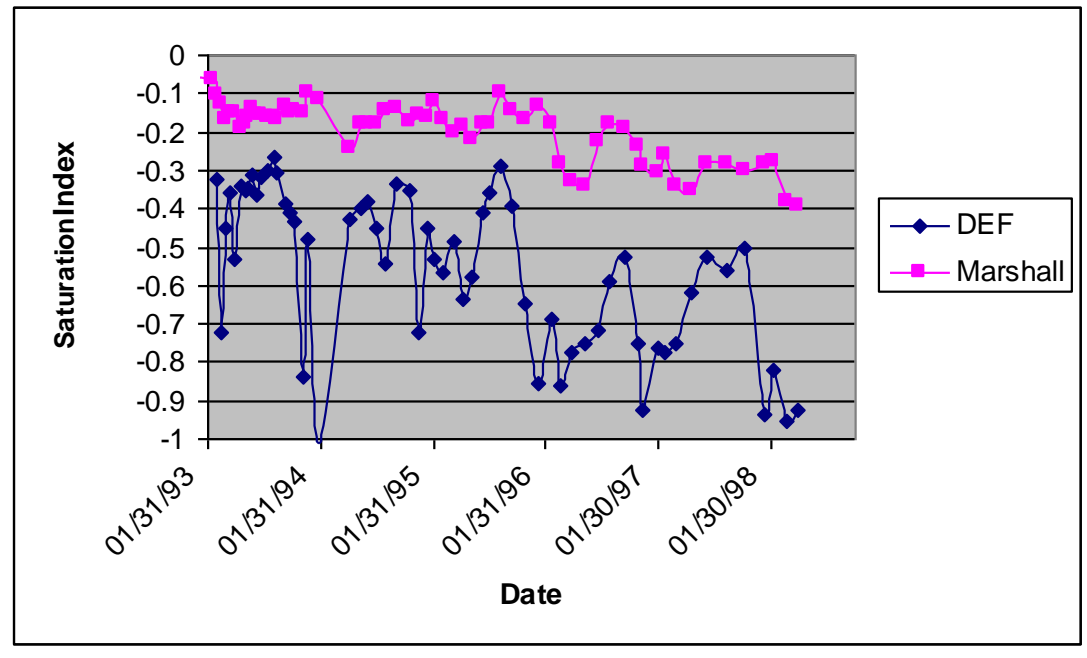

Figure 8. Gypsum Saturation Indices for Marshall and DEF Sites.

\section{Flux(Loading)}

Trends for flux data (chemical concentration $\mathrm{x}$ flow) versus time were poorly described by exponential or other simple mathematical functions that did not account for variable flow rates. Figure 9 is a scatter plot of sulfate flux (load) and flow rate from the Treatment Inlet for the period 1993-2002. There is a pronounced seasonal effect in flow and flux, with both constituents reaching maximums during the spring of the year and minimums in the fall. Sulfate flux is strongly correlated to flow ( $r=0.78$ ), as are Acidity, Fe, Al, and TDS loadings ( $r=0.77$ to 0.82). An extensive study of surface mine discharges also found flow to be the dominant component of flux (Hawkins, 1994).

Within the 9 year record there is an observable trend of long-term decline in sulfate flux. Figure 9 also includes the trace of the best fit regression line from a linear model. The regression slope indicates the long term decline in flux, but clearly does not account for the seasonal cycles. Simple models cannot estimate short term flux because of variable flow rates. In turn, discharge quantity is driven by precipitation and recharge events, and changes in mine hydrology. 


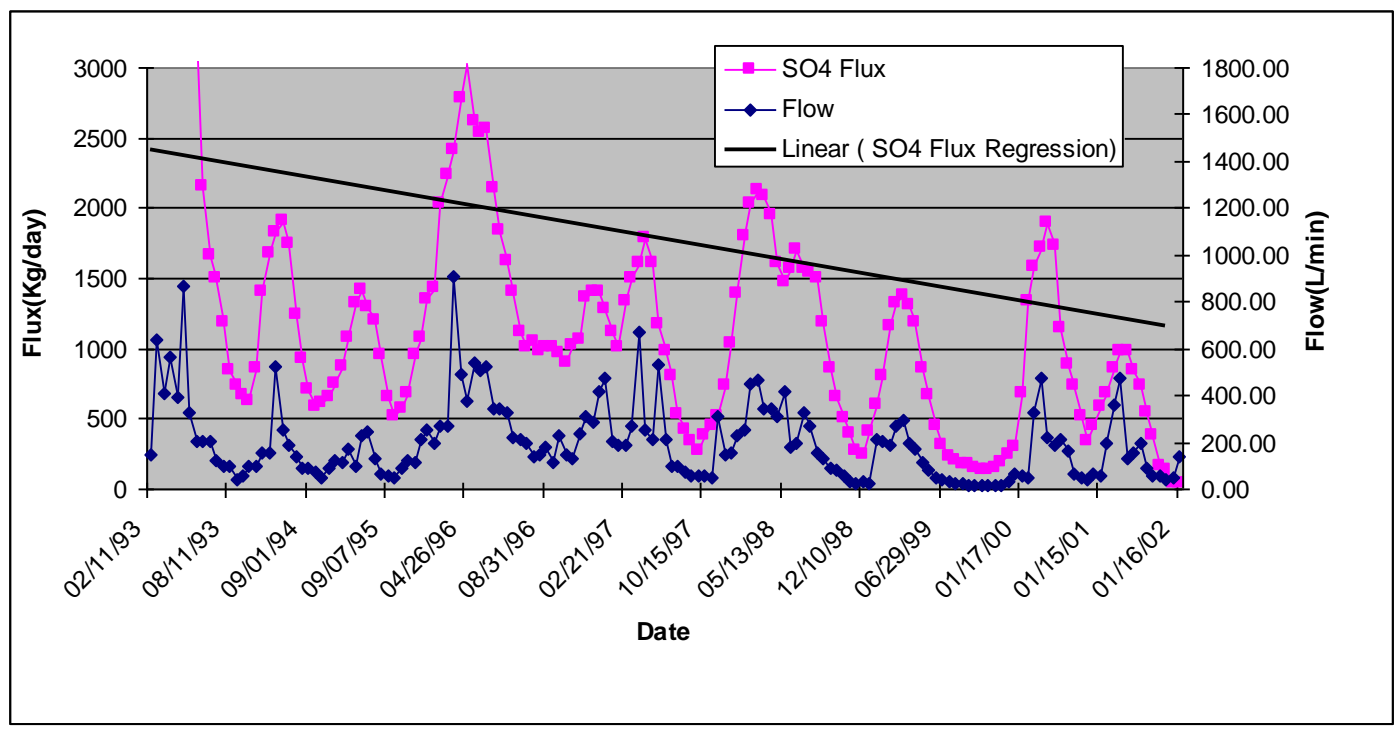

Figure 9. Sulfate Flux and Flow, 1993 to 2002, Treatment Inlet.

Table 3 summarizes estimates of time to half flux generated from best fit regression models for the Treatment Inlet. These values represent the long-term decline, and do not model the seasonal cyclical features seen in Figure 9.

Table 3. Time to Half Flux Estimates, $\mathrm{t}_{50 \mathrm{~F}}$, Regression Models, Treatment Inlet. ${ }^{(1)}$

\begin{tabular}{ccccccc}
\hline \multirow{2}{*}{ Method } & $\begin{array}{c}\text { Acid } \\
\text { Flux }\end{array}$ & $\begin{array}{c}\mathrm{Al} \\
\text { Flux }\end{array}$ & $\begin{array}{c}\mathrm{Fe} \\
\text { Flux }\end{array}$ & $\begin{array}{c}\mathrm{SO}_{4} \\
\text { Flux }\end{array}$ & $\begin{array}{c}\mathrm{Co} \\
\text { Flux }\end{array}$ & $\begin{array}{c}\mathrm{Ni} \\
\text { Flux }\end{array}$ \\
\hline Regression & 106 & 169 & 85 & 77 & 64 & 56 \\
\hline
\end{tabular}

(1)Time in months. "Best fit" flux models are square root of time functions, except Co and Ni which show linear functions with time.

Comparing the Treatment Inlet time to half flux in Table 3, to time to half concentration (Table 2), shows that flux is declining more slowly than concentration. Thus, most of the improvement in mine-pool chemical discharge is attributable to decreasing concentrations instead of changes in flow.

Seasonality

Chemical concentration and flux both exhibit seasonal variation. Median values for each month were divided into two seasons, corresponding to periods of minimum and maximum trend values. The "spring season" for high flux data is February to July, and the "Fall Season" is August to January. Selected data from the Treatment Inlet site are shown in Figure 10, and Tables 4 and 5.

Median flux and flow for the spring season is about 2 to 3 times greater than that for the fall, and peak fluxes occur around March to April (Figure 10). About $75 \%$ of the total yearly flux is 
discharged during the spring season. Flux is at a minimum in October to December. All median flux values and flow values for spring and fall seasons are significantly different at alpha probability $=0.01$, using the nonparametric Mann-Whitney test.

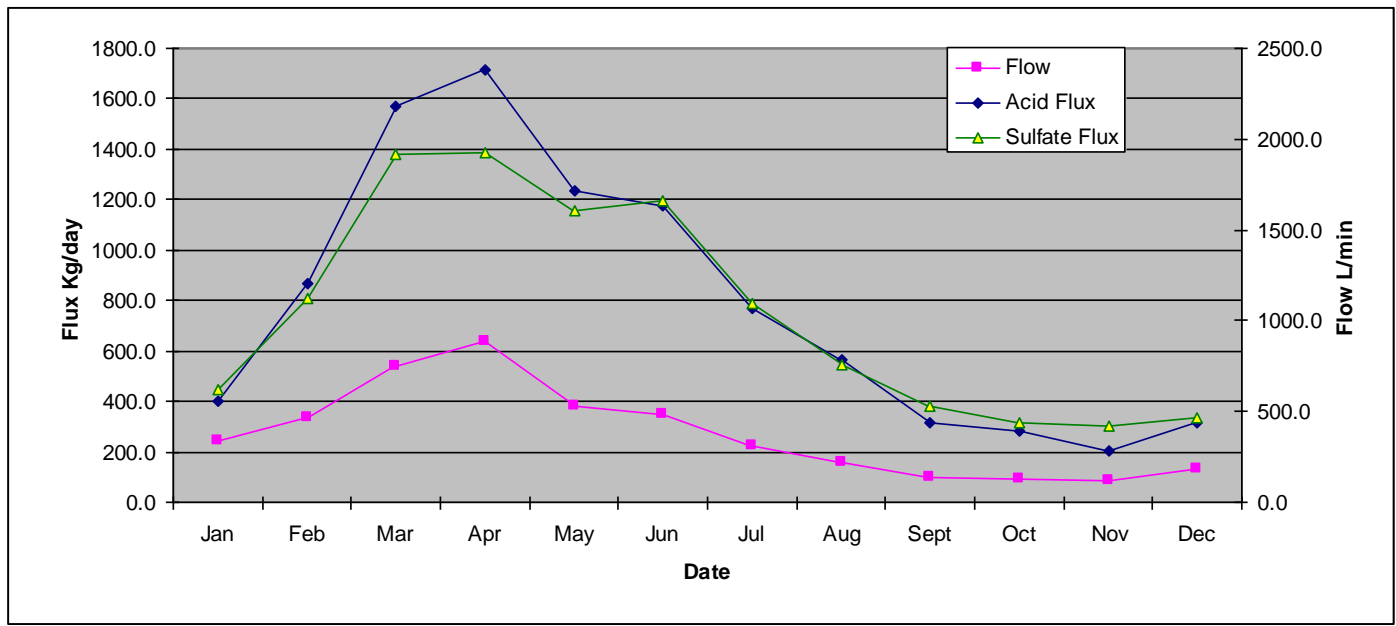

Figure 10. Median Monthly Flow, Acid Flux and Sulfate Flux at the Treatment Inlet Site Showing Seasonality Trend.

Table 4. Median Seasonal Flux and Flow for Treatment Inlet ${ }^{(1)}$

\begin{tabular}{cccccc}
\hline Season & Flow & Acidity & $\mathrm{Al}$ & $\mathrm{Fe}$ & $\mathrm{SO}_{4}$ \\
\hline Spring & 393 & 1219 & 62.6 & 501 & 1556 \\
Fall & 149 & 428 & 20.9 & 309 & 589 \\
Significant & Yes & Yes & Yes & Yes & Yes \\
Difference & & & & & \\
\hline
\end{tabular}

(1) Flux in $\mathrm{Kg} /$ day, flow in L/min. Significant differences at $\mathrm{p}=0.01$.

There is a weak inverse relationship, or slight dilution effect, between flow and concentration by season (Table 5). Median concentrations are greater in the low- flow fall season, while lower concentrations occur in the spring season. The differences are not statistically significant for Fe and $\mathrm{Al}$, however.

Table 5. Median Seasonal Concentrations for Treatment Inlet. ${ }^{(1)}$

\begin{tabular}{ccccccc}
\hline Season & Acidity & $\mathrm{Al}$ & $\mathrm{Fe}$ & $\mathrm{SO}_{4}$ & $\mathrm{Co}$ & $\mathrm{Ni}$ \\
\hline Spring & 1875 & 105 & 465 & 2454 & 0.78 & 1.64 \\
Fall & 2042 & 114 & 501 & 2870 & 0.95 & 2.04 \\
Significant & Yes & $\mathrm{No}$ & $\mathrm{No}$ & Yes & Yes & Yes \\
Difference & & $(\mathrm{p}=0.31)$ & $(\mathrm{p}=0.10)$ & & & \\
\hline
\end{tabular}

(1)Concentrations in $\mathrm{mg} / \mathrm{L}$. Significant differences at $\mathrm{p}=0.01$. 


\section{$\underline{\text { Summary and Conclusions }}$}

The Omega mine has been discharging acidic drainage containing elevated amounts of acidity, Fe, $\mathrm{Al}, \mathrm{SO}_{4}$ and trace elements for about 14 years. Pollutant concentrations declined over an 8 year period, but there was little change in $\mathrm{pH}$. The continuing concentration decline likely reflects a combination of depletion of oxidizable pyrite, continued leaching of stored acidity, in-situ neutralization, and inactivation of some pyrite surfaces by sedimentation, precipitation or other means. An exponential function described the long term concentration trends, but there are both seasonal (cyclic) and short-term irregular departures. Short-term variation represents response to transient features such as rapid recharge events. Concentrations of $\mathrm{Fe}, \mathrm{SO}_{4}$, and acidity were estimated to decline by half over about 5 to 8 years for individual mine drainage springs and the composite mine-pool.

Aluminum concentrations declined 2 to 3 times slower, and mine-waters are near apparent equilibrium for the Al-hydroxysulfate mineral jurbanite. The very acid conditions which remain in the mine-pool ( $\mathrm{pH} \sim 2.5$ to 3.5) favor the dissolution of alumino-silicates and Al hydroxides. As long as $\mathrm{pH}$ remains below about 4.0, the reservoir of potentially mobile $\mathrm{Al}$ is large.

Metals and sulfate concentration declines estimated from exponential functions compared reasonably well to actual data. Concentrations estimates were usually within $15 \%$ of actual values and most were within $30 \%$.

Concentrations of trace elements $\mathrm{Co}, \mathrm{Ni}$, and $\mathrm{Zn}$ were estimated to decline by half in about 3 to 5 years. These elements occur as trace inclusions in pyrite and may be a surrogate for recently generated acidity.

Iron cycling in the Omega mine is complex. No Fe bearing hydroxysulfate mineral was identified as controlling soluble Fe. Apparent equilibrium is indicated for goethite, based on a few measurements, and this oxyhydroxide may control soluble $\mathrm{Fe}$ in the long term. The presence of specific minerals cannot be confirmed because the mine works are not accessible for sediment sampling.

An apparent long-term trend for near equilibrium for jurbanite, and possibly goethite, suggests that the mine-pool chemistry is partially controlled by local equilibrium conditions. The mine-pool is however, periodically stressed by seasonal and single event recharge pulses that usually result in dilution.

Soluble acid weathering products are not uniformly leached from the mine works, due to preferential flow paths and zones of limited or slow ground water circulation. Zones with little flushing accumulate acid products, which may only be mobilized when the system is subjected to large stress. Grout injection completely filled one section of the mine works, displaced stored acidity, and caused a short-lived increase in acidity and metals concentrations. Leachate 
mobilization from the mine works is ultimately transport controlled. Aggressive reclamation strategies such as grout injection can increase pollutant discharge in the short term.

Flux or load is controlled mostly by flow, and there is a distinct seasonality to the mine-pool discharge. About $75 \%$ of the total yearly flux is discharged in the spring season. The most rapid abatement method for pollutant flux for the Omega mine-pool would be to reduce mine recharge, and grouting a portion of the mine did ultimately reduce flux from that section. However, grouting an entire underground mine complex post-closure can be technologically difficult or cost prohibitive.

It is uncertain if the Omega mine-pool will continue to follow the decline shown in its' first 10 years of activity, or if the trend will become asymptotic in the future. Most of the mine-water chemistry improvement results from declining concentrations. Current behavior shows that minepool drainage quality improvement occurs on the order of years to decades.

\section{$\underline{\text { Acknowledgements }}$}

We thank Mike Reese and Charles Miller of the West Virginia Department of Environmental Protection for generously sharing their data, time, site access, and site observations and experiences with us. We also thank William Aljoe of the US Department of Energy who also graciously provided data, reports and insight into the Omega mine. The manuscript also benefited from the comments of several anonymous reviewers.

\section{$\underline{\text { Literature Cited }}$}

Bigham, J. M. and D. K. Nordstrom, 2000, Iron and Aluminum Hydroxysulfates from Acid Sulfate Waters, in Sulfate Minerals: Crystallography, Geochemistyr and Environmental Significance, Alpers, C.N. J.L. Jambor, D.K. Nordstrom (eds), Reviews in Mineralogy and Geochemistry Vol 40, Mineralogical Society of America.

Bruemmer, G.W., J. Gerth and K.G. Tiller, 1988, Reaction Kinetics of the Adsorption and Desorption of Nickel, Zinc and Cadmium by Goethite. I, Adsorption and Diffusion of Metals. Journal of Soil Science, Vol 39, pp 37-52.

Cleveland, W.S. and I.J. Terpenning, 1982, Graphical Methods for Seasonal Adjustment, Journal of American Statistical Association, Vol 77, No 377, pp 52-62.

Cleveland, W.S. and S.J. Devlin, 1988, Locally Weighted Regression: An Approach to Regression Analysis by Local Fitting. Journal. of American Statistical Association, Vol 83, No 403, pp 596-610. 
Demchek, J., J. Skousen and L.M. McDonald, (in press) Longevity of Acid Discharges from Above-Drainage Underground Mines, Journal of Environmental Quality.

Dulong, F.T, Fedorko, N., Renton, J.J., and C. B. Cecil, 2002, Chemical And Mineralogical Analyses of Coal-Bearing Strata In The Appalachian Basin, US Geological Survey Open file report 02-489.

EPRI, 2001, Omega Mine Injection Program: Monongalia County, West Virginia, report prepared by GAI Consultants for Electric Power Research Institute, Allegheny Energy Supply, and US Dept of Energy, EPRI, Palo Alto, CA.

Giehyeon, Lee, J. M. Bigham, and G. Faure, 2002, Removal of Trace Metals by Coprecipitation with $\mathrm{Fe}, \mathrm{Al}$ and $\mathrm{Mn}$ from Natural Waters Contaminated With Acid Mine Drainage in the Ducktown Mining District, Tennessee. Applied Geochemistry, Vol 17, Issue 5, pp. 569-581.

Glover, H.G., 1983, Mine Water Pollution- An Overview of Problems and Control Strategies in the United Kingdom, Water Sci. Technology, Vol 15, pp 59-70.

Gray, T.A., T.C. Moran, D.W. Broschart, and G.A. Smith, 1998, Plan for Injection of Coal Combustion Byproducts into the Omega Mine for the Reduction of Acid Mine Drainage, in Proceedings of the Nineteenth Annual West Virginia Surface Mine Drainage Task Force Symposium. $9 \mathrm{p}$.

Hawkins, J. W., 1994, Assessment of Contaminant Load Changes Caused by Remining of Abandoned Coal Mines, in Proceedings International Land Reclamation and Mine Drainage Conference and Third International Conference on the Abatement of Acidic Drainage. Vol 1, pp20-29, US Bureau of Mines Special Publication SP 06A-94.

Helsel, D.R. and R.M. Hirsch, 1992, Statistical Methods in Water Resources, Studies in Environmental Science 49, Elesevier, 529 p.

Hennen, R.V. and D.B. Reger, 1913, West Virginia Geological Survey County Reports, Marion, Monongalia and Taylor Counties, Wheeling News Litho Co., Wheeling, WV.

Larsen, F. and D. Postma, 1997, Nickel Mobilization in a Groundwater Well Field: Release by Pyrite Oxidation and Desorption from Manganese Oxides. Environmental Science and Technology, Vol 31, No. 9, pp 2589-2595.

Nordstrom, D. K. 1982, Aqueous Pyrite Oxidation and the Consequent Formation of Secondary Iron Minerals. In J.A.Kittrick, D.S. Fanning and L.R. Hossner eds) Acid Sulfate Weathering. Soil Science Society of America Special Publication 10. 
Nordstrom, D. K. 1982b, The Effect of Sulfate on Aluminum Concentrations in Natural Waters, Some Stability Relationships in the System $\mathrm{Al}_{2} \mathrm{O}_{3}-\mathrm{SO}_{3}-\mathrm{H}_{2} \mathrm{O}$ at $298 \mathrm{~K}$, Geochemica et Cosmochimica Acta, Vol 46, pp 681-692.

Nuhfer, E , 1967. Efflorescent Minerals Associated with Coal. MS Geology Thesis, Department of Geology and Geography West Virginia University.

Parkhurst, D. L. , and C. A. J Appelo., 1999. User's Guide to PHREEQC (Version 2)- A Computer Program for Speciation, Batch-Reaction, One-Dimensional Transport, and Inverse Geochemical Calculations. US Geological Survey Water Resources Investigation Report 994259.

Rose, A. W. and C. A. Cravotta, 1998, Geochemistry of Coal Mine Drainage. In K. B. Brady, M. W. Smith and J. Scheuck (eds), Coal Mine Drainage Prediction and Pollution Prevention in Pennsylvania., Pennsylvania Dept. Environmental Protection.

Rimstidt, J.D., and D.J. Vaughan, 2003, Pyrite Oxidation: A State of the Art Assessment of the Reaction Mechanism, Geochemica et Cosmochimica Acta, Vol 67, No 5, pp. 873-880.

Younger, P.L.,1997, The Longevity of Minewater Pollution: A Basis for Decision Making, The Science of the Total Environment, Volume 194-195, pp. 457-466.

West Virginia Geological and Economic Survey, 2002, Trace Elements in West Virginia Coals, http://www.wvgs.wvnet.edu/www/datastat/te/index.htm. 


\section{$\underline{\text { Appendix B }}$}

Modelling rock-water interactions in flooded underground coal mines, Northern Appalachian Basin

Geochemistry: Exploration, Environment, Analysis, Vol. 1 2001, pp. 61-70 


\title{
Modelling rock-water interactions in flooded underground coal mines, Northern Appalachian Basin
}

\author{
Eric F. Perry ${ }^{1}$ \\ ${ }^{1}$ West Virginia University and US Dept of Interior, Office of Surface Mining 3 Parkway Center, Pittsburgh, Pennsylvania, \\ USA (e-mail: eperry@osmre.gov)
}

\begin{abstract}
Inverse geochemical modelling was used to investigate rock-water interactions in flooded underground coal mines in northern Appalachia, USA. In early flooding, Pittsburgh seam mine waters are usually acidic (c. pH 3), with dissolved metals $\mathrm{Fe}$ and $\mathrm{Al}$ ranging from 10 to $>100 \mathrm{mg} \mathrm{l}^{-1}$. Within a few decades, however, waters in fully flooded mines usually have $\mathrm{pH}$ of about 7 S.U., and alkalinity $>300 \mathrm{mg} \mathrm{l}^{-1} \mathrm{CaCO}_{3}$ Eq. Eh shifts from oxidizing (c. 500 to $700 \mathrm{mv}$ ) to reduced ( -100 to $-200 \mathrm{mv}$ ) conditions. Sodium concentrations may increase an order of magnitude; sulphate and iron concentrations may also increase. Water samples were collected from several mine-pools in West Virginia and Pennsylvania. A conceptual model was developed based on quantitative hydrology, mine-pool chemistry, mining conditions and mineralogy. The model was tested with the geochemical code PHREEQC. Simulations included mixing recharge and acid mine waters, precipitation-dissolution reactions involving carbonates, sulphates, oxyhydroxides and sulphides, and ion adsorption and exchange. Na exchange was a dominant process in all models. Carbonates are orders of magnitude undersaturated in the juvenile mine-pool, but near saturation in the mature mine-pool, suggesting they are a primary source of acid neutralization and alkalinity. The mature mine-pool is simultaneously near equilibrium with iron sulphide, iron carbonate and iron oxy-hydroxide mineral phases. The rapid change in mine-pool water quality has substantial implications for management of these systems. Corresponding author eperry@osmre.gov
\end{abstract}

KEYWORDS: mine-pool, acid drainage, Pittsburgh seam, neutralization, inverse model, ion exchange, sulphate salts

\section{INTRODUCTION}

Bituminous coals of the northern Appalachian basin of the U.S. have been mined by underground methods for over 100 years. One of the most valuable and extensively mined coal beds is the Pittsburgh seam (Monongahela group, upper Pennsylvanian system). During active mining, underground works are dewatered by pumping. When mines are closed, however, dewatering is discontinued, and the underground mine voids flood by infiltration from overlying aquifers, stream leakage and inflow from adjacent flooded mines. In early flooding of Pittsburgh seam mines, waters are often strongly acidic (c. $\mathrm{pH} 3.0$ ) with dissolved metals $\mathrm{Fe}$ and $\mathrm{Al}$, ranging from 10 to $>100 \mathrm{mg} \mathrm{l}^{-1}$. Sulphate concentrations may range from 1000 to $>7000 \mathrm{mg} \mathrm{l}^{-1}$.

Mining companies and regulatory agencies have observed a change in water quality in some flooded Pittsburgh seam mines located below base level drainage, where the coal bed does not crop out. Characteristic of this is a change from acidic to circumneutral conditions within a few decades after flooding. Few of these mines have been monitored systematically, however, for long periods after closure. Donovan et al. (1999) describe one well documented case of water quality evolution in below-drainage Pittsburgh seam mines, where a systematic

Geocbemistry: Exploration, Environment, Analysis, Vol. 1 2001, pp. 61-70 record was compiled, and mining history and geological conditions were known. They summarized 15 years of raw (untreated) water quality data from a pumping well in a Pennsylvania mine-pool. Based on reported pumping rates and analysis of detailed mine maps, the time to remove one pool volume was estimated to be about 7.4 years. Table 1 shows median values for about one year of monitoring during removal of the first pool volume (early flooding ) at about 4 years of pumping, and a second subset after about 14 years of pumping (late flooding) from the data compiled by Donovan et al. (1999). Over about a ten year period, $\mathrm{pH}$ increased about two S.U. and the water changed from net acid to net alkaline. Iron, the major dissolved metal, declined to about $10 \%$ of its initial concentration, as did manganese and metal acidity. Large concentrations of sodium and sulphate were attenuated to about 30 and $20 \%$ of their initial concentrations, respectively. Donovan et al. (1999) also reported the acid waters to be at or near saturation for gypsum in the first two years of flooding, and approaching saturation for calcite as the water turned net alkaline and $\mathrm{pH}$ increased. They attribute the change in pool quality, at least in part, to carbonate neutralization and flushing of acid weathering products.

Donovan et al. (1999) also noted the influence of hydrological setting in determining post-mining water quality of

1467-7873/01/\$15.00 C2001 AEG/Geological Sociery, London 
Table 1. Ean'y and late flooding quality from a pumped mine-pool in Pennsyluania, Pütsburgh Seam ${ }^{\gamma}$

\begin{tabular}{lcccrrrrrrrrr}
\hline Parameter & pH & Alkalinity & Metal acidity & Fe & Mn & Al & Ca & Mg & Na & K & $\mathrm{Cl}^{2}$ & $\mathrm{SO}_{4}$ \\
\hline Early $^{2}(n=50)$ & 4.4 & N.D. & 1831 & 931 & 15.8 & 20.6 & 371 & 200 & 2007 & 12 & 628 & 7000 \\
Late $^{3}(n=14)$ & 6.6 & 357 & 158 & 87 & 1.3 & 0.2 & 142 & 49 & 774 & 5.6 & 310 & 1445 \\
\hline
\end{tabular}

${ }^{1}$ Data excerpted from Donovan et al. 1999. pH in S.U., metal acidity in $\mathrm{CaCO}_{3}$ Eq, all others in $\mathrm{mg} / \mathrm{l}^{-1} \cdot{ }^{2}$ Median of samples from July 1984-July 1985. ${ }^{3}$ Median of samples from February 1994-October 1995.

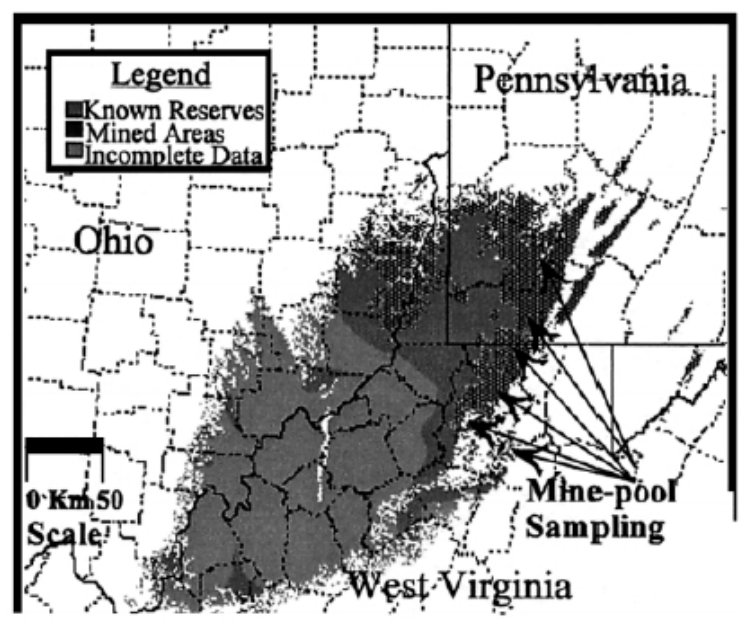

Fig. 1. Arcal extent of the Pittsburgh coal and mined areas (after Ruppert ef al. 1999), and counties with mine-pool quality sampling.

underground mines. They summarized data for six Pittsburgh seam discharges located above base level drainage, and compared them to water quality from below drainage mines. The above drainage mines are free draining and discharge strongly acidic water ( $\mathrm{pH} 2-3$, metal acidity about 1100 to $1800 \mathrm{mg} \mathrm{l}^{-1}$ $\mathrm{CaCO}_{3} \mathrm{Eq}$ ) and showed little change in composition after 20 years. The flooded below drainage mines have circumneutral $\mathrm{pH}$ and about $10 \%$ of the metal acidity concentrations of the above drainage waters.

Flooding controls on mine water quality are usually attributed to eliminating oxidizers, either oxygen or $\mathrm{Fe}$ (III) for sulphide oxidation. Flooding has been advocated to limit sulphide oxidation in tailings (Robertson et al. 1997) and reduced pollutant loads in some Appalachian underground coal mines (Bucek \& Emel 1977). This study was an initial investigation of processes controlling the observed evolution of waters from acidic to alkaline conditions in below drainage Pittsburgh seam mine-pools. The processes investigated included mixing of recharge and acid mine waters, precipitation-dissolution reactions involving carbonates, sulphates, oxy-hydroxides and sulphides; and ion adsorption and exchange. These initial investigations were not intended as site specific transport modelling efforts.

\section{Stratigraphy and structure}

The Pittsburgh coal bed is located at the base of the Monongahela group of the Upper Pennsylvanian system. This coal bed is in an elongated basin, with the main axis trending SW to NE in northen Appalachia, USA. A series of small anticlines and synclines are superimposed on the main structure. It covers parts of Pennsylvania, Maryland, West Virginia and Ohio (Fig. 1). Throughout much of the basin, the coal lies

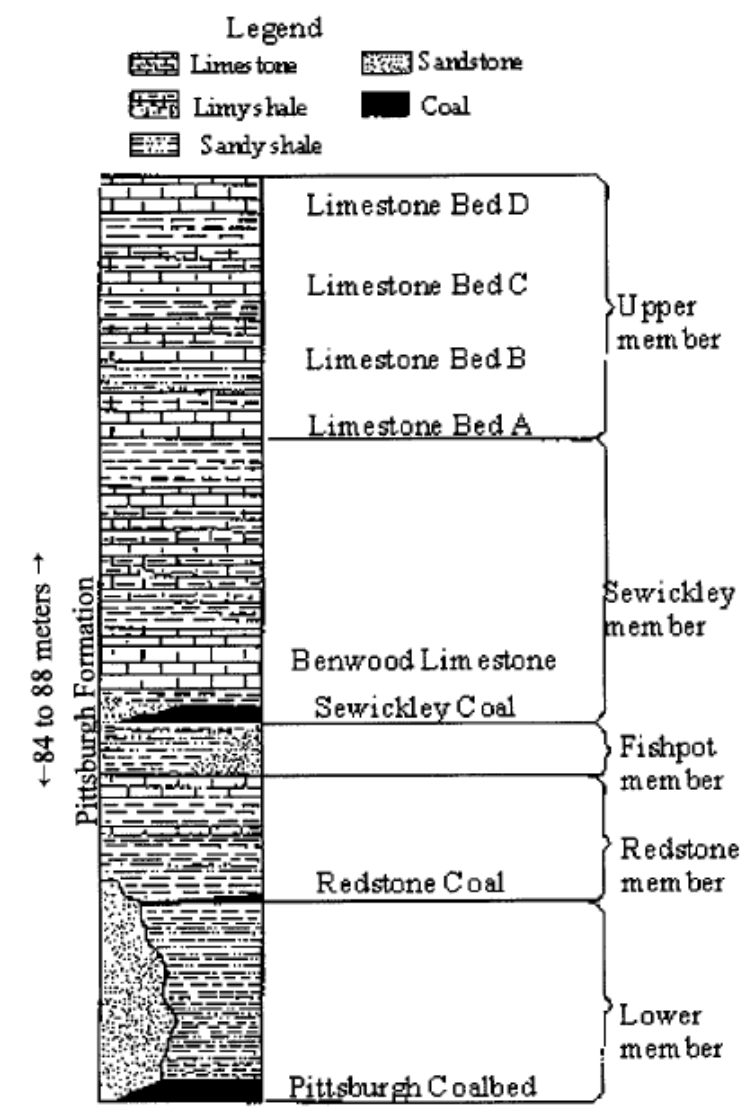

Fig. 2. Generalized stratigraphic column of the Pittsburgh coal and overburden, lower Monongahela group (after McCullogh et al. 1975).

below elevation of local major drainage systems, at depths ranging from 60 to $>300 \mathrm{~m}$, but is at or near outcrop along parts of the basin margin (McCullogh et al. 1975). Of the estimated 31 billion tonnes of original reserves, about 14 billion tonnes remain (Ruppert et al. 1999).

The Pittsburgh coal is typically $2-3 \mathrm{~m}$ thick, and is overlain by a sequence of interbedded calcareous shales, siltstones, limestones, coals and sandstones. A generalized stratigraphic column for the lower part of the Monongahela group is shown in Figure 2. Over much of the basin, limestones and calcareous shales overlie the coal, but rapid facies changes produced channel sandstone roofrock in some areas (McCullogh et al. 1975). The seatrock beneath the coal varies from limestone to shale to sandstone (Donaldson et al. 1979) and is usually calcareous. Kaolinite and illite are the most common clay minerals in the overburden (O'Neill \& Barnes 1979) and coal (Renton 1979). 
Table 2. Representative sulpbor and carbonate equivalent content of overburden above the Pittsbungh codl

\begin{tabular}{lcccc}
\hline Lithology & $\begin{array}{c}\text { Thickness } \\
(\mathrm{m})\end{array}$ & $\begin{array}{c}\text { Height above coal } \\
(\mathrm{m})\end{array}$ & $\begin{array}{c}\% \mathrm{~S} \\
\text { (total) }\end{array}$ & $\begin{array}{c}\% \\
\mathrm{CaCO}_{3} \text { Eq. }\end{array}$ \\
\hline Shale & 0.79 & 7.70 & 0.82 & 3.9 \\
Shale & 1.18 & 6.52 & 0.49 & 4.2 \\
Redstone coal & 0.04 & 6.48 & 6.81 & 1.6 \\
Shale & 0.62 & 5.86 & 0.74 & 3.2 \\
Limestone & 0.94 & 4.92 & 0.88 & 51.3 \\
Limestone & 0.97 & 3.95 & 0.04 & 66.8 \\
Limestone & 0.94 & 3.01 & 0.09 & 54.5 \\
Claystone & 1.17 & 1.84 & 0.74 & 22.7 \\
Claystone & 1.16 & 0.68 & 0.73 & 13.8 \\
Limestone & 0.23 & 0.45 & 1.90 & 49.0 \\
Shale & 0.45 & 0 & 1.44 & 7.1 \\
Pittsburgh coal & 2.13 & - & - & - \\
Shale & 0.94 & - & 0.84 & 4.7 \\
& \multicolumn{4}{l}{} \\
\hline
\end{tabular}

Table 2 shows representative total sulphur and calcium carbonate equivalent content for about $8 \mathrm{~m}$ of overburden directly above the Pittsburgh seam in a West Virginia mine. The analyses are unpublished data from a mine permit application, and were generated using Acid/Base Accounting (ABA). ABA was developed to assess the acid and alkalinity generating capacity of rocks on mines (Sobek et al. 1978), and is widely used in the Appalachian basin for mine assessments. In unweathered sedimentary rocks in Appalachia, except for coals and carbonaceous shales, total sulphur closely corresponds to pyrite content (Sobek et al. 1978). It is used to estimate potential acid generation from pyrite oxidation. $\mathrm{ABA}$ also reports a percentage $\mathrm{CaCO}_{3}$ equivalent or acid neutralizers for the rock. This analysis does not identify the specific minerals contributing to the measurement but reports them on the basis of pure calcite equivalent. Most of the interval in Table 2 between the Pittsburgh coal and Redstone coal horizon is an impure limestone interbedded with calcareous shale. Analyses of the Redstone limestone horizon in West Virginia show a Ca:Mg molar ratio ranging from about $13: 1$ to as low as about $3: 1$ (McCue et al. 1939). The Pittsburgh coal itself contains about $1-3 \%$ total sulphur with higher concentrations in the top and bottom of the bed and shale partings (Donaldson et al. 1979).

\section{Mining methods}

Coal extraction in Pittsburgh seam mines includes room and pillar with retreat mining, and modern longwall extraction. Extraction rates typically range from about $60-80 \%$. In longwall mines, subsidence is immediate, but more difficult to predict over room and pillar mines, where voids may stand open for decades. Before subsidence, the mine- pool aquifer consists principally of mine voids. After subsiding, the overburden rocks include a collapsed rubble zone which is estimated to extend upwards from two to eight times coal height (Peng 1986), and an overlying fractured zone estimated to extend to a height 30 to 60 times coal thickness (Tieman \& Rauch 1987). The mine-pool aquifer then consists of any remaining void at coal elevation plus the collapsed zone. Thus, water quality of the mine-pool aquifer is controlled by rocks at mine level, part of the collapsed overburden, and by leakage from overlying strata.

\section{Groundwater flow system}

The mine-pool is composed of water that infiltrates from overlying strata, leakage from adjacent flooded mines, leakage

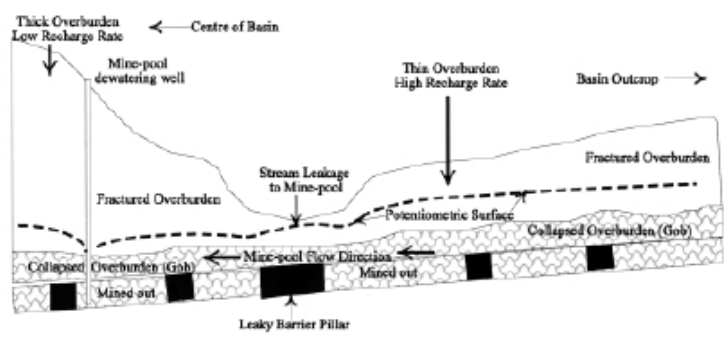

Fig. 3. Generalized cross-section of Pittsburgh Seam mine-pool flow system (no scale).

from streams, and sometimes injection of treated wastewater. The key features controlling mine-pool recharge, flow direction and storage are overburden thickness, barrier pillars, mine dewatering and structure. Figure 3 is a simplified cross-section of flow and recharge in a below drainage mine-pool. In early flooding, the down-dip mine voids fill first. As flooding progresses, hydraulic head increases until the mine either floods completely, the pool discharges to the surface or another mine, or is controlled by pumping. In a completely flooded below drainage mine, the pool acts a as leaky confined aquifer. The potentiometric surface measured in one West Virginia mine-pool ranges from about 6 to $>45 \mathrm{~m}$ above mine level.

The overburden above the coal behaves like a leaky aquitard with vertical leakance strongly dependent on mine depth. Stoner et al. (1987) estimated mine recharge rates as ranging from about $2 \mathrm{~cm} \mathrm{a}^{-1}$ to $12.3 \mathrm{~cm} \mathrm{a}^{-1}$ in Pittsburgh seam mines in Pennsylvania. Highest rates were under thinner overburden. Leavitt (pers. comm. 1998) developed an exponential relationship between mine recharge rate and overburden thickness, based on records from 16 underground mines, most in the Pittsburgh seam. Mine recharge rate decreases as overburden thickness increases in Leavitt's model. Thickness effects likely relate to a decrease in fracture density and size with increasing depth (Schmidt 1985). Hobba (1984) noted that some undermined watersheds in the Pittsburgh seam contained losing streams that were leaking into (recharging) the mine-pool. Mine-pool recharge rates are therefore, not uniformly distributed, but tend to be highest under thin overburden and losing stream valleys.

The simplified mine-pool scenario shown in Figure 3 contains a barrier pillar, a zone of unmined coal left in place between mines. Barrier pillars may be as thin as $10 \mathrm{~m}$, but are often $60 \mathrm{~m}$ or greater in modern mining, and thickness greatly influences the leakage rate between mines. In Figure 3, the down-dip barrier pillar is thin and leaky, and flow is down dip toward the centre of the basin. Leakage is accelerated by pumping from a down-dip well. If the barrier pillars are thick enough to minimize leakage, flow direction can be reversed and the mine-pool discharges at the coal outcrop. That scenario is also occurring within the basin.

\section{METHODS}

Water samples were collected along the eastern margin of the basin in counties in West Virginia and Pennsylvania (Fig. 1) and supplemented with selected literature data. Samples were collected where the mine- pool flow path was known or inferred from mine maps, water level measurements and discharge data. Samples were classed as juvenile (beginning of flowpath), intermediate or mature (end of flowpath). Water quality samples were collected after purging wells until stable temperature and specific conductance readings were obtained. Field 
measurements and analytical parameters from monitoring wells, springs and mine shafts included:

(1) Field measured $\mathrm{pH}$, temperature, Specific Conductance, and Eh (Pt electrode);

(2) Lab measured $\mathrm{pH}$, Specific Conductance, Alkalinity, Total Acidity, Total Fe, Mn and Al, Total Dissolved Solids and Total Suspended Solids;

(3) Dissolved $\mathrm{Ca}, \mathrm{Mg}, \mathrm{Na}, \mathrm{K}, \mathrm{Cl}, \mathrm{SO} 4, \mathrm{Fe}, \mathrm{Mn}, \mathrm{Al}$;

(4) Trace elements $\mathrm{As}, \mathrm{Ba}, \mathrm{Cd}, \mathrm{Co}, \mathrm{Cr}, \mathrm{Cu}, \mathrm{Ni}, \mathrm{Pb}, \mathrm{Sb}, \mathrm{Se}, \mathrm{Zn}$; and

(5) Selected samples for dissolved sulphide and ferrous iron.

Samples for dissolved constituents and trace elements were field filtered $(0.45 \mu \mathrm{m}$ pore size); total and dissolved metals were preserved with $\mathrm{HNO}_{3}$, ferrous iron samples were preserved with $\mathrm{HCl}$, and dissolved sulphide samples were preserved with $\mathrm{Zn}$ acetate. Samples were chilled and delivered to a commercial lab within $48 \mathrm{~h}$ of collection. Lab analyses were conducted following standard methods (Cherceri et al. 1998). Charge balance on reported analyses was typically within 2 to $3 \%$.

Geochemical modelling simulations were run with the code PHREEQC (Parkhurst 1995; Parkhurst \& Appelo 1999). Inverse modelling was conducted using three solutions, representing 'average' compositions for a juvenile mine water, a mature mine water and a recharge water. Composition of the juvenile and mine-pool waters are median values from analyses collected or reviewed in this work and were developed from about two dozen analyses of Pittsburgh seam mine waters. 'Average' composition of the recharge water is from data compiled by Hobba (1984) for groundwater analyses from 38 wells in the Monongahela Group in West Virginia. No Eh values were reported for the recharge water, so the PHREEQC default, pe equal to 4, was assigned. Initially, the three solutions were speciated using PHREEQC, and the results examined for mineral saturation indices, and partial pressures of gases. Inverse model simulations included only mixing and mineral precipitation/dissolution, followed by runs which also included ion exchange.

\section{MINE-POOL AND RECHARGE WATER COMPOSITION}

Median composition of the recharge, juvenile and mature mine-pool water used in geochemical modelling are shown in Table 2. In keeping with the objective of an initial investigation and modelling, makeup of these solutions represents a 'typical' water, not necessarily a site specific case. For each solution however, there are individual sample analyses that correspond closely to the 'average' composition. For most parameters, a range of values from which the median was taken is also shown in Table 3. Mine waters are especially variable in dissolved iron and aluminium content, yet each solution exhibits distinctive properties.

The juvenile mine water is a calcium-magnesium sulphate solution that is strongly acidic, and contains elevated concentrations of $\mathrm{Fe}, \mathrm{Al}$ and sulphate, all characteristic of acid drainage in the northern Appalachian basin. Dissolved solids content is about $2800 \mathrm{mg} \mathrm{l}^{-1}$. The mature mine water is a sodium sulphate solution and shows a $\mathrm{pH}$ increase of about 4 S.U., alkalinity about $500 \mathrm{mgl}^{-1} \mathrm{CaCO}_{3}$ equivalent, a tenfold increase in sodium content, and $50 \%$ increase in sulphate concentration compared to the juvenile mine water. Dissolved solids content is about $5700 \mathrm{mg} \mathrm{l}^{-1}$. Redox potential declines from oxidized $(\mathrm{Eh}=+511 \mathrm{mv})$ in the juvenile mine water to reduced conditions ( $\mathrm{Eh}=-170 \mathrm{mv})$ in the mature mine water. The recharge water is a calcium bicarbonate solution and is
Table 3. Composition of solutions used in inverse modelling

\begin{tabular}{|c|c|c|c|}
\hline Parameter & $\begin{array}{l}\text { Juvenile } \\
\text { mine water }\end{array}$ & $\begin{array}{c}\text { Recharge } \\
\text { water }\end{array}$ & $\begin{array}{c}\text { Mature } \\
\text { mine water }\end{array}$ \\
\hline $\mathrm{pH}$ & $\begin{array}{c}3.3 \\
(2.2-4.8)\end{array}$ & $\begin{array}{c}7.4 \\
(5.8-9.0)\end{array}$ & $\begin{array}{c}7.3 \\
(6.6-8.4)\end{array}$ \\
\hline Eh, mv & $\begin{array}{c}511 \\
(80-648)\end{array}$ & $\begin{array}{l}227 \\
-\end{array}$ & $\begin{array}{c}-170 \\
(-14 \text { to }-230)\end{array}$ \\
\hline Temperature $\left(\mathrm{C}^{\circ}\right)$ & 13 & 13 & 13 \\
\hline Alkalinity $\left(\mathrm{mg} / \mathrm{LCaCO}_{3} \mathrm{Eq}\right)$ & $<1$ & $\begin{array}{c}259 \\
(5-754)\end{array}$ & $\begin{array}{c}510 \\
(230-1000)\end{array}$ \\
\hline $\mathrm{Ca}$ & $\begin{array}{c}340 \\
(280-710)\end{array}$ & $\begin{array}{c}27 \\
(1.1-69)\end{array}$ & $\begin{array}{c}305 \\
(90-448)\end{array}$ \\
\hline $\mathrm{Mg}$ & $\begin{array}{c}134 \\
(57-225)\end{array}$ & $\begin{array}{c}7 \\
(0.3-19)\end{array}$ & $\begin{array}{c}103 \\
(30-200)\end{array}$ \\
\hline $\mathrm{Na}$ & $\begin{array}{c}139 \\
(105-823)\end{array}$ & $\begin{array}{c}120 \\
(9-356)\end{array}$ & $\begin{array}{c}1330 \\
(540-1700)\end{array}$ \\
\hline K & $\begin{array}{c}6 \\
(3-10)\end{array}$ & - & $\begin{array}{c}13 \\
(5-32)\end{array}$ \\
\hline $\mathrm{SO}_{4}$ & $\begin{array}{c}2050 \\
(600-7300)\end{array}$ & $\begin{array}{c}40 \\
(2-203)\end{array}$ & $\begin{array}{c}3185 \\
(900-5450)\end{array}$ \\
\hline $\mathrm{Cl}$ & $\begin{array}{c}30 \\
(5-174)\end{array}$ & $\begin{array}{c}19.1 \\
(1-66)\end{array}$ & $\begin{array}{c}108 \\
(11-1300)\end{array}$ \\
\hline $\mathrm{Fe}$ & $\begin{array}{c}45 \\
(7-1655)\end{array}$ & $\begin{array}{c}1.06 \\
(0.1-16)\end{array}$ & $\begin{array}{c}138 \\
(3-202)\end{array}$ \\
\hline $\mathrm{Al}$ & $\begin{array}{c}30 \\
(1.5-203)\end{array}$ & - & $\begin{array}{c}0.04 \\
(0.02-0.2)\end{array}$ \\
\hline $\mathrm{Si}$ & 20 & 15 & 15 \\
\hline
\end{tabular}

$\overline{{ }^{1} \text { Elemental concentrations in } \mathrm{mg} \mathrm{l}^{-1} \text {. Mine water median values based on } 24}$ analyses, recharge water based on 38 values reported by Hobba (1984). Values in parentheses are ranges.

much less mineralized than either mine water, with dissolved solids content of about $500 \mathrm{mg} \mathrm{l}^{-1}$.

\section{CONCEPTUAL MODEL OF MINE-POOL EVOLUTION}

Pittsburgh seam mine-pools often shift from acid, oxidized conditions to reduced, alkaline, conditions within a few decades of mine closure and flooding. Mineralization increases, and solution composition evolves from calcium-magnesium sulphate to sodium sulphate with high concentrations of dissolved iron (Table 3 ). The observed water quality changes suggest that significant acid neutralization and generation of alkalinity occurs, and that readily soluble minerals and a sodium source are present. A conceptual model was formulated that would account for acid neutralization, soluble minerals and a sodium source, based on examination of solution compositions (Table 3), mineral saturation indices calculated in PHREEQC (Table 4), mineralogy and mine-pool flow path system. The model is focused on the behaviour of the major components $\mathrm{Fe}, \mathrm{Ca}, \mathrm{Mg}$, $\mathrm{Na}$ and $\mathrm{S}$, in the mine-pool system. Processes included acid neutralization, sulphate salt and carbonate dissolution, and ion exchange. Sulphate and iron oxide reduction, and carbonate and sulphide precipitation were also considered possible secondary processes. The mature mine-pool water is considered to be a product of:

(1) The initial flooding solution or juvenile mine-pool;

(2) mixing of the juvenile mine-pool with recharged (leakage) from overlying aquifers and streams, and sometimes leakage from adjacent flooded mines; and

(3) mineral precipitation/dissolution and ion exchange reactions along the flowpath.

The conceptual model is shown in Figure 4. 
Table 4. Seleded mineral saturation indices for solutions used in inverse modelling

\begin{tabular}{lccc}
\hline Mineral phase & $\begin{array}{c}\text { Juvenile } \\
\text { mine water }\end{array}$ & $\begin{array}{c}\text { Recharge } \\
\text { water }\end{array}$ & $\begin{array}{c}\text { Mature } \\
\text { mine water }\end{array}$ \\
\hline $\mathrm{Al}(\mathrm{OH})_{3}(\mathrm{a})$ & -6.18 & - & -0.80 \\
$\mathrm{Alunite}$ & -2.01 & - & -2.75 \\
$\mathrm{pCO}_{2}(\mathrm{~g})$ & -1.00 & -1.98 & -1.69 \\
$\mathrm{Calcite}_{\text {Dolomite }}$ & -6.77 & -0.32 & 0.38 \\
Dolomite(d) & -13.76 & -1.05 & 0.48 \\
$\mathrm{Fe}(\mathrm{OH})_{3}(\mathrm{a})$ & -14.36 & -1.65 & -0.12 \\
$\mathrm{Fe}(\mathrm{OH})_{\mathrm{B}}$ & -2.91 & 2.84 & -2.62 \\
$\mathrm{FeS}(\mathrm{ppt})$ & -13.25 & 4.89 & -4.38 \\
Goethite & -64.70 & -60.47 & -0.27 \\
Gypsum & 2.54 & 8.29 & 2.83 \\
$\mathrm{~K}-$ Jarosite & -0.18 & -2.35 & -0.18 \\
Jurbanite & -3.96 & - & -14.48 \\
Melanterite & -0.11 & - & -2.57 \\
Pyrite & -3.40 & -6.36 & -2.96 \\
Siderite & -96.80 & -96.80 & 7.77 \\
Siderite(d) & -5.38 & 0.28 & 2.21 \\
& -5.75 & -0.08 & 1.85 \\
\hline
\end{tabular}

${ }^{1}$ Mineral saturation indices calculated in PHREEQC as log (Ion Activity Product/Equilibrium Constant).

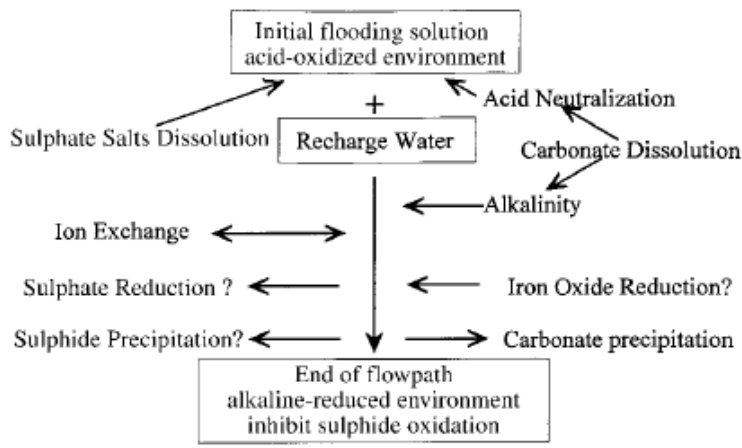

Fig. 4. Conceptual model of mine-pool water quality cvolution.

\section{Sulphate salts}

During active coal removal, the mineworks are dewatered and ventilated. The humid aerated mine atmosphere provides ideal conditions for the oxidation of pyrite to produce acidity and metal oxy-hydroxide minerals as shown in the following summary equation:

$$
\mathrm{FeS}_{2}+3.75 \mathrm{O}_{2}+3.5 \mathrm{H}_{2} \mathrm{O} \rightarrow 4 \mathrm{H}^{+}+2 \mathrm{SO}_{4}^{2-}+\mathrm{Fe}(\mathrm{OH})_{3} \text { (1) }
$$

In many instances, however, sulphate minerals form as intermediate products of sulphide oxidation in coal and mine waste rock, and are often readily visible in mines as white and yellow precipitates. Some sulphate minerals that have been identified in Pittsburgh seam mines and Appalachian coal measures include gypsum, melanterite, halotrichite, pickeringite, copiapite, rozenite, and various jarosites (Nuhfer 1967; Rose \& Cravotta 1998). Many of these salts are moderately soluble and can redissolve when the mine floods. Table 4 shows both the juvenile and mature mine waters to be slightly under saturated with respect to gypsum, and three or more orders of magnitude under saturated for melanterite and K-Jarosite. Similar trends for sulphate mineral saturation indices exist in about 24 individual mine water analyses compiled by the author (unpublished data). These minerals, if present, should dissolve during mine flooding, and could account for the observed increase in sulphate concentration from juvenile to mature mine water. Even though they are present in mines, some complex sulphate salts like copiapite lack consistent thermodynamic data, and are not included in PHREEQC model calculations. Except for gypsum, sulphate minerals can be a source of stored metals and acidity as shown by the net reaction for complete dissolution of copiapite, followed by oxidation and hydrolysis of iron.

$$
\begin{aligned}
\mathrm{Fe}(\mathrm{II}) \mathrm{Fe}_{4}(\mathrm{III})\left(\mathrm{SO}_{4}\right)_{6}(\mathrm{OH})_{2} \cdot 20 \mathrm{H}_{2} \mathrm{O}+1 / 4 \mathrm{O}_{2} \\
\rightarrow 5 \mathrm{Fe}(\mathrm{OH})_{3}+12 \mathrm{H}^{+}+6 \mathrm{SO}_{4}^{2-}+71 / 2 \mathrm{H}_{2} \mathrm{O}
\end{aligned}
$$

If iron hydrolysis is incomplete, the solution accumulates high concentrations of dissolved iron.

\section{Inhibiting sulphide oxidation}

Pyrite is characteristically oxidized by either $\mathrm{Fe}(\mathrm{III})$ or $\mathrm{O}_{2}$ (Rose \& Cravotta 1998). In fully flooded Pittsburgh seam mines, for 12 samples, the author has not found detectable levels of dissolved oxygen. In about 15 samples speciated for $\mathrm{Fe}(\mathrm{II}) /$ $\mathrm{Fe}(\mathrm{III})$, ferrous iron typically is $99 \%$ or more of the dissolved fraction, and $\mathrm{Fe}(\mathrm{III})$ is often below detection. Thus, after initial flooding, dissolved oxygen and $\mathrm{Fe}(\mathrm{III})$ are present only in small concentrations and further sulphide oxidation should be inhibited.

\section{Acid neutralization and alkalinity}

Collapsed overburden or 'gob' frequently contains horizons with five to $>50 \%$ carbonate (Table 2), and the seat-earth or mine floor rock is often calcareous (Donaldson et al. 1979). Brady (1998) reports that calcite, dolomite and siderite have been identified as the dominant carbonate minerals in the Monongahela and overlying Dunkard groups in Pennsylvania. All carbonate minerals are orders of magnitude undersaturated in the juvenile mine-pool (Table 4). The mature mine-pool, however, is slightly oversaturated for both calcite and dolomite, and about two orders of magnitude oversaturated for the iron carbonate siderite. Similar trends for carbonate mineral saturation indices exist in about 24 individual mine water analyses compiled by the author (unpublished data). Carbonate minerals are at first dissolving, neutralizing acidity and generating alkalinity in the mine-pool, and perhaps precipitating at the end of the flowpath. The recharge water is undersaturated for calcite and dolomite (Table 4), indicating both carbonates should dissolve and generate alkalinity. Acid neutralization available from the gob zone of fractured, broken carbonate rock and continuous infiltration of alkaline recharge water exceed the overall acid generating capacity (estimated from total sulphur content) of acid forming rock remaining in the mine-pool aquifer. Thus, given sufficient recharge and reaction time, acidity present initially should be neutralized, and the system should eventually turn alkaline.

\section{Ion exchange}

Sodium increases by roughly tenfold in mature mine water, and evolution from $\mathrm{Ca} / \mathrm{Mg}$ dominated to $\mathrm{Na}$ dominated water may result from cation exchange of $\mathrm{Ca}, \mathrm{Mg}$ or $\mathrm{Fe}(\mathrm{II})$ with adsorbed sodium. Donovan et al. (1999) also report high concentrations of sodium in Pittsburgh seam mine waters (Table 1). Chloride concentrations do not increase stoichiometrically with sodium in the mature mine water, as would be expected if brine water is entering the mine-pool. Back (1966) in a study of hydrochemical facies and groundwater flow, noted a progressive 


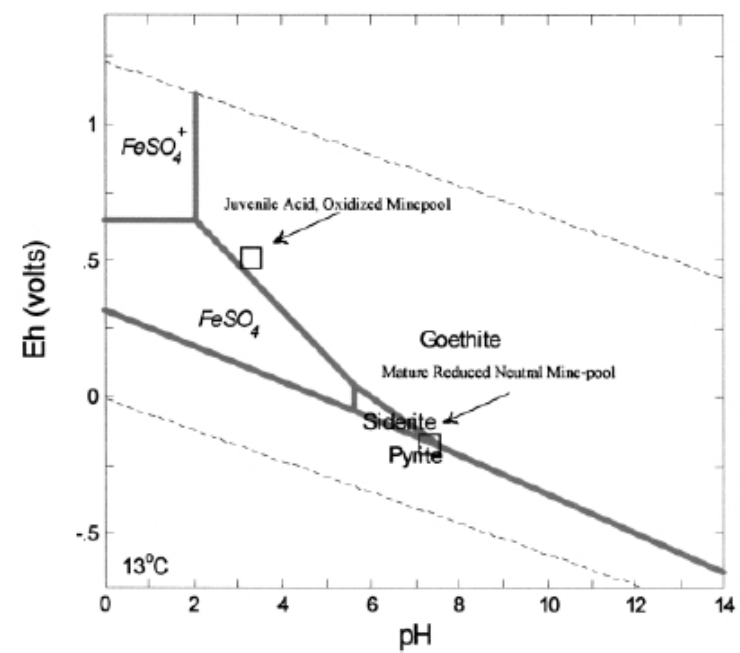

Fig. 5. Eh/ $/ \mathrm{pH}$ iron stability fields for mine-pool waters with Gocthite at $13^{\circ} \mathrm{C}$.

change from $\mathrm{Ca} / \mathrm{Mg}$ dominated water to $\mathrm{Na}$ dominated water along a flow path in some Atlantic Coastal Plain aquifers. The differentiation was attributed to ion exchange.

The mineral fraction of northern Appalachian coals and the seat-rock and overburden have been reported to contain kaolinite and illite (McCullogh et al. 1975; Renton 1979) and Johnson \& Skousen (1995) reported cation exchange capacity of $10-30 \mathrm{cmol} \mathrm{kg}^{-1}$ in 25 to 33 year old waste rock from surface mine sites on the Pittsburgh seam.

\section{Iron oxy-hydroxide minerals}

Iron floc precipitating from acid mine waters commonly contains a mixture of mineral phases ranging from poorly crystalline $\mathrm{Fe}(\mathrm{OH})_{3}$, to ferrihydrite, schwertmannite and goethite (Ferris et al. 1989; Bigham et al. 1996; Rose \& Elliot $2000)$. The more soluble oxy-hydroxide minerals $\mathrm{Fe}(\mathrm{OH})_{3}(\mathrm{am})$ and ferrihydrite, are under saturated by more than two orders of magnitude in both the juvenile and mature mine-pool waters (Table 4), indicating that these minerals are not likely to precipitate. Twenty four of 28 individual mine water samples (authors unpublished data) are under saturated for $\mathrm{Fe}(\mathrm{OH})_{3}(\mathrm{am})$ and ferrihydrite by two or more orders of magnitude. If they are already present in the aquifer at flooding, they could dissolve, or convert to more stable oxide minerals, as suggested by Nordstrom's (1982) diagram of pyrite weathering. Goethite is over saturated by more than two orders of magnitude in both the juvenile and mature mine waters (Table 4) and 28 individual analyses, showing that precipitation of this mineral is possible.

Figure 5 is an $\mathrm{Eh} / \mathrm{pH}$ plot of iron stability fields with goethite as the dominant Fe(III) mineral, and contains the juvenile and mature mine-pool waters. Iron activity in the acid juvenile water appears to be controlled by oxy-hydroxide minerals. The mature mine-pool water, however, plots near the intersection of the goethite, siderite and pyrite stability fields, suggesting that iron has several possible source/sink minerals.

\section{Sulphate reduction}

Sulphate reducing bacteria (SRB) have been detected in a present/absent test in four wells in a West Virginia mine pool.
Eh and $\mathrm{pH}$ conditions (Table 3 ) are within a range considered conducive to SRB activity (Baas Becking et al. 1960; Barton 1995). Individual mine-pool samples contain trace to about $0.6 \mathrm{mg} \mathrm{l}^{-1}$ dissolved sulphide, and the characteristic 'rotten egg smell' of $\mathrm{H}_{2} \mathrm{~S}$ gas has been noted in some samples.

\section{Sulphide precipitation}

Pyrite is over saturated and FeS precipitate (ppt) is approaching saturation in the mature mine-pool (Table 4). Mineral saturation indices plus the presence of dissolved sulphide and ferrous iron suggests that precipitation of an iron monosulphide is possible. Once precipitated, monosulphides gradually convert to pyrite (Schoonen \& Barnes 1991).

Equilibrium Eh values were computed for several redox couples with the Nernst equation to determine how closely the mature solution approaches equilibrium for several iron sulphide and oxyhydroxide minerals. Equilibrium constants $(K)$ from the PHREEQC databases and the standard potential $\mathrm{E}^{\circ}$ were corrected for temperature effects. For FeS(ppt), the computed equilibrium $\mathrm{Eh}$ is $-173 \mathrm{mv}$, which is close to the solution Eh of $-170 \mathrm{mv}$. This suggests that the mature solution is near equilibrium with an iron sulphide. For pyrite, ferrihydrite and $\mathrm{Fe}(\mathrm{OH})_{3}(\mathrm{am})$, the computed equilibrium Eh values were $-139 \mathrm{mv},-45 \mathrm{mv}$ and $-24 \mathrm{mv}$, respectively.

\section{PHREEQC model}

The conceptual model was tested with an inverse geochemical model containing three solutions; the juvenile mine-pool, recharge water and mature mine-pool. Mixing, mineral precipitation/dissolution reactions, and ion exchange from clays and hydrous ferric oxides were simulated. The PHREEQC input file is shown in Appendix A. Modelling is based on an aquifer about $8 \mathrm{~m}$ thick, or four times the original coal thickness (void plus collapsed zone), and a $70 \%$ coal extraction rate. This yields an aquifer porosity, n, of about $17 \%$ and a fluid to rock mass ratio of about 1:13.

PHREEQC is a low temperature aqueous geochemical modelling system that calculates aqueous speciation and mineral saturation indices, simulates ion exchange reactions, mixing, reaction paths and transport, and solves inverse models. It is based on equilibrium chemistry concepts, and solves inverse models by simultaneous equations that maintain balance for mole fraction, charge, alkalinity, and ionic strength. For speciation and mineral saturation indices, PHREEQC estimates activities from either the extended Debye-Huckel or Davies equations. The code calculates mineral saturation indices from a user selected database of equilibrium constants.

Inverse modelling finds sets of mineral and gas mole transfers that satisfy differences in composition between waters, and is often used to account for the changes that occur along a flowpath between starting and ending waters. For further details of PHREEQC's capabilities, limitations and execution, the reader should consult Parkhurst (1995) and Parkhurst \& Appelo (1999). Modelling included the following mineral phases:

(1) Carbonates; calcite, dolomite and siderite

(2) Sulphates; gypsum, melanterite, jarosite and jurbanite

(3) Sulphide $\mathrm{FeS}$ (ppt)

(4) Oxy-hydroxides goethite, $\mathrm{Fe}(\mathrm{OH})_{3}(\mathrm{am}), \mathrm{Al}(\mathrm{OH}) 3$ (am) Siderite and goethite are about two orders of magnitude oversaturated in the mature mine-pool, and were constrained in modelling to precipitate only as potential end products. Gypsum, melanterite and $\mathrm{K}$-jarosite were included as potential sources of soluble sulphate and metals, and were constrained to 
Table 5. Mixing perventages and pbase transfers for 8 inverse models ${ }^{1}$

\begin{tabular}{|c|c|c|c|c|c|c|c|c|}
\hline $\begin{array}{l}\text { Mixing } \\
\text { Percent }^{1}\end{array}$ & $\begin{array}{c}\text { Model } 1 \\
72.3(\mathrm{~J}) \\
27.1(\mathrm{R})\end{array}$ & $\begin{array}{c}\text { Model } 2 \\
14.6(\mathrm{~J}) \\
85.3(\mathrm{R})\end{array}$ & $\begin{array}{c}\text { Model } 3 \\
10.1(\mathrm{~J}) \\
89.4(\mathrm{R})\end{array}$ & $\begin{array}{c}\text { Model } 4 \\
35.9(\mathrm{~J}) \\
63.8(\mathrm{R})\end{array}$ & $\begin{array}{c}\text { Model } 5 \\
26.7 \text { (J) } \\
72.9 \text { (R) }\end{array}$ & $\begin{array}{c}\text { Model } 6 \\
14.6(\mathrm{~J}) \\
85.3(\mathrm{R})\end{array}$ & $\begin{array}{c}\text { Model } 7 \\
1(\mathrm{~J}) \\
99(\mathrm{R})\end{array}$ & $\begin{array}{c}\text { Model } 8 \\
1 \text { (J) } \\
99(\mathrm{R})\end{array}$ \\
\hline $\mathrm{NaX}$ & $+4.719 \mathrm{e}-2$ & $+4.767 \mathrm{e}-2$ & $+4.772 \mathrm{e}-2$ & $+4.750 \mathrm{c}-2$ & $+4.758 \mathrm{c}-2$ & $+4.767 \mathrm{e}-2$ & $+4.779 \mathrm{e}-2$ & $+4.779 \mathrm{c}-2$ \\
\hline $\mathrm{CAX} 2$ & $-2.360 \mathrm{e}-2$ & $-2.897 \mathrm{c}-3$ & - & - & - & $-2.384 \mathrm{c}-2$ & $-2.771 \mathrm{e}-2$ & $-3.137 \mathrm{e}-2$ \\
\hline MGX2 & - & - & $+3.263 \mathrm{e}-3$ & $-1.801 \mathrm{c}-3$ & - & - & $+3.809 \mathrm{c}-3$ & - \\
\hline $\mathrm{FeX} 2$ & - & $+5.135 \mathrm{c}-3$ & $-2.712 \mathrm{c}-3$ & $-2.195 \mathrm{c}-3$ & $-2.379 \mathrm{c}-3$ & & - & $+7.477 \mathrm{e}-3$ \\
\hline Calcite & $+2.420 \mathrm{c}-3$ & - & $+5.790 \mathrm{e}-3$ & & $+2.059 \mathrm{c}-3$ & - & $+5.180 \mathrm{e}-3$ & - \\
\hline Dolomite & - & $+3.019 \mathrm{c}-2$ & - & $+3.658 \mathrm{c}-3$ & $+2.357 \mathrm{c}-3$ & $+3.019 \mathrm{c}-3$ & - & $+3.809 \mathrm{c}-3$ \\
\hline Melanterite & $+2.011 \mathrm{c}-2$ & $+4.055 \mathrm{c}-2$ & $+3.224 \mathrm{c}-2$ & $+2.724 \mathrm{c}-2$ & $+2.902 \mathrm{c}-2$ & $2.355 \mathrm{c}-3$ & $+5.037 \mathrm{c}-3$ & - \\
\hline Gypsum & - & $+2.859 \mathrm{c}-2$ & - & - & - & - & $+2.914 \mathrm{c}-2$ & $+3.418 \mathrm{c}-2$ \\
\hline K-Jarosite & $+2.226 \mathrm{c}-4$ & $+3.119 \mathrm{c}-4$ & $+3.187 \mathrm{c}-4$ & $+2.792 \mathrm{c}-4$ & $2.932 c-4$ & $+3.119 \mathrm{c}-4$ & $3.341 \mathrm{c}-4$ & $+3.341 \mathrm{c}-4$ \\
\hline $\mathrm{FeS}$ (ppt) & $-4.278 \mathrm{c}-4$ & $-3.089 \mathrm{c}-4$ & $-3.028 \mathrm{c}-3$ & $-3.448 \mathrm{c}-4$ & $-3.299 \mathrm{c}-4$ & - & $-2.853 \mathrm{c}-4$ & $-2.851 \mathrm{c}-3$ \\
\hline Siderite & $-1.437 \mathrm{e}-2$ & - & - & - & - & - & - & $-2.441 \mathrm{c}-4$ \\
\hline Goethite & $-4.092 \mathrm{c}-3$ & $-3.411 \mathrm{c}-2$ & $-3.068 \mathrm{c}-2$ & $-3.599 \mathrm{c}-4$ & $-3.522 \mathrm{c}-3$ & $-9.394 \mathrm{c}-4$ & $-3.289 \mathrm{c}-3$ & $-3.288 \mathrm{c}-2$ \\
\hline
\end{tabular}

${ }^{1}$ Values in $\mathrm{m} \mathrm{kg}^{-1}$. '+' indicates the phase enters the solution; '- ' indicates the phase leaves the solution. No entry indicates the phase is not contained in the model. ${ }^{2} \mathrm{~J}$ ' designates mixing percentage of juvenile acid mine-pool; ' $\mathrm{R}$ ' refers to recharge water.

dissolve only. $\mathrm{Fe}(\mathrm{OH}) 3(\mathrm{am})$ is undersaturated in both mine waters and was therefore constrained to dissolve only. $\mathrm{Al}(\mathrm{OH})_{3}$ was included as a likely sink for $\mathrm{Al}$ in the mature mine-pool.

Cation exchange capacity (CEC) was fixed at $1 \mathrm{M}$, equivalent to about $100 \mathrm{meq} / \mathrm{kg}$ of aquifer, corresponding to the lower range of CEC reported by Johnson \& Skousen (1995) for weathered waste rock on Pittsburgh seam surface mines. Exchange species included $\mathrm{Na}, \mathrm{Ca}, \mathrm{Mg}$ and $\mathrm{Fe}(\mathrm{II})$. Exchanger composition was determined from equilibration with the mature mine-pool solution.

A hydrous ferric oxide surface (Hfo) surface was included in modelling to examine sulphate desorption as mine pool $\mathrm{pH}$ increases from acid to neutral conditions. Rose \& Elliot (2000) noted substantial desorption of sulphate from ferric precipitates in acid drainage, as the sediments were amended with liming agents. The aquifer matrix was assumed to contain $1 \% \mathrm{Hfo}$ and properties were assigned following summary data and the model suggested by Dzombak \& Morel (1990). The Hfo was equilibrated with both mine water solutions to estimate its starting and ending compositions.

\section{RESULTS AND DISCUSSION}

PHREEQC produced about 250 inverse models that could explain the evolution of the mature mine-pool. About 60 were examined further, because they included both the juvenile mine-pool and the recharge water as components, and had mixing fractions that summed to c. $100 \%$. The remaining models were examined, then discarded from further analysis because they did not include both the juvenile mine-pool and the recharge water as components, or the mixing fractions differed significantly from $100 \%$. The main geochemical transfers included ion exchange of adsorbed $\mathrm{Na}$ with $\mathrm{Ca}, \mathrm{Mg}$, or $\mathrm{Fe}(\mathrm{II})$, carbonate and sulphate dissolution, with lesser amounts of sulphide and hydroxide minerals precipitated.

Most sets of models showed the mature mine-pool to consist mainly of recharge water. Models contained from 64-99\% recharge water, and $1-36 \%$ juvenile mine water. Recharge water contains over $250 \mathrm{mg} \mathrm{l}^{-1}$ alkalinity and provides initial neutralization of the juvenile mine-pool. Mixing percentages are consistent with the flow system described previously; recharge enters the mine-pool to mix, react with, and eventually displace the initial pool volume. One model set was exceptional, and showed the mature mine- pool to consist of $73 \%$ juvenile water
Table 6. Initial composition of exchanger and maximum amounts of species transfer in models

\begin{tabular}{lcccc}
\hline Species & $\begin{array}{c}\text { Moles } \\
\text { adsorbed }\end{array}$ & $\begin{array}{c}\text { Exchanger } \\
\text { composition } \\
(\%)\end{array}$ & $\begin{array}{c}\text { Maximum } \\
\text { transfer } \\
(\mathrm{M})\end{array}$ & $\begin{array}{c}\text { Maximum } \\
\text { fraction exchanged } \\
(\%)\end{array}$ \\
\hline $\mathrm{NaX}$ & $2.839 \mathrm{c}-1$ & 28.4 & $4.779 \mathrm{c}-2$ & 16.8 \\
$\mathrm{CaX} 2$ & $2.382 \mathrm{c}-1$ & 47.7 & $3.137 \mathrm{e}-2$ & 13.2 \\
$\mathrm{MgX} 2$ & $8.701 \mathrm{e}-1$ & 17.4 & $3.809 \mathrm{c}-3$ & 4.3 \\
$\mathrm{FeX} 2$ & $2.886 \mathrm{c}-2$ & 5.8 & $7.447 \mathrm{e}-3$ & 25.8 \\
\hline
\end{tabular}

and $27 \%$ recharge water. However, these models allowed no $\mathrm{Mg}$ transfer; that is no exchange of $\mathrm{Mg}$ or dolomite reaction. This severely constrained scenario is considered unlikely. Models consisting of end member mixes of $99 \%$ recharge water are considered unlikely, because they require very efficient flushing of the mine-pool.

Table 5 shows calculated mineral and exchange transfers for eight inverse models, selected to represent the range of results obtained in the 60 models that passed initial screening. Sodium exchange is a dominant process in every model, transferring about $4 \times 10^{-2} \mathrm{M} \mathrm{kg}^{-1}$ into solution from the exchanger. The exchanging cations that leave solution include $\mathrm{Ca}, \mathrm{Mg}$, or $\mathrm{Fe}(\mathrm{II})$. Initial exchanger composition, in equilibrium with the mature mine-pool, consists mostly of $\mathrm{Ca}$ and $\mathrm{Na}$, with lesser amounts of $\mathrm{Mg}$ and $\mathrm{Fe}$ (II) (Table 6). Five of eight models in Table 5 exchange solution $\mathrm{Ca}$ for adsorbed $\mathrm{Na}$, and this accounts for the large increase in $\mathrm{Na}$ concentration in the mature mine-pool. Exchange behaviour of $\mathrm{Mg}$ and $\mathrm{Fe}$ (II) was inconsistent among model sets. Adsorbed $\mathrm{Mg}$ enters solution by exchange with solution $\mathrm{Ca}$ and $\mathrm{Fe}$ (II) in two models, but leaves solution in one model by exchange with $\mathrm{Na}$. Ferrous iron leaves solution by exchange with $\mathrm{Na}$ in three models, but enters solution by exchange with $\mathrm{Ca}$ in two other models. $\mathrm{Ca}$ for $\mathrm{Na}$ exchange is considered the most feasible exchange modelling, due to abundance of these ions in solution, the propensity of $\mathrm{Ca}$ to displace weakly adsorbed $\mathrm{Na}$, consistent model behaviour, and identification of $\mathrm{Ca} / \mathrm{Na}$ exchange in other groundwater systems (Back 1966). Smaller amounts of $\mathrm{Mg}$ and $\mathrm{Fe}(\mathrm{II})$ exchange are possible. For this initial modelling, however, and absent more specific exchanger characterization, no attempt was made to force all exchange species into a single model. 
The maximum fraction of adsorbed species transferred in any model is small relative to the total adsorbed species, even with a conservative estimate of CEC. The maximum fractions transferred are about 17 and $13 \%$ for $\mathrm{Na}$ and $\mathrm{Ca}$, respectively (Table 6). Thus, ion exchange could continue through the circulation of at least several mine-pool volumes. Removing $\mathrm{Ca}$ or $\mathrm{Mg}$ from solution by $\mathrm{Na}$ exchange should cause under saturation for calcite or dolomite, and induce more carbonate to dissolve.

Dissolution of calcite, dolomite, or both, occurs in all models, as a source of alkalinity and acid neutralization in the mine-pool. Given the mixed carbonate mineralogy reported for limestones and calcareous rocks of the Monongahela group (McCue et al. 1939; Brady 1998), model results can represent combinations of calcite, magnesian calcite and dolomite. Mineral transfers are on the order of $10^{-3} \mathrm{M} \mathrm{l}^{-1}$ (Table 5) and constitute a very small fraction of carbonate in the aquifer. For a 1:13 fluid to solid ratio used in modelling, aquifer rocks containing $5 \%$ calcite provide about 6.5 moles of carbonate per litre of solution. Siderite, which was constrained to precipitate, appears in only two of eight models (Table 5). One was considered infeasible because it did not allow $\mathrm{Mg}$ transfer, and the second occurs in a mix containing $99 \%$ recharge water. Siderite precipitation is therefore considered unlikely under the conditions modelled.

Sulphate salt dissolution appears in every model as sources of sulphate, $\mathrm{Fe}(\mathrm{II}), \mathrm{Fe}(\mathrm{III}), \mathrm{Ca}$, or $\mathrm{K}$ (Table 5). Maximum melanterite dissolution is about $4 \times 10^{-2} \mathrm{M} \mathrm{l}^{-1}$, equivalent to about $0.08 \%$ of the aquifer. These transfers are feasible, considering that the residual coal has $1 \%$ or more total $\mathrm{S}$ (Donaldson et al. 1979) and the collapsed gob may contain $>0.5 \%$ total S (Table 2). Only a fraction of the total S need be available as sulphate salts to account for the mineral transfers. Sulphate salts could persist through a number of mine-pool volumes before depletion. Melanterite dissolution provides most of the observed increase in iron and sulphate concentrations in the mature mine-pool. Gypsum dissolution appears in three models, but two of them are considered unlikely solutions containing $99 \%$ recharge water.

Iron sulphide precipitation was included in 7 of 8 models shown in Table 5. Mole transfers are equivalent to removing a total of about $10 \mathrm{mg} \mathrm{l}^{-1}$ sulphide (as S) from solution, and require that sulphate reduction take place as the mine-pool evolves. Ferrous iron is supplied by melanterite dissolution.

Goethite is included in every model as a sink for Fe(III). Poorly crystalline $\mathrm{Fe}(\mathrm{OH})_{3}(\mathrm{am})$ is not in any model, even though it was included as dissolving phase in PHREEQC. $\mathrm{K}$-Jarosite dissolution provides $\mathrm{Fe}$ (III) for goethite formation. The lack of $\mathrm{Fe}(\mathrm{OH})_{3}(\mathrm{am})$ dissolution indicates that no $\mathrm{Fe}$ (III) reduction is taking place in any model, even though the mine-pool is progressively reduced as it matures. $\mathrm{Fe}(\mathrm{OH})_{3}(\mathrm{am})$, rather than dissolve, may convert to a more stable oxy-hydroxide. Additional modelling showed, however, that dissolution of $\mathrm{Fe}(\mathrm{OH})_{3}(\mathrm{am})$, could be forced into a feasible model, if the quantity of melanterite is arbitrarily limited.

Postma \& Jakobsen (1996) used a partial equilibrium approach to demonstrate that simultaneous Fe (III) and sulphate reduction is possible, rather than occurring in discrete steps. They summarize several field studies where apparent simultaneous reduction has been reported, including $\mathrm{pH}$ and $\mathrm{Fe}$ (II) activity conditions similar to the mature mine-pool. Postma \& Jakobsen (1996) developed a set of equations representing equal energy yield between $\mathrm{Fe}$ (III) reduction and sulphate reduction for several iron oxyhydroxide minerals including goethite and $\mathrm{Fe}(\mathrm{OH})_{3}$. For a solution dominated by $\mathrm{Fe}(\mathrm{II})$ the summary reaction is:

$$
\begin{aligned}
& 9 \mathrm{Fe}^{2+}+\mathrm{SO}_{4}^{2-}+20 \mathrm{H}_{2} \mathrm{O} \rightarrow 8 \mathrm{Fe}(\mathrm{OH})_{3}+\mathrm{FeS}+16 \mathrm{H}^{+} \\
& \log \mathrm{K}_{3}-8 \log \mathrm{K}_{1}-\log \mathrm{K}_{7} \\
&=-16 \mathrm{pH}-9 \log \left[\mathrm{Fe}^{2+}\right]-\log \left[\mathrm{SO}_{4}^{2-}\right]
\end{aligned}
$$

where $\log \mathrm{K}_{3}$ is the equilibrium constant for sulphate/sulphide couple, $\log \mathrm{K}_{1}$ is the equilibrium constant for $\mathrm{Fe}(\mathrm{III})$ mineral/ $\mathrm{Fe}^{+}$couple, and $\log \mathrm{K}_{7}$ is the equilibrium constant for $\mathrm{FeS}$ precipitation. Solving equation 4 for goethite in the mature mine-pool yields a $\mathrm{pH}$ of 6.41 for equal energy yield. The solution $\mathrm{pH}$ is 7.3 , therefore, with respect to goethite, sulphate reduction is favoured over $\mathrm{Fe}(\mathrm{III})$ reduction, from which $\mathrm{FeS}$ precipitation may follow. $\mathrm{For} \mathrm{Fe}(\mathrm{OH})_{3}(\mathrm{am})$, however, equation 4 gives an equal energy yield at $\mathrm{pH} 9.14$ and $\mathrm{Fe}(\mathrm{III})$ reduction is the favoured process. This contradicts the modelling results where no $\mathrm{Fe}(\mathrm{OH})_{3}$ (am) dissolution occurred. Since mine drainage sediments usually contain a mixture of iron oxyhydroxide minerals (Ferris et al. 1989; Bigham et al. 1996; Rose \& Elliot 2000), simultaneous reduction of sulphate and Fe(III) minerals is thermodynamically possible. Stability of the Fe(III) minerals will have a large influence on which reductive processes dominate the system.

Model results show hydrous ferric oxide (Hfo) surfaces could be sinks for $\mathrm{Fe}(\mathrm{II})$, and sources for sulphate as the mine-pool evolves from acid to alkaline conditions. About half of the sulphate originally bound to the Hfo is desorbed, while Fe(II) is removed from solution. Ninety-nine percent of 'strong' binding sites are occupied by proton acidity in the acid mine water, and by $\mathrm{Fe}(\mathrm{II})$ in the alkaline solution. 'Weak' binding sites are 53 and $47 \%$ saturated with proton acidity and sulphate, respectively, in the acid solution. In the alkaline mine-pool, 'weak' sites contain $58 \% \mathrm{Fe}(\mathrm{II})$ and $26 \% \mathrm{~S}(6)$ species. Hfo surfaces can adsorb both cations and anions, with distribution and amount of adsorbed species strongly influenced by $\mathrm{pH}$ (Parfitt \& Smart 1978; Harrison \& Berkheiser 1982; Davis \& Kent 1990). In general, anion adsorption dominates at low $\mathrm{pH}$, and decreases with increasing $\mathrm{pH}$. Overall influence of Hfo's on mine water chemistry will depend on its concentration in the aquifer, and number of binding sites.

\section{SUMMARY AND CONCLUSIONS}

A conceptual model of mine-pool evolution from acid to alkaline conditions was examined with inverse modelling. The model includes infiltration of alkaline recharge water, dissolution of carbonates and sulphate salts, and sulphide and oxy-hydroxide precipitation. These processes could account for water quality changes occurring in flooded underground coal mines of the Pittsburgh coal seam. About 60 inverse models were obtained that included both juvenile mine water and recharge water, and had mixing fractions totaling about $100 \%$. Most of these models showed the mature mine-pool to consist mainly of recharge water, consistent with the groundwater flow system. The inverse models differ in mixing percentages and specific mineral transfers.

Neutralization of the juvenile acid mine-pool can be explained with two sources; recharge from alkaline groundwater in overlying aquifers, and reaction with broken calcareous rock collapsing from the overburden (gob) immediately above the mine. Carbonate content of the gob zone exceeds acid generating capacity from sulphide oxidation in the system. Recharge water infiltrates the mine-pool continuously and will ultimately displace most of the initial pool volume. 
Ion exchange of adsorbed $\mathrm{Na}$ for solution $\mathrm{Ca}$ is a dominant process in all models, and provides a feasible explanation for the large $\mathrm{Na}$ increases in mature mine-pools. No other $\mathrm{Na}$ bearing minerals are known to occur in large concentrations in the Monongahela group that could account for the observed increases. Mine water compositions also do not reflect brine water leakage. Exchange reactions involving $\mathrm{Mg}$ and $\mathrm{Fe}$ (II) were simulated in some models, but their actual participation in mine- pool evolution is less conclusive.

Carbonates are likely the principal sources for $\mathrm{Ca}$ and $\mathrm{Mg}$ in the mine-pool aquifer, in addition to ion exchange. Carbonate composition ranges from calcite to dolomite, and one or both of these minerals dissolves in every model. They are orders of magnitude under saturated in the juvenile mine water, but near to slightly over saturation in the mature mine-pool. Calcite and dolomite provide initial acid neutralization, but could precipitate in the mature mine-pool. Siderite is near redox equilibrium with the mature mine water, but appeared in few models.

Dissolution of sulphate salts like melaneterite, K-Jarosite and gypsum can account for the sulphate rich mature minepool, and are in every feasible model. They may also provide soluble $\mathrm{Fe}(\mathrm{II}), \mathrm{Fe}(\mathrm{III}), \mathrm{Ca}$ or $\mathrm{K}$. Other complex sulphates like copiapite and halotrichite are present in mine waste rock, but were not modelled, due to lack of consistent thermodynamic data. FeS precipitation was included in most models and requires sulphate reduction. Thermodynamic calculations show that sulphate reduction is possible in the mature mine-pool. Sulphate desorption from hydrous ferric oxide surfaces could occur, as the mine-pool evolves, but its significance depends on the amount of Hfo and binding sites present in the aquifer.

Iron is the most complex cycle in the mine-pool system. Iron sources included sulphate salt dissolution, ion exchange and dissolution of $\mathrm{Fe}(\mathrm{OH})_{3}(\mathrm{am})$. Sinks included precipitation of $\mathrm{FeS}$, goethite, siderite and binding to Hfo's in the mature mine-pool. Sulphate salt dissolution provides a feasible explanation for soluble iron. $\mathrm{Fe}(\mathrm{OH})_{3}(\mathrm{am})$ dissolution was not in any model, yet thermodynamic calculations show $\mathrm{Fe}(\mathrm{OH})_{3}(\mathrm{am})$ if present, could be reduced to Fe(II). The mature mine-pool is near equilibrium for $\mathrm{FeS}$, siderite and goethite. All are feasible products of mine-pool evolution, and FeS and goethite consistently appear in inverse models. Exchange of Fe(II) and binding to Hfo surfaces in the mature mine water are shown in some models, but their importance in the overall system is not known.

Inverse modelling required some assumptions and approximations for these initial efforts. All mineral phases were assumed present in excess, no solid solution phases were specified, and near equilibrium conditions were assumed. Some minerals known to be present in mine waste rock, lack suitable data for modelling, and were not included.

Inverse modelling results support the major processes identified in the conceptual model. Mixing of alkaline recharge water, dissolution of carbonates and sulphate salts, and $\mathrm{Na}$ exchange were consistently identified as major inverse model components. These processes provide feasible explanation of the observed water quality changes in flooded underground Pittsburgh seam coal mines. Significance of some secondary processes requires further investigation, and iron cycling in the mine-pool is especially complex. Calculated mineral transfers show that these processes are able to continue through cycling of at least several pool volumes. Flushing of sulphate, iron and other constituents may therefore continue for a long period. These changes have substantial implications for treatment and management of mine-pools.

\section{APPENDIX A}

\section{PHREEQC input file for Inverse Modelling}

Title: Inverse model of mature mine-pool water from Recharge and acid Juvenile mine water.

SOLUTION 1 Acid Juvenile Water, start flowpath.

temp 13

$\mathrm{pH} 3.3$

units $\mathrm{mg} \mathrm{l}^{-1}$

density 1

pe 9.0

Ca 340

$\mathrm{Na} 140$

$\mathrm{Mg} 134$

K 6

$\mathrm{Fe} 45$

$\mathrm{Al} 30$

$\mathrm{Cl} 30$

S 2050

Si 20

equilibrium_phases

$\mathrm{CO} 2(\mathrm{~g})-1.0$

SOLUTION 2 Median value recharge water quality (Hobba 1984 in WV).

Units $\mathrm{mg}^{-1}$

temp 13

$\mathrm{pH} 7.4$

Alkalinity 259

Ca 27

$\mathrm{Mg} 7$

$\mathrm{Na} 120$

Cl 19.1

$\mathrm{S} 40$

Fe 1.06

Si 15

SOLUTION 3 Mature mine-pool (end of flowpath).

temp 13

$\mathrm{pH} 7.3$

$\mathrm{pe}-3$

units $\mathrm{mg} \mathrm{l}^{-1}$

redox $\mathrm{Pe}$

Alkalinity 510

Ca 305

$\mathrm{Na} 1330$

$\mathrm{Mg} 103$

K 13

Fe 138

Al 0.05

Si 15

Cl 108

S 3185

-water 1 \# kg

Exchange 1 exchanger defined, equilibrate with end flowpath water. -equilibrate 3

$\times 1.0$

Inverse_Modelling 1

-solutions 123

-uncertainty .05

-balances Alkalinity .2

-tolerance 1e-9

-minimal

-phases

$\mathrm{NaX}$

$\mathrm{CaX} 2$

$\mathrm{MgX} 2$

$\mathrm{FeX} 2$

calcite

dolomite

gypsum dis

melanterite dis

$\mathrm{FeS}$ (ppt) ppt

jurbanite 
halite

jarosite- $\mathrm{k}$ dis

siderite $\mathrm{ppt}$

$\mathrm{Al}(\mathrm{OH})_{3}$ (a) $\mathrm{ppt}$

$\mathrm{Fc}(\mathrm{OH})_{3}$ (a) dis

Gocthite ppt

Surface 1 Iron Oxy-hydroxide surfaces

-equilibrate with solution 1

Hfo_w 0.48600216

Hfo_s 0.012

Surface 2 Iron Oxy-hydroxide surfaces

-equilibrate with solution 3

Hfo_w 0.48600216

Hfo_s 0.012

\section{REFERENCES}

BAAS BECKING, L. G., KAPLAN, R. \& MOORE, D. 1960. Limits of the Natural Environment in Terms of $\mathrm{pH}$ and Oxidation-Reduction Potentials. Joumal of Geology, 68, 243-284.

BACK, W. 1966. Hydrochemical Facies and Ground-Water Flow Patterns in Northern Part of Atlantic Coastal Plain. US Gedogical Survey Professional Paper 498- $A$.

BARTON, L. (cd.) 1995. Sulfate-Reducing Bacteria. Biotecbnology Handbooks 8. Plenum Publishing.

BIGHAM, J. M., SCHWERTMANN, U., TRAINA, S. J., WINLAND, R. L. \& WOLF, M. 1996. Schwertmannite and the Chemical Modeling of Iron in Acid Sulfate Waters. Geochemica Cosmochemica Acta, 60, 2111-2121.

BRADY, K. B. 1998. Influence of Geology on Post Mining Water Quality: Northern Appalachian Basin. Codl Mine Drainage Prediction and Pollution Prevention in Pennsyluanid. Pennsylvania Dept. of Environmental Protection, Harrisburg, $\mathrm{Pa}$.

BUCEK, M. F. \& EMEL, J. L. 1977. Long Term Effectiveness of Close Down Procedures-Eastem Underground Coal Mines. HRB Singer Inc, for US Environmental Protection Agency, EPA-600/7-77-083.

CHERCERI, L. S., GREFNBURG, A. E. \& EATON, A. D. 1998. Standard Methods for the Examination of Water and Waste Water, 20th edition. American Public Health Association.

DAVIS, J. A. \& KENT, D. B. 1990. Surface Complexation Modeling in Aqueous Geochemistry. Reviews in Mineralogy, 23. Mineral Water Interface Geochemistry, Mineralogical Society of America.

DONALDSON, A. C., RENTON, J., KIMUTIS, R., LINGER, D. \& ZAIDI, M. 1979. Distribution Pattern of Total Sulfur Content In the Pittsburgh Coal. Carboniferous Caal Gridebook. Bulletin B-37-3. West Virginia Geologic and Economic Survey.

DONOVAN, J. J., FLETCHER, J, STRAGER, M. \& WERNER, E. 1999. Hydrogeological and Geochemical Response to Mine Flooding in the Pittsburgh Coal Basin, Southern Monongahela River Basin. West Virginia University, National Mined Land Reclamation Center Project WV-132, Final report to US Environmental Protection Agency.

DZOMBAK, D. A. \& MOREL, F. M. 1990. Surface Complexation ModelingHydrous Ferric Oxide. John Wiley \& Sons, New York.

FERRIS, F. G., TAZAKI, K. \& FRYE, W. S. 1989. Iron Oxides in Acid Mine Drainage Environments and Their Association With Bacteria. Cbemical Geology, 74, 321-330.

GROWITZ, D. 1967. Geochemistry of Mine Water, Nortbern Bituminous Field, West Virginia. MSc Thesis, West Virginia University.

HARRISON, J. B. \& BERKHEISER, V. E. 1982. Anion Interactions With Freshly Prepared Hydrous Iron Oxides. Clays and Clay Minerals, 30, 97-102.

HOBBA. 1984. Ground Water Hydrology of the Monongabela River Basin. US Geological Survey in cooperation with the West Virginia Dept of Natural Resources.
JOHNSON, C. \& SKOUSEN, J. 1995. Minesoil Properties of 15 Abandoned Mine land Sites in West Virginia. Journal of Environmental Quality, 24, 635-643.

McCUE, J., LUCKE, J. \& WOODWARD, H. 1939. Limestones of West Vinginia. West Virginia Geological Survey Vol XII.

McCULLOGH, C. M., DIAMOND, W. P., BENCH, B. M. \& DUEL, M. 1975. Selected Geologic Factors Affecting Mining of the Pittsburgh Coalbed. Repont of Investigations 8093. US Bureau of Mines.

NORDSTROM, D. K. 1982. Aqueous Pyrite Oxidation and the Consequent Formation of Secondary Iron Minerals. Acid Sulfate Weatbering. Soil Science Society of America Special Publication 10.

NUHFER, E. 1967. Effloressent Minerals Associated With Coal. MSc Thesis, West Virginia University.

O'NEILL, B. J. \& BARNES, J. H. 1979. Properties and Uses of Shales and Clays, Soutbuestern Pennsyluania. Mineral Resources Report 77.

PARFITT, R. L \& SMART, R. C. 1978. The Mechanism of Sulfate Adsorption on Iron Oxides. Soil Science of America Journal, 42, 48-50.

PARKHURST, D. L. 1995. User's Givide to PHREEQC - A Computer Program For Speciation, Readtion-Path, Advective-Transport, and Inverse Geochemical Calculations. US Geological Survey Water Resources Investigation Report 954227.

PARKHURST, D. L. \& APPELO, C. A. J. 1999. User's Gride to PHREEQC (Version 2)-A Computer Program For Speciation, Batch-Reaction, One-Dimensiondl Transport, and Inverse Geochemical Calculations. US Geological Survey Water Resources Investigation Report 99-4259.

PENG, S. 1986. Coal Mine Ground Control, 2nd ed. John Wiley \& Sons, New York.

POSTMA, D. \& JAKOBSEN, R. 1996. Redox zonation: Equilibrium Constraints on the $\mathrm{Fe}(\mathrm{III}) / \mathrm{SO} 4$ Reduction Interface. Geochemica Casmo cbemica Acta, 60, 3169-3175.

RENTON, J. 1979. The Mineral Content of Coal. Carboniferous Coal Gridebook. Bulletin B-37-1. West Virginia Geologic and Economic Survey.

ROBERTSON, J. D., TREMBLAY, G. A. \& FRASER, W. W. 1997. Subaqueous Tailings Disposal: A Sound Solution for Reactive Tailings Disposal. Proceedings of the Fourtb Intemational Conference on Acid Rock Drainage, 3, 1027-1041.

ROSE, A. W. \& CRAVOTTA, C. A. 1998. Geochemistry of Coal Mine Drainage. Coal Mine Drainage Prediction and Pollution Prevention in Penngyluania. Pennsylvania Dept. Environmental Protection.

ROSE, S. \& ELLIOT, W. C. 2000. The Effects of pH Regulation on the Release of Sulfate From Ferric Precipitates Formed in Acid Mine Drainage. Applied Geochemistry, 15, 27-34.

RUPPERT, L. F, TEWALT, S. J., BRAGG, L. J. \& WALLACK, R. N. 1999. A Digital Resource Model of the Upper Pennsylvanian Pittsburgh Coal Bed, Monongahela Group, Northern Appalachian Basin Coal Region, USA. Intermational Journal of Codl Geology, 41, 3-24.

SCHIMDT, R. D. 1985. Fracture Zone Dewatering To Control Ground Water Inflow in Undengrownd Mines. US Bureau of Mines Report of Investigations 8981.

SCHOONEN, M. A. \& BARNES, H. L. 1991. Reactions Forming Pyrite and Marcasite From Solution II: Via FeS Precursors Below $100^{\circ} \mathrm{C}$. Geochemea Cosmochemica Acta, 55, 1501-1514.

SOBEK, A., SCHULLER, W., FREEMAN, J. R. \& Smith, R. M. 1978. Field and Laboratory Metbads Applicable To Overburdens and Minesoils. West Virginia University. U.S Environmental Protection Agency EPA600/2-78-054.

STONER, J. D., WILLIAMS, D. R., BUCKWALTER, T. E., FELBINGER, J. K. \& PATTISON, K. L. 1987. Water Resoures and the Effects of Cod Mining, Greene County, Pennglvania. Pennsylvania Geological Survey Water Resources Report 63.

TIEMAN, G. E. \& RAUCH, H. W. 1987. Study of Dewatering Effects at an Underground Longwall Mine Site in the Pittsburgh Seam of Northern Appalachia. Procedings Eastem Cadl Mine Geomecbanics, Bureau of Mines Tecbnology Seminar, Information Circular 9137. US Bureau of Mines. 


\section{$\underline{\text { Appendix C }}$}

\section{GROUND-WATER FLOW AND QUALITY IN A FULLY FLOODED UNDERGROUND COMPLEX}

2004 National meeting of the American Society of Mining and

Reclamation and the 25th West Virginia Surface Mine Drainage Task Force, April 18-24, 2004. Published by ASMR, 3134 Montavesta Rd., Lexington KY 40502 


\title{
GROUND-WATER FLOW AND QUALITY IN A FULLY FLOODED UNDERGROUND COMPLEX ${ }^{(1)}$
}

\author{
Eric F. Perry ${ }^{(2)}$ and Jay W. Hawkins
}

\begin{abstract}
Water quantity and quality conditions are described for a mine-pool aquifer in a fully flooded complex of underground mines in northern West Virginia. Abandoned mines in the Pittsburgh coal bed are contiguous, and separated by coal barrier pillars ranging from as little as 9 to about $60 \mathrm{~m}$ thick. Barrier pillars are transmissive enough to circulate significant quantities of water between mines, yet they control head distribution and flow direction within the aquifer. The mine-pool acts as a confined aquifer, and recharge is approximately balanced by withdrawal of about $5700 \mathrm{~L} / \mathrm{min}$, leakage to adjacent mines, and unquantified outflow to unmined areas. Resulting drawdown prevents the minepool from discharging directly into overlying streams. A centrally located subgroup of mines within the aquifer currently acts as a ground-water sink, but water levels are slowly increasing in the sink, and in some outflow areas. Mine waters are highly reduced, with circumneutral $\mathrm{pH}$, and variable $\mathrm{Fe}$ concentrations from 5 to over $100 \mathrm{mg} / \mathrm{L}$. Total alkalinity is about $200 \mathrm{mg} / \mathrm{L}$ with a mixed Ca-Na$\mathrm{HCO}_{3}-\mathrm{SO}_{4}$ composition in recharge areas. End of flow path waters contain up to $600 \mathrm{mg} / \mathrm{L}$ alkalinity, and are $\mathrm{Na}-\mathrm{SO}_{4}$ type waters with higher dissolved solids and metals concentrations. The shift from $\mathrm{Ca}$ to $\mathrm{Na}$ dominated waters is attributed mainly to cation exchange. Rising head in parts of the aquifer indicates withdrawal from the mine-pool may have to be increased in the future to prevent discharge. Mine-pool quality remains poor and has shown slow improvement in 6 years of monitoring.
\end{abstract}

Additional Key Words: barrier pillar, leakage, confined aquifer, cation exchange

${ }^{1}$ Paper was presented at the 2004 National meeting of the American Society of Mining and Reclamation and the $25^{\text {th }}$ West Virginia Surface Mine Drainage Task Force, April 18-24, 2004. Published by ASMR, 3134 Montavesta Rd., Lexington KY 40502

${ }^{2}$ Eric Perry and Jay Hawkins are Hydrologists, Office of Surface Mining, 3 Parkway Center, Pittsburgh PA 15220. 


\section{$\underline{\text { Introduction }}$}

Underground mining in the Pittsburgh coal bed of northern Appalachia has been ongoing for over 200 years. Of the original estimated reserves of about 31 billion tonnes, about 14 billion tonnes remain, and Pittsburgh seam production remains the largest in northern Appalachia (Ruppert et al., 1999). Many of the Pittsburgh seam mines are aerially extensive, covering several thousand $\mathrm{Ha}$, and they frequently adjoin other mines in the same coal bed. When these mines are closed and abandoned, ground-water infiltrates from overlying aquifers, stream leakage and adjacent flooded mines. The flooding process usually occurs over a period of years to a few decades, and flooding may be complete or partial, depending on hydrological setting. Mine water quality ranges from strongly acidic to alkaline, with objectionable concentrations of $\mathrm{Fe}$ and $\mathrm{SO}_{4}$. This paper reports on ground-water flow, storage, and quality characteristics of a fully flooded mine-pool near Fairmont, West Virginia, gathered from five years of monitoring effort.

\section{Background}

\section{Geologic Setting}

The Pittsburgh coal bed is present over portions of the states of PA, WV, MD and OH, extending over about 28,000 km² (McCullogh et al., 1975; Ruppert et al., 1999) as shown in Figure 1. The

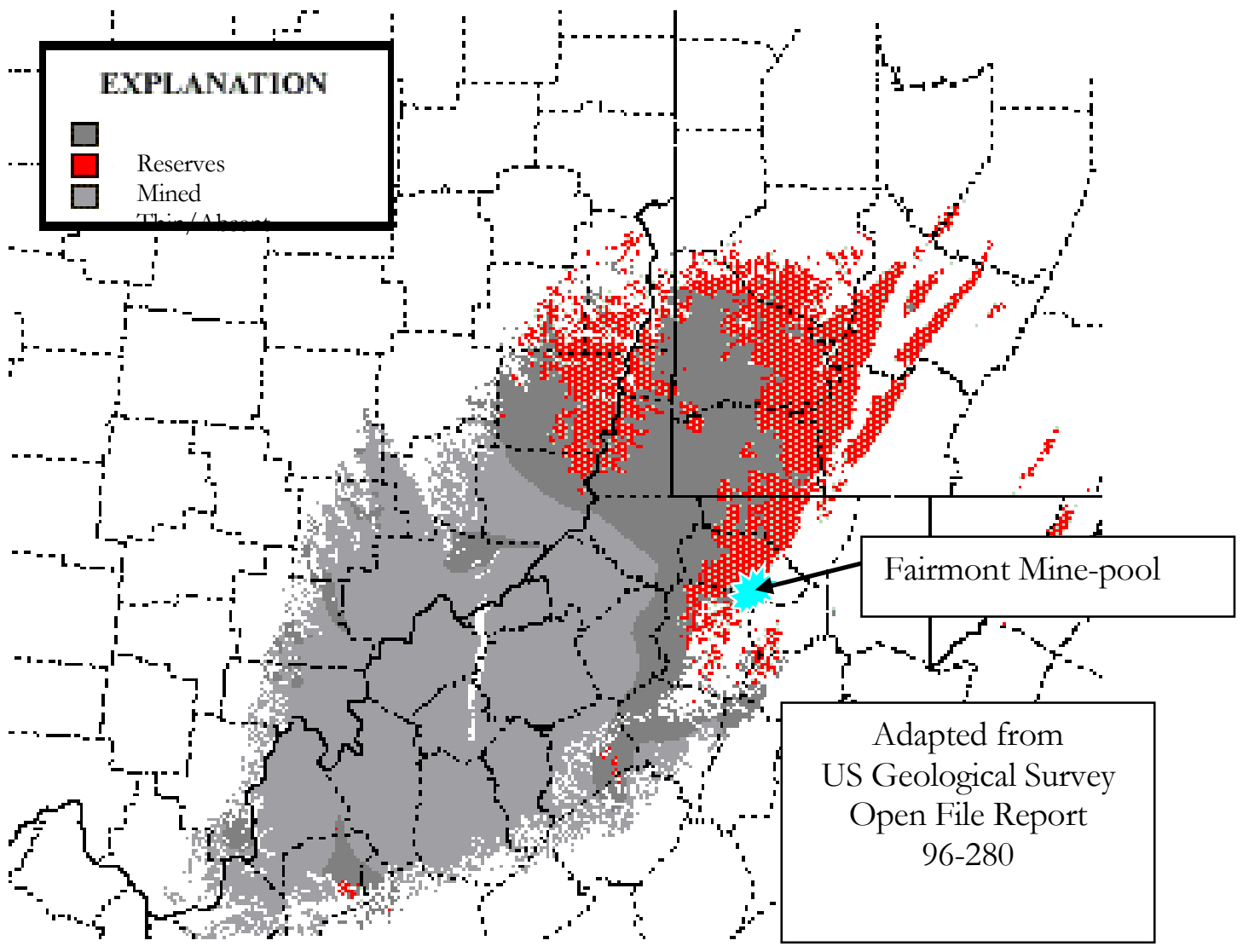

Figure 1. Extent of Pittsburgh coal bed and location of Fairmont mine-pool. (Adapted from Ruppert and Tewalt,1997). 
bed is in an elongated basin with the main axis extending southwest to northeast. A series of small anticlines and synclines is superimposed on the main basin structure. Deformation including folding, and regional uplift facilitated erosion of some of the original deposit. Throughout much of the basin, the coal bed is located at depths of 60 to $>300 \mathrm{~m}$, but is at or near outcrop along basin margins.

Stratigraphically, the Pittsburgh is located at the base of the Monongahela Group, which ranges from about 70 to 130 meters in thickness (McCullogh et al.; 1975, Berryhill et.al.,1971; Hennen and Reger, 1913). The lower members of the Group include several limestones, calcareous shales and mudstones, interbedded with fine to medium grained sandstones. The coal bed itself is 2 to $3 \mathrm{~m}$ thick and characteristically is divided into several benches (Hennen and Reger, 1913).

\section{Project Setting}

A complex of abandoned, fully flooded underground mines, termed the "Fairmont mine-pool" in this paper, has been monitored by the Office of Surface Mining (OSM) since the mid 1990's. The Fairmont mine-pool is located on the eastern margin of the basin (figure 1) and the rocks dip at a low angle to the northwest toward the center of the basin. This structure results in the Pittsburgh coal cropping out or being present at shallow depths along the West Fork and Monongahela Rivers near Fairmont. Thus, the rivers and tributaries are potential discharge zones for the mine-pool.

Figure 2 shows the location of principal underground mines comprising the Fairmont mine-pool and several adjacent mines that interact with it. The mine-pool extends over about 10,000 Ha and across several drainage basins. Mines closed at various dates from the 1940's to the 1980's, and were developed mostly by room and pillar methods with retreat mining in some areas. Active underground operations are located further to the northwest and southwest under thicker overburden. Barrier pillars, ranging in thickness from about 9 to $60 \mathrm{~m}$, separate individual mines. In one location, Mine 38 (figure 2), a barrier pillar is breached, allowing direct hydraulic connection between two mines.

An internal coal company report (Leavitt, 1993) predicted that hydraulic head in parts of the Fairmont mine-pool would increase to potential discharge elevation by the mid 1990's. In 1997, the mining company began withdrawing water from the Fairmont mine-pool at the Dakota mine (figure 2), to prevent a pollutional discharge to surface waters. Water is siphoned over a barrier pillar at estimated rate of about $5700 \mathrm{~L} / \mathrm{min}$ into the adjacent Jordan mine complex. From there, mine water is routed to a centralized treatment facility. OSM, on behalf of the state of West Virginia, began monitoring water levels in the Fairmont mine-pool in 1997 to determine if the siphon withdrawal would maintain mine-pool head below discharge elevation. West Virginia University and a mining company also began measuring water levels, and monitoring continues to the present. 


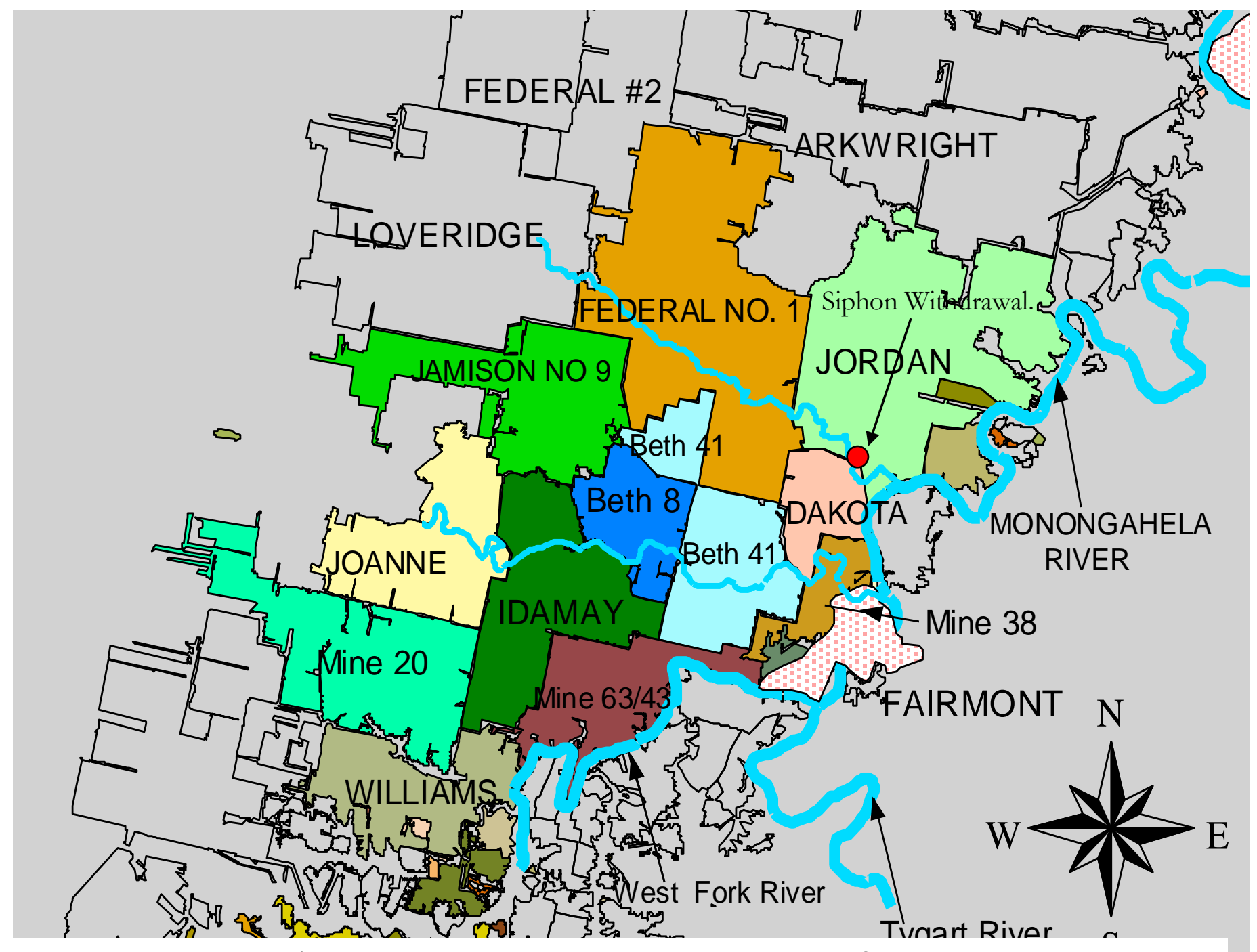

Figure 2. Principal and Adjacent Mines in the Fairmont mine-pool, and Siphon Withdrawal. 


\section{Methodology}

OSM began collecting water levels on a monthly basis at six existing locations in the Fairmont mine-pool. In 1999, OSM drilled 4 additional monitoring wells to provide data from specific mines where no monitoring access had been available. Another 3 wells were drilled in 2002 to provide additional information in the western and southern parts of the mine-pool. All wells were drilled using air rotary methods, with a screened interval placed at mine elevation. Several boreholes were examined with a down-hole video camera to determine the degree of fracturing and collapse in the overburden and at mine level. Pressure transducers were installed in five OSM wells and programmed to record water level and temperature on an hourly basis. Wells without transducers are read at a monthly frequency. Weather data including hourly precipitation, air temperature, and barometric pressure were obtained for weather stations at Clarksburg and Morgantown, WV, each located within 15 to $20 \mathrm{~km}$ of the project area. Daily summary weather readings were also obtained for a station at Mannington, WV, located within the project area.

Water quality samples have been collected from selected mine-pool wells at semiannual to annual intervals, and more frequently at the Dakota mine siphon. Wells were purged until stable readings were obtained for $\mathrm{pH}$, temperature and specific conductance. Collected samples were analyzed for Alkalinity, dissolved $\mathrm{Fe}, \mathrm{Al}, \mathrm{Mn}, \mathrm{Ca}, \mathrm{Mg}, \mathrm{Na}, \mathrm{K}, \mathrm{SO}_{4}, \mathrm{Cl}, \mathrm{As}, \mathrm{Ba}, \mathrm{Be}, \mathrm{Cd}, \mathrm{Co}, \mathrm{Cr}$, $\mathrm{Cu}, \mathrm{Ni}, \mathrm{Pb}, \mathrm{Sb}, \mathrm{Se}, \mathrm{Zn}$. Field parameters include $\mathrm{pH}$, Eh, temperature and specific conductance and total acidity is calculated from dissolved metals and $\mathrm{pH}$. Selected samples have also been analyzed for $\mathrm{Fe}(\mathrm{II})$ and S(-II). A simple presence/absence biological reactivity test for sulfate reducing bacteria has been run on selected wells.

Geochemical calculations were performed using PHREEQC (Parkhurst and Appelo, 1999) and statistical calculations were run in Statgraphics for Windows ver 4.1.

\section{$\underline{\text { Mine Pool Flow }}$}

The Fairmont mine-pool includes at least eight large individual mines that respond to recharge, discharge and other stresses in unison. From south to north (figure 2), they include Williams, Mine 63/43, Idamay, Beth 41, Beth 8, Mine 38, Dakota, and Federal 1. Head in other mines to the north, west, and south is less than the Fairmont mine-pool. In general, these other mines receive leakage or outflow from the Fairmont mine-pool. Head is increasing, however, in the Joanne mine to west, and this complex may become a more active participant in the Fairmont mine-pool in the future.

Inferred ground-water flow directions are shown in Figure 3, based on average head measurements compiled for the year 2002. The flow pattern is complex, and results from barrier pillars maintaining head differences between mines, and different mine closure dates and flooding records. The general direction of flow within the pool is from south to north towards the Dakota siphon. Much of the flow through the Fairmont mine-pool originates from the Williams and Idamay mines, and is apparently funneled through Mine 43/63 and Mine 38 (Figure 3) adjacent to the West Fork and Monongahela rivers. The Beth 41/8 mines in the center 


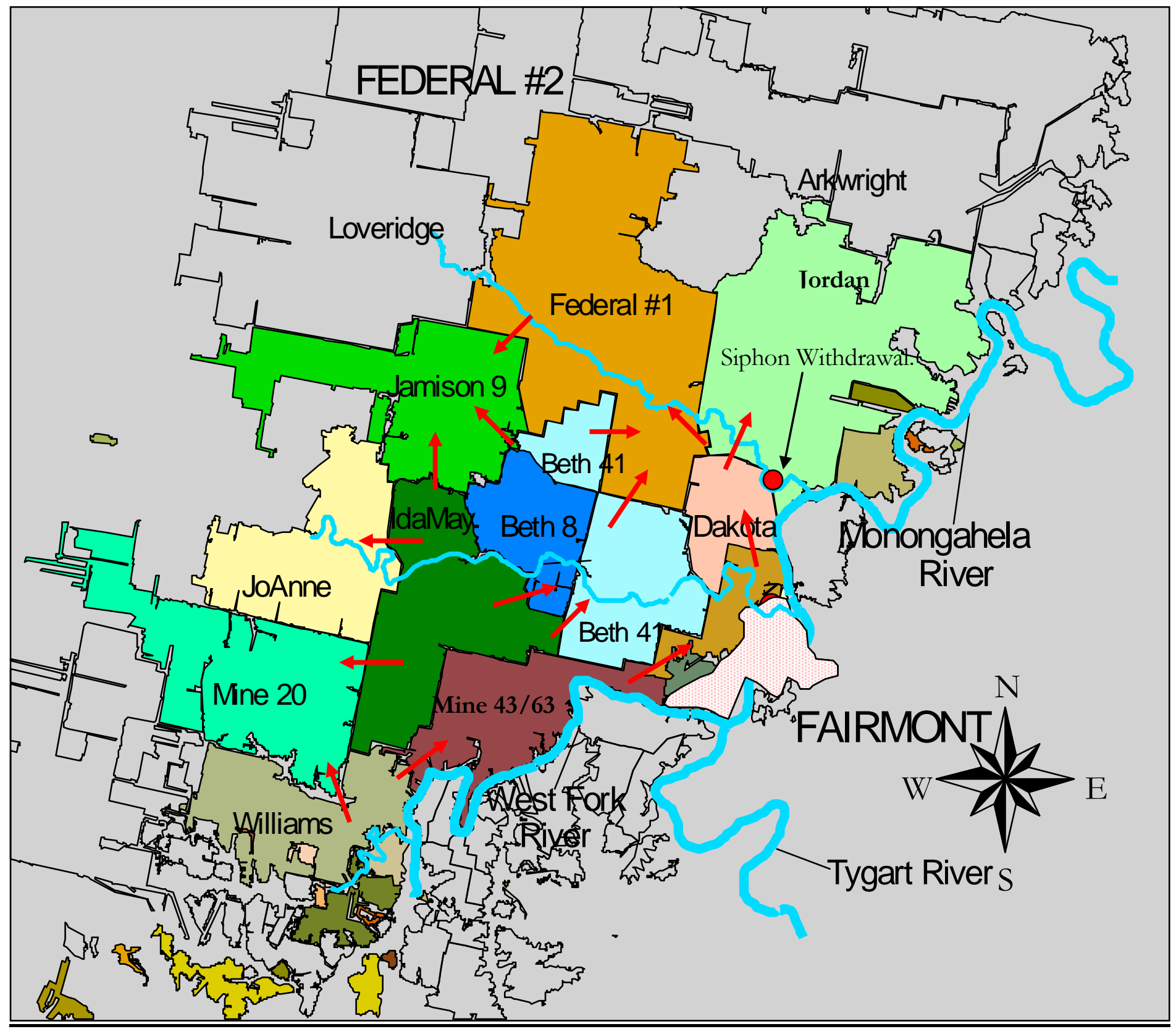

Figure 3 Generalized Ground-water Flow Pattern in the Fairmont mine-pool. Arrows indicate inferred

flow direction based on head measurements and mine conditions. 
of the mine-pool currently are ground-water sinks; that is water flows into it from surrounding mines on the east, south and southwest, and it does not contribute flow to the siphon. However, head is increasing and should equal or exceed the siphon within 3 to 5 years. At that time, the Beth 41/8 mines will cease to be a sink for the mine-pool and will instead contribute to outflow.

Federal \#1 constitutes the northwest part of the Fairmont mine pool. Its' potentiometric head is about six to eight $\mathrm{m}$ lower than the north end of Beth $41 / 8$ which adjoin it, and about $10 \mathrm{~m}$ less than the Dakota siphon. Leakage from Beth $41 / 8$ to Federal \#1 is probably occurring. Federal \#1 is a second major ground-water sink for the mine-pool. Both the Beth mines complex and Federal \#1 have potentiometric head exceeding the Jamison 9 mine to the west, and are leaking into it.

Mine 20 and Jamison 9 to the southwest and northwest of the Fairmont mine-pool are pumped to protect nearby active mining. Large potentiometric head differences, on the order of 30 to $60 \mathrm{~m}$ or more exist across the barrier pillars separating these mines from the Fairmont mine-pool. Leakage across the barrier pillars is another outflow for the mine-pool.

Mine-pool Response to Dakota Siphon Withdrawal

The Dakota siphon began operating in April, 1997 and runs for about 10 months during the year. Figure 4 shows water levels at the siphon; mine 38 located about $2.5 \mathrm{~km}$ distant, and the Williams mine well, which is about $18 \mathrm{~km}$ from the siphon. The mine-pool was drawn down 4

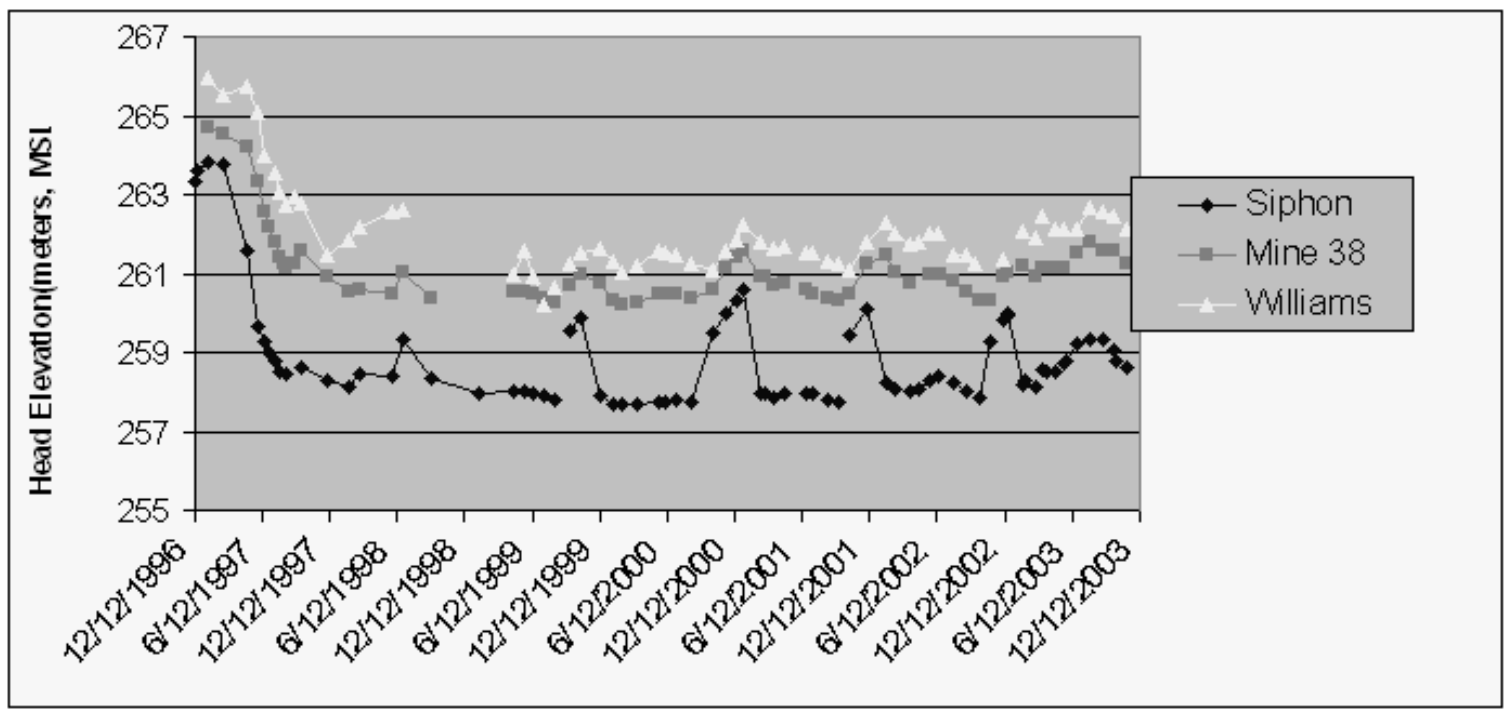

Figure 4. Water Levels at Dakota Siphon, Mine 38 and Williams Mine, 1997-2003.

to 5 meters once the siphon began operating, even at the Williams mine at the opposite end of the mine-pool. The response is indicative of a confined aquifer. The drawdown is maintaining the mine-pool below the unregulated discharge elevation, preventing a pollutional discharge to surface waters. Figure 4 also shows that when the siphon is shutoff, head begins to increase at the siphon, and that recovery is mirrored at Mine 38 and Williams. After several months, when 
withdrawal resumes, the mine-pool is drawn down again. The siphon will likely have to continue operation for the foreseeable term to maintain the mine-pool below discharge elevation.

\section{Mine-pool Conductance Properties}

Water levels have been measured at three locations within the Beth $41 / 8$ complex. Head at the three locations differs by less than two $\mathrm{m}$ at wells separated by several $\mathrm{km}$. The very low hydraulic gradient existing within the mine complex suggests that individual mines have relatively high internal hydraulic conductivity, and head differences between mines are controlled mostly by barrier pillars. We have observed similar conditions of very low gradient between three wells of less than $1 \mathrm{~m}$ difference over $\sim 2 \mathrm{~km}$ in a single mine in Pennsylvania, with simultaneous head difference of $20 \mathrm{~m}$ across a barrier pillar (authors unpublished data).

We estimated barrier pillar leakage for one common boundary between the Beth 41/8 complex and Federal 1 mines (figure 3) from water level data, mine map information and horizontal hydraulic conductivity (K) data of McCoy (2002). He estimated effective hydraulic conductivity from pumping records and water level data for barrier pillars in two mines on the western side of the Fairmont mine-pool. McCoy reported a range of barrier pillar hydraulic conductivity of 0.03 to $0.15 \mathrm{~m} /$ day, and an average of $0.091 \mathrm{~m} /$ day. Using McCoy's average barrier pillar K, and an average head difference of about $7 \mathrm{~m}$, we estimate that about $208 \mathrm{~L} / \mathrm{min}$ flows through the barrier between the Beth Mines complex to Federal 1, using a Darcy's law calculation . This barrier is just one a number of mine boundaries within the Fairmont mine-pool where flow across barriers must be taking place. The total quantity of water circulating between mines is significant from the standpoint of managing the mine-pool.

\section{Mine-pool Storage Properties}

Ground-water storage in the Fairmont mine-pool includes water in the pore space of open mine voids and collapsed and fractured overburden, as well as an elastic storage component. Figure 4 is a plot of hourly head versus barometric pressure for a well in the Beth 41/8 complex during October, 2002. The two parameters are near mirror images of each other, a behavior that is characteristic of confined aquifers. The barometric efficiency (BE) of a well can be used to estimate specific storage $S_{s}$, and porosity n, of the aquifer (Domenico and Schwartz (1990) from the relationships:

$$
\mathrm{BE}=\left(\mathrm{y}_{\mathrm{w}} * \mathrm{dh}\right) / \mathrm{dP}_{\mathrm{a}}
$$

where $\mathrm{y}_{\mathrm{w}}$ is the unit weight of water; $\mathrm{dh}$ is the head change; and $\mathrm{dP}_{\mathrm{a}}$ is the change in atmospheric pressure.

$$
\begin{aligned}
& \mathrm{TE}=1-\mathrm{BE} \\
& \mathrm{TE}=\left(\mathrm{p}_{\mathrm{w}} * \mathrm{~g} * \mathrm{~B}_{\mathrm{p}}\right) / \mathrm{S}_{\mathrm{s}}
\end{aligned}
$$

where $\mathrm{p}_{\mathrm{w}}$ is fluid density, $\mathrm{g}$ is the gravitational acceleration constant; and $\mathrm{B}_{\mathrm{p}}$ is compressibility of the aquifer matrix, either measured or estimated. Finally, porosity, $n$ is estimated from: 


$$
\mathrm{BE}=\left(\mathrm{p}_{\mathrm{w}} \mathrm{gnB} \mathrm{B}_{\mathrm{w}}\right) / \mathrm{S}_{\mathrm{s}}
$$

where $S_{s}, p_{w}$ and $g$ are as previously defined, and $B_{w}$ is fluid compressibility.

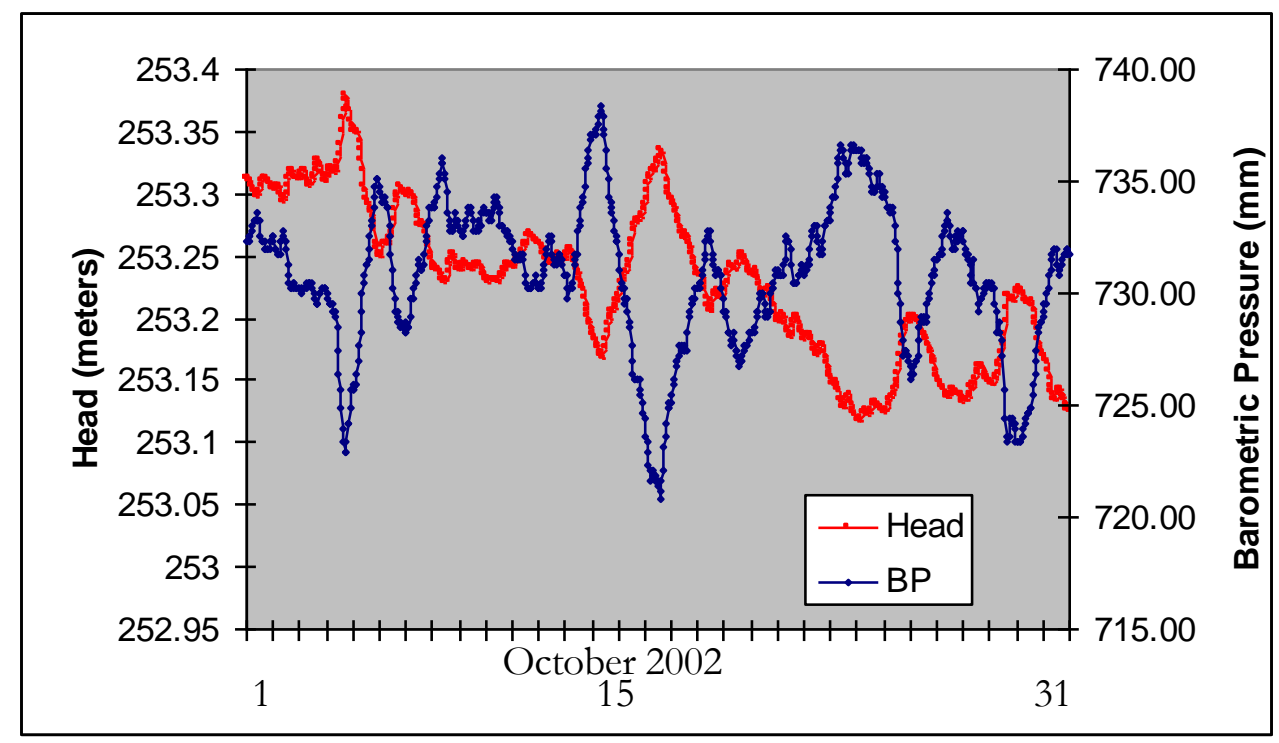

Figure 4. Hourly mine-pool head versus barometric pressure, Beth41/8 mine complex, October, 2002.

Portions of the record were selected where a change in barometric pressure persisted for at least 18 to 24 hours, such as occurred in mid October in Figure 4. Underlying trends of rising or falling head due other factors such as seasonal variation were removed using regression methods similar to those described by Davis and Rasmussen (1993). Specific storage and porosity then were calculated using relationships 1 to 4 . The process was applied to 3 to 5 different segments of the record to determine if reproducible results were obtained. For individual wells, estimated values were generally within $25 \%$ relative difference.

Specific storage, $\mathrm{S}_{\mathrm{s}}$ was estimated to be on the order of 1.5 to $2.5 \times 10^{-6} / \mathrm{m}$, and porosity estimates ranged from about 12 to $35 \%$ at three different wells. Most porosity values fell between 15 and 25\%. These wells are completed in partially caved zones and crushed coal pillars, based on drilling observations. Since coal recovery typically ranged from at least 50 to upwards of $80 \%$, these porosity data suggest the mine-pool aquifer thickness exceeds the coal thickness, perhaps by $2 \mathrm{x}$ to $6 \mathrm{x}$. On this basis, storage coefficient, $\mathrm{S}$, for the aquifer, is estimated to range from about $6 \times 10^{-6}$ to $2 \times 10^{-5}$. Crouch et al. (1980), working, in a mine-pool aquifer in Ohio, derived a storage coefficient of about $3 \times 10^{-4}$ from a 29 day pump test after adjusting their hydrographs for barometric and seasonal effects. They concluded that pumped water was derived mostly from induced recharge and intercepted discharge. The apparent low storage coefficient for the Fairmont mine-pool results in relatively larger drawdown when it is pumped (siphoned). 


\section{Mine-Pool Water Quality}

Mine-pool water quality shows significant spatial variability. Table 1 includes analyses from wells located in a recharge area (mine 38 well), intermediate flow-path (Mine 63) and end of flow-path for the mine-pool (Dakota siphon). A fourth sample, Beth 42 overburden, is indicative of water quality in overlying aquifers that infiltrate and recharge the mine-pool. The mine-pool has circumneutral $\mathrm{pH}$ at each well, in each part of the flow system. Although the initial charge of

Table 1. Representative Water Quality of Fairmont Mine-pool ${ }^{(1)}$

\begin{tabular}{cccccccccccc}
\hline Site & $\begin{array}{c}\mathrm{pH} \\
\text { (field) }\end{array}$ & Alkalinity & $\mathrm{TDS}$ & $\begin{array}{c}\text { Eh } \\
\text { (millivolts) }\end{array}$ & $\mathrm{Fe}$ & $\mathrm{Mn}$ & $\mathrm{Ca}$ & $\mathrm{Mg}$ & $\mathrm{Na}$ & $\mathrm{Cl}$ & $\mathrm{SO}_{4}$ \\
\hline Mine 38 & 7.32 & 179.8 & 548 & -94 & 3.44 & 0.53 & 60.7 & 14.1 & 105.7 & 34.1 & 207 \\
Mine 63 & 7.31 & 589.6 & 3301 & -130 & 33.9 & 0.64 & 158.4 & 33.1 & 853.4 & 44.2 & 1697 \\
$\begin{array}{l}\text { Dakota } \\
\text { Siphon }\end{array}$ & 7.20 & 568.7 & 5194 & -159 & 134.8 & 1.63 & 250.6 & 89.7 & 1254 & 119.9 & 2812 \\
$\begin{array}{c}\text { Beth 41 } \\
\text { Overburden }\end{array}$ & 8.57 & 263 & 454 & -146 & 0.04 & 0.016 & 21.0 & 5.0 & 138.3 & 52.1 & 47.9 \\
\hline
\end{tabular}

(1) $\mathrm{pH}$ in S.U., Alkalinity in $\mathrm{mg} / \mathrm{L} \mathrm{CaCO}_{3}$, Eh in millivolts, all others in $\mathrm{mg} / \mathrm{L}$. TDS= total dissolved Solids. Mine-pool samples collected 12/17/2002. Overburden sample collected 4/8/99.

mine water in Pittsburgh seam mines is frequently acidic, complete flooding seems to curtail pyrite oxidation and can bring about a shift of 3 to 5 S.U. in pH. Watzlaf (1992), in lab studies found acid production was curtailed in saturated pyritic mine wastes, but continued in unsaturated materials. Donavan et al. (1999) report a Pittsburgh seam mine-pool where $\mathrm{pH}$ shifted from about 4 to 6.5 after passage of about one pool volume. Winters (2000) describes a Pittsburgh seam mine-pool where acidic waters are present in the unsaturated up-dip end of the mine complex, shifting to circumneutral $\mathrm{pH}$ with titrateable alkalinity in the down-dip flooded end. Measured Eh values in the Fairmont mine-pool indicate moderate to strongly reducing conditions prevail, even in the recharge area at Mine 38. A reduced environment is consistent with inhibiting further pyrite oxidation once the mine-pool is fully flooded.

There is about a tenfold increase in dissolved solids between recharge and discharge locations in Table 1, and about a threefold increase in alkalinity. During active mining, coal, roof and floor rock were exposed to humid oxidizing conditions, an ideal environment for pyrite oxidation and subsequent dissolution of other minerals, and formation of hydroxysulfates, oxides and other weathering products. Nuhfer (1967) reported finding hydroxysulfate minerals such as melanterite $\left(\mathrm{FeSO}_{4} * 7 \mathrm{H}_{2} \mathrm{O}\right)$ and gypsum on exposed coal. Other metal sulfates including copiapite and halotrichite (Jambor et.al., 2000) have also been identified in coal mines. These minerals are moderately soluble, and can be expected to dissolve in the saturated mine-pool, yielding dissolved $\mathrm{Fe}, \mathrm{SO}_{4}{ }^{2-}, \mathrm{Ca}^{2+}, \mathrm{Mg}^{2+}, \mathrm{H}^{+}$and other constituents. 
Total alkalinities approach $600 \mathrm{mg} / \mathrm{L}$ in the intermediate flowpath and discharge locations. These are among the highest values we have seen for nonsaline ground-waters circulating within 100 meters of the surface of upper Pennsylvanian rocks. The large alkalinity concentrations are likely due to a combination of carbonate dissolution and cation exchange. Limestones and calcareous rocks are abundant in the lower section of the Monongahela group (Hennen and Reger, 1913). The mine-pool aquifer consists not only of the residual coal, but also a zone of collapsed and severely fractured rock, which can range from $6 \mathrm{x}$ to $10 \mathrm{x}$ coal thickness (Kendorski, 1993). Rocks containing as little as 5 to $10 \%$ carbonate would be a large reservoir for generating solution alkalinity. Exchange of adsorbed $\mathrm{Na}$ for solution $\mathrm{Ca}$ and $\mathrm{Mg}$ would favor further dissolution of carbonates and production of alkalinity. Geochemical modeling has shown that carbonate dissolution and cation exchange are possible explanations for the observed changes in mine-pool composition (Perry, 2001). Sulfate reduction could also generate alkalinity. Sulfate reducing bacteria have been detected in the mine-pool along with trace levels of dissolved sulfide, ranging up to about $0.5 \mathrm{mg} / \mathrm{L}$.

Rocks of the Monongahela group commonly contain the clay minerals illite, chlorite and kaolinite (Berryhill et al., 1971, Dulong et al., 2001). Reported analyses show clay mineral content of mudstones and shales can easily exceed 20\%. Cation exchange capacity (CEC) of kaolinite ranges from 3 to $15 \mathrm{meq} / 100 \mathrm{~g}$, and 10 to $40 \mathrm{meq} / 100 \mathrm{~g}$ for illite and chlorite (Langmuir, 1997). For the clay mineral kaolinite, the lyotropic series for adsorption affinity is: $\mathrm{Na}<\mathrm{H}<\mathrm{K}<$ $\mathrm{Ca}=\mathrm{Mg}$. Calcium and $\mathrm{Mg}$ are more strongly adsorbed to exchange sites than $\mathrm{Na}$. Exchange coefficients for $\mathrm{Ca}$ and $\mathrm{Mg}$, with respect to $\mathrm{Na}$, are about 0.40 and 0.50 , following GainesThompson convention (Appelo and Postma, 1993). Thus, desorption of $\mathrm{Na}$ and adsorption of $\mathrm{Ca}$ and $\mathrm{Mg}$ should be favored in these waters.

Even assuming a conservative CEC of $5 \mathrm{meq} / 100 \mathrm{~g}$ of rock, a large quantity of exchange sites are theoretically available in the aquifer along a flow path covering $\mathrm{kms}$ to tens of $\mathrm{km}$, with a residence time of years to decades.

Composition of waters also varies by location in the flow system. Recharge water at Mine 38 is a mixed $\mathrm{Na}-\mathrm{Ca}-\mathrm{HCO}_{3}-\mathrm{SO}_{4}$ type; Mine 63 at an intermediate flowpath position is a $\mathrm{Na}-\mathrm{SO}_{4}$ $\mathrm{HCO}_{3}$ type water, while the Dakota siphon at the end of flowpath is a $\mathrm{Na}_{-} \mathrm{SO}_{4}$ water. Mine-pool composition becomes progressively enriched in $\mathrm{Na}$ and $\mathrm{SO}_{4}$ as water moves from recharge to discharge. The changes are consistent with $\mathrm{Na}$ exchange and dissolution of sulfate minerals. The overburden aquifer is a $\mathrm{Na}-\mathrm{HCO}_{3}$ water. Its' composition is similar to ground-water in Monongahela group rocks summarized by Hobba (1984) and Stoner et al. 1987.

Table 2 shows mineral saturation indices for mine-pool waters calculated using PHREEQC (Parkhurst and Appelo, 1999). Recharge waters (mine 38) are under saturated for both calcite and dolomite, indicating carbonates should dissolve. Intermediate and end of flowpath waters are slightly over saturated for calcite and dolomite, suggesting that as water flows from recharge areas through the mine-pool, carbonates are dissolving. Mine waters are 3 to 5 orders under saturated for melanterite, indicating that if present initially, it is dissolving. Gypsum is also under 
saturated, but approaches equilibrium at end of flow path, suggesting additional mineral dissolution in the mine-pool. Amorphous or poorly crystalline $\mathrm{Fe}(\mathrm{OH})_{3}$ is several orders of

Table 2 Mineral Saturation Indices for mine-pool waters. ${ }^{(1)}$

\begin{tabular}{llllllll}
\hline Site & $\mathrm{pCO} 2$ & Calcite & Dolomite & Gypsum & Goethite & $\mathrm{Fe}(\mathrm{OH})_{3}(\mathrm{am})$ & Melanterite \\
\hline Mine 38 & -1.82 & -0.52 & -1.49 & -1.40 & 2.29 & -3.17 & -5.09 \\
Mine 63 & -1.61 & 0.30 & 0.10 & -0.54 & 2.93 & -2.49 & -3.68 \\
Dakota & -1.54 & 0.27 & 0.28 & -0.29 & 2.77 & -2.70 & -3.01 \\
Siphon & & & & & & & \\
\hline
\end{tabular}

(1)Saturation Index calculated as log (Ion Activity Product/Equilibrium constant)

magnitude under saturated, indicating that if present, it can dissolve. Goethite is, however; over saturated for all waters, suggesting that some Fe could be removed from solution by formation of $\mathrm{FeOOH}$. It has not been possible to collect sediments from the mine-pool for mineralogical analyses to verify the presence of specific minerals, however, the presence of each mineral in table 2 is considered probable.

Iron is the chief pollutant of concern in the mine-pool because of deleterious effects on biota, aesthetics, and consumptive use at relatively low concentrations. Fe concentrations at the Dakota siphon are about 40x greater than the recharge area at Mine 38. Periodic sampling of these wells and others in the mine-pool have shown that Fe exhibits a high degree of spatial variability, and that variation is maintained through time. Other constituent concentrations also vary spatially, but generally to a lesser degree. Each well, however, tends to show a characteristic composition through time suggesting that a local equilibrium condition exists.

Figures 5 and 6 show $\mathrm{Fe}$ and $\mathrm{SO}_{4}$ concentrations, and a moving average based trend, for the six year period of 1997 to 2003 . Both parameters, especially Fe, show some scatter in raw data. Fe concentrations increased for about the first year of mine-pool withdrawal. Both parameters then began a gradual, somewhat irregular decline continuing to the present. First order decay functions were fit to the trend data for $\mathrm{Fe}$ and $\mathrm{SO}_{4}$ from late 1998 to present using the following:

$$
\mathrm{C}_{\mathrm{t}}=\mathrm{C}_{0} * \exp ^{-\mathrm{kt}}
$$

where $\mathrm{C}_{\mathrm{t}}$ is concentration at time $\mathrm{t}, \mathrm{C}_{0}$ is concentration at time zero, $\mathrm{k}$ is the decay constant in time $^{-1}$ and $t$ is elapsed time. The decay constant was derived from a plot of $\ln \left(C_{t} / C_{0}\right)$ versus $t$, and estimating the slope with simple linear regression. Statistically significant results were obtained, however, the fitted relationships are weak to moderate ( $\mathrm{r}=0.48$ and 0.67 for $\mathrm{Fe}$ and $\mathrm{SO}_{4}$, respectively) correlations, due to short term variation. Some of the observed variation seem to be seasonal. Half life estimates are about 12 years for $\mathrm{Fe}$ and 14 years for $\mathrm{SO}_{4}$. For the period of record, sulfate concentrations have declined from about 4,000 to 3,000 mg/L and Fe from about 150 to around $100 \mathrm{mg} / \mathrm{L}$. Mine-pool quality is improving, but slowly. 


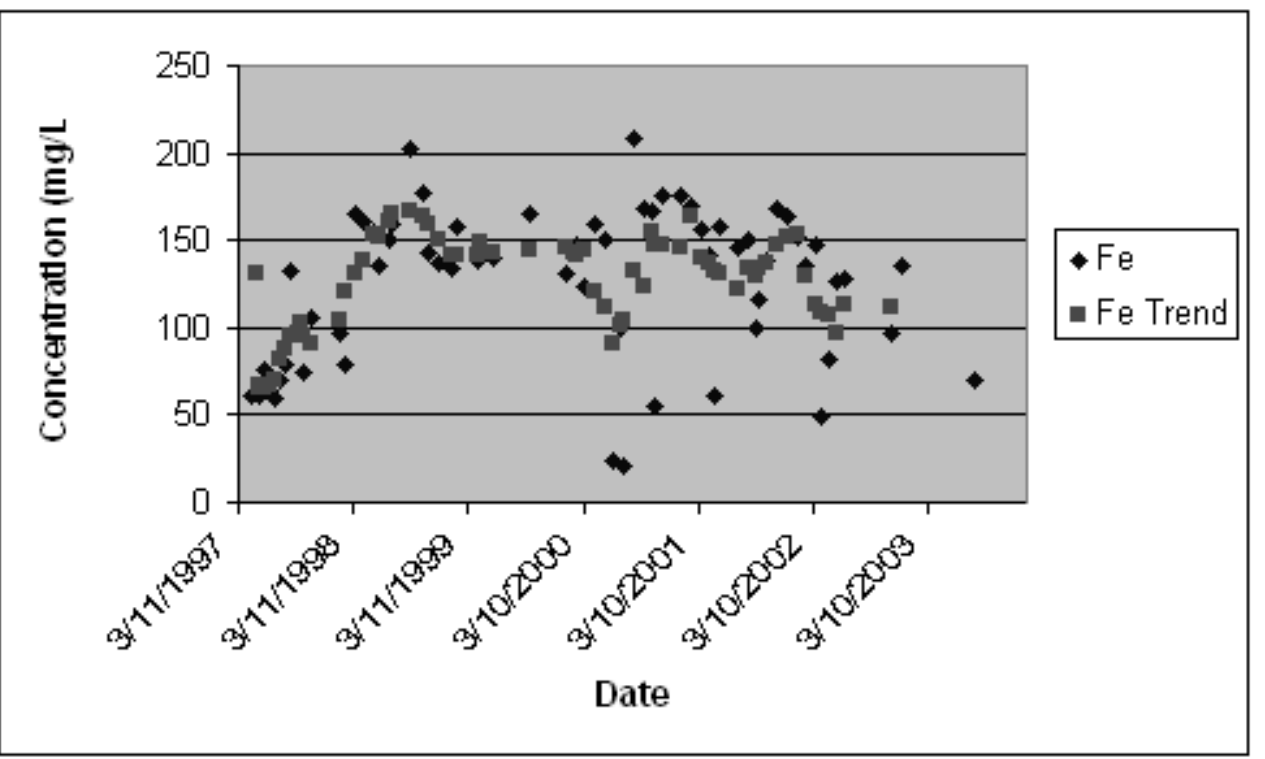

Figure 5. Raw and trend Fe concentrations, Dakota mine siphon.

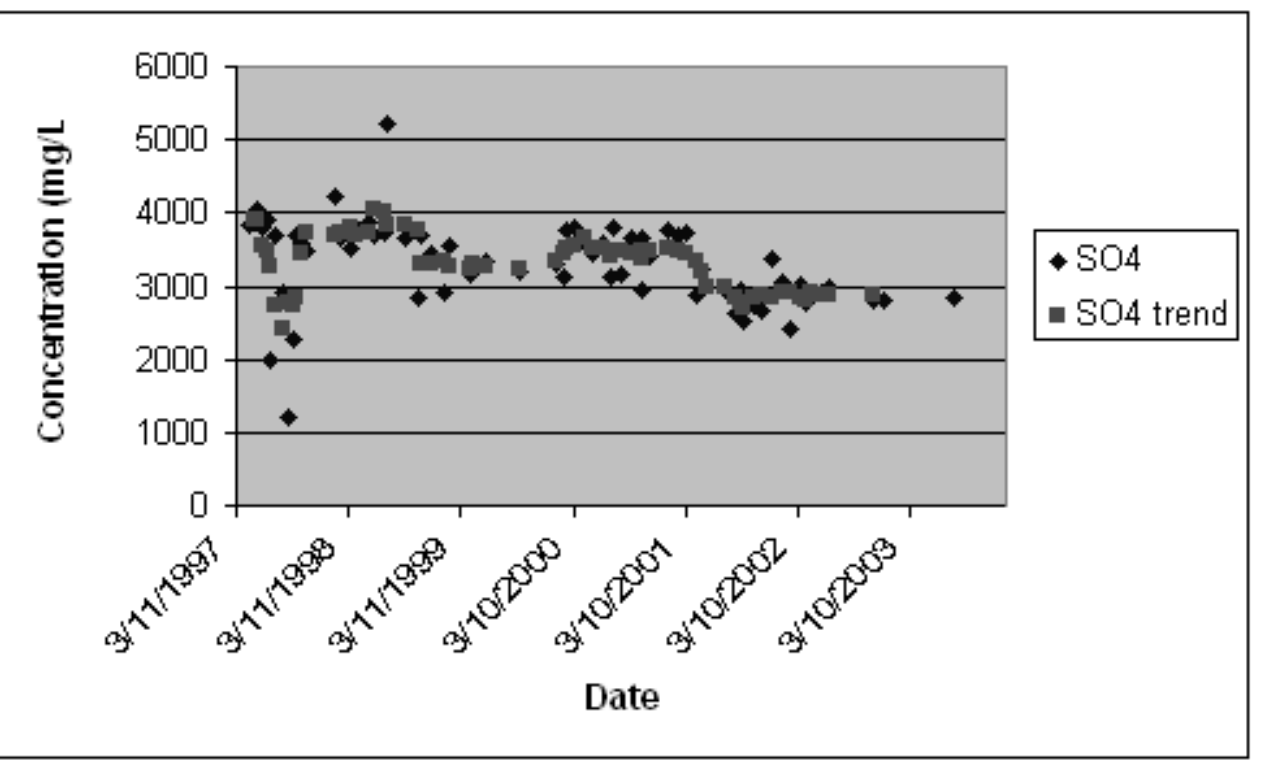

Figure 6. Raw and trend SO4 concentrations, Dakota siphon 


\section{Conclusions}

The Fairmont mine-pool is a group of hydraulically connected and fully flooded abandoned underground mines. The mine-pool responds to stresses, such as pumping, as a confined aquifer. Individual mines have relatively high internal conductance, with small hydraulic gradients. Most head difference occurs across barrier pillars, and the location and orientation of barrier pillars, and flooding history result in complex flow patterns. Recharge to the mine-pool is offset by withdrawal from the Dakota siphon, leakage to adjacent mines and outflow to unmined areas.

The Dakota siphon has maintained the mine-pool below surface discharge elevation for over 6 years, and influences portions of the mine-pool located more than $15 \mathrm{~km}$ away. However the mine-pool has not yet reached a final steady state, as head continues to increase in some mines in and adjacent to the mine-pool. The rate of withdrawal from the siphon will likely need to be increased in the future to maintain the overall mine-pool below discharge elevation. Head levels would increase to discharge elevation within a short period, if the siphon withdrawal was stopped.

Mine-pool quality exhibits both spatial and temporal variation, especially for soluble Fe. Mineralization is least in inferred recharge areas, and increases as water moves through the flow system. Water composition evolves from mixed in recharge areas, to $\mathrm{Na}-\mathrm{SO}_{4}$ type waters at the end of flow path with high concentrations of alkalinity. The changes are consistent with dissolution of soluble sulfate minerals and cation exchange.

Complete flooding yields a reduced environment that seems to prevent further sulfide oxidation. The mine-pool is now undergoing a slow flushing of soluble weathering products. Discharge quality at the siphon has shown some improvement through 6 years of monitoring, but remains unacceptable without treatment.

The Fairmont mine-pool will require continuing management for the foreseeable term to prevent a pollutional discharge.

\section{$\underline{\text { Literature Cited }}$}

Appelo, C.A.J., and D. Postma, 1993, "Geochemistry, groundwater and pollution", A.A. Balkema, Rotterdam, 536 pps.

Berryhill, H.L., Schweinfurth, S.P., and B.H. Kent, 1971, Coal-Bearing Upper Pennsylvanian and Lower Permian Rocks, Washington Area, Pennsylvania, U.S. Geological Survey Professional paper 621, 47 pps.

Crouch, T. M., Collins H.R., and J.O. Helgesen, 1980, Abandoned Subsurface Coal Mines as A Source of Water for Coal Conversion in Eastern Ohio. Report of Investigations 118, Ohio Dept of Natural Resources, Division of Geological Survey. 
Davis, D.R. , and T.C. Rasmussen, 1993, A Comparison of Linear Regression With Clark's Method for Estimating Barometric Efficiency of Confined Aquifers, Water Resources Research, Vol. 29,No.6, pps1849-1854.

Domenico, P.A., and F.W. Schwartz, 1990, Physical And Chemical Hydrogeology, 824 pps.

Donovan, J. J., Fletcher, J., Strager, M. and E. Werner, 1999, Hydrogeological and Geochemical Response to Mine Flooding in the Pittsburgh Coal Basin, Southern Monongahela River Basin, West Virginia University, National Mined Land Reclamation Center Project WV-132, Final report to U.S. Environmental Protection Agency,111 pps.

Dulong, F.T, Fedorko, N., Renton, J.J., and C. B. Cecil, "Chemical And Mineralogical Analyses of Coal-Bearing Strata In The Appalachian Basin”, U.S. Geological Survey Open File Report 02-489.

Hennen, R.V and D.B. Reger, 1913, West Virginia Geological Survey County Reports, Marion, Monongalia and Taylor counties, Wheeling News Litho Co., Wheeling, WV.

Hobba, W.A. 1984, Ground-Water Hydrology of the Monongahela River Basin. U.S. Geological Survey in cooperation with the West Virginia Dept. of Natural Resources.

Jambor, J.L., Nordstrom, D.K. and C.N. Alpers, 2000, Metal-sulfate salts From Sulfide Mineral Oxidation, In Sulfate Minerals Crystallography, Geochemistry and Environmental Significance, Reviews in Mineralogy and Geochemistry Vol. 40, p305-350.

Kendorski, F.S., 1993, Effect of High Extraction Mining on Surface and Ground Waters, In Proceedings $12^{\text {th }}$ Conference on Ground Control in Mining, West Virginia University, Morgantown, WV.

Langmuir, D., 1997, Aqueous Environmental Geochemistry, Prentice Hall Publishers, 600 pps.

Leavitt, B.R., 1993, Discharge Potential of the Fairmont Mine-pool, Unpublished Internal Report for Consol Inc.

McCoy, K.J. 2002, Estimation of Vertical Infiltration Into Deep Pittsburgh Coal Mines of WVPA: A Fluid Mass Balance Approach, Unpublished Thesis, West Virginia University, Dept of Geology and Geography,151 pps.

McCullogh, C. M., Diamond, W. P., Bench, B. M. and M. Duel. 1975. Selected Geologic Factors Affecting Mining of the Pittsburgh Coal Bed. Report of Investigations 8093. U.S. Bureau of Mines. 
Nuhfer, E., 1967. Efflorescent Minerals Associated With Coal. Unpublished Thesis, Dept of Geology and Geography, West Virginia University.

Parkhurst, D. L., and C. A. J. Appelo, 1999. User's Guide to PHREEQC (Version 2) - A Computer Program For Speciation, Batch-Reaction, One-Dimensional Transport, and Inverse Geochemical Calculations. U.S. Geological Survey Water Resources Investigation Report 99-4259.

Perry, E. F., 2001, Modeling Rock-Water Interactions in Flooded Underground Coal Mines, Northern Appalachian Basin, Geochemistry: Exploration, Environment, Analysis, Vol. 1, 2001, pp. 61-70.

Ruppert, L. F., Tewalt, S.J., and L. Bragg, 1997, Map Showing Areal Extent of Pittsburgh Coal Bed and Horizon and Mined areas of the Pittsburgh coal bed in Pennsylvania, Ohio, West Virginia and Maryland, digitally compiled by Tully, J., Pierce, J., Weller, A., and J. Yarnel, U.S. Geological Survey Open File Report 96-280.

Ruppert, L. F., Tewalt, S. J., Bragg, L. J. and R. N. Wallack, 1999. A Digital Resource Model of the Upper Pennsylvanian Pittsburgh Coal Bed, Monongahela Group, Northern Appalachian Basin Coal Region, USA, International Journal of Coal Geology, 41, 3-24.

Stoner, J. D., Williams, D. R., Buckwalter, T. E., Felbinger, J. K. and K. L. Pattison, 1987. Water Resources and the Effects of Coal Mining, Greene County, Pennsylvania, Pennsylvania Geological Survey Water Resources Report 63.

Watzlaf, G. R., 1992. Pyrite oxidation in saturated and unsaturated coal waste, In Proceedings of the 1992 National Meeting of the American Society for Surface Mining and Reclamation, Duluth, MN, 191-205.

Winters, W.R., 2000, Hydrologic and Geochemical Evolution of a Bituminous Coal Basin: Irwin Syncline, Westmoreland County, Pennsylvania, Thesis, University of Pittsburgh, Geology and Planetary Science Dept. 


\section{$\underline{\text { Appendix D }}$}

\section{WATER QUALITY TRENDS IN A FLOODED 35 YEAR OLD MINE-POOL}

2005 National Meeting of the American Society of Mining and Reclamation, Breckenridge CO, June, 19-23 2005. Published by ASMR, 3134 Montavesta Rd., Lexington, KY 40502 


\title{
WATER QUALITY TRENDS IN A FLOODED 35 YEAR OLD MINE-POOL ${ }^{1}$
}

Eric F. Perry ${ }^{2}$, Jay W. Hawkins, Mike Dunn, Robert S. Evans, and John K. Felbinger

\begin{abstract}
Thirty five years of water quality data from a pumped, mostly flooded, mine-pool were examined for trends in mine drainage parameters. At the start of pumping in 1970, the Lancashire 15 mine-pool discharged acidic water with average iron $(\mathrm{Fe})$ concentration exceeding $900 \mathrm{mg} / \mathrm{L}$. Average sulfate $\left(\mathrm{SO}_{4}\right)$ concentration was about $3700 \mathrm{mg} / \mathrm{L}$. After 14 years of pumping about 21 minepool volumes, $\mathrm{Fe}$ and $\mathrm{SO}_{4}$ were about $20 \%$ of their initial concentrations. Alkalinity had increased from less than 50 to about $120 \mathrm{mg} / \mathrm{L}$, and $\mathrm{pH}$ was about 6.0. In 1986, an overlying mine complex closed and flooded. Its' waters have low concentrations of $\mathrm{Fe}$ and $\mathrm{SO}_{4}$, and are hydraulically connected to the Lancashire 15 mine-pool. The combined mine-pool waters reduced $\mathrm{Fe}$ by about $50 \%$ in Lancashire 15. Since 1986, Fe and $\mathrm{SO}_{4}$ concentrations have continued a slow, irregular decline at the rate of 1 to $2 \mathrm{mg} / \mathrm{L} / \mathrm{yr}$ for $\mathrm{Fe}$ and about 10 to $15 \mathrm{mg} / \mathrm{L} / \mathrm{yr}$ for $\mathrm{SO}_{4}$. Short term fluctuations due to seasonal and pump rate variations occur, but long term concentration trends can be described with curvilinear models.
\end{abstract}

The Lancashire 15 discharge is sodium-sulfate $\left(\mathrm{Na}-\mathrm{SO}_{4}\right)$ type water. Geochemical calculations show that cation exchange of calcium $(\mathrm{Ca})$ for $\mathrm{Na}$ is a feasible explanation for the observed water composition. Mixing calculations show that mine-pool composition can be explained by cation exchange; continuing dissolution of iron and sulfur bearing minerals, iron oxyhydroxide formation and about $80 \%$ of recharge as leakage from adjacent and overlying mines, and $20 \%$ recharge from unmined strata.

The Lancashire 15 mine-pool quality has improved significantly since closure and flooding. After leaching an estimated 55 pool volumes, Fe concentrations are about $5 \%$ of original values, and the waters are net alkaline. Continued mineral dissolution, and inefficient leaching due to dispersion and short circuiting, are likely responsible for current water quality conditions.

Additional Key Words: acid mine drainage, mineral solubility, pyrite, Eh

${ }^{1}$ Paper was presented at the 2005 National Meeting of the American Society of Mining and Reclamation, Breckenridge CO, June, 19-23 2005. Published by ASMR, 3134 Montavesta Rd., Lexington, KY 40502

${ }^{2}$ Eric F. Perry, Hydrologist, Office of Surface Mining, 3 Parkway Center, Pittsburgh, PA,15220, email eperry@osmre.gov (will present paper), Jay Hawkins, Robert Evans, and John Felbinger are Hydrologists; Mike Dunn is a Geologist, all at Office of Surface Mining, Pittsburgh, PA, 15220. 


\section{$\underline{\text { Introduction }}$}

Drainage from closed underground coal mines are a significant source of water pollution in northern Appalachia and elsewhere (Kleinmann et al., 2000; Younger, 1997). Mine-pool quality is controlled by geochemistry of the immediate roof and floor rock, residual coal, composition of recharge water, and extent of flooding of the mineworks. Mine-pool quality changes after closure with the poorest water quality discharged in the initial flush, followed by a gradual, (i.e. years to decades) improvement in composition. Skousen et al. (2004) reported that iron concentration had decreased an average of $80 \%$ in 44 free draining underground mine discharges over a 30 year period. Wood et al. (1999) concluded that pollution from closed underground coal mines in Scotland was most severe in the first few decades, and that iron concentrations would decline to $30 \mathrm{mg} / \mathrm{L}$ or less within 40 years. The final chemical composition of initially acidic, highly polluted mine-pools is uncertain after early flushing. In the long term, these mine-pools may also be important ground-water resources, because they are frequently transmissive enough to sustain relatively large yields when pumped (Donovan et al., 2004; Perry and Hawkins, 2004).

In this paper we describe water quality trends and geochemical processes for iron and sulfate in a 35 year old mine-pool, Lancashire 15, that is about 79\% flooded (approximately $4690 \mathrm{Ha}$ ). The physical hydrogeology is detailed in a companion paper (Hawkins et al., 2005) and information on pool volume and storage are used to interpret observed chemical trends. The mine-pool has one principal pumped discharge that yields over 24,000 L/min and has been sampled since closure and initial flooding.

\section{Geologic and Hydrogeologic Setting}

The Lancashire 15 (L-15) mine-pool is located in Cambria County, Pennsylvania and is largely contained within an enclosed basin defined by the Barnesboro syncline, and Nolo anticline on the west and Laurel Hill anticline to the east (fig. 1). The axes of the syncline and anticlines are oriented about $\mathrm{N} \mathrm{30^{ \circ }}$ East, and form an elongated basin about $24 \mathrm{~km}$ long. This geologic structure influences extent of flooding and the flow direction of water in the mine-pool. The L15 mine-pool is pumped from the Duman plant at the low point of the basin (fig. 1). The main L-15 mine-pool is in the Lower Kittanning coal bed, and is partially overlain by a second set of flooded mine works in the Lower Freeport coal bed. The vertical interval between coals is around $50 \mathrm{~m}$. The two mine-pools are hydraulically connected as shown by pumping and other data (Hawkins et al., 2005). Mine works located near the crest of the two anticlines are not fully flooded, and water in these areas flows down-dip to recharge the main pool. The presence or absence of complete flooding also influences water chemistry. Unflooded or free draining areas are more likely to undergo continuing pyrite oxidation and leaching and produce acid drainage, while fully flooded mineworks may yield water with circumneutral $\mathrm{pH}$ and net alkaline conditions. 


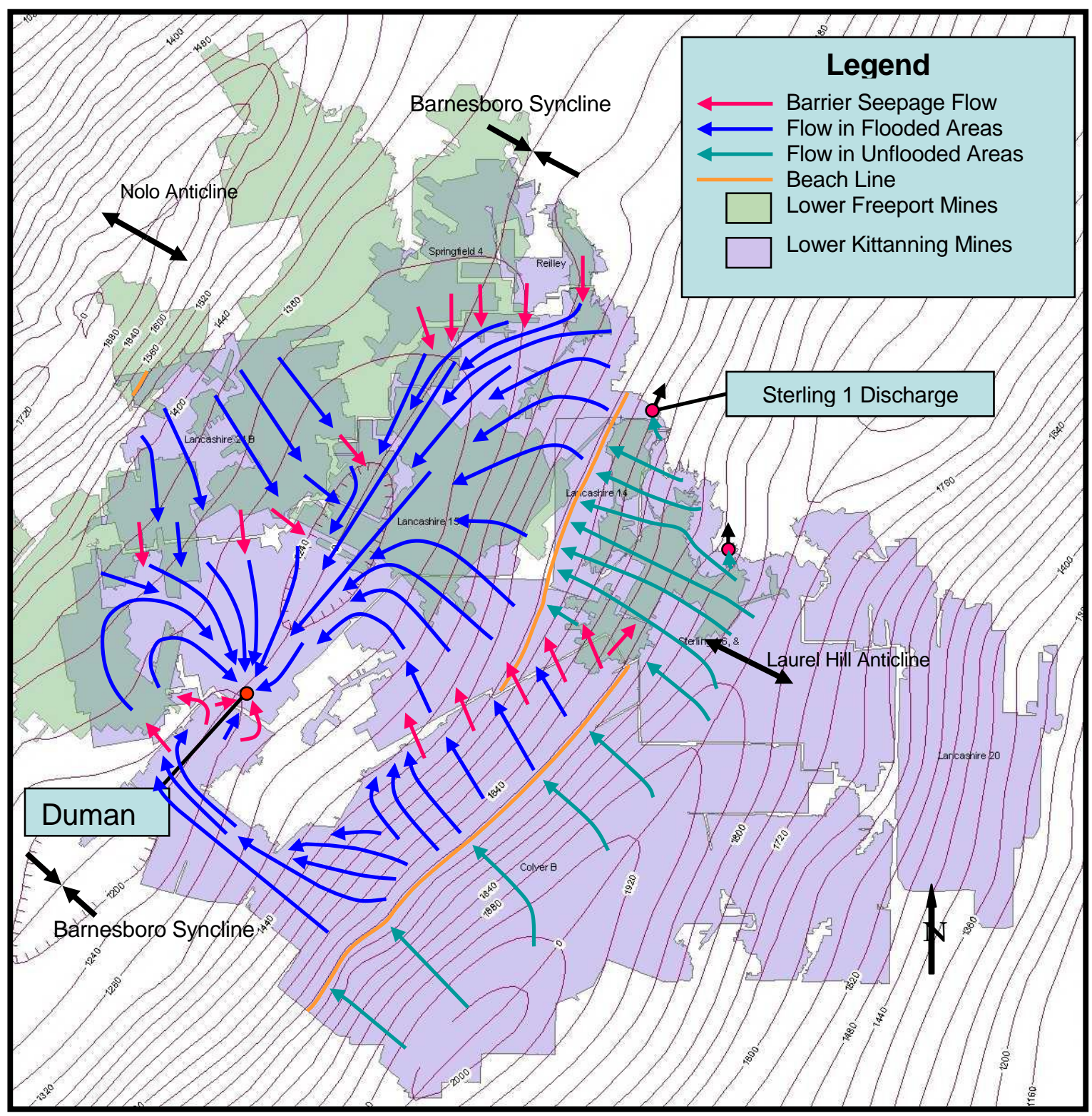

Figure 1. L-15 Mine-pool Flow Paths and Geologic Structure.

The L-15 mine-pool is also recharged by leakage through barrier pillars from adjoining flooded or partially flooded mines. About $30 \%$ of the flow at Duman is estimated to be barrier seepage from the Colver mine-pool located to the east (Hawkins et al., 2005). Some ground water also enters the mine-pool through unmined strata.

The rocks are Pennsylvanian age, Allegheny group, consisting in descending order of the Freeport, Kittanning and Clarion formations. Rock strata of this area are characterized by sandstones interbedded with shales, mineable coal beds and thin but persistent limestones near 
the Lower Freeport coal bed. Rocks in the Kittanning formation generally lack carbonates. The Lower Kittanning seam elevation varies from a high of about $610 \mathrm{~m}$ on the Laurel Hill anticline to a low of about $366 \mathrm{~m}$ near the Duman treatment plant. The Lower Kittanning seam averages about $1 \mathrm{~m}$ thick, and the Lower Freeport is about $1.4 \mathrm{~m}$. Area geology is described in more detail by McElroy (1998) and references cited therein.

\section{Mine Closure and Flooding History}

The L-15 mine-pool formed in adjacent and interconnected mineworks of about 15 different mines (Hawkins et al., 2005). Coal development began in the late 1800's by room and pillar methods, and many areas had retreat mining. Later mining included longwall extraction. By the mid 1980's all significant underground mining was completed. The L-15 mine-pool began to form after the closure of several larger mineworks in the Lower Kittanning seam in 1969. At that time, dewatering was halted and the mineworks were allowed to flood. About one year later, a major blowout occurred at the north end of the mine-pool, discharging an estimated 4000 to $8000 \mathrm{~L} / \mathrm{min}$ into the West Branch of the Susquehanna River. Discharge quality was extremely poor with iron and total acidity concentrations ranging from 2500 to $4000 \mathrm{mg} / \mathrm{L}$, and about 7000 to $10,000 \mathrm{mg} / \mathrm{L}$, respectively. A major fish kill occurred, and the Commonwealth of Pennsylvania began emergency treatment of the West Branch of the Susquehanna River. The mining company began pumping and treating at the Duman facility until water level was below breakout elevation and discharge to the West Branch of the Susquehanna River ceased.

In 1986, mines in the overlying Lower Freeport seam and one Lower Kittanning seam mine closed and flooded. Closure of these mines increased the required pumping rate at Duman by about $60 \%$ (Hawkins et al., 2005) indicating they contribute part of the recharge to the L-15 mine-pool. The L-15 mine-pool has been pumped and treated since 1970. As shown in fig. 1, flow within the mine-pool is from northeast to southwest along the synclinal axis, and from the anticlinal axes toward the center of the basin. The northern end of the mine-pool is unflooded (about $1246 \mathrm{Ha}$ ). The Sterling 1 discharge (fig. 1) drains a portion of the unflooded mineworks.

\section{Methodology}

Over 1400 analyses of Duman raw water quality from offices of the Pennsylvania Dept of Environmental Resources (PADEP) (Kernic, 1999), and mine drainage reports for Blacklick Creek and West Branch of Susquehanna (Michael Baker Consulting Engineers, 1978; Gwin, Dobson and Foreman, 1972) and unpublished data (Lloyd, 2004) were used in this study. Sampling frequency ranged from daily to monthly to quarterly, and there were several years for which no data were located. However, a good record of initial water quality conditions at Duman was available, and continuous sampling of monthly frequency exists for about the last 7 years.

The compiled analyses vary in reported parameters, and were run by different laboratories which may not have used identical analytical methods. Iron, $\mathrm{pH}$ and acidity are the most consistently reported parameters. Values for sulfate, manganese and aluminum were reported for some but 
not all samples. Acidity was calculated from reported $\mathrm{pH}$ and iron concentration, counting all iron as $\mathrm{Fe}(\mathrm{II})$, based on theoretical and practical considerations of iron speciation in mine waters (Kirby and Cravotta, 2004; Cravotta and Kirby, 2004). Calculated acidity was determined as:

Acidity Calc $=50 *\left((\mathrm{Fe} * 2 / 55.85)+1000 *\left(10^{-\mathrm{pH}}\right)\right)$

The available analyses show relatively small amounts of manganese present (generally less than $2 \mathrm{mg} / \mathrm{L}$ ), and except in acid waters, concentrations of soluble aluminum are low. Therefore, for most samples, iron should represent most of the acidity. The calculated acidity values were used in subsequent analysis.

To supplement the historical data, four complete suite samples of the Duman raw water were collected at different seasons of the year in 2004. Samples from the unflooded works of the Sterling 1 mine (Lower Kittanning seam), and the upper mine-pool (Lower Freeport seam) and several other mine discharges were also collected. Water quality samples included field filtered, acid preserved, sub-samples for major cations ( $\mathrm{Ca}, \mathrm{Mg}, \mathrm{Na}, \mathrm{K})$, metals ( $\mathrm{Fe}, \mathrm{Mn}, \mathrm{Al})$, trace elements(As, $\mathrm{Ba}, \mathrm{Be}, \mathrm{Cd}, \mathrm{Co}, \mathrm{Cr}, \mathrm{Cu}, \mathrm{Ni}, \mathrm{Pb}, \mathrm{Sb}, \mathrm{Se}, \mathrm{Zn}$ ), raw unpreserved sub-samples for anions $\left(\mathrm{SO}_{4}, \mathrm{Cl}\right)$ and general chemistry $(\mathrm{pH}$, acidity, alkalinity, specific conductance, Total Dissolved Solids, and Total Suspended Solids). Field measurements of $\mathrm{pH}$, specific conductance, temperature, oxidation reduction potential (Eh), and dissolved oxygen were also collected. Geochemical calculations of mineral saturation indices, inverse modeling and solution mixing were performed using PHREEQC (Parkhurst and Appelo, 1999). Statistical analyses were performed using Statgraphics for Windows, version 5.1.

\section{$\underline{\text { Results and Discussion }}$}

\section{Temporal Trends}

During the initial year of treatment at the Duman plant, overall water quality was very poor. Influent water $\mathrm{pH}$ varied from strongly acidic $(\sim 3.5)$ to circumneutral ( 6.3); alkalinity from zero to a maximum of about $100 \mathrm{mg} / \mathrm{L}$ and acidity was usually in excess of $1000 \mathrm{mg} / \mathrm{L}$. Iron and sulfate concentrations also showed short term fluctuation, but were typically in excess of 500 and $3000 \mathrm{mg} / \mathrm{L}$, respectively. Table 1 summarizes median water quality conditions for initial conditions from August, 1970 to December 1971, and recent data from February, 1998 to May, 2004 at the Duman plant.

Table 1. Median Water Quality, Historical and Current Conditions, Duman Treatment Plant ${ }^{(1)}$

\begin{tabular}{cccccc}
\hline Date & $\mathrm{pH}$ & Acidity $^{(2)}$ & Alkalinity & $\mathrm{Fe}$ & $\mathrm{SO}_{4}$ \\
\hline $8 / 70$ to $12 / 71$ & 5.10 & 1500 & 0 & 837.50 & 3432 \\
$2 / 98$ to $5 / 04$ & 6.51 & 98.3 & 172.9 & 43.75 & 397 \\
\hline
\end{tabular}

(1) $\mathrm{pH}$ in Standard units, acidity and alkalinity in $\mathrm{mg} / \mathrm{L} \mathrm{CaCO} \mathrm{Ca}_{3} \mathrm{Eq}$, iron and sulfate in $\mathrm{mg} / \mathrm{L}$.

(2) Acidity is calculated from iron and $\mathrm{pH}$ data as described in text. 
After about 35 years of leaching, L-15 mine-pool quality has improved substantially, although treatment is still required. The raw influent water is now typically net alkaline and median iron concentration has declined to about $5 \%$ of initial values. Fig. 2 shows the trend in average annual iron concentration at Duman from 1970 to present. Concentrations exceeded $900 \mathrm{mg} / \mathrm{L}$ during initial flooding and discharge, but declined rapidly afterwards, dropping to about 200 $\mathrm{mg} / \mathrm{L}$ after about 8 years. This period likely represents active flushing of soluble metal sulfate salts and stored acidity. After 1986 when the overlying mine-pool flooded, iron declined further to current values of around $40 \mathrm{mg} / \mathrm{L}$. Sulfate concentration initially declined more slowly, to about $1000 \mathrm{mg} / \mathrm{L}$ over a 10 year period, and is now about $11 \%$ of initial conditions.

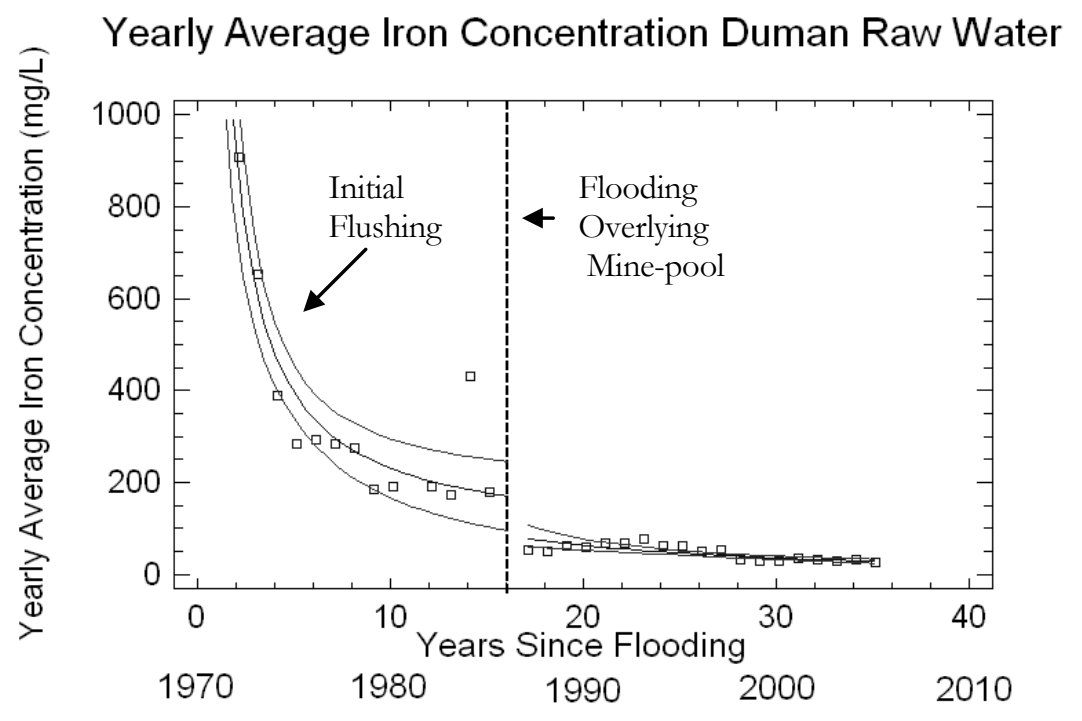

Figure 2. Plot of Average Annual Iron Concentration with Fitted Regressions, Duman Site.

The iron data in fig. 2 from 1971 to 1986 can be fitted to a reciprocal model of the form:

Fe Average $(\mathrm{mg} / \mathrm{L})=82.5+(1579.8 /$ Years since flooding $) \quad r=0.92$

In 1986, the L-15 mine-pool was affected by closure and flooding of mines in the overlying mine-pool (Lower Freeport seam). The resultant influx of water of differing chemical composition, generally containing iron of less than $5 \mathrm{mg} / \mathrm{L}$, changed the long term chemical behavior of the L-15 mine-pool. As seen in fig. 2, average iron concentration dropped abruptly from about 200 to $60 \mathrm{mg} / \mathrm{L}$ from dilution and mixing with the overlying mine-pool. In addition to dilution, increased precipitation of iron oxyhydroxides and/or carbonates may also have 
occurred. Flooding of the Lower Freeport mine-pool increased average alkalinity in the L-15 mine-pool from 120 to $290 \mathrm{mg} / \mathrm{L}$ and $\mathrm{pH}$ increased from 6.0 to 6.7. No Eh or iron speciation measurements are available for the 1986 flooding period. However, the 2004 water samples are slightly oversaturated for both siderite and poorly crystalline iron oxyhydroxides, indicating these minerals could precipitate. The post 1986 iron data can be fitted to a model of the form:

Fe Average $(\mathrm{mg} / \mathrm{L})=1 /\left(7.59 * 10^{\wedge-4} *\right.$ Years since Flooding $) \quad r=0.83$

After 1986, iron concentration continues to decline with time, but more slowly.

Younger (1997, 2000) and Wood et al. (1999) have reported similar discharge chemistry behavior of iron concentration in closed underground mines in the United Kingdom. Younger (1997) reports on several discharges where iron follows an exponential decay function. He attributes this behavior to depletion of "vestigal" or stored acidity, similar to the 8 year flushing period in the L-15 mine-pool. After 10 to 20 years, the curves in the British mines become asymptotic and solution iron is controlled by juvenile or ongoing acid generation. Younger (2000) concluded the main period of flushing of stored acidity is about four times as long as the flooding period, and that short-term to long term iron concentrations are about 8:1 (mg/L basis) with some site specific variation. For the L-15 mine-pool, flushing appears to be about 8 times as long as the flooding period, and is a function of flow path length and tortuosity, residence time, and extent of flooding. Initial iron to longer term concentrations is about $4: 1$ before the 1986 flooding, and about 19:1 when compared to current conditions. The 4:1 ratio suggests a slower rate of iron removal than observed by Younger, or greater ongoing acid production in L15. The 19:1 ratio is influenced by the 1986 flooding, and shows that the quality of the recharge water can significantly affect iron behavior.

Yearly average sulfate concentration data and fitted regressions are shown in fig. 3. The pre1986 sulfate data has a best fit model of:

$\mathrm{SO}_{4}$ Average $(\mathrm{mg} / \mathrm{L})=1 /\left(2.93 * 10^{\wedge-4}+6.04 * 10^{\wedge^{-5}} *\right.$ Years since Flooding $) \quad r=0.91$

The post 1986 sulfate model is similar with a best fit regression of:

$\mathrm{SO}_{4}$ Average $(\mathrm{mg} / \mathrm{L})=1 /\left(6.14 * 10^{\wedge-5} *\right.$ Years since Flooding $) \quad \mathrm{r}=0.73$

Unlike iron, sulfate concentration shows a small response to the 1986 mine flooding. Slopes of the pre and post flooding regressions (equations 4 and 5) are nearly the same. The small response in sulfate concentration to the 1986 flooding reflects its' conservative behavior in L-15. Gypsum and other common sulfate minerals are one or more orders of magnitude undersaturated in flooded sections and do not control sulfate concentration.

The curvilinear models and post 1986 flooding behavior for both iron and sulfate suggest that the system will approach long term geochemical equilibrium slowly, on the order of decades. 


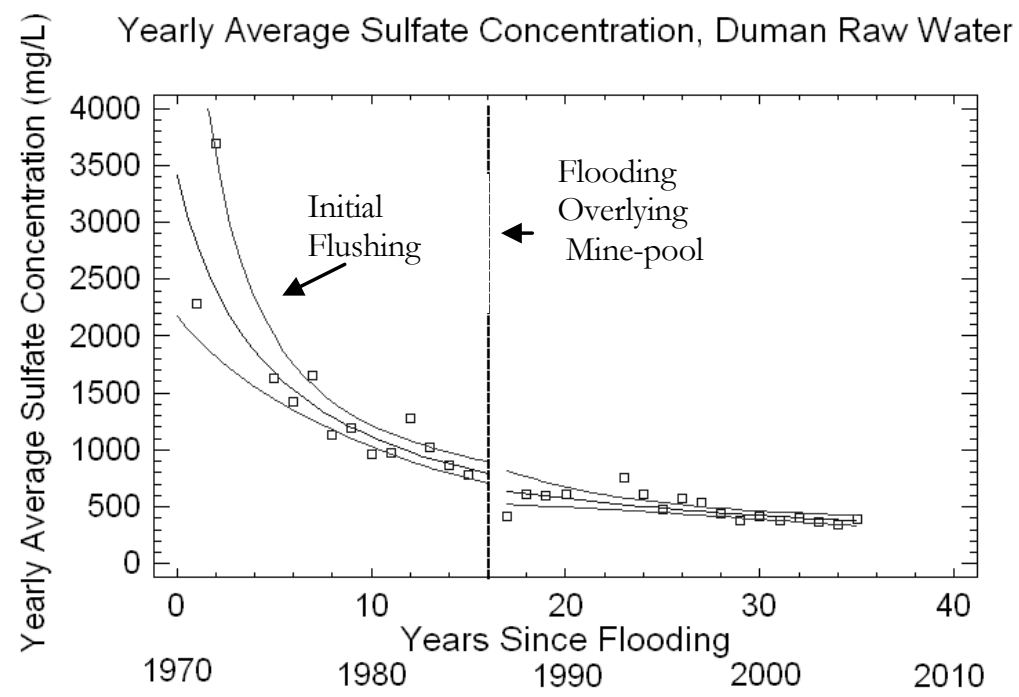

Figure 3. Plot of Average Annual Sulfate Concentration With Fitted Regressions, Duman Site.

Fig. 4 is a plot of simple moving average and raw data for iron concentration at the Duman plant for recent conditions (2000-2004). The overall trend has a current rate of decline of 1 to $2 \mathrm{mg} / \mathrm{L}$ year but there are short term and seasonal fluctuations in concentration. Most of the raw data are within about $25 \%$ of the trend line. Sulfate exhibits similar behavior, displaying a slow irregular decline of about $10 \mathrm{mg} / \mathrm{L}$-year in concentration over time. It is not known whether the trends will continue to decline or become asymptotic and approach equilibrium where iron is maintained at elevated concentrations indefinitely. Even if the current trends continue, it will be decades before water quality approaches some acceptable criteria. The curvilinear function derived for iron, based on post 1986 data, projects approximately 131 years from mine closure for iron to reach $10 \mathrm{mg} / \mathrm{L}$, assuming current hydrologic and geochemical conditions are still applicable in the future. The curvilinear function for sulfate based on post 1986 data, projects approximately 65 years from mine closure for sulfate to reach $250 \mathrm{mg} / \mathrm{L}$.

The L-15 mine-pool has been pumped at a rate equivalent to about 2 pool volumes a year based on storage calculations reported by Hawkins et al. (2005), and is approaching a total of 60 pool volumes. If the mineworks function as a simple flow through system, then soluble constituents should have been rapidly leached from the L-15 mine-pool within the first few years or pool volumes, when most flushing took place. In fact, both iron and sulfate persist in the mine-pool, suggesting that the flow system has elements of dispersion, short circuiting and no-flow zones, and that some chemical reactions are continuing. 
Simple Moving Average Plot, Duman Influent Iron, 2000-2004

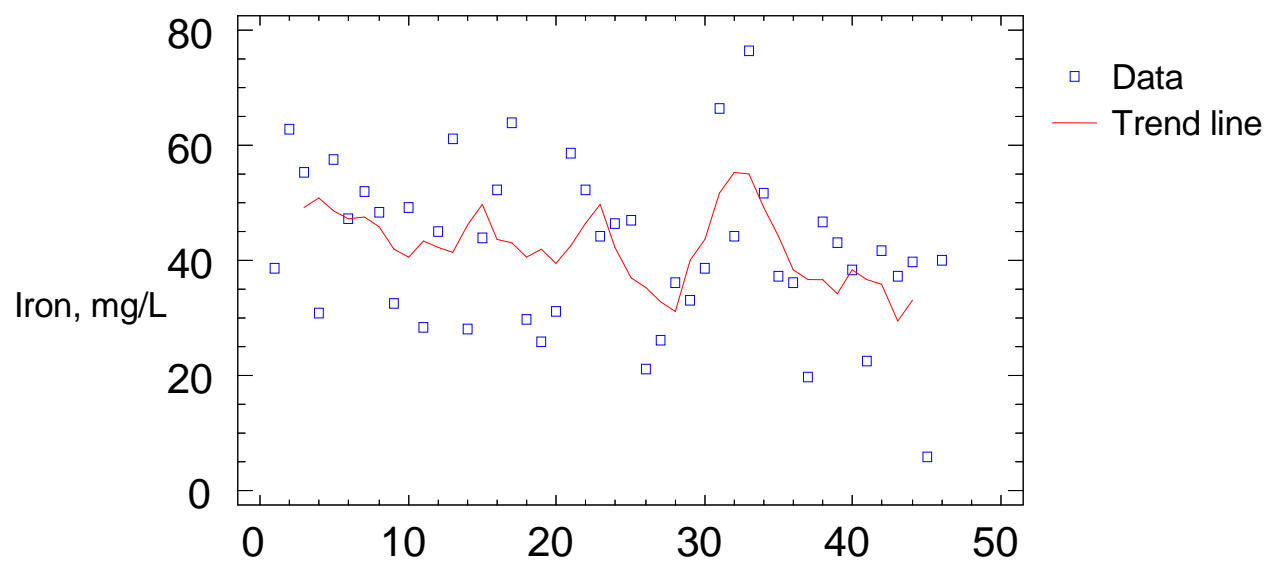

Figure 4. Plot of Simple Moving Average and Recent Iron Concentration, Duman site.

Pyrite oxidation in theory yields an $\mathrm{Fe}$ to $\mathrm{SO}_{4}$ mole ratio of 0.5 . Fig. 5 is a plot of $\mathrm{Fe}$ to $\mathrm{SO}_{4}$

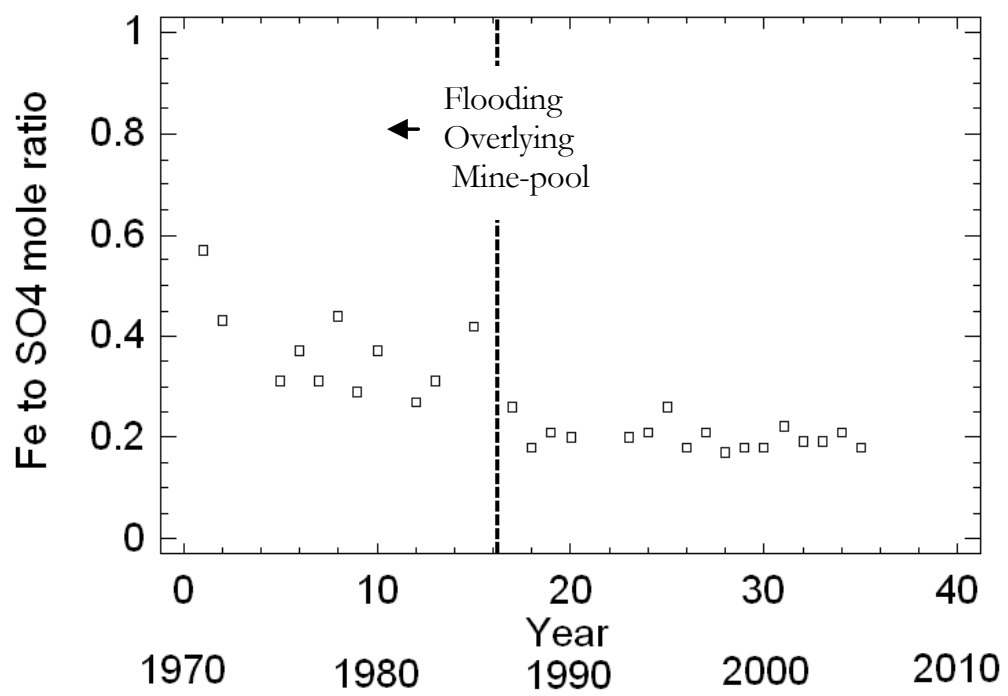

Figure 5. Plot of Average Annual Iron to Sulfate Mole Ratio, Duman Site.

mole ratio based on average annual data for the Duman site. The ratio declines over a 15 year period to around 0.2. Assuming sulfate behaves as a mostly conservative ion in the L-15 minepool and is derived from pyrite; about $60 \%$ of the iron is now being attenuated in the mine-pool by adsorption, precipitation or other reactions. In the first few years after flooding, less iron was retained in the mine-pool aquifer matrix. 
Fig. 6 is a plot of average annual alkalinity for the Duman discharge. For at least 6 years after flooding, corresponding to the period of initial flushing, alkalinity remained at about $50 \mathrm{mg} / \mathrm{L}$ or less. After the initial flushing of the L-15 mine-pool, alkalinity continued to increase to over 100 $\mathrm{mg} / \mathrm{L}$ and peaked at about $300 \mathrm{mg} / \mathrm{L}$ after flooding of the overlying Lower Freeport mines. Since that time alkalinity has remained around $200 \mathrm{mg} / \mathrm{L}$ and $\mathrm{pH}$ has stabilized at about 6.5.

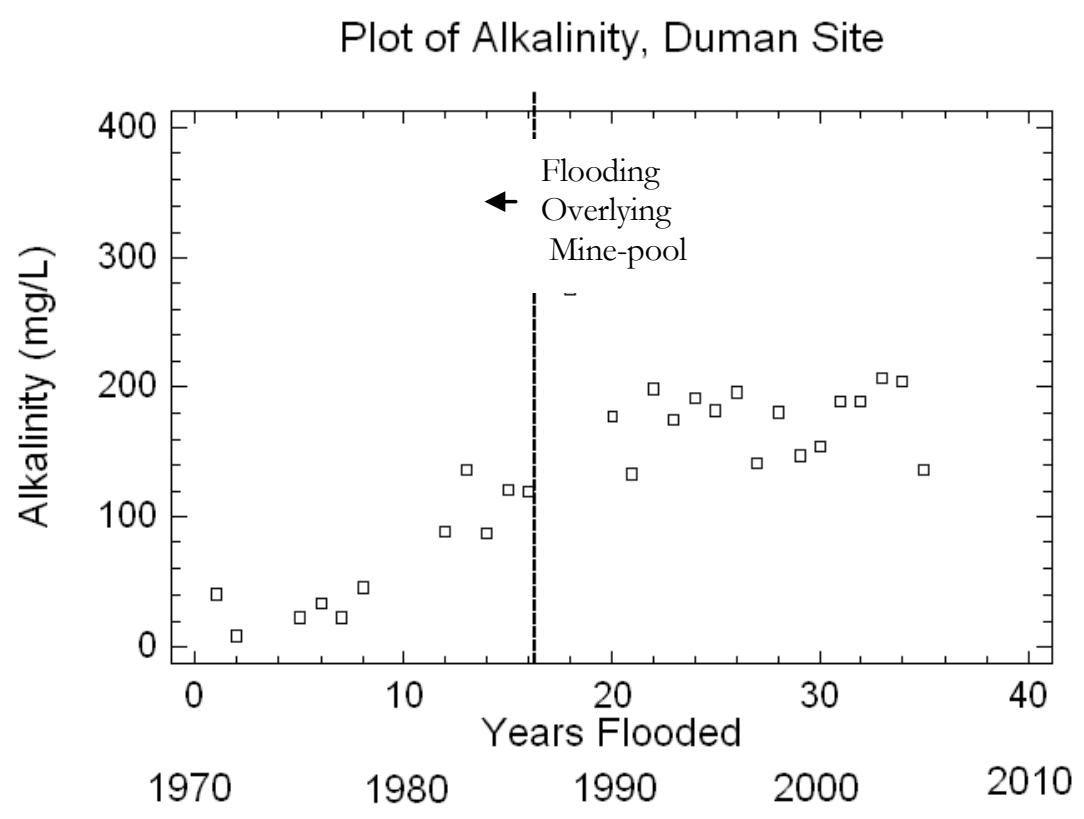

Figure 6. Plot of Average Annual Alkalinity at Duman Site

Mine-pool Chemical Composition

The Duman influent is a combination of several source waters that have mixed and reacted with the aquifer matrix as they flow toward the pump station. From the discussion of quantitative hydrogeology (Hawkins et al.,2005) and examination of water quality data, the following waters contribute to the Duman influent in varying fractions: a) leakage through a barrier pillar from the Colver mine-pool, located east of the main L-15 pool, estimated as approximately $30 \%$ of the influent, b) leakage from the overlying Lower Freeport seam mines, estimated to be about 40 to $50 \%$ of the influent, c) ground water recharge from unmined strata, and d) acidic water from unflooded areas at the northern end of the mine-pool and flanks of the two anticlines that are the eastern and western boundaries of the Lancashire 15 mine-pool. Representative analyses of each of these waters collected during 2004 are shown in table 2.

The Duman influent represents the end of the flow system for the Lancashire 15 mine-pool. It is a Na-SO $\mathrm{SO}_{4}$ type water and is usually net alkaline. Iron and sulfate concentrations are about 40 and $400 \mathrm{mg} / \mathrm{L}$, respectively. On several site visits, dissolved oxygen (D.O.) and/or Eh were measured on the raw influent. Fig. 7 is an $\mathrm{Eh} / \mathrm{pH}$ diagram for iron in the Duman influent waters. 
Table 2. Representative Full Suite Analyses of Mine-pool Waters, $2004^{(1)}$

\begin{tabular}{ccccccccccccc}
\hline $\begin{array}{c}\text { Source } \\
\text { water }\end{array}$ & $\mathrm{pH}$ & Alkalinity & Acidity & $\mathrm{Fe}$ & $\mathrm{Al}$ & $\mathrm{Mn}$ & $\mathrm{Ca}$ & $\mathrm{Mg}$ & $\mathrm{Na}$ & $\mathrm{K}$ & $\mathrm{SO}_{4}$ & $\mathrm{Cl}$ \\
\hline $\begin{array}{c}\text { Duman } \\
\text { (L. K.) }\end{array}$ & 6.55 & 137 & 75 & 40 & 0.19 & 1.0 & 39.9 & 15.1 & 159 & 1.89 & 390 & 7.0 \\
$\begin{array}{c}\text { Colver } \\
\text { (L. K.) }\end{array}$ & 6.35 & 63 & 114 & 62 & 0.05 & 1.17 & 95.7 & 30.2 & 69.8 & 4.63 & 417 & 8.0 \\
$\quad \begin{array}{c}\text { Lower } \\
\text { Freeport } \\
\text { Ground } \\
\text { water }\end{array}$ & 6.32 & 124 & 2 & 0.26 & 0.21 & 0.34 & 75.2 & 19.4 & 11.2 & 2.4 & 157 & 4.0 \\
$\begin{array}{c}\text { Sterling 1 } \\
\text { (Unflooded } \\
\text { L. K.) }\end{array}$ & 2.78 & 142 & 1 & 0.32 & 0.14 & 0.03 & 42.9 & 6.2 & 1.7 & 1.64 & 27 & 6.3 \\
\hline
\end{tabular}

(1)pH in S.U., alkalinity and acidity in $\mathrm{mg} / \mathrm{L} \mathrm{CaCO}_{3}$ Eq.; all others in $\mathrm{mg} / \mathrm{L}$.

(2)L. K. = Lower Kittanning coal bed.

(3)Ground water from unmined area strata. Data from McElroy,1998.

Two samples are plotted against iron oxyhydroxide, siderite and pyrite, based on field measured $\mathrm{pH}$ and Eh. The samples are slightly oversaturated for poorly crystalline iron oxyhydroxide, and well outside the pyrite stability field, indicating that pyrite could undergo dissolution and iron oxyhydroxide could precipitate. The dominant soluble iron species is $\mathrm{Fe}^{2+}$. Speciation calculations using the geochemical code PHREEQC (Parkhurst and Appelo, 1999) show that $\mathrm{Fe}(\mathrm{II})$ species comprise almost all of the soluble iron, and $\mathrm{Fe}(\mathrm{III})$ species are present only in small concentrations.

The Colver mine water composition is similar to the Duman influent with respect to mine drainage parameters, with iron and sulfate concentrations of about 60 and $400 \mathrm{mg} / \mathrm{L}$, respectively (table 2). It contains less sodium than the Duman discharge however, and is a Ca-Na-SO $\mathrm{S}_{4}$ type water. The Sterling 1 sample was collected from the unflooded free draining north end of the mine-pool (fig. 1). Its' composition differs sharply from waters in the flooded part of the minepool. It is strongly acidic with $\mathrm{pH}$ less than 3.0, total acidity of near $600 \mathrm{mg} / \mathrm{L}$, and higher concentrations of iron and sulfate, with significant quantities of soluble aluminum. Both Eh and dissolved oxygen measurements (+786 millivolts and $8.1 \mathrm{mg} / \mathrm{L}$, respectively) indicate a well aerated, oxidizing environment. Acid generation is ongoing in this portion of the mineworks.

Water from Lower Freeport seam mines can contain 100 to $200 \mathrm{mg} / \mathrm{L}$ alkalinity, with metal concentrations of about $5 \mathrm{mg} / \mathrm{L}$ or less. These waters, if mixed with the Lower Kittanning seam mine-pool, would have a net dilution effect on metals concentrations, and add alkalinity to the L15 mine-pool. The Lower Freeport seam sample in table 2 is mixed composition $\mathrm{Ca}-\mathrm{Mg}_{-} \mathrm{SO}_{4}-$ $\mathrm{HCO}_{3}$ type water. 


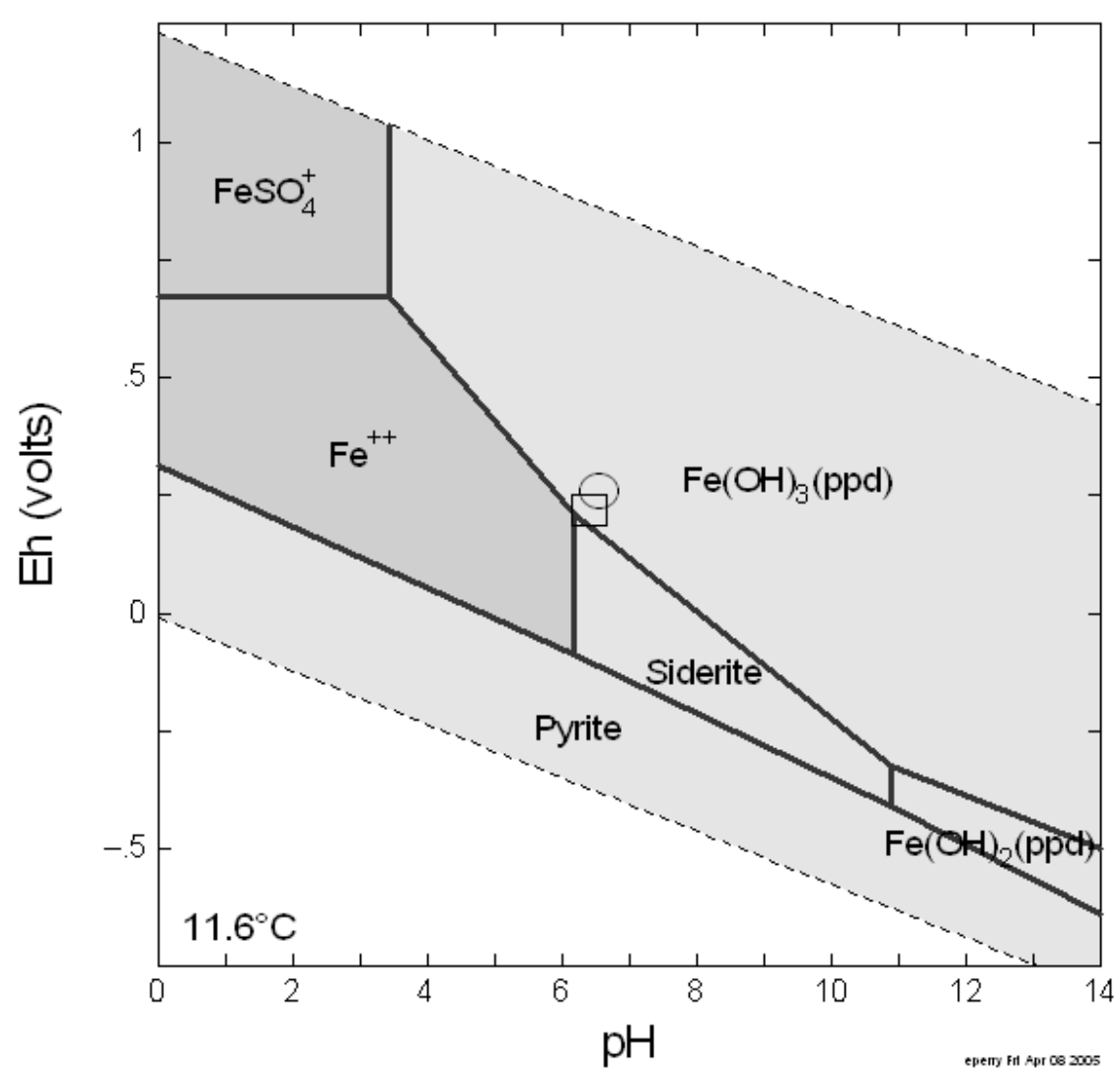

Figure 7. Eh/pH plot of Duman site mine waters for ıwu sainple events, 2004.

McElroy (1998) reported on ground water quality and quantity for Cambria County, Pennsylvania including wells in rocks above and adjacent to the L-15 mine-pool. Ground water in the Allegheny group contains about 150 to $300 \mathrm{mg} / \mathrm{L}$ dissolved solids, and the waters are mixed $\mathrm{Ca}-\mathrm{Mg}-\mathrm{HCO}_{3}$ or $\mathrm{Ca}-\mathrm{Mg}-\mathrm{HCO}_{3}-\mathrm{SO}_{4}$ type waters. Unlike the Duman plant influent, ground waters in unmined strata contain low concentrations of sodium. Median composition data from McElroy's report was used to represent ground water from unmined areas in geochemical modeling simulations.

Geochemical Modeling of Mine-pool Water Composition

A conceptual geochemical model of mine-pool quality at the Duman plant was developed and tested with PHREEQC using inverse and forward modeling. The purpose was to determine which geochemical processes were likely to generate water of the observed composition in table 2 for the Duman site, by mixing fractions indicated by quantitative data, and using the simplest possible models. The analyses in table 2 show that most elemental transfer in mixing and reacting involves iron, calcium, magnesium, sodium and sulfate, and in acid waters, aluminum. Simulations were therefore focused on these elements. 
The Duman influent is enriched in sodium and depleted in calcium and magnesium compared to the Colver mine-pool and Lower Freeport seam waters, which are the two principal components of the Lancashire 15 mine-pool. Cation exchange of adsorbed sodium for dissolved calcium and magnesium is a feasible explanation for the observed behavior, and has been postulated in ground water flow systems (Back, 1964; Stoner et al., 1985). To obtain the concentrations of iron and sulfate found in the Duman influent, additional sources of these elements were needed when Colver mine water, Lower Freeport seam and ground waters were mixed. Based on Eh measurements and other calculations, pyrite could still be dissolving in the mine-pool (see fig. 7) and is the likely source of additional iron and sulfate. Other geochemical processes were considered as alternatives to cation exchange and pyrite dissolution. They were abandoned as unlikely if they produced unrealistic solutions in numeric modeling or required minerals not likely to be present in these rocks.

Inverse modeling solved for all possible mathematical solutions and produced a large set of potential mixes and reactions. The results were screened for mixing fractions that were consistent with pumping records and other quantitative data, and that invoked reactions consistent with mine-pool chemistry and mineralogy. Many inverse model simulations showed that Lower Freeport seam and Colver mine waters comprise most of the source water for Duman. Acid water from the unflooded area was typically included in very small amounts of less than $1 \%$. Scenarios with infeasible mixing fractions or very large mineral transfers were rejected.

Based on the initial screening with inverse modeling, a forward model was developed using cation exchange and adsorption, pyrite dissolution and formation of goethite, a common iron oxyhydroxide mineral. In forward modeling, a starting solution is allowed to undergo specified reactions to produce final water. Element and mineral amounts were adjusted until the final solution had a composition similar to the Duman influent. The comparison of simulated and actual water is shown in table 3. The principal constraints and conditions used in the forward model are:

Mixing Fractions - Lower Freeport seam water 50\%, Colver water 30\%, ground water 19\%, "acid drainage" water $1 \%$.

Mineral reactions - Dissolve pyrite $9 \times 10^{-4}$ moles/liter solution; precipitate goethite if oversaturated, fix partial pressure $\mathrm{CO}_{2} 10^{-1.4} \mathrm{~atm}$.

Cation Exchange - add exchangeable cations, calcium $3 \times 10^{-2}$ moles, magnesium $1.3 \times 10^{-2}$ moles, sodium $1.3 \times 10^{-2}$ moles, total exchange capacity $9.9 \times 10^{-2}$ moles.

Table 3. Forward Modeling Simulation and Actual Composition of Duman Influent ${ }^{(1)}$

\begin{tabular}{ccccccc}
\hline Solution & $\mathrm{pH}$ & $\mathrm{Fe}$ & $\mathrm{Ca}$ & $\mathrm{Mg}$ & $\mathrm{Na}$ & $\mathrm{SO}_{4}$ \\
\hline Simulation & 6.69 & 35.7 & 37.3 & 15.1 & 146 & 388 \\
Actual & 6.55 & 40.0 & 39.9 & 15.1 & 159 & 390 \\
\hline
\end{tabular}

(1) $\mathrm{pH}$ in S.U., all others in $\mathrm{mg} / \mathrm{L}$ 
In general the simulated and actual concentrations were in close agreement. The quantities of pyrite dissolved, goethite precipitated, and cation exchange capacity were small in comparison to the aquifer matrix encountered along a flow path of several $\mathrm{km}$ or more in length. The simulation showed that some of the dissolved iron was removed by exchange and adsorption. Additional iron was removed by the formation of goethite. These results were consistent with the $\mathrm{Fe}$ to $\mathrm{SO}_{4}$ mole ratio plot (fig. 5) showing that about $60 \%$ of the iron dissolved from pyrite was attenuated within the mine-pool. Exchange also decreased the amount of dissolved calcium and magnesium and increased dissolved sodium. A second forward model using the calcium sulfate salt gypsum and pyrite dissolution also produced a good match between simulated and actual waters. However, solubility calculations showed that all mine waters were at least one order of magnitude or more undersaturated for gypsum. These saturation indices suggest that gypsum is not controlling sulfate concentration, and we have no mineralogical data to confirm or refute its' presence.

The initial modeling efforts showed that the Duman influent mine waters could be satisfactorily described as a product of mixing several source waters, cation exchange, pyrite dissolution and goethite formation. These modeling results were similar to work reported by Chen et al. (1999), who found that mixing, pyrite oxidation, calcite dissolution and goethite formation were the main processes controlling mine water evolution at a Scottish colliery. There are undoubtedly additional mineral reactions and processes taking place in the L-15 mine-pool, but they seem to influence water chemistry and composition to a lesser extent.

\section{Flooded versus Free Draining Mineworks}

There are large contrasts in water chemistry between flooded mineworks at the Duman site versus unflooded mineworks at the Sterling 1 discharge. These two sites discharge water from adjoining mines in the same Lower Kittanning coal bed. The unflooded works, which have been abandoned for more than 50 years, still discharge acid water, while the Duman site began discharging circumneutral alkaline water within 10 years after flooding. Water quality data collected in 1984, 1994 and 2004 from the Sterling 1 discharge are summarized in table 4 and compared to the Duman site for the same years. Median sulfate and $\mathrm{pH}$ concentrations in the unflooded mineworks are essentially unchanged for the period. In the flooded mineworks, median $\mathrm{pH}$ increased about 0.6 units, and sulfate concentrations declined about $50 \%$. Total acidity has declined from about 700 to $500 \mathrm{mg} / \mathrm{L}$ at the Sterling discharge in 20 years, and the difference is statistically significant at $\mathrm{p}=0.01$. Acidity at Duman in 2004 is $68 \mathrm{mg} / \mathrm{L}$ or about $20 \%$ of its' 1984 concentration. The unflooded Sterling 1 mine-water parameters of sulfate, iron and acidity remain 2 to 7 times greater than concentrations than at Duman, even though the Sterling mines have been abandoned for a longer time. Flooding inhibits pyrite oxidation and increases the rate of natural remediation occurring in mine-pools. Stortz et al. (2001) also found that mine flooding results in more rapid water quality improvement. They noted significant increases in $\mathrm{pH}$, and reductions in acid load, dissolved solids and other parameters in a mine that was mostly flooded compared to a nearby unflooded mine in the same geologic and hydrologic setting. 
Table 4. Median Annual Water Quality at unflooded Sterling 1 Discharge and Flooded Duman L-15 Minepool, 1983-2004 ${ }^{(1)}$

\begin{tabular}{ccccccc}
\hline Year & Location & $\mathrm{pH}$ & T. Acidity & Alkalinity & $\mathrm{Fe}$ & $\mathrm{SO}_{4}$ \\
\hline $1983-84$ & Sterling 1 & 2.62 & 710 & 0 & 85 & 850 \\
1994 & Sterling 1 & 2.7 & 604 & 0 & 60 & 920 \\
2004 & Sterling 1 & 2.7 & 497 & 0 & 102 & 837 \\
1984 & Duman & 5.98 & 340 & 121 & 190 & 775 \\
1994 & Duman & 6.48 & 131 & 182 & 73 & 478 \\
2004 & Duman & 6.58 & 68 & 136 & 38 & 388 \\
\hline
\end{tabular}

(1) $\mathrm{pH}$ in S.U., acidity and alkalinity in $\mathrm{mg} / \mathrm{L} \mathrm{CaCO}_{3}$, Eq, others in $\mathrm{mg} / \mathrm{L}$.

\section{Summary and Conclusions}

Water quality in the 35 year old mostly flooded L-15 mine-pool has improved significantly since closure. Changes in water quality occur in two phases, a short term initial flushing of stored relatively soluble acid products, and long term leaching of additional materials and continuing geochemical reactions. Younger (1997) characterizes this process as production of vestigial (stored) and juvenile (continuing pyrite oxidation) acidities. In the L-15 mine-pool, the main period of flushing lasted about 8 years, and iron and sulfate concentrations declined to about 20 to $25 \%$ of their initial values. In 1986, closure and flooding of mines in the overlying Lower Freeport coal bed introduced water of different water chemistry into the L-15 mine-pool. Mixing of these waters abruptly lowered iron concentration from about 200 to $60 \mathrm{mg} / \mathrm{L}$, while sulfate concentration was less affected. Composition of the recharge water influences mine-pool chemistry. The Fe to $\mathrm{SO}_{4}$ mole ratio rapidly declined in the L-15 mine-pool to around 0.2. About $60 \%$ of the iron dissolved from pyrite is now attenuated by precipitation, cation exchange or other reactions within the mine-pool. Iron attenuation was much less in the initial flushing phase.

The temporal declines in iron and sulfate concentration can be described using curvilinear models. Current mine-pool behavior shows a decline of about 1 to $2 \mathrm{mg} / \mathrm{L}-y e a r$ and 10 to 15 $\mathrm{mg} / \mathrm{L}-\mathrm{year}$ for iron and sulfate, respectively. This behavior suggests that geochemical equilibrium will be approached slowly, over a period of decades.

Long term predictions of iron, sulfate or other mine drainage parameters at future dates can be generated from curvilinear models of the current data. However, long term predictions are uncertain because slope of the curvilinear function is a statistical estimate; there may be changes in the mine-pool aquifer and flow system, and mineral solubility constraints could control solution chemistry at low concentrations. The estimated slopes for functions derived for iron and sulfate have standard errors of about 13 to $16 \%$, thus any future projected concentration values should be expressed as a range. A small change in the predictive function can change the estimated time to achieve a target concentration by years. 
Mine-pools are young aquifers that are undergoing rapid physical and chemical changes. These changes can include continuing physical breakdown of rocks, collapse or subsidence of roof rock and coal pillars, and opening or closing of other mines nearby. These features may change flow paths, tortuosity, residence time and pumping and seepage rates, all of which may influence mine-pool chemistry. Predicting the exact composition of mine waters as they approach long term equilibrium requires detailed knowledge of the mineralogy and flow characteristics of the aquifer; information which may not always be available. While a local equilibrium condition seems to exist at a given sample point, overall mine-pool composition can be heterogeneous (Perry and Hawkins, 2004).

The L-15 mine-pool is actually a mixture of seepage water from the adjacent Colver mine-pool (about 30\%), leakage from the overlying Lower Freeport mine-pool (about 40 to 50\%), acid waters from the unflooded northern end of the mine complex, and ground water from unmined strata. Inverse modeling with PHREEQC (Parkhurst and Appelo, 1999) was used to develop and test models of the L-15 mine-pool. The goal was to approximate mixing percentages and geochemical reactions that produce the water quality of the Duman discharge. Simple mixing alone does not explain Duman's chemistry. Forward modeling showed that the continuing dissolution of small quantities of pyrite and formation of goethite provided a close match of modeled and actual water quality.

The Duman discharge is a Na-SO $\mathrm{SO}_{4}$ type water, while the waters that contribute to it are of mixed cation composition, where $\mathrm{Na}$ is a secondary cation. Cation exchange of dissolved calcium and magnesium for adsorbed sodium provides a feasible explanation for the observed dominance of sodium at Duman. The presence of small amounts of exchangeable sodium along a flowpath as much as $8 \mathrm{~km}$ in length would be sufficient to produce a $\mathrm{Na}-\mathrm{SO}_{4}$ solution. Back (1966) in a study of water quality evolution in Coastal Plain aquifers, observed increasing dominance of sodium over calcium and magnesium the further ground water moved along its flowpath.

Comparison of mine waters from flooded and unflooded sections of the L-15 complex shows that the rate of water quality improvement is much more rapid when the mineworks are inundated. Drainage from unflooded sections remains strongly acidic 50 years after closure, while the Duman site began discharging circumneutral water within 10 years of flooding. Chemical concentrations are higher in the free draining section.

The L-15 mine-pool has been pumped at a rate equivalent to about 2 pool volumes a year and is approaching a total of 60 pool volumes. The persistence of iron and sulfate in the mine-pool after this amount of leaching suggests that dispersion, short circuiting and no-flow zones are important, and that some chemical reactions are continuing. The L-15 mine-pool is expected to continue slow improvement in water chemistry, but is likely to require treatment for an extended period. 


\section{$\underline{\text { Acknowledgements }}$}

We thank Daniel Sammarco and Richard Beam of the Pennsylvania Department of Environmental Protection, Bureau of Abandoned Mined Lands, for their support on this project. We also thank Dennis Lloyd of Lloyd Environmental Services for providing data, insight and historical account of the L-15 mine-pool. Comments from three anonymous reviewers improved the quality of the original manuscript.

\section{$\underline{\text { Literature Cited }}$}

Back, W. 1966. Hydrochemical Facies and Ground-Water Flow Patterns in Northern Part of Atlantic Coastal Plain. US Geological Survey Professional Paper 498-A.

Chen, M., C. Soulsby and P Younger. 1999. Modelling the Evolution of Minewater Pollution at the Polkemmet Colliery, Almond Catchment, Scotland, p 351-362, Quarterly Journal of Engineering Geology, 32.

Cravotta, C. A. III and C. S. Kirby. 2004. Acidity and Alkalinity in Mine Drainage: Practical Considerations, p334-365, In R. I. Barnhisel (ed) Proc. Joint Conference of American Society of Mining and Reclamation $21^{\text {st }}$ Annual National Conference and $25^{\text {th }}$ West Virginia Surface Mine Drainage Task Force Symposium April 18-22, Morgantown West Virginia, , ASMR 3134 Montavesta Rd. Lexington, KY 40502.

Donovan, J and B. Leavitt. 2004. The Future of Mine-Water Discharges From Underground Coal Mines of The Pittsburgh Coal Basin, WV-PA, p518-528 In R. I. Barnhisel (ed) Proc. Joint Conference American Society Mining and Reclamation $21^{\text {st }}$ Annual National Conference and $25^{\text {th }}$ West Virginia Surface Mine Drainage Task Force Symposium, April 18-22, Morgantown WV, ASMR, 3134 Montavesta Rd, Lexington KY, 40502 .

Gwin, Dobson, \& Foreman. 1972. West Branch Susquehanna River Mine Drainage Pollution Abatement Project, Operation Scarlift, prepared for Commonwealth of Pennsylvania, $181 \mathrm{p}$.

Hawkins J., E. Perry and M. Dunn. 2005. Hydrologic Characterization Of A Large Underground Mine Pool In Central Pennsylvania, In R. I. Barnhisel (ed) Proc. Conference American Society Mining and Reclamation $22^{\text {st }}$ Annual National Conference, June 19-24, Breckinridge CO, ASMR, 3134 Montavesta Rd, Lexington KY, 40502 .

Lloyd, D. 2004. personal communication, unpublished water quality data for Lancashire 15 mine-pool and associated mines, Lloyd Environmental Services, Commodore, PA.

McElroy, T. 1998. Groundwater Resources of Cambria County Pennsylvania, 49pps, Water Resources Report 67, Pennsylvania Dept of Conservation and Natural Resources, Bureau of Topographic and Geologic Survey, Harrisburg, PA. 
Kernic, J. 1999. Barnes and Tucker Company, Lancashire 15 and 20 Mines, Cambria County, Mine Pool and Discharge Report, unpublished report prepared for Pennsylvania Dept Environmental Protection, McMurray District Office, 11 pages.

Kirby, C.S. and C.A. Cravotta. 2004. Acidity and Alkalinity in Mine Drainage: Theoretical considerations, p1076-1093, In R. I. Barnhisel (ed) Proc. Joint Conference of American Society of Mining and Reclamation 21st Annual National Conference and $25^{\text {th }}$ West Virginia Surface Mine Drainage Task Force Symposium April 18-22, Morgantown West Virginia, ASMR 3134 Montavesta Rd. Lexington, KY 40502.

Kleinmann, R.L., R. Hornberger, B. Leavitt and D. Hyman. 2000. Introduction and Recommendation, The Nature of the Problem, In Prediction of Water Quality at Surface Coal Mines, Acid Drainage Technology Initiative, Prediction Workgroup, National Mined Land Reclamation Center, West Virginia University, Morgantown WV.

Michael Baker Consulting Engineers. 1978. Operation Scarlift Report SL-185, Blacklick Creek Watershed, Indiana Cambria Counties, prepared for Pennsylvania Dept of Environmental Resources, $152 \mathrm{p}$.

Parkhurst, D. L., and C.A.J. Appelo. 1999. User's Guide to PHREEQC (Version 2)- A Computer Program For Speciation, Batch-Reaction, One-Dimensional Transport, and Inverse Geochemical Calculations, US Geological Survey Water Resources Investigation Report 994259.

Perry, E.F. and J. Hawkins. 2004. Ground-Water Flow and Quality in A Fully Flooded Underground Mine Complex, p1460-1479 In R. I. Barnhisel (ed) Proc. Joint Conference American Society Mining and Reclamation $21^{\text {st }}$ Annual National Conference and $25^{\text {th }}$ West Virginia Surface Mine Drainage Task Force Symposium, April 18-22, Morgantown WV, ASMR, 3134 Montavesta Rd, Lexington KY, 40502 .

Skousen J., L M. McDonald and J. Demchak. 2004. Longevity of Acid Discharges From Underground Mines Lying Above the Regional Water Table. p 1769, In R. I. Barnhisel (ed) Proc. Joint Conference American Society Mining and Reclamation $21^{\text {st }}$ Annual National Conference and $25^{\text {th }}$ West Virginia Surface Mine Drainage Task Force Symposium, April 1822, Morgantown WV, ASMR, 3134 Montavesta Rd, Lexington KY, 40502 .

Stoner, J. D., D. R. Williams, T. E. Buckwalter, J. K. Felbinger and K. L. Pattison. 1987. Water Resources and the Effects of Coal Mining, Greene County, Pennsylvania, prepared by the US Geological Survey Water Resources Division, Pennsylvania Geological Survey Water Resources Report 63, Harrisburg, Pa. 
Stortz, M., M Hughes, N. Wanner and M. Farley. 2001. Long Term Water Quality Trends at a Sealed Partially Flooded Underground Mine, p 51-65, Environmental and Engineering Geoscience, Vol VII, No.1.

Wood, S.C., P. Younger and N. Robins. 1999. Long-term changes in the Quality of Polluted Minewater Discharges from Abandoned Underground Coal Workings in Scotland, p 69-79, Quarterly Journal of Engineering Geology, 32.

Younger, P. 1997. The Longevity of Minewater Pollution: A Basis for Decision Making, p 457466, The Science of the Total Environment, 194\&195.

Younger, P. 2000. Predicting Temporal Changes in Total Iron Concentrations in Waters Flowing From Abandoned Deep Mines: A First Approximation, p 47-69, Journal of Contaminant Hydrology, 44(2000). 
$\underline{\text { Appendix E }}$

Omega Mine-pool Raw Chemical Data 


\begin{tabular}{|c|c|c|c|c|c|c|c|c|c|}
\hline Sampled By & Date & Location & Flow gpm & $\mathrm{pH}$ & $\begin{array}{c}\text { Sp. } \\
\text { Conductance umhos/cm }\end{array}$ & TDS, mg/L & Temp, C & $\begin{array}{c}\text { Acid load, lbs/day } \\
\text { CaCO3 Eq }\end{array}$ & $\begin{array}{c}\text { Calc Total Acidity } \\
\text { CaCO3 Eq }\end{array}$ \\
\hline DOE & $2 / 11 / 1993$ & Treatment Inlet & 65.0 & 2.86 & & 5705 & & 2052.2 & 2626.7 \\
\hline DOE & $3 / 3 / 1993$ & Treatment Inlet & 280.0 & 2.79 & & 6549 & & 10515.1 & 3124.3 \\
\hline DOE & $3 / 18 / 1993$ & Treatment Inlet & 180.8 & 2.85 & & 3525 & & 3394.5 & 1562.0 \\
\hline DOE & $4 / 2 / 1993$ & Treatment Inlet & 248.2 & 2.62 & & 5316 & & 7473.5 & 2505.3 \\
\hline DOE & 4/14/1993 & Treatment Inlet & 171.4 & 2.57 & & 6410 & & 6200.3 & 3010.1 \\
\hline DOE & 4/29/1993 & Treatment Inlet & 380.3 & 2.68 & & 4465 & & 9393.1 & 2054.7 \\
\hline $\mathrm{DOE}$ & $5 / 20 / 1993$ & Treatment Inlet & 142.7 & 2.76 & & 6179 & & 5066.5 & 2953.1 \\
\hline DOE & $6 / 3 / 1993$ & Treatment Inlet & 91.5 & 2.90 & & 4730 & & 1991.7 & 1810.5 \\
\hline DOE & $6 / 10 / 1993$ & Treatment Inlet & 91.5 & 2.89 & & 5249 & & 2416.5 & 2196.6 \\
\hline DOE & 6/23/1993 & Treatment Inlet & 91.5 & 2.81 & & 6049 & & 2918.5 & 2653.0 \\
\hline DOE & $7 / 8 / 1993$ & Treatment Inlet & 55.5 & 2.81 & & 6147 & & 1829.6 & 2740.8 \\
\hline DOE & $7 / 22 / 1993$ & Treatment Inlet & 42.7 & 2.92 & & 6160 & & 1343.5 & 2617.3 \\
\hline $\mathrm{DOE}$ & $8 / 11 / 1993$ & Treatment Inlet & 42.7 & 2.97 & & 5589 & & 1141.9 & 2224.6 \\
\hline DOE & 9/10/1993 & Treatment Inlet & 16.3 & 3.03 & & 5247 & & 372.3 & 1905.8 \\
\hline $\mathrm{DOE}$ & $10 / 7 / 1993$ & Treatment Inlet & 25.4 & 2.89 & & 4773 & & 484.9 & 1589.6 \\
\hline DOE & $10 / 25 / 1993$ & Treatment Inlet & 42.7 & 2.89 & & 4657 & & 842.7 & 1641.8 \\
\hline DOE & 11/10/1993 & Treatment Inlet & 42.7 & 2.80 & & 4393 & & 784.3 & 1527.9 \\
\hline DOE & 12/7/1993 & Treatment Inlet & 69.9 & 2.96 & & 2592 & & 834.0 & 992.2 \\
\hline DOE & $12 / 23 / 1993$ & Treatment Inlet & 69.9 & 2.74 & & 5457 & & 2117.8 & 2519.5 \\
\hline DOE & $1 / 28 / 1994$ & Treatment Inlet & 230.8 & 3.01 & & 3416 & & 3808.9 & 1373.2 \\
\hline DOE & $5 / 5 / 1994$ & Treatment Inlet & 110.6 & 2.70 & & 4937 & & 3089.5 & 2323.9 \\
\hline DOE & 6/10/1994 & Treatment Inlet & 82.5 & 2.76 & & 4757 & & 2084.8 & 2102.8 \\
\hline DOE & $7 / 6 / 1994$ & Treatment Inlet & 60.2 & 2.74 & & 4717 & & 1382.2 & 1911.3 \\
\hline DOE & $8 / 3 / 1994$ & Treatment Inlet & 39.6 & 3.02 & & 4397 & & 807.8 & 1698.0 \\
\hline DOE & 9/1/1994 & Treatment Inlet & 40.7 & 2.65 & & 3694 & & 688.0 & 1407.9 \\
\hline DOE & $10 / 7 / 1994$ & Treatment Inlet & 33.7 & 3.03 & & 4816 & & 774.7 & 1910.9 \\
\hline DOE & $11 / 16 / 1994$ & Treatment Inlet & 21.2 & 3.16 & & 4888 & & 435.0 & 1707.5 \\
\hline DOE & $12 / 14 / 1994$ & Treatment Inlet & 40.4 & 2.97 & & 3456 & & 589.5 & 1214.1 \\
\hline DOE & $1 / 10 / 1995$ & Treatment Inlet & 53.4 & 2.74 & & 3719 & & 1010.0 & 1573.2 \\
\hline $\mathrm{DOE}$ & $2 / 3 / 1995$ & Treatment Inlet & 49.6 & 2.81 & & 4283 & & 1161.8 & 1950.7 \\
\hline DOE & $3 / 2 / 1995$ & Treatment Inlet & 77.4 & 2.99 & & 3566 & & 1358.6 & 1460.8 \\
\hline DOE & 4/7/1995 & Treatment Inlet & 42.5 & 2.70 & & 6319 & & 1563.7 & 3063.8 \\
\hline DOE & $5 / 10 / 1995$ & Treatment Inlet & 100.5 & 2.91 & & 3968 & & 2100.6 & 1738.9 \\
\hline DOE & 6/6/1995 & Treatment Inlet & 109.3 & 2.92 & & 4414 & & 2297.3 & 1748.6 \\
\hline DOE & $7 / 13 / 1995$ & Treatment Inlet & 57.5 & 2.84 & & 5600 & & 1814.7 & 2628.0 \\
\hline
\end{tabular}


Table E-1a, Omega Mine-pool, Treatment Inlet, Raw Chemical Data

\begin{tabular}{|c|c|c|c|c|c|c|c|c|c|}
\hline Sampled By & Date & Location & Flow gpm & $\mathrm{pH}$ & $\begin{array}{c}\text { Sp. } \\
\text { Conductance umhos/cm }\end{array}$ & TDS, mg/L & Temp, C & $\begin{array}{c}\text { Acid load, lbs/day } \\
\text { CaCO3 Eq }\end{array}$ & $\begin{array}{l}\text { Calc Total Acidity } \\
\text { CaCO3 Eq }\end{array}$ \\
\hline DOE & 8/3/1995 & Treatment Inlet & 28.8 & 2.77 & & 4837 & & 670.7 & 1936.4 \\
\hline DOE & 9/7/1995 & Treatment Inlet & 26.2 & 2.94 & & 4925 & & 530.9 & 1686.5 \\
\hline DOE & 10/12/1995 & Treatment Inlet & 20.2 & 2.97 & & 4629 & & 375.5 & 1543.5 \\
\hline DOE & $11 / 22 / 1995$ & Treatment Inlet & 40.8 & 3.13 & & 3021 & & 347.1 & 707.7 \\
\hline DOE & $1 / 5 / 1996$ & Treatment Inlet & 53.4 & 3.07 & & 2741 & & 560.1 & 872.4 \\
\hline WVDEP & $1 / 16 / 1996$ & Treatment Inlet & 50.6 & 2.90 & 7140 & 4342 & 7.8 & 891.5 & 1465.2 \\
\hline WVDEP & 2/15/1996 & Treatment Inlet & 93.6 & 2.60 & 563 & 3183 & 12.2 & 967.7 & 859.9 \\
\hline DOE & $2 / 21 / 1996$ & Treatment Inlet & 112.2 & 2.63 & & 3874 & & 2640.7 & 1958.1 \\
\hline WVDEP & $3 / 1 / 1996$ & Treatment Inlet & 87.8 & 2.60 & 4500 & 3840 & 10 & 1209.9 & 1146.3 \\
\hline WVDEP & $3 / 15 / 1996$ & Treatment Inlet & 117.8 & 2.60 & 5650 & 4520 & 12.2 & 1925.3 & 1359.5 \\
\hline DOE & $3 / 18 / 1996$ & Treatment Inlet & 118.0 & 2.97 & & 2576 & & 1451.7 & 1023.5 \\
\hline WVDEP & $3 / 28 / 1996$ & Treatment Inlet & 398.7 & 2.90 & 4510 & 2765 & 12.2 & 2486.1 & 518.7 \\
\hline WVDEP & $4 / 15 / 1996$ & Treatment Inlet & 216.4 & 2.80 & 5110 & 3317 & 14.4 & 1840.0 & 707.5 \\
\hline DOE & $4 / 26 / 1996$ & Treatment Inlet & 166.1 & 2.75 & & 3120 & & 2894.3 & 1449.7 \\
\hline WVDEP & $4 / 29 / 1996$ & Treatment Inlet & 237.4 & 2.50 & 6150 & 4194 & 14.4 & 4109.6 & 1439.9 \\
\hline WVDEP & $5 / 15 / 1996$ & Treatment Inlet & 224.5 & 2.60 & 5150 & 2813 & 11.1 & 3833.6 & 1421.0 \\
\hline WVDEP & $5 / 31 / 1996$ & Treatment Inlet & 229.4 & 2.60 & 4510 & 2450 & 13.3 & 2965.9 & 1075.7 \\
\hline DOE & $6 / 7 / 1996$ & Treatment Inlet & 151.2 & 2.65 & & 3785 & & 3163.3 & 1740.6 \\
\hline WVDEP & 6/14/1996 & Treatment Inlet & 151.4 & 2.60 & 5960 & 3608 & 15.6 & 3722.0 & 2045.0 \\
\hline WVDEP & $6 / 28 / 1996$ & Treatment Inlet & 144.7 & 2.70 & 6190 & 3642 & 14.4 & 1148.1 & 660.1 \\
\hline WVDEP & $7 / 15 / 1996$ & Treatment Inlet & 97.7 & 2.70 & 5540 & 3200 & 15.6 & 1111.4 & 946.8 \\
\hline DOE & 7/23/1996 & Treatment Inlet & 94.7 & 2.77 & & 2513 & & 1082.4 & 950.9 \\
\hline WVDEP & $7 / 30 / 1996$ & Treatment Inlet & 88.3 & 2.70 & 5580 & 3507 & 14.4 & 1390.9 & 1311.1 \\
\hline WVDEP & $8 / 14 / 1996$ & Treatment Inlet & 59.6 & 2.80 & 6310 & 4202 & 15.6 & 1203.9 & 1681.1 \\
\hline DOE & 8/28/1996 & Treatment Inlet & 63.5 & 2.95 & & 4130 & & 1216.0 & 1593.0 \\
\hline WVDEP & $8 / 31 / 1996$ & Treatment Inlet & 78.0 & 2.70 & 2370 & 4257 & 13.3 & 1509.8 & 1611.4 \\
\hline WVDEP & 9/16/1996 & Treatment Inlet & 50.6 & 2.70 & 5790 & 3675 & 15 & 946.1 & 1554.9 \\
\hline WVDEP & 9/30/1996 & Treatment Inlet & 101.7 & 2.80 & 5130 & 3096 & 14.4 & 1681.2 & 1375.3 \\
\hline WVDEP & 10/14/1996 & Treatment Inlet & 63.6 & 2.70 & 6100 & 4028 & 15.6 & 1173.7 & 1534.8 \\
\hline DOE & 10/16/1996 & Treatment Inlet & 57.5 & 2.84 & & 3944 & & 1047.2 & 1516.5 \\
\hline WVDEP & 10/30/1996 & Treatment Inlet & 103.9 & 2.50 & 5290 & 3384 & 14.4 & 1632.6 & 1306.7 \\
\hline WVDEP & $11 / 15 / 1996$ & Treatment Inlet & 136.6 & 2.70 & 5950 & 3971 & 12.2 & 2725.9 & 1659.7 \\
\hline DOE & $11 / 26 / 1996$ & Treatment Inlet & 124.3 & 2.70 & & 3195 & & 2166.3 & 1449.9 \\
\hline DOE & 12/13/1996 & Treatment Inlet & 182.2 & 2.82 & & 3154 & & 3198.9 & 1460.7 \\
\hline WVDEP & 12/15/1996 & Treatment Inlet & 210.6 & 2.80 & 5710 & 3057 & 12.2 & 3712.7 & 1466.9 \\
\hline WVDEP & $1 / 14 / 1997$ & Treatment Inlet & 89.6 & 2.80 & 5440 & 3313 & 10 & 712.6 & 661.7 \\
\hline DOE & $1 / 28 / 1997$ & Treatment Inlet & 84.4 & 2.78 & & 1633 & & 741.6 & 731.3 \\
\hline
\end{tabular}


Table E-1a, Omega Mine-pool, Treatment Inlet, Raw Chemical Data

\begin{tabular}{|c|c|c|c|c|c|c|c|c|c|}
\hline Sampled By & Date & Location & Flow gpm & $\mathrm{pH}$ & $\begin{array}{c}\text { Sp. } \\
\text { Conductance umhos/cm }\end{array}$ & TDS, mg/L & Temp, C & $\begin{array}{l}\text { Acid load, Ibs/day } \\
\text { CaCO3 Eq }\end{array}$ & $\begin{array}{l}\text { Calc Total Acidity } \\
\text { CaCO3 Eq }\end{array}$ \\
\hline DOE & $2 / 21 / 1997$ & Treatment Inlet & 84.4 & 2.89 & & 2450 & & 927.6 & 914.6 \\
\hline WVDEP & $3 / 17 / 1997$ & Treatment Inlet & 119.6 & 2.60 & 3810 & 3098 & 12.2 & 3094.1 & 2151.9 \\
\hline $\mathrm{DOE}$ & $3 / 26 / 1997$ & Treatment Inlet & 295.8 & 2.88 & & 2348 & & 3905.6 & 1098.5 \\
\hline WVDEP & $4 / 14 / 1997$ & Treatment Inlet & 113.3 & 2.60 & 3600 & 2793 & 12.2 & 3745.9 & 2749.6 \\
\hline WVDEP & $5 / 14 / 1997$ & Treatment Inlet & 95.4 & 2.60 & 3100 & 2281 & 14.4 & 1706.9 & 1488.2 \\
\hline $\mathrm{DOE}$ & $5 / 20 / 1997$ & Treatment Inlet & 234.7 & 2.96 & & 1840 & & 2315.1 & 820.6 \\
\hline WVDEP & $6 / 16 / 1997$ & Treatment Inlet & 94.5 & 2.50 & 3420 & 2624 & 16.7 & 3166.8 & 2787.0 \\
\hline $\mathrm{DOE}$ & $7 / 10 / 1997$ & Treatment Inlet & 44.2 & 2.68 & & 3570 & & 844.1 & 1589.3 \\
\hline WVDEP & $7 / 16 / 1997$ & Treatment Inlet & 44.8 & 2.50 & 3780 & 3478 & 15.6 & 668.0 & 1240.4 \\
\hline WVDEP & $8 / 17 / 1997$ & Treatment Inlet & 33.6 & 2.70 & 6080 & 3497 & 23.9 & 957.9 & 2371.7 \\
\hline $\mathrm{DOE}$ & 9/10/1997 & Treatment Inlet & 24.9 & 2.75 & & 3466 & & 425.6 & 1421.4 \\
\hline WVDEP & 9/15/1997 & Treatment Inlet & 25.5 & 2.60 & 3780 & 3585 & 15.6 & 292.9 & 954.2 \\
\hline WVDEP & 10/15/1997 & Treatment Inlet & 24.6 & 2.60 & 6150 & 3133 & & 487.7 & 1646.5 \\
\hline $\mathrm{DOE}$ & $11 / 5 / 1997$ & Treatment Inlet & 22.5 & 2.83 & & 3127 & & 351.4 & 1300.3 \\
\hline WVDEP & $11 / 14 / 1997$ & Treatment Inlet & 135.7 & 2.70 & 3140 & 2232 & & 1001.3 & 613.7 \\
\hline WVDEP & $12 / 15 / 1997$ & Treatment Inlet & 65.9 & 2.60 & 2530 & 2322 & & 911.0 & 1150.7 \\
\hline DOE & $1 / 12 / 1998$ & Treatment Inlet & 70.0 & 2.71 & & 2288 & & 895.5 & 1064.2 \\
\hline WVDEP & $1 / 16 / 1998$ & Treatment Inlet & 102.6 & 2.70 & 5680 & 3790 & & 1752.2 & 1421.0 \\
\hline DOE & 2/9/1998 & Treatment Inlet & 112.2 & 2.71 & & 3959 & & 2685.9 & 1991.6 \\
\hline WVDEP & $2 / 15 / 1998$ & Treatment Inlet & 199.4 & 2.70 & 5510 & 4009 & & 3530.0 & 1473.1 \\
\hline WVDEP & $3 / 16 / 1998$ & Treatment Inlet & 205.2 & 2.70 & 5860 & 3700 & & 2532.4 & 1026.8 \\
\hline $\mathrm{DOE}$ & $3 / 26 / 1998$ & Treatment Inlet & 151.2 & 2.78 & & 2906 & & 2615.2 & 1438.9 \\
\hline WVDEP & 4/15/1998 & Treatment Inlet & 149.6 & 2.60 & 5920 & 3456 & & 3079.2 & 1712.0 \\
\hline DOE & $4 / 29 / 1998$ & Treatment Inlet & 137.3 & 2.92 & & 2821 & & 2241.3 & 1358.1 \\
\hline WVDEP & $5 / 13 / 1998$ & Treatment Inlet & 184.6 & 2.60 & 5110 & 3698 & & 3876.5 & 1747.2 \\
\hline $\mathrm{DOE}$ & $5 / 28 / 1998$ & Treatment Inlet & 79.4 & 3.05 & & 3397 & & 1453.8 & 1522.5 \\
\hline WVDEP & 6/15/1998 & Treatment Inlet & 85.1 & 2.60 & 6120 & 3544 & & 1644.5 & 1607.3 \\
\hline DOE & $6 / 25 / 1998$ & Treatment Inlet & 144.1 & 3.12 & & 4110 & & 1937.2 & 1118.4 \\
\hline WVDEP & $7 / 15 / 1998$ & Treatment Inlet & 119.6 & 2.60 & 7130 & 5272 & & 1988.4 & 1382.9 \\
\hline $\mathrm{DOE}$ & $8 / 5 / 1998$ & Treatment Inlet & 70.0 & 3.09 & & 4580 & & 1487.0 & 1767.3 \\
\hline WVDEP & $8 / 13 / 1998$ & Treatment Inlet & 57.8 & 2.70 & 7300 & 4766 & & 1097.1 & 1579.4 \\
\hline DOE & 9/3/1998 & Treatment Inlet & 39.0 & 2.98 & & 5294 & & 1123.7 & 2397.2 \\
\hline WVDEP & 9/15/1998 & Treatment Inlet & 37.6 & 2.60 & 11100 & 5615 & & 1177.1 & 2602.5 \\
\hline WVDEP & $10 / 15 / 1998$ & Treatment Inlet & 25.5 & 2.60 & 43700 & 7002 & & 1038.9 & 3384.1 \\
\hline DOE & 10/29/1998 & Treatment Inlet & 14.0 & 5.19 & & 4089 & & 243.1 & 1444.6 \\
\hline WVDEP & $11 / 15 / 1998$ & Treatment Inlet & 11.7 & 2.60 & 7420 & 4359 & & 179.5 & 1282.1 \\
\hline DOE & $12 / 10 / 1998$ & Treatment Inlet & 15.0 & 9.13 & & 3902 & & 262.1 & 1453.8 \\
\hline
\end{tabular}


Table E-1a, Omega Mine-pool, Treatment Inlet, Raw Chemical Data

\begin{tabular}{|c|c|c|c|c|c|c|c|c|c|}
\hline Sampled By & Date & Location & Flow gpm & $\mathrm{pH}$ & $\begin{array}{c}\text { Sp. } \\
\text { Conductance umhos/cm }\end{array}$ & TDS, mg/L & Temp, C & $\begin{array}{c}\text { Acid load, lbs/day } \\
\text { CaCO3 Eq }\end{array}$ & $\begin{array}{c}\text { Calc Total Acidity } \\
\text { CaCO3 Eq }\end{array}$ \\
\hline WVDEP & 12/15/1998 & Treatment Inlet & 11.7 & 2.60 & 7800 & 4465 & & 249.6 & 1782.3 \\
\hline WVDEP & $1 / 17 / 1999$ & Treatment Inlet & 93.6 & 2.90 & 3360 & 1591 & & 690.2 & 613.3 \\
\hline WVDEP & $2 / 14 / 1999$ & Treatment Inlet & 91.4 & 2.70 & 5480 & 2719 & & 1526.0 & 1389.1 \\
\hline DOE & $2 / 18 / 1999$ & Treatment Inlet & 83.0 & 3.20 & & 3377 & & 1493.6 & 1497.1 \\
\hline WVDEP & $3 / 14 / 1999$ & Treatment Inlet & 120.1 & 2.70 & 5040 & 2832 & & 1846.3 & 1279.4 \\
\hline DOE & $3 / 30 / 1999$ & Treatment Inlet & 128.0 & 3.10 & & 3769 & & 2745.3 & 1785.0 \\
\hline WVDEP & $4 / 13 / 1999$ & Treatment Inlet & 86.0 & 2.70 & 6690 & 4492 & & 2272.8 & 2198.1 \\
\hline DOE & $4 / 29 / 1999$ & Treatment Inlet & 74.0 & 2.69 & & 4385 & & 1984.8 & 2232.1 \\
\hline WVDEP & 5/17/1999 & Treatment Inlet & 51.1 & 2.70 & 7460 & 4445 & & 1478.0 & 2407.7 \\
\hline DOE & $5 / 26 / 1999$ & Treatment Inlet & 35.6 & 2.67 & & 4417 & & 879.7 & 2057.7 \\
\hline WVDEP & $6 / 14 / 1999$ & Treatment Inlet & 22.9 & 2.50 & 18800 & 5308 & & 673.4 & 2452.0 \\
\hline DOE & $6 / 29 / 1999$ & Treatment Inlet & 16.4 & 4.71 & & 4825 & & 394.2 & 1999.6 \\
\hline WVDEP & $7 / 13 / 1999$ & Treatment Inlet & 13.0 & 2.60 & 8310 & 5722 & & 404.9 & 2593.1 \\
\hline DOE & $7 / 27 / 1999$ & Treatment Inlet & 10.1 & 3.03 & & 5220 & & 282.5 & 2320.6 \\
\hline WVDEP & $8 / 14 / 1999$ & Treatment Inlet & 9.9 & 2.80 & 7990 & 5903 & & 311.2 & 2625.7 \\
\hline DOE & $8 / 26 / 1999$ & Treatment Inlet & 8.0 & 2.93 & & 5498 & & 235.1 & 2445.1 \\
\hline WVDEP & 9/14/1999 & Treatment Inlet & 8.1 & 2.80 & 9750 & 5722 & & 248.3 & 2562.7 \\
\hline DOE & 9/29/1999 & Treatment Inlet & 8.8 & 2.79 & & 4551 & & 204.3 & 1931.9 \\
\hline WVDEP & 10/15/1999 & Treatment Inlet & 7.2 & 2.70 & 8250 & 4968 & & 185.2 & 2148.7 \\
\hline DOE & 10/29/1999 & Treatment Inlet & 7.6 & 2.91 & & 4211 & & 149.7 & 1631.4 \\
\hline WVDEP & 11/15/1999 & Treatment Inlet & 5.8 & 2.80 & 8670 & 4703 & & 138.3 & 1977.1 \\
\hline DOE & $12 / 7 / 1999$ & Treatment Inlet & 14.4 & 2.56 & & 4131 & & 305.4 & 1769.6 \\
\hline WVDEP & 12/15/1999 & Treatment Inlet & 30.0 & 2.60 & 5870 & 3386 & & 506.1 & 1402.5 \\
\hline WVDEP & $1 / 17 / 2000$ & Treatment Inlet & 24.0 & 2.70 & 7120 & 4323 & & 546.4 & 1893.1 \\
\hline WVDEP & $2 / 9 / 2000$ & Treatment Inlet & 22.0 & 2.80 & 7750 & 4860 & & 539.8 & 2041.4 \\
\hline WVDEP & $3 / 14 / 2000$ & Treatment Inlet & 143.0 & 2.70 & 6540 & 3826 & & 3094.2 & 1800.2 \\
\hline WVDEP & $4 / 14 / 2000$ & Treatment Inlet & 209.0 & 2.70 & 5770 & 3371 & & 4313.1 & 1717.0 \\
\hline WVDEP & $5 / 15 / 2000$ & Treatment Inlet & 99.0 & 2.80 & 6400 & 5354 & & 860.5 & 723.1 \\
\hline WVDEP & $6 / 15 / 2000$ & Treatment Inlet & 83.0 & 2.60 & 4980 & 2606 & & 1205.4 & 1208.0 \\
\hline WVDEP & $7 / 18 / 2000$ & Treatment Inlet & 92.0 & 2.70 & 6170 & 4018 & & 1705.9 & 1542.3 \\
\hline WVDEP & $8 / 15 / 2000$ & Treatment Inlet & 73.0 & 2.70 & 5720 & 3325 & & 1326.5 & 1512.2 \\
\hline WVDEP & $9 / 15 / 2000$ & Treatment Inlet & 29.0 & 2.60 & 5570 & 3934 & & 571.8 & 1641.0 \\
\hline WVDEP & $10 / 15 / 2000$ & Treatment Inlet & 20.9 & 2.70 & 5190 & 3522 & & 337.5 & 1342.3 \\
\hline WVDEP & $11 / 15 / 2000$ & Treatment Inlet & 18.0 & 2.80 & 5710 & 3727 & & 340.2 & 1571.4 \\
\hline WVDEP & $12 / 15 / 2000$ & Treatment Inlet & 28.0 & 2.90 & 5870 & 3974 & & 418.0 & 1241.9 \\
\hline WVDEP & $1 / 15 / 2001$ & Treatment Inlet & 24.0 & 2.80 & 4720 & 2589 & & 264.2 & 915.4 \\
\hline WVDEP & $2 / 13 / 2001$ & Treatment Inlet & 88.0 & 2.90 & 6340 & 4309 & & 1951.8 & 1845.4 \\
\hline
\end{tabular}


Table E-1a, Omega Mine-pool, Treatment Inlet, Raw Chemical Data

\begin{tabular}{|c|c|c|c|c|c|c|c|c|c|}
\hline Sampled By & Date & Location & Flow gpm & $\mathrm{pH}$ & $\begin{array}{c}\text { Sp. } \\
\text { Conductance umhos/cm }\end{array}$ & TDS, mg/L & Temp, C & $\begin{array}{c}\text { Acid load, lbs/day } \\
\text { CaCO3 Eq }\end{array}$ & $\begin{array}{c}\text { Calc Total Acidity } \\
\text { CaCO3 Eq }\end{array}$ \\
\hline WVDEP & $3 / 13 / 2001$ & Treatment Inlet & 158.0 & 2.80 & 4210 & 2703 & & 2219.1 & 1168.4 \\
\hline WVDEP & $4 / 16 / 2001$ & Treatment Inlet & 209.0 & 3.00 & 3930 & 2128 & & 2513.6 & 1000.6 \\
\hline WVDEP & $5 / 15 / 2001$ & Treatment Inlet & 58.0 & 2.80 & 5780 & 3834 & & 1216.0 & 1743.6 \\
\hline WVDEP & $6 / 18 / 2001$ & Treatment Inlet & 68.0 & 2.80 & 5290 & 3343 & & 1168.7 & 1429.6 \\
\hline WVDEP & $7 / 15 / 2001$ & Treatment Inlet & 87.0 & 2.80 & 4680 & 3148 & & 1299.5 & 1242.7 \\
\hline WVDEP & $8 / 15 / 2001$ & Treatment Inlet & 38.0 & 2.50 & 5610 & 3470 & & 688.7 & 1508.1 \\
\hline WVDEP & $9 / 14 / 2001$ & Treatment Inlet & 24.0 & 2.80 & 5370 & 3584 & & 481.9 & 1669.8 \\
\hline WVDEP & $10 / 15 / 2001$ & Treatment Inlet & 24.6 & 2.70 & 3100 & 3960 & 14.4 & 112.9 & 381.1 \\
\hline WVDEP & $11 / 15 / 2001$ & Treatment Inlet & 17.9 & 2.70 & 2890 & 4016 & 4 & 341.2 & 1584.1 \\
\hline WVDEP & $12 / 14 / 2001$ & Treatment Inlet & 22.0 & 2.80 & 2860 & 2948 & 10.5 & 241.9 & 916.7 \\
\hline WVDEP & $1 / 16 / 2002$ & Treatment Inlet & 59.6 & 3.00 & 1418 & 1892 & 21.6 & 434.8 & 607.1 \\
\hline WVDEP & $2 / 14 / 2002$ & Treatment Inlet & 83.8 & 3.00 & 1894 & 2264 & & 667.1 & 662.4 \\
\hline WVDEP & $3 / 15 / 2002$ & Treatment Inlet & 55.9 & 3.10 & 2290 & 2852 & 11.1 & 715.8 & 1065.8 \\
\hline WVDEP & 4/15/2002 & Treatment Inlet & 164.4 & 2.90 & 1660 & 1668 & 13.3 & 1389.3 & 702.9 \\
\hline WVDEP & $5 / 15 / 2002$ & Treatment Inlet & 129.5 & 2.90 & 2940 & 2624 & 13.3 & 1387.0 & 891.3 \\
\hline WVDEP & $6 / 18 / 2002$ & Treatment Inlet & 77.9 & 3.00 & 2120 & 2936 & 14.4 & 403.8 & 431.5 \\
\hline WVDEP & $7 / 16 / 2002$ & Treatment Inlet & 0.0 & & & & & 0.0 & \\
\hline WVDEP & $8 / 12 / 2002$ & Treatment Inlet & 28.9 & 2.80 & 2950 & 3632 & 15.5 & 432.3 & 1242.7 \\
\hline Perry & $8 / 20 / 2002$ & Treatment Inlet & 7.5 & 2.77 & 3040 & 3457 & 17.4 & 107.4 & 1191.5 \\
\hline WVDEP & $9 / 16 / 2002$ & Treatment Inlet & 20.0 & 2.80 & 3040 & 3992 & 15.5 & 202.5 & 843.0 \\
\hline WVDEP & $10 / 15 / 2002$ & Treatment Inlet & 19.3 & 2.80 & 3010 & 3700 & 15.5 & 208.6 & 900.9 \\
\hline WVDEP & $11 / 15 / 2002$ & Treatment Inlet & 28.9 & 2.80 & 239 & 2560 & 14.4 & 292.4 & 840.4 \\
\hline WVDEP & $12 / 15 / 2002$ & Treatment Inlet & 74.9 & 3.00 & 1523 & 71 & 6.1 & 360.6 & 400.7 \\
\hline WVDEP & $1 / 14 / 2003$ & Treatment Inlet & 107.8 & 2.90 & 2980 & 3604 & 7.8 & 1753.6 & 1353.4 \\
\hline WVDEP & $2 / 24 / 2003$ & Treatment Inlet & 289.5 & 2.90 & 1845 & 1712 & 6.7 & 2140.8 & 615.3 \\
\hline WVDEP & $3 / 18 / 2003$ & Treatment Inlet & 98.6 & 2.76 & 3310 & 3616 & 14.44 & 2178.0 & 1838.4 \\
\hline WVDEP & $4 / 15 / 2003$ & Treatment Inlet & 112.0 & 2.84 & 2790 & 2648 & 13.89 & 1259.4 & 935.5 \\
\hline WVDEP & $5 / 20 / 2003$ & Treatment Inlet & 107.5 & 2.64 & 2900 & 3372 & 15.56 & 1976.4 & 1529.3 \\
\hline WVDEP & $6 / 17 / 2003$ & Treatment Inlet & 192.6 & 2.89 & 1536 & 172 & 14.44 & 1094.2 & 472.5 \\
\hline WVDEP & $8 / 13 / 2003$ & Treatment Inlet & 58.2 & 2.73 & 2570 & 2880 & 15.56 & 741.3 & 1059.0 \\
\hline Perry & $8 / 28 / 2003$ & Treatment Inlet & 44.4 & 2.70 & 2450 & 2357 & 16.4 & 484.5 & 907.9 \\
\hline WVDEP & 9/15/2003 & Treatment Inlet & 62.7 & 2.65 & 2360 & 2520 & 15 & 646.6 & 857.7 \\
\hline WVDEP & $10 / 13 / 2003$ & Treatment Inlet & 53.8 & 2.69 & 2710 & 3036 & 15.5 & 718.3 & 1111.6 \\
\hline WVDEP & 11/18/2003 & Treatment Inlet & 94.1 & 2.88 & 2280 & 2204 & 12.2 & 403.1 & 356.4 \\
\hline WVDEP & $12 / 19 / 2003$ & Treatment Inlet & 179.2 & 2.66 & 2150 & 2012 & 13.3 & 1437.8 & 667.5 \\
\hline WVDEP & $1 / 14 / 2004$ & Treatment Inlet & 116.5 & 2.94 & 2810 & 3468 & 12.2 & 1774.1 & 1267.1 \\
\hline WVDEP & $2 / 17 / 2004$ & Treatment Inlet & 112.0 & 2.90 & 2690 & 3020 & 12.2 & 1437.9 & 1068.1 \\
\hline
\end{tabular}


Table E-1a, Omega Mine-pool, Treatment Inlet, Raw Chemical Data

\begin{tabular}{|c|c|c|c|c|c|c|c|c|c|}
\hline Sampled By & Date & Location & Flow gpm & $\mathrm{pH}$ & $\begin{array}{c}\text { Sp. } \\
\text { Conductance umhos/cm }\end{array}$ & TDS, mg/L & Temp, C & $\begin{array}{c}\text { Acid load, lbs/day } \\
\text { CaCO3 Eq }\end{array}$ & $\begin{array}{c}\text { Calc Total Acidity } \\
\text { CaCO3 Eq }\end{array}$ \\
\hline WVDEP & $3 / 23 / 2004$ & Treatment Inlet & 138.9 & 2.80 & 2130 & 1932 & 10 & 1123.6 & 673.1 \\
\hline WVDEP & $4 / 13 / 2004$ & Treatment Inlet & 210.6 & 2.88 & 1812 & 1520 & 11.1 & 207.1 & 81.8 \\
\hline WVDEP & $5 / 18 / 2004$ & Treatment Inlet & 53.8 & 2.77 & 2440 & 2348 & 11.67 & 603.2 & 933.5 \\
\hline WVDEP & $6 / 15 / 2004$ & Treatment Inlet & 89.6 & 2.94 & 2210 & 2400 & 15.56 & 427.4 & 396.8 \\
\hline WVDEP & $7 / 12 / 2004$ & Treatment Inlet & 44.8 & 2.82 & 2270 & 2224 & 15.6 & 358.6 & 666.0 \\
\hline WVDEP & $8 / 9 / 2004$ & Treatment Inlet & 26.9 & 2.65 & 2790 & 3244 & 15.6 & 366.0 & 1132.6 \\
\hline WVDEP & $9 / 14 / 2004$ & Treatment Inlet & 31.4 & 2.66 & 2520 & 2696 & 15.6 & 309.4 & 820.7 \\
\hline WVDEP & $10 / 18 / 2004$ & Treatment Inlet & 26.9 & 2.82 & 2760 & 3084 & 10 & 318.1 & 984.4 \\
\hline WVDEP & $11 / 16 / 2004$ & Treatment Inlet & 58.3 & 2.82 & 1955 & 1704 & 6.1 & 374.8 & 534.5 \\
\hline WVDEP & $12 / 15 / 2004$ & Treatment Inlet & 71.8 & 2.83 & 2190 & 2304 & 7.22 & 764.1 & 885.3 \\
\hline WVDEP & $1 / 10 / 2005$ & Treatment Inlet & 179.5 & 2.83 & 1936 & 1696 & 5.56 & 1788.5 & 828.9 \\
\hline WVDEP & $2 / 15 / 2005$ & Treatment Inlet & 210.9 & 2.74 & 2240 & 2060 & 10 & 2141.5 & 844.6 \\
\hline WVDEP & $3 / 15 / 2005$ & Treatment Inlet & 152.6 & 2.88 & 2400 & 2652 & 9.4 & 2366.5 & 1290.2 \\
\hline Perry & $3 / 22 / 2005$ & Treatment Inlet & 75.0 & 2.53 & 3320 & 2904 & 11 & 1318.1 & 1462.1 \\
\hline WVDEP & $4 / 11 / 2005$ & Treatment Inlet & 125.7 & 2.64 & 2780 & 3420 & 12.2 & 1397.2 & 925.0 \\
\hline WVDEP & $5 / 24 / 2005$ & Treatment Inlet & 94.2 & 2.78 & 2350 & 2760 & 10.6 & 1108.5 & 978.5 \\
\hline WVDEP & $6 / 14 / 2005$ & Treatment Inlet & 49.4 & 2.89 & 2606 & 3128 & 15 & 555.5 & 936.1 \\
\hline WVDEP & $7 / 11 / 2005$ & Treatment Inlet & 31.4 & 2.59 & 3130 & 3984 & 20 & 572.5 & 1516.0 \\
\hline WVDEP & $8 / 15 / 2005$ & Treatment Inlet & 22.4 & 2.57 & 3090 & 3972 & 15.6 & 324.4 & 1202.7 \\
\hline WVDEP & $9 / 14 / 2005$ & Treatment Inlet & 18.0 & 2.59 & 3200 & 4092 & 16.7 & 314.3 & 1456.5 \\
\hline WVDEP & $10 / 12 / 2005$ & Treatment Inlet & 13.5 & 2.61 & 3140 & 4128 & 15.6 & 200.9 & 1241.6 \\
\hline WVDEP & $11 / 15 / 2005$ & Treatment Inlet & 31.4 & 2.68 & 2630 & 3008 & 15 & 348.4 & 922.7 \\
\hline WVDEP & $12 / 13 / 2005$ & Treatment Inlet & 49.4 & 2.53 & 2820 & 3632 & 14.4 & 746.8 & 1258.5 \\
\hline WVDEP & $1 / 10 / 2006$ & Treatment Inlet & 103.2 & 2.75 & 2560 & 3368 & 7.78 & 1697.8 & 1368.4 \\
\hline WVDEP & $2 / 14 / 2006$ & Treatment Inlet & 166.1 & 2.59 & 2880 & 3576 & 7.22 & 2387.5 & 1196.2 \\
\hline WVDEP & $3 / 13 / 2006$ & Treatment Inlet & 94.2 & 2.63 & 2250 & 2352 & 12.2 & 899.5 & 794.0 \\
\hline WVDEP & $4 / 17 / 2006$ & Treatment Inlet & 98.7 & 2.47 & 2360 & 2544 & 13.3 & 1135.6 & 956.8 \\
\hline WVDEP & $5 / 15 / 2006$ & Treatment Inlet & 80.8 & 2.67 & 2070 & 2324 & 15.6 & 697.4 & 718.2 \\
\hline Perry & $5 / 24 / 2006$ & Treatment Inlet & 139.8 & 2.64 & 2300 & 2572 & 13.2 & 1693.3 & 1007.7 \\
\hline WVDEP & $6 / 12 / 2006$ & Treatment Inlet & 62.8 & 2.36 & 2590 & 2888 & 13.3 & 912.3 & 1208.0 \\
\hline WVDEP & $7 / 11 / 2006$ & Treatment Inlet & 53.9 & 2.64 & 2490 & 2840 & 14.4 & 732.7 & 1131.9 \\
\hline WVDEP & $8 / 14 / 2006$ & Treatment Inlet & 49.4 & 2.55 & 3000 & 4176 & 15.6 & 832.8 & 1403.5 \\
\hline WVDEP & $9 / 12 / 2006$ & Treatment Inlet & 26.9 & 2.50 & 3260 & 3520 & 15.6 & 447.3 & 1382.0 \\
\hline WVDEP & $10 / 17 / 2006$ & Treatment Inlet & 62.7 & 2.80 & 2610 & 2784 & 14.44 & 610.6 & 810.0 \\
\hline WVDEP & $11 / 13 / 2006$ & Treatment Inlet & 89.6 & 2.73 & 2150 & 2148 & 14.4 & 792.5 & 735.9 \\
\hline WVDEP & $12 / 13 / 2006$ & Treatment Inlet & 53.8 & 2.79 & 3090 & 3796 & 12.2 & 877.3 & 1357.6 \\
\hline WVDEP & $1 / 15 / 2007$ & Treatment Inlet & 219.5 & 2.72 & 1826 & 1472 & 15 & 1384.4 & 524.7 \\
\hline
\end{tabular}


Table E-1a, Omega Mine-pool, Treatment Inlet, Raw Chemical Data

\begin{tabular}{|c|c|c|c|c|c|c|c|c|c|}
\hline Sampled By & Date & Location & Flow gpm & $\mathrm{pH}$ & $\begin{array}{c}\text { Sp. } \\
\text { Conductance umhos/cm }\end{array}$ & TDS, mg/L & Temp, C & $\begin{array}{c}\text { Acid load, Ibs/day } \\
\text { CaCO3 Eq }\end{array}$ & $\begin{array}{l}\text { Calc Total Acidity } \\
\text { CaCO3 Eq }\end{array}$ \\
\hline WVDEP & $2 / 14 / 2007$ & Treatment Inlet & 76.2 & 2.59 & 2700 & 2840 & 15 & 987.0 & 1078.2 \\
\hline WVDEP & $3 / 14 / 2007$ & Treatment Inlet & 179.2 & 2.68 & 2380 & 2572 & 15.6 & 2040.2 & 947.2 \\
\hline WVDEP & $4 / 18 / 2007$ & Treatment Inlet & 259.8 & 2.70 & 1709 & 1308 & 15.6 & 1670.9 & 535.0 \\
\hline WVDEP & $5 / 16 / 2007$ & Treatment Inlet & 71.7 & 2.63 & 2580 & 2988 & 17.8 & 649.9 & 754.3 \\
\hline Perry & $5 / 3 / 2007$ & Treatment Inlet & 86.0 & 2.65 & 2318 & 2508 & 13.7 & 1073.5 & 1038.5 \\
\hline WVDEP & $6 / 14 / 2007$ & Treatment Inlet & 40.3 & 2.51 & 2990 & 3148 & 13.33 & 544.2 & 1122.8 \\
\hline WVDEP & $7 / 17 / 2007$ & Treatment Inlet & 35.8 & 2.71 & 3070 & 3664 & 12 & 517.9 & 1202.3 \\
\hline Perry & $8 / 13 / 2007$ & Treatment Inlet & 22.5 & 2.47 & 3360 & 3062 & 16.6 & 340.0 & 1257.3 \\
\hline WVDEP & $8 / 15 / 2007$ & Treatment Inlet & 22.4 & 2.46 & 3120 & 3124 & 12 & 347.5 & 1290.8 \\
\hline WVDEP & 9/12/2007 & Treatment Inlet & 22.4 & 2.55 & 2960 & 3316 & 12 & 289.2 & 1074.0 \\
\hline WVDEP & $10 / 10 / 2007$ & Treatment Inlet & 17.9 & 2.55 & 3130 & 3388 & 12 & 252.1 & 1170.3 \\
\hline WVDEP & $11 / 26 / 2007$ & Treatment Inlet & 13.4 & 2.78 & 2820 & 3412 & 10 & 188.7 & 1167.8 \\
\hline
\end{tabular}


Table E-1b, Omega Mine-pool, Treatment Inlet, Raw Chemical Data

\begin{tabular}{|c|c|c|c|c|c|c|c|c|c|c|c|c|c|}
\hline $\begin{array}{c}\text { Sampled } \\
\text { By }\end{array}$ & Date & Location & $\begin{array}{l}\text { Fe3+, } \\
\mathrm{mg} / \mathrm{L}\end{array}$ & $\begin{array}{l}\mathrm{Fe} 2+, \\
\mathrm{mg} / \mathrm{L}\end{array}$ & $\begin{array}{c}\text { Fe Total, } \\
\mathrm{mg} / \mathrm{L}\end{array}$ & $\begin{array}{c}\mathrm{Ca}, \\
\mathrm{mg} / \mathrm{L}\end{array}$ & $\begin{array}{l}\mathrm{Mg}, \\
\mathrm{mg} / \mathrm{L}\end{array}$ & $\begin{array}{c}\mathrm{Na}, \\
\mathrm{mg} / \mathrm{L}\end{array}$ & $\begin{array}{c}\mathrm{K}, \\
\mathrm{mg} / \mathrm{L}\end{array}$ & $\begin{array}{c}\mathrm{Al}, \\
\mathrm{mg} / \mathrm{L}\end{array}$ & $\begin{array}{c}\mathrm{Mn}, \\
\mathrm{mg} / \mathrm{L}\end{array}$ & $\begin{array}{l}\mathrm{SO} 4, \\
\mathrm{mg} / \mathrm{L}\end{array}$ & $\begin{array}{c}\mathrm{Cl}, \\
\mathrm{mg} / \mathrm{L}\end{array}$ \\
\hline DOE & $2 / 11 / 93$ & Treatment & 212 & 693 & 905 & 321.0 & 168.0 & 8.3 & 5.7 & 167.0 & 5.32 & 4098 & 10 \\
\hline$\overline{D O E}$ & $3 / 3 / 1993$ & Treatment & 315 & 783 & 1098 & 289.0 & 157.0 & 7.2 & 5.2 & 192.0 & 5.90 & 4772 & 7.1 \\
\hline DOE & $3 / 18 / 1993$ & Treatment & 303 & 234 & 537 & 172.0 & 85.9 & 17.6 & 4.7 & 94.5 & 2.70 & 2581 & 20.2 \\
\hline $\mathrm{DOE}$ & $4 / 2 / 1993$ & Treatment & 469 & 391 & 860 & 224.0 & 116.0 & 8.8 & 3.6 & 151.0 & 3.70 & 3925 & 10 \\
\hline DOE & $4 / 14 / 1993$ & Treatment & 487 & 556 & 1043 & 265.0 & 138.0 & 8.3 & 3.9 & 180.0 & 4.50 & 4744 & 6.6 \\
\hline DOE & $4 / 29 / 1993$ & Treatment & 415 & 291 & 706 & 222.0 & 102.0 & 7.9 & 4 & 122.0 & 4.70 & 3274 & 9.9 \\
\hline DOE & $5 / 20 / 1993$ & Treatment & 450 & 584 & 1034 & 281.0 & 145.0 & 7.3 & 5.8 & 181.0 & 5.20 & 4494 & 8.7 \\
\hline $\mathrm{DOE}$ & $6 / 3 / 1993$ & Treatment & 363 & 245 & 608 & 278.0 & 143.0 & 9.0 & 5.7 & 117.0 & 5.00 & 3542 & 8.5 \\
\hline $\mathrm{DOE}$ & $\begin{array}{ll}6 / 10 / 1993 \\
\end{array}$ & Treatment & 342.08 & 409 & 751.08 & 286.1 & 148.1 & 8.7 & 6.93 & 140.1 & 5.20 & 3877 & 11.6 \\
\hline DOE & $6 / 23 / 1993$ & Treatment & 327.59 & 599 & 926.59 & 308.1 & 158.1 & 7.9 & 5.96 & 163.1 & 5.76 & 4446 & 11.8 \\
\hline DOE & $7 / 8 / 1993$ & Treatment & 308.05 & 650 & 958.05 & 318.7 & 159.5 & 7.4 & 7.67 & 168.6 & 6.25 & 4499 & 6.2 \\
\hline $\mathrm{DOE}$ & $7 / 22 / 1993$ & Treatment & 271.6 & 663 & 934.6 & 340.9 & 171.4 & 7.9 & 8.47 & 156.9 & 6.69 & 4511 & 7.2 \\
\hline $\mathrm{DOE}$ & $8 / 11 / 1993$ & Treatment & 269.95 & 522 & 791.95 & 347.5 & 172.0 & 7.8 & 9.15 & 133.4 & 6.54 & 4107 & \\
\hline DOE & $9 / 10 / 1993$ & Treatment & 265.77 & 408.2 & 673.97 & 349.4 & 167.1 & 9.1 & 9.86 & 115.4 & 6.47 & 3904 & \\
\hline DOE & $10 / 7 / 1993$ & Treatment & 238.77 & 310 & 548.77 & 328.7 & 156.7 & 10.2 & 9.46 & 95.8 & 5.86 & 3603 & 15 \\
\hline $\mathrm{DOE}$ & $10 / 25 / 1993$ & Treatment & 244.89 & 325 & 569.89 & 313.1 & 153.6 & 12.7 & 8.43 & 98.4 & 5.69 & 3465 & 20 \\
\hline DOE & 11/10/1993 & Treatment & 265.02 & 260 & 525.02 & 304.9 & 145.9 & 12.5 & 8.99 & 89.7 & 5.68 & 3282 & 18 \\
\hline DOE & $12 / 7 / 1993$ & Treatment & 155.84 & 180 & 335.84 & 161.68 & 79.4 & 12.8 & 2.59 & 59.5 & 2.93 & 1909 & 22.3 \\
\hline $\mathrm{DOE}$ & $12 / 23 / 1993$ & Treatment & 353.1 & 517.4 & 870.5 & 264.1 & 137.7 & 7.9 & 4.38 & 155.1 & 4.69 & 3981 & 17.6 \\
\hline $\mathrm{DOE}$ & $1 / 28 / 1994$ & Treatment & 209.23 & 240.6 & 449.83 & 186.0 & 92.3 & 16.1 & 4.13 & 92.3 & 3.32 & 2535 & 27.7 \\
\hline DOE & $5 / 5 / 1994$ & Treatment & 318.36 & 460.5 & 778.86 & 235.3 & 103.9 & 8.5 & 4.46 & 148.1 & 3.80 & 3608 & 33.73 \\
\hline DOE & $6 / 10 / 1994$ & Treatment & 208.5 & 482.8 & 691.3 & 262.4 & 120.4 & 12.5 & 5.84 & 138.7 & 4.36 & 3458 & 51.1 \\
\hline DOE & $7 / 6 / 1994$ & Treatment & 249.76 & 381.2 & 630.96 & 289.6 & 130.7 & 13.1 & 6.93 & 122.7 & 4.97 & 3475 & 31.5 \\
\hline DOE & $8 / 3 / 1994$ & Treatment & 222.53 & 361.7 & 584.23 & 275.6 & 128.1 & 13.6 & 7.08 & 107.2 & 5.00 & 3223 & 42.5 \\
\hline$\overline{D O E}$ & 9/1/1994 & Treatment & 212.55 & 234.2 & 446.75 & 238.6 & 108.4 & 15.4 & 6.47 & 87.9 & 4.30 & 2734 & 43.1 \\
\hline DOE & $10 / 7 / 1994$ & Treatment & 224.67 & 414.6 & 639.27 & 293.3 & 137.6 & 12.7 & 6.86 & 127.8 & 5.25 & 3544 & 38.22 \\
\hline$\overline{\mathrm{DOE}}$ & $11 / 16 / 1994$ & Treatment & 149 & 443.52 & 592.52 & 323.2 & 148.9 & 11.6 & 10.07 & 108.2 & 6.18 & 3648 & 29.2 \\
\hline DOE & $12 / 14 / 1994$ & Treatment & 137.72 & 263.2 & 400.92 & 223.6 & 103.3 & 15.9 & 6.38 & 78.2 & 4.68 & 2581 & 34.84 \\
\hline DOE & $1 / 10 / 1995$ & Treatment & 171.16 & 343.1 & 514.26 & 222.9 & 109.2 & 14.4 & 1.35 & 99.7 & 4.28 & 2707 & 36.9 \\
\hline DOE & 2/3/1995 & Treatment & 155.97 & 488.71 & 644.68 & 238.2 & 113.7 & 14.9 & 6.34 & 128.0 & 4.26 & 3088 & 33.92 \\
\hline $\mathrm{DOE}$ & $3 / 2 / 1995$ & Treatment & 135.34 & 329.73 & 465.07 & 203.3 & 94.1 & 15.3 & 5.7 & 102.3 & 4.96 & 2631 & 37.5 \\
\hline DOE & $4 / 7 / 1995$ & Treatment & 373.27 & 680.2 & 1053.47 & 273.32 & 127.9 & 8.21 & 4.54 & 192.14 & 5.79 & 4608 & 33.43 \\
\hline$\overline{D O E}$ & $5 / 10 / 1995$ & Treatment & 145.76 & 430 & 575.76 & 212.1 & 96.7 & 9.8 & 6.04 & 114.9 & 4.48 & 2917 & 23.3 \\
\hline DOE & $6 / 6 / 1995$ & Treatment & 188.95 & 381.1 & 570.05 & 211.0 & 96.3 & 9.5 & 5.7 & 118.9 & 3.98 & 3364 & 26.4 \\
\hline DOE & $7 / 13 / 1995$ & Treatment & 171.74 & 708.8 & 880.54 & 280.65 & 127.2 & 8.07 & 6.58 & 174.36 & 5.83 & 4087.54 & 18.3 \\
\hline DOE & $8 / 3 / 1995$ & Treatment & 182.01 & 452 & 634.01 & 309.7 & 134.5 & 9.6 & 8.68 & 126.9 & 6.27 & 3569 & 28.3 \\
\hline
\end{tabular}


Table E-1b, Omega Mine-pool, Treatment Inlet, Raw Chemical Data

\begin{tabular}{|c|c|c|c|c|c|c|c|c|c|c|c|c|c|}
\hline $\begin{array}{c}\text { Sampled } \\
\text { By }\end{array}$ & Date & Location & $\begin{array}{c}\text { Fe3+, } \\
\mathrm{mg} / \mathrm{L}\end{array}$ & $\begin{array}{l}\text { Fe2+, } \\
\mathrm{mg} / \mathrm{L}\end{array}$ & $\begin{array}{c}\text { Fe Total, } \\
\mathrm{mg} / \mathrm{L}\end{array}$ & $\begin{array}{c}\mathrm{Ca}, \\
\mathrm{mg} / \mathrm{L}\end{array}$ & $\begin{array}{l}\mathrm{Mg}, \\
\mathrm{mg} / \mathrm{L}\end{array}$ & $\begin{array}{c}\mathrm{Na}, \\
\mathrm{mg} / \mathrm{L}\end{array}$ & $\begin{array}{c}\mathrm{K}, \\
\mathrm{mg} / \mathrm{L}\end{array}$ & $\begin{array}{c}\mathrm{Al}, \\
\mathrm{mg} / \mathrm{L}\end{array}$ & $\begin{array}{c}\mathrm{Mn}, \\
\mathrm{mg} / \mathrm{L}\end{array}$ & $\begin{array}{l}\mathrm{SO} 4, \\
\mathrm{mg} / \mathrm{L}\end{array}$ & $\begin{array}{c}\mathrm{Cl}, \\
\mathrm{mg} / \mathrm{L}\end{array}$ \\
\hline DOE & 9/7/1995 & Treatment & 66.62 & 494.2 & 560.82 & 345.64 & 150.5 & 10.92 & 10.4 & 110 & 7.75 & 3693.09 & 26.1 \\
\hline DOE & $10 / 12 / 1995$ & Treatment & 125.27 & 392 & 517.27 & 350.25 & 149.6 & 12.23 & 10.4 & 98.97 & 7.79 & 3456.69 & 15.85 \\
\hline DOE & $11 / 22 / 1995$ & Treatment & 55.04 & 160.4 & 215.44 & 268.8 & 110.0 & 10.4 & 10.26 & 48.3 & 9.33 & 2321 & 22.3 \\
\hline DOE & 1/5/1996 & Treatment & 43.57 & 233.5 & 277.07 & 215.2 & 88.9 & 9.3 & 7.97 & 58.1 & 6.14 & 2055 & 18.31 \\
\hline WVDEP & $1 / 16 / 1996$ & Treatment & & & 485 & & & & & 93.1 & 9.29 & 3080 & \\
\hline WVDEP & $2 / 15 / 1996$ & Treatment & & & 406 & & & & & & 4.11 & 2120 & \\
\hline DOE & 2/21/1996 & Treatment & 286.93 & 323 & 609.93 & 169.9 & 76.6 & 15.0 & 2.79 & 133.8 & 3.20 & 2822 & 31.7 \\
\hline WVDEP & 3/1/1996 & Treatment & & & 567 & & & & & & 3.05 & 2360 & \\
\hline WVDEP & $3 / 15 / 1996$ & Treatment & & & 686 & & & & & & 3.14 & 3090 & \\
\hline DOE & $3 / 18 / 1996$ & Treatment & 188 & 124.6 & 312.6 & 151.5 & 65.6 & 10.3 & 4.38 & 73.0 & 2.76 & 1927 & 21.09 \\
\hline WVDEP & $3 / 28 / 1996$ & Treatment & & & 252 & & & & & & 2.56 & 1870 & \\
\hline WVDEP & $4 / 15 / 1996$ & Treatment & & & 347 & & & & & & 3.87 & 2320 & \\
\hline DOE & 4/26/1996 & Treatment & 237.52 & 213.2 & 450.72 & 175.7 & 73.6 & 9.4 & 4.31 & 98.5 & 3.62 & 2281 & 16.73 \\
\hline WVDEP & $4 / 29 / 1996$ & Treatment & & & 711 & & & & & & 4.91 & 2920 & \\
\hline WVDEP & $5 / 15 / 1996$ & Treatment & & & 423 & & & & & 95.7 & 3.54 & 2020 & \\
\hline WVDEP & $5 / 31 / 1996$ & Treatment & & & 304 & & & & & 72.1 & 2.93 & 1640 & \\
\hline DOE & 6/7/1996 & Treatment & 265.68 & 263 & 528.68 & 201.9 & 83.3 & 8.8 & 4.9 & 121.5 & 3.96 & 2811 & 13.28 \\
\hline WVDEP & 6/14/1996 & Treatment & & & 620 & & & & & 144 & 5.18 & 2700 & \\
\hline WVDEP & $6 / 28 / 1996$ & Treatment & & & 307 & & & & & 0.23 & 5.24 & 2100 & \\
\hline WVDEP & $7 / 15 / 1996$ & Treatment & & & 282 & & & & & 59.9 & 5.24 & 1760 & \\
\hline DOE & $7 / 23 / 1996$ & Treatment & 195.87 & 80.5 & 276.37 & 184.2 & 70.6 & 12.4 & 4.9 & 65.6 & 3.90 & 1868 & 21.7 \\
\hline WVDEP & $7 / 30 / 1996$ & Treatment & & & 401 & & & & & 87.1 & 5.27 & 2570 & \\
\hline WVDEP & $8 / 14 / 1996$ & Treatment & & & 508 & & & & & 123 & 4.98 & 2540 & \\
\hline DOE & $8 / 28 / 1996$ & Treatment & 217.52 & 283.5 & 501.02 & 290.4 & 110.0 & 11.8 & 8.39 & 113.4 & 5.39 & 3061 & 19.84 \\
\hline WVDEP & $8 / 31 / 1996$ & Treatment & & & 485 & & & & & 114 & 5.53 & 2770 & \\
\hline WVDEP & $9 / 16 / 1996$ & Treatment & & & 465 & & & & & 110 & 6.42 & 2190 & \\
\hline WVDEP & 9/30/1996 & Treatment & & & 424 & & & & & 95 & 5.1 & 2500 & \\
\hline WVDEP & $10 / 14 / 1996$ & Treatment & & & 472 & & & & & 106 & 0.6 & 2280 & \\
\hline DOE & $10 / 16 / 1996$ & Treatment & 207.86 & 266 & 473.86 & 282.5 & 109.2 & 11.6 & 8.1 & 105.5 & 5.32 & 2909 & 29.68 \\
\hline WVDEP & 10/30/1996 & Treatment & & & 379 & & & & & 83 & 4.98 & 1450 & \\
\hline WVDEP & $11 / 15 / 1996$ & Treatment & & & 526 & & & & & 110 & 3.94 & 1580 & \\
\hline DOE & $11 / 26 / 1996$ & Treatment & 203.25 & 237 & 440.25 & 191.77 & 79.08 & 9.06 & 6.16 & 99.86 & 3.96 & 2342.04 & 16.38 \\
\hline DOE & $12 / 13 / 1996$ & Treatment & 238.81 & 213 & 451.81 & 175.28 & 72.1 & 8.44 & 5.19 & 102.47 & 3.77 & 2321.13 & 7.5 \\
\hline WVDEP & 12/15/1996 & Treatment & & & 467 & & & & & 98 & 3.97 & 989 & \\
\hline WVDEP & $1 / 14 / 1997$ & Treatment & & & 4.56 & & & & & 102 & 4.27 & 1640 & \\
\hline DOE & $1 / 28 / 1997$ & Treatment & 96.46 & 108 & 204.46 & 107.62 & 46.08 & 5.83 & 3.05 & 49.99 & 2.5 & 1197.62 & 12.4 \\
\hline
\end{tabular}


Table E-1b, Omega Mine-pool, Treatment Inlet, Raw Chemical Data

\begin{tabular}{|c|c|c|c|c|c|c|c|c|c|c|c|c|c|}
\hline $\begin{array}{c}\text { Sampled } \\
\text { By }\end{array}$ & Date & Location & $\begin{array}{l}\text { Fe3+, } \\
\mathrm{mg} / \mathrm{L}\end{array}$ & $\begin{array}{l}\mathrm{Fe} 2+, \\
\mathrm{mg} / \mathrm{L}\end{array}$ & $\begin{array}{c}\text { Fe Total, } \\
\mathrm{mg} / \mathrm{L}\end{array}$ & $\begin{array}{c}\mathrm{Ca}, \\
\mathrm{mg} / \mathrm{L}\end{array}$ & $\begin{array}{l}\mathrm{Mg}, \\
\mathrm{mg} / \mathrm{L}\end{array}$ & $\begin{array}{l}\mathrm{Na}, \\
\mathrm{mg} / \mathrm{L}\end{array}$ & $\begin{array}{c}\mathrm{K}, \\
\mathrm{mg} / \mathrm{L}\end{array}$ & $\begin{array}{c}\mathrm{Al}, \\
\mathrm{mg} / \mathrm{L}\end{array}$ & $\begin{array}{c}\mathrm{Mn}, \\
\mathrm{mg} / \mathrm{L}\end{array}$ & $\begin{array}{l}\mathrm{SO} 4, \\
\mathrm{mg} / \mathrm{L}\end{array}$ & $\begin{array}{c}\mathrm{Cl}, \\
\mathrm{mg} / \mathrm{L}\end{array}$ \\
\hline WVDEP & $2 / 21 / 1997$ & Treatment & 131.04 & 141 & 272.04 & 189.2 & 72.71 & 11.8 & 4.94 & 64.2 & 3.66 & 1803 & 23.3 \\
\hline WVDEP & $3 / 17 / 1997$ & Treatment & & & 671 & & & & & 147 & 4.62 & 2640 & \\
\hline $\mathrm{DOE}$ & $3 / 26 / 1997$ & Treatment & 201.42 & 134.1 & 335.52 & 130.0 & 52.2 & 7.0 & 3.77 & 76.8 & 2.90 & 1724 & 11.2 \\
\hline WVDEP & $4 / 14 / 1997$ & Treatment & & & 742 & & & & & 232 & 3.66 & 2580 & \\
\hline WVDEP & $5 / 14 / 1997$ & Treatment & & & 457 & & & & & 96.7 & 4.01 & 2150 & \\
\hline $\mathrm{DOE}$ & $5 / 20 / 1997$ & Treatment & 90.59 & 158.1 & 248.69 & 117.0 & 47.6 & 7.2 & 3.71 & 56.9 & 2.56 & 1352 & \\
\hline WVDEP & $6 / 16 / 1997$ & Treatment & & & 831 & & & & & 204 & 4.3 & 1560 & \\
\hline DOE & $7 / 10 / 1997$ & Treatment & 258.94 & 213.5 & 472.44 & 225.2 & 87.1 & 9.5 & 6.16 & 113.6 & 4.45 & 2628 & 17.15 \\
\hline WVDEP & $7 / 16 / 1997$ & Treatment & & & 344 & & & & & 82.5 & 4.51 & 2450 & \\
\hline WVDEP & $8 / 17 / 1997$ & Treatment & & & 403 & & & & & 101 & 554 & 1420 & \\
\hline DOE & 9/10/1997 & Treatment & 248.78 & 177.1 & 425.88 & 250.2 & 99.2 & 11.6 & 6.86 & 100.9 & 5.40 & 2514 & 44.75 \\
\hline WVDEP & $9 / 15 / 1997$ & Treatment & & & 458 & & & & & & 4.8 & 2220 & \\
\hline WVDEP & $10 / 15 / 1997$ & Treatment & & & 500 & & & & & 111 & 5.05 & 1460 & \\
\hline DOE & $11 / 5 / 1997$ & Treatment & 190.52 & 205.6 & 396.12 & 233.7 & 93.3 & 12.3 & 6.19 & 91.3 & 5.43 & 2262 & 20.05 \\
\hline WVDEP & 11/14/1997 & Treatment & & & 171 & & & & & 36.4 & 3.1 & 1080 & \\
\hline WVDEP & $12 / 15 / 1997$ & Treatment & & & 319 & & & & & 80.4 & 4.09 & 1850 & \\
\hline DOE & $1 / 12 / 1998$ & Treatment & 106.56 & 209.9 & 316.46 & 136.1 & 56.1 & 13.5 & 4.07 & 71.3 & 2.36 & 1660 & 24.2 \\
\hline WVDEP & 1/16/1998 & Treatment & & & 428 & & & & & 98.8 & 3.34 & 2310 & \\
\hline DOE & $2 / 9 / 1998$ & Treatment & 315.56 & 287.3 & 602.86 & 189.2 & 79.3 & 10.35 & 4.21 & 145.5 & 3.5 & 2893 & 22.48 \\
\hline WVDEP & $2 / 15 / 1998$ & Treatment & & & 429 & & & & & 108 & 2.91 & 2410 & \\
\hline WVDEP & $3 / 16 / 1998$ & Treatment & & & 511 & & & & & 1.28 & 2.79 & 2420 & \\
\hline $\mathrm{DOE}$ & $3 / 26 / 1998$ & Treatment & 228.97 & 205.5 & 434.47 & 146.2 & 60.2 & 11.1 & 3.8 & 103.2 & 2.76 & 2138 & \\
\hline WVDEP & $4 / 15 / 1998$ & Treatment & & & 489 & & & & & 127 & 2.98 & 2180 & \\
\hline DOE & $4 / 29 / 1998$ & Treatment & 203.91 & 207.5 & 411.41 & 148.7 & 60.3 & 9.5 & 4.19 & 100.0 & 3.11 & 2079 & \\
\hline WVDEP & $5 / 13 / 1998$ & Treatment & & & 502 & & & & & 129 & 3.44 & 1900 & \\
\hline DOE & $5 / 28 / 1998$ & Treatment & 192.9 & 271.7 & 464.6 & 242.2 & 71.4 & 11.8 & 7.06 & 115.2 & 3.51 & 2454 & 19.72 \\
\hline WVDEP & $6 / 15 / 1998$ & Treatment & & & 435 & & & & & 125 & 4.68 & 2260 & \\
\hline WVDEP & $\begin{array}{ll}6 / 25 / 1998 \\
\end{array}$ & Treatment & 15.6 & 365.8 & 381.4 & 630.0 & 64.9 & 17.5 & 16.24 & 70.7 & 2.79 & 2897 & 25.12 \\
\hline WVDEP & $7 / 15 / 1998$ & Treatment & & & 697 & & & & & 0 & 5.22 & 3410 & \\
\hline DOE & $8 / 5 / 1998$ & Treatment & 119.14 & 427.7 & 546.84 & 396.9 & 95.7 & 32.8 & 39.36 & 133.1 & 4.42 & 3282 & 39.99 \\
\hline WVDEP & $\begin{array}{l}8 / 13 / 1998 \\
\end{array}$ & Treatment & & & 461 & & & & & 116 & 5.47 & 2870 & \\
\hline DOE & $9 / 3 / 1998$ & Treatment & 226.27 & 517.7 & 743.97 & 333.6 & 117.1 & 25.0 & 26.63 & 180.5 & 5.47 & 3818 & 32.32 \\
\hline WVDEP & 9/15/1998 & Treatment & & & 761 & & & & & 199 & 4.89 & 3660 & \\
\hline WVDEP & $10 / 15 / 1998$ & Treatment & & & 983 & & & & & 268 & 5.34 & 4160 & \\
\hline DOE & $10 / 29 / 1998$ & Treatment & 362.8 & 74.3 & 437.1 & 298.83 & 120.6 & 23.84 & 10.47 & 117.36 & 5.4 & 3021.04 & 44.49 \\
\hline DOE & $11 / 15 / 1998$ & Treatment & & & 348 & & & & & 93.6 & 7.49 & 2640 & \\
\hline DOE & $12 / 10 / 1998$ & Treatment & 351.17 & 91.73 & 442.9 & 302.4 & 117.6 & 24.4 & 14.19 & 117.0 & 6.21 & 2838 & 30.2 \\
\hline
\end{tabular}


Table E-1b, Omega Mine-pool, Treatment Inlet, Raw Chemical Data

\begin{tabular}{|c|c|c|c|c|c|c|c|c|c|c|c|c|c|}
\hline $\begin{array}{c}\text { Sampled } \\
\text { By }\end{array}$ & Date & Location & $\begin{array}{l}\text { Fe3+, } \\
\mathrm{mg} / \mathrm{L}\end{array}$ & $\begin{array}{l}\mathrm{Fe} 2+, \\
\mathrm{mg} / \mathrm{L}\end{array}$ & $\begin{array}{c}\text { Fe Total, } \\
\mathrm{mg} / \mathrm{L}\end{array}$ & $\begin{array}{c}\mathrm{Ca}, \\
\mathrm{mg} / \mathrm{L}\end{array}$ & $\begin{array}{l}\mathrm{Mg}, \\
\mathrm{mg} / \mathrm{L}\end{array}$ & $\begin{array}{l}\mathrm{Na}, \\
\mathrm{mg} / \mathrm{L}\end{array}$ & $\begin{array}{c}\mathrm{K}, \\
\mathrm{mg} / \mathrm{L}\end{array}$ & $\begin{array}{c}\mathrm{Al}, \\
\mathrm{mg} / \mathrm{L}\end{array}$ & $\begin{array}{c}\mathrm{Mn}, \\
\mathrm{mg} / \mathrm{L}\end{array}$ & $\begin{array}{l}\mathrm{SO} 4, \\
\mathrm{mg} / \mathrm{L}\end{array}$ & $\begin{array}{c}\mathrm{Cl}, \\
\mathrm{mg} / \mathrm{L}\end{array}$ \\
\hline WVDEP & 12/15/1998 & Treatment & & & 526 & & & & & 127 & 5.25 & 2520 & \\
\hline WVDEP & $1 / 17 / 1999$ & Treatment & & & 149 & & & & & 50.2 & 2.61 & 867 & \\
\hline WVDEP & $2 / 14 / 1999$ & Treatment & & & 391 & & & & & 105 & 3.32 & 2100 & \\
\hline DOE & 2/18/1999 & Treatment & 212.29 & 213.7 & 425.99 & 202.8 & 84.4 & 17.3 & 7.96 & 125.2 & 4.04 & 2474 & 27.03 \\
\hline WVDEP & $3 / 14 / 1999$ & Treatment & & & 370 & & & & & 92.1 & 3.07 & 1940 & \\
\hline DOE & $3 / 30 / 1999$ & Treatment & 234.18 & 285.1 & 519.28 & 209.0 & 83.6 & 19.2 & 8.3 & 145.4 & 4.36 & 2740 & 31.49 \\
\hline WVDEP & 4/13/1999 & Treatment & & & 724 & & & & & 143 & 4.24 & 2740 & \\
\hline DOE & 4/29/1999 & Treatment & 665.88 & 4.54 & 670.42 & 220.9 & 96.1 & 19.4 & 10.65 & 165.7 & 5.10 & 3162 & 25.8 \\
\hline WVDEP & $5 / 17 / 1999$ & Treatment & & & 639 & & & & & 208 & 4.6 & 2970 & \\
\hline DOE & 5/26/1999 & Treatment & 221.36 & 386.3 & 607.66 & 250.0 & 104.4 & 19.4 & 11.11 & 153.5 & 5.56 & 3193 & 61.6 \\
\hline DOE & $6 / 14 / 1999$ & Treatment & & & 748 & & & & & 170 & 5.66 & 2410 & \\
\hline DOE & 6/29/1999 & Treatment & 333.21 & 291.5 & 624.71 & 292.53 & 120.0 & 18.66 & 12.47 & 156.58 & 5.71 & 3562.43 & 20.91 \\
\hline WVDEP & $7 / 13 / 1999$ & Treatment & & & 833 & & & & & 174 & 5.21 & 2140 & \\
\hline DOE & $7 / 27 / 1999$ & Treatment & 322.29 & 394.4 & 716.69 & 318.0 & 132.2 & 20.5 & 14.07 & 176.4 & 6.14 & 3796 & 28.81 \\
\hline WVDEP & $8 / 14 / 1999$ & Treatment & & & 870 & & & & & 176 & 6.1 & 3500 & \\
\hline DOE & 8/26/1999 & Treatment & 713.33 & 50.39 & 763.72 & 343.6 & 141.4 & 23.5 & 15.26 & 181.4 & 6.41 & 3983 & 28.37 \\
\hline WVDEP & 9/14/1999 & Treatment & & & 854 & & & & & 170 & 5.55 & 3260 & \\
\hline DOE & 9/29/1999 & Treatment & 191.61 & 374.7 & 566.31 & 331.8 & 127.9 & 22.5 & 13.29 & 148.2 & 7.55 & 3300 & 23.1 \\
\hline WVDEP & $10 / 15 / 1999$ & Treatment & & & 673 & & & & & 150 & 5.95 & 2840 & \\
\hline DOE & $10 / 29 / 1999$ & Treatment & 256.02 & 194.2 & 450.22 & 319.4 & 131.4 & 19.4 & 7 & 135.5 & 6.08 & 3096 & 35.5 \\
\hline WVDEP & $11 / 15 / 1999$ & Treatment & & & 602 & & & & & 146 & 4.95 & 3480 & \\
\hline DOE & 12/7/1999 & Treatment & 312.2 & 204.7 & 516.9 & 298.0 & 116.3 & 24.5 & 12.16 & 125.3 & 5.80 & 2983 & 40.2 \\
\hline WVDEP & $12 / 15 / 1999$ & Treatment & & & 388 & & & & & 103 & 5.57 & 2180 & \\
\hline WVDEP & $1 / 17 / 2000$ & Treatment & & & 536 & & & & & 148 & 6.4 & 3240 & \\
\hline WVDEP & $2 / 9 / 2000$ & Treatment & & & 627 & & & & & 149 & 6.59 & 2980 & \\
\hline WVDEP & $3 / 14 / 2000$ & Treatment & & & 516 & & & & & 138 & 5.5 & 2590 & \\
\hline WVDEP & $4 / 14 / 2000$ & Treatment & & & 496 & & & & & 130 & 3.85 & 3080 & \\
\hline WVDEP & $5 / 15 / 2000$ & Treatment & & & 15 & & & & & 109 & 6.39 & 2970 & \\
\hline WVDEP & $6 / 15 / 2000$ & Treatment & & & 335 & & & & & 85.5 & 4.27 & 2380 & \\
\hline WVDEP & $7 / 18 / 2000$ & Treatment & & & 450 & & & & & 113 & 5.04 & 2490 & \\
\hline WVDEP & $8 / 15 / 2000$ & Treatment & & & 430 & & & & & 114 & 5.14 & 3010 & \\
\hline WVDEP & $9 / 15 / 2000$ & Treatment & & & 429 & & & & & 133 & 4.69 & 3630 & \\
\hline WVDEP & $10 / 15 / 2000$ & Treatment & & & 370 & & & & & 102 & 7.47 & 3210 & \\
\hline WVDEP & $11 / 15 / 2000$ & Treatment & & & 469 & & & & & 116 & 4.48 & 2790 & \\
\hline WVDEP & $12 / 15 / 2000$ & Treatment & & & 358 & & & & & 94.8 & 6.33 & 1300 & \\
\hline WVDEP & $1 / 15 / 2001$ & Treatment & & & 222 & & & & & 77.4 & 4.87 & 2210 & \\
\hline WVDEP & $2 / 13 / 2001$ & Treatment & & & 570 & & & & & 136 & 3.55 & 2390 & \\
\hline
\end{tabular}


Table E-1b, Omega Mine-pool, Treatment Inlet, Raw Chemical Data

\begin{tabular}{|c|c|c|c|c|c|c|c|c|c|c|c|c|c|}
\hline $\begin{array}{c}\text { Sampled } \\
\text { By }\end{array}$ & Date & Location & $\begin{array}{c}\mathrm{Fe} 3+ \\
\mathrm{mg} / \mathrm{L}\end{array}$ & $\begin{array}{c}\mathrm{Fe} 2+, \\
\mathrm{mg} / \mathrm{L}\end{array}$ & $\begin{array}{c}\text { Fe Total, } \\
\text { mg/L }\end{array}$ & $\begin{array}{c}\mathrm{Ca}, \\
\mathrm{mg} / \mathrm{L}\end{array}$ & $\begin{array}{l}\mathrm{Mg}, \\
\mathrm{mg} / \mathrm{L}\end{array}$ & $\begin{array}{c}\mathrm{Na}, \\
\mathrm{mg} / \mathrm{L}\end{array}$ & $\begin{array}{c}\mathrm{K}, \\
\mathrm{mg} / \mathrm{L}\end{array}$ & $\begin{array}{c}\mathrm{Al}, \\
\mathrm{mg} / \mathrm{L}\end{array}$ & $\begin{array}{c}\mathrm{Mn}, \\
\mathrm{mg} / \mathrm{L}\end{array}$ & $\begin{array}{l}\mathrm{SO} 4, \\
\mathrm{mg} / \mathrm{L}\end{array}$ & $\begin{array}{c}\mathrm{Cl}, \\
\mathrm{mg} / \mathrm{L}\end{array}$ \\
\hline WVDEP & $3 / 13 / 2001$ & Treatment & & & 331 & & & & & 88.4 & 3.02 & 1200 & \\
\hline WVDEP & $4 / 16 / 2001$ & Treatment & & & 298 & & & & & 74.2 & 2.69 & 674 & \\
\hline WVDEP & $5 / 15 / 2001$ & Treatment & & & 476 & & & & & 145 & 3.64 & 3340 & \\
\hline WVDEP & $6 / 18 / 2001$ & Treatment & & & 400 & & & & & 113 & 3.57 & 2420 & \\
\hline WVDEP & $7 / 15 / 2001$ & Treatment & & & 351 & & & & & 95.3 & 3.1 & 2480 & \\
\hline WVDEP & $8 / 15 / 2001$ & Treatment & & & 378 & & & & & 120 & 3.64 & 1480 & \\
\hline WVDEP & $9 / 14 / 2001$ & Treatment & & & 450 & & & & & 140 & 3.92 & 2100 & \\
\hline WVDEP & $10 / 15 / 2001$ & Treatment & & & 145 & & & & & 2.96 & 2.96 & 2677 & \\
\hline WVDEP & $11 / 15 / 2001$ & Treatment & & & 472.77 & & & & & 113.41 & 4.37 & 2715 & \\
\hline WVDEP & $12 / 14 / 2001$ & Treatment & & & 229.13 & & & & & 74.23 & 8.28 & 1993 & \\
\hline WVDEP & $1 / 16 / 2002$ & Treatment & & & 126.87 & & & & & 58.57 & 2.55 & 1279 & \\
\hline WVDEP & $2 / 14 / 2002$ & Treatment & & & 152.88 & & & & & 60.16 & 2.5 & 1530 & \\
\hline WVDEP & $3 / 15 / 2002$ & Treatment & & & 301.95 & & & & & 86.49 & 2.78 & 1928 & \\
\hline WVDEP & $4 / 15 / 2002$ & Treatment & & & 191.39 & & & & & 52.88 & 1.98 & 1128 & \\
\hline WVDEP & $5 / 15 / 2002$ & Treatment & & & 265.83 & & & & & 62.75 & 2.1 & 1774 & \\
\hline WVDEP & $6 / 18 / 2002$ & Treatment & & & 132.67 & & & & & 25.66 & 0.79 & 1985 & \\
\hline WVDEP & $7 / 16 / 2002$ & Treatment & & & & & & & & & & & \\
\hline WVDEP & 8/12/2002 & Treatment & & & 312.42 & & & & & 107.79 & 2.92 & 2455 & \\
\hline PERRY & $8 / 20 / 2002$ & Treatment & 60.27 & 241.10 & 301.37 & 247.04 & 77.52 & 15.4 & 13.64 & 100.84 & 3.806 & 2116.3 & 12.6 \\
\hline WVDEP & 9/16/2002 & Treatment & & & 92.9 & & & & & 106.35 & 3.71 & 2699 & \\
\hline WVDEP & 10/15/2002 & Treatment & & & 214.92 & & & & & 77.71 & 2.86 & 2501 & \\
\hline WVDEP & $11 / 15 / 2002$ & Treatment & & & 220.75 & & & & & 64.99 & 2.74 & 1731 & \\
\hline WVDEP & $12 / 15 / 2002$ & Treatment & & & 87.91 & & & & & 34.3 & 1.55 & 48 & \\
\hline WVDEP & $1 / 14 / 2003$ & Treatment & & & 384.44 & & & & & 107.62 & 2.39 & 2436 & \\
\hline WVDEP & $2 / 24 / 2003$ & Treatment & & & 154.23 & & & & & 48.62 & 3.42 & 1157 & \\
\hline WVDEP & $3 / 18 / 2003$ & Treatment & & & 578.53 & & & & & 128.12 & 2.18 & 2444 & \\
\hline WVDEP & 4/15/2003 & Treatment & & & 243.46 & & & & & 76.27 & 2.02 & 1790 & \\
\hline WVDEP & $5 / 20 / 2003$ & Treatment & & & 434.29 & & & & & 113.93 & 2.34 & 2279 & \\
\hline WVDEP & $6 / 17 / 2003$ & Treatment & & & 96.31 & & & & & 42.1 & 1 & 116 & \\
\hline WVDEP & $8 / 13 / 2003$ & Treatment & & & 281.15 & & & & & 82.57 & 2.09 & 1947 & \\
\hline PERRY & $8 / 28 / 2003$ & Treatment & 175.3 & 16 & 191 & 155 & 52.3 & 20.3 & 6.48 & 83.1 & 2.5 & 1404 & 5.8 \\
\hline WVDEP & $9 / 15 / 2003$ & Treatment & & & 182.29 & & & & & 74.79 & 2.16 & 1704 & \\
\hline WVDEP & $10 / 13 / 2003$ & Treatment & & & 285.45 & & & & & 89.1 & 1.89 & 2052 & \\
\hline WVDEP & $11 / 18 / 2003$ & Treatment & & & 0.23 & & & & & 52.21 & 0.03 & 1490 & \\
\hline WVDEP & $12 / 19 / 2003$ & Treatment & & & 160.24 & & & & & 48.4 & 1.29 & 1360 & \\
\hline WVDEP & $1 / 14 / 2004$ & Treatment & & & 384.26 & & & & & 93.25 & 2.03 & 2344 & \\
\hline WVDEP & $2 / 17 / 2004$ & Treatment & & & 338.31 & & & & & 71.26 & 1.95 & 2042 & \\
\hline
\end{tabular}


Table E-1b, Omega Mine-pool, Treatment Inlet, Raw Chemical Data

\begin{tabular}{|c|c|c|c|c|c|c|c|c|c|c|c|c|c|}
\hline $\begin{array}{c}\text { Sampled } \\
\text { By }\end{array}$ & Date & Location & $\begin{array}{c}\text { Fe3+, } \\
\mathrm{mg} / \mathrm{L}\end{array}$ & $\begin{array}{l}\text { Fe2+, } \\
\mathrm{mg} / \mathrm{L}\end{array}$ & $\begin{array}{c}\text { Fe Total, } \\
\mathrm{mg} / \mathrm{L}\end{array}$ & $\begin{array}{c}\mathrm{Ca}, \\
\mathrm{mg} / \mathrm{L}\end{array}$ & $\begin{array}{l}\mathrm{Mg}, \\
\mathrm{mg} / \mathrm{L}\end{array}$ & $\begin{array}{c}\mathrm{Na}, \\
\mathrm{mg} / \mathrm{L}\end{array}$ & $\begin{array}{c}\mathrm{K}, \\
\mathrm{mg} / \mathrm{L}\end{array}$ & $\begin{array}{c}\mathrm{Al}, \\
\mathrm{mg} / \mathrm{L}\end{array}$ & $\begin{array}{c}\mathrm{Mn}, \\
\mathrm{mg} / \mathrm{L}\end{array}$ & $\begin{array}{l}\mathrm{SO} 4, \\
\mathrm{mg} / \mathrm{L}\end{array}$ & $\begin{array}{c}\mathrm{Cl}, \\
\mathrm{mg} / \mathrm{L}\end{array}$ \\
\hline WVDEP & $3 / 23 / 2004$ & Treatment & & & 164.61 & & & & & 53.47 & 1.15 & 1306 & \\
\hline WVDEP & $4 / 13 / 2004$ & Treatment & & & 0.7 & & & & & 2.02 & 1.93 & 1028 & \\
\hline WVDEP & $5 / 18 / 2004$ & Treatment & & & 215.24 & & & & & 82.82 & 1.74 & 1587 & \\
\hline WVDEP & $6 / 15 / 2004$ & Treatment & & & 95.85 & & & & & 29.72 & 1.51 & 1622 & \\
\hline WVDEP & $7 / 12 / 2004$ & Treatment & & & 133.01 & & & & & 62.76 & 1.94 & 1503 & \\
\hline WVDEP & $8 / 9 / 2004$ & Treatment & & & 244.58 & & & & & 104.16 & 2.3 & 2193 & \\
\hline WVDEP & $9 / 14 / 2004$ & Treatment & & & 160.39 & & & & & 75.62 & 2.25 & 1822 & \\
\hline WVDEP & $10 / 18 / 2004$ & Treatment & & & 233.22 & & & & & 87.66 & 2.33 & 2085 & \\
\hline WVDEP & $11 / 16 / 2004$ & Treatment & & & 113.31 & & & & & 45.59 & 1.49 & 1152 & \\
\hline WVDEP & $12 / 15 / 2004$ & Treatment & & & 222.02 & & & & & 73.99 & 1.54 & 1558 & \\
\hline WVDEP & $1 / 10 / 2005$ & Treatment & & & 225.12 & & & & & 62.97 & 1.11 & 1146 & \\
\hline WVDEP & $2 / 15 / 2005$ & Treatment & & & 200.57 & & & & & 70.53 & 1.5 & 1393 & \\
\hline WVDEP & $3 / 15 / 2005$ & Treatment & & & 354.5 & & & & & 105.5 & 1.94 & 1793 & \\
\hline PERRY & $3 / 22 / 2005$ & Treatment & 267.1 & 105.5 & 372 & 210.75 & 61.03 & 18.1 & 13.28 & 115.91 & 2.54 & 2171.1 & 44 \\
\hline WVDEP & $4 / 11 / 2005$ & Treatment & & & 229.7 & & & & & 71.24 & 1.9 & 2312 & \\
\hline WVDEP & $5 / 24 / 2005$ & Treatment & & & 222.04 & & & & & 89 & 1.97 & 1866 & \\
\hline WVDEP & $6 / 14 / 2005$ & Treatment & & & 234.61 & & & & & 80.76 & 1.64 & 2115 & \\
\hline WVDEP & $7 / 11 / 2005$ & Treatment & & & 354.87 & & & & & 134.45 & 2.85 & 2693 & \\
\hline WVDEP & $8 / 15 / 2005$ & Treatment & & & 292.35 & & & & & 97.17 & 2.7 & 2685 & \\
\hline WVDEP & $9 / 14 / 2005$ & Treatment & & & 314.2 & & & & & 136.88 & 2.8 & 2766 & \\
\hline WVDEP & $10 / 12 / 2005$ & Treatment & & & 252.95 & & & & & 119 & 2.71 & 2791 & \\
\hline WVDEP & $11 / 15 / 2005$ & Treatment & & & 205.72 & & & & & 80.24 & 2.29 & 2033 & \\
\hline WVDEP & $12 / 13 / 2005$ & Treatment & & & 286.03 & & & & & 107.19 & 1.83 & 2455 & \\
\hline WVDEP & $1 / 10 / 2006$ & Treatment & & & 382.03 & & & & & 106.41 & 2.38 & 2277 & \\
\hline WVDEP & $2 / 14 / 2006$ & Treatment & & & 325.29 & & & & & 86.72 & 1.92 & 2417 & \\
\hline WVDEP & $3 / 13 / 2006$ & Treatment & & & 189.97 & & & & & 60.16 & 1.38 & 1590 & \\
\hline WVDEP & $4 / 17 / 2006$ & Treatment & & & 207.22 & & & & & 74.42 & 1.65 & 1720 & \\
\hline WVDEP & $5 / 15 / 2006$ & Treatment & & & 159.75 & & & & & 58.01 & 1.66 & 1571 & \\
\hline PERRY & $5 / 24 / 2006$ & Treatment & 130 & 123.3 & 253.3 & 144.8 & 45.1 & 15 & 6.6 & 78.52 & 1.89 & 1537.5 & 50 \\
\hline WVDEP & $6 / 12 / 2006$ & Treatment & & & 260.63 & & & & & 93.58 & 1.78 & 1952 & \\
\hline WVDEP & $7 / 11 / 2006$ & Treatment & & & 224.21 & & & & & 110.21 & 2.01 & 1920 & \\
\hline WVDEP & $8 / 14 / 2006$ & Treatment & & & 308.17 & & & & & 127.08 & 2.68 & 2823 & \\
\hline WVDEP & $9 / 12 / 2006$ & Treatment & & & 258.08 & & & & & 136.25 & 2.72 & 2380 & \\
\hline WVDEP & 10/17/2006 & Treatment & & & 187.43 & & & & & 70.49 & 1.98 & 1882 & \\
\hline WVDEP & $11 / 13 / 2006$ & Treatment & & & 153.34 & & & & & 65.83 & 1.4 & 1452 & \\
\hline WVDEP & $12 / 13 / 2006$ & Treatment & & & 360.95 & & & & & 112.61 & 2.6 & 2566 & \\
\hline WVDEP & $1 / 15 / 2007$ & Treatment & & & 95.83 & & & & & 46.1 & 0.95 & 995 & \\
\hline
\end{tabular}


Table E-1b, Omega Mine-pool, Treatment Inlet, Raw Chemical Data

\begin{tabular}{|c|c|c|c|c|c|c|c|c|c|c|c|c|c|}
\hline $\begin{array}{c}\text { Sampled } \\
\text { By }\end{array}$ & Date & Location & $\begin{array}{l}\mathrm{Fe3+}, \\
\mathrm{mg} / \mathrm{L}\end{array}$ & $\begin{array}{l}\mathrm{Fe} 2+, \\
\mathrm{mg} / \mathrm{L}\end{array}$ & $\begin{array}{l}\text { Fe Total, } \\
\text { mg/L }\end{array}$ & $\begin{array}{c}\mathrm{Ca}, \\
\mathrm{mg} / \mathrm{L}\end{array}$ & $\begin{array}{l}\mathrm{Mg}, \\
\mathrm{mg} / \mathrm{L}\end{array}$ & $\begin{array}{l}\mathrm{Na}, \\
\mathrm{mg} / \mathrm{L}\end{array}$ & $\begin{array}{c}\mathrm{K}, \\
\mathrm{mg} / \mathrm{L}\end{array}$ & $\begin{array}{c}\mathrm{Al}, \\
\mathrm{mg} / \mathrm{L}\end{array}$ & $\begin{array}{l}\mathrm{Mn}, \\
\mathrm{mg} / \mathrm{L}\end{array}$ & $\begin{array}{l}\mathrm{SO} 4, \\
\mathrm{mg} / \mathrm{L}\end{array}$ & $\begin{array}{c}\mathrm{Cl}, \\
\mathrm{mg} / \mathrm{L}\end{array}$ \\
\hline WVDEP & $2 / 14 / 2007$ & Treatment & & & 241.07 & & & & & 92.6 & 1.99 & 1920 & \\
\hline WVDEP & $3 / 14 / 2007$ & Treatment & & & 248.73 & & & & & 71.1 & 1.31 & 1739 & \\
\hline WVDEP & $4 / 18 / 2007$ & Treatment & & & 111.98 & & & & & 41.96 & 0.9 & 884 & \\
\hline WVDEP & $5 / 16 / 2007$ & Treatment & & & 185.56 & & & & & 54.35 & 1.63 & 2020 & \\
\hline PERRY & $5 / 3 / 2007$ & Treatment & 185.6 & 85.6 & 270.6 & 164 & 43.16 & 15.55 & 10.38 & 79.02 & 1.724 & 1679 & \\
\hline WVDEP & $6 / 14 / 2007$ & Treatment & & & 254.73 & & & & & 91.45 & 2.34 & 2128 & \\
\hline PERRY & $7 / 17 / 2007$ & Treatment & & & 285.24 & & & & & 106.18 & 2.34 & 2477 & \\
\hline WVDEP & $8 / 13 / 2007$ & Treatment & & & 259.3 & 181.5 & 61.48 & 34.55 & & 111.3 & 2.942 & 2021 & 70 \\
\hline WVDEP & $8 / 15 / 2007$ & Treatment & & & 266.69 & & & & & 114.36 & 2.55 & 2112 & \\
\hline WVDEP & 9/12/2007 & Treatment & & & 214.5 & & & & & 98.19 & 1.98 & 2242 & \\
\hline WVDEP & $10 / 10 / 2007$ & Treatment & & & 252.72 & & & & & 103.02 & 2.56 & 2290 & \\
\hline WVDEP & $11 / 26 / 2007$ & Treatment & & & 243.61 & & & & & 115.92 & 2.62 & 2307 & \\
\hline
\end{tabular}


Table E-1c, Omega Mine-pool, PM-21 Spring, Raw Chemical Data

\begin{tabular}{|c|c|c|c|c|c|c|c|c|c|}
\hline Sampled By & Date & Location & Flow gpm & $\mathrm{pH}$ & $\begin{array}{c}\text { Sp. } \\
\text { Conductance } \\
\text { umhos/cm }\end{array}$ & TDS, mg/L & Temp, C & $\begin{array}{l}\text { Acid load, } \\
\text { lbs/day } \\
\text { CaCO3 Eq }\end{array}$ & $\begin{array}{l}\text { Calc Total } \\
\text { Acidity } \\
\text { CaCO3 Eq }\end{array}$ \\
\hline DOE & 11/15/1991 & PM-21 & & 2.88 & & 4767 & & 0.0 & 530.2 \\
\hline DOE & $2 / 11 / 1993$ & PM-21 & & 3.06 & & 3288 & & 0.0 & 449.2 \\
\hline DOE & $3 / 3 / 1993$ & PM-21 & 198.6 & 2.98 & & 3035 & & 1060.7 & 444.3 \\
\hline DOE & 3/18/1993 & PM-21 & 32.6 & 3.09 & & 1638 & & 122.5 & 312.3 \\
\hline DOE & 4/2/1993 & PM-21 & 27.2 & 2.98 & & 2148 & & 153.7 & 470.2 \\
\hline DOE & 4/14/1993 & PM-21 & 39.9 & 2.95 & & 2808 & & 278.0 & 579.8 \\
\hline DOE & 4/29/1993 & PM-21 & 77.5 & 2.94 & & 2243 & & 427.4 & 459.0 \\
\hline DOE & $5 / 20 / 1993$ & PM-21 & 31.6 & 3.00 & & 3587 & & 273.2 & 718.4 \\
\hline DOE & $6 / 3 / 1993$ & PM-21 & 35.4 & 3.00 & & 4128 & & 334.6 & 787.0 \\
\hline DOE & 6/10/1993 & PM-21 & 24.0 & 2.98 & & 3892 & & 197.0 & 682.3 \\
\hline DOE & $6 / 23 / 1993$ & PM-21 & 22.8 & 2.99 & & 3972 & & 171.4 & 626.4 \\
\hline DOE & $7 / 8 / 1993$ & PM-21 & 17.2 & 2.97 & & 4026 & & 126.6 & 613.6 \\
\hline DOE & 7/22/1993 & PM-21 & 26.2 & 2.97 & & 4374 & & 211.5 & 671.4 \\
\hline DOE & $8 / 11 / 1993$ & PM-21 & 18.0 & 2.96 & & 4427 & & 129.3 & 599.1 \\
\hline DOE & 9/10/1993 & PM-21 & 2.9 & 2.94 & & 4405 & & 19.4 & 561.0 \\
\hline DOE & $10 / 7 / 1993$ & PM-21 & 14.8 & 2.99 & & 3899 & & 77.0 & 431.6 \\
\hline DOE & $10 / 25 / 1993$ & PM-21 & 25.5 & 3.04 & & 3875 & & 131.1 & 427.1 \\
\hline DOE & $11 / 10 / 1993$ & PM-21 & 25.4 & 2.95 & & 3525 & & 127.6 & 417.7 \\
\hline DOE & 12/7/1993 & PM-21 & 4.9 & 3.13 & & 2107 & & 18.8 & 319.3 \\
\hline DOE & $12 / 23 / 1993$ & PM-21 & 29.5 & 3.08 & & 2709 & & 156.8 & 442.6 \\
\hline DOE & $1 / 28 / 1994$ & PM-21 & 84.6 & 3.14 & & 2237 & & 416.9 & 410.0 \\
\hline DOE & $5 / 5 / 1994$ & PM-21 & 14.7 & 3.09 & & 2365 & & 77.3 & 436.1 \\
\hline DOE & $6 / 10 / 1994$ & PM-21 & 29.0 & 3.14 & & 3399 & & 217.2 & 622.9 \\
\hline DOE & $7 / 6 / 1994$ & PM-21 & 36.5 & 3.12 & & 3849 & & 268.7 & 612.2 \\
\hline DOE & $8 / 3 / 1994$ & PM-21 & 19.5 & 2.99 & & 3688 & & 130.9 & 558.3 \\
\hline DOE & 9/1/1994 & PM-21 & 21.4 & 2.96 & & 3216 & & 123.6 & 480.8 \\
\hline DOE & $10 / 7 / 1994$ & PM-21 & 15.6 & 3.35 & & 3689 & & 108.5 & 576.9 \\
\hline DOE & $11 / 16 / 1994$ & PM-21 & 8.5 & 3.05 & & 3986 & & 57.6 & 560.7 \\
\hline DOE & $12 / 14 / 1994$ & PM-21 & 15.8 & 3.16 & & 3952 & & 100.6 & 530.3 \\
\hline DOE & 1/10/1995 & PM-21 & 19.6 & 3.03 & & 3538 & & 153.1 & 649.5 \\
\hline DOE & $2 / 3 / 1995$ & PM-21 & 10.6 & 3.01 & & 3161 & & 91.4 & 716.9 \\
\hline DOE & $3 / 2 / 1995$ & PM-21 & 9.9 & 3.33 & & 2807 & & 68.6 & 576.2 \\
\hline DOE & 4/7/1995 & PM-21 & 11.7 & 3.1 & & 3064 & & 79.2 & 561.8 \\
\hline DOE & $5 / 10 / 1995$ & PM-21 & 25.4 & 3.10 & & 2969 & & 178.9 & 585.2 \\
\hline
\end{tabular}


Table E-1c, Omega Mine-pool, PM-21 Spring, Raw Chemical Data

\begin{tabular}{|c|c|c|c|c|c|c|c|c|c|}
\hline Sampled By & Date & Location & Flow gpm & $\mathrm{pH}$ & $\begin{array}{c}\text { Sp. } \\
\text { Conductance } \\
\text { umhos/cm }\end{array}$ & TDS, mg/L & Temp, C & $\begin{array}{l}\text { Acid load, } \\
\text { lbs/day } \\
\text { CaCO3 Eq }\end{array}$ & $\begin{array}{l}\text { Calc Total } \\
\text { Acidity } \\
\text { CaCO3 Eq }\end{array}$ \\
\hline DOE & 6/6/1995 & PM-21 & 16.0 & 3.09 & & 2733 & & 87.5 & 453.4 \\
\hline DOE & $7 / 13 / 1995$ & PM-21 & 9.5 & 3.02 & & 3564 & & 62.9 & 549.9 \\
\hline DOE & 8/3/1995 & PM-21 & 11.5 & 2.98 & & 4011 & & 91.0 & 659.2 \\
\hline DOE & 9/7/1995 & PM-21 & 9.8 & 3.14 & & 4391 & & 80.7 & 683.6 \\
\hline DOE & $10 / 12 / 1995$ & PM-21 & 7.3 & 3.3 & & 4204 & & 56.9 & 647.1 \\
\hline DOE & 11/22/1995 & PM-21 & 10.0 & 3.22 & & 4099 & & 65.8 & 546.8 \\
\hline DOE & 1/5/1996 & PM-21 & 13.4 & 3.32 & & 3124 & & 85.4 & 528.8 \\
\hline WVDEP & $1 / 16 / 1996$ & PM-21 & 9.9 & 3.2 & 6790 & 4066 & 8.9 & 90.6 & 764.6 \\
\hline WVDEP & $2 / 15 / 1996$ & PM-21 & 17.0 & 2.9 & 4550 & 2550 & 13.3 & 64.2 & 313.8 \\
\hline DOE & $2 / 21 / 1996$ & PM-21 & 26.7 & 3.28 & & 1797 & & 134.6 & 418.7 \\
\hline WVDEP & 3/1/1996 & PM-21 & 20.2 & 3 & 2700 & 1662 & 8.9 & 49.8 & 205.6 \\
\hline WVDEP & 3/15/1996 & PM-21 & 74.8 & 2.9 & 3110 & 1819 & 11.1 & 200.7 & 223.2 \\
\hline DOE & $3 / 18 / 1996$ & PM-21 & 85.9 & 3.35 & & 1550 & & 296.6 & 287.4 \\
\hline WVDEP & $3 / 28 / 1996$ & PM-21 & 197.1 & & & & 11.1 & 0.0 & \\
\hline DOE & $4 / 26 / 1996$ & PM-21 & 28.8 & 3.02 & & 2146 & & 120.4 & 348.2 \\
\hline WVDEP & $4 / 29 / 1996$ & PM-21 & 35.8 & 2.9 & 4650 & 2505 & 13.3 & 76.0 & 176.5 \\
\hline WVDEP & $5 / 15 / 1996$ & PM-21 & 39.9 & 3 & 3480 & 1670 & 11.1 & 131.0 & 273.4 \\
\hline WVDEP & $5 / 31 / 1996$ & PM-21 & 61.4 & 2.9 & 3340 & 1504 & 13.3 & 208.3 & 282.3 \\
\hline DOE & $6 / 7 / 1996$ & PM-21 & 28.3 & 3.00 & & 2363 & & 144.4 & 425.3 \\
\hline WVDEP & $6 / 14 / 1996$ & PM-21 & 26.0 & 2.8 & 5560 & 2539 & 13.3 & 173.7 & 556.3 \\
\hline WVDEP & 6/28/1996 & PM-21 & 25.1 & 2.8 & 6360 & 3550 & 14.4 & 111.2 & 368.7 \\
\hline WVDEP & $7 / 15 / 1996$ & PM-21 & 22.0 & 2.8 & 6960 & 3926 & 14.4 & 164.0 & 621.6 \\
\hline DOE & $7 / 23 / 1996$ & PM-21 & 30.1 & 2.96 & & 2643 & & 176.6 & 488.6 \\
\hline WVDEP & 7/30/1996 & PM-21 & 23.7 & 2.8 & 6390 & 3536 & 14.4 & 162.0 & 567.7 \\
\hline WVDEP & $8 / 14 / 1996$ & PM-21 & 23.7 & 2.9 & 6360 & 3709 & 11.1 & 189.6 & 664.5 \\
\hline DOE & $8 / 28 / 1996$ & PM-21 & 16.9 & 3.07 & & 3675 & & 133.8 & 658.8 \\
\hline WVDEP & $8 / 31 / 1996$ & PM-21 & 26.0 & 2.9 & 9300 & 3774 & 12.2 & 177.7 & 569.0 \\
\hline WVDEP & $9 / 16 / 1996$ & PM-21 & 19.7 & 2.8 & 6490 & 4098 & 12.2 & 165.0 & 696.7 \\
\hline WVDEP & 9/30/1996 & PM-21 & 20.6 & 3 & 6600 & 3718 & 13.3 & 137.1 & 553.2 \\
\hline WVDEP & 10/14/1996 & PM-21 & 22.9 & 2.8 & 6220 & 2949 & 14.4 & 186.5 & 679.1 \\
\hline DOE & $10 / 16 / 1996$ & PM-21 & 19.0 & 3.00 & & 3720 & & 149.7 & 655.1 \\
\hline WVDEP & $10 / 30 / 1996$ & PM-21 & 309.1 & 2.7 & 5400 & 2874 & 14.4 & 2271.3 & 611.3 \\
\hline WVDEP & $11 / 15 / 1996$ & PM-21 & 37.6 & 2.9 & 5060 & 2342 & 11.1 & 185.9 & 411.0 \\
\hline DOE & $11 / 26 / 1996$ & PM-21 & 22.0 & 2.97 & & 2787 & & 153.2 & 579.9 \\
\hline DOE & $12 / 13 / 1996$ & PM-21 & 37.0 & 3.04 & & 2136 & & 190.5 & 428.8 \\
\hline WVDEP & $12 / 15 / 1996$ & PM-21 & 42.6 & 3 & 4350 & 2255 & 11.1 & 200.5 & 391.9 \\
\hline
\end{tabular}


Table E-1c, Omega Mine-pool, PM-21 Spring, Raw Chemical Data

\begin{tabular}{|c|c|c|c|c|c|c|c|c|c|}
\hline Sampled By & Date & Location & Flow gpm & $\mathrm{pH}$ & $\begin{array}{c}\text { Sp. } \\
\text { Conductance } \\
\text { umhos } / \mathrm{cm}\end{array}$ & TDS, mg/L & Temp, C & $\begin{array}{l}\text { Acid load, } \\
\text { lbs/day } \\
\text { CaCO3 Eq }\end{array}$ & $\begin{array}{l}\text { Calc Total } \\
\text { Acidity } \\
\text { CaCO3 Eq }\end{array}$ \\
\hline WVDEP & $1 / 14 / 1997$ & PM-21 & 31.8 & 3.1 & 459 & 2347 & 10 & 135.7 & 354.9 \\
\hline DOE & $1 / 28 / 1997$ & PM-21 & 21.1 & 3 & & 1790 & & 88.7 & 349.8 \\
\hline DOE & $2 / 21 / 1997$ & PM-21 & 22.3 & 3.11 & & 2200 & & 113.1 & 422.1 \\
\hline WVDEP & $3 / 17 / 1997$ & PM-21 & 36.7 & 3 & 2800 & 1999 & 12.2 & 157.7 & 357.1 \\
\hline DOE & $3 / 26 / 1997$ & PM-21 & 85.6 & 3.25 & & 1484 & & 304.9 & 296.3 \\
\hline WVDEP & 4/14/1997 & PM-21 & 17.9 & 2.8 & 2980 & 2167 & 11.1 & 100.3 & 465.6 \\
\hline WVDEP & $5 / 14 / 1997$ & PM-21 & 14.8 & 2.8 & 5310 & 2596 & 14.4 & 114.4 & 643.9 \\
\hline DOE & $5 / 20 / 1997$ & PM-21 & 97.4 & 3.12 & & 1657 & & 442.1 & 377.8 \\
\hline WVDEP & $6 / 16 / 1997$ & PM-21 & 13.9 & 2.7 & 3320 & 2676 & 15.6 & 115.2 & 690.0 \\
\hline DOE & $7 / 10 / 1997$ & PM-21 & 10.6 & 2.97 & & 2966 & & 90.7 & 711.9 \\
\hline WVDEP & $7 / 16 / 1997$ & PM-21 & 7.6 & 2.8 & 3920 & 3171 & 20 & 66.6 & 727.7 \\
\hline WVDEP & $8 / 17 / 1997$ & PM-21 & 6.7 & 2.8 & 6110 & 3498 & 15.6 & 63.7 & 789.0 \\
\hline DOE & 9/10/1997 & PM-21 & 5.8 & 2.91 & & 3392 & & 56.9 & 816.0 \\
\hline WVDEP & 9/15/1997 & PM-21 & 6.7 & 2.8 & 4300 & 3543 & 15 & 39.2 & 485.6 \\
\hline WVDEP & $10 / 15 / 1997$ & PM-21 & 2.7 & 2.9 & 6400 & 3591 & & 29.8 & 921.6 \\
\hline DOE & $11 / 5 / 1997$ & PM-21 & 4.5 & 2.99 & & 3658 & & 51.3 & 957.9 \\
\hline WVDEP & $11 / 14 / 1997$ & PM-21 & 49.7 & 2.9 & 3330 & 2403 & & 213.8 & 357.7 \\
\hline WVDEP & 12/15/1997 & PM-21 & 13.9 & 2.8 & 2990 & 2357 & & 130.8 & 783.2 \\
\hline DOE & $1 / 12 / 1998$ & PM-21 & 30.3 & 2.93 & & 1770 & & 171.5 & 471.5 \\
\hline WVDEP & $1 / 16 / 1998$ & PM-21 & 179.2 & 2.8 & 4540 & 2372 & & 1440.4 & 668.7 \\
\hline DOE & 2/9/1998 & PM-21 & 27.3 & 2.96 & & 2500 & & 246.9 & 752.6 \\
\hline WVDEP & $2 / 15 / 1998$ & PM-21 & 15.7 & 2.9 & 3650 & 2436 & & 122.5 & 650.2 \\
\hline WVDEP & $3 / 15 / 1998$ & PM-21 & 33.6 & 2.8 & 4530 & 2128 & & 269.2 & 666.5 \\
\hline DOE & 3/26/1998 & PM-21 & 52.2 & 3.00 & & 1618 & & 317.8 & 506.7 \\
\hline WVDEP & $4 / 15 / 1998$ & PM-21 & 19.7 & 2.7 & 3050 & 2389 & & 185.4 & 782.5 \\
\hline DOE & $4 / 29 / 1998$ & PM-21 & 35.3 & 2.96 & & 1852 & & 253.1 & 597.0 \\
\hline WVDEP & $5 / 14 / 1998$ & PM-21 & 22.4 & 2.8 & 4240 & 2235 & & 184.9 & 686.8 \\
\hline DOE & $5 / 28 / 1998$ & PM-21 & 20.0 & 3.15 & & 2433 & & 179.8 & 746.9 \\
\hline WVDEP & $6 / 15 / 1998$ & PM-21 & 17.9 & 2.7 & 5330 & 3010 & & 177.5 & 824.1 \\
\hline DOE & $6 / 25 / 1998$ & PM-21 & 18.8 & 2.95 & & 2308 & & 140.8 & 624.3 \\
\hline WVDEP & $7 / 15 / 1998$ & PM-21 & 17.9 & 2.8 & 5660 & 3394 & & 152.5 & 707.8 \\
\hline DOE & $8 / 5 / 1998$ & PM-21 & 14.3 & 2.95 & & 3538 & & 155.6 & 904.6 \\
\hline WVDEP & 8/13/1998 & PM-21 & 12.5 & 2.8 & 6480 & 3315 & & 142.4 & 944.4 \\
\hline DOE & 9/3/1998 & PM-21 & 11.8 & 2.96 & & 3429 & & 124.3 & 875.4 \\
\hline WVDEP & 9/15/1998 & PM-21 & 9.9 & 2.8 & 8320 & 3577 & & 106.7 & 900.7 \\
\hline WVDEP & $10 / 15 / 1998$ & PM-21 & 5.8 & 2.8 & 6580 & 3646 & & 56.7 & 810.5 \\
\hline
\end{tabular}


Table E-1c, Omega Mine-pool, PM-21 Spring, Raw Chemical Data

\begin{tabular}{|c|c|c|c|c|c|c|c|c|c|}
\hline Sampled By & Date & Location & Flow gpm & $\mathrm{pH}$ & $\begin{array}{c}\text { Sp. } \\
\text { Conductance } \\
\text { umhos } / \mathrm{cm}\end{array}$ & TDS, mg/L & Temp, C & $\begin{array}{l}\text { Acid load, } \\
\text { lbs/day } \\
\text { CaCO3 Eq }\end{array}$ & $\begin{array}{l}\text { Calc Total } \\
\text { Acidity } \\
\text { CaCO3 Eq }\end{array}$ \\
\hline DOE & 10/29/1998 & PM-21 & 5.4 & 2.96 & & 3979 & & 63.4 & 969.3 \\
\hline WVDEP & $11 / 15 / 1998$ & PM-21 & 3.6 & 2.8 & 7540 & 3752 & & 42.0 & 976.2 \\
\hline DOE & $12 / 10 / 1998$ & PM-21 & 3.7 & 2.96 & & 4003 & & 44.2 & 999.3 \\
\hline WVDEP & $12 / 15 / 1998$ & PM-21 & 2.7 & 2.8 & 7330 & 3998 & & 30.5 & 942.3 \\
\hline WVDEP & $1 / 17 / 1999$ & PM-21 & 26.9 & 3 & 4110 & 1712 & & 158.8 & 491.6 \\
\hline WVDEP & 2/14/1999 & PM-21 & 25.5 & 2.8 & 6220 & 3272 & & 353.6 & 1151.8 \\
\hline $\mathrm{DOE}$ & $2 / 18 / 1999$ & PM-21 & 25.1 & 3.03 & & 3537 & & 371.9 & 1234.3 \\
\hline WVDEP & $3 / 14 / 1999$ & PM-21 & 30.9 & 2.9 & 4800 & 2546 & & 320.8 & 863.4 \\
\hline DOE & 3/30/1999 & PM-21 & 28.4 & 3.09 & & 2693 & & 314.3 & 920.0 \\
\hline WVDEP & $4 / 13 / 1999$ & PM-21 & 33.2 & 2.8 & 5390 & 3113 & & 383.5 & 962.4 \\
\hline DOE & $4 / 29 / 1999$ & PM-21 & 15.5 & 2.84 & & 2835 & & 179.6 & 965.2 \\
\hline WVDEP & $5 / 17 / 1999$ & PM-21 & 18.8 & 2.7 & 6140 & 3254 & & 259.4 & 1146.6 \\
\hline DOE & $5 / 26 / 1999$ & PM-21 & 16.0 & 2.62 & & 3142 & & 211.4 & 1098.8 \\
\hline WVDEP & $6 / 14 / 1999$ & PM-21 & 9.0 & 2.7 & 6770 & 3536 & & 120.4 & 1117.6 \\
\hline DOE & $6 / 29 / 1999$ & PM-21 & 5.4 & 2.78 & & 3479 & & 70.1 & 1085.4 \\
\hline WVDEP & $7 / 14 / 1999$ & PM-21 & 4.0 & 2.8 & 6510 & 4221 & & 50.6 & 1044.6 \\
\hline DOE & $7 / 27 / 1999$ & PM-21 & 3.1 & 2.99 & & 3743 & & 41.4 & 1101.3 \\
\hline WVDEP & 8/14/1999 & PM-21 & 3.1 & 2.8 & 6630 & 3937 & & 47.7 & 1265.0 \\
\hline DEO & $8 / 26 / 1999$ & PM-21 & 2.7 & 2.90 & & 3955 & & 38.2 & 1173.9 \\
\hline WVDEP & $9 / 14 / 1999$ & PM-21 & 1.8 & 2.8 & 8480 & 4411 & & 24.2 & 1122.9 \\
\hline DOE & 9/29/1999 & PM-21 & 2.2 & 2.81 & & 3906 & & 30.3 & 1170.3 \\
\hline WVDEP & $10 / 15 / 1999$ & PM-21 & 1.8 & 2.8 & 7580 & 4036 & & 24.6 & 1142.9 \\
\hline DOE & $10 / 29 / 1999$ & PM-21 & 1.6 & 1.57 & & 6220 & & 48.5 & 2559.5 \\
\hline WVDEP & $11 / 15 / 1999$ & PM-21 & 0.9 & 2.8 & 8150 & 4471 & & 14.1 & 1303.1 \\
\hline DOE & 12/7/1999 & PM-21 & 5.2 & 2.67 & & 3988 & & 81.9 & 1301.4 \\
\hline DOE & $12 / 15 / 1999$ & PM-21 & 7.2 & 2.8 & 6290 & 3452 & & 105.3 & 1221.9 \\
\hline WVDEP & $1 / 17 / 2000$ & PM-21 & 8.0 & 2.8 & 6940 & 4471 & & 157.8 & 1636.6 \\
\hline WVDEP & $2 / 8 / 2000$ & PM-21 & 6.0 & 2.8 & 6990 & 4590 & & 108.8 & 1508.9 \\
\hline WVDEP & $3 / 15 / 2000$ & PM-21 & 30.0 & 2.7 & 5630 & 2958 & & 474.8 & 1315.7 \\
\hline WVDEP & $4 / 14 / 2000$ & PM-21 & 46.0 & 2.8 & 4220 & 2447 & & 468.1 & 846.4 \\
\hline WVDEP & $5 / 15 / 2000$ & PM-21 & 25.0 & 2.8 & 5010 & 2977 & & 319.4 & 1063.0 \\
\hline WVDEP & $6 / 15 / 2000$ & PM-21 & 23.0 & 2.7 & 4780 & 2640 & & 297.9 & 1078.6 \\
\hline WVDEP & $7 / 18 / 2000$ & PM-21 & 25.0 & 2.8 & 4990 & 2578 & & 326.5 & 1086.5 \\
\hline WVDEP & $8 / 15 / 2000$ & PM-21 & 19.0 & 2.8 & 5340 & 3453 & & 274.1 & 1200.0 \\
\hline WVDEP & $9 / 15 / 2000$ & PM-21 & 10.0 & 2.8 & 5140 & 3549 & & 161.7 & 1346.3 \\
\hline WVDEP & $10 / 15 / 2000$ & PM-21 & 7.0 & 2.8 & 4910 & 3218 & & 111.7 & 1330.0 \\
\hline
\end{tabular}


Table E-1c, Omega Mine-pool, PM-21 Spring, Raw Chemical Data

\begin{tabular}{|c|c|c|c|c|c|c|c|c|c|}
\hline Sampled By & Date & Location & Flow gpm & $\mathrm{pH}$ & $\begin{array}{c}\text { Sp. } \\
\text { Conductance } \\
\text { umhos/cm }\end{array}$ & TDS, mg/L & Temp, C & $\begin{array}{l}\text { Acid load, } \\
\text { lbs/day } \\
\text { CaCO3 Eq }\end{array}$ & $\begin{array}{c}\text { Calc Total } \\
\text { Acidity } \\
\text { CaCO3 Eq }\end{array}$ \\
\hline WVDEP & $11 / 15 / 2000$ & PM-21 & 4.0 & 2.8 & 5910 & 3380 & & 94.6 & 1973.5 \\
\hline WVDEP & $12 / 15 / 2000$ & PM-21 & 4.0 & 2.7 & 6040 & 3877 & & 64.4 & 1342.4 \\
\hline WVDEP & $1 / 15 / 2001$ & PM-21 & 7.0 & 2.7 & 5960 & 3750 & & 105.7 & 1257.7 \\
\hline WVDEP & $2 / 13 / 2001$ & PM-21 & 20.0 & 2.8 & 5010 & 2814 & & 336.0 & 1399.2 \\
\hline WVDEP & $3 / 13 / 2001$ & PM-21 & 37.0 & 2.8 & 3710 & 2334 & & 418.4 & 940.8 \\
\hline WVDEP & 4/16/2001 & PM-21 & 59.0 & 2.9 & 3370 & 1786 & & 560.8 & 790.7 \\
\hline WVDEP & $5 / 15 / 2001$ & PM-21 & 19.0 & 2.8 & 4940 & 3476 & & 313.6 & 1373.1 \\
\hline WVDEP & $6 / 18 / 2001$ & PM-21 & 18.0 & 2.8 & 4640 & 3105 & & 266.2 & 1229.4 \\
\hline WVDEP & $7 / 15 / 2001$ & PM-21 & 19.0 & 2.8 & 4140 & 2687 & & 225.1 & 985.4 \\
\hline WVDEP & $8 / 15 / 2001$ & PM-21 & 12.0 & 2.6 & 5670 & 3590 & & 206.6 & 1430.8 \\
\hline WVDEP & $9 / 14 / 2001$ & PM-21 & 7.0 & 2.7 & 5020 & 3585 & & 123.3 & 1468.0 \\
\hline WVDEP & $10 / 15 / 2001$ & PM-21 & 5.8 & 2.6 & 3760 & 4920 & 10.5 & 100.6 & 1438.5 \\
\hline WVDEP & $11 / 15 / 2001$ & PM-21 & 4.5 & 2.7 & 3110 & 4168 & 11.1 & 72.3 & 1342.3 \\
\hline WVDEP & $12 / 14 / 2001$ & PM-21 & 4.0 & 2.9 & 3530 & 4052 & 10.5 & 47.2 & 985.0 \\
\hline WVDEP & 1/16/2002 & PM-21 & 15.7 & 3 & 1604 & 2220 & 23.4 & 141.5 & 750.8 \\
\hline WVDEP & $2 / 14 / 2002$ & PM-21 & 19.0 & 2.9 & 2370 & 2792 & 11.1 & 195.8 & 859.6 \\
\hline WVDEP & $3 / 14 / 2002$ & PM-21 & 14.8 & 2.9 & 2500 & 3096 & 14.4 & 13.8 & 77.8 \\
\hline WVDEP & $5 / 15 / 2002$ & PM-21 & 20.6 & 3 & 2600 & 2436 & 12.2 & 194.5 & 785.3 \\
\hline WVDEP & $6 / 18 / 2002$ & PM-21 & 20.0 & 3.1 & 1978 & 2332 & 14.4 & 61.4 & 255.6 \\
\hline WVDEP & $7 / 16 / 2002$ & PM-21 & 0.0 & & & & & & \\
\hline WVDEP & $8 / 12 / 2002$ & PM-21 & 0.0 & & & & & & \\
\hline PERRY & $8 / 20 / 2002$ & PM-21 & 7.1 & 2.87 & 3150 & 3664 & 11.8 & 108.6 & 1279.9 \\
\hline WVDEP & 9/16/2002 & PM-21 & 0.0 & & & & & & \\
\hline WVDEP & $10 / 15 / 2002$ & PM-21 & 2.7 & 2.9 & 3280 & 4024 & 14.4 & 33.2 & 1028.1 \\
\hline WVDEP & $1 / 14 / 2003$ & PM-21 & 0.0 & & & & & & \\
\hline WVDEP & $2 / 24 / 2003$ & PM-21 & 39.9 & 3.1 & 1661 & 1448 & 5.6 & 233.0 & 485.5 \\
\hline WVDEP & 4/15/2003 & PM-21 & 0.0 & & & & & & \\
\hline WVDEP & $4 / 15 / 2003$ & PM-21 & 0.0 & & & & & & \\
\hline WVDEP & $5 / 20 / 2003$ & PM-21 & 0.0 & & & & & & \\
\hline WVDEP & $6 / 17 / 2003$ & PM-21 & 98.6 & 2.96 & 1288 & 2840 & 15.56 & 372.7 & 314.6 \\
\hline WVDEP & $8 / 13 / 2003$ & PM-21 & & & & & & & \\
\hline PERRY & $8 / 28 / 2003$ & PM-21 & 11.0 & 2.81 & 3190 & 3021 & 12.6 & 159.0 & 1201.6 \\
\hline WVDEP & 9/15/2003 & PM-21 & 9.0 & 2.59 & 2670 & 3012 & 15 & 104.2 & 967.8 \\
\hline WVDEP & $10 / 14 / 2003$ & PM-21 & & & & & & & \\
\hline WVDEP & $1 / 14 / 2004$ & PM-21 & 31.4 & 2.81 & 2150 & 1896 & 7.2 & 274.8 & 729.0 \\
\hline WVDEP & $4 / 13 / 2004$ & PM-21 & 80.6 & 2.88 & 1791 & 1268 & 12.2 & 75.5 & 77.9 \\
\hline
\end{tabular}


Table E-1c, Omega Mine-pool, PM-21 Spring, Raw Chemical Data

\begin{tabular}{|c|c|c|c|c|c|c|c|c|c|}
\hline Sampled By & Date & Location & Flow gpm & $\mathrm{pH}$ & $\begin{array}{c}\text { Sp. } \\
\text { Conductance } \\
\text { umhos/cm }\end{array}$ & TDS, mg/L & Temp, C & $\begin{array}{l}\text { Acid load, } \\
\text { lbs/day } \\
\text { CaCO3 Eq }\end{array}$ & $\begin{array}{c}\text { Calc Total } \\
\text { Acidity } \\
\text { CaCO3 Eq }\end{array}$ \\
\hline WVDEP & $7 / 12 / 2004$ & PM-21 & 9.0 & 2.68 & 3120 & 3188 & 14.4 & 125.5 & 1165.3 \\
\hline WVDEP & $8 / 9 / 2004$ & PM-21 & 0.0 & & & & & & \\
\hline WVDEP & $10 / 18 / 2004$ & PM-21 & 9.0 & 2.7 & 3360 & 3776 & 12.2 & 144.5 & 1341.4 \\
\hline PERRY & $3 / 22 / 2005$ & PM-21 & 21.8 & 3.02 & 3180 & 5432 & 10.9 & 700.4 & 2671.7 \\
\hline PERRY & $5 / 24 / 2006$ & PM-21 & 24.3 & 2.48 & 3470 & 4094 & 11.9 & 522.1 & 1787.4 \\
\hline PERRY & $5 / 3 / 2007$ & PM-21 & 25.3 & 2.52 & 2915 & 3308 & 12 & 470.8 & 1548.2 \\
\hline PERRY & 9/13/2007 & PM-21 & 6.9 & 2.35 & 4630 & 5196 & 11.7 & 181.6 & 2189.5 \\
\hline
\end{tabular}


Table E-1d, Omega Mine-pool, PM-21 Spring, Raw Chemical Data

\begin{tabular}{|c|c|c|c|c|c|c|c|c|c|c|c|c|c|}
\hline $\begin{array}{l}\text { Sampled } \\
\text { By }\end{array}$ & Date & Location & $\begin{array}{l}\mathrm{Fe3+}, \\
\mathrm{mg} / \mathrm{L}\end{array}$ & $\begin{array}{l}\mathrm{Fe} 2+, \\
\mathrm{mg} / \mathrm{L}\end{array}$ & $\begin{array}{l}\text { Fe Total, } \\
\mathrm{mg} / \mathrm{L}\end{array}$ & $\begin{array}{c}\mathrm{Ca}, \\
\mathrm{mg} / \mathrm{L}\end{array}$ & $\begin{array}{c}\mathrm{Mg}, \\
\mathrm{mg} / \mathrm{L}\end{array}$ & $\mathrm{Na}, \mathrm{mg} / \mathrm{L}$ & $\mathrm{K}, \mathrm{mg} / \mathrm{L}$ & $\begin{array}{c}\mathrm{Al}, \\
\mathrm{mg} / \mathrm{L}\end{array}$ & $\begin{array}{l}\mathrm{Mn}, \\
\mathrm{mg} / \mathrm{L}\end{array}$ & $\begin{array}{l}\mathrm{SO} 4, \\
\mathrm{mg} / \mathrm{L}\end{array}$ & $\mathrm{Cl}, \mathrm{mg} / \mathrm{L}$ \\
\hline DOE & $11 / 15 / 1991$ & PM-21 & 139.8 & 2.2 & 142 & 607.0 & 194.0 & 9.8 & & 36.5 & 4.00 & 3750 & 23.5 \\
\hline DOE & $2 / 11 / 1993$ & PM-21 & 91.4 & 3 & 91.4 & 316.0 & 141.0 & 7.7 & 10.5 & 42.2 & 4.14 & 2656 & 10.9 \\
\hline $\mathrm{DOE}$ & $3 / 3 / 1993$ & PM-21 & 86.8 & 7 & 93.8 & 261.0 & 126.0 & 7.4 & 8.4 & 39.1 & 3.70 & 2482 & 6.5 \\
\hline DOE & $3 / 18 / 1993$ & PM-21 & 72.5 & 2.7 & 75.2 & 139.0 & 63.5 & 7.5 & 6.1 & 24.1 & 1.70 & 1310 & 7.3 \\
\hline DOE & $4 / 2 / 1993$ & PM-21 & 116.8 & 5.2 & 122 & 173.0 & 77.8 & 6.1 & 6.1 & 35.2 & 2.10 & 1713 & 7.3 \\
\hline DOE & $4 / 14 / 1993$ & PM-21 & 138.7 & 10.3 & 149 & 214.0 & 98.3 & 6.9 & 6.1 & 45.4 & 2.60 & 2270 & 9.2 \\
\hline DOE & 4/29/1993 & PM-21 & 108.7 & 8.3 & 117 & 174.0 & 76.2 & 5.6 & 6.5 & 33.9 & 2.10 & 1817 & 5.6 \\
\hline DOE & $5 / 20 / 1993$ & PM-21 & 156.4 & 42.6 & 199 & 296.0 & 140.0 & 8.4 & 10.4 & 54.6 & 4.80 & 2855 & 7.8 \\
\hline DOE & $6 / 3 / 1993$ & PM-21 & 182.6 & 40.4 & 223 & 352.0 & 173.0 & 10.2 & 12.7 & 58.8 & 6.10 & 3274 & 7 \\
\hline DOE & $6 / 10 / 1993$ & PM-21 & 160.71 & 23.6 & 184.31 & 322.3 & 160.4 & 8.9 & 10.93 & 52.2 & 5.48 & 3128 & 7.7 \\
\hline DOE & $6 / 23 / 1993$ & PM-21 & 154.39 & 8.7 & 163.09 & 333.7 & 160.4 & 9.5 & 11.15 & 49.2 & 5.46 & 3222 & 7.8 \\
\hline DOE & $7 / 8 / 1993$ & PM-21 & 161.31 & 6.2 & 167.51 & 349.2 & 167.4 & 9.3 & 11.68 & 44.7 & 6.49 & 3250 & 9.3 \\
\hline DOE & $7 / 22 / 1993$ & PM-21 & 172.84 & 25.2 & 198.04 & 380.5 & 183.8 & 10.0 & 12.37 & 45.2 & 6.81 & 3517 & 9.7 \\
\hline DOE & $8 / 11 / 1993$ & PM-21 & 152.5 & 12.3 & 164.8 & 394.83 & 192.8 & 9.9 & $\begin{array}{l}13.66 \\
\end{array}$ & 42.7 & 6.64 & 3593 & \\
\hline $\mathrm{DOE}$ & $9 / 10 / 1993$ & PM-21 & 140.17 & 9.7 & 149.87 & 401.3 & 191.2 & 9.9 & \begin{tabular}{|l|}
15.08 \\
\end{tabular} & 40.3 & 6.26 & 3583 & \\
\hline DOE & $10 / 7 / 1993$ & PM-21 & 106.68 & 5.3 & 111.98 & 348.5 & 166.3 & 9.4 & 12.71 & 30.7 & 5.05 & 3203 & 11.7 \\
\hline DOE & $10 / 25 / 1993$ & PM-21 & 112.06 & 3.3 & 115.36 & 358.6 & 173.6 & 9.8 & 12.99 & 29.7 & 5.56 & 3157 & 5.9 \\
\hline DOE & $11 / 10 / 1993$ & PM-21 & 100.48 & 4.3 & 104.78 & 333.7 & 157.3 & 10.4 & 12.09 & 29.6 & 5.15 & 2858 & 13.3 \\
\hline DOE & 12/7/1993 & PM-21 & 66.01 & 8.6 & 74.61 & 195.9 & 93.8 & 6.9 & 7.39 & 25.8 & 2.87 & 1682 & 12.4 \\
\hline DOE & $12 / 23 / 1993$ & PM-21 & 88.92 & 3.6 & 92.52 & 242.9 & 119.3 & 7.4 & 8.18 & 41.2 & 3.70 & 2172 & 13.9 \\
\hline DOE & $1 / 28 / 1994$ & PM-21 & 84.6 & 3.14 & 77.66 & 7.7 & 85.36 & 193.5 & 92.6 & 6.0 & 6.5 & 38.8 & 3.03 \\
\hline $\mathrm{DOE}$ & $5 / 5 / 1994$ & PM-21 & 14.7 & 3.09 & 64.49 & 29.5 & 93.99 & 199.2 & 90.8 & 6.8 & 7.42 & 39.8 & 3.34 \\
\hline DOE & $6 / 10 / 1994$ & PM-21 & 29.0 & 3.14 & 52.43 & 92.8 & 145.23 & 278.4 & 124.4 & 12.1 & 9.34 & 57.4 & 4.15 \\
\hline DOE & $7 / 6 / 1994$ & PM-21 & 36.5 & 3.12 & 49.36 & 119 & 168.36 & 327.4 & 145.7 & 14.1 & 10.55 & 47.3 & 5.47 \\
\hline DOE & 8/3/1994 & PM-21 & 19.5 & 2.99 & 39.9 & 112.7 & 152.6 & 317.7 & 145.1 & 17.4 & 10.35 & 40.3 & 5.60 \\
\hline DOE & $9 / 1 / 1994$ & PM-21 & 21.4 & 2.96 & 24.81 & 105.6 & 130.41 & 279.8 & 125.5 & 13.4 & 10.82 & 33.1 & 4.83 \\
\hline DOE & $10 / 7 / 1994$ & PM-21 & 15.6 & 3.35 & 22.53 & 144.4 & 166.93 & 326.2 & 151.2 & 12.7 & 10.42 & 44.0 & 6.08 \\
\hline DOE & $11 / 16 / 1994$ & PM-21 & 8.5 & 3.05 & 27.94 & 130.85 & 158.79 & 351.8 & 164.3 & 13.7 & 11.59 & 39.7 & 6.31 \\
\hline DOE & $12 / 14 / 1994$ & PM-21 & 15.8 & 3.16 & 15.81 & 138.9 & 154.71 & 352.9 & 162.6 & 13.9 & 13.07 & 37.3 & 6.45 \\
\hline DOE & $1 / 10 / 1995$ & PM-21 & 19.6 & 3.03 & 17.59 & 165.2 & 182.79 & 309.4 & 149.4 & 11.3 & 9.9 & 47.8 & 5.65 \\
\hline DOE & $2 / 3 / 1995$ & PM-21 & 10.6 & 3.01 & 11.23 & 163.69 & 174.92 & 273.9 & $\begin{array}{l}27.5 \\
\end{array}$ & 10.0 & 8.49 & 62.3 & 4.72 \\
\hline DOE & $3 / 2 / 1995$ & PM-21 & 9.9 & 3.33 & 16.99 & 124.41 & 141.4 & 242.7 & 112.8 & 9.4 & 8.09 & 52.6 & 4.00 \\
\hline DOE & $4 / 7 / 1995$ & PM-21 & 11.7 & 3.1 & 8.83 & 125.5 & 134.33 & 248.67 & 108.81 & 9.46 & 7.86 & 49.23 & 4.45 \\
\hline $\mathrm{DOE}$ & $5 / 10 / 1995$ & PM-21 & 25.4 & 3.10 & 12.48 & 124.8 & 137.28 & 236.1 & 102.7 & 8.3 & 7.42 & 52.6 & 4.24 \\
\hline DOE & 6/6/1995 & PM-21 & 16.0 & 3.09 & 41.57 & 54.6 & 96.17 & 222.3 & 94.6 & 7.3 & 7.77 & 42.0 & 3.95 \\
\hline
\end{tabular}


Table E-1d, Omega Mine-pool, PM-21 Spring, Raw Chemical Data

\begin{tabular}{|c|c|c|c|c|c|c|c|c|c|c|c|c|c|}
\hline $\begin{array}{c}\text { Sampled } \\
\text { By }\end{array}$ & Date & Location & $\begin{array}{l}\text { Fe3+, } \\
\text { mg/L }\end{array}$ & $\begin{array}{l}\text { Fe2+, } \\
\mathrm{mg} / \mathrm{L}\end{array}$ & $\begin{array}{c}\text { Fe Total, } \\
\mathrm{mg} / \mathrm{L}\end{array}$ & $\begin{array}{c}\mathrm{Ca}, \\
\mathrm{mg} / \mathrm{L}\end{array}$ & $\begin{array}{l}\mathrm{Mg}, \\
\mathrm{mg} / \mathrm{L}\end{array}$ & $\begin{array}{c}\mathrm{Na}, \\
\mathrm{mg} / \mathrm{L}\end{array}$ & $\mathrm{K}, \mathrm{mg} / \mathrm{L}$ & $\begin{array}{c}\mathrm{Al}, \\
\mathrm{mg} / \mathrm{L}\end{array}$ & $\begin{array}{c}\mathrm{Mn}, \\
\mathrm{mg} / \mathrm{L}\end{array}$ & $\begin{array}{l}\mathrm{SO} 4, \\
\mathrm{mg} / \mathrm{L}\end{array}$ & $\begin{array}{c}\mathrm{Cl}, \\
\mathrm{mg} / \mathrm{L}\end{array}$ \\
\hline DOE & 7/13/1995 & PM-21 & 9.5 & 3.02 & 32.51 & 106.8 & 139.31 & 302.5 & 129.77 & 9.22 & 9.54 & 43.59 & 5.82 \\
\hline DOE & $8 / 3 / 1995$ & PM-21 & 7.55 & 186 & 193.55 & 370.9 & 149.5 & 10.4 & 11.8 & 44.5 & 7.17 & 3187 & 26.1 \\
\hline DOE & 9/7/1995 & PM-21 & 11.37 & 209.2 & 220.57 & 404.72 & 168.7 & 11.05 & 13.03 & 42.84 & 7.96 & 3491 & 21.2 \\
\hline DOE & $10 / 12 / 1995$ & PM-21 & 0 & 216.09 & 216.09 & 396.07 & 168.9 & 10.41 & 12.76 & 39.8 & 7.69 & 3323 & 19.61 \\
\hline DOE & $11 / 22 / 1995$ & PM-21 & 20.95 & 150 & 170.95 & 396.7 & 162.7 & 10.9 & 13.59 & 35.4 & 7.57 & 3278 & 15.5 \\
\hline DOE & $1 / 5 / 1996$ & PM-21 & 2.31 & 142.3 & 144.61 & 299.0 & 120.1 & 9.5 & 9.69 & 42.3 & 5.94 & 2465 & 21.43 \\
\hline WVDEP & $1 / 16 / 1996$ & PM-21 & & & 194 & & & & & 67 & 7.42 & 3060 & \\
\hline WVDEP & $2 / 15 / 1996$ & PM-21 & & & 136 & & & & & & 4.05 & 1710 & \\
\hline DOE & $2 / 21 / 1996$ & PM-21 & 18.89 & 69.2 & 88.09 & 167.6 & 67.9 & 6.7 & 5.16 & 41.2 & 3.22 & 1403 & 8.88 \\
\hline WVDEP & 3/1/1996 & PM-21 & & & 84.1 & & & & & & 2.74 & 1230 & \\
\hline WVDEP & $3 / 15 / 1996$ & PM-21 & & & 86.2 & & & & & & 3.25 & 1560 & \\
\hline DOE & $3 / 18 / 1996$ & PM-21 & 22.82 & 35.3 & 58.12 & 141.8 & 58.0 & 5.4 & 5.34 & 28.1 & 2.68 & 1237 & 9.58 \\
\hline WVDEP & $3 / 28 / 1996$ & PM-21 & & & & & & & & & & & \\
\hline DOE & $4 / 26 / 1996$ & PM-21 & 52.09 & 1.5 & 53.59 & 193.7 & 80.6 & 7.1 & 7.52 & 35.7 & 3.46 & 1752 & 7.44 \\
\hline WVDEP & $4 / 29 / 1996$ & PM-21 & & & 59.5 & & & & & & 3.87 & 2050 & \\
\hline WVDEP & $5 / 15 / 1996$ & PM-21 & & & 41.8 & & & & & 25.9 & 2.57 & 1170 & \\
\hline WVDEP & $5 / 31 / 1996$ & PM-21 & & & 44.5 & & & & & 24.4 & 2.26 & 1090 & \\
\hline DOE & $6 / 7 / 1996$ & PM-21 & 74.01 & 3.5 & 77.51 & 216.4 & 87.1 & 7.1 & 7.78 & 41.3 & 4.05 & 1903 & 12.16 \\
\hline WVDEP & $6 / 14 / 1996$ & PM-21 & & & 103 & & & & & 51 & 5.13 & 2430 & \\
\hline WVDEP & $6 / 28 / 1996$ & PM-21 & & & 131 & & & & & 8.02 & 5.68 & 2350 & \\
\hline WVDEP & 7/15/1996 & PM-21 & & & 111 & & & & & 59.8 & 6.29 & 2620 & \\
\hline DOE & $7 / 23 / 1996$ & PM-21 & 94.54 & 8.7 & 103.24 & 258.7 & 98.9 & 7.8 & 8.04 & 43.2 & 4.87 & 2093 & 19 \\
\hline WVDEP & $7 / 30 / 1996$ & PM-21 & & & 128 & & & & & 44.9 & 5.39 & 2540 & \\
\hline WVDEP & 8/14/1996 & PM-21 & & & 139 & & & & & 61.6 & 5.77 & 2510 & \\
\hline DOE & $8 / 28 / 1996$ & PM-21 & 131.91 & 9.1 & 141.01 & 370.8 & 138.3 & 10.3 & 11.07 & 63.5 & 6.14 & 2909 & 14.56 \\
\hline WVDEP & $8 / 31 / 1996$ & PM-21 & & & 114 & & & & & 51.2 & 9.6 & 2600 & \\
\hline WVDEP & 9/16/1996 & PM-21 & & & 149 & & & & & 60.9 & 6.76 & 2650 & \\
\hline WVDEP & 9/30/1996 & PM-21 & & & 124 & & & & & 48.8 & 5.55 & 2620 & \\
\hline WVDEP & $10 / 14 / 1996$ & PM-21 & & & 151 & & & & & 57.2 & 6.43 & 2380 & \\
\hline DOE & 10/16/1996 & PM-21 & 121.38 & 27.5 & 148.88 & 368.9 & 141.9 & 10.5 & 10.83 & 58.6 & 7.07 & 2943 & 20.24 \\
\hline WVDEP & $10 / 30 / 1996$ & PM-21 & & & 95.8 & & & & & 59 & 6.72 & 1930 & \\
\hline WVDEP & $11 / 15 / 1996$ & PM-21 & & & 81.4 & & & & & 35.2 & 3.71 & 1890 & \\
\hline DOE & $11 / 26 / 1996$ & PM-21 & 101.73 & 28.3 & 130.03 & 260.2 & 105.5 & 8.06 & 8.98 & 51.19 & 5.04 & 2198 & 11.88 \\
\hline DOE & $12 / 13 / 1996$ & PM-21 & 75.56 & 21.2 & 96.76 & 201.43 & 80.31 & 6.93 & 7.53 & 36.49 & 3.98 & 1687 & 10.82 \\
\hline WVDEP & $12 / 15 / 1996$ & PM-21 & & & 84.6 & & & & & 33.1 & 3.6 & 1160 & \\
\hline WVDEP & $1 / 14 / 1997$ & PM-21 & & & 72.3 & & & & & 32.1 & 4.05 & 1350 & \\
\hline DOE & $1 / 28 / 1997$ & PM-21 & 55.104 & 13.776 & 68.88 & 173.62 & 69.81 & 5.78 & 5.95 & 30.65 & 3.39 & 1417 & 10.1 \\
\hline
\end{tabular}


Table E-1d, Omega Mine-pool, PM-21 Spring, Raw Chemical Data

\begin{tabular}{|c|c|c|c|c|c|c|c|c|c|c|c|c|c|}
\hline $\begin{array}{c}\text { Sampled } \\
\text { By }\end{array}$ & Date & Location & $\begin{array}{l}\text { Fe3+, } \\
\mathrm{mg} / \mathrm{L}\end{array}$ & $\begin{array}{c}\mathrm{Fe} 2+ \\
\mathrm{mg} / \mathrm{L}\end{array}$ & $\begin{array}{c}\text { Fe Total, } \\
\mathrm{mg} / \mathrm{L}\end{array}$ & $\begin{array}{c}\mathrm{Ca}, \\
\mathrm{mg} / \mathrm{L}\end{array}$ & $\begin{array}{l}\mathrm{Mg}, \\
\mathrm{mg} / \mathrm{L}\end{array}$ & $\begin{array}{l}\mathrm{Na}, \\
\mathrm{mg} / \mathrm{L}\end{array}$ & $\mathrm{K}, \mathrm{mg} / \mathrm{L}$ & $\begin{array}{c}\mathrm{Al}, \\
\mathrm{mg} / \mathrm{L}\end{array}$ & $\begin{array}{l}\mathrm{Mn}, \\
\mathrm{mg} / \mathrm{L}\end{array}$ & $\begin{array}{l}\mathrm{SO} 4, \\
\mathrm{mg} / \mathrm{L}\end{array}$ & $\begin{array}{c}\mathrm{Cl}, \\
\mathrm{mg} / \mathrm{L}\end{array}$ \\
\hline DOE & 2/21/1997 & PM-21 & 81.2 & 19.9 & 101.1 & 231.4 & 82.21 & 6.5 & 7.22 & 35.1 & 3.96 & 1715 & 12.7 \\
\hline WVDEP & $3 / 17 / 1997$ & PM-21 & & & 81.4 & & & & & 28 & 3.18 & 1380 & \\
\hline DOE & $3 / 26 / 1997$ & PM-21 & 29.26 & 40.7 & 69.96 & 144.6 & 53.8 & 5.4 & 5.41 & 24.8 & 2.76 & 1167 & 7 \\
\hline WVDEP & $4 / 14 / 1997$ & PM-21 & & & 100 & & & & & 36 & 4.04 & 1620 & \\
\hline WVDEP & $5 / 14 / 1997$ & PM-21 & & & 169 & & & & & 45.6 & 4.79 & 1950 & \\
\hline DOE & $5 / 20 / 1997$ & PM-21 & 27.54 & 66.4 & 93.94 & 159.5 & 60.4 & 5.3 & 5.4 & 29.9 & 2.97 & 1295 & \\
\hline WVDEP & 6/16/1997 & PM-21 & & & 188 & & & & & 44.2 & 4.46 & 1220 & \\
\hline DOE & $7 / 10 / 1997$ & PM-21 & 67.52 & 118.6 & 186.12 & 287.2 & 106.2 & 7.9 & 8.1 & 56.7 & 5.61 & 2289 & 11.65 \\
\hline WVDEP & $7 / 16 / 1997$ & PM-21 & & & 166 & & & & & 61.3 & 5.86 & 2210 & \\
\hline WVDEP & $8 / 17 / 1997$ & PM-21 & & & 220 & & & & & 54.9 & 5.99 & 1720 & \\
\hline DOE & 9/10/1997 & PM-21 & 80.46 & 149.2 & 229.66 & 342.4 & 130.9 & 8.8 & 8.66 & 59.6 & 6.76 & 2582 & 13.87 \\
\hline WVDEP & 9/15/1997 & PM-21 & & & 221 & & & & & & 5.84 & 2250 & \\
\hline WVDEP & $10 / 15 / 1997$ & PM-21 & & & 294 & & & & & 57.9 & 5.8 & 2100 & \\
\hline DOE & $11 / 5 / 1997$ & PM-21 & 35.16 & 256.5 & 291.66 & 353.4 & 140.5 & 10.0 & 8.73 & 67.2 & 6.29 & 2757 & 13 \\
\hline WVDEP & $11 / 14 / 1997$ & PM-21 & & & 81.1 & & & & & 26 & 2.82 & 1370 & \\
\hline WVDEP & $12 / 15 / 1997$ & PM-21 & & & 170 & & & & & 70.3 & 4.93 & 2140 & \\
\hline DOE & $1 / 12 / 1998$ & PM-21 & 60.25 & 37 & 97.25 & 164.1 & 67.5 & 7.2 & 5.57 & 42.0 & 3.00 & 1369 & 8.4 \\
\hline WVDEP & 1/16/1998 & PM-21 & & & 129 & & & & & 63.2 & 4.05 & 1830 & \\
\hline DOE & $2 / 9 / 1998$ & PM-21 & 102.09 & 50.1 & 152.19 & 221.5 & 90.3 & 6.65 & 4.88 & 75.2 & 4.1 & 1925 & 11.81 \\
\hline WVDEP & $2 / 15 / 1998$ & PM-21 & & & 141 & & & & & 59.2 & 3.22 & 1710 & \\
\hline WVDEP & 3/15/1998 & PM-21 & & & 127 & & & & & 63.7 & 3.26 & 1610 & \\
\hline DOE & $3 / 26 / 1998$ & PM-21 & 73.82 & 28.9 & 102.72 & 145.9 & 57.6 & 5.7 & 3.68 & 48.2 & 2.65 & 1246 & \\
\hline WVDEP & 4/15/1998 & PM-21 & & & 162 & & & & & 69.6 & 3.32 & 1600 & \\
\hline DOE & $4 / 29 / 1998$ & PM-21 & 68.93 & 55.3 & 124.23 & 161.2 & 64.1 & 5.7 & 4.1 & 56.6 & 2.94 & 1427 & \\
\hline WVDEP & $5 / 14 / 1998$ & PM-21 & & & 154 & & & & & 58.7 & 3.12 & 1500 & \\
\hline DOE & $5 / 28 / 1998$ & PM-21 & 63.54 & 103 & 166.54 & 219.1 & 85.6 & 8.0 & 5.08 & 73.1 & 4.04 & 1842 & 21.77 \\
\hline WVDEP & $6 / 15 / 1998$ & PM-21 & & & 162 & & & & & 76.6 & 4.81 & 2060 & \\
\hline DOE & $6 / 25 / 1998$ & PM-21 & 42.18 & 86.1 & 128.28 & 212.3 & 83.7 & 8.1 & 5.02 & 59.5 & 4.36 & 1788 & 10.43 \\
\hline WVDEP & $7 / 15 / 1998$ & PM-21 & & & 141 & & & & & 65.9 & 5.47 & 2460 & \\
\hline DOE & $8 / 5 / 1998$ & PM-21 & 139.97 & 25 & 164.97 & 331.4 & 133.7 & 12.0 & 8.05 & 97.3 & 6.92 & 2757 & 14.74 \\
\hline WVDEP & $8 / 13 / 1998$ & PM-21 & & & 198 & & & & & 89.9 & 6.16 & 2420 & \\
\hline DOE & 9/3/1998 & PM-21 & 126.93 & 56.3 & 183.23 & 318.7 & 131.3 & 10.0 & 7.38 & 86.4 & 6.89 & 2658 & 16.48 \\
\hline WVDEP & 9/15/1998 & PM-21 & & & 198 & & & & & 81.8 & 6.86 & 2580 & \\
\hline WVDEP & $10 / 15 / 1998$ & PM-21 & & & 171 & & & & & 74.4 & 6.46 & 2140 & \\
\hline DOE & $10 / 29 / 1998$ & PM-21 & 115.11 & 109.1 & 224.21 & 379.0 & 156.3 & 13.6 & 7.38 & 89.8 & 7.67 & 3071 & 16.95 \\
\hline WVDEP & $11 / 15 / 1998$ & PM-21 & & & 192 & & & & & 97.1 & 7.55 & 2300 & \\
\hline DOE & 12/10/1998 & PM-21 & 124.15 & 114.86 & 239.01 & 388.6 & 158.8 & 12.9 & 6.69 & 90.6 & 7.31 & 3073 & 13.2 \\
\hline
\end{tabular}


Table E-1d, Omega Mine-pool, PM-21 Spring, Raw Chemical Data

\begin{tabular}{|c|c|c|c|c|c|c|c|c|c|c|c|c|c|}
\hline $\begin{array}{c}\text { Sampled } \\
\text { By }\end{array}$ & Date & Location & $\begin{array}{l}\text { Fe3+, } \\
\mathrm{mg} / \mathrm{L}\end{array}$ & $\begin{array}{l}\mathrm{Fe} 2+, \\
\mathrm{mg} / \mathrm{L}\end{array}$ & $\begin{array}{c}\text { Fe Total, } \\
\mathrm{mg} / \mathrm{L}\end{array}$ & $\begin{array}{c}\mathrm{Ca}, \\
\mathrm{mg} / \mathrm{L}\end{array}$ & $\begin{array}{l}\mathrm{Mg}, \\
\mathrm{mg} / \mathrm{L}\end{array}$ & $\begin{array}{l}\mathrm{Na}, \\
\mathrm{mg} / \mathrm{L}\end{array}$ & $\mathrm{K}, \mathrm{mg} / \mathrm{L}$ & $\begin{array}{c}\mathrm{Al}, \\
\mathrm{mg} / \mathrm{L}\end{array}$ & $\begin{array}{c}\mathrm{Mn}, \\
\mathrm{mg} / \mathrm{L}\end{array}$ & $\begin{array}{l}\mathrm{SO} 4, \\
\mathrm{mg} / \mathrm{L}\end{array}$ & $\begin{array}{c}\mathrm{Cl}, \\
\mathrm{mg} / \mathrm{L}\end{array}$ \\
\hline WVDEP & $12 / 15 / 1998$ & PM-21 & & & 231 & & & & & 79 & 5.83 & 2520 & \\
\hline WVDEP & $1 / 17 / 1999$ & PM-21 & & & 92.8 & & & & & 48.5 & 3.28 & 1190 & \\
\hline WVDEP & $2 / 14 / 1999$ & PM-21 & & & 225 & & & & & 119 & 4.7 & 2430 & \\
\hline DOE & 2/18/1999 & PM-21 & 177.18 & 55.2 & 232.38 & 279.02 & 115.12 & 9.74 & 4.87 & 136.98 & 5.79 & 2727 & 14.21 \\
\hline WVDEP & $3 / 14 / 1999$ & PM-21 & & & 169 & & & & & 88.3 & 4 & 1950 & \\
\hline DOE & 3/30/1999 & PM-21 & 142.91 & 19.84 & 162.75 & 224.0 & 88.0 & 8.1 & 4.64 & 104.4 & 4.52 & 2074 & 11.74 \\
\hline WVDEP & $4 / 13 / 1999$ & PM-21 & & & 166 & & & & & 104 & 4.51 & 2070 & \\
\hline DOE & 4/29/1999 & PM-21 & 142.61 & 24.04 & 166.65 & 239.9 & 96.6 & 8.6 & 4.48 & 105.3 & 5.35 & 2183 & 13.35 \\
\hline WVDEP & $5 / 17 / 1999$ & PM-21 & & & 260 & & & & & 103 & 4.99 & 2280 & \\
\hline DOE & $5 / 26 / 1999$ & PM-21 & 150.7 & 49.8 & 200.5 & 258.0 & 106.5 & 8.4 & 4.81 & 109.8 & 5.59 & 2422 & 13.6 \\
\hline WVDEP & $6 / 14 / 1999$ & PM-21 & & & 215 & & & & & 112 & 5.86 & 2120 & \\
\hline DOE & $6 / 29 / 1999$ & PM-21 & 134.07 & 68.5 & 202.57 & 301.9 & 124.09 & 8.94 & 5.26 & 113.07 & 6.33 & 2691 & 12.59 \\
\hline WVDEP & $7 / 14 / 1999$ & PM-21 & & & 198 & & & & & 108 & 5.96 & 2100 & \\
\hline DOE & $7 / 27 / 1999$ & PM-21 & 124.19 & 97.78 & 221.97 & 337.7 & 141.6 & 9.9 & 5.07 & 115.3 & 6.62 & 2873 & 18.48 \\
\hline WVDEP & $8 / 14 / 1999$ & PM-21 & & & 283 & & & & & 120 & 6.79 & 2800 & \\
\hline DEO & 8/26/1999 & PM-21 & 130.6 & 115.2 & 245.8 & 360.4 & 151.1 & 12.9 & 5.29 & 118.6 & 6.73 & 3025 & 16.18 \\
\hline WVDEP & $9 / 14 / 1999$ & PM-21 & & & 248 & & & & & 106 & 5.91 & 2510 & \\
\hline DOE & 9/29/1999 & PM-21 & 115.04 & 138.21 & 253.25 & 367.2 & 151.0 & 11.0 & 4.77 & 112.9 & 6.76 & 2969 & 16.9 \\
\hline WVDEP & $10 / 15 / 1999$ & PM-21 & & & 249 & & & & & 109 & 6.77 & 2500 & \\
\hline DOE & $10 / 29 / 1999$ & PM-21 & 133.4 & 159.3 & 292.7 & 387.3 & 163.0 & 10.6 & 4.21 & 121.9 & 6.94 & 3220 & 2000 \\
\hline WVDEP & $11 / 15 / 1999$ & PM-21 & & & 299 & & & & & 122 & 5.91 & 3360 & \\
\hline DOE & 12/7/1999 & PM-21 & 153.45 & 120.6 & 274.05 & 351.1 & 149.4 & 10.3 & 4.24 & 124.6 & 6.47 & 3037 & 16.6 \\
\hline DOE & $12 / 15 / 1999$ & PM-21 & & & 248 & & & & & 124 & 5.37 & 2630 & \\
\hline WVDEP & $1 / 17 / 2000$ & PM-21 & & & 314 & & & & & 177 & 6.5 & 3410 & \\
\hline WVDEP & $2 / 8 / 2000$ & PM-21 & & & 296 & & & & & 160 & 5.95 & 3120 & \\
\hline WVDEP & $3 / 15 / 2000$ & PM-21 & & & 222 & & & & & 146 & 4.06 & 2000 & \\
\hline WVDEP & $4 / 14 / 2000$ & PM-21 & & & 131 & & & & & 94.8 & 3.29 & 2010 & \\
\hline WVDEP & $5 / 15 / 2000$ & PM-21 & & & 166 & & & & & 122 & 4.8 & 2740 & \\
\hline WVDEP & $6 / 15 / 2000$ & PM-21 & & & 167 & & & & & 121 & 4.18 & 2360 & \\
\hline WVDEP & $7 / 18 / 2000$ & PM-21 & & & 183 & & & & & 121 & 4.07 & 2170 & \\
\hline WVDEP & $8 / 15 / 2000$ & PM-21 & & & 205 & & & & & 134 & 5.11 & 3220 & \\
\hline WVDEP & $9 / 15 / 2000$ & PM-21 & & & 240 & 264 & & & & 149 & 5.25 & 2840 & \\
\hline WVDEP & $10 / 15 / 2000$ & PM-21 & & & 249 & & & & & 143 & 5.75 & 2890 & \\
\hline WVDEP & $11 / 15 / 2000$ & PM-21 & & & 162 & & & & & 287 & 5.35 & 2620 & \\
\hline WVDEP & $12 / 15 / 2000$ & PM-21 & & & 261 & & & & & 138 & 4.77 & 2630 & \\
\hline WVDEP & $1 / 15 / 2001$ & PM-21 & & & 223 & & & & & 135 & 4.75 & 3430 & \\
\hline WVDEP & $2 / 13 / 2001$ & PM-21 & & & 237 & & & & & 160 & 3.71 & 2810 & \\
\hline
\end{tabular}


Table E-1d, Omega Mine-pool, PM-21 Spring, Raw Chemical Data

\begin{tabular}{|c|c|c|c|c|c|c|c|c|c|c|c|c|c|}
\hline $\begin{array}{c}\text { Sampled } \\
\text { By }\end{array}$ & Date & Location & $\begin{array}{l}\text { Fe3+, } \\
\text { mg/L }\end{array}$ & $\begin{array}{c}\text { Fe2+, } \\
\mathrm{mg} / \mathrm{L}\end{array}$ & $\begin{array}{c}\text { Fe Total, } \\
\mathrm{mg} / \mathrm{L}\end{array}$ & $\begin{array}{c}\mathrm{Ca}, \\
\mathrm{mg} / \mathrm{L}\end{array}$ & $\begin{array}{l}\mathrm{Mg}, \\
\mathrm{mg} / \mathrm{L}\end{array}$ & $\begin{array}{c}\mathrm{Na}, \\
\mathrm{mg} / \mathrm{L}\end{array}$ & $\mathrm{K}, \mathrm{mg} / \mathrm{L}$ & $\begin{array}{c}\mathrm{Al}, \\
\mathrm{mg} / \mathrm{L}\end{array}$ & $\begin{array}{c}\mathrm{Mn}, \\
\mathrm{mg} / \mathrm{L}\end{array}$ & $\begin{array}{l}\mathrm{SO} 4, \\
\mathrm{mg} / \mathrm{L}\end{array}$ & $\begin{array}{c}\mathrm{Cl}, \\
\mathrm{mg} / \mathrm{L}\end{array}$ \\
\hline WVDEP & 3/13/2001 & PM-21 & & & 146 & & & & & 107 & 3.12 & 1860 & \\
\hline WVDEP & $4 / 16 / 2001$ & PM-21 & & & 145 & & & & & 83.4 & 2.64 & 1500 & \\
\hline WVDEP & $5 / 15 / 2001$ & PM-21 & & & 206 & & & & & 165 & 4.57 & 2530 & \\
\hline WVDEP & $6 / 18 / 2001$ & PM-21 & & & 197 & & & & & 142 & 4.72 & 2610 & \\
\hline WVDEP & $7 / 15 / 2001$ & PM-21 & & & 161 & & & & & 110 & 3.75 & 2000 & \\
\hline WVDEP & $8 / 15 / 2001$ & PM-21 & & & 231 & & & & & 159 & 4.55 & 1820 & \\
\hline WVDEP & $9 / 14 / 2001$ & PM-21 & & & 248 & & & & & 165 & 4.15 & 2220 & \\
\hline WVDEP & $10 / 15 / 2001$ & PM-21 & & & 241 & & & & & 157 & 5.03 & 3326 & \\
\hline WVDEP & $11 / 15 / 2001$ & PM-21 & & & 267.5 & & & & & 135.75 & 5.16 & 2818 & \\
\hline WVDEP & $12 / 14 / 2001$ & PM-21 & & & 193.28 & & & & & 102.09 & 4.87 & 2739 & \\
\hline WVDEP & $1 / 16 / 2002$ & PM-21 & & & 119.01 & & & & & 87.02 & 2.37 & 1501 & \\
\hline WVDEP & $2 / 14 / 2002$ & PM-21 & & & 121.57 & & & & & 103.34 & 2.7 & 1887 & \\
\hline WVDEP & 3/14/2002 & PM-21 & & & 0.08 & & & & & 2.26 & 1.21 & 2093 & \\
\hline WVDEP & $5 / 15 / 2002$ & PM-21 & & & 138.51 & & & & & 86.98 & 2.24 & 1647 & \\
\hline WVDEP & $6 / 18 / 2002$ & PM-21 & & & 95.8 & & & & & 7.74 & 0.73 & 1576 & \\
\hline WVDEP & $7 / 16 / 2002$ & PM-21 & & & & & & & & & & & \\
\hline WVDEP & $8 / 12 / 2002$ & PM-21 & & & & & & & & & & & \\
\hline PERRY & 8/20/2002 & PM-21 & 45.478 & 181.912 & 227.39 & 214.41 & 87.18 & 9.8 & 3.69 & 143.75 & 3.703 & 2195 & 11.1 \\
\hline WVDEP & 9/16/2002 & PM-21 & & & & & & & & & & & \\
\hline WVDEP & $10 / 15 / 2002$ & PM-21 & & & 189.43 & & & & & 111.49 & 3.65 & 2720 & \\
\hline WVDEP & $1 / 14 / 2003$ & PM-21 & & & & & & & & & & & \\
\hline WVDEP & $2 / 24 / 2003$ & PM-21 & & & 73.44 & & & & & 55.56 & 3.1 & 979 & \\
\hline WVDEP & $4 / 15 / 2003$ & PM-21 & & & & & & & & & & & \\
\hline WVDEP & 4/15/2003 & PM-21 & & & & & & & & & & & \\
\hline WVDEP & $5 / 20 / 2003$ & PM-21 & & & & & & & & & & & \\
\hline WVDEP & $6 / 17 / 2003$ & PM-21 & & & 46.01 & & & & & 31.69 & 0.75 & 1920 & \\
\hline WVDEP & 8/13/2003 & PM-21 & & & & & & & & & & & \\
\hline PERRY & $8 / 28 / 2003$ & PM-21 & 68.7 & 103.8 & 209 & 169 & 68.2 & 11.3 & & 134 & 3 & 1792 & \\
\hline WVDEP & $9 / 15 / 2003$ & PM-21 & & & 158.49 & & & & & 99.33 & 2.03 & 2036 & \\
\hline WVDEP & $10 / 14 / 2003$ & PM-21 & & & & & & & & & & & \\
\hline WVDEP & $1 / 14 / 2004$ & PM-21 & & & 118.41 & & & & & 78.62 & 1.54 & 1282 & \\
\hline WVDEP & $4 / 13 / 2004$ & PM-21 & & & 1.13 & & & & & 1.5 & 0.89 & 857 & \\
\hline WVDEP & $7 / 12 / 2004$ & PM-21 & & & 184.86 & & & & & 130.62 & 2.28 & 2155 & \\
\hline WVDEP & $8 / 9 / 2004$ & PM-21 & & & & & & & & & & & \\
\hline WVDEP & $10 / 18 / 2004$ & PM-21 & & & 218.24 & & & & & 152.22 & 2.87 & 2553 & \\
\hline PERRY & $3 / 22 / 2005$ & PM-21 & 381.00 & 280.00 & 658.2 & 178.23 & 95.26 & 4.68 & 2.8 & 259.07 & 3.36 & 3858 & 20 \\
\hline PERRY & $5 / 24 / 2006$ & PM-21 & 321.00 & 111.60 & 431.4 & 153.6 & 60.8 & 5.36 & 2.3 & 152.1 & 2.43 & 2411 & 6 \\
\hline
\end{tabular}


Table E-1d, Omega Mine-pool, PM-21 Spring, Raw Chemical Data

\begin{tabular}{|c|c|c|c|c|c|c|c|c|c|c|c|c|c|}
\hline $\begin{array}{c}\text { Sampled } \\
\text { By }\end{array}$ & Date & Location & $\begin{array}{l}\text { Fe3+, } \\
\mathrm{mg} / \mathrm{L}\end{array}$ & $\begin{array}{l}\mathrm{Fe} 2+, \\
\mathrm{mg} / \mathrm{L}\end{array}$ & $\begin{array}{c}\text { Fe Total, } \\
\mathrm{mg} / \mathrm{L}\end{array}$ & $\begin{array}{c}\mathrm{Ca}, \\
\mathrm{mg} / \mathrm{L}\end{array}$ & $\begin{array}{l}\mathrm{Mg}, \\
\mathrm{mg} / \mathrm{L}\end{array}$ & $\begin{array}{c}\mathrm{Na}, \\
\mathrm{mg} / \mathrm{L}\end{array}$ & $\mathrm{K}, \mathrm{mg} / \mathrm{L}$ & $\begin{array}{c}\mathrm{Al}, \\
\mathrm{mg} / \mathrm{L}\end{array}$ & $\begin{array}{c}\mathrm{Mn}, \\
\mathrm{mg} / \mathrm{L}\end{array}$ & $\begin{array}{l}\mathrm{SO4}, \\
\mathrm{mg} / \mathrm{L}\end{array}$ & $\begin{array}{c}\mathrm{Cl}, \\
\mathrm{mg} / \mathrm{L}\end{array}$ \\
\hline PERRY & $5 / 3 / 2007$ & PM-21 & 86.00 & 294.00 & 379.27 & 121.1 & 46.6 & 5.07 & 2.72 & 128.58 & 2.07 & 2340 & 35 \\
\hline PERRY & $9 / 13 / 2007$ & PM-21 & & & 432 & 206.5 & 87.23 & 39.36 & 2.108 & 213.2 & 4.02 & 3212 & 80 \\
\hline
\end{tabular}


Table E-1e, Omega Mine-pool, Marshall Spring, Raw Chemical Data

\begin{tabular}{|c|c|c|c|c|c|c|c|c|c|}
\hline Sampled By & Date & Location & Flow gpm & $\mathrm{pH}$ & $\begin{array}{c}\text { Sp. } \\
\text { Conductance } \\
\text { umhos } / \mathrm{cm}\end{array}$ & TDS, mg/L & Temp, C & $\begin{array}{l}\text { Acid load, } \\
\text { lbs/day } \\
\text { CaCO3 Eq }\end{array}$ & $\begin{array}{l}\text { Calc Total } \\
\text { Acidity } \\
\text { CaCO3 Eq }\end{array}$ \\
\hline DOE & $11 / 15 / 91$ & Marshall & & 3.12 & & 6770 & & & 2631.1 \\
\hline DOE & $02 / 11 / 93$ & Marshall & & 2.51 & & 10961 & & & 5957.6 \\
\hline DOE & $03 / 03 / 93$ & Marshall & 39.6 & 2.54 & & 10313 & & 2632.5 & 5533.3 \\
\hline DOE & $03 / 18 / 93$ & Marshall & 20.5 & 2.49 & & 10212 & & 1366.8 & 5553.4 \\
\hline DOE & $04 / 02 / 93$ & Marshall & 65.3 & 2.37 & & 10703 & & 4635.3 & 5903.6 \\
\hline DOE & $04 / 14 / 93$ & Marshall & 69.2 & 2.31 & & 11060 & & 5117.6 & 6150.5 \\
\hline DOE & $04 / 29 / 93$ & Marshall & 65.3 & 2.37 & & 10650 & & 4635.3 & 5903.6 \\
\hline DOE & $05 / 20 / 93$ & Marshall & 57.7 & 2.52 & & 8540 & & 3209.6 & 4630.8 \\
\hline DOE & 06/03/93 & Marshall & 5.0 & 2.62 & & 8306 & & 269.6 & 4482.2 \\
\hline DOE & $06 / 10 / 93$ & Marshall & 14.9 & 2.60 & & 8398 & & 812.6 & 4551.2 \\
\hline DOE & $06 / 23 / 93$ & Marshall & 31.2 & 2.59 & & 8688 & & 1743.4 & 4643.7 \\
\hline DOE & $07 / 08 / 93$ & Marshall & 27.9 & 2.67 & & 8215 & & 1498.3 & 4466.4 \\
\hline DOE & $07 / 22 / 93$ & Marshall & 10.1 & 2.72 & & 7508 & & 482.5 & 3972.2 \\
\hline DOE & $08 / 11 / 93$ & Marshall & 18.6 & 2.94 & & 6680 & & 771.1 & 3457.3 \\
\hline DOE & $09 / 02 / 93$ & Marshall & 8.8 & 2.95 & & 6442 & & 342.5 & 3228.0 \\
\hline DOE & $09 / 10 / 93$ & Marshall & 8.8 & 2.94 & & 6373 & & 340.4 & 3208.9 \\
\hline DOE & $10 / 07 / 93$ & Marshall & 5.2 & 3.01 & & 6561 & & 200.9 & 3216.9 \\
\hline DOE & $10 / 25 / 93$ & Marshall & 7.6 & 2.97 & & 6855 & & 322.7 & 3516.7 \\
\hline DOE & $11 / 10 / 93$ & Marshall & 7.6 & 3.01 & & 6667 & & 308.2 & 3358.8 \\
\hline DOE & $12 / 07 / 93$ & Marshall & 10.2 & 3.22 & & 6443 & & 388.7 & 3173.4 \\
\hline DOE & $12 / 23 / 93$ & Marshall & 10.2 & 2.65 & & 9569 & & 627.1 & 5119.1 \\
\hline DOE & $01 / 28 / 94$ & Marshall & 27.9 & 2.61 & & 10216 & & 1862.4 & 5551.5 \\
\hline DOE & $05 / 05 / 94$ & Marshall & 49.2 & 2.55 & & 6781 & & 2088.7 & 3528.5 \\
\hline DOE & $06 / 10 / 94$ & Marshall & 27.9 & 2.70 & & 6874 & & 1215.0 & 3621.8 \\
\hline DOE & $07 / 06 / 94$ & Marshall & 12.8 & 2.74 & & 6519 & & 524.8 & 3406.7 \\
\hline DOE & $08 / 03 / 94$ & Marshall & 11.5 & 2.88 & & 6345 & & 452.4 & 3268.0 \\
\hline DOE & $09 / 01 / 94$ & Marshall & 6.3 & 2.86 & & 6931 & & 269.5 & 3552.7 \\
\hline DOE & $10 / 07 / 94$ & Marshall & 8.2 & 2.90 & & 7048 & & 355.4 & 3625.3 \\
\hline DOE & $11 / 16 / 94$ & Marshall & 8.1 & 3.04 & & 6500 & & 319.9 & 3266.3 \\
\hline DOE & $12 / 14 / 94$ & Marshall & 7.6 & 3.09 & & 6502 & & 290.0 & 3166.4 \\
\hline DOE & $01 / 10 / 95$ & Marshall & 7.7 & 3.05 & & 6594 & & 312.9 & 3368.7 \\
\hline DOE & $02 / 03 / 95$ & Marshall & 10.0 & 2.92 & & 7147 & & 438.8 & 3666.8 \\
\hline DOE & $03 / 02 / 95$ & Marshall & 10.0 & 2.68 & & 7447 & & 462.2 & 3859.9 \\
\hline DOE & $04 / 07 / 95$ & Marshall & 11.3 & 2.55 & & 7915 & & 567.0 & 4191.3 \\
\hline DOE & $05 / 10 / 95$ & Marshall & 36.2 & 2.91 & & 7256 & & 1656.9 & 3808.8 \\
\hline DOE & $06 / 06 / 95$ & Marshall & 36.8 & 2.69 & & 7600 & & 1803.7 & 4080.6 \\
\hline
\end{tabular}


Table E-1e, Omega Mine-pool, Marshall Spring, Raw Chemical Data

\begin{tabular}{|c|c|c|c|c|c|c|c|c|c|}
\hline Sampled By & Date & Location & Flow gpm & $\mathrm{pH}$ & $\begin{array}{c}\text { Sp. } \\
\text { Conductance } \\
\text { umhos } / \mathrm{cm}\end{array}$ & TDS, mg/L & Temp, C & $\begin{array}{l}\text { Acid load, } \\
\text { lbs/day } \\
\text { CaCO3 Eq }\end{array}$ & $\begin{array}{l}\text { Calc Total } \\
\text { Acidity } \\
\text { CaCO3 Eq }\end{array}$ \\
\hline DOE & $07 / 13 / 95$ & Marshall & 36.8 & 3.78 & & 6855 & & 1566.7 & 3537.5 \\
\hline DOE & $08 / 03 / 95$ & Marshall & 10.7 & 2.94 & & 6470 & & 437.5 & 3401.3 \\
\hline DOE & 09/07/95 & Marshall & 7.5 & 3.07 & & 6860 & & 302.7 & 3355.5 \\
\hline DOE & $10 / 12 / 95$ & Marshall & 6.1 & 3.19 & & 6249 & & 225.9 & 3102.7 \\
\hline DOE & $11 / 22 / 95$ & Marshall & 5.6 & 3.21 & & 5801 & & 194.9 & 2872.8 \\
\hline DOE & $01 / 05 / 96$ & Marshall & 11.2 & 3.13 & & 6915 & & 476.9 & 3542.2 \\
\hline DOE & $02 / 21 / 96$ & Marshall & 23.4 & 2.29 & & 10310 & & 1650.3 & 5856.1 \\
\hline DOE & $03 / 18 / 96$ & Marshall & 64.3 & 2.44 & & 8108 & & 3429.1 & 4436.0 \\
\hline DOE & $04 / 26 / 96$ & Marshall & 56.4 & 2.51 & & 6103 & & 2249.0 & 3319.2 \\
\hline DOE & $06 / 07 / 96$ & Marshall & 31.0 & 2.62 & & 5576 & & 1111.0 & 2984.4 \\
\hline DOE & $07 / 23 / 96$ & Marshall & 15.1 & 3.00 & & 5617 & & 532.2 & 2938.0 \\
\hline DOE & $08 / 28 / 96$ & Marshall & 19.2 & 2.87 & & 6229 & & 744.0 & 3227.8 \\
\hline DOE & $10 / 16 / 96$ & Marshall & 17.0 & 3.00 & & 5811 & & 603.3 & 2944.1 \\
\hline DOE & $11 / 26 / 96$ & Marshall & 32.8 & 2.75 & & 6121 & & 1259.5 & 3194.1 \\
\hline DOE & $12 / 13 / 96$ & Marshall & 57.7 & 2.66 & & 6087 & & 2243.8 & 3235.1 \\
\hline DOE & $01 / 28 / 97$ & Marshall & 13.3 & 2.63 & & 5755 & & 502.8 & 3154.3 \\
\hline DOE & $02 / 21 / 97$ & Marshall & 9.5 & 2.69 & & 5801 & & 356.5 & 3113.3 \\
\hline DOE & $03 / 26 / 97$ & Marshall & 65.2 & 2.57 & & 6025 & & 2540.3 & 3241.7 \\
\hline DOE & $05 / 20 / 97$ & Marshall & 40.6 & 2.91 & & 4634 & & 1180.9 & 2418.6 \\
\hline DOE & $07 / 10 / 97$ & Marshall & 17.6 & 2.90 & & 5152 & & 570.8 & 2690.6 \\
\hline DOE & 09/10/97 & Marshall & 9.5 & 3.03 & & 4692 & & 273.4 & 2404.5 \\
\hline DOE & $11 / 05 / 97$ & Marshall & 7.1 & 3.04 & & 4375 & & 191.0 & 2227.7 \\
\hline DOE & $01 / 12 / 98$ & Marshall & 23.4 & 2.75 & & 5391 & & 802.9 & 2849.3 \\
\hline DOE & 02/09/98 & Marshall & 53.7 & 2.54 & & 6946 & & 2433.4 & 3770.5 \\
\hline DOE & $03 / 26 / 98$ & Marshall & 78.1 & 2.74 & & 5446 & & 2746.5 & 2924.1 \\
\hline DOE & $04 / 29 / 98$ & Marshall & 63.5 & 2.74 & & 4763 & & 1884.8 & 2468.2 \\
\hline WVDEP & $05 / 14 / 98$ & Marshall & 51.5 & 2.70 & 6900 & 4915 & & 1518.5 & 2452.0 \\
\hline DOE & $05 / 28 / 98$ & Marshall & 53.2 & 2.91 & & 4622 & & 1445.2 & 2261.0 \\
\hline WVDEP & $06 / 15 / 98$ & Marshall & 26.9 & 2.70 & 17100 & 6002 & & 43.7 & 135.4 \\
\hline DOE & $06 / 25 / 98$ & Marshall & 115.6 & 3.07 & & 5543 & & 1941.5 & 1397.4 \\
\hline WVDEP & $07 / 15 / 98$ & Marshall & 47.5 & 2.60 & 9500 & 7923 & & 1136.8 & 1991.6 \\
\hline DOE & $08 / 05 / 98$ & Marshall & 45.6 & 3.43 & & 5580 & & 1264.1 & 2306.2 \\
\hline WVDEP & $08 / 13 / 98$ & Marshall & 25.5 & 3.00 & 8050 & 6641 & & 623.4 & 2030.7 \\
\hline DOE & 09/03/98 & Marshall & 17.1 & 3.15 & & 8625 & & 912.3 & 4432.4 \\
\hline WVDEP & $09 / 15 / 98$ & Marshall & 16.6 & 2.80 & 26300 & 10256 & & 983.1 & 4933.1 \\
\hline WVDEP & $10 / 15 / 98$ & Marshall & 5.8 & 2.80 & 24700 & 12705 & & 225.7 & 3226.3 \\
\hline
\end{tabular}


Table E-1e, Omega Mine-pool, Marshall Spring, Raw Chemical Data

\begin{tabular}{|c|c|c|c|c|c|c|c|c|c|}
\hline Sampled By & Date & Location & Flow gpm & $\mathrm{pH}$ & $\begin{array}{c}\text { Sp. } \\
\text { Conductance } \\
\text { umhos } / \mathrm{cm}\end{array}$ & TDS, mg/L & Temp, C & $\begin{array}{l}\text { Acid load, } \\
\text { lbs/day } \\
\text { CaCO3 Eq }\end{array}$ & $\begin{array}{l}\text { Calc Total } \\
\text { Acidity } \\
\text { CaCO3 Eq }\end{array}$ \\
\hline DOE & $10 / 29 / 98$ & Marshall & 2.0 & 3.37 & & 8772 & & 102.9 & 4279.3 \\
\hline WVDEP & $11 / 15 / 98$ & Marshall & 2.7 & 3.00 & 16200 & 8281 & & 111.8 & 3458.4 \\
\hline DOE & $12 / 10 / 98$ & Marshall & 2.5 & 3.23 & & 8006 & & 117.5 & 3926.3 \\
\hline WVDEP & $12 / 15 / 98$ & Marshall & 1.8 & 2.90 & 10900 & 9048 & & 87.3 & 4055.2 \\
\hline WVDEP & $01 / 17 / 99$ & Marshall & 1.8 & 3.30 & 10600 & 7925 & & 67.6 & 3142.8 \\
\hline WVDEP & $02 / 14 / 99$ & Marshall & 6.7 & 3.00 & 15400 & 9650 & & 174.2 & 2157.2 \\
\hline $\mathrm{DOE}$ & $02 / 18 / 99$ & Marshall & 7.4 & 3.46 & & 9325 & & 416.2 & 4678.4 \\
\hline WVDEP & $03 / 14 / 99$ & Marshall & 9.0 & 3.10 & 15300 & 9936 & & 539.8 & 5012.4 \\
\hline DOE & $03 / 30 / 99$ & Marshall & 9.0 & 3.40 & & 13352 & & 824.8 & 7663.6 \\
\hline WVDEP & $04 / 13 / 99$ & Marshall & 8.1 & 3.00 & 28600 & 19803 & & 1024.1 & 10570.7 \\
\hline WVDEP & $04 / 26 / 99$ & Marshall & 8.1 & 3.20 & 29100 & 20130 & & 937.5 & 9676.9 \\
\hline DOE & $04 / 29 / 99$ & Marshall & 7.5 & 3.10 & & 16313 & & 858.5 & 9496.1 \\
\hline WVDEP & $05 / 17 / 99$ & Marshall & 7.2 & 3.00 & 27400 & 15987 & & 4.3 & 50.0 \\
\hline DOE & $05 / 26 / 99$ & Marshall & 5.8 & 2.96 & & 13381 & & 521.8 & 7531.7 \\
\hline WVDEP & $06 / 14 / 99$ & Marshall & 4.9 & 2.70 & 25500 & 13069 & & 421.6 & 7113.8 \\
\hline DOE & $06 / 29 / 99$ & Marshall & 3.9 & 2.80 & & 10728 & & 276.5 & 5831.5 \\
\hline WVDEP & $07 / 13 / 99$ & Marshall & 3.6 & 3.00 & 19100 & 11058 & & 235.0 & 5462.2 \\
\hline DOE & $07 / 27 / 99$ & Marshall & 3.6 & 3.34 & & 8971 & & 203.0 & 4675.0 \\
\hline WVDEP & $08 / 14 / 99$ & Marshall & 4.0 & 3.20 & 14900 & 9542 & & 209.1 & 4315.8 \\
\hline DOE & $08 / 26 / 99$ & Marshall & 3.3 & 3.22 & & 8581 & & 175.2 & 4400.6 \\
\hline WVDEP & $09 / 14 / 99$ & Marshall & 3.1 & 2.90 & 18400 & 8831 & & 154.6 & 4097.1 \\
\hline DOE & 09/29/99 & Marshall & 2.7 & 3.10 & & 7984 & & 130.3 & 4077.8 \\
\hline WVDEP & $10 / 15 / 99$ & Marshall & 1.8 & 3.00 & 15900 & 8396 & & 83.7 & 3887.9 \\
\hline DOE & $10 / 29 / 99$ & Marshall & 3.1 & 3.19 & & 7586 & & 141.9 & 3815.7 \\
\hline WVDEP & $11 / 15 / 99$ & Marshall & 1.8 & 3.10 & 14800 & 8444 & & 86.0 & 3998.5 \\
\hline DOE & $12 / 07 / 99$ & Marshall & 5.0 & 2.69 & & 7150 & & 214.8 & 3597.0 \\
\hline WVDEP & $12 / 15 / 99$ & Marshall & 7.2 & 3.00 & 8980 & 6383 & & 312.0 & 3620.7 \\
\hline WVDEP & $01 / 18 / 00$ & Marshall & 8.0 & 3.20 & 9840 & 7990 & & 382.1 & 3989.0 \\
\hline WVDEP & $02 / 08 / 00$ & Marshall & 5.0 & 3.50 & 9690 & 7653 & & 236.3 & 3916.9 \\
\hline WVDEP & $03 / 15 / 00$ & Marshall & 6.0 & 2.50 & 6390 & 3195 & & 458.3 & 6354.5 \\
\hline WVDEP & $04 / 14 / 00$ & Marshall & 9.0 & 3.10 & 17800 & 9684 & & 541.3 & 5003.5 \\
\hline WVDEP & $05 / 15 / 00$ & Marshall & 7.0 & 3.40 & 9780 & 7726 & & 314.3 & 3740.7 \\
\hline WVDEP & $06 / 16 / 00$ & Marshall & 6.0 & 2.90 & 7610 & 6144 & & 266.3 & 3692.0 \\
\hline WVDEP & $07 / 18 / 00$ & Marshall & 8.0 & 3.30 & 8860 & 6854 & & 336.3 & 3489.0 \\
\hline WVDEP & $08 / 15 / 00$ & Marshall & 7.0 & 3.40 & 7450 & 5545 & & 207.0 & 2463.3 \\
\hline WVDEP & $09 / 15 / 00$ & Marshall & 4.0 & 3.10 & 6460 & 5114 & & 114.8 & 2392.9 \\
\hline
\end{tabular}


Table E-1e, Omega Mine-pool, Marshall Spring, Raw Chemical Data

\begin{tabular}{|c|c|c|c|c|c|c|c|c|c|}
\hline Sampled By & Date & Location & Flow gpm & $\mathrm{pH}$ & $\begin{array}{c}\text { Sp. } \\
\text { Conductance } \\
\text { umhos } / \mathrm{cm}\end{array}$ & TDS, mg/L & Temp, C & $\begin{array}{l}\text { Acid load, } \\
\text { lbs/day } \\
\text { CaCO3 Eq }\end{array}$ & $\begin{array}{l}\text { Calc Total } \\
\text { Acidity } \\
\text { CaCO3 Eq }\end{array}$ \\
\hline WVDEP & $10 / 15 / 00$ & Marshall & 3.0 & 3.20 & 6000 & 4041 & & 122.0 & 3383.9 \\
\hline WVDEP & $11 / 15 / 00$ & Marshall & 3.0 & 3.60 & 7310 & 5718 & & 86.7 & 2403.9 \\
\hline WVDEP & $12 / 14 / 00$ & Marshall & 5.0 & 3.40 & 5445 & 5445 & & 132.5 & 2196.6 \\
\hline WVDEP & $01 / 15 / 01$ & Marshall & 7.0 & 3.20 & 6180 & 4998 & & 163.1 & 1941.8 \\
\hline WVDEP & $02 / 13 / 01$ & Marshall & 27.0 & 3.40 & 7290 & 5618 & & 120.3 & 370.6 \\
\hline WVDEP & 03/13/01 & Marshall & 27.0 & 3.50 & 5790 & 4710 & & 571.3 & 1759.6 \\
\hline WVDEP & $04 / 16 / 01$ & Marshall & 38.0 & 3.40 & 6920 & 5066 & & 2950.7 & 6461.7 \\
\hline WVDEP & $05 / 15 / 01$ & Marshall & 24.0 & 3.50 & 5910 & 4562 & & 669.5 & 2319.7 \\
\hline WVDEP & 06/18/01 & Marshall & 18.0 & 3.20 & 5620 & 4441 & & 722.5 & 3337.4 \\
\hline WVDEP & $07 / 15 / 01$ & Marshall & 21.0 & 3.40 & 4930 & 3932 & & 482.7 & 1911.3 \\
\hline WVDEP & $08 / 15 / 01$ & Marshall & 16.0 & 3.30 & 5870 & 4840 & & 305.2 & 1588.0 \\
\hline WVDEP & $09 / 14 / 01$ & Marshall & 8.0 & 3.30 & 4920 & 4001 & & 205.4 & 2131.1 \\
\hline WVDEP & $10 / 15 / 01$ & Marshall & 9.0 & 3.10 & 3840 & 5180 & 20 & 198.1 & 1839.6 \\
\hline WVDEP & $11 / 15 / 01$ & Marshall & 9.0 & 3.10 & 3110 & 4536 & 11.1 & 202.1 & 1876.2 \\
\hline WVDEP & $12 / 14 / 01$ & Marshall & 6.0 & 3.10 & 3730 & 4488 & 10.5 & 91.8 & 1281.8 \\
\hline WVDEP & $01 / 16 / 02$ & Marshall & 10.8 & 3.40 & 2500 & 4404 & 8.4 & 112.7 & 872.4 \\
\hline WVDEP & $02 / 14 / 02$ & Marshall & 24.2 & 3.60 & 3340 & 4804 & 4.4 & 512.6 & 1762.8 \\
\hline WVDEP & $03 / 14 / 02$ & Marshall & 16.9 & 3.60 & 3190 & 4632 & 16.7 & 337.5 & 1658.7 \\
\hline WVDEP & $04 / 15 / 02$ & Marshall & 44.8 & 3.30 & 3350 & 4860 & 13.8 & 1107.3 & 2056.3 \\
\hline WVDEP & $05 / 15 / 02$ & Marshall & 53.8 & 3.40 & 4630 & 5448 & 11.6 & 1283.4 & 1986.0 \\
\hline WVDEP & $06 / 18 / 02$ & Marshall & 29.6 & 3.60 & 3050 & 4360 & 15.5 & 145.0 & 408.0 \\
\hline WVDEP & $07 / 18 / 02$ & Marshall & 0.0 & & & & & 0.0 & \\
\hline WVDEP & $08 / 12 / 02$ & Marshall & 11.0 & 3.50 & 3320 & 4408 & 15.5 & 197.5 & 1496.5 \\
\hline Perry & $08 / 20 / 02$ & Marshall & 6.2 & 3.48 & 3310 & 4203 & 13.8 & 112.7 & 1525.0 \\
\hline WVDEP & 09/16/02 & Marshall & 7.0 & 3.60 & 3340 & 4200 & 16.5 & 113.2 & 1347.6 \\
\hline WVDEP & $10 / 15 / 02$ & Marshall & 5.8 & 3.20 & 3360 & 4164 & 14.4 & 69.2 & 988.6 \\
\hline WVDEP & $11 / 15 / 02$ & Marshall & 7.0 & 3.30 & 3325 & 3808 & 15 & 110.6 & 1316.4 \\
\hline WVDEP & $12 / 15 / 02$ & Marshall & 12.0 & 3.30 & 3652 & 4120 & 13.3 & 180.1 & 1252.4 \\
\hline WVDEP & $01 / 14 / 03$ & Marshall & 39.9 & 3.50 & 3740 & 4756 & 8.9 & 783.3 & 1632.4 \\
\hline WVDEP & $02 / 24 / 03$ & Marshall & 38.0 & 3.50 & 3460 & 4148 & 11.7 & 370.4 & 812.0 \\
\hline WVDEP & $03 / 18 / 03$ & Marshall & 35.8 & 3.47 & 3990 & 4644 & 14.44 & 908.5 & 2108.8 \\
\hline WVDEP & $04 / 15 / 03$ & Marshall & 26.9 & 3.51 & 3470 & 4140 & 14.44 & 534.0 & 1652.7 \\
\hline WVDEP & $05 / 20 / 03$ & Marshall & 44.8 & 3.25 & 3800 & 4760 & 15.56 & 1165.5 & 2164.4 \\
\hline WVDEP & $06 / 17 / 03$ & Marshall & 49.3 & 3.53 & 3550 & 3956 & 15.56 & 745.0 & 1257.6 \\
\hline WVDEP & $08 / 13 / 03$ & Marshall & 26.9 & 3.38 & 2920 & 3208 & 15.56 & 414.8 & 1283.9 \\
\hline Perry & $08 / 28 / 03$ & Marshall & 12.9 & 3.60 & 3980 & 3092 & 14.7 & 244.5 & 1576.6 \\
\hline
\end{tabular}


Table E-1e, Omega Mine-pool, Marshall Spring, Raw Chemical Data

\begin{tabular}{|c|c|c|c|c|c|c|c|c|c|}
\hline Sampled By & Date & Location & Flow gpm & $\mathrm{pH}$ & $\begin{array}{c}\text { Sp. } \\
\text { Conductance } \\
\text { umhos/cm }\end{array}$ & TDS, mg/L & Temp, C & $\begin{array}{l}\text { Acid load, } \\
\text { lbs/day } \\
\text { CaCO3 Eq }\end{array}$ & $\begin{array}{l}\text { Calc Total } \\
\text { Acidity } \\
\text { CaCO3 Eq }\end{array}$ \\
\hline WVDEP & $09 / 15 / 03$ & Marshall & 26.9 & 3.38 & 3040 & 3376 & 15.56 & 346.5 & 1072.4 \\
\hline WVDEP & $10 / 14 / 03$ & Marshall & 22.4 & 3.26 & 2910 & 3312 & 14.4 & 292.6 & 1086.8 \\
\hline WVDEP & $11 / 18 / 03$ & Marshall & 26.9 & 3.27 & 3060 & 3588 & 9.44 & 227.3 & 703.7 \\
\hline WVDEP & $12 / 19 / 03$ & Marshall & 44.8 & 3.05 & 3470 & 3764 & 14.4 & 606.6 & 1126.5 \\
\hline WVDEP & $01 / 14 / 04$ & Marshall & 44.8 & 3.37 & 3300 & 3716 & 12.2 & 715.2 & 1328.1 \\
\hline WVDEP & $02 / 17 / 04$ & Marshall & 49.3 & 3.52 & 3440 & 4052 & 14.4 & 832.8 & 1405.9 \\
\hline WVDEP & $03 / 23 / 04$ & Marshall & 44.8 & 3.16 & 3070 & 3364 & 8.9 & 615.3 & 1142.7 \\
\hline WVDEP & $04 / 13 / 04$ & Marshall & 44.8 & 3.37 & 2900 & 3016 & 10 & 511.5 & 949.9 \\
\hline WVDEP & $05 / 18 / 04$ & Marshall & 22.4 & 3.66 & 2620 & 2828 & 12.78 & 268.9 & 998.8 \\
\hline WVDEP & $06 / 14 / 04$ & Marshall & 26.9 & 3.70 & 2620 & 2728 & 15 & 232.2 & 718.6 \\
\hline WVDEP & $07 / 12 / 04$ & Marshall & 17.9 & 3.34 & 2540 & 2712 & 15.6 & 191.6 & 889.5 \\
\hline WVDEP & 08/09/04 & Marshall & 9.0 & 3.48 & 2540 & 2744 & 15 & 103.8 & 964.0 \\
\hline WVDEP & $09 / 14 / 04$ & Marshall & 9.0 & 3.34 & 2470 & 2440 & 15 & 75.5 & 701.4 \\
\hline WVDEP & $10 / 18 / 04$ & Marshall & 13.4 & 3.60 & 2520 & 2584 & 9.4 & 149.8 & 927.3 \\
\hline Perry & $03 / 22 / 05$ & Marshall & 36.4 & 3.78 & 2940 & 2788 & 12.8 & 449.6 & 1028.7 \\
\hline Perry & $05 / 26 / 06$ & Marshall & 28.8 & 3.54 & 2150 & 2418 & 13.8 & 256.8 & 741.9 \\
\hline Perry & $05 / 03 / 07$ & Marshall & 45.6 & 3.52 & 2565 & 2162 & 13.6 & 427.7 & 780.3 \\
\hline Perry & 09/13/07 & Marshall & 10.1 & 3.45 & 2640 & 2152 & 13.4 & 83.5 & 687.8 \\
\hline
\end{tabular}


Table E-1f, Omega Mine-pool, Marshall Spring, Raw Chemical Data

\begin{tabular}{|c|c|c|c|c|c|c|c|c|c|c|c|c|c|}
\hline $\begin{array}{c}\text { Sampled } \\
\text { By }\end{array}$ & Date & Location & $\begin{array}{c}\text { Fe3+, } \\
\mathrm{mg} / \mathrm{L}\end{array}$ & $\begin{array}{c}\text { Fe2+, } \\
\mathrm{mg} / \mathrm{L}\end{array}$ & $\begin{array}{c}\text { Fe Total, } \\
\mathrm{mg} / \mathrm{L}\end{array}$ & $\begin{array}{c}\mathrm{Ca}, \\
\mathrm{mg} / \mathrm{L}\end{array}$ & $\begin{array}{l}\mathrm{Mg}, \\
\mathrm{mg} / \mathrm{L}\end{array}$ & $\begin{array}{c}\mathrm{Na}, \\
\mathrm{mg} / \mathrm{L}\end{array}$ & $\mathrm{K}, \mathrm{mg} / \mathrm{L}$ & Al, mg/L & $\begin{array}{c}\mathrm{Mn}, \\
\mathrm{mg} / \mathrm{L}\end{array}$ & $\begin{array}{l}\mathrm{SO} 4, \\
\mathrm{mg} / \mathrm{L}\end{array}$ & $\begin{array}{c}\mathrm{Cl}, \\
\mathrm{mg} / \mathrm{L}\end{array}$ \\
\hline DOE & $11 / 15 / 91$ & Marshall & 0 & 1091 & 1091 & 389.0 & 207.0 & 5.0 & & 113.0 & 6.70 & 4950 & 8.5 \\
\hline DOE & $02 / 11 / 93$ & Marshall & 334 & 1816 & 2150 & 373.0 & 221.0 & 2.7 & 6.8 & 349.0 & 8.16 & 7815 & 10 \\
\hline DOE & 03/03/93 & Marshall & 204 & 1771 & 1975 & 338.0 & 203.0 & 3.5 & 6.1 & 331.0 & 7.80 & 7425 & 1 \\
\hline DOE & 03/18/93 & Marshall & 422 & 1567 & 1989 & 329.0 & 197.0 & 8.2 & 6.6 & 327.0 & 7.60 & 7319 & 5 \\
\hline DOE & $04 / 02 / 93$ & Marshall & 700 & 1388 & 2088 & 308.0 & 187.0 & 2.7 & 3.5 & 349.0 & 7.20 & 7725 & 5 \\
\hline DOE & $04 / 14 / 93$ & Marshall & 650 & 1527 & 2177 & 319.0 & 191.0 & 3.4 & 3.7 & 359.0 & 7.40 & 7967 & 5 \\
\hline DOE & 04/29/93 & Marshall & 634 & 1463 & 2097 & 318.0 & 184.0 & 4.9 & 2.9 & 346.0 & 7.50 & 7657 & 5.69 \\
\hline DOE & $05 / 20 / 93$ & Marshall & 349 & 1281 & 1630 & 296.0 & 162.0 & 3.1 & 5.1 & 279.0 & 6.30 & 6132 & 5 \\
\hline DOE & $06 / 03 / 93$ & Marshall & 278 & 1305 & 1583 & 300.0 & 164.0 & 3.7 & 5 & 273.0 & 6.30 & 5941 & 10 \\
\hline DOE & 06/10/93 & Marshall & 246.76 & 1366 & 1612.76 & 314.2 & 170.2 & 4.3 & 6.84 & 274.7 & 6.51 & 5974 & 13.1 \\
\hline DOE & $06 / 23 / 93$ & Marshall & 266.5 & 1393 & 1659.5 & 326.7 & 175.3 & 4.7 & 6.48 & 275.7 & 6.72 & 6205 & 6.9 \\
\hline DOE & $07 / 08 / 93$ & Marshall & 157.84 & 1443 & 1600.84 & 316.3 & 167.2 & 3.9 & 6.43 & 266.7 & 6.48 & 5824 & 3.1 \\
\hline DOE & 07/22/93 & Marshall & 56 & 1394 & 1450 & 319.9 & 168.1 & 4.7 & 7.46 & 228.5 & 6.47 & 5302 & 2.9 \\
\hline DOE & $08 / 11 / 93$ & Marshall & 43.03 & 1243 & 1286.03 & 324.9 & 166.2 & 5.7 & 7.35 & 195.5 & 6.25 & 4672 & \\
\hline DOE & $09 / 02 / 93$ & Marshall & 50.07 & 1170 & 1220.07 & 318.5 & 157.5 & 5.2 & 8.48 & 175.8 & 5.85 & 4535 & \\
\hline DOE & 09/10/93 & Marshall & 72.05 & 1146 & 1218.05 & 320.3 & 157.1 & 5.8 & 8.4 & 172.8 & 5.89 & 4470 & \\
\hline DOE & $10 / 07 / 93$ & Marshall & 77.76 & 1156 & 1233.76 & 341.0 & 163.3 & 6.5 & 10.22 & 170.7 & 6.09 & 4621 & 9.3 \\
\hline DOE & $10 / 25 / 93$ & Marshall & 36.14 & 1300 & 1336.14 & 329.0 & 164.2 & 6.1 & 10.08 & 190.8 & 6.07 & 4784 & 13.9 \\
\hline DOE & $11 / 10 / 93$ & Marshall & 93.79 & 1207 & 1300.79 & 336.2 & 161.0 & 7.5 & 12.3 & 174.6 & 6.10 & 4658 & 10.6 \\
\hline DOE & $12 / 07 / 93$ & Marshall & 74.88 & 1158 & 1232.88 & 330.1 & 160.2 & 8.1 & 10.84 & 166.6 & 5.90 & 4500 & 14.7 \\
\hline DOE & $12 / 23 / 93$ & Marshall & 276.75 & 1605 & 1881.75 & 350.9 & 190.4 & 3.8 & 7.06 & 292.5 & 7.30 & 6803 & 11.9 \\
\hline DOE & $01 / 28 / 94$ & Marshall & 524.43 & 1465 & 1989.43 & 337.3 & 183.7 & 5.1 & 5.6 & 333.6 & 7.38 & 7319 & 13.1 \\
\hline DOE & $05 / 05 / 94$ & Marshall & 360.97 & 876.8 & 1237.77 & 271.3 & 115.3 & 4.4 & 5.48 & 209.3 & 4.73 & 4902 & 15.35 \\
\hline DOE & $06 / 10 / 94$ & Marshall & 66.69 & 1202 & 1268.69 & 305.3 & 135.5 & 4.6 & 8.76 & 223.4 & 5.23 & 4896 & 11.5 \\
\hline DOE & $07 / 06 / 94$ & Marshall & 21.83 & 1188 & 1209.83 & 311.7 & 136.8 & 4.7 & 9.45 & 205.2 & 5.33 & 4609 & 13 \\
\hline DOE & $08 / 03 / 94$ & Marshall & 38.48 & 1151 & 1189.48 & 310.7 & 141.4 & 5.2 & 9.72 & 191.3 & 5.44 & 4460 & 17.8 \\
\hline DOE & $09 / 01 / 94$ & Marshall & 25.6 & 1273.2 & 1298.8 & 327.1 & 146.4 & 4.6 & 11.91 & 206.7 & 5.58 & 4904 & 11.2 \\
\hline DOE & $10 / 07 / 94$ & Marshall & 47.84 & 1266 & 1313.84 & 331.4 & 149.9 & 4.4 & 10.41 & 215.9 & 5.82 & 4992 & 9.38 \\
\hline DOE & $11 / 16 / 94$ & Marshall & 0 & 1200.95 & 1200.95 & 308.5 & 141.3 & 4.8 & 8.9 & 190.9 & 5.54 & 4566 & 59.9 \\
\hline DOE & $12 / 14 / 94$ & Marshall & 0 & 1162.56 & 1162.56 & 313.4 & 141.7 & 5.7 & 8.87 & 186.1 & 5.78 & 4664 & 0.85 \\
\hline DOE & $01 / 10 / 95$ & Marshall & 0.01 & 1236 & 1236.01 & 314.2 & 145.9 & 5.1 & 9.16 & 198.1 & 5.80 & 4657 & 9.49 \\
\hline DOE & 02/03/95 & Marshall & 0 & 1325.89 & 1325.89 & 341.18 & 152.96 & 6.4 & 10.66 & 219.89 & 6.17 & 5053.93 & 15.77 \\
\hline DOE & $03 / 02 / 95$ & Marshall & 163.25 & 1202.66 & 1365.91 & 308.3 & 145.9 & 6.3 & 5.44 & 233.8 & 6.02 & 5343 & 17.66 \\
\hline DOE & $04 / 07 / 95$ & Marshall & 342.15 & 1109 & 1451.15 & 287.96 & 136.94 & 5.28 & 2.59 & 259.47 & 5.95 & 5736.81 & 14.65 \\
\hline DOE & 05/10/95 & Marshall & 147.37 & 1187 & 1334.37 & 296.7 & 136.1 & 5.6 & 8.3 & 242.6 & 5.70 & 5198 & 14.5 \\
\hline DOE & $06 / 06 / 95$ & Marshall & 333.02 & 1056 & 1389.02 & 278.0 & 128.6 & 4.9 & 6.46 & 266.7 & 5.48 & 5488 & 19 \\
\hline DOE & $07 / 13 / 95$ & Marshall & 96.24 & 1144 & 1240.24 & 293.14 & 134.72 & 5.31 & 6.8 & 233.76 & 5.51 & 4908.41 & 14.1 \\
\hline
\end{tabular}


Table E-1f, Omega Mine-pool, Marshall Spring, Raw Chemical Data

\begin{tabular}{|c|c|c|c|c|c|c|c|c|c|c|c|c|c|}
\hline $\begin{array}{l}\text { Sampled } \\
\text { By }\end{array}$ & Date & Location & $\begin{array}{l}\text { Fe3+, } \\
\mathrm{mg} / \mathrm{L}\end{array}$ & $\begin{array}{l}\mathrm{Fe} 2+, \\
\mathrm{mg} / \mathrm{L}\end{array}$ & $\begin{array}{c}\text { Fe Total, } \\
\mathrm{mg} / \mathrm{L}\end{array}$ & $\begin{array}{c}\mathrm{Ca}, \\
\mathrm{mg} / \mathrm{L}\end{array}$ & $\begin{array}{l}\mathrm{Mg}, \\
\mathrm{mg} / \mathrm{L}\end{array}$ & $\begin{array}{c}\mathrm{Na}, \\
\mathrm{mg} / \mathrm{L}\end{array}$ & $\mathrm{K}, \mathrm{mg} / \mathrm{L}$ & $\mathrm{Al}, \mathrm{mg} / \mathrm{L}$ & $\begin{array}{l}\mathrm{Mn}, \\
\mathrm{mg} / \mathrm{L}\end{array}$ & $\begin{array}{l}\mathrm{SO} 4, \\
\mathrm{mg} / \mathrm{L}\end{array}$ & $\begin{array}{c}\mathrm{Cl}, \\
\mathrm{mg} / \mathrm{L}\end{array}$ \\
\hline DOE & $08 / 03 / 95$ & Marshall & 0 & 1215.23 & 1215.23 & 306.6 & 136.3 & 5.1 & 9.74 & 208.5 & 5.41 & 4556 & 14.6 \\
\hline DOE & $09 / 07 / 95$ & Marshall & 28.48 & 1215.5 & 1243.98 & 358.33 & 150.12 & 6.98 & 11.75 & 193.49 & 5.98 & 4862.04 & 15.2 \\
\hline $\mathrm{DOE}$ & $10 / 12 / 95$ & Marshall & 0 & 1151.03 & 1151.03 & 330.38 & 141.34 & 6.85 & 10.98 & 179.89 & 5.64 & 4394.77 & 16.9 \\
\hline DOE & $11 / 22 / 95$ & Marshall & 2.25 & 1069 & 1071.25 & 319.9 & 132.9 & 7.1 & 9.77 & 164.5 & 5.50 & 4072 & 8.1 \\
\hline DOE & $01 / 05 / 96$ & Marshall & 0 & 1282.65 & 1282.65 & 332.7 & 147.4 & 5.8 & 10.82 & 215.5 & 6.22 & 4887 & 16.04 \\
\hline DOE & $02 / 21 / 96$ & Marshall & 523.71 & 1426 & 1949.71 & 300.9 & 146.0 & 4.5 & 4.43 & 377.4 & 6.65 & 7496 & 5.11 \\
\hline DOE & $03 / 18 / 96$ & Marshall & 620.61 & 866 & 1486.61 & 247.7 & 122.2 & 4.0 & 3.17 & 284.9 & 5.68 & 5919 & 20.55 \\
\hline DOE & $04 / 26 / 96$ & Marshall & 362.12 & 735.4 & 1097.52 & 232.3 & 101.1 & 4.3 & 4.17 & 214.5 & 4.43 & 4433 & 1 \\
\hline DOE & $06 / 07 / 96$ & Marshall & 300.73 & 676 & 976.73 & 227.0 & 93.3 & 3.8 & 5.41 & 199.5 & 4.07 & 4055 & 1 \\
\hline DOE & $07 / 23 / 96$ & Marshall & 31.81 & 989.8 & 1021.61 & 285.8 & 110.1 & 5.8 & 8.7 & 189.1 & 4.48 & 3968 & 13.44 \\
\hline DOE & $08 / 28 / 96$ & Marshall & 118.2 & 987.5 & 1105.7 & 314.2 & 112.3 & 5.8 & 10.26 & 211.0 & 4.77 & 4442 & 12.24 \\
\hline DOE & $10 / 16 / 96$ & Marshall & 28.63 & 992 & 1020.63 & 305.6 & 114.0 & 5.8 & 9.95 & 190.5 & 4.61 & 4133 & 17.57 \\
\hline DOE & $11 / 26 / 96$ & Marshall & 239.96 & 807 & 1046.96 & 275.6 & 111.3 & 4.9 & 7.6 & 219.9 & 4.9 & 4433.5 & 6.31 \\
\hline DOE & $12 / 13 / 96$ & Marshall & 384.37 & 670 & 1054.37 & 253.92 & 102.42 & 4.61 & 5.65 & 221.35 & 4.54 & 4418.7 & 11.48 \\
\hline DOE & $01 / 28 / 97$ & Marshall & 98.91 & 925 & 1023.91 & 241.86 & 95.18 & 3.96 & 7.53 & 215.35 & 4.12 & 4145.61 & 7.7 \\
\hline DOE & $02 / 21 / 97$ & Marshall & 108.74 & 927 & 1035.74 & 266.7 & 95.5 & 4.1 & 6.81 & 206.8 & 4.32 & 4155 & 18 \\
\hline DOE & $03 / 26 / 97$ & Marshall & 380.6 & 669.5 & 1050.1 & 224.5 & 90.7 & 3.7 & 3.81 & 219.5 & 4.12 & 4412 & 6.5 \\
\hline DOE & $05 / 20 / 97$ & Marshall & 56.45 & 740.3 & 796.75 & 220.5 & 84.8 & 4.2 & 6.32 & 166.3 & 3.61 & 3344 & \\
\hline DOE & $07 / 10 / 97$ & Marshall & 61.7 & 836.3 & 898 & 253.4 & 92.1 & 4.7 & 9.29 & 182.3 & 3.99 & 3690 & 9.5 \\
\hline DOE & $09 / 10 / 97$ & Marshall & 39.93 & 800.2 & 840.13 & 262.5 & 98.9 & 5.4 & 9.53 & 152.3 & 4.08 & 3303 & 8.68 \\
\hline DOE & $11 / 05 / 97$ & Marshall & 26.37 & 759.2 & 785.57 & 258.3 & 96.3 & 7.3 & 9.16 & 138.3 & 4.05 & 3058 & 11.02 \\
\hline DOE & $01 / 12 / 98$ & Marshall & 63.96 & 909.5 & 973.46 & 255.5 & 96.5 & 5.4 & 8.79 & 181.8 & 4.13 & 3849 & 8.2 \\
\hline $\mathrm{DOE}$ & $02 / 09 / 98$ & Marshall & 469.44 & 737.7 & 1207.14 & 257.3 & 106.1 & 3.42 & 4.26 & 262.2 & 4.6 & 5047 & 43.44 \\
\hline DOE & $03 / 26 / 98$ & Marshall & 365.11 & 577.4 & 942.51 & 209.0 & 84.5 & 3.5 & 5.07 & 206.2 & 0.00 & 3987 & \\
\hline DOE & $04 / 29 / 98$ & Marshall & 266.96 & 520.7 & 787.66 & 205.7 & 81.4 & 3.2 & 4.81 & 172.9 & 3.52 & 3495 & \\
\hline WVDEP & $05 / 14 / 98$ & Marshall & & & 761 & & & & & 177 & 3.56 & 2980 & \\
\hline DOE & $05 / 28 / 98$ & Marshall & 102.65 & 620.4 & 723.05 & 322.2 & 69.0 & 10.8 & 11.02 & 161.9 & 3.05 & 3303 & 11.43 \\
\hline WVDEP & $06 / 15 / 98$ & Marshall & & & 9.22 & & & & & 2.34 & 3.43 & 3890 & \\
\hline DOE & $06 / 25 / 98$ & Marshall & -16.59 & 530 & 513.41 & 949.7 & 68.8 & 18.8 & 23.87 & 77.6 & 2.52 & 3863 & 21.06 \\
\hline WVDEP & $07 / 15 / 98$ & Marshall & & & 131 & & & & & 292 & 5.14 & 5380 & \\
\hline DOE & $08 / 05 / 98$ & Marshall & 22.72 & 775.2 & 797.92 & 496.0 & 88.5 & 45.2 & 65.66 & 153.5 & 3.55 & 3879 & 42.98 \\
\hline WVDEP & $08 / 13 / 98$ & Marshall & & & 712 & & & & & 126 & 3.28 & 3690 & \\
\hline DOE & $09 / 03 / 98$ & Marshall & 0 & 1497.39 & 1497.39 & 466.7 & 138.3 & 38.9 & 60.19 & 307.0 & 5.76 & 6059 & 36.67 \\
\hline WVDEP & $09 / 15 / 98$ & Marshall & & & 1530 & & & & & 379 & 4.93 & 5090 & \\
\hline WVDEP & $10 / 15 / 98$ & Marshall & & & 258 & & & & & 481 & 7.23 & 7920 & \\
\hline DOE & $10 / 29 / 98$ & Marshall & 58.18 & 1491 & 1549.18 & 459.9 & 164.5 & 60.8 & 53.75 & 265.2 & 6.03 & 6163 & 33.77 \\
\hline WVDEP & $11 / 15 / 98$ & Marshall & & & 1320 & & & & & 186 & 6.52 & 5430 & \\
\hline
\end{tabular}


Table E-1f, Omega Mine-pool, Marshall Spring, Raw Chemical Data

\begin{tabular}{|c|c|c|c|c|c|c|c|c|c|c|c|c|c|}
\hline $\begin{array}{c}\text { Sampled } \\
\text { By }\end{array}$ & Date & Location & $\begin{array}{l}\text { Fe3+, } \\
\text { mg/L }\end{array}$ & $\begin{array}{l}\text { Fe2+, } \\
\mathrm{mg} / \mathrm{L}\end{array}$ & $\begin{array}{c}\text { Fe Total, } \\
\mathrm{mg} / \mathrm{L}\end{array}$ & $\begin{array}{c}\mathrm{Ca}, \\
\mathrm{mg} / \mathrm{L}\end{array}$ & $\begin{array}{l}\mathrm{Mg}, \\
\mathrm{mg} / \mathrm{L}\end{array}$ & $\begin{array}{c}\mathrm{Na}, \\
\mathrm{mg} / \mathrm{L}\end{array}$ & $\mathrm{K}, \mathrm{mg} / \mathrm{L}$ & Al, mg/L & $\begin{array}{c}\mathrm{Mn}, \\
\mathrm{mg} / \mathrm{L}\end{array}$ & $\begin{array}{l}\mathrm{SO} 4, \\
\mathrm{mg} / \mathrm{L}\end{array}$ & $\begin{array}{c}\mathrm{Cl}, \\
\mathrm{mg} / \mathrm{L}\end{array}$ \\
\hline DOE & 12/10/98 & Marshall & 21.93 & 1399.78 & 1421.71 & 453.3 & 157.2 & 57.7 & 54.93 & 241.0 & 7.05 & 5574 & 26.5 \\
\hline WVDEP & $12 / 15 / 98$ & Marshall & & & 1480 & & & & & 240 & 5.01 & 5220 & \\
\hline WVDEP & $01 / 17 / 99$ & Marshall & & & 1200 & & & & & 173 & 4.5 & 5100 & \\
\hline WVDEP & $02 / 14 / 99$ & Marshall & & & 180 & & & & & 319 & 7.1 & 5910 & \\
\hline DOE & $02 / 18 / 99$ & Marshall & 0 & 1687.52 & 1687.52 & 487.4 & 181.9 & 50.7 & 52.08 & 292.4 & 8.53 & 6527 & 22.58 \\
\hline WVDEP & $03 / 14 / 99$ & Marshall & & & 1830 & & & & & 303 & 7.13 & 6120 & \\
\hline DOE & 03/30/99 & Marshall & 0.84 & 2553 & 2553.84 & 535.6 & 234.7 & 49.4 & 55.22 & 549.1 & 11.51 & 9320 & 19.22 \\
\hline WVDEP & $04 / 13 / 99$ & Marshall & & & 3690 & & & & & 701 & 10.8 & 12800 & \\
\hline WVDEP & $04 / 26 / 99$ & Marshall & & & 3390 & & & & & 639 & 14.3 & 12800 & \\
\hline DOE & $04 / 29 / 99$ & Marshall & 534.92 & 2672 & 3206.92 & 505.7 & 267.9 & 44.1 & 52.08 & 663.9 & 14.50 & 11513 & 15.84 \\
\hline WVDEP & $05 / 17 / 99$ & Marshall & & & & & & & & & & 9540 & \\
\hline DOE & $05 / 26 / 99$ & Marshall & 0 & 2694.41 & 2694.41 & 479.2 & 230.0 & 41.6 & 47.95 & 473.4 & 12.76 & 9377 & 0 \\
\hline WVDEP & 06/14/99 & Marshall & & & 2610 & & & & & 418 & 10.4 & 7080 & \\
\hline DOE & $06 / 29 / 99$ & Marshall & 579.4045 & 1536.23555 & 2115.64 & 423.74 & 189.72 & 37.75 & 46.77 & 350.54 & 9.37 & 7519.73 & 17.13 \\
\hline WVDEP & $07 / 13 / 99$ & Marshall & & & 2080 & & & & & 301 & 8.82 & 4310 & \\
\hline DOE & $07 / 27 / 99$ & Marshall & 0 & 1742.22 & 1742.22 & 416.9 & 172.7 & 37.0 & 41.79 & 273.0 & 9.09 & 6236 & 27.07 \\
\hline WVDEP & $08 / 14 / 99$ & Marshall & & & 1680 & & & & & 227 & 8.42 & 6340 & \\
\hline DOE & 08/26/99 & Marshall & 0 & 1654.74 & 1654.74 & 428.3 & 170.4 & 40.7 & 41.04 & 250.6 & 8.66 & 5947 & 26.49 \\
\hline WVDEP & $09 / 14 / 99$ & Marshall & & & 1560 & & & & & 221 & 7.39 & 4950 & \\
\hline DOE & 09/29/99 & Marshall & 0 & 1521.04 & 1521.04 & 418.1 & 161.9 & 38.5 & 40.59 & 234.0 & 8.32 & 5526 & 22.2 \\
\hline WVDEP & $10 / 15 / 99$ & Marshall & & & 1490 & & & & & 208 & 8.09 & 2340 & \\
\hline DOE & $10 / 29 / 99$ & Marshall & 0 & 1449.87 & 1449.87 & 410.7 & 156.8 & 36.6 & 37.54 & 211.1 & 8.23 & 5239 & 23.49 \\
\hline WVDEP & $11 / 15 / 99$ & Marshall & & & 1500 & & & & & 227 & 6.69 & 5620 & \\
\hline DOE & $12 / 07 / 99$ & Marshall & 24.62 & 1304 & 1328.62 & 413.0 & 144.8 & 34.0 & 38.47 & 198.6 & 7.06 & 4946 & 28.1 \\
\hline WVDEP & $12 / 15 / 99$ & Marshall & & & 1380 & & & & & 196 & 6.12 & 1940 & \\
\hline WVDEP & $01 / 18 / 00$ & Marshall & & & 1500 & & & & & 227 & 5.91 & 2300 & \\
\hline WVDEP & 02/08/00 & Marshall & & & 1510 & & & & & 213 & 7.91 & 2180 & \\
\hline WVDEP & $03 / 15 / 00$ & Marshall & & & 2250 & & & & & 388 & 6.83 & 2120 & \\
\hline WVDEP & $04 / 14 / 00$ & Marshall & & & 1820 & & & & & 305 & 5.96 & 9270 & \\
\hline WVDEP & $05 / 15 / 00$ & Marshall & & & 1390 & & & & & 220 & 5.48 & 7160 & \\
\hline WVDEP & $06 / 16 / 00$ & Marshall & & & 1340 & & & & & 220 & 4.22 & 5860 & \\
\hline WVDEP & $07 / 18 / 00$ & Marshall & & & 1260 & & & & & 216 & 4.44 & 4600 & \\
\hline WVDEP & $08 / 15 / 00$ & Marshall & & & 876 & & & & & 156 & 4.64 & 4640 & \\
\hline WVDEP & 09/15/00 & Marshall & & & 851 & 329 & & & & 148 & 4.04 & 4400 & \\
\hline WVDEP & $10 / 15 / 00$ & Marshall & & & 1370 & & & & & 160 & 5.84 & 3190 & \\
\hline WVDEP & $11 / 15 / 00$ & Marshall & & & 900 & & & & & 139 & 4.28 & 3890 & \\
\hline WVDEP & $12 / 14 / 00$ & Marshall & & & 886 & & & & & 105 & 3.89 & 3190 & \\
\hline
\end{tabular}


Table E-1f, Omega Mine-pool, Marshall Spring, Raw Chemical Data

\begin{tabular}{|c|c|c|c|c|c|c|c|c|c|c|c|c|c|}
\hline $\begin{array}{c}\text { Sampled } \\
\text { By }\end{array}$ & Date & Location & $\begin{array}{c}\text { Fe3+, } \\
\text { mg/L }\end{array}$ & $\begin{array}{c}\text { Fe2+, } \\
\mathrm{mg} / \mathrm{L}\end{array}$ & $\begin{array}{c}\text { Fe Total, } \\
\mathrm{mg} / \mathrm{L}\end{array}$ & $\begin{array}{c}\mathrm{Ca}, \\
\mathrm{mg} / \mathrm{L}\end{array}$ & $\begin{array}{l}\mathrm{Mg}, \\
\mathrm{mg} / \mathrm{L}\end{array}$ & $\begin{array}{c}\mathrm{Na}, \\
\mathrm{mg} / \mathrm{L}\end{array}$ & $\mathrm{K}, \mathrm{mg} / \mathrm{L}$ & Al, mg/L & $\begin{array}{c}\mathrm{Mn}, \\
\mathrm{mg} / \mathrm{L}\end{array}$ & $\begin{array}{l}\mathrm{SO} 4, \\
\mathrm{mg} / \mathrm{L}\end{array}$ & $\begin{array}{c}\mathrm{Cl}, \\
\mathrm{mg} / \mathrm{L}\end{array}$ \\
\hline WVDEP & $01 / 15 / 01$ & Marshall & & & 721 & & & & & 110 & 4.58 & 4490 & \\
\hline WVDEP & $02 / 13 / 01$ & Marshall & & & 127 & & & & & 22 & 0.63 & 4970 & \\
\hline WVDEP & $03 / 13 / 01$ & Marshall & & & 645 & & & & & 105 & 3.1 & 3380 & \\
\hline WVDEP & $04 / 16 / 01$ & Marshall & & & 573 & & & & & 973 & 5.75 & 4310 & \\
\hline WVDEP & $05 / 15 / 01$ & Marshall & & & 827 & & & & & 147 & 3.6 & 2720 & \\
\hline WVDEP & $06 / 18 / 01$ & Marshall & & & 821 & & & & & 329 & 4.49 & 3360 & \\
\hline WVDEP & $07 / 15 / 01$ & Marshall & & & 696 & & & & & 115 & 3.52 & 3190 & \\
\hline WVDEP & $08 / 15 / 01$ & Marshall & & & 536 & & & & & 84.8 & 74 & 2230 & \\
\hline WVDEP & $09 / 14 / 01$ & Marshall & & & 785 & & & & & 125 & 3.41 & 2130 & \\
\hline WVDEP & $10 / 15 / 01$ & Marshall & & & 682.68 & & & & & 102.75 & 3.75 & 3450 & \\
\hline WVDEP & $11 / 15 / 01$ & Marshall & & & 728.17 & & & & & 94.73 & 3.6 & 3021 & \\
\hline WVDEP & $12 / 14 / 01$ & Marshall & & & 474.68 & & & & & 69.35 & 3.86 & 2989 & \\
\hline WVDEP & $01 / 16 / 02$ & Marshall & & & 127.41 & & & & & 111.28 & 3.45 & 2933 & \\
\hline WVDEP & $02 / 14 / 02$ & Marshall & & & 640.83 & & & & & 107.53 & 3.04 & 3199 & \\
\hline WVDEP & $03 / 14 / 02$ & Marshall & & & 628.53 & & & & & 92.75 & 3.07 & 3085 & \\
\hline WVDEP & $04 / 15 / 02$ & Marshall & & & 770.83 & & & & & 116.84 & 1.1 & 3237 & \\
\hline WVDEP & $05 / 15 / 02$ & Marshall & & & 754.53 & & & & & 109.79 & 2.9 & 3628 & \\
\hline WVDEP & 06/18/02 & Marshall & & & 218.73 & & & & & 0.52 & 0.52 & 2904 & \\
\hline WVDEP & $07 / 18 / 02$ & Marshall & & & & & & & & & & & \\
\hline WVDEP & $08 / 12 / 02$ & Marshall & & & 540.53 & & & & & 91.47 & 2.65 & 2936 & \\
\hline Perry & 08/20/02 & Marshall & & 550 & 564.25 & 298.07 & 71.01 & 18.1 & 25.36 & 88.73 & 2.94 & 2462.4 & 11.9 \\
\hline WVDEP & $09 / 16 / 02$ & Marshall & & & 466.25 & & & & & 89.13 & 2.83 & 2797 & \\
\hline WVDEP & $10 / 15 / 02$ & Marshall & & & 351.08 & & & & & 58.23 & 2.78 & 2773 & \\
\hline WVDEP & $11 / 15 / 02$ & Marshall & & & 513.99 & & & & & 65.91 & 2.71 & 2536 & \\
\hline WVDEP & $12 / 15 / 02$ & Marshall & & & 474.39 & & & & & 67.27 & 2.39 & 2744 & \\
\hline WVDEP & $01 / 14 / 03$ & Marshall & & & 573.94 & & & & & 105.1 & 2.82 & 3167 & \\
\hline WVDEP & $02 / 24 / 03$ & Marshall & & & 228.71 & & & & & 68.77 & 2.6 & 2763 & \\
\hline WVDEP & $03 / 18 / 03$ & Marshall & & & 770.53 & & & & & 127.35 & 2.66 & 3093 & \\
\hline WVDEP & $04 / 15 / 03$ & Marshall & & & 524.22 & & & & & 125.29 & 1.42 & 2757 & \\
\hline WVDEP & $05 / 20 / 03$ & Marshall & & & 745.92 & & & & & 143.29 & 2.63 & 3170 & \\
\hline WVDEP & $06 / 17 / 03$ & Marshall & & & 443.62 & & & & & 80.1 & 2 & 2635 & \\
\hline WVDEP & $08 / 13 / 03$ & Marshall & & & 487.12 & & & & & 69.72 & 2 & 2137 & \\
\hline Perry & $08 / 28 / 03$ & Marshall & & & 460 & 162 & 59.5 & 35.8 & 12.8 & 133 & 0.83 & 2200 & \\
\hline WVDEP & 09/15/03 & Marshall & & & 386.9 & & & & & 63.96 & 1.97 & 2248 & \\
\hline WVDEP & $10 / 14 / 03$ & Marshall & & & 386.01 & & & & & 65.71 & 1.76 & 2206 & \\
\hline WVDEP & $11 / 18 / 03$ & Marshall & & & 199.03 & & & & & 57.1 & 1.8 & 2390 & \\
\hline WVDEP & $12 / 19 / 03$ & Marshall & & & 388.63 & & & & & 68.8 & 2.14 & 2507 & \\
\hline
\end{tabular}


Table E-1f, Omega Mine-pool, Marshall Spring, Raw Chemical Data

\begin{tabular}{|c|c|c|c|c|c|c|c|c|c|c|c|c|c|}
\hline $\begin{array}{c}\text { Sampled } \\
\text { By }\end{array}$ & Date & Location & $\begin{array}{c}\text { Fe3+, } \\
\text { mg/L }\end{array}$ & $\begin{array}{l}\mathrm{Fe} 2+, \\
\mathrm{mg} / \mathrm{L}\end{array}$ & $\begin{array}{c}\text { Fe Total, } \\
\mathrm{mg} / \mathrm{L}\end{array}$ & $\begin{array}{c}\mathrm{Ca}, \\
\mathrm{mg} / \mathrm{L}\end{array}$ & $\begin{array}{l}\mathrm{Mg}, \\
\mathrm{mg} / \mathrm{L}\end{array}$ & $\begin{array}{l}\mathrm{Na}, \\
\mathrm{mg} / \mathrm{L}\end{array}$ & $\mathrm{K}, \mathrm{mg} / \mathrm{L}$ & Al, mg/L & $\begin{array}{l}\mathrm{Mn}, \\
\mathrm{mg} / \mathrm{L}\end{array}$ & $\begin{array}{l}\mathrm{SO} 4, \\
\mathrm{mg} / \mathrm{L}\end{array}$ & $\begin{array}{c}\mathrm{Cl}, \\
\mathrm{mg} / \mathrm{L}\end{array}$ \\
\hline WVDEP & $01 / 14 / 04$ & Marshall & & & 483.23 & & & & & 78.89 & 1.81 & 2475 & \\
\hline WVDEP & $02 / 17 / 04$ & Marshall & & & 524.53 & & & & & 80.51 & 2.46 & 2699 & \\
\hline WVDEP & $03 / 23 / 04$ & Marshall & & & 393.1 & & & & & 72.2 & 1.77 & 2240 & \\
\hline WVDEP & $04 / 13 / 04$ & Marshall & & & 322.12 & & & & & 62.81 & 1.63 & 2009 & \\
\hline WVDEP & $05 / 18 / 04$ & Marshall & & & 355.37 & & & & & 62.75 & 1.66 & 1883 & \\
\hline WVDEP & $06 / 14 / 04$ & Marshall & & & 238.66 & & & & & 50.12 & 1.62 & 1817 & \\
\hline WVDEP & $07 / 12 / 04$ & Marshall & & & 313.25 & & & & & 54.55 & 1.54 & 1806 & \\
\hline WVDEP & 08/09/04 & Marshall & & & 352.49 & & & & & 56.37 & 1.78 & 1828 & \\
\hline WVDEP & $09 / 14 / 04$ & Marshall & & & 233.96 & & & & & 46.07 & 2.05 & 1625 & \\
\hline WVDEP & $10 / 18 / 04$ & Marshall & & & 337.16 & & & & & 55.39 & 1.86 & 1721 & \\
\hline Perry & $03 / 22 / 05$ & Marshall & 233 & 155 & 377.49 & 326.26 & 53.04 & 17.92 & 28.54 & 61.36 & 2 & 1994 & \\
\hline Perry & $05 / 26 / 06$ & Marshall & 0.6 & 281 & 280.97 & 232.9 & 42.3 & 12.2 & & 39.86 & 1.67 & 1451 & \\
\hline Perry & $05 / 03 / 07$ & Marshall & 3.3 & 284 & 286.84 & 271.7 & 41.9 & 16.04 & 24.85 & 44.8 & 1.55 & 1665 & 35 \\
\hline Perry & $09 / 13 / 07$ & Marshall & & & 255.1 & 211.6 & 42.08 & 28.07 & 16.22 & 37.73 & 2.07 & 1401 & 40 \\
\hline
\end{tabular}


Table E-1g, Omega Mine-pool, DEF Spring, Raw Chemical Data

\begin{tabular}{|c|c|c|c|c|c|c|c|c|c|}
\hline Sampled By & Date & Location & Flow gpm & $\mathrm{pH}$ & $\begin{array}{c}\text { Sp. } \\
\text { Conductance } \\
\text { umhos } / \mathrm{cm}\end{array}$ & TDS, mg/L & Temp, C & $\begin{array}{l}\text { Acid load, } \\
\text { lbs/day } \\
\text { CaCO3 Eq }\end{array}$ & $\begin{array}{l}\text { Calc Total } \\
\text { Acidity } \\
\text { CaCO3 Eq }\end{array}$ \\
\hline DOE & $11 / 15 / 1991$ & DEF & & 2.59 & & 5204 & & 0.0 & 2021.2 \\
\hline DOE & $3 / 3 / 1993$ & DEF & 31.8 & 2.83 & & 4311 & & 754.1 & 1973.5 \\
\hline DOE & $3 / 18 / 1993$ & DEF & 74.6 & 2.76 & & 2374 & & 971.4 & 1083.8 \\
\hline DOE & $4 / 2 / 1993$ & DEF & 68.9 & 2.64 & & 4088 & & 1632.3 & 1971.9 \\
\hline DOE & $4 / 14 / 1993$ & DEF & 53.9 & 2.57 & & 4921 & & 1564.8 & 2413.6 \\
\hline DOE & 4/29/1993 & DEF & 58.8 & 2.65 & & 3622 & & 1254.4 & 1774.8 \\
\hline $\mathrm{DOE}$ & $5 / 20 / 1993$ & DEF & 36.4 & 2.76 & & 4599 & & 951.1 & 2173.9 \\
\hline DOE & $6 / 3 / 1993$ & DEF & 27.6 & 2.80 & & 4719 & & 740.9 & 2233.4 \\
\hline DOE & $6 / 10 / 1993$ & DEF & 27.3 & 2.74 & & 4699 & & 732.9 & 2233.3 \\
\hline DOE & 6/23/1993 & DEF & 18.2 & 2.73 & & 4875 & & 496.4 & 2266.8 \\
\hline DOE & $7 / 8 / 1993$ & DEF & 8.7 & 2.72 & & 4379 & & 210.7 & 2026.9 \\
\hline DOE & $7 / 22 / 1993$ & DEF & 6.4 & 2.65 & & 4704 & & 169.3 & 2204.3 \\
\hline DOE & $8 / 11 / 1993$ & DEF & 6.2 & 2.70 & & 4840 & & 171.7 & 2304.5 \\
\hline DOE & 9/2/1993 & DEF & 3.9 & 2.62 & & 5196 & & 113.2 & 2431.3 \\
\hline DOE & 9/10/1993 & DEF & 4.5 & 2.63 & & 4701 & & 119.0 & 2175.6 \\
\hline DOE & 10/7/1993 & DEF & 5.3 & 2.65 & & 4074 & & 116.5 & 1817.3 \\
\hline DOE & $10 / 25 / 1993$ & DEF & 9.5 & 2.73 & & 3883 & & 197.3 & 1722.7 \\
\hline DOE & 11/10/1993 & DEF & 9.7 & 2.63 & & 3736 & & 191.6 & 1651.4 \\
\hline DOE & 12/7/1993 & DEF & 42.8 & 2.95 & & 1790 & & 389.1 & 755.8 \\
\hline DOE & $12 / 23 / 1993$ & DEF & 19.4 & 2.68 & & 3773 & & 411.6 & 1763.8 \\
\hline DOE & $1 / 28 / 1994$ & DEF & 75.4 & 2.89 & & 1508 & & 625.6 & 689.9 \\
\hline DOE & $5 / 5 / 1994$ & DEF & 32.6 & 2.60 & & 4221 & & 801.5 & 2047.1 \\
\hline DOE & $6 / 10 / 1994$ & DEF & 20.7 & 2.71 & & 4263 & & 508.1 & 2041.4 \\
\hline DOE & 7/6/1994 & DEF & 9.9 & 2.65 & & 4318 & & 247.9 & 2078.8 \\
\hline DOE & $8 / 3 / 1994$ & DEF & 8.6 & 2.82 & & 3672 & & 174.5 & 1697.1 \\
\hline DOE & 9/1/1994 & DEF & 13.0 & 2.65 & & 3150 & & 225.3 & 1446.1 \\
\hline DOE & 10/7/1994 & DEF & 9.9 & 2.75 & & 4523 & & 252.1 & 2114.1 \\
\hline DOE & $11 / 16 / 1994$ & DEF & 4.5 & 2.71 & & 4385 & & 111.3 & 2058.4 \\
\hline DOE & 12/14/1994 & DEF & 17.0 & 2.87 & & 2203 & & 187.2 & 916.4 \\
\hline DOE & 1/10/1995 & DEF & 15.4 & 2.84 & & 3604 & & 303.2 & 1637.3 \\
\hline DOE & $2 / 3 / 1995$ & DEF & 10.6 & 2.74 & & 3091 & & 180.6 & 1414.0 \\
\hline DOE & 3/2/1995 & DEF & 19.2 & 2.86 & & 2542 & & 269.1 & 1163.8 \\
\hline DOE & 4/7/1995 & DEF & 8.9 & 2.81 & & 3433 & & 172.2 & 1600.8 \\
\hline DOE & 5/10/1995 & DEF & 14.4 & 2.89 & & 2626 & & 205.3 & 1184.1 \\
\hline DOE & $6 / 6 / 1995$ & DEF & 12.3 & 2.75 & & 2966 & & 204.4 & 1382.5 \\
\hline DOE & 7/13/1995 & DEF & 7.1 & 2.63 & & 4093 & & 169.3 & 1975.6 \\
\hline
\end{tabular}


Table E-1g, Omega Mine-pool, DEF Spring, Raw Chemical Data

\begin{tabular}{|c|c|c|c|c|c|c|c|c|c|}
\hline Sampled By & Date & Location & Flow gpm & $\mathrm{pH}$ & $\begin{array}{c}\text { Sp. } \\
\text { Conductance } \\
\text { umhos } / \mathrm{cm}\end{array}$ & TDS, mg/L & Temp, C & $\begin{array}{l}\text { Acid load, } \\
\text { lbs/day } \\
\text { CaCO3 Eq }\end{array}$ & $\begin{array}{l}\text { Calc Total } \\
\text { Acidity } \\
\text { CaCO3 Eq }\end{array}$ \\
\hline DOE & $8 / 3 / 1995$ & DEF & 6.4 & 2.63 & & 4565 & & 172.1 & 2241.5 \\
\hline DOE & 9/7/1995 & DEF & 3.6 & 2.67 & & 4996 & & 99.4 & 2303.8 \\
\hline DOE & $10 / 12 / 1995$ & DEF & 3.1 & 2.65 & & 4206 & & 74.7 & 2023.1 \\
\hline DOE & $11 / 22 / 1995$ & DEF & 13.2 & 2.70 & & 2656 & & 190.4 & 1202.5 \\
\hline DOE & $1 / 5 / 1996$ & DEF & 24.2 & 2.67 & & 2011 & & 258.3 & 886.4 \\
\hline WVDEP & 1/16/1996 & DEF & 14.3 & 2.6 & 5880 & 3122 & 11.1 & 211.4 & 1226.5 \\
\hline WVDEP & $2 / 15 / 1996$ & DEF & 17.0 & 2.6 & 4870 & 2832 & 11.1 & 166.7 & 814.7 \\
\hline DOE & $2 / 21 / 1996$ & DEF & 45.6 & 2.55 & & 2843 & & 794.7 & 1451.4 \\
\hline WVDEP & $3 / 1 / 1996$ & DEF & 30.0 & 2.7 & 2930 & 1905 & 11.1 & 179.5 & 497.4 \\
\hline WVDEP & $3 / 15 / 1996$ & DEF & 31.8 & 2.6 & 4580 & 2520 & 12.2 & 289.4 & 757.0 \\
\hline DOE & $3 / 18 / 1996$ & DEF & 32.6 & 2.72 & & 1946 & & 360.8 & 920.4 \\
\hline WVDEP & $3 / 28 / 1996$ & DEF & 35.8 & 2.6 & 3880 & 1882 & 0 & 198.5 & 460.7 \\
\hline WVDEP & $4 / 15 / 1996$ & DEF & 22.9 & 2.7 & 3670 & 2405 & 13.3 & 203.0 & 738.9 \\
\hline DOE & $4 / 26 / 1996$ & DEF & 18.2 & 2.62 & & 2175 & & 229.2 & 1047.6 \\
\hline WVDEP & 4/29/1996 & DEF & 22.9 & 2.6 & 4560 & 2499 & 14.4 & 38.2 & 139.0 \\
\hline WVDEP & $5 / 15 / 1996$ & DEF & 31.8 & 2.6 & 3420 & 1453 & 11.1 & 171.3 & 448.1 \\
\hline WVDEP & $5 / 31 / 1996$ & DEF & 58.7 & 2.6 & 4140 & 2094 & 15 & 801.2 & 1135.7 \\
\hline DOE & 6/7/1996 & DEF & 16.6 & 2.63 & & 2483 & & 248.7 & 1243.2 \\
\hline WVDEP & $6 / 14 / 1996$ & DEF & 13.9 & 2.5 & 5050 & 3032 & 13.9 & 276.3 & 1655.0 \\
\hline WVDEP & $6 / 28 / 1996$ & DEF & 21.1 & 2.6 & 5530 & 3232 & 14.4 & 417.4 & 1649.1 \\
\hline WVDEP & 7/15/1996 & DEF & 9.0 & 2.6 & 5540 & 3668 & 13.3 & 159.6 & 1481.9 \\
\hline DOE & $7 / 23 / 1996$ & DEF & 21.6 & 2.72 & & 2434 & & 308.3 & 1185.3 \\
\hline WVDEP & $7 / 30 / 1996$ & DEF & 14.8 & 2.6 & 5090 & 2918 & 14.4 & 200.3 & 1127.2 \\
\hline WVDEP & 8/14/1996 & DEF & 10.8 & 2.5 & 4420 & 2503 & 13.3 & 163.4 & 1264.5 \\
\hline DOE & $8 / 28 / 1996$ & DEF & 8.2 & 2.74 & & 2765 & & 129.7 & 1313.0 \\
\hline WVDEP & 8/31/1996 & DEF & 9.0 & 2.6 & 5670 & 3264 & 13.3 & 128.9 & 1197.2 \\
\hline WVDEP & 9/16/1996 & DEF & 9.0 & 2.6 & 4800 & 2820 & 14.4 & 162.3 & 1506.6 \\
\hline WVDEP & 9/30/1996 & DEF & 15.7 & 2.7 & 4910 & 2763 & 13.3 & 202.8 & 1075.8 \\
\hline WVDEP & 10/14/1996 & DEF & 7.6 & 2.6 & 4880 & 2918 & 14.4 & 125.5 & 1370.6 \\
\hline DOE & 10/16/1996 & DEF & 6.1 & 2.72 & & 3016 & & 102.3 & 1394.6 \\
\hline WVDEP & $10 / 30 / 1996$ & DEF & 33.8 & 2.5 & 3750 & 1978 & 10 & 398.5 & 980.2 \\
\hline WVDEP & $11 / 15 / 1996$ & DEF & 22.0 & 2.6 & 4040 & 1781 & 11.1 & 185.2 & 702.0 \\
\hline DOE & $11 / 26 / 1996$ & DEF & 10.6 & 2.72 & & 2167 & & 129.4 & 1018.0 \\
\hline DOE & 12/13/1996 & DEF & 19.1 & 2.8 & & 1544 & & 161.7 & 703.1 \\
\hline WVDEP & $12 / 15 / 1996$ & DEF & 22.0 & 2.8 & 3500 & 1351 & 12.2 & 149.1 & 565.1 \\
\hline WVDEP & $1 / 14 / 1997$ & DEF & 19.3 & 2.7 & 3990 & 2248 & 12.2 & 222.6 & 961.7 \\
\hline
\end{tabular}


Table E-1g, Omega Mine-pool, DEF Spring, Raw Chemical Data

\begin{tabular}{|c|c|c|c|c|c|c|c|c|c|}
\hline Sampled By & Date & Location & Flow gpm & $\mathrm{pH}$ & $\begin{array}{c}\text { Sp. } \\
\text { Conductance } \\
\text { umhos/cm }\end{array}$ & TDS, mg/L & Temp, C & $\begin{array}{l}\text { Acid load, } \\
\text { lbs/day } \\
\text { CaCO3 Eq }\end{array}$ & $\begin{array}{c}\text { Calc Total } \\
\text { Acidity } \\
\text { CaCO3 Eq }\end{array}$ \\
\hline DOE & $1 / 28 / 1997$ & DEF & 11.6 & 2.75 & & 2114 & & 143.8 & 1033.0 \\
\hline DOE & $2 / 21 / 1997$ & DEF & 13.2 & 2.76 & & 1926 & & 140.1 & 884.4 \\
\hline WVDEP & $3 / 17 / 1997$ & DEF & 16.1 & 2.6 & 3120 & 2970 & 14.4 & 349.8 & 1804.3 \\
\hline DOE & $3 / 26 / 1997$ & DEF & 21.8 & 2.68 & & 2486 & & 326.7 & 1249.0 \\
\hline WVDEP & 4/14/1997 & DEF & 19.7 & 2.6 & 3130 & 3497 & 14.4 & 389.4 & 1643.5 \\
\hline WVDEP & $5 / 14 / 1997$ & DEF & 19.7 & 2.6 & 2980 & 2109 & 14.4 & 395.6 & 1669.7 \\
\hline DOE & $5 / 20 / 1997$ & DEF & 24.9 & 2.76 & & 2878 & & 425.3 & 1421.0 \\
\hline WVDEP & $6 / 16 / 1997$ & DEF & 17.9 & 2.5 & 3220 & 3003 & 15.6 & 407.0 & 1889.3 \\
\hline DOE & $7 / 10 / 1997$ & DEF & 11.6 & 2.75 & & 3319 & & 228.2 & 1637.5 \\
\hline WVDEP & $7 / 16 / 1997$ & DEF & 9.9 & 2.6 & 3480 & 3164 & 15.6 & 162.4 & 1370.5 \\
\hline WVDEP & $8 / 17 / 1997$ & DEF & 9.0 & 2.7 & 6310 & 3867 & 15.6 & 188.3 & 1748.5 \\
\hline DOE & 9/10/1997 & DEF & 6.7 & 2.82 & & 3006 & & 116.5 & 1438.2 \\
\hline WVDEP & 9/15/1997 & DEF & 83.8 & 2.7 & 3260 & 2343 & 15 & 792.0 & 786.5 \\
\hline WVDEP & $10 / 15 / 1997$ & DEF & 7.6 & 2.7 & 5460 & 3469 & & 144.2 & 1573.9 \\
\hline DOE & $11 / 5 / 1997$ & DEF & 6.1 & 2.77 & & 3328 & & 119.1 & 1619.9 \\
\hline WVDEP & $11 / 14 / 1997$ & DEF & 20.6 & 2.6 & 2680 & 2160 & & 278.7 & 1125.1 \\
\hline WVDEP & $12 / 15 / 1997$ & DEF & 12.5 & 2.6 & 2590 & 2229 & & 169.9 & 1127.2 \\
\hline DOE & 1/12/1998 & DEF & 32.7 & 2.64 & & 1722 & & 321.0 & 816.2 \\
\hline WVDEP & $1 / 16 / 1998$ & DEF & 20.6 & 2.6 & 3860 & 1918 & & 236.1 & 953.2 \\
\hline DOE & 2/9/1998 & DEF & 21.6 & 2.76 & & 1903 & & 234.7 & 903.4 \\
\hline WVDEP & 2/15/1998 & DEF & 29.6 & 2.7 & 3750 & 1876 & & 299.4 & 842.3 \\
\hline WVDEP & $3 / 15 / 1998$ & DEF & 25.5 & 2.7 & 3720 & 1716 & & 249.9 & 814.0 \\
\hline DOE & $3 / 26 / 1998$ & DEF & 32.6 & 2.79 & & 1568 & & 297.9 & 759.4 \\
\hline WVDEP & 4/15/1998 & DEF & 29.6 & 2.6 & 2630 & 2088 & & 366.9 & 1032.4 \\
\hline DOE & 4/29/1998 & DEF & 23.1 & 2.82 & & 1631 & & 212.2 & 762.4 \\
\hline WVDEP & $5 / 14 / 1998$ & DEF & 25.5 & 2.7 & 3570 & 1771 & & 250.6 & 816.3 \\
\hline DOE & 5/28/1998 & DEF & 11.0 & 2.75 & & 2402 & & 156.0 & 1182.0 \\
\hline WVDEP & $6 / 15 / 1998$ & DEF & 9.0 & 2.6 & 5370 & 2881 & & 166.0 & 1541.7 \\
\hline DOE & $6 / 25 / 1998$ & DEF & 14.8 & 2.54 & & 2104 & & 183.9 & 1031.4 \\
\hline WVDEP & 7/15/1998 & DEF & 12.5 & 2.6 & 5370 & 3199 & & 143.8 & 954.2 \\
\hline DOE & $8 / 5 / 1998$ & DEF & 9.9 & 2.64 & & 3626 & & 218.7 & 1830.8 \\
\hline WVDEP & $8 / 13 / 1998$ & DEF & 9.9 & 2.7 & 6240 & 3969 & & 224.9 & 1897.4 \\
\hline DOE & 9/3/1998 & DEF & 9.0 & 2.67 & & 3444 & & 183.7 & 1703.7 \\
\hline WVDEP & 9/15/1998 & DEF & 7.6 & 2.6 & 7680 & 3967 & & 275.0 & 3002.4 \\
\hline WVDEP & $10 / 15 / 1998$ & DEF & 7.2 & 2.7 & 30300 & 7990 & & 148.8 & 1726.9 \\
\hline DOE & $10 / 29 / 1998$ & DEF & 5.3 & 2.73 & & 3983 & & 118.6 & 1874.4 \\
\hline
\end{tabular}


Table E-1g, Omega Mine-pool, DEF Spring, Raw Chemical Data

\begin{tabular}{|c|c|c|c|c|c|c|c|c|c|}
\hline Sampled By & Date & Location & Flow gpm & $\mathrm{pH}$ & $\begin{array}{c}\text { Sp. } \\
\text { Conductance } \\
\text { umhos } / \mathrm{cm}\end{array}$ & TDS, mg/L & Temp, C & $\begin{array}{l}\text { Acid load, } \\
\text { lbs/day } \\
\text { CaCO3 Eq }\end{array}$ & $\begin{array}{l}\text { Calc Total } \\
\text { Acidity } \\
\text { CaCO3 Eq }\end{array}$ \\
\hline WVDEP & $11 / 15 / 1998$ & DEF & 1.8 & 2.6 & 6690 & 3594 & & 35.3 & 1639.6 \\
\hline DOE & $12 / 10 / 1998$ & DEF & 2.5 & 2.78 & & 3673 & & 51.5 & 1738.2 \\
\hline WVDEP & $12 / 15 / 1998$ & DEF & 1.8 & 2.7 & 6620 & 3875 & & 38.4 & 1784.9 \\
\hline WVDEP & $1 / 17 / 1999$ & DEF & 39.9 & 2.6 & 3240 & 1037 & & 198.0 & 413.2 \\
\hline WVDEP & $2 / 14 / 1999$ & DEF & 19.7 & 2.7 & 4110 & 1937 & & 212.1 & 895.3 \\
\hline DOE & $2 / 18 / 1999$ & DEF & 15.1 & 2.72 & & 2421 & & 199.0 & 1094.2 \\
\hline WVDEP & $3 / 14 / 1999$ & DEF & 24.2 & 2.7 & 3460 & 1555 & & 193.0 & 663.8 \\
\hline DOE & $3 / 30 / 1999$ & DEF & 17.8 & 2.80 & & 2001 & & 199.5 & 932.5 \\
\hline WVDEP & $4 / 13 / 1999$ & DEF & 12.1 & 2.7 & 5640 & 3118 & & 198.1 & 1361.7 \\
\hline DOE & $4 / 29 / 1999$ & DEF & 11.6 & 2.69 & & 2678 & & 176.2 & 1260.6 \\
\hline WVDEP & $5 / 17 / 1999$ & DEF & 8.1 & 2.7 & 5870 & 3118 & & 197.1 & 2034.6 \\
\hline DOE & $5 / 26 / 1999$ & DEF & 6.8 & 2.70 & & 3319 & & 128.3 & 1560.6 \\
\hline WVDEP & $6 / 14 / 1999$ & DEF & 4.9 & 2.6 & 6390 & 3622 & & 100.7 & 1700.0 \\
\hline DOE & $6 / 29 / 1999$ & DEF & 5.4 & 2.63 & & 3623 & & 109.7 & 1704.9 \\
\hline WVDEP & 7/13/1999 & DEF & 4.9 & 2.6 & 6480 & 4096 & & 110.9 & 1870.6 \\
\hline DOE & $7 / 27 / 1999$ & DEF & 3.3 & 2.76 & & 3959 & & 75.1 & 1874.7 \\
\hline WVDEP & $8 / 14 / 1999$ & DEF & 3.1 & 2.6 & 6400 & 4275 & & 78.3 & 2074.3 \\
\hline DOE & 8/26/1999 & DEF & 2.3 & 2.71 & & 4242 & & 54.5 & 2004.5 \\
\hline WVDEP & 9/14/1999 & DEF & 1.8 & 2.7 & 8220 & 4586 & & 44.1 & 2049.7 \\
\hline DOE & 9/29/1999 & DEF & 1.4 & 2.81 & & 4038 & & 32.4 & 1922.9 \\
\hline WVDEP & 10/15/1999 & DEF & 1.8 & 2.7 & 6370 & 3807 & & 40.9 & 1903.2 \\
\hline DOE & $10 / 29 / 1999$ & DEF & 2.8 & 2.68 & & 3435 & & 53.6 & 1570.1 \\
\hline WVDEP & $11 / 15 / 1999$ & DEF & 1.8 & 2.6 & 6680 & 3630 & & 34.2 & 1589.4 \\
\hline DOE & 12/7/1999 & DEF & 3.9 & 2.47 & & 2438 & & 52.6 & 1114.8 \\
\hline WVDEP & $12 / 15 / 1999$ & DEF & 5.8 & 2.6 & 5000 & 2466 & & 43.3 & 619.0 \\
\hline WVDEP & $1 / 17 / 2000$ & DEF & 5.0 & 2.5 & 5650 & 3103 & & 79.7 & 1320.8 \\
\hline WVDEP & $2 / 8 / 2000$ & DEF & 6.0 & 2.6 & 8420 & 3440 & & 91.5 & 1268.6 \\
\hline WVDEP & $3 / 15 / 2000$ & DEF & 20.0 & 3.3 & 18100 & 11514 & & 329.7 & 1373.0 \\
\hline WVDEP & $4 / 14 / 2000$ & DEF & 32.0 & 2.7 & 3250 & 1516 & & 279.9 & 727.9 \\
\hline WVDEP & $5 / 15 / 2000$ & DEF & 13.0 & 2.7 & 5170 & 2553 & & 182.3 & 1167.6 \\
\hline WVDEP & $6 / 15 / 2000$ & DEF & 12.0 & 2.6 & 4340 & 2126 & & 158.8 & 1100.0 \\
\hline WVDEP & $7 / 18 / 2000$ & DEF & 15.0 & 2.6 & 4300 & 1814 & & 155.3 & 860.8 \\
\hline WVDEP & $8 / 15 / 2000$ & DEF & 9.0 & 4.5 & 487 & 278 & & 123.4 & 1140.4 \\
\hline WVDEP & $9 / 15 / 2000$ & DEF & 5.0 & 2.7 & 5040 & 3284 & & 100.7 & 1668.5 \\
\hline WVDEP & $10 / 15 / 2000$ & DEF & 6.0 & 2.6 & 5230 & 3554 & & 133.2 & 1846.3 \\
\hline WVDEP & $11 / 15 / 2000$ & DEF & 5.0 & 2.7 & 5510 & 4097 & & 110.9 & 1838.4 \\
\hline
\end{tabular}


Table E-1g, Omega Mine-pool, DEF Spring, Raw Chemical Data

\begin{tabular}{|c|c|c|c|c|c|c|c|c|c|}
\hline Sampled By & Date & Location & Flow gpm & $\mathrm{pH}$ & $\begin{array}{c}\text { Sp. } \\
\text { Conductance } \\
\text { umhos } / \mathrm{cm}\end{array}$ & TDS, mg/L & Temp, C & $\begin{array}{l}\text { Acid load, } \\
\text { lbs/day } \\
\text { CaCO3 Eq }\end{array}$ & $\begin{array}{l}\text { Calc Total } \\
\text { Acidity } \\
\text { CaCO3 Eq }\end{array}$ \\
\hline WVDEP & $12 / 14 / 2000$ & DEF & 4.0 & 2.6 & 5770 & 4117 & & 77.8 & 1623.0 \\
\hline WVDEP & $1 / 15 / 2001$ & DEF & 6.0 & 2.6 & 5050 & 3159 & & 97.7 & 1354.1 \\
\hline WVDEP & $2 / 13 / 2001$ & DEF & 14.0 & 2.6 & 4030 & 2176 & & 159.1 & 943.8 \\
\hline WVDEP & $3 / 13 / 2001$ & DEF & 14.0 & 2.6 & 3780 & 2311 & & 197.1 & 1169.4 \\
\hline WVDEP & $4 / 16 / 2001$ & DEF & 31.0 & 2.7 & 2910 & 1264 & & 206.2 & 553.5 \\
\hline WVDEP & $5 / 15 / 2001$ & DEF & 7.0 & 2.6 & 4800 & 3185 & & 128.8 & 1533.1 \\
\hline WVDEP & $6 / 18 / 2001$ & DEF & 9.0 & 2.7 & 4450 & 2841 & & 117.1 & 1082.5 \\
\hline WVDEP & $7 / 15 / 2001$ & DEF & 17.0 & 2.7 & 5020 & 2059 & & 172.0 & 842.8 \\
\hline WVDEP & $8 / 15 / 2001$ & DEF & 8.0 & 2.6 & 5080 & 3160 & & 139.3 & 1444.5 \\
\hline WVDEP & $9 / 14 / 2001$ & DEF & 5.0 & 2.6 & 3310 & 3310 & & 105.3 & 1763.1 \\
\hline WVDEP & $10 / 25 / 2001$ & DEF & 5.8 & 2.6 & 3270 & 4368 & 11.6 & 99.7 & 1424.5 \\
\hline WVDEP & $11 / 15 / 2001$ & DEF & 4.5 & 2.7 & 3000 & 3976 & 11.1 & 78.8 & 1463.4 \\
\hline WVDEP & $12 / 14 / 2001$ & DEF & 4.0 & 2.8 & 3300 & 3688 & 10.5 & 44.0 & 918.3 \\
\hline WVDEP & $1 / 16 / 2002$ & DEF & 16.9 & 2.7 & 1766 & 2096 & 11.1 & 141.4 & 695.0 \\
\hline WVDEP & $2 / 14 / 2002$ & DEF & 11.1 & 2.8 & 2250 & 2320 & 11.1 & 112.0 & 838.3 \\
\hline WVDEP & $3 / 14 / 2002$ & DEF & 8.0 & 2.8 & 2270 & 2278 & 14.4 & 91.0 & 950.1 \\
\hline WVDEP & $4 / 15 / 2002$ & DEF & 15.7 & 2.9 & 1980 & 2328 & 13.3 & 163.6 & 868.3 \\
\hline WVDEP & $5 / 15 / 2002$ & DEF & 15.7 & 2.8 & 2700 & 2020 & 12.2 & 134.5 & 713.4 \\
\hline WVDEP & $6 / 18 / 2002$ & DEF & 17.0 & 2.8 & 2000 & 2012 & 14.4 & 48.9 & 239.7 \\
\hline WVDEP & $7 / 18 / 2002$ & DEF & 0.0 & & & & & 0.0 & \\
\hline WVDEP & $8 / 12 / 2002$ & DEF & 6.9 & 2.7 & 3000 & & 15.5 & 108.6 & 1302.0 \\
\hline Perry & $8 / 20 / 2002$ & DEF & & 2.50 & 3150.00 & 3196.00 & 13.50 & 0.0 & 1396.5 \\
\hline WVDEP & 9/16/2002 & DEF & 0.0 & & & & & & \\
\hline WVDEP & $10 / 15 / 2002$ & DEF & 9.9 & 2.7 & 2800 & 3068 & 14.4 & 101.2 & 853.5 \\
\hline WVDEP & $11 / 15 / 2002$ & DEF & 0.0 & & & & & & \\
\hline WVDEP & $12 / 15 / 2002$ & DEF & & & & & & & \\
\hline WVDEP & $1 / 14 / 2003$ & DEF & 0.0 & & & & & & \\
\hline WVDEP & $2 / 24 / 2003$ & DEF & 59.9 & 2.5 & 3770 & 4084 & 6.1 & 1179.6 & 1638.3 \\
\hline WVDEP & $3 / 18 / 2003$ & DEF & 0.0 & & & & & & \\
\hline WVDEP & $4 / 15 / 2003$ & DEF & 0.0 & & & & & & \\
\hline WVDEP & $5 / 20 / 2003$ & DEF & & & & & & & \\
\hline WVDEP & $6 / 17 / 2003$ & DEF & 9.0 & 2.74 & 2030 & 3988 & 15.6 & 71.2 & 660.7 \\
\hline WVDEP & $8 / 13 / 2003$ & DEF & & & & & & 0.0 & \\
\hline Perry & $8 / 27 / 2003$ & DEF & 7.7 & 2.86 & 4140.00 & 2820.00 & 13.40 & 123.4 & 1337.1 \\
\hline WVDEP & 9/15/2003 & DEF & 9.0 & 2.68 & 2670 & 5656 & 15.6 & 107.6 & 998.6 \\
\hline WVDEP & $10 / 14 / 2003$ & DEF & & & & & & & \\
\hline
\end{tabular}


Table E-1g, Omega Mine-pool, DEF Spring, Raw Chemical Data

\begin{tabular}{|c|c|c|c|c|c|c|c|c|c|}
\hline Sampled By & Date & Location & Flow gpm & $\mathrm{pH}$ & $\begin{array}{c}\text { Sp. } \\
\text { Conductance } \\
\text { umhos } / \mathrm{cm}\end{array}$ & $\mathrm{TDS}, \mathrm{mg} / \mathrm{L}$ & Temp, C & $\begin{array}{l}\text { Acid load, } \\
\text { lbs/day } \\
\text { CaCO3 Eq }\end{array}$ & $\begin{array}{l}\text { Calc Total } \\
\text { Acidity } \\
\text { CaCO3 Eq }\end{array}$ \\
\hline WVDEP & $11 / 18 / 2003$ & DEF & & & & & & & \\
\hline WVDEP & $12 / 19 / 2003$ & DEF & & & & & & & \\
\hline WVDEP & $1 / 14 / 2004$ & DEF & 4.0 & 2.75 & 2310 & 2284 & 10 & 40.5 & 844.1 \\
\hline WVDEP & $2 / 17 / 2004$ & DEF & & & & & & & \\
\hline WVDEP & $3 / 23 / 2004$ & DEF & & & & & & & \\
\hline WVDEP & $4 / 13 / 2004$ & DEF & 17.9 & 2.78 & 1936 & 1496 & 11.1 & 36.7 & 170.5 \\
\hline WVDEP & $5 / 18 / 2004$ & DEF & & & & & & & \\
\hline WVDEP & $6 / 14 / 2004$ & DEF & & & & & & & \\
\hline WVDEP & $7 / 12 / 2004$ & DEF & 9.0 & 2.75 & 2590 & 2596 & 15 & 117.8 & 1093.5 \\
\hline WVDEP & $8 / 9 / 2004$ & DEF & 0.0 & & & & & & \\
\hline WVDEP & $9 / 14 / 2004$ & DEF & & & & & & & \\
\hline WVDEP & $10 / 18 / 2004$ & DEF & 17.9 & 2.76 & 2880 & 3252 & 12.2 & 273.6 & 1270.4 \\
\hline Perry & $3 / 22 / 2005$ & DEF & 16.5 & 2.56 & 2420 & 1614 & 11.2 & 167.9 & 846.5 \\
\hline Perry & $5 / 24 / 2006$ & DEF & 19.9 & 2.58 & 2152 & 1874 & 12.4 & 193.0 & 806.9 \\
\hline Perry & $5 / 3 / 2007$ & DEF & 23.4 & 2.57 & 2565 & 2162 & 12 & 273.0 & 970.6 \\
\hline Perry & $9 / 13 / 2007$ & DEF & 5.9 & 2.41 & 3540 & 2550 & 13.2 & 80.2 & 1131.0 \\
\hline
\end{tabular}


Table E-1g, Omega Mine-pool, DEF Spring, Raw Chemical Data

\begin{tabular}{|c|c|c|c|c|c|c|c|c|c|c|c|c|c|}
\hline $\begin{array}{l}\text { Sampled } \\
\text { By }\end{array}$ & Date & Location & $\begin{array}{l}\mathrm{Fe} 3+, \\
\mathrm{mg} / \mathrm{L}\end{array}$ & $\begin{array}{l}\mathrm{Fe} 2+ \\
\mathrm{mg} / \mathrm{L}\end{array}$ & $\begin{array}{c}\mathrm{Fe} \\
\text { Total, } \\
\mathrm{mg} / \mathrm{L}\end{array}$ & $\begin{array}{l}\mathrm{Ca}, \\
\mathrm{mg} / \mathrm{L}\end{array}$ & $\begin{array}{l}\mathrm{Mg}, \\
\mathrm{mg} / \mathrm{L}\end{array}$ & $\begin{array}{l}\mathrm{Na}, \\
\mathrm{mg} / \mathrm{L}\end{array}$ & $\mathrm{K}, \mathrm{mg} / \mathrm{L}$ & $\mathrm{Al}, \mathrm{mg} / \mathrm{L}$ & $\begin{array}{l}\mathrm{Mn}, \\
\mathrm{mg} / \mathrm{L}\end{array}$ & $\begin{array}{l}\mathrm{SO} 4, \\
\mathrm{mg} / \mathrm{L}\end{array}$ & $\begin{array}{c}\mathrm{Cl}, \\
\mathrm{mg} / \mathrm{L}\end{array}$ \\
\hline DOE & $11 / 15 / 1991$ & DEF & 472 & 168 & 640 & 313.0 & 165.0 & 9.3 & & 133.0 & 4.40 & 3925 & 14 \\
\hline DOE & $3 / 3 / 1993$ & DEF & 229 & 423.5 & 652.5 & 246.5 & 124.0 & 13.7 & 2.6 & 130.5 & 3.50 & 3107 & 17 \\
\hline DOE & $3 / 18 / 1993$ & DEF & 241 & 106 & 347 & 121.0 & 58.2 & 23.1 & 2 & 67.1 & 1.60 & 1710 & 36.7 \\
\hline DOE & $4 / 2 / 1993$ & DEF & 397 & 253 & 650 & 194.0 & 93.0 & 15.4 & 0.7 & 124.0 & 2.60 & 2974 & 22 \\
\hline DOE & $4 / 14 / 1993$ & DEF & 426 & 378 & 804 & 232.0 & 114.0 & 12.0 & 1 & 150.0 & 3.40 & 3574 & 15.5 \\
\hline DOE & 4/29/1993 & DEF & 304 & 290 & 594 & 165 & 85.4 & 14.8 & 1.8 & 107.0 & 2.70 & 2624 & 16.5 \\
\hline DOE & $5 / 20 / 1993$ & DEF & 306 & 431 & 737 & 237 & 120.0 & 10.4 & 2.7 & 137.0 & 3.50 & 3326 & 11 \\
\hline DOE & $6 / 3 / 1993$ & DEF & 303 & 459 & 762 & 228 & 125.0 & 10.0 & 1.8 & 141.0 & 3.60 & 3424 & 9.3 \\
\hline DOE & $6 / 10 / 1993$ & DEF & 282.89 & 474 & 756.89 & 232.51 & 127.0 & 11.6 & 2.31 & 140.5 & 3.64 & 3395.73 & 14.5 \\
\hline DOE & $6 / 23 / 1993$ & DEF & 317.14 & 465 & 782.14 & 248.32 & 137.4 & 12.1 & 2.58 & 137.9 & 3.94 & 3520.99 & 14.1 \\
\hline DOE & $7 / 8 / 1993$ & DEF & 266.57 & 409 & 675.57 & 227.1 & 124.5 & 13.3 & 1.12 & 128.8 & 3.65 & 3175.82 & 15.8 \\
\hline DOE & $7 / 22 / 1993$ & DEF & 216.42 & 506 & 722.42 & 247.78 & 133.5 & 13.6 & 1.1 & 142.5 & 3.96 & 3406.07 & 19 \\
\hline DOE & $8 / 11 / 1993$ & DEF & 236.07 & 514 & 750.07 & 256.98 & 141.0 & 12.7 & 0.67 & 153.7 & 4.27 & 3506.09 & \\
\hline DOE & 9/2/1993 & DEF & 253.78 & 538 & 791.78 & 272.66 & 149.3 & 11.2 & 0.89 & 159.4 & 4.49 & 3790.16 & \\
\hline DOE & 9/10/1993 & DEF & 231.21 & 471.3 & 702.51 & 252.2 & 137.5 & 15.5 & 0.6 & 142.8 & 4.10 & 3431.79 & \\
\hline DOE & $10 / 7 / 1993$ & DEF & 246.22 & 332 & 578.22 & 217.05 & 120.1 & 21.3 & 0.38 & 119.4 & 3.74 & 2977.62 & 36.3 \\
\hline DOE & $10 / 25 / 1993$ & DEF & 235.26 & 329 & 564.26 & 208.1 & 117.1 & 22.6 & 0.67 & 110.4 & 3.50 & 2805.24 & 40.5 \\
\hline DOE & $11 / 10 / 1993$ & DEF & 229.81 & 312 & 541.81 & 201.7 & 112.3 & 22.4 & 0.76 & 100.5 & 3.33 & 2708 & 46 \\
\hline DOE & $12 / 7 / 1993$ & DEF & 132.91 & 107.8 & 240.71 & 95.3 & 49.9 & 25.3 & 1.81 & 47.9 & 1.54 & 1290 & 33 \\
\hline $\mathrm{DOE}$ & $12 / 23 / 1993$ & DEF & 266.82 & 298.9 & 565.72 & 180.8 & 97.6 & 16.9 & 0.1 & 115.4 & 2.82 & 2754 & 29 \\
\hline DOE & $1 / 28 / 1994$ & DEF & 128.25 & 72.6 & 200.85 & 71.5 & 35.5 & 29.1 & 0.92 & 47.5 & 1.03 & 1057 & 60.6 \\
\hline DOE & $5 / 5 / 1994$ & DEF & 281.61 & 364 & 645.61 & 204.4 & 98.3 & 16.8 & 1.4 & 136.8 & 3.03 & 3019 & 83.22 \\
\hline DOE & $6 / 10 / 1994$ & DEF & 210.52 & 448.8 & 659.32 & 213.9 & 106.9 & 16.9 & 1.15 & 136.3 & 3.43 & 3021 & 91.3 \\
\hline DOE & $7 / 6 / 1994$ & DEF & 205.31 & 464.4 & 669.71 & 222.0 & 112.4 & 18.4 & 1.13 & 137.1 & 3.49 & 3052 & 89.2 \\
\hline DOE & 8/3/1994 & DEF & 153.27 & 404.3 & 557.57 & 194.0 & 104.5 & 19.3 & 1.04 & 111.1 & 3.15 & 2601 & 69.4 \\
\hline DOE & $9 / 1 / 1994$ & DEF & 148.77 & 299.7 & 448.47 & 165.3 & 85.3 & 20.6 & 1.42 & 94.8 & 2.63 & 2239 & 83.4 \\
\hline DOE & $10 / 7 / 1994$ & DEF & 103.24 & 564 & 667.24 & 233.2 & 121.5 & 16.9 & 0.42 & 148.3 & 3.84 & 3261 & 58.75 \\
\hline DOE & $11 / 16 / 1994$ & DEF & 101.66 & 541.97 & 643.63 & 224.7 & 119.9 & 17.6 & 0.4 & 144.4 & 3.61 & 3183 & 36.3 \\
\hline DOE & $12 / 14 / 1994$ & DEF & 110.18 & 171.2 & 281.38 & 114.2 & 59.4 & 22.9 & 1.01 & 61.5 & 2.06 & 1595 & 59.83 \\
\hline DOE & $1 / 10 / 1995$ & DEF & 142.76 & 374.8 & 517.56 & 188.7 & 101.6 & 19.7 & 0.76 & 113.9 & 3.22 & 2593 & 55.76 \\
\hline DOE & $2 / 3 / 1995$ & DEF & 117.74 & 312.8 & 430.54 & 165.8 & 85.4 & 21.0 & 0.83 & 98.5 & 2.70 & 2229 & 48.86 \\
\hline DOE & $3 / 2 / 1995$ & DEF & 121.46 & 232.12 & 353.58 & 132.4 & 66.9 & 24.9 & 1.24 & 82.5 & 2.01 & 1817 & 55.34 \\
\hline DOE & 4/7/1995 & DEF & 121.3 & 355.4 & 476.7 & 177.39 & 90.24 & 20.66 & 0.98 & 119.7 & 2.69 & 2483.21 & 51.92 \\
\hline DOE & $5 / 10 / 1995$ & DEF & 133.2 & 226.4 & 359.6 & 136.0 & 70.0 & 22.3 & 1.2 & 85.0 & 2.10 & 1891 & 51.9 \\
\hline DOE & $6 / 6 / 1995$ & DEF & 141.16 & 258.9 & 400.06 & 150.7 & 75.5 & 20.6 & 0.64 & 103.2 & 2.32 & 2157 & 48.9 \\
\hline DOE & $7 / 13 / 1995$ & DEF & 155.33 & 434.5 & 589.83 & 204.94 & 106.54 & 18.82 & 0.59 & 143.36 & 3.26 & 2967.2 & 47.8 \\
\hline
\end{tabular}


Table E-1g, Omega Mine-pool, DEF Spring, Raw Chemical Data

\begin{tabular}{|c|c|c|c|c|c|c|c|c|c|c|c|c|c|}
\hline $\begin{array}{c}\text { Sampled } \\
\text { By }\end{array}$ & Date & Location & $\begin{array}{l}\mathrm{Fe} 3+ \\
\mathrm{mg} / \mathrm{L}\end{array}$ & $\begin{array}{l}\mathrm{Fe} 2+ \\
\mathrm{mg} / \mathrm{L}\end{array}$ & $\begin{array}{c}\mathrm{Fe} \\
\text { Total, } \\
\mathrm{mg} / \mathrm{L}\end{array}$ & $\begin{array}{c}\mathrm{Ca}, \\
\mathrm{mg} / \mathrm{L}\end{array}$ & $\begin{array}{l}\mathrm{Mg}, \\
\mathrm{mg} / \mathrm{L}\end{array}$ & $\begin{array}{l}\mathrm{Na}, \\
\mathrm{mg} / \mathrm{L}\end{array}$ & $\mathrm{K}, \mathrm{mg} / \mathrm{L}$ & $\mathrm{Al}, \mathrm{mg} / \mathrm{L}$ & $\begin{array}{l}\mathrm{Mn}, \\
\mathrm{mg} / \mathrm{L}\end{array}$ & $\begin{array}{l}\mathrm{SO} 4, \\
\mathrm{mg} / \mathrm{L}\end{array}$ & $\begin{array}{c}\mathrm{Cl}, \\
\mathrm{mg} / \mathrm{L}\end{array}$ \\
\hline DOE & $8 / 3 / 1995$ & DEF & 107.69 & 568 & 675.69 & 225.4 & 119.6 & 16.2 & 0.59 & 163.4 & 3.84 & 3297 & 51.4 \\
\hline DOE & 9/7/1995 & DEF & 711.68 & & 711.68 & 253.11 & 133.03 & 19.88 & 1.38 & 164.67 & 4.34 & 3642.85 & 53.1 \\
\hline DOE & 10/12/1995 & DEF & 67.77 & 537.4 & 605.17 & 207.69 & 113.95 & 18.12 & 0.5 & 147.79 & 3.67 & 3050.37 & 48.1 \\
\hline DOE & $11 / 22 / 1995$ & DEF & 161.62 & 198.5 & 360.12 & 136.1 & 70.3 & 33.7 & 0.57 & 81.7 & 2.29 & 1902 & 63.2 \\
\hline DOE & $1 / 5 / 1996$ & DEF & 102.1 & 139.1 & 241.2 & 106.6 & 51.8 & 32.5 & 0.87 & 62.0 & 1.68 & 1417 & 93.71 \\
\hline WVDEP & 1/16/1996 & DEF & & & 341 & & & & & 87.1 & 3.6 & 2280 & \\
\hline WVDEP & $2 / 15 / 1996$ & DEF & & & 383 & & & & & & 1.85 & 1720 & \\
\hline DOE & $2 / 21 / 1996$ & DEF & 203.18 & 206 & 409.18 & 125.2 & 61.1 & 25.1 & 0.95 & 103.4 & 1.89 & 2067 & 41.89 \\
\hline WVDEP & 3/1/1996 & DEF & & & 221 & & & & & & 1.06 & 1360 & \\
\hline WVDEP & $3 / 15 / 1996$ & DEF & & & 351 & & & & & & 1.63 & 1840 & \\
\hline DOE & $3 / 18 / 1996$ & DEF & 156.72 & 96.5 & 253.22 & 93.1 & 43.8 & 25.9 & 0.79 & 66.5 & 1.33 & 1403 & 54.54 \\
\hline WVDEP & $3 / 28 / 1996$ & DEF & & & 186 & & & & & & 1.14 & 1310 & \\
\hline WVDEP & $4 / 15 / 1996$ & DEF & & & 355 & & & & & & 1.98 & 1560 & \\
\hline DOE & $4 / 26 / 1996$ & DEF & 134.3 & 147.3 & 281.6 & 108.0 & 51.9 & 24.2 & 0.49 & 75.7 & 1.49 & 1577 & 49.27 \\
\hline WVDEP & $4 / 29 / 1996$ & DEF & & & 7.46 & & & & & & 0.04 & 1800 & \\
\hline WVDEP & $5 / 15 / 1996$ & DEF & & & 18.7 & & & & & 51.6 & 1.31 & 1000 & \\
\hline WVDEP & $5 / 31 / 1996$ & DEF & & & 318 & & & & & 78.7 & 1.95 & 1320 & \\
\hline DOE & 6/7/1996 & DEF & 139.42 & 207 & 346.42 & 107.4 & 52.4 & 22.2 & 0.82 & 90.4 & 1.85 & 1815 & 40.75 \\
\hline WVDEP & $6 / 14 / 1996$ & DEF & & & 464 & & & & & 119 & 2.78 & 2140 & \\
\hline WVDEP & $6 / 28 / 1996$ & DEF & & & 454 & & & & & 127 & 2.81 & 1960 & \\
\hline WVDEP & $7 / 15 / 1996$ & DEF & & & 432 & & & & & 104 & 2.8 & 2310 & \\
\hline DOE & $7 / 23 / 1996$ & DEF & 160.8 & 190.2 & 351 & 119.6 & 49.7 & 25.5 & 0.42 & 82.5 & 1.74 & 1743 & 55.43 \\
\hline WVDEP & $7 / 30 / 1996$ & DEF & & & 321 & & & & & 76.1 & 2.3 & 1890 & \\
\hline WVDEP & $8 / 14 / 1996$ & DEF & & & 342 & & & & & 88.2 & 2.28 & 1680 & \\
\hline DOE & 8/28/1996 & DEF & 127.51 & 243.6 & 371.11 & 152.6 & 68.1 & 24.3 & 0.05 & 99.8 & 1.90 & 1990 & 51.12 \\
\hline WVDEP & $8 / 31 / 1996$ & DEF & & & 328 & & & & & 86 & 3.66 & 1990 & \\
\hline WVDEP & $9 / 16 / 1996$ & DEF & & & 424 & & & & & 111 & 2.88 & 1880 & \\
\hline WVDEP & $9 / 30 / 1996$ & DEF & & & 299 & & & & & 78.6 & 2.25 & 1720 & \\
\hline WVDEP & $10 / 14 / 1996$ & DEF & & & 389 & & & & & 97.9 & 2.56 & 1740 & \\
\hline DOE & $10 / 16 / 1996$ & DEF & 102.55 & 300.5 & 403.05 & 169.0 & 75.1 & 23.4 & 0.57 & 103.3 & 2.26 & 2184 & 48.6 \\
\hline WVDEP & $10 / 30 / 1996$ & DEF & & & 257 & & & & & 64.6 & 1.71 & 1210 & \\
\hline WVDEP & $11 / 15 / 1996$ & DEF & & & 173 & & & & & 47.6 & 1.21 & 574 & \\
\hline DOE & $11 / 26 / 1996$ & DEF & 103.92 & 175.00 & 278.92 & 111.56 & 54.08 & 21.86 & 0.72 & 75.65 & 1.72 & 1574.41 & 43.5 \\
\hline DOE & 12/13/1996 & DEF & 85.52 & 98.2 & 183.72 & 82.63 & 38.67 & 23.11 & 0.98 & 52.71 & 1.17 & 1121.44 & 36.02 \\
\hline WVDEP & $12 / 15 / 1996$ & DEF & & & 129 & & & & & 45.5 & 1.16 & 642 & \\
\hline WVDEP & $1 / 14 / 1997$ & DEF & & & 254 & & & & & 72.7 & 1.82 & 1060 & \\
\hline
\end{tabular}


Table E-1g, Omega Mine-pool, DEF Spring, Raw Chemical Data

\begin{tabular}{|c|c|c|c|c|c|c|c|c|c|c|c|c|c|}
\hline $\begin{array}{c}\text { Sampled } \\
\text { By }\end{array}$ & Date & Location & $\begin{array}{l}\mathrm{Fe} 3+ \\
\mathrm{mg} / \mathrm{L}\end{array}$ & $\begin{array}{l}\mathrm{Fe} 2+ \\
\mathrm{mg} / \mathrm{L}\end{array}$ & $\begin{array}{c}\mathrm{Fe} \\
\text { Total, } \\
\mathrm{mg} / \mathrm{L}\end{array}$ & $\begin{array}{c}\mathrm{Ca}, \\
\mathrm{mg} / \mathrm{L}\end{array}$ & $\begin{array}{l}\mathrm{Mg}, \\
\mathrm{mg} / \mathrm{L}\end{array}$ & $\begin{array}{l}\mathrm{Na}, \\
\mathrm{mg} / \mathrm{L}\end{array}$ & $\mathrm{K}, \mathrm{mg} / \mathrm{L}$ & $\mathrm{Al}, \mathrm{mg} / \mathrm{L}$ & $\begin{array}{l}\mathrm{Mn}, \\
\mathrm{mg} / \mathrm{L}\end{array}$ & $\begin{array}{l}\mathrm{SO} 4, \\
\mathrm{mg} / \mathrm{L}\end{array}$ & $\begin{array}{c}\mathrm{Cl}, \\
\mathrm{mg} / \mathrm{L}\end{array}$ \\
\hline DOE & $1 / 28 / 1997$ & DEF & 91.82 & 186 & 277.82 & 109.11 & 53.59 & 18.26 & 0.83 & 79.87 & 1.61 & 1555.48 & 12.9 \\
\hline DOE & $2 / 21 / 1997$ & DEF & 182.78 & 55.5 & 238.28 & 117.9 & 48.1 & 23.8 & 0.61 & 66.3 & 1.47 & 1370 & 55.6 \\
\hline WVDEP & $3 / 17 / 1997$ & DEF & & & 569 & & & & & 118 & 2.45 & 1920 & \\
\hline DOE & $3 / 26 / 1997$ & DEF & 133.76 & 216.9 & 350.66 & 107.8 & 51.7 & 21.8 & 0.79 & 92.4 & 1.88 & 1811 & 42.7 \\
\hline WVDEP & $4 / 14 / 1997$ & DEF & & & 451 & & & & & 127 & 2.68 & 3440 & \\
\hline WVDEP & $5 / 14 / 1997$ & DEF & & & 481 & & & & & 122 & 2.86 & 1340 & \\
\hline DOE & $5 / 20 / 1997$ & DEF & 139.28 & 271 & 410.28 & 138.0 & 66.3 & 17.2 & 0.25 & 107.1 & 2.50 & 2130 & \\
\hline WVDEP & $6 / 16 / 1997$ & DEF & & & 536 & & & & & 138 & 2.69 & 1530 & \\
\hline DOE & 7/10/1997 & DEF & 130.52 & 347.9 & 478.42 & 164.1 & 77.6 & 16.8 & 0.88 & 123.7 & 2.70 & 2411 & 36.07 \\
\hline WVDEP & 7/16/1997 & DEF & & & 383 & & & & & 100 & 2 & 2190 & \\
\hline WVDEP & $8 / 17 / 1997$ & DEF & & & 493 & & & & & 137 & 2.76 & 1340 & \\
\hline DOE & 9/10/1997 & DEF & 96.99 & 322.2 & 419.19 & 156.2 & 78.1 & 20.3 & 1.05 & 109.3 & 2.66 & 2170 & 42.3 \\
\hline WVDEP & 9/15/1997 & DEF & & & 381 & & & & & & 2.54 & 1880 & \\
\hline WVDEP & $10 / 15 / 1997$ & DEF & & & 467 & & & & & 114 & 2.6 & 1500 & \\
\hline DOE & $11 / 5 / 1997$ & DEF & 92.52 & 384.7 & 477.22 & 173.7 & 87.0 & 19.1 & 1.14 & 121.6 & 2.93 & 2398 & 39.89 \\
\hline WVDEP & $11 / 14 / 1997$ & DEF & & & 373 & & & & & 59.2 & 1.52 & 840 & \\
\hline WVDEP & $12 / 15 / 1997$ & DEF & & & 299 & & & & & 83 & 2.86 & 1650 & \\
\hline DOE & $1 / 12 / 1998$ & DEF & 136.58 & 87.7 & 224.28 & 81.2 & 37.4 & 28.9 & 1.33 & 53.6 & 1.20 & 1247 & 44.5 \\
\hline WVDEP & $1 / 16 / 1998$ & DEF & & & 241 & & & & & 70.8 & 1.57 & 1440 & \\
\hline DOE & $2 / 9 / 1998$ & DEF & 118.4 & 109.8 & 228.2 & 102.8 & 46.3 & 33.3 & 1.86 & 73.0 & 1.36 & 1362 & 49.92 \\
\hline WVDEP & $2 / 15 / 1998$ & DEF & & & 220 & & & & & 62.4 & 1.09 & 1240 & \\
\hline WVDEP & $3 / 15 / 1998$ & DEF & & & 198 & & & & & 64.4 & 1.06 & 1260 & \\
\hline DOE & $3 / 26 / 1998$ & DEF & 118.41 & 73.4 & 191.81 & 78.8 & 36.6 & 34.3 & 1 & 59.9 & 1.04 & 1162 & \\
\hline WVDEP & $4 / 15 / 1998$ & DEF & & & 251 & & & & & 81.9 & 1.31 & 1400 & \\
\hline DOE & $4 / 29 / 1998$ & DEF & 104.17 & 89.66 & 193.83 & 86.2 & 40.4 & 29.8 & 1.02 & 60.8 & 1.17 & 1214 & \\
\hline WVDEP & $5 / 14 / 1998$ & DEF & & & 203 & & & & & 63.1 & 1.42 & 1160 & \\
\hline DOE & $5 / 28 / 1998$ & DEF & 92.84 & 218 & 310.84 & 120.9 & 58.8 & 24.1 & 1.03 & 96.6 & 0.00 & 1730 & 55.09 \\
\hline WVDEP & $6 / 15 / 1998$ & DEF & & & 401 & & & & & 125 & 2.05 & 2040 & \\
\hline DOE & $6 / 25 / 1998$ & DEF & 115.4 & 145 & 260.4 & 111.5 & 48.8 & 29.5 & 0.87 & 75.8 & 0.02 & 1520 & 53.2 \\
\hline WVDEP & 7/15/1998 & DEF & & & 433 & & & & & 8.73 & 2.68 & 1960 & \\
\hline DOE & $8 / 5 / 1998$ & DEF & 143.2 & 353.6 & 496.8 & 175.1 & 83.6 & 18.8 & 0.8 & 147.9 & 2.72 & 2649 & 42.93 \\
\hline WVDEP & $8 / 13 / 1998$ & DEF & & & 511 & & & & & 158 & 2.75 & 2380 & \\
\hline DOE & 9/3/1998 & DEF & 111.92 & 353.7 & 465.62 & 170.9 & 83.1 & 20.4 & 0.73 & 136.5 & 2.79 & 2509 & 47.71 \\
\hline WVDEP & 9/15/1998 & DEF & & & 52.6 & & & & & 500 & 2.73 & 2500 & \\
\hline WVDEP & $10 / 15 / 1998$ & DEF & & & 480 & & & & & 137 & 3.67 & 2320 & \\
\hline DOE & 10/29/1998 & DEF & 118.55 & 423.7 & 542.25 & 199.4 & 99.7 & 21.9 & 1.36 & 144.8 & 3.26 & 2916 & 45.18 \\
\hline
\end{tabular}


Table E-1g, Omega Mine-pool, DEF Spring, Raw Chemical Data

\begin{tabular}{|c|c|c|c|c|c|c|c|c|c|c|c|c|c|}
\hline $\begin{array}{c}\text { Sampled } \\
\text { By }\end{array}$ & Date & Location & $\begin{array}{l}\mathrm{Fe} 3+ \\
\mathrm{mg} / \mathrm{L}\end{array}$ & $\begin{array}{l}\mathrm{Fe} 2+ \\
\mathrm{mg} / \mathrm{L}\end{array}$ & $\begin{array}{c}\mathrm{Fe} \\
\text { Total, } \\
\mathrm{mg} / \mathrm{L}\end{array}$ & $\begin{array}{c}\mathrm{Ca}, \\
\mathrm{mg} / \mathrm{L}\end{array}$ & $\begin{array}{l}\mathrm{Mg}, \\
\mathrm{mg} / \mathrm{L}\end{array}$ & $\begin{array}{l}\mathrm{Na}, \\
\mathrm{mg} / \mathrm{L}\end{array}$ & $\mathrm{K}, \mathrm{mg} / \mathrm{L}$ & $\mathrm{Al}, \mathrm{mg} / \mathrm{L}$ & $\begin{array}{l}\mathrm{Mn}, \\
\mathrm{mg} / \mathrm{L}\end{array}$ & $\begin{array}{l}\mathrm{SO} 4, \\
\mathrm{mg} / \mathrm{L}\end{array}$ & $\begin{array}{c}\mathrm{Cl}, \\
\mathrm{mg} / \mathrm{L}\end{array}$ \\
\hline WVDEP & $11 / 15 / 1998$ & DEF & & & 439 & & & & & 130 & 3.24 & 2560 & \\
\hline DOE & $12 / 10 / 1998$ & DEF & 101.16 & 374.81 & 475.97 & 212.6 & 95.8 & 21.9 & 1.12 & 143.5 & 3.25 & 2665 & 46.2 \\
\hline WVDEP & $12 / 15 / 1998$ & DEF & & & 504 & & & & & 140 & 2.79 & 2230 & \\
\hline WVDEP & $1 / 17 / 1999$ & DEF & & & 84.6 & & & & & 24.3 & 0.65 & 507 & \\
\hline WVDEP & $2 / 14 / 1999$ & DEF & & & 221 & & & & & 71.5 & 1.47 & 1440 & \\
\hline DOE & 2/18/1999 & DEF & 110.22 & 164.6 & 274.82 & 134.7 & 56.6 & 29.0 & 0.81 & 90.6 & 1.93 & 1747 & 81.29 \\
\hline WVDEP & $3 / 14 / 1999$ & DEF & & & 166 & & & & & 47.7 & 1.04 & 952 & \\
\hline DOE & $3 / 30 / 1999$ & DEF & 98.45 & 133 & 231.45 & 111.9 & 46.5 & 31.7 & 1.37 & 78.5 & 1.53 & 1440 & 54.49 \\
\hline WVDEP & 4/13/1999 & DEF & & & 349 & & & & & 114 & 2.09 & 1910 & \\
\hline DOE & 4/29/1999 & DEF & 116.79 & 204.9 & 321.69 & 144.6 & 62.4 & 23.4 & 0.6 & 104.2 & 2.10 & 1960 & 53.06 \\
\hline WVDEP & $5 / 17 / 1999$ & DEF & & & 644 & & & & & 140 & 2.24 & 1900 & \\
\hline DOE & $5 / 26 / 1999$ & DEF & 156.68 & 263 & 419.68 & 187.3 & 81.0 & 22.3 & 0.68 & 126.8 & 2.76 & 2424 & 47.2 \\
\hline WVDEP & $6 / 14 / 1999$ & DEF & & & 470 & & & & & 131 & 2.84 & 1940 & \\
\hline DOE & 6/29/1999 & DEF & 123.18 & 326.6 & 449.78 & 199.84 & 88.94 & 16.88 & 0.68 & 139.78 & 3.24 & 2682.33 & 33.72 \\
\hline WVDEP & 7/13/1999 & DEF & & & 528 & & & & & 143 & 2.92 & 2040 & \\
\hline DOE & $7 / 27 / 1999$ & DEF & 139.66 & 361.2 & 500.86 & 217.1 & 100.4 & 16.8 & 0.87 & 159.3 & 3.50 & 2906 & 45.65 \\
\hline WVDEP & $8 / 14 / 1999$ & DEF & & & 573 & & & & & 165 & 3.43 & 2830 & \\
\hline DOE & 8/26/1999 & DEF & 125.3 & 420 & 545.3 & 238.7 & 109.8 & 20.9 & 1.48 & 166.3 & 3.77 & 3101 & 45.61 \\
\hline WVDEP & $9 / 14 / 1999$ & DEF & & & 583 & & & & & 162 & 3.38 & 2280 & \\
\hline DOE & 9/29/1999 & DEF & 99.32 & 418.32 & 517.64 & 226.3 & 104.6 & 18.0 & 1.03 & 164.1 & 3.80 & 2953 & 40 \\
\hline WVDEP & 10/15/1999 & DEF & & & 523 & & & & & 155 & 3.31 & 2640 & \\
\hline DOE & $10 / 29 / 1999$ & DEF & 164.2 & 238.6 & 402.8 & 195.0 & 89.9 & 27.3 & 10.5 & 133.0 & 3.08 & 2498 & 67.86 \\
\hline WVDEP & $11 / 15 / 1999$ & DEF & & & 399 & & & & & 134 & 2.76 & 2310 & \\
\hline DOE & 12/7/1999 & DEF & 144.91 & 117.6 & 262.51 & 139.1 & 62.6 & 37.9 & 0.91 & 84.9 & 2.10 & 1764 & 79.8 \\
\hline WVDEP & $12 / 15 / 1999$ & DEF & & & 25.6 & & & & & 79.9 & 2.05 & 1660 & \\
\hline WVDEP & $1 / 17 / 2000$ & DEF & & & 318 & & & & & 106 & 2.5 & 1920 & \\
\hline WVDEP & $2 / 8 / 2000$ & DEF & & & 322 & & & & & 101 & 3.01 & 2650 & \\
\hline WVDEP & $3 / 15 / 2000$ & DEF & & & 369 & & & & & 123 & 2.21 & 7370 & \\
\hline WVDEP & $4 / 14 / 2000$ & DEF & & & 166 & & & & & 59.2 & 1.16 & 1340 & \\
\hline WVDEP & $5 / 15 / 2000$ & DEF & & & 278 & & & & & 102 & 1.92 & 2450 & \\
\hline WVDEP & $6 / 15 / 2000$ & DEF & & & 274 & & & & & 86.5 & 1.82 & 845 & \\
\hline WVDEP & $7 / 18 / 2000$ & DEF & & & 215 & & & & & 62.6 & 1.39 & 1590 & \\
\hline WVDEP & $8 / 15 / 2000$ & DEF & & & 311 & & & & & 104 & 2.34 & 225 & \\
\hline WVDEP & 9/15/2000 & DEF & & & 436 & 146 & & & & 141 & 2.67 & 2980 & \\
\hline WVDEP & $10 / 15 / 2000$ & DEF & & & 495 & & & & & 149 & 3.73 & 2960 & \\
\hline WVDEP & $11 / 15 / 2000$ & DEF & & & 487 & & & & & 155 & 3.11 & 3660 & \\
\hline
\end{tabular}


Table E-1g, Omega Mine-pool, DEF Spring, Raw Chemical Data

\begin{tabular}{|c|c|c|c|c|c|c|c|c|c|c|c|c|c|}
\hline $\begin{array}{c}\text { Sampled } \\
\text { By }\end{array}$ & Date & Location & $\begin{array}{c}\mathrm{Fe} 3+ \\
\mathrm{mg} / \mathrm{L}\end{array}$ & $\begin{array}{l}\mathrm{Fe} 2+ \\
\mathrm{mg} / \mathrm{L}\end{array}$ & $\begin{array}{c}\mathrm{Fe} \\
\text { Total, } \\
\mathrm{mg} / \mathrm{L}\end{array}$ & $\begin{array}{c}\mathrm{Ca}, \\
\mathrm{mg} / \mathrm{L}\end{array}$ & $\begin{array}{l}\mathrm{Mg}, \\
\mathrm{mg} / \mathrm{L}\end{array}$ & $\begin{array}{l}\mathrm{Na}, \\
\mathrm{mg} / \mathrm{L}\end{array}$ & $\mathrm{K}, \mathrm{mg} / \mathrm{L}$ & $\mathrm{Al}, \mathrm{mg} / \mathrm{L}$ & $\begin{array}{l}\mathrm{Mn}, \\
\mathrm{mg} / \mathrm{L}\end{array}$ & $\begin{array}{l}\mathrm{SO} 4, \\
\mathrm{mg} / \mathrm{L}\end{array}$ & $\begin{array}{c}\mathrm{Cl}, \\
\mathrm{mg} / \mathrm{L}\end{array}$ \\
\hline WVDEP & $12 / 14 / 2000$ & DEF & & & 455 & & & & & 122 & 2.79 & 3850 & \\
\hline WVDEP & $1 / 15 / 2001$ & DEF & & & 345 & & & & & 109 & 2.91 & 2210 & \\
\hline WVDEP & 2/13/2001 & DEF & & & 224 & & & & & 74.5 & 1.83 & 1270 & \\
\hline WVDEP & $3 / 13 / 2001$ & DEF & & & 282 & & & & & 96.4 & 1.86 & 1930 & \\
\hline WVDEP & $4 / 16 / 2001$ & DEF & & & 110 & & & & & 45.9 & 0.97 & 1938 & \\
\hline WVDEP & $5 / 15 / 2001$ & DEF & & & 365 & & & & & 135 & 2.21 & 3197 & \\
\hline WVDEP & $6 / 18 / 2001$ & DEF & & & 269 & & & & & 89.6 & 1.88 & 2964 & \\
\hline WVDEP & $7 / 15 / 2001$ & DEF & & & 196 & & & & & 70.1 & 1.5 & 3343 & \\
\hline WVDEP & $8 / 15 / 2001$ & DEF & & & 362 & & & & & 120 & 2.28 & 3383 & \\
\hline WVDEP & $9 / 14 / 2001$ & DEF & & & 462 & & & & & 145 & 2.67 & 2204 & \\
\hline WVDEP & $10 / 25 / 2001$ & DEF & & & 359 & & & & & 117.25 & 2.63 & 2178 & \\
\hline WVDEP & $11 / 15 / 2001$ & DEF & & & 391.24 & & & & & 118.47 & 2.75 & 1998 & \\
\hline WVDEP & $12 / 14 / 2001$ & DEF & & & 190.28 & & & & & 89.08 & 1.94 & 2198 & \\
\hline WVDEP & $1 / 16 / 2002$ & DEF & & & 126.84 & & & & & 65.86 & 1.25 & 1176 & \\
\hline WVDEP & 2/14/2002 & DEF & & & 179.35 & & & & & 78.37 & 1.44 & 1499 & \\
\hline WVDEP & $3 / 14 / 2002$ & DEF & & & 249.74 & & & & & 75.82 & 1.39 & 1512 & \\
\hline WVDEP & 4/15/2002 & DEF & & & 234.34 & & & & & 69.06 & 1.17 & 1319 & \\
\hline WVDEP & $5 / 15 / 2002$ & DEF & & & 173.21 & & & & & 57.99 & 1.06 & 1798 & \\
\hline WVDEP & $6 / 18 / 2002$ & DEF & & & 77.42 & & & & & 3.68 & 0.77 & 1332 & \\
\hline WVDEP & $7 / 18 / 2002$ & DEF & & & & & & & & & & & \\
\hline WVDEP & 8/12/2002 & DEF & & & 314.52 & & & & & 114.45 & 1.82 & 1998 & \\
\hline Perry & $8 / 20 / 2002$ & DEF & 67.742 & 270.968 & 338.71 & 135.1 & 65.4 & 23.0 & 1.12 & 113.0 & 2.25 & 1931 & 58.3 \\
\hline WVDEP & 9/16/2002 & DEF & & & & & & & & & & & \\
\hline WVDEP & $10 / 15 / 2002$ & DEF & & & 204.7 & & & & & 69.12 & 1.82 & 1865 & \\
\hline WVDEP & $11 / 15 / 2002$ & DEF & & & & & & & & & & & \\
\hline WVDEP & $12 / 15 / 2002$ & DEF & & & & & & & & & & & \\
\hline WVDEP & $1 / 14 / 2003$ & DEF & & & & & & & & & & & \\
\hline WVDEP & $2 / 24 / 2003$ & DEF & & & 451.68 & & & & & 120.02 & 2.61 & 2511 & \\
\hline WVDEP & $3 / 18 / 2003$ & DEF & & & & & & & & & & & \\
\hline WVDEP & 4/15/2003 & DEF & & & & & & & & & & & \\
\hline WVDEP & $5 / 20 / 2003$ & DEF & & & & & & & & & & & \\
\hline WVDEP & $6 / 17 / 2003$ & DEF & & & 138 & & & & & 57.75 & 0.99 & 1352 & \\
\hline WVDEP & $8 / 13 / 2003$ & DEF & & & & & & & & & & & \\
\hline Perry & $8 / 27 / 2003$ & DEF & & & 349 & 126.0 & 60.2 & 26.0 & 1.04 & 115.0 & 2.43 & 1811 & \\
\hline WVDEP & 9/15/2003 & DEF & & & 248.94 & & & & & 80.19 & 1.65 & 1778 & \\
\hline WVDEP & $10 / 14 / 2003$ & DEF & & & & & & & & & & & \\
\hline
\end{tabular}


Table E-1g, Omega Mine-pool, DEF Spring, Raw Chemical Data

\begin{tabular}{|c|c|c|c|c|c|c|c|c|c|c|c|c|c|}
\hline $\begin{array}{c}\text { Sampled } \\
\text { By }\end{array}$ & Date & Location & $\begin{array}{l}\mathrm{Fe} 3+, \\
\mathrm{mg} / \mathrm{L}\end{array}$ & $\begin{array}{l}\mathrm{Fe} 2+ \\
\mathrm{mg} / \mathrm{L}\end{array}$ & $\begin{array}{c}\mathrm{Fe} \\
\text { Total, } \\
\mathrm{mg} / \mathrm{L}\end{array}$ & $\begin{array}{c}\mathrm{Ca}, \\
\mathrm{mg} / \mathrm{L}\end{array}$ & $\begin{array}{l}\mathrm{Mg}, \\
\mathrm{mg} / \mathrm{L}\end{array}$ & $\begin{array}{l}\mathrm{Na}, \\
\mathrm{mg} / \mathrm{L}\end{array}$ & $\mathrm{K}, \mathrm{mg} / \mathrm{L}$ & $\mathrm{Al}, \mathrm{mg} / \mathrm{L}$ & $\begin{array}{l}\mathrm{Mn}, \\
\mathrm{mg} / \mathrm{L}\end{array}$ & $\begin{array}{l}\mathrm{SO} 4, \\
\mathrm{mg} / \mathrm{L}\end{array}$ & $\begin{array}{c}\mathrm{Cl}, \\
\mathrm{mg} / \mathrm{L}\end{array}$ \\
\hline WVDEP & $11 / 18 / 2003$ & DEF & & & & & & & & & & & \\
\hline WVDEP & $12 / 19 / 2003$ & DEF & & & & & & & & & & & \\
\hline WVDEP & $1 / 14 / 2004$ & DEF & & & 187.45 & & & & & 75.11 & 1.25 & 1538 & \\
\hline WVDEP & $2 / 17 / 2004$ & DEF & & & & & & & & & & & \\
\hline WVDEP & $3 / 23 / 2004$ & DEF & & & & & & & & & & & \\
\hline WVDEP & $4 / 13 / 2004$ & DEF & & & 0.65 & & & & & 14.16 & 4.29 & 1289 & \\
\hline WVDEP & $5 / 18 / 2004$ & DEF & & & & & & & & & & & \\
\hline WVDEP & $6 / 14 / 2004$ & DEF & & & & & & & & & & & \\
\hline WVDEP & $7 / 12 / 2004$ & DEF & & & 254.49 & & & & & 98.29 & 1.63 & 1725 & \\
\hline WVDEP & $8 / 9 / 2004$ & DEF & & & & & & & & & & & \\
\hline WVDEP & $9 / 14 / 2004$ & DEF & & & & & & & & & & & \\
\hline WVDEP & $10 / 18 / 2004$ & DEF & & & 310.41 & & & & & 112.32 & 2.1 & 1918 & \\
\hline Perry & $3 / 22 / 2005$ & DEF & 104.7 & 63.3 & 168.03 & 102.74 & 42.46 & 37.26 & 1.51 & 72.99 & 1.38 & 1232.9 & 65 \\
\hline Perry & $5 / 24 / 2006$ & DEF & 121.7 & 48.3 & 169.79 & 94.2 & 40.4 & 28.96 & 1.33 & 66.4 & 1.37 & 1184 & 82 \\
\hline Perry & $5 / 3 / 2007$ & DEF & 56.7 & 141.4 & 197.75 & 96.23 & 41.7 & 26.66 & 1.06 & 86.3 & 1.41 & 1435 & 60 \\
\hline Perry & $9 / 13 / 2007$ & DEF & & & 224.9 & 109.3 & 51.24 & 41.14 & 0.77 & 95.4 & 2.1 & 1615 & 100 \\
\hline
\end{tabular}


$\underline{\text { Appendix F }}$

T\&T Mine-pool Raw Chemical Data 
Table F-1, T\&T Mine-pool, Raw Chemical Data

\begin{tabular}{|c|c|c|c|c|c|c|c|c|c|c|c|}
\hline Site & Date & $\begin{array}{l}\text { Flow, } \\
\text { gpm }\end{array}$ & $\mathrm{pH}$ & $\begin{array}{c}\text { Acdity } \\
\mathrm{CaCO}_{3} \\
\mathrm{Eq}\end{array}$ & $\begin{array}{l}\text { Sp Cond. } \\
\text { umhos/cm }\end{array}$ & $\begin{array}{l}\text { TDS, } \\
\mathrm{mg} / \mathrm{L}\end{array}$ & $\begin{array}{l}\mathrm{Fe}, \\
\mathrm{mg} / \mathrm{L}\end{array}$ & $\begin{array}{c}\mathrm{Al}, \\
\mathrm{mg} / \mathrm{L}\end{array}$ & $\begin{array}{l}\mathrm{Mn}, \\
\mathrm{mg} / \mathrm{L}\end{array}$ & $\begin{array}{l}\mathrm{SO} 4, \\
\mathrm{mg} / \mathrm{L}\end{array}$ & $\begin{array}{l}\mathrm{Ca}, \\
\mathrm{mg} / \mathrm{L}\end{array}$ \\
\hline$T \& T$ & $4 / 8 / 1994$ & & & 1247 & & & 1024 & & 5.1 & 4000 & \\
\hline$T \& T$ & $4 / 25 / 1994$ & & & 1843 & & & 700 & & 3.6 & & \\
\hline T\&T & $6 / 13 / 1994$ & & & 1260 & & & 316 & 75.3 & 3.14 & 1860 & \\
\hline $\mathrm{T} \& \mathrm{~T}$ & $6 / 24 / 1994$ & & 2.8 & 990 & 3890 & & 455 & 90 & 3.14 & 1910 & 287 \\
\hline$T \& T$ & $7 / 17 / 1994$ & & & 1400 & & & 152 & & 2.6 & 3010 & \\
\hline T\&T & $7 / 26 / 1994$ & & & 277 & & & 512 & & 2.6 & 2650 & \\
\hline$T \& T$ & $7 / 29 / 1994$ & & & 921 & & & 241 & & 1.4 & 2870 & \\
\hline T\&T & $8 / 11 / 1994$ & & & 434 & & & 177 & & 1 & 2900 & \\
\hline T\&T & $8 / 23 / 1994$ & & & 319 & & & 10.4 & & 0.5 & & \\
\hline $\mathrm{T} \& \mathrm{~T}$ & $8 / 26 / 1994$ & & & 20 & & & 321 & & 0.5 & 2680 & \\
\hline T\&T & $8 / 29 / 1994$ & & & 576 & & & 1220 & & 5.53 & 2400 & \\
\hline T\&T & $9 / 4 / 1994$ & & & 2194 & & & 47.4 & & 2.07 & 2400 & \\
\hline T\&T & 9/20/1994 & & & 89 & & & 789 & & 5.79 & 2500 & \\
\hline$T \& T$ & 9/23/1994 & & & 1423 & & & 413 & & 2.72 & 2040 & \\
\hline$T \& T$ & $10 / 3 / 1994$ & 100 & & 744 & & & 600 & & 2.98 & 1850 & \\
\hline T\&T & $10 / 25 / 1994$ & & & 1080 & & & 311 & & 2.67 & 2480 & \\
\hline$T \& T$ & $10 / 31 / 1994$ & 175 & & 562 & & & 70.9 & & 0.61 & 2370 & \\
\hline$T \& T$ & $11 / 14 / 1994$ & 150 & & 128 & & & 220 & & 1.42 & 2725 & \\
\hline$T \& T$ & $11 / 28 / 1994$ & 200 & & 396 & & & 581 & & 4.21 & 2340 & \\
\hline$T \& T$ & 12/13/1994 & 775 & & 1048 & & & 154 & & 0.96 & 1380 & \\
\hline$T \& T$ & $12 / 16 / 1994$ & 550 & & 277 & & & 265 & & 1.94 & 2090 & \\
\hline T\&T & $12 / 27 / 1994$ & 550 & & 478 & & & 324 & & 2.49 & 2360 & \\
\hline$T \& T$ & $1 / 3 / 1995$ & 575 & & 585 & & & 393 & & 3.38 & 2780 & \\
\hline$T \& T$ & $1 / 6 / 1995$ & 150 & & 710 & & & 110 & & 0.92 & 2140 & \\
\hline T\&T & $1 / 9 / 1995$ & 550 & & 199 & & & 269 & & 1.91 & 1890 & \\
\hline$T \& T$ & $1 / 12 / 1995$ & & & 485 & & & 13.8 & & 0.66 & 2650 & \\
\hline$T \& \mathrm{~T}$ & $1 / 27 / 1995$ & 900 & & 26 & & & 209 & & 1.7 & 2170 & \\
\hline T\&T & $2 / 9 / 1995$ & 600 & & 377 & & & 316 & & 2.77 & 2300 & \\
\hline T\&T & 2/23/1995 & 600 & & 571 & & & 225 & & 2.32 & 1880 & \\
\hline T\&T & $2 / 28 / 1995$ & & & 407 & & & 170 & & 1.86 & 1830 & \\
\hline T\&T & $3 / 5 / 1995$ & & & 308 & & & 5220 & & 21.3 & 10600 & \\
\hline T\&T & $3 / 9 / 1995$ & & & 9384 & & & 2500 & & 16.5 & 13400 & \\
\hline T\&T & $4 / 10 / 1995$ & 800 & & 4506 & & & 1220 & & 5.84 & 4840 & \\
\hline T\&T & $4 / 3 / 1996$ & 928 & 2.6 & 2195 & 3800 & 2194 & 251 & & 2.81 & 1600 & \\
\hline T\&T & $5 / 1 / 1996$ & 888 & 2.6 & 580 & 4210 & 2058 & 231 & & 2.31 & 1210 & \\
\hline T\&T & $5 / 8 / 1996$ & 968 & 2.6 & 543 & 3560 & 1930 & 39.4 & & 0.54 & 1300 & \\
\hline T\&T & $5 / 15 / 1996$ & 1012 & 2.6 & 197 & 5250 & 2163 & 205 & & 2.44 & 1540 & \\
\hline$T \& T$ & $5 / 22 / 1996$ & 1137 & 2.4 & 497 & 5430 & 2701 & 336 & & 2.65 & 1780 & \\
\hline T\&T & $5 / 29 / 1996$ & 1146 & 2.5 & 805 & 4350 & 2014 & 216 & & 1.98 & 1330 & \\
\hline T\&T & 6/5/1996 & 1057 & 2.6 & 548 & 4270 & 2375 & 261 & & 2.56 & 1420 & \\
\hline$T \& T$ & $6 / 12 / 1996$ & 703 & 3.6 & 597 & 4340 & 1897 & 246 & & 2.41 & 1400 & \\
\hline$T \& T$ & $6 / 19 / 1996$ & 793 & 2.6 & 457 & 4040 & 1932 & 202 & & 2.01 & 1250 & \\
\hline T\&T & $6 / 26 / 1996$ & 529 & 2.7 & 491 & 3810 & 1932 & 229 & & 1.88 & 1300 & \\
\hline$T \& T$ & $7 / 3 / 1996$ & 422 & 2.6 & 513 & 4500 & 2002 & 208 & & 2.02 & 1050 & \\
\hline$T \& T$ & $7 / 10 / 1996$ & 422 & 2.7 & 502 & 3950 & 1954 & 191 & & 2.12 & 1230 & \\
\hline T\&T & $7 / 17 / 1996$ & 383 & 2.6 & 446 & 4130 & 2102 & 246 & 46 & 2.32 & 1560 & \\
\hline$T \& T$ & 7/24/1996 & 721 & 2.6 & 826 & 4220 & 2030 & 196 & 32.6 & 1.9 & 1550 & \\
\hline T\&T & $7 / 31 / 1996$ & 569 & 2.6 & 661 & 4120 & 2309 & 230 & 36.1 & 2.43 & 1450 & \\
\hline T\&T & 8/7/1996 & 650 & 2.6 & 742 & 3930 & 1956 & 216 & 38.3 & 2.48 & 1320 & \\
\hline
\end{tabular}


Table F-1, T\&T Mine-pool, Raw Chemical Data

\begin{tabular}{|c|c|c|c|c|c|c|c|c|c|c|c|}
\hline Site & Date & $\begin{array}{l}\text { Flow, } \\
\text { gpm }\end{array}$ & $\mathrm{pH}$ & $\begin{array}{c}\text { Acdity } \\
\mathrm{CaCO}_{3} \\
\mathrm{Eq}\end{array}$ & $\begin{array}{l}\text { Sp Cond. } \\
\text { umhos/cm }\end{array}$ & $\begin{array}{l}\text { TDS, } \\
\mathrm{mg} / \mathrm{L}\end{array}$ & $\begin{array}{l}\mathrm{Fe}, \\
\mathrm{mg} / \mathrm{L}\end{array}$ & $\begin{array}{c}\mathrm{Al}, \\
\mathrm{mg} / \mathrm{L}\end{array}$ & $\begin{array}{l}\mathrm{Mn}, \\
\mathrm{mg} / \mathrm{L}\end{array}$ & $\begin{array}{l}\mathrm{SO} 4 \\
\mathrm{mg} / \mathrm{L}\end{array}$ & $\begin{array}{l}\mathrm{Ca}, \\
\mathrm{mg} / \mathrm{L}\end{array}$ \\
\hline$T \& T$ & $8 / 14 / 1996$ & 569 & 2.6 & 658 & 3690 & 2014 & 182 & 36.5 & 2.2 & 1330 & \\
\hline$T \& T$ & $8 / 21 / 1996$ & 491 & 2.6 & 700 & 4160 & 1940 & 190 & 41.3 & 2.58 & 1320 & \\
\hline$T \& T$ & $8 / 28 / 1996$ & 408 & 2.7 & 796 & 2010 & 1934 & 265 & 39.1 & 2.35 & 1330 & \\
\hline$T \& T$ & 9/3/1996 & 371 & 2.6 & 728 & 5350 & 2485 & 213 & 39.1 & 2.34 & 1130 & \\
\hline$T \& T$ & 9/11/1996 & 335 & 2.7 & 161 & 4520 & 2141 & 8.17 & 7.98 & 1.51 & 1240 & \\
\hline$T \& T$ & 9/17/1996 & 290 & 3.6 & 666 & 3760 & 2102 & 232 & 42 & 2.39 & 1260 & \\
\hline$T \& T$ & 9/24/1996 & 301 & 2.7 & 661 & 3910 & 2446 & 181 & 42 & 2.26 & 1110 & \\
\hline T\&T & $10 / 2 / 1996$ & 301 & 2.6 & 764 & 3820 & 2410 & 229 & 40.3 & 2.34 & 1230 & \\
\hline T\&T & $10 / 8 / 1996$ & 301 & 2.6 & 798 & 4270 & 2217 & 232 & 45.4 & 2.58 & 1290 & \\
\hline$T \& T$ & 10/15/1996 & 301 & 2.7 & 763 & 4420 & 2662 & 234 & 43.3 & 2.35 & 1160 & \\
\hline$T \& T$ & 10/23/1996 & 435 & 2.7 & 727 & 4780 & 1986 & 213 & 43.7 & 1.94 & 1170 & \\
\hline T\&T & $10 / 30 / 1996$ & 491 & 2.6 & 788 & 4440 & 2237 & 250 & 38 & 2.28 & 1410 & \\
\hline$T \& T$ & 11/4/1996 & 516 & 2.6 & 760 & 4790 & 2222 & 227 & 40.3 & 2.4 & 1050 & \\
\hline$T \& T$ & $11 / 12 / 1996$ & 536 & 2.6 & 711 & 5440 & 2070 & 214 & 35.7 & 2.37 & 1170 & \\
\hline T\&T & $11 / 20 / 1996$ & 569 & 2.6 & 811 & 5720 & 2470 & 246 & 43.2 & 2.71 & 1270 & \\
\hline T\&T & $11 / 27 / 1996$ & 551 & 2.6 & 760 & 4890 & 2408 & 231 & 38.9 & 2.57 & 1170 & \\
\hline$T \& T$ & 12/2/1996 & 569 & 3.2 & 58 & 864 & 545 & 13.3 & & 1.4 & 265 & \\
\hline$T \& T$ & $12 / 11 / 1996$ & 703 & 2.5 & 808 & 4900 & 2247 & 232 & 41.2 & 3.13 & 986 & \\
\hline$T \& T$ & $12 / 18 / 1996$ & 618 & 2.6 & 753 & 4820 & 1940 & 235 & 36.4 & 2.71 & 1150 & \\
\hline$T \& T$ & 12/23/1996 & 582 & 2.6 & 704 & 4450 & 2321 & 212 & 34.9 & 2.56 & 1350 & \\
\hline$T \& T$ & $12 / 30 / 1996$ & 569 & 2.6 & 700 & 4710 & 2096 & 214 & 33.7 & 2.35 & 772 & \\
\hline$T \& T$ & $1 / 7 / 1997$ & 618 & 2.6 & 675 & 4390 & 2068 & 202 & 33 & 2.36 & 978 & \\
\hline$T \& T$ & $1 / 15 / 1997$ & 614 & 2.6 & 642 & 4310 & 1921 & 187 & 32 & 2.16 & 1310 & \\
\hline$T \& T$ & $1 / 22 / 1997$ & 536 & 2.7 & 687 & 4320 & 1972 & 206 & 38.6 & 2.37 & 1380 & \\
\hline T\&T & $1 / 29 / 1997$ & 533 & 2.6 & 677 & 4430 & 1729 & 187 & 38.2 & 2.3 & 1230 & \\
\hline$T \& T$ & $3 / 5 / 1997$ & 650 & 2.6 & 1154 & 2510 & 1642 & 470 & 33 & 1.89 & 1030 & \\
\hline$T \& T$ & $4 / 2 / 1997$ & 668 & 2.5 & 714 & 2467 & 1815 & 201 & 34.6 & 2.2 & 1210 & \\
\hline$T \& T$ & $5 / 7 / 1997$ & 521 & 2.5 & 674 & 2230 & 1716 & 170 & 37.3 & 2.13 & 1270 & \\
\hline$T \& T$ & $6 / 4 / 1997$ & 582 & 2.6 & 601 & 2630 & 1906 & 171 & 29.6 & 2.71 & 1130 & \\
\hline$T \& T$ & $7 / 2 / 1997$ & 463 & 2.6 & 580 & 2470 & 1833 & 147 & 33.9 & 1.75 & 1040 & \\
\hline$T \& T$ & $8 / 5 / 1997$ & 301 & 2.6 & 630 & 2360 & 2216 & 172 & 34.7 & 2.06 & 1030 & \\
\hline$T \& T$ & 9/2/1997 & 288 & 2.7 & 614 & 2620 & 1938 & 174 & 35.8 & 1.91 & 980 & \\
\hline$T \& T$ & 10/1/1997 & 290 & 2.7 & 606 & 4670 & 1996 & 186 & 30.6 & 1.67 & 1220 & \\
\hline$T \& T$ & $11 / 5 / 1997$ & 240 & 2.6 & 709 & 2710 & 296 & 199 & 40.2 & 2.09 & 953 & \\
\hline$T \& T$ & $12 / 1 / 1997$ & 422 & 2.5 & 732 & 3000 & 2597 & 189 & 41.6 & 2.55 & 864 & \\
\hline$T \& T$ & $1 / 2 / 1998$ & 358 & 2.6 & 576 & 4120 & 2161 & 147 & 33 & 2.26 & 1290 & \\
\hline T\&T & $2 / 5 / 1998$ & 569 & 2.6 & 639 & 3870 & 1675 & 188 & 31.2 & 2.16 & 1390 & \\
\hline$T \& T$ & $3 / 4 / 1998$ & 569 & 3.2 & 511 & 762 & 528 & 166 & 32.1 & 2.34 & 321 & \\
\hline$T \& T$ & $4 / 2 / 1998$ & 551 & 2.7 & 570 & 2250 & 1771 & 162 & 31.8 & 2.04 & 1210 & \\
\hline$T \& T$ & $5 / 4 / 1998$ & 536 & 2.7 & 508 & 3530 & 1956 & 154 & 23.4 & 1.56 & 1150 & \\
\hline T\&T & $6 / 3 / 1998$ & 422 & 2.7 & 492 & 3640 & 1686 & 139 & 25.2 & 1.7 & 994 & \\
\hline$T \& T$ & 7/7/1998 & 491 & 2.6 & 557 & 3720 & 1820 & 127 & 35.9 & 2.66 & 1040 & \\
\hline$T \& T$ & 8/7/1998 & 358 & 2.6 & 546 & 3880 & 1522 & 137 & 30.9 & 1.7 & 782 & \\
\hline T\&T & 9/2/1998 & 280 & 2.7 & 187 & 3870 & 1950 & 15.2 & 10.3 & 1.35 & 828 & \\
\hline$T \& T$ & $10 / 7 / 1998$ & 178 & 2.7 & 624 & 5010 & 2415 & 196 & 30.7 & 1.73 & 1020 & \\
\hline$T \& T$ & $11 / 2 / 1998$ & 133 & 2.7 & 569 & 3970 & 2154 & 141 & 38.4 & 1.97 & 1240 & \\
\hline$T \& T$ & $12 / 7 / 1998$ & 120 & 2.7 & 605 & 4350 & 2066 & 144 & 43.9 & 2.14 & 988 & \\
\hline$T \& T$ & $12 / 7 / 1998$ & 121 & 3 & 608 & 2361 & & 166 & 46.2 & 2.3 & 1360 & 92 \\
\hline$T \& T$ & $12 / 14 / 1998$ & 102 & 3.1 & 580 & 2960 & 2222 & 158 & 45.8 & 1.84 & 1250 & 156 \\
\hline$T \& T$ & $12 / 21 / 1998$ & 102 & 3.2 & 704 & 2406 & 2253 & 204 & 54.8 & 1.76 & 1424 & 148 \\
\hline$T \& T$ & $12 / 28 / 1998$ & 91 & 3.1 & 629 & 2453 & 2244 & 185 & 45.8 & 1.79 & 1430 & 155 \\
\hline
\end{tabular}


Table F-1, T\&T Mine-pool, Raw Chemical Data

\begin{tabular}{|c|c|c|c|c|c|c|c|c|c|c|c|}
\hline Site & Date & $\begin{array}{l}\text { Flow, } \\
\text { gpm }\end{array}$ & $\mathrm{pH}$ & 730 & $\begin{array}{l}\text { Sp Cond. } \\
\text { umhos/cm }\end{array}$ & $\begin{array}{l}\text { TDS, } \\
\mathrm{mg} / \mathrm{L}\end{array}$ & $\begin{array}{c}\mathrm{Fe}, \\
\mathrm{mg} / \mathrm{L}\end{array}$ & $\begin{array}{c}\mathrm{Al}, \\
\mathrm{mg} / \mathrm{L}\end{array}$ & $\begin{array}{c}\mathrm{Mn}, \\
\mathrm{mg} / \mathrm{L}\end{array}$ & $\begin{array}{l}\mathrm{SO} 4, \\
\mathrm{mg} / \mathrm{L}\end{array}$ & $\begin{array}{c}\mathrm{Ca}, \\
\mathrm{mg} / \mathrm{L}\end{array}$ \\
\hline$T \& T$ & $1 / 4 / 1999$ & 91 & 3.4 & 613 & 4400 & 2293 & 191 & 44.7 & 1.77 & 1431 & 132 \\
\hline$T \& T$ & $1 / 6 / 1999$ & 91 & 2.8 & 587 & 3650 & 2114 & 155 & 40.9 & 1.95 & 1340 & \\
\hline T\&T & $1 / 11 / 1999$ & 97 & 2.7 & 644 & 2970 & 2294 & 179 & 39.7 & 1.83 & 1510 & 104 \\
\hline$T \& T$ & $1 / 18 / 1999$ & 280 & 2.7 & 624 & 2576 & 2108 & 173 & 38.6 & 0.16 & 1510 & 77 \\
\hline T\&T & $1 / 25 / 1999$ & 423 & 3 & 542 & 2420 & 1978 & 154 & 38.4 & 1.49 & 1190 & 66 \\
\hline T\&T & 2/1/1999 & 256 & 2.8 & 599 & 4020 & 2174 & 151 & 44.1 & 2.5 & 1340 & \\
\hline$T \& T$ & 2/8/1999 & 280 & 3.2 & 524 & 2719 & 2198 & 165 & 34.7 & 2.16 & 1340 & 160 \\
\hline T\&T & $2 / 15 / 1999$ & 318 & 2.7 & 509 & 2578 & 1821 & 141 & 27.5 & 2 & 1270 & 155 \\
\hline T\&T & $2 / 22 / 1999$ & 240 & 2.6 & 559 & 2024 & 1968 & 146 & 30.2 & 2.12 & 1260 & 144 \\
\hline$T \& T$ & $3 / 1 / 1999$ & 221 & 2.7 & 514 & 2568 & 2174 & 131 & 31.7 & 2.04 & 1270 & 142 \\
\hline$T \& T$ & $3 / 3 / 1999$ & 247 & 2.8 & 586 & 4000 & 1795 & 172 & 35.1 & 2.33 & 1220 & \\
\hline T\&T & $3 / 8 / 1999$ & 250 & 2.8 & 530 & 2412 & 1973 & 141 & 35.1 & 2.12 & 1160 & 109 \\
\hline$T \& T$ & 3/15/1999 & 439 & 2.8 & 582 & 2930 & 2284 & 169 & 35.4 & 2.22 & 1480 & 127 \\
\hline$T \& T$ & $3 / 22 / 1999$ & 423 & 2.9 & 470 & 3190 & 2042 & 127 & 31.6 & 2.14 & 1210 & 126 \\
\hline T\&T & $3 / 29 / 1999$ & 436 & 2.9 & 607 & 3600 & 2126 & 177 & 40.1 & 2.58 & 1480 & 105 \\
\hline T\&T & $4 / 5 / 1999$ & 422 & 2.7 & 539 & 3800 & 2037 & 147 & 30.9 & 2.17 & 1130 & \\
\hline$T \& T$ & $4 / 5 / 1999$ & 423 & 2.9 & 483 & 3310 & 1962 & 134 & 31.7 & 2.12 & 1140 & 126 \\
\hline T\&T & $4 / 12 / 1999$ & 378 & 3 & 449 & 3050 & 1810 & 131 & 29 & 2.12 & 1070 & 143 \\
\hline T\&T & $4 / 19 / 1999$ & 396 & 3.2 & 379 & 2166 & 1701 & 112 & 25.8 & 1.84 & 1090 & 137 \\
\hline$T \& T$ & 4/26/1999 & 302 & 3.3 & 454 & 3010 & 1750 & 109 & 41.5 & 1.85 & 1030 & 164 \\
\hline T\&T & $5 / 3 / 1999$ & 302 & 3.3 & 388 & 3950 & 1752 & 122 & 25.4 & 1.96 & 1040 & 146 \\
\hline T\&T & $5 / 4 / 1999$ & 301 & 2.7 & 464 & 3780 & 1691 & 120 & 26.2 & 1.89 & 1090 & \\
\hline $\mathrm{T} \& \mathrm{~T}$ & $5 / 10 / 1999$ & 250 & 3.3 & 436 & 3040 & 1751 & 126 & 32.7 & 1.98 & 1050 & 151 \\
\hline T\&T & $5 / 17 / 1999$ & 212 & 3.2 & 513 & 2400 & 1740 & 118 & 48.1 & 1.85 & 1090 & 162 \\
\hline T\&T & $5 / 24 / 1999$ & 260 & 3.2 & 467 & 1410 & 1834 & 104 & 44.3 & 1.56 & 937 & 150 \\
\hline$T \& T$ & $5 / 31 / 1999$ & 221 & 3.2 & 497 & 2355 & 1876 & 111 & 47.4 & 1.71 & 912 & 150 \\
\hline T\&T & $6 / 2 / 1999$ & 211 & 2.7 & 466 & 3930 & 1628 & 115 & 28.3 & 1.84 & 1080 & \\
\hline T\&T & $7 / 13 / 1999$ & 192 & 2.7 & 526 & 3670 & 1675 & 139 & 31.3 & 1.78 & 1160 & \\
\hline$T \& T$ & $7 / 14 / 1999$ & 193 & 3.1 & 559 & 2192 & 2036 & 117 & 55.1 & 1.97 & 1140 & 148 \\
\hline T\&T & $7 / 29 / 1999$ & 175 & 2.7 & 568 & 2345 & 2005 & 142 & 37.8 & 2.17 & 1230 & 142 \\
\hline T\&T & $7 / 30 / 1999$ & 175 & 2.9 & 478 & 2345 & 1968 & 125 & 33.8 & 1.84 & 1210 & 163 \\
\hline$T \& T$ & $8 / 2 / 1999$ & 180 & 3.1 & 484 & 2347 & 2087 & 130 & 37.4 & 2.07 & 1180 & 136 \\
\hline T\&T & $8 / 10 / 1999$ & 134 & 2.8 & 540 & 3790 & 2476 & 144 & 35.9 & 2.05 & 1300 & \\
\hline T\&T & $8 / 30 / 1999$ & 102 & 3.1 & 444 & 2256 & 2078 & 121 & 33.2 & 1.85 & 1390 & 125 \\
\hline$T \& T$ & 9/14/1999 & 96 & 2.7 & 554 & 4560 & 2134 & 142 & 35.4 & 1.93 & 842 & \\
\hline$T \& T$ & 10/7/1999 & 80 & 2.8 & 569 & 4220 & 2319 & 152 & 38.6 & 2.01 & 1120 & \\
\hline$T \& T$ & $10 / 11 / 1999$ & 86 & 3.3 & 501 & 2402 & 1995 & 141 & 39.6 & 2.04 & 1190 & 151 \\
\hline$T \& T$ & 11/1/1999 & 91 & 2.8 & 546 & 4590 & 2500 & 138 & 38.8 & 2.09 & 1150 & \\
\hline$T \& T$ & $11 / 9 / 1999$ & 86 & 3.1 & 458 & 2470 & 2166 & 127 & 33.8 & 1.98 & 1200 & 186 \\
\hline T\&T & $11 / 17 / 1999$ & 91 & 3.3 & 458 & 2780 & 2196 & 132 & 34.7 & 1.97 & 1160 & 153 \\
\hline T\&T & $11 / 30 / 1999$ & 171 & 3.1 & 533 & 2625 & 2119 & 155 & 38.2 & 1.79 & 1320 & 144 \\
\hline$T \& T$ & $12 / 10 / 1999$ & 95 & 2.86 & 599 & 2482 & 1975 & 166 & 41.2 & 2.29 & 1000 & 127 \\
\hline T\&T & $12 / 14 / 1999$ & 109 & 2.8 & 523 & 3950 & 2001 & 139 & 34.4 & 2.07 & 1120 & \\
\hline T\&T & $1 / 11 / 2000$ & 135 & 2.8 & 548 & 4170 & 2244 & 139 & 38.7 & 2.63 & 1320 & \\
\hline T\&T & $1 / 11 / 2000$ & 135 & 2.8 & 495 & 2601 & 2282 & 129 & 32.4 & 2.47 & 1340 & 149 \\
\hline$T \& T$ & $2 / 3 / 2000$ & 151 & 3 & 594 & 2486 & 2207 & 169 & 42.7 & 2.43 & 1340 & 176 \\
\hline T\&T & $2 / 16 / 2000$ & 232 & 2.7 & 541 & 3800 & 2009 & 116 & 41.1 & 2.69 & 1250 & \\
\hline T\&T & $2 / 28 / 2000$ & 576 & 2.9 & 976 & 3292 & 2997 & 309 & 63.6 & 3.58 & 2280 & 159 \\
\hline$T \& T$ & $3 / 8 / 2000$ & 284 & 2.7 & 728 & 4630 & 2207 & 210 & 44.6 & 2.64 & 1650 & \\
\hline$T \& T$ & $3 / 17 / 2000$ & 232 & 2.79 & 705 & 2495 & 1961 & 182 & 52.5 & 3.59 & 1450 & 222 \\
\hline T\&T & $3 / 31 / 2000$ & 291 & 2.59 & 695 & 2449 & 2004 & 175 & 44.5 & 3.08 & 1280 & 157 \\
\hline$T \& T$ & $4 / 3 / 2000$ & 297 & 2.7 & 511 & 4210 & 2113 & 125 & 33 & 2.36 & 1540 & 213 \\
\hline
\end{tabular}


Table F-1, T\&T Mine-pool, Raw Chemical Data

\begin{tabular}{|c|c|c|c|c|c|c|c|c|c|c|c|}
\hline Site & Date & $\begin{array}{l}\text { Flow, } \\
\text { gpm }\end{array}$ & $\mathrm{pH}$ & 730 & $\begin{array}{l}\text { Sp Cond. } \\
\text { umhos/cm }\end{array}$ & $\begin{array}{l}\text { TDS, } \\
\mathrm{mg} / \mathrm{L}\end{array}$ & $\begin{array}{c}\mathrm{Fe}, \\
\mathrm{mg} / \mathrm{L}\end{array}$ & $\begin{array}{c}\mathrm{Al}, \\
\mathrm{mg} / \mathrm{L}\end{array}$ & $\begin{array}{l}\mathrm{Mn}, \\
\mathrm{mg} / \mathrm{L}\end{array}$ & $\begin{array}{l}\mathrm{SO} 4, \\
\mathrm{mg} / \mathrm{L}\end{array}$ & $\begin{array}{c}\mathrm{Ca}, \\
\mathrm{mg} / \mathrm{L}\end{array}$ \\
\hline T\&T & $5 / 3 / 2000$ & 445 & 2.85 & 518 & 2223 & 1897 & 130 & 37.9 & 2.02 & 973 & 147 \\
\hline$T \& T$ & $5 / 10 / 2000$ & 354 & 2.7 & 495 & 370 & 1828 & 117 & 32.7 & 2.03 & 1410 & 187 \\
\hline$T \& T$ & $6 / 5 / 2000$ & 290 & 2.8 & 403 & 3720 & 1607 & 83.6 & 30.7 & 2.04 & 1380 & 225 \\
\hline$T \& T$ & $6 / 7 / 2000$ & 348 & 2.78 & 501 & 2183 & 1848 & 114 & 37.7 & 2.68 & 1130 & 160 \\
\hline$T \& T$ & $6 / 20 / 2000$ & 411 & 2.7 & 634 & 4640 & 2036 & 180 & 37.4 & 2.34 & 1930 & \\
\hline$T \& T$ & $6 / 28 / 2000$ & 286 & 2.62 & 757 & 3200 & 3070 & 185 & 54.1 & 2.78 & 1720 & 222 \\
\hline$T \& T$ & $7 / 10 / 2000$ & 172 & 2.6 & 838 & 5510 & 3240 & 220 & 56.6 & 2.24 & 2410 & 481 \\
\hline T\&T & $7 / 18 / 2000$ & 198 & 2.66 & 1594 & 3790 & 4110 & 384 & 142 & 4.34 & 2420 & 328 \\
\hline T\&T & $8 / 1 / 2000$ & 196 & 2.6 & 1252 & 4950 & 3636 & 375 & 81 & 2.74 & 3200 & 729 \\
\hline$T \& T$ & $8 / 1 / 2000$ & 196 & 2.67 & 903 & 3870 & 3610 & 209 & 75 & 2.66 & 2210 & 393 \\
\hline$T \& T$ & $8 / 25 / 2000$ & 171 & 2.57 & 864 & 3590 & 3180 & 187 & 70.2 & 2.73 & 1860 & 502 \\
\hline T\&T & $9 / 6 / 2000$ & 160 & 2.8 & 754 & 4630 & 3214 & 168 & 66.5 & 2.77 & 2800 & 397 \\
\hline$T \& T$ & $9 / 12 / 2000$ & 130 & 2.78 & 659 & 3090 & 3130 & 146 & 56 & 2.23 & 1780 & 388 \\
\hline$T \& T$ & $9 / 22 / 2000$ & 139 & 2.79 & 1087 & 3130 & 3020 & 246 & 101 & 2.35 & 1810 & 598 \\
\hline$T \& T$ & $10 / 4 / 2000$ & 150 & 2.8 & 566 & 2995 & 2865 & 117 & 49.3 & 2.11 & 870 & 324 \\
\hline T\&T & $10 / 12 / 2000$ & 129 & 2.7 & 661 & 4190 & 2822 & 145 & 53.5 & 2.35 & 2620 & 390 \\
\hline$T \& T$ & $10 / 20 / 2000$ & 130 & 2.7 & 530 & 3030 & 2570 & 104 & 43.3 & 2.17 & 1800 & 363 \\
\hline$T \& T$ & $11 / 3 / 2000$ & 73 & 2.76 & 548 & 3040 & 2950 & 107 & 47.8 & 2.17 & 1990 & 319 \\
\hline$T \& T$ & $11 / 6 / 2000$ & 86 & 2.7 & 684 & 3830 & 3007 & 135 & 60.8 & 2.5 & 1990 & 365 \\
\hline$T \& T$ & $12 / 1 / 2000$ & 69 & 2.8 & 616 & 4570 & 2731 & 143 & 49.8 & 2.1 & 1960 & 393 \\
\hline$T \& T$ & $12 / 1 / 2000$ & 70 & 2.8 & 587 & 2920 & 3150 & 121 & 51.6 & 2.25 & 1460 & 343 \\
\hline$T \& T$ & $1 / 2 / 2001$ & 73 & 2.79 & 568 & 2850 & 2450 & 122 & 47.6 & 2.02 & 1770 & 322 \\
\hline$T \& T$ & $1 / 2 / 2001$ & 73 & 2.8 & 575 & 4170 & 2887 & 133 & 45.8 & 1.93 & 2180 & 346 \\
\hline$T \& T$ & $2 / 1 / 2001$ & 171 & 2.56 & 739 & 2893 & 2150 & 167 & 53.6 & 2.49 & 1720 & 367 \\
\hline$T \& T$ & $2 / 5 / 2001$ & 171 & 2.7 & 495 & 4120 & 2398 & 102 & 37.7 & 1.93 & 1450 & 288 \\
\hline$T \& T$ & $2 / 28 / 2001$ & 219 & 2.62 & 719 & 2965 & 2610 & 158 & 56.3 & 1.98 & 2050 & 232 \\
\hline$T \& T$ & $3 / 7 / 2001$ & 232 & 2.8 & 528 & 3980 & 2362 & 114 & 43.2 & 2.65 & 2210 & 372 \\
\hline$T \& T$ & $4 / 2 / 2001$ & 223 & 2.93 & 409 & 2710 & 2420 & 96 & 31.4 & 2.14 & 1550 & 336 \\
\hline$T \& T$ & $4 / 9 / 2001$ & 126 & 2.8 & 458 & 3340 & 2382 & 58.9 & 47.8 & 4.18 & 1410 & 252 \\
\hline T\&T & $5 / 1 / 2001$ & 175 & 2.8 & 436 & 4190 & 1734 & 106 & 29.4 & 2.28 & 1480 & 278 \\
\hline$T \& T$ & $5 / 3 / 2001$ & 180 & 2.85 & 381 & 2582 & 2240 & 85 & 27.7 & 2.22 & 1640 & 283 \\
\hline$T \& T$ & $6 / 4 / 2001$ & 143 & 2.74 & 352 & 2416 & 2175 & 76 & 21.9 & 2.03 & 1470 & 301 \\
\hline$T \& T$ & $6 / 18 / 2001$ & 142 & 2.8 & 357 & 3500 & 2279 & 76.8 & 24.7 & 1.93 & 1160 & 389 \\
\hline T\&T & $7 / 2 / 2001$ & 158 & 2.8 & 403 & 2758 & 2072 & 94 & 27.3 & 2.2 & 1480 & 342 \\
\hline$T \& T$ & $7 / 10 / 2001$ & 157 & 2.8 & 376 & 3580 & 1995 & 82.2 & 26.1 & 2.32 & 1850 & 278 \\
\hline$T \& T$ & $8 / 1 / 2001$ & 185 & 2.69 & 443 & 2960 & 2302 & 108 & 25.7 & 2.49 & 1470 & 296 \\
\hline T\&T & $8 / 8 / 2001$ & 209 & 2.8 & 431 & 3730 & 2549 & 108 & 27.6 & 2.65 & 1220 & 341 \\
\hline$T \& T$ & $8 / 21 / 2001$ & 258 & 3.1 & 386 & 4520 & 2739 & 127 & 20.6 & 2.59 & 1410 & 517 \\
\hline$T \& T$ & $8 / 24 / 2001$ & 245 & 2.66 & 411 & 3270 & 2767 & 100 & 21.2 & 2.48 & 1800 & 603 \\
\hline$T \& T$ & $8 / 27 / 2001$ & 278 & 3.1 & 314 & 4150 & 2810 & 75.8 & 24.1 & 2.78 & 1600 & 467 \\
\hline$T \& T$ & $8 / 27 / 2001$ & 216 & 3.1 & 315 & 4260 & 2900 & 75.5 & 24.4 & 2.72 & 1570 & 458 \\
\hline$T \& T$ & $8 / 28 / 2001$ & 228 & 3 & 324 & 4100 & 2810 & 76.6 & 23.9 & 2.54 & 1470 & 500 \\
\hline$T \& T$ & $9 / 4 / 2001$ & 177 & 3 & 324 & 4050 & 2690 & 67.9 & 26.5 & 2.76 & 1590 & 501 \\
\hline T\&T & 9/4/2001 & 178 & 2.91 & 354 & 2940 & 2674 & 66.6 & 30.2 & 2.81 & 1740 & 439 \\
\hline$T \& T$ & $9 / 24 / 2001$ & 186 & 3.33 & 169 & 2960 & 3036 & 37 & 13.4 & 2.61 & 1840 & 685 \\
\hline$T \& T$ & $10 / 1 / 2001$ & 163 & 3.51 & 268 & 3175 & 3189 & 44.6 & 30.2 & 2.77 & 2080 & 576 \\
\hline$T \& T$ & $10 / 1 / 2001$ & 162 & 4.5 & 112 & 4210 & 3122 & 41.8 & 5.42 & 3.05 & 1765 & 1020 \\
\hline$T \& T$ & $11 / 1 / 2001$ & 96 & 2.75 & 371 & 3120 & 2900 & 112 & 13.4 & 3.73 & 2060 & 405 \\
\hline$T \& T$ & $11 / 7 / 2001$ & 75 & 3 & 417 & 2920 & 2948 & 92.91 & 35.13 & 2.83 & 330 & 360 \\
\hline$T \& T$ & $12 / 3 / 2001$ & 66 & 2.85 & 331 & 3055 & 2967 & 125 & 5.7 & 2.91 & 1820 & 437 \\
\hline$T \& T$ & $12 / 4 / 2001$ & 66 & 2.9 & 631 & 3060 & 3032 & 138.6 & 56.36 & 3.98 & 1759 & 592 \\
\hline$T \& T$ & $1 / 2 / 2002$ & 86 & 2.73 & 615 & 3060 & 2750 & 118 & 55.1 & 2.49 & 1680 & 353 \\
\hline
\end{tabular}


Table F-1, T\&T Mine-pool, Raw Chemical Data

\begin{tabular}{|c|c|c|c|c|c|c|c|c|c|c|c|}
\hline Site & Date & $\begin{array}{l}\text { Flow, } \\
\text { gpm }\end{array}$ & $\mathrm{pH}$ & 730 & $\begin{array}{l}\text { Sp Cond. } \\
\text { umhos/cm }\end{array}$ & $\begin{array}{l}\text { TDS, } \\
\mathrm{mg} / \mathrm{L}\end{array}$ & $\begin{array}{c}\mathrm{Fe}, \\
\mathrm{mg} / \mathrm{L}\end{array}$ & $\begin{array}{c}\mathrm{Al}, \\
\mathrm{mg} / \mathrm{L}\end{array}$ & $\begin{array}{l}\mathrm{Mn}, \\
\mathrm{mg} / \mathrm{L}\end{array}$ & $\begin{array}{l}\mathrm{SO} 4, \\
\mathrm{mg} / \mathrm{L}\end{array}$ & $\begin{array}{c}\mathrm{Ca}, \\
\mathrm{mg} / \mathrm{L}\end{array}$ \\
\hline T\&T & $1 / 3 / 2002$ & 86 & 2.8 & 504 & 2780 & 2876 & 113.2 & 39.13 & 2.39 & 1668 & 293 \\
\hline T\&T & $2 / 4 / 2002$ & 95 & 2.6 & 571 & 2900 & 2664 & 120.0 & 40.98 & 1.69 & 1545 & 24 \\
\hline$T \& T$ & $3 / 4 / 2002$ & 82 & 2.8 & 508 & 3320 & 2800 & 104.6 & 42.43 & 2.94 & 1624 & 210 \\
\hline$T \& T$ & $4 / 1 / 2002$ & 101 & 2.8 & 477 & 3710 & 2868 & 88.75 & 41.8 & 3.44 & 1663 & 310 \\
\hline$T \& T$ & $4 / 21 / 2002$ & 63 & 2.8 & 864 & 3170 & 3260 & 257.4 & 57.52 & 2.66 & 1891 & 309 \\
\hline$T \& T$ & $5 / 1 / 2002$ & 359 & 2.7 & 657 & 2340 & 2776 & 167.1 & 45.61 & 2.26 & 1610 & 232 \\
\hline$T \& T$ & $6 / 2 / 2002$ & 348 & 2.8 & 577 & 2330 & 2568 & 171.4 & 33.62 & 2.13 & 1489 & 280 \\
\hline$T \& T$ & $7 / 1 / 2002$ & 330 & 2.8 & 436 & 2650 & 2732 & 133.8 & 20.43 & 2 & 1585 & 249 \\
\hline$T \& T$ & $8 / 4 / 2002$ & 269 & 2.9 & 339 & 2650 & 2412 & 99.28 & 17.06 & 1.89 & 1399 & 294 \\
\hline$T \& T$ & $9 / 2 / 2002$ & 99 & 3 & 373 & 2630 & 2672 & 103.5 & 23.93 & 2.37 & 1550 & 274 \\
\hline$T \& T$ & $9 / 2 / 2002$ & 99 & 3 & 373 & 2630 & 2672 & 103.5 & 23.93 & 2.37 & 1550 & 274 \\
\hline$T \& T$ & $10 / 1 / 2002$ & 133 & 2.9 & 468 & 2600 & 2600 & 116.6 & 34.52 & 2.59 & 1508 & 239 \\
\hline$T \& T$ & $11 / 2 / 2002$ & 102 & 3 & 399 & 268 & 2556 & 86.59 & 34.32 & 2.12 & 1482 & 310 \\
\hline$T \& T$ & $12 / 3 / 2002$ & 141 & 2.9 & 447 & 244 & 116 & 153.6 & 19.08 & 1.86 & 67 & 336 \\
\hline$T \& T$ & $1 / 2 / 2003$ & 536 & 2.9 & 555 & 2700 & 2908 & 165.4 & 34.73 & 1.77 & 1687 & 382 \\
\hline$T \& T$ & $1 / 7 / 2003$ & 650 & 3 & 474 & 2470 & 2408 & 142.6 & 29.77 & 1.64 & 1397 & 330 \\
\hline$T \& T$ & $2 / 4 / 2003$ & 685 & 3 & 276 & 2570 & 2324 & 66.23 & 18.5 & 2.33 & 1348 & 324 \\
\hline$T \& T$ & $3 / 16 / 2003$ & 1165 & 2.74 & 659 & 2610 & 2344 & 182.5 & 43.04 & 1.22 & 1360 & 105 \\
\hline$T \& T$ & $4 / 1 / 2003$ & 735 & 3.12 & 876 & & 2992 & 253.9 & 68.09 & 2.74 & & 258 \\
\hline$T \& T$ & $4 / 15 / 2003$ & 977 & 2.5 & 2518 & 5190 & 7224 & 834.4 & 154.7 & 3.5 & 4190 & 400 \\
\hline$T \& T$ & $4 / 18 / 2003$ & 753 & 2.64 & 1829 & 4210 & 5152 & 580.3 & 120.4 & 3.51 & 2988 & 266 \\
\hline T\&T & $4 / 19 / 2003$ & 717 & 2.64 & 1762 & 4420 & 5264 & 552.3 & 117.2 & 3.65 & 3053 & 268 \\
\hline$T \& T$ & $4 / 20 / 2003$ & 1295 & 2.66 & 1631 & 4080 & & 508.1 & 109 & 3.52 & & 262 \\
\hline$T \& T$ & $4 / 21 / 2003$ & 1460 & 2.7 & 1471 & 3800 & 4252 & 457.6 & 98.26 & 3.25 & 2466 & 256 \\
\hline$T \& T$ & $4 / 22 / 2003$ & 1142 & 2.75 & 1288 & 3650 & 4032 & 397.9 & 86.59 & 3.23 & 2339 & 239 \\
\hline$T \& T$ & $4 / 23 / 2003$ & 851 & 2.71 & 1464 & 3730 & 3848 & 446.8 & 101.0 & 2.96 & 2232 & 239 \\
\hline$T \& T$ & $4 / 24 / 2003$ & 551 & 2.65 & 1371 & 3710 & 3904 & 398.0 & 97.37 & 2.96 & 2264 & 243 \\
\hline$T \& T$ & $4 / 25 / 2003$ & 892 & 2.68 & 1317 & 3490 & 3756 & 382.7 & 93.97 & 2.96 & 2178 & 237 \\
\hline$T \& T$ & $4 / 26 / 2003$ & 753 & 2.72 & 1161 & 3280 & 3312 & 338.2 & 81.93 & 2.47 & 1921 & 226 \\
\hline$T \& T$ & $4 / 26 / 2003$ & 753 & 2.72 & 1161 & 3280 & 3312 & 338.2 & 81.93 & 2.66 & 1921 & 226 \\
\hline$T \& T$ & $4 / 27 / 2003$ & 596 & 4 & 1161 & 3400 & 3500 & 364.6 & 89.79 & 2.23 & 2030 & 217 \\
\hline$T \& T$ & $5 / 5 / 2003$ & 578 & 2.66 & 977 & 3190 & 3304 & 274.1 & 67.06 & 2.23 & 1916 & 345 \\
\hline$T \& T$ & $6 / 2 / 2003$ & 488 & 2.91 & 557 & 2640 & 2472 & 148.1 & 40.62 & 2.47 & 1434 & 145 \\
\hline$T \& T$ & $8 / 4 / 2003$ & 470 & 2.85 & 410 & 2230 & 1812 & 96.22 & 29.34 & 2.28 & 1051 & 233 \\
\hline$T \& T$ & $9 / 1 / 2003$ & 421 & 2.75 & 1206 & 2280 & 2520 & 104.8 & 166.6 & 2.18 & 1462 & 44 \\
\hline$T \& T$ & $10 / 2 / 2003$ & 735 & 2.76 & 422 & 2300 & 2032 & 79.7 & 34.2 & 1.52 & 1179 & 382 \\
\hline$T \& T$ & $11 / 2 / 2003$ & 475 & 2.63 & 377 & 2310 & 1848 & 64.39 & 25.44 & 1.92 & 1072 & 218 \\
\hline$T \& T$ & $12 / 2 / 2003$ & 668 & 2.81 & 81 & 2260 & 1916 & 0.19 & & 1.73 & 1111 & 233 \\
\hline$T \& T$ & $1 / 6 / 2004$ & 918 & 2.81 & 125 & 1982 & 1576 & 12.75 & 3.95 & 1.64 & 914 & 84 \\
\hline$T \& T$ & $2 / 15 / 2004$ & 981 & 2.85 & 409 & 2100 & 1576 & 91.2 & 31.58 & 0.03 & 914 & 223 \\
\hline$T \& T$ & $3 / 1 / 2004$ & 739 & 2.92 & 349 & 2030 & 1492 & 73.29 & 28.02 & 1.21 & 865 & 205 \\
\hline$T \& T$ & $4 / 4 / 2004$ & 811 & 2.86 & 340 & 1960 & 1472 & 77.25 & 23.27 & 1.66 & 854 & 176 \\
\hline$T \& T$ & $5 / 2 / 2004$ & 793 & 2.8 & 337 & 1918 & 1420 & 69.68 & 23.14 & 2.51 & 824 & 152 \\
\hline$T \& T$ & $6 / 1 / 2004$ & 650 & 2.93 & 347 & 2020 & 1544 & 72.41 & 28.23 & 1.27 & 896 & 201 \\
\hline$T \& T$ & $7 / 1 / 2004$ & 354 & 2.94 & 286 & 1951 & 1560 & 61.5 & 20.89 & 1.39 & 905 & 205 \\
\hline$T \& T$ & $8 / 1 / 2004$ & 220 & 3.03 & 311 & 2050 & 1620 & 61.41 & 27.34 & 1.44 & 940 & 243 \\
\hline$T \& T$ & $11 / 7 / 2004$ & 372 & 2.81 & 381 & 2290 & 1972 & 80.37 & 28.24 & 1.43 & 1144 & 325 \\
\hline$T \& T$ & $12 / 5 / 2004$ & 538 & 2.69 & 334 & 2210 & 1644 & 60.36 & 21.5 & 2.39 & 954 & 101 \\
\hline$T \& T$ & $1 / 31 / 2005$ & 596 & 3.02 & 214 & 1985 & 1708 & 60.98 & 1.59 & 26.83 & 991 & 210 \\
\hline$T \& T$ & $3 / 4 / 2005$ & 551 & 2.83 & 293 & 2050 & 1504 & 48.92 & 23.15 & 1.39 & 872 & 207 \\
\hline$T \& T$ & $4 / 4 / 2005$ & 851 & 2.9 & 292 & 2120 & 1704 & 46.15 & 26.12 & 0.96 & 988 & 207 \\
\hline$T \& T$ & $5 / 9 / 2005$ & 533 & 2.87 & 276 & 1943 & 1488 & 44.85 & 22.7 & 1.29 & 863 & 182 \\
\hline
\end{tabular}


Table F-1, T\&T Mine-pool, Raw Chemical Data

\begin{tabular}{|c|r|r|r|r|r|r|r|r|r|r|r|}
\hline Site & \multicolumn{1}{|c|}{ Date } & $\begin{array}{c}\text { Flow, } \\
\text { gpm }\end{array}$ & \multicolumn{1}{|c|}{$\mathrm{pH}$} & 730 & $\begin{array}{c}\text { Sp Cond. } \\
\text { umhos/cm }\end{array}$ & $\begin{array}{l}\text { TDS, } \\
\mathrm{mg} / \mathrm{L}\end{array}$ & $\begin{array}{c}\mathrm{Fe}, \\
\mathrm{mg} / \mathrm{L}\end{array}$ & $\begin{array}{c}\mathrm{Al}, \\
\mathrm{mg} / \mathrm{L}\end{array}$ & $\begin{array}{c}\mathrm{Mn}, \\
\mathrm{mg} / \mathrm{L}\end{array}$ & $\begin{array}{c}\text { SO4, } \\
\mathrm{mg} / \mathrm{L}\end{array}$ & $\begin{array}{c}\mathrm{Ca}, \\
\mathrm{mg} / \mathrm{L}\end{array}$ \\
\hline T\&T & $6 / 1 / 2005$ & 488 & 2.85 & 255 & 2010 & 1500 & 40.98 & 19.64 & 1.33 & 870 & 202 \\
\hline T\&T & $7 / 4 / 2005$ & 246 & 2.9 & 290 & 1992 & 1727 & 41.98 & 26.87 & 1.43 & 1002 & 247 \\
\hline T\&T & $8 / 1 / 2005$ & 246 & 2.91 & 274 & 2120 & 1768 & 39.4 & 25.02 & 1.5 & 1025 & 215 \\
\hline T\&T & $9 / 11 / 2005$ & 143 & 2.86 & 249 & 2050 & 1708 & 40.51 & 18.87 & 1.49 & 991 & 220 \\
\hline T\&T & $10 / 2 / 2005$ & 99 & 2.77 & 314 & 2170 & 1868 & 44.17 & 26.38 & 1.73 & 1083 & 23 \\
\hline T\&T & $11 / 3 / 2005$ & 99 & 2.87 & 329 & 2140 & 1796 & 65.64 & 25.4 & 1.88 & 1042 & 253 \\
\hline T\&T & $12 / 1 / 2005$ & 461 & 2.6 & 406 & 2330 & 1976 & 78.83 & 24.73 & 1.03 & 1146 & 146 \\
\hline T\&T & $1 / 9 / 2006$ & 573 & 2.68 & 305 & 2460 & 2124 & 55.41 & 17.61 & 1.89 & 1232 & 323 \\
\hline T\&T & $2 / 12 / 2006$ & 520 & 2.82 & 319 & 2090 & 1752 & 50.26 & 27.01 & 2.03 & 1016 & 234 \\
\hline T\&T & $3 / 1 / 2006$ & 358 & 2.76 & 243 & 2000 & 1540 & 34.13 & 16.6 & 1.28 & 893 & 184 \\
\hline T\&T & $4 / 2 / 2006$ & 305 & 2.83 & 227 & 1974 & 1604 & 41.2 & 13.73 & 1.42 & 930 & 359 \\
\hline T\&T & $5 / 6 / 2006$ & 318 & 2.78 & 294 & 1989 & 1668 & 47.82 & 22.08 & 1.66 & 967 & 262 \\
\hline T\&T & $6 / 4 / 2006$ & 206 & 2.68 & 338 & 1895 & 1552 & 48.09 & 25.94 & 1.69 & 900 & 255 \\
\hline T\&T & $7 / 4 / 2006$ & 502 & 2.72 & 320 & 2040 & 1584 & 44.7 & 25.63 & 1.41 & 919 & 254 \\
\hline T\&T & $8 / 8 / 2006$ & 309 & 2.79 & 323 & 2110 & 1768 & 43.68 & 28.93 & 1.62 & 1025 & 127 \\
\hline T\&T & $9 / 10 / 2006$ & 211 & 2.65 & 332 & 2180 & 1812 & 40.83 & 25.93 & 1.61 & 1051 & 209 \\
\hline T\&T & $10 / 2 / 2006$ & 152 & 2.87 & 279 & 2180 & 1728 & 39.15 & 24.93 & 1.45 & 1002 & 284 \\
\hline T\&T & $11 / 5 / 2006$ & 228 & 2.83 & 295 & 2230 & 1656 & 40.87 & 26.35 & 1.08 & 960 & 192 \\
\hline T\&T & $12 / 3 / 2006$ & 300 & 2.97 & 257 & 2250 & 1600 & 45.48 & 21.66 & 0.95 & 928 & 163 \\
\hline T\&T & $1 / 1 / 2007$ & 349 & 2.94 & 383 & 2250 & 1684 & 55.87 & 39.91 & 2.22 & 977 & 32 \\
\hline T\&T & $3 / 13 / 2007$ & 614 & 2.88 & 359 & 2160 & 1748 & 66.38 & 30.64 & 2.02 & 1014 & 243 \\
\hline T\&T & $9 / 4 / 2007$ & 367 & 2.96 & 280 & 2220 & 1724 & 47.79 & 24.66 & 1.31 & 1000 & 262 \\
\hline
\end{tabular}




\section{Appendix G}

Hahn Mine-pool, Raw Chemical Data 
Table G-1, Hahn Mine-pool Raw Chemical Data

\begin{tabular}{|c|c|c|c|c|c|c|c|c|c|c|c|}
\hline Site & Date & $\mathrm{pH}$ & $\begin{array}{c}\text { Alkalinity, } \\
\mathrm{mg} / \mathrm{L}\end{array}$ & $\begin{array}{c}\mathrm{Fe}, \\
\mathrm{mg} / \mathrm{L}\end{array}$ & $\begin{array}{l}\mathrm{SO} 4, \\
\mathrm{mg} / \mathrm{L}\end{array}$ & $\begin{array}{l}\text { TDS, } \\
\mathrm{mg} / \mathrm{L}\end{array}$ & $\begin{array}{c}\mathrm{Ca}, \\
\mathrm{mg} / \mathrm{L}\end{array}$ & $\begin{array}{l}\mathrm{Mg}, \\
\mathrm{mg} / \mathrm{L}\end{array}$ & $\begin{array}{l}\mathrm{Na}, \\
\mathrm{mg} / \mathrm{L}\end{array}$ & $\begin{array}{c}\mathrm{K}, \\
\mathrm{mg} / \mathrm{L}\end{array}$ & $\begin{array}{c}\mathrm{Cl}, \\
\mathrm{mg} / \mathrm{L}\end{array}$ \\
\hline Hahn & $10 / 7 / 1980$ & 3.20 & & & & 454 & & & & & \\
\hline Hahn & $12 / 4 / 1980$ & 4.90 & 5 & 113 & & 119 & & & & & \\
\hline Hahn & $2 / 9 / 1981$ & 3.60 & & & & 596 & & & & & \\
\hline Hahn & $6 / 8 / 1982$ & 7.90 & 352 & 2.5 & & 424 & & & & & \\
\hline Hahn & $10 / 20 / 1983$ & 6.30 & 303 & 424 & & 814 & & & & & \\
\hline Hahn & $10 / 21 / 1983$ & 6.30 & 460 & 422 & & 999 & & & & & \\
\hline Hahn & $11 / 3 / 1983$ & 6.30 & 321 & 360 & & 765 & & & & & \\
\hline Hahn & $11 / 8 / 1983$ & 6.20 & 310 & 441 & & 84 & & & & & \\
\hline Hahn & $11 / 28 / 1983$ & 5.80 & 151 & 382 & 8400 & 8977 & & & & & \\
\hline Hahn & $12 / 1 / 1983$ & 4.90 & 11 & 478 & 7754 & 8261 & & & & & \\
\hline Hahn & $12 / 6 / 1983$ & 6.05 & 211 & 480 & 6515 & 7269 & & & & & \\
\hline Hahn & $12 / 9 / 1983$ & 6.00 & 89 & 547 & 7508 & 8177 & & & & & \\
\hline Hahn & $12 / 21 / 1983$ & 4.30 & & 596 & & 7060 & & & 6450 & & \\
\hline Hahn & $3 / 1 / 1984$ & 4.30 & & 656 & 7600 & 17734 & & & 9460 & & \\
\hline Hahn & $3 / 21 / 1984$ & 3.85 & & 739 & 7250 & 15933 & 385 & 183 & 6425 & 27.5 & 905 \\
\hline Hahn & $3 / 28 / 1984$ & 5.45 & 70 & 879 & 8050 & 12897 & 360 & 190 & 2490 & 15 & 800 \\
\hline Hahn & $4 / 4 / 1984$ & 4.75 & & 811 & 5920 & 14144 & 320 & 118 & 6050 & 13.5 & 885 \\
\hline Hahn & $4 / 11 / 1984$ & 4.15 & & 750 & 6000 & 14072 & 352 & 110 & 6000 & 12.7 & 825 \\
\hline Hahn & $5 / 9 / 1984$ & 5.60 & 90 & 750 & 9000 & 14082 & 430 & 192 & 9000 & 12.5 & 985 \\
\hline Hahn & $5 / 11 / 1984$ & 5.60 & 106 & 891 & 6900 & 11726 & 240 & 197 & 6900 & 12.2 & 860 \\
\hline Hahn & $6 / 4 / 1984$ & 6.15 & 235 & 762 & 7620 & 14010 & 862 & 152 & 7620 & 11.5 & 1125 \\
\hline Hahn & $6 / 5 / 1984$ & 6.10 & 226 & 719 & 7200 & 13603 & 840 & 156 & 7200 & 12 & 1085 \\
\hline Hahn & $6 / 6 / 1984$ & 6.20 & 186 & 618 & 7700 & 13897 & 357 & 195 & 3550 & 11.2 & 1225 \\
\hline Hahn & $6 / 8 / 1984$ & 5.00 & & 757 & 6300 & 11985 & 385 & 207 & 3325 & 11.2 & 970 \\
\hline Hahn & $6 / 11 / 1984$ & 4.55 & & 905 & 7620 & 12955 & 430 & 203 & 2925 & 9.9 & 834 \\
\hline Hahn & $6 / 14 / 1984$ & 4.90 & & 967 & 7320 & 12602 & 490 & 204 & 2800 & 9.7 & 775 \\
\hline Hahn & $6 / 20 / 1984$ & 4.20 & & 903 & 7100 & 11394 & 337 & 154 & 2136 & 13.2 & 715 \\
\hline Hahn & $6 / 24 / 1984$ & 4.70 & 4 & 896 & 8030 & 12371 & 337 & 153 & 2200 & 13 & 700 \\
\hline Hahn & $7 / 2 / 1984$ & 4.70 & & 1008 & 6650 & 11199 & 367 & 210 & 2220 & 9.1 & 693 \\
\hline Hahn & $7 / 3 / 1984$ & 4.80 & & 923 & 7000 & 11521 & 357 & 211 & 2240 & 9.1 & 741 \\
\hline Hahn & $7 / 5 / 1984$ & 5.30 & 47 & 896 & 6800 & 11450 & 350 & 211 & 2320 & 9.2 & 777 \\
\hline Hahn & $7 / 9 / 1984$ & 3.50 & & 880 & 7300 & 11638 & 387 & 199 & 2040 & 11.7 & 785 \\
\hline Hahn & $7 / 16 / 1984$ & 4.65 & & 907 & 7100 & 11555 & 366 & 201 & 2150 & 12.2 & 790 \\
\hline Hahn & $7 / 30 / 1984$ & 5.00 & 28 & 986 & 7500 & 12088 & 380 & 192 & 2160 & 12.5 & 790 \\
\hline Hahn & $8 / 5 / 1984$ & 4.40 & & 784 & 6890 & 11066 & 385 & 198 & 2050 & 12.2 & 704 \\
\hline Hahn & $8 / 7 / 1984$ & 4.30 & & 891 & 6650 & 11575 & 405 & 214 & 2570 & 12.5 & 809 \\
\hline Hahn & $8 / 15 / 1984$ & 6.20 & 64 & 840 & 3200 & 8076 & 393 & 204 & 2480 & 12 & 846 \\
\hline Hahn & $8 / 17 / 1984$ & 4.30 & & 930 & 6800 & 11151 & 392 & 196 & 2048 & 12.2 & 736 \\
\hline Hahn & $8 / 30 / 1984$ & 5.00 & 25 & 932 & 6730 & 11371 & 370 & 191 & 2345 & 11.5 & 732 \\
\hline Hahn & 9/13/1984 & 4.55 & & 986 & 7200 & 11064 & 377 & 202 & 2100 & 12.2 & 685 \\
\hline Hahn & 9/19/1984 & 3.80 & & 914 & 6900 & 11496 & 364 & 183 & 2335 & 12.9 & 750 \\
\hline Hahn & 9/24/1984 & 4.20 & & 990 & 7300 & 11973 & 356 & 179 & 2320 & 12.8 & 787 \\
\hline Hahn & 10/8/1984 & 5.60 & 35 & 699 & 5800 & 11218 & 415 & 216 & 3250 & 12.5 & 764 \\
\hline Hahn & 10/17/1984 & 4.70 & & 974 & 6850 & 11233 & 375 & 200 & 2095 & & 678 \\
\hline Hahn & 10/23/1984 & 4.40 & & 903 & 7375 & 11667 & 395 & 199 & 2063 & 10.5 & 675 \\
\hline Hahn & 10/30/1984 & 4.40 & & 908 & 8000 & 12075 & 310 & 174 & 1932 & 10.4 & 687 \\
\hline Hahn & $11 / 5 / 1984$ & 4.65 & & 1019 & 6970 & 11313 & 327 & 193 & 2085 & 10.5 & 657 \\
\hline Hahn & $11 / 14 / 1984$ & 4.20 & & 978 & 7300 & 11428 & 367 & 175 & 1945 & 11.7 & 610 \\
\hline Hahn & 11/21/1984 & 3.95 & & 851 & & 4023 & 370 & 214 & & 10 & 610 \\
\hline
\end{tabular}


Table G-1, Hahn Mine-pool Raw Chemical Data

\begin{tabular}{|c|c|c|c|c|c|c|c|c|c|c|c|}
\hline Site & Date & $\mathrm{pH}$ & $\begin{array}{c}\text { Alkalinity, } \\
\mathrm{mg} / \mathrm{L}\end{array}$ & $\begin{array}{l}\mathrm{Fe}, \\
\mathrm{mg} / \mathrm{L}\end{array}$ & $\begin{array}{l}\mathrm{SO} 4, \\
\mathrm{mg} / \mathrm{L}\end{array}$ & $\begin{array}{l}\text { TDS, } \\
\mathrm{mg} / \mathrm{L}\end{array}$ & $\begin{array}{l}\mathrm{Ca}, \\
\mathrm{mg} / \mathrm{L}\end{array}$ & $\begin{array}{l}\mathrm{Mg}, \\
\mathrm{mg} / \mathrm{L}\end{array}$ & $\begin{array}{l}\mathrm{Na}, \\
\mathrm{mg} / \mathrm{L}\end{array}$ & $\begin{array}{c}\mathrm{K}, \\
\mathrm{mg} / \mathrm{L}\end{array}$ & $\begin{array}{c}\mathrm{Cl}, \\
\mathrm{mg} / \mathrm{L}\end{array}$ \\
\hline Hahn & $11 / 27 / 1984$ & 4.90 & & 968 & 6900 & 12962 & 365 & 219 & 2830 & 995 & 632 \\
\hline Hahn & 2/12/1984 & 60 & & 1079 & 6350 & 10649 & 365 & 205 & 1980 & 10 & 617 \\
\hline Hahn & 2/17/1984 & 80 & & 1030 & 8300 & 12526 & 345 & 202 & 1965 & 10.9 & 622 \\
\hline Hahn & $2 / 28 / 1984$ & 50 & & 1082 & 7000 & 11276 & 325 & 260 & 1935 & 12.7 & 617 \\
\hline Hahn & $1 / 2 / 1985$ & 30 & & 1059 & 6900 & 1114 & 337 & 260 & 1905 & 12.5 & 594 \\
\hline Hahn & 1/8/1985 & 80 & & 1001 & 7120 & 1373 & 342 & 252 & 1985 & 12.2 & 610 \\
\hline Hahn & $1 / 15 / 1985$ & 80 & & 1008 & 6700 & 11025 & 352 & 197 & 2065 & 12.5 & 647 \\
\hline Hahn & $1 / 22 / 1985$ & .60 & & 1019 & 6500 & 10770 & 370 & 204 & 2005 & & 613 \\
\hline Hahn & 1/29/1985 & 60 & & 977 & 7500 & 11207 & 349 & 146 & 1570 & & 613 \\
\hline Hahn & $2 / 5 /$ & 40 & & 945 & 6500 & 10797 & 345 & 251 & 2065 & & 637 \\
\hline Hahn & 2/12/1985 & 60 & & 932 & 7200 & 11371 & 362 & 218 & & & 612 \\
\hline Hahn & 2/18/1 & 60 & & 990 & 6800 & 11188 & 485 & 222 & & & 645 \\
\hline Hahn & $2 / 26 /$ & 70 & & 952 & 7400 & 1609 & 382 & 186 & & & 634 \\
\hline Hahn & $3 / 5$ & 70 & & 930 & 7000 & 11250 & 432 & 197 & & & 639 \\
\hline Hahn & $3 / 12 /$ & 45 & & 941 & 9400 & 13530 & 382 & 200 & 1950 & 12.5 & 605 \\
\hline Hahn & $3 / 27 /$ & 3.20 & & 1042 & 6610 & 10872 & 360 & 195 & 2005 & 13.2 & 609 \\
\hline Hahn & 85 & 10 & & 1013 & 7170 & 1410 & 377 & 195 & 2010 & 13.2 & 599 \\
\hline Hahn & $4 / 9$ & 80 & & 946 & 7180 & 11362 & 372 & 197 & 2005 & 12.7 & 607 \\
\hline Hahn & $4 / 16$ & 3.50 & & 847 & 9150 & 13189 & 402 & 192 & 1950 & 13.2 & 604 \\
\hline Hahn & $4 / 24$ & .20 & & 845 & 9150 & 13160 & 382 & 192 & 1945 & 12.7 & 603 \\
\hline Hahn & $4 / 30$ & 65 & & 921 & 9100 & 13272 & 407 & 200 & 1995 & 13.2 & 606 \\
\hline Hahn & $5 / 7$ & .30 & & 896 & 8450 & 12541 & 412 & 202 & 1960 & 13 & 575 \\
\hline Hahn & $5 / 14$ & 4.40 & & 918 & 8400 & 12489 & 407 & 200 & 1935 & 13 & 591 \\
\hline Hahn & $5 / 21$ & 3.60 & & 873 & 9600 & 13633 & 397 & 200 & 1990 & 16.2 & 534 \\
\hline Hahn & $6 / 4$ & 4.50 & & 896 & 9600 & 13643 & 382 & 192 & 1915 & 16 & 620 \\
\hline Hahn & $6 / 11$ & 3.80 & & 878 & 6800 & 10878 & 385 & 202 & 1975 & 12.5 & 604 \\
\hline Hahn & 35 & 4.20 & & 874 & 7400 & 11469 & 415 & 200 & 1945 & 12.5 & 601 \\
\hline Hahn & $6 / 26$ & .95 & & 862 & 5800 & 9877 & 365 & 200 & 2000 & 13 & 619 \\
\hline Hahn & 35 & .90 & & 840 & 5800 & 9864 & 370 & 195 & 2005 & 12.5 & 624 \\
\hline Hahn & $7 / 9 /$ & 5.00 & & 848 & 5500 & 9638 & 367 & 192 & 2010 & 13 & 680 \\
\hline Hahn & $7 / 16 /$ & 5.60 & 72 & 871 & 5500 & 9761 & 362 & 192 & 2070 & 13 & 650 \\
\hline Hahn & $7 / 23$ & .90 & & 829 & 7080 & 11324 & 387 & 202 & 2100 & 16 & 606 \\
\hline Hahn & $7 / 30 /$ & 5.40 & 6 & 801 & 7400 & 11543 & 385 & 195 & 2025 & 15.2 & 630 \\
\hline Hahn & 85 & 60 & 5 & 762 & 7000 & 11166 & 382 & 162 & 2095 & 14.7 & 641 \\
\hline Hahn & $8 / 13$ & 5.75 & 81 & 757 & 6500 & 10871 & 470 & 277 & 2117 & 12.5 & 620 \\
\hline Hahn & $8 / 19$ & 5.10 & & 762 & 6500 & 10654 & 445 & 180 & 2065 & 13 & 644 \\
\hline Hahn & $8 / 27 /$ & 5.70 & 5 & 778 & 7500 & 11742 & 450 & 182 & 2095 & 13 & 638 \\
\hline Hahn & 85 & .40 & 4 & 739 & 6815 & 11064 & 412 & 170 & 2172 & 12.2 & 667 \\
\hline Hahn & $9 / 10 /$ & 6.05 & 104 & 750 & 7125 & 11546 & 427 & 172 & 2240 & 12.5 & 675 \\
\hline Hahn & 9/18/1985 & 4.45 & & 727 & 6800 & 10878 & 307 & 172 & 2150 & 11.2 & 696 \\
\hline Hahn & 9/24/1985 & .00 & & 724 & 7150 & 11419 & 337 & 180 & 2275 & 11.5 & 708 \\
\hline Hahn & $10 / 1 /$ & 5.80 & 26 & 727 & 7500 & 11697 & 337 & 180 & 2230 & 11.2 & 666 \\
\hline Hahn & 10/8/1985 & 5.40 & & 683 & 6900 & 11139 & 345 & 202 & 2275 & 13.3 & 682 \\
\hline Hahn & J/15/1985 & 5.40 & 75 & 728 & 6900 & 11149 & 340 & 195 & 2175 & 11.2 & 694 \\
\hline Hahn & 10/22/1985 & 5.60 & 111 & 722 & 7000 & 11277 & 327 & 192 & 2187 & 11 & 688 \\
\hline Hahn & 10/29/1985 & 4.20 & & 643 & 6650 & 10684 & 355 & 177 & 2122 & 10.7 & 713 \\
\hline Hahn & $11 / 5 / 1985$ & 3.90 & & 661 & 7500 & 11662 & 352 & 182 & 2200 & 13 & 740 \\
\hline Hahn & 1/12/1985 & 6.00 & 18 & 668 & 7500 & 12075 & 375 & 185 & 2375 & 13.2 & 725 \\
\hline Hahn & 85 & & 8 & 678 & 7300 & 11447 & 300 & 177 & 2165 & 10.7 & 698 \\
\hline Hahn & $11 / 27 /$ & & 2 & 610 & 7375 & 11560 & 345 & 172 & 2297 & 10.5 & 701 \\
\hline Hahn & 85 & & 70 & 666 & 7375 & 11665 & 335 & 167 & 2290 & 10.7 & 723 \\
\hline Hahn & 12/11/1985 & 6.20 & 161 & 706 & 6600 & 10943 & 382 & 175 & 2147 & 12 & 711 \\
\hline
\end{tabular}


Table G-1, Hahn Mine-pool Raw Chemical Data

\begin{tabular}{|c|c|c|c|c|c|c|c|c|c|c|c|}
\hline Site & Date & $\mathrm{pH}$ & $\begin{array}{c}\text { Alkalinity, } \\
\mathrm{mg} / \mathrm{L}\end{array}$ & $\begin{array}{l}\mathrm{Fe}, \\
\mathrm{mg} / \mathrm{L}\end{array}$ & $\begin{array}{l}\mathrm{SO} 4, \\
\mathrm{mg} / \mathrm{L}\end{array}$ & $\begin{array}{l}\text { TDS, } \\
\mathrm{mg} / \mathrm{L}\end{array}$ & $\begin{array}{l}\mathrm{Ca}, \\
\mathrm{mg} / \mathrm{L}\end{array}$ & $\begin{array}{l}\mathrm{Mg}, \\
\mathrm{mg} / \mathrm{L}\end{array}$ & $\begin{array}{l}\mathrm{Na}, \\
\mathrm{mg} / \mathrm{L}\end{array}$ & $\begin{array}{c}\mathrm{K}, \\
\mathrm{mg} / \mathrm{L}\end{array}$ & $\begin{array}{c}\mathrm{Cl}, \\
\mathrm{mg} / \mathrm{L}\end{array}$ \\
\hline Hahn & $2 / 18 / 1985$ & 6.00 & 119 & 678 & 5999 & 10200 & 365 & 170 & 2095 & 11.7 & 723 \\
\hline Hahn & 86 & & 118 & 650 & 4970 & 9189 & 357 & 177 & 2457 & 11.5 & 713 \\
\hline Hahn & $1 / 9 / 1986$ & & 106 & 605 & 5589 & 9724 & 360 & 180 & 2140 & 11.2 & 700 \\
\hline Hahn & $1 / 16 / 1986$ & 60 & 25 & 655 & 6176 & 10344 & 347 & 190 & 2225 & 11 & 697 \\
\hline Hahn & $1 / 23 / 1986$ & & 152 & 650 & 6193 & 10500 & 325 & 182 & 2240 & 11.5 & 701 \\
\hline Hahn & $1 / 31 / 1986$ & 30 & 26 & 594 & 6047 & 9998 & 362 & 177 & 2050 & 10.7 & 715 \\
\hline Hahn & $2 / 6 / 1986$ & 00 & 108 & 630 & 6194 & 10507 & 347 & 195 & 2268 & 11.5 & 720 \\
\hline Hahn & $2 / 13 / 1986$ & 40 & 211 & 633 & 6359 & 0843 & 352 & 195 & 2325 & 11.7 & 700 \\
\hline Hahn & $2 / 20 / 1986$ & 05 & 163 & 638 & 6221 & 0561 & 380 & 187 & 2207 & 12 & 704 \\
\hline Hahn & $2 / 27 / 1986$ & 28 & 108 & 648 & 6253 & 10542 & 417 & 177 & 2175 & 11.7 & 717 \\
\hline Hahn & $3 / 10 / 1986$ & .33 & 143 & 594 & 5437 & 9843 & 397 & 177 & 2302 & 12 & 738 \\
\hline Hahn & $3 / 27 / 1986$ & 15 & 158 & 627 & 6253 & 10257 & 365 & 170 & 1935 & 8.8 & 695 \\
\hline Hahn & $4 / 3 / 1986$ & 33 & 138 & 649 & 6164 & 10195 & 390 & 160 & 1955 & 8.8 & 689 \\
\hline Hahn & $4 / 10 / 1986$ & 7 & 190 & 627 & 6332 & 10407 & 357 & 157 & 1960 & 8.5 & 724 \\
\hline Hahn & $4 / 18 / 1$ & 28 & 175 & 689 & 6159 & 10549 & 375 & 162 & 2030 & 9.5 & 900 \\
\hline Hahn & $4 / 24 / 1$ & 99 & 160 & 638 & 5963 & 9869 & & 157 & 1897 & 9.3 & 626 \\
\hline Hahn & 66 & & 80 & 666 & 6039 & 9873 & 370 & 145 & 1890 & 9.3 & 646 \\
\hline Hahn & $5 / 8 /$ & 4 & 175 & 627 & 6185 & 10320 & 415 & 165 & 2022 & 9.3 & 671 \\
\hline Hahn & $5 / 15$ & 9 & 206 & 683 & 6034 & 10120 & 382 & 152 & 1936 & 10 & 661 \\
\hline Hahn & $5 / 22 / 1$ & 0 & 167 & 661 & 5790 & 9841 & 392 & 152 & 1990 & 9.5 & 632 \\
\hline Hahn & $5 / 29 /$ & 17 & 170 & 618 & 5960 & 10340 & 390 & 178 & 2360 & 12.3 & 602 \\
\hline Hahn & 36 & 02 & 173 & 623 & 6100 & 10347 & 378 & 167 & 2242 & 12.4 & 602 \\
\hline Hahn & $6 / 10$ & .09 & 200 & 672 & 5965 & 10103 & 372 & 164 & 2080 & 13.4 & 582 \\
\hline Hahn & 6110 & 4 & 172 & 666 & 5865 & 9817 & 365 & 175 & 1925 & 10.8 & 588 \\
\hline Hahn & $6 / 26$ & & 222 & 650 & 5560 & 9539 & 357 & 155 & 1950 & 9.4 & 577 \\
\hline Hahn & $7 / 7$ & 6 & 165 & 627 & 5750 & 9906 & 384 & 159 & 2183 & 10.6 & \\
\hline Hahn & 6 & .22 & 248 & 644 & 5840 & 10017 & 385 & 158 & 2098 & 10.2 & 569 \\
\hline Hahn & $7 / 17$ & .0 & 189 & 638 & 5855 & 9924 & 373 & 155 & 2074 & 9.5 & 579 \\
\hline Hahn & $7 / 24$ & 0 & 229 & 638 & 5811 & 9801 & 380 & 147 & 1953 & 9.3 & 574 \\
\hline Hahn & $7 / 3$ & & 250 & 638 & 5770 & 9859 & 338 & 135 & 2087 & 9.9 & 568 \\
\hline Hahn & & & 255 & 644 & 5890 & 9882 & 372 & 140 & 1940 & 9.8 & 566 \\
\hline Hahn & & & 248 & 666 & 5678 & 9642 & 349 & 131 & 1934 & 9.5 & 563 \\
\hline Hahn & & & 246 & 644 & 5655 & 9666 & 394 & 132 & 1950 & 10.2 & 572 \\
\hline Hahn & $8 / 29$ & & 246 & 648 & 5665 & 9901 & 404 & 133 & 2137 & 10.8 & 594 \\
\hline Hahn & & & 239 & 571 & 5835 & 9841 & 401 & 137 & 1952 & 11.7 & 633 \\
\hline Hahn & & & 252 & 553 & 5591 & 9521 & 378 & 140 & 1978 & 10.7 & 556 \\
\hline Hahn & & & 249 & 532 & 5570 & 9455 & 381 & 139 & 1940 & 10.5 & 572 \\
\hline Hahn & & & 238 & 551 & 5372 & 9260 & 396 & 138 & 1940 & 10.1 & 554 \\
\hline Hahn & & & 244 & 544 & 5735 & 9668 & 366 & 139 & 2022 & 10.5 & 546 \\
\hline Hahn & & & 258 & 522 & 5931 & 9784 & 364 & 130 & 1938 & 10 & 567 \\
\hline Hahn & & & 261 & 508 & 5251 & 9055 & 363 & 133 & 1915 & 10.6 & 549 \\
\hline Hahn & $10 / 2$ & & 247 & 508 & 4609 & 8749 & 358 & 133 & 1949 & 10.3 & 873 \\
\hline Hahn & & & 255 & 511 & 5260 & 8984 & 323 & 127 & 1850 & 10.3 & 584 \\
\hline Hahn & 36 & & 259 & 537 & 5240 & 9264 & 395 & 156 & 2020 & 10.6 & 580 \\
\hline Hahn & & & 259 & 498 & 4900 & 8667 & 355 & 139 & 1866 & 9.8 & 577 \\
\hline Hahn & $11 / 2$ & & 249 & 471 & 5770 & 9508 & 362 & 142 & 1868 & 10 & 575 \\
\hline Hahn & 36 & & 253 & 452 & 5670 & 9285 & 355 & 137 & 1832 & 10.1 & 514 \\
\hline Hahn & 6 & & 255 & 495 & 5295 & 8950 & 354 & 153 & 1740 & 10.6 & 585 \\
\hline Hahn & 6 & & 259 & 513 & 5295 & 8930 & 347 & 151 & 1727 & 11.5 & 583 \\
\hline Hahn & 36 & & 256 & 531 & 7375 & 11050 & 360 & 153 & 1721 & 10.7 & 580 \\
\hline Hahn & $12 / 29$ & & 97 & 528 & 5159 & 8581 & 369 & 157 & 1703 & 10.9 & 529 \\
\hline Hahn & $1 / 8 / 1987$ & 6.40 & 255 & 504 & 5900 & 9495 & 321 & 142 & 1765 & 10.4 & 538 \\
\hline
\end{tabular}


Table G-1, Hahn Mine-pool Raw Chemical Data

\begin{tabular}{|c|c|c|c|c|c|c|c|c|c|c|c|}
\hline Site & Date & $\mathrm{pH}$ & $\begin{array}{c}\text { Alkalinity, } \\
\mathrm{mg} / \mathrm{L}\end{array}$ & $\begin{array}{c}\mathrm{Fe}, \\
\mathrm{mg} / \mathrm{L}\end{array}$ & $\begin{array}{l}\mathrm{SO} 4, \\
\mathrm{mg} / \mathrm{L}\end{array}$ & $\begin{array}{l}\text { TDS, } \\
\mathrm{mg} / \mathrm{L}\end{array}$ & $\begin{array}{c}\mathrm{Ca}, \\
\mathrm{mg} / \mathrm{L}\end{array}$ & $\begin{array}{l}\mathrm{Mg}, \\
\mathrm{mg} / \mathrm{L}\end{array}$ & $\begin{array}{c}\mathrm{Na}, \\
\mathrm{mg} / \mathrm{L}\end{array}$ & $\begin{array}{c}\mathrm{K}, \\
\mathrm{mg} / \mathrm{L}\end{array}$ & $\begin{array}{c}\mathrm{Cl}, \\
\mathrm{mg} / \mathrm{L}\end{array}$ \\
\hline Hahn & $1 / 14 / 1987$ & 6.08 & 200 & 504 & 5400 & 8976 & 347 & 144 & 1806 & 9.7 & 5015 \\
\hline Hahn & $1 / 28 / 1987$ & & 262 & 495 & 5355 & 8776 & 322 & 127 & 1617 & 7.3 & 525 \\
\hline Hahn & $2 / 4 / 1987$ & & 259 & 509 & 4789 & 8337 & 344 & 138 & 1703 & 12.2 & 518 \\
\hline Hahn & $2 / 11 / 1987$ & 36 & 210 & 487 & 5420 & 8868 & 334 & 138 & 1689 & 10.2 & 525 \\
\hline Hahn & $2 / 20 / 1987$ & 41 & 257 & 537 & 5630 & 9344 & 311 & 129 & 1612 & 7.7 & 795 \\
\hline Hahn & $2 / 25 / 1987$ & 17 & 309 & 548 & 5169 & 8661 & 320 & 128 & 1601 & 7.8 & 503 \\
\hline Hahn & 3/4/1987 & 19 & 250 & 565 & 4659 & 8213 & 309 & 136 & 1697 & 9.3 & 526 \\
\hline Hahn & $3 / 18 / 1987$ & 12 & 213 & 615 & 5285 & 8629 & 312 & 134 & 1526 & 6.6 & 483 \\
\hline Hahn & $3 / 25 / 1987$ & 58 & 247 & 551 & 5490 & 8876 & 309 & 125 & 1565 & 11.2 & 515 \\
\hline Hahn & 4/3/1987 & 39 & 200 & 525 & 4000 & 7224 & 296 & 126 & 1499 & 9.6 & 515 \\
\hline Hahn & $4 / 9 / 1987$ & 14 & 219 & 563 & 8537 & 8537 & 307 & 133 & 1668 & 8.8 & 508 \\
\hline Hahn & $4 / 15 / 1987$ & .78 & 4 & 536 & 4600 & 7667 & 300 & 132 & 1568 & 10.4 & 507 \\
\hline Hahn & $4 / 23 / 1987$ & 6.25 & 128 & 534 & 4300 & 7528 & 300 & 115 & 1599 & 10.4 & 504 \\
\hline Hahn & $4 / 29 / 1987$ & 29 & 197 & 539 & 4000 & 7252 & 305 & 128 & 1514 & 7.9 & 510 \\
\hline Hahn & $5 / 6 / 1987$ & 20 & 245 & 501 & 4900 & 8037 & 332 & 122 & 1342 & 6.8 & 527 \\
\hline Hahn & $5 / 13 / 1987$ & 30 & 186 & 549 & 5000 & 8221 & 312 & 123 & 1448 & 6.8 & 549 \\
\hline Hahn & $5 / 19 /$ & 39 & 196 & 530 & 4900 & 8152 & 332 & 127 & 1478 & 5.1 & 534 \\
\hline Hahn & $5 / 27 / 1$ & 18 & 154 & 548 & 4400 & 7862 & 321 & 135 & 1747 & 8.3 & 508 \\
\hline Hahn & $6 / 3 / 1$ & 6.24 & 224 & 563 & 5000 & 8427 & 304 & 130 & 1630 & 8.3 & 512 \\
\hline Hahn & $6 / 10 /$ & .29 & 181 & 563 & 4700 & 8008 & 302 & 129 & 1560 & 7.1 & 519 \\
\hline Hahn & $6 / 16 / 1$ & 36 & 222 & 508 & 4600 & 8033 & 310 & 132 & 1656 & 8 & 541 \\
\hline Hahn & $6 / 23 /$ & .35 & 204 & 537 & 4700 & 8184 & 313 & 133 & 1704 & 9.9 & 531 \\
\hline Hahn & $7 / 2 / 1$ & .09 & 168 & 469 & 3700 & 6967 & 306 & 128 & 1612 & 8.6 & 532 \\
\hline Hahn & $7 / 8 / 1$ & 01 & 75 & 482 & 4700 & 7881 & 314 & 131 & 1616 & 8.6 & 531 \\
\hline Hahn & $7 / 15 / 1$ & .44 & 172 & 522 & 4750 & 8072 & 314 & 126 & 1588 & 8.6 & 547 \\
\hline Hahn & $7 / 29 /$ & 35 & 220 & 486 & 4572 & 7822 & 303 & 127 & 1508 & 8.9 & 542 \\
\hline Hahn & $8 / 6 / 1$ & .40 & 181 & 468 & 5117 & 8406 & & 134 & 1573 & 8.6 & 562 \\
\hline Hahn & $8 / 12 / 1$ & 6.50 & 181 & 463 & 4564 & 7930 & 315 & 130 & 1660 & 7.3 & 563 \\
\hline Hahn & $8 / 18 /$ & a & 119 & 452 & 4404 & 8097 & 300 & 134 & 1924 & 8.6 & 724 \\
\hline Hahn & $8 / 26 /$ & 6.27 & 171 & 441 & 4285 & 7590 & 296 & 124 & 1648 & 8.9 & 572 \\
\hline Hahn & 87 & 6.48 & 272 & 450 & 4360 & 7622 & 290 & 136 & 1460 & 7.4 & 581 \\
\hline Hahn & 0 & 6.24 & 196 & 441 & 4457 & 7765 & 306 & 128 & 1612 & 8.6 & 567 \\
\hline Hahn & 87 & 6.31 & 212 & 433 & 4297 & 7717 & 310 & 125 & 1696 & 9.2 & 583 \\
\hline Hahn & $9 / 23 /$ & 80 & 139 & 440 & 4517 & 7970 & 312 & 124 & 1788 & 8.9 & 605 \\
\hline Hahn & & & 159 & 411 & 4244 & 7547 & 288 & 117 & 1672 & 7.7 & 608 \\
\hline Hahn & $10 / 7 /$ & 6.43 & 269 & 411 & 4419 & 7929 & & 116 & 1772 & 7.3 & 612 \\
\hline Hahn & $\mid / 17 /$ & $f_{0}$ & 184 & 419 & 4480 & 7868 & & 117 & 1716 & 7.3 & 639 \\
\hline Hahn & $10 / 2 \varepsilon$ & & 235 & 355 & 4245 & 7740 & & 106 & 1776 & 7.3 & 700 \\
\hline Hahn & $11 /$ & 6.71 & 310 & 332 & 4063 & 7464 & 248 & 96 & 1660 & 8.2 & 675 \\
\hline Hahn & 110 & 6. & 157 & 238 & 3905 & 7277 & & 95 & 1850 & 9 & 725 \\
\hline Hahn & & & 561 & 302 & 4301 & 8114 & 274 & 103 & 1768 & 8.8 & 669 \\
\hline Hahn & $11 / 24$ & 6 & 532 & 319 & 3899 & 7696 & 251 & 97 & 1769 & 8.5 & 700 \\
\hline Hahn & $12 / 1 /$ & & 445 & 310 & 4070 & 7756 & 259 & 101 & 1766 & 7.4 & 695 \\
\hline Hahn & $2 / 8 /$ & 7.00 & 366 & 307 & 4049 & 7727 & 257 & 99 & 1882 & 8.7 & 675 \\
\hline Hahn & $/ 22 /$ & & 413 & 280 & 4496 & 8211 & 276 & 105 & 1839 & 7.9 & 700 \\
\hline Hahn & $12 / 29$ & 7.10 & 425 & 275 & 4064 & 7826 & 277 & 108 & 1888 & 8.9 & 685 \\
\hline Hahn & & & 391 & 296 & 4211 & 7861 & 288 & 107 & 1756 & 7.5 & 715 \\
\hline Hahn & 8 & 7.02 & 360 & 203 & 4021 & 8072 & 279 & 103 & 2220 & 9.1 & 795 \\
\hline Hahn & $1 / 20$ & & 378 & 291 & 4357 & 8181 & 294 & 116 & 1977 & 9.2 & 674 \\
\hline Hahn & 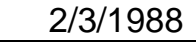 & & 365 & 303 & 4182 & 7937 & 289 & 112 & 1903 & 8.7 & 690 \\
\hline Hahn & $2 / 10 /$ & 7 & 398 & 321 & 4362 & 8175 & 281 & 111 & 1921 & 8.3 & 681 \\
\hline Hahn & $2 / 17 / 1988$ & 6.90 & 365 & 287 & 4099 & 7863 & 275 & 108 & 1941 & 8.9 & 695 \\
\hline
\end{tabular}


Table G-1, Hahn Mine-pool Raw Chemical Data

\begin{tabular}{|c|c|c|c|c|c|c|c|c|c|c|c|}
\hline Site & Date & $\mathrm{pH}$ & $\begin{array}{c}\text { Alkalinity, } \\
\mathrm{mg} / \mathrm{L}\end{array}$ & $\begin{array}{l}\mathrm{Fe}, \\
\mathrm{mg} / \mathrm{L}\end{array}$ & $\begin{array}{l}\mathrm{SO} 4, \\
\mathrm{mg} / \mathrm{L}\end{array}$ & $\begin{array}{l}\text { TDS, } \\
\mathrm{mg} / \mathrm{L}\end{array}$ & $\begin{array}{l}\mathrm{Ca}, \\
\mathrm{mg} / \mathrm{L}\end{array}$ & $\begin{array}{l}\mathrm{Mg}, \\
\mathrm{mg} / \mathrm{L}\end{array}$ & $\begin{array}{l}\mathrm{Na}, \\
\mathrm{mg} / \mathrm{L}\end{array}$ & $\begin{array}{c}\mathrm{K}, \\
\mathrm{mg} / \mathrm{L}\end{array}$ & $\begin{array}{c}\mathrm{Cl}, \\
\mathrm{mg} / \mathrm{L}\end{array}$ \\
\hline Hahn & $2 / 24 / 1988$ & 6.77 & 410 & 285 & 4023 & 7677 & 263 & 102 & 1830 & 7.8 & 663 \\
\hline Hahn & $3 / 9 / 1988$ & & 239 & 279 & 4142 & 7843 & 267 & 105 & 1818 & 6.9 & 928 \\
\hline Hahn & 3/16/1988 & & 316 & 297 & 4211 & 7739 & 271 & 107 & 1823 & 9.1 & 632 \\
\hline Hahn & $3 / 23 / 1988$ & 60 & 388 & 296 & 4515 & 8217 & 291 & 116 & 1905 & 9.6 & 607 \\
\hline Hahn & $3 / 30 / 1988$ & & 208 & 313 & 4126 & 7552 & 271 & 109 & 1841 & 9.2 & 625 \\
\hline Hahn & $4 / 6 / 1988$ & 34 & 166 & 302 & 3952 & 7168 & 258 & 104 & 1722 & 8.8 & 615 \\
\hline Hahn & $4 / 15 / 1988$ & .54 & 72 & 323 & 3970 & 7041 & 259 & 102 & 1667 & 8.2 & 620 \\
\hline Hahn & $4 / 27 / 1988$ & .71 & 296 & 313 & 3981 & 7445 & 256 & 106 & 1775 & 8.5 & 641 \\
\hline Hahn & $5 / 4 / 1988$ & .65 & 220 & 321 & 3980 & 7308 & & 105 & 1736 & 8.4 & 625 \\
\hline Hahn & $5 / 11 / 1988$ & 39 & 334 & 310 & 4052 & 7576 & 262 & 108 & 1781 & 8.7 & 643 \\
\hline Hahn & $5 / 18 / 1988$ & .66 & 276 & 318 & 3955 & 7286 & 253 & 106 & 1691 & 8.5 & 614 \\
\hline Hahn & $5 / 25 / 1988$ & .22 & 152 & 340 & 4070 & 7244 & 269 & 110 & 1666 & 8.4 & 591 \\
\hline Hahn & $6 / 2 / 1988$ & 68 & 263 & 352 & 4038 & 7374 & 262 & 112 & 1688 & 8.5 & 588 \\
\hline Hahn & $6 / 9 / 1988$ & 36 & 107 & 363 & 3966 & 7089 & 265 & 111 & 1647 & 8.5 & 593 \\
\hline Hahn & $6 / 15 / 1988$ & .31 & 97 & 380 & 4049 & 7238 & 270 & 114 & 1686 & 8.7 & 607 \\
\hline Hahn & $6 / 22 / 1988$ & .57 & 289 & 366 & 4027 & 7360 & 266 & 111 & 1659 & 8.4 & 565 \\
\hline Hahn & $6 / 29 / 1$ & 46 & 217 & 369 & 3914 & 7071 & 259 & 107 & 1580 & 8.2 & 564 \\
\hline Hahn & $7 / 6 / 1$ & 31 & 190 & 396 & 4045 & 7293 & 272 & 112 & 1650 & 9 & 572 \\
\hline Hahn & $7 / 14 / 1$ & .68 & 173 & 363 & 4021 & 7229 & 270 & 111 & 1649 & 8.4 & 590 \\
\hline Hahn & $7 / 25 / 1$ & 6.22 & 62 & 400 & 3834 & 6741 & 274 & 104 & 1501 & 7.7 & 540 \\
\hline Hahn & $8 / 3 / 1$ & 6.87 & 261 & 377 & 4165 & 7463 & 279 & 110 & 1623 & 8.5 & 577 \\
\hline Hahn & $8 / 8 / 1$ & 6.65 & 242 & 372 & 3901 & 7051 & 267 & 105 & 1552 & & 554 \\
\hline Hahn & $8 / 23 / 1$ & 6.64 & 163 & 366 & 3900 & 7044 & 251 & 105 & 1609 & 9.1 & 600 \\
\hline Hahn & 9/2/1988 & 6.74 & 140 & 372 & 3983 & 7091 & 226 & 107 & 1645 & 8.5 & 574 \\
\hline Hahn & $9 / 6 /$ & .71 & 114 & 352 & 3826 & 6658 & 266 & 107 & 1464 & 8.3 & 490 \\
\hline Hahn & $0 / 13$ & 5.75 & 21 & 358 & 3901 & 6801 & 262 & 104 & 1577 & 8.6 & 560 \\
\hline Hahn & $9 / 20$ & 6.69 & 234 & 358 & 3916 & 7125 & 265 & 106 & 1629 & 8.4 & 552 \\
\hline Hahn & $9 / 26$ & 6.83 & 347 & 358 & 3880 & 7240 & 258 & 104 & 1623 & 8.3 & 580 \\
\hline Hahn & 88 & $f_{0}$ & 130 & 361 & 3971 & 7138 & 268 & 107 & 1693 & 8.7 & 566 \\
\hline Hahn & 38 & 6.78 & 265 & 363 & 3896 & 7180 & 263 & 105 & 1611 & 8.3 & 605 \\
\hline Hahn & 88 & 6.71 & 259 & 361 & 3961 & 7256 & 266 & 108 & 1661 & 8.6 & 570 \\
\hline Hahn & 88 & & 182 & 366 & 3966 & 7173 & 267 & 108 & 1636 & 8.6 & 594 \\
\hline Hahn & & 6 & 98 & 363 & 3913 & 7015 & 264 & 107 & 1650 & 8.5 & 585 \\
\hline Hahn & 88 & 6.59 & 241 & 366 & 3963 & 7245 & 269 & 107 & 1639 & 8.4 & 594 \\
\hline Hahn & & & 214 & 362 & 3749 & 6885 & 254 & 102 & 1574 & 8.5 & 570 \\
\hline Hahn & $11 / 22$ & 2 & 164 & 371 & 3959 & 7087 & 265 & 104 & 1599 & 8.5 & 576 \\
\hline Hahn & & $\tilde{f}$ & 203 & 349 & 3847 & 7027 & 299 & 103 & 1609 & 8.2 & 600 \\
\hline Hahn & 8 & 4 & 130 & 355 & 3954 & 7087 & 268 & 105 & 1653 & 8.2 & 579 \\
\hline Hahn & $12 / 14$ & & 176 & 361 & 3900 & 7090 & 262 & 104 & 1653 & 8.1 & 583 \\
\hline Hahn & $12 / 20$ & 0 & 107 & 350 & 3939 & 7022 & 270 & 107 & 1677 & 8.8 & 535 \\
\hline Hahn & $12 / 27$ & & 118 & 345 & 3945 & 7076 & 265 & 107 & 1710 & 8.8 & 547 \\
\hline Hahn & & 6.71 & 207 & 413 & 3858 & 7094 & 259 & 104 & 1646 & 8.3 & 549 \\
\hline Hahn & & & 152 & 327 & 3801 & 6851 & 253 & 101 & 1611 & 8 & 560 \\
\hline Hahn & $1 /$ & 5 & 188 & 336 & 3753 & 6859 & 252 & 100 & & 7.8 & \\
\hline Hahn & $1 / 24 /$ & $\underline{0}$ & 296 & 369 & 3715 & 7001 & & 102 & 1611 & 7.8 & 571 \\
\hline Hahn & & 3 & 141 & 355 & 3959 & 7110 & 267 & 108 & 1661 & 8.2 & 575 \\
\hline Hahn & 39 & & 100 & 349 & 4009 & 7050 & 271 & 109 & 1634 & 8.3 & 542 \\
\hline Hahn & $2 / 14 /$ & & 210 & 349 & 3954 & 7209 & 268 & 108 & 1659 & 10.4 & 600 \\
\hline Hahn & $2 / 21$ & & 190 & 349 & 3839 & 6989 & 259 & 104 & 1618 & 8.5 & 575 \\
\hline Hahn & & & 186 & 338 & 3810 & 6905 & 260 & 99 & 1618 & 7.8 & 540 \\
\hline Hahn & & & 249 & 321 & 3869 & 7074 & 268 & 102 & 1628 & 7.9 & 570 \\
\hline Hahn & $3 / 17 / 1989$ & 6.26 & 137 & 340 & 3910 & 6944 & 272 & 104 & 1608 & 8.6 & 560 \\
\hline
\end{tabular}


Table G-1, Hahn Mine-pool Raw Chemical Data

\begin{tabular}{|c|c|c|c|c|c|c|c|c|c|c|c|}
\hline Site & Date & $\mathrm{pH}$ & $\begin{array}{c}\text { Alkalinity, } \\
\mathrm{mg} / \mathrm{L}\end{array}$ & $\begin{array}{c}\mathrm{Fe}, \\
\mathrm{mg} / \mathrm{L}\end{array}$ & $\begin{array}{l}\mathrm{SO} 4, \\
\mathrm{mg} / \mathrm{L}\end{array}$ & $\begin{array}{l}\text { TDS, } \\
\mathrm{mg} / \mathrm{L}\end{array}$ & $\begin{array}{c}\mathrm{Ca}, \\
\mathrm{mg} / \mathrm{L}\end{array}$ & $\begin{array}{l}\mathrm{Mg}, \\
\mathrm{mg} / \mathrm{L}\end{array}$ & $\begin{array}{l}\mathrm{Na}, \\
\mathrm{mg} / \mathrm{L}\end{array}$ & $\begin{array}{c}\mathrm{K}, \\
\mathrm{mg} / \mathrm{L}\end{array}$ & $\begin{array}{c}\mathrm{Cl}, \\
\mathrm{mg} / \mathrm{L}\end{array}$ \\
\hline Hahn & $3 / 21 / 1989$ & 6.85 & 140 & 349 & 3807 & 6928 & 264 & 100 & 1638 & 8 & 587 \\
\hline Hahn & $3 / 28 / 1989$ & 6.40 & 138 & 341 & 3916 & 7034 & 275 & 104 & 1647 & 8.2 & 570 \\
\hline Hahn & 4/4/1989 & 6.56 & 212 & 329 & 4057 & 7338 & 279 & 108 & 1721 & 8.9 & 572 \\
\hline Hahn & 4/11/1989 & 6.72 & 222 & 352 & 4002 & 7251 & 282 & 107 & 1694 & 8.5 & 530 \\
\hline Hahn & $4 / 18 / 1989$ & 6.71 & 148 & 359 & 3869 & 6931 & 273 & & 1620 & 8.5 & 509 \\
\hline Hahn & $4 / 25 / 1989$ & 6.61 & 151 & 352 & 3954 & 7035 & & 107 & 1638 & 8.5 & 510 \\
\hline Hahn & $5 / 2 / 1989$ & 6.72 & 168 & 358 & 3856 & 6894 & 275 & 104 & 1578 & 8.2 & 505 \\
\hline Hahn & $5 / 9 / 1989$ & 6.61 & 173 & 361 & 3779 & 6754 & 268 & 102 & 1520 & 8.7 & 499 \\
\hline Hahn & $5 / 16 / 1989$ & 6.66 & 224 & 352 & 3802 & 6868 & 270 & 103 & 1556 & 8.4 & 498 \\
\hline Hahn & $5 / 23 / 1989$ & 6.29 & 150 & 355 & 3960 & 7017 & 273 & 106 & 1503 & 8.6 & 523 \\
\hline Hahn & $5 / 30 / 1989$ & 6.41 & 146 & 358 & 3866 & 6909 & 268 & 104 & 1587 & 8.3 & 535 \\
\hline Hahn & 6/6/1989 & 6.86 & 167 & 349 & 3832 & 6843 & 264 & 102 & 1558 & 8.4 & 521 \\
\hline Hahn & $6 / 13 / 1989$ & 6.37 & 153 & 331 & 3796 & 6225 & 265 & 101 & 1532 & 8.2 & \\
\hline Hahn & $6 / 20 / 1989$ & 6.58 & 238 & 349 & 3836 & 6439 & 277 & 101 & 1572 & 8.4 & \\
\hline Hahn & $6 / 27 / 1989$ & 6.63 & 191 & 341 & 3779 & 6345 & 259 & 99 & 1522 & 7.7 & \\
\hline Hahn & $7 / 5 / 1989$ & 6.47 & 207 & 324 & 3777 & 6306 & 263 & 100 & 1577 & 8.5 & \\
\hline Hahn & $7 / 11 / 1989$ & 6.65 & 168 & 252 & 3522 & 5965 & 237 & 88 & 1649 & 8.2 & \\
\hline Hahn & $7 / 11 / 1989$ & 6.38 & 85 & 327 & 3610 & 5855 & 259 & 97 & 1448 & 8.1 & \\
\hline Hahn & $7 / 18 / 1989$ & 6.47 & 224 & 285 & 3575 & 6005 & 251 & 93 & 1515 & 8.5 & \\
\hline Hahn & $7 / 18 / 1989$ & 6.48 & 239 & 312 & 3600 & 6008 & 252 & 94 & 1444 & 8.9 & \\
\hline Hahn & $7 / 25 / 1989$ & 6.56 & 203 & 310 & 3547 & 5943 & 249 & 94 & 1483 & 8.1 & \\
\hline Hahn & $7 / 25 / 1989$ & 6.56 & 228 & 292 & 3612 & 6125 & 248 & 94 & 1591 & 8.1 & \\
\hline Hahn & 8/1/1989 & 6.49 & 219 & 294 & 3558 & 6008 & 250 & 95 & 1532 & 8.2 & \\
\hline Hahn & $8 / 1 / 1989$ & 6.61 & 244 & 301 & 3514 & 5940 & 243 & 93 & 1479 & 8.5 & \\
\hline Hahn & 8/8/1989 & 6.15 & 108 & 291 & 3500 & 5775 & & 92 & 1503 & 8.2 & \\
\hline Hahn & $8 / 8 / 1989$ & 6.29 & 101 & 288 & 3537 & 5817 & & 94 & 1518 & 7.9 & \\
\hline Hahn & $8 / 15 / 1989$ & 6.32 & 253 & 274 & 3464 & 5903 & 241 & 91 & 1513 & 8 & \\
\hline Hahn & $8 / 22 / 1989$ & 6.5 & 290 & 286 & 3372 & 5868 & 253 & 94 & 1497 & 8 & \\
\hline Hahn & 8/29/1989 & 6.62 & 110 & 283 & 3522 & 5828 & 249 & 94 & 1532 & 8.5 & \\
\hline Hahn & 9/6/1989 & 6.55 & 96 & 296 & 3487 & 5774 & 247 & 92 & 1522 & 8.6 & \\
\hline Hahn & 9/12/1989 & 6.98 & 326 & 269 & 3442 & 5975 & 246 & 91 & 1517 & 8.4 & \\
\hline Hahn & 9/19/1989 & 6.98 & 354 & 267 & 3489 & 6080 & 248 & 91 & 1541 & 8.6 & \\
\hline Hahn & 9/26/1989 & 6.62 & 378 & 264 & 3500 & 6123 & 242 & 89 & 1555 & 8.6 & \\
\hline Hahn & 10/3/1989 & 7.09 & 343 & 262 & 3457 & 6040 & 241 & 89 & 1561 & 8.1 & \\
\hline Hahn & 10/10/1989 & 6.8 & 351 & 260 & 3444 & 6028 & 240 & 88 & 1554 & 8.1 & \\
\hline Hahn & 10/17/1989 & 6.34 & 90 & 271 & 3449 & 5714 & 236 & 88 & 1549 & 8.1 & \\
\hline Hahn & 10/24/1989 & 6.42 & 312 & 156 & 3449 & 6007 & 242 & 88 & 1579 & 8.1 & \\
\hline Hahn & 11/1/1989 & 6.47 & 122 & 257 & 3616 & 6015 & 246 & 91 & 1644 & 8.2 & \\
\hline Hahn & 11/7/1989 & 6.62 & 221 & 254 & 3522 & 6007 & 244 & 89 & 1616 & 8.1 & \\
\hline Hahn & 12/1/1989 & 6.76 & 325 & 241 & 3519 & 6071 & 236 & 86 & 1580 & 8.4 & \\
\hline Hahn & $12 / 5 / 1989$ & 6.69 & 388 & 235 & 3421 & 6057 & 232 & 85 & 1599 & 7.9 & \\
\hline Hahn & $12 / 12 / 1989$ & 6.68 & 338 & 231 & 3336 & 5838 & 228 & 83 & 1537 & 7.9 & \\
\hline Hahn & 12/19/1989 & 6.76 & 341 & 231 & 3337 & 5672 & & 83 & 1570 & 8.1 & \\
\hline Hahn & 12/29/1989 & 6.96 & 363 & 229 & 3395 & 5970 & 232 & 84 & 1576 & 7.9 & \\
\hline Hahn & $1 / 2 / 1990$ & 6.90 & 399 & 227 & 3350 & 5970 & 229 & 83 & 1583 & 8 & \\
\hline Hahn & $1 / 9 / 1990$ & 7.03 & 329 & 216 & 3302 & 5793 & 222 & 82 & 1559 & 7.9 & \\
\hline Hahn & 1/16/1990 & 6.72 & 434 & 214 & 3303 & 5915 & 226 & 81 & 1550 & 7.9 & \\
\hline Hahn & $1 / 23 / 1990$ & 6.81 & 410 & 208 & 3202 & 5758 & 220 & 80 & 1537 & 7.8 & \\
\hline Hahn & 2/2/1990 & 6.80 & 403 & 235 & 3236 & 5885 & 209 & 81 & 1621 & 8.3 & \\
\hline Hahn & $2 / 6 / 1990$ & 6.35 & 326 & 234 & 3207 & 5713 & 210 & 80 & 1573 & 8 & \\
\hline Hahn & $2 / 13 / 1990$ & 6.63 & 392 & 173 & 3126 & 5570 & 215 & 78 & 1489 & 7.4 & \\
\hline Hahn & $2 / 20 / 1990$ & 6.77 & 304 & 196 & 3156 & 5506 & 226 & 78 & 1488 & 7.3 & \\
\hline
\end{tabular}


Table G-1, Hahn Mine-pool Raw Chemical Data

\begin{tabular}{|c|c|c|c|c|c|c|c|c|c|c|c|}
\hline Site & Date & $\mathrm{pH}$ & $\begin{array}{c}\text { Alkalinity, } \\
\mathrm{mg} / \mathrm{L}\end{array}$ & $\begin{array}{c}\mathrm{Fe}, \\
\mathrm{mg} / \mathrm{L}\end{array}$ & $\begin{array}{l}\mathrm{SO} 4, \\
\mathrm{mg} / \mathrm{L}\end{array}$ & $\begin{array}{l}\text { TDS, } \\
\mathrm{mg} / \mathrm{L}\end{array}$ & $\begin{array}{c}\mathrm{Ca}, \\
\mathrm{mg} / \mathrm{L}\end{array}$ & $\begin{array}{l}\mathrm{Mg}, \\
\mathrm{mg} / \mathrm{L}\end{array}$ & $\begin{array}{c}\mathrm{Na}, \\
\mathrm{mg} / \mathrm{L}\end{array}$ & $\begin{array}{c}\mathrm{K}, \\
\mathrm{mg} / \mathrm{L}\end{array}$ & $\begin{array}{c}\mathrm{Cl}, \\
\mathrm{mg} / \mathrm{L}\end{array}$ \\
\hline Hahn & $3 / 1 / 1990$ & 6.82 & 382 & 204 & 3221 & 5748 & 222 & 80 & 1543 & 7.6 & \\
\hline Hahn & $3 / 6 / 1990$ & 6.68 & 405 & 196 & 3177 & 5723 & 219 & 79 & 1547 & 7.3 & \\
\hline Hahn & $3 / 13 / 1990$ & 6.55 & 287 & 192 & 3069 & 5412 & 210 & 77 & 1503 & 7.5 & \\
\hline Hahn & $3 / 27 / 1990$ & 6.81 & 328 & 190 & 3037 & 5387 & 212 & 78 & 1464 & 7.4 & \\
\hline Hahn & $4 / 3 / 1990$ & 6.84 & 304 & 186 & 3001 & 5312 & 201 & 74 & 1460 & 7.3 & \\
\hline Hahn & $4 / 10 / 1990$ & 6.90 & 254 & 179 & 2982 & 5243 & 202 & 73 & 1487 & 7.2 & \\
\hline Hahn & $4 / 17 / 1990$ & 7.07 & 301 & 188 & 3035 & 5388 & 210 & 75 & 1503 & 7.8 & \\
\hline Hahn & $4 / 24 / 1990$ & 6.68 & 338 & 186 & 2998 & 5375 & 207 & 74 & 1490 & 7.7 & \\
\hline Hahn & $5 / 1 / 1990$ & 6.81 & 313 & 191 & 3109 & 5515 & 215 & 77 & 1530 & 7.7 & \\
\hline Hahn & $5 / 8 / 1990$ & 6.88 & 419 & 180 & 2908 & 5338 & 222 & 73 & 1434 & 7.3 & \\
\hline Hahn & $5 / 15 / 1990$ & 6.90 & 417 & 186 & 2979 & 5444 & 209 & 75 & 1477 & 7.4 & \\
\hline Hahn & $5 / 22 / 1990$ & 6.63 & 358 & 179 & 2901 & 5236 & 201 & 73 & 1436 & 7.4 & \\
\hline Hahn & $5 / 29 / 1990$ & 6.67 & 298 & 181 & 2893 & 5162 & 206 & 73 & 1435 & 7.5 & \\
\hline Hahn & $6 / 5 / 1990$ & 6.99 & 417 & 177 & 2860 & 5238 & 203 & 72 & 1407 & 7.3 & \\
\hline Hahn & $6 / 12 / 1990$ & 6.65 & 198 & 177 & 2798 & 4891 & 196 & 71 & 1400 & 7.3 & \\
\hline Hahn & $6 / 19 / 1990$ & 6.96 & 355 & 173 & 2721 & 4964 & 194 & 69 & 1365 & 7.2 & \\
\hline Hahn & $6 / 26 / 1990$ & 6.86 & 316 & 183 & 2918 & 5251 & 202 & 74 & 1479 & 7.4 & \\
\hline Hahn & $7 / 3 / 1990$ & 7.28 & 190 & 177 & 2835 & 4913 & 204 & 72 & 1384 & 7.3 & \\
\hline Hahn & $7 / 10 / 1990$ & 6.84 & 351 & 186 & 2910 & 5250 & 209 & 74 & 1432 & 7.8 & \\
\hline Hahn & $7 / 17 / 1990$ & 6.64 & 423 & 181 & 2822 & 5200 & 198 & 72 & 1401 & 7.3 & \\
\hline Hahn & $7 / 24 / 1990$ & 6.90 & 425 & 180 & 2796 & 5172 & 201 & 72 & 1395 & 7.4 & \\
\hline Hahn & $8 / 1 / 1990$ & 6.85 & 387 & 175 & 2747 & 4989 & 192 & 69 & 1324 & 6.9 & \\
\hline Hahn & $8 / 7 / 1990$ & 6.73 & 430 & 180 & 2742 & 5682 & 195 & 71 & 1400 & 7.3 & 560 \\
\hline Hahn & $8 / 14 / 1990$ & 6.84 & 411 & 184 & 2773 & 5118 & 201 & 71 & 1377 & 7.6 & \\
\hline Hahn & $8 / 21 / 1990$ & 6.89 & 368 & 179 & 2723 & 4993 & 198 & 70 & 1364 & 6.8 & \\
\hline Hahn & $8 / 28 / 1990$ & 6.94 & 414 & 180 & 2756 & 5079 & 198 & 71 & 1359 & 7.6 & \\
\hline Hahn & $9 / 4 / 1990$ & 6.76 & 298 & 183 & 2729 & 4936 & 197 & 72 & 1382 & 7.3 & \\
\hline Hahn & $9 / 11 / 1990$ & 6.78 & 405 & 161 & 2682 & 5006 & 188 & 68 & 1404 & 7 & \\
\hline Hahn & 9/18/1990 & 6.65 & 342 & 171 & 2598 & 4737 & 188 & 67 & 1287 & 6.5 & \\
\hline Hahn & 9/25/1990 & 6.73 & 221 & 175 & 2676 & 4709 & 191 & 69 & 1319 & 6.7 & \\
\hline Hahn & $10 / 2 / 1990$ & 6.88 & 368 & 171 & 2649 & 4816 & 188 & 68 & 1283 & 6.4 & \\
\hline Hahn & 10/9/1990 & 7.19 & 353 & 174 & 2693 & 4905 & 194 & 69 & 1334 & 7.1 & \\
\hline Hahn & 10/16/1990 & 6.92 & 364 & 165 & 2545 & 4684 & 185 & 66 & 1270 & 6.7 & \\
\hline Hahn & $10 / 23 / 1990$ & 6.95 & 379 & 168 & 2577 & 4776 & 185 & 57 & 1308 & 6.9 & \\
\hline Hahn & $10 / 30 / 1990$ & 6.65 & 339 & 166 & 2579 & 4716 & 185 & 66 & 1297 & 7 & \\
\hline Hahn & $11 / 6 / 1990$ & 6.91 & 224 & 172 & 2655 & 4758 & 196 & 70 & 1381 & 7.9 & \\
\hline Hahn & $11 / 13 / 1990$ & 6.72 & 332 & 164 & 2595 & 4734 & 188 & 67 & 1306 & 6.7 & \\
\hline Hahn & $11 / 20 / 1990$ & 6.46 & 263 & 167 & 2662 & 4759 & 195 & 69 & 1336 & 7 & \\
\hline Hahn & $11 / 28 / 1990$ & 6.41 & 282 & 164 & 2599 & 4705 & 187 & 67 & 1334 & 7 & \\
\hline Hahn & $12 / 4 / 1990$ & 6.60 & 366 & 163 & 2559 & 4755 & 187 & 67 & 1325 & 6.9 & \\
\hline Hahn & $12 / 11 / 1990$ & 6.70 & 428 & 166 & 2642 & 4969 & 193 & 69 & 1368 & 7.4 & \\
\hline Hahn & $1 / 4 / 1991$ & 7.16 & 355 & 149 & 2394 & 4447 & 177 & 61 & 1224 & 6.7 & \\
\hline Hahn & $1 / 8 / 1991$ & 7.12 & 360 & 157 & 2496 & 4621 & 186 & 63 & 1270 & 6.8 & \\
\hline Hahn & $1 / 29 / 1991$ & 6.53 & 296 & 174 & 2542 & 4543 & 196 & 68 & 1194 & 7 & \\
\hline Hahn & $1 / 29 / 1991$ & 6.45 & 310 & 158 & 2520 & 4603 & 188 & 66 & 1284 & 7.1 & \\
\hline Hahn & $2 / 12 / 1991$ & 6.62 & 282 & 169 & 2427 & 4391 & 189 & 66 & 1187 & 6.8 & \\
\hline Hahn & $2 / 12 / 1991$ & 6.76 & 399 & 143 & 2313 & 4436 & 169 & 60 & 1255 & 6.7 & \\
\hline Hahn & $2 / 26 / 1991$ & 6.57 & 323 & 165 & 2339 & 4391 & 177 & 69 & 1237 & 7.1 & \\
\hline Hahn & $2 / 26 / 1991$ & 6.58 & 398 & 144 & 2323 & 4476 & 167 & 65 & 1283 & 6.8 & \\
\hline Hahn & $3 / 12 / 1991$ & 7.16 & 202 & 69 & 2326 & 4086 & 188 & 67 & 1181 & 6.6 & \\
\hline Hahn & $3 / 12 / 1991$ & 7.41 & 336 & 48 & 2258 & 4188 & 166 & 62 & 1236 & 6.7 & \\
\hline Hahn & 3/26/1991 & 6.82 & 301 & 155 & 2344 & 4331 & 178 & 67 & 1211 & 6.8 & \\
\hline
\end{tabular}


Table G-1, Hahn Mine-pool Raw Chemical Data

\begin{tabular}{|c|c|c|c|c|c|c|c|c|c|c|c|}
\hline Site & Date & $\mathrm{pH}$ & $\begin{array}{c}\text { Alkalinity, } \\
\mathrm{mg} / \mathrm{L}\end{array}$ & $\begin{array}{l}\mathrm{Fe}, \\
\mathrm{mg} / \mathrm{L}\end{array}$ & $\begin{array}{l}\mathrm{SO} 4, \\
\mathrm{mg} / \mathrm{L}\end{array}$ & $\begin{array}{l}\text { TDS, } \\
\mathrm{mg} / \mathrm{L}\end{array}$ & $\begin{array}{l}\mathrm{Ca}, \\
\mathrm{mg} / \mathrm{L}\end{array}$ & $\begin{array}{l}\mathrm{Mg}, \\
\mathrm{mg} / \mathrm{L}\end{array}$ & $\begin{array}{l}\mathrm{Na}, \\
\mathrm{mg} / \mathrm{L}\end{array}$ & $\begin{array}{c}\mathrm{K}, \\
\mathrm{mg} / \mathrm{L}\end{array}$ & $\begin{array}{c}\mathrm{Cl}, \\
\mathrm{mg} / \mathrm{L}\end{array}$ \\
\hline Hahn & $3 / 26 / 1991$ & 6.75 & 339 & 145 & 2336 & 4400 & 171 & 65 & 1261 & 6.7 & \\
\hline Hahn & $4 / 9 / 1991$ & 6.74 & 303 & 148 & 2256 & 4190 & 172 & 65 & 1171 & 6.6 & \\
\hline Hahn & 4/9/1991 & 6.62 & 333 & 138 & 2242 & 4272 & 164 & 63 & 1250 & 6.6 & \\
\hline Hahn & 4/23/1991 & 6.71 & 313 & 139 & 2257 & 4207 & 169 & 63 & 1189 & 6.6 & \\
\hline Hahn & $4 / 23 / 1991$ & 6.63 & 401 & 127 & 2202 & 4267 & 160 & 60 & 1220 & 6.7 & \\
\hline Hahn & $5 / 14 / 1991$ & 6.68 & 279 & 128 & 2173 & 4047 & 164 & 61 & 1173 & 6.3 & \\
\hline Hahn & $6 / 11 / 1991$ & 6.80 & 383 & 110 & 2096 & 4092 & 150 & 57 & 1204 & 6.4 & \\
\hline Hahn & $6 / 11 / 1991$ & 6.86 & 447 & 126 & 2126 & 4141 & 160 & 59 & 1116 & 6.4 & \\
\hline Hahn & $6 / 25 / 1991$ & 6.85 & 339 & 118 & 2027 & 3846 & 152 & 56 & 1072 & 5.8 & \\
\hline Hahn & $6 / 25 / 1991$ & 7.01 & 398 & 104 & 1935 & 3839 & 138 & 53 & 1117 & 5.7 & \\
\hline Hahn & 7/9/1991 & 6.51 & 303 & 119 & 2022 & 3778 & 155 & 56 & 1049 & 5.9 & \\
\hline Hahn & $7 / 9 / 1991$ & 6.65 & 371 & 102 & 2103 & 4067 & 149 & 56 & 1197 & 6.1 & \\
\hline Hahn & $7 / 23 / 1991$ & 7.01 & 455 & 100 & 1985 & 3989 & 143 & 54 & 1144 & 6.1 & \\
\hline Hahn & $8 / 2 / 1991$ & 7 & 442 & 106 & 2067 & 4085 & 151 & 57 & 1157 & 6.1 & \\
\hline Hahn & $8 / 13 / 1991$ & 6.95 & 477 & 103 & 2027 & 4065 & 148 & 56 & 1142 & 6.1 & \\
\hline Hahn & $9 / 3 / 1991$ & 6.91 & 466 & 104 & 2093 & 4097 & 152 & 56 & 1115 & 6.2 & \\
\hline Hahn & 9/18/1991 & 7.15 & 463 & 101 & 1995 & 4000 & 146 & 56 & 1130 & 6.9 & \\
\hline Hahn & 10/8/1991 & 6.84 & 338 & 109 & 2050 & 3945 & 151 & 57 & 1160 & 6.7 & \\
\hline Hahn & 10/22/1991 & 6.77 & 330 & 87 & 2111 & 4024 & 157 & 61 & 1197 & 6.9 & \\
\hline Hahn & 11/1/1991 & 7.16 & 352 & 113 & 2062 & 4003 & 153 & 59 & 1179 & 6.4 & \\
\hline Hahn & $11 / 19 / 1991$ & 7.07 & 447 & 117 & 2019 & 4008 & 153 & 58 & 1107 & 6.6 & \\
\hline Hahn & 12/4/1991 & 7 & 300 & 107 & 1954 & 3700 & 151 & 57 & 1058 & 5.7 & \\
\hline Hahn & $12 / 10 / 1991$ & 6.36 & 365 & 86 & 2038 & 3895 & 149 & 57 & 1112 & 6.1 & \\
\hline Hahn & 1/8/1992 & 6.73 & 317 & 111 & 2066 & 3921 & 156 & 59 & 1134 & 6.3 & \\
\hline Hahn & $1 / 21 / 1992$ & 6.59 & 387 & 121 & 2045 & 4000 & 166 & 61 & 1127 & 6.7 & \\
\hline Hahn & $2 / 11 / 1992$ & 6.66 & 464 & 117 & 2103 & 4132 & 161 & 60 & 1117 & 6 & \\
\hline Hahn & 3/10/1992 & 7.32 & 273 & 64 & 2457 & 4536 & 226 & 77 & 1366 & 11.3 & \\
\hline Hahn & $3 / 24 / 1992$ & 6.71 & 253 & 94 & 2066 & 3792 & 167 & 61 & 1088 & 6.1 & \\
\hline Hahn & 4/8/1992 & 7.48 & 253 & 33 & 2097 & 3767 & 173 & 62 & 1085 & 6.8 & \\
\hline Hahn & $5 / 5 / 1992$ & 6.78 & 400 & 107 & 2262 & 4278 & 167 & 62 & 1184 & 6.6 & \\
\hline Hahn & $5 / 19 / 1992$ & 7.05 & 291 & 147 & 2138 & 3870 & 179 & 64 & 979 & 6.7 & \\
\hline Hahn & 6/9/1992 & 6.82 & 343 & 142 & 2109 & 3986 & 172 & 63 & 1073 & 5.9 & \\
\hline Hahn & $6 / 23 / 1992$ & 6.68 & 380 & 150 & 2120 & 4022 & 172 & 64 & 1043 & 6.6 & \\
\hline Hahn & $7 / 15 / 1992$ & 6.68 & 402 & 144 & 2099 & 4029 & 170 & 64 & 1054 & 6.1 & \\
\hline Hahn & $8 / 11 / 1992$ & 6.87 & 432 & 138 & 2079 & 4035 & 167 & 62 & 1054 & 6 & \\
\hline Hahn & $8 / 26 / 1992$ & 6.95 & 394 & 94 & 1943 & 3764 & 160 & 58 & 1020 & 6.1 & \\
\hline Hahn & 9/8/1992 & 6.93 & 385 & 129 & 2044 & 3952 & 160 & 61 & 1081 & 6.5 & \\
\hline Hahn & 10/6/1992 & 7.19 & 282 & 126 & 2004 & 3775 & 165 & 60 & 1068 & 6.3 & \\
\hline Hahn & 10/11/1992 & 7.22 & 355 & 126 & 2043 & 3925 & 165 & 61 & 1089 & 6.1 & \\
\hline Hahn & 11/17/1992 & 7.26 & 374 & 121 & 2028 & 3899 & 160 & 59 & 1067 & 6.5 & \\
\hline Hahn & 12/8/1992 & 6.79 & 458 & 121 & 1974 & 3952 & 160 & 58 & 1072 & 5.9 & \\
\hline Hahn & 12/15/1992 & 6.61 & 413 & 127 & 2044 & 4015 & 166 & 61 & 1105 & 6.1 & \\
\hline Hahn & $1 / 12 / 1993$ & 7.00 & 364 & 127 & 2085 & 3991 & 169 & 63 & 1095 & 6.5 & \\
\hline Hahn & 1/19/1993 & 6.77 & 332 & 134 & 2028 & 3868 & 165 & 62 & 1066 & 6.6 & \\
\hline Hahn & $2 / 2 / 1993$ & 6.97 & 334 & 107 & 2053 & 3837 & 166 & 61 & 1035 & 6.1 & \\
\hline Hahn & $3 / 2 / 1993$ & 6.96 & 390 & 122 & 1978 & 3870 & 159 & & 1068 & 6.1 & \\
\hline Hahn & $3 / 16 / 1993$ & 7.10 & 454 & 139 & 1982 & 3948 & 170 & 61 & 1034 & 6.1 & \\
\hline Hahn & $4 / 6 / 1993$ & 6.88 & 411 & 136 & 2159 & 4195 & 177 & & 1153 & 6.1 & \\
\hline Hahn & $4 / 20 / 1993$ & 7.13 & 386 & 121 & 1982 & 3793 & 167 & 59 & 985 & 6.1 & \\
\hline Hahn & $5 / 18 / 1993$ & 7.09 & 404 & 118 & 1838 & 3651 & 158 & 57 & 979 & 6.4 & \\
\hline Hahn & $6 / 15 / 1993$ & 6.75 & 410 & 115 & 1807 & 3670 & 150 & 56 & 1034 & 6.1 & \\
\hline Hahn & 7/6/1993 & 7.32 & 318 & 114 & 1911 & 3685 & 158 & 57 & 1049 & 6.2 & \\
\hline
\end{tabular}


Table G-1, Hahn Mine-pool Raw Chemical Data

\begin{tabular}{|c|c|c|c|c|c|c|c|c|c|c|c|}
\hline Site & Date & $\mathrm{pH}$ & $\begin{array}{c}\text { Alkalinity, } \\
\mathrm{mg} / \mathrm{L}\end{array}$ & $\begin{array}{c}\mathrm{Fe}, \\
\mathrm{mg} / \mathrm{L}\end{array}$ & $\begin{array}{l}\mathrm{SO} 4, \\
\mathrm{mg} / \mathrm{L}\end{array}$ & $\begin{array}{l}\text { TDS, } \\
\mathrm{mg} / \mathrm{L}\end{array}$ & $\begin{array}{c}\mathrm{Ca}, \\
\mathrm{mg} / \mathrm{L}\end{array}$ & $\begin{array}{l}\mathrm{Mg}, \\
\mathrm{mg} / \mathrm{L}\end{array}$ & $\begin{array}{c}\mathrm{Na}, \\
\mathrm{mg} / \mathrm{L}\end{array}$ & $\begin{array}{c}\mathrm{K}, \\
\mathrm{mg} / \mathrm{L}\end{array}$ & $\begin{array}{c}\mathrm{Cl}, \\
\mathrm{mg} / \mathrm{L}\end{array}$ \\
\hline Hahn & $8 / 3 / 1993$ & 7.10 & 358 & 109 & 1895 & 3709 & 154 & 57 & 1050 & 6.1 & \\
\hline Hahn & 9/3/1993 & 7.08 & 459 & 103 & 1871 & 3798 & 149 & 55 & 1052 & 6.5 & \\
\hline Hahn & $10 / 5 / 1993$ & 6.95 & 360 & 98 & 1739 & 3227 & 142 & 52 & 749 & 6.2 & \\
\hline Hahn & $11 / 16 / 1993$ & 6.91 & 364 & 96 & 1746 & 3443 & 150 & 51 & 949 & 5.9 & \\
\hline Hahn & $12 / 7 / 1993$ & 7.06 & 457 & 98 & 1711 & 3631 & 144 & 53 & 1060 & 6.3 & \\
\hline Hahn & $2 / 8 / 1994$ & 7.10 & 351 & 93 & 1593 & 3236 & 138 & 51 & 926 & 5.8 & \\
\hline Hahn & $3 / 22 / 1994$ & 6.93 & 425 & 95 & 1603 & 3407 & 138 & 54 & 992 & 5.8 & \\
\hline Hahn & $4 / 12 / 1994$ & 6.81 & 361 & 91 & 1608 & 3218 & 140 & 49 & 882 & 5.5 & \\
\hline Hahn & $5 / 3 / 1994$ & 6.66 & 439 & 95 & 1593 & 3322 & 140 & 51 & 901 & 5.6 & \\
\hline Hahn & $6 / 22 / 1994$ & 6.53 & 379 & 91 & 1600 & 3263 & 136 & 50 & 917 & 5.5 & \\
\hline Hahn & $7 / 6 / 1994$ & 6.55 & 370 & 86 & 1416 & 2705 & 129 & 47 & 569 & 5.4 & \\
\hline Hahn & 9/13/1994 & 6.70 & 454 & 55 & 1250 & 2739 & 118 & 35 & 718 & 7.3 & \\
\hline Hahn & $10 / 13 / 1994$ & 6.59 & 354 & 83 & 1450 & 3015 & 134 & 48 & 861 & 5.9 & \\
\hline Hahn & $11 / 23 / 1994$ & 6.56 & 343 & 89 & 1440 & 2970 & 142 & 49 & 826 & 5.4 & \\
\hline Hahn & 12/12/1994 & 6.66 & 439 & 92 & 1560 & 3246 & 149 & 52 & 850 & 5.9 & \\
\hline Hahn & $1 / 25 / 1995$ & 6.43 & 294 & 94 & 1500 & 2932 & 152 & 51 & 769 & 5.5 & \\
\hline Hahn & 2/21/1995 & 6.60 & 395 & 94 & 1460 & 3047 & 150 & 61 & 803 & 5.5 & \\
\hline Hahn & $3 / 7 / 1995$ & 6.61 & 344 & 91 & 1450 & 2937 & 150 & 50 & 770 & 5.5 & \\
\hline Hahn & $4 / 3 / 1995$ & 6.63 & 272 & 85 & 1460 & 2860 & 150 & 53 & 774 & 5.6 & \\
\hline Hahn & $5 / 23 / 1995$ & 6.56 & 344 & 92 & 1520 & 2999 & 154 & 52 & 755 & 5.6 & \\
\hline Hahn & 6/6/1995 & 6.52 & 386 & 88 & 1350 & 3196 & & 50 & 770 & 5.8 & 310 \\
\hline Hahn & $8 / 1 / 1995$ & 6.43 & 338 & 87 & 1370 & 2842 & 141 & 49 & 775 & 5.8 & \\
\hline Hahn & 9/6/1995 & 6.68 & 364 & 84 & 1320 & 2814 & 138 & 47 & 774 & 5.5 & \\
\hline Hahn & $10 / 10 / 1995$ & 6.44 & 360 & 83 & 1390 & 2920 & 142 & 49 & 811 & 5.6 & \\
\hline Hahn & 12/12/1995 & 7.40 & 316 & 85 & 1200 & 1672 & & & & & \\
\hline Hahn & $1 / 9 / 1996$ & 7.40 & 314 & 81 & 1288 & 1753 & & & & & \\
\hline Hahn & $1 / 20 / 1996$ & 6.60 & 373 & 67 & 1213 & 1736 & & & & & \\
\hline Hahn & $2 / 19 / 1996$ & 6.90 & 310 & 92 & 1350 & 1821 & & & & & \\
\hline Hahn & $3 / 27 / 1996$ & 6.80 & 295 & 95 & 1600 & 2056 & & & & & \\
\hline Hahn & $4 / 5 / 1996$ & 8.20 & 297 & 68 & 1625 & 2057 & & & & & \\
\hline Hahn & $5 / 6 / 1996$ & 8.20 & 289 & 41 & 1450 & 1845 & & & & & \\
\hline Hahn & $6 / 3 / 1996$ & 6.80 & 313 & 95 & 1300 & 1779 & & & & & \\
\hline Hahn & $7 / 8 / 1996$ & 6.80 & 370 & 23 & 1275 & 1750 & & & & & \\
\hline Hahn & $8 / 5 / 1996$ & 7.60 & 370 & 70 & 1400 & 1922 & & & & & \\
\hline Hahn & 9/9/1996 & 7.00 & 383 & 74 & 1325 & 1867 & & & & & \\
\hline Hahn & 10/7/1996 & 7.00 & 400 & 65 & 1175 & 1729 & & & & & \\
\hline Hahn & 11/4/1996 & 7.30 & 413 & 56 & 1500 & 2061 & & & & & \\
\hline Hahn & 12/2/1996 & 6.90 & 397 & 62 & 1150 & 1697 & & & & & \\
\hline Hahn & $1 / 20 / 1997$ & 6.60 & 373 & 67 & 1213 & 1736 & & & & & \\
\hline Hahn & $2 / 3 / 1997$ & 6.60 & 361 & 70 & 1225 & 1737 & & & & & \\
\hline Hahn & $3 / 3 / 1997$ & 6.60 & 366 & 61 & 1063 & 1571 & & & & & \\
\hline Hahn & 3/20/1997 & 7.04 & 396 & 182 & 2931 & 5301 & 202 & 72 & 1420 & 6.9 & \\
\hline Hahn & 4/7/1997 & 6.80 & 309 & 74 & 1175 & 1627 & & & & & \\
\hline Hahn & $5 / 5 / 1997$ & 6.60 & 340 & 59 & 1138 & 1613 & & & & & \\
\hline Hahn & $6 / 2 / 1997$ & 7.30 & 460 & 60 & 1025 & 1647 & & & & & \\
\hline Hahn & $8 / 11 / 1997$ & 8.50 & 379 & 70 & 1050 & 1584 & & & & & \\
\hline Hahn & 9/1/1997 & 6.70 & 378 & 72 & 1075 & 1609 & & & & & \\
\hline Hahn & 10/6/1997 & 6.80 & 372 & 68 & 1213 & 1736 & & & & & \\
\hline Hahn & $11 / 3 / 1997$ & 6.90 & 385 & 72 & 1050 & 1592 & & & & & \\
\hline Hahn & $12 / 8 / 1997$ & 6.60 & 318 & 49 & 1150 & 1585 & & & & & \\
\hline Hahn & $1 / 5 / 1998$ & 7.30 & 392 & 65 & 1050 & 1594 & & & & & \\
\hline Hahn & 1/20/1998 & 6.60 & 373 & 67 & 1231 & 1754 & & & & & \\
\hline
\end{tabular}


Table G-1, Hahn Mine-pool Raw Chemical Data

\begin{tabular}{|c|c|c|c|c|c|c|c|c|c|c|c|}
\hline Site & Date & $\mathrm{pH}$ & $\begin{array}{c}\text { Alkalinity, } \\
\mathrm{mg} / \mathrm{L}\end{array}$ & $\begin{array}{c}\mathrm{Fe}, \\
\mathrm{mg} / \mathrm{L}\end{array}$ & $\begin{array}{l}\mathrm{SO} 4, \\
\mathrm{mg} / \mathrm{L}\end{array}$ & $\begin{array}{l}\text { TDS, } \\
\mathrm{mg} / \mathrm{L}\end{array}$ & $\begin{array}{l}\mathrm{Ca}, \\
\mathrm{mg} / \mathrm{L}\end{array}$ & $\begin{array}{l}\mathrm{Mg}, \\
\mathrm{mg} / \mathrm{L}\end{array}$ & $\begin{array}{l}\mathrm{Na}, \\
\mathrm{mg} / \mathrm{L}\end{array}$ & $\begin{array}{c}\mathrm{K}, \\
\mathrm{mg} / \mathrm{L}\end{array}$ & $\begin{array}{c}\mathrm{Cl}, \\
\mathrm{mg} / \mathrm{L}\end{array}$ \\
\hline Hahn & 2/2/1998 & 6.70 & 392 & 64 & 1063 & 1606 & & & & & \\
\hline Hahn & $3 / 2 / 1998$ & 6.80 & 390 & 72 & 1038 & 1587 & & & & & \\
\hline Hahn & $3 / 24 / 1998$ & 6.71 & 312 & 94 & 2066 & 3864 & 167 & 61 & 1088 & 6.1 & \\
\hline Hahn & $4 / 6 / 1998$ & 6.90 & 404 & 62 & 1100 & 1656 & & & & & \\
\hline Hahn & $5 / 4 / 1998$ & 7.30 & 392 & 64 & 1075 & 1618 & & & & & \\
\hline Hahn & $6 / 1 / 1998$ & 8.40 & 379 & 69 & 1075 & 1607 & & & & & \\
\hline Hahn & 7/13/1998 & 7.00 & 367 & 71 & 1050 & 1569 & & & & & \\
\hline Hahn & $8 / 3 / 1998$ & 7.00 & 421 & 52 & 888 & 1454 & & & & & \\
\hline Hahn & 9/14/1998 & 7.10 & 435 & 26 & 975 & 1532 & & & & & \\
\hline Hahn & 10/5/1998 & 8.30 & 423 & 61 & 950 & 1528 & & & & & \\
\hline Hahn & $11 / 3 / 1998$ & 6.90 & 433 & 59 & 963 & 1551 & & & & & \\
\hline Hahn & $12 / 7 / 1998$ & 6.90 & 438 & 46 & 900 & 1481 & & & & & \\
\hline Hahn & 2/1/1999 & 7.10 & 413 & 66 & 950 & 1520 & & & & & \\
\hline Hahn & 2/8/1999 & 6.76 & 425 & 46.9 & & & & & & & \\
\hline Hahn & $3 / 2 / 1999$ & 7.4 & 415 & 63.29 & & & & & & & \\
\hline Hahn & $4 / 6 / 1999$ & 7.2 & 390 & 61.61 & & & & & & & \\
\hline Hahn & $5 / 3 / 1999$ & 7.2 & 392 & 73.42 & & & & & & & \\
\hline Hahn & $5 / 12 / 1999$ & 7.23 & 393 & 56.9 & & & & & & & \\
\hline Hahn & $6 / 8 / 1999$ & 7 & 383 & 75.83 & & & & & & & \\
\hline Hahn & 6/10/1999 & & & 58.7 & & & & & & & \\
\hline Hahn & $7 / 5 / 1999$ & 6.9 & 384 & 64.72 & & & & & & & \\
\hline Hahn & $7 / 6 / 1999$ & 6.49 & 397 & 55.8 & & & & & & & \\
\hline Hahn & $8 / 9 / 1999$ & 8.2 & 415 & 56.68 & & & & & & & \\
\hline Hahn & 9/7/1999 & 7.1 & 508 & 40.95 & & & & & & & \\
\hline Hahn & $10 / 4 / 1999$ & 7.1 & 418 & 51.15 & & & & & & & \\
\hline Hahn & $11 / 1 / 1999$ & 7.4 & 429 & 51.97 & & & & & & & \\
\hline Hahn & $12 / 6 / 1999$ & 7.6 & 422 & 53.81 & & & & & & & \\
\hline Hahn & $1 / 3 / 2000$ & 7.1 & 477 & 45.72 & & & & & & & \\
\hline Hahn & $2 / 7 / 2000$ & 8.3 & 408 & 61.21 & & & & & & & \\
\hline Hahn & $3 / 6 / 2000$ & 6.9 & 413 & 65.25 & & & & & & & \\
\hline Hahn & $4 / 3 / 2000$ & 7.3 & 392 & 58.09 & & & & & & & \\
\hline Hahn & $5 / 1 / 2000$ & 6.9 & 403 & 62.73 & & & & & & & \\
\hline Hahn & $6 / 5 / 2000$ & 6.9 & 398 & 65.88 & & & & & & & \\
\hline Hahn & $7 / 11 / 2000$ & 7.3 & 458 & 65.28 & & & & & & & \\
\hline Hahn & $8 / 8 / 2000$ & 7.1 & 395 & 68.9 & & & & & & & \\
\hline Hahn & $8 / 15 / 2000$ & 6.31 & 405 & 54.7 & & & & & & & \\
\hline Hahn & $9 / 5 / 2000$ & 8.5 & 424 & 62.17 & & & & & & & \\
\hline Hahn & $10 / 2 / 2000$ & 7.3 & 439 & 51.03 & & & & & & & \\
\hline Hahn & $11 / 6 / 2000$ & 7.3 & 412 & 55.55 & & & & & & & \\
\hline Hahn & $11 / 21 / 2000$ & 6.82 & 444 & 36.4 & & & & & & & \\
\hline Hahn & $12 / 4 / 2000$ & 8.4 & 443 & 49.82 & & & & & & & \\
\hline Hahn & $1 / 2 / 2001$ & 7.3 & 463 & 42.57 & & & & & & & \\
\hline Hahn & $2 / 5 / 2001$ & 7.4 & 438 & 46.02 & & & & & & & \\
\hline Hahn & $3 / 5 / 2001$ & 7.2 & 433 & 50.96 & & & & & & & \\
\hline Hahn & $4 / 2 / 2001$ & 7.8 & 446 & 29.82 & & & & & & & \\
\hline Hahn & $5 / 7 / 2001$ & 8.2 & 432 & 49.93 & & & & & & & \\
\hline Hahn & $6 / 4 / 2001$ & 7.1 & 428 & 47.74 & & & & & & & \\
\hline Hahn & $7 / 2 / 2001$ & 8.1 & 423 & 51.24 & & & & & & & \\
\hline Hahn & $8 / 6 / 2001$ & 7 & 441 & 43.45 & & & & & & & \\
\hline Hahn & $9 / 4 / 2001$ & 7.4 & 459 & 43.29 & & & & & & & \\
\hline Hahn & $10 / 1 / 2001$ & 7.3 & 474 & 38.01 & & & & & & & \\
\hline Hahn & $11 / 5 / 2001$ & 8.2 & 472 & 40.97 & & & & & & & \\
\hline
\end{tabular}


Table G-1, Hahn Mine-pool Raw Chemical Data

\begin{tabular}{|c|r|r|r|r|r|r|r|r|r|r|l|}
\hline Site & \multicolumn{1}{|c|}{ Date } & $\mathrm{pH}$ & $\begin{array}{c}\text { Alkalinity, } \\
\mathrm{mg} / \mathrm{L}\end{array}$ & $\begin{array}{c}\mathrm{Fe}, \\
\mathrm{mg} / \mathrm{L}\end{array}$ & $\begin{array}{c}\mathrm{SO} 4, \\
\mathrm{mg} / \mathrm{L}\end{array}$ & $\begin{array}{l}\mathrm{TDS}, \\
\mathrm{mg} / \mathrm{L}\end{array}$ & $\begin{array}{c}\mathrm{Ca}, \\
\mathrm{mg} / \mathrm{L}\end{array}$ & $\begin{array}{c}\mathrm{Mg}, \\
\mathrm{mg} / \mathrm{L}\end{array}$ & $\begin{array}{c}\mathrm{Na}, \\
\mathrm{mg} / \mathrm{L}\end{array}$ & $\begin{array}{c}\mathrm{K}, \\
\mathrm{mg} / \mathrm{L}\end{array}$ & $\begin{array}{c}\mathrm{Cl}, \\
\mathrm{mg} / \mathrm{L}\end{array}$ \\
\hline Hahn & $12 / 3 / 2001$ & 8.4 & 429 & 42.34 & & & & & & & \\
\hline Hahn & $1 / 14 / 2002$ & 6.82 & 473 & 34.5 & & & & & & & \\
\hline Hahn & $5 / 8 / 2002$ & 6.51 & 444 & 41.5 & & & & & & & \\
\hline Hahn & $8 / 14 / 2002$ & 6.46 & 471 & 43.8 & & & & & & & \\
\hline Hahn & $12 / 4 / 2002$ & 6.7 & 469 & 34.6 & & & & & & & \\
\hline Hahn & $12 / 12 / 2002$ & 6.7 & 469 & 34.6 & & & & & & & \\
\hline Hahn & $2 / 18 / 2003$ & 6.75 & 582 & 28.1 & & & & & & & \\
\hline Hahn & $3 / 3 / 2003$ & 8.2 & 451 & 40.31 & & & & & & & \\
\hline Hahn & $3 / 5 / 2003$ & 6.78 & 466 & 37.8 & & & & & & \\
\hline Hahn & $4 / 1 / 2003$ & 7.1 & 450 & 40.01 & & & & & & & \\
\hline Hahn & $5 / 5 / 2003$ & 7.3 & 456 & 37.91 & & & & & & & \\
\hline Hahn & $6 / 2 / 2003$ & 7.2 & 463 & 38.15 & & & & & & & \\
\hline Hahn & $7 / 1 / 2003$ & 7.2 & 480 & 30.77 & & & & & & & \\
\hline Hahn & $8 / 4 / 2003$ & 7.9 & 417 & 37.06 & & & & & & & \\
\hline Hahn & $9 / 1 / 2003$ & 7.4 & 418 & 35.74 & & & & & & & \\
\hline Hahn & $10 / 6 / 2003$ & 8.88 & 562 & 25.9 & & & & & & & \\
\hline Hahn & $10 / 6 / 2003$ & 7.3 & 489 & 31.26 & & & & & & & \\
\hline Hahn & $12 / 1 / 2003$ & 7.03 & 475 & 23.86 & & & & & & & \\
\hline Hahn & $1 / 5 / 2004$ & 6.94 & 105 & 26.05 & & & & & & & \\
\hline Hahn & $2 / 2 / 2004$ & 7.02 & 459 & 21.38 & & & & & & & \\
\hline Hahn & $4 / 5 / 2004$ & 7.14 & 384 & 28.6 & & & & & & & \\
\hline Hahn & $5 / 3 / 2004$ & 7.04 & 364 & 31.42 & & & & & & & \\
\hline Hahn & $6 / 1 / 2004$ & 6.94 & 442 & 29.05 & & & & & & & \\
\hline Hahn & $7 / 6 / 2004$ & 6.8 & 351 & 29.12 & & & & & & & \\
\hline Hahn & $7 / 7 / 2004$ & 7.2 & 480 & 30.77 & & & & & & & \\
\hline Hahn & $9 / 20 / 2004$ & 6.93 & 511 & 25.4 & & & & & & \\
\hline Hahn & $9 / 20 / 2004$ & 6.63 & 342 & 38.7 & & & & & & & \\
\hline Hahn & $10 / 4 / 2004$ & 7.2 & 340 & 34.99 & & & & & & & \\
\hline
\end{tabular}


$\underline{\text { Appendix H }}$

Barnes \& Tucker Mine-pool, Raw Chemical Data 
Table H -1, Barnes \& Tucker Mine-pool Raw Chemical Data, Yearly Average

\begin{tabular}{|c|r|r|r|r|r|r|}
\hline Site & Year & \multicolumn{1}{|c|}{$\mathrm{pH}$} & $\begin{array}{r}\text { Alkalinity, } \\
\mathrm{mg} / \mathrm{L}\end{array}$ & $\mathrm{Fe}, \mathrm{mg} / \mathrm{L}$ & $\mathrm{SO}, \mathrm{mg} / \mathrm{L}$ & $\begin{array}{c}\text { Discharge, } \\
\text { gpm }\end{array}$ \\
\hline Barnes\&Tucker & 1970 & 5.62 & 40.8 & 751.2 & 2285.8 & 3374 \\
\hline Barnes\&Tucker & 1971 & 5.61 & 8.5 & 919.7 & 3692.6 & 4799 \\
\hline Barnes\&Tucker & 1972 & & & 665.8 & & 5221 \\
\hline Barnes\&Tucker & 1973 & & & 401.7 & & 4687 \\
\hline Barnes\&Tucker & 1974 & 4.51 & 21.5 & 295 & 1625.0 & 4191 \\
\hline Barnes\&Tucker & 1975 & 4.86 & 33.2 & 304.2 & 1420.4 & 4335 \\
\hline Barnes\&Tucker & 1976 & 4.79 & 22.6 & 295 & 1651.3 & 3891 \\
\hline Barnes\&Tucker & 1977 & 5.74 & 45.25 & 287.5 & 1126.8 & 3681 \\
\hline Barnes\&Tucker & 1978 & & & 197.5 & 1189.0 & 2543 \\
\hline Barnes\&Tucker & 1979 & & & 204.2 & 958.3 & 2497 \\
\hline Barnes\&Tucker & 1980 & & & & 970.3 & 4851 \\
\hline Barnes\&Tucker & 1981 & 5.75 & 89.40 & 201.62 & 1273.78 & 5131 \\
\hline Barnes\&Tucker & 1982 & 5.87 & 136.4 & 185.7 & 1022.5 & 4792 \\
\hline Barnes\&Tucker & 1983 & 6 & 86.74 & 443.7 & 887.7 & 4236 \\
\hline Barnes\&Tucker & 1984 & 5.98 & 121 & 190.4 & 775.0 & 2926 \\
\hline Barnes\&Tucker & 1985 & 6.04 & 120 & & & 2473 \\
\hline Barnes\&Tucker & 1986 & 6.7 & 289.5 & 63.5 & 420.6 & 4432 \\
\hline Barnes\&Tucker & 1987 & 6.53 & 274.6 & 63.4 & 614.6 & 6629 \\
\hline Barnes\&Tucker & 1988 & 6.63 & 309.6 & 74.4 & 597.0 & 7088 \\
\hline Barnes\&Tucker & 1989 & 6.16 & 177.4 & 71.6 & 606.9 & 6517 \\
\hline Barnes\&Tucker & 1990 & 6.19 & 133 & 79 & & 6843 \\
\hline Barnes\&Tucker & 1991 & 6.03 & 198.3 & 80 & & 6715 \\
\hline Barnes\&Tucker & 1992 & 5.84 & 175 & 90 & 759.0 & 5472 \\
\hline Barnes\&Tucker & 1993 & 6.17 & 191.4 & 72.8 & 607.3 & 6382 \\
\hline Barnes\&Tucker & 1994 & 6.48 & 181.9 & 73.3 & 478.3 & 6156 \\
\hline Barnes\&Tucker & 1995 & 6.74 & 196.3 & 60.6 & 573.7 & 5920 \\
\hline Barnes\&Tucker & 1996 & 6.5 & 141 & 66 & 535.0 & 5679 \\
\hline Barnes\&Tucker & 1997 & 6.79 & 180 & 45.2 & 445.5 & 6639 \\
\hline Barnes\&Tucker & 1998 & 6.46 & 146.9 & 40.2 & 375.2 & 5680 \\
\hline Barnes\&Tucker & 1999 & 6.52 & 148.4 & 43.2 & 413.0 & 4967 \\
\hline Barnes\&Tucker & 2000 & 6.48 & 187.8 & 49.1 & 386.1 & 5284 \\
\hline Barnes\&Tucker & 2001 & 6.57 & 191.8 & 44.3 & 410.2 & 5028 \\
\hline Barnes\&Tucker & 2002 & 6.66 & 207.2 & 40.2 & 372.8 & 4406 \\
\hline Barnes\&Tucker & 2003 & 6.64 & 203.5 & 42.6 & 347.0 & 5253 \\
\hline Barnes\&Tucker & 2004 & 6.58 & 135.6 & 37.7 & 388.4 & \\
\hline Barnes\&Tucker & 2005 & 6.60 & 197.7 & 43.5 & 266.0 & \\
\hline & & & & & & \\
\hline
\end{tabular}




\section{Appendix I}

Arden Mine-pool Raw Chemical Data 
Table I-1, Arden Mine-pool Raw Chemical Data

\begin{tabular}{|c|c|c|c|c|c|c|c|c|c|c|c|}
\hline Site & Date & $\mathrm{pH}$ & $\begin{array}{c}\text { Alkalinity, } \\
\mathrm{mg} / \mathrm{L}\end{array}$ & $\begin{array}{c}\mathrm{Fe}, \\
\mathrm{mg} / \mathrm{L}\end{array}$ & $\begin{array}{l}\mathrm{SO} 4, \\
\mathrm{mg} / \mathrm{L}\end{array}$ & $\begin{array}{l}\text { TDS, } \\
\mathrm{mg} / \mathrm{L}\end{array}$ & $\begin{array}{c}\mathrm{Ca}, \\
\mathrm{mg} / \mathrm{L}\end{array}$ & $\begin{array}{l}\mathrm{Mg}, \\
\mathrm{mg} / \mathrm{L}\end{array}$ & $\begin{array}{l}\mathrm{Na}, \\
\mathrm{mg} / \mathrm{L}\end{array}$ & $\begin{array}{c}\mathrm{K}, \\
\mathrm{mg} / \mathrm{L}\end{array}$ & $\begin{array}{c}\mathrm{Cl}, \\
\mathrm{mg} / \mathrm{L}\end{array}$ \\
\hline Arden & $9 / 8 / 1986$ & 6.86 & 277 & 24 & 672 & 1369 & 125 & 38 & 165 & 4.6 & 0.6 \\
\hline Arden & $10 / 1 / 1986$ & 7.08 & 273 & 24 & 671 & 1366 & 124 & 36 & 171 & 4.5 & 0.6 \\
\hline Arden & $10 / 8 / 1986$ & 6.97 & 272 & 23 & 657 & 1359 & 120 & 36 & 184 & 4.4 & 1.2 \\
\hline Arden & $10 / 15 / 1986$ & 6.85 & 303 & 28 & 615 & 1362 & 122 & 36 & 184 & 4.5 & 0.9 \\
\hline Arden & $10 / 22 / 1986$ & 6.91 & 305 & 22 & 585 & 1362 & 126 & 38 & 195 & 4.5 & 17.3 \\
\hline Arden & $10 / 29 / 1986$ & 7.02 & 291 & 25 & 603 & 1353 & 132 & 39 & 184 & 5 & 8.4 \\
\hline Arden & $11 / 5 / 1986$ & 6.91 & 296 & 31 & 725 & 1580 & 148 & 47 & 228 & 5.4 & 31.4 \\
\hline Arden & $11 / 12 / 1986$ & 6.94 & 290 & 32 & 725 & 1594 & 159 & 51 & 226 & 5.3 & 38.8 \\
\hline Arden & $11 / 26 / 1986$ & 6.76 & 292 & 38 & 1020 & 1925 & 172 & 54 & 234 & 5.4 & 42 \\
\hline Arden & $12 / 3 / 1986$ & 6.8 & 283 & 46 & 1057 & 1976 & 183 & 57 & 238 & 5.5 & 41.2 \\
\hline Arden & $12 / 10 / 1986$ & 7 & 260 & 58 & 1170 & 2117 & 201 & 65 & 243 & 6.5 & 53 \\
\hline Arden & $12 / 17 / 1986$ & 6.76 & 277 & 68 & 1024 & 2020 & 211 & 69 & 247 & 6.5 & 53 \\
\hline Arden & $12 / 23 / 1986$ & 7 & 164 & 73 & 943 & 1838 & 225 & 73 & 258 & 6.8 & 55 \\
\hline Arden & $12 / 29 / 1986$ & 6.8 & 176 & 76 & 1402 & 2327 & 237 & 76 & 251 & 7.7 & 59 \\
\hline Arden & $3 / 18 / 1987$ & 6.75 & 264 & 38 & 884 & 1703 & 155 & 53 & 204 & 4.9 & 39.5 \\
\hline Arden & $3 / 25 / 1987$ & 6.87 & 260 & 41 & 825 & 1657 & 162 & 49 & 209 & 5.2 & 45 \\
\hline Arden & 4/3/1987 & 6.72 & 273 & 25 & 800 & 1715 & 183 & 59 & 257 & 5.7 & 49 \\
\hline Arden & 4/9/1987 & 6.52 & 265 & 59 & 1100 & 1995 & 164 & 56 & 235 & 4.2 & 51 \\
\hline Arden & $4 / 15 / 1987$ & 7.11 & 171 & 71 & 1100 & 1927 & 187 & 61 & 238 & 4.6 & 53 \\
\hline Arden & $4 / 23 / 1987$ & 6.89 & 262 & 78 & 1125 & 2095 & & 61 & 254 & 5 & 59 \\
\hline Arden & $5 / 6 / 1987$ & 7.3 & 143 & 89 & 1100 & 1968 & 261 & 63 & 209 & 4.5 & 62 \\
\hline Arden & $5 / 13 / 1987$ & 6.6 & 219 & 114 & 1475 & 2506 & 230 & 72 & 264 & 5.8 & 74 \\
\hline Arden & $5 / 19 / 1987$ & 6.56 & 218 & 123 & 1375 & 2456 & 260 & 77 & 272 & 6.2 & 72 \\
\hline Arden & $6 / 3 / 1987$ & 6.52 & 201 & 114 & 1925 & 2991 & 243 & 86 & 300 & 6.4 & 67 \\
\hline Arden & $6 / 10 / 1987$ & 6.43 & 205 & 119 & 1510 & 2595 & 254 & 83 & 305 & 5.3 & 63 \\
\hline Arden & $6 / 16 / 1987$ & 6.58 & 231 & 114 & 1450 & 2593 & 264 & 88 & 319 & 5.6 & 65 \\
\hline Arden & $6 / 23 / 1987$ & 6.56 & 230 & 131 & 1550 & 2717 & 259 & 87 & 332 & 6.9 & 65 \\
\hline Arden & $7 / 2 / 1987$ & 6.59 & 194 & 116 & 1375 & 2440 & 248 & 83 & 308 & 6.6 & 62 \\
\hline Arden & 7/8/1987 & 6.51 & 129 & 133 & 1600 & 2612 & 253 & 85 & 306 & 6.5 & 66 \\
\hline Arden & $7 / 15 / 1987$ & 6.52 & 171 & 89 & 1662 & 2713 & 272 & 85 & 313 & 6.9 & 71 \\
\hline Arden & $7 / 22 / 1987$ & 6.88 & 160 & 134 & 1675 & 2799 & 282 & 94 & 332 & 7 & 74 \\
\hline Arden & $7 / 29 / 1987$ & 6.49 & 174 & 136 & 1504 & 2495 & & 78 & 256 & 5.7 & 38 \\
\hline Arden & $8 / 5 / 1987$ & 6.66 & 178 & 148 & 1554 & 2630 & & 80 & 290 & 6.4 & 69 \\
\hline Arden & $8 / 12 / 1987$ & 6.49 & 153 & 136 & 1512 & 2591 & 271 & 91 & 317 & 6.5 & 65 \\
\hline Arden & 8/18/1987 & 6.48 & 133 & 145 & 1574 & 2617 & 261 & 88 & 302 & 6.2 & 73 \\
\hline Arden & $8 / 26 / 1987$ & 6.44 & 152 & 140 & 1560 & 2618 & 261 & 87 & 284 & 6 & 89 \\
\hline Arden & $9 / 2 / 1987$ & 6.56 & 187 & 143 & 1536 & 2638 & 257 & 87 & 304 & 6.4 & 71 \\
\hline Arden & 9/9/1987 & 6.34 & 130 & 148 & 1660 & 2699 & 258 & 87 & 305 & 6.4 & 70 \\
\hline Arden & 9/16/1987 & 6.4 & 163 & 148 & 1342 & 2408 & 252 & 86 & 298 & 7.3 & 70 \\
\hline Arden & $10 / 7 / 1987$ & 6.59 & 161 & 151 & 1672 & 2759 & & 84 & 314 & 7.1 & 79 \\
\hline Arden & $10 / 13 / 1987$ & 6.36 & 160 & 162 & 1560 & 2654 & & 85 & 319 & 6.5 & 71 \\
\hline Arden & $10 / 21 / 1987$ & 6.54 & 96 & 143 & 1560 & 2565 & 252 & 85 & 324 & 6.3 & 72 \\
\hline Arden & $10 / 28 / 1987$ & 6.4 & 134 & 165 & 1580 & 2609 & 238 & 81 & 291 & 6 & 79 \\
\hline Arden & $11 / 5 / 1987$ & 6.71 & 149 & 165 & 1476 & 2495 & 230 & 79 & 277 & 5.6 & 75 \\
\hline Arden & $11 / 10 / 1987$ & 6.25 & 10 & 137 & 1559 & 2446 & & 85 & 316 & 6.1 & 75 \\
\hline Arden & $11 / 18 / 1987$ & 6.43 & 192 & 152 & 1624 & 2726 & 252 & 84 & 296 & 6.2 & 72 \\
\hline Arden & $11 / 24 / 1987$ & 6.63 & 208 & 151 & 1598 & 2709 & 246 & 82 & 291 & 6.2 & 75 \\
\hline Arden & $4 / 13 / 1988$ & 7.46 & 129 & 91 & 1172 & 2025 & 196 & 65.8 & 276 & 5.9 & 57 \\
\hline Arden & $4 / 20 / 1988$ & 6.64 & 171 & 94 & 1187 & 2143 & & 68.1 & 282 & 5.8 & 83 \\
\hline
\end{tabular}


Table I-1, Arden Mine-pool Raw Chemical Data

\begin{tabular}{|c|c|c|c|c|c|c|c|c|c|c|c|}
\hline Site & Date & $\mathrm{pH}$ & $\begin{array}{c}\text { Alkalinity, } \\
\mathrm{mg} / \mathrm{L}\end{array}$ & $\begin{array}{c}\mathrm{Fe}, \\
\mathrm{mg} / \mathrm{L}\end{array}$ & $\begin{array}{l}\mathrm{SO} 4, \\
\mathrm{mg} / \mathrm{L}\end{array}$ & $\begin{array}{l}\text { TDS, } \\
\mathrm{mg} / \mathrm{L}\end{array}$ & $\begin{array}{c}\mathrm{Ca}, \\
\mathrm{mg} / \mathrm{L}\end{array}$ & $\begin{array}{l}\mathrm{Mg}, \\
\mathrm{mg} / \mathrm{L}\end{array}$ & $\begin{array}{c}\mathrm{Na}, \\
\mathrm{mg} / \mathrm{L}\end{array}$ & $\begin{array}{c}\mathrm{K}, \\
\mathrm{mg} / \mathrm{L}\end{array}$ & $\begin{array}{c}\mathrm{Cl}, \\
\mathrm{mg} / \mathrm{L}\end{array}$ \\
\hline Arden & $4 / 27 / 1988$ & 6.77 & 199 & 108 & 1254 & 2280 & 221 & 72.1 & 293 & 6.3 & 78 \\
\hline Arden & $5 / 4 / 1988$ & 6.72 & 156 & 113 & 1340 & 2358 & & 77.2 & 311 & 6.5 & 84 \\
\hline Arden & $5 / 11 / 1988$ & 6.44 & 160 & 122 & 1461 & 2547 & 241 & 83.9 & 334 & 6.8 & 98 \\
\hline Arden & $5 / 18 / 1988$ & 6.74 & 202 & 134 & 1176 & 2310 & 243 & 82.7 & 316 & 6.4 & 100 \\
\hline Arden & $5 / 25 / 1988$ & 6.43 & 104 & 136 & 1597 & 2660 & 265 & 90 & 332 & 7 & 100 \\
\hline Arden & $6 / 2 / 1988$ & 6.64 & 168 & 151 & 1640 & 2819 & 264 & 91.2 & 350 & 7.1 & 105 \\
\hline Arden & $6 / 9 / 1988$ & 6.68 & 132 & 154 & 1687 & 2799 & 268 & 88.9 & 337 & 7 & 90 \\
\hline Arden & $6 / 15 / 1988$ & 6.67 & 127 & 163 & 1673 & 2812 & 276 & 91.5 & 351 & 7.2 & 89 \\
\hline Arden & $6 / 22 / 1988$ & 6.71 & 187 & 162 & 1714 & 2932 & 276 & 93.3 & 353 & 7.1 & 92 \\
\hline Arden & $6 / 29 / 1988$ & 6.62 & 164 & 137 & 1700 & 2848 & 274 & 91.9 & 347 & 7 & 85 \\
\hline Arden & $7 / 6 / 1988$ & 6.25 & 105 & 162 & 1711 & 2816 & 275 & 92.5 & 352 & 7.1 & 82 \\
\hline Arden & $7 / 20 / 1988$ & 6.38 & 117 & 151 & 1719 & 2856 & 275 & 92.8 & 357 & 7.3 & 105 \\
\hline Arden & $7 / 25 / 1988$ & 6.52 & 91 & 149 & 1634 & 2675 & 261 & 88.3 & 340 & 7 & 79 \\
\hline Arden & $8 / 3 / 1988$ & 6.79 & 173 & 154 & 1701 & 2860 & 269 & 88.6 & 333 & 6.9 & 90 \\
\hline Arden & $8 / 24 / 1988$ & 6.8 & 160 & 151 & 1754 & 2876 & 253 & 87.4 & 333 & 6.9 & 90 \\
\hline Arden & $9 / 2 / 1988$ & 6.8 & 106 & 187 & 1614 & 2712 & 261 & 86.4 & 332 & 6.9 & 89 \\
\hline Arden & 9/13/1988 & 6.44 & 91 & 154 & 1625 & 2663 & 254 & 86.9 & 334 & 6.9 & 85 \\
\hline Arden & 10/11/1988 & 6.69 & 131 & 137 & 1531 & 2577 & 243 & 83.3 & 331 & 6.8 & 80 \\
\hline Arden & 10/18/1988 & 6.84 & 167 & 148 & 1631 & 2784 & 254 & 87.7 & 351 & 7.1 & 96 \\
\hline Arden & 11/1/1988 & 6.45 & 75 & 162 & 1626 & 2665 & 254 & 87.8 & 350 & 7.1 & 81 \\
\hline Arden & $11 / 8 / 1988$ & 6.48 & 165 & 162 & 1611 & 2749 & 251 & 86.3 & 339 & 6.9 & 86 \\
\hline Arden & 11/15/1988 & 6.49 & 157 & 165 & 1581 & 2708 & 252 & 84.5 & 328 & 6.8 & 94 \\
\hline Arden & 12/1/1988 & 6.47 & 81 & 182 & 1753 & 2859 & 267 & 92.6 & 365 & 7.3 & 87 \\
\hline Arden & $12 / 6 / 1988$ & 6.87 & 129 & 162 & 1695 & 2838 & 263 & 95 & 356 & 7.1 & 96 \\
\hline Arden & $12 / 14 / 1988$ & 6.61 & 135 & 159 & 1680 & 2807 & 262 & 89.2 & 347 & 7 & 92 \\
\hline Arden & $12 / 20 / 1988$ & 6.4 & 60 & 148 & 1633 & 2659 & 258 & 87.6 & 349 & 7.1 & 97 \\
\hline Arden & $1 / 3 / 1989$ & 6.72 & 166 & 198 & 1802 & 3074 & 276 & 95.9 & 395 & 8 & 91 \\
\hline Arden & $4 / 11 / 1989$ & 6.66 & 218 & 106 & 1139 & 2134 & 197 & 63.7 & 293 & 6.1 & 60 \\
\hline Arden & 4/25/1989 & 7 & 168 & 123 & 1296 & 2267 & 204 & 66.6 & 304 & 6 & 58 \\
\hline Arden & $5 / 2 / 1989$ & 7.14 & 185 & 126 & 1293 & 2309 & 208 & 68.5 & 312 & 6.2 & 65 \\
\hline Arden & $5 / 9 / 1989$ & 6.78 & 204 & 134 & 1373 & 2417 & 217 & 70.1 & 310 & 6.3 & 53 \\
\hline Arden & $5 / 16 / 1989$ & 6.58 & 211 & 137 & 1482 & 2586 & 234 & 74.3 & 322 & 6.5 & 68 \\
\hline Arden & $5 / 23 / 1989$ & 6.42 & 164 & 136 & 1492 & 2544 & 234 & 77.5 & 338 & 6.8 & 55 \\
\hline Arden & $5 / 30 / 1989$ & 6.63 & 180 & 140 & 1536 & 2764 & 242 & 79 & 444 & 6.8 & 91 \\
\hline Arden & $6 / 13 / 1989$ & 6.4 & 74 & 106 & 1315 & 2111 & 222 & 74 & 293 & 6.1 & \\
\hline Arden & $6 / 20 / 1989$ & 6.59 & 187 & 150 & 1640 & 2740 & 264 & 83.3 & 362 & 7.2 & \\
\hline Arden & $6 / 27 / 1989$ & 6.49 & 165 & 143 & 1732 & 2825 & 262 & 86.6 & 387 & 7.4 & \\
\hline Arden & $7 / 5 / 1989$ & 6.41 & 152 & 134 & 1591 & 2606 & 250 & 81.2 & 352 & 7.2 & \\
\hline Arden & $7 / 11 / 1989$ & 6.67 & 102 & 109 & 1314 & 2153 & 224 & 70.3 & 300 & 6.3 & \\
\hline Arden & $7 / 25 / 1989$ & 6.02 & 22 & 127 & 1525 & 2342 & 237 & 77.2 & 337 & 6.9 & \\
\hline Arden & $8 / 1 / 1989$ & 6.4 & 187 & 131 & 1547 & 2569 & 237 & 78.7 & 335 & 6.9 & \\
\hline Arden & 8/8/1989 & 6.6 & 84 & 127 & 1521 & 2405 & 236 & 77 & 330 & 6.8 & \\
\hline Arden & $8 / 22 / 1989$ & 6.5 & 194 & 121 & 1439 & 2449 & 240 & 77.4 & 323 & 6.9 & \\
\hline Arden & $8 / 29 / 1989$ & 6.69 & 77 & 125 & 1433 & 2344 & 227 & 73.2 & 312 & 6.7 & \\
\hline Arden & $9 / 6 / 1989$ & 6.1 & 46 & 92 & 1426 & 2198 & 227 & 73.1 & 312 & 6.9 & \\
\hline Arden & 9/12/1989 & 6.76 & 180 & 123 & 1413 & 2376 & 226 & 72.5 & 310 & 6.6 & \\
\hline Arden & 9/19/1989 & 6.79 & 188 & 122 & 1456 & 2461 & 227 & 73.5 & 341 & 6.9 & \\
\hline Arden & 9/27/1989 & 6.66 & 183 & 121 & 1409 & 2359 & 223 & 71.5 & 299 & 7.2 & \\
\hline Arden & $10 / 10 / 1989$ & 6.6 & 181 & 124 & 1458 & 2439 & 233 & 74.7 & 317 & 6.7 & \\
\hline Arden & $10 / 17 / 1989$ & 6.57 & 72 & 119 & 1411 & 2229 & 231 & 76 & 293 & 6.3 & \\
\hline Arden & $10 / 24 / 1989$ & 6.3 & 172 & 129 & 1523 & 2527 & 243 & 78.2 & 332 & 6.9 & \\
\hline Arden & 11/1/1989 & 6.56 & 61 & 154 & 1537 & 2406 & 231 & 76.3 & 321 & 6.7 & \\
\hline
\end{tabular}


Table I-1, Arden Mine-pool Raw Chemical Data

\begin{tabular}{|c|c|c|c|c|c|c|c|c|c|c|c|}
\hline Site & Date & $\mathrm{pH}$ & $\begin{array}{c}\text { Alkalinity, } \\
\mathrm{mg} / \mathrm{L}\end{array}$ & $\begin{array}{c}\mathrm{Fe}, \\
\mathrm{mg} / \mathrm{L}\end{array}$ & $\begin{array}{l}\mathrm{SO} 4, \\
\mathrm{mg} / \mathrm{L}\end{array}$ & $\begin{array}{l}\text { TDS, } \\
\mathrm{mg} / \mathrm{L}\end{array}$ & $\begin{array}{c}\mathrm{Ca}, \\
\mathrm{mg} / \mathrm{L}\end{array}$ & $\begin{array}{c}\mathrm{Mg}, \\
\mathrm{mg} / \mathrm{L}\end{array}$ & $\begin{array}{c}\mathrm{Na}, \\
\mathrm{mg} / \mathrm{L}\end{array}$ & $\begin{array}{c}\mathrm{K}, \\
\mathrm{mg} / \mathrm{L}\end{array}$ & $\begin{array}{c}\mathrm{Cl}, \\
\mathrm{mg} / \mathrm{L}\end{array}$ \\
\hline Arden & 11/7/1989 & 6.43 & 108 & 88 & 1005 & 1858 & 234 & 75.9 & 312 & 6.6 & \\
\hline Arden & 11/13/1989 & 6.64 & 75 & 125 & 1005 & 1862 & 237 & 76.4 & 315 & 6.8 & \\
\hline Arden & $11 / 21 / 1989$ & 6.38 & 100 & 136 & 1622 & 2558 & 244 & 79.7 & 342 & 7.1 & \\
\hline Arden & $12 / 1 / 1989$ & 6.5 & 155 & 121 & 1482 & 2417 & 228 & 74.3 & 311 & 6.7 & \\
\hline Arden & $12 / 5 / 1989$ & 6.79 & 164 & 126 & 1444 & 2389 & 226 & 73.2 & 308 & 6.5 & \\
\hline Arden & $12 / 12 / 1989$ & 6.42 & 156 & 122 & 1457 & 2393 & 226 & 73.8 & 312 & 6.5 & \\
\hline Arden & $1 / 2 / 1990$ & 6.47 & 180 & 130 & 1542 & 2551 & 240 & 77.9 & 329 & 6.9 & \\
\hline Arden & $1 / 9 / 1990$ & 6.83 & 148 & 127 & 1537 & 2502 & 238 & 77.6 & 330 & 6.9 & \\
\hline Arden & $1 / 16 / 1990$ & 6.49 & 185 & 133 & 1595 & 2640 & 247 & 84 & 343 & 7.2 & \\
\hline Arden & $1 / 23 / 1990$ & 6.53 & 179 & 128 & 1530 & 2538 & 242 & 76.1 & 332 & 6.9 & \\
\hline Arden & $2 / 2 / 1990$ & 6.59 & 189 & 131 & 1504 & 2510 & 233 & 75.8 & 324 & 6.7 & \\
\hline Arden & $2 / 6 / 1990$ & 6.16 & 161 & 134 & 1455 & 2414 & 213 & 74.3 & 330 & 6.7 & \\
\hline Arden & $2 / 13 / 1990$ & 6.31 & 163 & 130 & 1546 & 2530 & 239 & 77.8 & 327 & 6.6 & \\
\hline Arden & $2 / 20 / 1990$ & 6.5 & 129 & 129 & 1504 & 2430 & 241 & 75.2 & 312 & 6.5 & \\
\hline Arden & $3 / 1 / 1990$ & 6.49 & 159 & 133 & 1534 & 2519 & 239 & 77.2 & 330 & 6.9 & \\
\hline Arden & $3 / 6 / 1990$ & 6.37 & 184 & 133 & 1544 & 2564 & 239 & 77.5 & 334 & 6.8 & \\
\hline Arden & $3 / 13 / 1990$ & 6.46 & 141 & 129 & 1500 & 2450 & 233 & 76.1 & 328 & 6.8 & \\
\hline Arden & $3 / 27 / 1990$ & 6.71 & 139 & 131 & 1491 & 2429 & 231 & 74.7 & 320 & 6.7 & \\
\hline Arden & $4 / 10 / 1990$ & 6.62 & 173 & 126 & 1429 & 2382 & 223 & 71.3 & 311 & 6.3 & \\
\hline Arden & $4 / 17 / 1990$ & 6.84 & 95 & 137 & 1517 & 2424 & 232 & 75 & 335 & 6.7 & \\
\hline Arden & $4 / 24 / 1990$ & 6.44 & 138 & 131 & 1521 & 2479 & 232 & 75.6 & 339 & 6.8 & \\
\hline Arden & $5 / 1 / 1990$ & 6.31 & 66 & 129 & 1487 & 2346 & 232 & 74.5 & 331 & 6.9 & \\
\hline Arden & $5 / 8 / 1990$ & 6.72 & 176 & 127 & 1448 & 2421 & 226 & 72.3 & 322 & 6.5 & \\
\hline Arden & $5 / 15 / 1990$ & 6.58 & 176 & 130 & 1502 & 2501 & 231 & 74.9 & 337 & 6.7 & \\
\hline Arden & $5 / 22 / 1990$ & 6.46 & 163 & 128 & 1494 & 2471 & 229 & 74.3 & 335 & 6.5 & \\
\hline Arden & $5 / 29 / 1990$ & 6.42 & 92 & 127 & 1476 & 2360 & 230 & 73.7 & 330 & 6.6 & \\
\hline Arden & $6 / 5 / 1990$ & 6.68 & 183 & 129 & 1493 & 2504 & 237 & 75.2 & 335 & 6.8 & \\
\hline Arden & $6 / 12 / 1990$ & 5.98 & 6 & 126 & 1464 & 2262 & 246 & 74.2 & 333 & 7 & \\
\hline Arden & $6 / 19 / 1990$ & 6.54 & 140 & 126 & 1421 & 2348 & 222 & 70.6 & 326 & 6.6 & \\
\hline Arden & $6 / 26 / 1990$ & 6.44 & 140 & 131 & 1500 & 2460 & 227 & 74.5 & 345 & 6.7 & \\
\hline Arden & $8 / 7 / 1990$ & 6.63 & 187 & 98 & 1246 & 2250 & 215 & 73 & 302 & 6.3 & 78 \\
\hline Arden & $8 / 14 / 1990$ & 6.51 & 196 & 112 & 1345 & 2318 & 212 & 68 & 331 & 6.6 & \\
\hline Arden & $8 / 21 / 1990$ & 6.64 & 178 & 103 & 1222 & 2109 & 192 & 62 & 303 & 5.7 & \\
\hline Arden & $8 / 28 / 1990$ & 6.77 & 179 & 127 & 1505 & 2533 & 232 & 75.8 & 363 & 7.2 & \\
\hline Arden & $9 / 4 / 1990$ & 5.52 & 157 & 119 & 1392 & 2333 & 215 & 70 & 334 & 6.6 & \\
\hline Arden & 9/11/1990 & 6.42 & 186 & 115 & 1354 & 2309 & 209 & 67.8 & 326 & 6.4 & \\
\hline Arden & 9/18/1990 & 6.5 & 136 & 115 & 1344 & 2230 & 206 & 67.2 & 321 & 6.4 & \\
\hline Arden & 9/25/1990 & 6.19 & 116 & 137 & 1650 & 2660 & 250 & 81.5 & 387 & 7.4 & \\
\hline Arden & $10 / 2 / 1990$ & 6.37 & 263 & 117 & 1407 & 2463 & 212 & 68.8 & 327 & 6.2 & \\
\hline Arden & $10 / 16 / 1990$ & 6.83 & 158 & 116 & 1387 & 2342 & 233 & 70 & 332 & 6.5 & \\
\hline Arden & $10 / 23 / 1990$ & 6.98 & 375 & 121 & 1414 & 2652 & 243 & 77 & 329 & 6.4 & \\
\hline Arden & $10 / 30 / 1990$ & 6.62 & 158 & 118 & 1404 & 2350 & 218 & 69.7 & 337 & 6.5 & \\
\hline Arden & $11 / 6 / 1990$ & 6.73 & 96 & 120 & 1443 & 2332 & 224 & 71.9 & 345 & 6.5 & \\
\hline Arden & $11 / 13 / 1990$ & 6.53 & 241 & 112 & 1372 & 2398 & 214 & 68 & 327 & 6.3 & \\
\hline Arden & $11 / 20 / 1990$ & 6.05 & 73 & 116 & 1425 & 2271 & 221 & 72 & 337 & 6.5 & \\
\hline Arden & $11 / 28 / 1990$ & 5.78 & 70 & 113 & 1372 & 2195 & 220 & 67.9 & 326 & 6.3 & \\
\hline Arden & $12 / 4 / 1990$ & 6.5 & 137 & 108 & 1330 & 2215 & 206 & 66 & 327 & 6.3 & \\
\hline Arden & $12 / 11 / 1990$ & 6.47 & 164 & 114 & 1474 & 2318 & 213 & 68 & 338 & 6.5 & \\
\hline Arden & $1 / 15 / 1991$ & 6.52 & 178 & 104 & 1294 & 2213 & 204 & 64.9 & 319 & 6.2 & \\
\hline Arden & $1 / 29 / 1991$ & 6.31 & 162 & 106 & 1294 & 2222 & 231 & 65.2 & 318 & 6.2 & \\
\hline Arden & 2/12/1991 & 6.46 & 139 & 103 & 1275 & 2137 & 200 & 63.4 & 316 & 6.1 & \\
\hline Arden & 2/26/1991 & 6.31 & 164 & 113 & 1285 & 2209 & 219 & 67.4 & 314 & 6.2 & \\
\hline
\end{tabular}


Table I-1, Arden Mine-pool Raw Chemical Data

\begin{tabular}{|c|c|c|c|c|c|c|c|c|c|c|c|}
\hline Site & Date & $\mathrm{pH}$ & $\begin{array}{c}\text { Alkalinity, } \\
\text { mg/L }\end{array}$ & $\begin{array}{l}\mathrm{Fe}, \\
\mathrm{mg} / \mathrm{L}\end{array}$ & $\begin{array}{l}\mathrm{SO} 4, \\
\mathrm{mg} / \mathrm{L}\end{array}$ & $\begin{array}{l}\text { TDS, } \\
\mathrm{mg} / \mathrm{L}\end{array}$ & $\begin{array}{l}\mathrm{Ca}, \\
\mathrm{mg} / \mathrm{L}\end{array}$ & $\begin{array}{l}\mathrm{Mg}, \\
\mathrm{mg} / \mathrm{L}\end{array}$ & $\begin{array}{l}\mathrm{Na}, \\
\mathrm{mg} / \mathrm{L}\end{array}$ & $\begin{array}{c}\mathrm{K}, \\
\mathrm{mg} / \mathrm{L}\end{array}$ & $\begin{array}{c}\mathrm{Cl}, \\
\mathrm{mg} / \mathrm{L}\end{array}$ \\
\hline Arden & $3 / 12 / 1991$ & 6.31 & 67 & 73 & 1205 & 1935 & 193 & 63.7 & 309 & 6 & \\
\hline Arden & $3 / 26 / 1991$ & 6.45 & 126 & 100 & 1226 & 2063 & 195 & 65 & 314 & 6.1 & \\
\hline Arden & 4/9/1991 & 6.17 & 100 & 97 & 1193 & 1992 & 190 & 64.2 & 316 & 6.2 & \\
\hline Arden & 4/23/1991 & 6.28 & 146 & 95 & 1194 & 2037 & 190 & 62.6 & 308 & 6.1 & \\
\hline Arden & $5 / 14 / 1991$ & 6.52 & 137 & 94 & 1209 & 2051 & 190 & 64 & 317 & 6.1 & \\
\hline Arden & $5 / 28 / 1991$ & 6.58 & 117 & 90 & 1156 & 1945 & 182 & 61.1 & 304 & 5.8 & \\
\hline Arden & $6 / 11 / 1991$ & 6.45 & 170 & 94 & 1234 & 2131 & 206 & 64.6 & 315 & 6.1 & \\
\hline Arden & $6 / 25 / 1991$ & 6.48 & 141 & 90 & 1176 & 1991 & 180 & 61.2 & 303 & 5.7 & \\
\hline Arden & 7/9/1991 & 6.57 & 178 & 90 & 1168 & 2030 & 184 & 61.2 & 301 & 5.8 & \\
\hline Arden & $7 / 23 / 1991$ & 6.8 & 191 & 92 & 1122 & 2022 & 185 & 63 & 318 & 6.1 & \\
\hline Arden & 8/1/1991 & 6.64 & 169 & 90 & 1190 & 2047 & 185 & 62.5 & 304 & 5.8 & \\
\hline Arden & 8/13/1991 & 6.64 & 215 & 101 & 1257 & 2256 & 231 & 67.8 & 327 & 6.2 & \\
\hline Arden & $9 / 3 / 1991$ & 6.54 & 199 & 98 & 1230 & 2184 & 211 & 66.5 & 326 & 6.1 & \\
\hline Arden & 9/18/1991 & 7.02 & 158 & 97 & 1267 & 2166 & 201 & 67.4 & 331 & 6.3 & \\
\hline Arden & 10/8/1991 & 6.41 & 122 & 104 & 1320 & 2207 & 204 & 70.1 & 350 & 6.6 & \\
\hline Arden & 10/22/1991 & 6.08 & 113 & 102 & 1328 & 2201 & 206 & 70 & 347 & 6.6 & \\
\hline Arden & 11/1/1991 & 6.76 & 131 & 101 & 1326 & 2211 & 202 & 69.5 & 343 & 6.3 & \\
\hline Arden & 11/19/1991 & 6.8 & 181 & 101 & 1320 & 2272 & 203 & 69.9 & 347 & 6.4 & \\
\hline Arden & 12/4/1991 & 6.5 & 54 & 102 & 1334 & 2138 & 205 & 70.3 & 351 & 6.3 & \\
\hline Arden & $12 / 10 / 1991$ & 5.77 & 70 & 104 & 1369 & 2217 & 207 & 72.4 & 369 & 6.6 & \\
\hline Arden & $1 / 8 / 1992$ & 6.48 & 129 & 106 & 1369 & 2298 & 214 & 72.7 & 368 & 6.7 & \\
\hline Arden & $2 / 11 / 1992$ & 6.39 & 200 & 115 & 1425 & 2482 & 236 & 74.2 & 377 & 6.6 & \\
\hline Arden & $2 / 25 / 1992$ & 6.7 & 175 & 108 & 1431 & 2430 & 215 & 74 & 378 & 6.6 & \\
\hline Arden & 3/10/1992 & 7.06 & 110 & 109 & 1377 & 2275 & 213 & 71 & 361 & 6.4 & \\
\hline Arden & $3 / 17 / 1992$ & 6.75 & 185 & 110 & 1418 & 2429 & 221 & 73.1 & 371 & 6.4 & \\
\hline Arden & $4 / 8 / 1992$ & 6.03 & 46 & 100 & 1285 & 2068 & 202 & 66.9 & 348 & 6.3 & \\
\hline Arden & $4 / 21 / 1992$ & 6.64 & 45 & 106 & 1378 & 2207 & 208 & 79 & 371 & 6.5 & \\
\hline Arden & $5 / 5 / 1992$ & 6.34 & 120 & 108 & 1390 & 2291 & 215 & 71.3 & 350 & 6.5 & \\
\hline Arden & $5 / 19 / 1992$ & 6.88 & 168 & 110 & 1410 & 2381 & 217 & 72.1 & 356 & 6.6 & \\
\hline Arden & $6 / 9 / 1992$ & 6.71 & 100 & 106 & 1357 & 2234 & 205 & 69.9 & 364 & 6.3 & \\
\hline Arden & $6 / 16 / 1992$ & 6.35 & 150 & 108 & 1378 & 2337 & 211 & 71.9 & 375 & 6.6 & \\
\hline Arden & 7/15/1992 & 6.41 & 208 & 104 & 1352 & 2365 & 204 & 74 & 367 & 6.5 & \\
\hline Arden & $8 / 11 / 1992$ & 6.54 & 214 & 94 & 1241 & 2201 & 190 & 65.1 & 340 & 6 & \\
\hline Arden & $8 / 26 / 1992$ & 6.77 & 202 & 98 & 1356 & 2361 & 202 & 73 & 375 & 6.6 & \\
\hline Arden & 9/8/1992 & 6.6 & 182 & 103 & 1358 & 2331 & 200 & 69.4 & 369 & 6.4 & \\
\hline Arden & 9/23/1992 & 6.9 & 155 & 101 & 1322 & 2249 & 201 & 68 & 358 & 6.3 & \\
\hline Arden & 10/6/1992 & 6.91 & 44 & 103 & 1352 & 2172 & 205 & 69.3 & 379 & 6.6 & \\
\hline Arden & 10/11/1992 & 6.85 & 176 & 99 & 1325 & 2288 & 199 & 68.3 & 372 & 6.4 & \\
\hline Arden & $11 / 17 / 1992$ & 7.05 & 197 & 110 & 1306 & 2297 & 203 & 66.7 & 361 & 6.4 & \\
\hline Arden & $12 / 8 / 1992$ & 6.67 & 180 & 98 & 1260 & 2200 & 194 & 64.7 & 354 & 6.1 & \\
\hline Arden & $12 / 15 / 1992$ & 6.35 & 192 & 94 & 1238 & 2181 & 191 & 64.4 & 350 & 6.1 & \\
\hline Arden & $1 / 12 / 1993$ & 6.71 & 173 & 98 & 1312 & 2257 & 195 & 66.8 & 364 & 6.4 & \\
\hline Arden & $4 / 20 / 1993$ & 7.04 & 171 & 91 & 1222 & 2121 & 190 & 62.2 & 338 & 6.1 & \\
\hline Arden & $5 / 18 / 1993$ & 6.86 & 194 & 89 & 1197 & 2116 & 181 & 61.3 & 342 & 6.1 & \\
\hline Arden & $7 / 6 / 1993$ & 6.76 & 116 & 84 & 1141 & 1936 & 175 & 59 & 327 & 5.8 & \\
\hline Arden & 9/14/1993 & 6.85 & 85 & 77 & 1057 & 1790 & 171 & 56 & 316 & 6.4 & \\
\hline Arden & 10/19/1993 & 6.69 & 181 & 85 & 1193 & 2102 & 180 & 67 & 347 & 6.2 & \\
\hline Arden & 11/24/1993 & 6.8 & 154 & 76 & 1051 & 1853 & 168 & 55.6 & 306 & 5.5 & \\
\hline Arden & 12/7/1993 & 6.67 & 203 & 82 & 1100 & 2005 & 171 & 58.3 & 337 & 5.9 & \\
\hline Arden & $1 / 26 / 1994$ & 7.09 & 110 & 72 & 1689 & 2430 & 155 & 49.7 & & 9.1 & \\
\hline Arden & 2/13/1994 & 7.09 & 158 & 89 & 1245 & 2149 & 188 & 63.5 & 361 & 6.4 & \\
\hline Arden & 3/22/1994 & 6.64 & 215 & 89 & 1218 & 2195 & 184 & 63.9 & 368 & 6.5 & \\
\hline
\end{tabular}


Table I-1, Arden Mine-pool Raw Chemical Data

\begin{tabular}{|c|c|c|c|c|c|c|c|c|c|c|c|}
\hline Site & Date & $\mathrm{pH}$ & $\begin{array}{c}\text { Alkalinity, } \\
\text { mg/L }\end{array}$ & $\begin{array}{l}\mathrm{Fe}, \\
\mathrm{mg} / \mathrm{L}\end{array}$ & $\begin{array}{l}\mathrm{SO} 4, \\
\mathrm{mg} / \mathrm{L}\end{array}$ & $\begin{array}{l}\text { TDS, } \\
\mathrm{mg} / \mathrm{L}\end{array}$ & $\begin{array}{l}\mathrm{Ca}, \\
\mathrm{mg} / \mathrm{L}\end{array}$ & $\begin{array}{l}\mathrm{Mg}, \\
\mathrm{mg} / \mathrm{L}\end{array}$ & $\begin{array}{l}\mathrm{Na}, \\
\mathrm{mg} / \mathrm{L}\end{array}$ & $\begin{array}{c}\mathrm{K}, \\
\mathrm{mg} / \mathrm{L}\end{array}$ & $\begin{array}{c}\mathrm{Cl}, \\
\mathrm{mg} / \mathrm{L}\end{array}$ \\
\hline Arden & $4 / 12 / 1994$ & 6.31 & 81 & 93 & 1228 & 2147 & 195 & 80 & 416 & 28.9 & \\
\hline Arden & $5 / 3 / 1994$ & 6.51 & 200 & 79 & 1096 & 1964 & 167 & 55.6 & 314 & 5.6 & \\
\hline Arden & 7/6/1994 & 6.78 & 159 & 77 & 1027 & 1845 & 166 & 54.8 & 318 & 5.8 & \\
\hline Arden & $9 / 12 / 1994$ & 6.41 & 188 & 70 & 928 & 1723 & 157 & 50.2 & 281 & 5.1 & \\
\hline Arden & $10 / 11 / 1994$ & 6.14 & 113 & 73 & 1030 & 1770 & 164 & 53.4 & 304 & 5.6 & \\
\hline Arden & $11 / 23 / 1994$ & 6.16 & 115 & 74 & 1030 & 1787 & 167 & 53.6 & 314 & 5.6 & \\
\hline Arden & $12 / 23 / 1994$ & 6.49 & 207 & 82 & 1190 & 2118 & 184 & 60.1 & 340 & 6.4 & \\
\hline Arden & $1 / 25 / 1995$ & 6.04 & 90 & 77 & 1090 & 1841 & 174 & 55.9 & 326 & 5.8 & \\
\hline Arden & 2/21/1995 & 6.4 & 193 & 74 & 1040 & 1888 & 170 & 53.2 & 307 & 5.6 & \\
\hline Arden & 3/29/1995 & 6.27 & 160 & 77 & 1090 & 1928 & 171 & 56.7 & 330 & 5.9 & \\
\hline Arden & $5 / 30 / 1995$ & 6.18 & 144 & 74 & 1040 & 1826 & 166 & 53.1 & 310 & 5.4 & \\
\hline Arden & $6 / 27 / 1995$ & 6.18 & 102 & 72 & 1030 & 1766 & 166 & 53.6 & 312 & 5.7 & \\
\hline Arden & $7 / 25 / 1995$ & 6.28 & 130 & 63 & 907 & 1617 & 151 & 48.4 & 282 & 5.2 & \\
\hline Arden & $8 / 1 / 1995$ & 6.19 & 138 & 67 & 923 & 1674 & 164 & 49.7 & 294 & 5.4 & \\
\hline Arden & 9/5/1995 & 6.25 & 110 & 76 & 1070 & 1842 & 172 & 55.5 & 327 & 5.8 & \\
\hline Arden & 10/10/1995 & 6.44 & 181 & 79 & 1130 & 2015 & 176 & 57.4 & 344 & 6.1 & \\
\hline Arden & 11/7/1995 & 6.2 & 98 & 54 & 1075 & 1812 & & & & & \\
\hline Arden & 12/26/1995 & 7.2 & 115 & 69 & 887 & 1660 & & & & & \\
\hline Arden & $1 / 2 / 1996$ & 7 & 109 & 70 & 962 & 1729 & & & & & \\
\hline Arden & $8 / 5 / 1996$ & 7 & 157 & 58 & 900 & 1713 & & & & & \\
\hline Arden & 9/9/1996 & 6.6 & 128 & 63 & 950 & 1733 & & & & & \\
\hline Arden & $10 / 7 / 1996$ & 6.6 & 111 & 63 & 875 & 1636 & & & & & \\
\hline Arden & $11 / 4 / 1996$ & 6.6 & 119 & 58 & 938 & 1705 & & & & & \\
\hline Arden & 12/2/1996 & 6.3 & 109 & 64 & 925 & 1685 & & & & & \\
\hline Arden & $1 / 20 / 1997$ & 6.3 & 125 & 67 & 963 & 1746 & & & & & \\
\hline Arden & $2 / 3 / 1997$ & 6.1 & 106 & 72 & 950 & 1715 & & & & & \\
\hline Arden & $3 / 3 / 1997$ & 6.1 & 108 & 68 & 925 & 1689 & & & & & \\
\hline Arden & $5 / 5 / 1997$ & 6.3 & 139 & 59 & 850 & 1642 & & & & & \\
\hline Arden & $6 / 2 / 1997$ & 7.3 & 130 & 65 & 875 & 1663 & & & & & \\
\hline Arden & $8 / 11 / 1997$ & 6.3 & 125 & 65 & 838 & 1619 & & & & & \\
\hline Arden & 9/1/1997 & 6.9 & 121 & 64 & 825 & 1601 & & & & & \\
\hline Arden & 10/6/1997 & 6.6 & 124 & 58 & 775 & 1548 & & & & & \\
\hline Arden & $11 / 3 / 1997$ & 6.4 & 128 & 66 & 800 & 1586 & & & & & \\
\hline Arden & 12/8/1997 & 6.3 & 141 & 43 & 863 & 1642 & & & & & \\
\hline Arden & $1 / 5 / 1998$ & 6.3 & 130 & 71 & 900 & 1693 & & & & & \\
\hline Arden & 2/2/1998 & 6.4 & 127 & 75 & 1000 & 1794 & & & & & \\
\hline Arden & $3 / 2 / 1998$ & 6.8 & 137 & 76 & 913 & 1720 & & & & & \\
\hline Arden & $5 / 4 / 1998$ & 6.9 & 160 & 61 & 775 & 1594 & & & & & \\
\hline Arden & $6 / 2 / 1998$ & 8.2 & 146 & 67 & 888 & 1697 & & & & & \\
\hline Arden & $7 / 13 / 1998$ & 6.6 & 157 & 73 & 970 & 1798 & & & & & \\
\hline Arden & 9/14/1998 & 6.9 & 159 & 57 & 838 & 1653 & & & & & \\
\hline Arden & $10 / 5 / 1998$ & 7.8 & 138 & 34 & 725 & 1491 & & & & & \\
\hline Arden & $11 / 3 / 1998$ & 6.5 & 146 & 78 & 963 & 1783 & & & & & \\
\hline Arden & 1/5/1999 & 7.1 & 163 & 60 & 875 & 1697 & & & & & \\
\hline Arden & 2/1/1999 & 6.7 & 164 & 73 & 788 & 1625 & & & & & \\
\hline
\end{tabular}


$\underline{\text { Appendix J }}$

PHREEQCI Files 
PHREEQCI Input Files

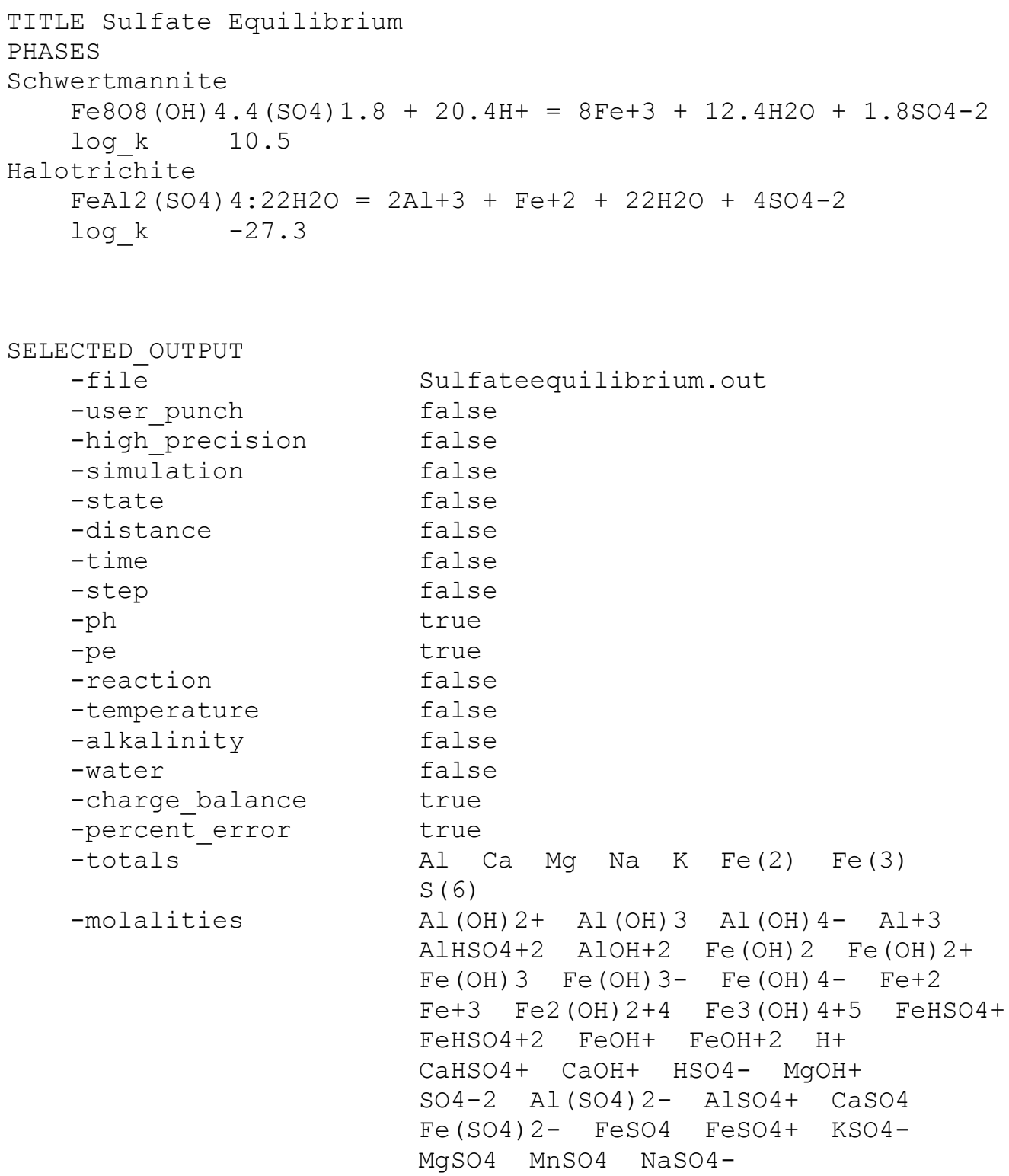




\section{PHREEQCI Input Files}

-saturation_indices
AlumK Basaluminite Chlorite14A Fe(OH) $3(\mathrm{a})$ Fe3 $(\mathrm{OH}) 8$ Gibbsite Gypsum Halotrichite Jarosite(ss) JarositeH Jarosite-K Jarosite-Na Jurbanite Kaolinite Melanterite Schwertmannite Al $(\mathrm{OH}) 3(\mathrm{a})$ Goethite

false

SOLUTION SPREAD

$\begin{array}{ll}\text {-pe } & 0 \\ \text {-units } & \mathrm{mg} / \mathrm{I}\end{array}$

Description Number Temperature $\mathrm{pH} \quad \mathrm{Al} \quad \mathrm{Ca} \quad \mathrm{Cl} \quad \mathrm{K} \quad \mathrm{Mg} \quad \mathrm{Mn} \quad \mathrm{Na} \quad \mathrm{S}(6)$

$\begin{array}{cr}\text { Hahn Early } & 1 \\ \text { Hahn Late } & 2 \\ \text { Omega Early } & 3 \\ \text { Omega Late } & 4 \\ \text { Omega } 2008 & 5 \\ \text { Arden } 1989 & 6 \\ \text { Arden } 1996 & 7 \\ \text { T\&T } 1994 & 8 \\ \text { T\&T 2008 } & 9 \\ \text { B\&T 2005 } & 10\end{array}$
$\mathrm{mg} / \mathrm{l} \mathrm{mg} / \mathrm{l} \mathrm{mg} / \mathrm{l} \mathrm{mg} / \mathrm{l} \mathrm{mg} / \mathrm{l} \mathrm{mg} / \mathrm{l} \mathrm{mg} / \mathrm{l} \mathrm{mg} / \mathrm{l}$

Si Fe Alkalinity pe $\mathrm{mg} / \mathrm{l}$

$20 \quad 1082 \quad 0$

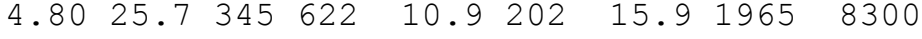
$\begin{array}{llllllll}7.09 & 0.21 & 158 & 6.4 & 57 & 1.7 & 979 & 1838\end{array}$ $\begin{array}{llllllllll}2.86 & 167 & 321 & 5 & 5.7 & 168 & 5.32 & 8.3 & 4098\end{array}$ $\begin{array}{lllllllll}3.03 & 176 & 318 & 28.8 & 14 & 132 & 6.14 & 20.5 & 3796\end{array}$ $\begin{array}{lllllllll}2.43 & 112 & 162 & 40 & 6.9 & 56.6 & 2.65 & 10.8 & 1923\end{array}$ $\begin{array}{lllllllll}6.72 & .2 & 276 & 91 & 8 & 95.9 & 6.16 & 395 & 1802\end{array}$ $\begin{array}{lllllllll}7.0 & .2 & 150 & 60 & 5.5 & 50 & 1.9 & 310 & 900\end{array}$ $\begin{array}{lllllllll}2.4 & 90 & 287 & 5.6 & 2.3 & 68.4 & 3.1 & 5.6 & 1910\end{array}$ $\begin{array}{lllllllll}2.7 & 23.4 & 152 & 6 & 2.4 & 37.5 & 1.17 & 6 & 840\end{array}$

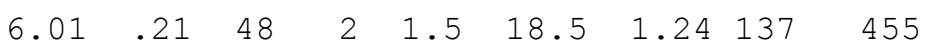

10
20
20
43
10
10
20
14
9

118

905 404

716.7 258

END

TITLE Equilibrate with Gypsum Hahn Early

USE solution 1

EQUILIBRIUM PHASES 1

END

$$
\text { Gypsum } 010
$$

TITLE Equilibrate Gypsum Hahn Late

USE solution 2

EQUILIBRIUM PHASES 1

$$
\text { Gypsum - } 010
$$

END

TITLE Equilibrate Gypsum Omega Early

USE solution 3

EQUILIBRIUM PHASES 1

END

$$
\text { Gypsum - } 010
$$

TITLE Equilibrate Gypsum Omega Late

USE solution 4

EQUILIBRIUM_PHASES 1 
PHREEQCI Input Files

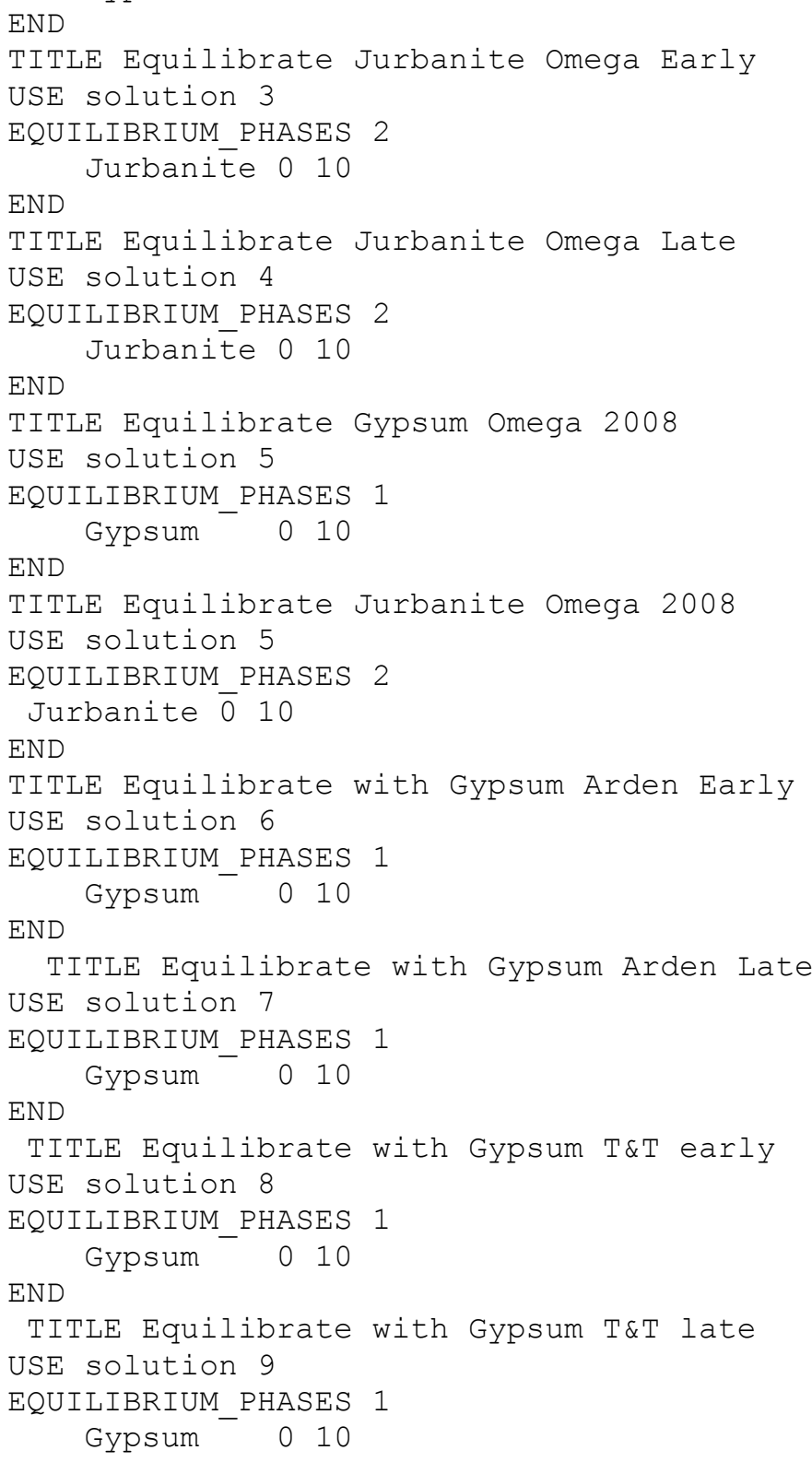




\section{PHREEQCI Input Files}

END

TITLE Equilibrate with Gypsum B\&T Late USE solution 10

EQUILIBRIUM_PHASES 1

END

Gypsum - 010

TITLE Equilibrate with Fe(OH) 3 Hahn Early USE solution 1

EQUILIBRIUM PHASES 1 $\mathrm{Fe}(\mathrm{OH}) 3 \overline{(a}) \quad 0 \quad 10$

END

TITLE Equilibrate with $\mathrm{Fe}(\mathrm{OH}) 3$ Hahn Late USE solution 2

EQUILIBRIUM PHASES 2 $\mathrm{Fe}(\mathrm{OH}) 3 \overline{(a)} \quad 0 \quad 10$

END

TITLE Equilibrate Fe(OH) 3 Omega Early

USE solution 3

EQUILIBRIUM PHASES 3

$\mathrm{Fe}(\mathrm{OH}) 3 \overline{(a)} \quad 0 \quad 10$

END

TITLE Equilibrate Fe $(\mathrm{OH}) 3$ Omega Late

USE solution 4

EQUILIBRIUM PHASES 4

$\mathrm{Fe}(\mathrm{OH}) 3 \overline{(a)} \quad 0 \quad 10$

END

TITLE Equilibrate $\mathrm{Fe}(\mathrm{OH}) 3$ Omega 2008

USE solution 5

EQUILIBRIUM PHASES 2

$\mathrm{Fe}(\mathrm{OH}) 3(\mathrm{a})$ - 010

END

TITLE Equilibrate with Fe(OH) 3 Arden Early USE solution 6

EQUILIBRIUM PHASES 1 $\mathrm{Fe}(\mathrm{OH}) \overline{3}(\mathrm{a}) \quad 0 \quad 10$

END

TITLE Equilibrate with Fe(OH) 3 Arden Late USE solution 7

EQUILIBRIUM PHASES 1 $\mathrm{Fe}(\mathrm{OH}) \overline{3}(\mathrm{a}) \quad 0 \quad 10$

END 
PHREEQCI Input Files

TITLE Equilibrate with Fe(OH) 3 T\&T early USE solution 8

EQUILIBRIUM PHASES 1 $\mathrm{Fe}(\mathrm{OH}) \overline{3}(\mathrm{a}) \quad 0 \quad 10$

END

TITLE Equilibrate with $\mathrm{Fe}(\mathrm{OH}) 3 \mathrm{~T} \& \mathrm{~T}$ late USE solution 9

EQUILIBRIUM PHASES 1 $\mathrm{Fe}(\mathrm{OH}) 3 \overline{(a)} \quad 0 \quad 10$

END

TITLE Equilibrate with Fe(OH) 3 B\&T late USE solution 10

EQUILIBRIUM PHASES 1 $\mathrm{Fe}(\mathrm{OH}) 3 \overline{(a)} \quad 0 \quad 10$

END

TITLE Equilibrate Hahn Early with Pyrite USE solution 1

EQUILIBRIUM_PHASES 3
Pyrite
010

END

TITLE Equilibrate Hahn Late with Pyrite

USE solution 2

EQUILIBRIUM_PHASES 4

Pyrite ${ }^{-} 010$

END

TITLE Equilibrate Omega Early with Pyrite

USE solution 3

EQUILIBRIUM_PHASES 5

Pyrite ${ }^{-} 010$

END

TITLE Equilibrate Omega Late with Pyrite USE solution 4

EQUILIBRIUM PHASES 6

Pyrite ${ }^{-} 010$

END

TITLE Equilibrate Omega 2008 with Pyrite

USE solution 5

EQUILIBRIUM_PHASES 6

Pyrite $\quad 010$

END 
PHREEQCI Input Files

TITLE Equilibrate Arden 1989 with Pyrite USE solution 6

EQUILIBRIUM PHASES 7

$$
\text { Pyrite } 010
$$

END

TITLE Equilibrate Arden 1996 with Pyrite USE solution 7

EQUILIBRIUM PHASES 8

END
Pyrite
010

TITLE Equilibrate T\&T 1994 with Pyrite

USE solution 8

EQUILIBRIUM PHASES 9

END
Pyrite
010

TITLE Equilibrate T\&T 2008 with Pyrite

USE solution 9

EOUILIBRIUM PHASES 10
Pyrite
010

END

TITLE Equilibrate B\&T 2005 with Pyrite

USE solution 10

EQUILIBRIUM PHASES 11

END
Pyrite
010

TITLE Equilibrate Jurbanite T\&T Early

USE solution 8

EQUILIBRIUM PHASES 2

Jurbanite $\overline{0} 10$

END

TITLE Equilibrate Jurbanite T\&T 2008

USE solution 9

EQUILIBRIUM PHASES 2

Jurbanite $\overline{0} 10$

END 


\section{PHREEQCI Input Files}

TITLE Long Term Equilibrium of Aged Acid and Net Alkaline Mine-pools

PHASES

Schwertmannite

Fe808 $(\mathrm{OH}) 4.4(\mathrm{SO}) 1.8+20.4 \mathrm{H}+=8 \mathrm{Fe}+3+12.4 \mathrm{H} 2 \mathrm{O}+1.8 \mathrm{SO} 4-2$

$\log \mathrm{k} \quad 10.5$

Halotrichite

FeAl2 (SO4) $4: 22 \mathrm{H} 2 \mathrm{O}=2 \mathrm{Al}+3+\mathrm{Fe}+2+22 \mathrm{H} 2 \mathrm{O}+4 \mathrm{SO} 4-2$

$\log \mathrm{k} \quad-27.3$

SOLUTION 1 Long Term Acid Discharge Based on Ruthbell Drainage 5/17/05 sample, T\&T Mine-pool

temp $\quad 10.7$

$\mathrm{pH} \quad 2.68$

pe $\quad 13.03$

redox pe

units $\mathrm{mg} / \mathrm{I}$

density 1

Al 4.76

$\mathrm{Cl} 5$

$\mathrm{Fe} \quad 6.63$

K 1.15

$\mathrm{Mg} \quad 14.1$

$\mathrm{Mn} \quad 0.19$

$\mathrm{Na} \quad 1.23$

S (6) 235

Si $\quad 6.8$

$\mathrm{Ca} \quad 40.5$

-water 1 \# kg

SOLUTION 2 Long Term Alkaline Discharge Based on Acme Mine Discharge, Fairmont Minepool 6/5/2008

temp $\quad 13.8$

$\mathrm{pH} \quad 6.25$

pe $\quad 1.83$

redox pe

units $\mathrm{mg} / \mathrm{I}$

density 1

Al 0.05

$\mathrm{Cl} 6$

$\mathrm{Fe} \quad 5.15$

K 4.47

Mg $\quad 39.8$

Mn $\quad 0.65$

$\mathrm{Na} \quad 165$ 
PHREEQCI Input Files
$S(6) \quad 543$
$\mathrm{Si} \quad 5$
Ca 104.3
Alkalinity 263
-water 1 \# $\mathrm{kg}$

END

USE solution 1

REACTION 1 Add CaCO3 in Increments Mixed Buffer Ruthbell Water Calcite 1

5 millimoles in 100 steps

EQUILIBRIUM_PHASES 1

$\mathrm{Al}(\mathrm{OH}) 3(\mathrm{a}) \quad 0 \quad 0$

$\mathrm{CO} 2(\mathrm{~g}) \quad-1.5 \quad 10$

$\mathrm{Fe}(\mathrm{OH}) 3(\mathrm{a}) \quad 0 \quad 0$

$\mathrm{Fe} 3(\mathrm{OH}) 80$

Jarosite-K 00

Jurbanite 0

Kaolinite 00

O2 (g) $\quad-21 e-006$

Schwertmannite 00

SELECTED_OUTPUT

-file

-ionic_strength

-percent_error

-totals

LongtermEquilibrium

true

true

Al Alkalinity Ca $\mathrm{Fe}(2) \quad \mathrm{Fe}(3) \quad \mathrm{K} \quad \mathrm{Mg}$

$\mathrm{Na} \quad \mathrm{S}(-2) \quad \mathrm{S}(6) \quad \mathrm{Si}$

$\mathrm{Al}(\mathrm{OH}) 2+\quad \mathrm{Al}(\mathrm{OH}) 3 \quad \mathrm{Al}(\mathrm{OH}) 4-\mathrm{Al}(\mathrm{SO} 4) 2-$

$\mathrm{Al}+3 \quad \mathrm{AlHSO} 4+2 \quad \mathrm{AlOH}+2 \quad \mathrm{AlSO} 4+$

$\mathrm{Fe}(\mathrm{OH}) 2 \mathrm{Fe}(\mathrm{OH}) 2+\mathrm{Fe}(\mathrm{OH}) 3 \mathrm{Fe}(\mathrm{OH}) 3-$

$\mathrm{Fe}(\mathrm{OH}) 4-\mathrm{Fe}(\mathrm{SO} 4) 2-\mathrm{Fe}+2 \quad \mathrm{Fe}+3$

$\mathrm{Fe} 2(\mathrm{OH}) 2+4 \quad \mathrm{Fe} 3(\mathrm{OH}) 4+5 \mathrm{FeCl}+\mathrm{FeCl}+2$

$\mathrm{FeCl} 2+\mathrm{FeCl} 3$ FeCO3 FeHCO3+

$\mathrm{FeOH}+\mathrm{FeOH}+2 \quad \mathrm{FeSO} 4 \quad \mathrm{FeSO} 4+$

-activities

$\mathrm{Al}+3 \quad \mathrm{Ca}+2 \quad \mathrm{CO} 2 \mathrm{Fe}+2$

$\mathrm{Fe}+3 \mathrm{H}+\mathrm{K}+\mathrm{Mg}+2$

$\mathrm{Na}+\mathrm{O} 2 \mathrm{SO} 4-2$ H4SiO4

$\mathrm{Al}(\mathrm{OH}) 2+\mathrm{Al}(\mathrm{OH}) 3 \quad \mathrm{Al}(\mathrm{OH}) 4-\mathrm{Al}(\mathrm{SO} 4) 2-$

$\mathrm{AlHSO} 4+2 \mathrm{AlOH}+2 \quad \mathrm{AlSO} 4+\mathrm{Fe}(\mathrm{OH}) 2$

$\mathrm{Fe}(\mathrm{OH}) 2+\mathrm{Fe}(\mathrm{OH}) 3 \quad \mathrm{Fe}(\mathrm{OH}) 3-\quad \mathrm{Fe}(\mathrm{OH}) 4-$

Fe (SO4)2- Fe2 $(\mathrm{OH}) 2+4 \quad \mathrm{Fe} 3(\mathrm{OH}) 4+5 \quad \mathrm{FeCl}+$ 


\section{PHREEQCI Input Files}

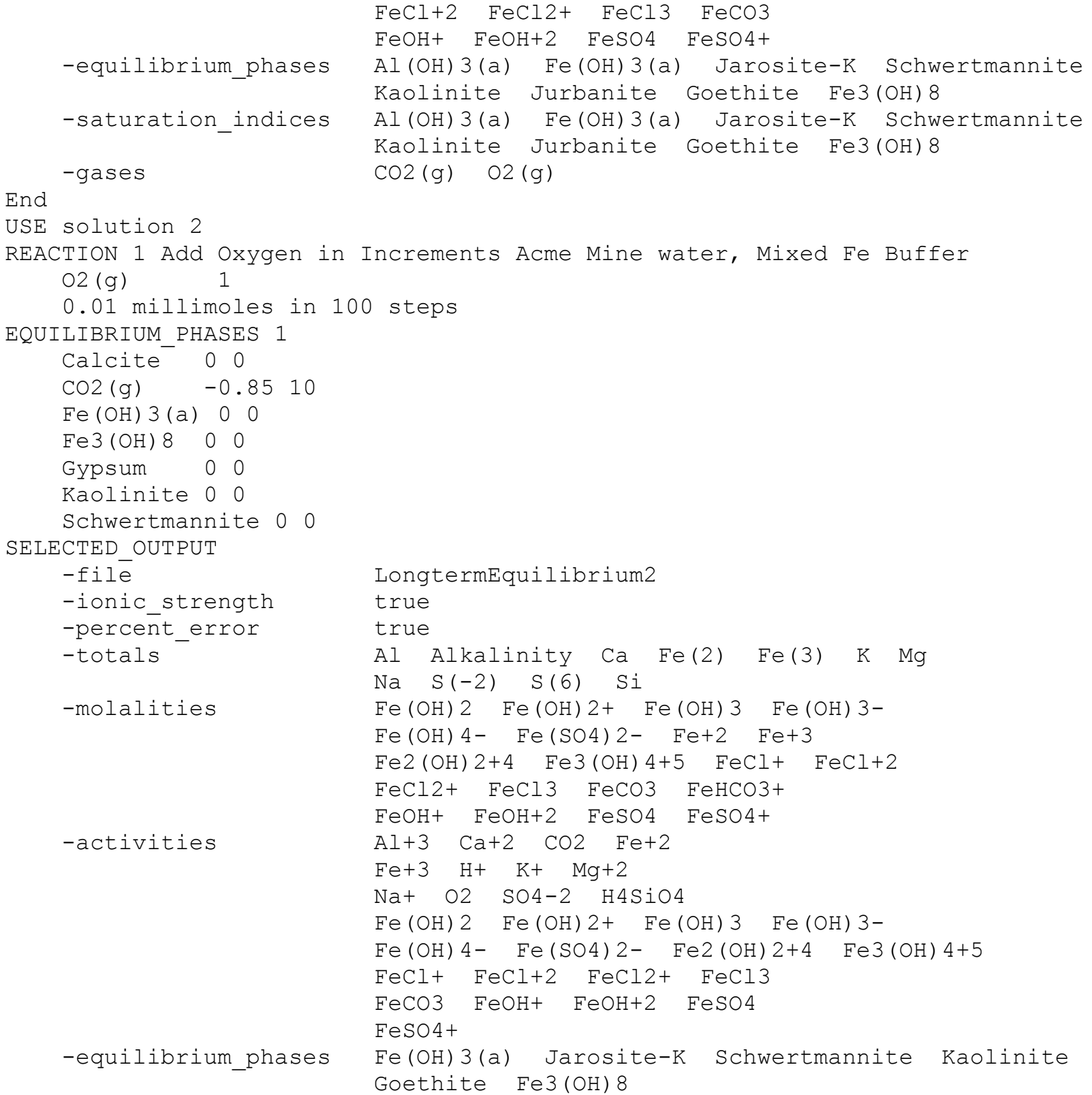




\section{PHREEQCI Input Files}

-saturation_indices

-gases
$\mathrm{Fe}(\mathrm{OH}) 3(\mathrm{a}) \quad$ Jarosite-K Schwertmannite Kaolinite Goethite $\mathrm{Fe} 3(\mathrm{OH}) 8$ Siderite

$\mathrm{CO} 2(\mathrm{~g}) \quad \mathrm{O} 2(\mathrm{~g})$

End

USE solution 1

REACTION 1 Add CaCO3 in Increments Kaolinite Buffer Ruth Bell Water

Calcite 0.5

5 millimoles in 100 steps

EQUILIBRIUM_PHASES 1
$\mathrm{CO} 2(\mathrm{~g})$ $-1.510$

$\mathrm{Fe}(\mathrm{OH}) 3(\mathrm{a}) \quad 0 \quad 0$

Jarosite-K 00

Kaolinite 00

$02(\mathrm{~g}) \quad-2 \quad 1 e-006$

SELECTED OUTPUT

-file

-ionic_strength

-percent error

-totals

-molalities

-activities

\section{LongtermEquilibrium3}

true

true

Al Alkalinity Ca $\mathrm{Fe}(2) \quad \mathrm{Fe}(3) \quad \mathrm{K} \quad \mathrm{Mg}$

$\mathrm{Na} \quad \mathrm{S}(-2) \quad \mathrm{S}(6) \quad \mathrm{Si}$

$\mathrm{Al}(\mathrm{OH}) 2+\mathrm{Al}(\mathrm{OH}) 3 \quad \mathrm{Al}(\mathrm{OH}) 4-\mathrm{Al}(\mathrm{SO} 4) 2-$

$\mathrm{Al}+3 \quad \mathrm{AlHSO} 4+2 \quad \mathrm{AlOH}+2 \quad \mathrm{AlSO} 4+$

$\mathrm{Fe}(\mathrm{OH}) 2 \mathrm{Fe}(\mathrm{OH}) 2+\mathrm{Fe}(\mathrm{OH}) 3 \mathrm{Fe}(\mathrm{OH}) 3-$

$\mathrm{Fe}(\mathrm{OH}) 4-\mathrm{Fe}(\mathrm{SO} 4) 2-\mathrm{Fe}+2 \mathrm{Fe}+3$

$\mathrm{Fe} 2(\mathrm{OH}) 2+4 \quad \mathrm{Fe} 3(\mathrm{OH}) 4+5 \quad \mathrm{FeCl}+\mathrm{FeCl}+2$

$\mathrm{FeCl} 2+\mathrm{FeCl} 3$ FeCO3 FeHCO3+

$\mathrm{FeOH}+\mathrm{FeOH}+2 \quad \mathrm{FeSO} 4 \quad \mathrm{FeSO} 4+$

$\mathrm{Al}+3 \quad \mathrm{Ca}+2 \quad \mathrm{CO} 2 \mathrm{Fe}+2$

$\mathrm{Fe}+3 \mathrm{H}+\mathrm{K}+\mathrm{Mg}+2$

$\mathrm{Na}+\mathrm{O} 2$ SO4-2 $\mathrm{H} 4 \mathrm{SiO} 4$

$\mathrm{Al}(\mathrm{OH}) 2+\mathrm{Al}(\mathrm{OH}) 3 \quad \mathrm{Al}(\mathrm{OH}) 4-\mathrm{Al}(\mathrm{SO} 4) 2-$

$\mathrm{AlHSO}+2 \quad \mathrm{AlOH}+2 \quad \mathrm{AlSO} 4+\mathrm{Fe}(\mathrm{OH}) 2$

$\mathrm{Fe}(\mathrm{OH}) 2+\mathrm{Fe}(\mathrm{OH}) 3 \quad \mathrm{Fe}(\mathrm{OH}) 3-\mathrm{Fe}(\mathrm{OH}) 4-$

$\mathrm{Fe}(\mathrm{SO} 4) 2-\mathrm{Fe} 2(\mathrm{OH}) 2+4 \quad \mathrm{Fe} 3(\mathrm{OH}) 4+5 \quad \mathrm{FeCl}+$

$\mathrm{FeCl}+2 \mathrm{FeCl} 2+\mathrm{FeCl} 3 \quad \mathrm{FeCO} 3$

$\mathrm{FeOH}+\mathrm{FeOH}+2 \quad \mathrm{FeSO} 4 \mathrm{FeSO} 4+$

-equilibrium phases

Al $(\mathrm{OH}) 3(\mathrm{a}) \quad \mathrm{Fe}(\mathrm{OH}) 3(\mathrm{a})$ Jarosite-K Schwertmannite Kaolinite Jurbanite Goethite

-saturation_indices

Al $(\mathrm{OH}) 3(\mathrm{a}) \quad \mathrm{Fe}(\mathrm{OH}) 3(\mathrm{a})$ Jarosite-K Schwertmannite Kaolinite Jurbanite Goethite

-gases

$\mathrm{CO} 2(\mathrm{~g}) \quad \mathrm{O} 2(\mathrm{~g})$ 


\section{PHREEQCI Input Files}

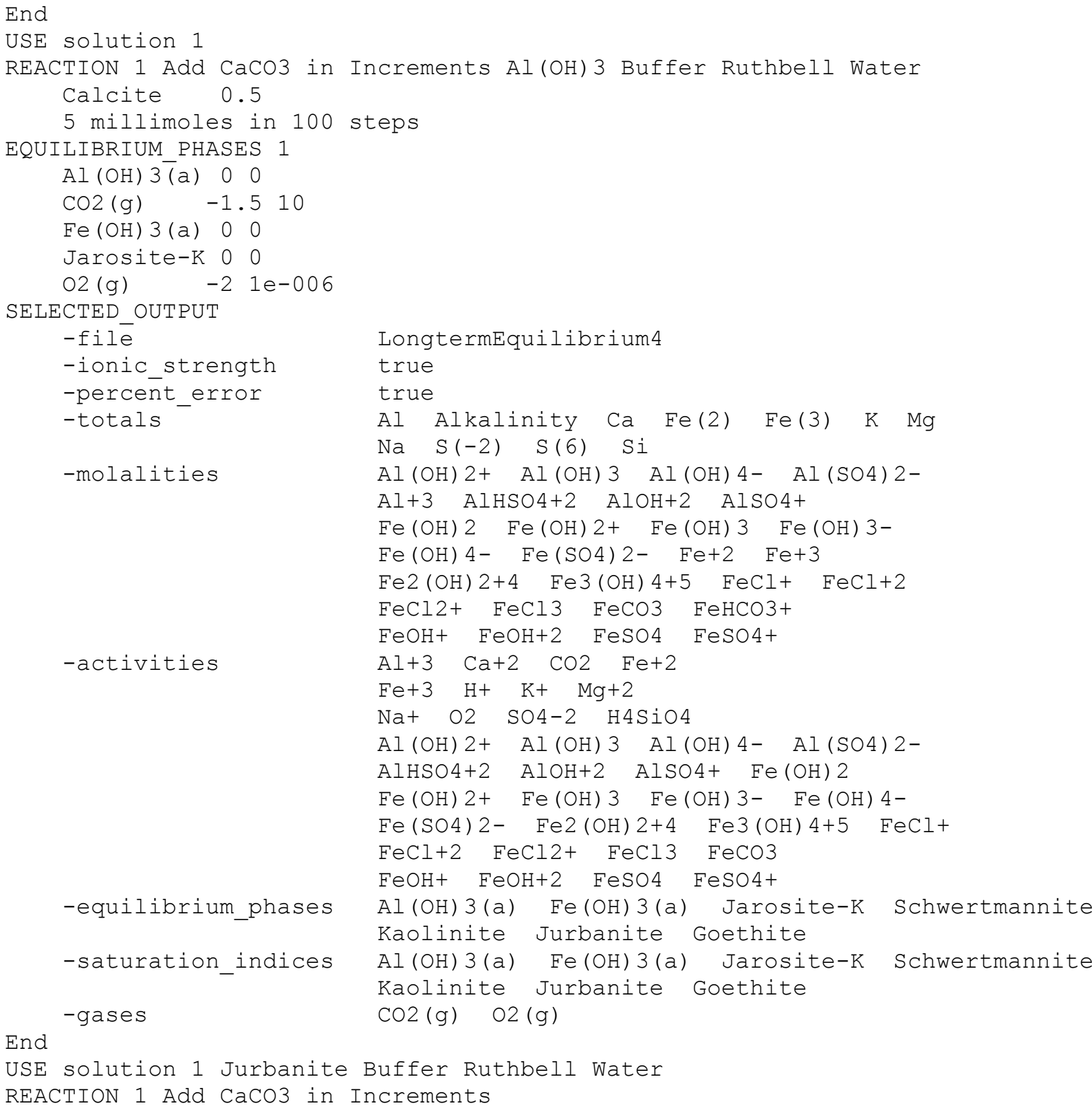

USE solution 1 Jurbanite Buffer Ruthbell Water

REACTION 1 Add $\mathrm{CaCO} 3$ in Increments 


\section{PHREEQCI Input Files}

Calcite 0.5

5 millimoles in 100 steps

EQUILIBRIUM PHASES 1

$\mathrm{CO} 2(\mathrm{~g})--1.510$

$\mathrm{Fe}(\mathrm{OH}) 3(\mathrm{a}) \quad 0 \quad 0$

Jarosite-K 00

Jurbanite 00

$02(\mathrm{~g}) \quad-2 \quad 1 e-006$

SELECTED_OUTPUT

-file

-ionic strength

-percent_error

-totals

-molalities

-activities

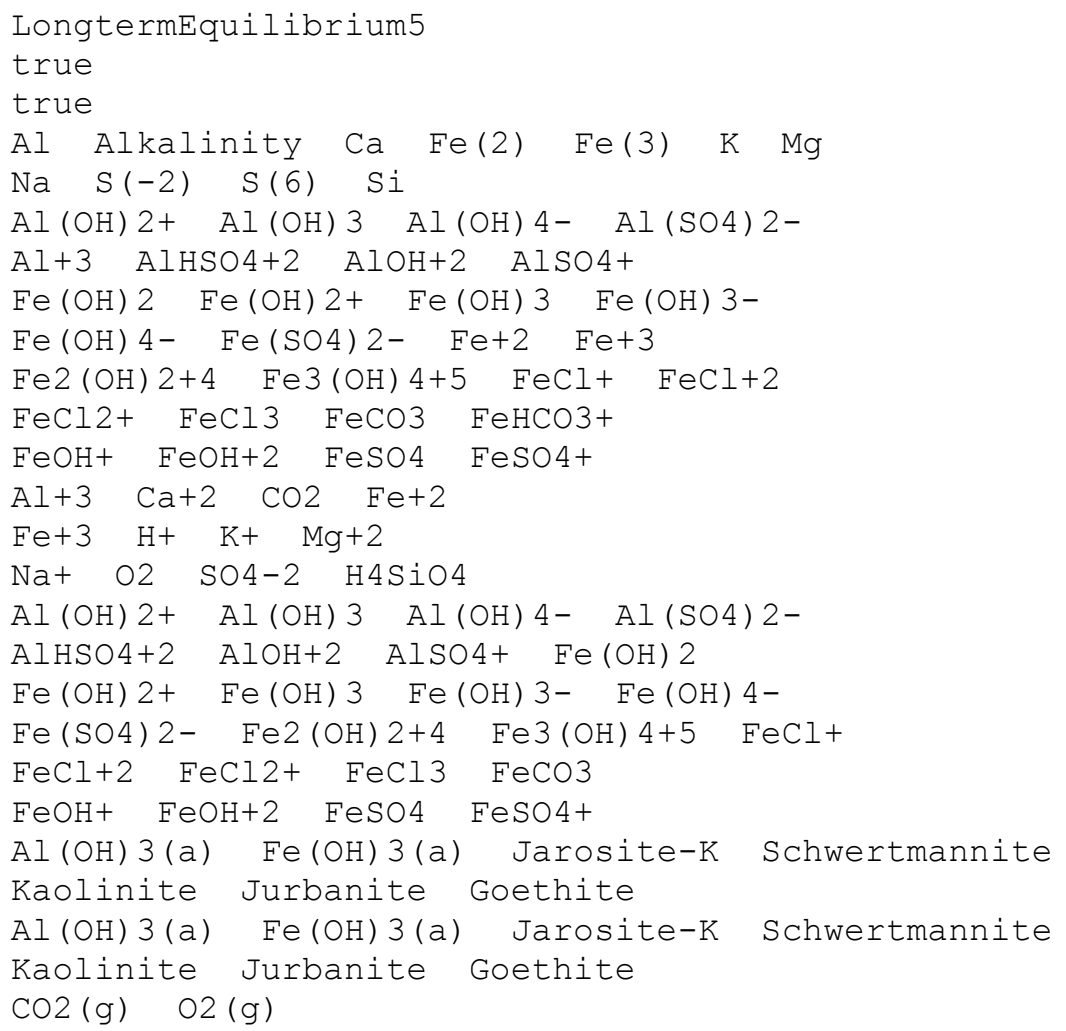

USE solution 1

REACTION 1 Add CaCO3 in Increments No Schwertmannite Ruthbell water

Calcite 1

5 millimoles in 100 steps

EQUILIBRIUM_PHASES 1 


\section{PHREEQCI Input Files}

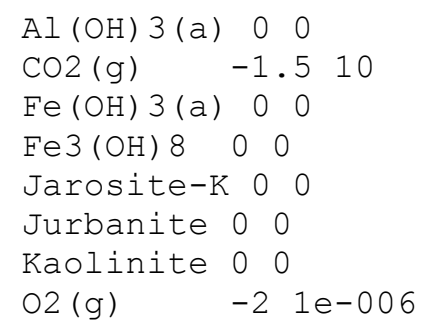

SELECTED_OUTPUT

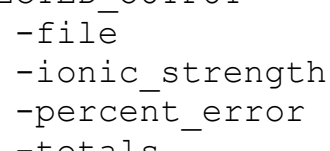

-totals

-molalities

-activities

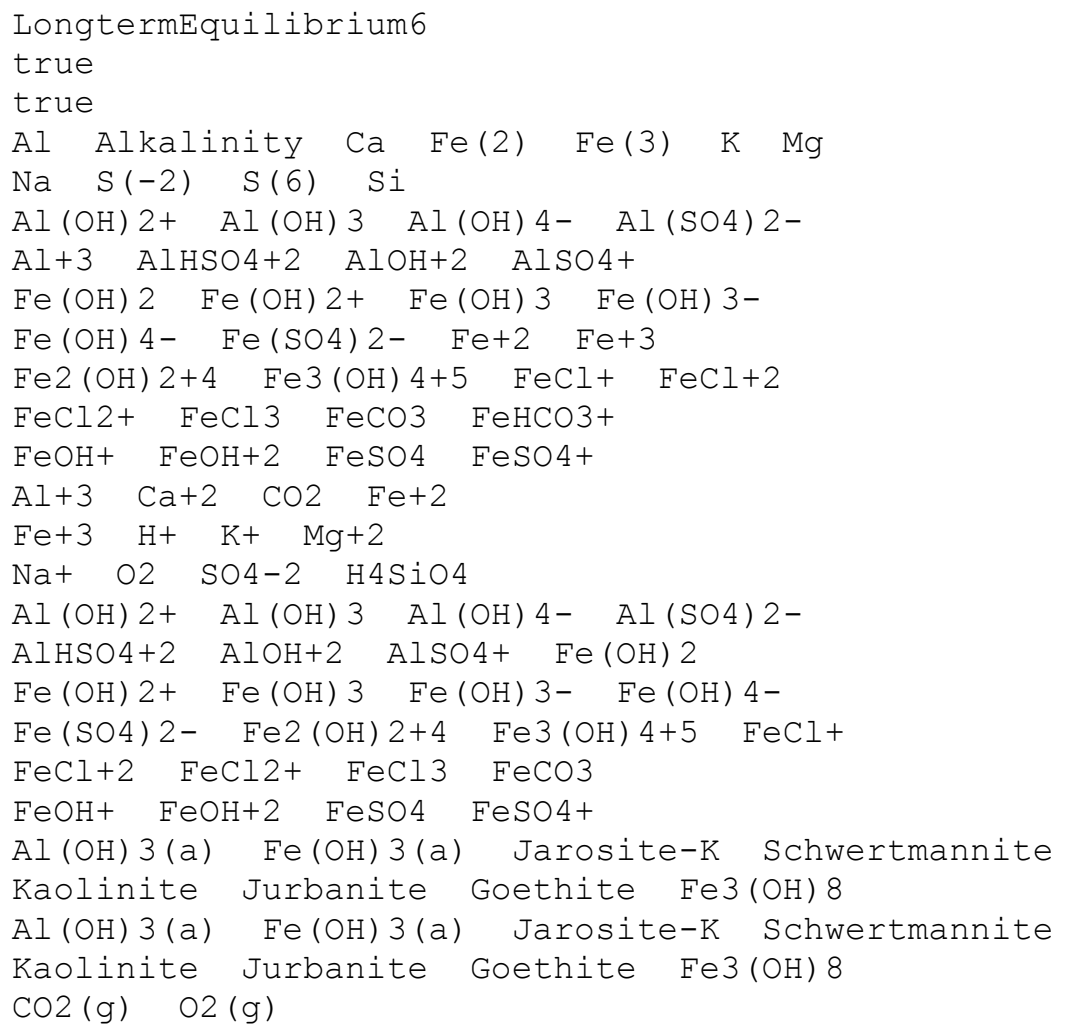




\section{PHREEQCI Input Files}

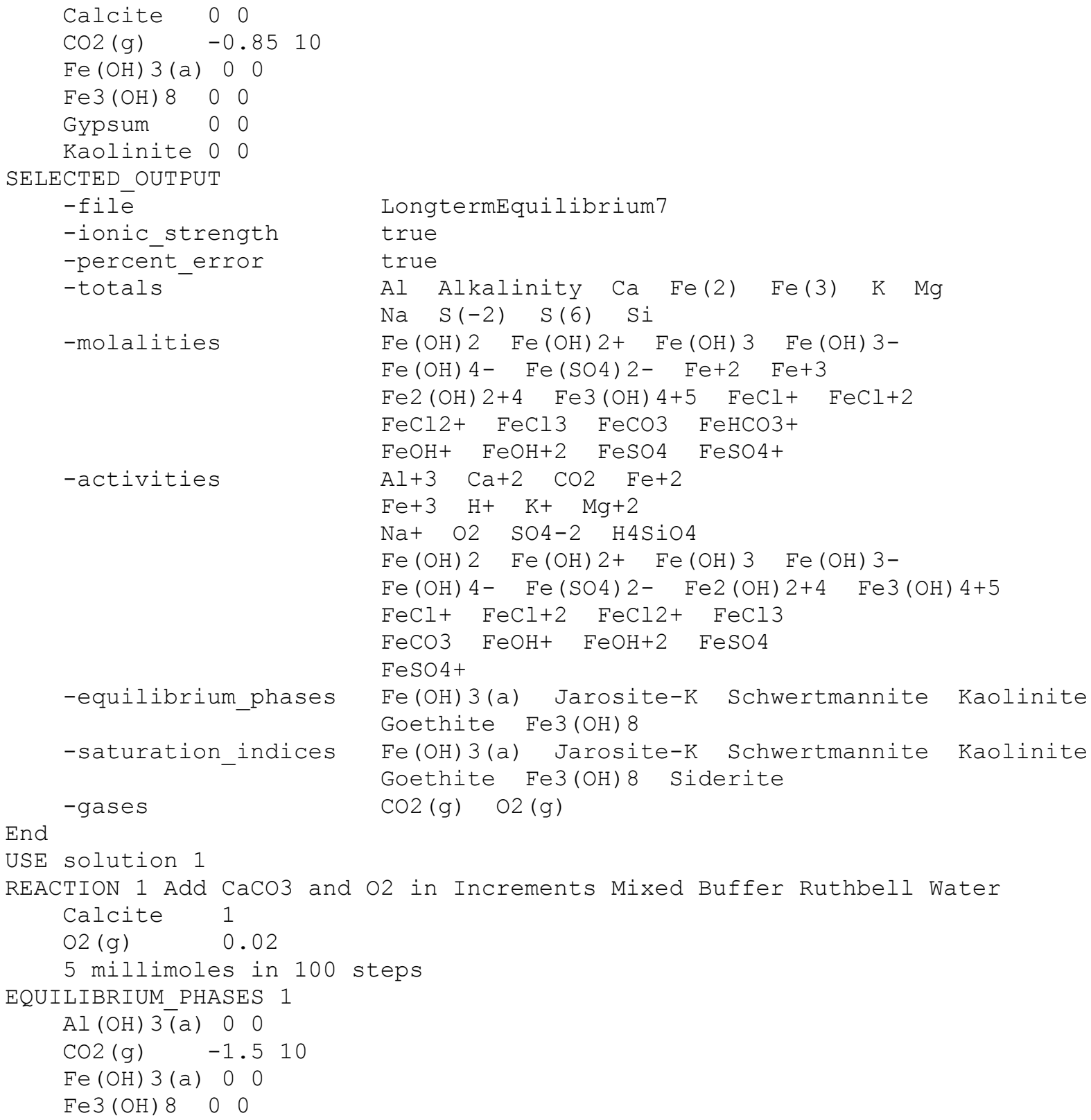

REACTION 1 Add $\mathrm{CaCO} 3$ and $\mathrm{O} 2$ in Increments Mixed Buffer Ruthbell Water Calcite 1

5 millimoles in 100 steps

EQUILIBRIUM_PHASES 1

$\mathrm{Al}(\mathrm{OH}) 3(\mathrm{a}) \quad 0 \quad 0$

$\mathrm{CO} 2(\mathrm{~g}) \quad-1.5 \quad 10$

$\mathrm{Fe}(\mathrm{OH}) 3(\mathrm{a}) \quad 0$

$\mathrm{Fe} 3(\mathrm{OH}) 80$

USE solution 1 


\section{PHREEQCI Input Files}

Jarosite-K 00

Jurbanite 00

Kaolinite 0

$\mathrm{O} 2(\mathrm{~g}) \quad-21 \mathrm{e}-006$

Schwertmannite 00

SELECTED OUTPUT

-file

-ionic strength

-percent_error

-totals

-molalities

-activities

-equilibrium phases

-saturation indices

-gases
LongtermEquilibrium8

true

true

Al Alkalinity $\mathrm{Ca} \quad \mathrm{Fe}(2) \quad \mathrm{Fe}(3) \quad \mathrm{K} \quad \mathrm{Mg}$

$\mathrm{Na} \quad \mathrm{S}(-2) \quad \mathrm{S}(6) \quad \mathrm{Si}$

$\mathrm{Al}(\mathrm{OH}) 2+\quad \mathrm{Al}(\mathrm{OH}) 3 \quad \mathrm{Al}(\mathrm{OH}) 4-\mathrm{Al}(\mathrm{SO} 4) 2-$

$\mathrm{Al}+3 \quad \mathrm{AlHSO} 4+2 \quad \mathrm{AlOH}+2 \quad \mathrm{AlSO} 4+$

$\mathrm{Fe}(\mathrm{OH}) 2 \mathrm{Fe}(\mathrm{OH}) 2+\mathrm{Fe}(\mathrm{OH}) 3 \quad \mathrm{Fe}(\mathrm{OH}) 3-$

$\mathrm{Fe}(\mathrm{OH}) 4-\mathrm{Fe}(\mathrm{SO} 4) 2-\mathrm{Fe}+2 \quad \mathrm{Fe}+3$

$\mathrm{Fe} 2(\mathrm{OH}) 2+4 \quad \mathrm{Fe} 3(\mathrm{OH}) 4+5 \quad \mathrm{FeCl}+\mathrm{FeCl}+2$

FeCl2+ FeCl3 FeCO3 FeHCO3+

$\mathrm{FeOH}+\mathrm{FeOH}+2 \quad \mathrm{FeSO} 4 \quad \mathrm{FeSO} 4+$

$\mathrm{Al}+3 \quad \mathrm{Ca}+2 \quad \mathrm{CO} 2 \mathrm{Fe}+2$

$\mathrm{Fe}+3 \mathrm{H}+\mathrm{K}+\mathrm{Mg}+2$

$\mathrm{Na}+\mathrm{O} 2 \quad \mathrm{SO} 4-2 \quad \mathrm{H} 4 \mathrm{SiO} 4$

$\mathrm{Al}(\mathrm{OH}) 2+\mathrm{Al}(\mathrm{OH}) 3 \quad \mathrm{Al}(\mathrm{OH}) 4-\quad \mathrm{Al}(\mathrm{SO} 4) 2-$

$\mathrm{AlHSO} 4+2 \quad \mathrm{AlOH}+2 \quad \mathrm{AlSO} 4+\mathrm{Fe}(\mathrm{OH}) 2$

$\mathrm{Fe}(\mathrm{OH}) 2+\mathrm{Fe}(\mathrm{OH}) 3 \quad \mathrm{Fe}(\mathrm{OH}) 3-\quad \mathrm{Fe}(\mathrm{OH}) 4-$

$\mathrm{Fe}(\mathrm{SO} 4) 2-\mathrm{Fe} 2(\mathrm{OH}) 2+4 \quad \mathrm{Fe} 3(\mathrm{OH}) 4+5 \quad \mathrm{FeCl}+$

$\mathrm{FeCl}+2 \mathrm{FeCl} 2+\mathrm{FeCl} 3 \quad \mathrm{FeCO} 3$

$\mathrm{FeOH}+\mathrm{FeOH}+2 \quad \mathrm{FeSO} 4$ FeSO4+

Al $(\mathrm{OH}) 3(\mathrm{a}) \quad \mathrm{Fe}(\mathrm{OH}) 3(\mathrm{a})$ Jarosite-K Schwertmannite

Kaolinite Jurbanite Goethite Fe3(OH) 8

Al $(\mathrm{OH}) 3(\mathrm{a}) \quad \mathrm{Fe}(\mathrm{OH}) 3(\mathrm{a})$ Jarosite-K Schwertmannite

Kaolinite Jurbanite Goethite Fe3(OH) 8

$\mathrm{CO} 2(\mathrm{~g}) \quad \mathrm{O} 2(\mathrm{~g})$ 


\section{CURRICULUM VITAE}

Name: $\quad$ Eric F. Perry

Parents: $\quad$ William and Frances Perry

Birthplace: $\quad$ Fort Riley, Kansas

Date of Birth: $\quad$ February 3, 1954

Schools and Colleges Attended:

Sparrows Point High School, Sparrows Point, MD 1970-1972

West Virginia University, Morgantown, WV 1972-1978

Degrees Received:

Bachelor of Science in Plant and Soil Science, West Virginia University, 1976

Master of Science in Plant and Soil Science, West Virginia Ubiversity, 1978

Present Position: Hydrologist

US Dept Interior Office of Surface Mining Pittsburgh, PA 